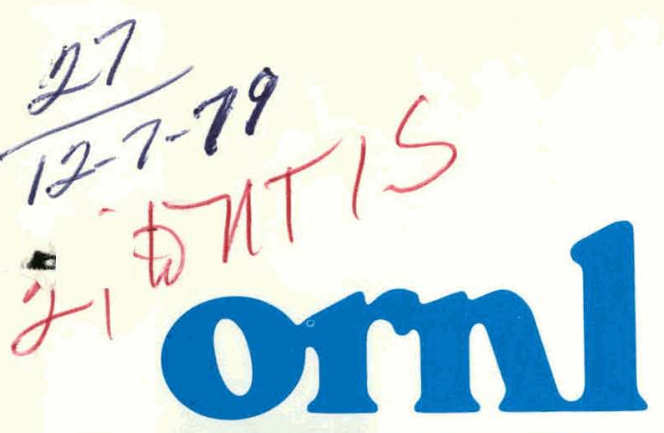

OAK

RIDGE

NATIONAL

LABORATORY

UNION

CARBIDE

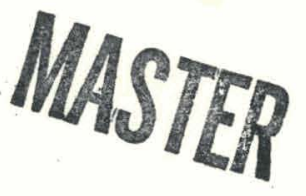

\title{
Energy Availabilities for State and Local Development: Projected Energy Patterns for 1985 and 1990
}

D. P. Vogt

P. L. Rice

T. A. Corey

V.P. Pai

OPERATED BY

UNION CARBIDE CORPORATION

FOR THE UNITED STATES

DEPARTMENT OF ENERGY 


\section{DISCLAIMER}

This report was prepared as an account of work sponsored by an agency of the United States Government. Neither the United States Government nor any agency Thereof, nor any of their employees, makes any warranty, express or implied, or assumes any legal liability or responsibility for the accuracy, completeness, or usefulness of any information, apparatus, product, or process disclosed, or represents that its use would not infringe privately owned rights. Reference herein to any specific commercial product, process, or service by trade name, trademark, manufacturer, or otherwise does not necessarily constitute or imply its endorsement, recommendation, or favoring by the United States Government or any agency thereof. The views and opinions of authors expressed herein do not necessarily state or reflect those of the United States Government or any agency thereof. 


\section{DISCLAIMER}

Portions of this document may be illegible in electronic image products. Images are produced from the best available original document. 
Printed in the United States of America. Available from National Technical Information Service

U.S. Department of Commerce

5285 Port Royal Road, Springfield, Virginia 22161

NTIS price codes-Printed Copy: A25 Microfiche A01

This report was prepared as an account of work sponsored by an agency of the United States Government. Neither the United States nor any agency thereof, nor any of their employees, makes any warranty, expressed or implied, or assumes any legal liability or responsibility for any third party's use or the results of such use of any information, apparatus, product or process disclosed in this report, or represents that its use by such third party would not infringe privately owned rights. 
ORNL/TM-5890/S5

Contract No. W-7405-eng-26

ENERGY AVAILABILITIES FOR STATE AND LOCAL DEVELOPMENT:

PROJECTED ENERGY PATTERNS FOR 1985 AND 1990

D. P. Vogt
P. L. Rice
T. A. Corey
V. P. Pai

Economic Analysis Section

Energy Division

Date Published: November 1979

Research sponsored by

Economic Development Administration

of the

U.S. Department of Commerce

OAK RIDGE NATIONAL LABORATOR:

Oak Ridge, Tennessee 37830

opcrated by

UNION CARBIDE CORPORATION

for the

DEPARTMENT OF ENERGY

DISCLAIMER

This book was prepared as an account of mork sponsored by an agency of the United States Government.

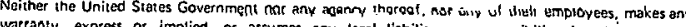
andiv. express or implied, or assumes any legal liability of responsibility tor the accuracy.

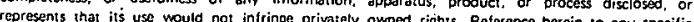

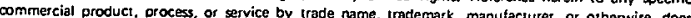
not necesserily constitute or imply its endorsement, recommendstion or favoring by the United States Government or any agcncy thereot. The views and opinions of authors expressed herein United necessarily state of reflect those of the United States Government or any agency thereof. 


\section{THIS PAGE \\ WAS INTENTIONALLY \\ LEFT BLANK}


CONTENTS

$\underline{\text { Page }}$

ABSTRACT . . . . . . . . . . . . . . . . . . . . . . . v

I. INTRODUCTION . . . . . . . . . . . . . . . . . . 1

II. THE STRUCTURE OF THE REGIONAL ENERGY BALANCE STATEMENT • • • 5

Regional Consumption . . . . . . . . . . . . . . . . . 6

Regional Supply . . . . . . . . . . . . . . . . . . 11

Regional Imports..................... 12

III. THE NATIONAL ENERGY PROJECTIONS . . .. . . . . . . . . . 15

An Overview of the National Energy Projections . . . . . . . 15

Special Characteristics of the Projected Data Series . . . 19

Comparison of the Mid-Mid Scenario to the Earlier

NEO 76 Scenario . . . . . . . . . . . . . . 24

IV. REGIONALIZATION OF THE DOE SCENARIO . . . . . . . . . . 29

The Regional Consumption of Energy . . . . . . . . . . . . . 29

The Electric Utility Sector . . . . . . . . . . . . 34

Supply and Transformation of Fossil. Fuels . . . . . . . . 38

New Technologies . . . . . . . . . . . . . 47

V. CONVERSION FACTORS . . . . . . . . . . . . . . 51

VI. MULTIREGION POPULATION PROJECTIONS . . . . . . . . . . 53

VII. MULTIREGION EMPLOYMENT PROIECTIONS . . . . . . . . . 63

FOOTNOTES ........................ 73

REGIONAL ENFRGY BALANCE TABLES . . . . . . . . . . . . . . . . 79

Census Region Tables for 1985 . . . . . . . . . . . . . 81

State Tables for 1985 . . . . . . . . . . . . . . . 93

BEA Region Tables for 1985 . . . . . . . . . . . . . 147

Census Region Tables for 1990 . . . . . . . . . . . . 323

State Tables for 1990 . . . . . . . . . . . . . . 335

BEA Region Tables for 1990 . . . . . . . . . . . . 389 
THIS PAGE

\section{WAS INTENTIONALLY LEFT BLANK}


ABSTRACT

This report is one of a continuing series developed by the Oak Ridge National Laboratory with financial support from the Economic Development Administration. It presents projections of the energy supply, demand and net imports of seven fuel types and four final consuming sectors. To facilitate detailed regional analysis these projections have been prepared for Bureau of Economic Analysis (BEA) areas, states, census regions, and the nation for 1985 and 1990. The data are formatted to present regional energy availability from primary extraction, as well as from energy transformation processes. The tables depict energy balances between availability and use for each specific fuel.

The objective of this series is to provide a consistent base of historic and projected energy information within a standard format. Such a framework should aid regional policymakers in their consideration of regional growth issues that may be influenced by the regional energy system. However, for analysis of specific regions this basic data should be supplemented by additional information which only the local policy analyst can bring to bear in his or her assessment of the energy conditions which characterize the region.

Earlier volumes in this series have proved useful for both specific and general analysis of this type, and it is hoped that the current volume will prove equally so. This volume presents an updated benchmark projection series, which captures recent developments in the "business as usual" projections of energy supply and consumption due to national policy developments since the 1976 Natiorial Energy Outlook projection series were prepared. 


\section{INTRODUCTION}

This volume supplements earlier releases in the series Energy Availabilities for State and Local Development published by Oak Ridge National Laboratory (ORNL) under the sponsorship of the Economic Development Administration (EDA). The earlier volumes included historical data describing regional energy patterns for the years 1972 through 1974 and will be supplemented by an additional volume presenting daca for 1975 . As a companion to the historical series, ORNL also prepared a reference case scenario, in the same format as the historic series, for the years 1980 and 1985 based on the National Energy Outlook (NEO76) projections produced by the Department of Energy (then the Federal Energy Administration). ${ }^{1}$

This volume complements the previously released scenario, presenting an alternative reference scenario which reflects the changes in energy conditions and energy policies that have occurred since 1976. The regional energy patterns contained in this volume are based on the reference case scenario released by the Department of Energy (DOE) in the Annual Report to Congress, Volume II, 1977 nf the Ensrgy Informatiun Agency. ${ }^{2}$ Energy supply and demand patterns are presented in tabular form for the United States, nine census regions, 50 states, and 173 Burèau of Economic Analysis (BEA) areas. The timespan of these projections has been extended to 1990 .

A major objective of this series is to develop a consistent reporting

format that can be used to present energy supply and consumption information for both historic and projected periods. To meet this goal, we formulated 
the Regional Energy Balance Statement, and have consistently used this format throughout the series. In the present volume (as in the previous volumes) energy consumption, transformation, production, and net imports information is presented for seven fuel rypes. Final demand is separated into four sectors, transformation into four processes, and fuel extraction into four energy forms.

As far as possible, the data in this volume are definitionally consistent with those in the prcvious volumes. ${ }^{3}$ This procedure facilitates identifying potential changes in regional energy conditions that in the past were measured or projected only at the national level. 4

These data are not intended to suggest historical or potential limits to growth for specific regions. Such a determination can only be made by someone who is familiar with the region in question and who can bring additional, region-specific information to the analysis of regional growth potentials. For chls puspuse, thcsc data provide a starting point, but not definitive conclusions, for regional analysis. These series are intended to provide a consistent description of historlc and projected energy conditions, at a variety of regional levels, which may be used to analyze the United States in terms of its spatial components. Coupled with information measuring other regional characteristics, such as economfc and demographic structure, they provide a foundation for both detailed and general analysis.

To manipulate the large body of data necessary to prepare these statements, ORNL has developed a computerized Regional Energy Balance System (REBS). 5 In designing the behavioral relationships embodied by this system, we have focused primarily on the relationship between economic 
activity and energy usage. The selection of an appropriate regional grid on which to base this system is highly important, and a system of functional economic regions for which reliable economic data were available appeared appropriate. The Bureau of Economic Analysis (BEA) grid fits this criteria. BEA areas, by design, follow labor market boundaries and approximate energy demand centers (Fig. 1). Moreover, BEA's can be disaggregated by county groups, and these BEA portions reaggregated to form states. By using each. of the 173 regions as a basic unit of analysis and at the same time maintaining a state-consistent cross reference identifier, we have retained a sufficient level of detail to conduct analysis at the substate, state, and multistate leve1s.

In examining the data contained in this volume, one should bear in mind that any set of energy projections must be interpreted in the light of considerable uncertainty as to the course of future government energy policies and future economic conditions. These projections are based on the DOE "mid-mid" scenario which generally contains "middle of the road" assumptions. There exist, however, a large number of additional scenarios which could also be regionalized. ${ }^{6}$ The current projections should be viewed as an updated benchmark series. 


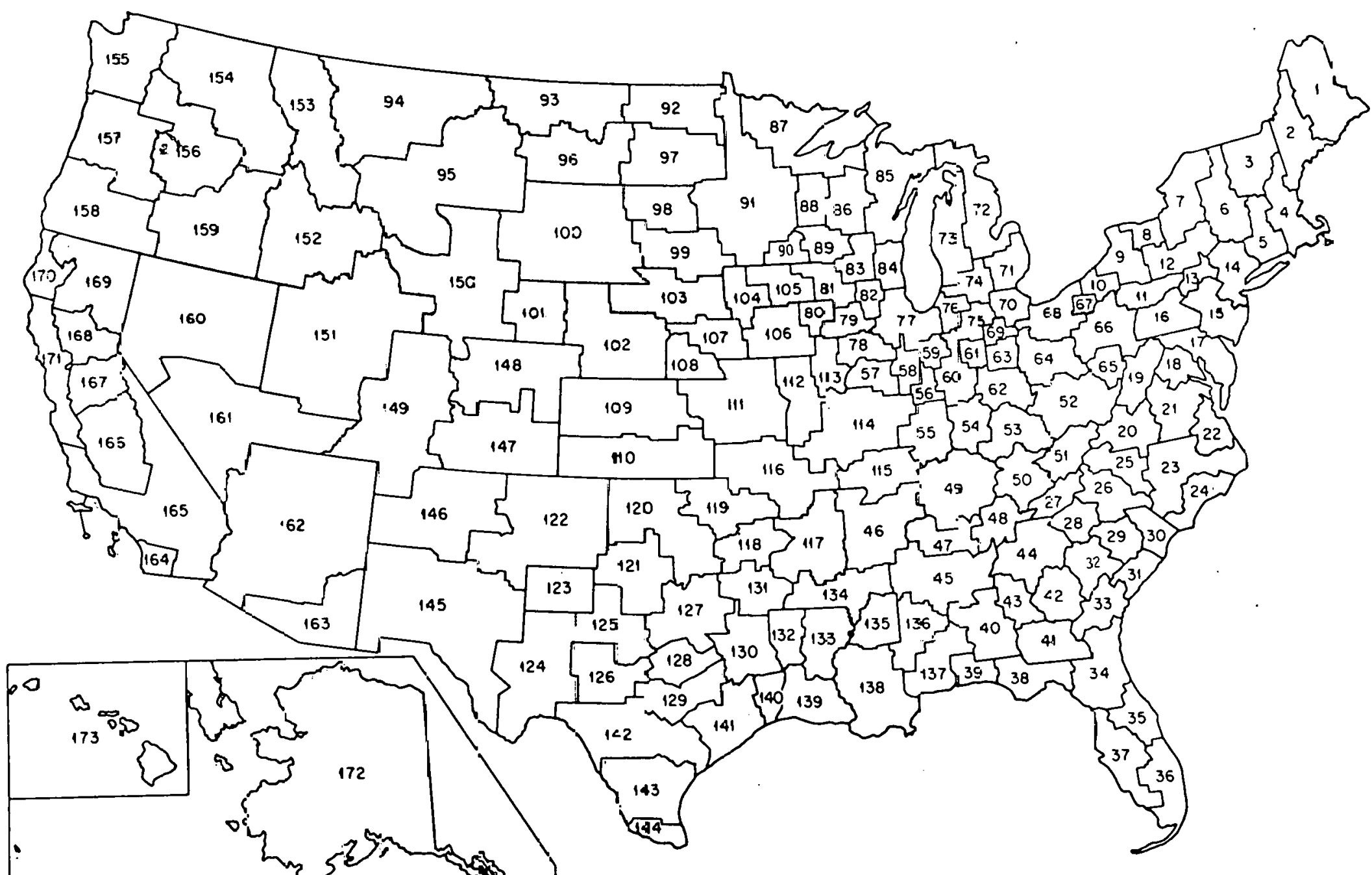

=ig. 1. NOTE: BEA definitions are presented in Section VI 
II. THE STRUCTURE OF THE REGIONAL ENERGY BALANCE STATEMENT

The Regional Energy Balance Statement is designed to show where and in what fuel form a region's energy is expected to be used and how this. energy is likely to be provided. Each table is separated into three major sections representing energy consumption, domestic production, and energy imports of the region. To maintain consistency, the data are internally processed in thermal equivalent units, based on the average conversion measures listed in Section $V$.

The consumption section is further classified into two subsections. The first category reports energy used by ultimate consumers in the residential and commercial, industrial, transportation, and "miscellaneous". sectors. This category is termed "final demand." The second category considered contains energy transformation processes. These processes consume energy in one form and provide it to final demand sectors in a second form. Total energy consumption by the transformation sector is defined as a (net) conversion loss and interpreted as a component of final region demand. A positive number in the transformation sector represents an input to the conversion process, and a negative number represents an output.

The energy supply sector consists of fossil fuel extraction, electricity generated by hydropower, nuclear, solar, and geothermal sources. Nuclear power generation is included here, because it was felt that it was unnecessary to trace the flow of uranium from point of extraction to point. of processing, to point of end use. Most BEA areas using enriched urantum must import it. 
Finally, regional net imports represent the projected balance between energy consumption and production in the region. The net imports reflect the underlying regional capacity to provide fuel to local users. However, this figure does not measure the gross volume of exports and imports, since there may be substantial counterflows. Moreover, the tables do not describe the sourcc, destination, or reliability of the actual interregional energy flows. ${ }^{7}$

\section{Regivinal Cunsunnption}

Table 1 illustrates the 1985 projections of energy produrtion and usage in the U.S. Although only 1985 data will be discussed in detail, the 1990 data are presented in Table 2 for the readers benefit. Both tables follow the same format.

'lotal energy consumption for all final demand sectors is projected to be 72.0 quadrillion Btus (quads) in 1985. Residential and commercial demand accounts for 19.3 quads of the final demand, industrial use accounts fus 30.7 quads, Lransportation usè accounts for 21.0 quads, and miscellaneous use accounts tor 0.6 quads. Natural gas consumption of 7.9 quads accounts for the greatest single share (for the listed fuels) of energy demand. The analysis assumes that final demand sectors do not consume unprocessed stude oil.

A portion of electricity generation is included as a transformation sector. Output is total electricity generated by fossil fuel plants (in Btus) less the Btu content of the fuels consumed. The conversion rate used for electrical output is that of end use rather than fossil fuel equivalents. The projected output (indicated as negative demand) of electricity generated 
REGIONAL ENERGY BALANCE STATEMENT

PIES MID MID SCENARIO

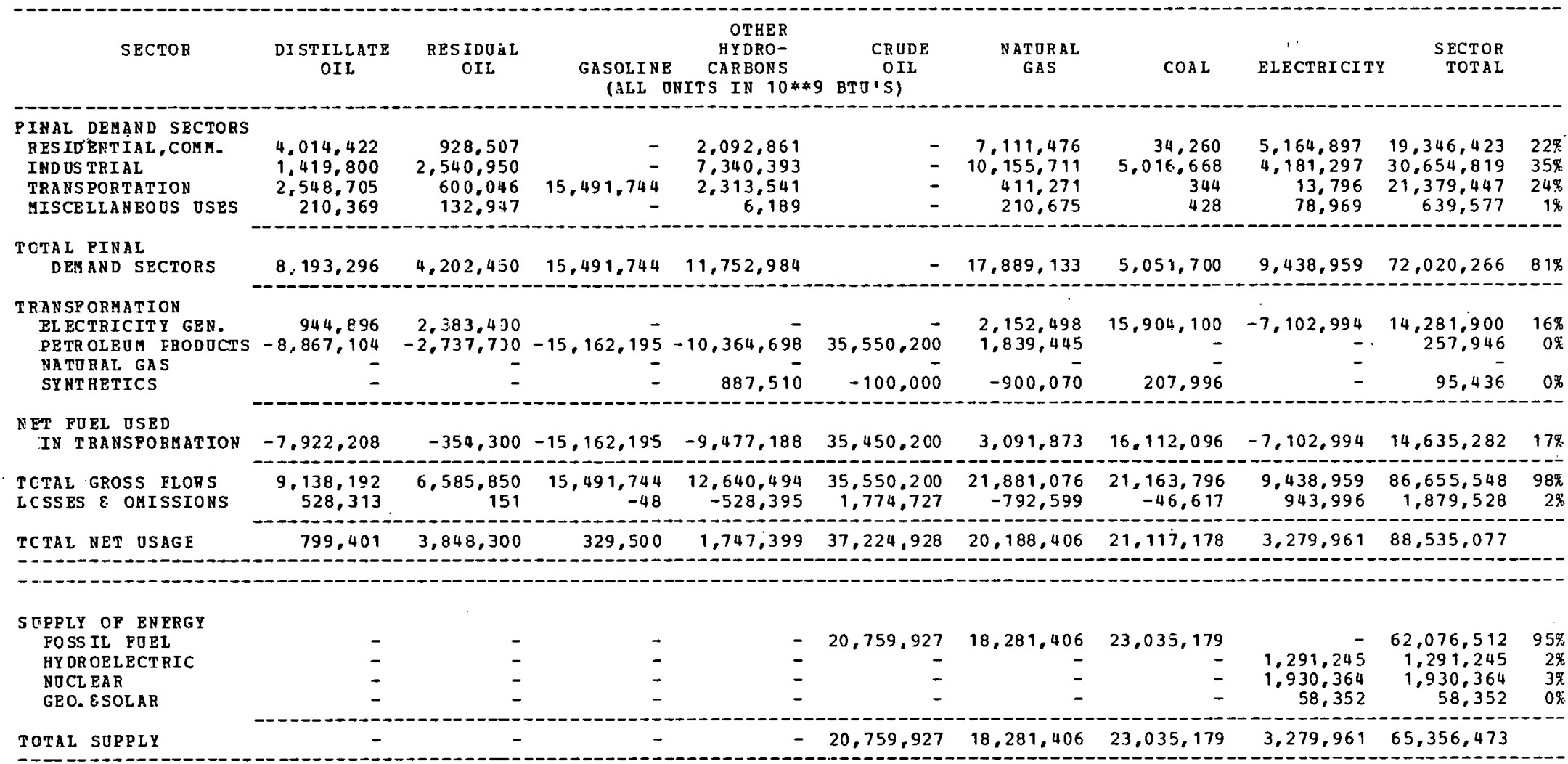

-

NET IM PORTS

OF REGION

$799,401 \quad 3,848,300$

329.500

$16,465,001$

$1,907,000-1,918,000$

$23,178,60$

NO TES:

TRANSFORHATION LOSS ZOR TRANSFORAATION LOSS POR TRANSFORMATION LOSS PDR TRAN SPORMLTI ON IOSS POR

ELECTRICITY GEN.

PETROLEOM PRODOCTS $=0.69$

ATORAL GAS

SYNTHETICS
$=66.78 \%$

$=0.0 \%$

$=8.71 \%$ 


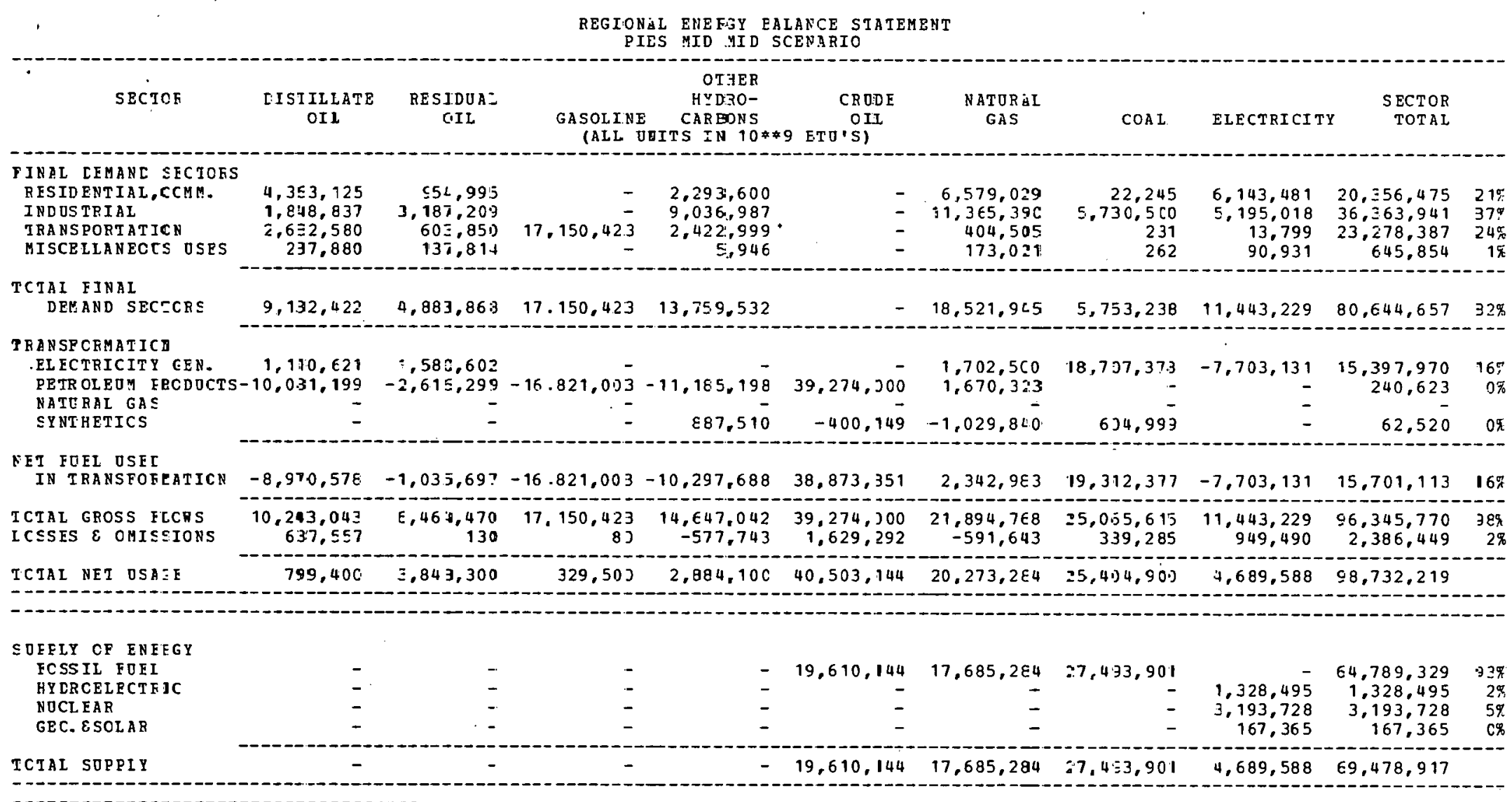

NET IM FCRTS
OF REGION


by fossil fuel plants in 1985 is 7.1 quads. This output requires total fuel consumption of 2.1 quads of natural gas, 15.9 quads of coal, and 3. 3 quads of petroleum products. The fuel loss in the conversion process, treated as consumption by this sector, is 14.3 quads, implying an efficiency of $33.2 \%$.

Petroleum refining is also reported as a transformation process. The inputs to this process are crude oil. and natural gas liquids (1isted as natural gas in the tables). The sector's outputs (negative values) are residual oil, distillates, gasoline, and other petroleum products (other hydrocarbons). These outputs values are interpreted as gross outputs of the refining process. Fuels consumed by the refining sector (for heat and power requirements) are reported with total industrial demand. This convention differs from that employed in earlier volumes, as well as from that used in the DOE model. However, we believe this is a better method for organizing the projections data since it is consistent with fuel use in the manufacturing sector as reported by the Census Bureau (in Annual Survey of Manufactures). ${ }^{8}$ The fuel consumed (interpreted as purchased fuels) by the refining sector, while reported in the industrial total, is projected independently based on DOE projections. 9

In 1985 the refining process is projected to use 35.6 quads of crude oil and 1.8 quads of natural gas liquids as inputs to produce 8.9 quads of distillate oil, 2.7 quads of residuals, 15.2 quads of gasoline, and 10.4 quads of miscellaneous petroleum products. The current approach for projecting conversion processes used by DOE maintains a Btu balance between inputs and outputs. Thus, the sector's net consumption of 0.3 quads is an artifact of the DOE model rather than sectorial consumption or Btu's lost through the conversion process. 
In the projections for the years 1985 and 1990, DOE has indirated the emmergence of several new technologies (coal gasification and shale oil production), which are reported as "synthetics." This line will be discussed more fully below.

The net consumption of fuel used in all transformation sectors is presented in the row labeled "Net Fuel Used in Transformation." In the 1985 scenario, the transformation sector converts 35.5 quads of oil, 3.1 quads of nacural gas, and 16.1 quads of coal into 32.9 quads $n$ refined petroleum products and 7.1 quads of electricity. The transformation process is projected to consume 11.0 quads of energy.

Two additional summary rows are presented in the consumption portion of the tables. The row labeled "Total Gross Flows" is the column sum of the positive elements in both the final demand and transformation sectors. This value represents the gross consumption of each fuel, omitting the regional production of transformed energy products. It is used primarily to allucare "losses and omissions."

The losses and omissions row has different interpretationo in the projected and historic data series. For the hietoric data series, a postelve error value indicates an underassignment of fuels to specific categories, inventory accumulations, and/or distribution 1osses. A negative error value indicates an overassignment of consumption to a particular fuel or sector, understatement of production, and/or a depletion of stocks. In the case of the projected data series, the interpretation of the error figures is less straightforward. A portion of the error is due to the characteristics of the DOE model. Limitations of the PIES systems to generate complete equality between supply and 
demand in the integrating component of the model introduces some error. Minor differences in data format between DOE's model and our procedure create additional errors in the table. 10 Finally, the transmission loss of electricity distribution is reported, in our tables, in the losses and omissions line. The overall error, indicated in the "Sector Total" column was $2 \%$ of total net usage for both 1985 and 1990 .

The total regional demand for fuel, less the supply of energy by the transformation sector, is presented in the row labeled "total net usage" 88.5 quads in 1985. This energy demand is met by regional production and regional imports.

\section{Regional Supply}

The total supply of all forms of primary energy is given in the row labeled "total supply." Distillates, residual oil, gasoline, and other hydrocarbons have zero values, indicating that these products are not regarded as primary energy sources. Crude oil, natural gas, and coal constitute the fossil fuels. The other primary fuels considered include electricity generated by hydroelectric power, nuclear, geothermal, and solar sources.

It should be noted that primary electricity generation from hydro and nuclear sources was converted to Btue by the end uee rate of 3412.8 Btue per kilowatt hour, rather than by fossil fuel equivalents. Fossil fuel equivalent conversion rates are often used in supply-oriented analysis to address the potential effects on resource requirements of fuel switching in electrical generation. This approach would artificially inflate 
the total Btus produced in a region, however, and might lead to an improper interpretation of the importance of each fuel and its contribution to end use electricity consumption.

The energy saved due to fuel switching in electricity generation (e.g., the total reduction in demand for fossil fuels brought about by an increase in the same generation from hydro and nuclear power) can be derived by using the appropriate transformation loss for the region. These losses can be obtained from the regional efficiency rates presenter in the table nules.

No effort was made in this study to provide a direct comparison of the fossil fuel savings attained from substituting nuclear, geothermal, solar or hydroelectric inputs, though this can be done easily. For example, the average transformation loss for fossil fuel generation of electricity in. 1972 was approximately 68\%. For every kilowatt hour generated by hydro or nuclear sources, there is a net energy savings in the system of 7,252 Btus (i.e., to get the same end use availability of electricity, 7,252 Btus of fossil fuels need not be extracted). Since the uranium refinement process itself requires electricity, the net saving in nuclear generation would be somewhat less than for hydro, geothermal, or solar generation.

Regional Imports

The data in the tables project spatial patterns of consumption and production, but do not characterize the interrelationships of the flows. The concept of regional imports contained in the statements is a simple accounting relationship calculated as the difference between how much of 
a given fuel is used in a region and how much of the fuel is produced in the region. Regional imports are not a direct measure of projected flows; however, national imports (exports) are measures of projected flows, as discussed below. The tables were constructed to balance so that the sum of the row totals equals the sum of the column totals. The last row, therefore, represents the net regional imports by fuel (a negative number indicates exports). The number in the last row and last column indicates the net energy imports of the region. This is a rough measure of each region's external reliance upon energy supplies.

Care should be used in interpreting the regional imports data. A region may appear as a net importer of energy; however, these imports may be supplied under long-term contractual agreement with producers in other regions. Consequently, even though a region may appear vulnerable to changes in the energy distribution system, it could actual have a. fairly stable energy position. In a number of cases, there are substantial counterflows of energy, where a region may export as well as import a given fuel. The net entries in the tables conceal such flows.

AL Llie national lcvel, the tables report estimated net imports equal to projected imports (23.3 quads in 1985). Any initial differences, between estimated and forecasted net imports at the national level, are then allocated to regions based on their share of total gross usage of each fuel. These differences are reported in the row labeled "losses and omissions." 


\section{THIS PAGE WAS INTENTIONALLY LEFT BLANK}


III. THE NATIONAL ENERGY PROJECTIONS

Future regional patterns of energy consumption and production are determined jointly by regional factors and by changes in national economic activity, energy prices, and energy policies. The regionalization procedure adopted by ORNL uses historic and forecasted regional characteristics to allocate national production and consumption totals. In this way, the model attempts to capture both local and national effects which are likely to determine the regional level of consumption and production of energy products. Consequently, the regional projections included in this volume are quite sensitive to the assumptions underlying the national energy scenario.

The national energy and economic projections for the Mid-Mid scenario, a detailed discussion of the implications of the forecasts, and the assumptions used in developing the projections is provided in the Annual Report to Congress, $1977^{11}$ and will not be detailed here. However, because the regional projections are derived from the national scenario, an overview of the economic and energy policy conditions underlying the scenario is necessary.

An Overview of the National Energy Projections

The DOE projections of energy consumption and production are prepared with the use of an extensive computer simulation model (PIES).12 The PIES model is essentially a system of smaller computer models, including an econometric demand model, a set of cost-minimization supply models for each major energy product, and an integrating model. Future energy demlands 
are estimated given projections of economic activity and initial energy prices. The minimum cost fuel bundle for meeting these demands is determined, and in the integrating model, initial supplies and demands are compared. If they are not equated at the initially estimated energy prices, the prices are adjusted and demands are re-estimated. Demand and supply forecasts are iterated through the system until prices bring about market-clearing.

The procedure that DOE has adopted allows considerable flexibilitity in handling alternative policy constraints within the general framework of a market-oriented solution. The model permits the examination of a wide variety of alternative energy futures through the impusition of auxiliary constraints. However, flexibility in the development of scenarios requires that a description of the major conditions or assumptions imposed on the solution be presented in order to evaluate the results of a particular scenario appropriately.

The Department of Energy developed its forecast of eronnmis activity with the Data Resources Incorporated (DRI) econometric model, which is described and for which summary results are presented in the Annual Report to Congress, 1977.13 A summary of the major nationa1 eronomic and demographic activity projections from the DRI forecast, which have been used in the current reference scenarin, are presented in Tablc 3 . Also included in chis table are the forecasted growth rates for the "equilibrium" energy prices generated by the PIES integrating model.

Several special constraints have been placed on the PIES model for the reference case solution. A summary of the key energy supply and conservation assumptions for the reference case is presented in Table 4. 
Table 3. Projections of national economic activity used in forecasting energy demands

\begin{tabular}{|c|c|c|c|c|c|}
\hline \multirow[t]{2}{*}{ " } & \multicolumn{3}{|c|}{ Projection year } & \multicolumn{2}{|c|}{$\begin{array}{l}\text { Average annual } \\
\text { growth rate }(\%)\end{array}$} \\
\hline & 1977 & 1985 & 1990 & $1977-1985$ & $1985-1990$ \\
\hline$\frac{\text { Economic activity variables }}{\text { (Billions of } 1977 \text { dollars) }}$ & & & & & \\
\hline $\begin{array}{l}\text { Gross national product } \\
\text { Gross private-domestic investment } \\
\text { Personal consumption expenditures } \\
\text { Personal income } \\
\text { Exports of goods and services } \\
\text { Imports of goods and services } \\
\text { Index of industrial production }(1977=100) \\
\text { Unemployment rate }(\%) \\
\text { Employment (millions of persons) } \\
\text { Population (millions of persons) }\end{array}$ & $\begin{array}{r}1888.7 \\
291.9 \\
1209.8 \\
1534.0 \\
181.2 \\
189.8 \\
100.0 \\
7.1 \\
90.4 \\
217.0\end{array}$ & $\begin{array}{r}2623.1 \\
417.7 \\
1626.1 \\
2086.9 \\
267.7 \\
262.6 \\
147.5 \\
4.7 \\
106.7 \\
234.3\end{array}$ & $\begin{array}{r}3033.0 \\
481.0 \\
1921.3 \\
2494.9 \\
333.2 \\
353.3 \\
181.4 \\
4.6 \\
113.4 \\
245.3\end{array}$ & $\begin{array}{r}4.2 \\
4.6 \\
3.8 \\
3.9 \\
5.0 \\
4.1 \\
5.0 \\
-5.0 \\
2.1 \\
1.0\end{array}$ & $\begin{array}{r}2.9 \\
2.9 \\
3.4 \\
3.6 \\
4.5 \\
6.1 \\
4.2 \\
-0.4 \\
1.2 \\
0.9\end{array}$ \\
\hline$\frac{\text { Prices }}{\text { (Index: } \quad 1977=100)}$ & & & & & \\
\hline $\begin{array}{l}\text { GNP implicit price deflator } \\
\text { Consumer price index } \\
\text { Wholesale price index } \\
\text { Unit labor costs }\end{array}$ & $\begin{array}{l}100 \\
100 \\
100 \\
100\end{array}$ & $\begin{array}{l}154.3 \\
151.6 \\
155.6 \\
174.3\end{array}$ & $\begin{array}{l}191.9 \\
188.0 \\
188.6 \\
239.2\end{array}$ & $\begin{array}{l}5.6 \\
5.3 \\
5.7 \\
7.2\end{array}$ & $\begin{array}{l}4.5 \\
4.4 \\
3.9 \\
6.5\end{array}$ \\
\hline $\begin{array}{l}\text { Energy prices } \\
\text { World oil prices ( } \$ 15 / 1 \mathrm{~b}) \\
\text { Energy (Index based on PIES model solution } 1977=100 \text { ) } \\
\text { Electricity (Index based on PIJS model solution } \\
\quad 1977=100 \text { ) }\end{array}$ & $\begin{array}{l}100 \\
100\end{array}$ & $\begin{array}{l}100 \\
153.3\end{array}$ & $\begin{array}{l}100 \\
164.8\end{array}$ & $\begin{array}{l}0 \\
2.5\end{array}$ & $\begin{array}{l}0 \\
1.5\end{array}$ \\
\hline
\end{tabular}

Source: Annual Report to Congress, Volume II, 1977 and DRI Trendlong 0977 Model Report. 
Table 4. Key energy supply and conservation assumptions tor the Mid-Mid scenario

Oi1:

1. World oil prices held constant at $\$ 15.00$ (1977 dollars).

2. No change in current composite price control schedule for domestic oil.

3. A pipeline from west coast to eastern markets assumed to be built by 1985 .

\section{Natural gas:}

1. Continued regulation of interstate gas prices at levels below oil and intrastate gas (prior to Natural Gas Act of 1978).

2. Assumes a gas pipeline from Alaska to north central U.S. will be built by 1985 .

Other fuel supply:

1. Coal exports are determined exogenously.

2. Synthetic fucls development has marginal impact.

\section{Cunservalion:}

The projected effects of five major conservation programs are included in the scenarios.

1. Weatherization of homes.

2. Federal Energy Management Program (to reduce energy consumption in federal buildings).

3. New car fuel economy standards.

4. Appliance efflclency standards.

5. State energy conservation programs.

The net effect of these programs is estimated to generate a shift from fossil fuel to direct solar of 120 trillinn Rrus in 1985 and 276 trillion Btus in 1990 in the residential, commercial, and industrial sectors.

Source: Annual Report to Congress Volume II, 1977. 
For our purposes, the outputs (i.e., the projected energy consumption and supply patterns) provided in the DOE scenarios are taken as exogenous conditions for the regionalization. Thus, an overview of the national energy future, which has been regionalized, is provided by the national energy balance statements. However, to place these forecasts in perspective, with respect to the $1 \mathrm{mplications}$ of predicted national changes, it is useful to examine the growth rates in production consumption of the various energy products. Table 5 indicates the growth rates from 1974 and 1985, and Table 6 shows the growth rates from 1985 to 1990. These tables indicate the projected patterns of change for the nation as a whole. One may also compare the forecasted changes of individual regions to these national changes.

Special Characteristics of the Projected Data Series

The format and methodology used to construct the Regional Energy Balance Statements has been designed to provide a consistent framework for examining the variety of interactions that characterize energy production and consumpliul. Althügli we have attempted to maintain uniformity with the historic and projected data series on which our compilations are based, differences between sources have not always permitted maintaining exact correspondence. Instead, we consistently modified each series in a desire to achieve compatibility between our historic and projected data series. For this reason, differences between our statements and other sources, such as the Bureau of Mines and DOE, arise in several instances. The following discussion documents these 
TABLE 5

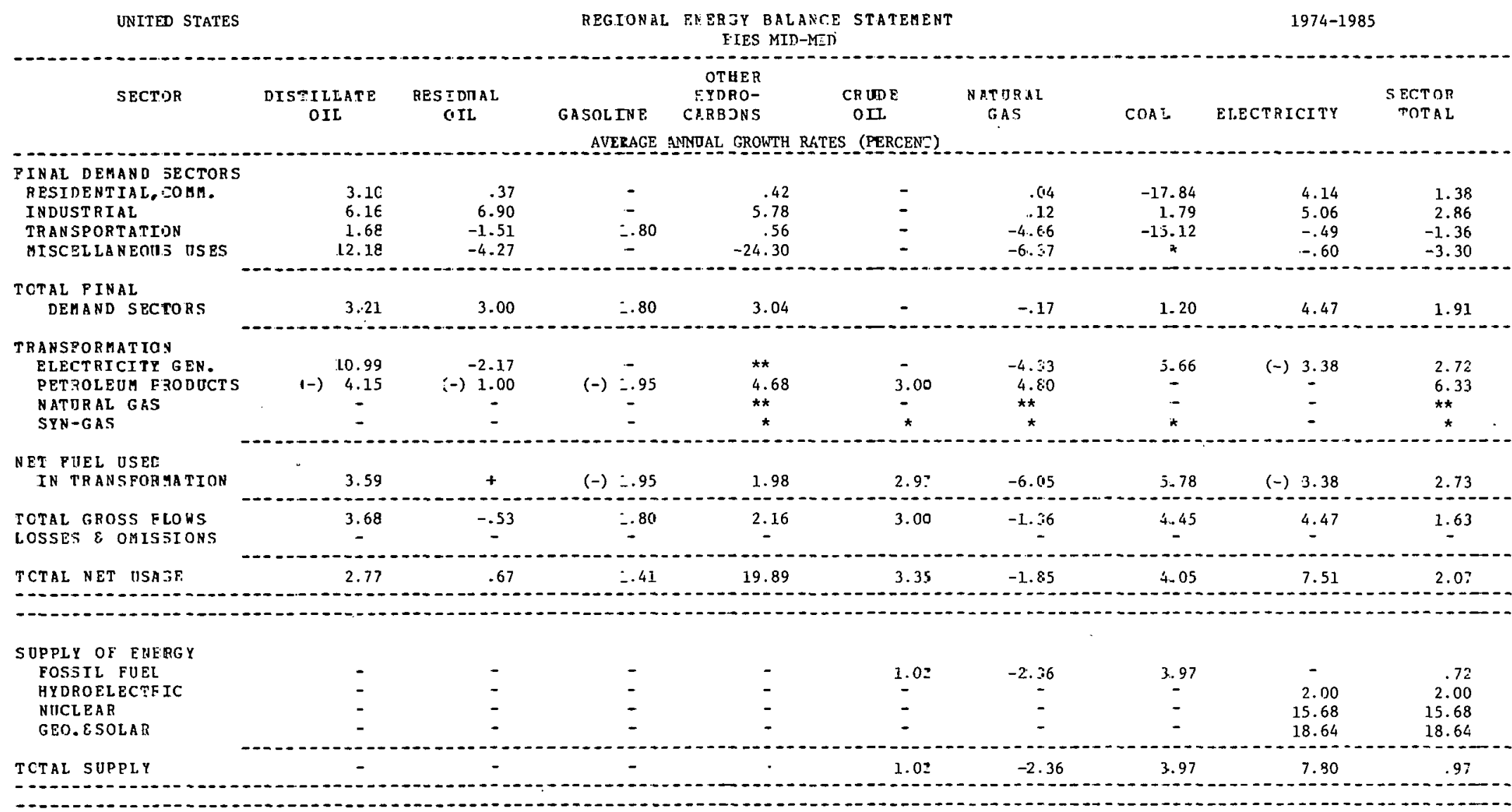

NET IMPORTS

OF REGION

2.77

$-67$

$-3.4 i$

19.89

55.06

5.86

(-) 3.09 $+$

NOTES:

o - No growth rate

* - None in base year

** - None in projectioa year

+ - Years switch sign
+ - Projection year 0

(-) - Negative eritry on Energy Balance Statement 
TABLE 6.

UNITED STATES

EEGIONAL ENERGY BALANCE STATEMENT

$1985-1990$

PIES MID-MID

\begin{tabular}{|c|c|c|c|c|c|c|c|c|c|}
\hline SECTOR & $\begin{array}{l}\text { DISTILLATE } \\
\text { OIL }\end{array}$ & $\begin{array}{l}\text { RESIIDUAL } \\
\text { OIL }\end{array}$ & GASOL INE & $\begin{array}{r}\text { OTHER } \\
\text { HYDRO- } \\
\text { CARBONS }\end{array}$ & $\begin{array}{l}\text { CRIDE } \\
\text { OIL }\end{array}$ & $\begin{array}{l}\text { NATURAL } \\
\text { GAS }\end{array}$ & COAL & ELFCTRICITY & $\begin{array}{l}\text { SECTOR } \\
\text { TOTAL }\end{array}$ \\
\hline 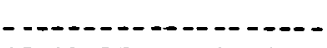 & & & AVERAG & NNUAL GROWTH & (?ERCENI & & & & \\
\hline \multicolumn{10}{|l|}{ FINAL DEMAND SECTORS } \\
\hline BESIDENTIAL, COMA. & 1.68 & .56 & - & 1.85 & - & -1.54 & -8.27 & 3.53 & 1.02 \\
\hline INDUSTRIAL & 5.42 & 4.64 & - & 4.25 & - & 2.28 & 2.70 & 4.44 & 3.47 \\
\hline TRANSPORTATION & 1.03 & .13 & 2.06 & .93 & - & -.33 & -7.66 & 0 & 1.72 \\
\hline IISCELLANEOUS US $3 S$ & 2.49 & .72 & - & -.79 & - & -3.86 & -9.35 & 2.86 & .20 \\
\hline \multirow{2}{*}{$\begin{array}{l}\text { TOTAL PINAL } \\
\text { DEMAND SECTORS }\end{array}$} & & & & & & & & & \\
\hline & 2.19 & 3.05 & 2.06 & 3.20 & - & .70 & 2.63 & 3.93 & 2.29 \\
\hline \multirow{5}{*}{$\begin{array}{l}\text { TRANSPORMATION } \\
\text { ELECTRICITY GEN. } \\
\text { PETROLEOM PRODOCTS } \\
\text { NATURAL GAS } \\
\text { SYN-GAS. }\end{array}$} & & & & & & & & & \\
\hline & 3.28 & -7.89 & - & - & - & -4.58 & 3.30 & $(-) 1.64$ & 1.52 \\
\hline & $(-) 2.60$ & $(-)-.90$ & (-) 2.10 & (-) 1.54 & 2.01 & -1.91 & - & - & -1.38 \\
\hline & - & - & - & - & - & & - & - & \\
\hline & - & - & - & 0 & $(-) 31.96$ & $(-) 2.73$ & 23.81 & - & -8.11 \\
\hline NET PUEL USED & & & & & & & & & \\
\hline IN TRANSFOR MATION & $(-) 2.52$ & $(-)=3.93$ & $(-) 2.10$ & $(-) 1.67$ & 1.86 & -5.40 & 3.69 & $(-) 1.64$ & 1.42 \\
\hline TOTAL GROSS FLONS & 2.31 & -1.08 & 2.06 & 3.20 & 2.01 & .05 & 3.44 & 3.93 & 2.17 \\
\hline LOSSES $\mathcal{E}$ OMISSIOHS & - & - & - & - & - & - & - & - & - \\
\hline TOTAL NET USAGE & 0 & 0 & 0 & 10.54 & 1.70 & .08 & 3.77 & 7.41 & 2.20 \\
\hline SUPPLY OF ENERGY & & & & & & & & & \\
\hline POSSIL PUEL & - & - & - & - & -13.31 & -.66 & 3.60 & - & .86 \\
\hline HYDROELECTRIC & - & - & - & - & - & - & - & .57 & .57 \\
\hline NUCL EAR & - & - & - & - & - & - & - & 10.59 & 10.59 \\
\hline GEO. ESOLAR & - & - & - & - & - & - & - & 23.46 & 23.46 \\
\hline TCTAL SUPPLY & - & - & - & - & -13.31 & -.66 & 3.60 & .7 .41 & 1.23 \\
\hline
\end{tabular}

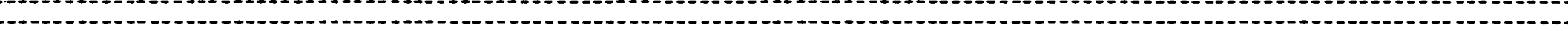

NET IMPORTS

ET IMPORTS
OP REGION

NOTES

0 - No growth rate

* - None in

$\star *$ - None in
+ - Years switch sign

(-) - Negative entry on Energy Balanc Statement 
modifications and is intended to provide the reader with suffi, ient information to reconcile our energy statements with those of other agencies.

The basis for our projected energy statements is the Annual Report to Congress, 1977.14 In the report, the Energy Information Administration (EIA) projected a $2.9 \%$ annual rate of growth, for its reference case, in total energy demand between 1975 and 1990. At this rate, total energy consumption would increase to 108.5 quads hy 199n. This figure represente the "gross" inpur of all fuel used by the nation and is comparable to the concept of "total net usage" (98.4 quads) reported above in Table 2 for 1990.

The difference between our measure of net usage and the DOE total, "gross energy inputs," results. from our use of alternative conversion factors for electricity generated from nuclear, hydro, and geothermal sources. The Department of Energy uses a fossil fuel equivalents approach (the Btu value of fossil fuels needed to generate this electricity by conventional fossil fuel plants) to value electricity produced through "unconventional" means, while we evaluate electricity at the end use rate of 3412.8 Btus per kilowatt hour.

For the 1974 data set, our approach resulted in a reduction of reported total net energy consumption by 2.5 quads. This was equal to $3.4 \%$ of "gross energy inputs" reported by the Bureau of Mines. 15 Because the quantity of electriclty generated through non-fossil fuel technologies is projected to increase, differences in the total energy consumption measured by the two techniques will similarly increase. 
Under DOE projections, this increasing share will cause the fossil fuels equivalent approach to add an additional 6.5 quads $(6.8 \%$ of gross input) in 1985 and 9.8 quads (9.0\% of gross inputs) in 1990 to total net usage. Between 1974 and 1990, our procedure yields a $2.1 \%$ average annual rate of growth in total net usage, as compared with the DOE growth rate of $2.7 \%$. This 0.6 difference is explained by the shift to non-fossil fuel technologies, rather than by increased fossil fuel resource input. It should be noted, however, that using nuclear fuel does require extensive energy inputs by the industrial sector, and to the extent that the scope of energy intensity of this activity is not fully captured in our methodology, total fuel consumption may be understated. A more detailed treatment of the uranium fuel cycle is possible, but infeasible for the purpose of this volume.

With respect to net energy inputs, the figure reported by DOE is identical to that reported in our tables. 16 However, the Bureau of Mines, in its historic data, allocates the transmission loss of electricity distribution to the final demand sectors and thus obtains a slightly higher value for the historic final demand of electricity.

The computer output of the DOE nodel does not appear to contain sufficient information to regionalize the transformation process for the natural gas processing sector adequately. We, therefore, have not estimated this sector in our forecast series, although it is included in our historic data series.

The estimates of electric generation and fuel consumption for the projected utility transformation sector are somewhat different than in the historic series. Because of the aggregate level at which DOE's 
model reports its output, it has been necessary to use the average heat rates and capacity factors which are implicit in the scenarios. ${ }^{17}$ The implication of this assumption is discussed more fully below.

Comparison of the Mid-Mid Scenario to the Earlier NEO 76 Scenario Comparison of the current scenario with that used in our earlier projections volume, indicates that several changes have occurred in the "most likely" growth path of nur nation's pnergy sectors. Table 7 reproduces the U.S. table published in our NE076 projections for 1985, and Table 8 shows the percent differences between the two scenarios for 1985.18

Our current scenario projects a decline in energy consumption in the final demand sectors of $9.4 \%$ relative to NEO76. Of the major sectors, the industrial sector is affected most with a decline of $12 \%$. In the industrial sector, we see a shift away from natural gas towards coal. For the residential sector, however, the Mid-Mid policies suggest an increase in natural gas usage, but a decline in the consumption of petroleum products and electricity. Comparison of the transportation sectors' projections indicates that the Mid-Mid scenario indicates a decline in all fuels, except gasoline which is projected to increase $7 \%$ over the earlier scenario.

Also indicative of the changes that have occurred since the NE076 period, is the decline in projected electricity consumption with a consequent decrease in nuclear-generated electricity $(-34 \%)$. Fossil fuel generated electricity rises slightly (2\%) relative to NE076 with a shift away from natural gas (down 29\%) as input fuel to coal (up 3\%), 
REGIONAL ENERGI BALANCE STATEHENT

BT SECTOR AHD FOEL TIPQ

\begin{tabular}{|c|c|c|c|c|c|c|c|c|c|c|}
\hline SECTOR & $\begin{array}{l}\text { DISTIILATE } \\
\text { OIL }\end{array}$ & $\begin{array}{l}\text { RES IDEAL } \\
\text { OIL }\end{array}$ & $\begin{array}{l}\text { GASOLINE } \\
\text { (ALL D }\end{array}$ & $\begin{array}{c}\text { OT HER } \\
\text { HYDBO- } \\
\text { CARBOSS } \\
\text { JHITS IN } 10 * * 9\end{array}$ & $\begin{array}{c}\text { CRODR } \\
\text { OIL } \\
\text { BTO'SI }\end{array}$ & $\begin{array}{l}\text { NATORAL } \\
\text { GAS }\end{array}$ & $\operatorname{COA} L$ & ZLPCT BICITI & $\begin{array}{r}\text { SECTOR } \\
\text { TOTAL }\end{array}$ & \\
\hline $\begin{array}{l}\text { IINAL DEGANE SECTORS } \\
\text { RESID RNTIAL, COHA. } \\
\text { IRDOSTRIAL } \\
\text { TRANSPORTATION } \\
\text { KI SCE LIAHEOOS OSES }\end{array}$ & $\begin{array}{r}2.266 .385 \\
1.297 .874 \\
2.875,399 \\
50.004\end{array}$ & $\begin{array}{l}1.312 .947 \\
1.735 .416 \\
634.700 \\
158.046\end{array}$ & 14.040 .224 & $\begin{array}{r}2.505,087 \\
5,063,053 \\
4,016,730 \\
19.984\end{array}$ & $\begin{array}{l}\overline{-} \\
-\end{array}$ & $\begin{array}{r}6.115,767 \\
14.021 .867 \\
811.140 \\
324.557\end{array}$ & $\begin{array}{r}114,074 \\
9,816,802 \\
2,382 \\
-\end{array}$ & $\begin{array}{r}6.308 .870 \\
3.864 .765 \\
14.415 \\
125,047\end{array}$ & $\begin{array}{r}20.623,130 \\
30,849,777 \\
23,194,990 \\
687,638\end{array}$ & $\begin{aligned} 238 \\
348 \\
2 \leq 4 \\
18\end{aligned}$ \\
\hline $\begin{array}{l}\text { TCTAL PINAL } \\
\text { DEMAND SECTORS }\end{array}$ & $8,489,662$ & $3,901,109$ & $19,940,224$ & 12.004 .854 & - & $21,273,331$ & $4.933,258$ & 10.313 .097 & 75.355 .535 & 838 \\
\hline $\begin{array}{l}\text { TRANSPORHATIOH } \\
\text { RLECTRICITY GEN. } \\
\text { PETROL ROA PRO DOCTS } \\
\text { NATORAL GAS } \\
\text { STN-GAS }\end{array}$ & $\begin{array}{r}401,807 \\
-8,713,947 \\
- \\
-\end{array}$ & $\begin{array}{r}2.296 .051 \\
-0.017 .637 \\
-\end{array}$ & $\begin{array}{r}42.457 \\
=\end{array}$ & $\begin{array}{r}-12.981,731- \\
-\end{array}$ & $\begin{array}{r}38,013.854 \\
-\end{array}$ & $\begin{array}{r}3,047.275 \\
1,145,727 \\
-\end{array}$ & $\begin{array}{r}15.385,017 \\
= \\
260,760\end{array}$ & $\begin{array}{r}-6.968 .429 \\
= \\
-87.160\end{array}$ & $\begin{array}{r}14.161 .721 \\
-1.296 .191 \\
173.600\end{array}$ & $\begin{array}{r}168 \\
08\end{array}$ \\
\hline $\begin{array}{l}\text { NET FOEL OSED } \\
\text { IN TRANSPORATION }\end{array}$ & $-8,312,140$ & -2.121 .586 & -14.342 .457 & -12.981 .731 & 38.013 .854 & $4.193,002$ & $15,645,777$ & $-7,055.589$ & 13.039 .130 & 148 \\
\hline $\begin{array}{l}\text { TOTAL GROSS PLONS } \\
\text { LOSSPS E OMISSICNS }\end{array}$ & $\begin{array}{r}8.891 .469 \\
-372\end{array}$ & $\begin{array}{r}6,197,160 \\
-1,546\end{array}$ & $\begin{array}{r}14.440 .229 \\
-4.291\end{array}$ & $\begin{array}{r}12.004,854 \\
1.514 .939\end{array}$ & $\begin{array}{r}38,013,854 \\
-3,563\end{array}$ & $\begin{array}{r}25,466.333 \\
270.511\end{array}$ & $\begin{array}{r}20.579 .035 \\
-12.419\end{array}$ & $\begin{array}{r}10,313.097 \\
1.049,525\end{array}$ & $\begin{array}{r}89.690 .856 \\
2.812 .783\end{array}$ & $\begin{aligned} 9 \varepsilon 9 \\
3 x\end{aligned}$ \\
\hline TCTAL NET OSAGE & 177.149 & 1.777 .976 & 93.475 & 538,062 & $38,010,290$ & $25,736,844$ & $20,566,615$ & .4 .307 .033 & 91.207 .448 & \\
\hline $\begin{array}{l}\text { SOPPLY OF ENERG I } \\
\text { FOSS IL POEL } \\
\text { HIDROELRCTRIC } \\
\text { NOCLEAR } \\
\text { GEO.E SOL AR }\end{array}$ & $\begin{array}{l}\overline{-} \\
-\end{array}$ & $\overline{-}$ & $\begin{array}{l}\overline{-} \\
\overline{-}\end{array}$ & $\begin{array}{l}- \\
- \\
-\end{array}$ & $\begin{array}{r}28.130 .675 \\
= \\
=\end{array}$ & $\begin{array}{r}24.341 .054 \\
- \\
-\end{array}$ & $\begin{array}{r}22,366,616 \\
- \\
-\end{array}$ & $\begin{array}{r}1,285,385 \\
2,957,763 \\
63,885\end{array}$ & $\begin{array}{r}74.838,345 \\
1.285 .385 \\
2,957.763 \\
63,885\end{array}$ & $\begin{array}{r}5 \leq x \\
28 \\
49 \\
68\end{array}$ \\
\hline TCTAL SUPPLY & - & - & - & - & $28,130,675$ & 24.341 .054 & $22.366,616$ & $4,307,033$ & 79.145 .378 & \\
\hline
\end{tabular}

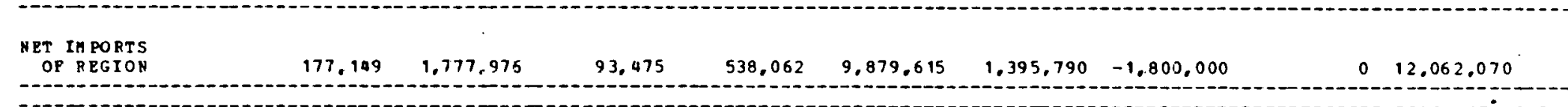

ROTES:

1 TRANSPORHATICN LOSS POR TLECT BICITY GEM. $=67.02 x$

IRANSFORAATION LOSS POR EETROLROA PRODUCTS $=-3.31$

IRANSPORATICH LOSS FOR MATORAL GAS 
TABLE 8

REGTGNAL ENTRGY BALANCE STATEGENT

MID-MIJ COMPARED TO NEO 1975

\begin{tabular}{|c|c|c|c|c|c|c|c|c|c|}
\hline \multirow[t]{2}{*}{ SEETOR } & \multirow[t]{2}{*}{$\begin{array}{l}\text { DISTILLATE } \\
\text { OIL }\end{array}$} & \multirow[t]{2}{*}{$\begin{array}{l}\text { RES IDUAL } \\
\text { OIL. }\end{array}$} & \multirow[t]{2}{*}{ GASOL INE } & $\begin{array}{c}\text { OTHER } \\
\text { HYDRO- } \\
\text { CAEBONS }\end{array}$ & \multirow{2}{*}{$\begin{array}{l}\text { CRIDE } \\
\text { OIL }\end{array}$} & \multirow[t]{2}{*}{$\begin{array}{l}\text { GAT URAL } \\
\text { GAS }\end{array}$} & \multirow[t]{2}{*}{$\operatorname{COHL}$} & \multirow[t]{2}{*}{ ELECTRICITY } & \multirow[t]{2}{*}{$\begin{array}{l}\text { SECTOR } \\
\text { TOTAL }\end{array}$} \\
\hline & & & & \% DIFFER & & & & & \\
\hline $\begin{array}{l}\text { TRANSFORMATZON } \\
\text { ELECTRICIFY GEN. } \\
\text { PETROLEITH PRODUCTS } \\
\text { NATTRAL GAS } \\
\text { SYITHETICS }\end{array}$ & $\begin{array}{c}35.15 \\
(-) \quad 1.76 \\
- \\
-\end{array}$ & $\begin{array}{r}3.80 \\
-38.03 \\
- \\
-\end{array}$ & $\begin{array}{c}- \\
5 . \overline{i 2} \\
- \\
-\end{array}$ & $\begin{array}{l}- \\
-20.16 \\
\star \\
\star \star\end{array}$ & $\begin{array}{c}- \\
-6 .<\varepsilon \\
\star \\
\star\end{array}$ & $\begin{array}{c}-29.36 \\
60.55 \\
- \\
\star \star\end{array}$ & $\begin{array}{c}3.37 \\
- \\
- \\
-20.73\end{array}$ & $\begin{array}{c}(-) \quad 1.93 \\
- \\
\vdots\end{array}$ & $\begin{array}{c}.85 \\
+45.0 \Xi\end{array}$ \\
\hline $\begin{array}{l}\text { NET PUEL USED } \\
\text { IN TRANSFORMATION }\end{array}$ & -4.69 & $-\varepsilon 3.30$ & $5 . i 2$ & -27.00 & -6.74 & -26.26 & 2.98 & $(-)$ & 12.24 \\
\hline $\begin{array}{l}\text { TCTAL GROSS PLONS } \\
\text { LOSSES F. OMIJSIONS }\end{array}$ & 1.89 & $\begin{array}{c}-7.64 \\
-\end{array}$ & $\begin{array}{c}7 . \check{c} 8 \\
-\end{array}$ & -10.53 & $\begin{array}{c}-6 .<8 \\
--\end{array}$ & -17.71 & 2.84 & -8.48 & $\begin{array}{c}-7.5 \varepsilon \\
-\end{array}$ \\
\hline TCTAL NET DSAGE & 251.26 & 16.44 & 152.50 & 124.76 & $-2 . C 7$ & -21.56 & 2.68 & -23.85 & $-2.9 \Xi$ \\
\hline $\begin{array}{l}\text { SUPPIY OF ENERGY } \\
\text { FOSSIL FUEE } \\
\text { HYDROELECTXIC } \\
\text { NIICLEAR } \\
\text { GEO. ESOLA. }\end{array}$ & $\begin{array}{l}- \\
- \\
-\end{array}$ & - & $\begin{array}{l}- \\
- \\
-\end{array}$ & $\begin{array}{l}- \\
-\end{array}$ & $\begin{array}{c}-26: 20 \\
- \\
- \\
-\end{array}$ & $\begin{array}{c}-24.89 \\
- \\
-\end{array}$ & $\begin{array}{l}2.99 \\
= \\
-\end{array}$ & $\begin{array}{r}- \\
.46 \\
-34.74 \\
-9.66\end{array}$ & $\begin{array}{r}-17.05 \\
.46 \\
-34.74 \\
-8.66\end{array}$ \\
\hline TCTAL SUPPLY & - & - & - & - & 26.20 & -24.89 & 2.99 & -3.66 & -18.85 \\
\hline $\begin{array}{l}\text { NET IMPORTS } \\
\text { OF REGION }\end{array}$ & 251.26 & 16.44 & $15 z \dot{z} .50$ & 124.76 & $66: 65$ & 36.63 & $(-) \quad 6.56$ & 0 & 92.1 .5 \\
\hline
\end{tabular}

DOTES:

ICOAPUTED COMFARE:TIVE RATES - EXCLUJE REFINERY USE JF VATURAL IAS AND PETROLEUM PROJUCTS WHICF AFE INCLUDED IN TABLES 2 AND 3 (SEE TEXT)

*NINE IN MID-HITD

* MiNE IN EDA

+S:ENARIO VALUES haVE DIFFEFENT SIG IS 
residual oil (up $4 \%$ ), and distillate oil (up $35 \%$ ). Finally the Mid-Mid scenario projects a lower level of domestic oil and gas production than the NEO76 scenario. Coal production, however, following current policy objectives, is higher in the Mid-Mid scenario than in the earlier NE076.

In summary, the current reference case scenario suggests an overall lower growth rate in energy consumption, a lower profile for nuclear energy, and a shift towards coal. Âlso projected is a lower rate of domestic oil and gas production and refining activities, which is only partially offset by increased coal production and consumption. More natural gas is expected to be available for residential and commercial consumers, because of policies that encourage the industrial and electric utility sectors to shift from natural gas to coal. However, net consumption of petroleum products is higher under the Mid-Mid scenario which results in greater imports than in the NEO76 projections. 


\section{THIS PAGE}

\section{WAS INTENTIONALLY \\ LEFT BLANK}


IV. REGIONALIZATION OF THE DOE SCENARIO

The regional energy demand, transformation, and production projections presented in the Regional Energy Balance Tables have been regionalized independently from the PIES Mid-Mid control totals. Consequently, we do not account for intraregional interactions and linkages which may jointly determine supply and demand patterns. For example, we do not necessarily expand production of coal in those BEA areas which are nearer to regions with increasing coal demands. The only exception to this general limitation is in the determination of electric utility expansion or retirements.

Separate disaggregation methodologies have been developed for the component sector projections. The following discussion is organized by the type of allocation procedure utilized rather than in the framework presented in the REBS tables.

\section{The Regional Consumption of Energy}

The methodology that has been used to regionalize the DOE-PIES federal region projections is described in detail in Volume $I$ of this series. Briefly, the procedure is to estimate initial energy demands, by fuel and sector, by multiplying historic data of energy used per worker (or per capita) times the projected regional level of activity (i.e., the number of workers or persons). The regional demands are then proportionately adjusted so that they add up to the federal region projections by the major sectors and fuels provided in the PIES scenario. 
Figure 2 shows the federal regions for which the PIES model provides projections of energy consumption.

To derive these initial demand estimates, a set of regional activity projections and base year energy-use coefficients are necessary. The regional projections of population and employment are generated using ORNL's MULTIREGION model. 19 MULTIREGION is a scenario-oriented model which allocates a given set of national population and employment projections to BEA areas. For this study, a special series of population and employment projections were prepared using the DRI national projections of employment by sector as exogenous assumptions. ${ }^{20}$ The BEA projections of population and employment are further regionalized to counties to facilitate the conversion of energy demands from state to BEA areas.21

The use of the MULTIREGION model is a significant improvement over the' procedure that was used in our earlier NE076 regionalization, in which OBERS based employment and population projections were used. 22 The current procedure ties the regional employment and population projection consistently to the assumptions underlying the national economic/energy scenarios. Differences in the regional projections of energy consumption between our two energy scenarios may reflect both energy scenario differences, as well as differences in regional population and employment patterns.

The regional energy coefficients are basically the same as used in the previous volumes and discussed in Volume I. They have, however, been modified to match the sectoral definitions used by the MULTIREGION model. Table 9 presents the employment detail available from MULTIREGION. The model also projects detailed population characteristics for BEA areas, 


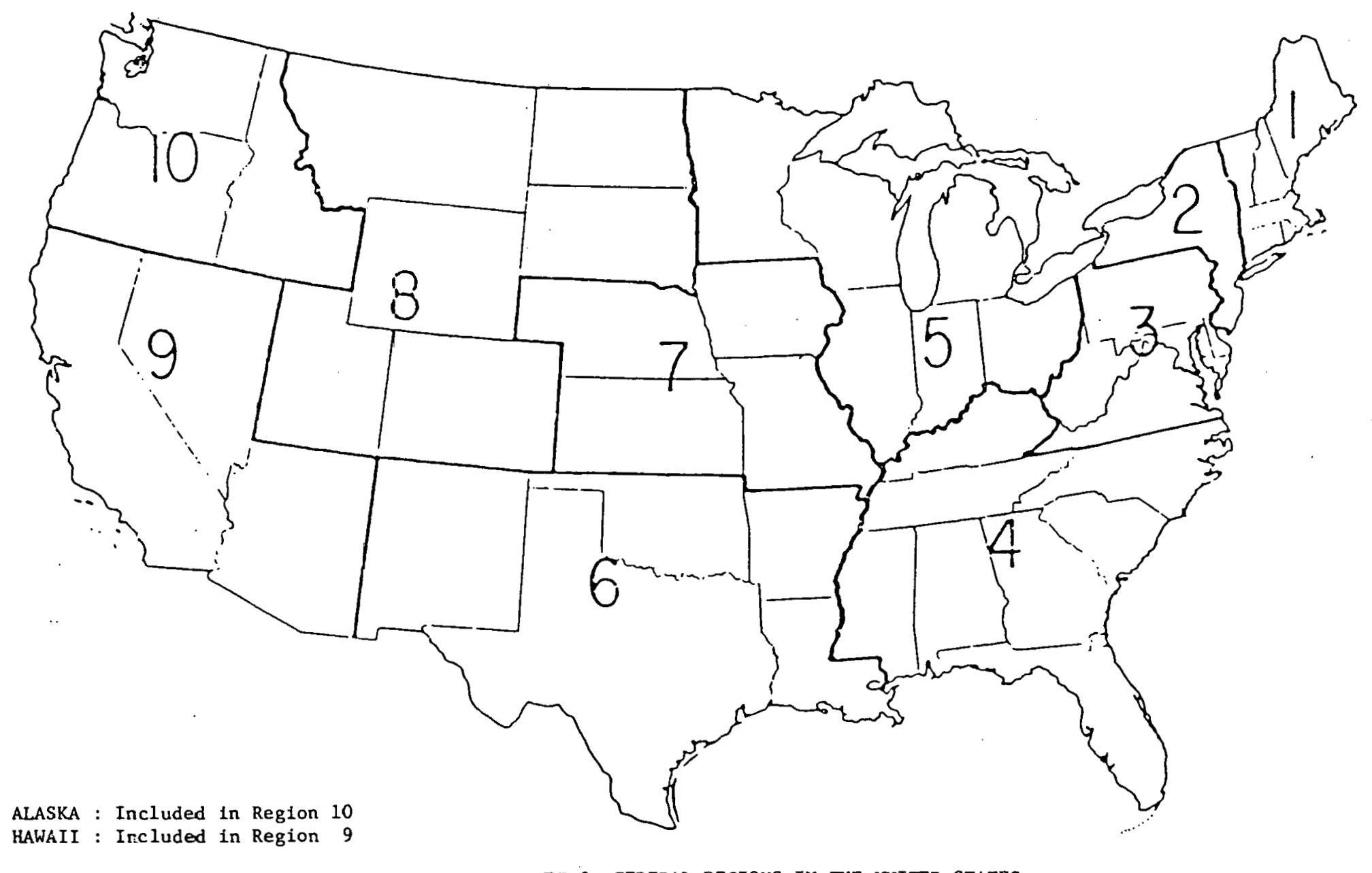

FIGURE 2 FEDERAL REGIONS IN THE UNITED STATES 
Table 9. MULTIREGION sectors and their relationship to PIES sectors

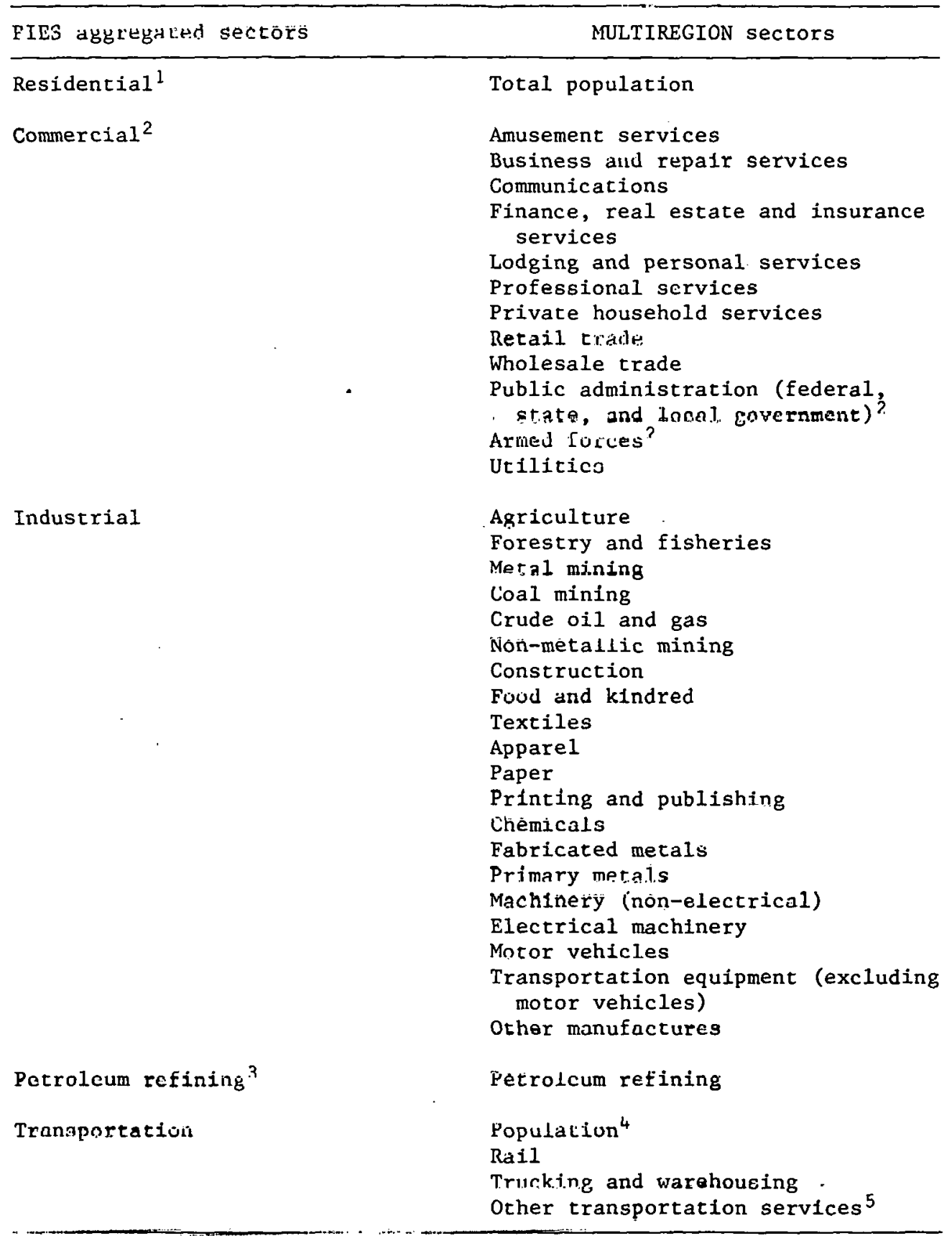

${ }^{1}$ Reported in tables as residential demand.

${ }^{2}$ Reported in tables as miscellaneous.

${ }^{3}$ PIES includes the consumption of electricity and coal by the refining sector in the jndustrial rotal, but separately report petroleuu products and natural gas demands for the sector. We follow their convention in the allocations, but report all fuels used in the refining sectors in the industrial total.

${ }^{4}$ Population is used to regionalize gasoline demands.

${ }^{5}$ Includes air and water transportation employment. 
although the energy demand regionalization procedure utilizes only the total population estimates.

The regional energy coefficients (developed at the state level) have been constructed from a variety of standard sources. Table 10 presents the fuels for which individual projections are made. However, the published primary data sources do not provide a consistent series for all sectors and fuels considered in the regionalization process, and many approximations and independent judgements were necessary in developing the coefficients. ${ }^{23}$ The major data sources used to estimate the coefficients were reported in Volume I and are not repeated here.

Table 10. Definition of Fuel Aggregates and Their Relationship $*$. . . to PIES Projected Fuel Aggregates

\begin{tabular}{lll}
\hline $\begin{array}{c}\text { Fuels defined in the } \\
\text { regionalization procedure }\end{array}$ & \multicolumn{1}{c}{$\begin{array}{c}\text { PIES aggregated } \\
\text { fuel category }\end{array}$} & Table entry \\
\hline Anthracite & Coal & Coal \\
Bituminous & Coal & Coal \\
Metalurgical coal & Coal & Coal \\
Natural gas & Natural gas & Natural gas \\
Kerosene & Distillate oils & Otherhydro \\
Diesel fuel & Distillate oils & Distillate \\
Distillate fuel oil & Distillate oils & Distillate \\
Gasoline & Gasoline & Gasoline \\
Asphal.t & Asphalt & otherhydro \\
Liquid propane gas & Liquid gas & Otherhydro \\
Jet fuel & Jet fuel & Otherhydro \\
Liquid refinery gas & Liquid gas & Otherhydro \\
Still gas & Liquid gas & Otherhydro \\
Naphtha & Naphtha & Otherhydro \\
Special naphtha & Liquid gas & Otherhydro \\
Petroleum coke & Miscellaneous oil products & Otherhydro \\
Lubricants and waxes & Miscellaneous oil products & Otherhydro \\
Miscellaneous liquid gases & Liquid gas & Otherhydro \\
Miscellaneous oil products & Miscellaneous oil products & Otherhydro \\
\hline
\end{tabular}


The Electric Utility Sector

The regional forecasts of electrical generation are primarily based on the announced plans of utilities for planned capacity expansion and plant retirements. Such information is reported to the Federal Energy Regulatory Commission (FERC) by the utilities for each plant and is available on computer tape from FERC on request. 24

For our purposes, however, the scheduled capacity reported by the utility industry must be reconciled with the DOE projections. This has been accomplished by using DOE's projections of generation, capacity, and fuel consumption as regional control totals. The utilities' planned expansion for each federal region can then be compared with the DOE projection for prime mover and fuel categories.

To make the comparison between actual utility plans and the scenario, information of each generation source should be similarly structured. Consequently, we developed a procedure to classify each plant according to its primc movcr and major fuel consumed. the categories considered for this analysis are presented in Table 11. In some cases, more detailed information of basic energy sources in the PIES model was aggregated (e.g., coal consumption by sulfur content was aggregated). The expansions planned by the utilities were modified by a simple siting schcme. First, an estimate of schedule generation of electricity, for each of the substate regions considered in the demand analysis, was obtained by aggregating the FERC unit record file. Regions were classified according to the level of excess regional demand for electricity, which was computed by comparing the estimated regional demands for electricity 
Táble 11. Classification of electric generation by plant and fuel type

\begin{tabular}{|c|c|c|c|c|}
\hline \multicolumn{3}{|r|}{ Generation class } & \multicolumn{2}{|c|}{$\begin{array}{l}\text { Generation characteristics } \\
\text { (Average of DOE region values) }\end{array}$} \\
\hline Class & $\begin{array}{l}\text { Fue1 } \\
\text { type }\end{array}$ & Prime mover & $\begin{array}{c}\text { Capacity factor } \\
\text { Percent }\end{array}$ & $\begin{array}{l}\text { Heat rate } \\
\text { Btu/kwh }\end{array}$ \\
\hline 01 & Coa1 & Conventicnal & 63 & 10,595 \\
\hline 32 & Coa1 & Advanced (combine cycle) & 36 & 9,750 \\
\hline D3 & $0 i 1$ & Conventicnal steam & 32 & 10,620 \\
\hline 04 & $0 i 1$ & Combusticn turbine & 12 & 10,248 \\
\hline 05 & Gas & Conventicnal steam & 32 & 10,750 \\
\hline 06 & Gas & Combustian turbine & 7 & 15,643 \\
\hline 07 & Hydro & Conventianal & 49 & 10,572 \\
\hline 08 & Hydro & Pump storage (and Peaking) & 9 & 10,605 \\
\hline 09 & Nuclear & Conventional steam & 65 & \\
\hline 10 & Nuclear & Advanced (breeder and high temperature gas) & 54 & \\
\hline 11 & Other & Geothermal & 80 & \\
\hline 12 & Other & Solar & 36 & \\
\hline 13 & Other & Waste heat (steam turbine) & 36 & \\
\hline 14 & Other & Refuse (steam turbine) & 36 & \\
\hline 15 & Other & Synthetics & & \\
\hline
\end{tabular}


with the schedule generation. Next, two decision rules were applied: (1) where the FERC projections indicated the number of plants for a particular technology would be overbuilt; we proportionally decreased the forecasted capacity in all subareas treating each technology separately. Changes in capacity were allocated proportionally to existing capacity, and, (2) where additional units were required (according to DOE projections) plants were located in the regions of greatest need (i.e forecasted demand in excess of scheduled supp1y). Rather than allocate all now capacity to one or two regione, however, we allocated the new capacity proportionally to excess demand in each region.

Using these modifications of planned expansion, we estimated both generation and fuel consumption. These forecasts, however, needed to be consistent with the "average technology" imbedded in the DOE scenario. The scenario assumptions of an "average technology" in the electric utility sector is summarized in the assumed values for heat rates and capacity factors. Average heat rates and capacity of each of the technologies considered were derived for each federal region from the DOE scenario. Capacity factors indicate the average amount of generation relative to potential capacity. ${ }^{25}$ Turbine generators, for example, are used primarily to satisfy peaking requirements; they operate infrequently, and thus have low capacity factors. Nuclear plants and conventional fossilfired steam plants are generally base load plants with high average utilization rates and high capacity factors. The averages of the capacity factors across the federal regions are presented in Table 11 . It should be noted that the actual analysis incorporated federal region factors. 
The average capacity factors have been applied to the planned capacity of each plant in order to determine the probable generation of electricity. The plant estimates were aggregated to provide total generation for each category in each federal region.

Fuel consumption for each Federal Region is estimated using average heat rates which are computed from the DOE model. A heat rate indicates. the amount of fuel consumed to produce one kilowatt hour of electricity. These heat rates were applied to the plant generation estimates to derive total fuel consumption for each plant. The estimates of fuel consumption, electric generation, and capacity were constrained to the DOE scenario.

Because of the nature of the approach used in our analysis, two considerations should be kept in mind when examining speciflc regional forecasts. The first relates to the use of "average" federal region characteristics and the second to the implications of the simplified siting scheme.

Aggregate heat rates and capacity factors were used to maintain consistency with the DOE scenario. However, individual plants may have historically deviated from these averages. For example, a plant may be utilized to satisfy intermediate load requirements for a utility, although we.classify it as a base load plant. Each plant is treated as an "average" plant in our analysts. It would be extremely difficult to retain and utilize historical characteristics for each plant, as well as to forecast the precise load structure for each plant in the future. Consequently, the concept of assuming that each plant has averaged regional characteristics is the only feasible approach. The analysis does remain consistent with the DOE scenario, though individual plants may be incorrectly 
estimated. If a particular plant has a significantly different capacity factor or heat rate, we may misrepresent its generation and fuel use. For those regions in which there are few plants, the forecasts should be considered with utmost care. For those regions in which there are several plants, the totals presented for the region are more reliable.

Since the siting analysis ignores all factors except regional excess demand, projected additions to capacity should also be carefully examined. A detailed siting analysis could and perhaps should consider factors other than excess demand. Oak Ridge Nat1onal Laboratory has developed several procedures to do such analysis at the county level, which consider population density, water availability, seismic risk, and air quality standards, among other variables. However, such a* detailed approach was not possible for this study. of course, any given region can be analyzed in more detail, based on the information presented in the tables.

Previous ORNL̈ ctudies indicate that significant changes need not be made to scheduled utility plans to achieve conformity with the DOE scenarios until 1985.26 The siting algorithm considers the additions to or retirements of a small number of plants relative to total capacity. After 1985, however, many factors in the national policy scenarios can alter the potential mix of utility capactities.

Supply and Transformation of Fossil Fuels

The projected supply and transformation of fossil fuels in 1985 and 1990 was based primarily upon the broad regional projections in the. 
Mid-Mid Scenario and was supplemented by state and county level information on cumulative production, remaining reserves, and actual production in 1972, 1973, and 1974. In the case of oil refining the projections were based on the location and capacity of refineries (by county) on January 1 , 1977, and the announced refinery expansions and additions by 1980 and 1985 published by DOE. 27

$\underline{\text { Coal }}$

The Department of Energy projects coal supply by 12 coal supply regions (Fig. 3) and includes bituminous coal, sub-bituminous coal, lignite, and anthracite. These 12 regions were then subdivided into states or state portions in the following manner:

1. Northern Appalachia was defined to include Pennsylvania, Maryland, Ohio, and part of West Virginia.

2. Central Appalachia was defined to include Virginia and parts of Kentucky and West Virginia.

3. Southern Appalachia was defined to include Alabama, Georgia, and Tennessee.

4. Midwest was defined to include Illinois, Indiana, and part of Kentucky.

5. Central West was defined to include Kansas, Iowa, Missouri, Nebraska, Oklahoma, and Arkansas.

6. Gulf was defined as Texas.

7. Eastern Northern Great Plans was defined to include North Dakota, South Dakota, and part of Montana. 


\section{Coal Supply Regions}

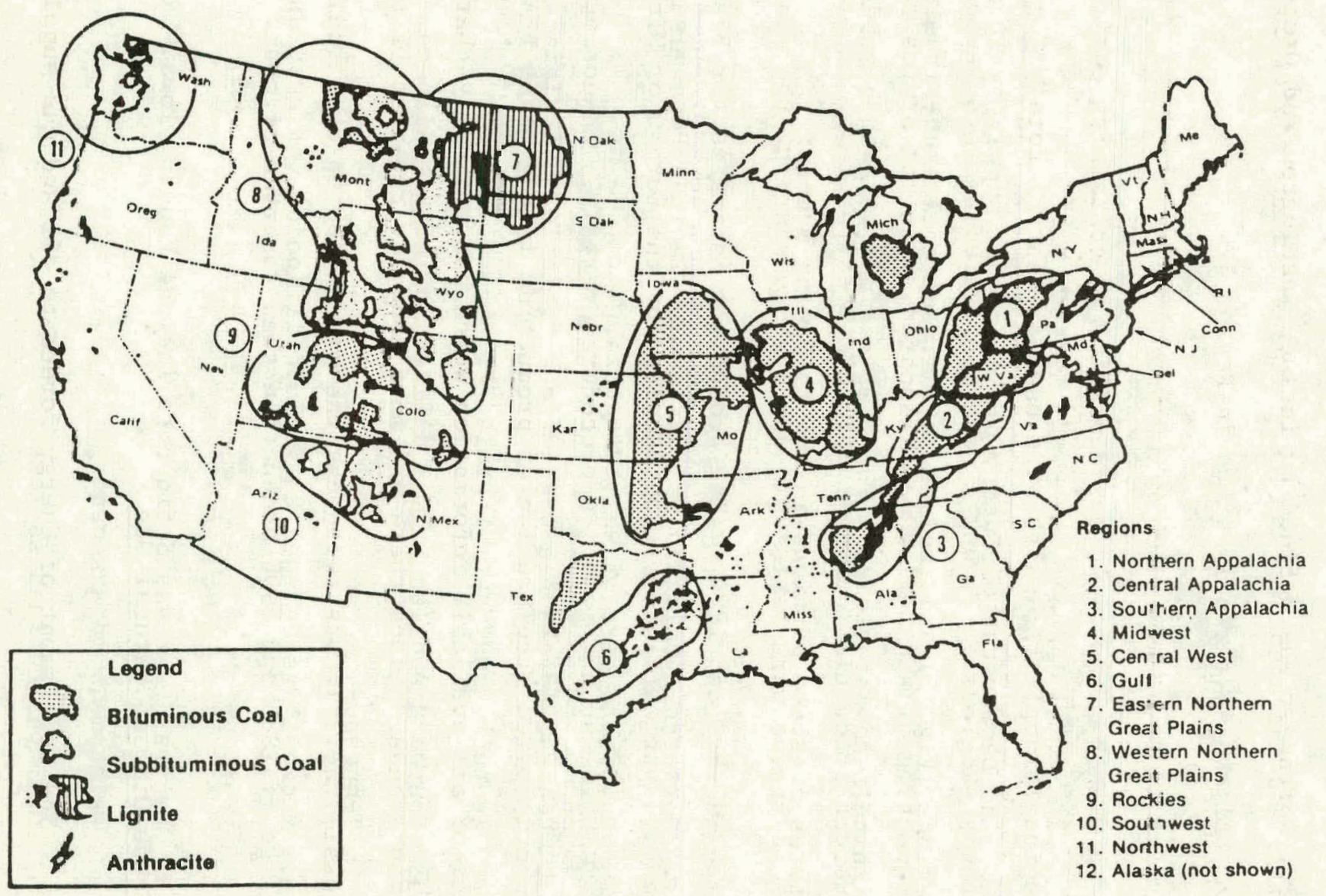


8. Western Northern Great Plains was defined to include Wyoming and parts of Colorado and Montana.

9. Rockies was defined to include Utah and part of Colorado.

10. Southwest was defined to include Arizona and New Mexico.

11. Northwest was defined to include Washington and Oregon.

12. Alaska is the only state in'Region 12 .

When regions could be identified as containing entire states, these regional supply forecasts were used as control totals for the constitutent states (Regions 1, 2, and 4 were aggregated as were Regions 7, 8, and 9). Production of the region was allocated among the states according to the average production during 1976. BEA area forecasts of production within these states were based upon the average share of the state's coal production in 1973 and 1974. (The production estimates for BEAs were based upon county-specific information provided by the Bureau of Mines.)

While such allocation procedures certainly cannot account for unanticipated acceleration of production in any given BEA, they do make use of all available information which has typically characterized production trends. Since there are more abundant reserves of coal than any other fossil fuel, it was felt that the production of coal would be a better gauge of 1985 and 1990 production than reserves of coal.

\section{Crude Oil and Natural Gas}

The Department of Energy forecasts ofl and gas supply for eight onshore regions, three offshore regions, and Alaska (Fig. 4). Given the nature of these regions, it was not possible to disaggregate the regions into 


\section{Oil and Gas Regions}

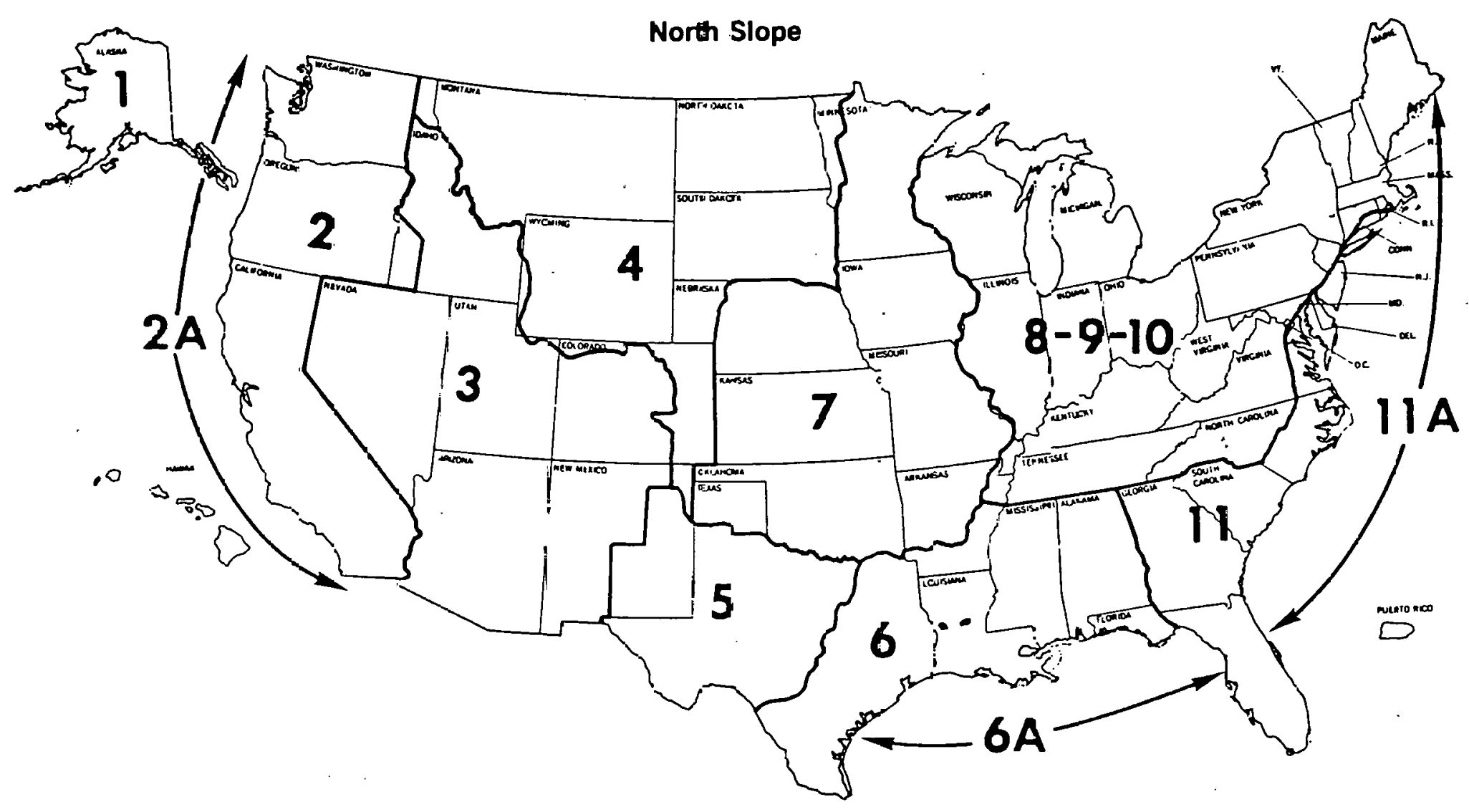


state portions precisely. The assignment of states to the aggregate oil and gas regions used in PIES is presented in Table 12.

The disaggregation procedure was based upon the results of an econometric analysis of the determinants of state oil and gas production in 1972, 1973, and 1974. Among the explanatory variables examined separately for oil and gas were exploratory drilling activity, cumulative production, oil or gas in place, remaining reserves, indicated and inferred reserves, and estimated ultimate production. Remaining proven reserves of each state were used to allocate the regional control total for 1985. Proven, indicated, and inferred reserves of each state were used to allocate the regional control total for 1990. Natural gas production was allocated similarly, though there are no indicated reserves of natural gas. The BEA natural gas production was estimated based upon the average share of the state's production in 1972; 1973, and 1974.

This particular method of allocation was used because we did not have BEA estimates of remaining reserves but we did have county production estimates for 1972, 1973, and 1974, representing actual production figures supplied by the oil and gas agencies in each stace. It is noted, however, that such an allocation procedure might not be applicable after 1985 , when resources of oil and gas are dwindling and remaining reserves may be the determining factor characterizing production.

Transformation of Crude $0 i 1$ and Natural Gas

The Department of Energy forecasts the outputs of refineries and their demand for crude oil and natural gas inputs for five Petroleum Administration 
Table 12. Assignments of States to Oil and Gas Producing Regions

\begin{tabular}{|c|c|c|}
\hline Oil and gas regions & States & included \\
\hline 1. Alaska & Alaska & \\
\hline 2 and 2a. Pacific Cost & $\begin{array}{l}\text { California } \\
\text { Oregon }\end{array}$ & $\begin{array}{l}\text { Hawaii } \\
\text { Washington }\end{array}$ \\
\hline 3. West Rocky Mountains & $\begin{array}{l}\text { Arizona } \\
\text { Idaho } \\
\text { New Mexico }\end{array}$ & $\begin{array}{l}\text { Colorado } \\
\text { Nevada } \\
\text { Utah }\end{array}$ \\
\hline 4. East Rocky Mountain & $\begin{array}{l}\text { Montana } \\
\text { South Dakota }\end{array}$ & $\begin{array}{l}\text { North Dakota } \\
\text { Wyoming }\end{array}$ \\
\hline $\begin{array}{l}\text { 5. West Texas and ( } 6 \text { and } 6 a) \\
\text { Gulf Basin }\end{array}$ & $\begin{array}{l}\text { Alabama } \\
\text { Loulsiana } \\
\text { Texas }\end{array}$ & $\begin{array}{l}\text { Arkansas } \\
\text { M1ss1ss1pp1 }\end{array}$ \\
\hline 7. Midcontinent & $\begin{array}{l}\text { Iowa } \\
\text { Minnesota } \\
\text { Nebraska }\end{array}$ & $\begin{array}{l}\text { Kansas } \\
\text { Missouri } \\
\text { Oklahoma }\end{array}$ \\
\hline $\begin{array}{l}\text { 8, } 9 \text { and 10. Michigan Basin } \\
\text { and Interior Appalachia }\end{array}$ & $\begin{array}{l}\text { Connecticut } \\
\text { Indiana } \\
\text { Maine } \\
\text { Michigan } \\
\text { New York } \\
\text { Ohio } \\
\text { Rhode Islaud } \\
\text { V-rmont } \\
\text { West Virginia }\end{array}$ & $\begin{array}{l}\text { Illinois } \\
\text { Kentucky } \\
\text { Massachusetts } \\
\text { New Hampshire } \\
\text { North Carolina } \\
\text { Pénsylvania } \\
\text { Temuessee } \\
\text { Virginia } \\
\text { Wisconsin }\end{array}$ \\
\hline 11 and 11a. Atlantic Coast & $\begin{array}{l}\text { Delaware } \\
\text { Florida } \\
\text { Maryland } \\
\text { South Carolina }\end{array}$ & $\begin{array}{l}\text { District of Columbia } \\
\text { Georgia } \\
\text { New Jersey }\end{array}$ \\
\hline
\end{tabular}


Districts (PAD's). These regions are shown in Fig. 5. The Pads may be disaggregated into states in the following manner:

PAD 1 - Connecticut, Delaware, Florida, Georgia, Maine, Maryland, Massachusetts, New Hampshire, New Jersey, New York, North Carolina, Pennsylvania, Rhode Island, South Carolina, Vermont, Virginia, and West Virginia

PAD 2 - T11inois, Indiana, Iowa, Kansas, Kentucky, Michigan, Minnesota, Missouri, Nebraska, North Dakota, Ohio, Oklahoma, South Dakota, Tennessee, and Wisconsin

PAD 3 - Alabama, Arkansas; Louisiana, Mississippi, New Mexico, and Texas

PAD 4 - Colorado, Idaho, Montana, Utah, and Wyoming

Pad 5 - Alaska, Arizona, California, Hawaii, Nevada, Oregon, and Washington

The refining capacity of each of these states as of January 1, 1977, was adjusted by the announced plans of the refiners concerning the expansion of facilities and the building of new plants by 1985 and 1990. Projected refinery capacity by state was utilized to allocate the output of gasoline, dietillate oil, residual oil, and nther hydrocarbons forecast for each of the refining reginns. To be consistent with our historical data volumes, we included jet fuel with other hydrocarbons. The BEA production levels of these outputs were determined based on our projected estimates of refining capacity by county in 1985 and 1990 . 

The demand for crude oil and natural gas liquids by refiners was estimated based upon refining capacity. The national estimates of the demand for crude oil and natural gas liquids were allocated to states and BEAs based on projected refining capacity in 1985 and 1990.

The demand for natural gas liquids as an input of refiners was determined by DOE's projected demands for both crude oil and natural gas liquids which are given by refining region. Actual crude oil demand for each region was subtracted from the aggregate consumption of refiners to determine the demand for natural gas liquids (NGL). The national proportion of crude oil to NGL inputs was assumed to apply at the regional level as we11. The regional totals were allocated to states and BEA areas. The conversion factors for gasoline, disti.l.tate oil, residual oil, other hydrocarbons, crude oil, and natural gas liquids are listed in section V.

\section{New Technologies}

The Department of Energy's energy supply projections include estimates of the possible penetration of several new technologies (Table 13). The procedures for regionalizing these are primarily judgemental. We have included several of these new supply technologies in the preparation of our regional tables in order to maintain consistency with the national projections presented in PIES. Because the regional projections are essentially educated guesses, it is desirable to report them separately in the regional tables. 
Solar and Geothermal

In the case of direct solar utilization in the residential, commercial, and industrial sectors, the PIES scenario projects likely penetration only at the national level (Table 13). Because it is assumed that the use of direct solar lowers the demand for other energy sources in these sectors, the regional effect of solar is accounted for by a decrease in the demand for other fuels and is captured in the PIFs projertinns. We havo not attempted to project regionally the amount of substitution that takes place, (i.e., the demand for direct solar). Central station solar and geothermal (i.e., electricity generated by solar and geothermal technologies in the utility sector) has been regionalized by the procedure discussed in the earlier section pertaining to the utility sector.

\section{Synthetics}

Three emerging fuel courcco arc included in the syulletles caregory. The Department of Energy projects that a small amount of synthetic gas will be derived from coal and liquid petroleum products. These two processes are indicated separately in the tables. In addition, the projections include some production of crude oil from oil shale deposits. These fuel sources are included in the synthetics line of the tables.

The regional allocation of synthetic gas from coal was performed by first estimating the number of "average size" installations which would be required to meet the federal region tutal production presented in the PIES projections. These installations were then sited in particular BEA areas. The candidate BEA areas were selected based on the (current or planned) 
Table 13. Production projections for new and Emerging lechnologies $\left(10^{15} \mathrm{Btu}\right)$

\begin{tabular}{lll}
\hline & 1985 & 1990 \\
\hline Synthetic fuels & 0.10 & 0.35 \\
Shale & 0 & 0.05 \\
Syncrude & 0.10 & 0.23 \\
High Btu Gas & $\underline{0}$ & $\underline{0.07}$ \\
$\quad$ Subtotal & 0.20 & 0.70 \\
Geothermal energy & & \\
Electric utility mode & 0.2 & 0.4 \\
Dispersed mode & $\underline{0.1}$ & $\underline{0.3}$ \\
$\quad$ Subtotal & 0.3 & 0.7 \\
Solar heating and cooling & & 0.144 \\
Buildings & 0.068 & 0.08 \\
Wind energy & & 0.03 \\
Electric utility mode \\
Photovoltaic applications \\
Solar thermal energy
\end{tabular}

Source: Annual Report to Congress. 
presence of a demonstration plant. If no demonstration plants were scheduled to be built in a federal region for which synthetic gas production was projected, the units were allocated based on regional coal availability. Similarly, average size plants which would produce the projected synthetic gas based on liquid petroleum products conversion were located in candidate BEA areas. The locations, in this case, were based on the (current or planned) presence of a demonstration synthetics plant or a petroleum refinery.

'l'he regional production of synthetic gas by either of these two processes is included in the tables by a (negative) value of synthetic gas produced and a positive (input) entry reflecting either the coal or petroleum 1iquids (other hydrocarbons) consumed.

The third energy source considered in the synthetics line is the production of oil from shale oil reserves. The production of shale oil wae located only in those BEA areas which have shale nil. xeserves. We have indicated the production of shale oil as a synthetic fuel rather than as a component of crude oil supply in order to indicațe the locations we have selected as likely production centers. The regional production of shale oil is represented as a negative (output) number in the crude oil column. There is, however, no matching positive (input) entry. 
SECTION V. CONVERSION FACTORS

\begin{tabular}{lc} 
Crude oil & $5,800,000$ Btus per barrel \\
Natural gas (consumption) & $1,021,000$ Btus per thousand cubic feet \\
Natural gas (production) & $1,093,000$ Btus per thousand cubic feet \\
Electricity & $3,412,000$ Btus per thousand kilowatt \\
hours & $5,825,000$ Btus per barrel \\
Distillate oil & $6,287,000$ Btus per barrel \\
Residual oil & $5,248,000$ Btus per barrel \\
Gasoline & $5,670,000$ Btus per barrel \\
Kerosene and jet fuel & $5,068,000$ Btus per barrel \\
Other hydrocarbons (1980) & $5,020,700$ Btus per barrel \\
Other hydrocarbons (1985) & $4,032,629$ Btus per barrel \\
Natural gas liquids & $21,890,000$ Btus per short ton \\
Coal (1980) . & $21,520,000$ Btus per short ton \\
Coal (1985) & \\
\hline
\end{tabular}

NOTE: To convert each of these factors to metric units, the appropriate rate of conversion is $1 \mathrm{Btu}=1054.8$ joules. 


\section{THIS PAGE \\ WAS INTENTIONALLY \\ LEFT BLANK}


r 


\section{THIS PAGE \\ WAS INTENTIONALLY \\ LEFT BLANK}


MULT I REGI ON POPUL AT ION PROJECTIONS

BASEJ ON DOE MID-M ID SCENARIO

THOUS ANCS DF PERSONS

\begin{tabular}{clrrrrr} 
FEAREG & \multicolumn{1}{c}{ FEA } & Y1970 & Y1975 & Y1980 & Y1985 & Y1990 \\
0 & UNITED STATES & 203212 & 213445 & 222768 & 234064 & 245074 \\
1 & NEW ENGLAND & 11842 & 12249 & 12656 & 13207 & 13844 \\
2 & N.Y.JN.J. & 25405 & 25405 & 25353 & 25603 & 25925 \\
3 & MD. ATLANTIC & 23414 & 24238 & 24912 & 25734 & 26477 \\
4 & S. ATLANTIC & 31855 & 35069 & 37934 & 41019 & 43930 \\
5 & MIDWEST & 44057 & 45041 & 45916 & 47298 & 48626 \\
6 & SCUTHWST & 20337 & 21969 & 23523 & 25269 & 26999 \\
7 & CENTRAL & 11231 & 11490 & 11691 & 11966 & 12218 \\
8 & N. CENTRAL & 5577 & 6134 & 6680 & 7289 & 7873 \\
9 & WEST & 22981 & 2486 & 2666 & 28748 & 30783 \\
10 & NORTHWEST & 6514 & 6983 & 7437 & 7931 & 8398
\end{tabular}


MULTIREGICN EOPULAT ION PROJECTIONS

\begin{tabular}{cl} 
CENNO & \multicolumn{1}{c}{ CENSUS } \\
0 & UNITED STATES \\
1 & NEW ENGLAND \\
2 & MD. ATLANT IC \\
3 & E. N. CENTRAL \\
4 & W.N. CENTRAL \\
5 & SQ. ATEANT IC \\
6 & E.S. CENTRAL \\
7 & W.S. CENTRAL \\
8 & MCUNTAIN \\
9 & PACIFIC
\end{tabular}

YTUS ANCS OF PER SONS

$Y 1970$

$Y 1975$

$Y 1980$

203212

213445

222768

11842

12249

222768
12656

37420

41079

37511

41820

4025

16762

17118

36550

36550
14139

30671

33738

13554

19321

8.282
$2 \epsilon .523$

20847

28283

22286

10769

10769
29920

Y1ฐ85. Y1990

234064

245074

13207

13844

$\begin{array}{ll}37964 & 38468 \\ 43013 & 44158\end{array}$

$17625 \quad 18102$

$39576 \quad 42425$

$1481 \% 15440$

12140

13491 
MULT IREGION POPULATION PROJECTIONS

BASED ON DOE MID-M ID SCENAR

\begin{tabular}{|c|c|c|c|c|c|c|}
\hline FIPST & STATE & $Y 1970$ & Y1975 & Y1980 & Y1s85 & Y1990 \\
\hline $\begin{array}{l}0 \\
1 \\
2 \\
4 \\
5 \\
6 \\
8 \\
9 \\
10 \\
11 \\
12 \\
13 \\
15 \\
16 \\
17 \\
18 \\
19 \\
20 \\
21 \\
22 \\
23 \\
24 \\
25 \\
26 \\
27 \\
28 \\
29 \\
30 \\
31 \\
32 \\
33 \\
34 \\
35 \\
36 \\
37 \\
38 \\
39 \\
40 \\
41 \\
42 \\
44 \\
45 \\
46 \\
47 \\
48 \\
49 \\
50 \\
51 \\
53 \\
54 \\
55 \\
56\end{array}$ & 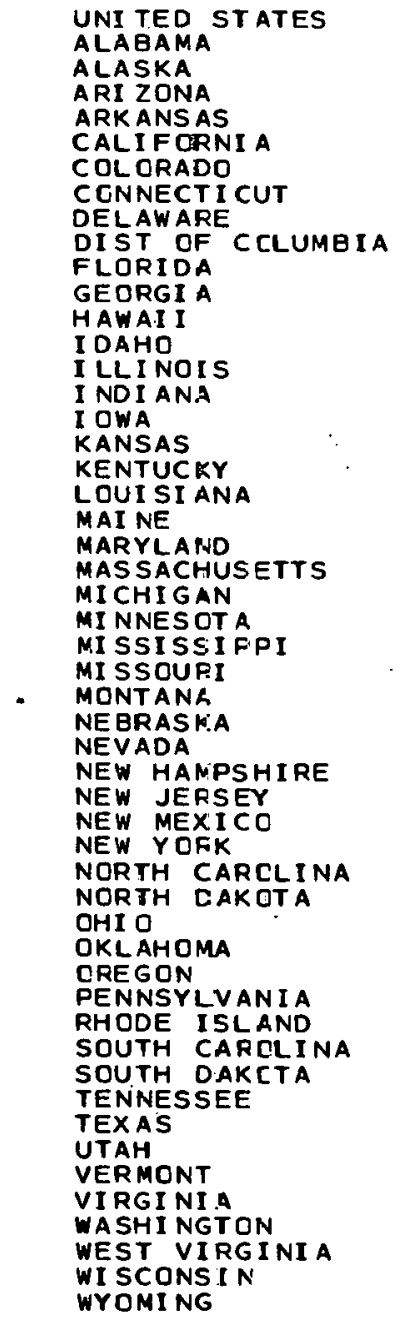 & $\begin{array}{r}203212 \\
3444 \\
300 \\
1771 \\
1923 \\
19953 \\
2207 \\
3032 \\
548 \\
757 \\
6789 \\
4590 \\
769 \\
713 \\
11114 \\
5194 \\
2824 \\
2247 \\
3219 \\
3641 \\
992 \\
3922 \\
5689 \\
8875 \\
3805 \\
2217 \\
4677 \\
694 \\
1483 \\
489 \\
773 \\
7168 \\
1016 \\
18237 \\
5082 \\
618 \\
10652 \\
2559 \\
2091 \\
11794 \\
947 \\
2591 \\
666 \\
3924 \\
11197 \\
1059 \\
444 \\
4648 \\
3409 \\
1744 \\
4418 \\
332\end{array}$ & $\begin{array}{r}213445 \\
363 \\
350 \\
2181 \\
2086 \\
21233 \\
2521 \\
3102 \\
574 \\
716 \\
8256 \\
4967 \\
864 \\
795 \\
11195 \\
5327 \\
2879 \\
2290 \\
3387 \\
3788 \\
1055 \\
4160 \\
5877 \\
9155 \\
3961 \\
2318 \\
4783 \\
734 \\
1538 \\
592 \\
769 \\
7186 \\
1122 \\
18219 \\
5470 \\
633 \\
10791 \\
2736 \\
2288 \\
12015 \\
974 \\
2821 \\
679 \\
4217 \\
12236 \\
1211 \\
472 \\
4970 \\
3550 \\
1802 \\
4611 \\
357\end{array}$ & $\begin{array}{r}22768 \\
3769 \\
400 \\
2611 \\
2239 \\
22424 \\
2831 \\
3181 \\
597 \\
716 \\
9703 \\
5314 \\
943 \\
884 \\
11289 \\
5456 \\
2924 \\
2303 \\
3516 \\
3902 \\
1108 \\
4368 \\
6070 \\
9368 \\
4096 \\
2398 \\
4875 \\
780 \\
1585 \\
689 \\
800 \\
7204 \\
1237 \\
18149 \\
5768 \\
645 \\
10902 \\
2897 \\
2473 \\
12158 \\
999 \\
3010 \\
686 \\
4456 \\
13248 \\
1353 \\
497 \\
5227 \\
3679 \\
1847 \\
4805 \\
384\end{array}$ & $\begin{array}{r}234064 \\
3928 \\
467 \\
3083 \\
2409 \\
23841 \\
3153 \\
3298 \\
623 \\
716 \\
11192 \\
5717 \\
1025 \\
980 \\
11524 \\
5624 \\
2989 \\
2321 \\
3676 \\
4049 \\
1159 \\
4623 \\
6347 \\
9720 \\
4285 \\
2524 \\
5013 \\
836 \\
1643 \\
798 \\
841 \\
7313 \\
1364 \\
18291 \\
6081 \\
677 \\
11092 \\
3055 \\
2659 \\
12360 \\
1039 \\
3212 \\
698 \\
4688 \\
14393 \\
1510 \\
523 \\
5509 \\
3825 \\
1903 \\
5052 \\
416\end{array}$ & $\begin{array}{r}245074 \\
4074 \\
533 \\
3568 \\
2579 \\
25205 \\
3462 \\
3421 \\
647 \\
716 \\
12625 \\
6116 \\
1102 \\
1070 \\
11763 \\
5785 \\
3057 \\
2330 \\
3833 \\
4209 \\
1203 \\
4867 \\
6692 \\
10060 \\
4469 \\
2644 \\
5141 \\
887 \\
1690 \\
908 \\
889 \\
7432 \\
1488 \\
18493 \\
6344 \\
706 \\
11262 \\
3204 \\
2834 \\
12543 \\
1093 \\
3405 \\
710 \\
4890 \\
15520 \\
1661 \\
5547 \\
5756 \\
3962 \\
1948 \\
5288 \\
447\end{array}$ \\
\hline
\end{tabular}


WULTIREJION POPLLATION PROJECTIONS

BASED ON DOE AID MID SCENAR IO

BEA

UNI TED STATES TOTAL

BANGOR MAINE

POR TLAND-SOUTH PORTLAND MAINE

BURLING TON VERMCNT

BOSTON MA SSACRUSETT

ALBANY-SCHE NECTADY-TRCY NEW YOFK

SYRACUSE NEW YOFK

ROCHESTER NEW YCRK

ROCFALO NEW Y:JRR:

WILLIAMSPORT JEMNSYLVANIA

BINGHAMTON NE W YORK

WE

NEW YORK NEW YORK

SYLVANI A-PJEW JERSEY

PALT

WA SHINGTON-DC MAFYLAND-VIRGINIA

STA LNTON VIRGI N-A

ROANOKE VIRGINIA

RICHMONO VIRGIN..A

NOPF OLK-PORTSMOITH VIRGINI

NDREIGH NORTH C TROLINA

WI LMINGTON NCRTH CAFCLINA

作

A SHEVILL NCETH CAROLINA

GREENVILLE SOUT 1 CAFELINA

COLUMBIA SOUIIH CARCLINA

FLORENCE SOUTH CAROLIAA

CHARLESTON SIUTH CARCLINA

A UG USTA GEOREI A

SA VANNAH GE ORGI A

ORLANDO FLORIDA

MI AMI FLORD I A

TAMPA-SAINT PETERSBURG FLCRIDA

TALLAHASSEE FLCRIDA

PENSACOLA FLDRIDA

MONTGOMERY ALAEAMA

A LBANY GE OREI A

CO!UMB US GE ORG A-ALABAMA

A TANTA GEOROI IA

ME YPHI S TENHESSEE-ARKALSAS

CFATTANOOGA TENAESSEE-GEORGIA

NASH VI LLE TENNESSEE

BF: I STOL VIRGI NE A-TENNESSEE

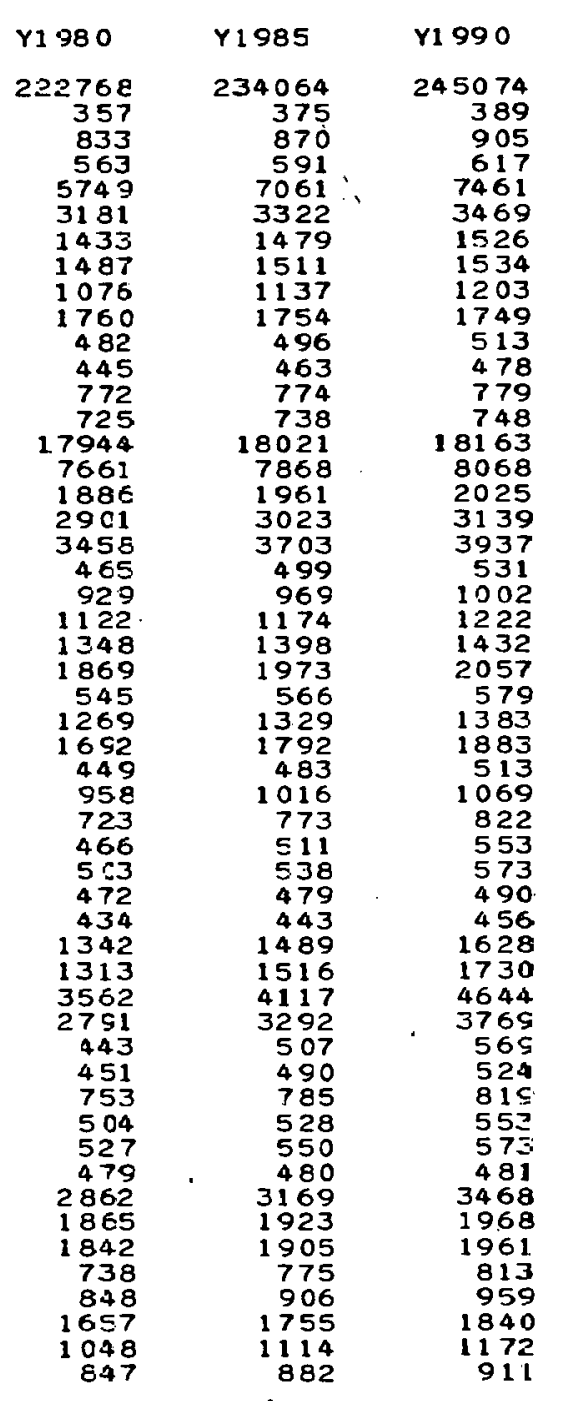


MULT IREGION POPULAT ION PROJECTIONS

THOUSANOS OF PERSONS

EANO
52
53
54
54
55
56
57
58
59
60
61
62
63
63
64
65
66
67
68
69
70
71
72
73
73
74
75
76
77
78
79
80
81
82
83
84
84
85
86
87
98
99
39
90
91
92
93
94
95
96
97
98
99
180
101
102
103

BEA

$Y 1970$

HUNTI NG TON-ASHLAND WEST VIRGINIA-KENTUCKY-OHIO

LEXI NG TON KENTUCKY

LOUI SVILLE KENTUCKY-INDIANA
EVANSVILLE INDI ANA-KENTUEKY

TERRE HAUTE I NDI INA

CHA MPAI GN-URB ANA ILLINCIS

LAFAYETTE-WEST LAFAYETTE INDI ANA

I ND I ANAPOLIS I NDI ANA

ANDERSON I NDI ANA

CINCI NNATI OHIO-KENT UCKY I I NDI ANA

DAYTON OHIO

CLLUMEUS OHIO

YOUNG STOWN-WARREN OHIC

CLEVELAND OHIO

LIMA OHIO

OETROI T MICHIGAN

GRAND RAPIDS MICHIGAN

LANSING MICHIGAN

FORT WAYNE INDI ANA

CHICAGO IULINOIS

PEORIA IILLINOIS

DA VENPORT-ROCK ISLAND-MOLI NE IOWA-ILLINOIS

CEDAR RAPIOS IOWA

DLB UQUE I OW

ROCKFORD ILLINOIS

MIL WAUKEE WI SCONSIN

WCCNSIN

DUR UTH-SUPE RI OR MINNESCT A-WIS CONS IN

EAU CLAIRE WI SCCINS IN

LA CROSSE WISCONSIN

MINNEAPOLIS-SAINT PAUL MI VNES OT A

GRAND FORKS NORTH DAKCTA

GREAT FALLS MONTANA

GREAT FALLS MONTAN

BI LLINGS MONTANA

FARG O MORTH DAKOTA TKTT A-YINNESOT A

ABERDEEN SOUTH DAKOTA

SI OUX FALLS SOUTH DAKCTA

RAPID CI TY SOUTH DAKOTA

SCOTTSBLUFF. NEBRASKA

GRAND I SLAND NE BRASKA
SI OUX CITY I OWA-NEBRASKA

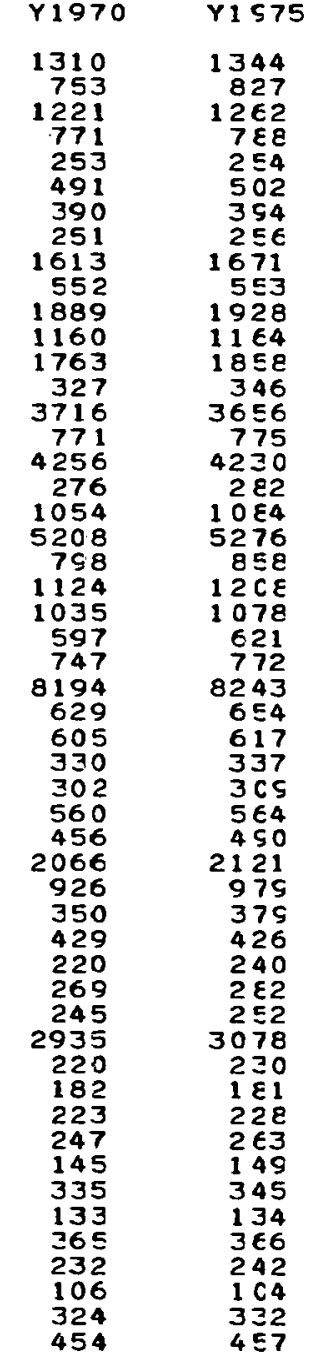

\begin{tabular}{|c|c|c|}
\hline Y1980 & Y1985 & Y1990 \\
\hline $\begin{array}{r}1361 \\
892 \\
1284 \\
798 \\
263 \\
514 \\
401 \\
262 \\
1732 \\
549 \\
1959 \\
1164 \\
1944 \\
368 \\
3574 \\
777 \\
4205 \\
287 \\
1112 \\
5305 \\
914 \\
1269 \\
1123 \\
641 \\
793 \\
8307 \\
683 \\
627 \\
345 \\
315 \\
566 \\
530 \\
2173 \\
1021 \\
404 \\
418 \\
269 \\
296 \\
259 \\
3208 \\
238 \\
179 \\
235 \\
282 \\
155 \\
350 \\
133 \\
364 \\
253 \\
101 \\
338 \\
455\end{array}$ & $\begin{array}{r}1376 \\
966 \\
1320 \\
819 \\
277 \\
530 \\
410 \\
271 \\
1795 \\
550 \\
1995 \\
1177 \\
2035 \\
400 \\
3521 \\
788 \\
4221 \\
299 \\
1143 \\
5448 \\
580 \\
1344 \\
1170 \\
669 \\
811 \\
8484 \\
718 \\
645 \\
357 \\
326 \\
577 \\
574 \\
2249 \\
1064 \\
439 \\
412 \\
302 \\
315 \\
269 \\
3381 \\
254 \\
183 \\
239 \\
304 \\
165 \\
363 \\
135 \\
362 \\
265 \\
98 \\
346 \\
451\end{array}$ & $\begin{array}{r}1385 \\
1044 \\
1354 \\
842 \\
291 \\
547 \\
418 \\
279 \\
1853 \\
552 \\
2027 \\
1186 \\
2118 \\
427 \\
3466 \\
796 \\
4235 \\
311 \\
1172 \\
5588 \\
1045 \\
1418 \\
1211 \\
698 \\
827 \\
8657 \\
753 \\
667 \\
370 \\
337 \\
590 \\
615 \\
2320 \\
1106 \\
473 \\
403 \\
334 \\
333 \\
279 \\
3550 \\
270 \\
186 \\
241 \\
326 \\
176 \\
372 \\
137 \\
362 \\
275 \\
92 \\
353 \\
447\end{array}$ \\
\hline
\end{tabular}


MLLT IFEGION POPUL AT ION PROJECTIONS

THOUSAVCS OF PERSONS

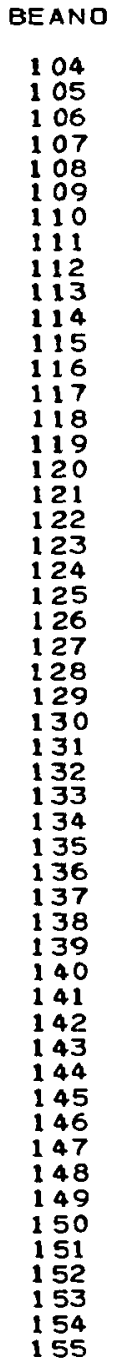

BEA

FORT DOC'SE IOWA

WA TERLOO I OWA

DES MOI MES I OWA

LI NC OLN NEBRASKA

SALI NA HANSAS

WANSAS CI TY MISSOURI - K. ANS AS

OULNCY

ST. LOUIS MISSCURI-ILLINOIS

PADUCAH KENTUCKY

LI TTLE POCK-NORTH LLITTLE ROCK ARK ANSAS

FORT SMITH ARKANSAS-OKLAHOMA

TULSA OKLAHCMA

OKLAHOMA CITY CKLAHOM

WICHI TA = ALLS TEXAS.

AMARBOCK TEXAS

DDESSA TEXIS

ABI LENE TEXAS

SAN ANGELO TEXAS

DALLAS TEXAS

KILLEEN-TE HPLE TEXAS

AUSTIN TEXAS

TEXARKANA TEXAS-AFKANS AS

SHRE VEPORT LOUISI PUA

CE LOUI SI ANA

GREENVI LLE MISSISSIPP

MACKSON MI SSISSI PFI

MOBI LE ALAGAMA

NEW ORLEANS LDUISI ANA

BEAUMONT-PJRT ARTHUR-DRANSE TEX 25

HOUSTON TEXAS

SAN ANTZNID TEXAS

CORPUS CHRI STEXAS

MCALLEN-PHARR-EDI M BURJ TEKAS

EL PASO TEXAS

COLORADE SPRI NGS CCLCRADO

GENVER TOLORADC

CHEYENNE COLCRADO

SALT LAKE CITY UT

IDATO LARE CITY UTAH

BUTTE MENTANA

SPOKANE WASHINGT ON

\begin{tabular}{|c|c|c|c|c|}
\hline Y 1970 & Y 1975 & Y1930 & Y1985 & Y1990 \\
\hline $\begin{array}{r}266 \\
426 \\
783 \\
794 \\
324 \\
349 \\
728 \\
2249 \\
397 \\
299 \\
3248 \\
559 \\
830 \\
865 \\
289 \\
1014 \\
1157 \\
456 \\
438 \\
329 \\
319 \\
265 \\
125 \\
2736 \\
404 \\
560 \\
553 \\
330 \\
454 \\
533 \\
507 \\
510 \\
393 \\
724 \\
2149 \\
748 \\
395 \\
2363 \\
1229 \\
516 \\
355 \\
682 \\
573 \\
509 \\
1523 \\
252 \\
229 \\
1062 \\
300 \\
235 \\
687 \\
2364\end{array}$ & $\begin{array}{r}265 \\
431 \\
808 \\
835 \\
337 \\
348 \\
729 \\
2296 \\
425 \\
295 \\
2242 \\
586 \\
901 \\
962 \\
340 \\
1029 \\
1241 \\
460 \\
440 \\
337 \\
321 \\
274 \\
131 \\
2946 \\
466 \\
672 \\
599 \\
356 \\
464 \\
546 \\
456 \\
550 \\
411 \\
774 \\
2253 \\
775 \\
403 \\
2696 \\
1343 \\
533 \\
413 \\
744 \\
642 \\
571 \\
1750 \\
289 \\
246 \\
1210 \\
337 \\
256 \\
730 \\
2434\end{array}$ & $\begin{array}{r}262 \\
434 \\
830 \\
874 \\
351 \\
341 \\
715 \\
2340 \\
457 \\
291 \\
3232 \\
603 \\
953 \\
1045 \\
410 \\
1155 \\
1314 \\
449 \\
435 \\
347 \\
322 \\
273 \\
144 \\
3152 \\
521 \\
780 \\
642 \\
386 \\
469 \\
556 \\
482 \\
582 \\
425 \\
820 \\
2338 \\
796 \\
406 \\
3051 \\
1428 \\
549 \\
480 \\
809 \\
718 \\
629 \\
1971 \\
335 \\
266 \\
1346 \\
375 \\
279 \\
772 \\
2498\end{array}$ & $\begin{array}{r}264 \\
440 \\
854 \\
518 \\
365 \\
332 \\
700 \\
2401 \\
494 \\
290 \\
3251 \\
637 \\
1007 \\
1138 \\
487 \\
1217 \\
1380 \\
442 \\
436 \\
356 \\
325 \\
285 \\
164 \\
3393 \\
583 \\
897 \\
696 \\
421 \\
482 \\
567 \\
476 \\
632 \\
455 \\
874 \\
2444 \\
822 \\
424 \\
3416 \\
1529 \\
570 \\
555 \\
883 \\
801 \\
691 \\
2198 \\
385 \\
289 \\
1497 \\
417 \\
311 \\
813 \\
2577\end{array}$ & $\begin{array}{r}265 \\
449 \\
874 \\
960 \\
378 \\
323 \\
682 \\
2450 \\
530 \\
291 \\
3275 \\
663 \\
1056 \\
1228 \\
569 \\
1272 \\
1442 \\
434 \\
433 \\
362 \\
329 \\
292 \\
187 \\
3630 \\
639 \\
1015 \\
746 \\
458 \\
499 \\
596 \\
476 \\
679 \\
481 \\
925 \\
2547 \\
842 \\
441 \\
3780 \\
1626 \\
588 \\
633 \\
953 \\
882 \\
748 \\
2417 \\
436 \\
313 \\
1641 \\
456 \\
341 \\
847 \\
2649\end{array}$ \\
\hline
\end{tabular}


MULT I REGI ON POPUL AT ION PROJECTIONS

BASED ON DOE MID-MID SCENARIO

BEANO
156
157
158
159
160
161
162
163
164
165
166
167
168
169
170
171
172
173

BEA

YAKIMA WASHINGTCN

PORTLAND OREGCN-WASHINGTON

BOISE CITY I DAHC

QE NO NEVADA

LAS VEGAS NEVADA

TUC SON ARI ZCNA

SAN DIEGO CAL I FCRNIA

LOS ANGELES-LONG

STOCKTON CALIFORNI A

CALIFORNI A

GURKA CALIFCRNIA

SAN FRANC I SCO-OAKLAND CALIFORN IA

ANCHORAGE ALASKA

HONOL ULU HAWAII $\checkmark 1970 \quad Y 1975$

407
1637
541

429

429
1781
605

265

317

1316

1358
0436

10436
1037

643
1089

1089
177

5022

300
769

304

249
385
1637

1637
544

1574

10943

1102
705

1204

194

126
5383
350

530
350
Y1580 Y1985

448
1907

2034
742

742
397

338
519

2339

1938

12032

1224

831
1457

246

129
5983

467
1025

1025

,
Y1990

495
2154

805

444

592

2721
847

2099

12642

1289
900

1588

129
6278

6278
533
1102 
THIS PAGE

\section{WAS INTENTIONALLY LEFT BLANK}


VII. MULTIREGION EMPLOYMENT PROJECTIONS 


\section{THIS PAGE}

WAS INTENTIONALLY

LEFT BLANK 
MULTIREGION EMPLOYMENT PROJECTIONS
BASED ON DOE MID-MID SCENARIO

BASED ON DOE MID-MID SCENARIO
THOUSANDS OF PERSONS

\begin{tabular}{|c|c|c|c|c|c|c|}
\hline FEAREG & FEA & Y1970 & Y1975 & Y1980 & Y1985 & Y 1990 \\
\hline $\begin{array}{r}0 \\
1 \\
2 \\
3 \\
4 \\
5 \\
6 \\
7 \\
8 \\
9 \\
10\end{array}$ & $\begin{array}{l}\text { US TOTAL } \\
\text { NEW ENGLAND } \\
\text { N.Y. NN.J. } \\
\text { MD. ATL ANT IC } \\
\text { S. ATR ANT I C } \\
\text { MI OWEST } \\
\text { SOUTHWEST } \\
\text { CENTRAL } \\
\text { N. CENTRAL } \\
\text { WEST } \\
\text { NORTHWEST }\end{array}$ & $\begin{array}{r}79280 \\
4888 \\
10109 \\
9218 \\
12113 \\
17130 \\
7586 \\
4452 \\
2139 \\
9141 \\
2505\end{array}$ & $\begin{array}{r}87689 \\
5228 \\
10700 \\
10101 \\
13932 \\
18705 \\
8571 \\
4780 \\
2427 \\
10435 \\
2812\end{array}$ & $\begin{array}{r}96205 \\
5566 \\
11029 \\
10875 \\
15895 \\
19998 \\
9849 \\
5077 \\
2840 \\
11876 \\
3201\end{array}$ & $\begin{array}{r}105680 \\
5973 \\
11574 \\
11777 \\
18032 \\
21522 \\
11183 \\
5432 \\
3251 \\
13354 \\
3581\end{array}$ & $\begin{array}{r}109428 \\
6056 \\
11535 \\
12037 \\
19157 \\
21876 \\
11913 \\
5490 \\
3478 \\
14127 \\
3758\end{array}$ \\
\hline
\end{tabular}


MULTIREGION EMPLOYMENT PROJECTIONS

BASED ON DOE MID-MID SCENARIO

\begin{tabular}{|c|c|c|c|c|c|c|}
\hline CENNO & CENSUS & Y1970 & Y 1975 & Y1980 & Y 1985 & Y1990 \\
\hline $\begin{array}{l}0 \\
1 \\
2 \\
3 \\
4 \\
5 \\
6 \\
7 \\
8 \\
9\end{array}$ & $\begin{array}{l}\text { US TOTAL } \\
\text { NEW ENGLAND } \\
\text { MD. ATLANTIC } \\
\text { E-N. CENTRAL } \\
\text {-N. CENTRAL } \\
\text { SO. ATLANTIC } \\
\text { E.S. CENTRAL } \\
\text { U. S. CENTRAL } \\
\text { MOUNTAIN } \\
\text { PACIFIC }\end{array}$ & $\begin{array}{r}79280 \\
4888 \\
14699 \\
15627 \\
6428 \\
12122 \\
4619 \\
7241 \\
3145 \\
10511\end{array}$ & $\begin{array}{r}87689 \\
5228 \\
15627 \\
17040 \\
6943 \\
13919 \\
5187 \\
8173 \\
3703 \\
11870\end{array}$ & $\begin{array}{r}95205 \\
5566 \\
15212 \\
15142 \\
7489 \\
15751 \\
5835 \\
9373 \\
4493 \\
13343\end{array}$ & $\begin{array}{r}105680 \\
5973 \\
17064 \\
19490 \\
8071 \\
17812 \\
6507 \\
10637 \\
5279 \\
14847\end{array}$ & $\begin{array}{r}109428 \\
6056 \\
17027 \\
19780 \\
8204 \\
18905 \\
6797 \\
11330 \\
5734 \\
15544\end{array}$ \\
\hline
\end{tabular}


ULTIREGION EMPLOYMENT PRO JECTIONS THOUSANDS OF PERSONS

\begin{tabular}{|c|c|c|c|c|c|c|}
\hline FIPST & STATE & Y1970 & Y1975 & Y1980 & Y1985 & Y1990 \\
\hline $\begin{array}{l}0 \\
1 \\
2 \\
4 \\
5 \\
6 \\
8 \\
9 \\
10 \\
11 \\
12 \\
13 \\
15 \\
16 \\
17 \\
18 \\
19 \\
20 \\
21 \\
22 \\
23 \\
24 \\
25 \\
26 \\
27 \\
28 \\
29 \\
30 \\
31 \\
32 \\
33 \\
34 \\
35 \\
36 \\
37 \\
38 \\
39 \\
40 \\
41 \\
42 \\
44 \\
45 \\
46 \\
47 \\
48 \\
49 \\
50 \\
51 \\
53 \\
54 \\
55 \\
56\end{array}$ & 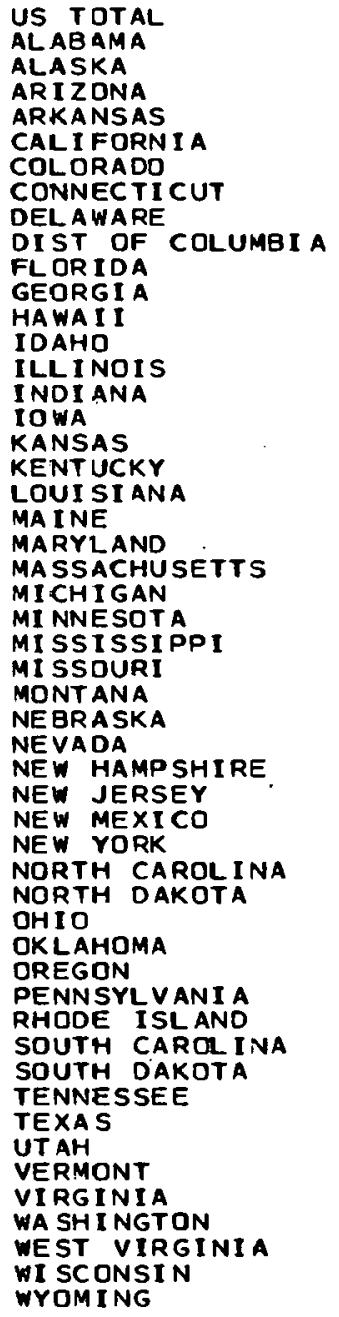 & $\begin{array}{r}79280 \\
1233 \\
124 \\
650 \\
669 \\
7936 \\
891 \\
1280 \\
219 \\
343 \\
2567 \\
1837 \\
342 \\
271 \\
4518 \\
2037 \\
1118 \\
905 \\
1139 \\
1214 \\
382 \\
1615 \\
2348 \\
3237 \\
1503 \\
751 \\
1825 \\
255 \\
605 \\
213 \\
301 \\
2924 \\
344 \\
7185 \\
2073 \\
220 \\
4104 \\
981 \\
792 \\
4590 \\
405 \\
1017 \\
252 \\
1496 \\
4377 \\
391 \\
170 \\
1897 \\
1318 \\
555 \\
1732 \\
130\end{array}$ & $\begin{array}{r}87689 \\
1366 \\
140 \\
818 \\
763 \\
8989 \\
1050 \\
1377 \\
241 \\
393 \\
393 \\
3107 \\
2107 \\
377 \\
308 \\
4865 \\
2228 \\
1200 \\
940 \\
1281 \\
1344 \\
1414 \\
414 \\
1813 \\
2508 \\
3554 \\
1665 \\
824 \\
1987 \\
283 \\
653 \\
653 \\
251 \\
320 \\
3100 \\
398 \\
7600 \\
2374 \\
232 \\
4467 \\
4087 \\
1087 \\
907 \\
4927 \\
418 \\
1157 \\
267 \\
1716 \\
4979 \\
453 \\
190 \\
2118 \\
1457 \\
608 \\
1925 \\
142\end{array}$ & $\begin{array}{r}96205 \\
1540 \\
176 \\
1051 \\
886 \\
10103 \\
1229 \\
1478 \\
251 \\
449 \\
3756 \\
2366 \\
410 \\
370 \\
5099 \\
2346 \\
1277 \\
975 \\
1433 \\
1533 \\
444 \\
1990 \\
2670 \\
3900 \\
1855 \\
951 \\
2129 \\
334 \\
696 \\
313 \\
337 \\
3143 \\
476 \\
7886 \\
2643 \\
270 \\
4684 \\
1188 \\
1034 \\
5183 \\
432 \\
1295 \\
286 \\
1911 \\
5765 \\
553 \\
206 \\
2319 \\
1621 \\
682 \\
2113 \\
168\end{array}$ & $\begin{array}{r}105680 \\
1705 \\
207 \\
1285 \\
1018 \\
11234 \\
1433 \\
1578 \\
271 \\
506 \\
4438 \\
2682 \\
458 \\
425 \\
5410 \\
2531 \\
1373 \\
1016 \\
1605 \\
1719 \\
483 \\
2200 \\
2865 \\
4252 \\
2032 \\
1064 \\
2297 \\
379 \\
746 \\
378 \\
361 \\
3278 \\
547 \\
8297 \\
2933 \\
301 \\
4987 \\
1315 \\
1169 \\
5489 \\
457 \\
1472 \\
306 \\
2133 \\
6585 \\
639 \\
229 \\
2565 \\
1780 \\
745 \\
2309 \\
192\end{array}$ & $\begin{array}{r}109428 \\
1775 \\
233 \\
1461 \\
1098 \\
11760 \\
1562 \\
1602 \\
278 \\
537 \\
4885 \\
2845 \\
482 \\
455 \\
5443 \\
2580 \\
1394 \\
1001 \\
1679 \\
1798 \\
492 \\
2302 \\
2899 \\
4366 \\
2096 \\
1115 \\
2340 \\
400 \\
755 \\
425 \\
365 \\
3246 \\
583 \\
8289 \\
3064 \\
312 \\
5012 \\
1371 \\
1237 \\
5492 \\
457 \\
1566 \\
306 \\
2228 \\
7063 \\
693 \\
240 \\
2671 \\
1834 \\
757 \\
2380 \\
205\end{array}$ \\
\hline
\end{tabular}


MULT:REGI GN IEMPLOYMENT PROJECTIOTS THOUSANDS OF PERSONS

$8 E A N O$
0
1
2
3
4
4
5
6
7
8
9
10
11
12
13
14
15
16
17
18
19
20
21
22
23
24
25
26
27
28
29
30
31
32
33
34
35
36
37
38
39
40
41
42
43
44
45
45
47
48
49
50
51

BEA

UNITEO STATES TOTAL

BANGOR MAINE PORTLAND-SOUTH PORTL AND MAENE

BURL I NGTON YERMONT

BOSTON MASSACHUSETT

ALBANY-SCHENECTADY-TROY NEY YORK

SYRACUSE NEW YORK

RUCHESTER NEW YORK

DUFHALTER NEW YORK

WILL I AMSPORT PENNSY VANIA

BINGHAMTON NEW YORK-PENNSYLVANIA

WILKES-BARRE-HAZLETON PENNSYLVANIA

PHILADEL PHI A PENNSYLVANIA-NEW JERSEY

HARRI SBURG PENNSYLVANIA

BALT IMORE MARYLAND

WASHINGTON-DC MARYLAND-VIRGINIA

STAUNTON VIRGINIA

RICHMOMD VIRGINIA

NORFOLK-PORT SMOUTH VIRGINI A

RALEIGH MORTH CAROL TNA

GREENSTON WR

CRANSBOW-MINSTON SALEM-H

A SHEVILLE NORTH CAFOL INA

AREENVILLE SOUTH CAROLINA

COLUMBIA SO UTH CARO INA

CHARLESTON SOUTH CAROLINA

AUGUSTA GEORGIA

SAVANNAH GEDRG I A

JACK SONV ILLE FLOR

ORLANDO FLORIDA

MIAMI FLORDIA

TAMPA-SAINT PETERSEUR

PENSACDLA FLORIOA

MONTGOMERY ALABAMA

ALBANY GEOR-IIA

MACON GEORGIA

CCLUMBUS GETRGIA-ALABAMA

ATLANTA GEORGIA

BIRMINGHAM TLABAMA

作

SEE-GEORSI A

KNOXVILE TENNESSEE

BRISTOL IIRTINIA-TENNESSEE

\begin{tabular}{|c|c|c|}
\hline Y1970 & Y:1975 & Y:980 \\
\hline $\begin{array}{r}79280 \\
117 \\
295 \\
193 \\
2636 \\
1247 \\
517 \\
541 \\
413 \\
676 \\
171 \\
156 \\
288 \\
274 \\
7380 \\
2927 \\
712 \\
1089 \\
1349 \\
157 \\
329 \\
412 \\
506 \\
634 \\
198 \\
485 \\
637 \\
146 \\
337 \\
244 \\
143 \\
167 \\
179 \\
156 \\
410 \\
354 \\
968 \\
622 \\
128 \\
143 \\
256 \\
173 \\
185 \\
193 \\
956 \\
622 \\
606 \\
245 \\
276 \\
563 \\
305 \\
249\end{array}$ & $\begin{array}{r}87689 \\
127 \\
318 \\
216 \\
2792 \\
1358 \\
559 \\
570 \\
451 \\
705 \\
182 \\
168 \\
298 \\
294 \\
294 \\
7774 \\
3182 \\
787 \\
1208 \\
1540 \\
181 \\
374 \\
466 \\
545 \\
730 \\
214 \\
552 \\
739 \\
171 \\
387 \\
277 \\
164 \\
186 \\
198 \\
168 \\
4772 \\
433 \\
1169 \\
781 \\
151 \\
168 \\
276 \\
188 \\
204 \\
206 \\
1445 \\
680 \\
678 \\
282 \\
317 \\
644 \\
353 \\
284\end{array}$ & 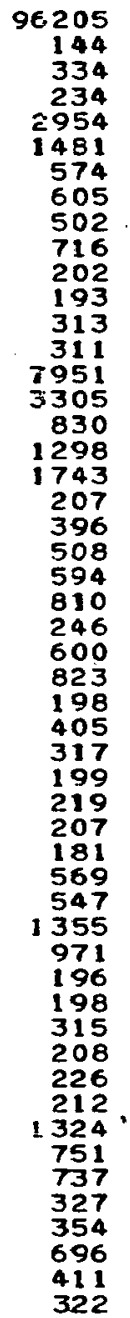 \\
\hline
\end{tabular}

Y1985

Y1990

105680

109428

$\begin{array}{ll}156 & 15 ? \\ 365 & 375\end{array}$

$260 \quad 3180$

3180
1645

$617 \quad 630$

$\begin{array}{ll}640 & 638 \\ 558 & 588\end{array}$

$741 \quad 726$

$225 \quad 235$

329 .

334

8279

3523

887
1420

1961

238

438
566

905

264

658
916

916
228

451

364

253

200

653

1595

1163

236
223

356
234

251
225
1529

813

806

303
775

774

463
354 
MULTIREGION EMPLOYMENT PROJECTIONS

BASED ON DOE MID-MID SCENAR
THOUSANDS OF PERSONS

BEANO
52
53
54
55
56
57
57
58
59
60
61
62
63
64
65
66
67
68
69
70
71
72
73
74
75
76
77
78
79
80
81
82
83
84
85
86
87
88
89
90
91
92
93
94
95
96
97
98
99
100
101
102
103
9

EEA

$r 1970$
388
358
478
282
95
199
160
101
644
212
711
457
674
108
1320
282
1672
104
403
1908
267
411
399
241
299
3374
252
239
136
114
228
189
839
335
128
149
81
101
100
1182
78
64
84
94
51
121
49
149
86
41
128
173
49

Y1975

$Y 1985$

Y1990

HUNTINGTON-ASHLAND WEST VIRGINIA-KENTUCKY-OHIO LOUISVILLE KENTUCKY-IAOTANA

TERRE ILLE INDIANA- IN

SPRINGFIELD ILLTNOIS

LAFAYETTE-WEST LAFAYETTE INDI ANA

C NOI ANAPOL TS INDIAA

CINCINNAT.I OHIO-KENTUCKY-INDI ANA

DAYTON OHIO

CLARKSBURG WEST VIRGINIA

PITTSBURGH PENNSYLVI

YOUNGSTOWN-WARREN OHIO

CLEVELANO OHIO

CTMA OHIO

DETROIT MICHIGAN

SAGINAW MICHIGAN

GRAND RAPIDS MICHI GAN

LANSING MICHIGAN

FORT WAYNE INOIANA

CHICAGO ILL INOIS

PAVE ILLINOIS

CEDAR RAPIDS IOWA

DUBUR RAPIOS

ROCKFORO IILINOIS

MADISON WISCONSIN

MALWAUKEE ISCONSIN

APPLETON-OSHKOSH MISCONSIN

WAUSAU WI SCONSIN

WULUTH-SUPERIOR MINNESOTA-WISCONSIN

EAU CLAIRE WI SCONSIN

ROCHESTER MINNESOTA

MINNEAPOLI S-SAINT PAUL MINNESOTA

GRAND FORK S NORTH DAKOTA

MINOT NORTH OAKOTA

GREAT FALLS MONTAN

BILLINGS MONTANA

FARGO-MOORHEAD NORTH DAKOTA-MINNESOTA

ABERDEEN SQUTH DAKOTA

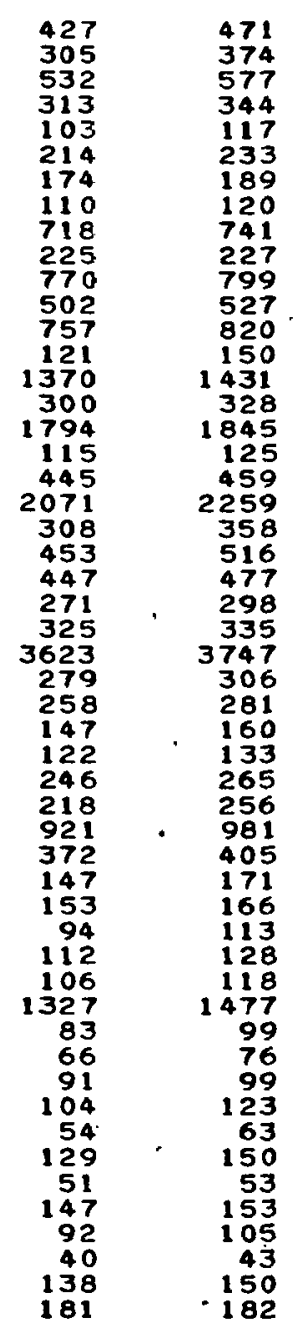

$\begin{array}{ll}503 & 499 \\ 449 & 492\end{array}$

$631 \quad 648$

131

$254 \quad 262$

$131 \quad 135$

$802 \quad 819$

$\begin{array}{ll}237 & 236 \\ 853 & 857\end{array}$

559
898

$175 \quad 186$

344
1475 $\quad \begin{array}{ll}1416 \\ 140\end{array}$

$1933 \quad 1917$

$\begin{array}{ll}138 & 144 \\ 495 & 504\end{array}$

$2440 \quad 2487$

$404 \quad 427$

$521 \quad 535$

$330-345$

3927

342

$175 \quad 183$

$147 \quad 151$

1039

460

$172-168$

135150

130

1622

83
103
141

141

72
164

57
162

162

CITY SOUTH DAKOT

SCOTTSBL UFF NEBRASKA

SIOUX CITY IOWA-NEBRASKA

181 
MULTIREGION EMPLOYMENT PROJECTIONS
BASED ON DOE MID-MID SCENARIO
THOUSAND.S DF PERSONS

BEANO
1104
105
106
107
107
108
109
110
111
112
113
114
115
116
117
118
119
120
121
122
123
124
125
126
127
128
129
130
131
132
133
134
135
136
137
138
139
140
141
142
143
144
145
146
147
148
149
150
151
152
153
154
155

BEA

\begin{tabular}{|c|c|c|c|c|}
\hline$Y 1970$ & Y1975 & Y1950 & Y1985 & $Y 1990$ \\
\hline $\begin{array}{r}101 \\
163 \\
320 \\
324 \\
139 \\
138 \\
294 \\
925 \\
156 \\
116 \\
1240 \\
190 \\
302 \\
310 \\
98 \\
387 \\
457 \\
185 \\
173 \\
124 \\
125 \\
104 \\
50 \\
1160 \\
168 \\
212 \\
206 \\
116 \\
155 \\
163 \\
159 \\
178 \\
131 \\
253 \\
724 \\
247 \\
143 \\
953 \\
454 \\
178 \\
103 \\
238 \\
192 \\
195 \\
631 \\
89 \\
99 \\
393 \\
115 \\
8.2 \\
250 \\
932\end{array}$ & $\begin{array}{r}105 \\
172 \\
348 \\
356 \\
151 \\
137 \\
289 \\
1012 \\
177 \\
121 \\
1328 \\
210 \\
330 \\
357 \\
129 \\
433 \\
510 \\
181 \\
173 \\
132 \\
128 \\
102 \\
135 \\
1329 \\
191 \\
268 \\
229 \\
132 \\
164 \\
179 \\
165 \\
202 \\
144 \\
1284 \\
806 \\
277 \\
151 \\
1151 \\
115 \\
502 \\
193 \\
122 \\
273 \\
229 \\
229 \\
744 \\
105 \\
100 \\
454 \\
131 \\
\end{array}$ & $\begin{array}{r}111 \\
182 \\
371 \\
378 \\
163 \\
134 \\
295 \\
1059 \\
203 \\
128 \\
1385 \\
252 \\
376 \\
423 \\
168 \\
476 \\
549 \\
187 \\
182 \\
144 \\
137 \\
113 \\
156 \\
1523 \\
242 \\
350 \\
267 \\
159 \\
188 \\
209 \\
182 \\
245 \\
175 \\
330 \\
907 \\
319 \\
173 \\
1314 \\
585 \\
219 \\
151 \\
320 \\
280 \\
278 \\
853 \\
132 \\
119 \\
553 \\
159 \\
120 \\
315 \\
1138\end{array}$ & $\begin{array}{r}117 \\
198 \\
395 \\
408 \\
176 \\
133 \\
300 \\
3101 \\
121 \\
232 \\
136 \\
1478 \\
283 \\
417 \\
489 \\
218 \\
528 \\
604 \\
190 \\
185 \\
152 \\
141 \\
120 \\
80 \\
1726 \\
283 \\
437 \\
309 \\
187 \\
211 \\
248 \\
196 \\
284 \\
200 \\
371 \\
1000 \\
357 \\
192 \\
1549 \\
652 \\
241 \\
178 \\
359 \\
327 \\
320 \\
993 \\
163 \\
138 \\
638 \\
182 \\
144 \\
344 \\
1242\end{array}$ & $\begin{array}{r}116 \\
203 \\
397 \\
417 \\
180 \\
126 \\
286 \\
1122 \\
250 \\
136 \\
1488 \\
297 \\
435 \\
530 \\
260 \\
549 \\
626 \\
186 \\
178 \\
151 \\
139 \\
120 \\
93 \\
1843 \\
306 \\
502 \\
335 \\
207 \\
219 \\
262 \\
195 \\
307 \\
212 \\
395 \\
1034 \\
381 \\
199 \\
1705 \\
681 \\
253 \\
196 \\
375 \\
354 \\
342 \\
1080 \\
189 \\
149 \\
690 \\
195 \\
159 \\
350 \\
1276\end{array}$ \\
\hline
\end{tabular}


MULTIREGION EMPLOYMENT PROJECTIONS

BASED ON DOUEN MANOS OF PERSONS
THOUSANOS

BEANO BEA

156
157

EUGENE ORE GON

RENO NEVADA

LAS VEGAS NE VADA

PHOENIX ARIZONA

TUCSON ARI ZONA

SAN DIEGOLSALIFORNIA

FRESNO CAL IFORNIA

STOCKTON CAL. IFORNIA

SACRAMENTO CALIFORNIA

REDO ING CALIFORNIA

SAN FRANCI SCD-OAKLAND CALIFORNIA

ANCHORAGE ALASKA

$\begin{array}{rrr}Y 1970 & Y 1975 & r 1980 \\ 150 & 161 & 189 \\ 632 & 714 & 793 \\ 192 & 228 & 275 \\ 106 & 123 & 152 \\ 90 & 103 & 134 \\ 136 & 162 & 196 \\ 486 & 616 & 797 \\ 164 & 202 & 254 \\ 570 & 662 & 784 \\ 4178 & 4707 & 5266 \\ 362 & 401 & 460 \\ 229 & 258 & 307 \\ 405 & 473 & 566 \\ 61 & 70 & 91 \\ 41 & 46 & 50 \\ 2089 & 2372 & 2579 \\ 124 & 140 & 176 \\ 342 & 377 & 410 \\ & & \end{array}$

$Y 1985 \quad Y 1990$

$\begin{array}{rr}216 & 228 \\ 888 & 934 \\ 318 & 342 \\ 180 & 198 \\ 158 & 175 \\ 239 & 272 \\ 981 & 1122 \\ 305 & 340 \\ 875 & 915 \\ 5838 & 6103 \\ 511 & 531 \\ 353 & 382 \\ 650 & 698 \\ 113 & 131 \\ 52 & 51 \\ 2841 & 2950 \\ 207 & 232 \\ 458 & 482\end{array}$




\section{THIS PAGE \\ WAS INTENTIONALLY \\ LEFT BLANK}


Footnotes

1. Federa1 Energy Administration, 1976 National Energy OutZook, Washington, D.C. February 1976.

2. Department of Energy, Energy Information Adminsitration Annual. Report to Congress 1977, DOE/EIA-0036, Apri1 1978.

3. Several changes in format however, have been necessary in the current volume from that used in earlier volumes. These differences are described in section III.

4. The Project Independence Evaluation System (PIES) is described in the 1976 National Energy Outlook. The level of regional detail presented in the PIES model is below the national level. Demand projections and electric utility projections are presented for Federal Regions. The supply of fuels is presented by several aggregated fuel specific regions. In all cases, the level of regional detail is very aggregate relative to the concerns in this report; hence, the PIES model is considered a "national" as opposed to a "regional" model.

5. The REBE syotcm io deocribed in: D. P. Vogt and P. L. Rice, RERS: A Methodology for Addressing the Regional Implications of National Energy Scenarios, ORNL/TM (forthcoming). 
6. The REBS model has been used to regionalize a wide variety of scenarios for various DOE related studies. In order to facilitate further detailed regional analysis, the regional projections of energy consumption by region, sector, and fuel are available from ORNL on computer tape for some of these alternative scenarios.

7. 'Ihe question of interregional flows of energy has been examined by ORNL for a concurrent EDA sponsored projert: P. T.. Rire, State Enargy Flowo in 1075, OnNL/TH (fortlicuining).

8. Ü.S. Department of Commerce, Anriuiz Survey of Manufactures 1975 , Fuels curd Electric Energy Consumed, M75(A5)-4, September 1977.

9. The DOE projections actually report electricity and coal use for Lhe refining sector as part of the Industrial sector total, and project refineries' use of fuel separately nnly for fuel oils and natural gas.

10. Several internal inconsistencies in our tables contributc to severa1 of the reported errors. The large error in distillate oil of .5 quads is matchod by tho -.5 quad crror in other liydlucalbulls (1985 Lable). This is because the demand allocation program included projected kerosene consumption ( 0.53 quads) in the "other hydrocarbons" total, while kernnrnr, whs included in tlie prujuctions of distillates output of the refining sector (rather than in otherhydro carbons). The large error for crude oil is due to a similar inconsistency. 
Natural gas liquids (NGL) used as inputs to the refining sector are reported in the tables as Natural Gas. However, these liquids (1.839 quads in 1985) are included in the supply total for crude oil rather than natural gas. Thus the error of 1.8 quads in the refining sector. This of course, means that the negative error for natural gas, (indicating consumed but not produced) is incorrect. Consequently, the error for natural gas should be 1.05 quads. The major portion ( 0.9 quads) of this error is due to our double counting synthetic gas production. Inadvertantly, synthetic gas was included both as an output in the synthetics line and also included in natural gas supply. Similarly this occurred for shale oil; the 0.1 quad of shale oil is included both as an output in the synthetics sector and as part of crude oil production. These inconsistencies were not caught until the final tables were produced. Since they are small and easily identifiable (we have reported the synthetic natural gas separated in the tables) it should pose no real hazard in interpreting the tables. The remaining small errors are due to the limitation of the PIES equilibriating process of the use of aggregate conversion factors.

11. Ibid, Volume II.

12. The Project Independence Evaluation System (PIES) was developed by the Federal Energy Administration (FEA) and used in preparing the 1976 National Energy Outlook projections. The PIES modeling framework has been continually undergoing revision and development. 
The current version of the system is now referred to as Midterm Energy Forecasting System (MEFS). The senearios developed for the Mid-Mid projections were done hefore the major revamping of the system, thus we still refer to the model in this report as PIES.

13. The summaries in the Annual. Report to Congress, 1977 were supplemented liy the delailed profectlons from DKL that were supplied to ORNL by DOE.

14. Ibid.

15. "Fuel and Energy Data: United States by States and Census Divisions, 1974," Bureau of Mines, U.S. Department of the Interior Information Circular 8739 , U.S. Government Printing Office, Washington, D.C., 1977 .

16. YL'S Mid-Mid Scenario Computer Printout obtained from DOE.

17. Heat rates measure the level of fuel consumption necessary to producc a. kilnwat hour of electricity. Average values have been computed for several technologies in each federal rogion based on fuel consumption and electricity generation projections reported in the DOE scenario. Capacity factors measure the utilization rate of the generating equipment. Average federal region values huve ulso been computed based on DOE's projections of capacity and generation. 
18. Because of the change in the method of reporting fuel used by oil refining activities in this report as compared to our NE076 tables, the fuel used by refineries is excluded in the industrial demands for the Mid-Mid scenario in the growth rate comparisons.

19. R. J. Olsen, et al., MULTIREGION A Simulation-Forecasting Model of BEA Economic Area Population and Employment, ORNL/RUS-25 (October 1977).

20. The DRI. trendlong 0977 (Feb. 1978) report was obtained from DOE.

21. The county profections computer program is briefly described in REBS: A Methodology for Addressing the Regional Implications of National Energy Scenarios, op cit. and will be formally documented in a forthcoming ORNL Technical Memorandum. In order to facilitate further regional analysis of the energy scenarios, the MULTIREGION population and employment projections, as well as the county allocations are available on computer tapes from ORNL.

22. The use of OBERS projections is discussed in the earlier projections volume: P. P. Vogt, P. L. Rice, and V. P. Pai, Energy Availabilities for State and Local Development: Projected Energy Patterns for 1980 and 1985.

23. A parallel effort to the current projections volume has been the development of a 1975 data volume. This work has provided a more 
refined and consistent data series than used in our earlier historic series. The additional work done for the 1975 data will provide updated and more internally conslslenl energy coefficients than the current base year coefficients. Unfortunately, this task was not able to be completed in time to be used for the current projections. These new energy coefficients will replace the earlier coefficients in future projections.

24. The utility file which is referred to as the Generallug Unit Reference File, was originally compiled by the federal Power Commission (FPC), and has been taken over by FERC in DOE, URNL has malncalned dnd updated its own version of the file.

25. In earlier volumes of this series, capacity factors were incorrectly referred to as load factors.

26. R. B. Honea, E. L. Hillsman, R. F. Mader, Oak Ridge Siting Analysis: A Baseline Assessment Focusing on the National Energy Plan, ORNL-TM (torthcoming).

27. Federal Energy Administration, Ireinds in Refiritrly cupueily urul Utilization, Washington, D.C., June 1975. 
THIS PAGE

\section{WAS INTENTIONALLY LEFT BLANK}


Census Region Tables for 1985 


\section{PAGES 81 to 82 WERE INTENTIONALLY LEFT BLANK}


REGIONAL ENE RGY BALANCE STATEMENT

PIES MID MID SCENARID

\begin{tabular}{|c|c|c|c|c|c|c|c|c|c|c|}
\hline SECTOE: & $\begin{array}{l}\text { DISTILLATE } \\
\text { OIL }\end{array}$ & $\begin{array}{l}\text { RESIDUAL } \\
\text { OIL }\end{array}$ & $\begin{array}{l}\text { GASOLINE } \\
\text { (ALL ONIT }\end{array}$ & $\begin{array}{c}\text { OTHER } \\
\text { HYDRO- } \\
\text { CARBONS } \\
\text { TS IN } 10 * * 9\end{array}$ & $\begin{array}{c}\text { CRODE } \\
\text { OIL } \\
\text { BTU'S) }\end{array}$ & $\begin{array}{l}\text { NATURhL } \\
\quad \text { GAS }\end{array}$ & $\operatorname{COAL}$ & ELECTRI CITY & $\begin{array}{r}\text { SECTOR } \\
\text { TOTAL }\end{array}$ & \\
\hline $\begin{array}{l}\text { PINAL DEHAND SECTORS } \\
\text { RES ID ENTIAL, CCMA. } \\
\text { IND USTRIAL } \\
\text { TRANSPORTATIOB } \\
\text { MISCE LLANEODS OSES }\end{array}$ & $\begin{array}{r}729,951 \\
21,728 \\
65,582 \\
11,418\end{array}$ & $\begin{array}{r}20.5,220 \\
20.6,330 \\
17,381 \\
8,479\end{array}$ & $\begin{array}{r}- \\
\overline{-} \\
777.571\end{array}$ & $\begin{array}{r}113,024 \\
107,048 \\
82,548 \\
166\end{array}$ & $\begin{array}{l}- \\
- \\
-\end{array}$ & $\begin{array}{r}236,159 \\
83,909 \\
12,229 \\
14,984\end{array}$ & $\begin{array}{r}61 \\
2.774 \\
9 \\
-\end{array}$ & $\begin{array}{r}190,778 \\
104,687 \\
99 \\
2,780\end{array}$ & $\begin{array}{r}1,475,193 \\
526,476 \\
955,419 \\
37,827\end{array}$ & $\begin{array}{r}42 \% \\
15 \% \\
27 \% \\
1 \%\end{array}$ \\
\hline $\begin{array}{l}\text { TOTAL PINAL } \\
\text { DEMAND SECTCRS }\end{array}$ & 828,679 & $43: 7,410$ & 777.571 & 302,786 & - & 347,281 & 2,844 & 298,344 & $2,994,915$ & $85 \%$ \\
\hline $\begin{array}{l}\text { TRANSPORYATION } \\
\text { BL ECTRICITY GEN. } \\
\text { PETR OLEOM FRCDOCTS } \\
\text { NATORAL GAS } \\
\text { SY NT HETICS }\end{array}$ & $\begin{array}{r}59,901 \\
-213,469 \\
- \\
-\end{array}$ & $\begin{array}{r}384,100 \\
-26,023 \\
- \\
-\end{array}$ & $\begin{array}{r}-246,119 \\
- \\
-\end{array}$ & $\begin{array}{r}-104,526 \\
59 \\
59,830\end{array}$ & $\begin{array}{r}587,176 \\
- \\
-\end{array}$ & $\begin{array}{r}\overline{-} \\
4,358 \\
-53,970\end{array}$ & $\begin{array}{r}228,800 \\
- \\
-\end{array}$ & $\begin{array}{r}-231,117 \\
- \\
-\end{array}$ & $\begin{array}{r}441,684 \\
1,397 \\
5,860\end{array}$ & $\begin{array}{r}13 \% \\
0 \%\end{array}$ \\
\hline $\begin{array}{l}\text { NET PUEL USED } \\
\text { IN TRANSPORMATION }\end{array}$ & $-153,568$ & 35.8 .077 & $-246,119$ & -44.696 & 587,176 & $-49,611$ & 228.800 & $-231,117$ & 448,941 & $13 \%$ \\
\hline $\begin{array}{l}\text { TOTAL GROSS FLCRS } \\
\text { L OSSES } \varepsilon \text { OMISSIONS }\end{array}$ & $\begin{array}{r}888,580 \\
51,372\end{array}$ & $\begin{array}{r}82.1,510 \\
18\end{array}$ & $\begin{array}{r}777.571 \\
-2\end{array}$ & $\begin{array}{r}362,616 \\
-15,157\end{array}$ & $\begin{array}{r}587,176 \\
29,312\end{array}$ & $\begin{array}{l}351,639 \\
-12,737\end{array}$ & $\begin{array}{r}231,644 \\
-510\end{array}$ & $\begin{array}{r}298,344 \\
29,837\end{array}$ & $\begin{array}{r}3,443,856 \\
82,133\end{array}$ & $\begin{array}{r}98 \% \\
2 \%\end{array}$ \\
\hline
\end{tabular}

SUPPLI OP ENRREY
$\begin{aligned} & \text { POSS IL POEL } \\ & \text { HYDRELECTRIC }\end{aligned}$
NOCL EAR

\begin{tabular}{|c|c|c|c|c|c|c|c|c|c|}
\hline $\begin{array}{l}\text { NET IM PORTS } \\
\text { OP R RGION }\end{array}$ & 726,483 & 795,505 & 531,449 & 242,932 & 616,488 & 284,932 & 231,133 & -4.567 & $3,424,358$ \\
\hline
\end{tabular}

NO TES :

\begin{tabular}{|c|c|c|c|c|}
\hline $\begin{array}{l}\text { TRAN SPORMATI ON } \\
\text { TRANSPORMATI ON }\end{array}$ & $\begin{array}{l}\text { LOSS } \\
\text { LOSS }\end{array}$ & & $\begin{array}{l}\text { ELECTRI CITY GEN. } \\
\text { PZTROLEUM PBODOCTS }\end{array}$ & $\begin{array}{l}=65.65 \% \\
=0.24 x\end{array}$ \\
\hline & LOS & FOR & NATURAL GAS & $.0 \%$ \\
\hline & & $0 \mathrm{OP}$ & STATHETICS & \\
\hline
\end{tabular}


REGIONIL ZNERGY BALANCE STITEMENT

PIES IID IIID SCENARIO

\begin{tabular}{|c|c|c|c|c|c|c|c|c|c|c|}
\hline SЕСТOR & $\begin{array}{l}\text { DI ST ILLATE } \\
\text { OIL }\end{array}$ & $\begin{array}{l}\text { BESIDOAL } \\
\text { DIL }\end{array}$ & $\begin{array}{l}\text { GESOLINE } \\
\text { VAIL OJ }\end{array}$ & $\begin{array}{c}\text { OTHER } \\
\text { HYDRO- } \\
\text { CARBONS } \\
\text { ITS IN } 10 * \$ 9\end{array}$ & $\begin{array}{c}\text { CRUDE } \\
\text { OIE } \\
\text { BTO'SI }\end{array}$ & $\begin{array}{l}\text { NAZURAL } \\
\text { GAS }\end{array}$ & $\operatorname{COAL}$ & ELECTRICIT' & $\begin{array}{l}\text { SECTOR } \\
\text { TOTAI }\end{array}$ & \\
\hline 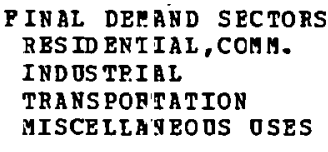 & $\begin{array}{r}1,201,303 \\
156,053 \\
227,407 \\
15,404\end{array}$ & $\begin{array}{r}412,266 \\
321,084 \\
98,382 \\
18,889\end{array}$ & $2,007,24 \frac{-}{-}$ & $\begin{array}{r}263,940 \\
507,512 \\
303,852 \\
325\end{array}$ & $\bar{z}$ & $\begin{array}{r}950,871 \\
526,229 \\
52,106 \\
33,290\end{array}$ & $\begin{array}{r}3,625 \\
1,150,770 \\
144 \\
119\end{array}$ & $\begin{array}{r}646,602 \\
452,872 \\
10,754 \\
10,503\end{array}$ & $\begin{array}{r}3,488,672 \\
3,114,520 \\
2,699,888 \\
78,530\end{array}$ & $\begin{array}{r}31 \% \\
27 \% \\
24 \% \\
1 \%\end{array}$ \\
\hline $\begin{array}{l}\text { TOTAL FINAL } \\
\text { DEMANE SECTORS }\end{array}$ & $1,600,174$ & 850,621 & $2,0<7,241$ & $1,075,629$ & - & $1,572,496$ & $1,154,718$ & $1,120,731$ & $9,381,610$ & $83 \%$ \\
\hline $\begin{array}{l}\text { T ZANSP ORMATION } \\
\text { BL ECTEICITY GEN. } \\
\text { PETR OLETH PRODOCTS } \\
\text { NATURAL GAS } \\
\text { SY NTHETICS }\end{array}$ & $\begin{array}{r}131,57) \\
-1,287,137 \\
- \\
-\end{array}$ & $\begin{array}{r}545,226 \\
-155,912 \\
- \\
-\end{array}$ & $\begin{array}{r}-1,4 \in 4,00 \overline{1} \\
-\end{array}$ & $\begin{array}{r}-630,25 \overline{-} \\
203,66 \overline{0}\end{array}$ & $\begin{array}{r}3,540,446 \\
-\end{array}$ & $\begin{array}{r}15,112 \\
26,282 \\
-133,710\end{array}$ & $\begin{array}{r}1,7 \subseteq 5,813 \\
= \\
-\end{array}$ & $\begin{array}{r}-823,571 \\
= \\
-\end{array}$ & $\begin{array}{r}1,664,1550 \\
8,4.27 \\
19,950\end{array}$ & $\begin{array}{r}15 \% \\
0 \%\end{array}$ \\
\hline $\begin{array}{l}\text { NET POEL JSED } \\
\text { IN TRANSFORHATION }\end{array}$ & $-1, \cdot 55,567$ & 383,313 & $-1,4 \varepsilon 4,001$ & $-426,590$ & $3,540,446$ & $-1+2,315$ & $1,7 \subseteq 5,813$ & $-823,571$ & $1,692,527$ & 158 \\
\hline $\begin{array}{l}\text { TOTAL GKOSS FLORS } \\
\text { LOSSES } \varepsilon \text { DHISIONS }\end{array}$ & $\begin{array}{r}1,731,74.8 \\
700,113\end{array}$ & $., 395,847$ & $\begin{array}{r}2,007,241 \\
-6\end{array}$ & $\begin{array}{r}1,279,289 \\
-53,476\end{array}$ & $\begin{array}{r}3,540,446 \\
176,745\end{array}$ & $\begin{array}{r}1,613,890 \\
-58,460\end{array}$ & $\begin{array}{r}2,950,531 \\
-6,499\end{array}$ & $\begin{array}{r}1,120,731 \\
112,034\end{array}$ & $\begin{array}{r}11,074,137 \\
270,538\end{array}$ & $\begin{array}{r}58 \% \\
2 \%\end{array}$ \\
\hline TOTAL NET OSAGE & $5.44,725$ & $.233,966$ & 523,233 & 595,561 & $3,717,191$ & $1,371,720$ & $2,944,031$ & 409,244 & $11.344,676$ & \\
\hline $\begin{array}{l}\text { S OPPLY CF ENERGY } \\
\text { POSS IL ?OEL } \\
\text { HY DR OELZCTRIC } \\
\text { NOCL EAR } \\
\text { GEO. \&SOLAR }\end{array}$ & $\begin{array}{l}\overline{-} \\
\overline{-}\end{array}$ & $\begin{array}{l}\overline{-} \\
-\end{array}$ & $\begin{array}{l}\overline{-} \\
\overline{-}\end{array}$ & $\begin{array}{l}\overline{-} \\
\overline{-}\end{array}$ & $\begin{array}{r}54,524 \\
- \\
-\end{array}$ & $\begin{array}{r}90,422 \\
- \\
-\end{array}$ & $\begin{array}{r}2,644,570 \\
- \\
-\end{array}$ & $\begin{array}{r}135,728 \\
338,853 \\
851\end{array}$ & $\begin{array}{r}2,798,616 \\
135,7.28 \\
338, E 53 \\
851\end{array}$ & $\begin{array}{r}\varepsilon 5 \% \\
4 \% \\
10 \% \\
0 \%\end{array}$ \\
\hline TOTAL SUP?LY & - & - & - & - & 54,624 & 90,422 & $2,644,570$ & 475,432 & $3,274,048$ & \\
\hline
\end{tabular}

\section{NET III PORES}

OP R EGIO

\section{NOTES:}

TXANSPORMATION LCSS POR TIANSPORAATION LCSS POR TRANSPORIATI ON LCSS POP TRANSPORMATI ON LCSS POR
ELECTRICITY GEN.

FEROLEOA PRODOCTS $=66.89 \%$

$\begin{aligned} & =6.824 \% \\ & =0.0 \%\end{aligned}$

$\begin{array}{ll}\text { SYNTHETICS } & =9.0 \\ & =9.80 \%\end{array}$ 
REGIONAL ENERGY BALANCE STATEMENT

IES MID HID SCENAFIO

\begin{tabular}{|c|c|c|c|c|c|c|c|c|c|c|}
\hline SECTOR & $\begin{array}{l}\text { DISTILIATE } \\
\text { OIL }\end{array}$ & $\begin{array}{l}\text { RESIDJhL } \\
\text { JIL }\end{array}$ & $\begin{array}{l}\text { GASOLINE } \\
\text { (ALL U? }\end{array}$ & $\begin{array}{c}\text { OTHER } \\
\text { HYDRO- } \\
\text { CARBONS } \\
\text { NITS IN } 10 * * 9\end{array}$ & $\begin{array}{c}\text { CRODE } \\
\text { OIL } \\
\text { BTO'S) }\end{array}$ & $\begin{array}{l}\text { NATURAL } \\
\text { GAS }\end{array}$ & $\mathrm{COAL}$ & ELECTRICITY & $\begin{array}{r}\text { SECTCR } \\
\text { TOTAL }\end{array}$ & \\
\hline $\begin{array}{l}\text { PINAL DEMAND SECTORS } \\
\text { RESID ERTIAL, CCMH. } \\
\text { INDUSTRIAL } \\
\text { TRANSPORTATION } \\
\text { MISCELLANEOOS USES }\end{array}$ & $\begin{array}{r}963,992 \\
343,198 \\
452,283 \\
45,495\end{array}$ & $\begin{array}{r}143,491 \\
348,398 \\
8,493 \\
26,303\end{array}$ & $2,832,02 \overline{-}$ & $\begin{array}{r}470,736 \\
1,135,201 \\
242,583 \\
1,147\end{array}$ & $\begin{array}{l}- \\
-\end{array}$ & $\begin{array}{r}2,235,370 \\
553,094 \\
82,926 \\
29,501\end{array}$ & $\begin{array}{r}15,017 \\
2,115,723 \\
5 \\
67\end{array}$ & $\begin{array}{r}797,727 \\
887,250 \\
+\quad 1,200 \\
9.571\end{array}$ & $\begin{array}{r}4,626,333 \\
5,382,864 \\
3,619,511 \\
112,084\end{array}$ & $\begin{array}{r}28 \% \\
32 \% \\
22 \% \\
1 \%\end{array}$ \\
\hline $\begin{array}{l}\text { TOTAL PINAL } \\
\text { DEMAID SECTORS }\end{array}$ & $1,804,968$ & 526,685 & $2,832,021$ & $1,849,667$ & - & $2,900,891$ & $2,130,812$ & $1,695,748$ & $13,740,792$ & $82 \%$ \\
\hline $\begin{array}{l}\text { TRANSF ORMATION } \\
\text { ELECTRICITY EEN. } \\
\text { PETR OLEOM PRCDOCTS } \\
\text { NATORAL GAS } \\
\text { SY HT HSTICS }\end{array}$ & $\begin{array}{r}84,728 \\
-1,343,658 \\
- \\
-\end{array}$ & $\begin{array}{r}19.8,786 \\
-575,013 \\
- \\
-\end{array}$ & $\begin{array}{r}-2,486,59 \bar{z} \\
- \\
-\end{array}$ & $\begin{array}{r}-1,154,210 \\
313,510\end{array}$ & $\begin{array}{r}- \\
5,335,168 \\
-\end{array}$ & $\begin{array}{r}40,389 \\
268,945 \\
-282,800\end{array}$ & $\begin{array}{r}3,748,076 \\
- \\
-\end{array}$ & $\begin{array}{r}-1,435,637 \\
- \\
-\end{array}$ & $\begin{array}{r}2,636,342 \\
44,639 \\
30,710\end{array}$ & $\begin{array}{r}16 \% \\
0 \%\end{array}$ \\
\hline $\begin{array}{l}\text { NET FOEL OSED } \\
\text { IN TRANSFORMATION }\end{array}$ & $-1,258,930$ & $-376,227$ & $-2,486,592$ & $-840,700$ & $5,335,168$ & 26,534 & $3,748,076$ & $-1,435,637$ & $2,711,691$ & $16 \%$ \\
\hline $\begin{array}{l}\text { TOTAL GROSS FLCRS } \\
\text { LOSSES } \varepsilon \text { OMISSIONS }\end{array}$ & $\begin{array}{r}1,889,696 \\
109,250\end{array}$ & $\begin{array}{r}725,471 \\
16\end{array}$ & $\begin{array}{r}2,832,021 \\
-8\end{array}$ & $\begin{array}{r}2,163,177 \\
-90,424\end{array}$ & $\begin{array}{r}5,335,168 \\
266,340\end{array}$ & $\begin{array}{r}3,210,225 \\
-116,284\end{array}$ & $\begin{array}{r}5,878,888 \\
-12,949\end{array}$ & $\begin{array}{r}1,695,748 \\
169,592\end{array}$ & $\begin{array}{r}16,452,483 \\
325 ; 533\end{array}$ & $\begin{array}{r}98 \% \\
2 \%\end{array}$ \\
\hline
\end{tabular}

\begin{tabular}{|c|c|c|c|c|c|c|c|c|c|c|}
\hline$S$ OPPLY OP ENERGY & & & & & & & & & & \\
\hline FOSSIL FOEL & - & - & - & - & 407,783 & 183,635 & $4,087,063$ & - & $4,678,481$ & $91 \%$ \\
\hline HY DROEL ECTRIC & - & $=$ & - & - & - & - & - & 16,083 & 16,083 & $0 \%$ \\
\hline NOCL EAR & - & - & - & - & - & - & - & 430,295 & 430,295 & $8 \%$ \\
\hline GEO. ESOLAR & - & - & - & - & - & - & - & 777 & 777 & $0 \%$ \\
\hline TOTAL SOPPLY & - & - & - & - & 407,783 & 183,635 & $4,087,063$ & 447,155 & $5,125,636$ & \\
\hline
\end{tabular}

NET IM PORTS
OP REGION


REG ONAL EJERGY BALANCE STATEMENT
PIES M=D MI D SCENARIO

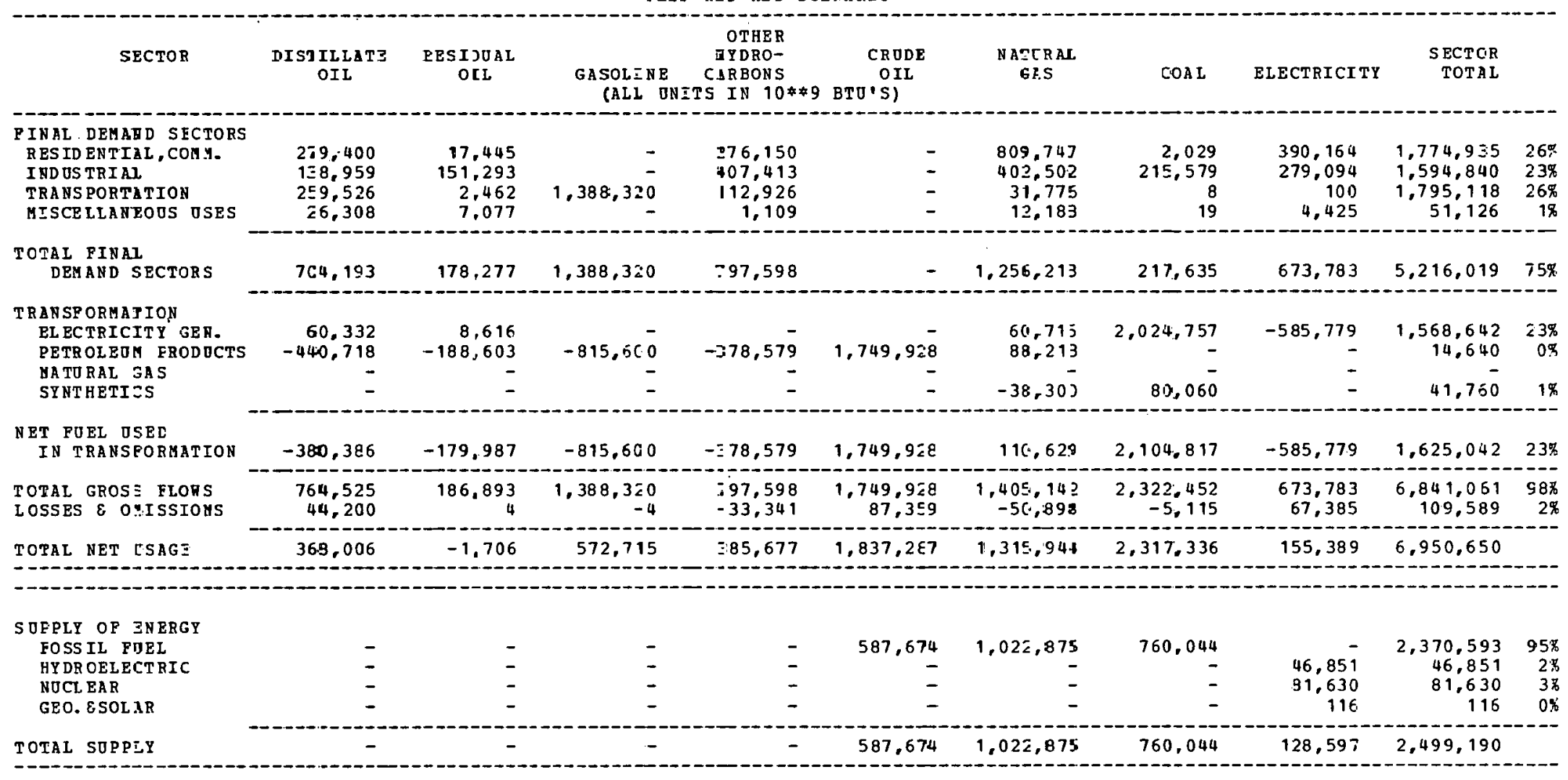

\begin{tabular}{l} 
NET IM PORTS \\
OP REGIOE \\
\hline NOTES:
\end{tabular}


REGIONAL ENE RGY BALANCE STATEMENT

PIES MID MID SCENARIO

\begin{tabular}{|c|c|c|c|c|c|c|c|c|c|c|}
\hline SECTOR & $\begin{array}{l}\text { DISTILLATE } \\
\text { OIL }\end{array}$ & $\begin{array}{l}\text { RESIOUALL } \\
\text { OIL }\end{array}$ & $\begin{array}{l}\text { GASOLINE } \\
\text { (ALL O }\end{array}$ & $\begin{array}{c}\text { OTHER } \\
\text { RYDRO- } \\
\text { CARBONS } \\
\text { ITS IN } 10 * * 9\end{array}$ & $\begin{array}{c}\text { CRODE } \\
\text { OIL } \\
\text { BTO'S) }\end{array}$ & $\begin{array}{l}\text { NATURAL } \\
\text { GAS }\end{array}$ & $\cos L$ & ELECTRICITY & $\begin{array}{l}\text { SECTOR } \\
\text { TOTAL }\end{array}$ & \\
\hline $\begin{array}{l}\text { PINAL DEHAND SECTORS } \\
\text { RESID ENTIAL, CCHM. } \\
\text { IND OS TRIAL } \\
\text { TRANS POPTATION } \\
\text { HISCELLANEOOS OSES }\end{array}$ & $\begin{array}{r}427,363 \\
223,530 \\
365,657 \\
32,335\end{array}$ & $\begin{array}{r}74,058 \\
355,159 \\
103,307 \\
18,016\end{array}$ & $2,754,88 \overline{-}$ & $\begin{array}{r}284,893 \\
417,001 \\
457,828 \\
1,260\end{array}$ & $\begin{array}{l}\overline{-} \\
\overline{-}\end{array}$ & $\begin{array}{r}473,978 \\
635,534 \\
49,631 \\
45,796\end{array}$ & $\begin{array}{r}9,075 \\
628,845 \\
145 \\
185\end{array}$ & $\begin{array}{r}1,089,831 \\
689,389 \\
744 \\
21,740\end{array}$ & $\begin{array}{r}2,359,198 \\
2,949,458 \\
3,732,196 \\
119,332\end{array}$ & $\begin{array}{r}20 \% \\
25 \% \\
31 \% \\
1 \%\end{array}$ \\
\hline $\begin{array}{l}\text { TOTAL PINAL } \\
\text { DEMAND SECTOBS }\end{array}$ & $1,048,885$ & 550,540 & $2,754,884$ & $1,160,982$ & - & $1,204,939$ & 638,250 & $1,801,704$ & $9,160,184$ & $76 \%$ \\
\hline $\begin{array}{l}\text { TRANSP ORMATION } \\
\text { ELECTRICITY GEN. } \\
\text { PETR OLEOM FRODOCTS } \\
\text { NATORAL GAS } \\
\text { SY NT HETICS }\end{array}$ & $\begin{array}{r}240,490 \\
-229,393 \\
- \\
-\end{array}$ & $\begin{array}{r}668,597 \\
-27,964 \\
- \\
-\end{array}$ & $\begin{array}{r}-264.477 \\
-\end{array}$ & $\begin{array}{r}-112,32 \frac{-}{-} \\
250,490\end{array}$ & $\begin{array}{r}630.978 \\
- \\
-\end{array}$ & $\begin{array}{r}29,481 \\
4,684 \\
-225,950\end{array}$ & $\begin{array}{r}3,036,050 \\
- \\
-\end{array}$ & $\begin{array}{r}-1,345,950 \\
- \\
-\end{array}$ & $\begin{array}{r}2,628,668 \\
1,504 \\
- \\
24,540\end{array}$ & $\begin{array}{r}22 x \\
0 \%\end{array}$ \\
\hline $\begin{array}{l}\text { NET FUEL USED } \\
\text { IN TRARSPORHATION }\end{array}$ & 11,096 & 640,632 & $-264,477$ & 138,167 & 630,978 & -191.784 & $3,036,050$ & $-1,345,950$ & $2,654,712$ & $22 \%$ \\
\hline $\begin{array}{l}\text { TOTAL GROSS FLORS } \\
\text { LOSSES } \& \text { OHISSIONS }\end{array}$ & $\begin{array}{r}1,289,375 \\
74,543\end{array}$ & $\begin{array}{r}1,219,137 \\
27\end{array}$ & $\begin{array}{r}2,754,884 \\
-8\end{array}$ & $\begin{array}{r}1,411,472 \\
-59,002\end{array}$ & $\begin{array}{r}630,978 \\
31,499\end{array}$ & $\begin{array}{r}1,239,104 \\
-44,884\end{array}$ & $\begin{array}{r}3,674,300 \\
-8,093\end{array}$ & $\begin{array}{r}1,801,704 \\
180,189\end{array}$ & $\begin{array}{r}11,814,898 \\
174,272\end{array}$ & $\begin{array}{r}99 \% \\
1 \%\end{array}$ \\
\hline TOTAL NET USAGE & $1,134,525$ & $1,191,200$ & $2,490,397$ & $1,240,147$ & 662.477 & 968,270 & $3,666,206$ & 635,943 & $11,989,16 \varepsilon$ & \\
\hline
\end{tabular}

\begin{tabular}{|c|c|c|c|c|c|c|c|c|c|c|}
\hline SOPPLY OP ENERGY & & & & & & & & & & \\
\hline POSS IL POEL & - & - & - & - & 921,882 & 390,985 & $4,671,920$ & - & $5,984,787$ & $93 \%$ \\
\hline HY DR OELECTRIC & - & - & - & - & - & - & - & 87,382 & 87,382 & $1 \%$ \\
\hline NOCL EAR & - & - & - & - & - & - & - & 380,159 & 380,159 & $6 \%$ \\
\hline GEO. ESOLAR & - & - & - & - & - & - & - & - & - & \\
\hline TOTAL SUPPLY & - & - & - & - & 921,882 & 390,985 & $4,671,920$ & 467,541 & $6,452,328$ & \\
\hline
\end{tabular}

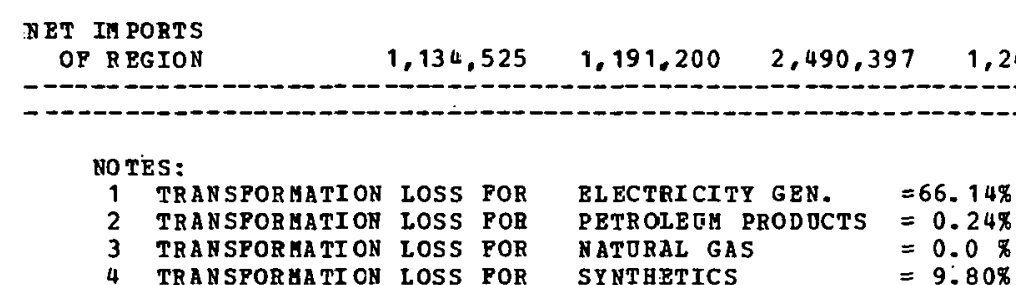

TRANSPOR HATION LOSS POR 
REGI DHAL ZNERGY BALANCE STATEHENT

PIBS MID MID SCENARIO

\begin{tabular}{|c|c|c|c|c|c|c|c|c|c|c|}
\hline SECTOR & $\begin{array}{c}\text { DI ST }=L L A T E \\
\text { OII }\end{array}$ & $\begin{array}{l}\text { RESIDJAL } \\
\text { OIZ }\end{array}$ & $\begin{array}{l}\text { GASOLIJE } \\
\text { (ALI ONI }\end{array}$ & $\begin{array}{l}\text { OTHER } \\
\text { HYDRO- } \\
\text { CARBONS } \\
\text { S IN } 10 * \star 9\end{array}$ & $\begin{array}{c}\text { CRUDE } \\
\text { OIL } \\
\text { BTO'S) }\end{array}$ & $\begin{array}{l}\text { NATBEAL } \\
\quad \text { GIS }\end{array}$ & COAL & ELECTRICITY & $\begin{array}{l}\text { SECTOR } \\
\text { TOTAL }\end{array}$ & \\
\hline $\begin{array}{l}\text { PINAL DEMAND SECTORS } \\
\text { RESIDENTIAI, COMI. } \\
\text { INDOSTRIAL } \\
\text { TRANSPORTATION } \\
\text { MISCELLANEOOS USES }\end{array}$ & $\begin{array}{r}4 \epsilon ., 830 \\
2 c, 149 \\
24 \because .316 \\
\varepsilon, 092\end{array}$ & $\begin{array}{r}4,348 \\
38,902 \\
25,308 \\
4,607\end{array}$ & $1,026,934$ & $\begin{array}{r}114,077 \\
221,791 \\
54,335 \\
461\end{array}$ & $\begin{array}{l}- \\
-\end{array}$ & $\begin{array}{r}268:=88 \\
577: 53 \\
8.217 \\
12: 566\end{array}$ & $\begin{array}{r}3,200 \\
317,230 \\
4 \\
23\end{array}$ & $\begin{array}{r}453,820 \\
593,248 \\
- \\
4,589\end{array}$ & $\begin{array}{r}891,163 \\
1,772,473 \\
1,372,614 \\
30,338\end{array}$ & $\begin{array}{r}15 \% \\
30 \% \\
23 \% \\
1 \%\end{array}$ \\
\hline $\begin{array}{l}\text { TOTAI PINAL } \\
\text { DEMAND SICTORS }\end{array}$ & $32 \epsilon, 887$ & 73,665 & $1,026,934$ & 430,664 & - & $866, \equiv 24$ & 320,457 & $1,051,657$ & $4,066,588:$ & $6 \varepsilon \%$ \\
\hline $\begin{array}{l}\text { TRANSF ORMATION } \\
\text { ELECTRICISY GEN. } \\
\text { PETR OLEOM ERODOCTS } \\
\text { NATORAL GAS } \\
\text { SYNT HETICS }\end{array}$ & $\begin{array}{r}16 \subseteq, 537 \\
-33 L, 006 \\
- \\
-\end{array}$ & $\begin{array}{r}66.376 \\
-65.245 \\
- \\
-\end{array}$ & $\begin{array}{r}-580,72 \overline{-} \\
- \\
-\end{array}$ & $\begin{array}{r}-449,99 \overline{-} \\
-\end{array}$ & $1,346,649$ & $\begin{array}{r}30,410 \\
99,788 \\
- \\
-\end{array}$ & $\begin{array}{r}2,362,337 \\
- \\
-\end{array}$ & $\begin{array}{r}-903,192 \\
- \\
-\end{array}$ & $\begin{array}{r}1,725,468 \\
12,463 \\
- \\
-\end{array}$ & $\begin{aligned} 25 \% \\
0 \%\end{aligned}$ \\
\hline $\begin{array}{l}\text { NET FOEL OSZD } \\
\text { IE TRANSFORMATION }\end{array}$ & $-164,469$ & $-2,869$ & $-580,72^{\circ}$ & $-449,996$ & $1,346,649$ & 130,198 & $2,362,337$ & $-903,192$ & $1,737,935$ & 29\% \\
\hline $\begin{array}{l}\text { TOTAL GROSS FLOTS } \\
\text { LOSSES } \& \text { OMISSIONS }\end{array}$ & $\begin{array}{r}49 E, 424 \\
2 E, 700\end{array}$ & $\begin{array}{r}140,041 \\
3\end{array}$ & $\begin{array}{r}1,026,936 \\
-3\end{array}$ & $\begin{array}{r}430,664 \\
-16,748\end{array}$ & $\begin{array}{r}1,346,64 \mathrm{~S} \\
67,227\end{array}$ & $\begin{array}{l}996,522 \\
-36,097\end{array}$ & $\begin{array}{r}2,682,794 \\
-5,909\end{array}$ & $\begin{array}{r}1,051,657 \\
105,176\end{array}$ & $\begin{array}{r}5,804,524 \\
142,349\end{array}$ & $\begin{array}{r}9 \varepsilon \% \\
2 \%\end{array}$ \\
\hline TOTAL NET USAGE & 191,117 & 70,798 & 446,209 & $-56,080$ & $1,413,87 E$ & 960,425 & $2,676,884$ & 253,641 & $5,946,873$ & \\
\hline $\begin{array}{l}\text { SOPPLY OF EDERGY } \\
\text { POSS IL FOEL } \\
\text { HYDROELECERIC } \\
\text { NDCL EAR } \\
\text { GEO. ESOLAE }\end{array}$ & $\begin{array}{l}- \\
-\end{array}$ & $\begin{array}{l}- \\
\overline{-} \\
-\end{array}$ & $\begin{array}{l}\bar{z} \\
\overline{-}\end{array}$ & $\begin{array}{l}\bar{z} \\
\bar{z}\end{array}$ & $\begin{array}{r}380,567 \\
- \\
=\end{array}$ & $\begin{array}{r}191.715 \\
- \\
-\end{array}$ & $\begin{array}{r}4,946,997 \\
- \\
-\end{array}$ & $\begin{array}{r}77,733 \\
281,971 \\
-\end{array}$ & $\begin{array}{r}5,519,279 \\
77,733 \\
281,971\end{array}$ & $\begin{array}{r}94 \% \\
1 \% \\
5 \%\end{array}$ \\
\hline TOTAL SUPPLI & - & - & - & - & 380,567 & 191.715 & $4,946,997$ & 359,704 & $5,878,983$ & \\
\hline
\end{tabular}

-

\section{NET IM PORTS}

OP REGION

191,117

70,798

446,205

$-66,080$

$1,033,305$

$768,710 \quad-2,270,112$

$-106,062$

NO TES :

TRASSPORMATION LOSS POR

TRAYSPORMATION LOSS POR

TRASSPORMATI ON LOSS POR
TRASSFORMETI ON LOSS POR

EL. 3CTRICITY GEN.

PETROLEU PEODUCTS $=0$. \$E. 
REGIONAL ENERGY BALANCE STATEMENT

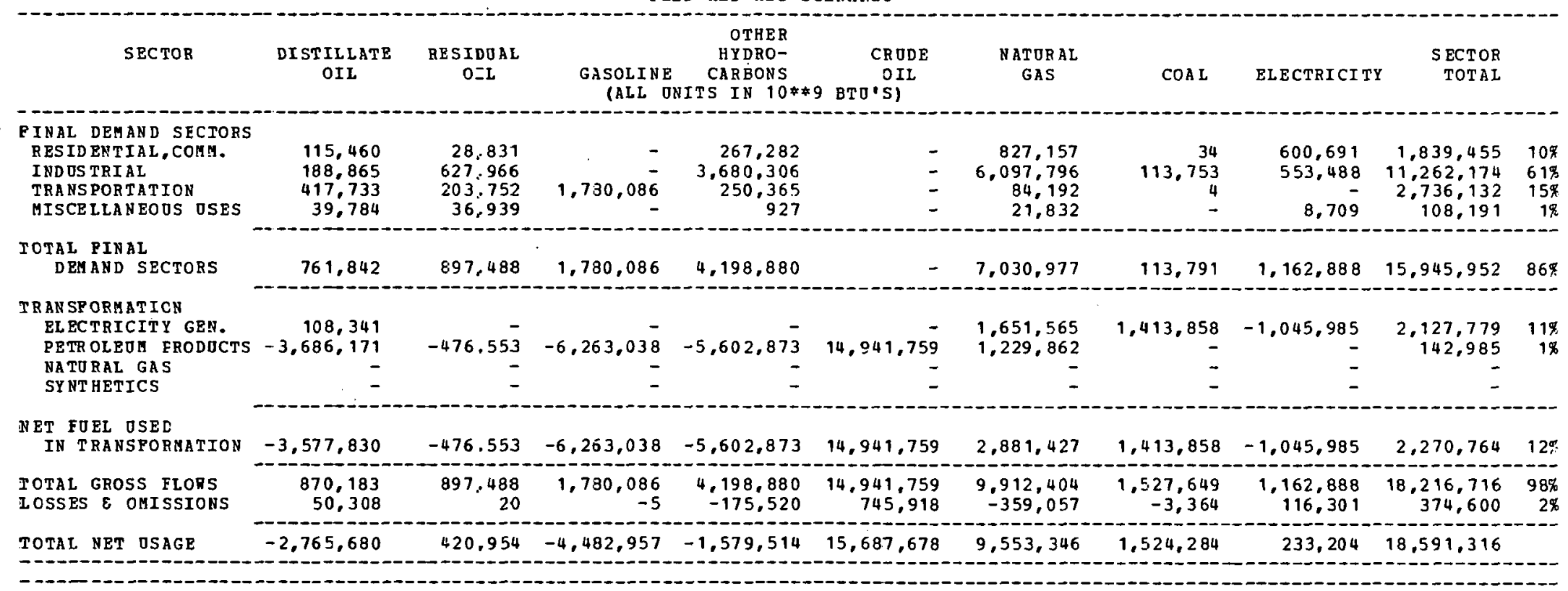

\begin{tabular}{|c|c|c|c|c|c|c|c|c|c|c|}
\hline $\begin{array}{l}S \text { UPPLY OP ENERGY } \\
\text { POSS IL POEL }\end{array}$ & - & - & - & - & $10,478,832$ & $10,372,376$ & 740,510 & - & $21,591,718$ & $99 \%$ \\
\hline HY DR OEL ECT RIC & - & - & - & - & - & - & - & 33,151 & 33,151 & $0 \%$ \\
\hline NOCL EAR & - & - & - & - & - & - & - & 144,670 & 144,670 & $1 \%$ \\
\hline GEO. ESOLAR & - & - & - & - & - & - & - & 301 & 301 & $0 *$ \\
\hline TOTAL SUPPIY & - & - & - & - & $10,478,832$ & $10,372,376$ & 740,510 & 178,122 & $21,769,840$ & \\
\hline
\end{tabular}

\begin{tabular}{l}
$\begin{array}{l}\text { NET IM PORTS } \\
\text { OP R EGION }\end{array}$ \\
\hline
\end{tabular}


FESTONAL ENERGY BALANCE STATEMENT

POAL EMERGY BALANCE S
PIES MID MID.SCENAIO

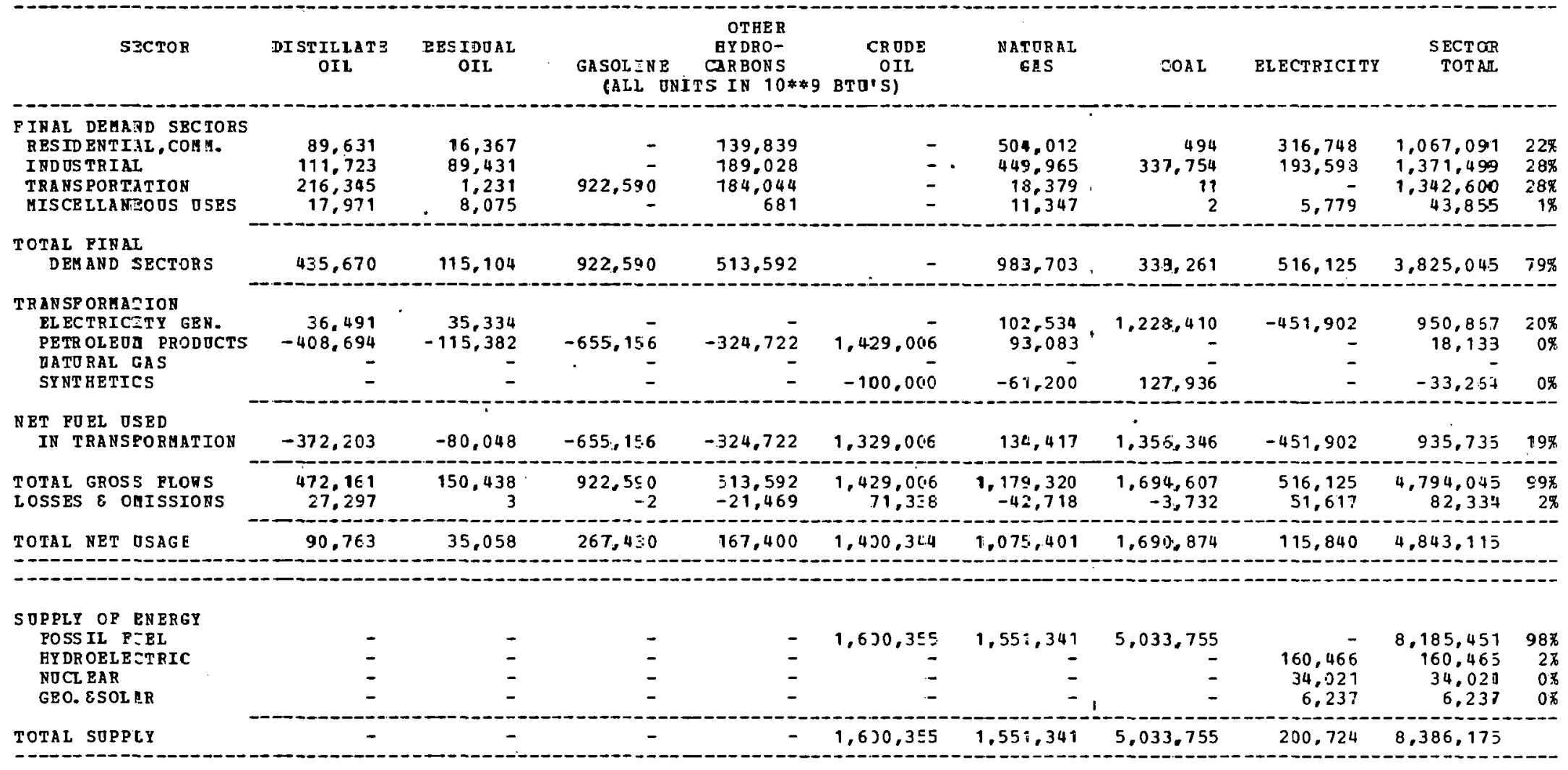

\section{NET IM PORTE}

CP REGIO:

90,763

35,058

267,430

167,400

$-2,30,010 \quad-475,930-3,342,880$

$-84,883 \quad-3,543.053$

\section{No TES :}

1 TRANSPORMATION LOSS POR TRYNSPOREATION LOSS POR TRANSFCRUATI ON LOSS FO TRANSPORHATI ON LOSS POR

ELZCTBICITS GEN.

PETROLEOM PRODOCTO $=67.79 \%$

NTIORAL GAS

SENTHETICS $\begin{aligned} & =67.79 \% \\ & =1.19 \% \\ & =0.0 \% \\ & =\$ \$ \$ \$\end{aligned}$ 
REGIONAL ENERGY BALANCE STATEMENT

PIES MID MID SCENARIO

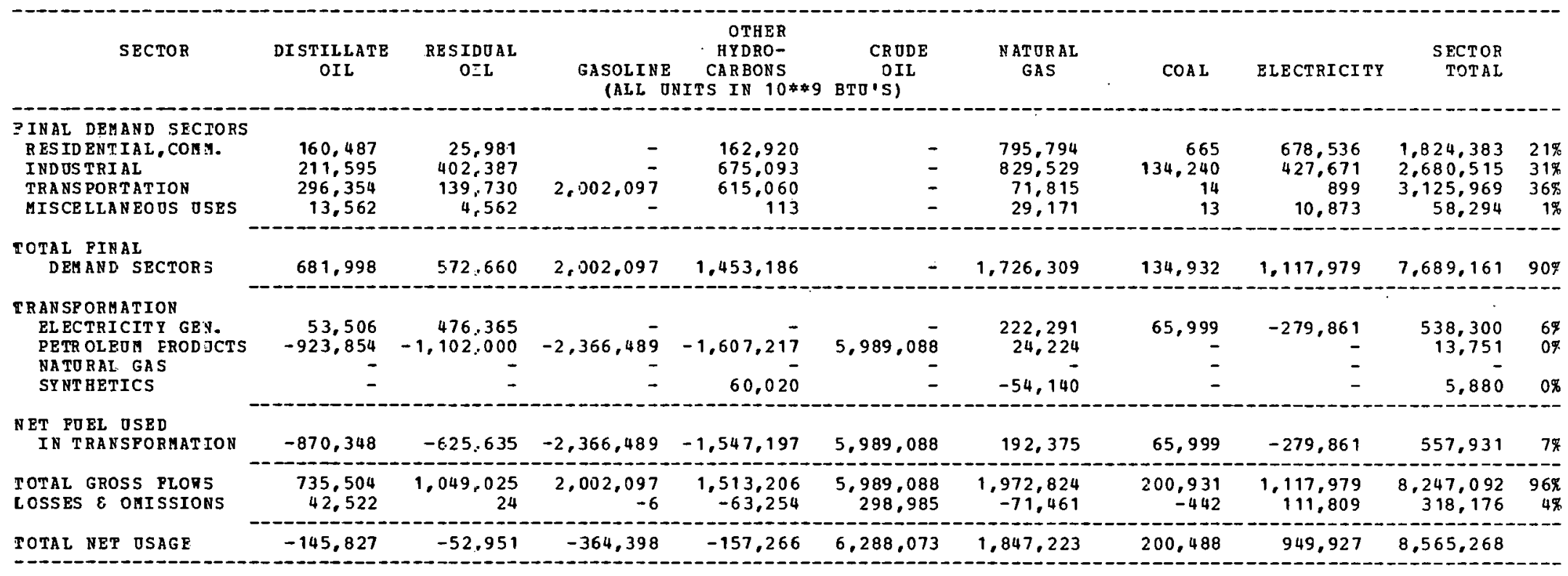

I0TAL WER OSRGE

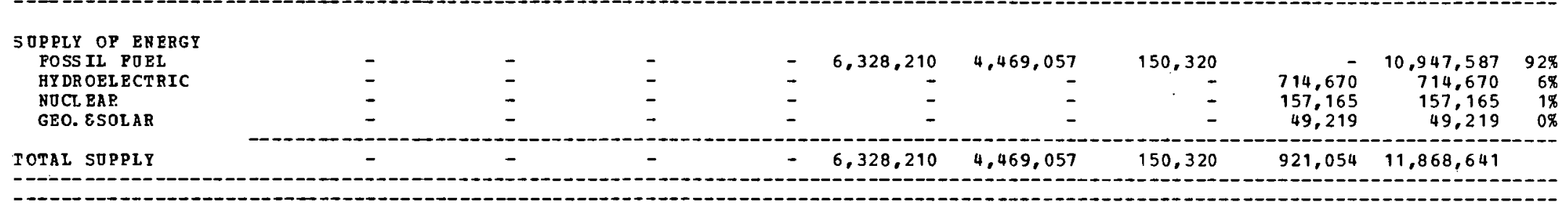

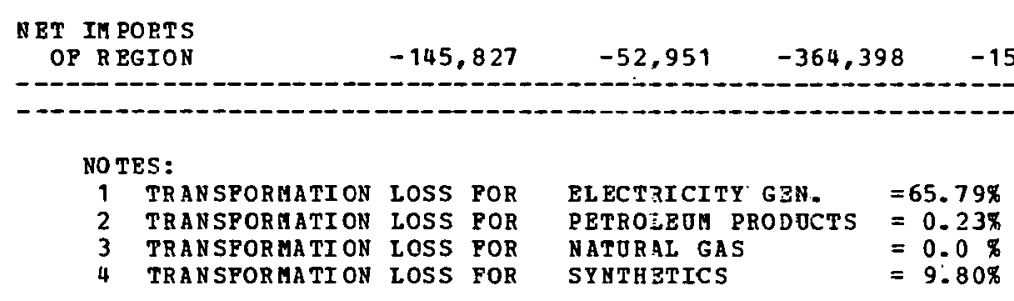




\section{THIS PAGE \\ WAS INTENTIONALLY \\ LEFT BLANK}


State Tables for 1985 


\section{THIS PAGE \\ WAS INTENTIONALLY \\ LEFT BLANK}


REGIONAL ENERGY BALANCE STATEMENT

PIES MID MID SCENARIO

\begin{tabular}{|c|c|c|c|c|c|c|c|c|c|c|}
\hline SECTOZ & $\begin{array}{l}\text { DISTILLATE } \\
\text { OIL }\end{array}$ & $\begin{array}{l}\text { RESIDIJAL } \\
\text { OIL }\end{array}$ & $\begin{array}{l}\text { GA SOLI NE } \\
\text { CALL O }\end{array}$ & $\begin{array}{c}\text { OTHER } \\
\text { HYDRO- } \\
\text { CARBOES } \\
\text { TS IN } 10 * * 9\end{array}$ & $\begin{array}{c}\text { CRODE } \\
\text { OIL } \\
\text { BTJ'S }\end{array}$ & $\begin{array}{l}\text { NATTRAL } \\
\text { GAS }\end{array}$ & $\operatorname{COAL}$ & ELECTRICI TY & $\begin{array}{l}\text { SECTOR } \\
\text { TOTAL }\end{array}$ & \\
\hline $\begin{array}{l}\text { PINAL DEMAND SECTORS } \\
\text { RES IDENTIAL, COMM. } \\
\text { IND OS TRIAL } \\
\text { TRA PSPORTATIOR } \\
\text { MISCELLANEOOS OSES }\end{array}$ & $\begin{array}{r}11.499 \\
10,033 \\
.54,635 \\
2.698\end{array}$ & $\begin{array}{r}1,769 \\
14,407 \\
22,705 \\
1,537\end{array}$ & $272,68 \overline{-}$ & $\begin{array}{r}30.008 \\
59.830 \\
10.840 \\
150\end{array}$ & $\begin{array}{l}- \\
\overline{-} \\
-\end{array}$ & $\begin{array}{r}64,834 \\
171,852 \\
3,190 \\
3,924\end{array}$ & $\begin{array}{r}403 \\
128,415 \\
1 \\
9\end{array}$ & $\begin{array}{r}119,296 \\
124,098 \\
- \\
1,295\end{array}$ & $\begin{array}{r}227,864 \\
508,635 \\
374,059 \\
9,613\end{array}$ & $\begin{array}{r}14 \% \\
32 \% \\
23 \% \\
1 \%\end{array}$ \\
\hline $\begin{array}{l}\text { TOTAL FINAL } \\
\text { DEMAND SECTORS }\end{array}$ & 33,865 & 40,418 & 272,688 & 100,828 & - & 243,850 & 128,833 & 244,689 & $1.120,171$ & $69 \%$ \\
\hline $\begin{array}{l}\text { TRAN SFORMATION } \\
\text { EL ECTRICITY.GEN. } \\
\text { PETR OL EOM FRODJCTS } \\
\text { NATURAL GAS } \\
\text { SY NT HETICS }\end{array}$ & $\begin{array}{r}39,434 \\
-45,914 \\
- \\
-\end{array}$ & $\begin{array}{r}-4,618 \\
- \\
-\end{array}$ & $\begin{array}{r}- \\
-77,341 \\
-\end{array}$ & $\begin{array}{r}- \\
-72,703 \\
-\end{array}$ & $\begin{array}{r}- \\
186,474 \\
-\end{array}$ & $\begin{array}{r}1,950 \\
15,907 \\
- \\
-\end{array}$ & $\begin{array}{r}669,484 \\
- \\
-\end{array}$ & $\begin{array}{r}-244,773 \\
- \\
-\end{array}$ & $\begin{array}{r}466,095 \\
1,805 \\
- \\
-\end{array}$ & $\begin{array}{r}29 \% \\
0 \%\end{array}$ \\
\hline $\begin{array}{l}\text { NET POEI OSED } \\
\text { IN TRANSFORMLTION }\end{array}$ & $-6,480$ & $-4,618$ & $-77,341$ & $-72,703$ & 186,474 & 17,857 & 669,484 & $-244,773$ & 467,900 & $29 \%$ \\
\hline $\begin{array}{l}\text { TOTAL GROSS FLORS } \\
\text { LOSSES E OMISSIONS }\end{array}$ & $\begin{array}{r}128,299 \\
7,417\end{array}$ & $\begin{array}{r}40,418 \\
0\end{array}$ & $\begin{array}{r}272,688 \\
-0\end{array}$ & $\begin{array}{r}100,828 \\
-4,214\end{array}$ & $\begin{array}{r}186,474 \\
9,309\end{array}$ & $\begin{array}{r}261,707 \\
-9,479\end{array}$ & $\begin{array}{r}798,317 \\
-1,758\end{array}$ & $\begin{array}{r}244,689 \\
24,471\end{array}$ & $\begin{array}{r}1,588,071 \\
25,745\end{array}$ & $\begin{array}{r}98 \% \\
2 \%\end{array}$ \\
\hline
\end{tabular}

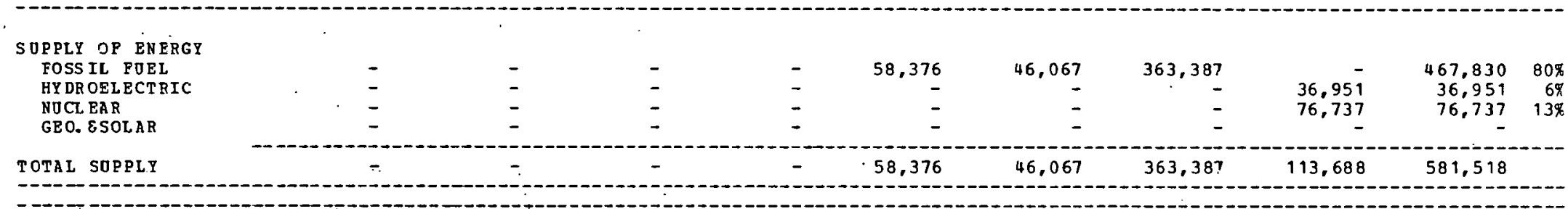

NET IM PORTS
OP REGION


REGIONAL ENERGY BALANCE STATEMENT

PIES IID HID SCENARIO

\begin{tabular}{|c|c|c|c|c|c|c|c|c|c|}
\hline SECTOR & $\underset{\text { OIL }}{\text { DISTILLTE }}$ & $\begin{array}{l}\text { RESIDOAL } \\
\text { DIL. }\end{array}$ & $\begin{array}{l}\text { GASOLINE } \\
\text { (ALL O }\end{array}$ & $\begin{array}{c}\text { OTHER } \\
\text { HYDRO- } \\
\text { CARBONS } \\
:=\text { IN 10** }\end{array}$ & $\begin{array}{c}\text { CRODE } \\
\text { OII } \\
\text { BTO'S) }\end{array}$ & $\begin{array}{l}\text { N } \triangle T \text { JRAL } \\
\text { EAS }\end{array}$ & $\operatorname{COAL}$ & ELECTRICITY & $\begin{array}{l}\text { SECTJa } \\
\text { TOTAL }\end{array}$ \\
\hline $\begin{array}{l}\text { PINAL DEMAND SECTORS } \\
\text { BESID ENTIAL, CCHM. } \\
\text { INDOS TRILL } \\
\text { TRANSPOREATION } \\
\text { MISCELLAEEOOS DSES }\end{array}$ & $\begin{array}{r}12,265 \\
41,092 \\
18,764 \\
799\end{array}$ & $\begin{array}{r}123 \\
53.152 \\
5,209 \\
332\end{array}$ & $23,61 \overline{1}$ & $\begin{array}{r}5,076 \\
16,233 \\
66,605 \\
8\end{array}$ & $\begin{array}{l}- \\
-\end{array}$ & $\begin{array}{r}13,738 \\
7,832 \\
259 \\
2,351\end{array}$ & $\begin{array}{r}73 \\
3,488 \\
-\end{array}$ & $\begin{array}{r}9,631 \\
2,998 \\
- \\
529\end{array}$ & $\begin{array}{r}40,965 \\
124,795 \\
114,459 \\
4,021\end{array}$ \\
\hline $\begin{array}{l}\text { TOTAL PINAL } \\
\text { DEM AND SECTORS }\end{array}$ & 72,920 & $5.3,816$ & 23,611 & 87,922 & - & 24,250 & 3,563 & 13,158 & 284,240 \\
\hline $\begin{array}{l}\text { TRANSF ORMATION } \\
\text { EL ECTRICITY GEN. } \\
\text { PETR OLEOA FRODOCTS } \\
\text { NATURAL GAS } \\
\text { SY NT HETECS }\end{array}$ & $\begin{array}{r}692 \\
-28,688 \\
-\end{array}$ & $\begin{array}{r}-31,220 \\
-\end{array}$ & $\begin{array}{r}-73,486 \\
-\end{array}$ & $\begin{array}{r}-49.909 \\
-\end{array}$ & $\begin{array}{r}185,978 \\
-\end{array}$ & $\begin{array}{r}752 \\
-\end{array}$ & $\begin{array}{l}\overline{-} \\
\overline{-}\end{array}$ & $\begin{array}{r}-223 \\
- \\
-\end{array}$ & $\begin{array}{r}469 \\
427 \\
- \\
-\end{array}$ \\
\hline $\begin{array}{l}\text { NET POEL DSED } \\
\text { IN TRANSFORMATION }\end{array}$ & $-27,996$ & $-34,220$ & $-73,486$ & $-49,909$ & 185,978 & 752 & - & -223 & 8.96 \\
\hline $\begin{array}{l}\text { TOTAL GFOSS FLORS } \\
\text { LOSSES \& OMISSIONS }\end{array}$ & $\begin{array}{r}73,612 \\
4,255 \\
\end{array}$ & $\begin{array}{r}5 B, 816 \\
1\end{array}$ & $\begin{array}{r}23,611 \\
-0\end{array}$ & $\begin{array}{r}87,922 \\
-3,675\end{array}$ & $\begin{array}{r}185,978 \\
9,284\end{array}$ & $\begin{array}{r}25,092 \\
-905\end{array}$ & $\begin{array}{r}3,563 \\
-7\end{array}$ & $\begin{array}{r}13,158 \\
1,315\end{array}$ & $\begin{array}{r}285,136 \\
10,268\end{array}$ \\
\hline TOTAL NET OSAGE & 49,179 & 24,597 & $-49,875$ & 34,337 & 195,262 & $2 L .096$ & 3,555 & 14,250 & 295,404 \\
\hline
\end{tabular}

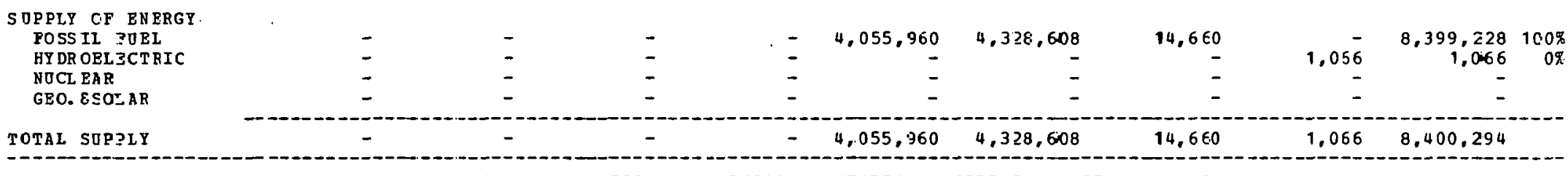

(1)

\section{N $3 T$ IM POATS}

\section{NO TRS :}

1 TZANSPORMATIC: LOSS POR 2 TZANSPORMATI CO LOSS POR
TZANSPORHATI CH LOS POB TZANSPORMATICO LOSS FOR
BLECTRICITY GEN.

$=67.77 \%$

MTURAL GAS

SYMTHETICS

\section{$=67.77 \%$
$=.23 \%$}

$=0.0 \%$ 
REGIONAL ENERGY BALANCE STATEMENT

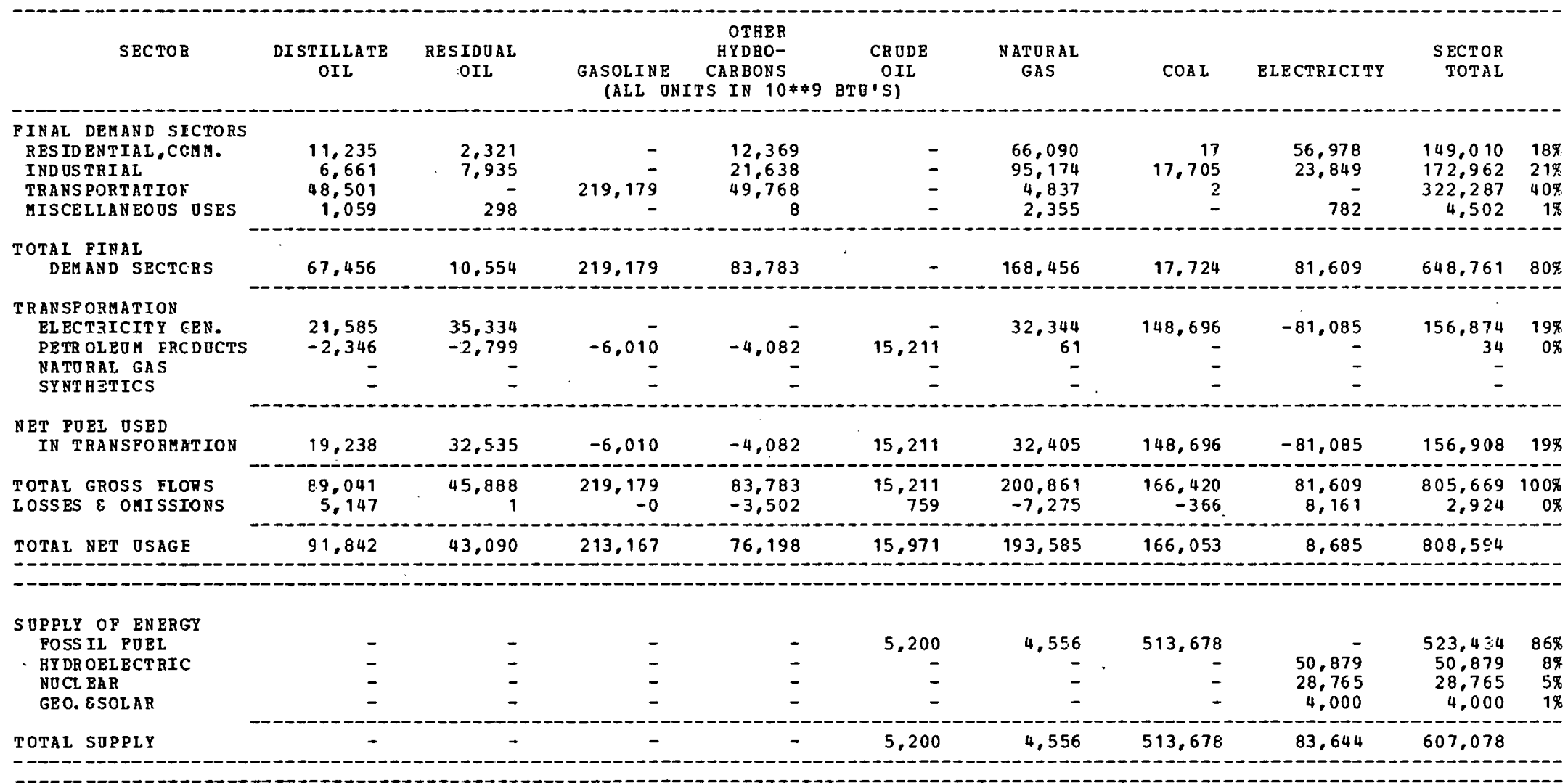

\section{NET IM PORTS}

OP REGION

91,842

43,090

213,167

76,198

10,771

189,029

$-347,624$

$-74,958$

201,516 
R3GIONAL EIERGY BALANCE STATEMENT

\begin{tabular}{|c|c|c|c|c|c|c|c|c|c|c|}
\hline SECTOR & $\begin{array}{l}\text { IX STILLATE } \\
\text { OIL }\end{array}$ & $\underset{0=1}{3 E \leq I D D A L}$ & $\begin{array}{l}\text { GAS JLINE } \\
\text { (ALL O }\end{array}$ & $\begin{array}{c}\text { OTHER } \\
\text { EYDRO- } \\
\text { CARBONS } \\
\text { TS IN 10**9 }\end{array}$ & $\begin{array}{c}\text { CRUDE } \\
\text { OIL } \\
\text { BTO'S) }\end{array}$ & $\begin{array}{l}\text { NAJURAL } \\
\text { EAS }\end{array}$ & $\operatorname{COAL}$ & ELECTRICITY & $\begin{array}{l}\text { SECTOR } \\
\text { TOTAL }\end{array}$ & \\
\hline $\begin{array}{l}\text { PIHAL DEMAUD SECTORS } \\
\text { RESID ENTIAL, COMA. } \\
\text { IHDUSTRIAL } \\
\text { TEANSPORTATION } \\
\text { MISCELLANEOUS OSES }\end{array}$ & $\begin{array}{r}19.452 \\
43.104 \\
57.817 \\
2,939\end{array}$ & $\begin{array}{r}7.014 \\
140.674 \\
- \\
2.729\end{array}$ & $\begin{array}{r}- \\
172.417 \\
-\end{array}$ & $\begin{array}{r}27,250 \\
140,816 \\
11,648 \\
59\end{array}$ & $\begin{array}{l}\overline{-} \\
-\end{array}$ & $\begin{array}{r}9 \subseteq, 880 \\
19 \epsilon, 487 \\
6 ., 920 \\
., 583\end{array}$ & $\begin{array}{r}8 \\
8,944 \\
1 \\
-\end{array}$ & $\begin{array}{r}51,687 \\
53,740 \\
- \\
518\end{array}$ & $\begin{array}{r}205,29.2 \\
583,765 \\
246,80.5 \\
7,83.3\end{array}$ & $\begin{array}{r}17.8 \\
478 \\
20.8 \\
1.6\end{array}$ \\
\hline $\begin{array}{l}\text { TOTAL PINAL } \\
\text { DEMAND SECTORS }\end{array}$ & 123,312 & 150,417 & 172,417 & 179,773 & - & 302.873 & 8,953 & 105,945 & $1,043,69.5$ & $84 . \%$ \\
\hline $\begin{array}{l}\text { TRANSF ORMAIION } \\
\text { ELECTRICITY GER. } \\
\text { PETR OLETE PRODOCTS } \\
\text { HATURAL GAS } \\
\text { SY NTHETICS }\end{array}$ & $\begin{array}{r}9,864 \\
-29,479 \\
- \\
-\end{array}$ & $\begin{array}{r}-2,96 \overline{5} \\
-\end{array}$ & $\begin{array}{r}-49,65 \overline{7} \\
- \\
-\end{array}$ & $\begin{array}{r}-46,679 \\
-\end{array}$ & $119,7=\overline{-}$ & $\begin{array}{r}55.060 \\
10,21.3 \\
- \\
-\end{array}$ & $\begin{array}{r}219.487 \\
- \\
-\end{array}$ & $\begin{array}{r}-95,348 \\
- \\
-\end{array}$ & $\begin{array}{r}193,063 \\
1,153 \\
-\end{array}$ & $\begin{array}{r}16 \% \\
0 \%\end{array}$ \\
\hline $\begin{array}{l}\text { NET FOEI OSED } \\
\text { IN TRANSORMATION }\end{array}$ & $-19,615$ & -2.965 & $-49,657$ & $-46,679$ & 119,725 & $69,27.3$ & 219,487 & $-95,348$ & 194,221 & $16 \%$ \\
\hline $\begin{array}{l}\text { TOTAL GROSS PLONS } \\
\text { LOSSES } \varepsilon \text { ODISSIONS }\end{array}$ & $\begin{array}{r}133,176 \\
7,699\end{array}$ & $\begin{array}{r}150.417 \\
3\end{array}$ & $\begin{array}{r}172.417 \\
-0\end{array}$ & $\begin{array}{r}179,773 \\
-7,514\end{array}$ & $\begin{array}{r}119,725 \\
5,9 \div 6\end{array}$ & $\begin{array}{r}372,151 \\
-13,480\end{array}$ & $\begin{array}{r}228.440 \\
-503\end{array}$ & $\begin{array}{r}105,945 \\
10,595\end{array}$ & $\begin{array}{r}1,237,915 \\
2,775\end{array}$ & $\begin{array}{r}100 \% \\
0 \%\end{array}$ \\
\hline
\end{tabular}

\begin{tabular}{|c|c|c|c|c|c|c|c|c|c|c|}
\hline SOPPLY OF ENERGY & & & & & & & & & & \\
\hline HY DR OELECT RIC & - & _- & - & $=$ & $110,3.0$ & 113,463 & 10,151 & $15.59 \overline{9}$ & $247,18.7$ & 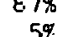 \\
\hline NOCL EAR & - & - & - & - & - & - & - & $\begin{array}{l}12,399 \\
21,263\end{array}$ & $\begin{array}{l}15,599 \\
21,263\end{array}$ & $7 \%$ \\
\hline GEO. ESOLAR & - & - & - & - & - & - & - & 28 & 28 & $0 \%$ \\
\hline
\end{tabular}

NET IM POFTS
OP R RGIOA


REGIONAL ENERGY BALANCE STATERENT

PIES MID MID SCENARIO

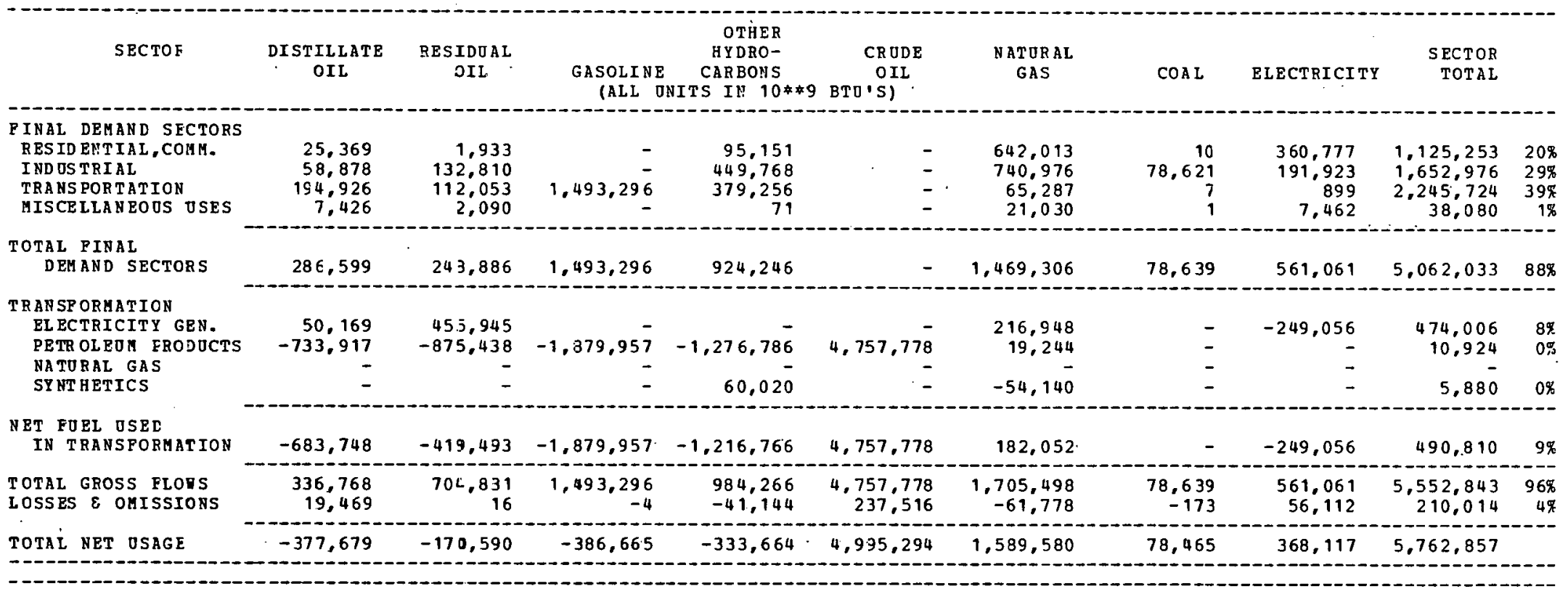

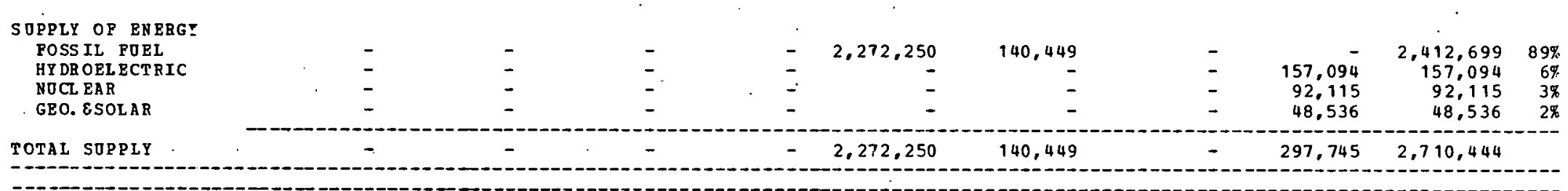

\begin{tabular}{|c|c|c|c|c|c|c|c|c|c|}
\hline OP REGION & $-377,679$ & $-170,590$ & -386.665 & $-333,664$ & $2,723,044$ & 1.449 .131 & 78,465 & 70,372 & $3,052,413$ \\
\hline
\end{tabular}

\begin{tabular}{|c|c|c|c|c|c|}
\hline \multicolumn{6}{|c|}{ NOTES: } \\
\hline 1 & TRAN SPOBMATI ON & LoSS & FOR & RL 3CTRI CITY GEN. & $=65.56 \%$ \\
\hline 2 & TRANSPOBMATI OS & Loss & POR & PETROLEUM PRODOCTS & $=0.23$ \\
\hline 3 & TRANSPORMATI OY & Loss & FOR & NATURAL GAS & 0.0 \\
\hline 4 & TR AN SPORHATI ON & Loss & POR & SYNTHETICS & $=9.80 \%$ \\
\hline
\end{tabular}


REGIONAL BYERGY BALANCE STATEMENT

PIES. HED MID SCENARIO

\begin{tabular}{|c|c|c|c|c|c|c|c|c|c|c|}
\hline SECTOR & $\begin{array}{c}\text { MISTILLATE } \\
\text { DIL }\end{array}$ & $\begin{array}{l}\text { RESIDUAL } \\
\text { OIL }\end{array}$ & $\begin{array}{l}\text { GASJUINE } \\
\text { (AEI O }\end{array}$ & $\begin{array}{l}\text { OTHER } \\
\text { EYDRO- } \\
\text { CYRBONS } \\
\text { S IN } 10 * 9\end{array}$ & $\begin{array}{c}\text { CRODE } \\
\text { OIL } \\
\text { BTO'S) }\end{array}$ & $\begin{array}{l}\text { NAT JRAL } \\
\text { CAS }\end{array}$ & $\operatorname{COAL}$ & ELECTRICITY & $\begin{array}{l}\text { SECTOR } \\
\text { TOTAL }\end{array}$ & \\
\hline $\begin{array}{l}\text { PINAL DEMAED SECTORS } \\
\text { RES IDENTIAL, CCHA. } \\
\text { INDOS TRIAL } \\
\text { TEANSPORTATION } \\
\text { MISCELLANEOOS OSES }\end{array}$ & $\begin{array}{r}77,430 \\
71,841 \\
24,683 \\
5,505\end{array}$ & $\begin{array}{r}4.342 \\
15.979 \\
70 \\
1.954\end{array}$ & $218,46 . \overline{-}$ & $\begin{array}{r}52,534 \\
52,669 \\
63,770 \\
284\end{array}$ & 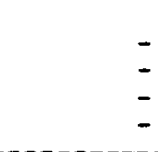 & $\begin{array}{r}191.13 .5 \\
57.047 \\
4.797 \\
3.037\end{array}$ & $\begin{array}{r}129 \\
116,572 \\
2 \\
-\end{array}$ & $\begin{array}{r}90,080 \\
12,407 \\
1,834\end{array}$ & $\begin{array}{r}355,650 \\
286,517 \\
311,792 \\
12,616\end{array}$ & $\begin{array}{l}327 \\
26 \% \\
28 \% \\
1 \%\end{array}$ \\
\hline $\begin{array}{l}\text { TOTAL PINAL } \\
\text { DEMAND SECTORS }\end{array}$ & 79,459 & 22,345 & $218,+68$ & 169,257 & - & 256,022 & 115,703 & 104,321 & 966,575 & $86 \%$ \\
\hline $\begin{array}{l}\text { TRANSP ORMAEION } \\
\text { ELECTRICITY GEY. } \\
\text { PETR OLEUI PRODJCTS } \\
\text { HA TORAL GAS } \\
\text { SYNTHETICS }\end{array}$ & $\begin{array}{r}4,088 \\
-40,695 \\
- \\
-\end{array}$ & $\begin{array}{r}-12,295 \\
- \\
-\end{array}$ & $\begin{array}{r}-64,509 \\
- \\
-\end{array}$ & $\begin{array}{r}- \\
-27,519 \\
-\end{array}$ & $\begin{array}{r}138,225 \\
-50,090\end{array}$ & $\begin{array}{r}1,017 \\
3.636 \\
- \\
-\end{array}$ & $\begin{array}{r}284,290 \\
- \\
-\end{array}$ & $\begin{array}{r}-90,237 \\
- \\
-\end{array}$ & $\begin{array}{r}199,160 \\
1,842 \\
-50,000\end{array}$ & $\begin{array}{r}18 \% \\
0 \% \\
-3 \%\end{array}$ \\
\hline $\begin{array}{l}\text { NET FOEL USED } \\
\text { IN T RANSFORMATION }\end{array}$ & $-\vdots 6,607$ & $-12,295$ & $-64,509$ & $-27,519$ & 88,225 & 9.655 & 284,290 & $-90,237$ & 151,002 & $13 \%$ \\
\hline $\begin{array}{l}\text { TOTAL GROSS FLORS } \\
\text { IOSSES } \& \text { CMISSIONS }\end{array}$ & $\begin{array}{r}83,547 \\
4,830\end{array}$ & $\begin{array}{r}22,345 \\
0\end{array}$ & $\begin{array}{r}218,458 \\
-0\end{array}$ & $\begin{array}{r}169,257 \\
-7,075\end{array}$ & $\begin{array}{r}138,225 \\
6,900\end{array}$ & $\begin{array}{r}265,677 \\
-9,623\end{array}$ & $\begin{aligned} & 400, 993 \\
&-883\end{aligned}$ & $\begin{array}{r}104,321 \\
10,433\end{array}$ & $\begin{array}{r}1,167,577 \\
4,581\end{array}$ & $\begin{array}{r}104 \% \\
0 \%\end{array}$ \\
\hline TOTAL NET JSAGE & 4.681 & 10,050 & 155.958 & 134,662 & 95,125 & $255,0 \subseteq 3$ & 400,100 & 24,517 & $1,122,159$ & \\
\hline $\begin{array}{l}\text { SOPPLY OP ENERGY } \\
\text { POSS IL FOEL } \\
\text { HYDR OELECTRIC } \\
\text { NOCL EAR } \\
\text { GEO. ESOLAR }\end{array}$ & $=$ & = & $\begin{array}{l}\overline{-} \\
\overline{-}\end{array}$ & $\begin{array}{l}\overline{-} \\
\overline{-}\end{array}$ & $\begin{array}{r}32,073 \\
- \\
-\end{array}$ & $\begin{array}{r}149,0 \leq 0 \\
- \\
-\end{array}$ & $\begin{array}{r}509,342 \\
= \\
-\end{array}$ & $\begin{array}{r}9,42 \overline{2} \\
1,990 \\
75\end{array}$ & $\begin{array}{r}790,465 \\
9,422 \\
1,990 \\
75\end{array}$ & $\begin{array}{l}99 \% \\
19 \\
0 \% \\
0 \%\end{array}$ \\
\hline TOTAL SOPPIY & - & - & - & - & $132,0.73$ & $149,05.0$ & $50 \cdot 9,342$ & 11,487 & 801,952 & \\
\hline
\end{tabular}

\begin{tabular}{l}
$\begin{array}{l}\text { NET IM PORZS } \\
\text { OP REGION }\end{array}$ \\
\hline
\end{tabular}

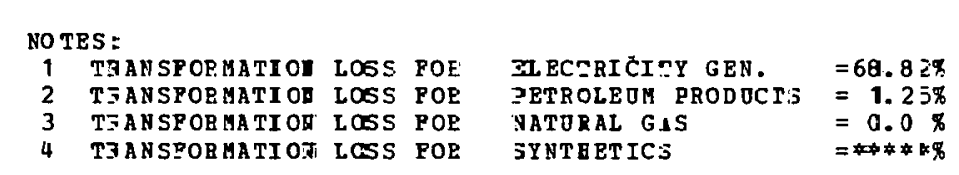


REGIONAL RNE RGY BALANCE STATEMENT

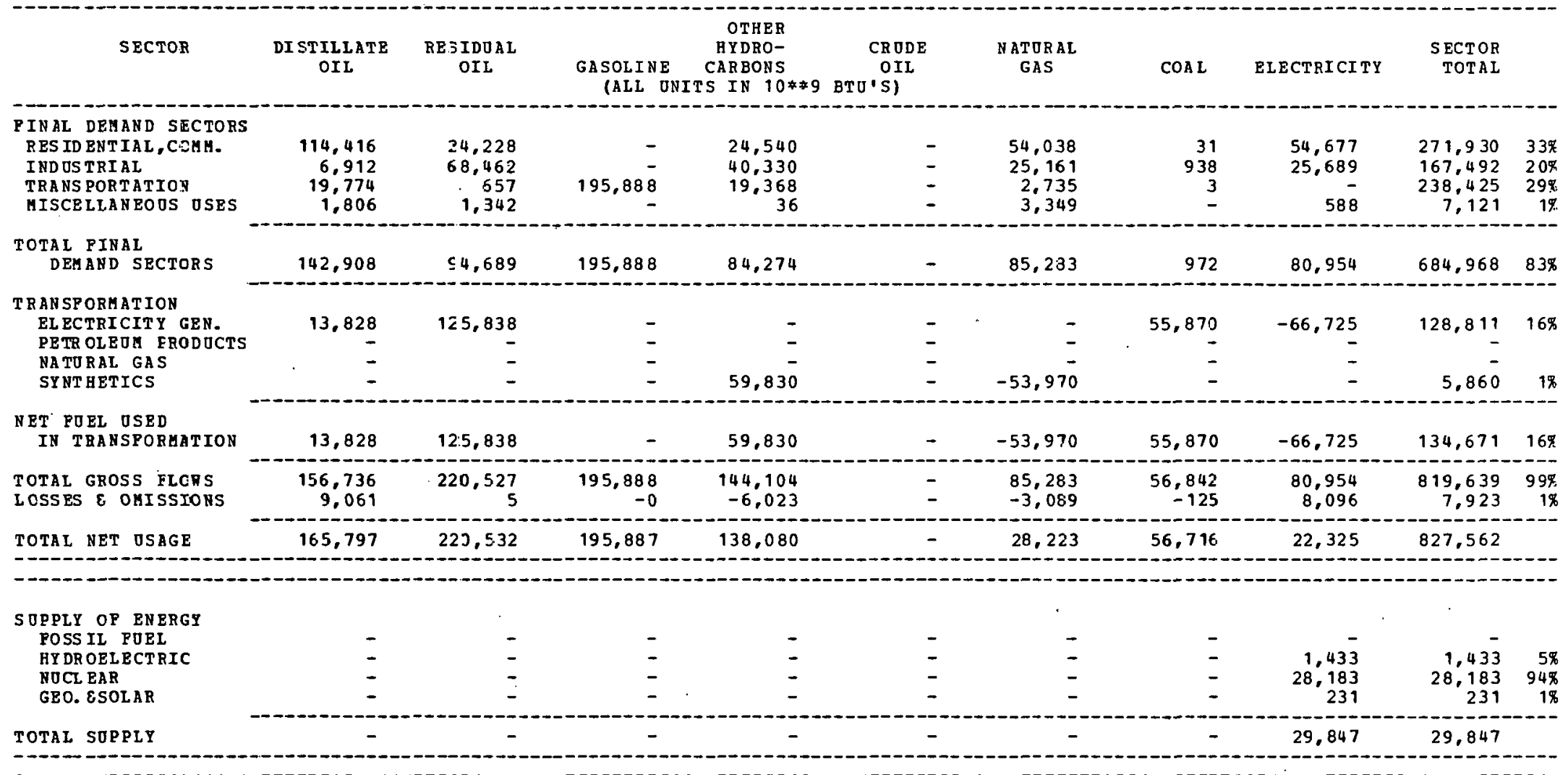

$\begin{array}{llll}\begin{array}{l}\text { NET IM PORTS } \\ \text { OP REGION }\end{array} & 165,797 & 220,532 & 195,887\end{array}$


REGIONAL ENERGY BALANCE STATEMENT

PIES MID IID SCENARIO

\begin{tabular}{|c|c|c|c|c|c|c|c|c|c|c|}
\hline SECTOR & $\begin{array}{l}\text { EISTILLATT } \\
\text { OIL }\end{array}$ & $\begin{array}{l}\text { FESIDOAL } \\
O=L\end{array}$ & $\begin{array}{l}\text { GASOLJNE } \\
\text { (ALE ONI }\end{array}$ & $\begin{array}{c}\text { OTHER } \\
\text { IY DRO- } \\
\text { CIRBONS } \\
\text { TS IN } 10 * 9\end{array}$ & $\begin{array}{c}\text { GR ODE } \\
\text { OIL } \\
\text { BTOיS.) }\end{array}$ & $\begin{array}{l}\text { NAZORAZ } \\
\text { GAS }\end{array}$ & $\operatorname{COAL}$ & ELECTRICITY & $\begin{array}{r}\text { SECTOR } \\
\text { TOTAL }\end{array}$ & \\
\hline $\begin{array}{l}\text { PINAL DEMAND SECTORS } \\
\text { R SSID ENTIAL, COMY. } \\
\text { IND TS TRIAZ } \\
\text { TRANS PORTITION } \\
\text { MISCE LIANZOOS OSES }\end{array}$ & $\begin{array}{r}17,551 \\
13,635 \\
2,090 \\
318\end{array}$ & $\begin{array}{r}1,243 \\
40,818 \\
8,780 \\
173\end{array}$ & 43,995 & $\begin{array}{r}4,398 \\
35,676 \\
571 \\
6\end{array}$ & $\begin{array}{l}- \\
-\end{array}$ & $\begin{array}{r}10.119 \\
15,466 \\
887 \\
476\end{array}$ & $\begin{array}{r}228 \\
7,085 \\
5 \\
2\end{array}$ & $\begin{array}{r}29,811 \\
43,600 \\
-\end{array}$ & $\begin{array}{r}63,350 \\
156,280 \\
56,228 \\
1,119\end{array}$ & $\begin{array}{r}73 \% \\
45 \% \\
17 \% \\
3 \%\end{array}$ \\
\hline $\begin{array}{l}\text { TOTAL FINAL, } \\
\text { DEMAND SECTORS }\end{array}$ & $\$ 3,594$ & 51,014 & $43,8 \ni 5$ & 40,651 & - & 25,948 & $: .320$ & 73,555 & 276,977 & $82 \%$ \\
\hline $\begin{array}{l}\text { TRANSFORMAIION } \\
\text { ELECTRICIT GEN. } \\
\text { PETROLETA PRODOCTS } \\
\text { NATURAL GAS } \\
\text { SYNTHETICS }\end{array}$ & $\begin{array}{r}2,507 \\
-119,543 \\
.-\end{array}$ & $\begin{array}{r}9,100 \\
-14,573 \\
- \\
-\end{array}$ & $\begin{array}{r}-137,826 \\
- \\
-\end{array}$ & $\begin{array}{r}-58,534 \\
- \\
-\end{array}$ & $\begin{array}{r}328,819 \\
- \\
-\end{array}$ & $\begin{array}{r}2.450 \\
2.4 \div 1 \\
- \\
-\end{array}$ & $\begin{array}{r}39,634 \\
- \\
-\end{array}$ & $\begin{array}{r}-17,494 \\
- \\
-\end{array}$ & $\begin{array}{r}36,1 \subseteq 7 \\
7 \in 3 \\
- \\
-\end{array}$ & $\begin{array}{r}11 \% \\
9 \%\end{array}$ \\
\hline $\begin{array}{l}\text { NET FOEL TSED } \\
\text { IN TRARSORMATION }\end{array}$ & $-117,036$ & $-5,473$ & $-137,826$ & $-58,534$ & $328,8.18$ & $4,8 \subseteq 1$ & 59,634 & -17.494 & 36.080 & $11 \%$ \\
\hline $\begin{array}{l}\text { TOTAL GROSS FLORS } \\
\text { L CSSES } \varepsilon \text { CMISSICNS }\end{array}$ & $\begin{array}{r}3.6,101 i \\
2,087\end{array}$ & $\begin{array}{r}60,114 \\
1\end{array}$ & $\begin{array}{r}43,895 \\
-0\end{array}$ & $\begin{array}{l}40,651 \\
-1.699\end{array}$ & $\begin{array}{r}328,818 \\
16,415\end{array}$ & $\begin{array}{l}\equiv 1,8: 9 \\
-1,153\end{array}$ & $\begin{array}{r}45,954 \\
-103\end{array}$ & $\begin{array}{r}73,555 \\
7,356\end{array}$ & $\begin{array}{r}313,957 \\
22,003\end{array}$ & $\begin{array}{r}\subseteq 3 \% \\
7 \%\end{array}$ \\
\hline TOTAL NET OSAGE & $-31,354$ & 45,542 & $-93,9 \cdot 31$ & $-19,582$ & 345,233 & $\equiv 0,635$. & 45,850 & 63,417 & 336,850 & \\
\hline
\end{tabular}

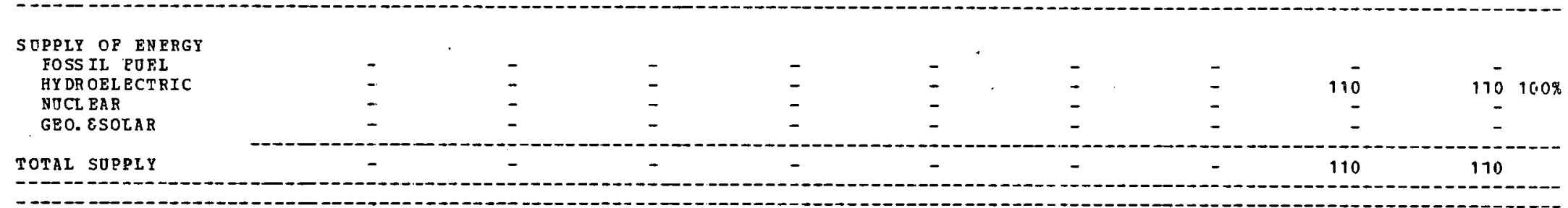

\section{NET IM PORES}

$-81,35$

45,542

$-9 \cdot 3,931$

$-19,582$

345,233

36.635

46,850

63,307

No TES:

1 TRANSFORMATIC LOSS POZ TRANSPORMATIC: LOSS FOZ TZANSFORMATI CG LOSS POZ

ELECTRICITY GEN.

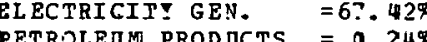

4 TzANSPORA

IATORAL GAS

$=0.24 \%$

SYNTHETICS 
RBGIONAL ENERGY BALPNCE STATEMENT

\begin{tabular}{|c|c|c|c|c|c|c|c|c|c|c|}
\hline SECTOR & $\begin{array}{l}\text { DISTILLATE } \\
\text { OIL }\end{array}$ & $\begin{array}{l}\text { RESIDUAL } \\
\text { OIL }\end{array}$ & $\begin{array}{l}\text { GASOLINE } \\
\text { (ALL O }\end{array}$ & $\begin{array}{c}\text { OTHER } \\
\text { HYDRO- } \\
\text { CARBONS } \\
\text { TS IR } 10 * 9\end{array}$ & $\begin{array}{c}\text { CRODE } \\
\text { OIL } \\
\text { BTU'S) }\end{array}$ & $\begin{array}{l}\text { NATURAL. } \\
\text { GAS }\end{array}$ & $\operatorname{COAI}$ & ELECTRICITY & $\begin{array}{r}\text { SECTOR } \\
\text { TOTAL }\end{array}$ & \\
\hline $\begin{array}{l}\text { PINAL DEMAND SECTORS } \\
\text { RESIDENTIAI, CCHM. } \\
\text { INDOSTRIAL } \\
\text { TRANSPORTATION } \\
\text { MISCELLAMEOOS OSES }\end{array}$ & $\begin{array}{r}28,461 \\
188 \\
4,889 \\
2,480\end{array}$ & $\begin{array}{r}11,301 \\
291 \\
7,951 \\
1,351\end{array}$ & $\begin{array}{r}- \\
- \\
41,614 \\
-\end{array}$ & $\begin{array}{r}3.946 \\
781 \\
23 \\
44\end{array}$ & $\begin{array}{l}\overline{-} \\
\overline{-}\end{array}$ & $\begin{array}{r}16,876 \\
278 \\
2.671 \\
3,539\end{array}$ & $\begin{array}{r}85 \\
618 \\
2 \\
18\end{array}$ & $\begin{array}{r}16,708 \\
1,334 \\
42 \\
1,175\end{array}$ & $\begin{array}{r}77,377 \\
3,490 \\
57,192 \\
8,607\end{array}$ & $\begin{array}{r}49 \% \\
2 \% \\
36 \% \\
5 \%\end{array}$ \\
\hline $\begin{array}{l}\text { TCTAL PINAL } \\
\text { DEMAND SECTORS }\end{array}$ & 36,018 & 20,394 & 41,614 & 4.794 & - & 23,364 & 723 & 19,259 & 146,666 & $93 \%$ \\
\hline $\begin{array}{l}\text { TRANSP ORHATICN } \\
\text { ELECTRICITY GEN. } \\
\text { PETROLEOA PRODOZTS } \\
\text { NATORAL GAS } \\
\text { SY HTHETICS }\end{array}$ & $\begin{array}{r}2,374 \\
- \\
-\end{array}$ & $\begin{array}{r}7,349 \\
- \\
-\end{array}$ & $\begin{array}{l}\overline{-} \\
\overline{-}\end{array}$ & $\begin{array}{l}\overline{-} \\
\overline{-}\end{array}$ & $\begin{array}{l}- \\
-\end{array}$ & $\begin{array}{r}642 \\
- \\
-\end{array}$ & $\begin{array}{l}\overline{-} \\
\overline{-}\end{array}$ & $\begin{array}{r}-3,235 \\
- \\
- \\
-\end{array}$ & $\begin{array}{r}7.630 \\
- \\
-\end{array}$ & $5 \pi$ \\
\hline $\begin{array}{l}\text { WET FOEL OSED } \\
\text { IN TRANSPORHATION }\end{array}$ & $2,374^{\circ}$ & 7,849 & - & - & - & 642 & - & -3.235 & 7,630 & $5 \%$ \\
\hline $\begin{array}{l}\text { TOTAL GROSS FLORS } \\
\text { LOSSES } \& \text { OMISSIONS }\end{array}$ & $\begin{array}{r}38,392 \\
2,219\end{array}$ & $\begin{array}{r}28,743 \\
0\end{array}$ & $\begin{array}{r}41,614 \\
-0\end{array}$ & $\begin{array}{r}4,794 \\
-200\end{array}$ & - & $\begin{array}{r}24,006 \\
-869\end{array}$ & $\begin{array}{r}723 \\
-1\end{array}$ & $\begin{array}{r}19,259 \\
1,926\end{array}$ & $\begin{array}{r}154,296 \\
3,074\end{array}$ & $\begin{array}{r}98 \% \\
2 \%\end{array}$ \\
\hline
\end{tabular}

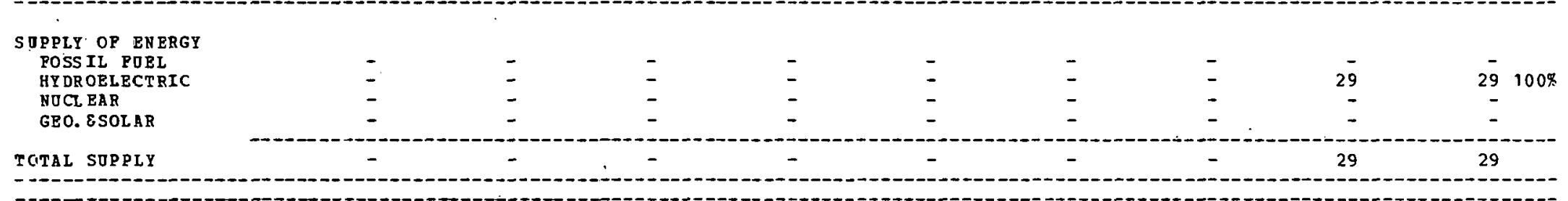

NET IM PORTS

OP REGIOII

40,611

28,743

41,613

4,593

23,136

721

17,921

157,341

NO TES:

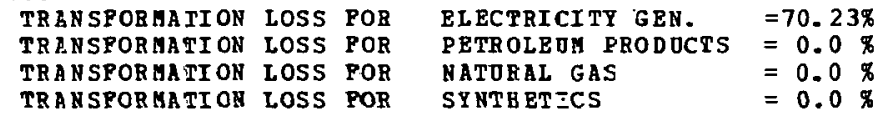


REGIONAL ENEPGY BALANCE STATEMENT

?IES MID MID SCENARIO

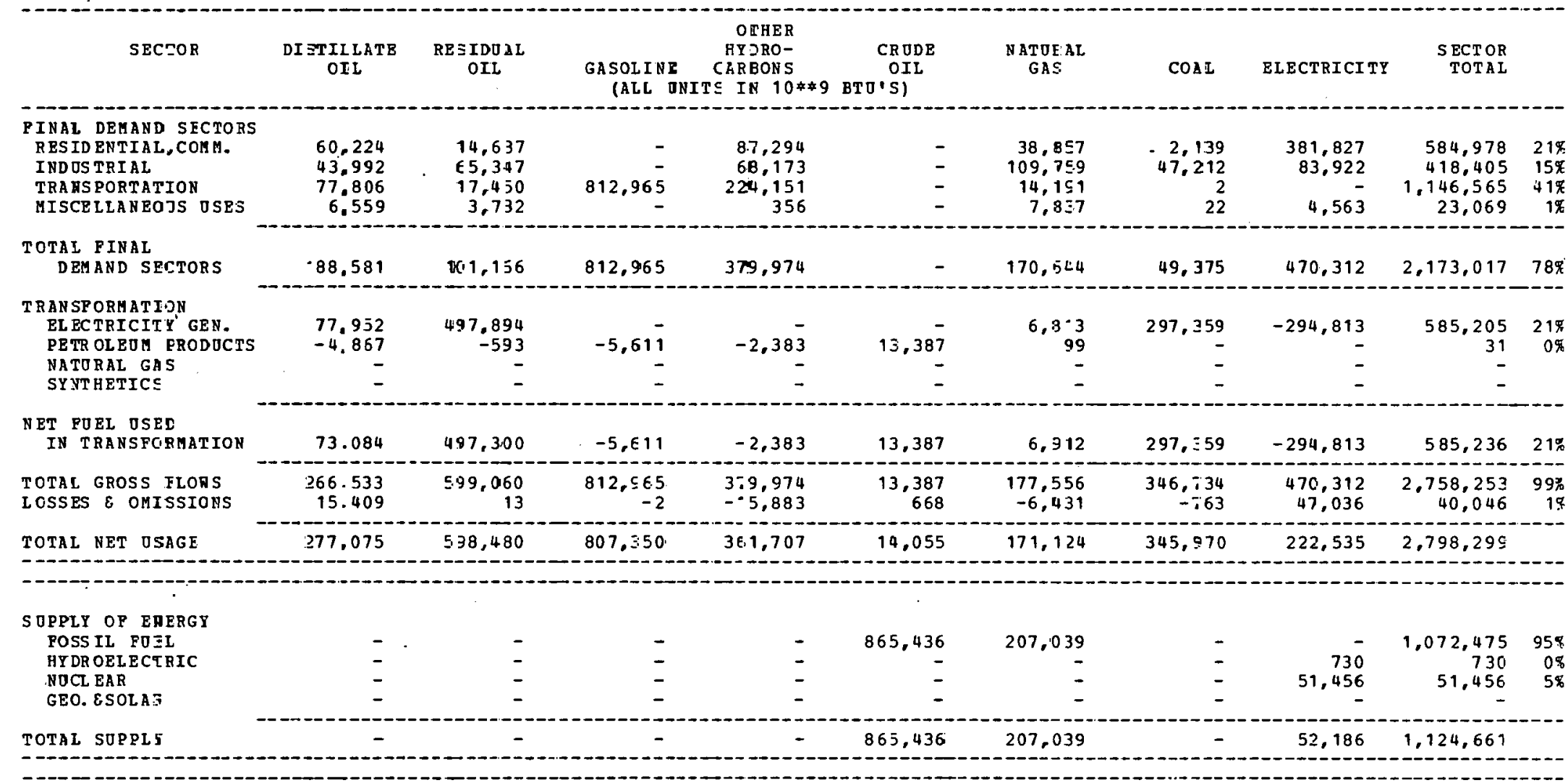

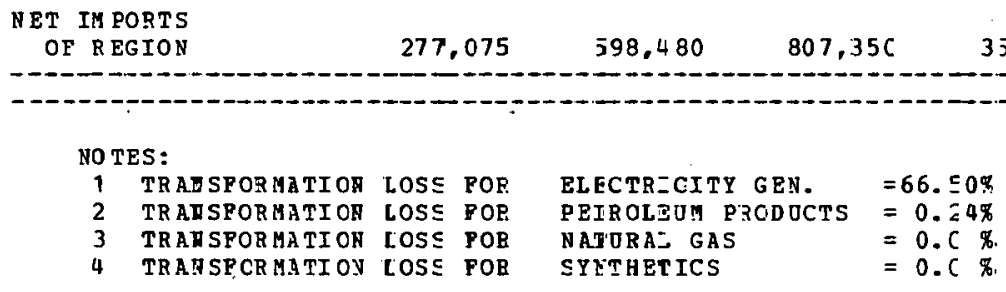


REGIONAL EHERGY BALANCE STATEMENT

\begin{tabular}{|c|c|c|c|c|c|c|c|c|c|c|}
\hline SECTOR & $\underset{\text { OIL }}{\text { DISTILLTE }}$ & $\begin{array}{l}\text { RESIDOAL } \\
\text { OIL }\end{array}$ & $\begin{array}{l}\text { GASOLINE } \\
\text { (ALL O }\end{array}$ & $\begin{array}{c}\text { OTHER } \\
\text { HYDRO- } \\
\text { CARBONS } \\
\text { CS IN } 10 * \$ 9\end{array}$ & $\begin{array}{c}\text { CRODE } \\
\text { OIL } \\
\text { BTD'S) }\end{array}$ & $\begin{array}{l}\text { NATURAL } \\
\text { GAS }\end{array}$ & $\operatorname{COAL}$ & ELECTRICITY & $\begin{array}{r}\text { SECTOR } \\
\text { TOTAL }\end{array}$ & \\
\hline $\begin{array}{l}\text { PINAL DEDAND SECTORS } \\
\text { RESID ENTIAL, CCHM. } \\
\text { IND USTRIAL } \\
\text { TRANSPORTATION } \\
\text { MISCELLANEOOS OSES }\end{array}$ & $\begin{array}{r}41,679 \\
24,244 \\
77,547 \\
4,633\end{array}$ & $\begin{array}{r}11.869 \\
48.005 \\
990 \\
2.635\end{array}$ & $434,32 \overline{1}$ & $\begin{array}{r}44,842 \\
57,697 \\
102,793 \\
239\end{array}$ & $\begin{array}{l}- \\
-\end{array}$ & $\begin{array}{r}101,458 \\
146,250 \\
6,355 \\
6,009\end{array}$ & $\begin{array}{r}276 \\
51,656 \\
1 \\
13\end{array}$ & $\begin{array}{r}164,362 \\
101,936 \\
- \\
1,912\end{array}$ & $\begin{array}{r}364,486 \\
429,788 \\
622,007 \\
15,441\end{array}$ & $\begin{array}{r}18 \% \\
22 \% \\
31 \% \\
1 \%\end{array}$ \\
\hline $\begin{array}{l}\text { TOTAL FINAL } \\
\text { DEMAND SECTORS }\end{array}$ & 148,103 & 63.499 & 434.321 & 205,571 & - & 260,072 & 51,946 & 268,210 & $1,431,722$ & $72 \%$ \\
\hline $\begin{array}{l}\text { TRANSP ORMATION } \\
\text { ELECTRICITY GEN. } \\
\text { PETROLEOM FRODJCTS } \\
\text { NATURAL GAS } \\
\text { SYNTHETICS }\end{array}$ & $\begin{array}{r}48,966 \\
-15,369 \\
- \\
-\end{array}$ & $\begin{array}{r}27.101 \\
-1,873 \\
- \\
-\end{array}$ & $\begin{array}{r}-17,720^{-} \\
-\end{array}$ & $\begin{array}{r}- \\
-7,525 \\
-\end{array}$ & $\begin{array}{r}- \\
42,276 \\
-\end{array}$ & $\begin{array}{r}3,945 \\
313 \\
- \\
-\end{array}$ & $\begin{array}{r}719,002 \\
- \\
-\end{array}$ & $\begin{array}{r}-274,852 \\
- \\
-\end{array}$ & $\begin{array}{r}524,162 \\
101 \\
- \\
-\end{array}$ & $\begin{array}{r}27 \% \\
0 \%\end{array}$ \\
\hline $\begin{array}{l}\text { SET FOEL OSED } \\
\text { - IN TRANSFORMATZON }\end{array}$ & 33,596 & 25,227 & $-17,720$ & $-7,525$ & 42,276 & 4,258 & 719,002 & $-274,852$ & 524,263 & $27 \%$ \\
\hline $\begin{array}{l}\text { TOTAL GROSS FLORS } \\
\text { lOSSES } \& \text { OMISSIOUS }\end{array}$ & $\begin{array}{r}197,069 \\
11,393\end{array}$ & $\begin{array}{r}90,600 \\
2 \\
\end{array}$ & $\begin{array}{r}434,321 \\
-1 \\
-\end{array}$ & $\begin{array}{r}205,571 \\
-8,593\end{array}$ & $\begin{array}{r}42,276 \\
2,110 \\
\end{array}$ & $\begin{array}{r}264,330 \\
-9,574 \\
\end{array}$ & $\begin{array}{r}770,948 \\
-1,698 \\
\end{array}$ & $\begin{array}{r}268,210 \\
26,823 \\
\end{array}$ & $\begin{array}{r}1,955,985 \\
20,462\end{array}$ & $\begin{aligned} 99 \% \\
1 \%\end{aligned}$ \\
\hline TOTAL NET USAGE & 193,092 & 88,728 & 416,599 & 189,451 & 44,387 & 254,756 & 769,249 & 20,181 & $1,976,447$ & \\
\hline $\begin{array}{l}\text { SUPPLY OP ENERGY } \\
\text { POSS IL POEL } \\
\text { HYDR OELECT RIC } \\
\text { NOCL EAR } \\
\text { GEO. ESOLAR }\end{array}$ & $\begin{array}{l}- \\
-\end{array}$ & $\begin{array}{l}- \\
-\end{array}$ & $\begin{array}{l}\overline{-} \\
-\end{array}$ & $\begin{array}{l}- \\
-\end{array}$ & $\begin{array}{l}- \\
-\end{array}$ & $\begin{array}{l}- \\
-\end{array}$ & $\begin{array}{l}- \\
- \\
-\end{array}$ & $\begin{array}{r}- \\
27,195 \\
49,230 \\
-\end{array}$ & $\begin{array}{r}- \\
27,195 \\
49,230\end{array}$ & $\begin{array}{l}36 \% \\
64 \%\end{array}$ \\
\hline TOTAL SOPPLY & - & - & - & - & - & - & - & 76.425 & 76,425 & \\
\hline
\end{tabular}

\begin{tabular}{|c|c|c|c|c|c|c|c|c|c|}
\hline OF REGION & 193,092 & 88,728 & 416,599 & 189,451 & 44,387 & 254.756 & 769,249 & $-56,243$ & $1,900,022$ \\
\hline
\end{tabular}

\section{NO TES:}

1 TBANSPORMATION LOSS FOR TEANSPORIATI ON LOSS POR

$\begin{array}{lll}\text { TEANSPORMATION LOSS FOR } & \text { NATURAL GAS } & =0.0 \% \\ \text { TRANSPORMATI ON LOSS POR } & & =0.0 \%\end{array}$

ELECTRZCITY GEN.

至 $=65.60$ 
REGIONAL EMERGY BALANCE STATEMERT

PIES RID MID SCENARIO.

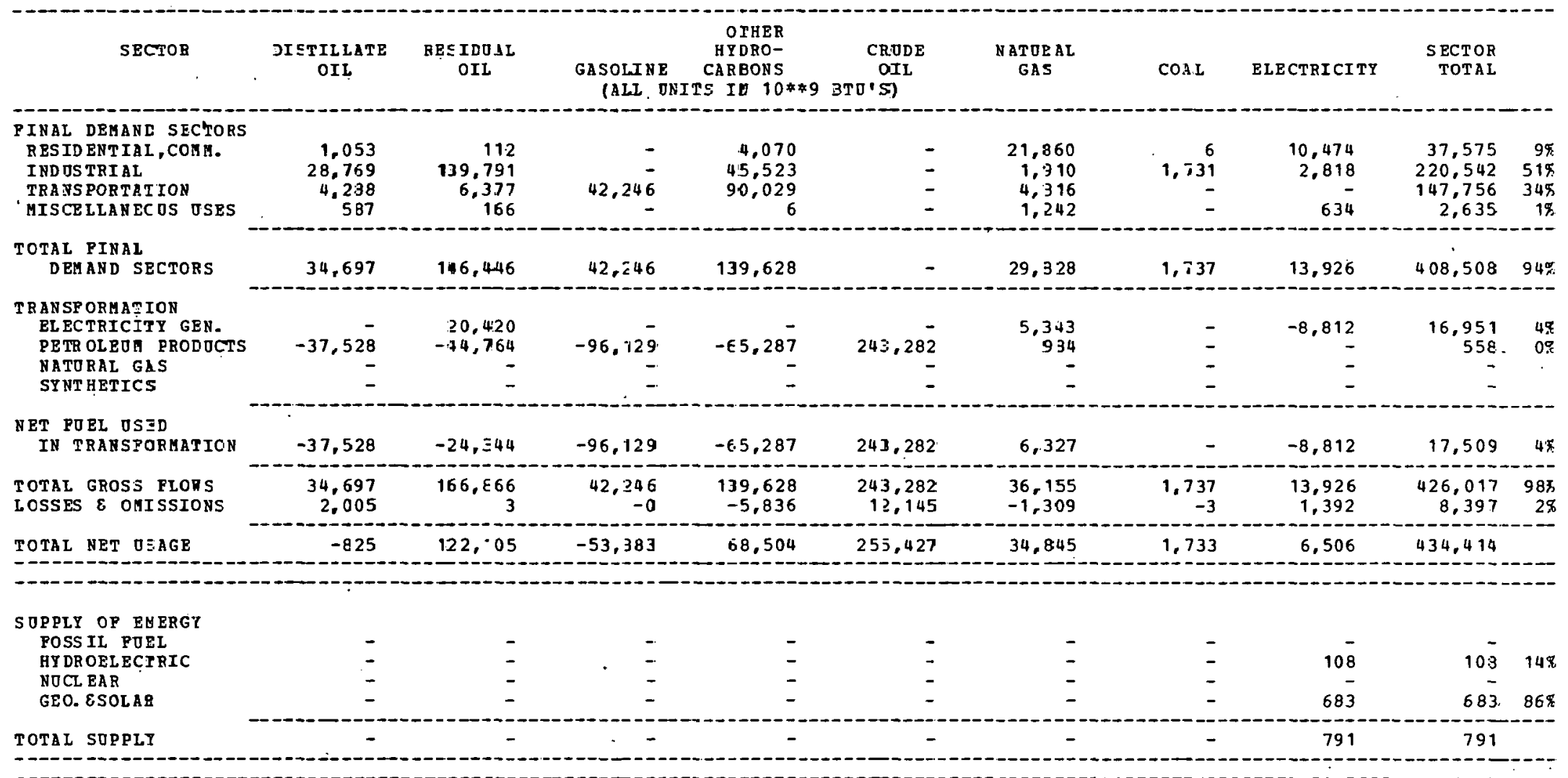

(1)

NET IM PORTS
OP REGION


REGIONAL ENERGY BALANCE STATEMENT
PIES MID MID SCENARIO

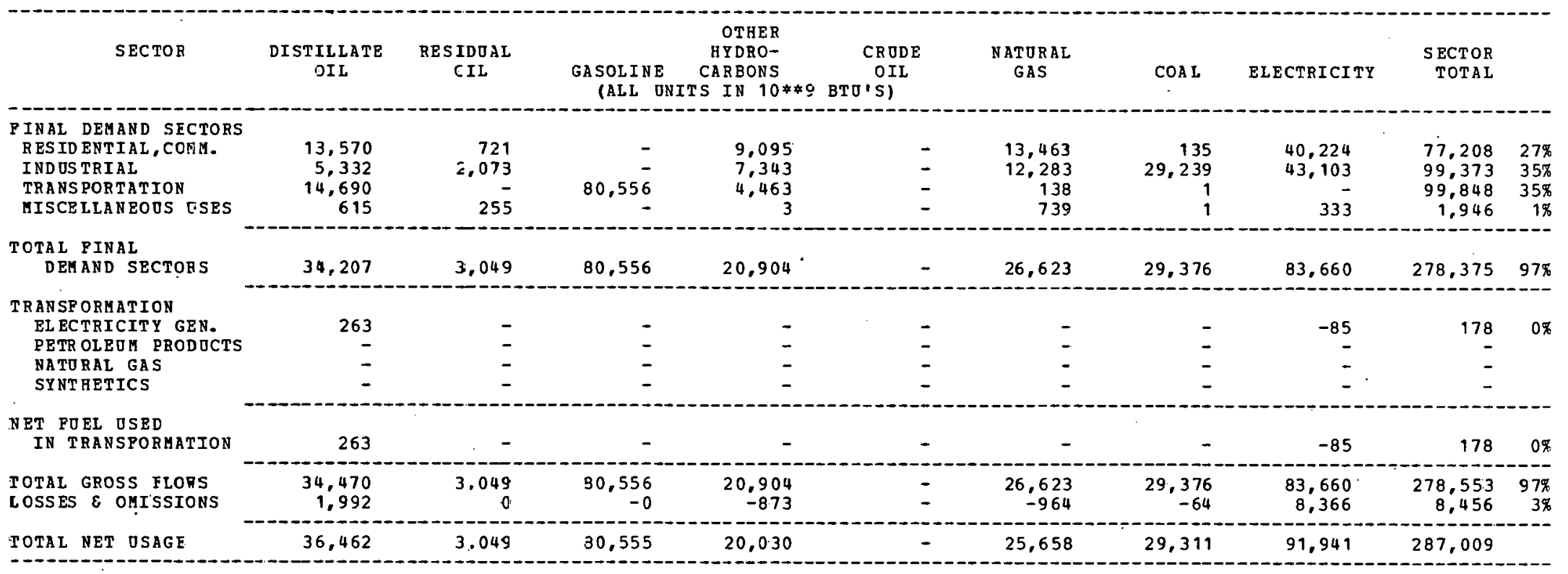

SOPPLY OP ENERGT
POSS IL POEL
HYDROELECRIC
NOCL EAR
GEO. ESOLAR

\begin{tabular}{l}
$\begin{array}{l}\text { IET IMPORTS. } \\
\text { OP REGION }\end{array}$ \\
\hline
\end{tabular}


RESIGNAL ENERGY PALANCE STATEMENT

EIES MIJ MID SCENARI.

\begin{tabular}{|c|c|c|c|c|c|c|c|c|c|c|}
\hline SECTOR & $\begin{array}{l}\text { DESTILLATE } \\
\text { OIL }\end{array}$ & $\begin{array}{l}\text { RESIDUAL } \\
\text { OIl }\end{array}$ & $\begin{array}{l}\text { GASOL I EE } \\
\text { (ALL UNI }\end{array}$ & $\begin{array}{c}\text { DTHER } \\
\text { HTDRO- } \\
\text { CA BONS } \\
\text { TS TN 10*9 }\end{array}$ & $\begin{array}{c}\text { CRUDE } \\
\text { JIL } \\
\text { BTD'SI }\end{array}$ & $\begin{array}{l}\text { NATCRAL } \\
\text { GR.S }\end{array}$ & $\operatorname{COAL}$ & ELECTRICITY & $\begin{array}{l}\text { SECTOR } \\
\text { TOTAL }\end{array}$ & \\
\hline $\begin{array}{l}\text { PINAL DEMAND SECTORS } \\
\text { RESID ENTIAL, COMM. } \\
\text { IND TS TRIAL. } \\
\text { TRANS PORTAIION } \\
\text { MISCE LLANEOUS OSES }\end{array}$ & $\begin{array}{r}297,579 \\
104,847 \\
134,428 \\
14,308\end{array}$ & $\begin{array}{r}81,267 \\
72,503 \\
1,638 \\
8,272\end{array}$ & 689.499 & $\begin{array}{r}122,208 \\
325,250 \\
30,394 \\
354\end{array}$ & $\begin{array}{l}\overline{-} \\
-\end{array}$ & $\begin{array}{r}635.293 \\
139.350 \\
43.236 \\
9.326\end{array}$ & $\begin{array}{r}4,192 \\
379,107 \\
3 \\
21\end{array}$ & $\begin{array}{r}211,569 \\
187,024 \\
1,017 \\
3,193\end{array}$ & $\begin{array}{r}1,352,103 \\
1,208,081 \\
950,215 \\
35,474\end{array}$ & $\begin{array}{r}31 \% \\
22 \% \\
22 \% \\
1 \%\end{array}$ \\
\hline $\begin{array}{l}\text { TOTAL PINAL } \\
\text { DEMAND SICTORS }\end{array}$ & 551,162 & 63.580 & 689.499 & 528,206 & - & 827.205 & 383,323 & 402,803 & $3,545,878$ & $82 \%$ \\
\hline $\begin{array}{l}\text { TRANSF ORHATION } \\
\text { ELECTRICITY GEN. } \\
\text { PETROLECA PRODOCTS } \\
\text { NATURAL GAS } \\
\text { STNTHETICS }\end{array}$ & $\begin{array}{r}21,128 \\
-627,546 \\
- \\
-\end{array}$ & $\begin{array}{r}69,595 \\
-268,556 \\
-\end{array}$ & $\begin{array}{r}-1,161,347 \\
- \\
-\end{array}$ & $\begin{array}{r}-539.065 \\
-\end{array}$ & $\begin{array}{r}2,491,754 \\
-\end{array}$ & $\begin{array}{r}10.278 \\
125: 609 \\
- \\
-\end{array}$ & $\begin{array}{r}844,063 \\
- \\
- \\
-\end{array}$ & $\begin{array}{r}-331,411 \\
- \\
-\end{array}$ & $\begin{array}{r}613,753 \\
20,847 \\
- \\
-\end{array}$ & $\begin{array}{r}14 \% \\
0 \%\end{array}$ \\
\hline $\begin{array}{l}\text { NET FOEL OSED } \\
\text { IN TRANSTJMATION }\end{array}$ & $-606,+18$ & $-198,361$ & $-1,161,347$ & $-5.39,065$ & $2,491,75$ & 135.887 & 844.063 & $-331,411$ & 634,600 & $15 \%$ \\
\hline $\begin{array}{l}\text { TOTAL GROSS FLOHS } \\
\text { LOSSES } \& \text { OMISSIONS }\end{array}$ & $\begin{array}{r}57.2,290 \\
33,086\end{array}$ & $\begin{array}{r}233,375 \\
5\end{array}$ & $\begin{array}{r}689,499 \\
-?\end{array}$ & $\begin{array}{l}528,206 \\
-22,079\end{array}$ & $\begin{array}{r}2,491,754 \\
124,392\end{array}$ & $\begin{array}{l}963,092 \\
-34,886\end{array}$ & $\begin{array}{r}1,227,386 \\
-2,703\end{array}$ & $\begin{array}{r}402,803 \\
40,284\end{array}$ & $\begin{array}{r}4,180,472 \\
138,097\end{array}$ & $\begin{aligned} 97 \% \\
3 \%\end{aligned}$ \\
\hline $\begin{array}{l}\text { S UPPLY OF ENERGY } \\
\text { FOSS IL POEL } \\
\text { HYDR OELECTRIC } \\
\text { NOCL EAR } \\
\text { GEO. ESOL LR }\end{array}$ & $\begin{array}{l}- \\
-\end{array}$ & $\begin{array}{l}- \\
-\end{array}$ & $\begin{array}{l}- \\
-\end{array}$ & $\begin{array}{l}- \\
-\end{array}$ & $\begin{array}{r}134,719 \\
- \\
-\end{array}$ & $\begin{array}{r}15,210 \\
- \\
-\end{array}$ & $\begin{array}{r}1,900,207 \\
= \\
-\end{array}$ & $\begin{array}{r}98 \overline{2} \\
180,685 \\
184\end{array}$ & $\begin{array}{r}2,050,13 \epsilon \\
98 E \\
180,68 E \\
184\end{array}$ & $\begin{array}{r}92 \% \\
0 \% \\
8 \% \\
0 \%\end{array}$ \\
\hline TOTAL SOPPLY & - & - & - & - & 134,713 & 15.210 & $1,900,207$ & 181,851 & $2,231,98 Z$ & \\
\hline
\end{tabular}

\section{NET IM POSTS}

OP REGIO

$-22,170$

$-35,176$

$-471.850$

$-32,939 \quad 2,481,423$

912,996

$-675,524$

$-70,174$

NOTES 1 TRANSPORMATION LOSS POR TR NSPCRMATT ON COSS POR TR $\rightarrow$ NFORMATI ON LOSS POR 
REG ONAL ENERGP BALANCE STATEMENT
PIES MID MID SCENARIO

\begin{tabular}{|c|c|c|c|c|c|c|c|c|c|c|}
\hline SECTOR & $\begin{array}{l}\text { DISTILLATE } \\
\text { OIL }\end{array}$ & $\begin{array}{l}\text { RES IDJAL } \\
\text { OIL }\end{array}$ & $\begin{array}{l}\text { GASOLINE } \\
\text { (ALL UN. }\end{array}$ & $\begin{array}{c}\text { OTHER } \\
\text { HYDRO- } \\
\text { CARBONS } \\
\text { TS IN } 10 * \$\end{array}$ & $\begin{array}{c}\text { CR DDE } \\
\text { OIL } \\
\text { BTO'S) }\end{array}$ & $\begin{array}{l}\text { NATORAL } \\
\text { GAS }\end{array}$ & $\operatorname{COAL}$ & ELECTRICITY & $\begin{array}{r}\text { SECTOR } \\
\text { TOTAL }\end{array}$ & \\
\hline $\begin{array}{l}\text { PINAL DEMAND SECTORS } \\
\text { RESIDENTIAL, CCMA. } \\
\text { INDOS TRIAL } \\
\text { TRANSPORTATION } \\
\text { MISCELLANEOOS OSES }\end{array}$ & $\begin{array}{r}183,575 \\
91,327 \\
82,992 \\
5,858\end{array}$ & $\begin{array}{r}35,748 \\
114,320 \\
1,363 \\
3,386\end{array}$ & $40 B, 13 \frac{-}{-}$ & $\begin{array}{r}64,711 \\
214,488 \\
94,511 \\
142\end{array}$ & $\begin{array}{l}- \\
- \\
-\end{array}$ & $\begin{array}{r}231,099 \\
94,601 \\
5,352 \\
3,609\end{array}$ & $\begin{array}{r}2,549 \\
340,622 \\
- \\
8\end{array}$ & $\begin{array}{r}109,366 \\
129,583 \\
62 \\
1,111\end{array}$ & $\begin{array}{r}627,048 \\
985,441 \\
592,918 \\
14,114\end{array}$ & $\begin{array}{r}22 \% \\
35 \% \\
21 \% \\
0 \%\end{array}$ \\
\hline $\begin{array}{l}\text { TOTAL PINAL } \\
\text { DEMAND SECTORS }\end{array}$ & 363,752 & 155,817 & 408,138 & 373,852 & - & 334,661 & 343,179 & 240,122 & $2,219,521$ & $78 \%$ \\
\hline $\begin{array}{l}\text { TR ANSP ORMATION } \\
\text { BL ECTRICITY GEN. } \\
\text { PETR OLEOM PRODOCTS } \\
\text { NA TORAL GAS } \\
\text { SY NTHETICS }\end{array}$ & $\begin{array}{r}12,850 \\
-295,773 \\
- \\
-\end{array}$ & $\begin{array}{r}38,075 \\
-126,574 \\
- \\
-\end{array}$ & $\begin{array}{r}-547,361 \\
- \\
-\end{array}$ & $\begin{array}{r}-254,070 \\
313,510\end{array}$ & $\begin{array}{r}1.174 .403 \\
-\end{array}$ & $\begin{array}{r}5,340 \\
59,201 \\
- \\
-282,800\end{array}$ & $\begin{array}{r}743,707 \\
- \\
-\end{array}$ & $\begin{array}{r}-282,733 \\
- \\
-\end{array}$ & $\begin{array}{r}517,239 \\
9.826 \\
- \\
30,710\end{array}$ & $\begin{array}{r}18 \% \\
0 \%\end{array}$ \\
\hline $\begin{array}{l}\text { N } 3 \text { T FURL OSED } \\
\text { IN TRANSPORMATION }\end{array}$ & $-282,923$ & $-88,499$ & $-547,361$ & 59,440 & $1,174,403$ & $-218,258$ & 743.707 & $-282,733$ & 557,775 & $20 \pi$ \\
\hline $\begin{array}{l}\text { TOTAL GROSS FLORS } \\
\text { LOSSES } \varepsilon \text { OMISSIONS }\end{array}$ & $\begin{array}{r}376,602 \\
21,772 \\
\end{array}$ & $\begin{array}{r}193,892 \\
4\end{array}$ & $\begin{array}{r}408,138 \\
-1\end{array}$ & $\begin{array}{r}687,362 \\
-28,732 \\
\end{array}$ & $\begin{array}{r}1,174,403 \\
58,628 \\
\end{array}$ & $\begin{array}{r}399,202 \\
-14,460 \\
-\end{array}$ & $\begin{array}{r}1,086,886 \\
-2,394 \\
\end{array}$ & $\begin{array}{r}240,122 \\
24,014 \\
\end{array}$ & $\begin{array}{r}2,777,296 \\
58,831 \\
\end{array}$ & $\begin{array}{r}98 \% \\
2 \%\end{array}$ \\
\hline TOTAL NET OSAGE & 102,601 & 67,321 & $-139,224$ & 404,559 & $1,233,031$ & 101,942 & $1,084,491$ & $-18,596$ & $2,836,127$ & \\
\hline $\begin{array}{l}\text { S OPPLY OP ENERGY } \\
\text { POSS IL POEL } \\
\text { HYDROELECTRIC } \\
\text { NOCL EAR } \\
\text { GEO. ESOLAR }\end{array}$ & $\begin{array}{l}\overline{-} \\
\overline{-}\end{array}$ & $\bar{z}$ & $\begin{array}{l}- \\
- \\
-\end{array}$ & $\begin{array}{l}- \\
-\end{array}$ & $\begin{array}{r}25,145 \\
- \\
-\end{array}$ & $\begin{array}{r}1,832 \\
- \\
-\end{array}$ & $\begin{array}{r}760,545 \\
- \\
-\end{array}$ & $\begin{array}{r}1,035 \\
35,145 \\
109\end{array}$ & $\begin{array}{r}787,522 \\
1,035 \\
35,145 \\
109\end{array}$ & $\begin{array}{r}96 \% \\
0 \% \\
4 \% \\
0 \%\end{array}$ \\
\hline TCTAL SOPPLY & - & - & - & - & 25,145 & 1,832 & 760,545 & 36,289 & 823,811 & \\
\hline
\end{tabular}

\begin{tabular}{l}
$\begin{array}{l}\text { NPT IM PORTS } \\
\text { OP R RGION }\end{array}$ \\
\hline
\end{tabular}


REGIONAL ENE BGY BALANCE STATEMENT
PIES HID MID SCEHARIO

\begin{tabular}{|c|c|c|c|c|c|c|c|c|c|c|}
\hline SECTOR & $\begin{array}{l}\text { DI FTILLATE } \\
\text { OIL }\end{array}$ & $\begin{array}{l}\text { RESIDVAL } \\
\text { OIL }\end{array}$ & $\begin{array}{l}\text { GASOLCNE } \\
\text { (ALL O }\end{array}$ & $\begin{array}{l}\text { OTHER } \\
\text { HYDRO- } \\
\text { CAR BONS } \\
\text { SIN } 10 * 9\end{array}$ & $\begin{array}{c}\text { CRODE } \\
\text { OIL } \\
\text { BTO'S) }\end{array}$ & $\begin{array}{l}\text { NATUE AL } \\
\text { GAS }\end{array}$ & $\operatorname{COAL}$ & ELECTRICITY & $\begin{array}{l}\text { SECTOR } \\
\text { TOTAL }\end{array}$ & \\
\hline $\begin{array}{l}\text { FINAL DEMAND SECTORS } \\
\text { RES ID ENTIAL,CCM.9. } \\
\text { IND OSTRIAL } \\
\text { TRA USPORTAT:ON } \\
\text { MISCELLANEOIS OSES }\end{array}$ & $\begin{array}{r}40,282 \\
22,300 \\
48,862 \\
4,369\end{array}$ & $\begin{array}{r}744 \\
14,469 \\
- \\
897\end{array}$ & $233, \frac{-}{54}$ & $\begin{array}{r}51,446 \\
69,550 \\
5,816 \\
166\end{array}$ & $\begin{array}{l}\text { - } \\
\overline{-} \\
\overline{-}\end{array}$ & $\begin{array}{r}154,881 \\
60,103 \\
1,907 \\
1,503\end{array}$ & $\begin{array}{r}209 \\
43,033 \\
1 \\
1\end{array}$ & $\begin{array}{r}63,928 \\
57,546 \\
- \\
606\end{array}$ & $\begin{array}{r}311,490 \\
258,091 \\
290,340 \\
7,542\end{array}$ & $\begin{array}{r}27 \% \\
23 \% \\
26 \% \\
1 \%\end{array}$ \\
\hline $\begin{array}{l}\text { TOTAL FINAL } \\
\text { DEMAND SECTORS }\end{array}$ & 115,813 & 16,110 & 233,754 & 117,978 & - & 218,184 & 43,244 & 122,080 & 867,463 & $77 \pi$ \\
\hline $\begin{array}{l}\text { TRANSPORMATION } \\
\text { ELECTRICITI GEN. } \\
\text { PETROLEOL ERODOCTS } \\
\text { NATORAL GAS } \\
\text { SY NT HETICS }\end{array}$ & $\begin{array}{r}13,463 \\
- \\
=\end{array}$ & $\begin{array}{l}\overline{-} \\
\overline{-}\end{array}$ & $\begin{array}{l}\overline{-} \\
\overline{-}\end{array}$ & $\begin{array}{l}\overline{-} \\
\overline{-}\end{array}$ & $\begin{array}{l}\overline{-} \\
\overline{-}\end{array}$ & $\begin{array}{r}1,1 \leq 5 \\
- \\
-\end{array}$ & $\begin{array}{r}332,445 \\
- \\
-\end{array}$ & $\begin{array}{r}-87,903 \\
- \\
-\end{array}$ & $\begin{array}{r}259,500 \\
- \\
-\end{array}$ & $23 \%$ \\
\hline $\begin{array}{l}\text { NET FOEL USED } \\
\text { IN TRANSCRMATION }\end{array}$ & 13.463 & - & - & - & - & 1,495 & $332,4.45$ & $-87,903$ & 259,500 & $23 \%$ \\
\hline $\begin{array}{l}\text { TOTAL GROSS FLONS } \\
\text { LOSSES \& OMISSIONS }\end{array}$ & $\begin{array}{r}129,276 \\
7,473\end{array}$ & $\begin{array}{r}16,110 \\
0\end{array}$ & $\begin{array}{r}233,754 \\
-0\end{array}$ & $\begin{array}{r}117,978 \\
-4,931\end{array}$ & - & $\begin{array}{r}219,779 \\
-7,768\end{array}$ & $\begin{array}{r}375,689 \\
-827\end{array}$ & $\begin{array}{r}122,080 \\
12,209\end{array}$ & $\begin{array}{r}1,126,963 \\
5,955\end{array}$ & $\begin{aligned} 99 \% \\
1 \%\end{aligned}$ \\
\hline TOTAL NET OSAGE & 136,749 & 16,110 & 233,753 & 113,046 & - & 212,010 & 374,861 & 46,386 & $1,132,918$ & \\
\hline $\begin{array}{l}\text { S OPPLY OP EUERGY } \\
\text { FOSS IL POIH } \\
\text { HY DR OEL ECPRIC } \\
\text { NOCL EAR } \\
\text { GEO. \&SOLAE }\end{array}$ & $\bar{z}$ & $\begin{array}{l}- \\
\overline{-} \\
-\end{array}$ & $\begin{array}{l}\overline{-} \\
\overline{-}\end{array}$ & $\begin{array}{l}\overline{-} \\
\overline{-}\end{array}$ & $\begin{array}{l}\overline{-} \\
\overline{-}\end{array}$ & $\begin{array}{l}- \\
\overline{-}\end{array}$ & $\begin{array}{r}12,633 \\
- \\
-\end{array}$ & $\begin{array}{r}1,654 \\
13,856 \\
-\end{array}$ & $\begin{array}{r}12,633 \\
1.654 \\
13,856 \\
-\end{array}$ & $\begin{array}{r}458 \\
6 \% \\
498\end{array}$ \\
\hline TOTAL SUPPLY & - & - & - & - & - & - & 12,533 & 15,510 & 28,143 & \\
\hline
\end{tabular}

\begin{tabular}{|c|c|c|c|c|c|}
\hline \multicolumn{2}{|c|}{$\begin{array}{l}\text { NET IM PORTS } \\
\text { OP REGION }\end{array}$} & 136,749 & 16,110 & \multicolumn{2}{|c|}{233,753} \\
\hline \multicolumn{6}{|c|}{ NO TES : } \\
\hline 1 & TRAASPOB BATIOR & LOSS FOR & ELXCTRICIT & GEN. & $=74.70 \%$ \\
\hline 2 & TRAYSPORMATI ON & LOSS FOR & PETROLEOM & FOD UCTS & $=0.0 \%$ \\
\hline 3 & TRASSPORAETI ON & LOSS FOR & NATURAL GA & & $=0.0 \%$ \\
\hline 4 & TRATSPORMATI OY & LOSS POR & SY XTHETICS & & $=0.0$ \\
\hline
\end{tabular}


REGIONAL ENERGY BALANCE STATEMENT

PIES MID MID SCENARIO

\begin{tabular}{|c|c|c|c|c|c|c|c|c|c|c|}
\hline SECTOR & $\begin{array}{l}\text { DISTILLATE } \\
\text { CII }\end{array}$ & $\begin{array}{l}\text { RESIDUAL } \\
\text { DIL }\end{array}$ & $\begin{array}{l}\text { TASOLINE } \\
\text { (ALL OI }\end{array}$ & $\begin{array}{c}\text { OTHER } \\
\text { HYDRO- } \\
\text { CARBONS } \\
\text { IS IN } 10 * * 9\end{array}$ & $\begin{array}{c}\text { CRODE } \\
\text { OIL } \\
\text { BTO'S) }\end{array}$ & $\begin{array}{l}\text { NaTURAL } \\
\text { GAS }\end{array}$ & $\operatorname{COAL}$ & ELECTRICITY & $\begin{array}{l}\text { SECTOR } \\
\text { TOTAL }\end{array}$ & \\
\hline $\begin{array}{l}\text { FINAL DEMAND SECTORS } \\
\text { RESIDEUTIAL, CCNM. } \\
\text { IND USTRIAL } \\
\text { TRANSPORTATION } \\
\text { MISCELLANEOOS DSES }\end{array}$ & $\begin{array}{r}6,565 \\
10,862 \\
40,051 \\
3,550\end{array}$ & $\begin{array}{r}407 \\
23.670 \\
131 \\
729\end{array}$ & $\begin{array}{r}- \\
- \\
-\end{array}$ & $\begin{array}{r}37,047 \\
91,712 \\
8,914 \\
200\end{array}$ & $\begin{array}{l}- \\
-\end{array}$ & $\begin{array}{r}135,456 \\
129,993 \\
2,950 \\
2,193\end{array}$ & $\begin{array}{r}159 \\
6,778 \\
2 \\
3\end{array}$ & $\begin{array}{r}55,821 \\
52,500 \\
- \\
558\end{array}$ & $\begin{array}{r}235,455 \\
320,515 \\
252,109 \\
7,233\end{array}$ & $\begin{array}{l}21 \% \\
28 \% \\
22 \% \\
1 \%\end{array}$ \\
\hline $\begin{array}{l}\text { TOTAL FINAL } \\
\text { DEMAAD SECTORS }\end{array}$ & 61,028 & 29,937 & 200,061 & 137,873 & - & 270,592 & 6.942 & 108,879 & 815,312 & $72 \%$ \\
\hline $\begin{array}{l}\text { TRANSP ORMATICN } \\
\text { ELECTRICITY GEN. } \\
\text { PETR OLEOM PRADUCTS } \\
\text { NATORAL GAS } \\
\text { SYNTHETICS }\end{array}$ & $\begin{array}{r}7,658 \\
-237,766 \\
- \\
-\end{array}$ & $\begin{array}{r}-101,751 \\
- \\
-\end{array}$ & $\begin{array}{r}-440,012 \\
- \\
-\end{array}$ & $\begin{array}{r}-204,24 \overline{-} \\
-\end{array}$ & $\begin{array}{r}94,078 \\
- \\
-\end{array}$ & $\begin{array}{r}43,441 \\
47,591 \\
- \\
-\end{array}$ & $\begin{array}{r}310,814 \\
- \\
-\end{array}$ & $\begin{array}{r}-92,919 \\
- \\
-\end{array}$ & $\begin{array}{r}268,994 \\
7,898 \\
- \\
-\end{array}$ & $\begin{array}{r}24 \% \\
1 \%\end{array}$ \\
\hline $\begin{array}{l}\text { NET FOEL OSED } \\
\text { IN TRANSFORMATION }\end{array}$ & $-230,108$ & $-101,751$ & -440.012 & $-204,242$ & 944,078 & 91,032 & $310 ; 814$ & $-92,919$ & 276,892 & $24 \%$ \\
\hline $\begin{array}{l}\text { TOTAL GROSS FLCRS } \\
\text { LOSSES } \& \text { OMISSJONS }\end{array}$ & $\begin{array}{r}68,686 \\
3,970\end{array}$ & $\begin{array}{r}29,937 \\
0\end{array}$ & $\begin{array}{r}200,061 \\
-0\end{array}$ & $\begin{array}{r}137,873 \\
-5,763\end{array}$ & $\begin{array}{r}944,078 \\
47,930\end{array}$ & $\begin{array}{r}361,624 \\
-13,099\end{array}$ & $\begin{array}{r}317,756 \\
-699\end{array}$ & $\begin{array}{r}108,879 \\
10,889\end{array}$ & $\begin{array}{r}1,092,204 \\
42,427\end{array}$ & $\begin{array}{r}96 \% \\
4 \%\end{array}$ \\
\hline
\end{tabular}

\begin{tabular}{|c|c|c|c|c|c|c|c|c|c|c|}
\hline $\begin{array}{l}\text { SOPPLY OF ENERGY } \\
\text { FOSS IL, FOEL }\end{array}$ & - & - & - & - & 401,659 & 974,826 & 17,602 & - & $1,394,087$ & $99 \%$ \\
\hline HYDROELECTRIC & - & - & - & - & - & - & - & 90 & & $0 \%$ \\
\hline NUCL EAR & - & - & - & - & - & - & - & 9,373 & 9,373 & 19. \\
\hline GEO. ESOLAR & - & - & - & - & - & - & - & - & - & \\
\hline
\end{tabular}

\begin{tabular}{l}
$\begin{array}{l}\text { NET IM PORTS } \\
\text { OP R EGION }\end{array}$ \\
\hline
\end{tabular}


REGIONaI ENERGY BALANCE STATEHEHT

PIES MID MID SCENARIO

\begin{tabular}{|c|c|c|c|c|c|c|c|c|c|}
\hline SECTOR & $\begin{array}{l}\text { DISTILLATE } \\
\text { OIL }\end{array}$ & $\begin{array}{l}\text { BESIDUAL } \\
\text { OII }\end{array}$ & $\begin{array}{l}\text { GASOLINE } \\
\quad \text { (ALL }\end{array}$ & $\begin{array}{l}\text { OTHER } \\
\text { HYDRO- } \\
\text { CARBONS } \\
\text { TS IN } 10 * * 9\end{array}$ & $\begin{array}{c}\text { CRODE } \\
\text { OIL } \\
\text { BTO'SI }\end{array}$ & $\begin{array}{l}\text { NATORAL } \\
\text { GAS }\end{array}$ & $\operatorname{COAL}$ & ELECTRICIT! & $\begin{array}{l}\text { SECTOR } \\
\text { TOTAL }\end{array}$ \\
\hline $\begin{array}{l}\text { P INAL DEMAND SECTORS } \\
\text { BESID ENTEAL, CCHM. } \\
\text { IND US TRIAL } \\
\text { TRA NSPOREATION } \\
\text { MISCELLAEEOOS USES }\end{array}$ & $\begin{array}{r}11,397 \\
4,134 \\
60,848 \\
2,180\end{array}$ & $\begin{array}{r}929 \\
4,162 \\
40 \\
1,241\end{array}$ & $\begin{array}{r}- \\
- \\
-\end{array}$ & $\begin{array}{r}28,341 \\
41,342 \\
16,474 \\
129\end{array}$ & $\begin{array}{l}- \\
-\end{array}$ & $\begin{array}{r}99,056 \\
112,251 \\
1,356 \\
\equiv, 734\end{array}$ & $\begin{array}{r}944 \\
76,861 \\
2 \\
5\end{array}$ & $\begin{array}{r}93,910 \\
193,660 \\
1,635\end{array}$ & $\begin{array}{r}234,587 \\
432,420 \\
323,597 \\
8,974\end{array}$ \\
\hline $\begin{array}{l}\text { TOTAL PINAL } \\
\text { DEMAND SECTORS }\end{array}$ & 78,555 & 6,372 & 244,961 & 86,286 & - & $2: 6,477$ & 77,812 & 289,205 & 999,658 \\
\hline $\begin{array}{l}\text { TEANSFORM TION } \\
\text { EL BCTRIEITY GEN. } \\
\text { PETR OLEOM PRODUCTS } \\
\text { NATORAL GAS } \\
\text { SY NTETICS }\end{array}$ & $\begin{array}{r}46,68= \\
-85,904 \\
-\end{array}$ & $\begin{array}{r}20,288 \\
-36,762 \\
-\end{array}$ & $\begin{array}{r}-153.976 \\
\overline{-}\end{array}$ & $\begin{array}{r}-73,79 \overline{2} \\
-\end{array}$ & $\begin{array}{r}341, \operatorname{c9} \frac{-}{-} \\
-\end{array}$ & $\begin{array}{r}390 \\
: 7,9.94 \\
-\end{array}$ & $\begin{array}{r}945,743 \\
- \\
-\end{array}$ & $\begin{array}{r}-348,885 \\
- \\
-\end{array}$ & $\begin{array}{r}665,224 \\
2,853 \\
-\end{array}$ \\
\hline $\begin{array}{l}\text { NET FOEL OSED } \\
\text { IN TRASSPORMATION }\end{array}$ & $-39,221$ & $-16,474$ & $-15.3,976$ & $-73,792$ & 341.094 & 17,584 & 945.748 & $-348,885$ & 668,077 \\
\hline $\begin{array}{l}\text { TOTAL GROSS FLORS } \\
\text { LOSSES } \varepsilon \text { OMISSICNS }\end{array}$ & $\begin{array}{r}125,238 \\
.7,240\end{array}$ & $\begin{array}{r}26,660 \\
0\end{array}$ & $\begin{array}{r}244,961 \\
-0\end{array}$ & $\begin{array}{l}86,286 \\
-3,606\end{array}$ & $\begin{array}{r}341,094 \\
17,028\end{array}$ & $\begin{array}{l}234.061 \\
.-8,4: 8\end{array}$ & $\begin{array}{r}1,024,560 \\
-2,256\end{array}$ & $\begin{array}{r}289,205 \\
28,923\end{array}$ & $\begin{array}{r}1,667,7+5 \\
38,8+9\end{array}$ \\
\hline TOTAL NET USAGE & 46,574 & $-10,101$ & 85.984 & 8,886 & 358,122 & $225,5 \varepsilon-3$ & $1,022,303$ & $-30,756$ & $1,706,595$ \\
\hline $\begin{array}{l}\text { S OPPLY OP ENERGY } \\
\text { FOSS IL FOEL } \\
\text { HYDROELEZTRIC } \\
\text { NOCL EAR } \\
\text { GEO. ESOLAR }\end{array}$ & $\begin{array}{l}\overline{-} \\
\overline{-}\end{array}$ & $\begin{array}{l}- \\
\overline{-}\end{array}$ & $\begin{array}{l}\bar{z} \\
\bar{z}\end{array}$ & $\begin{array}{l}\bar{z} \\
\overline{-}\end{array}$ & $\begin{array}{r}47.530 \\
= \\
-\end{array}$ & $\begin{array}{r}53.677 \\
=\end{array}$ & $\begin{array}{r}4,436,127 \\
= \\
=\end{array}$ & $\begin{array}{r}9.78 \overline{3} \\
\overline{-}\end{array}$ & $\begin{array}{r}4,537,384 \\
9,7 \varepsilon 3 \\
-\end{array}$ \\
\hline TOTAL SOPELY & - & - & - & - & 47,530 & $53,6 \pi 7$ & $4,436,127$ & 9.783 & $4,547,1 \in 7$ \\
\hline
\end{tabular}

NET IA PORTS

OP REGIOW

$46,574 \quad-10,101$

85,984

8,886

310,542

$171,906-3,41 \equiv, 823$

$-40,539-2,840,571$

\section{NOTES}

1 TRENSPORHATION LOSS POR TRANSPORHATION LOSS POR TRANSPCRHATIOH TOSS POR TRANSPORHA TI ON LOSS POR

EI.RCTRICITE GEN.

SRODUCTS $=0.80 \%$

$\begin{array}{ll}\text { MATURAL GAS } & =0.0 \% \\ \text { SYNTHETICS } & =0.0 \mathrm{\$}\end{array}$ 
REGIONAL ENERGY BALANCE STATEMENT

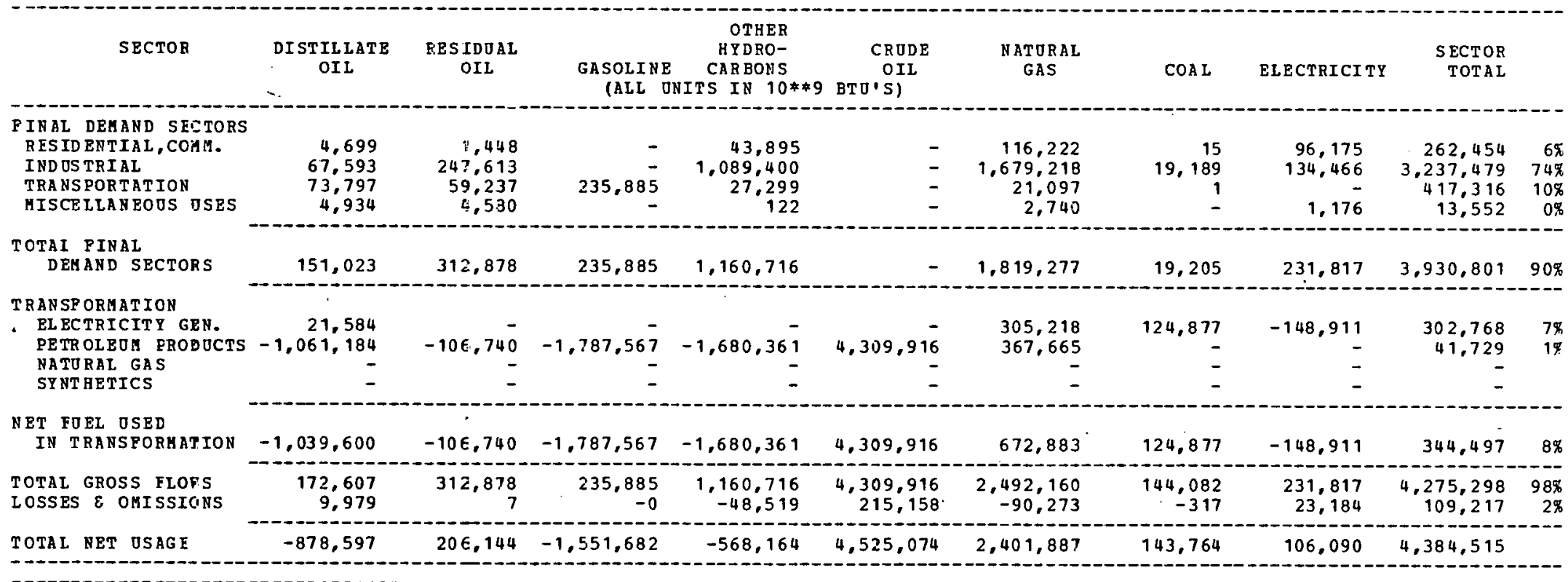

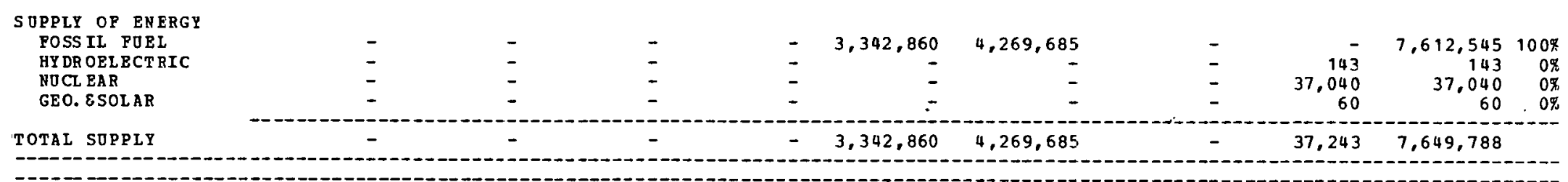

\section{NET IM PORTS}

OP R EGION

$-878,597$

$206,144 \quad-1,551,682$

$-568,164 \quad 1,182,214 \quad-1,867,797$

143,764

$68,847-3,265,272$

-

NOTES:

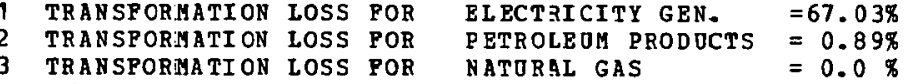

$\begin{array}{lll}\text { TRANSPORMA TI ON LOSS POR } & \text { NATURAL GAS } & =0.0 \% \\ \text { TRANSPORMATI ON LOSS POR } & \text { SYYTH ITICS } & =0.0 \%\end{array}$ 
REGIONAL ENERGY BALANCE STATEMENT

\begin{tabular}{|c|c|c|c|c|c|c|c|c|c|c|}
\hline$S E \simeq T O R$ & $\begin{array}{l}\text { DISTILLATE } \\
\text { OIL }\end{array}$ & $\begin{array}{l}\text { RESIDJAL } \\
\quad \text { OIL }\end{array}$ & $\begin{array}{l}\text { GASCLIAE } \\
\text { (ALI UNI }\end{array}$ & $\begin{array}{c}\text { OTHER } \\
\text { HTDRO- } \\
\text { CARBONS } \\
\text { S IN } 10 * * 9\end{array}$ & $\begin{array}{c}\text { CRUDE } \\
\text { OIL } \\
\text { BTO'SI) }\end{array}$ & $\begin{array}{l}\text { NATERAL } \\
\text { GAS }\end{array}$ & $\cos L$ & ELECTRICITY & $\begin{array}{l}\text { SECTOR } \\
\text { TOTAL }\end{array}$ & \\
\hline $\begin{array}{l}\text { PINAL DEMAND SECTORS } \\
\text { RES IDENTIAL, COMH. } \\
\text { IND OSTRIAI } \\
\text { TRANS PORTATION } \\
\text { HISCELLANEOS OSES }\end{array}$ & $\begin{array}{r}71,837 \\
5,782 \\
8,752 \\
1,336\end{array}$ & $\begin{array}{r}20,240 \\
67,103 \\
12,933 \\
992\end{array}$ & 81,225 & $\begin{array}{r}10,448 \\
3,787 \\
6,463 \\
16\end{array}$ & $\begin{array}{l}- \\
-\end{array}$ & $\begin{array}{r}1.858 \\
3.276 \\
655 \\
.1 .757\end{array}$ & $\begin{array}{r}10 \\
404 \\
3 \\
-\end{array}$ & $\begin{array}{r}15,359 \\
21,378 \\
- \\
260\end{array}$ & $\begin{array}{r}119,752 \\
101,730 \\
110,032 \\
3,761\end{array}$ & $\begin{array}{r}29 \% \\
24 \% \\
26 \% \\
1 \%\end{array}$ \\
\hline $\begin{array}{l}\text { TOTAL FINAI } \\
\text { DEMAND SECTORS }\end{array}$ & 87,707 & 101,268 & 81,225 & 20,714 & - & 6.946 & 417 & 36,997 & $335 ; 275$ & $80 \pi$ \\
\hline $\begin{array}{l}\text { TRAYSPORMATION } \\
\text { EI ECTRICIIY' GEN. } \\
\text { PETB OLEOE PRODUCTS } \\
\text { NATURAL GAS } \\
\text { SY NT HETICS }\end{array}$ & $\begin{array}{r}5,788 \\
-213,469 \\
- \\
-\end{array}$ & $\begin{array}{r}36,191 \\
-26,023 \\
-\end{array}$ & $\begin{array}{r}-246,119 \\
-\end{array}$ & $\begin{array}{r}-104,526 \\
-\end{array}$ & $\begin{array}{r}- \\
5 \varepsilon 7,176 \\
-\end{array}$ & $\begin{array}{r}-3 . \\
-. \\
-\end{array}$ & $\begin{array}{r}25,533 \\
- \\
-\end{array}$ & $\begin{array}{r}-23,182 \\
- \\
-\end{array}$ & $\begin{array}{r}44,330 \\
1,397 \\
- \\
-\end{array}$ & $\begin{array}{r}11 \% \\
0 \%\end{array}$ \\
\hline $\begin{array}{l}\text { NET FOEL USED } \\
\text { IN TRANSEJRMATION }\end{array}$ & $-207,581$ & 10,168 & $-246,119$ & -104.526 & $58.7,176$. & 4.358 & 25.533 & $-23,182$ & 45,727 & $11 \%$ \\
\hline $\begin{array}{l}\text { TOTAL GROSS FLOW } \\
\text { LCSSES } \varepsilon \text { ONISSIONS }\end{array}$ & $\begin{array}{r}93,495 \\
5,405\end{array}$ & $\begin{array}{r}137,459 \\
3\end{array}$ & $\begin{array}{r}81,225 \\
-3\end{array}$ & $\begin{array}{r}20.714 \\
-865\end{array}$ & $\begin{array}{r}587,176 \\
29,312\end{array}$ & $\begin{array}{r}.11 .304 \\
-409\end{array}$ & $\begin{array}{r}25,950 \\
-57\end{array}$ & $\begin{array}{r}36,997 \\
3,700\end{array}$ & $\begin{array}{r}381,00 \tilde{c} \\
37,08 \varepsilon\end{array}$ & $\begin{aligned} 91 \% \\
9 \pi\end{aligned}$ \\
\hline TOTAL NET USAGE & $-114,568$ & 111,439 & -164.893 & $-84,677$ & 616,483 & 10,895 & 25.892 & 17,515 & 418.091 & \\
\hline $\begin{array}{l}\text { S OPPLY OF EN ERGY } \\
\text { POSS IL FOEL } \\
\text { HY DR OELECTRIC } \\
\text { NOCL EAR } \\
\text { GEO. ESOLER }\end{array}$ & $\begin{array}{l}- \\
-\end{array}$ & $\begin{array}{l}\overline{-} \\
-\end{array}$ & $\begin{array}{l}- \\
- \\
-\end{array}$ & $\begin{array}{l}- \\
-\end{array}$ & $\begin{array}{l}- \\
-\end{array}$ & $\begin{array}{l}\bar{z} \\
\overline{-}\end{array}$ & $\begin{array}{l}\overline{-} \\
\overline{-}\end{array}$ & $\begin{array}{r} \\
4.032 \\
6.661 \\
105\end{array}$ & $\begin{array}{r}- \\
4.035 \\
6.661 \\
.105\end{array}$ & $\begin{array}{r}37 \% \\
62 \% \\
1 \%\end{array}$ \\
\hline TOTAL SUPPLY & - & - & - & - & - & - & - & 10,798 & $10,79 \varepsilon$ & \\
\hline
\end{tabular}

NET IM PORTS:

$-114,568$

111,439

$-164,893$

$-34,677 \quad 616,483$

10.395

25.892

6,717

$407,29 \equiv$

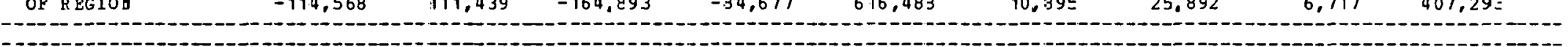

NOTES:

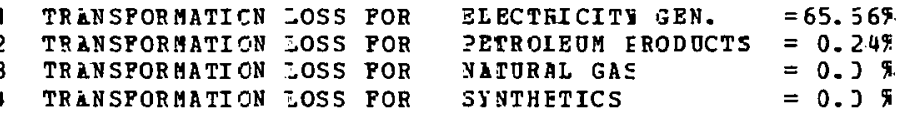


REG IONAL ENERGY BALANCE STATEMENT

PIES MID MID SCENARIO

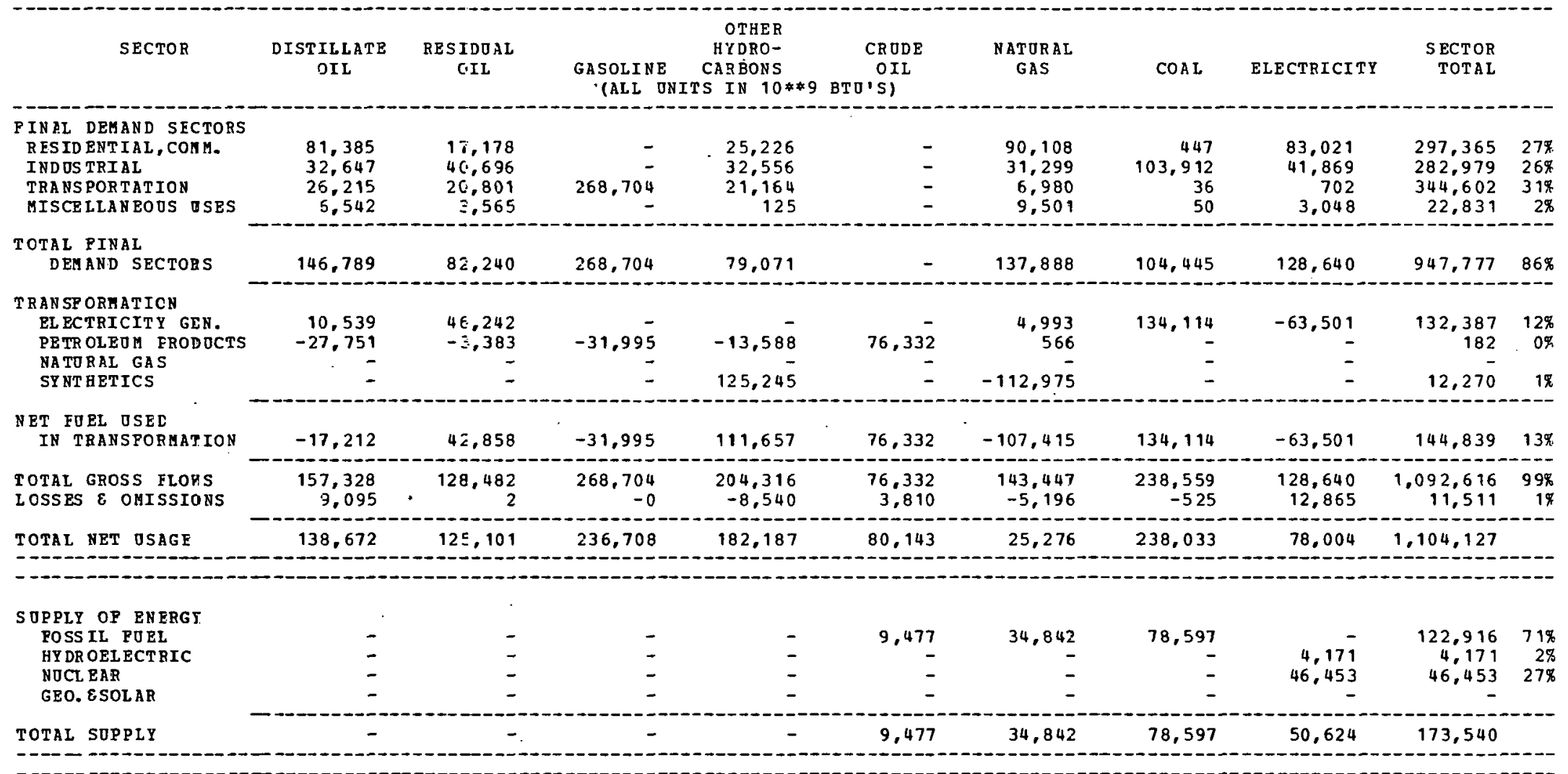

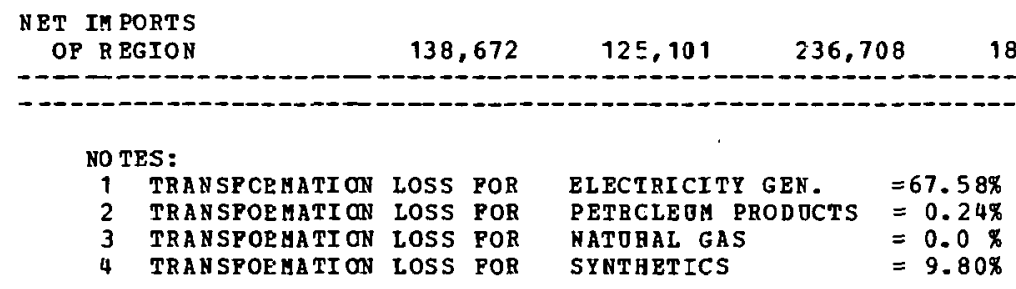


REGLONA: ENE RGY BALANCE STAIEMENT

PIE 5 FID MID SCENARIO

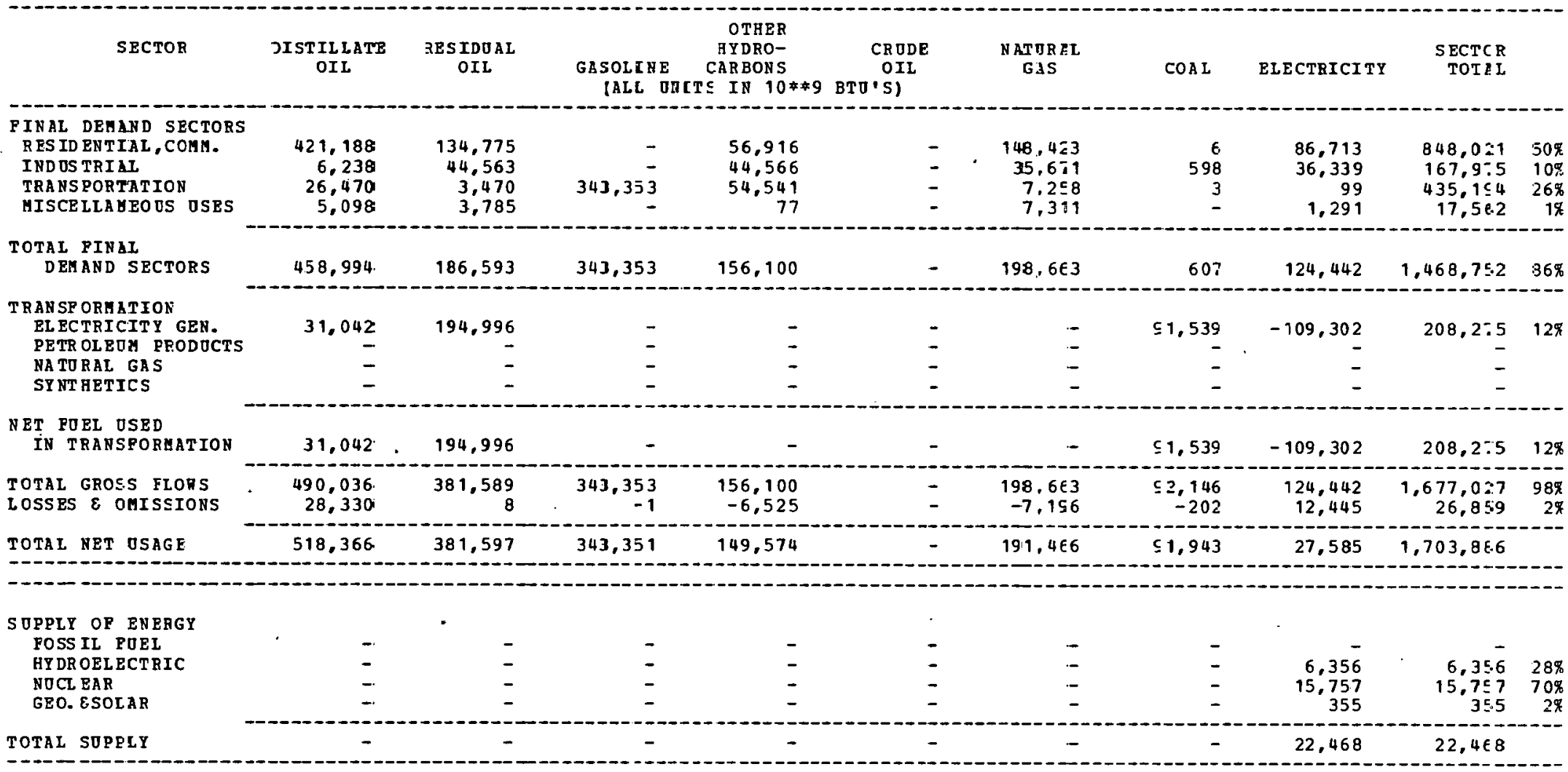

NET IM PORTS
OP REGIGN


REGIONAL ENERGY BALANCE STATEMENT

PIES MID UID SCENARIO

\begin{tabular}{|c|c|c|c|c|c|c|c|c|c|}
\hline SECTOR & $\begin{array}{l}\text { DISTILLATE } \\
\text {.OIL }\end{array}$ & $\begin{array}{l}\text { RESIDDAL } \\
\text { OIL }\end{array}$ & $\begin{array}{l}\text { GASOLINE } \\
\text { (ALL ONI }\end{array}$ & $\begin{array}{c}\text { OTHER } \\
\text { HYDRO- } \\
\text { CARBONS } \\
\text { TS IN } 10 * \$ 9\end{array}$ & $\begin{array}{c}\text { CRUDE } \\
\text { OIL } \\
\text { BTO'S) }\end{array}$ & $\begin{array}{l}\text { MATURAL } \\
\text { GAS }\end{array}$ & COAL & ELECTRICITY & $\begin{array}{l}\text { SECTOR } \\
\text { TOTAL }\end{array}$ \\
\hline $\begin{array}{l}\text { PINAL DEHAND SBCTORS } \\
\text { RESID ENTIAL, COEN. } \\
\text { IND TS TRIAL } \\
\text { TRANSPORTATION } \\
\text { MISCELLANEOOS OSES }\end{array}$ & $\begin{array}{r}227.587 \\
49.120 \\
66.969 \\
9,705\end{array}$ & $\begin{array}{r}13,792 \\
86.700 \\
2.927 \\
5,612\end{array}$ & 685,829 & $\begin{array}{r}111,756 \\
235,776 \\
28,836 \\
252\end{array}$ & $\begin{array}{l}\bar{z} \\
\overline{-}\end{array}$ & $\begin{array}{r}549,963 \\
102,440 \\
13,875 \\
6,480\end{array}$ & $\begin{array}{r}2,100 \\
467,715 \\
1 \\
14\end{array}$ & $\begin{array}{r}177,454 \\
200,413 \\
- \\
1,985\end{array}$ & $\begin{array}{r}1,080,652 \\
1,142,164 \\
798,437 \\
24,048\end{array}$ \\
\hline $\begin{array}{l}\text { TOTAL FINAL } \\
\text { DEHAND SECTOBS }\end{array}$ & 353,381 & 107,031 & 685,829 & 376,620 & - & 672,758 & 469,830 & 379,852 & $3,045,301$ \\
\hline $\begin{array}{l}\text { TBANSP ORYATION } \\
\text { ELECTRICITY GEN. } \\
\text { PETR OLZOI ERODOCTS } \\
\text { NATORAL GAS } \\
\text { SY NTBETICS }\end{array}$ & $\begin{array}{r}15,467 \\
-87,631 \\
- \\
-\end{array}$ & $\begin{array}{r}74,275 \\
-37,501 \\
- \\
-\end{array}$ & $\begin{array}{r}-162,174 \\
\overline{-} \\
-\end{array}$ & $\begin{array}{r}-75,27 \overline{7} \\
-\end{array}$ & $\begin{array}{r}347,957 \\
-\end{array}$ & $\begin{array}{r}9,252 \\
17,540 \\
- \\
-\end{array}$ & $\begin{array}{r}583,873 \\
- \\
- \\
-\end{array}$ & $\begin{array}{r}-237,390 \\
- \\
-\end{array}$ & $\begin{array}{r}445,477 \\
2,912 \\
- \\
-\end{array}$ \\
\hline $\begin{array}{l}\text { NET FOEL OSED } \\
\text { IN TRABSPORMATION }\end{array}$ & $-72,164$ & 36,773 & $-162,174$ & $-75,277$ & 347,957 & 26,792 & 583,873 & $-237,390$ & 448,389 \\
\hline $\begin{array}{l}\text { TOTAL GROSS FLORS } \\
\text { LOSSES \& OMISSIONS }\end{array}$ & $\begin{array}{r}368,848 \\
21,324\end{array}$ & $\begin{array}{r}181,306 \\
4\end{array}$ & $\begin{array}{r}685,829 \\
-2\end{array}$ & $\begin{array}{r}376,620 \\
-15,743\end{array}$ & $\begin{array}{r}347,957 \\
17,370\end{array}$ & $\begin{array}{l}699,550 \\
-25,339\end{array}$ & $\begin{array}{r}1,053,703 \\
-2,320\end{array}$ & $\begin{array}{r}379,852 \\
37,989\end{array}$ & $\begin{array}{r}3,493,690 \\
33,282\end{array}$ \\
\hline TOTAL NET OSAGE & 302,540 & 143,808 & 523,652 & 285,599 & 365,328 & 674,210 & $1,051,382$ & 180,451 & $3,526,972$ \\
\hline $\begin{array}{l}\text { SOPPLY OP ENERGY } \\
\text { FOSS IL FOEL } \\
\text { HY DR OEL RCTRIC } \\
\text { NOCL EAR } \\
\text { GEO. ESOLAR }\end{array}$ & $\begin{array}{l}\overline{-} \\
\overline{-}\end{array}$ & $\begin{array}{l}- \\
- \\
-\end{array}$ & $\begin{array}{l}- \\
-\end{array}$ & $\begin{array}{l}\overline{-} \\
\overline{-}\end{array}$ & $\begin{array}{r}142,373 \\
- \\
-\end{array}$ & $\begin{array}{r}85,399 \\
= \\
-\end{array}$ & $\begin{array}{l}\text { - } \\
\text { - }\end{array}$ & $\begin{array}{r}- \\
8,679 \\
77,779 \\
175\end{array}$ & $\begin{array}{r}227,772 \\
8.679 \\
77,779 \\
175\end{array}$ \\
\hline TOTAL SUPPLY & - & - & - & - & 142,373 & 85,399 & - & 86,633 & 314,405 \\
\hline
\end{tabular}

JET II PORTS

OP R BGION

302,540

143.808

523,652

285,599

222,955

$588,811 \quad 1,051,382$

$93,818 \quad 3,212,567$

NO TES

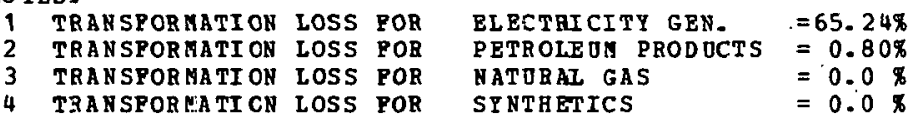


R3GIONAL EHERGY BALANCE STATEMBNT PIES MID MID SCENARIO

\begin{tabular}{|c|c|c|c|c|c|c|c|c|c|c|}
\hline $5 \Xi C T O R$ & $\begin{array}{l}\text { PI STILLATE } \\
\text { JIL }\end{array}$ & 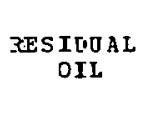 & $\begin{array}{l}\text { GAS.JLINE } \\
\text { (ALL U }\end{array}$ & $\begin{array}{c}\text { OTHER } \\
\text { EYDRO- } \\
\text { CARBONS } \\
\text { TS IN } 10 * 49\end{array}$ & $\begin{array}{c}\text { CRODE } \\
\text { OIL } \\
\text { BTO'S) }\end{array}$ & $\begin{array}{l}\text { NAT DRAL } \\
\quad \text { GAS }\end{array}$ & $\operatorname{CDAL}$ & ELECTRICITY & $\begin{array}{l}\text { SECTOR } \\
\text { TOTAZ }\end{array}$ & \\
\hline $\begin{array}{l}\text { PINAL DEMAED SECTORS } \\
\text { RESIDENTIZL, COMA. } \\
\text { INDOSTRIAL } \\
\text { TBANSPORTLTION } \\
\text { MISCELLANEOOS OSES }\end{array}$ & $\begin{array}{r}129.6983 \\
61,694 \\
42.610 \\
.3 .637\end{array}$ & $\begin{array}{r}8.151 \\
59.371 \\
1.432 \\
2.105\end{array}$ & $323,4=\overline{2}$ & $\begin{array}{r}52,319 \\
66,462 \\
32,350 \\
94\end{array}$ & $\begin{array}{l}\overline{-} \\
\overline{-}\end{array}$ & $\begin{array}{r}162,875 \\
40,324 \\
12,499 \\
2,270\end{array}$ & $\begin{array}{r}1.011 \\
61.483 \\
1 \\
4\end{array}$ & $\begin{array}{r}74,799 \\
81,214 \\
- \\
737\end{array}$ & $\begin{array}{r}429,133 \\
370,543 \\
414,324 \\
8,847\end{array}$ & $\begin{array}{r}29 \% \\
25 \% \\
28 \% \\
1 \%\end{array}$ \\
\hline $\begin{array}{l}\text { TOTAL PINAE } \\
\text { DEMAND SECTORS }\end{array}$ & 237,924 & 71.059 & $323,4 \Xi 2$ & 151.225 & - & 219,968 & 62,499 & 156,750 & $1,222,857$ & $83 \%$ \\
\hline $\begin{array}{l}\text { TRANSPORMAIION } \\
\text { ELECTRICITY GEN. } \\
\text { PETR OLEUA FRODJCTS } \\
\text { NATURAL SAS } \\
\text { SYNTHETICS }\end{array}$ & $\begin{array}{r}11,470 \\
-113,561 \\
- \\
-\end{array}$ & $\begin{array}{r}8.616 \\
-48,597 \\
- \\
-\end{array}$ & $\begin{array}{r}-210,158 \\
- \\
-\end{array}$ & $\begin{array}{r}-97,550 \\
- \\
-\end{array}$ & $\begin{array}{r}450,909 \\
- \\
-\end{array}$ & $\begin{array}{r}3,406 \\
22,730 \\
- \\
-\end{array}$ & $\begin{array}{r}293,123 \\
- \\
-\end{array}$ & $\begin{array}{r}-111,687 \\
- \\
-\end{array}$ & $\begin{array}{r}204,929 \\
3,772 \\
- \\
-\end{array}$ & $\begin{array}{r}14 \% \\
0 \%\end{array}$ \\
\hline $\begin{array}{l}\text { MET FOEL OJED } \\
\text { IN TRANSZORHATION }\end{array}$ & $-1<2,091$ & $-39,981$ & $-210,158$ & $-97,550$ & 450,9199 & 25,135 & $29 \equiv, 123$ & $-111,687$ & 208,700 & $14 \%$ \\
\hline $\begin{array}{l}\text { TOTAL GROS S FLONS } \\
\text { LOSSES \& CYISSIONS }\end{array}$ & $\begin{array}{r}249,394 \\
-4,418\end{array}$ & $\begin{array}{r}79,675 \\
1\end{array}$ & $\begin{array}{r}323,432 \\
-1\end{array}$ & $\begin{array}{r}151,225 \\
-6,321\end{array}$ & $\begin{array}{r}450,939 \\
22,510\end{array}$ & $\begin{array}{r}245,104 \\
-3,914\end{array}$ & $\begin{array}{r}35 E .622 \\
-783\end{array}$ & $\begin{array}{r}156,750 \\
15,676\end{array}$ & $\begin{array}{r}1,431,5 \leq 7 \\
36,5 \varepsilon 6\end{array}$ & $\begin{array}{r}98 \% \\
2 \%\end{array}$ \\
\hline TOTAL NET OSAGE & 150,251 & 31,079 & $11 \equiv, 272$ & 47,353 & 473,419 & 237,189 & $35 L .83 \varepsilon$ & 60,739 & $1,468,144$ & \\
\hline $\begin{array}{l}\text { SOPPLY OF ENEFGY } \\
\text { FOSS IL FOEL } \\
\text { HY DR OEL DXTRIC } \\
\text { NOCL EAR } \\
\text { GEO. ESOLAR }\end{array}$ & $\begin{array}{l}- \\
-\end{array}$ & $\begin{array}{l}- \\
\overline{-}\end{array}$ & $\bar{z}$ & $\begin{array}{l}- \\
-\end{array}$ & $\begin{array}{l}\overline{-} \\
\overline{-}\end{array}$ & $\begin{array}{l}- \\
\overline{-}\end{array}$ & $\begin{array}{l}- \\
-\end{array}$ & $\begin{array}{r}- \\
1,625 \\
19,067 \\
71\end{array}$ & $\begin{array}{r}1,6=5 \\
19,0.7 \\
\because 1\end{array}$ & $\begin{array}{r}8 \% \\
92 \% \\
0 \%\end{array}$ \\
\hline TOTAL SOPPLY & - & - & - & - & - & - & - & 20,763 & $20,70 \equiv$ & \\
\hline
\end{tabular}

\begin{tabular}{l}
$\begin{array}{l}\text { NET IM POEZS } \\
\text { OF R EGION }\end{array}$ \\
\hline
\end{tabular}


REGIONAL ENERGY BALANCE STATEMENT

PIES MID MID SCENARID

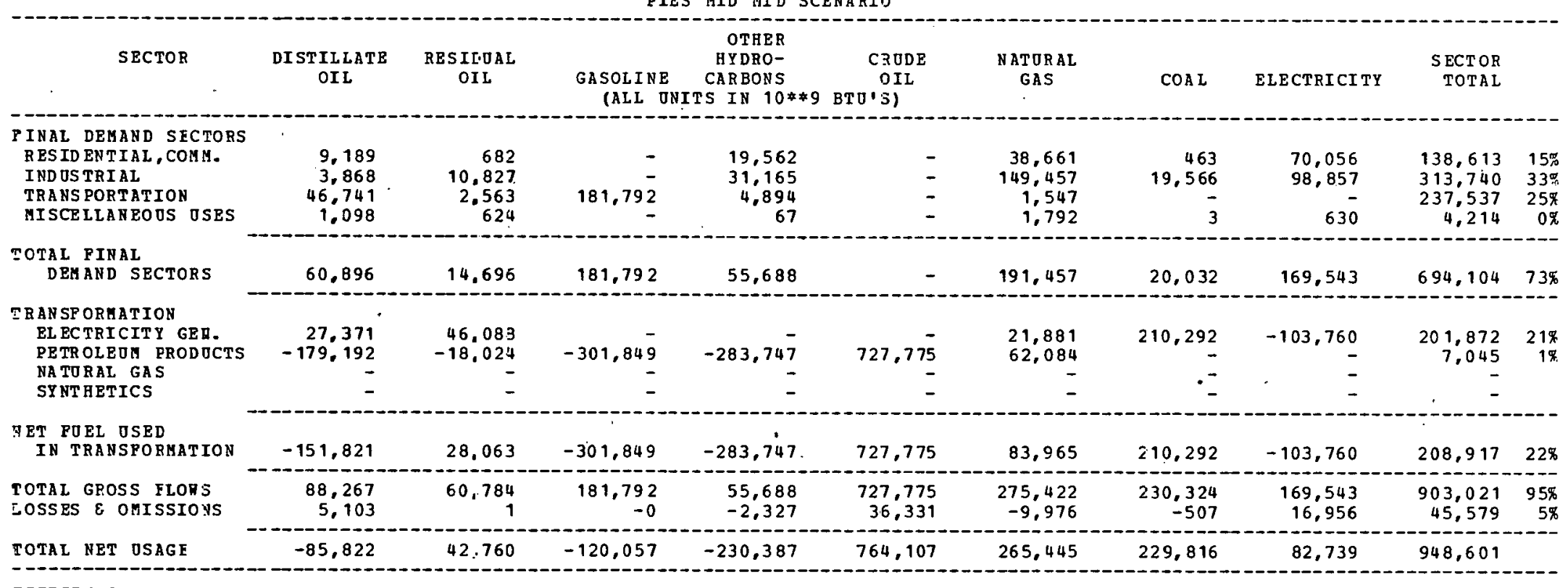

SOPPLY OP ENERGY
$\begin{aligned} & \text { FOSS IL FOEL } \\ & \text { HYDROELECTRIC }\end{aligned}$
NOCL EAR
GEO.ESOLAR

\begin{tabular}{l}
$\begin{array}{l}\text { NET IM PORTS } \\
\text { OP R BGION }\end{array}$ \\
\hline
\end{tabular}


REGI ONAL ENE RGY BLLANCE STAFEMENT

PIES MID MID SCENARIO

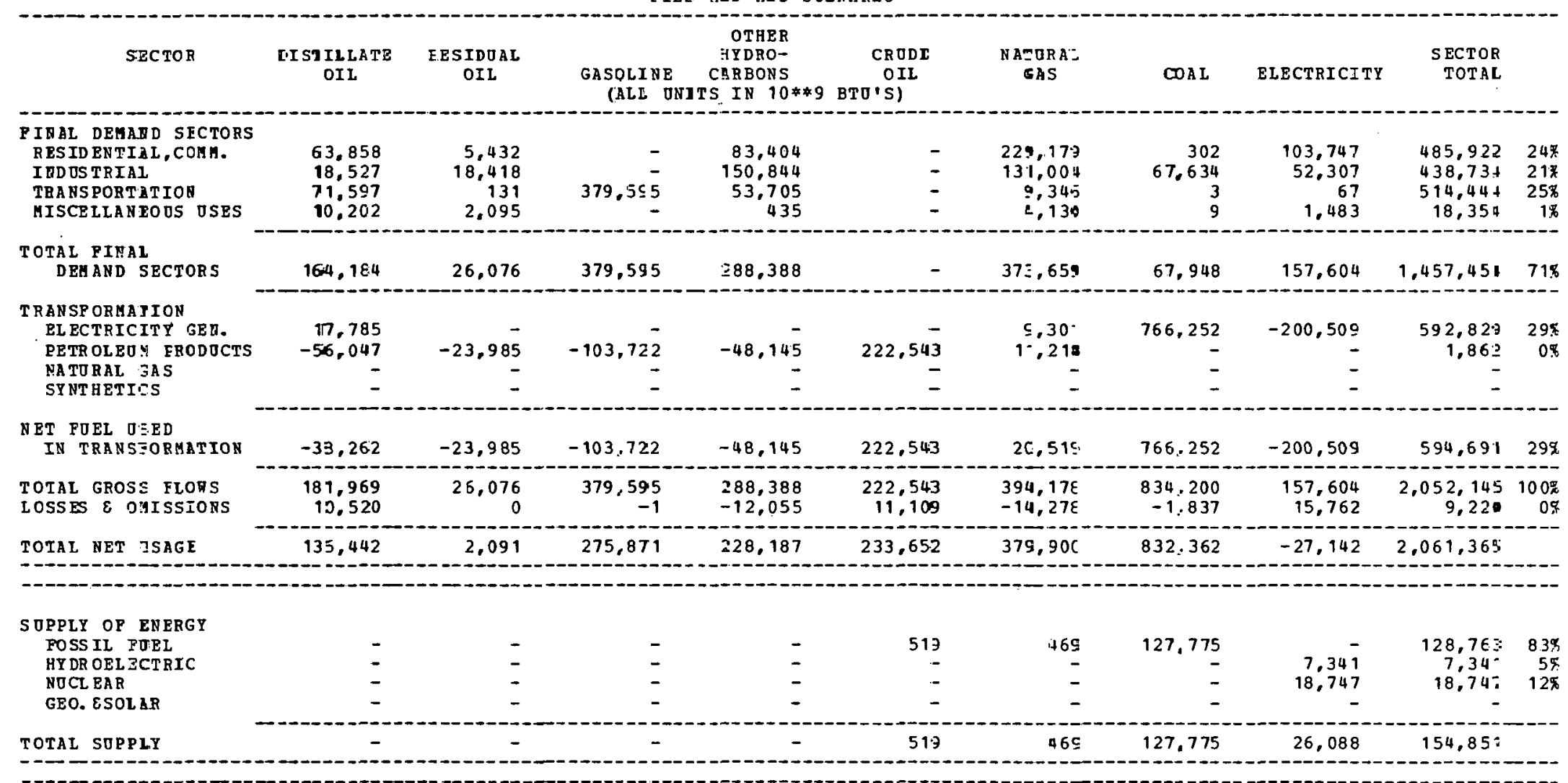

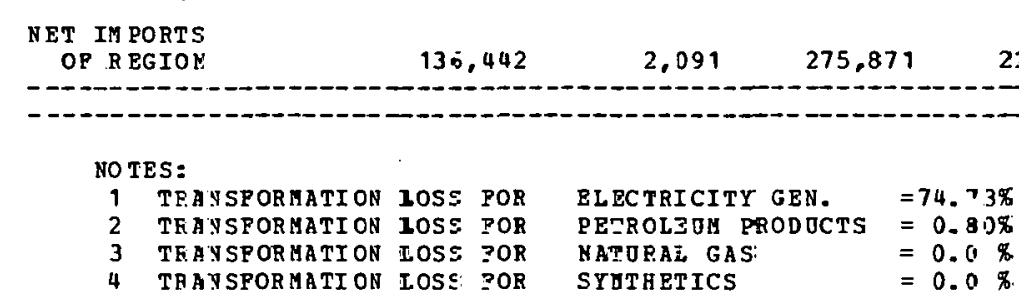


REGIONAL ENE RGY BALANCE STATEMENT

PIES MID MID SCENARIO

\begin{tabular}{|c|c|c|c|c|c|c|c|c|c|c|}
\hline SECTOF & $\begin{array}{c}\text { DISTIILATE } \\
\text { OII }\end{array}$ & $\begin{array}{l}\text { BESILUAL } \\
\text { OIL }\end{array}$ & $\begin{array}{l}\text { GASOLINI } \\
\text { (ALL }\end{array}$ & $\begin{array}{l}\text { OTHER } \\
\text { HYDRO- } \\
\text { CARBONS } \\
\text { TS IN } 10 * 9\end{array}$ & $\begin{array}{c}\text { CR ODE } \\
\text { OIL } \\
\text { BTO'S) }\end{array}$ & $\begin{array}{l}\text { NATURAL } \\
\text { GAS }\end{array}$ & COA L & ELECTRICITY & $\begin{array}{r}\text { SECTOR } \\
\text { TOTAL }\end{array}$ & \\
\hline $\begin{array}{l}\text { F INAL DEMAND SFCTORS } \\
\text { RES IDENTIAL, CCMM. } \\
\text { IND OSTRIAL } \\
\text { TRANSPORTATION } \\
\text { UISCELLANEOUS OSES }\end{array}$ & $\begin{array}{r}8,286 \\
12,423 \\
46,741 \\
1,486\end{array}$ & $\begin{array}{r}1,666 \\
15,586 \\
345 \\
526\end{array}$ & 67,107 & $\begin{array}{r}14,121 \\
24,536 \\
7,811 \\
66\end{array}$ & $\begin{array}{l}- \\
\bar{z}\end{array}$ & $\begin{array}{r}50,708 \\
30,491 \\
1.093 \\
659\end{array}$ & $\begin{array}{r}96 \\
33,728 \\
3 \\
-\end{array}$ & $\begin{array}{r}27,577 \\
69,480 \\
400\end{array}$ & $\begin{array}{r}102,454 \\
186,244 \\
123,100 \\
3,137\end{array}$ & $\begin{array}{l}20 \% \\
36 \% \\
24 \% \\
1 \%\end{array}$ \\
\hline $\begin{array}{l}\text { TOTAL FINAL } \\
\text { DEMAND SECTORS }\end{array}$ & 68,936 & 18,123 & 67,107 & 46,534 & - & 82,951 & 33,827 & 97,457 & 414,935 & $81 \%$ \\
\hline $\begin{array}{l}\text { TRAN SPORMATION } \\
\text { ELECTRICITY GEN. } \\
\text { PETROLEOM PRODUCTS } \\
\text { NATURAL GAS } \\
\text { SY NT HETICS }\end{array}$ & $\begin{array}{r}3,558 \\
-99,116 \\
- \\
-\end{array}$ & $\begin{array}{r}-29,94 \overline{-} \\
-\end{array}$ & $\begin{array}{r}-157.115 \\
- \\
-\end{array}$ & $\begin{array}{r}-67,024 \\
-\end{array}$ & $\begin{array}{r}336,655 \\
-\end{array}$ & $\begin{array}{r}952 \\
21,034 \\
-\end{array}$ & $\begin{array}{r}98,936 \\
- \\
- \\
-\end{array}$ & $\begin{array}{r}-32,245 \\
- \\
-\end{array}$ & $\begin{array}{r}71,201 \\
4,488 \\
- \\
-\end{array}$ & $\begin{array}{r}14 \pi \\
19\end{array}$ \\
\hline $\begin{array}{l}\text { NET FOEL OSED } \\
\text { IN TRANSFORMATION }\end{array}$ & $-95,558$ & $-29,946$ & $-157,115$ & -67.024 & 336,655 & 21,986 & 98,936 & $-32,245$ & 75,689 & $15 \%$ \\
\hline $\begin{array}{l}\text { TOTAL GROSS FLOHS } \\
\text { LOSSES \& OMISSIONS }\end{array}$ & $\begin{array}{r}72,494 \\
4,191\end{array}$ & $\begin{array}{r}18,123 \\
0\end{array}$ & $\begin{array}{r}67,107 \\
-0\end{array}$ & $\begin{array}{l}46,534 \\
-1,945\end{array}$ & $\begin{array}{r}336,655 \\
16,806\end{array}$ & $\begin{array}{r}104,937 \\
-3,801\end{array}$ & $\begin{array}{r}132,763 \\
-292\end{array}$ & $\begin{array}{r}97,457 \\
9,746\end{array}$ & $\begin{array}{r}490,624 \\
24,705\end{array}$ & $\begin{array}{r}95 \% \\
5 \%\end{array}$ \\
\hline IDTAL NET USAGE & $-22,431$ & $-11,822$ & $-90,008$ & $-22,435$ & 353,462 & 101,136 & 132,470 & 74,958 & 515,329 & \\
\hline
\end{tabular}

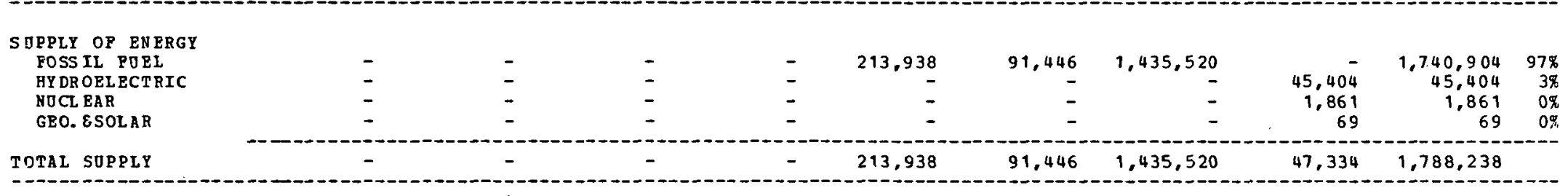

\section{NET IM PORTS}

OP REGION

$-22,431 \quad-11,822$

$-90,008$

$-22,435$

139.524

$9,690-1,303,049$

$27,624-1,272,908$

$\begin{array}{lllll}\text { NO TES: } & & & & \\ 1 & \text { TRANSPORMATI ON } & \text { LOSS FOR } & \text { ELECTRICITY GEN. } & =68.83 \% \\ 2 & \text { TRANSPORMATION LOSS FOR } & \text { PETROLEOM PRODOCTS } & =1.25 \% \\ 3 & \text { TRANSPORHATI ON LOSS POR } & \text { NATURAL GAS } & =0.0 \% \\ 4 & \text { TRANSPORMATI ON IOSS } & \text { FOR } & \text { SYNTHETICS } & =0.0 \%\end{array}$


AEGIONAL ENREGY BALANCE STATEMENT

\begin{tabular}{|c|c|c|c|c|c|c|c|c|c|c|}
\hline SECTOR & $\begin{array}{l}\text { DISTILIATE } \\
\text { OIL }\end{array}$ & $\begin{array}{l}\text { RESIDDiL } \\
\text { OIL }\end{array}$ & $\begin{array}{l}\text { GASOILAB } \\
\quad \text { (ALL }\end{array}$ & $\begin{array}{c}\text { OPHER } \\
\text { HYIRO- } \\
\text { CEREONS } \\
\text { TS IE } 10 * * 9\end{array}$ & $\begin{array}{c}\text { CRODE } \\
\text { OIL } \\
\text { BTO'SI }\end{array}$ & $\begin{array}{l}\text { NATUEAL } \\
\text { GAS: }\end{array}$ & $\cos I$ & ELECTRICITY & $\begin{array}{r}\text { SECTOR } \\
\text { TOTAL }\end{array}$ & \\
\hline $\begin{array}{l}\text { PINAL DEMAND SFCTORS } \\
\text { RESID ENTIAL, COHA. } \\
\text { IND US TRIAL } \\
\text { TRASSPORTATION } \\
\text { MISCE LLANEOUS OSES }\end{array}$ & $\begin{array}{r}19.562 \\
10.184 \\
.34 .419 \\
2.424\end{array}$ & $\begin{array}{r}1.056 \\
7.231 \\
758 \\
497\end{array}$ & $132,38 \overline{-}$ & $\begin{array}{r}27.650 \\
2 ., 439 \\
5.517 \\
110\end{array}$ & $\begin{array}{l}- \\
-\end{array}$ & $\begin{array}{r}86,916 \\
33,120 \\
1,3 \equiv 6 \\
1,155\end{array}$ & $\begin{array}{r}275 \\
14,355 \\
1 \\
2\end{array}$ & $\begin{array}{r}40,325 \\
26,691 \\
33 \\
413\end{array}$ & $\begin{array}{r}175,794 \\
112,070 \\
174,956 \\
4,581\end{array}$ & $\begin{array}{r}28 \% \\
18 \% \\
28 \% \\
1 \%\end{array}$ \\
\hline $\begin{array}{l}\text { TOTAL PINAL } \\
\text { DEHAND SECTORS }\end{array}$ & 66,589 & 9,612 & 132,882 & 53,716 & - & 422,5017 & $14, \in 33$ & 67.462 & 467.401 & $75 \%$ \\
\hline $\begin{array}{l}\text { TRANSP ORKATION } \\
\text { EL ECTRICITZ GEN. } \\
\text { PETR OLEOM ERODUCTS } \\
\text { RATORAL EAS } \\
\text { SY HTHETICS }\end{array}$ & $\begin{array}{r}6,593 \\
-2,619 \\
- \\
-\end{array}$ & $\begin{array}{r}-1,120 \\
-\end{array}$ & $\begin{array}{r}-4,846 \\
- \\
-\end{array}$ & $\begin{array}{r}-2,249 \\
- \\
-\end{array}$ & $\begin{array}{r}10,399 \\
-\end{array}$ & $\begin{array}{r}2,763 \\
524 \\
- \\
-\end{array}$ & $\begin{array}{r}191,089 \\
- \\
-\end{array}$ & $\begin{array}{r}-50,663 \\
- \\
-\end{array}$ & $\begin{array}{r}149,482 \\
87 \\
- \\
-\end{array}$ & $\begin{array}{r}24 \pi \\
0 \%\end{array}$ \\
\hline $\begin{array}{l}\text { NET FOEL OSED } \\
\text { IN TRANSPCRAATION }\end{array}$ & 3,974 & $-1,120$ & $-4, \varepsilon 46$ & $-2,249$ & $1 C, 399$ & 2,987 & 191,089 & $-50,663$ & 149,569 & $24 \%$ \\
\hline $\begin{array}{l}\text { TOTAL GROSS FLOHS } \\
\text { LOSSES \& OMISSIONS }\end{array}$ & $\begin{array}{r}73,132 \\
4.230\end{array}$ & $\begin{array}{r}9,6 \cdot 12 \\
0\end{array}$ & $\begin{array}{r}132,282 \\
-0\end{array}$ & $\begin{array}{l}5.3,716 \\
-2,245\end{array}$ & $\begin{aligned} & 16, 399 \\
& 519\end{aligned}$ & $\begin{array}{r}125,494 \\
-4,545\end{array}$ & $\begin{array}{r}205,722 \\
-6.53\end{array}$ & $\begin{array}{r}67,462 \\
6,746\end{array}$ & $\begin{array}{r}616,970 \\
4,252\end{array}$ & $\begin{array}{l}99 \% \\
19\end{array}$ \\
\hline TOTAZ NET OSAGE & 74.793 & 8,491 & 128,0134 & {$[.9,220$} & 10,918 & 120,948 & 205,268 & 23,545 & 621,222 & \\
\hline $\begin{array}{l}\text { SOPPLY OP RUERGY } \\
\text { POSS IL POEL } \\
\text { HY DROEL ECITRIC } \\
\text { NOCL EAR } \\
\text { GEO. ESOLAR }\end{array}$ & $\begin{array}{l}\bar{z} \\
\bar{z}\end{array}$ & $\begin{array}{l}\bar{z} \\
\bar{z}\end{array}$ & $\bar{z}$ & $\begin{array}{l}\overline{-} \\
\overline{-}\end{array}$ & $\begin{array}{r}43,838 . \\
= \\
=\end{array}$ & $\begin{array}{r}7,184 \\
= \\
=\end{array}$ & $\bar{z}$ & $\begin{array}{r}4,425 \\
19,423 \\
-\end{array}$ & $\begin{array}{r}51,022 \\
4.425 \\
19.423\end{array}$ & $\begin{array}{r}685 \\
65 \\
265\end{array}$ \\
\hline TOTAL SUPPLZ & - & - & - & - & 43,838 & 7,184 & - & 23,848 & 74.870 & \\
\hline
\end{tabular}

-

NET IM PORTS
OF R BGION


REGIONAL ENE RGY BALANCE STATEMENT
PIES MID MI D SCENARIO

\begin{tabular}{|c|c|c|c|c|c|c|c|c|c|c|}
\hline SECTOR & $\begin{array}{l}\text { DISTIILATE } \\
\text { OIL }\end{array}$ & $\begin{array}{l}\text { RESIDDAL } \\
\text { OI= }\end{array}$ & $\begin{array}{l}\text { GASOLINE } \\
\text { (ALL O) }\end{array}$ & $\begin{array}{c}\text { OTHER } \\
\text { HYDRO- } \\
\text { CARBONS } \\
\text { IS IN } 10 * * 9\end{array}$ & $\begin{array}{c}\text { CRODE } \\
\text { OIL } \\
\text { BTO'S) }\end{array}$ & $\begin{array}{l}\text { NATURAL } \\
\text { GAS }\end{array}$ & $\operatorname{COAL}$ & ELECTRICITY & $\begin{array}{r}\text { SECTOR } \\
\text { TOTAL }\end{array}$ & \\
\hline $\begin{array}{l}\text { PINAL DEMAND SECTORS } \\
\text { RESIDEVTIAL, CCMM. } \\
\text { IND TS TRIAL } \\
\text { TRANS PORTATION } \\
\text { MISCELLANEOOS OSES }\end{array}$ & $\begin{array}{r}7,359 \\
5,742 \\
10,904 \\
284\end{array}$ & $\begin{array}{r}95 \\
6,614 \\
- \\
80\end{array}$ & 70,650 & $\begin{array}{r}3,937 \\
7,953 \\
31,064 \\
2\end{array}$ & - & $\begin{array}{r}14,491 \\
38,626 \\
2.210 \\
709\end{array}$ & $\begin{array}{r}4 \\
7,353 \\
- \\
-\end{array}$ & $\begin{array}{r}20,481 \\
20,748 \\
- \\
242\end{array}$ & $\begin{array}{r}46,367 \\
87,036 \\
114,828 \\
1,317\end{array}$ & $\begin{array}{r}12 \% \\
23 \% \\
31 \% \\
0 \%\end{array}$ \\
\hline $\begin{array}{l}\text { TOTAL PINAL } \\
\text { DEMAND SECTORS }\end{array}$ & 24.289 & 6,789 & 70,650 & 42,956 & - & 56,036 & 7,357 & 41.471 & 249,548 & $67 \%$ \\
\hline $\begin{array}{l}\text { TRANSPORMATION } \\
\text { EL ECTRICITY GEN. } \\
\text { PETR OLEOM FRODOCTS } \\
\text { NATURAL GAS } \\
\text { SYNTHETICS }\end{array}$ & $\begin{array}{r}1,146 \\
- \\
- \\
-\end{array}$ & $\begin{array}{l}- \\
- \\
-\end{array}$ & $\begin{array}{l}- \\
-\end{array}$ & $\begin{array}{l}- \\
\overline{-}\end{array}$ & - & $\begin{array}{r}40,964 \\
- \\
-\end{array}$ & $\begin{array}{r}142,905 \\
- \\
-\end{array}$ & $\begin{array}{r}-61,307 \\
- \\
- \\
-\end{array}$ & $\begin{array}{r}123,708 \\
- \\
-\end{array}$ & $33 \%$ \\
\hline $\begin{array}{l}\text { 'NET POEL USED } \\
\text { IN TRANSFORMATION }\end{array}$ & 1,146 & - & - & - & - & 40,964 & 142,905 & $-61,307$ & 123,708 & $33 \%$ \\
\hline $\begin{array}{l}\text { TOTAL GROSS FLORS } \\
\text { LOSSES } \varepsilon \text { OMISSIONS }\end{array}$ & $\begin{array}{r}25,4: 35 \\
1,470\end{array}$ & $\begin{array}{r}6,789 \\
0\end{array}$ & $\begin{array}{r}70,650 \\
-0\end{array}$ & $\begin{array}{r}42,956 \\
-1,795\end{array}$ & - & $\begin{array}{l}97,000 \\
-3,513\end{array}$ & $\begin{array}{r}150,262 \\
-330\end{array}$ & $\begin{array}{r}41,471 \\
4,147\end{array}$ & $\begin{array}{r}373,256 \\
-22\end{array}$ & $\begin{array}{r}100 \% \\
0 \%\end{array}$ \\
\hline
\end{tabular}

-

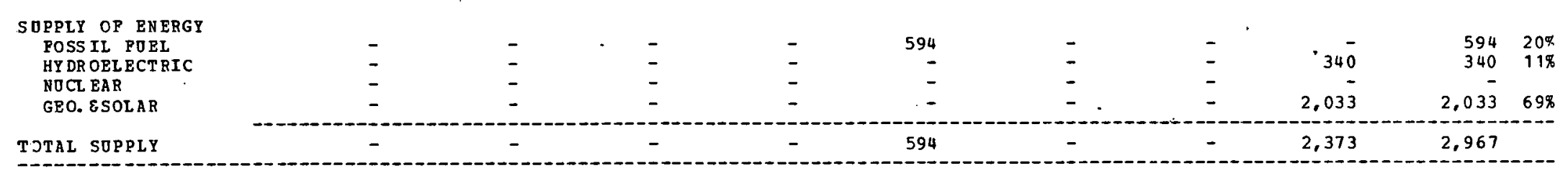

-

\begin{tabular}{l} 
NET IM PORTS \\
OP REGON \\
\hline
\end{tabular}

NO TES:

TRANSPORMATION LOSS POR TRANSFORMATION LOSS POR

TRANSPORMATI ON LOSS POR
TRANSFORMATI ON LOSS POR 
REGIOHAL PNE RGY BALANCE STATENENT

PEES IID RID SCEYARIO

\begin{tabular}{|c|c|c|c|c|c|c|c|c|c|c|}
\hline SEC IOR & $\begin{array}{l}\text { DISTILLATE } \\
\text { OIL }\end{array}$ & $\begin{array}{l}\text { RES IDUGL } \\
\text { OIL }\end{array}$ & $\begin{array}{l}\text { GASOLIINE } \\
\text { (ALI TNI }\end{array}$ & $\begin{array}{l}\text { OTHER } \\
\text { HYDRO- } \\
\text { CARBONS } \\
\text { IS IR } 10 * * 9\end{array}$ & $\begin{array}{c}\text { CRODE } \\
\text { OIL } \\
\text { 3TO'S.) }\end{array}$ & $\begin{array}{l}\text { NATUQAL } \\
\text { GAS }\end{array}$ & $\cosh$ & ELECTRICITY & $\begin{array}{r}\text { SECTOR } \\
\text { TOTAL }\end{array}$ & \\
\hline $\begin{array}{l}\text { PINAI DEMANL SECTORS } \\
\text { RESIDENTIAI, COHM. } \\
\text { IND USTRIAL } \\
\text { TRA NSPORTATION } \\
\text { MISCELLANBCOS OSES }\end{array}$ & $\begin{array}{r}45,696 \\
1.449 \\
2.739 \\
530\end{array}$ & $\begin{array}{r}0,353 \\
-4,353 \\
374\end{array}$ & $58,52 \frac{-}{-}$ & $\begin{array}{r}7,529 \\
4,373 \\
491 \\
8\end{array}$ & 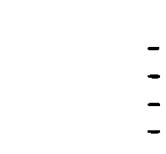 & $\begin{array}{r}8,373 \\
5,305 \\
109 \\
7 \% 9\end{array}$ & $\begin{array}{r}1 \\
214 \\
- \\
-\end{array}$ & $\begin{array}{r}11,801 \\
10,085 \\
- \\
142\end{array}$ & $\begin{array}{r}83,703 \\
36,279 \\
62,249 \\
1,853\end{array}$ & $\begin{array}{r}37 \% \\
16 \% \\
27 \% \\
1 \%\end{array}$ \\
\hline $\begin{array}{l}\text { TOTAL FINAL } \\
\text { DEMAND SEZTORS }\end{array}$ & 50,414 & 25,050 & $58,5.20$ & 12,401 & - & 15,456 & 215 & 22,028 & 184,084 & $31 \%$ \\
\hline $\begin{array}{l}\text { TRANSFORMATICN } \\
\text { EL ECTRICITY GEN. } \\
\text { PETROLEOM FRODOCTS } \\
\text { NATURAL GAS } \\
\text { SY NT HETICS }\end{array}$ & $\begin{array}{r}3.637 \\
= \\
-\end{array}$ & $\begin{array}{r}22,256 \\
- \\
-\end{array}$ & $\begin{array}{l}- \\
-\end{array}$ & $\begin{array}{l}- \\
\overline{-}\end{array}$ & $\begin{array}{l}- \\
\overline{-}\end{array}$ & $\begin{array}{l}- \\
\overline{-} \\
-\end{array}$ & $\begin{array}{r}32,274 \\
- \\
-\end{array}$ & $\begin{array}{r}-19,904 \\
- \\
-\end{array}$ & $\begin{array}{r}38,313 \\
- \\
- \\
-\end{array}$ & $17 \%$ \\
\hline $\begin{array}{l}\text { NET FOEL OSED } \\
\text { IN TRANSPGIRATION }\end{array}$ & 3,637 & 22,256 & - & - & - & - & 32,274 & $-19,904$ & 38,313 & $17 \pi$ \\
\hline $\begin{array}{l}\text { TOTAL GROSS FLOHS } \\
\text { LOSSES } \& \text { OMISSIONS }\end{array}$ & $\begin{array}{r}54,101 \\
3,127\end{array}$ & $\begin{array}{r}47.326 \\
1\end{array}$ & $\begin{array}{r}58,520 \\
-0\end{array}$ & $\begin{array}{r}12,401 \\
-518\end{array}$ & $\overline{-}$ & $\begin{array}{r}15,456 \\
-559\end{array}$ & $\begin{array}{r}32,489 \\
-71\end{array}$ & $\begin{array}{r}22,028 \\
2,203\end{array}$ & $\begin{array}{r}222,397 \\
4,181\end{array}$ & $\begin{array}{r}98 \% \\
2 \%\end{array}$ \\
\hline TOTAL NET USAGE & 57.228 & 47.397 & 58,519 & 11,882 & - & 14,396 & 32,417 & 4,327 & 226,578 & \\
\hline $\begin{array}{l}\text { S OPPLY OP ENERGY } \\
\text { FOSS IL YOEL } \\
\text { HYDR OELECTRIC } \\
\text { NOCL EAR } \\
\text { GED. ESOLAE. }\end{array}$ & $\begin{array}{l}- \\
- \\
-\end{array}$ & $\begin{array}{l}\overline{-} \\
-\end{array}$ & $\begin{array}{l}- \\
- \\
-\end{array}$ & $\begin{array}{l}- \\
-\end{array}$ & $\begin{array}{l}\text { - } \\
\text { - }\end{array}$ & $\begin{array}{l}- \\
\text { - } \\
-\end{array}$ & $\begin{array}{l}- \\
- \\
-\end{array}$ & $\begin{array}{r}- \\
4,905 \\
17,896 \\
63\end{array}$ & $\begin{array}{r}- \\
4,905 \\
17,896 \\
63\end{array}$ & $\begin{array}{r}215 \\
785 \\
0 \%\end{array}$ \\
\hline TOTAL SOPPLY & - & - & - & - & - & - & - & 22,864 & 22,864 & \\
\hline
\end{tabular}

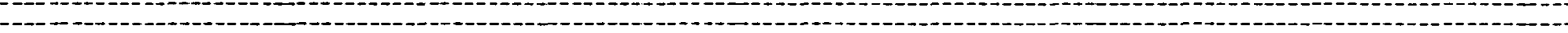

NET IM PORTS

ET IM PORTS
OF REGION

NO TES:

TRAFSFORIATION LOSS FOR TRANSPORMATION LOSS $P O R$ TRANSPCRMATION LOSS 
REGIONAL ENE RGY BALANCE STATEMENT
PIES MID MID SCENARIO

\begin{tabular}{|c|c|c|c|c|c|c|c|c|c|c|}
\hline SECTOR & $\begin{array}{l}\text { DISTILLATE } \\
\text { OIL }\end{array}$ & $\begin{array}{l}\text { RESIDOAL } \\
\text { OIL }\end{array}$ & $\begin{array}{l}\text { GASOLINE } \\
\text { CALL ONI }\end{array}$ & $\begin{array}{c}\text { OTHER } \\
\text { HYDRO- } \\
\text { CARBONS } \\
\text { TS IN } 10 * 49\end{array}$ & $\begin{array}{c}\text { CR ODE } \\
\text { OIL } \\
\text { BTO'S) }\end{array}$ & $\begin{array}{l}\text { NATURAL } \\
\text { GAS }\end{array}$ & $\operatorname{COAL}$ & ELECTRI CITY & $\begin{array}{r}\text { SECTOR } \\
\text { TOTAL }\end{array}$ & \\
\hline $\begin{array}{l}\text { FINAL DEMAND SECTCRS } \\
\text { ERS ID ENTIAL, COMM. } \\
\text { IND OSTRIAL } \\
\text { TRANSPORTATION } \\
\text { EISCELLANEOOS OSES }\end{array}$ & $\begin{array}{r}298,717 \\
35,637 \\
61,408 \\
3,218\end{array}$ & $\begin{array}{r}73,831 \\
131,265 \\
33,346 \\
5,066\end{array}$ & $\begin{array}{r}\overline{-} \\
455,205 \\
-\end{array}$ & $\begin{array}{r}60,291 \\
177,867 \\
40,868 \\
67\end{array}$ & $\overline{-}$ & $\begin{array}{r}183,350 \\
70,706 \\
6,982 \\
7,483\end{array}$ & $\begin{array}{r}212 \\
72,534 \\
3 \\
25\end{array}$ & $\begin{array}{r}138,255 \\
89,089 \\
22 \\
2,013\end{array}$ & $\begin{array}{r}754,656 \\
577,098 \\
597,834 \\
17,872\end{array}$ & $\begin{array}{r}33 \% \\
25 \% \\
26 \% \\
1 \%\end{array}$ \\
\hline $\begin{array}{l}\text { TOTAL FINAL } \\
\text { DEMAND SBCTORS }\end{array}$ & 398,980 & 243,508 & 455,205 & 279,093 & - & 268,521 & 72,774 & 229,379 & $1,947,460$ & $85 \%$ \\
\hline $\begin{array}{l}\text { TEANSPORMATION } \\
\text { BLECTRICITY GEN. } \\
\text { PETR OL EOM FRODUCTS } \\
\text { NATURAL GAS } \\
\text { SYNTRETICS }\end{array}$ & $\begin{array}{r}37.063 \\
-545.627 \\
-\end{array}$ & $\begin{array}{r}83,479 \\
-66,516 \\
-\end{array}$ & $\begin{array}{r}-629,079 \\
- \\
-\end{array}$ & $\begin{array}{r}-267,168 \\
101,830\end{array}$ & $1,500,821$ & $\begin{array}{r}687 \\
11,141 \\
-91,855\end{array}$ & $\begin{array}{r}231,913 \\
= \\
-\end{array}$ & $\begin{array}{r}-118,933 \\
= \\
-\end{array}$ & $\begin{array}{r}239,209 \\
3,572 \\
- \\
9,975\end{array}$ & $\begin{array}{r}10 \% \\
0 \%\end{array}$ \\
\hline $\begin{array}{l}\text { IET FUEL OSED } \\
\text { IN TRANSPORMATICN }\end{array}$ & $-508,564$ & 21.963 & $-629,079$ & $-165,338$ & $1,500,821$ & $-80,026$ & 231.913 & $-118,933$ & 252,756 & 118 \\
\hline $\begin{array}{l}\text { TOTAL GROSS FLORS } \\
\text { LOSSES } E \text { OMISSIONS }\end{array}$ & $\begin{array}{r}436,043 \\
25,209\end{array}$ & $\begin{array}{r}331,987 \\
7\end{array}$ & $\begin{array}{r}455,205 \\
-1\end{array}$ & $\begin{array}{r}380,923 \\
-15,923\end{array}$ & $\begin{array}{r}1,500,821 \\
74,923\end{array}$ & $\begin{array}{r}280,349 \\
-10,155\end{array}$ & $\begin{array}{r}304,687 \\
-671\end{array}$ & $\begin{array}{r}229,379 \\
22,940\end{array}$ & $\begin{array}{r}2,200,216 \\
96,329\end{array}$ & $\begin{array}{r}96 \% \\
4 \%\end{array}$ \\
\hline
\end{tabular}

\begin{tabular}{|c|c|c|c|c|c|c|c|c|c|c|}
\hline $\begin{array}{l}\text { SEPPLY OF ENERGY } \\
\text { POSS IL POEL }\end{array}$ & - & - & - & - & - & - & - & - & - & \\
\hline $\begin{array}{l}\text { FOSS IL PUEL } \\
\text { HY DR OEL ECTRIC }\end{array}$ & - & - & - & - & - & - & - & 12,145 & 12,145 & $14 \%$ \\
\hline SOCL EAR & - & - & - & - & - & - & - & 71,780 & 79,780 & $85 \%$ \\
\hline GE O. ESOL AR & - & - & - & - & - & - & - & 276 & 276 & $0 \%$ \\
\hline TCTAL SOPPLY & - & - & - & - & - & - & - & 84,201 & $84,20.1$ & \\
\hline
\end{tabular}

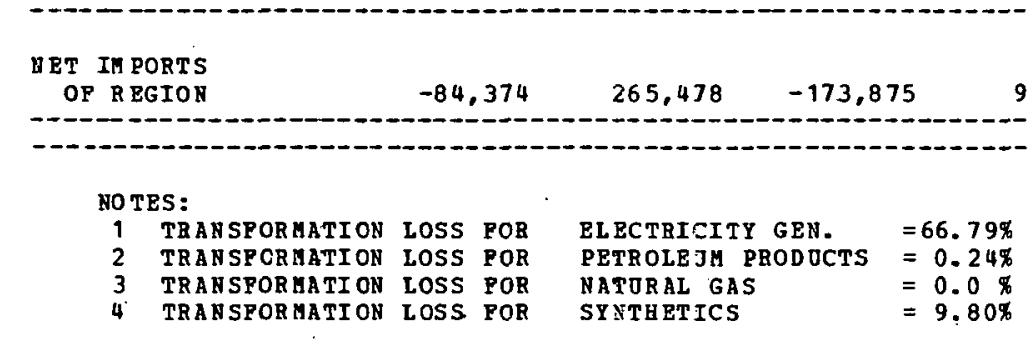


REGIONAL ENE RGY BALANCE STATEMENT

PIES R.ID. MID SCENARIO

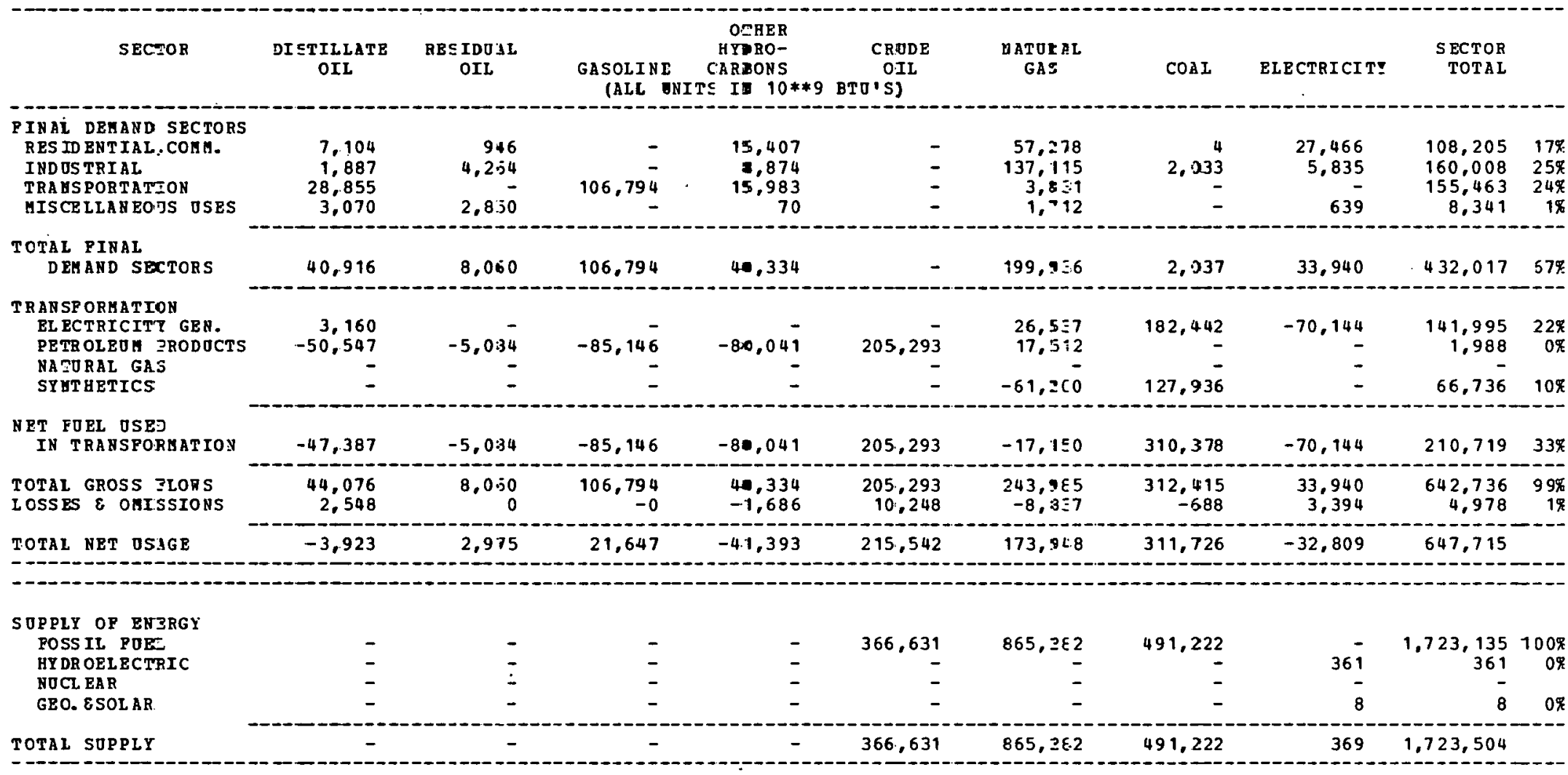

-

\section{NET IM PORTS}

OP REGION

$-3,923$

2,975

21,647

$-4.7,393$

$-151,088$

$-691,3 \equiv 3$

$-179,495$

$-33,178-1,075,788$

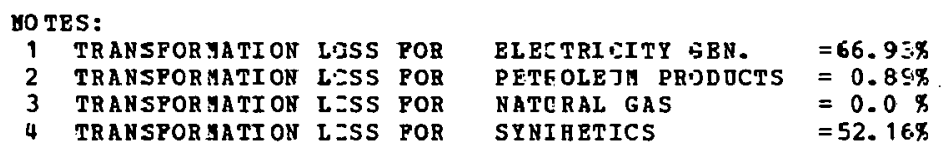


REGTONAL ENERGY BALANCE STATEMENT
PIES MID MID SCENARIO

\begin{tabular}{|c|c|c|c|c|c|c|c|c|c|c|}
\hline SECTOR & $\begin{array}{l}\text { DISTILLATE } \\
\text { GIL }\end{array}$ & $\begin{array}{l}\text { RESIDUAL } \\
\text { OIL }\end{array}$ & $\begin{array}{l}\text { GASOLINE } \\
\text { (ALL O }\end{array}$ & $\begin{array}{c}\text { OTHER } \\
\text { HYDRO- } \\
\text { CARBONS } \\
\text { TS IN } 10 * * 9\end{array}$ & $\begin{array}{c}\text { CRODE } \\
\text { OIL } \\
\text { BTO'S) }\end{array}$ & $\begin{array}{l}\text { NATURAL } \\
\text { GAS }\end{array}$ & $\operatorname{COAL}$ & ELECTRICITY & $\begin{array}{r}\text { SECTOR } \\
\text { TOTAL }\end{array}$ & \\
\hline $\begin{array}{l}\text { PINAL DEEAND SECTORS } \\
\text { RESIDENTIAL, COMY. } \\
\text { IND TS TRIAL } \\
\text { TRANS PORTATION } \\
\text { GISCELLANEOOS USES }\end{array}$ & $\begin{array}{r}641,251 \\
27,422 \\
59.383 \\
6,977\end{array}$ & $\begin{array}{r}297.556 \\
59.330 \\
40.383 \\
10.983\end{array}$ & $865,15 \overline{-}$ & $\begin{array}{r}130,136 \\
-114,704 \\
209,771 \\
155\end{array}$ & $\begin{array}{l}\overline{-} \\
\overline{-}\end{array}$ & $\begin{array}{r}414,462 \\
152,301 \\
28,978 \\
17,414\end{array}$ & $\begin{array}{r}753 \\
154,651 \\
6 \\
53\end{array}$ & $\begin{array}{r}304,084 \\
157,948 \\
7,878 \\
5,715\end{array}$ & $\begin{array}{r}1,788,242 \\
666,356 \\
1,211,553 \\
41,297\end{array}$ & $\begin{array}{l}40 \% \\
15 \% \\
27 \% \\
18\end{array}$ \\
\hline $\begin{array}{l}\text { TOTAL FIHAL } \\
\text { DEMAND SECTORS }\end{array}$ & 735.033 & 408,252 & 865,154 & 454.766 & - & 613,155 & 155,463 & 475,625 & $3,707,448$ & $83 \%$ \\
\hline $\begin{array}{l}\text { TR RANSPORAATION } \\
\text { EL ECTRICITY GEN. } \\
\text { PETROLEOM PRODOCTS } \\
\text { NATORAL GAS } \\
\text { SY NT HETICS }\end{array}$ & $\begin{array}{r}68,937 \\
-95,109 \\
- \\
-\end{array}$ & $\begin{array}{r}413,921 \\
-11,595 \\
- \\
-\end{array}$ & $\begin{array}{r}-109,656 \\
-\end{array}$ & $\begin{array}{r}-46,57 \overline{-} \\
101,830\end{array}$ & $\begin{array}{r}- \\
261,610 \\
-\end{array}$ & $\begin{array}{r}413 \\
1,942 \\
-91,855\end{array}$ & $\begin{array}{r}575,886 \\
- \\
- \\
-\end{array}$ & $\begin{array}{r}-348,247 \\
- \\
-\end{array}$ & $\begin{array}{r}710,910 \\
622 \\
- \\
9,975\end{array}$ & $\begin{array}{r}16 \% \\
0 \%\end{array}$ \\
\hline $\begin{array}{l}\text { NET FOEL OSBD } \\
\text { IN TRABSFORMATION }\end{array}$ & $-26,172$ & 402.326 & $-109,656$ & 55,260 & 261,610 & $-89,499$ & 575,886 & $-348,247$ & 721,507 & $16 \%$ \\
\hline $\begin{array}{l}\text { TOTAL GROSS FLOHS } \\
\text { LOSSES \& OMISSIONS }\end{array}$ & $\begin{array}{r}803,970 \\
46,480\end{array}$ & $\begin{array}{r}822,173 \\
18\end{array}$ & $\begin{array}{r}865,154 \\
-2\end{array}$ & $\begin{array}{l}556,596 \\
-23,266\end{array}$ & $\begin{array}{r}26.1,610 \\
13,060\end{array}$ & $\begin{array}{r}615,510 \\
-22,295\end{array}$ & $\begin{array}{r}731,349 \\
-1,610\end{array}$ & $\begin{array}{r}475,625 \\
47,567\end{array}$ & $\begin{array}{r}4,428,955 \\
59,950\end{array}$ & $\begin{array}{r}99 \% \\
1 \%\end{array}$ \\
\hline $\begin{array}{l}\text { SOPPLY OF ENERGY } \\
\text { POSS IL PUEL } \\
\text { HY DR OEL BCTRIC } \\
\text { NOCL EAR } \\
\text { GEO. \&SOLAR }\end{array}$ & $\begin{array}{l}\overline{-} \\
\overline{-}\end{array}$ & $\begin{array}{l}- \\
-\end{array}$ & $\begin{array}{l}- \\
- \\
-\end{array}$ & $\begin{array}{l}\bar{z} \\
\overline{-}\end{array}$ & $\begin{array}{r}7.064 \\
- \\
-\end{array}$ & $\begin{array}{r}9,526 \\
= \\
=\end{array}$ & $\begin{array}{l}- \\
-\end{array}$ & $\begin{array}{r}- \\
118,706 \\
106,980 \\
575\end{array}$ & $\begin{array}{r}16,590 \\
118,706 \\
106,980 \\
575\end{array}$ & $\begin{array}{r}7 \% \\
49 \% \\
44 \% \\
0 \%\end{array}$ \\
\hline TOTAL SOPPLY & - & - & - & - & 7,064 & 9,526 & - & 226,261 & 242,851 & \\
\hline
\end{tabular}

\begin{tabular}{l}
$\begin{array}{l}\text { NET IM PORTS } \\
\text { OP REGION }\end{array}$ \\
\hline
\end{tabular}


REGIONAL ENERGY BALANCE STATEMENT

PIES MID MID SCENARIO

\begin{tabular}{|c|c|c|c|c|c|c|c|c|c|c|}
\hline SECTOR & $\begin{array}{l}\text { DISTILLATE } \\
\text { OLL }\end{array}$ & $\begin{array}{l}\text { RESIDCAL } \\
\text { OII }\end{array}$ & $\begin{array}{l}\text { GASOEINE } \\
\quad(A=10\end{array}$ & $\begin{array}{l}\text { CTHER } \\
\text { H HDRC-- } \\
\text { CAEBOES } \\
\text { TS IN } 10 * * 9\end{array}$ & $\begin{array}{c}\text { CRODE } \\
\text { OIL } \\
\text { BTO'S) }\end{array}$ & $\begin{array}{l}\text { NATURAL } \\
\text { GAS }\end{array}$ & $\cos \mathrm{L}$ & ELECTRICITY & $\begin{array}{r}\text { SECTOB } \\
\text { TOTAL }\end{array}$ & \\
\hline $\begin{array}{l}\text { PIN RL DEMANT SECTORS } \\
\text { RESID ENTIAI, CCAM. } \\
\text { INDOSTRIAL } \\
\text { TRANSPORTAYION } \\
\text { MISCELLANEOS OSES }\end{array}$ & $\begin{array}{r}93,976 \\
39,040 \\
55,255 \\
3,565\end{array}$ & $\begin{array}{r}9,098 \\
60,587 \\
1,043 \\
2,029\end{array}$ & 434,795 & $\begin{array}{r}54,202 \\
\div 2,847 \\
-5, \quad 143 \\
210\end{array}$ & $\bar{z}$ & $\begin{array}{r}40,472 \\
103,0.49 \\
3.464 \\
4.206\end{array}$ & $\begin{array}{r}1,187 \\
75,466 \\
- \\
14\end{array}$ & $\begin{array}{r}178,729 \\
142,251 \\
- \\
2,303\end{array}$ & $\begin{array}{r}377,664 \\
493,240 \\
509,700 \\
12,327\end{array}$ & $\begin{array}{r}19 \% \\
25 \% \\
268 \\
1 \%\end{array}$ \\
\hline $\begin{array}{l}\text { TOTAL PINAL } \\
\text { DEMAND SECTOSS }\end{array}$ & $191.83 E$ & 72.757 & 434,795 & 142,402 & - & 151,191 & 76,667 & $.323,283$ & $1,392,931$ & $70 \%$ \\
\hline $\begin{array}{l}\text { TRANSP ORHATION } \\
\text { EL ECTRICIYY GZN. } \\
\text { PETR OLEO PRODOCTS } \\
\text { NATURAL GZS } \\
\text { SY NT HETICS }\end{array}$ & $\begin{array}{r}52,524 \\
= \\
-\end{array}$ & $\begin{array}{r}19,296 \\
= \\
-\end{array}$ & $\begin{array}{l}\bar{z} \\
\bar{z}\end{array}$ & $\begin{array}{l}\bar{E} \\
\bar{z}\end{array}$ & : & $\begin{array}{l}21 \\
- \\
-\end{array}$ & $\begin{array}{r}790,515 \\
- \\
-\end{array}$ & $\begin{array}{r}-297,010 \\
- \\
-\end{array}$ & $\begin{array}{r}565,345 \\
- \\
-\end{array}$ & $28 \%$ \\
\hline $\begin{array}{l}\text { NET FORL OSZD } \\
\text { IN TRANSPORHATION }\end{array}$ & $5 \overline{2}, 524$ & 19,296 & - & - & - & 21 & 790,515 & $-297,010$ & 565,346 & $28 \%$ \\
\hline $\begin{array}{l}\text { TOTAL GROSS FLORS } \\
\text { IOSSES } \& \text { OMISSIONS }\end{array}$ & $\begin{array}{r}244,360 \\
14,127\end{array}$ & $\begin{array}{r}92.153 \\
2\end{array}$ & $\begin{array}{r}434,795 \\
-1\end{array}$ & $\begin{array}{r}1+2,102 \\
-5,752\end{array}$ & - & $\begin{array}{r}1.51:<12 \\
-5:<77\end{array}$ & $\begin{array}{r}867,182 \\
-1,910\end{array}$ & $\begin{array}{r}323,283 \\
32,331\end{array}$ & $\begin{array}{r}1,958,277 \\
33,119\end{array}$ & $\begin{array}{r}98 \% \\
2 \%\end{array}$ \\
\hline TOTAL NET USAGE & $25 \varepsilon, 487$ & 92,255 & 434,793 & 136,449 & - & 145.734. & 865.271 & 58,604 & $1,991,396$ & \\
\hline
\end{tabular}

\begin{tabular}{|c|c|c|c|c|c|c|c|c|c|c|}
\hline SUP?LI OP ENERGY & & & & & & & & & & \\
\hline $\begin{array}{l}\text { FOSS IL PQRL } \\
\text { HT DR OELECTRIC }\end{array}$ & $\overline{-}$ & $\overline{-}$ & - & $\overline{-}$ & $\begin{array}{l}- \\
-\end{array}$ & $\overline{-}$ & - & $28.02 \overline{-}$ & $28.02 \bar{\varepsilon}$ & $30 \%$ \\
\hline NDCI EAR & - & - & - & - & - & - & - & 64,580 & $64.58 \mathrm{C}$ & $70 \%$ \\
\hline G30. ESOL PR & - & - & - & - & - & - & - & - & - & \\
\hline TOTAL SUPPLY & - & - & - & - & - & - & - & 92,602 & $92,60 \pi$ & \\
\hline
\end{tabular}

\section{NET IM PORTS}

OP R EGION

258,487

92,055

434.793

136.449

$-\quad 145,734$

865,271

$-33,997 \quad 1,898,796$

NOTES:

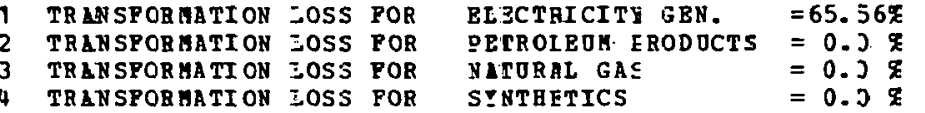

4 TRANSPORAATI ON EOSS FOR

INTEETICS

$=0.3 x$ 
REGIONAL ENERGY BALANCE STATEMENT

ONAL ENERGY BALANCE
PIES MID MID SCENAPIO

\begin{tabular}{|c|c|c|c|c|c|c|c|c|c|c|}
\hline SECTOR & $\begin{array}{l}\text { DISTILLATE } \\
\text { OIL }\end{array}$ & $\begin{array}{l}\text { RESIDUAL } \\
\text { OIL }\end{array}$ & $\begin{array}{l}\text { GASOLINE } \\
\text { (ALL ONI }\end{array}$ & $\begin{array}{c}\text { OTHER } \\
\text { HYDRO- } \\
\text { CARBONS } \\
\text { TS IN } 10 * \$ 9\end{array}$ & $\begin{array}{c}\text { CRODE } \\
\text { OIL } \\
\text { BTE'S) }\end{array}$ & $\begin{array}{l}\text { NATURAL } \\
\text { GAS }\end{array}$ & $\mathrm{COAL}$ & ELECTRICITY & $\begin{array}{r}\text { SECTOR } \\
\text { TOTAL }\end{array}$ & \\
\hline $\begin{array}{l}\text { PINAL DEMAND SECTORS } \\
\text { RESIDEVTIAL, CCMH. } \\
\text { INDUSTRIAL } \\
\text { TRANSPORTATION } \\
\text { MISCELLANEOUS OSES }\end{array}$ & $\begin{array}{r}11,492 \\
7,873 \\
15,540 \\
1,175\end{array}$ & $\begin{array}{r}1,548 \\
21,190 \\
- \\
417\end{array}$ & $\begin{array}{r}- \\
- \\
57,765 \\
-\end{array}$ & $\begin{array}{r}11,958 \\
13,507 \\
4,506 \\
58\end{array}$ & $\begin{array}{l}- \\
-\end{array}$ & $\begin{array}{r}18,839 \\
6,045 \\
962 \\
543\end{array}$ & $\begin{array}{r}54 \\
19,602 \\
- \\
-\end{array}$ & $\begin{array}{r}20,462 \\
5,020 \\
- \\
346\end{array}$ & $\begin{array}{r}64,353 \\
73,237 \\
78,773 \\
2,539\end{array}$ & $\begin{array}{r}19 \% \\
21 \% \\
23 \% \\
1 \%\end{array}$ \\
\hline $\begin{array}{l}\text { TOTAL PINAL } \\
\text { DEMAUD SECTORS }\end{array}$ & 36,080 & 23,155 & 57.765 & 30.029 & - & 26,389 & 19,656 & 25,828 & 218,902 & $63 \%$ \\
\hline $\begin{array}{l}\text { TRANSF ORHATION } \\
\text { ELECTRICITY GEN. } \\
\text { PETR OLEOM PRODOCTS } \\
\text { NATURAL GAS } \\
\text { SY NTHETICS }\end{array}$ & $\begin{array}{r}992 \\
-30,725 \\
- \\
-\end{array}$ & $\begin{array}{r}-13,149 \\
- \\
-\end{array}$ & $\begin{array}{r}- \\
-56,861 \\
-\end{array}$ & $\begin{array}{r}-26,39 \overline{2} \\
-\end{array}$ & $\begin{array}{r}- \\
- \\
-\end{array}$ & $\begin{array}{r}266 \\
6,149 \\
-38,300\end{array}$ & $\begin{array}{r}109,679 \\
- \\
80,060\end{array}$ & $\begin{array}{r}-34,593 \\
- \\
-\end{array}$ & $\begin{array}{r}76,344 \\
1,019 \\
- \\
41,760\end{array}$ & $\begin{array}{r}22 \% \\
0 \%\end{array}$ \\
\hline $\begin{array}{l}\text { NET FOEL OSED } \\
\text { IN TRANSFORMATION }\end{array}$ & $-29,733$ & $-13,149$ & $-56,861$ & $-26,392$ & $\$ 21,998$ & $-31,884$ & 189,739 & $-34,593$ & 119,123 & $34 \%$ \\
\hline $\begin{array}{l}\text { TOTAL GROSS FLONS } \\
\text { LOSSES \& OHISSIONS }\end{array}$ & $\begin{array}{r}37,072 \\
2,143\end{array}$ & $\begin{array}{r}23,155 \\
0\end{array}$ & $\begin{array}{r}57,765 \\
-0\end{array}$ & $\begin{array}{r}30.029 \\
-1.255\end{array}$ & $\begin{array}{r}121,998 \\
6,090\end{array}$ & $\begin{array}{r}32,804 \\
-1,188\end{array}$ & $\begin{array}{r}209,395 \\
-461\end{array}$ & $\begin{array}{r}25,828 \\
2,583\end{array}$ & $\begin{array}{r}338,025 \\
7,912\end{array}$ & $\begin{array}{r}98 \% \\
2 \%\end{array}$ \\
\hline $\begin{array}{l}\text { S JPPLY OP ENERGY } \\
\text { FOSS IL POEL } \\
\text { HYDR OELECTRIC } \\
\text { NOCL EAR } \\
\text { GEO. ESOLAR }\end{array}$ & $\bar{z}$ & $\begin{array}{l}- \\
-\end{array}$ & $\begin{array}{l}- \\
- \\
-\end{array}$ & $\begin{array}{l}- \\
-\end{array}$ & $\begin{array}{r}141,032 \\
- \\
-\end{array}$ & $\begin{array}{r}40,396 \\
- \\
-\end{array}$ & $\begin{array}{r}602,034 \\
- \\
-\end{array}$ & $\begin{array}{r}7.040 \\
492 \\
19\end{array}$ & $\begin{array}{r}783,462 \\
7,040 \\
492 \\
19\end{array}$ & $\begin{array}{r}99 \% \\
1 \% \\
0 \% \\
0 \%\end{array}$ \\
\hline TOTAL SUPPLY & - & - & - & - & 141,032 & 40,396 & 602,034 & 7,551 & 791,013 & \\
\hline
\end{tabular}

NET IM PORTS

OP REGION

11),006

903

2,380

$-12,942 \quad-47,079 \quad-393,100$

$-13,732$

NOTES:

1 TRANSFORAATION LOSS POR

TRANSPORMATION LOSS POR

TRANSPORMATI ON LOSS FOR

TRANSPORMATI ON LOSS POR

EL ECTRICITT GEN.

$=68.82 \%$
$=6.00 \%$

NATURAL GAS $=0.0$

SYNTEBTICS $\quad=52.16 \%$ 
REGIONAI ENERGY BALANCE STATEMENT

PIES MID IID SCENARTO

\begin{tabular}{|c|c|c|c|c|c|c|c|c|c|c|}
\hline SECTOR & $\begin{array}{l}\text { EISTILLATB } \\
\text { OIL }\end{array}$ & $\begin{array}{c}\text { GESIDUAL } \\
O=L\end{array}$ & $\begin{array}{l}\text { GAS SDINE } \\
\quad(A=I \quad O\end{array}$ & $\begin{array}{c}\text { OTHER } \\
\text { GYDRO- } \\
\text { CARBONS } \\
\text { TS IN 10**9 }\end{array}$ & $\begin{array}{c}=R O D E \\
\text { OIL } \\
\text { BTU'SI }\end{array}$ & $\begin{array}{l}\text { NATURAL } \\
\text { GAS }\end{array}$ & $\operatorname{CDAL}$ & ELECTRICITY & $\begin{array}{l}\text { SECTOR } \\
\text { TOTA: }\end{array}$ & \\
\hline $\begin{array}{l}\text { IHAL DEMAND SECTORS } \\
\text { RES ID ENTIRL, COMA. } \\
\text { IMD OS TRIAL } \\
\text { TRANSPORTRTION } \\
\text { MISCELLANEOUS OSES }\end{array}$ & $\begin{array}{r}110,067 \\
67,648 \\
127,532 \\
10,533\end{array}$ & $\begin{array}{r}8.272 \\
54.168 \\
1.721 \\
6.090\end{array}$ & $714,9=\overline{-}$ & $\begin{array}{r}110,824 \\
293,999 \\
28,628 \\
275\end{array}$ & $\begin{array}{l}\overline{-} \\
\overline{-}\end{array}$ & $\begin{array}{r}637,750 \\
171,111 \\
12,951 \\
\epsilon, 984\end{array}$ & $\begin{array}{r}3,690 \\
726,948 \\
1 \\
17\end{array}$ & $\begin{array}{r}204,249 \\
275,803 \\
121 \\
2,263\end{array}$ & $\begin{array}{r}1,074,85 ? \\
1,589,677 \\
886,27.5 \\
26,16 ?\end{array}$ & $\begin{array}{r}2.48 \\
35.8 \\
20 \% \\
1.8\end{array}$ \\
\hline $\begin{array}{l}\text { OTAL FINAL } \\
\text { DEMAND SECTORS }\end{array}$ & 316,180 & 70.251 & $714,9=1$ & 433,726 & - & $82 \varepsilon, 798$ & 730,656 & $4.32,436$ & $3,576,965$ & $80 \%$ \\
\hline $\begin{array}{l}\text { TRANSF ORMATION } \\
\text { BLECTRICITY GEU. } \\
\text { PETR OLEOY FRODOCTS } \\
\text { NATORAL JAS } \\
\text { SY NTHETIES }\end{array}$ & $\begin{array}{r}20,187 \\
-308,926 \\
- \\
-\end{array}$ & $\begin{array}{r}15,755 \\
-132.203 \\
.-\end{array}$ & $\begin{array}{r}-571,7 C 1 \\
-\end{array}$ & $\begin{array}{r}-265,369 \\
-\end{array}$ & $\begin{array}{r}1,226,6 \overline{z 8} \\
\overline{-}\end{array}$ & $\begin{array}{r}16,738 \\
51,834 \\
- \\
-\end{array}$ & $\begin{array}{r}1,222,186 \\
- \\
-\end{array}$ & $\begin{array}{r}-451,34 \Xi \\
- \\
-\end{array}$ & $\begin{array}{r}817,523 \\
10,263 \\
-\end{array}$ & $\begin{array}{r}18 \% \\
0.5\end{array}$ \\
\hline $\begin{array}{l}\text { NET FOEL USED } \\
\text { IN TRANSFORMATION }\end{array}$ & $-28: 8,739$ & -116.448 & $-571,701$ & $-265,369$ & $1,2 \geqslant 6,628$ & 72,572 & $1,222,186$ & $-451,343$ & 827,785 & $18 \%$ \\
\hline $\begin{array}{l}\text { TOPAL GROSE FLONS } \\
\text { LCSSES E OMISSIOUS }\end{array}$ & $\begin{array}{r}336,367 \\
18,446\end{array}$ & $\begin{array}{r}86.006 \\
1\end{array}$ & $\begin{array}{r}714,921 \\
-2\end{array}$ & $\begin{array}{r}33,726 \\
-18,130\end{array}$ & $\begin{array}{r}1,2 \geq 6,628 \\
51,235\end{array}$ & $\begin{array}{l}901,363 \\
-3 \pi, 650\end{array}$ & $\begin{array}{r}1,952,842 \\
-4,301\end{array}$ & $\begin{array}{r}432,436 \\
48,24 \varepsilon\end{array}$ & $\begin{array}{r}4,404,75 ? \\
73,84.3\end{array}$ & $\begin{array}{r}98 \% \\
2.8\end{array}$ \\
\hline TOTAL NET OSAGE & 46,887 & $-46,195$ & 143,217 & 150,226 & $1,237,8 \in 3$ & $86 \varepsilon, 718$ & $1,948,540$ & 79,341 & $4,478,60)$ & \\
\hline $\begin{array}{l}\text { SOPPLY OP ENERGY } \\
\text { POSS IL FJEL } \\
\text { HYDR OELE ETRIC } \\
\text { NOCL EAR } \\
\text { GEO. ESOL ER }\end{array}$ & $\begin{array}{l}- \\
- \\
-\end{array}$ & $\begin{array}{l}- \\
- \\
-\end{array}$ & $\begin{array}{l}\overline{-} \\
\overline{-}\end{array}$ & $\begin{array}{l}\overline{-} \\
\overline{-}\end{array}$ & $\begin{array}{r}125,546 \\
- \\
-\end{array}$ & $\begin{array}{r}81,194 \\
- \\
-\end{array}$ & $\begin{array}{r}1,426,311 \\
= \\
=\end{array}$ & $\begin{array}{r}1,170 \\
82,098 \\
221\end{array}$ & $\begin{array}{r}1,613,051 \\
1,17 . \\
82,093 \\
221\end{array}$ & $\begin{array}{r}95 \% \\
08 \\
5 \% \\
0 \%\end{array}$ \\
\hline TOTAL SUPPLY & - & - & - & - & 135,546 & $8 \div, 19.1$ & $1,426,311$ & 83,489 & $1,696,540$ & \\
\hline
\end{tabular}

NET IM PORTS

$46,887 \quad-46,195$

143,217

150,226

$78 \bar{i}, 52 \dot{L}$

522,229

$-4,147 \quad 2,782,06$

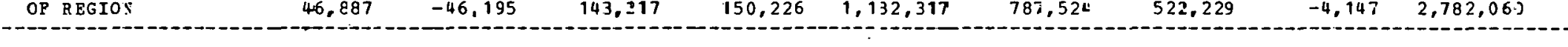

NO TES:

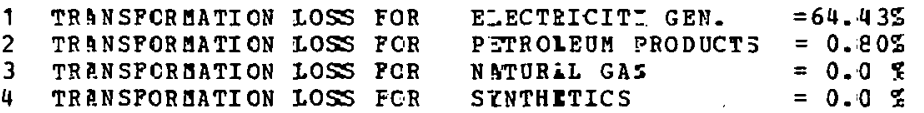


REGIONAL ENERGY BALANCE STATEMENT

PIES MID MID SCENARIO

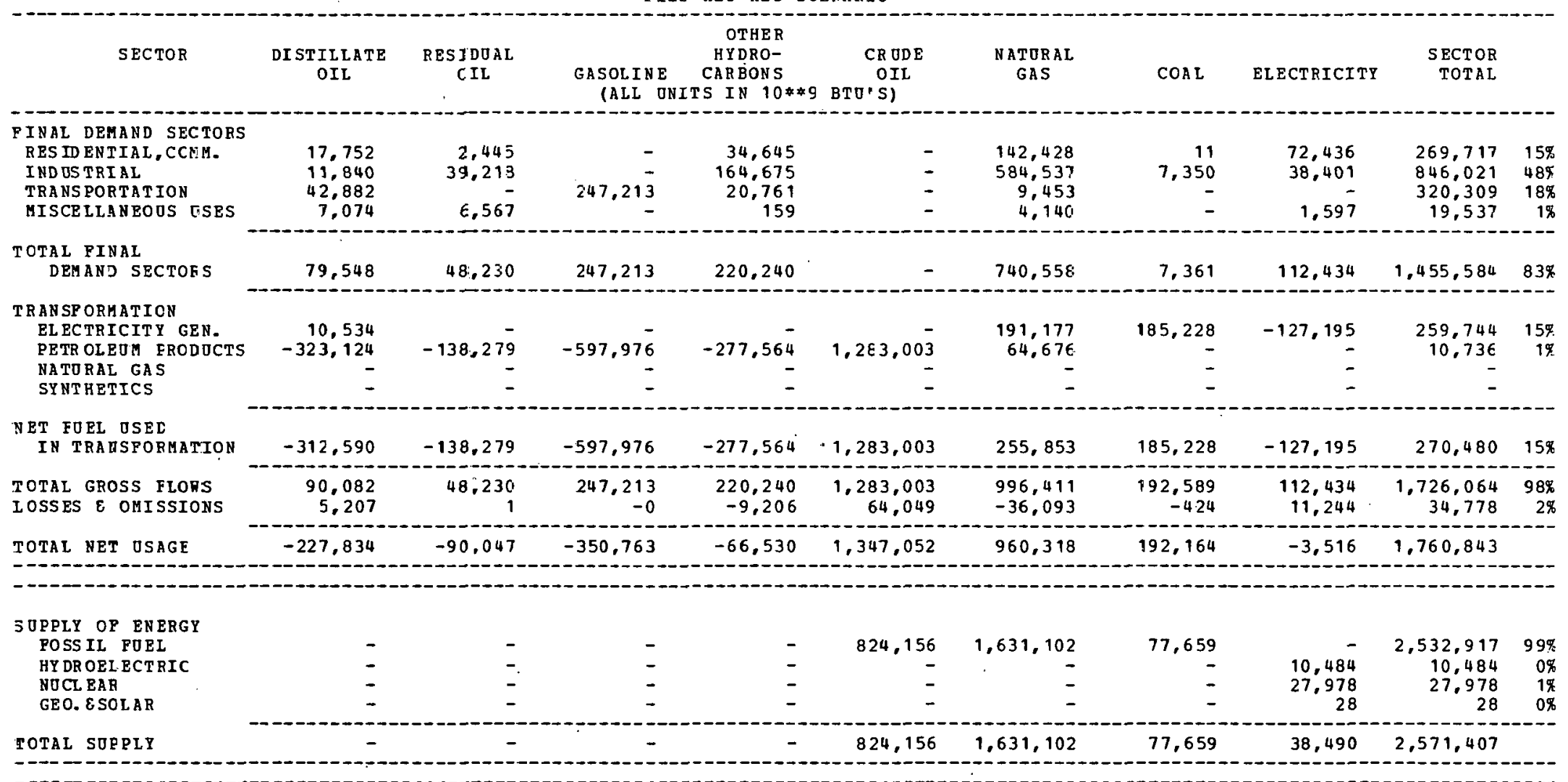

SET IM PORTS

$\begin{array}{lll}-227,834 & -90,047 \quad-350,763\end{array}$

$-66,530$

522,896

$-670,783$

114,505

$-42,006$

$-810,563$

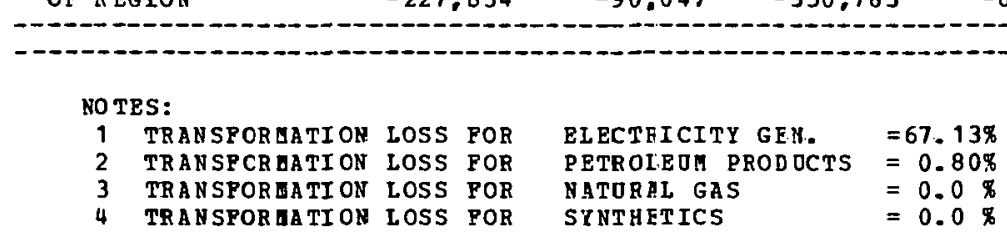


REG ONAL BNERGY BALANCE STACEMENT

ONAL BNERGY BALANCE STA
PIES MID IID.SCENARIO

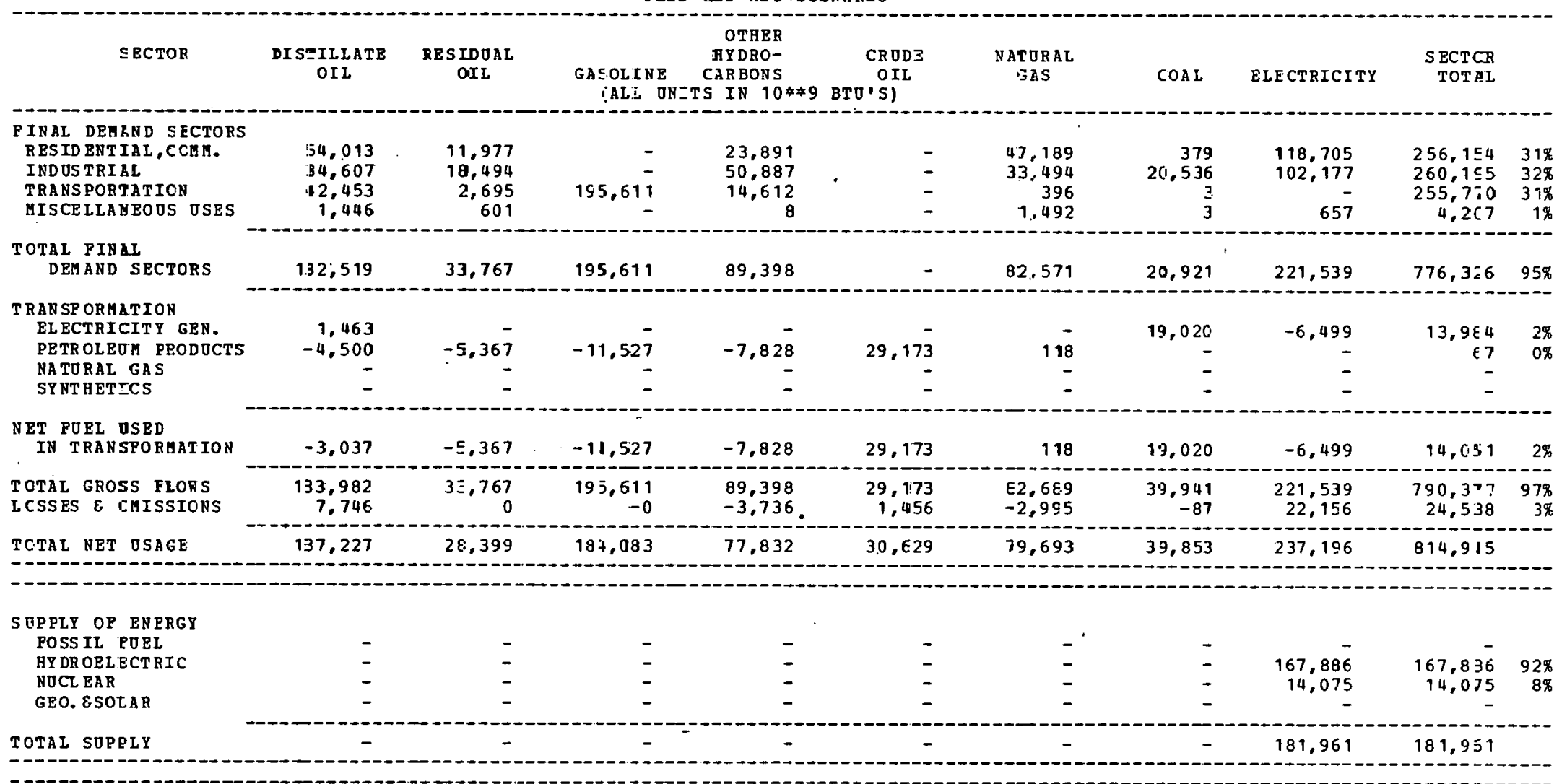

NET IM PORTS

OP REGION

137,227

23,399

184,083

77,832

30,629

79,693

39,853

55,235

632,954

NOTES:

TRANSPORHATION LC.SS POZ

TRANSPOBHATIOA LCSS POR

TRANSPORMATI La LOSS POR

TRANSPORMATI OO: LOSS POR

$\begin{array}{ll}\text { ELECIRRICITY GEN. } & =68.27 \% \\ \text { PETR JLEUM PRODUCTS } & =0.23 \%\end{array}$

$=68.27 \%$
$=0.23 \%$

SYNTERICS

$=0.0 \%$ 
REGIONAL ENERGY BALANCE STATEMENT

PIES IID MID SCENARIO

\begin{tabular}{|c|c|c|c|c|c|c|c|c|c|c|}
\hline SECTOF. & $\begin{array}{l}\text { DISTILLATE } \\
\text { OIL }\end{array}$ & $\begin{array}{l}\text { BESIDUAL } \\
\text { OIL }\end{array}$ & $\begin{array}{l}\text { GASOLINE } \\
\text { /ALI O }\end{array}$ & $\begin{array}{c}\text { OTHER } \\
\text { HYDRO- } \\
\text { CARBONS } \\
\text { TS IN } 10 * * 9\end{array}$ & $\begin{array}{c}\text { CRUDE } \\
\text { OIL } \\
\text { BTU'S) }\end{array}$ & $\begin{array}{l}\text { NATURAL } \\
\text { GAS }\end{array}$ & $\operatorname{COAL}$ & ELECTRICITY & $\begin{array}{r}\text { SECTOR } \\
\text { TOTAL }\end{array}$ & \\
\hline $\begin{array}{l}\text { PINAL DEHAND SECTORS } \\
\text { RESID EHTIAL, CCHA. } \\
\text { INDOSTRIAL } \\
\text { TRANS PORTATIOH } \\
\text { MISCELLANEOOS OSES }\end{array}$ & $\begin{array}{r}261,340 \\
92,994 \\
106,618 \\
5,209 .\end{array}$ & $\begin{array}{r}40,879 \\
130,489 \\
24,653 \\
2,840\end{array}$ & $\begin{array}{r}- \\
\overline{-} \\
686,882\end{array}$ & $\begin{array}{r}73,513 \\
214,941 \\
53,213 \\
103\end{array}$ & $\overline{-}$ & $\begin{array}{r}363,059 \\
303,222 \\
16,146 \\
8,393\end{array}$ & $\begin{array}{r}2,720 \\
923,585 \\
135 \\
41\end{array}$ & $\begin{array}{r}204,263 \\
205,835 \\
2,854 \\
2,775\end{array}$ & $\begin{array}{r}945,774 \\
1.879,066 \\
890,501 \\
19,361\end{array}$ & $\begin{array}{r}21 \% \\
41 \% \\
20 \% \\
0 \%\end{array}$ \\
\hline $\begin{array}{l}\text { TOTAL PIRAL } \\
\text { DEHAND SECTORS }\end{array}$ & 466,161 & 193,861 & 586,882 & 341,770 & - & 690,820 & 926,481 & 415,727 & $3,726,702$ & $82 \%$ \\
\hline $\begin{array}{l}\text { TRANSP ORHATION } \\
\text { EL ECTRICITY GEN. } \\
\text { PETR OLBOI FBODOCTS } \\
\text { NATURAL GAS } \\
\text { SYNT HETICS }\end{array}$ & $\begin{array}{r}25,570 \\
-646,401 \\
- \\
-\end{array}$ & $\begin{array}{r}42,826 \\
-73,801 \\
- \\
-\end{array}$ & $\begin{array}{r}-745,266 \\
-\end{array}$ & $\begin{array}{r}-316,512 \\
-\end{array}$ & $\begin{array}{r}1,778,015 \\
-\end{array}$ & $\begin{array}{r}14,012 \\
13,199 \\
- \\
-\end{array}$ & $\begin{array}{r}988,014 \\
- \\
-\end{array}$ & $\begin{array}{r}-356,391 \\
- \\
-\end{array}$ & $\begin{array}{r}714.031 \\
4.232 \\
- \\
-\end{array}$ & $\begin{array}{r}16 \% \\
0 \%\end{array}$ \\
\hline $\begin{array}{l}\text { NET POEL OSED } \\
\text { IN TRANSPORHATION }\end{array}$ & $-620,831$ & $-35,975$ & $-745,266$ & $-316,512$ & $1,778,015$ & 27,211 & 988,014 & $-356,391$ & 718,263 & $16 \%$ \\
\hline $\begin{array}{l}\text { TOTAL GROSS FLOVS } \\
\text { LOSSES \& OAISSIONS }\end{array}$ & $\begin{array}{r}491,731 \\
28,428\end{array}$ & $\begin{array}{r}24 i, 687 \\
5\end{array}$ & $\begin{array}{r}686,882 \\
-2\end{array}$ & $\begin{array}{l}341,770 \\
-14,286\end{array}$ & $\begin{array}{r}1,778,015 \\
38,761\end{array}$ & $\begin{array}{l}718,031 \\
-26,009\end{array}$ & $\begin{array}{r}1,914,495 \\
-4,217\end{array}$ & $\begin{array}{r}415,727 \\
41,577\end{array}$ & $\begin{array}{r}4,444,965 \\
114,258\end{array}$ & $\begin{array}{r}97 \% \\
3 \%\end{array}$ \\
\hline TOTAL NET OSAGE & $-125,241$ & 162,891 & $-58,386$ & 10,970 & $1,866,776$ & 692,021 & $1,910,277$ & 100,913 & $4,559,223$ & \\
\hline
\end{tabular}

\begin{tabular}{|c|c|c|c|c|c|c|c|c|c|c|}
\hline $\begin{array}{l}\text { SOPPLY OP BNERGY } \\
\text { FOSS IL POEL } \\
\text { BYDROELECTRIC } \\
\text { NOCL BAR }\end{array}$ & - & $\begin{array}{l}- \\
\end{array}$ & - & $\bar{z}$ & $\begin{array}{r}47,560 \\
-\end{array}$ & $\begin{array}{r}89,896 \\
-\end{array}$ & $\begin{array}{r}2,644,570 \\
- \\
-\end{array}$ & $\begin{array}{r}4.87 \overline{7} \\
160.093\end{array}$ & $\begin{array}{r}2,782,026 \\
4,877 \\
160,093\end{array}$ & $\begin{array}{r}94 \% \\
0 \% \\
5 \%\end{array}$ \\
\hline GEO. ESOLAR & - & - & - & - & - & - & - & - & - & \\
\hline TOTAL SUPPLY & - & - & - & - & 47,560 & 89,896 & $2,644,570$ & 164,970 & $2,946,996$ & \\
\hline
\end{tabular}

$-126,241$

162,891

$-58,386$

$10,970 \quad 1,819,216$

$602,125 \quad--734,292$

$-64,056 \quad 1,612,227$

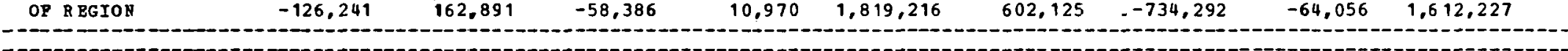

NO TES:

\begin{tabular}{|c|c|c|c|c|}
\hline $\begin{array}{l}\text { TRANSPORHATI OR } \\
\text { TRANSPORHATI OR }\end{array}$ & $\begin{array}{l}\text { I.OSS } \\
\text { LosS }\end{array}$ & $\begin{array}{l}\text { POR } \\
\text { POR }\end{array}$ & $\begin{array}{l}\text { ELECTRICITY GEN. } \\
\text { PETBOLEOH PROD OCTS }\end{array}$ & $\begin{array}{l}=66.719 \\
=0.249\end{array}$ \\
\hline TR ANSPORHA TI OU & LOSS & POR & HATORAL GAS & $=0.0 x$ \\
\hline TRANSPORUATI OV & LosS & POR & SYNTEZTICS & $=0.0 \%$ \\
\hline
\end{tabular}


RESTONAL ENZRGY BALANCE STATEMENT
PIES MI 2 MID SCENARIO

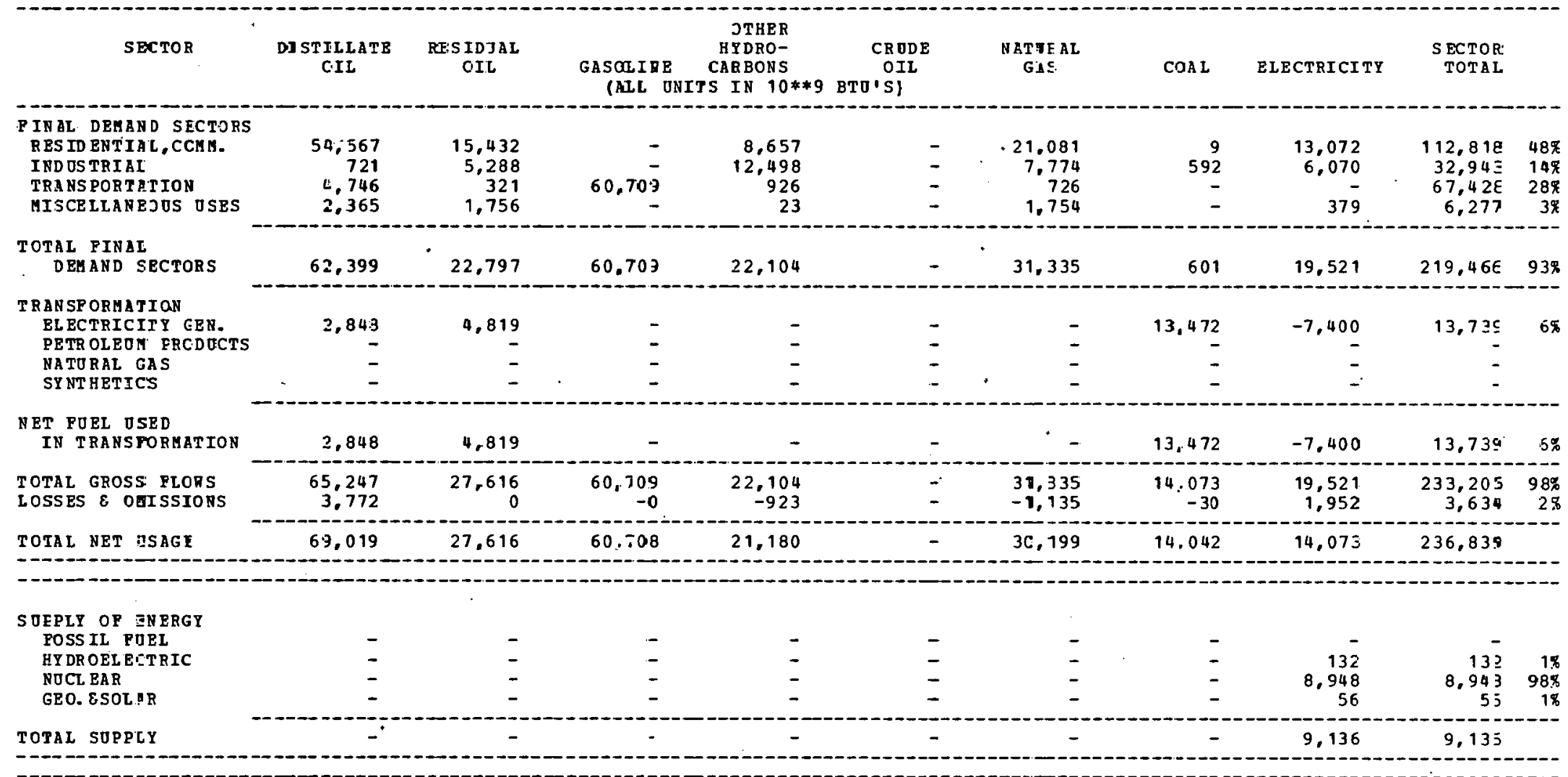

\begin{tabular}{l}
$\begin{array}{l}\text { NET IM PORTS } \\
\text { OP R EGIOU }\end{array}$ \\
\hline
\end{tabular}


ZEGIONAL ENE KGY BALANCE STATEMENT

PIES MID MID SCENARIO

\begin{tabular}{|c|c|c|c|c|c|c|c|c|c|c|}
\hline SECTOR & $\begin{array}{l}\text { DI STILLATE } \\
\text { OIL }\end{array}$ & $\begin{array}{l}\text { BESIDOAL } \\
\text { OIL }\end{array}$ & $\begin{array}{l}\text { GASOLINE } \\
\quad \text { iALL O }\end{array}$ & $\begin{array}{c}\text { OTHER } \\
\text { HYDRO- } \\
\text { CARBONS } \\
\text { TS IN } 10 * \$ 9\end{array}$ & $\begin{array}{c}\text { CRODE } \\
\text { OIL } \\
\text { BTD'S) }\end{array}$ & $\begin{array}{l}\text { NATURAL } \\
\text { GAS }\end{array}$ & $\operatorname{COAL}$ & ELECTRICITY & $\begin{array}{r}\text { SECTOR } \\
\text { TOTAL }\end{array}$ & \\
\hline $\begin{array}{l}\text { PINAL DEMAND SECTORS } \\
\text { BESTDENTIAL, CCHA. } \\
\text { IND OSTRIAL } \\
\text { TRABSPORTATION } \\
\text { MISCELLANEOOS OSZS }\end{array}$ & $\begin{array}{r}28,207 \\
17,269 \\
26,765 \\
1,697\end{array}$ & $\begin{array}{r}1, .178 \\
33,540 \\
16,227 \\
968\end{array}$ & 227,626 & $\begin{array}{r}26,755 \\
62,076 \\
6,465 \\
-\quad 126\end{array}$ & $\begin{array}{l}- \\
- \\
-\end{array}$ & $\begin{array}{r}28,183 \\
102,862 \\
1,295 \\
2,831\end{array}$ & $\begin{array}{r}683 \\
57.273 \\
- \\
6\end{array}$ & $\begin{array}{r}88,193 \\
110,430 \\
1,370\end{array}$ & $\begin{array}{r}173,199 \\
383,450 \\
278,378 \\
6,998\end{array}$ & $\begin{array}{r}17 \% \\
37 \% \\
27 \% \\
1 \%\end{array}$ \\
\hline $\begin{array}{l}\text { TOTAL FINAL } \\
\text { DEMAND SECTORS }\end{array}$ & 73,938 & $51, .913$ & 227,626 & 95,422 & - & 135,171 & 57,962 & 199,993 & 842,025 & $81 \%$ \\
\hline $\begin{array}{l}\text { TRANSP ORMATICN } \\
\text { EL ECTRICITY GEN. } \\
\text { PETR OLEOB FRODOCTS } \\
\text { NATURA GAS } \\
\text { SYNTHETICS }\end{array}$ & $\begin{array}{r}40,916 \\
= \\
=\end{array}$ & $\begin{array}{r}30,6.32 \\
= \\
-\end{array}$ & $\overline{-}$ & $\begin{array}{l}- \\
\overline{-}\end{array}$ & I & $\begin{array}{r}13 \\
- \\
- \\
-\end{array}$ & $\begin{array}{r}209,986 \\
- \\
-\end{array}$ & $\begin{array}{r}-97,128 \\
- \\
-\end{array}$ & $\begin{array}{r}184,419 \\
- \\
-\end{array}$ & $18 \%$ \\
\hline $\begin{array}{l}\text { NET POEL OSED } \\
\text { IN TRANSPORHATION }\end{array}$ & 40,916 & $30, \in 32$ & - & - & 1 & 13 & 209,986 & $-97,128$ & 184,419 & $18 \%$ \\
\hline $\begin{array}{l}\text { TOTAL GROSS FLORS } \\
\text { IOSSES E OHISSIONS }\end{array}$ & $\begin{array}{r}114,854 \\
6.640\end{array}$ & $\begin{array}{r}82,545 \\
1\end{array}$ & $\begin{array}{r}227,626 \\
-0\end{array}$ & $\begin{array}{l}95,422 \\
-3,988\end{array}$ & - & $\begin{array}{r}135,184 \\
-4,896\end{array}$ & $\begin{array}{r}267,948 \\
-590\end{array}$ & $\begin{array}{r}199,993 \\
20,001\end{array}$ & $\begin{array}{r}1,026,444 \\
17,166\end{array}$ & $\begin{array}{r}98 \% \\
2 \%\end{array}$ \\
\hline
\end{tabular}

\begin{tabular}{|c|c|c|c|c|c|c|c|c|c|c|}
\hline SUPPLY OP ENERGY & & & & & & & & & & \\
\hline POSS IL POBL & - & - & - & - & - & - & - & - & - & \\
\hline RY DR ORLECTRIC & - & - & - & - & - & - & - & 15,731 & 15,731 & $16 \%$ \\
\hline SOCL EAR & - & - & - & - & - & - & - & 81,515 & 81,515 & $84 \%$ \\
\hline GEO. ESOL AR & - & - & - & - & - & - & - & - & - $\quad-$ & \\
\hline TOTAL SOPPLY & - & - & - & - & - & - & - & 97,246 & 97,246 & \\
\hline
\end{tabular}

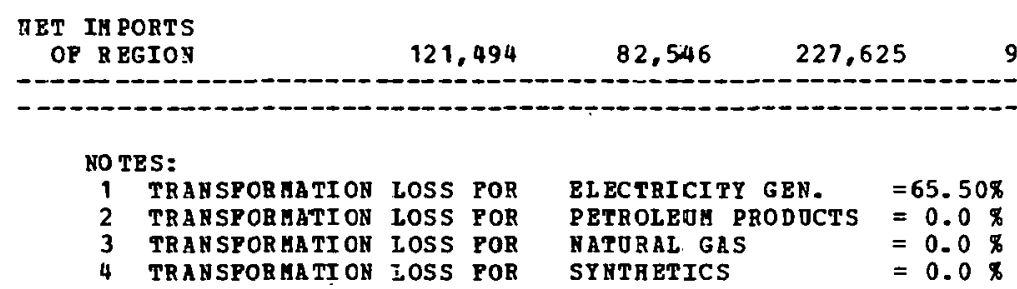


REg LONAL ETEEGY BALANCE STATEHzNT

FIES MID MID SCENARIO

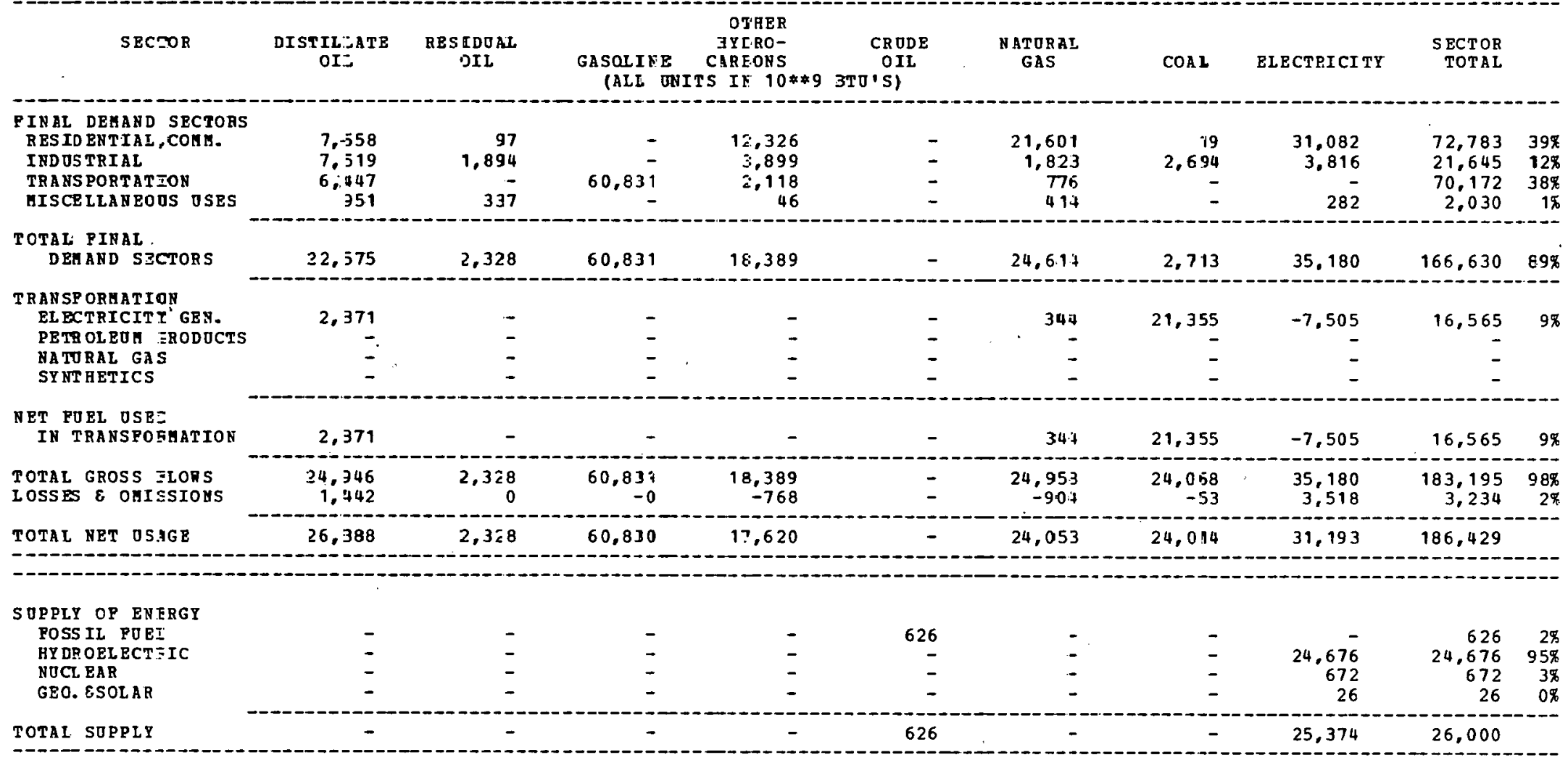

\section{NET IM PORTS}

OP R RGION

26,388

$2,3 \div 8$

60,830

17,620

$-626$

24, C 5.3

24,014

5,819

160,429

NO TES:

TRANSPORAATION LOSS PCR TRAN SPORTATION LOSS POR

TRANSPORMATI ON LOSS POR NATJRAL GAS
TRANSPORMATION LOSS POR SYNTHETES

EL ECTRICITY GEN.

$=E 8.82 \pi$ 
REGIONAL ENERGY BALANCE STATEMENT

PIES MID AID SCENARID

\begin{tabular}{|c|c|c|c|c|c|c|c|c|c|c|}
\hline SECTOR & $\begin{array}{l}\text { DISTILLATE } \\
\text { OIL }\end{array}$ & $\begin{array}{l}\text { RES IDUAL } \\
\text { OIL }\end{array}$ & GASOLIN & $\begin{array}{c}\text { OTHER } \\
\text { HYDRO- } \\
\text { CARBONS } \\
\text { ITS IN } 10 * 9\end{array}$ & $\begin{array}{c}\text { CRODE } \\
\text { OIL } \\
\text { BTO'S) }\end{array}$ & $\begin{array}{l}\text { NATURAL } \\
\text { GAS }\end{array}$ & $\operatorname{COAL}$ & ELECTRICITY & $\begin{array}{r}\text { SECTOR } \\
\text { TOTAL }\end{array}$ & \\
\hline $\begin{array}{l}\text { INAL DEMAN S SECTORS } \\
\text { RESID ENTIAL, CCHA. } \\
\text { IND OSTRIAL } \\
\text { TRANS PORTATION } \\
\text { MISCELLANEOUS OSES }\end{array}$ & $\begin{array}{r}14,745 \\
6,114 \\
75,596 \\
2,116\end{array}$ & $\begin{array}{r}1.468 \\
9.506 \\
1.205\end{array}$ & $327,49 \overline{-}$ & $\begin{array}{r}36,166 \\
89,454 \\
32,127 \\
115\end{array}$ & $\begin{array}{l}- \\
-\end{array}$ & $\begin{array}{r}65,777 \\
143,583 \\
2,114 \\
3,066\end{array}$ & $\begin{array}{r}1,385 \\
92,388 \\
1 \\
6\end{array}$ & $\begin{array}{r}170,558 \\
176,633 \\
1,029\end{array}$ & $\begin{array}{r}290,099 \\
517,678 \\
437,331 \\
7,537\end{array}$ & $\begin{array}{r}17 \% \\
31 \% \\
26 \% \\
0 \%\end{array}$ \\
\hline $\begin{array}{l}\text { TOTAL FINAL } \\
\text { DEMAND SBCTORS }\end{array}$ & 98,571 & 12,179 & 327,493 & 157,862 & - & 214,540 & 93,780 & 348,220 & $1,252.645$ & $75 \%$ \\
\hline $\begin{array}{l}\text { TRANSPORMATICN } \\
\text { ELECTRICIT Y GE :. } \\
\text { PETROLEJA FRODICTS } \\
\text { NATORAL GAS } \\
\text { SY NTHETICS }\end{array}$ & $\begin{array}{r}56,049 \\
-22,995 \\
-\end{array}$ & $\begin{array}{r}-9,840 \\
- \\
-\end{array}$ & $\begin{array}{r}-42,55 \overline{-} \\
-\end{array}$ & $\begin{array}{r}-19,753 \\
-\end{array}$ & $\begin{array}{r}91,305 \\
- \\
-\end{array}$ & $\begin{array}{r}6,189 \\
4,602 \\
- \\
-\end{array}$ & $\begin{array}{r}535,813 \\
\square \\
-\end{array}$ & $\begin{array}{r}-205,774 \\
- \\
-\end{array}$ & $\begin{array}{r}392,277 \\
764 \\
- \\
-\end{array}$ & $\begin{array}{r}23 \% \\
0 \%\end{array}$ \\
\hline $\begin{array}{l}\text { VET FORL DSED } \\
\text { IN TRANSPORHATION }\end{array}$ & 33,054 & $-9,340$ & $-42,555$ & $-19,753$ & 91,305 & 10,791 & 535,813 & $-205,774$ & 393,041 & $23 \%$ \\
\hline $\begin{array}{l}\text { TOTAL GROSS FLOHS } \\
\text { LCSSES } \varepsilon \text { OMISSIONS }\end{array}$ & $\begin{array}{r}154,620 \\
8,939\end{array}$ & $\begin{array}{r}12,179 \\
0\end{array}$ & $\begin{array}{r}327,493 \\
-1\end{array}$ & $\begin{array}{r}157,862 \\
-6,598\end{array}$ & $\begin{array}{r}91,305 \\
4,558\end{array}$ & $\begin{array}{r}225,331 \\
-8,162\end{array}$ & $\begin{array}{r}629,593 \\
-1,386\end{array}$ & $\begin{array}{r}348,220 \\
34,825\end{array}$ & $\begin{array}{r}1,645,686 \\
32,174\end{array}$ & $\begin{array}{r}98 \% \\
2 \%\end{array}$ \\
\hline IOTAL NET USAGE & 140,564 & 2,338 & 284,936 & 131,510 & 95,863 & 217,169 & 628,206 & 177,271 & $1,677,860$ & \\
\hline
\end{tabular}

\begin{tabular}{|c|c|c|c|c|c|c|c|c|c|c|}
\hline S OPPLY OP ENERGY & & & & & & & & & & \\
\hline POSS IL · POEL & - & - & - & - & 715 & - & 147,483 & - & 148,198 & 45\% \\
\hline HY DR OELECT RIC & - & - & - & - & - & - & - & 30,870 & 30,870 & \\
\hline NOCL EAR & - & - & - & - & - & - & - & 152,393 & 152,393 & $46 \%$ \\
\hline GE 0.\&SOL AR & - & - & - & - & - & - & - & - & 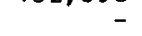 & \\
\hline TOTAL SOPPLY & - & - & - & - & 715 & - & 147,483 & 183,263 & 331,461 & \\
\hline
\end{tabular}

\begin{tabular}{l}
$\begin{array}{l}\text { NET IM PORTS } \\
\text { OP R RGICN }\end{array}$ \\
\hline
\end{tabular}


REGIOTAL ENERGT BALANCR STATEHENT

IOTAL ENERG BALANCR STAR
PIES AID MID SCENARIO

\begin{tabular}{|c|c|c|c|c|c|c|c|c|c|c|}
\hline SBCTOR & $\begin{array}{c}\text { DISTILLATE } \\
\text { OIL }\end{array}$ & $\begin{array}{l}\text { BESIDUAL } \\
\text { OIL }\end{array}$ & $\begin{array}{l}\text { GASOLLN } \\
\text { (ALL JV }\end{array}$ & $\begin{array}{c}\text { OTHER } \\
\text { HYDRO- } \\
\text { CARBONS } \\
\text { NITS IN } 10 * 9\end{array}$ & $\begin{array}{c}\text { CEUDE } \\
\text { CIL } \\
\text { BTO'S) }\end{array}$ & $\begin{array}{l}\text { YATUR:L } \\
\text { GAS }\end{array}$ & $\cos \mathrm{L}$ & ELECTRICITY & $\begin{array}{l}\text { SECTOR } \\
\text { TOTAL }\end{array}$ & \\
\hline $\begin{array}{l}\text { PINAL DEHANE SFCTORS } \\
\text { RES ID ENTIAL, COHM. } \\
\text { IND OSTRIAL } \\
\text { TRANSPORTATION } \\
\text { MISCELLANEOOS OSES }\end{array}$ & $\begin{array}{r}73.557 \\
66.328 \\
243.237 \\
24.837\end{array}$ & $\begin{array}{r}17,924 \\
200,461 \\
144,5.15 \\
23,063\end{array}$ & $1,124,57 \overline{-}$ & $\begin{array}{r}1 \in 1,492 \\
2,2 E 5,415 \\
1 \leq 0,657 \\
587\end{array}$ & $\begin{array}{l}\overline{-} \\
\overline{-}\end{array}$ & $\begin{array}{r}468,526 \\
3,637,554 \\
48,720 \\
13,354\end{array}$ & $\begin{array}{r}- \\
78,270 \\
2 \\
-\end{array}$ & $\begin{array}{r}380,393 \\
326,881 \\
- \\
5,418\end{array}$ & $\begin{array}{r}1,101,992 \\
6,594,909 \\
1,751,702 \\
67,269\end{array}$ & $\begin{array}{l}10 \% \\
59 \% \\
16 \% \\
1 \%\end{array}$ \\
\hline $\begin{array}{l}\text { TOTAL PINAL } \\
\text { DEMAND SECTOBS }\end{array}$ & 07.959 & 585,963 & $1,124,5.71$ & $2,6 \equiv 8,151$ & - & $4,168,254$ & 78,272 & 712,692 & $9,515,872$ & $85 \pi$ \\
\hline $\begin{array}{l}\text { TR ANSPORMATION } \\
\text { EL BCTRICITY GEN. } \\
\text { PETR OL EOH ERODOCTS } \\
\text { NATORAL GRS } \\
\text { SY NTEETICS }\end{array}$ & $\begin{array}{r}66.359 \\
-2, .272 .384 \\
- \\
-\end{array}$ & $\begin{array}{r}-228,569 \\
-\end{array}$ & $\begin{array}{r}-3,827,8 \equiv \overline{-} \\
-\end{array}$ & $\begin{array}{r}-3,5 \mathrm{c} 8,26 \overline{9} \\
-\end{array}$ & $9,229,115$ & $\begin{array}{r}1,096,110 \\
787,336 \\
- \\
-\end{array}$ & $\begin{array}{r}884,266 \\
- \\
-\end{array}$ & $\begin{array}{r}-674,531 \\
- \\
-\end{array}$ & $\begin{array}{r}1,372,204 \\
89,361 \\
- \\
-\end{array}$ & $\begin{array}{r}12 \% \\
1.8\end{array}$ \\
\hline $\begin{array}{l}\text { NET POEL OSED } \\
\text { IN TRANSPORMATION }\end{array}$ & $-2,206,025$ & $-228,569$ & $-3,827,858$ & $-3.598,269$ & $9,229,115$ & $1,883,416$ & 884,266 & $-674,531$ & $1,461,565$ & $13 \%$ \\
\hline $\begin{array}{l}\text { TOTAL GROSS PLORS } \\
\text { LOSSES \& OMISSIONS }\end{array}$ & $\begin{array}{r}+74,318 \\
27,422\end{array}$ & $\begin{array}{r}335,563 \\
8\end{array}$ & $\begin{array}{r}1,124,5: 1 \\
-3\end{array}$ & $\begin{array}{r}2,638,151 \\
-110,279\end{array}$ & $\begin{array}{r}9,229,115 \\
460,733\end{array}$ & $\begin{array}{r}6,051,680 \\
-219,210\end{array}$ & $\begin{array}{r}962,538 \\
-2,120\end{array}$ & $\begin{array}{r}712,692 \\
71,276\end{array}$ & $\begin{array}{r}10,977,437 \\
227,827\end{array}$ & $\begin{aligned} 98 \% \\
2 \%\end{aligned}$ \\
\hline $\begin{array}{l}\text { S OPPLY OP EYERGI } \\
\text { FOSS IL POEL } \\
\text { HY DR OELECTRIC } \\
\text { NOCL EAR } \\
\text { GEO. ESOLAE }\end{array}$ & $\begin{array}{l}\bar{z} \\
\overline{-}\end{array}$ & $\begin{array}{l}- \\
- \\
-\end{array}$ & $\begin{array}{l}\overline{-} \\
\overline{-}\end{array}$ & $\begin{array}{l}- \\
\overline{-} \\
-\end{array}$ & $\begin{array}{r}6,193,243 \\
= \\
-\end{array}$ & $\begin{array}{r}4,358,126 \\
= \\
-\end{array}$ & $\begin{array}{r}647,700 \\
- \\
-\end{array}$ & $\begin{array}{r}6,925 \\
53,389 \\
185\end{array}$ & $\begin{array}{r}11,199,069 \\
6,925 \\
58,389 \\
185\end{array}$ & $\begin{array}{r}99 \% \\
0 \% \\
1 \% \\
0 \%\end{array}$ \\
\hline TOTEL SUPPLI & - & - & - & - & $6,193,24 \Xi$ & $4,358,126$ & 647,700 & 65,499 & 11,$264 ; 568$ & \\
\hline
\end{tabular}

NET IM PORTS

$157,402 \quad-2,703,270 \quad-1,070,397$

$3,495,60 \epsilon \quad 1,474, \equiv 44$

312,717

43,938

$-59,303$

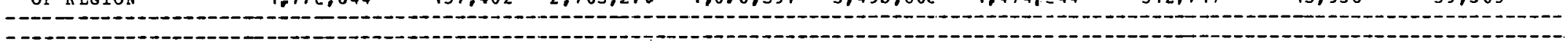

NOTES:

\begin{tabular}{|c|c|c|c|c|}
\hline & & & & \\
\hline TRAR SPOR MATI OK & coss & FOR & PETROLZOM PRODOCTS & $=0.89 \%$ \\
\hline TRAR SPOR SA TI ON & coss & FOR & NATOBA" GAS & \\
\hline TRAB SFOR HAT & coss & FOR & SYOTHECICS & 0.0 \\
\hline
\end{tabular}


REGIONAL ENERGY BALANCE STATEMBNT
PIES MID MID SCENARIO

\begin{tabular}{|c|c|c|c|c|c|c|c|c|c|c|}
\hline SECTOE: & $\begin{array}{l}\text { DISTILLATE } \\
\text { OIL }\end{array}$ & $\begin{array}{l}\text { RESIDUAL } \\
\text { OIL }\end{array}$ & $\begin{array}{l}\text { GASOLINE } \\
\text { (ALL O }\end{array}$ & $\begin{array}{l}\text { OTHER } \\
\text { HYDRO- } \\
\text { CARBONS } \\
\text { S IN } 10 * \$ 9\end{array}$ & $\begin{array}{c}\text { CRODE } \\
\text { OIL } \\
\text { BTO'S) }\end{array}$ & $\begin{array}{l}\text { NATURAL } \\
\text { GAS }\end{array}$ & COA L & ELECTRICITY & $\begin{array}{r}\text { SECTOR } \\
\text { TOTAL }\end{array}$ & \\
\hline $\begin{array}{l}\text { PINAL DEMAND SFCTORS } \\
\text { RESID ENTIAL, CCMM. } \\
\text { IND USTRIAL } \\
\text { TRANSPORTATION } \\
\text { MISCELLANEOOS OSES }\end{array}$ & $\begin{array}{r}15,870 \\
22,091 \\
20,846 \\
5,039\end{array}$ & $\begin{array}{r}3,829 \\
27,471 \\
59 \\
1,788\end{array}$ & $\begin{array}{r}- \\
- \\
116,326\end{array}$ & $\begin{array}{r}25,349 \\
49,390 \\
9,817 \\
210\end{array}$ & $\begin{array}{l}\bar{z} \\
\overline{-} \\
\overline{-}\end{array}$ & $\begin{array}{r}84,383 \\
31,483 \\
997 \\
1,761\end{array}$ & $\begin{array}{r}91 \\
96,125 \\
2 \\
1\end{array}$ & $\begin{array}{r}37,135 \\
11,514 \\
- \\
1,333\end{array}$ & $\begin{array}{r}166,657 \\
238,074 \\
148,047 \\
10,132\end{array}$ & $\begin{array}{r}27 \% \\
39 \% \\
24 \pi \\
2 \%\end{array}$ \\
\hline $\begin{array}{l}\text { TOTAL PINAL } \\
\text { DEMAUD SECTORS }\end{array}$ & $\in 3,846$ & 33,147 & 116,326 & 84,766 & - & 118,624 & 96,219 & 49,982 & 562,910 & $92 \%$ \\
\hline $\begin{array}{l}\text { TRANSPORMATION } \\
\text { EL ECTRICITY GEN. } \\
\text { PETR OLEOM FRODOCTS } \\
\text { NATORAL GAS } \\
\text { SYNTHETICS }\end{array}$ & $\begin{array}{r}1.826 \\
-96.463 \\
- \\
-\end{array}$ & $\begin{array}{r}-29,14 \overline{5} \\
- \\
-\end{array}$ & $\begin{array}{r}-152,909 \\
-\end{array}$ & $\begin{array}{r}-65,230 \\
- \\
-\end{array}$ & $\begin{array}{r}327,64 \overline{3} \\
-50,000\end{array}$ & $\begin{array}{r}487 \\
20,471 \\
- \\
-\end{array}$ & $\begin{array}{r}112,408 \\
- \\
-\end{array}$ & $\begin{array}{r}-35,770 \\
- \\
-\end{array}$ & $\begin{array}{r}78,951 \\
4.367 \\
- \\
-50,000\end{array}$ & $\begin{array}{r}13 \% \\
-1 \% \\
-7 \%\end{array}$ \\
\hline $\begin{array}{l}\text { NET FOEL USED } \\
\text { IN TRANSPORMATION }\end{array}$ & $-94,6337$ & $-29,145$ & $-152,909$ & $-65,230$ & 277,643 & 20,958 & 112,408 & $-35,770$ & 33,318 & $5 \%$ \\
\hline $\begin{array}{l}\text { TOTAL GHOSS FLOAS } \\
\text { LOSSES } \varepsilon \text { OIISSIONS }\end{array}$ & $\begin{array}{r}65,672 \\
3,796\end{array}$ & $\begin{array}{r}33,147 \\
0\end{array}$ & $\begin{array}{r}116,326 \\
-0\end{array}$ & $\begin{array}{l}84,766 \\
-3,543\end{array}$ & $\begin{array}{r}327,643 \\
16,356\end{array}$ & $\begin{array}{r}139,582 \\
-5,056\end{array}$ & $\begin{array}{r}208,627 \\
-459\end{array}$ & $\begin{array}{r}49,982 \\
4,998\end{array}$ & $\begin{array}{r}646,228 \\
16,093\end{array}$ & $\begin{array}{r}106 \% \\
3 \%\end{array}$ \\
\hline
\end{tabular}

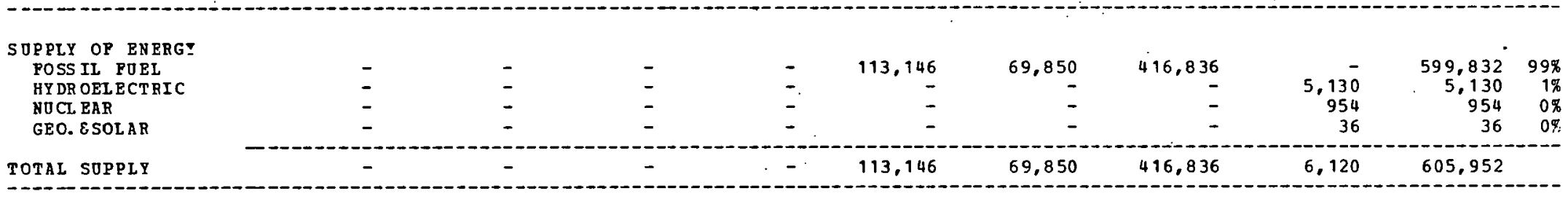

\begin{tabular}{|c|c|c|c|c|c|c|c|c|c|}
\hline $\begin{array}{r}\text { NET IM PORTS } \\
\text { OF REGION }\end{array}$ & $-26,994$ & 4,002 & -36.583 & 15,992 & 180,853 & 64,676 & $-208,668$ & 13,090 & 6,370 \\
\hline
\end{tabular}

\section{No TES: \\ TBANSPOBMATION LOSS FOR

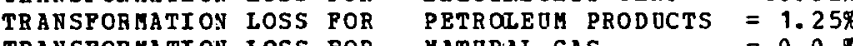 \\ TRANAPRATI}


REGIONAL ENERGY BALANCE STATEMENT

?IES YID MID SCENARIO

\begin{tabular}{|c|c|c|c|c|c|c|c|c|c|}
\hline SEZTOR & $\begin{array}{l}\text { LESTZLLATE } \\
\text { OIL }\end{array}$ & $\begin{array}{l}\text { FESIDOAL } \\
\text { OII }\end{array}$ & $\begin{array}{l}\text { GASCLINE } \\
\quad(\text { ILI UNI }\end{array}$ & $\begin{array}{c}\text { OTHER } \\
\text { HYDRO- } \\
\text { CARBONS } \\
5 \text { IN } 10 * 9\end{array}$ & $\begin{array}{c}\text { CRODE } \\
\text { OIL } \\
\text { BTO'SI }\end{array}$ & $\begin{array}{l}\text { NATJRAL } \\
\text { GAS }\end{array}$ & CCAL & ELECTRICITY & $\begin{array}{l}\text { SECTOF } \\
\text { TOTAI }\end{array}$ \\
\hline $\begin{array}{l}\text { PINAL DEMALD SECTORS } \\
\text { RESIDENTIAL, COMM. } \\
\text { IND OS TRIAL } \\
\text { TRANSPORTATION } \\
\text { MISCELLAEOOS OSES }\end{array}$ & $\begin{array}{r}22,247 \\
626 \\
3,101 \\
283\end{array}$ & $\begin{array}{r}242 \\
6,561 \\
- \\
210\end{array}$ & 37.875 & $\begin{array}{r}4,934 \\
1,494 \\
759 \\
6\end{array}$ & - & $\begin{array}{r}2,38 \epsilon \\
6.222 \\
35 \epsilon \\
634\end{array}$ & $\begin{array}{r}4 \\
28 \\
- \\
-\end{array}$ & $\begin{array}{r}9,156 \\
5,126 \\
- \\
120\end{array}$ & $\begin{array}{r}38,965 \\
20,05: \\
42,05 \\
1,25 \vdots\end{array}$ \\
\hline $\begin{array}{l}\text { TCTAL FINAL } \\
\text { DEMAND SECTORS }\end{array}$ & 25,257 & 7,013 & 37,875 & 7,193 & - & $9,59 \varepsilon$ & 32 & 14,402 & $102,37 c$ \\
\hline $\begin{array}{l}\text { TRANSF ORMA } I O N \\
\text { ELECTRIC:TY GEN. } \\
\text { PETROLEOA FRODUCTS } \\
\text { NATURAL GAS } \\
\text { SYNTHETICS }\end{array}$ & $\begin{array}{r}2,708 \\
- \\
-\end{array}$ & $\begin{array}{l}- \\
\overline{-}\end{array}$ & $\begin{array}{l}\overline{-} \\
\overline{-}\end{array}$ & $\begin{array}{l}\overline{-} \\
\overline{-}\end{array}$ & $\begin{array}{l}- \\
- \\
-\end{array}$ & $\begin{array}{l}- \\
-\end{array}$ & $\begin{array}{r}10.112 \\
- \\
- \\
-\end{array}$ & $\begin{array}{r}-4,604 \\
- \\
- \\
-\end{array}$ & $\begin{array}{r}8,216 \\
= \\
-\end{array}$ \\
\hline $\begin{array}{l}\text { NET FOEL JEED } \\
\text { IN TRANSIORMATION }\end{array}$ & 2,708 & - & - & - & - & - & 10,112 & $-4,604$ & 8,216 \\
\hline $\begin{array}{l}\text { TCTAL GROSE FLORS } \\
\text { LOSSES \& OथISSIOHS }\end{array}$ & $\begin{array}{r}23,965 \\
1,674\end{array}$ & $\begin{array}{r}7.013 \\
0\end{array}$ & $\begin{array}{r}37.875 \\
-0\end{array}$ & $\begin{array}{r}7,193 \\
-300\end{array}$ & - & $\begin{array}{r}5,598 \\
-34^{-}\end{array}$ & $\begin{array}{r}10.144 \\
-22\end{array}$ & $\begin{array}{r}14,402 \\
1,44 \mathrm{C}\end{array}$ & $\begin{array}{r}110,585 \\
2,44.4\end{array}$ \\
\hline TOTAL NET FSAGE & 30,639 & 7.013 & 37,874 & 6,892 & - & $\subseteq, 25 n$ & 10,121 & $11,23 \varepsilon$ & 113,034 \\
\hline
\end{tabular}

\begin{tabular}{|c|c|c|c|c|c|c|c|c|c|}
\hline $\begin{array}{l}\text { S UPFLY OF ENERGY } \\
\text { POSS IL PUEI }\end{array}$ & - & - & - & 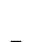 & 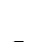 & & 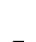 & - & - \\
\hline HY DROELECT RIC & - & - & - & - & - & - & - & 2,323 & 2,323 \\
\hline HOCL EAR & - & - & - & - & - & - & - & 4,155 & 4.155 \\
\hline GEO. \&SOLAR & - & - & - & - & - & - & - & 41 & 41 \\
\hline TOTAL SOPPLY & - & - & - & - & - & - & - & 6,519 & 6,517 \\
\hline
\end{tabular}

NET IM PORTS

$\equiv 0,639$

7,013

$37,8 ? 4$

6,892

9,253

10., 121

4,719

106,511

-

No TES :

THANSFORMATION LOSS POR TRQNSFORMATION LOSS FOR TFANSPORMATION LOSS POR 
REGIONAL ENERGY BALANCE STATEMENT

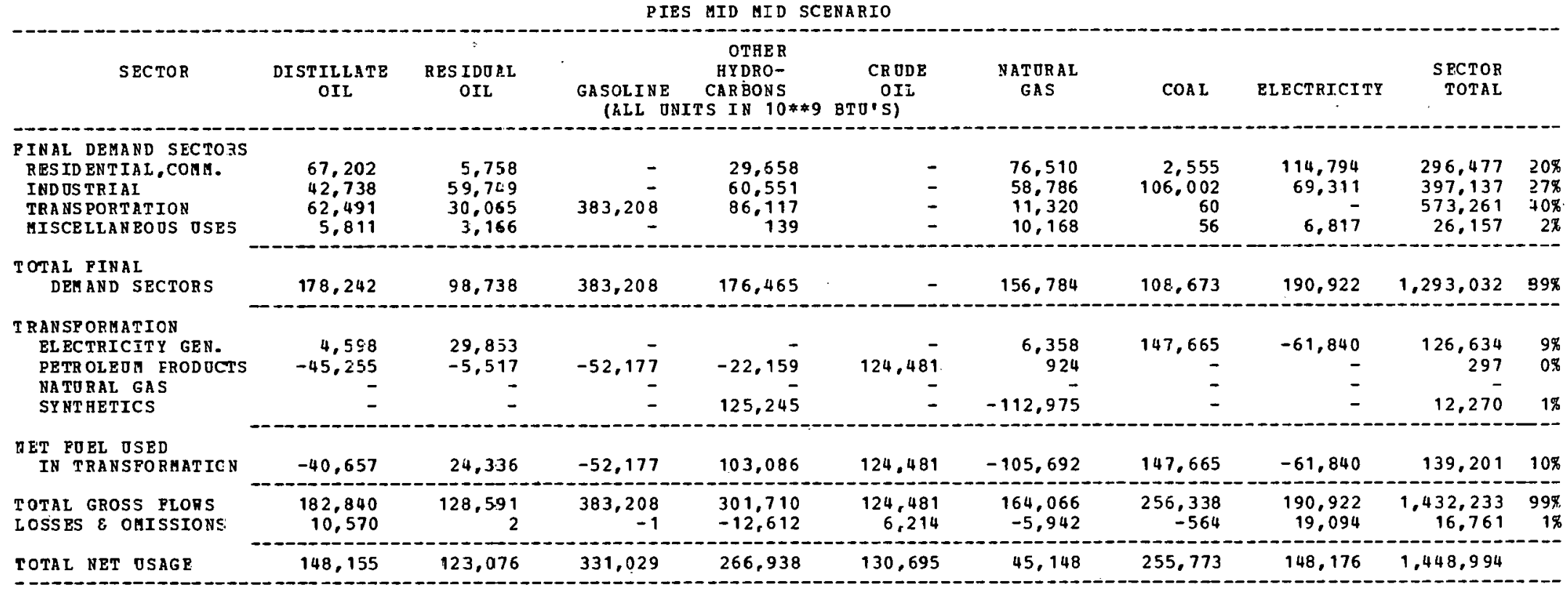

-

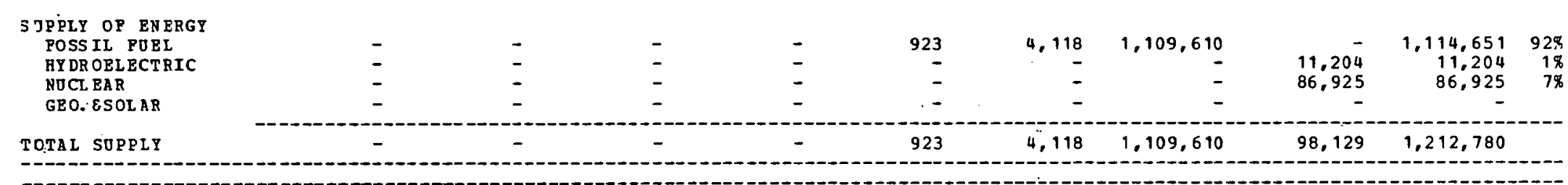

\begin{tabular}{|c|c|c|c|c|c|c|c|c|c|}
\hline $\begin{array}{l}\text { NET IM PORTS } \\
\text { OP R BGION }\end{array}$ & 148,155 & 123,076 & 331,029 & 266,938 & 129.772 & 41,030 & $-853,836$ & 50,047 & 236.214 \\
\hline
\end{tabular}

\footnotetext{
No TES :

TRANSFORAATION LOSS FOR TRANSPORMATI ON LOSS POB

BLECTRLCITY GEN.

GEN. $\quad=67.198$

PETROLEOM PBODOCTS $=0.24 \%$

NATURAL GAS

$=0.24 \%$
$=0.0 \%$
$=9.80 \%$
} 
R3GICNAL ENE RGY BALANCE STATEMENT

FIES III HID.SCENARIO

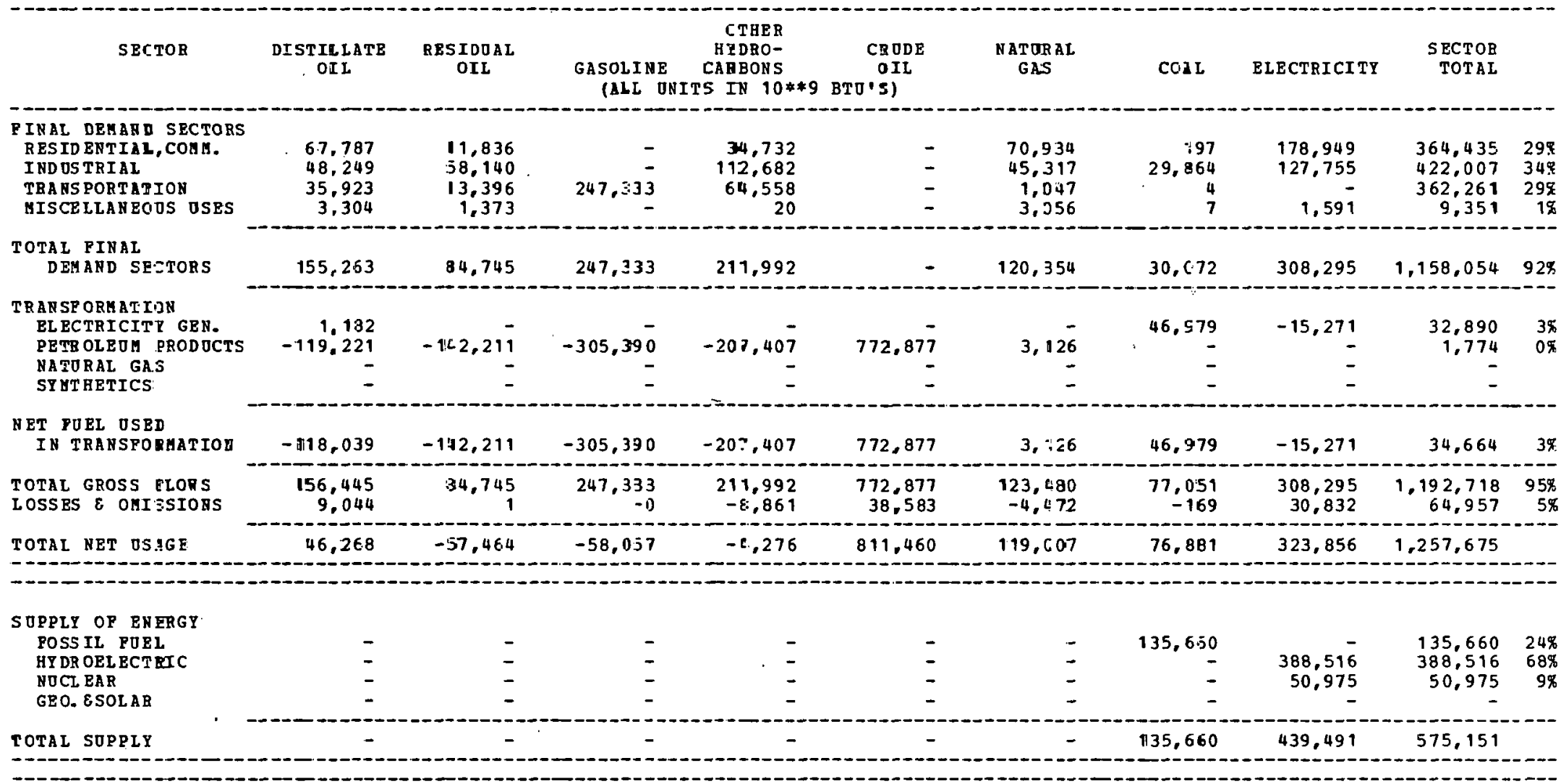

\section{NET IM PORTS}

OP B EGION

$46,268 \quad-57.464$

$-58,057$

$-4,276$

811.460

$119,0.07$

$-58,7 ; 8$

$-115,634$

682,524

\section{NOTES:}

TRANSFORMATION LO:SS EOB TRANSPORMATI ON LOSS EOB

TRANSTORMATI ON LOSS POB

TLECJRICETY G $3 N$.

TRANSFORHATI ON LOSS FOR

PETRCLEUA PROJUCTS $=0.23$

TATUKAL GAS

$=0.0 \%$
$=0.0$ 
REGIONAL ENERG BALANCE STATEMENT

PIES MID MID SCENARIO

\begin{tabular}{|c|c|c|c|c|c|c|c|c|c|c|}
\hline SECTOR & $\begin{array}{l}\text { DISTILLATE } \\
\text { Or }{ }^{-}\end{array}$ & $\begin{array}{l}\text { RESIDVAL } \\
\text { OIL }\end{array}$ & $\begin{array}{l}\text { GASOLINE } \\
\text { (ALL ONIT }\end{array}$ & $\begin{array}{l}\text { OTHER } \\
\text { HYDRO- } \\
\text { CARBONS } \\
\text { IS IN } 10 * \$ 9\end{array}$ & $\begin{array}{c}\text { CR ODE } \\
\text { OIL } \\
\text { BTU'S) }\end{array}$ & $\begin{array}{l}\text { NATURAL } \\
\text { GAS }\end{array}$ & $\operatorname{COAL}$ & ELECTRICITY & $\begin{array}{r}\text { SECTOR } \\
\text { TOTAL }\end{array}$ & \\
\hline $\begin{array}{l}\text { PINAL DEHAND SECEORS } \\
\text { RESIDENTIAL, CONA. } \\
\text { IND OSTRIAL } \\
\text { TRANS PORTATION } \\
\text { MISCEILANEOOS OSES }\end{array}$ & $\begin{array}{r}8,678 \\
9,777 \\
32,599 \\
730\end{array}$ & $\begin{array}{r}1,796 \\
6.126 \\
- \\
397\end{array}$ & $107,75 \frac{-}{-}$ & $\begin{array}{r}8,572 \\
26,644 \\
1,401 \\
15\end{array}$ & $\begin{array}{l}- \\
\overline{-}\end{array}$ & $\begin{array}{r}71,395 \\
67,785 \\
2,468 \\
1,229\end{array}$ & $\begin{array}{r}1,475 \\
179,621 \\
39 \\
4\end{array}$ & $\begin{array}{r}32,386 \\
94,736 \\
= \\
408\end{array}$ & $\begin{array}{r}124.302 \\
384,689 \\
144.263 \\
2.783\end{array}$ & $\begin{array}{r}11 \% \\
34 \% \\
13 \% \\
0 \%\end{array}$ \\
\hline $\begin{array}{l}\text { TOTAL FINAL } \\
\text { DEMAND SECTORS }\end{array}$ & 51,784 & 8,317 & 107,756 & 36,632 & - & 142,877 & 181,139 & 127,530 & 656,037 & $58 \%$ \\
\hline $\begin{array}{l}\text { TRANSPORHATION } \\
\text { ELECTRICITY.GEN. } \\
\text { PETR OLEOM FRODJCTS } \\
\text { NATORAL GAS } \\
\text { SYNT HETICS }\end{array}$ & $\begin{array}{r}114 \\
-16.607 \\
-\end{array}$ & $\begin{array}{r}630 \\
-2.024 \\
- \\
-\end{array}$ & $\begin{array}{r}-19,147 \\
-\end{array}$ & $\begin{array}{r}-8.132 \\
- \\
-\end{array}$ & $\begin{array}{r}45.682 \\
-\end{array}$ & $\begin{array}{r}4,246 \\
339 \\
- \\
-\end{array}$ & $\begin{array}{r}697,775 \\
- \\
-\end{array}$ & $\begin{array}{r}-236,077 \\
- \\
-\end{array}$ & $\begin{array}{r}466,688 \\
108 \\
- \\
-\end{array}$ & $\begin{array}{r}41 \% \\
0 \%\end{array}$ \\
\hline $\begin{array}{l}\text { NET FOEL OSED } \\
\text { IN TRANSPORMATION }\end{array}$ & $-16,493$ & -1.394 & $-19,147$ & $-8,132$ & 45,682 & 4,585 & 697,775 & -236.077 & 466,796 & $41 \%$ \\
\hline $\begin{array}{l}\text { TOTAL GROSS FLORS } \\
\text { LOSSES } \mathcal{E} \text { OHISSIONS }\end{array}$ & $\begin{array}{r}51,898 \\
3,000\end{array}$ & $\begin{array}{r}8,949 \\
0\end{array}$ & $\begin{array}{r}107,756 \\
-0\end{array}$ & $\begin{array}{r}36,632 \\
-1,531\end{array}$ & $\begin{array}{r}45,682 \\
2,280\end{array}$ & $\begin{array}{r}147,462 \\
-5,341\end{array}$ & $\begin{array}{r}878,914 \\
-1,935\end{array}$ & $\begin{array}{r}127,530 \\
12,754\end{array}$ & $\begin{array}{r}1,122,833 \\
9,226\end{array}$ & $\begin{array}{r}99 \% \\
1 \%\end{array}$ \\
\hline TOTAL NET OSAGE & $3 \varepsilon, 290$ & 6.924 & 88,607 & 26,968 & 47,962 & 142,120 & 876,978 & $-95,792$ & $1,132,059$ & \\
\hline
\end{tabular}

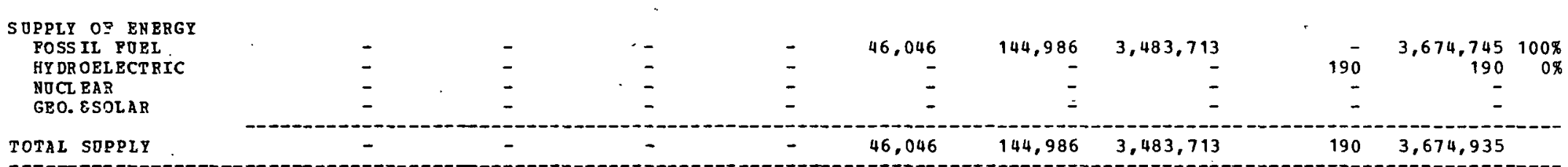

2010

\begin{tabular}{l}
$\begin{array}{l}\text { NET IM PORTS } \\
\text { OP R BGION }\end{array}$ \\
\hline
\end{tabular}


REG:ONAL ENERGY BALANCE STATENENT

PIES IIID MID SCENARIO

\begin{tabular}{|c|c|c|c|c|c|c|c|c|c|c|}
\hline SECTOR & $\begin{array}{l}\text { DI STILLATE } \\
\text { OIL }\end{array}$ & $\begin{array}{l}\text { EESIDOALL } \\
\text { OIL }\end{array}$ & $\begin{array}{l}\text { GASOLINE } \\
\text { CALL D }\end{array}$ & $\begin{array}{c}\text { OTHER } \\
\text { HYDRO- } \\
\text { CARBONS } \\
\text { TS IN } 10 * \% 9\end{array}$ & $\begin{array}{c}\text { CRUDE } \\
\text { OIL } \\
\text { BTU'S) }\end{array}$ & $\begin{array}{l}\text { NaECRAL } \\
\text { GeS }\end{array}$ & $\operatorname{COAL}$ & ELECTRICITY & $\begin{array}{l}\text { SECT OPR } \\
\text { TOTAI }\end{array}$ & \\
\hline $\begin{array}{l}\text { PIVAL DEHAID SECTORS } \\
\text { RESIDENTIAL, COHH. } \\
\text { INDOSTRIAI } \\
\text { TRANSPORTATION } \\
\text { HISCELIAHEOOS OSES }\end{array}$ & $\begin{array}{r}105,184 \\
\equiv 0,256 \\
\equiv 9,962 \\
5.091\end{array}$ & $\begin{array}{r}6,412 \\
20,207 \\
344 \\
2,943\end{array}$ & $333.5 \equiv \overline{4}$ & $\begin{array}{r}61,237 \\
65,688 \\
10,214 \\
124\end{array}$ & $\begin{array}{l}- \\
\overline{-}\end{array}$ & $\begin{array}{r}181,265 \\
45,592 \\
7,512 \\
3,102\end{array}$ & $\begin{array}{r}2,486 \\
207,331 \\
\overline{7}\end{array}$ & $\begin{array}{r}95,089 \\
94,427 \\
- \\
1,019\end{array}$ & $\begin{array}{r}491,673 \\
457,507 \\
391,665 \\
12,285\end{array}$ & $\begin{array}{r}30 \% \\
28 \% \\
24 \% \\
18\end{array}$ \\
\hline $\begin{array}{l}\text { TOTAL FINAL } \\
\text { DEMAND } \text { इECTORS }\end{array}$ & 220,493 & 29,906 & $333,6 \equiv 4$ & 137,263 & - & 237.479 & 203,824 & 190,535 & $1,353,125$ & $84 \%$ \\
\hline $\begin{array}{l}\text { TRANSP ORHATION } \\
\text { EL ECTRICITY GEN. } \\
\text { PETR OLEUH ERODUCTS } \\
\text { NA TURAL GAS } \\
\text { SY NT HETICS }\end{array}$ & $\begin{array}{r}15,096 \\
-23,781 \\
-\end{array}$ & $\begin{array}{r}986 \\
-10,177 \\
-\end{array}$ & $\begin{array}{r}-44,009 \\
- \\
-\end{array}$ & $\begin{array}{r}-20,428 \\
- \\
-\end{array}$ & $\begin{array}{r}34,42 \overline{4} \\
-\end{array}$ & $\begin{array}{r}4,781 \\
4,760 \\
- \\
-\end{array}$ & $\begin{array}{r}354,247 \\
- \\
-\end{array}$ & $\begin{array}{r}-132,760 \\
= \\
-\end{array}$ & $\begin{array}{r}242,35) \\
78-9 \\
- \\
-\end{array}$ & $\begin{array}{r}15 \% \\
0 \%\end{array}$ \\
\hline $\begin{array}{l}\text { NET FOEL USED } \\
\text { IN TRABSFORHATION }\end{array}$ & $-3,685$ & $-9,191$ & $-44,00.9$ & $-20,428$ & 34.424 & 9,541 & 35.1 .247 & $-132,760$ & 243,139 & $15 \%$ \\
\hline $\begin{array}{l}\text { TOTAL GROSS FLORS } \\
\text { LOSSES } \varepsilon \text { OUISSIONS }\end{array}$ & $\begin{array}{r}235,589 \\
13,620\end{array}$ & $\begin{array}{r}30,892 \\
0\end{array}$ & $\begin{array}{r}333,634 \\
-1\end{array}$ & $\begin{array}{r}37,263 \\
-5,737\end{array}$ & $\begin{array}{r}94,424 \\
4,713\end{array}$ & $\begin{array}{r}247,012 \\
-8,947\end{array}$ & $\begin{array}{r}552.071 \\
-1.229\end{array}$ & $\begin{array}{r}190,535 \\
19,055\end{array}$ & $\begin{array}{r}1,596,265 \\
21,474\end{array}$ & $\begin{array}{r}99 \% \\
1 \%\end{array}$ \\
\hline $\begin{array}{l}\text { S OPPLY OP ENERGY } \\
\text { POSS IL PUEL } \\
\text { AY DR OELECTRIC } \\
\text { NUCL EAR } \\
\text { GEO. ESOLA. }\end{array}$ & $\begin{array}{l}\bar{z} \\
\overline{-}\end{array}$ & $\begin{array}{l}\overline{-} \\
\overline{-}\end{array}$ & $\begin{array}{l}- \\
-\end{array}$ & $\begin{array}{l}- \\
\overline{-} \\
-\end{array}$ & $\begin{array}{l}- \\
-\end{array}$ & - & $\begin{array}{l}\overline{-} \\
\overline{-}\end{array}$ & $\begin{array}{r}- \\
4,217 \\
54,588 \\
88\end{array}$ & $\begin{array}{r}4,21 \overline{ } \\
54,5 \varepsilon \varepsilon \\
8 \varepsilon\end{array}$ & $\begin{array}{r}7 \% \\
93 \% \\
0 \%\end{array}$ \\
\hline TOTAL SOPPIT & - & - & - & - & - & - & - & 58,893 & $58,89 \equiv$ & \\
\hline
\end{tabular}

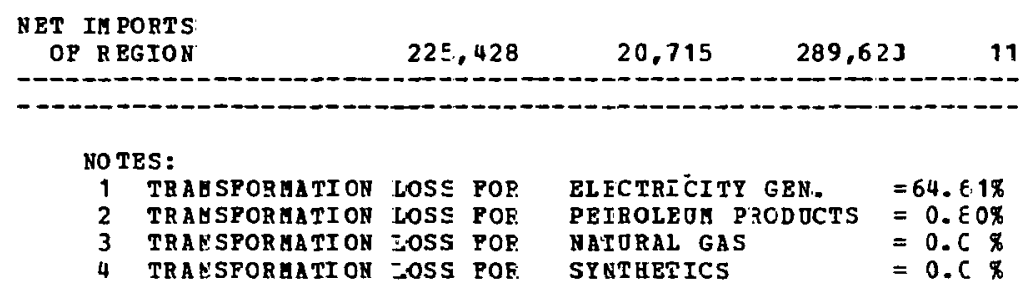


REGIONAL ENERGY BALANCE STATENENT

PIES MID MID SCENARIO

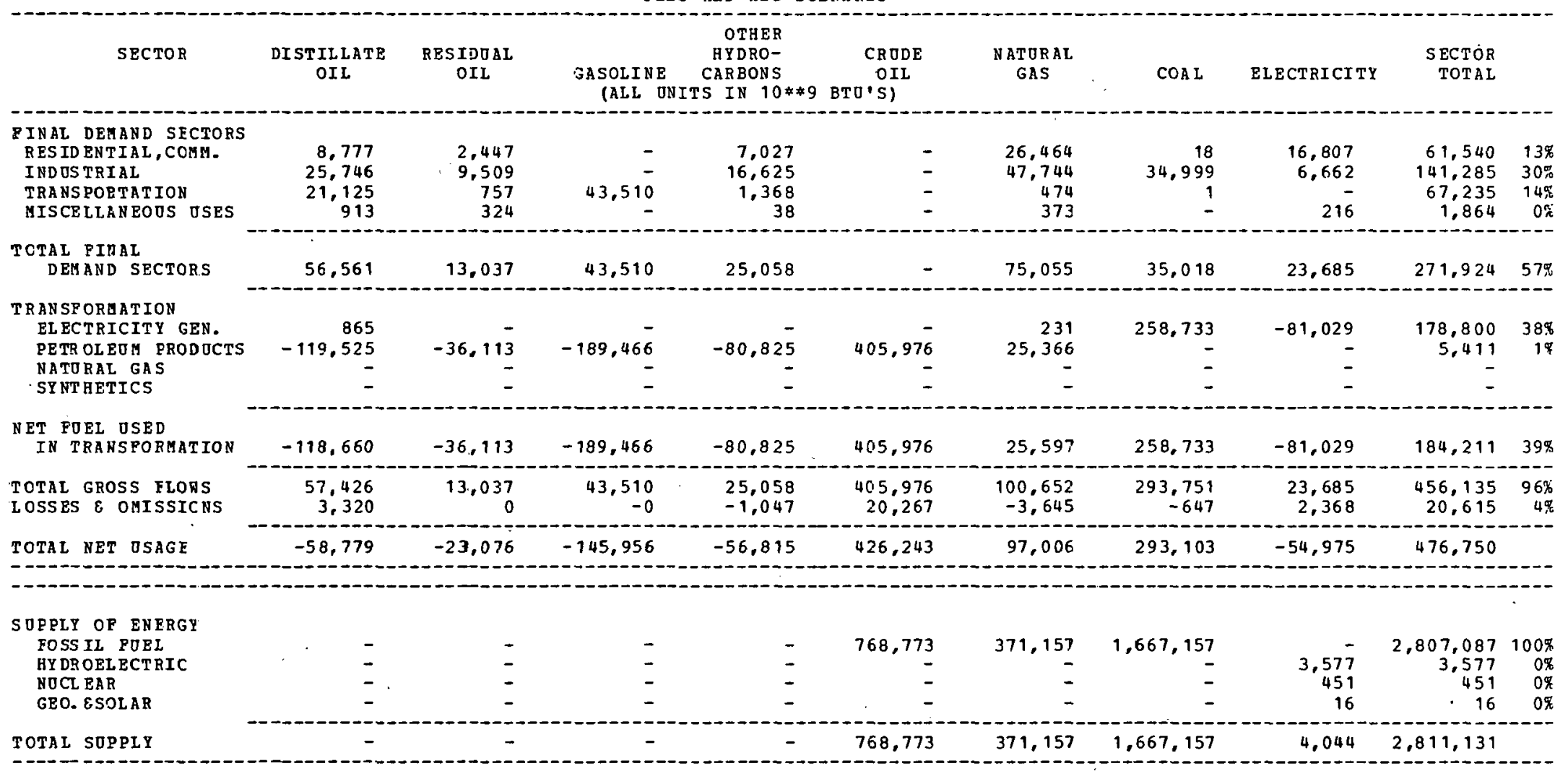

NET IM PORTS

OF REGION

$-58,779$

$-23,076 \quad-145,956$

$-56,815$

$-342,529$

$-274,150-1,374,053$

$-59,019 \quad-2,334,380$

\begin{tabular}{|c|c|c|c|c|c|}
\hline \\
\hline 1 & TRAN SPORMATI ON & Loss & POR & EL ECPRI EITY GZH. & $=68.81 \%$ \\
\hline & RANSFORMATI ON & Loss & & PETROLEOH PL & $1.25 \%$ \\
\hline 3 & TRA N SPOR MA TI ON & Loss & FOR & NATURAL GAS & $0.0 \%$ \\
\hline 4 & TRAN SPOR YA TI ON & Loss & POR & STNTEETICS & $=0.0 \%$ \\
\hline
\end{tabular}


THIS PAGE

WAS INTENTIONALLY

LEFT BLANK 
BEA Region Tables for 1985 


\section{THIS PAGE}

\section{WAS INTENTIONALLY LEFT BLANK}


REGIONAL ENERGY EALANCE STATEMENT
PIES MID MID SCENARIO

\begin{tabular}{|c|c|c|c|c|c|c|c|c|c|c|}
\hline SECTOE & $\begin{array}{l}\text { DISTILLATE } \\
\text { OIL }\end{array}$ & $\begin{array}{l}\text { RESIDOAL } \\
\text { OIL }\end{array}$ & $\begin{array}{l}\text { GASOLINE } \\
\text { (ALL ONI }\end{array}$ & $\begin{array}{c}\text { OTHER } \\
\text { HYDRO- } \\
\text { CARBONS } \\
\text { IS IN } 10 * \$ 9\end{array}$ & $\begin{array}{c}\text { CRODE } \\
\text { OIL } \\
\text { BTO'S) }\end{array}$ & $\begin{array}{l}\text { NaTURAL } \\
\text { GAS }\end{array}$ & $\operatorname{COA} L$ & ELECTRICITY & $\begin{array}{r}\text { SECTOR } \\
\text { TOTAL }\end{array}$ & \\
\hline $\begin{array}{l}\text { PIRIL DEMAND SECIORS } \\
\text { RESIDENTIAL,CCAE. } \\
\text { INDOSTRIAL } \\
\text { TRAYSPORTATICN } \\
\text { MISCELLAHECS OSES }\end{array}$ & $\begin{array}{r}22,769 \\
2,667 \\
2,755 \\
518\end{array}$ & $\begin{array}{r}6.198 \\
33.123 \\
6.789 \\
385\end{array}$ & $26.27 \overline{-}$ & $\begin{array}{r}3,378 \\
913 \\
3,392 \\
5\end{array}$ & $\begin{array}{l}\bar{z} \\
\bar{z}\end{array}$ & $\begin{array}{r}598 \\
1,945 \\
344 \\
286\end{array}$ & $\begin{array}{r}3 \\
105 \\
2 \\
-\end{array}$ & $\begin{array}{r}4,836 \\
9,853 \\
6 \quad 75\end{array}$ & $\begin{array}{r}37,782 \\
48,606 \\
39,558 \\
1,269\end{array}$ & $\begin{array}{r}22 \% \\
29 \% \\
23 \% \\
1 \%\end{array}$ \\
\hline $\begin{array}{l}\text { TCTAI FIRAL } \\
\text { DEMAND SECTORS }\end{array}$ & 28,709 & 46,495 & 26,276 & 7,688 & - & 3,173 & 110 & 14,764 & 127,215 & $75 \%$ \\
\hline $\begin{array}{l}\text { T RAN SPORHATICN } \\
\text { FLECTRICITY GEK. } \\
\text { PETR OLEO FBODCCTS } \\
\text { NATORAL GAS } \\
\text { SY NTEETICS }\end{array}$ & $\begin{array}{r}2,247 \\
-213,469 \\
-\end{array}$ & $\begin{array}{r}2,808 \\
-26,023 \\
-\end{array}$ & $\begin{array}{r}-246,119 \\
- \\
-\end{array}$ & $-104,52 \overline{-}$ & $587,17 \overline{-}$ & 4,358 & $\begin{array}{r}10,189 \\
- \\
-\end{array}$ & $\begin{array}{r}-5,360 \\
- \\
-\end{array}$ & $\begin{array}{r}9,884 \\
1,397 \\
-\end{array}$ & $\begin{array}{l}6 \% \\
1 \%\end{array}$ \\
\hline $\begin{array}{l}\text { EFT FOEL OSEL } \\
\text { IA TRABSPOEHATION }\end{array}$ & $-211,222$ & $-23,215$ & $-246,119$ & $-104,526$ & 587,176 & 4,358 & 10,189 & $-5,360$ & 11,281 & $7 \%$ \\
\hline $\begin{array}{l}\text { TCTAL GROSS FLCRS } \\
\text { LCSSES } \& \text { OBISSIOES }\end{array}$ & $\begin{array}{r}30,956 \\
1,789\end{array}$ & $\begin{array}{r}49,303 \\
1\end{array}$ & $\begin{array}{r}26,276 \\
-0\end{array}$ & $\begin{array}{r}7,688 \\
-321\end{array}$ & $\begin{array}{r}587,176 \\
29,312\end{array}$ & $\begin{array}{r}7,531 \\
-272\end{array}$ & $\begin{array}{r}10,299 \\
-22\end{array}$ & $\begin{array}{r}14,764 \\
1,476\end{array}$ & $\begin{array}{r}138,496 \\
31,963\end{array}$ & $\begin{array}{l}81 \% \\
19 \%\end{array}$ \\
\hline
\end{tabular}

\begin{tabular}{|c|c|c|c|c|c|c|c|c|c|c|}
\hline $\begin{array}{l}\text { SOFFLY OF EHFRGY } \\
\text { FOSS IL FOEI }\end{array}$ & - & - & - & - & - & - & - & - & - & \\
\hline BY DROELECTEIC & - & - & - & - & - & - & - & 546 & 546 & $93 \%$ \\
\hline NOCL EAR & - & - & - & - & - & - & - & - & - & \\
\hline GEO. ESOLAR & - & - & - & - & - & - & - & 42 & 42 & 78 \\
\hline TOTAL SOPPIY & - & - & - & - & - & - & - & 588 & 588 & \\
\hline
\end{tabular}

YRT IU PORTS
OR REGION

NOTES:

$\begin{array}{llll}\text { TRANSPCR AATI CN } & \text { LOSS POR } & \text { ELECTEICITY GEN. } & =64.84 \% \\ \text { TRANSPORDAIICN } & \text { LOSS POR } & \text { PETROLEOM PRODOCTS } & =0.24 \% \\ \text { TRANSPCRATION LOSS POR } & \text { NATURLL GAS } & =0.0 \% \\ \text { TRANSPOR LATICN LOSS FOR } & \text { SYNTHETICS } & =0.0 \%\end{array}$


RECIONAL ZNEFGY EALANCE STATEMENT
PIES ID UID SCENARIC

\begin{tabular}{|c|c|c|c|c|c|c|c|c|c|c|}
\hline SECIOR & $\underset{O=L}{\text { DISTILLAT3 }}$ & $\begin{array}{l}\text { RESIDUAL } \\
\text { OIL }\end{array}$ & $\begin{array}{l}\text { GASOLIN } \\
\text { (ALL }\end{array}$ & $\begin{array}{c}\text { CTHER } \\
\text { AYDRO- } \\
\text { CARBONS } \\
\text { TS IN } 10 * * 9\end{array}$ & $\begin{array}{c}\text { CF ODE } \\
\text { CIL } \\
\text { BTQ SI }\end{array}$ & $\begin{array}{l}\text { MATOZRL } \\
\text { GA.S }\end{array}$ & $\cos 2$ & ELECTRICITY & $\begin{array}{r}\text { SECTOR } \\
\text { TOTAL }\end{array}$ & \\
\hline $\begin{array}{l}\text { PINAL DEHANI SECTCBS } \\
\text { RESIDENTIAI, CCBN. } \\
\text { IND DSTRIAL } \\
\text { IRANSPORTATICN } \\
\text { HISCEILANECES OSES }\end{array}$ & $\begin{array}{r}53.553 \\
3.255 \\
6.093 \\
856\end{array}$ & $\begin{array}{r}14,953 \\
35,085 \\
6,144 \\
636\end{array}$ & $60,91 \frac{-}{-}$ & $\begin{array}{r}7,835 \\
3,488 \\
3,088 \\
12\end{array}$ & $\begin{array}{l}\overline{-} \\
\overline{-}\end{array}$ & $\begin{array}{r}2,1774 \\
2,252 \\
328 \\
938\end{array}$ & $\begin{array}{r}7 \\
: 15 \\
1 \\
-\end{array}$ & $\begin{array}{r}11,660 \\
12.548 \\
- \\
197\end{array}$ & $\begin{array}{r}90,092 \\
56,943 \\
76,570 \\
2,639\end{array}$ & $\begin{array}{l}34 \% \\
21 \% \\
29 \% \\
1 \%\end{array}$ \\
\hline $\begin{array}{l}\text { TCTAI FINAI } \\
\text { DZMAND SECTORS }\end{array}$ & 63.757 & 56,828 & 60,916 & 14,423 & - & 5,592 & $\equiv 23$ & 24,405 & 226,244 & $85 \%$ \\
\hline $\begin{array}{l}\text { TRARSPORHATICN } \\
\text { FLECTRICITR. GEN. } \\
\text { PETROLEOA ERCDOCTS } \\
\text { NATORAL GAS } \\
\text { SY HTHETICS }\end{array}$ & $\begin{array}{r}3.858 \\
- \\
-\end{array}$ & $\begin{array}{r}3,3 \\
\vdots \\
-\end{array}$ & $\begin{array}{l}\overline{-} \\
\overline{-}\end{array}$ & $\begin{array}{l}\overline{-} \\
\overline{-}\end{array}$ & $\bar{z}$ & $\begin{array}{l}\overline{-} \\
\overline{-}\end{array}$ & $\begin{array}{r}16,843 \\
- \\
-\end{array}$ & $\begin{array}{r}-18,467 \\
- \\
- \\
-\end{array}$ & $\begin{array}{r}35,617 \\
- \\
-\end{array}$ & $13 x$ \\
\hline $\begin{array}{l}\text { NET FOFL DSEE } \\
\text { IN TRANSFOEATIOY }\end{array}$ & 3.858 & $\equiv 3,333$ & - & - & - & - & $16 . \varepsilon 43$ & $-18,467$ & 35,617 & $13 \%$ \\
\hline $\begin{array}{l}\text { TCTAL GROSS ILORS } \\
\text { LCSSES \& OMISSIONS }\end{array}$ & $\begin{array}{r}67.615 \\
3.909\end{array}$ & $\begin{array}{r}90,211 \\
2\end{array}$ & $\begin{array}{r}60,9: 16 \\
-0\end{array}$ & $\begin{array}{r}14,423 \\
-602\end{array}$ & $\overline{-}$ & $\begin{array}{r}5,5 \leq 2 \\
-2<2\end{array}$ & $\begin{array}{l}17,766 \\
?-37\end{array}$ & $\begin{array}{r}24,405 \\
2,440\end{array}$ & $\begin{array}{r}261,861 \\
5,508\end{array}$ & $\begin{aligned} 98 \% \\
2 \pi\end{aligned}$ \\
\hline TOTAL NET OSAGE & 71.524 & 90,213 & 60,915 & 13,820 & - & $5,3 \& 9$ & $17, \pi 28$ & 8,378 & 267,369 & \\
\hline
\end{tabular}

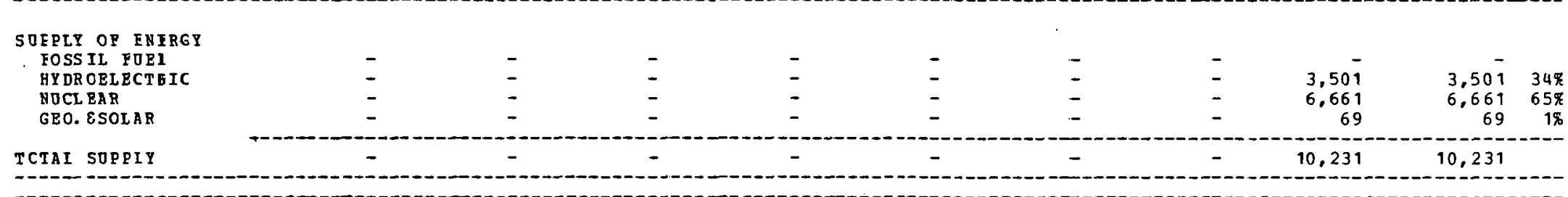

\begin{tabular}{l}
$\begin{array}{l}\text { YET IM FORTS } \\
\text { OF REGION }\end{array}$ \\
\hline
\end{tabular}


REGIONAL ENEEGY EALANCE STATEMENT

PIBS UID MID SCENARIO

\begin{tabular}{|c|c|c|c|c|c|c|c|c|c|c|}
\hline SECTOE & $\begin{array}{l}\text { DISTILLATE } \\
\text { OIL }\end{array}$ & $\begin{array}{l}\text { BESIDURLL } \\
\text { OIL }\end{array}$ & $\begin{array}{l}\text { GASOLINE } \\
\quad \text { ALL O }\end{array}$ & $\begin{array}{c}\text { OTHER } \\
\text { HYDRO- } \\
\text { CARBONS } \\
\text { TS IN } 10 * * 9\end{array}$ & $\begin{array}{c}\text { CRODE } \\
\text { OII } \\
\text { BTO'S) }\end{array}$ & $\begin{array}{l}\text { NATURAL } \\
\text { GAS }\end{array}$ & $\operatorname{COAL}$ & ELECTRICITY & $\begin{array}{r}\text { SECTOR } \\
\text { TOTAL }\end{array}$ & \\
\hline $\begin{array}{l}\text { PIHAL LEMANE SECTORS } \\
\text { RESIDENTIAL, CCHA. } \\
\text { IRD OSTRIAL } \\
\text { IRANS PORTATION } \\
\text { MISCELLANECOS OSES }\end{array}$ & $\begin{array}{r}26,973 \\
830 \\
3,200 \\
323\end{array}$ & $\begin{array}{r}2,0 \equiv 7 \\
8,678 \\
- \\
239\end{array}$ & $42,44 \overline{2}$ & $\begin{array}{r}5,516 \\
1.525 \\
739 \\
7\end{array}$ & - & $\begin{array}{r}3,467 \\
6.057 \\
376 \\
719\end{array}$ & $\begin{array}{r}4 \\
80 \\
- \\
-\end{array}$ & $\begin{array}{r}9,880 \\
7,141 \\
136\end{array}$ & $\begin{array}{r}47,877 \\
24,311 \\
46,757 \\
1,424\end{array}$ & $\begin{array}{r}36 \% \\
18 \% \\
35 \% \\
1 \%\end{array}$ \\
\hline $\begin{array}{l}\text { TCIAL FINAL } \\
\text { DEMAND SBCTORS }\end{array}$ & 31,326 & $10,95.4$ & 42,442 & 7,787 & - & 10,619 & 84 & 17,157 & 120,369 & $90 \%$ \\
\hline $\begin{array}{l}\text { TRANSFCRHATICN } \\
\text { ELECTRICITY GEH. } \\
\text { PETROLEOA FRCDOCTS } \\
\text { JATORAL GAS } \\
\text { SYHT BETICS }\end{array}$ & $\begin{array}{r}3,192 \\
- \\
-\end{array}$ & $\begin{array}{l}- \\
\overline{-} \\
-\end{array}$ & $\bar{z}$ & $\begin{array}{l}- \\
- \\
-\end{array}$ & $\overline{-}$ & $\begin{array}{l}\overline{-} \\
\overline{-}\end{array}$ & $\begin{array}{r}12,013 \\
- \\
-\end{array}$ & $\begin{array}{r}-5,459 \\
- \\
-\end{array}$ & $\begin{array}{r}9,746 \\
- \\
-\end{array}$ & $7 \%$ \\
\hline $\begin{array}{l}\text { NET FOEL OSFI } \\
\text { IN TRABSPOHATIOZ }\end{array}$ & 3,192 & - & - & - & - & - & 12,013 & $-5,459$ & 9,746 & $7 \%$ \\
\hline $\begin{array}{l}\text { TCTAL GROSS FLORS } \\
\text { LCSSES \& OMISSIONS }\end{array}$ & $\begin{array}{r}34,513 \\
1,995\end{array}$ & $\begin{array}{r}10,9 \leq 4 \\
0\end{array}$ & $\begin{array}{r}42,442 \\
-0\end{array}$ & $\begin{array}{r}7,787 \\
-325\end{array}$ & - & $\begin{array}{r}10,619 \\
-384\end{array}$ & $\begin{array}{r}12,097 \\
-26\end{array}$ & $\begin{array}{r}17,157 \\
1,715\end{array}$ & $\begin{array}{r}130,115 \\
2,974\end{array}$ & $\begin{array}{r}98 \% \\
2 \%\end{array}$ \\
\hline
\end{tabular}

\begin{tabular}{|c|c|c|c|c|c|c|c|c|c|c|}
\hline $\begin{aligned} & \text { SO } \equiv \text { FLY OP EHERGY } \\
& \text { FOSS IL FOEI }\end{aligned}$ & - & - & - & - & - & - & - & - & - & \\
\hline AY DR OELECT FIC & - & - & - & - & - & - & - & 5,355 & 5,355 & 99\% \\
\hline JOCL EAR & - & - & - & - & - & - & - & - & - & \\
\hline GEO. ESOLAR & - & - & - & - & - & - & - & 48 & 48 & $1 \%$ \\
\hline
\end{tabular}

-

\begin{tabular}{l} 
RPT III PORTS \\
OF REGION \\
\hline
\end{tabular}


REGIONAL EHZRGY BALANCE STITEMENT

\begin{tabular}{|c|c|c|c|c|c|c|c|c|c|c|}
\hline SECTOR & $\begin{array}{l}\text { DISTILLATE } \\
\text { OIL }\end{array}$ & $\begin{array}{l}\text { RESTJOAL } \\
\text { OIL }\end{array}$ & $\begin{array}{l}\text { GASOLIUE } \\
\text { GILL }\end{array}$ & $\begin{array}{c}\text { DTEER } \\
\text { HTDFO- } \\
\text { CARECNS } \\
\text { TS LN 10**9 }\end{array}$ & $\begin{array}{c}\text { CRODE } \\
\text { OII } \\
\text { BTOSI }\end{array}$ & $\begin{array}{c}\text { - NATURAL } \\
\text { GAS }\end{array}$ & COAL & BLECTRI CITY & $\begin{array}{r}\text { SECTOR } \\
\text { TOTAL }\end{array}$ & \\
\hline 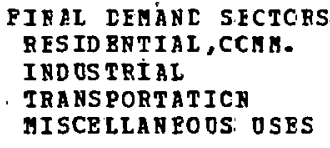 & $\begin{array}{r}447,937 \\
6,642 \\
29 ., 238 \\
7,058\end{array}$ & $\begin{array}{r}138,688 \\
47,052 \\
3,536 \\
5,241\end{array}$ & 395, 11 & $\begin{array}{r}52,649 \\
.50,948 \\
51,855 \\
96\end{array}$ & $\bar{z}$ & $\begin{array}{r}154,573 \\
40,383 \\
7,845 \\
8,653\end{array}$ & $\begin{array}{r}1 \epsilon \\
1,200 \\
.2 \\
-\end{array}$ & $\begin{array}{r}95,764 \\
40,508 \\
79 \\
1,606\end{array}$ & $\begin{array}{r}899,682 \\
136,739 \\
487,672 \\
22,654\end{array}$ & $\begin{array}{r}-8 \% \\
-0 \% \\
-6 \% \\
1 \%\end{array}$ \\
\hline $\begin{array}{l}\text { TCTAL FINAL } \\
\text { DEHAND SBCTCRS }\end{array}$ & 490,925 & 194,517 & 795,11. & 165,548 & - & 211,465 & 1,218 & 137,957 & $1,596,747$ & $\varepsilon 6 \%$ \\
\hline $\begin{array}{l}\text { TR AN SP ORHATICE } \\
\text { EL BCTRICIT I GEN. } \\
\text { EBTROLEON FBCDOCTS } \\
\text { NATURAL GAS } \\
\text { SY NT HETICS }\end{array}$ & $\begin{array}{r}25,210 \\
- \\
-\end{array}$ & $\begin{array}{r}207.997 \\
- \\
-\end{array}$ & $\begin{array}{l}- \\
\overline{-}\end{array}$ & $\begin{array}{r}- \\
- \\
59.330\end{array}$ & $\begin{array}{l}\overline{-} \\
\bar{z}\end{array}$ & $\begin{array}{r}\overline{-} \\
-53,97 j\end{array}$ & $\begin{array}{r}117,93 \\
- \\
-\end{array}$ & $\begin{array}{r}-119,963 \\
- \\
-\end{array}$ & $\begin{array}{r}231,181 \\
- \\
5,860\end{array}$ & $0 \%$ \\
\hline $\begin{array}{l}\text { NTI FOEL OSFE } \\
\text { IN TRANSOEDATICN }\end{array}$ & 25,210 & 207.997 & - & 59.830 & - & $-53,970$ & $117,93 i$ & $-119,563$ & 237,041 & $: 38$ \\
\hline $\begin{array}{l}\text { TCTAL GROSS FICRS } \\
\text { LCSSES } \& \text { ONISSIONS }\end{array}$ & $\begin{array}{r}518,135 \\
29,839\end{array}$ & $\begin{array}{r}402.514 \\
9\end{array}$ & $\begin{array}{r}395,11 i \\
-i\end{array}$ & $\begin{array}{r}225,378 \\
-9.429\end{array}$ & $\overline{-}$ & $\begin{array}{r}211,465 \\
-7,659\end{array}$ & $\begin{array}{r}119,155 \\
-26 \bar{c}\end{array}$ & $\begin{array}{r}137,957 \\
13,797\end{array}$ & $\begin{array}{r}1,833,788 \\
26,301\end{array}$ & $\begin{array}{r}\subseteq 9 \% \\
1 \%\end{array}$ \\
\hline TOTAL NET OSAGE & 545,974 & 402,523 & $.395,115$ & 215,956 & - & 149,835 & 118,892 & 31,791 & $1,860,089$ & \\
\hline $\begin{array}{l}\text { SOFPLY OP ENEEGY } \\
\text { FOSS IL FOEI } \\
\text { HYDR OELECTIIC } \\
\text { NOCL EAR } \\
\text { GEO. ESOLAR }\end{array}$ & $\begin{array}{l}\overline{-} \\
\overline{-}\end{array}$ & $\begin{array}{l}\overline{-} \\
\overline{-}\end{array}$ & $\begin{array}{l}- \\
-\end{array}$ & $\begin{array}{l}- \\
-\end{array}$ & I & $\begin{array}{l}- \\
-\end{array}$ & $\begin{array}{l}\text { - } \\
-\end{array}$ & $\begin{array}{r}1,319 \\
41,239 \\
394\end{array}$ & $\begin{array}{r}1.319 \\
41.239 \\
394\end{array}$ & $\begin{array}{r}3 \% \\
56 \% \\
1 \%\end{array}$ \\
\hline TCTAL SOPPIY & - & - & - & - & - & - & - & 42,952 & 42,952 & \\
\hline
\end{tabular}

\begin{tabular}{l}
$\begin{array}{l}\text { NFT IM FORTS } \\
\text { OP REGION }\end{array}$ \\
\hline
\end{tabular}


REGIONAL RNERGY EALANCE STATEMENT

PIONAL ENERGY EALANCE STAT
PIES MID MID SCENARIO

\begin{tabular}{|c|c|c|c|c|c|c|c|c|c|c|}
\hline SECTOE & $\begin{array}{l}\text { DISTILLATE } \\
\text { OIL }\end{array}$ & $\begin{array}{l}\text { RESIDOAL } \\
\text { OIL }\end{array}$ & $\begin{array}{l}\text { GASOLINI } \\
\text { (ALL }\end{array}$ & $\begin{array}{c}\text { OTHER } \\
\text { HYD.RO- } \\
\text { CARBONS } \\
\text { S IN } 10 * \$ 9\end{array}$ & $\begin{array}{c}\text { CRODE } \\
\text { OIL } \\
\text { BTO'S) }\end{array}$ & $\begin{array}{l}\text { NATURAL } \\
\text { GAS }\end{array}$ & $\mathrm{COAL}$ & ELECTRICITY & $\begin{array}{l}\text { SECTOR } \\
\text { TOTAI }\end{array}$ & \\
\hline $\begin{array}{l}\text { PIY PL CEHANC SECTOBS } \\
\text { RESIDENTIAL, CCMM. } \\
\text { INDOSTRIAL } \\
\text { TBANSPORTATICN } \\
\text { MISCELLANPCOS"OSES }\end{array}$ & $\begin{array}{r}139,977 \\
6,415 \\
19,434 \\
2,282\end{array}$ & $\begin{array}{r}34,807 \\
64,143 \\
622 \\
1,695\end{array}$ & $194,54 \overline{3}$ & $\begin{array}{r}25,981 \\
35,270 \\
15,439 \\
39\end{array}$ & $\begin{array}{l}- \\
\overline{-}\end{array}$ & $\begin{array}{r}58,787 \\
23,054 \\
2,196 \\
3,567\end{array}$ & $\begin{array}{r}24 \\
819 \\
3 \\
-\end{array}$ & $\begin{array}{r}53,185 \\
27,007 \\
18 \\
616\end{array}$ & $\begin{array}{r}312,761 \\
156,708 \\
232,255 \\
8,199\end{array}$ & $\begin{array}{l}37 \% \\
19 \% \\
28 \% \\
1 \%\end{array}$ \\
\hline $\begin{array}{l}\text { TCIAI FIMAI } \\
\text { DEMAND SPCTCRS }\end{array}$ & 168,108 & 101,267 & 194,542 & 76,729 & - & 87,604 & 846 & 80,826 & 709,923 & $85 \%$ \\
\hline $\begin{array}{l}\text { TRANSFCRMATICN } \\
\text { ELECTRICITY EEN. } \\
\text { EETROLEOM FRCDOCTS } \\
\text { NATURAL GAS } \\
\text { SYNTHETICS }\end{array}$ & $\begin{array}{r}21,416 \\
= \\
=\end{array}$ & $\begin{array}{r}100,1 \% 5 \\
- \\
-\end{array}$ & $\bar{z}$ & $\begin{array}{l}\overline{-} \\
\overline{-}\end{array}$ & $\begin{array}{l}\overline{-} \\
\overline{-}\end{array}$ & $\begin{array}{l}- \\
- \\
-\end{array}$ & $\begin{array}{r}55,782 \\
- \\
-\end{array}$ & $\begin{array}{r}-61,492 \\
- \\
-\end{array}$ & $\begin{array}{r}115,821 \\
- \\
-\end{array}$ & $14 \%$ \\
\hline $\begin{array}{l}\text { NEI FOEL OSEI } \\
\text { IN TRANSOEMATION }\end{array}$ & 21,416 & 100,115 & - & - & - & - & 55,782 & $-61,492$ & 115,821 & $14 \%$ \\
\hline $\begin{array}{l}\text { TCIAL GROSS FLCHS } \\
\text { LCSSES } \varepsilon \text { CHISSIONS }\end{array}$ & $\begin{array}{r}189,524 \\
10,957\end{array}$ & 201,382 & $\begin{array}{r}194,543 \\
-0\end{array}$ & $\begin{array}{l}76,729 \\
-3,207\end{array}$ & $\overline{-}$ & $\begin{array}{l}87,604 \\
-3,173\end{array}$ & $\begin{array}{r}56,628 \\
-124\end{array}$ & $\begin{array}{r}80,826 \\
8,083\end{array}$ & $\begin{array}{r}825,744 \\
12,539\end{array}$ & $\begin{array}{r}99 \% \\
1 \%\end{array}$ \\
\hline $\begin{array}{l}\text { SOEFLY OP ENERGY } \\
\text { FOSSIL FOEI } \\
\text { HYDRCELECTEIC } \\
\text { NOCLEAR } \\
\text { GEC. ESOLAR }\end{array}$ & $\begin{array}{l}\bar{z} \\
\overline{-}\end{array}$ & $\begin{array}{l}- \\
\overline{-} \\
-\end{array}$ & $\begin{array}{l}\overline{-} \\
\overline{-}\end{array}$ & $\begin{array}{l}- \\
- \\
-\end{array}$ & $\begin{array}{l}\overline{-} \\
\overline{-}\end{array}$ & $\begin{array}{l}\overline{-} \\
-\end{array}$ & $\begin{array}{l}- \\
-\end{array}$ & $\begin{array}{r}- \\
6,397 \\
33,700 \\
231\end{array}$ & $\begin{array}{r}6.397 \\
33,700 \\
231\end{array}$ & $\begin{array}{r}16 \% \\
84 \% \\
1 \%\end{array}$ \\
\hline TCTAL SOPPIY & - & - & - & - & - & $=$ & - & 40,328 & 40,328 & \\
\hline
\end{tabular}

-

\section{NET IM FORTS}

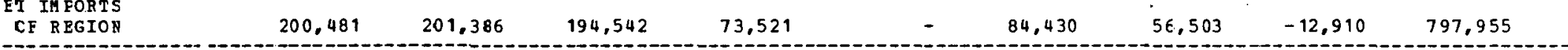

-

NOTES:

\begin{tabular}{|c|c|c|c|c|}
\hline & & $\begin{array}{l}\text { POR } \\
\text { POR }\end{array}$ & $\begin{array}{l}\text { ELECTRICITY GEN. } \\
\text { PETRCLEOM PRODOCTS }\end{array}$ & $=0.0$ \\
\hline & & $\mathbf{P C}$ & NATOYAL GAS & $=0.0$ \\
\hline & & & SYNTEETICS & $=0.0$ \\
\hline
\end{tabular}


REGIONAL SNEEGY EAIANCE STATEMENT

PIES YID HID SCENARIO

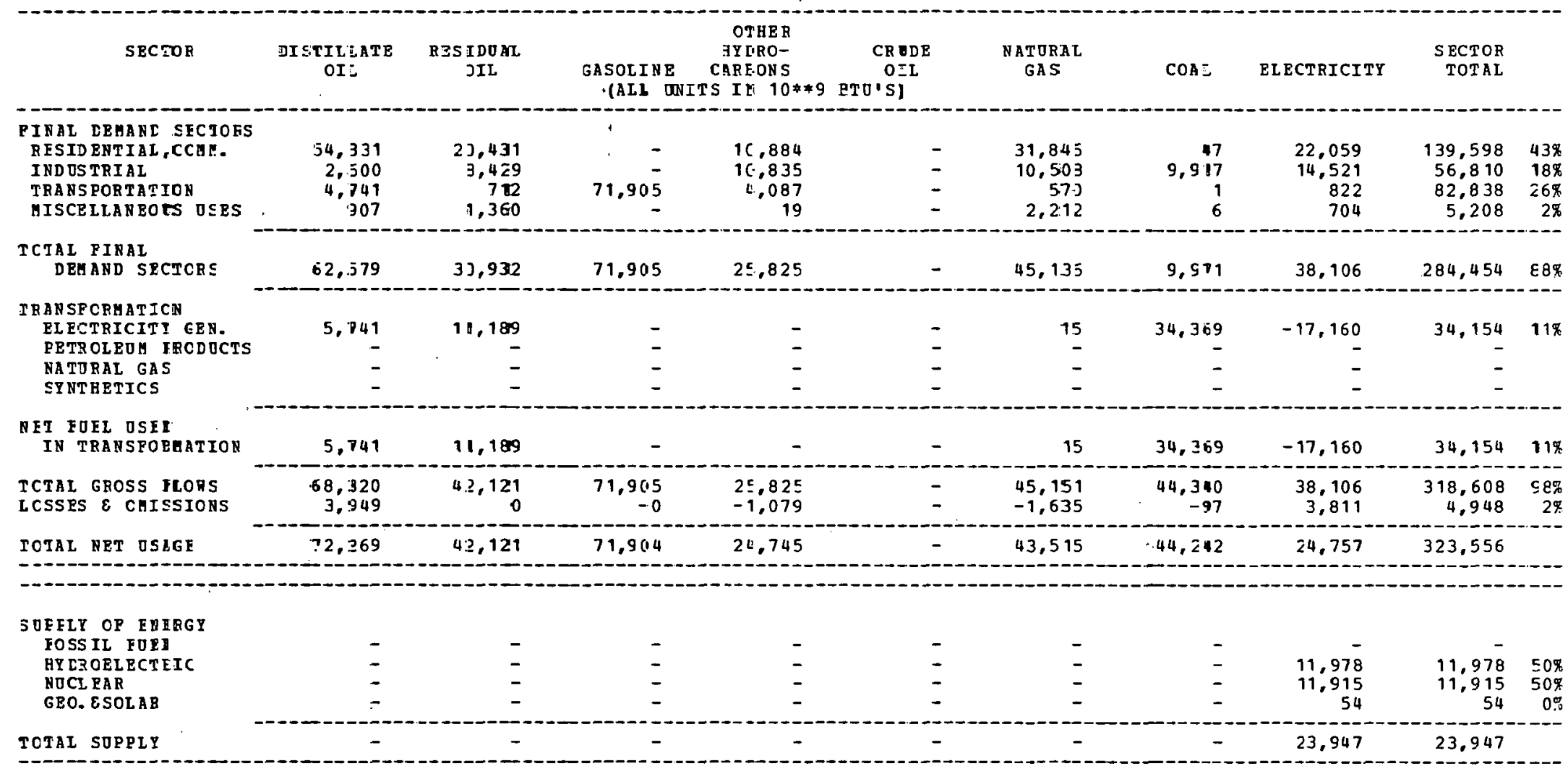

\begin{tabular}{l} 
NET IM PORTS \\
CP REGION \\
\hline
\end{tabular}

NOTES:

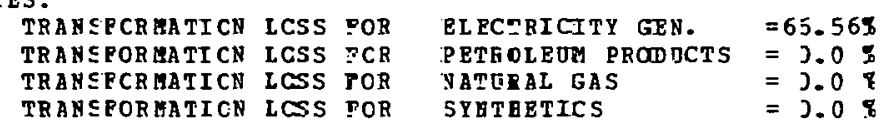

TRAMSPORHAICN LCSS TOR NaIGRALGAS 
BEGIONAL ENERGY. BALANCE STATEMENT

PIES MID MID SCENARIO

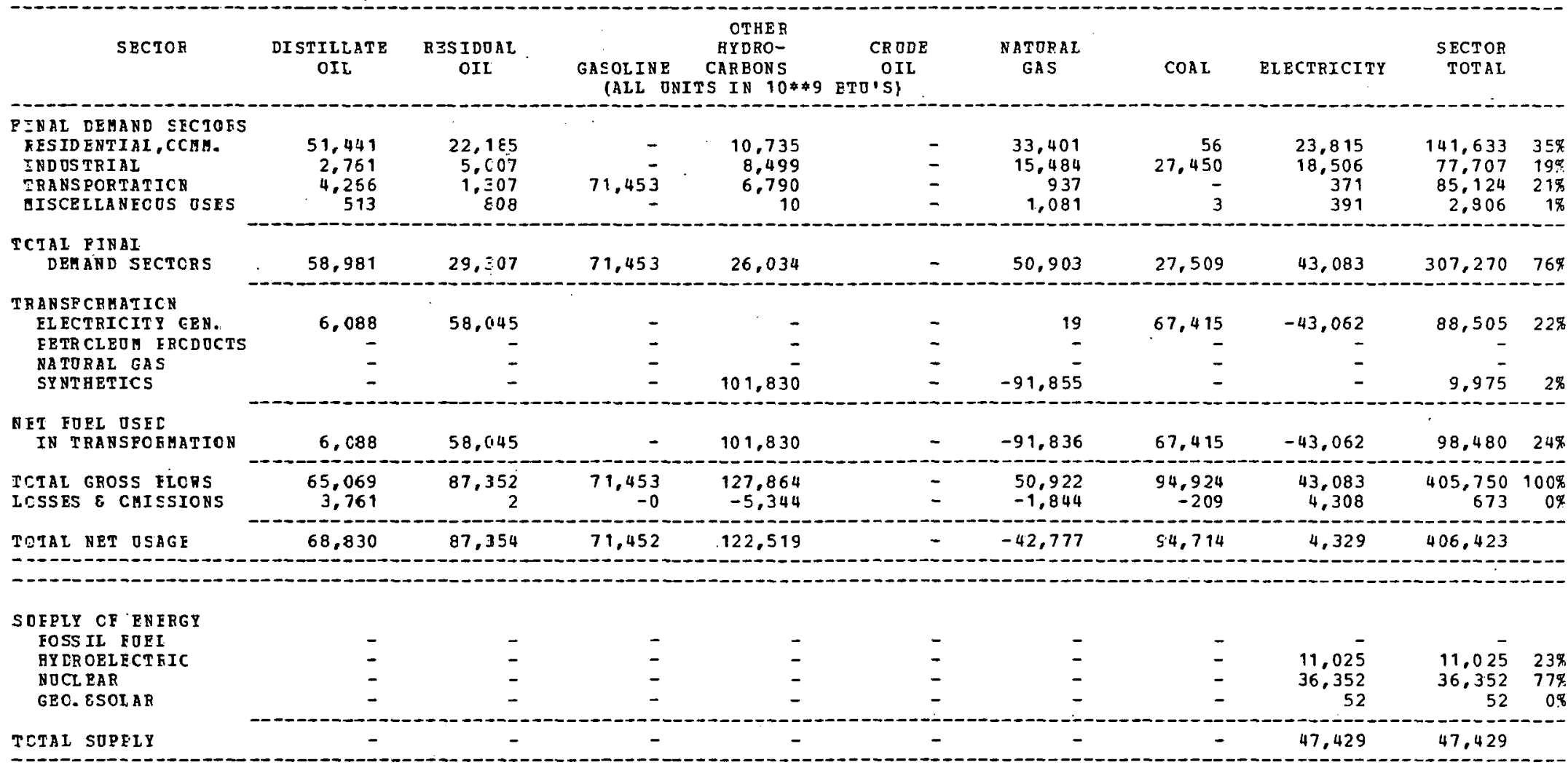

-

NPI IM PORTS
CP REGION

\begin{tabular}{|c|c|c|c|c|c|}
\hline \\
\hline 1 & THAN SFOR MATICN & Loss & FOR & ELECTRICITY GEN. & OTES: \\
\hline 2 & TR A N SPOR HA TI CN & ICSS & FOR & PETROL $30 \mathrm{OM}$ PROD & \\
\hline 3 & TRANSPOR MATICN & LosS & FOR & NATURA: GAS & $0.0 \%$ \\
\hline 4 & TRANSPORHATICN & LOSS & FOR & SYNTHETICS & $9.80 \%$ \\
\hline
\end{tabular}


REGIONAL ENEFGY EALANCE STATEMENT

PIES MID MID SCENARIO

\begin{tabular}{|c|c|c|c|c|c|c|c|c|c|c|}
\hline SECIOF & $\begin{array}{l}\text { EISIILLATE } \\
\text { OII }\end{array}$ & $\begin{array}{l}\text { RESJDUAL } \\
\text { EIL }\end{array}$ & $\begin{array}{l}\text { GASOLINE } \\
\text { (ALLI J }\end{array}$ & $\begin{array}{l}\text { OTHER } \\
\text { FYD.FO- } \\
\text { CAEBONS } \\
\text { S IN } 10 * 99\end{array}$ & $\begin{array}{c}\text { CR DDE } \\
\text { OIL } \\
\text { BTOSI) }\end{array}$ & $\begin{array}{l}\text { NATUR P.L } \\
\text { GAS }\end{array}$ & $\operatorname{COAL}$ & ELECTRICITY & $\begin{array}{l}\text { SECTOR } \\
\text { TOTAL }\end{array}$ & \\
\hline $\begin{array}{l}\text { FINAL CEMANL SECTCES } \\
\text { RESIDENTIAL, COAH. } \\
\text { INDOSTRIAI. } \\
\text { TRANSPORTATIEN } \\
\text { MISCELLANECS OSES }\end{array}$ & $\begin{array}{r}38,419 \\
3,609 \\
2,536 \\
259\end{array}$ & $\begin{array}{r}1 \mathrm{E}, 236 \\
\equiv .814 \\
596 \\
40 ?\end{array}$ & 53,763 & $\begin{array}{r}8.075 \\
3.450 \\
3.090 \\
\epsilon\end{array}$ & $\begin{array}{l}\overline{-} \\
\overline{-}\end{array}$ & $\begin{array}{r}24,9 \varepsilon 6 \\
15,5 \leqslant 9 \\
4=6 \\
6 \varepsilon 5\end{array}$ & $\begin{array}{r}41 \\
12,263 \\
- \\
2\end{array}$ & $\begin{array}{r}17,735 \\
14.890 \\
224 \\
217\end{array}$ & $\begin{array}{r}105,492 \\
55,582 \\
60,640 \\
1,576\end{array}$ & $\begin{array}{l}+1 \% \\
22 \% \\
24 \% \\
1 \%\end{array}$ \\
\hline $\begin{array}{l}\text { TCTAL FINAL } \\
\text { DEMAND SECDORS }\end{array}$ & 44,823 & 23,053 & 53,763 & 14.621 & - & 41,656 & 12,303 & 33,066 & 223,290 & $: 37 \%$ \\
\hline $\begin{array}{l}\text { TRANSFCRMATICS } \\
\text { ELECTRICITY, GEN. } \\
\text { PETROLEOA FECDOCTS } \\
\text { NATORAL GAS } \\
\text { SYNTHETICS }\end{array}$ & $\begin{array}{r}4.679 \\
- \\
-\end{array}$ & $\begin{array}{r}3,13 \vdots \\
= \\
=\end{array}$ & $\overline{-}$ & $\begin{array}{l}\overline{-} \\
\overline{-}\end{array}$ & $\begin{array}{l}\overline{-} \\
\overline{-}\end{array}$ & $\begin{array}{l}127 \\
- \\
-\end{array}$ & $\begin{array}{r}36,764 \\
- \\
-\end{array}$ & $\begin{array}{r}-14,914 \\
- \\
-\end{array}$ & $\begin{array}{r}29,789 \\
- \\
- \\
-\end{array}$ & $12 \%$ \\
\hline $\begin{array}{l}\text { NET FOEL OSEL } \\
\text { IN TRANSPOEHATION }\end{array}$ & 4,679 & 3.133 & - & - & - & 127 & $36,7 \in .4$ & $-14,914$ & 29.789 & $2 x$ \\
\hline $\begin{array}{l}\text { TCTAL GROSS FLORS } \\
\text { LCSSES } \varepsilon \text { CMISSIONS }\end{array}$ & $\begin{array}{r}49,5) 2 \\
2,851\end{array}$ & $26,18 \epsilon$ & $\begin{array}{r}53,768 \\
-0\end{array}$ & $\begin{array}{r}14.621 \\
-611\end{array}$ & $\overline{-}$ & $\begin{array}{l}41,783 \\
-1,513\end{array}$ & $\begin{array}{r}49.067 \\
-108\end{array}$ & $\begin{array}{r}33,066 \\
3,306\end{array}$ & $\begin{array}{r}253,079 \\
.3,936\end{array}$ & $\begin{aligned} P E \% \\
2 \%\end{aligned}$ \\
\hline TCIAL NET OSAGE & {$[2,353$} & $26,18 \epsilon$ & $53,76^{7}$ & 14,009 & - & 40,269 & 48,958 & 21,458 & 257.015 & \\
\hline $\begin{array}{l}\text { SUFELY CP ENFBGY. } \\
\text { FOSS IL FOEI } \\
\text { HYDRCELECTEIC } \\
\text { NDCL PAR } \\
\text { GEO. \&SOLAR }\end{array}$ & $\begin{array}{l}\overline{-} \\
\overline{-}\end{array}$ & $\begin{array}{l}\bar{z} \\
\overline{-}\end{array}$ & $\begin{array}{l}- \\
-\end{array}$ & $\begin{array}{l}- \\
- \\
-\end{array}$ & $\begin{array}{l}\overline{-} \\
\overline{-}\end{array}$ & $\begin{array}{l}- \\
- \\
-\end{array}$ & $\begin{array}{l}- \\
\overline{-} \\
-\end{array}$ & $\begin{array}{r}2,68 \overline{8} \\
4.667 \\
40\end{array}$ & $\begin{array}{r}- \\
2,688 \\
4,667 \\
40\end{array}$ & $\begin{array}{r}\vdots 6 \% \\
\epsilon 3 \% \\
1 \%\end{array}$ \\
\hline TCTAL SUPRIY & - & - & - & - & - & - & - & 7,395 & 7,395 & \\
\hline
\end{tabular}

(1)

NET IM FORTS

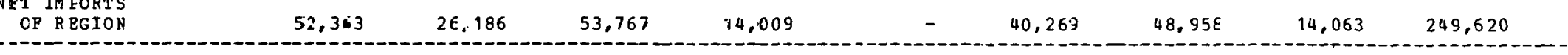

NOTES:

TRANSFCRAATICN LOSS PGB TRANSFCRAATI CN LOSE PGR TRANSFCRMATICN LCSE PGR

BERCIEICITY GEN. $\quad=66.64 \%$

4 TRANSFO

PITOLECH PRODOCTS $=0.0$

S. NTTET ICF

$=0.0 \%$
$=3.0 \%$ 
REGIONAL ENEFGY PALANCE STATEMENT

PIBS MID MID SCENARIO

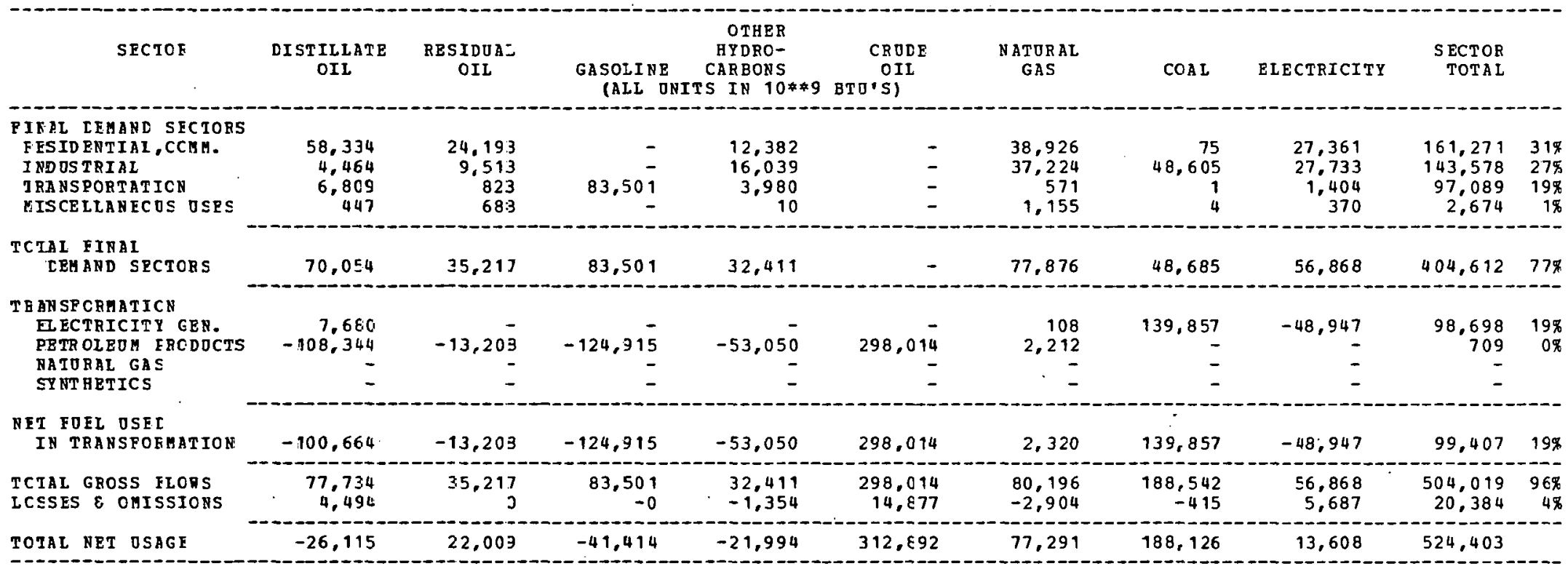

(1)

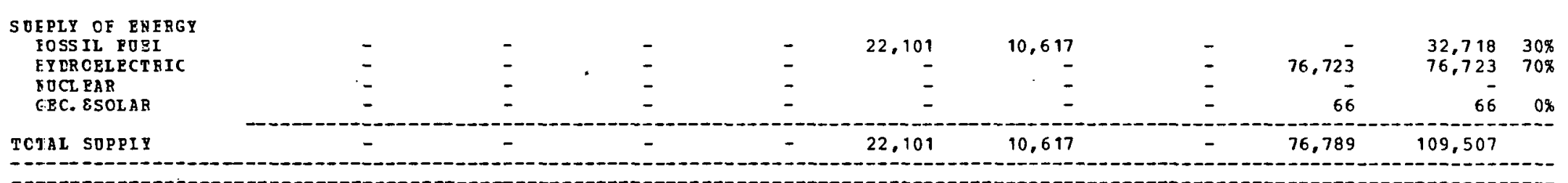

-

\begin{tabular}{l} 
RIT IM FORTS \\
OF REGION \\
\hline
\end{tabular}

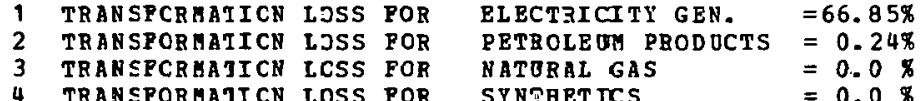


REGIONLL REEFIY EALANCE STATEMENT

PIES MID MID SCENARIO

\begin{tabular}{|c|c|c|c|c|c|c|c|c|c|}
\hline SECTOE & $\underset{\text { OII }}{\text { DISTILIATE }}$ & $\begin{array}{l}\text { RESIDUAS } \\
\quad=I L\end{array}$ & $\begin{array}{l}\text { GASOLINE } \\
\text { - GALL. JUI }\end{array}$ & $\begin{array}{c}\text { OT } 3 E R \\
\text { EYD } \\
\text { CERB } \\
\text { TS IN } 10 * 49\end{array}$ & $\begin{array}{c}\text { CRODP } \\
\text { OIL } \\
\text { ETO'S) }\end{array}$ & $\begin{array}{l}\text { NATURLI } \\
\text { GAS }\end{array}$ & COAL & ELECTRICITY & $\begin{array}{r}\text { SECTOR } \\
\text { TOTAL }\end{array}$ \\
\hline 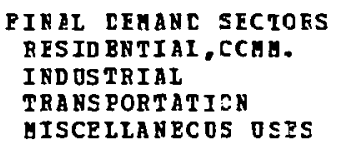 & $\begin{array}{r}10.230 \\
3.951 \\
4.269 \\
126\end{array}$ & $\begin{array}{r}1,500 \\
5,263 \\
430 \\
101\end{array}$ & $\begin{array}{r}- \\
27.56 \overline{7} \\
-\end{array}$ & $\begin{array}{r}2,947 \\
8,771 \\
906 \\
4\end{array}$ & $\begin{array}{l}\overline{-} \\
\overline{-}\end{array}$ & $\begin{array}{r}14,3 \cdot 7 \\
17,028 \\
273 \\
304\end{array}$ & $\begin{array}{r}107 \\
50,717 \\
7 \\
1\end{array}$ & $\begin{array}{r}7,912 \\
10,308 \\
151 \\
103\end{array}$ & $\begin{array}{r}37,013 \\
97,048 \\
33,603 \\
699\end{array}$ \\
\hline $\begin{array}{l}\text { TCIAL FINAI } \\
\text { DEHAND SBCTORS }\end{array}$ & 18,636 & 3,294 & $.27,56.7$ & 12.628 & - & $31,9 \leqslant 2$ & 50,832 & 18,474 & 168,363 \\
\hline $\begin{array}{l}\text { TRANSFCRBATICS } \\
\text { BLECTRICITY GBH. } \\
\text { PETROLEOM EFODOCTS } \\
\text { NATURAL GAS } \\
\text { SY NTHETICS }\end{array}$ & $\begin{array}{r}5.20 \\
-57.558 \\
- \\
-\end{array}$ & $\begin{array}{r}- \\
-7.018 \\
-\end{array}$ & $\begin{array}{r}- \\
-66,37.3 \\
-\end{array}$ & $\begin{array}{r}-28.189 \\
-\end{array}$ & $\begin{array}{r}- \\
158,350 \\
-\end{array}$ & $\begin{array}{r}615 \\
1,175 \\
- \\
-\end{array}$ & $\begin{array}{r}10,605 \\
- \\
- \\
-\end{array}$ & $\begin{array}{r}-3,886 \\
- \\
-\end{array}$ & $\begin{array}{r}7.854 \\
377 \\
- \\
-\end{array}$ \\
\hline $\begin{array}{l}\text { NET FOFL OSFC } \\
\text { IN TRANSFORATION }\end{array}$ & $-57,0+8$ & $-7.01 \varepsilon$ & $-66,373$ & $-28,189$ & 158,350 & 1,790 & 10,605 & $-3,886$ & 8,231 \\
\hline $\begin{array}{l}\text { TCTAL GROSS FLCNS } \\
\text { LCSSES } \& \text { CHISSIONS }\end{array}$ & $\begin{array}{r}19,156 \\
1,137\end{array}$ & $\begin{array}{r}8,294 \\
C\end{array}$ & $\begin{array}{r}27,567 \\
-0\end{array}$ & $\begin{array}{r}12,628 \\
-527\end{array}$ & $\begin{array}{r}158,350 \\
7,905\end{array}$ & $\begin{array}{r}33,722 \\
-1,221\end{array}$ & $\begin{array}{r}61,437 \\
-135\end{array}$ & $\begin{array}{r}18,474 \\
1,847\end{array}$ & $\begin{array}{r}176,594 \\
8,975\end{array}$ \\
\hline TOTAL RET OSAGF & $-57,334$ & $1.27 \epsilon$ & $-38,806$ & $-16,088$ & 166,255 & 32,500 & 61,301 & 16,435 & 185,570 \\
\hline
\end{tabular}

(1)

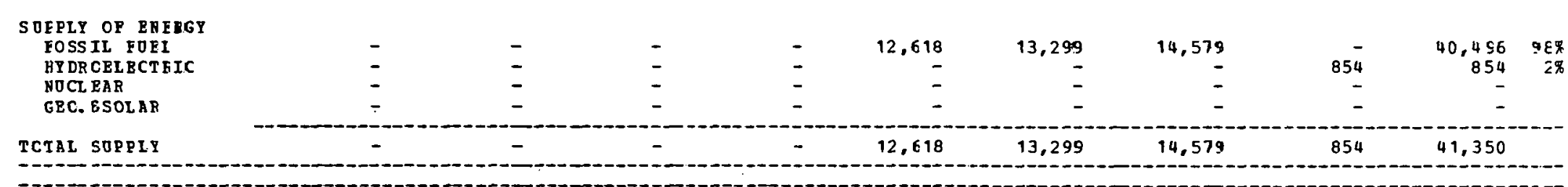

\section{NET IM PORTS}

OP REGION

$-37,344$

1.276

$-38,80 \epsilon$

153,637

19,201

15,581

144,220

NoTES:

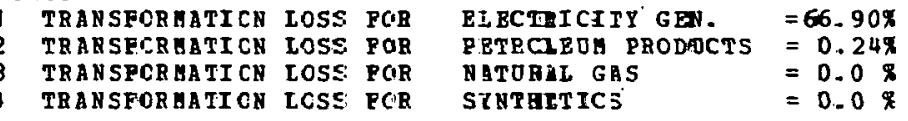


REGIONAL ENEEGY FALANCE STATEMENT

PIES MID MID SCENARIO

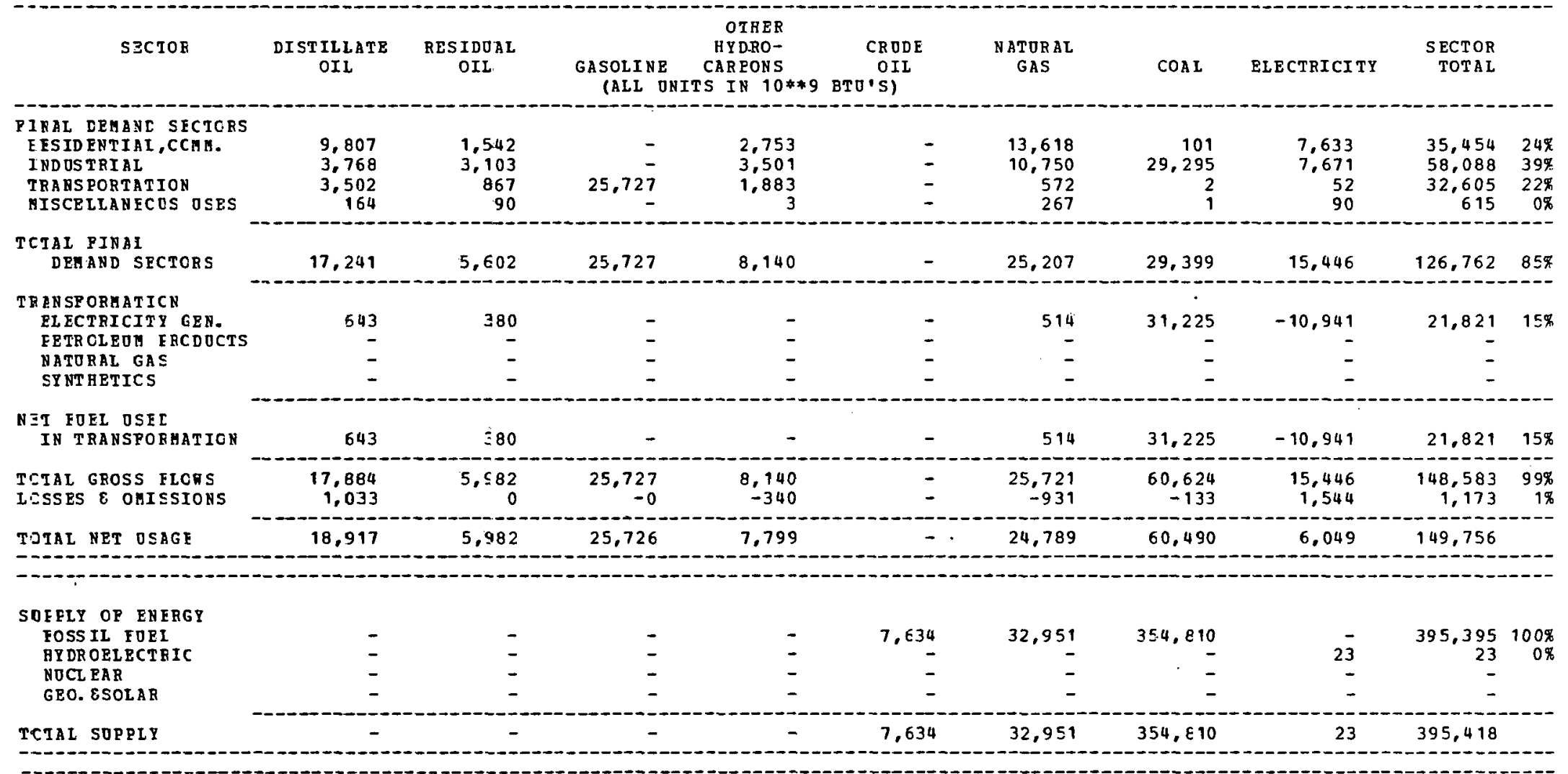

NET IM FORTS
CP R EGION


REGIONAL 3HE EGY EALANCE STATEMENT

PIES IID MID SCBNARIC

\begin{tabular}{|c|c|c|c|c|c|c|c|c|c|c|}
\hline SRCTOK & $\begin{array}{l}\text { DLSTIFLATE } \\
\text { OIL }\end{array}$ & $\begin{array}{l}\text { BESIDOAL } \\
\text { OIL }\end{array}$ & $\begin{array}{l}\text { GASOLIN3 } \\
\text { (ALL J }\end{array}$ & $\begin{array}{c}\text { OTAER } \\
\text { HYDRO- } \\
\text { CARBONS } \\
\text { IS IN } 10 * 9\end{array}$ & $\begin{array}{c}\text { CFODE } \\
\text { CII } \\
\text { BTO'SI }\end{array}$ & $\begin{array}{l}\text { NATOZAL } \\
\text { GAS }\end{array}$ & $\cos L$ & ELECTRICITY & $\begin{array}{r}\text { SECTOR } \\
\text { TOTAL }\end{array}$ & \\
\hline $\begin{array}{l}\text { PINAL CEMANC SECTORS } \\
\text { RESIDENTIAL, CCRH. } \\
\text { INDOSTRIAL } \\
\text { TRABSPORTATICA } \\
\text { MISCELLANECOS OSES }\end{array}$ & $\begin{array}{r}23.877 \\
2.163 \\
3.580 \\
233\end{array}$ & $\begin{array}{r}8,826 \\
2,852 \\
3,4 \\
3.28\end{array}$ & $\begin{array}{r}- \\
37.749 \\
-\end{array}$ & $\begin{array}{r}5,340 \\
4,321 \\
1,301 \\
6\end{array}$ & 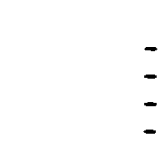 & $\begin{array}{r}17,651 \\
1,7<9 \\
2 C 7 \\
6 C 3\end{array}$ & $\begin{array}{r}48 \\
14,461 \\
1 \\
1\end{array}$ & $\begin{array}{r}11.589 \\
10,352 \\
458 \\
189\end{array}$ & $\begin{array}{r}67,331 \\
42,908 \\
43,600 \\
1,360\end{array}$ & $\begin{array}{r}39 \% \\
25 \% \\
25 \% \\
1 \%\end{array}$ \\
\hline $\begin{array}{l}\text { TCTAL PINAI } \\
\text { DEMAND SECTORS }\end{array}$ & 29.853 & $12,3 \geq 0$ & 37,749 & 13,968 & - & 27,210 & $14,5.11$ & 22,588 & 155,199 & $90 \%$ \\
\hline $\begin{array}{l}\text { TEANSPCRHATICN } \\
\text { EIFCTRICIT GEN. } \\
\text { PETRCIEO \#BCDOCTS } \\
\text { NATURAL GAS } \\
\text { ST NTEETICS }\end{array}$ & $\begin{array}{r}2,531 \\
- \\
-\end{array}$ & $\begin{array}{l}\overline{-} \\
\overline{-}\end{array}$ & $\begin{array}{l}- \\
\bar{z}\end{array}$ & $\begin{array}{l}\bar{z} \\
\bar{z}\end{array}$ & $\begin{array}{l}- \\
-\end{array}$ & $\begin{array}{r}340 \\
- \\
-\end{array}$ & $\begin{array}{r}19,833 \\
= \\
-\end{array}$ & $\begin{array}{r}-7.577 \\
- \\
- \\
-\end{array}$ & $\begin{array}{r}15,121 \\
= \\
=\end{array}$ & $9 \%$ \\
\hline $\begin{array}{l}\text { RET FOEL OSE } \\
\text { IN TRANSFOSHATION }\end{array}$ & 2,531 & - & - & - & - & $\equiv 34$ & 19,833 & $-7,577$ & 15,121 & $9 \%$ \\
\hline $\begin{array}{l}\text { TCTAL GROSS ELORS } \\
\text { LCSSBS } \varepsilon \text { OHISSIONS }\end{array}$ & $\begin{array}{r}32,384 \\
1,372\end{array}$ & $\begin{array}{r}12,3 \approx 0 \\
0\end{array}$ & $\begin{array}{r}37,749 \\
-0\end{array}$ & $\begin{array}{r}10,968 \\
-458\end{array}$ & - & $\begin{array}{r}27,544 \\
-997\end{array}$ & $\begin{array}{r}34,3+4 \\
-75\end{array}$ & $\begin{array}{r}22,588 \\
2,259\end{array}$ & $\begin{array}{r}170,320 \\
2,599\end{array}$ & $\begin{array}{r}98 \% \\
2 \%\end{array}$ \\
\hline TCIAL NET OSAGE & 34.256 & $i 2,3 \approx 0$ & 37,748 & 10,509 & - & 26,545 & 34,258 & 17,270 & 172,919 & \\
\hline
\end{tabular}

\begin{tabular}{|c|c|c|c|c|c|c|c|c|c|}
\hline $\begin{array}{l}\text { SOEPLY OP BDERGY } \\
\text { FOSS }\end{array}$ & - & - & - & - & - & - & 15,903 & - & 15,903 \\
\hline HY DRCELECTEIC & - & - & - & - & - & - & - & 956 & 956 \\
\hline NOCL EAR & - & - & - & - & - & - & $\overline{-}$ & $=$ & - \\
\hline GEC. E SOL AR & - & - & - & - & - & - & - & 22 & 22 \\
\hline TOTAL SUPPII & - & - & - & - & - & - & 15,903 & 978 & 16,881 \\
\hline
\end{tabular}

\section{QRT IM PORTS}

$34,: 56$

12,323

37,748

10.509

$26,54 \epsilon$

$18,3 \in 5$

16,292

156,038

-

NOTES:
TRANSPCRBATICN LOSS FOR
TRANSPORAATICN LOSS FOR
ILECIRICITY G BN. $=66.62 \mathrm{~N}$
Matoral gas
$=0.0 \pi$ 
REGICNAL ENE FGY EALANCE STATEMENT

PIES MID MID SCENARI

\begin{tabular}{|c|c|c|c|c|c|c|c|c|c|}
\hline SECTOK & $\begin{array}{l}\text { DISTILLATE } \\
\text { OIL }\end{array}$ & $\begin{array}{l}\text { RESIDUAL } \\
\text { OII }\end{array}$ & $\begin{array}{l}\text { GRSOLINE } \\
\text { CALL ONI }\end{array}$ & $\begin{array}{c}\text { OTHER } \\
\text { HYDRO- } \\
\text { CARBONS } \\
\text { TS IN } 10 * \%\end{array}$ & $\begin{array}{c}\text { CR ODE } \\
\text { OIL } \\
\text { BTU'S) }\end{array}$ & $\begin{array}{l}\text { NATURAL } \\
\text { GAS }\end{array}$ & $\operatorname{COAL}$ & ELECTRICITY & $\begin{array}{r}\text { SECTOR } \\
\text { TOTAL }\end{array}$ \\
\hline $\begin{array}{l}\text { PIHAL CEMAND SECTOKS } \\
\text { 3ESIDENTIAL, CCMH. } \\
\text { INDOSTRIAL } \\
\text { TRANSPORTATION } \\
\text { MISCELLANECOS OSZS }\end{array}$ & $\begin{array}{r}14,776 \\
5,394 \\
6,370 \\
364\end{array}$ & $\begin{array}{r}1,977 \\
4.960 \\
647 \\
198\end{array}$ & $\begin{array}{r}- \\
41.097 \\
-\end{array}$ & $\begin{array}{r}4,386 \\
3,893 \\
1,414 \\
7\end{array}$ & $\begin{array}{l}- \\
-\end{array}$ & $\begin{array}{r}20,831 \\
11,573 \\
427 \\
594\end{array}$ & $\begin{array}{r}158 \\
13,608 \\
1 \\
3\end{array}$ & $\begin{array}{r}11,235 \\
11,379 \\
22 \\
201\end{array}$ & $\begin{array}{r}53,363 \\
50,807 \\
49,978 \\
1,367\end{array}$ \\
\hline $\begin{array}{l}\text { TETAI FINAL } \\
\text { DEMAND SECTCRS }\end{array}$ & 26,904 & 7,782 & 41,097 & 9.700 & - & 33.425 & 13,770 & 22,837 & 155,515 \\
\hline $\begin{array}{l}\text { TRANSPCRHATICN } \\
\text { ELECTRICITY GEN- } \\
\text { PETROLEOM EBCDOCTS } \\
\text { NATORAL GAS } \\
\text { SYNTRETICS }\end{array}$ & $\begin{array}{r}757 \\
- \\
-\end{array}$ & $\begin{array}{l}- \\
\overline{-}\end{array}$ & $\begin{array}{l}- \\
- \\
-\end{array}$ & $\begin{array}{l}\overline{-} \\
\overline{-}\end{array}$ & $\begin{array}{l}\overline{-} \\
-\end{array}$ & $\begin{array}{r}760 \\
- \\
-\end{array}$ & $\begin{array}{r}2,464 \\
- \\
-\end{array}$ & $\begin{array}{r}-1,256 \\
- \\
-\end{array}$ & $\begin{array}{r}2,725 \\
- \\
-\end{array}$ \\
\hline $\begin{array}{l}\text { NET FOEL OSFL } \\
\text { IN TRANSFOEMATION }\end{array}$ & 757 & - & - & - & - & 760 & 2,464 & $-1,256$ & 2,725 \\
\hline $\begin{array}{l}\text { TCTAL GROSS FIORS } \\
\text { LCSSES } \& \text { OMISSIONS }\end{array}$ & $\begin{array}{r}27,661 \\
1,599\end{array}$ & $\begin{array}{r}7,782 \\
0\end{array}$ & $\begin{array}{r}41.097 \\
-0\end{array}$ & $\begin{array}{r}9,700 \\
-405\end{array}$ & $\overline{-}$ & $\begin{array}{l}34,185 \\
-1,238\end{array}$ & $\begin{array}{r}16,234 \\
-35\end{array}$ & $\begin{array}{r}22,837 \\
2,283\end{array}$ & $\begin{array}{r}158,240 \\
2,203\end{array}$ \\
\hline ICTAL NET OSAGE & 29,260 & 7.782 & 41,096 & 9,294 & - & 32,946 & 16,198 & 23,864 & 160,443 \\
\hline $\begin{array}{l}\text { SOEELY OP ENFBGY } \\
\text { FOSSIL FOEI } \\
\text { HYDRCELPCIEIC } \\
\text { NOCL EAR } \\
\text { GEC. ESOLAR }\end{array}$ & $\begin{array}{l}\overline{-} \\
\overline{-}\end{array}$ & $\begin{array}{l}- \\
-\end{array}$ & $\begin{array}{l}- \\
- \\
-\end{array}$ & $\begin{array}{l}\overline{-} \\
\overline{-} \\
\overline{-}\end{array}$ & $\begin{array}{l}- \\
- \\
-\end{array}$ & $\begin{array}{l}- \\
-\end{array}$ & $\begin{array}{r}59,984 \\
= \\
=\end{array}$ & $\begin{array}{r}34 \overline{-} \\
34,313 \\
-\end{array}$ & $\begin{array}{r}59,984 \\
341 \\
34,313 \\
-\end{array}$ \\
\hline ECTAL SOPPIY & - & - & - & - & - & - & 59,984 & 34,654 & 94,638 \\
\hline
\end{tabular}

SET IM FORTS

29,260

7.782

41,096

9,294

32,946

$-43,785$

$-10,789$

65,805

OF REGION

NOTES:

$\begin{array}{lllll}1 & \text { TRANSFCRHATICN } & \text { LOSS POR } & \text { ELECTRICITY GEN } & =68.45 \% \\ 2 & \text { TRANSFORAATICN } & \text { LOSS POR } & \text { PETROLEOM PRODOCTS } & =0.0 \% \\ 3 & \text { TRANSPORAATICN LCSS POR } & \text { NATURAL GAS } & =0.0 \% \\ 4 & \text { TRANSPCRMATICN LOSS POR } & \text { SYRTRETICS } & =0.0 \%\end{array}$


REGICNAL ENZ FGY EALANCE STATEMENT
EIES MID MID SCENARIT

\begin{tabular}{|c|c|c|c|c|c|c|c|c|c|c|}
\hline SE:TCR & $\begin{array}{l}\text { DESTILLATE } \\
\text { OIL }\end{array}$ & $\underset{\text { OIL }}{\operatorname{RBSIDCAL}}$ & $\begin{array}{l}\text { GASOEINE } \\
\text { (ALI ON }\end{array}$ & $\begin{array}{c}\text { OTHER } \\
\text { HIDRO- } \\
\text { CAREONS } \\
\text { TS IN } 10 * *\end{array}$ & $\begin{array}{c}\text { CRODF } \\
\text { OIL } \\
\text { BTO'S) }\end{array}$ & $\begin{array}{l}\text { NATERAL } \\
\text { GAS }\end{array}$ & $\cos I$ & ELECTRICITY & $\begin{aligned} \text { SECTOR } \\
\text { TOTAL }\end{aligned}$ & \\
\hline $\begin{array}{l}\text { PINEL LEMANL SECTCRS } \\
\text { RESIDENTIAE, COBA. } \\
\text { INDOSTRIAL } \\
\text { TRANSPORTATICH } \\
\text { MISCELLANECOS TSES }\end{array}$ & $\begin{array}{r}570,604 \\
42,138 \\
92,535 \\
6,785\end{array}$ & $\begin{array}{r}25 \varepsilon, 446 \\
744,891 \\
64,450 \\
10,431\end{array}$ & $939, \in 4 \overline{6}$ & $\begin{array}{r}1 \equiv 4,426 \\
2 \approx 5,918 \\
232,420 \\
151\end{array}$ & $\begin{array}{l}- \\
-\end{array}$ & $\begin{array}{r}421,157 \\
35,847 \\
33,236 \\
17,039\end{array}$ & $\begin{array}{r}687 \\
107,186 \\
7 \\
51\end{array}$ & $\begin{array}{r}319,475 \\
150,000 \\
4,648 \\
5,315\end{array}$ & $\begin{array}{r}1,814,795 \\
805,980 \\
1,366,942 \\
39,772\end{array}$ & $\begin{array}{l}38 \% \\
17 \% \\
29 \% \\
1 \%\end{array}$ \\
\hline $\begin{array}{l}\text { TCTAL FINAI } \\
\text { DEMAND SECTORS }\end{array}$ & 812,062 & 488,218 & 939,646 & $59.2,915$ & - & 607,279 & $107, \subseteq 31$ & 479,438 & $4,027,489$ & $84 \pi$ \\
\hline $\begin{array}{l}\text { T RANSPCRMATIEN } \\
\text { EL ICTRICITY, GEN. } \\
\text { PETROLEOM ERODOCTS } \\
\text { NATORAL GAE } \\
\text { SYUTHETICS }\end{array}$ & $\begin{array}{r}71,178 \\
-\$ 86,806 \\
- \\
-\end{array}$ & $\begin{array}{r}45.9,554 \\
-47,155 \\
- \\
-\end{array}$ & $\begin{array}{r}-445,967 \\
- \\
-\end{array}$ & $\begin{array}{r}-189,409 \\
- \\
-\end{array}$ & $1,063,962$ & $\begin{array}{r}880 \\
7,898 \\
- \\
-\end{array}$ & $\begin{array}{r}455,724 \\
- \\
-\end{array}$ & $\begin{array}{r}-325,096 \\
- \\
-\end{array}$ & $\begin{array}{r}662,250 \\
2,531 \\
- \\
-\end{array}$ & $\begin{array}{r}14 \% \\
0 \%\end{array}$ \\
\hline $\begin{array}{l}\text { NET TORL DSEI } \\
\text { IN TRANSOEHATION }\end{array}$ & $-315,628$ & 412,409 & $-445,9.57$ & $-189,401$ & $1,063,562$ & 8,778 & 455,724 & $-325,096$ & 664,781 & $14 \%$ \\
\hline $\begin{array}{l}\text { TCTAL GROSS ILOHS } \\
\text { LCSSES } \& \text { CMI }\end{array}$ & $\begin{array}{r}833,240 \\
51,0 \in 3\end{array}$ & $\begin{array}{r}947,7 \varepsilon 2 \\
21\end{array}$ & $\begin{array}{r}939,6+6 \\
-2\end{array}$ & $\begin{array}{l}592,915 \\
-20,784\end{array}$ & $\begin{array}{r}1,063,962 \\
53,114\end{array}$ & $\begin{array}{l}\in 16, C 57 \\
-22, \equiv 15\end{array}$ & $\begin{array}{r}563,655 \\
-1,2 \div 1\end{array}$ & $\begin{array}{r}479,438 \\
47,948\end{array}$ & $\begin{array}{r}4,692,270 \\
103,804\end{array}$ & $\begin{array}{r}98 \% \\
2 \%\end{array}$ \\
\hline ICIAL NET OSEGE & 547,497 & 900,648 & 493,676 & 378,729 & $1,117,076$ & 593,741 & 562,413 & 202,290 & $4.796,074$ & \\
\hline
\end{tabular}

SOFFLY OF ENERGY
$\begin{aligned} & \text { FOSS IL FOEI } \\ & \text { HYDRELECTFIC }\end{aligned}$
NOCL EAR
GEC.ESOLAR

\begin{tabular}{|c|c|c|c|c|c|c|c|c|c|}
\hline $\begin{array}{l}\text { YET IU FORTS } \\
\text { CP REGION }\end{array}$ & 547,497 & 000,648 & 493,676 & 378,729 & $1,117,076$ & $593,74:$ & 562,413 & 121,378 & $4,715,162$ \\
\hline
\end{tabular}

\section{NOTES:}

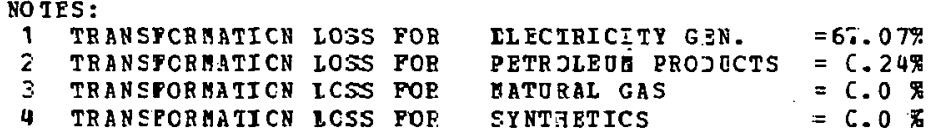


REGIONAL ENEEGY BALANCE STATEMENT

\begin{tabular}{|c|c|c|c|c|c|c|c|c|c|c|}
\hline SECTOK & $\begin{array}{l}\text { IISTILLATE } \\
\text { OIL }\end{array}$ & $\begin{array}{l}\text { RESIDEALL } \\
\text { OII }\end{array}$ & $\begin{array}{l}\text { GASOLINE } \\
\text { (ALL OI }\end{array}$ & $\begin{array}{c}\text { OTHER } \\
\text { HYDRO- } \\
\text { CARBONS } \\
\text { TS IN } 10 * \$ 9\end{array}$ & $\begin{array}{c}\text { CRODE } \\
\text { OIL } \\
\text { BTO'S) }\end{array}$ & $\begin{array}{l}\text { NATORAL } \\
\text { GAS }\end{array}$ & $\operatorname{CCAL}$ & ELECTRICITY & $\begin{array}{l}\text { SECTOR } \\
\text { TOTAL }\end{array}$ & \\
\hline $\begin{array}{l}\text { PINIL CEMANL SECTOKS } \\
\text { BESIDENTIAL, CCMA. } \\
\text { INDOSTRIAL } \\
\text { TRANSPORTAIION } \\
\text { MISCELLANECTS OSES }\end{array}$ & $\begin{array}{r}212,587 \\
55,871 \\
53,493 \\
4,401\end{array}$ & $\begin{array}{r}39,958 \\
138,822 \\
25,696 \\
3,928\end{array}$ & $457.97 \overline{-}$ & $\begin{array}{r}52,130 \\
193,641 \\
34,865 \\
86\end{array}$ & $\begin{array}{l}- \\
- \\
-\end{array}$ & $\begin{array}{r}217,359 \\
142,747 \\
10,195 \\
7,636\end{array}$ & $\begin{array}{r}1,397 \\
303,953 \\
55 \\
34\end{array}$ & $\begin{array}{r}150,564 \\
139,047 \\
1,020 \\
2,224\end{array}$ & $\begin{array}{r}673,995 \\
974,081 \\
583,302 \\
18,309\end{array}$ & $\begin{array}{r}25 \% \\
37 \% \\
22 \% \\
1 \%\end{array}$ \\
\hline $\begin{array}{l}\text { TCTAI FINAI } \\
\text { DEMAND SECTCRS }\end{array}$ & 326,352 & 208,404 & 457,978 & 280,722 & - & 377,937 & 305,439 & 292,855 & $2,249,687$ & $85 \%$ \\
\hline $\begin{array}{l}\text { TRANSPCAHATICN } \\
\text { ELECTRICITY GEN. } \\
\text { PETR OLEOA ERCDOCTS } \\
\text { NATORAL GAS } \\
\text { SYNTHETICS }\end{array}$ & $\begin{array}{r}32,117 \\
-848,156 \\
-\end{array}$ & $\begin{array}{r}50,953 \\
-103,396 \\
- \\
-\end{array}$ & $\begin{array}{r}-977,87 \overline{8} \\
-\end{array}$ & $\begin{array}{r}-415,30 \overline{1} \\
101,830\end{array}$ & $2,332,966$ & $\begin{array}{r}7,705 \\
17,318 \\
- \\
-91,855\end{array}$ & $\begin{array}{r}292,038 \\
- \\
-\end{array}$ & $\begin{array}{r}-125,774 \\
- \\
-\end{array}$ & $\begin{array}{r}257,039 \\
5,554 \\
- \\
9,975\end{array}$ & $\begin{array}{r}10 \% \\
0 \%\end{array}$ \\
\hline $\begin{array}{l}\text { NET FOEL OSEL } \\
\text { IN TRANSFOEMATIJN }\end{array}$ & $-816,039$ & $-52,443$ & $-977,878$ & $-313,471$ & $2,332,966$ & $-66,831$ & 292,038 & $-125,774$ & 272,568 & $10 \%$ \\
\hline $\begin{array}{l}\text { TCTAL GROSS FLORS } \\
\text { LCSSES \& CMISSIONS }\end{array}$ & $\begin{array}{r}358,469 \\
20,724\end{array}$ & $\begin{array}{r}259,357 \\
.5\end{array}$ & $\begin{array}{r}457,978 \\
-1\end{array}$ & $\begin{array}{l}382,552 \\
-15,991\end{array}$ & $\begin{array}{r}2,332,966 \\
116,465\end{array}$ & $\begin{array}{l}402,960 \\
-14,596\end{array}$ & $\begin{array}{r}597,477 \\
-1,316\end{array}$ & $\begin{array}{r}292,855 \\
29,288\end{array}$ & $\begin{array}{r}2,522,255 \\
134,579\end{array}$ & $\begin{array}{r}95 \% \\
5 \%\end{array}$ \\
\hline TCTAL NET OSAGE & $-468,962$ & 155.966 & $-519,901$ & $-48,740$ & $2,449,431$ & 296,509 & 596,160 & 196,369 & $2,656,834$ & \\
\hline
\end{tabular}

\begin{tabular}{|c|c|c|c|c|c|c|c|c|c|c|}
\hline $\begin{array}{l}\text { SOEFLY OP ENFRGY } \\
\text { FOSSIL FOEI }\end{array}$ & - & - & - & - & - & - & 102,398 & - & 102,398 & $48 \%$ \\
\hline HY DR CELECT FIC & - & - & - & - & - & - & - & 3,644 & 3,644 & $2 \%$ \\
\hline NOCL PAR & - & - & - & - & - & - & - & 106,256 & 106,256 & \\
\hline GEO. ESOLAR & - & - & - & - & - & - & - & 75 & 75 & \% \\
\hline TCTAL SUPPIY & - & - & - & - & - & - & 102,398 & 109,975 & 212,373 & \\
\hline
\end{tabular}

\begin{tabular}{l}
$\begin{array}{l}\text { NET IH FORTS } \\
\text { OP R RGION }\end{array}$ \\
\hline
\end{tabular}


REGIONBL ZNEEGY EALANCE STATE.MENT
PLES IID MID SCENARIO

\begin{tabular}{|c|c|c|c|c|c|c|c|c|c|c|}
\hline SECIOE & $\begin{array}{l}\text { DISTILLATE } \\
\text { OIL }\end{array}$ & $\begin{array}{l}\text { RESIDOAL } \\
\text { OIL }\end{array}$ & $\begin{array}{l}\text { GASOL I N } 3 \\
\text { (ALL J J }\end{array}$ & $\begin{array}{c}\text { OTHER } \\
\text { RYDRO- } \\
\text { CARBONS } \\
\text { TS IN } 10 * * 9\end{array}$ & $\begin{array}{c}\text { CEOCE } \\
\text { CII } \\
\text { BTO'SI }\end{array}$ & $\begin{array}{l}\text { HATUZ ZL } \\
\text { GA:S }\end{array}$ & $\operatorname{COAL}$ & ELECIRICITY & $\begin{array}{r}\text { SECTOR } \\
\text { TOTAL }\end{array}$ & \\
\hline $\begin{array}{l}\text { PINAL CFMANL SECTOKS } \\
\text { BFSIDENTIAI, CCHH. } \\
\text { IND DSTRIAL } \\
\text { TRANSPORTATICN } \\
\text { MISCELLANCDS OSES }\end{array}$ & $\begin{array}{r}40.542 \\
14.356 \\
22.663 \\
759\end{array}$ & $\begin{array}{r}5,996 \\
3,233 \\
1,830 \\
414\end{array}$ & 108,950 & $\begin{array}{r}11,649 \\
12,265 \\
3,891 \\
15\end{array}$ & $\begin{array}{l}\overline{-} \\
\overline{-}\end{array}$ & $\begin{array}{r}56,504 \\
38,519 \\
1,1 ? 1 \\
1,295\end{array}$ & $\begin{array}{r}427 \\
92,535 \\
27 \\
6\end{array}$ & $\begin{array}{r}31,439 \\
32,997 \\
565 \\
398\end{array}$ & $\begin{array}{r}146,687 \\
203,985 \\
139,097 \\
2,807\end{array}$ & $\begin{array}{r}24 \% \\
33 \% \\
22 \% \\
0 \%\end{array}$ \\
\hline $\begin{array}{l}\text { TCTAI FINAI } \\
\text { DEMAND SECICRS }\end{array}$ & 78,330 & $21,4.33$ & 108,950 & 27,820 & - & $97,5<9$ & 92,995 & 65,399 & 492,576 & 79 \\
\hline $\begin{array}{l}\text { TR R ANSPORMATICN } \\
\text { ELECTRICITY GEN. } \\
\text { PETROLEOM ERCDOCTS } \\
\text { NA FORAL GAS } \\
\text { SY YTHETICS }\end{array}$ & $\begin{array}{r}2,781 \\
= \\
=\end{array}$ & $\begin{array}{r}139 \\
- \\
-\end{array}$ & $\begin{array}{l}- \\
-\end{array}$ & $\begin{array}{l}- \\
- \\
-\end{array}$ & E & $\begin{array}{r}2,178 \\
= \\
=\end{array}$ & $\begin{array}{r}178,389 \\
- \\
-\end{array}$ & $\begin{array}{r}-61,589 \\
- \\
-\end{array}$ & $\begin{array}{r}122,388 \\
- \\
-\end{array}$ & $2 \mathrm{Cq}$ \\
\hline $\begin{array}{l}\text { NET FOEL OSEI } \\
\text { IN TRANSFOSHATIOA }\end{array}$ & 2,781 & 129 & - & - & - & $2, \cdot 78$ & 178,889 & $-61,589$ & 122,388 & $2 C \%$ \\
\hline $\begin{array}{l}\text { TCTAL GROSS FLOHS } \\
\text { LCSSES \& CMISSIONS }\end{array}$ & $\begin{array}{r}81,111 \\
4,689\end{array}$ & $\begin{array}{r}21,562 \\
0\end{array}$ & $\begin{array}{r}108,950 \\
-0\end{array}$ & $\begin{array}{r}27,820 \\
-1,162\end{array}$ & - & $\begin{array}{l}99,827 \\
-3,6.16\end{array}$ & $\begin{array}{r}271,884 \\
-598\end{array}$ & $\begin{array}{r}65,399 \\
6,540\end{array}$ & $\begin{array}{r}614,9 \in 4 \\
5,852\end{array}$ & $\begin{aligned} 95 \% \\
1 \%\end{aligned}$ \\
\hline TCTAL NET OSEGE & $B 5.800$ & $21,5 \in 2$ & 108,949 & 20.657 & - & $96, \approx 10$ & 271,285 & 10,350 & 620,816 & \\
\hline
\end{tabular}

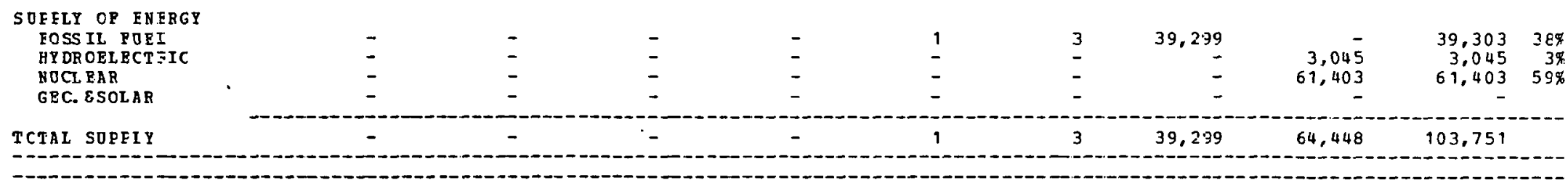

\begin{tabular}{l}
$\begin{array}{l}\text { NET IMFORTS } \\
\text { OP REGION }\end{array}$ \\
\hdashline$\quad 85,800$
\end{tabular}


REGIONAL ENE EGY EALANCE STATEMENT
PIES MID MID SCENARIO

\begin{tabular}{|c|c|c|c|c|c|c|c|c|c|c|}
\hline SECTOF & $\begin{array}{l}\text { DISTILIATE } \\
\text { OII }\end{array}$ & $\begin{array}{l}\text { RZSIDUAL } \\
\text { OII }\end{array}$ & $\begin{array}{l}\text { GASOL INE } \\
\text { GALL ON }\end{array}$ & $\begin{array}{c}\text { OTHER } \\
\text { HYDRO- } \\
\text { CARBONS } \\
\text { TS IN } 10 * * 9\end{array}$ & $\begin{array}{c}\text { CRIDE } \\
\text { OIL } \\
\text { ETO'S) }\end{array}$ & $\begin{array}{l}\text { NATURAL } \\
\text { GAS }\end{array}$ & $\operatorname{COAL}$ & ELECTRICITY & $\begin{array}{r}\text { SECTOR } \\
\text { TOTAL }\end{array}$ & \\
\hline $\begin{array}{l}\text { FINAL CEMANC SECTORS } \\
\text { RESIDENTIAL, CCAH. } \\
\text { INDOSTRIAL } \\
\text { TRANSPORTATICN } \\
\text { BISCELLANECOS OSES }\end{array}$ & $\begin{array}{r}53,893 \\
28,794 \\
19,920 \\
3,473\end{array}$ & $\begin{array}{r}10,527 \\
34,507 \\
13,8004 \\
1,860\end{array}$ & $\begin{array}{r}- \\
\overline{-} \\
178,511\end{array}$ & $\begin{array}{r}16,774 \\
28,630 \\
12,725 \\
65\end{array}$ & $\overline{-}$ & $\begin{array}{r}57.376 \\
28,123 \\
4.241 \\
4,975\end{array}$ & $\begin{array}{r}353 \\
98,692 \\
28 \\
26\end{array}$ & $\begin{array}{r}58,362 \\
41,584 \\
547 \\
1,592\end{array}$ & $\begin{array}{r}196,985 \\
260,330 \\
229,776 \\
11,931\end{array}$ & $\begin{array}{r}25 \% \\
33 \% \\
29 \% \\
2 \%\end{array}$ \\
\hline $\begin{array}{l}\text { TCTAL FINAI } \\
\text { DEMAND SBCTCRS }\end{array}$ & 106,020 & $60, \$ 98$ & 178,511 & 58,194 & - & 94,715 & $\$ 9,099$ & 102,085 & 699,022 & $88 \%$ \\
\hline $\begin{array}{l}\text { TEANSPCRHATION } \\
\text { ELECTRICITY GEN. } \\
\text { PETR OLEOM ERCDOCTS } \\
\text { NATORAL GAS } \\
\text { SY NTHETICS }\end{array}$ & $\begin{array}{r}8,865 \\
-27,751 \\
- \\
-\end{array}$ & $\begin{array}{r}27,438 \\
-3,383 \\
-\end{array}$ & $\begin{array}{r}-31,995 \\
-\end{array}$ & $\begin{array}{r}-13,58 \overline{-} \\
125,245\end{array}$ & 76,332 & $\begin{array}{r}4,109 \\
566 \\
- \\
-112,975\end{array}$ & $\begin{array}{r}66,200 \\
- \\
-\end{array}$ & $\begin{array}{r}-34,214 \\
- \\
-\end{array}$ & $\begin{array}{r}72,398 \\
182 \\
- \\
12,270\end{array}$ & $\begin{array}{l}9 \% \\
0 \%\end{array}$ \\
\hline $\begin{array}{l}\text { NET FOEL OSER } \\
\text { IN TRABSPOBHATION }\end{array}$ & $-18,886$ & 24,054 & $-31,995$ & 111,657 & 76,332 & $-108,299$ & 66,200 & $-34,214$ & 84,850 & $11 \%$ \\
\hline $\begin{array}{l}\text { TCTAL GROSS FLORS } \\
\text { IESSES \& OHISSIOHS }\end{array}$ & $\begin{array}{r}114,885 \\
6,641\end{array}$ & $\begin{array}{r}87,836 \\
2\end{array}$ & $\begin{array}{r}178,511 \\
-0\end{array}$ & $\begin{array}{r}183,439 \\
-7.668\end{array}$ & $\begin{array}{r}76,332 \\
3,810\end{array}$ & $\begin{array}{l}99,390 \\
-3,600\end{array}$ & $\begin{array}{r}165,299 \\
-364\end{array}$ & $\begin{array}{r}102,085 \\
10,209\end{array}$ & $\begin{array}{r}783,872 \\
9,031\end{array}$ & $\begin{array}{r}99 \% \\
1 \%\end{array}$ \\
\hline
\end{tabular}

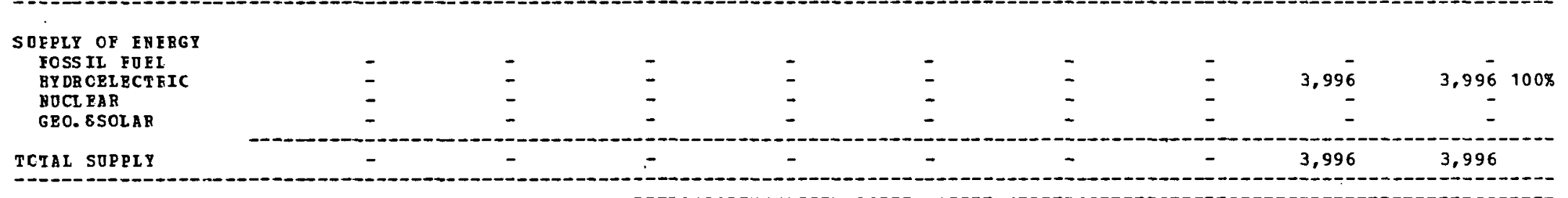

- - - - -

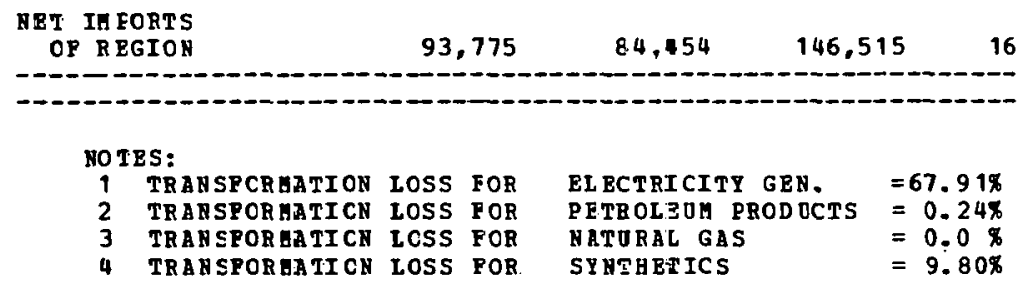


RBGIONAL 3NE FGY EALANCE STATEMENT

\begin{tabular}{|c|c|c|c|c|c|c|c|c|c|c|}
\hline SECTOR & $\underset{O=L}{\text { DISTILLATE }}$ & $\begin{array}{l}\text { RESIDUTAL } \\
\text { OIL }\end{array}$ & $\begin{array}{l}\text { GASOI INE } \\
\text { (ALL DNIT }\end{array}$ & $\begin{aligned} & \text { CTHER } \\
& \text { AYDRO- } \\
& \therefore \text { AABONS } \\
& \because \quad \text { IN } 10 * * 9\end{aligned}$ & $\begin{array}{c}\text { CRODE } \\
\text { OIL } \\
\text { BTO'S) }\end{array}$ & $\begin{array}{l}\text { NATURAL } \\
\text { GAS }\end{array}$ & COEL & ELECTRICITI & $\begin{array}{r}\text { SECTOR } \\
\text { TOTAI }\end{array}$ & \\
\hline $\begin{array}{l}\text { PINAL CEMANI SECTORS } \\
\text { BESIDENTIAI, CCHA. } \\
\text { IND DSTRIAL } \\
\text { TRA YSPORTATICN } \\
\text { WISCELLANECOS OSES }\end{array}$ & $\begin{array}{r}75.611 \\
6.548 \\
19.334 \\
8.416 \\
\end{array}$ & $\begin{array}{r}79,806 \\
10.600 \\
27.430 \\
4.536\end{array}$ & $230,18 \frac{-}{-}$ & $\begin{array}{r}20,176 \\
7,768 \\
40,434 \\
167\end{array}$ & $\begin{array}{l}\overline{-} \\
\overline{-}\end{array}$ & $\begin{array}{r}69,383 \\
6,714 \\
9,573 \\
12,301\end{array}$ & $\begin{array}{r}871 \\
6.756 \\
7 \\
69\end{array}$ & $\begin{array}{r}77,971 \\
11,805 \\
85 \\
5,276\end{array}$ & $\begin{array}{r}263,818 \\
49,321 \\
327,147 \\
31,415\end{array}$ & $\begin{array}{r}33 \% \\
6 \% \\
41 \% \\
4 \%\end{array}$ \\
\hline $\begin{array}{l}\text { TCTAI PINAI } \\
\text { DEMAND SECTCRS }\end{array}$ & 109,909 & $6.2,4 \geq 2$ & 230,184 & 68,545 & - & 98,401 & 7,103 & 95,137 & 671,701 & $84 \pi$ \\
\hline $\begin{array}{l}\text { TAEN SF CRHATICN } \\
\text { BLECTRICITY. GEN. } \\
\text { PBTROL OOH ERCDOCTS } \\
\text { NATORAL GAS } \\
\text { SY BTHETICS }\end{array}$ & $\begin{array}{r}6.035 \\
- \\
-\end{array}$ & $\begin{array}{r}38.8 .57 \\
- \\
-\end{array}$ & $\begin{array}{l}\overline{-} \\
\overline{-}\end{array}$ & $\begin{array}{l}\overline{-} \\
\overline{-}\end{array}$ & $\begin{array}{l}- \\
- \\
-\end{array}$ & $\begin{array}{r}3,16.9 \\
- \\
-\end{array}$ & $\begin{array}{r}132,025 \\
= \\
=\end{array}$ & $\begin{array}{r}-58,823 \\
- \\
-\end{array}$ & $\begin{array}{r}121,273 \\
- \\
-\end{array}$ & $15 \%$ \\
\hline $\begin{array}{l}\text { NET FOEL OSEI } \\
\text { IN TRANSFOEHATION }\end{array}$ & 6.035 & $\equiv 8.867$ & - & - & - & $3,1 \in 9$ & $132,1,25$ & $-58,823$ & 121,273 & $15 \%$ \\
\hline $\begin{array}{l}\text { TCTAL GROSS FLORS } \\
\text { ICSSES } \varepsilon \text { CMISSIOYS }\end{array}$ & $\begin{array}{r}115, .944 \\
6.703 \\
\end{array}$ & $\begin{array}{r}131,289 \\
2 \\
\end{array}$ & $\begin{array}{r}230,194 \\
-0 \\
-\end{array}$ & $\begin{array}{l}63,545 \\
-2,865 \\
-\end{array}$ & $\overline{-}$ & $\begin{array}{r}101,570 \\
-3,679 \\
\end{array}$ & $\begin{array}{r}139,128 \\
-306 \\
\end{array}$ & $\begin{array}{r}95,137 \\
9,514 \\
\end{array}$ & $\begin{array}{r}792,974 \\
9,368 \\
\end{array}$ & $\begin{array}{r}99 \% \\
19 \\
\end{array}$ \\
\hline TOTAL NET DSAGE & 122.647 & 101,291 & 230,193 & 65.679 & - & 97,890 & 138,821 & 45,828 & 802,342 & \\
\hline
\end{tabular}

SOEPIY OF ENERG
FOSSIL POEL
HYIROELECTIC
NOCLRAR
GEC.ESOLAR

NET IM FCRTS
OP REGION


REGIONAL BNEFGY BALANCE STATEMENT

PIES MID HID SCENARIO

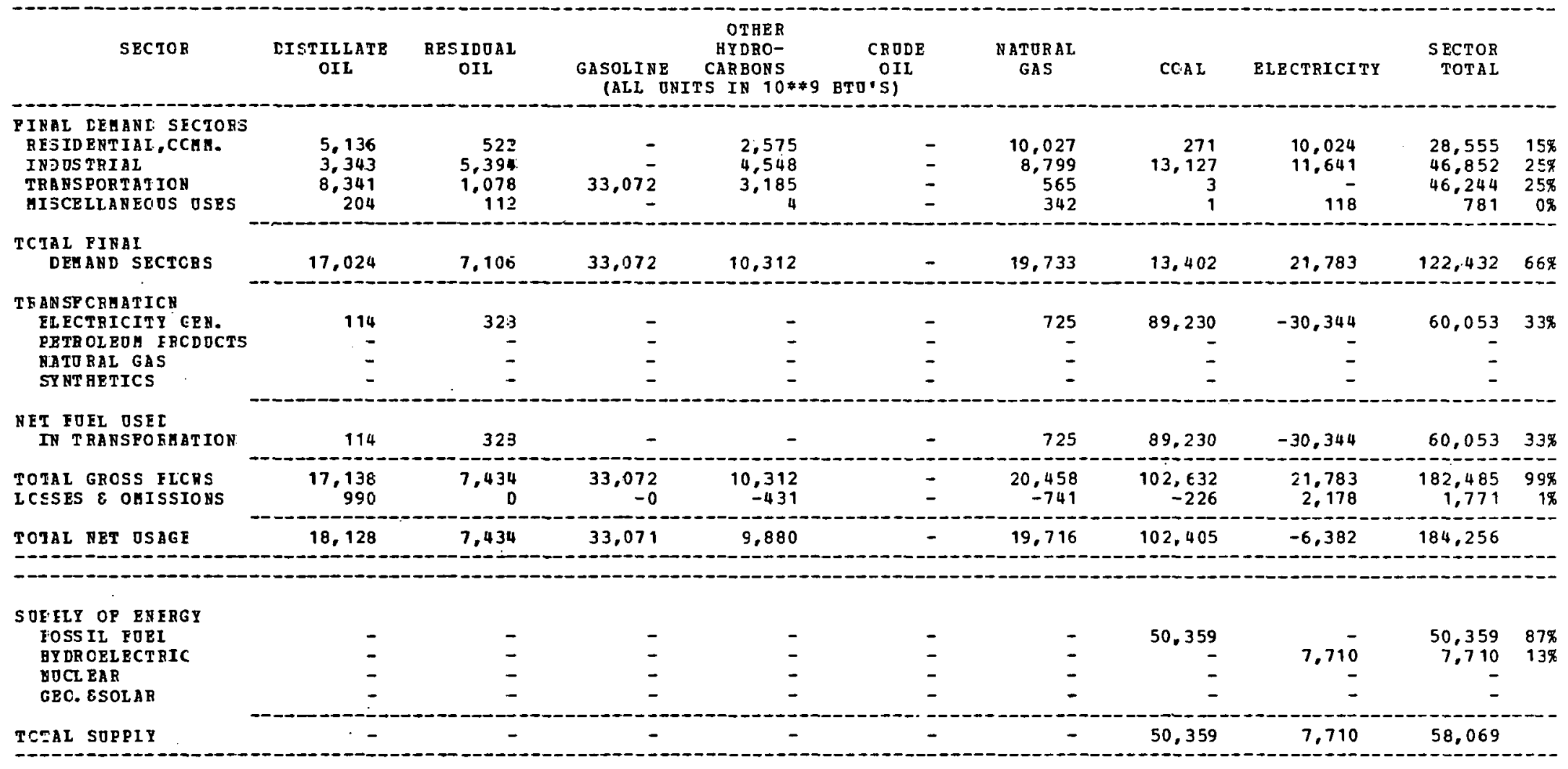

\section{RET IH PORTS}

OP R RGION

18,128

$7,4 \equiv 4$

33,071

9,880

19,716

52,046

$-14,092$

126,187

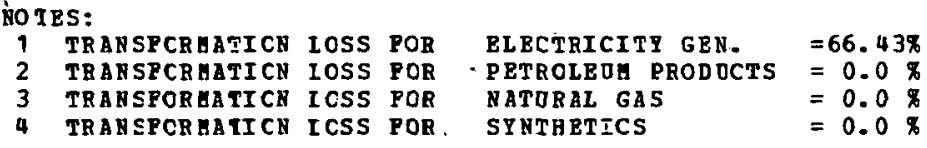


REGIONAL BHEEGY EALANCE STATEMENT

IONAL BHEEGY BALANCE STA
PIES NJD AID SCENARIO

\begin{tabular}{|c|c|c|c|c|c|c|c|c|c|}
\hline SECTOE & $\begin{array}{l}\text { DISTILLATB } \\
\text { OIL }\end{array}$ & $\begin{array}{l}\text { RES IDJAL } \\
\text { EIL }\end{array}$ & $\begin{array}{l}\text { GASOLINE } \\
\text { (ALI O }\end{array}$ & $\begin{array}{l}\text { OTHER } \\
\text { EYD } 20- \\
\text { CAPBDNS } \\
\text { S IN } 10 * 49\end{array}$ & $\begin{array}{c}\text { CRUDP } \\
\text { OIL } \\
\text { BTOSS) }\end{array}$ & $\begin{array}{l}\text { NaTOR2L } \\
\text { GAS }\end{array}$ & $\operatorname{COAL}$ & ELECTRICITY & $\begin{array}{l}\text { SECTOR } \\
\text { TOTAL }\end{array}$ \\
\hline $\begin{array}{l}\text { FIRLC DEMAND SECTORS } \\
\text { RESIDENTIAL,CCHA. } \\
\text { INDOSTRIAL } \\
\text { TRANSPORTATICA } \\
\text { MISCELLANECOE OSES }\end{array}$ & $\begin{array}{r}11,592 \\
10,758 \\
16,394 \\
.278\end{array}$ & $\begin{array}{r}862 \\
15,230 \\
2,259 \\
152\end{array}$ & $\begin{array}{r}- \\
- \\
- \\
-\end{array}$ & $\begin{array}{r}5.277 \\
18.775 \\
6.437 \\
5\end{array}$ & $\begin{array}{l}- \\
- \\
-\end{array}$ & $\begin{array}{r}12,678 \\
20,0 \equiv 6 \\
845 \\
457\end{array}$ & $\begin{array}{r}440 \\
45,023 \\
29 \\
2\end{array}$ & $\begin{array}{r}18,943 \\
21,902 \\
166\end{array}$ & $\begin{array}{r}49,792 \\
132,724 \\
93,351 \\
1,060\end{array}$ \\
\hline $\begin{array}{l}\text { TCTAL FINAL } \\
\text { DEM AND SBCTCRS }\end{array}$ & $\equiv 9,0 \geq 2$ & 19,503 & 57,387 & 30.494 & - & 34,016 & 45,490 & 41.011 & 276,927 \\
\hline $\begin{array}{l}\text { TRANSPCRMATICD } \\
\text { ELECTRICITY, GEN. } \\
\text { FETROLBOM EBCDOCTS } \\
\text { NATORAL GAS } \\
\text { SY NTERTCS }\end{array}$ & $\begin{array}{r}757 \\
- \\
-\end{array}$ & $\begin{array}{l}\bar{z} \\
\bar{z}\end{array}$ & I & $\begin{array}{l}\overline{-} \\
\bar{z}\end{array}$ & $\begin{array}{l}- \\
-\end{array}$ & $\begin{array}{r}1,325 \\
- \\
=\end{array}$ & $\begin{array}{r}19,891 \\
= \\
=\end{array}$ & $\begin{array}{r}-7,297 \\
- \\
-\end{array}$ & $\begin{array}{r}14,686 \\
- \\
-\end{array}$ \\
\hline $\begin{array}{l}\text { NET FOEL OSEL } \\
\text { IN TRANSPOERTION }\end{array}$ & $7 \in 7$ & - & - & - & - & 1.325 & 19,891 & $-7,297$ & 14,686 \\
\hline $\begin{array}{l}\text { TCIAL GROSS FLCHS } \\
\text { LCSSES } \& \text { OHISSIONS }\end{array}$ & $\begin{array}{r}35.7 E 9 \\
2.3 C 0\end{array}$ & $\begin{array}{r}19,503 \\
0\end{array}$ & $\begin{array}{r}67,387 \\
-0\end{array}$ & $\begin{array}{l}30,494 \\
-1,274\end{array}$ & - & $\begin{array}{l}35,341 \\
-1,280\end{array}$ & $\begin{array}{r}65,385 \\
-144\end{array}$ & $\begin{array}{r}41,011 \\
4,101\end{array}$ & $\begin{array}{r}291,613 \\
3,703\end{array}$ \\
\hline TCTAL DET OSAG: & $42,0 e 9$ & 19.503 & 67,386 & $=9.219$ & - & 34,060 & 65,240 & 37,815 & 295,316 \\
\hline
\end{tabular}

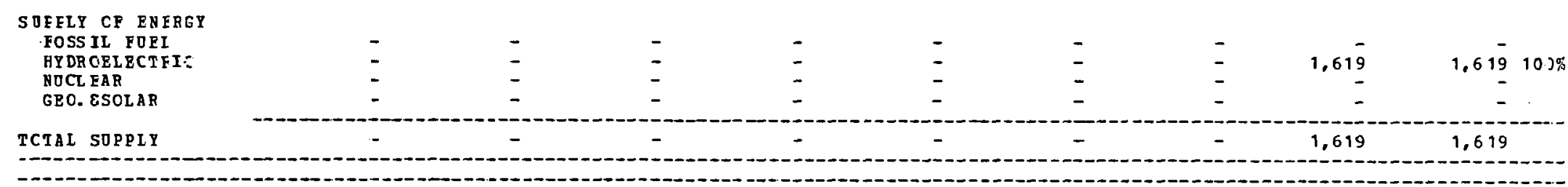

\begin{tabular}{|c|c|c|c|c|c|c|c|c|c|}
\hline $\begin{array}{l}\text { NET IM FORTS } \\
\text { OP REGION }\end{array}$ & $4 \bar{z}_{,} 089$ & 19,503 & $67,38 \epsilon$ & $23, \pi 19$ & - & 34,060 & 65.240 & 36,196 & 293,697 \\
\hline
\end{tabular}

\begin{tabular}{|c|c|c|c|c|c|}
\hline \multicolumn{6}{|c|}{ NO I } \\
\hline 1 & $\begin{array}{l}\text { TRANSPCBAATICN } \\
\text { TRANSPCBNATICN }\end{array}$ & $\begin{array}{l}\text { Loss } \\
\text { LOSS }\end{array}$ & $\begin{array}{l}\text { POE } \\
\text { POE }\end{array}$ & $\begin{array}{l}\text { EL ECTRICITY GEN. } \\
\text { PETROLEOE PRODOCTS }\end{array}$ & $\begin{array}{l}=66.31 \% \\
=0.0 \%\end{array}$ \\
\hline 3 & TR AN S FOR IA II CY & $\operatorname{tos} s$ & POE & EATORAL GAS & $=0.0 \%$ \\
\hline 4 & TR A S SPORHATI CY & $\operatorname{Lcss}$ & POE & SY मTEEATCS & \\
\hline
\end{tabular}


REGIONAL ENEFGY EAIANCE ST T ENENT

PIES MID MID SCENARIO

\begin{tabular}{|c|c|c|c|c|c|c|c|c|c|c|}
\hline SECTOF & $\begin{array}{l}\text { DIST ILLATE } \\
\text { OIL }\end{array}$ & $\begin{array}{l}\text { RESIDOALL } \\
\text { OIL }\end{array}$ & $\begin{array}{l}\text { GASCLINE } \\
\text { (ALL O }\end{array}$ & $\begin{array}{c}\text { OTHER } \\
\text { HYDRO- } \\
\text { CARBONS } \\
\text { TS IN 10**9 }\end{array}$ & $\begin{array}{c}\text { CEODF } \\
\text { OIL } \\
\text { BTO'S) }\end{array}$ & $\begin{array}{l}\text { NATURAL } \\
\text { GAS }\end{array}$ & COAL & ELECTRICITY & $\begin{array}{l}\text { SECTOR } \\
\text { TOTAL }\end{array}$ & \\
\hline $\begin{array}{l}\text { PIEAL CEMANL SECTOES } \\
\text { RISIDENTIAI, COMH. } \\
\text { IRDOSTRIAL } \\
\text { TRANSPORTATICN } \\
\text { MISCELLANEOOS OSES }\end{array}$ & $\begin{array}{r}14,575 \\
12,441 \\
15,958 \\
856\end{array}$ & $\begin{array}{r}1,368 \\
16,463 \\
4,665 \\
471\end{array}$ & $81.62 \frac{-}{-}$ & $\begin{array}{r}6,328 \\
18,268 \\
13,367 \\
19\end{array}$ & - & $\begin{array}{r}16,869 \\
20,270 \\
1,756 \\
1,473\end{array}$ & $\begin{array}{r}547 \\
32.247 \\
11 \\
7\end{array}$ & $\begin{array}{r}25,697 \\
18,518 \\
- \\
759\end{array}$ & $\begin{array}{r}65,384 \\
118,147 \\
117,389 \\
3,595\end{array}$ & $\begin{array}{r}18 \% \\
33 \% \\
33 \% \\
1 \%\end{array}$ \\
\hline $\begin{array}{l}\text { TOTAL PINAL } \\
\text { DEMAND SECTORS }\end{array}$ & 43,850 & 22,907 & 81,622 & 37,982 & - & 40,368 & 32,812 & 44,974 & 304,515 & $86 \%$ \\
\hline $\begin{array}{l}\text { TRANSP ORMATION } \\
\text { ZLECTRICITY GEN. } \\
\text { PETR OLEUM ERODUCTS } \\
\text { MATURAL GAS } \\
\text { SYNTHETICS }\end{array}$ & $\begin{array}{r}537 \\
- \\
-\end{array}$ & $\begin{array}{r}3,3 \leq 8 \\
= \\
=\end{array}$ & $\begin{array}{l}\overline{-} \\
\overline{-}\end{array}$ & $\begin{array}{l}\overline{-} \\
\overline{-}\end{array}$ & 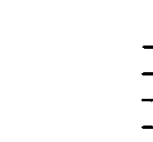 & $\begin{array}{r}1,498 \\
- \\
-\end{array}$ & $\begin{array}{r}65,718 \\
= \\
=\end{array}$ & $\begin{array}{r}-23,723 \\
= \\
-\end{array}$ & $\begin{array}{r}47,478 \\
- \\
-\end{array}$ & $13 \%$ \\
\hline $\begin{array}{l}\text { NET POEL OSED } \\
\text { IN TRANSPORMATIOY }\end{array}$ & 587 & $3,3 \subseteq 8$ & - & - & - & 1,498 & 65,718 & $-23,723$ & 47,478 & $13 \%$ \\
\hline $\begin{array}{l}\text { TOTAL GROSS FLONS } \\
\text { LOSSES \& OMISSIONS }\end{array}$ & $\begin{array}{r}44,437 \\
2,569\end{array}$ & $\begin{array}{r}26,30,5 \\
0\end{array}$ & $\begin{array}{r}81,622 \\
-0\end{array}$ & $\begin{array}{l}37,982 \\
-1,587\end{array}$ & - & $\begin{array}{l}41,866 \\
-1,516\end{array}$ & $\begin{array}{r}98,530 \\
-217\end{array}$ & $\begin{array}{r}44,974 \\
4,497\end{array}$ & $\begin{array}{r}351,993 \\
3,746\end{array}$ & $\begin{array}{r}99 \% \\
10\end{array}$ \\
\hline
\end{tabular}

-

SUPPLY OF ENERGY
FOSS IL POEL
HYDROEL ECTRIC
NOCL EAR
GEO. ESOLAR
TOTAL SOPPIY

$\begin{array}{rr}- & - \\ - & - \\ - & -\end{array}$

-

PLY

\begin{tabular}{l} 
NET IM PORTS \\
OP R EGION \\
\hline
\end{tabular}


REGIONAL ENEEGY BALAYCE STATEMENT

\begin{tabular}{|c|c|c|c|c|c|c|c|c|c|c|}
\hline SECTOR & $\begin{array}{l}\text { DISTILLATB } \\
\text { OIL }\end{array}$ & $\begin{array}{l}\text { RESIDULL } \\
\text { OIL }\end{array}$ & $\begin{array}{l}\text { GASOLTHE } \\
\text { (ALi }\end{array}$ & $\begin{array}{l}\text { OTHER } \\
\text { HYIRO- } \\
\text { OREONS } \\
\text { IS } 10 * 49\end{array}$ & $\begin{array}{c}\text { CRDDE } \\
\text { OIL } \\
\text { BTO'SJ }\end{array}$ & $\begin{array}{l}\text { NATURAL } \\
\text { GAS }\end{array}$ & $\operatorname{COAL}$ & ELECTRICITY & $\begin{array}{r}\text { SECT OR } \\
\text { TOTAL }\end{array}$ & \\
\hline $\begin{array}{l}\text { PINAL DEHAND SECTOFS } \\
\text { RESIDENTIAL, COHM. } \\
\text { INDOSTRIAL } \\
\text { TRANS PORTATION } \\
\text { MISCELLANEO DS OSES }\end{array}$ & $\begin{array}{r}17,252 \\
6,347 \\
11,598 \\
1,359\end{array}$ & $\begin{array}{r}1,409 \\
-15,995 \\
9,574 \\
960\end{array}$ & 97,410 & $\begin{array}{r}7,950 \\
13,262 \\
27,642 \\
52\end{array}$ & $\begin{array}{l}- \\
\bar{z}\end{array}$ & $\begin{array}{r}18,141 \\
7,470 \\
3,662 \\
3,235\end{array}$ & $\begin{array}{r}614 \\
13,938 \\
13 \\
20\end{array}$ & $\begin{array}{r}29,351 \\
13,877 \\
3,189\end{array}$ & $\begin{array}{r}74,717 \\
70,889 \\
149,999 \\
9,216\end{array}$ & $\begin{array}{r}22 \% \\
21 \% \\
45 \% \\
3 \%\end{array}$ \\
\hline $\begin{array}{l}\text { TOTAL PINAL } \\
\text { DEMAND SECTORS }\end{array}$ & 37,356 & 27,938 & 97,410 & 48,906 & - & 32,509 & $14,5: 35$ & 46,417 & 304,821 & $91 \%$ \\
\hline $\begin{array}{l}\text { TRANSF ORIATION } \\
\text { BL ECTRICITY GEN. } \\
\text { PETR OLEUT PRODUCTS } \\
\text { NATTRAL GAS } \\
\text { SY NT BETICS }\end{array}$ & $\begin{array}{r}3,031 \\
-45,255 \\
- \\
-\end{array}$ & $\begin{array}{r}15,069 \\
-5,517 \\
-\end{array}$ & $\begin{array}{r}-52,17 \overline{7} \\
-\end{array}$ & $\begin{array}{r}-22.159 \\
125.245\end{array}$ & $\begin{array}{r}124,481 \\
-\end{array}$ & $\begin{array}{r}1,333 \\
924 \\
-112,975\end{array}$ & $\begin{array}{r}933 \\
- \\
-\end{array}$ & $\begin{array}{r}-6,228 \\
- \\
-\end{array}$ & $\begin{array}{r}14,138 \\
297 \\
12,270\end{array}$ & $\begin{array}{l}4 \% \\
0 \%\end{array}$ \\
\hline $\begin{array}{l}\text { YET FUEL USEL } \\
\text { IN TRANSPFIATION }\end{array}$ & $-42,224$ & 9,552 & $-52,177$ & 103,086 & 124,481 & $-110.71 ?$ & 933 & $-6,228$ & 26,705 & $8 \pi$ \\
\hline $\begin{array}{l}\text { TOTAL GROSS FEORS } \\
\text { LOSSES E OHISIIONS }\end{array}$ & $\begin{array}{r}40,087 \\
2,317\end{array}$ & $\begin{array}{r}43,007 \\
0\end{array}$ & $\begin{array}{r}97,410 \\
-0\end{array}$ & $\begin{array}{r}174.151 \\
-7.279\end{array}$ & $\begin{array}{r}124,481 \\
6,214\end{array}$ & $\begin{array}{l}34,756 \\
-1,259\end{array}$ & $\begin{aligned} 15,518 \\
-\equiv 4\end{aligned}$ & $\begin{array}{r}46,417 \\
4,642\end{array}$ & $\begin{array}{r}331,526 \\
4,601\end{array}$ & $\begin{aligned} 99 \% \\
1 \%\end{aligned}$ \\
\hline MOTAL NET OSAGE & $-2,850$ & 37.490 & 45,232 & $: 44.712$ & 130,695 & $-79,458$ & $15,4 \in 3$ & 44,831 & 336,127 & \\
\hline
\end{tabular}

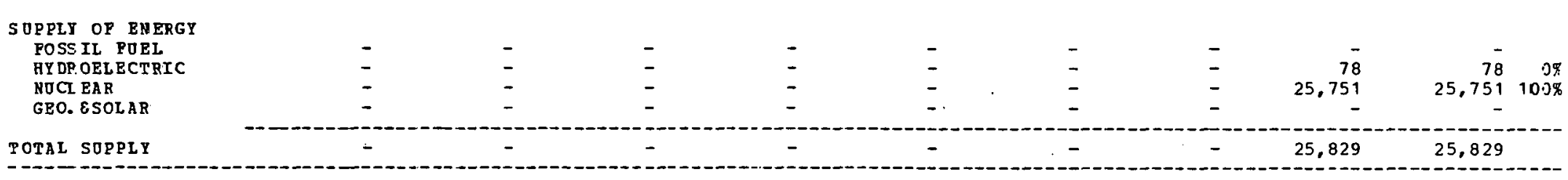

NET IMPORTS
OP REGION


REGIONAL ENERGY BALAICE.STATEMENT

PIES MID MID SCEHARID

\begin{tabular}{|c|c|c|c|c|c|c|c|c|c|c|}
\hline SECTOR & $\begin{array}{l}\text { DISTILLATE } \\
\text { OIL }\end{array}$ & $\begin{array}{l}\text { RES IDJALL } \\
\text { OIL }\end{array}$ & $\begin{array}{l}\text { GASOLINE } \\
\text { (ALL UNI }\end{array}$ & $\begin{array}{c}\text { OTHER } \\
\text { HYDBO- } \\
\text { CARBONS } \\
\text { TS IN } 10 * * 9\end{array}$ & $\begin{array}{c}\text { CRODE } \\
\text { OIL } \\
\text { BTO'S) }\end{array}$ & $\begin{array}{l}\text { NATUR AL } \\
\text { GAS }\end{array}$ & COAL & ELECTRICITY & $\begin{array}{r}\text { SECTOR } \\
\text { TOTAL }\end{array}$ & \\
\hline $\begin{array}{l}\text { PINAL DEHAND SECTJRS } \\
\text { RESID ENTYAL, COHA- } \\
\text { IND USTRIAL } \\
\text { TRANSPORTATION } \\
\text { MISCELLANEOOS OSES }\end{array}$ & $\begin{array}{r}30,826 \\
10,150 \\
10,905 \\
1,580\end{array}$ & $\begin{array}{r}3,140 \\
14,795 \\
237 \\
399\end{array}$ & $141,08 \overline{-}$ & $\begin{array}{r}17,622 \\
17,578 \\
3,372 \\
97\end{array}$ & - & $\begin{array}{r}13,465 \\
24,115 \\
773 \\
1,845\end{array}$ & $\begin{array}{r}387 \\
16,052 \\
- \\
7\end{array}$ & $\begin{array}{r}59,691 \\
36,082 \\
1,068\end{array}$ & $\begin{array}{r}125,131 \\
118,772 \\
156,375 \\
5,496\end{array}$ & $\begin{array}{r}19 \% \\
18 \% \\
24 \% \\
1 \%\end{array}$ \\
\hline $\begin{array}{l}\text { TOTAL PINAL } \\
\text { DEMAND SECTORS }\end{array}$ & 53,461 & 19,371 & 141,088 & 38,669 & - & 40,198 & 16,446 & 96.841 & 405,774 & $62 \%$ \\
\hline $\begin{array}{l}\text { TRANSPORHATICN } \\
\text { BLECTRICITY GEN. } \\
\text { PETR OLEOM FRODOCTS } \\
\text { NATURAL GAS } \\
\text { SYNTEETICS }\end{array}$ & $\begin{array}{r}15,773 \\
- \\
=\end{array}$ & $\begin{array}{l}- \\
-\end{array}$ & $\begin{array}{l}- \\
\overline{-} \\
-\end{array}$ & $\begin{array}{l}- \\
\overline{-} \\
-\end{array}$ & $\begin{array}{l}- \\
-\end{array}$ & $\begin{array}{l}6 \\
- \\
-\end{array}$ & $\begin{array}{r}356,153 \\
- \\
-\end{array}$ & $\begin{array}{r}-128,076 \\
- \\
-\end{array}$ & $\begin{array}{r}243,856 \\
- \\
-\end{array}$ & $37 \%$ \\
\hline $\begin{array}{l}\text { WET PUEL OSED } \\
\text { IN TRANSPORMATION }\end{array}$ & 15.773 & - & - & - & - & 6 & 356,153 & $-128,076$ & 243,856 & $37 \%$ \\
\hline $\begin{array}{l}\text { TOTAL GROSS FLORS } \\
\text { LOSSES } \varepsilon \text { OMISSIONS }\end{array}$ & $\begin{array}{r}69,234 \\
4,002\end{array}$ & $\begin{array}{r}19,071 \\
0\end{array}$ & $\begin{array}{r}141,088 \\
-0\end{array}$ & $\begin{array}{r}38,669 \\
-1,616\end{array}$ & $\begin{array}{l}- \\
-\end{array}$ & $\begin{array}{l}40,204 \\
-1,456\end{array}$ & $\begin{array}{r}372,599 \\
-820\end{array}$ & $\begin{array}{r}96,841 \\
9,685\end{array}$ & $\begin{array}{r}649,630 \\
9,794\end{array}$ & $\begin{array}{r}99 \% \\
1 \%\end{array}$ \\
\hline TOTAL NET OSAGE & 73,236 & $19,07 i$ & 141.087 & 37,052 & - & 38.747 & 371,778 & $-21,549$ & 659,424 & \\
\hline $\begin{array}{l}\text { S UPPLY OP ENERGY } \\
\text { FOSS IL PUEL } \\
\text { HY DR OEL ECT RIC } \\
\text { HOCL EAR } \\
\text { GEO. \& SOLAR }\end{array}$ & $\begin{array}{l}\overline{-} \\
\overline{-}\end{array}$ & $\begin{array}{l}- \\
-\end{array}$ & $\begin{array}{l}- \\
\overline{-}\end{array}$ & $\begin{array}{l}\overline{-} \\
\overline{-}\end{array}$ & $\begin{array}{l}- \\
\overline{-} \\
-\end{array}$ & $\begin{array}{l}- \\
- \\
-\end{array}$ & $\begin{array}{l}\overline{-} \\
-\end{array}$ & $\begin{array}{r}5,388 \\
9,449\end{array}$ & $\begin{array}{r}- \\
5,388 \\
9,449\end{array}$ & $\begin{array}{l}36 \% \\
64 \%\end{array}$ \\
\hline TOTAL SUPPIY & - & - & - & - & - & - & - & 14,837 & 14,837 & \\
\hline
\end{tabular}

\section{ET IN PORTS}

73,236

19.071

141,087

37.052

38.747

371,778

$-36,386$

644,587

-

\section{NOTES:}

1 TRANSPORAATIOK LOSS POR TRANSPORAATION LOSS POR TRANSPORMATI ON LOSS FOA TRA NSPOR YATI ON LOSS POR

ELECTEICITY GEN. $\quad=65.56 \%$

PTROLE JH PROD

SYNTHETICS

\section{$=65.56 \%$
$=0.0 \%$}

$=0.0 \%$

$=0.0 \%$ 
REGIONAL ENERGY BALANCE STATEMENT

PIES MID MID SCZNARIO

\begin{tabular}{|c|c|c|c|c|c|c|c|c|c|c|}
\hline SECTOR & $\begin{array}{l}\text { DISTILLATE } \\
\text { CIL }\end{array}$ & $\cdot e^{\text {RES IDDAL }}$ & $\begin{array}{l}\text { GASOLIYE } \\
\text { (ALE ONIT }\end{array}$ & $\begin{array}{c}\text { JTHER } \\
\text { HYDRO- } \\
\text { CA } \cong B O N S \\
\text { IS IN } 10 \$ 4\end{array}$ & $\begin{array}{c}\text { CRODE } \\
\text { OIL } \\
\text { BTO'S) }\end{array}$ & $\begin{array}{l}\text { NATURAL } \\
\text { GIS. }\end{array}$ & $\cos L$ & ELECTRICITY & $\begin{array}{l}\text { SECTOZ } \\
\text { TOTAL }\end{array}$ & \\
\hline $\begin{array}{l}\text { PINAL DEMAND SECTORS } \\
\text { RESIDENTIAE, COHA. } \\
\text { INDOSTRIAL } \\
\text { TRANSPORTATION } \\
\text { MISCELLANE'US OSES }\end{array}$ & $\begin{array}{r}8.456 \\
3,440 \\
2,616 \\
805\end{array}$ & $\begin{array}{r}683 \\
6,408 \\
205 \\
458\end{array}$ & $\begin{array}{r}- \\
- \\
40,+155 \\
-\end{array}$ & $\begin{array}{r}5,015 \\
10,177 \\
3,004 \\
56\end{array}$ & $\begin{array}{l}- \\
-\end{array}$ & $\begin{array}{r}3.480 \\
10.195 \\
696 \\
905\end{array}$ & $\begin{array}{r}108 \\
5,310 \\
- \\
4\end{array}$ & $\begin{array}{r}15,216 \\
10,742 \\
639\end{array}$ & $\begin{array}{r}32,958 \\
45,972 \\
46,976 \\
2,867\end{array}$ & $\begin{array}{r}22 \% \\
31 \% \\
31 \% \\
2 \%\end{array}$ \\
\hline $\begin{array}{l}\text { TOTAL FINAL } \\
\text { DEMAND SZCTORS }\end{array}$ & 15,317 & 7.754 & 40,455 & 8,252 & - & 15,276 & 5,122 & 26,597 & 128,773 & $86 \%$ \\
\hline $\begin{array}{l}\text { TRANSF ORMATION } \\
\text { ELECTRICIEY. GEN. } \\
\text { PETR OLEUM FRODOCTS } \\
\text { NATURAL GAS } \\
\text { SY HT HETICS }\end{array}$ & $\begin{array}{r}4,316 \\
- \\
-\end{array}$ & $\begin{array}{r}19,296 \\
= \\
=\end{array}$ & $\begin{array}{l}- \\
-\end{array}$ & $\begin{array}{l}- \\
\overline{-}\end{array}$ & $\bar{z}$ & $\begin{array}{l}2 \\
- \\
-\end{array}$ & $\begin{array}{r}3,892 \\
- \\
-\end{array}$ & $\begin{array}{r}-9,204 \\
= \\
=\end{array}$ & $\begin{array}{r}18,302 \\
= \\
=\end{array}$ & $12 \%$ \\
\hline $\begin{array}{l}\text { NET FOBL USED } \\
\text { IN TRANSGGMATION }\end{array}$ & .4 .316 & 19,296 & - & - & - & 2 & 3,892 & -9.204 & 18,302 & $12 \%$ \\
\hline $\begin{array}{l}\text { TOTAL GROSS FLONS } \\
\text { LOSSES } \varepsilon \text { OMISSIONS }\end{array}$ & $\begin{array}{r}19.633 \\
1.135\end{array}$ & $\begin{array}{r}27,050 \\
-\quad 0\end{array}$ & $\begin{array}{r}40,455 \\
-0\end{array}$ & $\begin{array}{r}13.252 \\
-762\end{array}$ & $\overline{-}$ & $\begin{array}{r}15,278 \\
-553\end{array}$ & $\begin{aligned} 9, & <14 \\
- & -19\end{aligned}$ & $\begin{array}{r}26,597 \\
2,659\end{array}$ & $\begin{array}{r}147,075 \\
2,459\end{array}$ & $\begin{array}{r}98 \% \\
2 \%\end{array}$ \\
\hline TOTAL NET OSAGE & 20.768 & 27.050 & 40,454 & 17,489 & - & 14,724 & $8, \subseteq 94$ & 20,052 & 149,534 & \\
\hline
\end{tabular}

\section{SUPPEY OP ENERGY \\ POSS IL YORI}

HY DR OELECT ZIC

NOCL EAR

TOTAL SOPPLY

-
-
-
-

$\begin{array}{lll}- & - & - \\ - & - & -\end{array}$

\section{-}

-
-

-
-
-

16,914

$2 \overline{0}$

$16,914,7009$

- - - - -

$-$

$-\quad 16,934$

16,934

-

\section{NET IM PORTS}

$20.76 \dot{8}$

27,050

40,454

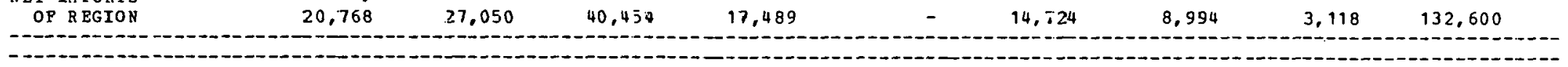

14,724

8,994

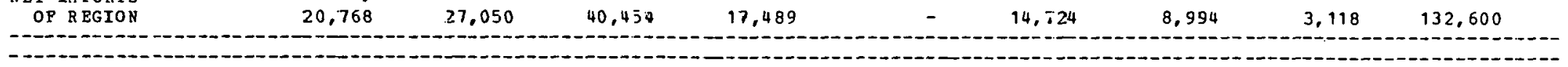

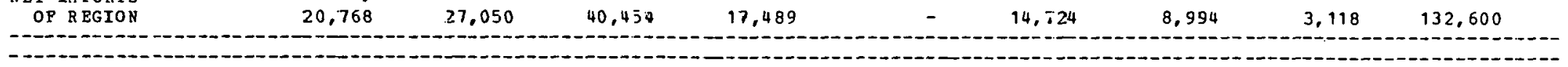

NOTES:

TRAN FOR DATION LOSS FOR

TRANEPCR AATION LOJS POR

TRANEPORATION LOSS POR NATURAL GAS

BLECTRICITY EEN.

$=0.0$ 
FEGIONAL ENERGY BALANCE STATEMENT

PIES MID HI D SCENARIO

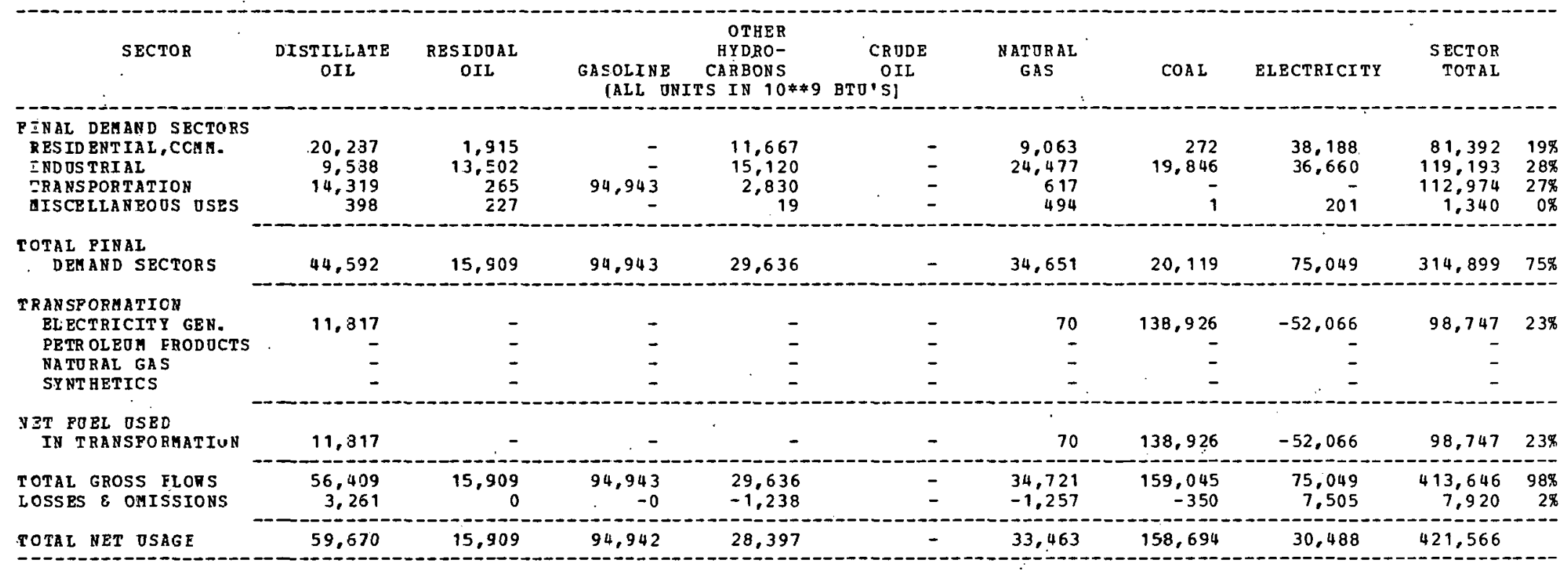

r.

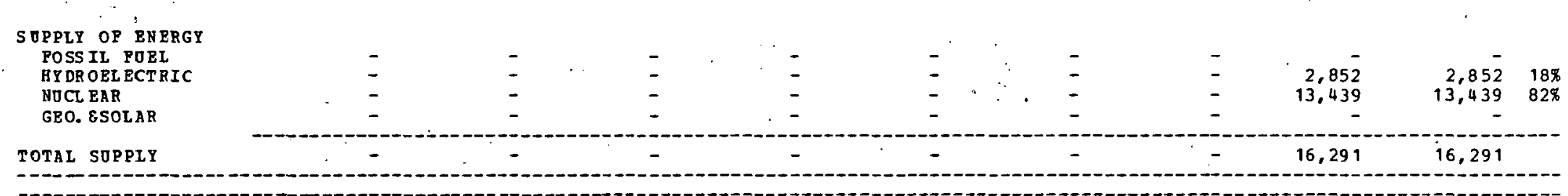

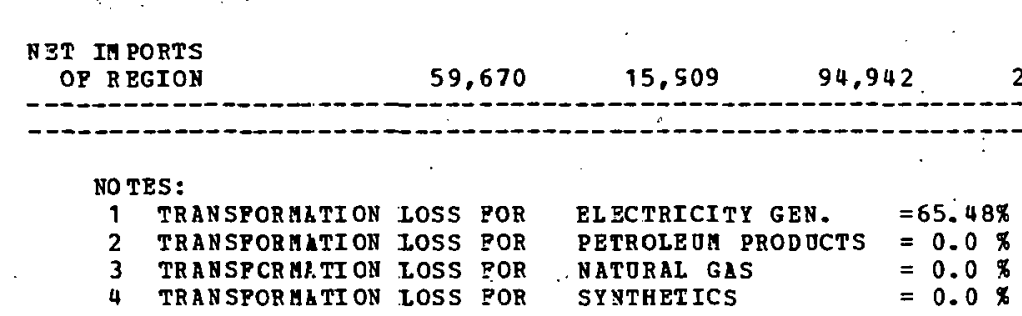


REGIOUAL FUETGY BALANCE STATEHENT

\begin{tabular}{|c|c|c|c|c|c|c|c|c|c|c|}
\hline SECEOR & $\begin{array}{c}\text { DI } \equiv T \text { ILLATB } \\
\text { OII }\end{array}$ & $\begin{array}{c}\text { BE } \leq \text { IDUdI } \\
\text { OIL }\end{array}$ & $\begin{array}{l}\text { GASOLINE } \\
\text { (ALL ENI? }\end{array}$ & $\begin{array}{c}\text { OMBER } \\
\text { HYSRO- } \\
\text { CARBONS } \\
\text { TE II } 10 * * 9\end{array}$ & $\begin{array}{c}\text { CRODE } \\
\text { OIL } \\
\text { BTO'S) }\end{array}$ & $\begin{array}{l}\text { NATUEAL } \\
\text { GAS }\end{array}$ & COAI & ELECTRICITY & $\begin{array}{r}\text { SECTOR } \\
\text { TOTAL }\end{array}$ & \\
\hline $\begin{array}{l}\text { PINAL DEHAKD SECTORS } \\
\text { RESIDENTIAL, COH!. } \\
\text { IND TSTRIAL } \\
\text { TRANSPORTATION } \\
\text { MISCELLAROOS OSES }\end{array}$ & $\begin{array}{l}26,633 \\
12,748 \\
25,106 \\
523\end{array}$ & $\begin{array}{r}2,594 \\
20,596 \\
1,466 \\
298\end{array}$ & $\begin{array}{r}- \\
- \\
-\end{array}$ & $\begin{array}{r}15,881 \\
25,876 \\
5,006 \\
25\end{array}$ & $\begin{array}{l}- \\
-\end{array}$ & $\begin{array}{r}12,527 \\
43,352 \\
1,125 \\
647\end{array}$ & $\begin{array}{r}358 \\
29,792 \\
- \\
1\end{array}$ & $\begin{array}{r}53,116 \\
52,923 \\
- \\
263\end{array}$ & $\begin{array}{r}111,109 \\
188,287 \\
160,728 \\
1,757\end{array}$ & $\begin{array}{r}17 \% \\
29 \% \\
24 \% \\
0 \%\end{array}$ \\
\hline $\begin{array}{l}\text { TOTAL FINAI } \\
\text { DEMAND SECTORS }\end{array}$ & 65,010 & 24,954 & 128,025 & 49,788 & - & 57,651 & 30,151 & 106,302 & 461,881 & $70 \%$ \\
\hline $\begin{array}{l}\text { TRANSFORMATICH } \\
\text { BLECTRICITY GEN. } \\
\text { PETR OLEOH FRODDCTS } \\
\text { NATORAL GAS } \\
\text { STNTHETICS }\end{array}$ & $\begin{array}{r}17,329 \\
- \\
-\end{array}$ & $\begin{array}{l}- \\
-\end{array}$ & $\begin{array}{l}- \\
- \\
-\end{array}$ & $\begin{array}{l}- \\
-\end{array}$ & - & $\begin{array}{l}7 \\
- \\
-\end{array}$ & $\begin{array}{r}268,273 \\
- \\
-\end{array}$ & $\begin{array}{r}-98,481 \\
- \\
-\end{array}$ & $\begin{array}{r}187,128 \\
- \\
- \\
-\end{array}$ & $28 \%$ \\
\hline $\begin{array}{l}\text { BET POEL USED } \\
\text { IN TRANSPOEHATION }\end{array}$ & 17.329 & - & - & - & - & 7 & 268,273 & $-98 ; 481$ & 187,128 & $28 \pi$ \\
\hline $\begin{array}{l}\text { TOTAL GROSS TLORS } \\
\text { LOSSBS } E \text { OMISSIONS }\end{array}$ & $\begin{array}{r}82,339 \\
4,760\end{array}$ & $\begin{array}{r}24,954 \\
0\end{array}$ & $\begin{array}{r}128,025 \\
-0\end{array}$ & $\begin{array}{l}4 \Xi, 788 \\
-=081\end{array}$ & - & $\begin{array}{r}57,658 \\
-2,088\end{array}$ & $\begin{array}{r}298,424 \\
-657\end{array}$ & $\begin{array}{r}106,302 \\
10,631\end{array}$ & $\begin{array}{r}649,009 \\
10,564\end{array}$ & $\begin{array}{r}98 \% \\
2 \%\end{array}$ \\
\hline TOTAL NET OSAGE & B7, 099 & 24,954 & 128,024 & 47.706 & - & $55,5 \in 9$ & 297,766 & 18,452 & $659,5.73$ & \\
\hline
\end{tabular}

\begin{tabular}{|c|c|c|c|c|c|c|c|c|c|c|}
\hline $\begin{array}{l}\text { SOPPLY OP ENERGY } \\
\text { POSS IL POEL }\end{array}$ & - & - & - & - & & - & 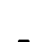 & - & - & \\
\hline HY DR OBIECTEIC & - & - & - & - & - & - & - & 10,313 & 10,313 & $17 \%$ \\
\hline NOCL EAR & - & - & - & - & - & - & - & 48,989 & 48,989 & $83 \%$ \\
\hline GEO. ESOLAR & - & - & - & - & - & - & - & - & - & \\
\hline TOTAL SOPPLY & - & - & - & - & - & - & - & 59,302 & 59,302 & \\
\hline
\end{tabular}

\section{ET IN PORTS}

NO TES: TRANEROR UATION LOSS POR TRANEPORDATION LOSS POR TRAN SPOREATION LOSS POR 
REGIONAL ENERGY BALANCE STATEMENT

PIES MID MID SCENARIO

\begin{tabular}{|c|c|c|c|c|c|c|c|c|c|c|}
\hline SECTOR & $\begin{array}{l}\text { DISTILLATE } \\
\text { OIL }\end{array}$ & $\begin{array}{l}\text { BESIIJAL } \\
\text { OII }\end{array}$ & $\begin{array}{l}\text { GASOLINE } \\
\text { (ALL ONI? }\end{array}$ & $\begin{array}{c}\text { OTBER } \\
\text { HYDRO- } \\
\text { CARBONS } \\
\text { TS IN 10**9 }\end{array}$ & $\begin{array}{c}\text { CR JDE } \\
\text { OIL } \\
\text { BTO'S) }\end{array}$ & $\begin{array}{l}\text { NATURAL } \\
\text { GAS }\end{array}$ & $\operatorname{COAL}$ & ELECTRICITY & $\begin{array}{r}\text { SECTCR } \\
\text { TOTAL }\end{array}$ & \\
\hline $\begin{array}{l}\text { PINAL DEMAND SECTORS } \\
\text { RESID ENTIAL, COAH. } \\
\text { INDOS TRIAL } \\
\text { TRANSPORTATION } \\
\text { MISCELLANEODS OSES }\end{array}$ & $\begin{array}{r}7,344 \\
4,321 \\
3,167 \\
229\end{array}$ & $\begin{array}{r}651 \\
7,973 \\
93 \\
130\end{array}$ & $\begin{array}{r}\overline{-} \\
34.569 \\
-\end{array}$ & $\begin{array}{r}4,297 \\
5,229 \\
1,344 \\
11\end{array}$ & $\begin{array}{l}- \\
- \\
-\end{array}$ & $\begin{array}{r}3,095 \\
8,625 \\
309 \\
283\end{array}$ & $\begin{array}{r}92 \\
7,470 \\
- \\
1\end{array}$ & $\begin{array}{r}13,663 \\
12,145 \\
- \\
114\end{array}$ & $\begin{array}{r}29,142 \\
45,763 \\
39,482 \\
768\end{array}$ & $\begin{array}{r}21 \% \\
34 \% \\
29 \% \\
1 \%\end{array}$ \\
\hline $\begin{array}{l}\text { TOTAL PINAL } \\
\text { DEMAND SECTORS }\end{array}$ & 15,061 & 8,847 & 34,569 & 10,881 & - & 12,312 & 7,563 & 25,922 & 115,155 & $84 \%$ \\
\hline $\begin{array}{l}\text { TRANSP ORAATICN } \\
\text { BL ECTRICITY GEN. } \\
\text { PETROLEOA PRODOCTS } \\
\text { NATURAL GAS } \\
\text { SY NTHETICS }\end{array}$ & $\begin{array}{r}4,172 \\
=\end{array}$ & $\begin{array}{l}\overline{-} \\
\overline{-}\end{array}$ & $\begin{array}{l}\overline{-} \\
\bar{z}\end{array}$ & $\begin{array}{l}\overline{-} \\
\bar{z}\end{array}$ & $\begin{array}{l}- \\
\overline{-}\end{array}$ & $\begin{array}{l}2 \\
-\end{array}$ & $\begin{array}{r}24.074 \\
- \\
-\end{array}$ & $\begin{array}{r}-9,802 \\
- \\
- \\
-\end{array}$ & $\begin{array}{r}18,446 \\
= \\
=\end{array}$ & $14 \%$ \\
\hline $\begin{array}{l}\text { NET FOEL OSED } \\
\text { IN TRABSFORMATION }\end{array}$ & 4,172 & - & - & - & - & 2 & 24,074 & $-9,802$ & $18 ; 446$ & $14 \%$ \\
\hline $\begin{array}{l}\text { TOTAL GROSS FLORS } \\
\text { LOSSES \& OBISSICNS }\end{array}$ & $\begin{array}{r}19,233 \\
1,111\end{array}$ & 8,847 & $\begin{array}{r}34,569 \\
-0\end{array}$ & $\begin{array}{r}10,881 \\
-454\end{array}$ & $\overline{-}$ & $\begin{array}{r}12,314 \\
-446\end{array}$ & $\begin{array}{r}31,637 \\
-69\end{array}$ & $\begin{array}{r}25,922 \\
2,592\end{array}$ & $\begin{array}{r}133,601 \\
2,733\end{array}$ & $\begin{array}{r}98 \% \\
2 \%\end{array}$ \\
\hline
\end{tabular}

\begin{tabular}{|c|c|c|c|c|c|c|c|c|c|}
\hline $\begin{array}{l}\text { SUPPLY OF BNERGT. } \\
\text { POSS IL POEL }\end{array}$ & - & - & . & - & - & - & - & - & - \\
\hline BY DR OEL BCTRIC & - & - & - & - & - & - & - & 9,374 & 9,374 \\
\hline NOCL EAR & - & - & - & - & - & - & - & - & - \\
\hline GEO. ESOLAR & - & - & - & - & - & - & - & - & - \\
\hline TOTAL SUPPLY & - & - & - & - & - & - & - & 9,374 & 9,374 \\
\hline
\end{tabular}

\begin{tabular}{l} 
NET IM PORTS \\
OP R EGION \\
\hline
\end{tabular}

\footnotetext{
NOTES:

TRANSPCRMATION LOSS POB TRANSPCRHATI ON LOSS POR

ELECTRICITY GEN. $=65.30 \%$ PBTROLEOM PRODOCTS $=0.0 \%$

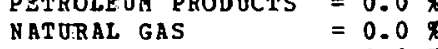

4 TRARSPGRYTTI ON LOSS POR 
RZEIONAL 3AERGY BALANCE STITEHENT

PIES MID UID.SCENARIO

\begin{tabular}{|c|c|c|c|c|c|c|c|c|c|c|}
\hline SECTOR & $\underset{\text { OIL }}{\text { DI STILILTE }}$ & $\begin{array}{l}\text { RESIDUAL } \\
\text { OIL }\end{array}$ & $\begin{array}{l}\text { GASOLINE. } \\
\text { (ILL ORD }\end{array}$ & $\begin{array}{c}\text { OTHER } \\
\text { HYDRO- } \\
\text { EARBONS } \\
\text { T IN } 10 * * 9\end{array}$ & $\begin{array}{c}\text { CROLE } \\
\text { OII } \\
\text { BTO'S) }\end{array}$ & $\begin{array}{l}\text { N LTOR IL } \\
\text { GAS }\end{array}$ &. $\operatorname{COAL}$ & ELECTRICITY & $\begin{array}{r}\text { SEC: JR } \\
\text { TOT } 1 \mathrm{~L}\end{array}$ & \\
\hline $\begin{array}{l}\text { PINAL DEMAND SECTORS } \\
\text { RES ID ENTIAL, COHA. } \\
\text { IND TS TRIAL } \\
\text { TRANSPOREATION } \\
\text { MISCELLAUEOOS OSES }\end{array}$ & $\begin{array}{l}8,91 \epsilon \\
5,061 \\
9,844 \\
213\end{array}$ & $\begin{array}{r}330 \\
8.917 \\
2.857 \\
121\end{array}$ & $\begin{array}{r}- \\
\overline{-} \\
-037\end{array}$ & $\begin{array}{r}8,453 \\
24,494 \\
1,159 \\
10\end{array}$ & 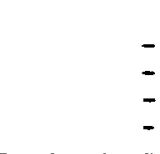 & $\begin{array}{r}8,5 \geq 8 \\
42.493 \\
229 \\
2: 1\end{array}$ & $\begin{array}{r}216 \\
22.097 \\
-\end{array}$ & $\begin{array}{r}26,866 \\
37,910 \\
- \\
109\end{array}$ & $\begin{array}{r}53,309 \\
140,972 \\
86,126 \\
725\end{array}$ & $\begin{array}{r}17 \% \\
45 \% \\
28 \% \\
0 \%\end{array}$ \\
\hline $\begin{array}{l}\text { TOTAL PINLL } \\
\text { DEMAND SECTORS }\end{array}$ & 24,034 & 12,225 & 72.037 & 34,116 & - & $5.1,5=1$ & 22,314 & 64,885 & $281,1 \vdots 2$ & $90 \%$ \\
\hline $\begin{array}{l}\text { TR AN SP ORHATION } \\
\text { BL ECTRICITY GEN. } \\
\text { PBTROLEAH. PRODOCTS } \\
\text { NATURAL GAS } \\
\text { SYNTHETICS }\end{array}$ & $\begin{array}{r}0,476 \\
- \\
=\end{array}$ & $\begin{array}{r}991 \\
- \\
-\end{array}$ & $\overline{-}$ & $\begin{array}{l}- \\
-\end{array}$ & $\begin{array}{l}- \\
\overline{-}\end{array}$ & $\begin{array}{l}4 \\
-\end{array}$ & $\begin{array}{r}26,163 \\
- \\
-\end{array}$ & $\begin{array}{r}-13,164 \\
- \\
-\end{array}$ & $\begin{array}{r}24.4 .0 \\
- \\
-\end{array}$ & $8 \%$ \\
\hline $\begin{array}{l}\text { RET FOEL USED } \\
\text { IN TRANSPORHATION }\end{array}$ & 10,476 & 991 & - & - & - & 4 & 26,163 & $-13,164$ & 24,470 & $8 \%$ \\
\hline $\begin{array}{l}\text { TOTAL GROSS FLOHS } \\
\text { LOSSES } \varepsilon \text { OMISSIOHS }\end{array}$ & $\begin{array}{r}34.510 \\
1.995\end{array}$ & $\begin{array}{r}13,216 \\
0\end{array}$ & $\begin{array}{r}72,037 \\
-0\end{array}$ & $\begin{array}{r}34,116 \\
-1,426\end{array}$ & - & $\begin{array}{r}51,525 \\
-1,865\end{array}$ & $\begin{array}{r}42,477 \\
-106\end{array}$ & $\begin{array}{r}64,885 \\
6,489\end{array}$ & $\begin{array}{r}305,602 \\
5,035\end{array}$ & $\begin{array}{r}98 \% \\
2 \%\end{array}$ \\
\hline TOTAL NET DSAGP & $36,50.5$ & 13,216 & $72,0 \equiv 6$ & 32,689 & - & 49,653 & 43,370 & 58,210 & $310,6.37$ & \\
\hline
\end{tabular}

\begin{tabular}{|c|c|c|c|c|c|c|c|c|c|c|}
\hline $\begin{array}{l}\text { S OEPLY OP } 3 \text { NERGY } \\
\text { FOSS IL YDEL }\end{array}$ & - & - & - & & & & & & & \\
\hline HY DR OELECTRIC & - & - & - & - & - & - & - & $3.15 \overline{6}$ & $3,15 \overline{5}$ & 78 \\
\hline NOCL BAR & - & - & - & - & - & - & - & 40,873 & 40,873 & $93 \%$ \\
\hline GEO.ESOLAR & - & - & - & - & - & - & - & - & - & \\
\hline TOTAL SUPPLY & .. & - & - & - & - & - & - & 44,029 & 44,029 & \\
\hline
\end{tabular}

NET IM PORTS

36,505

13,216

72.035

32,689

49,658

48,370

14,181

$266,65 \varepsilon$

-

\section{NO TES :}

1 TRADSPORMATION COSE POB TRATSPORMATION LOSS POB TRAYSPOR TRAY SPORAATI ON JOSS POR

ELACTRICITY GEN.

EATROLZOH PZODOCTS $=65.02 \%$

NATUHAE GAS 
REGIONAL ENERGY BALANCE STATEMENT

PIES MID MID SCENARIO

\begin{tabular}{|c|c|c|c|c|c|c|c|c|c|c|}
\hline SECTOR & $\begin{array}{l}\text { DISTILLATE } \\
\text { OIL }\end{array}$ & $\begin{array}{l}\text { RESIDJAL } \\
\text { OIL }\end{array}$ & $\begin{array}{l}\text { GASOLINE } \\
\text { (ALI O }\end{array}$ & $\begin{array}{c}\text { OTHER } \\
\text { HYDRO- } \\
\text { CARBONS } \\
\text { IS IN 10** }\end{array}$ & $\begin{array}{c}\text { CRODE } \\
\text { OIL } \\
\text { BTO'SI) }\end{array}$ & $\begin{array}{l}\text { NATURAL } \\
\text { GAS }\end{array}$ & $\operatorname{COAL}$ & ELECTRICITY & $\begin{array}{r}\text { SECTOR } \\
\text { TOTAL }\end{array}$ & \\
\hline $\begin{array}{l}\text { PINAL DEKAND SECTORS } \\
\text { RESID ENTIAL, COMM. } \\
\text { INDOSTRIAL } \\
\text { TRANS POBTATION } \\
\text { MISCELLANEOOS OSES }\end{array}$ & $\begin{array}{r}6,881 \\
3,095 \\
5,841 \\
544\end{array}$ & $\begin{array}{r}334 \\
4.861 \\
2.926 \\
309\end{array}$ & $\begin{array}{r}- \\
54,809 \\
-\end{array}$ & $\begin{array}{r}6.466 \\
15.733 \\
1.169 \\
45\end{array}$ & $\bar{I}$ & $\begin{array}{r}7,184 \\
21,456 \\
233 \\
975\end{array}$ & $\begin{array}{r}166 \\
12,907 \\
- \\
2\end{array}$ & $\begin{array}{r}22,416 \\
20,575 \\
490\end{array}$ & $\begin{array}{r}43,447 \\
78,627 \\
64,978 \\
2,365\end{array}$ & $\begin{array}{r}18 \% \\
33 \% \\
28 \% \\
1 \%\end{array}$ \\
\hline $\begin{array}{l}\text { TOTAL FINAL } \\
\text { DEHAND SECTORS }\end{array}$ & 16,361 & $8: 430$ & 54,809 & 23,413 & - & 29,848 & 13,075 & 43,481 & 189,417 & $80 \%$ \\
\hline $\begin{array}{l}\text { TRANSPORHATION } \\
\text { ELECTRICITY GEN. } \\
\text { PETROLZOM EROL.DCTS } \\
\text { NATURAE GAS } \\
\text { SYNTHETICS }\end{array}$ & $\begin{array}{r}7.162 \\
- \\
-\end{array}$ & $\begin{array}{r}1.270 \\
= \\
-\end{array}$ & $\begin{array}{l}- \\
\overline{-}\end{array}$ & $\overline{-}$ & $\begin{array}{l}\overline{-} \\
\overline{-}\end{array}$ & $\begin{array}{l}3 \\
- \\
-\end{array}$ & $\begin{array}{r}57,555 \\
- \\
-\end{array}$ & $\begin{array}{r}-22,810 \\
- \\
-\end{array}$ & $\begin{array}{r}43,180 \\
- \\
- \\
-\end{array}$ & $18 \%$ \\
\hline $\begin{array}{l}\text { NET FOEL USED } \\
\text { IN TRANSFORMATION }\end{array}$ & 7,162 & 1,270 & - & - & - & 3 & 57,555 & $-22,810$ & 43,180 & $18 \%$ \\
\hline $\begin{array}{l}\text { TOTAL GROSS FLOFS } \\
\text { LOSSES } 8 \text { OMISSIONS }\end{array}$ & $\begin{array}{r}23,523 \\
1,359\end{array}$ & $\begin{array}{r}9,700 \\
0\end{array}$ & $\begin{array}{r}54,809 \\
-0\end{array}$ & $\begin{array}{r}23,413 \\
-978\end{array}$ & - & $\begin{array}{l}-29,851 \\
-1,081\end{array}$ & $\begin{array}{r}70,630 \\
-155\end{array}$ & $\begin{array}{r}43,481 \\
4,348\end{array}$ & $\begin{array}{r}232,597 \\
3,492\end{array}$ & $\begin{array}{r}99 \% \\
1 \%\end{array}$ \\
\hline
\end{tabular}

\begin{tabular}{|c|c|c|c|c|c|c|c|c|c|c|}
\hline $\begin{array}{l}S \text { OPPLY OP ENERGE } \\
\text { POSS IL POEL }\end{array}$ & - & - & - & - & - & - & - & - & - & \\
\hline HY DR OELECTRIC & - & - & - & - & - & - & - & 9,322 & 9,322 & $50 \pi$ \\
\hline NUCL EAR & - & - & - & - & - & - & - & 9,449 & 9,449 & $50 \%$ \\
\hline GEO. ESOLAR & - & - & - & - & - & - & - & - & - & \\
\hline TOTAL SOPPLY & - & - & - & - & - & - & - & 18,771 & 18,771 & \\
\hline
\end{tabular}

\section{NET IM PCRTS.}

OF R BGION

24,882

9,700

54,808

22,434

28,769

70,474

6,248

217,318

\begin{tabular}{|c|c|c|c|c|c|}
\hline \\
\hline 1 & TRANSPORMATI ON & $\operatorname{coss}+>1$ & POR & ELECTRICITY GE & \\
\hline & TRANSPORIATI ON & LOSS & POR & PETROLEOM PBODUCTS & 0.0 \\
\hline 3 & TRANSPOR YATI ON & LOSS & FOR & NATORAL GAS & 0.0 \\
\hline 4 & TRAN SPOR MATI ON & Los S & FOR & SY NTHET ICS & 0.0 \\
\hline
\end{tabular}


R3GIONAL REERGY BALANCE STATEMENT PIES: MID MID SCENARIO

\begin{tabular}{|c|c|c|c|c|c|c|c|c|c|c|}
\hline S 3 CTOR & $\begin{array}{l}\text { DISTILLATE } \\
\text { JIL }\end{array}$ & $\begin{array}{l}\text { RES IDUAL } \\
\text { OIL }\end{array}$ & $\begin{array}{l}\text { GASOLINE } \\
\text { KALL UNIII }\end{array}$ & $\begin{array}{l}\text { OTHER } \\
\text { EYDRO- } \\
\text { CERBONS } \\
\text { IS IN } 10 * * 9\end{array}$ & $\begin{array}{c}\text { CRODE } \\
\text { OIL } \\
\text { BTO'S) }\end{array}$ & $\begin{array}{l}\text { NATUZAL } \\
\text { GAS }\end{array}$ & $\operatorname{COAL}$ & ELECTRICITY & $\begin{array}{l}\text { SECTOE } \\
\text { TOTAL }\end{array}$ & \\
\hline $\begin{array}{l}\text { PINAL DEMAUD SECTORS } \\
\text { RES IDENTIAL, COMG. } \\
\text { IND USTRIAI } \\
\text { TRANSPORTETION } \\
\text { MISCELIANEJOS OSES }\end{array}$ & $\begin{array}{r}4,500 \\
4,522 \\
1,840 \\
216\end{array}$ & $\begin{array}{r}197 \\
10,216 \\
3,770 \\
124\end{array}$ & 36,181 & $\begin{array}{r}4,255 \\
7,327 \\
1,498 \\
12\end{array}$ & $\begin{array}{l}- \\
-\end{array}$ & $\begin{array}{r}4.525 \\
13.349 \\
301 \\
291\end{array}$ & $\begin{array}{r}109 \\
0.978 \\
- \\
1\end{array}$ & $\begin{array}{r}14,049 \\
23,033 \\
- \\
124\end{array}$ & $\begin{array}{r}27,635 \\
67,425 \\
46,590 \\
76 \varepsilon\end{array}$ & $\begin{array}{r}14 \pi \\
33 \% \\
23 \% \\
0 \%\end{array}$ \\
\hline $\begin{array}{l}\text { TOTAL PINAI. } \\
\text { DEHAND } \leq \text { BCTORS }\end{array}$ & $1 c, 078$ & 14,307 & 36.181 & 13,092 & - & 18.466 & 9,088 & 37,206 & 142,418 & $70 \%$ \\
\hline $\begin{array}{l}\text { TRANSFORMATION } \\
\text { ELECTRICIIY GEN. } \\
\text { PETR OLBUM ERODUCTS } \\
\text { NATURAL GAS } \\
\text { SYNTHETICS }\end{array}$ & $\begin{array}{r}10.325 \\
= \\
-\end{array}$ & $\begin{array}{r}4,646 \\
- \\
-\end{array}$ & $\begin{array}{l}- \\
- \\
-\end{array}$ & $\begin{array}{l}- \\
-\end{array}$ & $\begin{array}{l}- \\
\overline{-}\end{array}$ & $\begin{array}{l}2 \\
- \\
-\end{array}$ & $\begin{array}{r}66,545 \\
- \\
-\end{array}$ & $\begin{array}{r}-29,633 \\
- \\
-\end{array}$ & $\begin{array}{r}55,885 \\
- \\
-\end{array}$ & $28 \%$ \\
\hline $\begin{array}{l}\text { NET POEL JSED } \\
\text { IN TRANSPSRMATION }\end{array}$ & 14,325 & 4,646 & - & - & - & 2 & 66,545 & -29.633 & 55,885 & $28 \%$ \\
\hline $\begin{array}{l}\text { TOTAL GROSS FLONS } \\
\text { LOSSES } E \text { OMISSIONS }\end{array}$ & $\begin{array}{r}28,403 \\
i, 642\end{array}$ & $\begin{array}{r}18,953 \\
0\end{array}$ & $\begin{array}{r}36,181 \\
-0\end{array}$ & $\begin{array}{r}13,092 \\
-547\end{array}$ & $\overline{-}$ & $\begin{array}{r}18,468 \\
-6.68\end{array}$ & $\begin{array}{r}75,533 \\
-166\end{array}$ & $\begin{array}{r}37,206 \\
3,720\end{array}$ & $\begin{array}{r}198,303 \\
3,980\end{array}$ & $\begin{array}{r}98 \% \\
2 \%\end{array}$ \\
\hline TOTAL NET $O \equiv A G E$ & 30.045 & 18,953 & 36.180 & 12,544 & - & 17.799 & 75,766 & 11,293 & 202,283 & \\
\hline
\end{tabular}

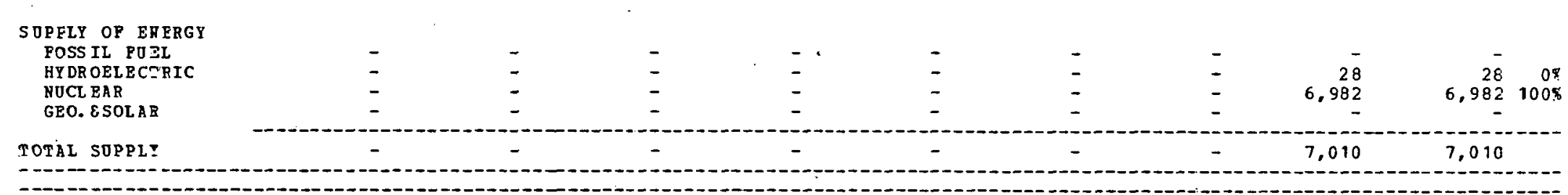

\begin{tabular}{l}
$\begin{array}{l}\text { NET IM PORTS } \\
\text { OF R RGION }\end{array}$ \\
\hline
\end{tabular}


REGIONAL ENERGY BALANCE STATEMENT
PIES MID MID SCENARIO

\begin{tabular}{|c|c|c|c|c|c|c|c|c|c|c|}
\hline SECTOR & $\begin{array}{l}\text { DISTILLATE } \\
\text { OIL }\end{array}$ & $\begin{array}{l}\text { RESIDUAL } \\
\text { OIL }\end{array}$ & $\begin{array}{r}\text { GASOLINE } \\
\text { (ALL D }\end{array}$ & $\begin{array}{l}\text { OTHER } \\
\text { HYDRO- } \\
\text { CARBONS } \\
\text { TS IN } 10 * 9\end{array}$ & $\begin{array}{c}\text { CRODE } \\
\text { OIL } \\
\text { BTO'S) }\end{array}$ & $\begin{array}{l}\text { NATORAL } \\
\text { GAS }\end{array}$ & $\operatorname{COAL}$ & ELECTRICITY & $\begin{array}{r}\text { SECTOR } \\
\text { TOTAL }\end{array}$ & \\
\hline $\begin{array}{l}\text { PINAL DEMAND SECTORS } \\
\text { RES ID ENTIAL, COMG. } \\
\text { IND OS TRIAL } \\
\text { TRANSPORTATION } \\
\text { MISCELLANEO OS OSES }\end{array}$ & $\begin{array}{r}4,733 \\
1,533 \\
4,133 \\
608\end{array}$ & $\begin{array}{r}204 \\
3.392 \\
4.635 \\
347\end{array}$ & $\begin{array}{r}- \\
\overline{3}, 098 \\
-\end{array}$ & $\begin{array}{r}4,482 \\
4,673 \\
1,837 \\
54\end{array}$ & $\begin{array}{l}- \\
- \\
-\end{array}$ & $\begin{array}{r}4,799 \\
7,608 \\
370 \\
1.143\end{array}$ & $\begin{array}{r}114 \\
4,207 \\
- \\
2\end{array}$ & $\begin{array}{r}15,095 \\
10,435 \\
- \\
586\end{array}$ & $\begin{array}{r}29,427 \\
31,848 \\
49,073 \\
2,740\end{array}$ & $\begin{array}{r}18 \% \\
20 \% \\
30 \% \\
2 \%\end{array}$ \\
\hline $\begin{array}{l}\text { TOTAL PINAL } \\
\text { DEMAND SECTORS }\end{array}$ & 11,007 & 8.578 & 38,098 & 11.046 & - & 13,920 & 4,323 & 26,116 & 113,088 & $70 \%$ \\
\hline $\begin{array}{l}\text { IRANSPORYATION } \\
\text { ELECTRICITY GEN. } \\
\text { PETR OLEOM PRODOCTS } \\
\text { NATURAL GAS } \\
\text { SY NT BETICS }\end{array}$ & $\begin{array}{r}4,289 \\
- \\
-\end{array}$ & $\begin{array}{r}23,725 \\
- \\
-\end{array}$ & $\overline{-}$ & $\overline{-}$ & $\begin{array}{l}- \\
- \\
-\end{array}$ & $\begin{array}{l}2 \\
- \\
-\end{array}$ & $\begin{array}{r}42,680 \\
- \\
-\end{array}$ & $\begin{array}{r}-23,952 \\
- \\
-\end{array}$ & $\begin{array}{r}46,744 \\
- \\
-\end{array}$ & $29 \%$ \\
\hline $\begin{array}{l}\text { NET POEL OSED } \\
\text { IN TRANSPORHATION }\end{array}$ & 4,289 & 23,725 & - & - & - & 2 & 42,680 & $-23,952$ & 46,744 & $29 \%$ \\
\hline $\begin{array}{l}\text { TOTAL GROSS FLONS } \\
\text { LOSSES \& OMISSIONS }\end{array}$ & $\begin{array}{r}15,296 \\
884\end{array}$ & $\begin{array}{r}32,303 \\
0\end{array}$ & $\begin{array}{r}38,098 \\
-0\end{array}$ & $\begin{array}{r}11,046 \\
-461\end{array}$ & $\overline{-}$ & $\begin{array}{r}13,922 \\
-504\end{array}$ & $\begin{array}{r}47,003 \\
-103\end{array}$ & $\begin{array}{r}26,116 \\
2,611\end{array}$ & $\begin{array}{r}159,832 \\
2,427\end{array}$ & $\begin{array}{r}99 \% \\
.1 \%\end{array}$ \\
\hline
\end{tabular}

SOPPLY OP ENERGY
$\begin{aligned} & \text { FOSS IL POEL } \\ & \text { HYDROELECTRIC }\end{aligned}$
NOCL EAR

\begin{tabular}{l}
$\begin{array}{l}\text { WET IM PORTS } \\
\text { OP B BGION }\end{array}$ \\
\hline
\end{tabular}


RZGIONAL EERRGY BALANCE STAIEMENT
PIES. MID MID SCENARIO

\begin{tabular}{|c|c|c|c|c|c|c|c|c|c|c|}
\hline S 3 CTOR & $\begin{array}{l}\text { DI STILLATE } \\
\text { כIL }\end{array}$ & $\begin{array}{l}\text { RESILOAL } \\
\text { OIL }\end{array}$ & $\begin{array}{l}\text { GASOLINE } \\
\quad \text { (ALL }\end{array}$ & $\begin{array}{c}\text { OTHER } \\
\text { GYDRO- } \\
\text { CIRBONS } \\
\text { TS IN } 10 * * 9\end{array}$ & $\begin{array}{c}\text { CRODE } \\
\text { OIL } \\
\text { BTO'S) }\end{array}$ & $\underset{\text { EAS }}{\text { NATURAI }}$ & COAL & ELECTRICITY & $\begin{array}{l}\text { SECTOR } \\
\text { TOTA: }\end{array}$ & \\
\hline $\begin{array}{l}\text { PINAL DEHAID SECTORS } \\
\text { RES ID ENTIAL, COMH. } \\
\text { IND OSTRIAL } \\
\text { TRANS PORTITION } \\
\text { HISCE LIANEOOS OSES }\end{array}$ & $\begin{array}{r}3,526 \\
3,354 \\
3,834 \\
499\end{array}$ & $\begin{array}{r}552 \\
6,994 \\
608 \\
284\end{array}$ & 35. $\frac{-}{-}$ & $\begin{array}{r}3,827 \\
9,022 \\
2,004 \\
29\end{array}$ & $\begin{array}{l}\overline{-} \\
\overline{-}\end{array}$ & $\begin{array}{r}6,+35 \\
2 C, 310 \\
156 \\
594\end{array}$ & $\begin{array}{r}49 \\
.975 \\
\end{array}$ & $\begin{array}{r}12,509 \\
15,601 \\
- \\
155\end{array}$ & $\begin{array}{r}26,898 \\
63,25: \\
42,08: \\
1,66:\end{array}$ & $\begin{array}{r}18 \% \\
42 \% \\
23 \% \\
1 \%\end{array}$ \\
\hline $\begin{array}{l}\text { TOTAL PINAL, } \\
\text { DEMAND SECTORS }\end{array}$ & 11,213 & 8,438 & 35.480 & 14,882 & - & 27,595 & $\varepsilon, 025$ & 28,265 & $133,89 \varepsilon$ & $89 \pi$ \\
\hline $\begin{array}{l}\text { TRANSPORMATION } \\
\text { EL ECTRICITY GRN. } \\
\text { PETROLEON PRODOCTS } \\
\text { NATORAL GAS } \\
\text { STHT HETICS }\end{array}$ & $\begin{array}{r}6,208 \\
- \\
-\end{array}$ & $\begin{array}{l}\overline{-} \\
\overline{-}\end{array}$ & $\begin{array}{l}- \\
- \\
-\end{array}$ & $\begin{array}{l}\overline{-} \\
\overline{-}\end{array}$ & $\begin{array}{l}- \\
\overline{-}\end{array}$ & $\begin{array}{l}2 \\
\vdots\end{array}$ & $\begin{array}{r}17.037 \\
- \\
-\end{array}$ & $\begin{array}{r}-8,135 \\
- \\
- \\
-\end{array}$ & $\begin{array}{r}15,112 \\
- \\
-\end{array}$ & $10 \%$ \\
\hline $\begin{array}{l}\text { NET POEL USED } \\
\text { IN TRANSFORMATION }\end{array}$ & $\epsilon .208$ & - & - & - & - & 2 & 17,037 & $-8,135$ & 15,112 & $10 \%$ \\
\hline $\begin{array}{l}\text { TOTAL GROSS FLORS } \\
\text { LOSSES \& OMISSIONS }\end{array}$ & $\begin{array}{r}17.421 \\
., 007\end{array}$ & $\begin{array}{r}2 .+38 \\
0\end{array}$ & $\begin{array}{r}35,480 \\
-0\end{array}$ & $\begin{array}{r}14,882 \\
-622\end{array}$ & - & $\begin{array}{r}27,597 \\
-5.99\end{array}$ & $\begin{array}{r}25,062 \\
-55\end{array}$ & $\begin{array}{r}28,265 \\
2.826\end{array}$ & $\begin{array}{r}149,010 \\
2,157\end{array}$ & $\begin{aligned} 99 \% \\
1 \%\end{aligned}$ \\
\hline
\end{tabular}

SOPPLT OP EYERG
$\begin{aligned} & \text { POSS IL PUEL } \\ & \text { RJDROELECTRIC }\end{aligned}$
NOCL EAR
GBO.ESOLAR

NET IM PORTS
OP R EGION


REGIONAL BNE RGY BALANCE STATEMENT

IONAL BNERGY BALANCE S
PIES MID MID SCEYARIO

\begin{tabular}{|c|c|c|c|c|c|c|c|c|c|c|}
\hline SECTOR & $\begin{array}{l}\text { DISTIL LATE } \\
\text { OIL }\end{array}$ & $\begin{array}{l}\text { EESIDJAL } \\
\text { OIL }\end{array}$ & $\begin{array}{l}\text { GASOLINI } \\
\text { (ALL }\end{array}$ & $\begin{array}{c}\text { OTHER } \\
\text { HYDRO- } \\
\text { CARBONS } \\
\text { CS IN } 10^{*}\end{array}$ & $\begin{array}{l}\text { CEODE } \\
\text { C.IL } \\
\text { BTO'S) }\end{array}$ & $\begin{array}{l}\text { NATURAL } \\
\text { GAS }\end{array}$ & $\operatorname{COAL}$ & ELECTRICITY & $\begin{array}{l}\text { SECTOR } \\
\text { TOTAL }\end{array}$ & \\
\hline $\begin{array}{l}\text { PINAL DEFAND SECTORS } \\
\text { RESIDENTIAL, COHA. } \\
\text { IND OSTRIAL } \\
\text { TRANSPORTATION } \\
\text { MISCELLAHEOOS OSES }\end{array}$ & $\begin{array}{r}2,983 \\
2,724 \\
4,800 \\
388\end{array}$ & $\begin{array}{r}745 \\
7.083 \\
367 \\
.221\end{array}$ & $33.62 \overline{-}$ & $\begin{array}{r}3,463 \\
7,210 \\
7,577 \\
21\end{array}$ & I- & $\begin{array}{r}7,335 \\
13,107 \\
485 \\
515\end{array}$ & $\begin{array}{r}19 \\
4.687 \\
-\end{array}$ & $\begin{array}{r}11,811 \\
10,492 \\
- \\
145\end{array}$ & $\begin{array}{r}26,356 \\
45,303 \\
46,853 \\
1,291\end{array}$ & $\begin{array}{r}18 \% \\
32 \% \\
33 \% \\
1 \%\end{array}$ \\
\hline $\begin{array}{l}\text { TOTAL PINAL } \\
\text { DEHAND SECTORS }\end{array}$ & 10,895 & 8,416 & 33,624 & 18,271 & - & 21,442 & 4,707 & 22,448 & 119,803 & $83 \%$ \\
\hline $\begin{array}{l}\text { THANSPORMATION } \\
\text { EL ECTRICITY GEH. } \\
\text { PETR OLEDM PRODUCTS } \\
\text { NATURAL GAS } \\
\text { SY NT RETICS }\end{array}$ & $\begin{array}{r}3,682 \\
-.11, .100 \\
-\end{array}$ & $\begin{array}{r}22,858 \\
-1,353 \\
- \\
-\end{array}$ & $\begin{array}{r}-12,798 \\
-\end{array}$ & $\begin{array}{r}-5.435 \\
- \\
-\end{array}$ & $\frac{30,533}{-}$ & $\begin{array}{r}1,107 \\
226 \\
- \\
-\end{array}$ & $\begin{array}{r}3,284 \\
- \\
-\end{array}$ & $\begin{array}{r}-10,250 \\
- \\
-\end{array}$ & $\begin{array}{r}20,681 \\
73 \\
- \\
-\end{array}$ & $\begin{array}{r}14 \% \\
0 \%\end{array}$ \\
\hline $\begin{array}{l}\text { IET POEL OSED } \\
\text { IN TRASPORHATION }\end{array}$ & -7.418 & 21.504 & $-12,798$ & $-5,435$ & 35.533 & $1 ; 333$ & 3.284 & $-10,250$ & 20,754 & $14 \%$ \\
\hline $\begin{array}{l}\text { TOTAL GROSS PLORS } \\
\text { LOSSES \& OMISSIONS }\end{array}$ & $\begin{array}{r}14.577 \\
842\end{array}$ & $\begin{array}{r}31,274 \\
0\end{array}$ & $\begin{array}{r}33,624 \\
-0\end{array}$ & $\begin{array}{r}18,271 \\
-763\end{array}$ & $\begin{array}{r}30,533 \\
1,524\end{array}$ & $\begin{array}{r}22,775 \\
-825\end{array}$ & $\begin{array}{r}7,991 \\
-17\end{array}$ & $\begin{array}{r}22,448 \\
2,245\end{array}$ & $\begin{array}{r}140,557 \\
3,006\end{array}$ & $\begin{array}{r}98 \% \\
28\end{array}$ \\
\hline
\end{tabular}

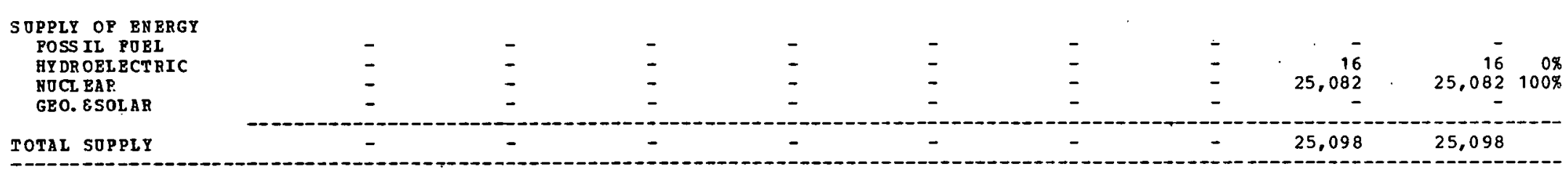

\begin{tabular}{l}
$\begin{array}{l}\text { WET IM PORTS } \\
\text { OP R RGION }\end{array}$ \\
\hline
\end{tabular}


REGICNAL ENE RGY BALANCE STATEMENT

\begin{tabular}{|c|c|c|c|c|c|c|c|c|c|c|}
\hline SECTOR & $\begin{array}{l}\text { DISTILLATE } \\
\text { OLL }\end{array}$ & $\begin{array}{l}\text { RES IDCAL } \\
\text { OIL }\end{array}$ & $\begin{array}{l}\text { GASO! I NE } \\
\text { (ALL ONIT }\end{array}$ & $\begin{array}{c}\text { CTHER } \\
\text { HEDRO- } \\
\text { 2AFBONS } \\
\text { IS IN } 10 * * 9\end{array}$ & $\begin{array}{c}\text { CzODE } \\
\text { OIL } \\
\text { BTU'S) }\end{array}$ & $\begin{array}{l}\text { NATURAL } \\
\text { GAS }\end{array}$ & $\cos \mathrm{L}$ & ELECTRICITY & $\begin{array}{r}\text { SECTOB } \\
\text { TOTAL }\end{array}$ & \\
\hline $\begin{array}{l}\text { PIRAL DRHAMD SECTORS } \\
\text { RESIDERTIAL, COHA. } \\
\text { IND OS TRIAL } \\
\text { TRAHSPORTATION } \\
\text { HISCELLANEOOS OSES }\end{array}$ & $\begin{array}{r}8.558 \\
11.391 \\
23.333 \\
1.188\end{array}$ & $\begin{array}{r}2,200 \\
25,894 \\
1,341 \\
675\end{array}$ & $\begin{array}{r}- \\
- \\
-757\end{array}$ & $\begin{array}{r}11,653 \\
10,033 \\
18,439 \\
70\end{array}$ & $\begin{array}{l}\overline{-} \\
\overline{-}\end{array}$ & $\begin{array}{r}7,810 \\
23,152 \\
1,152 \\
1,4112\end{array}$ & $\begin{array}{r}259 \\
11,924 \\
1 \\
4\end{array}$ & $\begin{array}{r}50,969 \\
16,617 \\
- \\
928\end{array}$ & $\begin{array}{r}81,449 \\
99,021 \\
153,033 \\
4,267\end{array}$ & $\begin{array}{r}208 \\
24 \% \\
37 \% \\
1 \%\end{array}$ \\
\hline $\begin{array}{l}\text { TOTAL PINAL } \\
\text { DEMAND SEETORS }\end{array}$ & 44,470 & 30,110 & 108,757 & $4 J, 195$ & - & 33,536 & $12, \cdot 88$ & $6 \varepsilon, 514$ & 337,770 & $82 \%$ \\
\hline $\begin{array}{l}\text { TR ANSP ORMATIDN } \\
\text { ELECTRICITY. GEN. } \\
\text { PETROLEDA ERODOCTS } \\
\text { NATORAL GAS } \\
\text { SY RT HETICS }\end{array}$ & $\begin{array}{r}15.319 \\
- \\
-\end{array}$ & $\begin{array}{r}72,818 \\
- \\
-\end{array}$ & $\begin{array}{l}\overline{-} \\
\overline{-}\end{array}$ & $\begin{array}{l}- \\
- \\
-\end{array}$ & $\begin{array}{l}- \\
-\end{array}$ & $\begin{array}{l}5 \\
- \\
-\end{array}$ & $\begin{array}{r}10, C 26 \\
- \\
-\end{array}$ & $\begin{array}{r}-32,779 \\
- \\
-\end{array}$ & $\begin{array}{r}65,389 \\
- \\
-\end{array}$ & $16 \%$ \\
\hline $\begin{array}{l}\text { NET POEL OSED } \\
\text { IN TRANSFORMATION }\end{array}$ & 15.319 & 72,818 & - & - & - & 5 & 10,026 & $-32,779$ & 65,389 & $16 \%$ \\
\hline $\begin{array}{l}\text { TOTAL GROSS FLORS } \\
\text { LOSSES } \varepsilon \text { OHISSIOYS }\end{array}$ & $\begin{array}{r}59.789 \\
3.456\end{array}$ & $\begin{array}{r}132,928 \\
2\end{array}$ & $\begin{array}{r}108,757 \\
-3\end{array}$ & $\begin{array}{l}40,195 \\
-1,680\end{array}$ & $\overline{-}$ & $\begin{array}{r}33,541 \\
-1,2: 14\end{array}$ & $\begin{array}{r}22,214 \\
-48\end{array}$ & $\begin{array}{r}68,514 \\
6,852\end{array}$ & $\begin{array}{r}403,159 \\
7,366\end{array}$ & $\begin{array}{r}98 \% \\
2 \%\end{array}$ \\
\hline TOTAL NET OSAGE & 63.245 & 102,930 & 108,755 & 38,514 & - & 32,326 & 22,165 & 42.587 & 410,525 & \\
\hline
\end{tabular}

\begin{tabular}{|c|c|c|c|c|c|c|c|c|c|}
\hline SOPPIY OP ENERGY & & & & & & & & & \\
\hline POSS IL ·POBI & $\overline{-}$ & $\overline{-}$ & - & $\overline{-}$ & $\overline{-}$ & $\overline{-}$ & - & $5 \overline{2}$ & $\overrightarrow{52}$ \\
\hline NOCL EAR & - & - & - & - & - & - & - & - & - \\
\hline GEO. ESOLAR & - & - & - & - & - & - & - & - & - \\
\hline TOTAL SOPPLT & - & - & - & - & - & $=$ & - & 52 & 52 \\
\hline
\end{tabular}

\section{NET IM PORTS}

OF 3 EGION

63,245

112,930

108,756

$38:, 514$

32,326

22,165

42,535

410,473

-

NoTES:

1 TRANSPORHATION LOSS rOz

TRAN STORHATI ON LOES YOR

TRANSPORMATION LOES rOR
TRANSTORMATION LOES BOR

3LEC ZRICITY GEQ. $\quad=65.619$

MATORAL JAS

GTMTBETIES

$=0.0 \%$ 


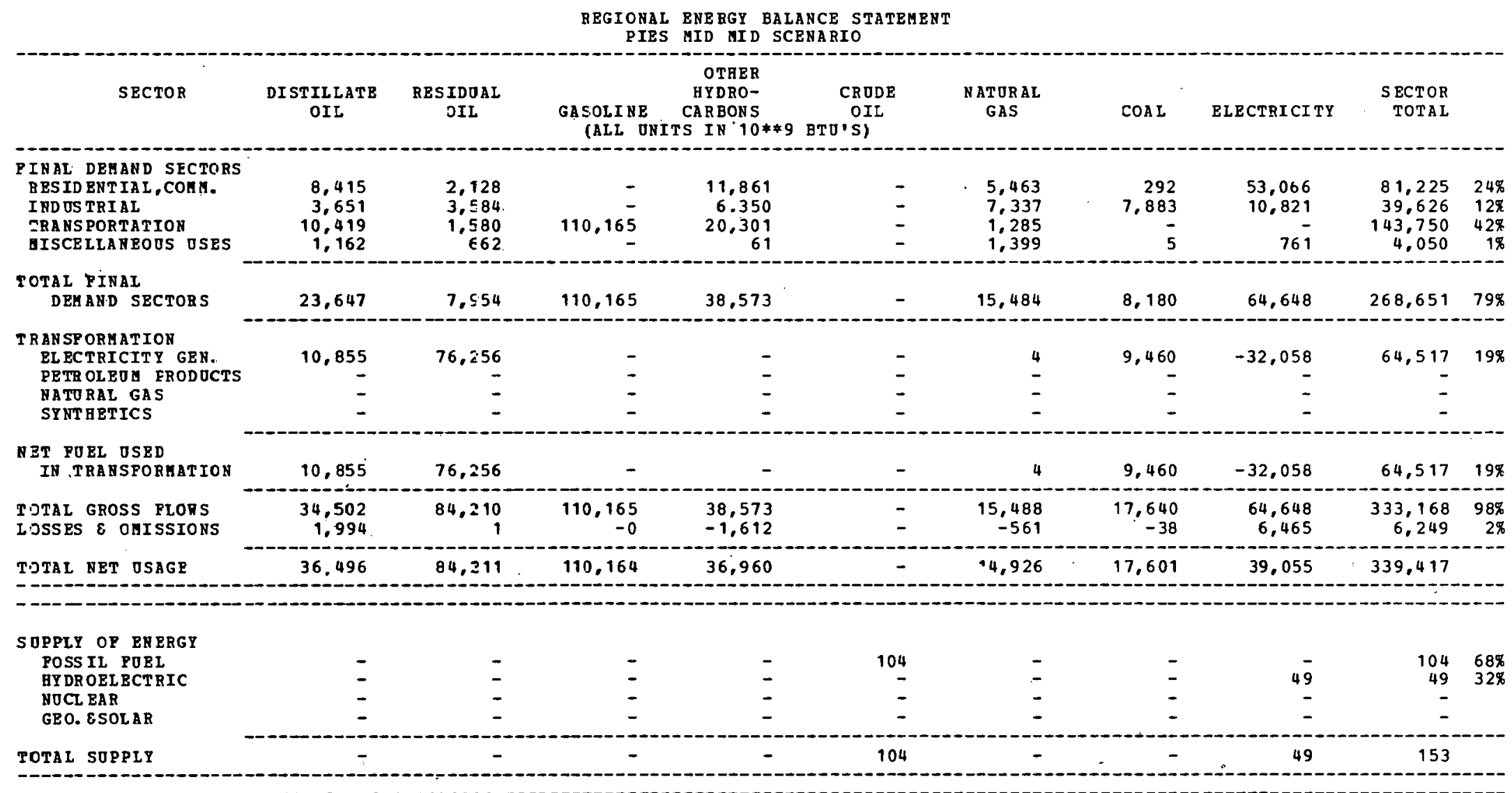

\begin{tabular}{|c|c|c|c|c|c|c|}
\hline \multicolumn{2}{|c|}{$\begin{array}{l}\text { RET IM PORTS } \\
\text { OF REGION }\end{array}$} & \multicolumn{2}{|c|}{36,496} & \multicolumn{3}{|c|}{110,164} \\
\hline so 1 & ES: & & & & & \\
\hline $\begin{array}{l}1 \\
2 \\
3\end{array}$ & $\begin{array}{l}\text { TRAN SPORAATI ON } \\
\text { TRANSPORAATI ON } \\
\text { TRABSPORAATI ON }\end{array}$ & $\begin{array}{l}\text { LOSS } \\
\text { LoSS } \\
\text { LOSS }\end{array}$ & $\begin{array}{l}\text { POR } \\
\text { POR } \\
\text { POR }\end{array}$ & $\begin{array}{l}\text { EL ECTRECITY } \\
\text { PETROLEOK PI } \\
\text { NATURAL GAS }\end{array}$ & $\begin{array}{l}\text { GEN. } \\
\text { ROD OCTS }\end{array}$ & $\begin{array}{l}=66.81 \% \\
=0.0 \% \\
=0.0 \%\end{array}$ \\
\hline 4 & TR A S SPOR UA TI OH & Loss & POR & SINTHETICS & & $=0.0 \%$ \\
\hline
\end{tabular}


REGIONAL BNERGY BALANCE STATEMENT

PIES UIL MID SCENARIO

\begin{tabular}{|c|c|c|c|c|c|c|c|c|c|c|}
\hline SBCTOR & $\begin{array}{l}\text { DISTILLATE } \\
\text { OJ: }\end{array}$ & $\begin{array}{l}\text { RES IDJAL } \\
\text { OIL }\end{array}$ & $\begin{array}{l}\text { GASOLII NE } \\
\text { (ALI ONI }\end{array}$ & $\begin{array}{c}\text { OTHER } \\
\text { HYDRO- } \\
\text { CARBONS } \\
\text { CS TIJ } 10 * * 9\end{array}$ & $\begin{array}{c}\text { CR DDE } \\
\text { OIL } \\
\text { 3TO'S) }\end{array}$ & $\begin{array}{l}\text { NATUREL } \\
\text { GAS }\end{array}$ & COAL & ELECTRICITT & $\begin{array}{r}\text { SECTOR } \\
\text { TOTAL }\end{array}$ & \\
\hline $\begin{array}{l}\text { PINAL DEHAND SECTORS } \\
\text { RESID ENTIAL, CCHH. } \\
\text { IND USTRIAL } \\
\text { TRAYS PORTATZON } \\
\text { HISCELLAREOTS OSES }\end{array}$ & $\begin{array}{r}22.1 .90 \\
9.930 \\
20.476 \\
1.715\end{array}$ & $\begin{array}{r}5,407 \\
10,756 \\
11,036 \\
976\end{array}$ & $299,01 \overline{-}$ & $\begin{array}{r}32,114 \\
14,051 \\
141,675 \\
88\end{array}$ & $\overline{-}$ & $\begin{array}{r}14,3714 \\
24,927 \\
8,975 \\
2,675\end{array}$ & $\begin{array}{r}791 \\
10,652 \\
6 \\
6\end{array}$ & $\begin{array}{r}140,712 \\
21,909 \\
1,073\end{array}$ & $\begin{array}{r}215,528 \\
92,225 \\
481,176 \\
5,933\end{array}$ & $\begin{array}{r}23 \% \\
10 \% \\
51 \% \\
1 \%\end{array}$ \\
\hline $\begin{array}{l}\text { TOTAL PINAL } \\
\text { DEMAND SECTORS }\end{array}$ & 54,311 & 28,175 & 299,014 & 187,928 & - & $50, \approx 91$ & 11,449 & 163,694 & 794,862 & $84 \%$ \\
\hline $\begin{array}{l}\text { TR ANSPORMATION } \\
\text { EL ECTRICITH. GER. } \\
\text { PETR OLEOA ERODOCTS } \\
\text { NATORAL GAE } \\
\text { ST NTHETICS }\end{array}$ & $\begin{array}{r}27.116 \\
= \\
=\end{array}$ & $\begin{array}{r}15.5,547 \\
=\end{array}$ & $\begin{array}{l}\bar{z} \\
\bar{z}\end{array}$ & $\begin{array}{l}\overline{-} \\
\overline{-}\end{array}$ & $\begin{array}{l}\overline{-} \\
\overline{-}\end{array}$ & $\begin{array}{r}1,353 \\
- \\
-\end{array}$ & $\begin{array}{r}23,954 \\
= \\
=\end{array}$ & $\begin{array}{r}-69,221 \\
- \\
-\end{array}$ & $\begin{array}{r}138,746 \\
= \\
-\end{array}$ & $15 \%$ \\
\hline $\begin{array}{l}\text { NET FOEI OSED } \\
\text { IN TRANSFORHATION }\end{array}$ & 27.116 & 155,547 & - & - & - & 1,350 & 23,954 & $-69,221$ & 138,746 & $15 \%$ \\
\hline $\begin{array}{l}\text { TOTAL GROSS FLONS } \\
\text { LOSSES \& OMISSIONS }\end{array}$ & $\begin{array}{r}81,127 \\
4,707\end{array}$ & $\begin{array}{r}1 \varepsilon 3,722 \\
4\end{array}$ & $\begin{array}{r}299,014 \\
-0\end{array}$ & $\begin{array}{r}18 \div .928 \\
-\because .855\end{array}$ & $\overline{-}$ & $\begin{array}{l}51,641 \\
-1,870\end{array}$ & $\begin{array}{r}35,403 \\
-77\end{array}$ & $\begin{array}{r}163,694 \\
16,371\end{array}$ & $\begin{array}{r}933,608 \\
11,277\end{array}$ & $\begin{array}{r}99.8 \\
1.8\end{array}$ \\
\hline TOTAL NET OSAGE & 86,134 & $1 \varepsilon, 3,726$ & 299,013 & $n 3 C, 072$ & - & 49,770 & 35,325 & 110,844 & 944,885 & \\
\hline $\begin{array}{l}\text { S OPPLI OF ENFRGY } \\
\text { POSS IL PUBI } \\
\text { HYDROELECTFIC } \\
\text { NOCL EAR } \\
\text { GEO. \&SOLAR }\end{array}$ & $\begin{array}{l}\overline{-} \\
\overline{-}\end{array}$ & $\begin{array}{l}- \\
-\end{array}$ & $\begin{array}{l}\bar{z} \\
\overline{-}\end{array}$ & $\overline{-}$ & $\begin{array}{r}90,256 \\
- \\
-\end{array}$ & $\begin{array}{r}1,795 \\
- \\
-\end{array}$ & $\begin{array}{l}- \\
-\end{array}$ & $\begin{array}{r}125 \\
42,794 \\
-\end{array}$ & $\begin{array}{r}91,961 \\
125 \\
42,794 \\
-\end{array}$ & $\begin{array}{r}68 \% \\
0 \% \\
32 \%\end{array}$ \\
\hline IOTAL SDPPLY & - & - & - & - & 90,256 & 1,705 & - & 42,919 & 134,880 & \\
\hline
\end{tabular}

UET IM PORTS
OP REGION


REGIONAL ENERGY BALANCE STATEMENT

PIES MID MID SCENARIO

\begin{tabular}{|c|c|c|c|c|c|c|c|c|c|c|}
\hline SECTOR & $\begin{array}{l}\text { DISTIL IATE } \\
\text { OII }\end{array}$ & $\begin{array}{l}\text { BESILUAL } \\
\text { OIL }\end{array}$ & $\begin{array}{l}\text { GASOLINE } \\
\text { (ALL O }\end{array}$ & $\begin{array}{c}\text { OTHER } \\
\text { HYDRO- } \\
\text { CARBONS } \\
\text { IS IN } 10 * \$ 9\end{array}$ & $\begin{array}{l}\text { CRDDE } \\
\text { OIL } \\
\text { BTO'S) }\end{array}$ & $\begin{array}{l}\text { NATURAL } \\
\text { GAS }\end{array}$ & $\operatorname{COAL}$ & ELECTRICITY & $\begin{array}{r}\text { SECTOR } \\
\text { TOTAL }\end{array}$ & \\
\hline $\begin{array}{l}\text { PINAL DEMAND SECTORS } \\
\text { RESTDENTIAL, CCME. } \\
\text { IND USTRIAL } \\
\text { TRANSPORTATION } \\
\text { MISCELLANEOOS OSES }\end{array}$ & $\begin{array}{r}17,226 \\
13,184 \\
21,609 \\
1,327\end{array}$ & $\begin{array}{r}4,029 \\
14,062 \\
2,116 \\
755\end{array}$ & $239,10 \overline{-}$ & $\begin{array}{r}25,616 \\
17,829 \\
27,216 \\
67\end{array}$ & $\begin{array}{l}- \\
- \\
-\end{array}$ & $\begin{array}{r}11,041 \\
30,213 \\
1,721 \\
1,616\end{array}$ & $\begin{array}{r}626 \\
13,845 \\
1 \\
4\end{array}$ & $\begin{array}{r}109,814 \\
23,373 \\
- \\
779\end{array}$ & $\begin{array}{r}168,352 \\
112,506 \\
291,770 \\
4,548\end{array}$ & $\begin{array}{r}20 \% \\
14 \% \\
35 \% \\
1 \%\end{array}$ \\
\hline $\begin{array}{l}\text { TOTAL PINAL } \\
\text { DEMAND ȘECTORS }\end{array}$ & 53,346 & 20,962 & 239.107 & 70,728 & - & 44,591 & 14,476 & 133,966 & 577,176 & $70 \%$ \\
\hline $\begin{array}{l}\text { GRANSP ORHATION } \\
\text { EL ECTRICITY GED. } \\
\text { PETR OLEOM PRODECTS } \\
\text { NATDRAL GAS } \\
\text { SYNTHETICS }\end{array}$ & $\begin{array}{r}22,255 \\
- \\
- \\
-\end{array}$ & $\begin{array}{r}168,680 \\
- \\
-\end{array}$ & $\begin{array}{l}- \\
- \\
-\end{array}$ & $\begin{array}{l}- \\
-\end{array}$ & $\begin{array}{l}- \\
\overline{-}\end{array}$ & $\begin{array}{l}9 \\
- \\
-\end{array}$ & $\begin{array}{r}168,484 \\
- \\
-\end{array}$ & $\begin{array}{r}-120,922 \\
- \\
-\end{array}$ & $\begin{array}{r}238,506 \\
- \\
- \\
-\end{array}$ & $29 x$ \\
\hline $\begin{array}{l}\text { YET POEL OSED } \\
\text { IN TRANSPORMATZON }\end{array}$ & 22,255 & 168,680 & - & - & - & 9 & 168,484 & $-120,922$ & $238,506^{\circ}$ & $29 \%$ \\
\hline $\begin{array}{l}\text { ZOTAL GROSS FLORS } \\
\text { LOSSES } \& \text { OHISSIORS }\end{array}$ & $\begin{array}{r}75,601 \\
4.370\end{array}$ & 189,642 & $239, \begin{array}{r}107 \\
-0\end{array}$ & $\begin{array}{l}70,728 \\
-2,956\end{array}$ & - & $\begin{array}{r}44,600 \\
-1,615\end{array}$ & $\begin{array}{r}182,960 \\
-403\end{array}$ & $\begin{array}{r}133,966 \\
13,398\end{array}$ & $\begin{array}{l}815,682 \\
.12,797\end{array}$ & $\begin{array}{r}98 \% \\
2 \%\end{array}$ \\
\hline TOTAL NET OSAGE & 79,971 & 189,646 & 239,106 & 67,771 & - & 42,984 & 182,556 & 26,442 & 828,479 & \\
\hline
\end{tabular}

(1)

\begin{tabular}{|c|c|c|c|c|c|c|c|c|c|c|}
\hline $\begin{array}{l}\text { SUPPLY OP ENERGY } \\
\text { POSS IL POEL }\end{array}$ & - & - & - & - & 15,936 & 375 & - & - & 16,311 & $65 \pi$ \\
\hline HY DR OELECTRIC & - & - & - & - & - & - & - & 102 & 102 & $0 \%$ \\
\hline NOCL $B A R$ & - & - & - & - & - & - & - & 8,662 & 8,662 & $35 \%$ \\
\hline GEO. ESOLAR & - & - & - & - & - & - & - & - & - & \\
\hline TOTAL SOPPLY & - & - & - & - & 15,936 & 375 & - & 8,764 & 25,075 & \\
\hline
\end{tabular}

\begin{tabular}{l}
$\begin{array}{l}\text { GET IM PORTS } \\
\text { OF R RGION }\end{array}$ \\
\hline
\end{tabular}


REGICNAL ENERGY BALANCE STATEMENT

PNAL ENERGY BALANCE STA
PIES MID MID DCENARIO

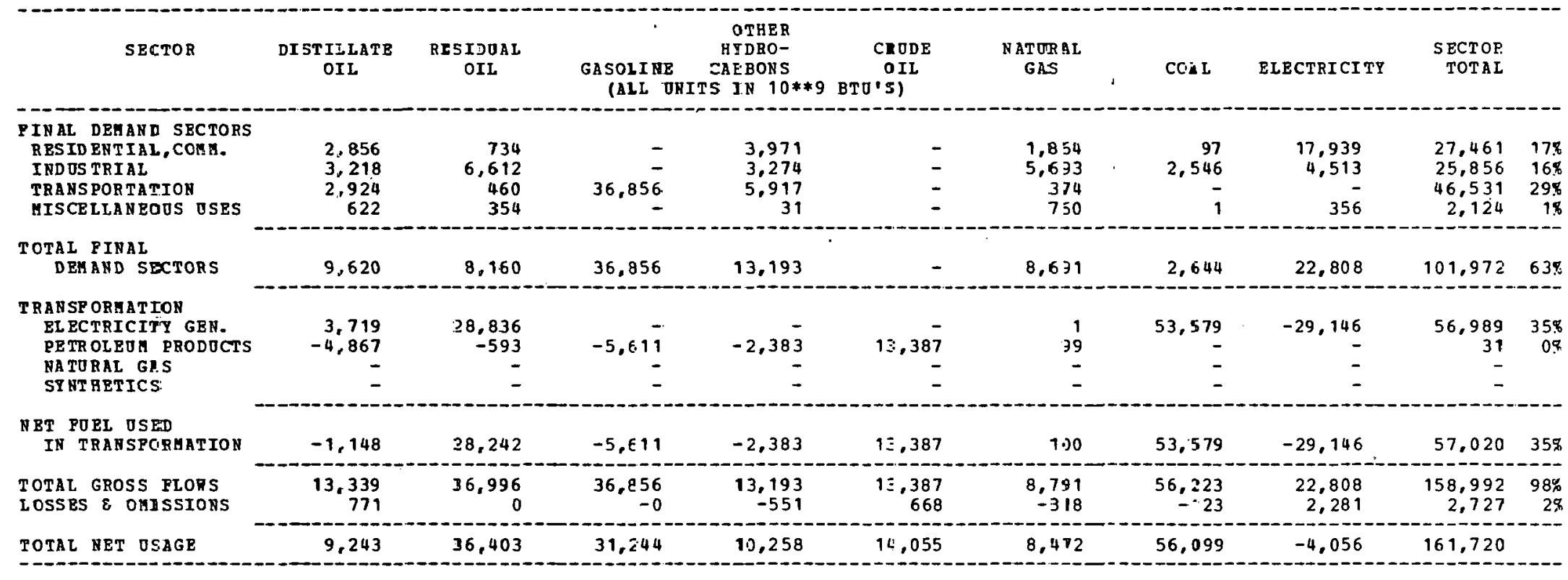

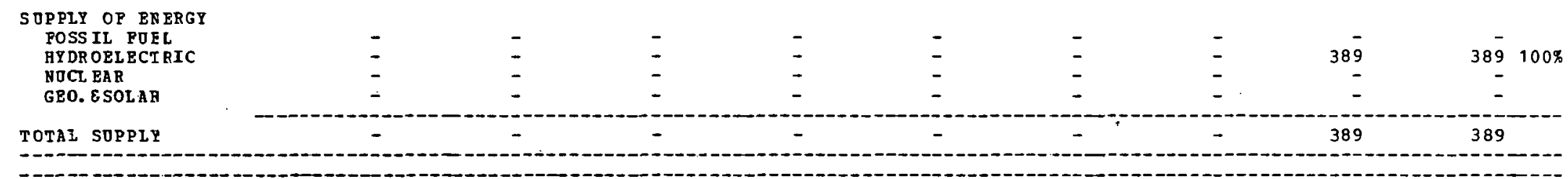

NET IM PORTS

0.943

31,244

10,258

14,055

$8,4\urcorner 2$

56,099

$-4.445$

161,331

-

HO TES:

TRANSPORMATION LESS POR TRANSPORAATION LESS POR TRA MISPORUA TI ON LESS POR TRA MSPOR MATY ON LESS POR

ELECTHICITY 3EN.

PBTE OLETM PR

WATRAL GAS

$=0.2 \pm 5$

$=0.0 \%$

$=0.0 \%$ 
REGIONAL REE RGY BALARCE STATEMENT

\begin{tabular}{|c|c|c|c|c|c|c|c|c|c|c|}
\hline SECTOR & $\begin{array}{l}\text { DISTILLATE } \\
\text { OIL }\end{array}$ & $\begin{array}{l}\text { RESIDOAL } \\
\text { OIL }\end{array}$ & $\begin{array}{r}\text { GASOLINE } \\
\text { (ALI OI }\end{array}$ & $\begin{array}{c}\text { OTHER } \\
\text { HYDRO- } \\
\text { CARBONS } \\
\text { TS IN } 10 * 9\end{array}$ & $\begin{array}{c}\text { CRODE } \\
\text { OIL } \\
\text { BTO'S) }\end{array}$ & $\begin{array}{l}\text { NATURAL } \\
\text { GAS }\end{array}$ & $\operatorname{COAL}$ & ELECTRICITY & $\begin{array}{r}\text { SECTOR } \\
\text { TOTAL }\end{array}$ & . \\
\hline $\begin{array}{l}\text { PINAL DEMAND SECTORS } \\
\text { RESID ENTIAL, COMH. } \\
\text { INDOS TRIAL } \\
\text { TRANS PORTATION } \\
\text { MISCE LLANEOOS OSES }\end{array}$ & $\begin{array}{r}2,305 \\
4,442 \\
3,199 \\
668\end{array}$ & $\begin{array}{r}\$ 76 \\
8,870 \\
1,214 \\
380\end{array}$ & $\begin{array}{r}- \\
35,459 \\
-\end{array}$ & $\begin{array}{r}3,784 \\
21,390 \\
12,078 \\
46\end{array}$ & $\begin{array}{l}- \\
-\end{array}$ & $\begin{array}{r}2,049 \\
30,320 \\
796 \\
744\end{array}$ & $\begin{array}{r}86 \\
5,418 \\
- \\
2\end{array}$ & $\begin{array}{r}15,369 \\
14,022 \\
- \\
715\end{array}$ & $\begin{array}{r}24,061 \\
84,462 \\
52,746 \\
2,555\end{array}$ & $\begin{array}{l}12 \% \\
44 \% \\
27 \% \\
1 \%\end{array}$ \\
\hline $\begin{array}{l}\text { TOTAL PINAL } \\
\text { DEMAND SECTORS }\end{array}$ & 10,614 & 10,940 & 35,459 & 37,298 & - & 33,901 & 5,506 & 30,106 & 163.824 & $85 \%$ \\
\hline $\begin{array}{l}\text { TRANSF ORMATION } \\
\text { ELECTRICITY GEN. } \\
\text { PETR OLEOM PRODOCTS } \\
\text { NATURAL GAS } \\
\text { SY HT HETICS }\end{array}$ & $\begin{array}{r}4,852 \\
= \\
-\end{array}$ & $\overline{-}$ & I & $\begin{array}{l}- \\
\overline{-}\end{array}$ & $\begin{array}{l}- \\
\overline{-} \\
-\end{array}$ & $\begin{array}{r}5,445 \\
- \\
-\end{array}$ & $\begin{array}{r}33,821 \\
= \\
=\end{array}$ & $\begin{array}{r}-15,012 \\
= \\
=\end{array}$ & $\begin{array}{r}29,106 \\
= \\
=\end{array}$ & $15 \%$ \\
\hline $\begin{array}{l}\text { NET POEL OSED } \\
\text { IN TRANSFORMATION }\end{array}$ & 4,852 & - & - & - & - & 5,445 & 33,821 & $-15,012$ & 29,106 & $15 \%$ \\
\hline $\begin{array}{l}\text { TOTAL GROSS FLORS } \\
\text { L JSSES } \varepsilon \text { OMISSIONS }\end{array}$ & $\begin{array}{r}15,466 \\
894\end{array}$ & $\begin{array}{r}10,940 \\
0\end{array}$ & $\begin{array}{r}35,459 \\
-0\end{array}$ & $\begin{array}{l}37,298 \\
-1,559\end{array}$ & $\overline{-}$ & $\begin{array}{l}39,346 \\
-1,425\end{array}$ & $\begin{array}{r}39,327 \\
-86\end{array}$ & $\begin{array}{r}30,106 \\
3,010\end{array}$ & $\begin{array}{r}192,930 \\
834\end{array}$ & $\begin{array}{r}100 \% \\
0 \%\end{array}$ \\
\hline $\begin{array}{l}\text { S JPFLY OP ENERGY } \\
\text { POSS IL POEL } \\
\text { HYDR OELECTRIC } \\
\text { NDCL EAR } \\
\text { GEO. ESOLAR }\end{array}$ & $\begin{array}{l}- \\
-\end{array}$ & $\begin{array}{l}- \\
- \\
-\end{array}$ & $\overline{-}$ & $\begin{array}{l}- \\
- \\
-\end{array}$ & $\begin{array}{r}782.089 \\
- \\
-\end{array}$ & $\begin{array}{r}239,690 \\
- \\
-\end{array}$ & $\begin{array}{l}- \\
- \\
-\end{array}$ & $\begin{array}{r}\overline{-} \\
\overline{-}\end{array}$ & $\begin{array}{r}1,021,779 \\
23 \\
- \\
-\end{array}$ & $\begin{array}{r}100 \% \\
0 \%\end{array}$ \\
\hline TOTAL SOPPLY & - & - & - & - & 782,089 & 239,690 & - & 23 & $1,021,802$ & \\
\hline
\end{tabular}

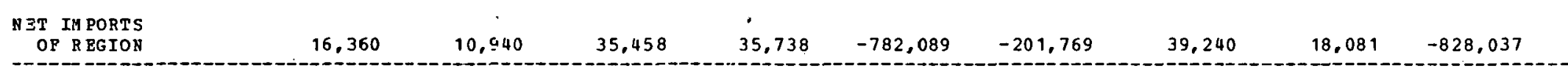

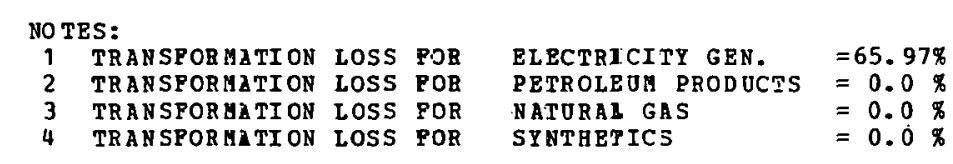


REIICNAL ENERGY BALANCE STATEMENT

EIES NID MID SCENARIO

\begin{tabular}{|c|c|c|c|c|c|c|c|c|c|}
\hline SE & $\begin{array}{c}D=\text {-STHLATE } \\
\text { OIL }\end{array}$ & $\begin{array}{l}\text { R } 3 \text { SIDUAL } \\
\text { OIL }\end{array}$ & $\begin{array}{c}\cdots \\
\text { GASO INE } \\
(A \mathrm{~L} \text { ONI }\end{array}$ & $\begin{array}{c}\text { OTHER } \\
H=D R O- \\
\text { CARBONS } \\
\text { TS } \equiv N \quad 10 * \# 9\end{array}$ & $\begin{array}{c}\text { CRODE } \\
\text { OIL } \\
\text { BTO'S) }\end{array}$ & $\begin{array}{l}\text { VATURAL } \\
\text { GAS }\end{array}$ & $\cos L$ & ELECTRICITY & $\begin{array}{l}\text { SECTOR } \\
\text { TOTAL }\end{array}$ \\
\hline $\begin{array}{l}\text { PINAL DEMAND SECTORS } \\
\text { RESID ENTIAL, COHA. } \\
\text { IND OS TRIAL } \\
\text { TRANSPORTATION } \\
\text { MISCELLANEIOS OSES }\end{array}$ & $\begin{array}{r}2.270 \\
1.378 \\
14.805 \\
718\end{array}$ & $\begin{array}{r}338 \\
1,660 \\
11,550 \\
410\end{array}$ & 54,473 & $\begin{array}{r}5,989 \\
2,893 \\
5,484 \\
47\end{array}$ & $\begin{array}{l}\overline{-} \\
\overline{-}\end{array}$ & $\begin{array}{r}12, .756 \\
17, .836 \\
1,624 \\
1, .255\end{array}$ & $\begin{array}{r}82 \\
8,769 \\
- \\
3\end{array}$ & $\begin{array}{r}23,471 \\
16,548 \\
- \\
335\end{array}$ & $\begin{array}{r}44,906 \\
49,084 \\
87,936 \\
2,768\end{array}$ \\
\hline $\begin{array}{l}\text { TOTAL PINAL } \\
\text { DEMAND SECTORS }\end{array}$ & 19,171 & 13,958 & 54,473 & 14,413 & - & 33,471 & 8.354 & 40,354 & 184,694 \\
\hline $\begin{array}{l}\text { TRANSFORMATION } \\
\text { ELECTRICITY GEN. } \\
\text { PETROLEOM FRODOCTS } \\
\text { NATURAL G:S } \\
\text { SY NT HETICE }\end{array}$ & $\begin{array}{r}6.495 \\
- \\
-\end{array}$ & $\begin{array}{l}\overline{-} \\
\overline{-}\end{array}$ & $\begin{array}{l}\overline{-} \\
\overline{-}\end{array}$ & $\begin{array}{l}- \\
-\end{array}$ & $\begin{array}{l}- \\
- \\
-\end{array}$ & $\begin{array}{r}423 \\
- \\
-\end{array}$ & $\begin{array}{r}5,905 \\
- \\
-\end{array}$ & $\begin{array}{r}-4.545 \\
- \\
- \\
-\end{array}$ & $\begin{array}{r}8,278 \\
- \\
-\end{array}$ \\
\hline $\begin{array}{l}\text { NET FOEL OSED } \\
\text { IN TRANSFCRMATION }\end{array}$ & 6.495 & - & - & - & - & 423 & 5,305 & $-4,545$ & 8,278 \\
\hline $\begin{array}{l}\text { TOTAL GROSS FLORS } \\
\text { LOSSES } \& \text { OMISSIONS }\end{array}$ & $\begin{array}{r}25,666 \\
1,483\end{array}$ & $\begin{array}{r}13,958 \\
0\end{array}$ & $\begin{array}{r}54,473 \\
-0\end{array}$ & $\begin{array}{r}14,413 \\
-602\end{array}$ & $\overline{-}$ & $\begin{array}{l}33,874 \\
-1,227\end{array}$ & $\begin{array}{r}14,759 \\
-32\end{array}$ & $\begin{array}{r}40,354 \\
4,035\end{array}$ & $\begin{array}{r}192,972 \\
3,657\end{array}$ \\
\hline
\end{tabular}

\begin{tabular}{|c|c|c|c|c|c|c|c|c|c|}
\hline $\begin{array}{l}S \text { UPPLY OF ENFRGY } \\
\text { POSS IL PUIL }\end{array}$ & - & - & - & - & - & - & - & - & - \\
\hline HY DR OELECLRIC & - & - & - & - & - & - & - & 10,088 & 10,088 \\
\hline NACL EAR & - & - & - & - & - & - & - & 17,722 & $17,7.22$ \\
\hline GEO. ESOLA & - & $\rightarrow$ & - & - & - & - & - & - & - \\
\hline TOTAL SUPPLZ & - & - & - & - & - & - & - & 27.810 & 27,810 \\
\hline
\end{tabular}

\section{NET III PORTS}

OP REGION

27.149

13,958

54,472

13,810

32,666

14,726

12,034

168,819

\begin{tabular}{|c|c|c|c|c|c|}
\hline \multicolumn{6}{|c|}{ NO TES: } \\
\hline & TRAHSFOPMATI ON & 1.JSS & FOR & ELEZTアICITY & $=64.568$ \\
\hline & TRANSPORMATI ON & 10s5 & FOR & PECROLEOM PEODOCT & $=0.0 \%$ \\
\hline & TRABSPORMATI ON & Loss & FOR & NACURAL GAS & $=0.0 \%$ \\
\hline 4 & TRAASFOP.MATI OY & E 355 & POR & SYDTHETICS & $=0.0 \%$ \\
\hline
\end{tabular}


REGIONAL ENERG BALANCE STATEMENT

ONAL ENERG BALANCE S
PIES MID MID SCENARIO

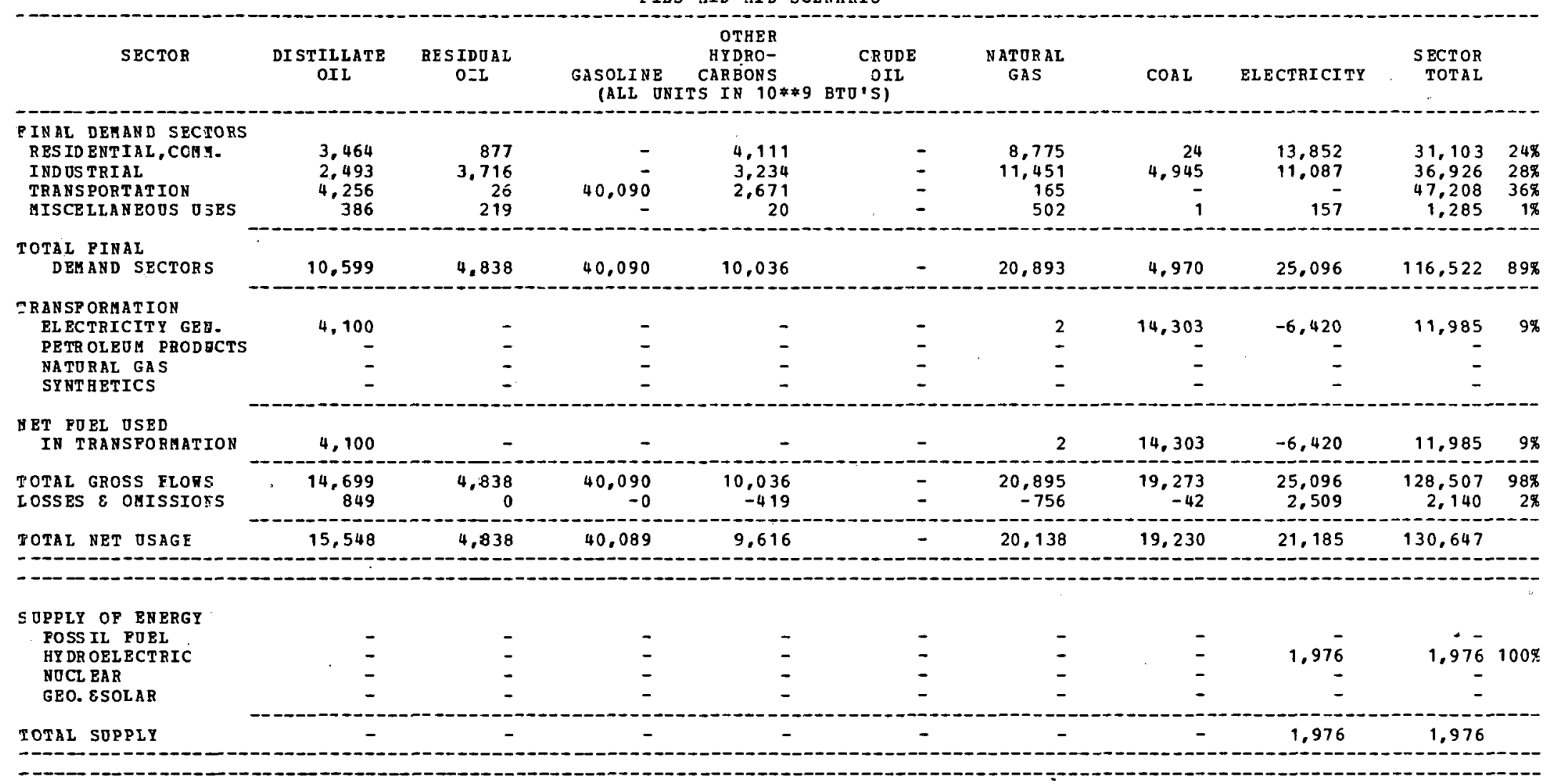

NET III PORTS

$15,548 \quad 4,338$

40,089

9,616

20,138

19,230

19,209

128,671 .

-

No TES:

TRARSPORMATION LOSS POR TRARSFORIATION LOSS POR TRANSPORMATI ON LOSS POB
TRANSPORAATI ON LOSS POB 
BBGIONAL ENERGY BALANCE STATEUENT

PIES GID IID SCENARIC

\begin{tabular}{|c|c|c|c|c|c|c|c|c|c|}
\hline SEC TOR & $\begin{array}{l}\text { DISTILLATE } \\
\text { OIL }\end{array}$ & $\begin{array}{l}\text { BESTOOAL } \\
\text { O=L }\end{array}$ & $\begin{array}{l}\text { GASOLINE } \\
\text { (ALL. J J }\end{array}$ & $\begin{array}{c}\text { OTHER } \\
\text { HYDRO- } \\
\text { CARBONS } \\
\text { TS IN } 10 * * 9\end{array}$ & $\begin{array}{c}\text { CFUDE } \\
\text { CIL } \\
\text { BTO'S) }\end{array}$ & $\begin{array}{l}\text { NATUZLL } \\
\text { GAS }\end{array}$ & CCA L & ELECTRICITY & $\begin{aligned} \text { SECTOR } \\
\text { TOTAL }\end{aligned}$ \\
\hline $\begin{array}{l}\text { PINAL DEHANE SECTORS } \\
\text { RESID ENTIAL, COMH. } \\
\text { IND OSTRIAL } \\
\text { TRA TSPORTATION } \\
\text { MISCELLAHECIOS OSES }\end{array}$ & $\begin{array}{r}3.723 \\
3.056 \\
4.672 \\
682\end{array}$ & $\begin{array}{r}978 \\
4.621 \\
28 \\
387\end{array}$ & $\begin{array}{r}- \\
- \\
-\end{array}$ & $\begin{array}{r}4,297 \\
3,947 \\
2,924 \\
33\end{array}$ & $\begin{array}{l}- \\
-\end{array}$ & $\begin{array}{r}9,325 \\
12,9.41 \\
1: 30 \\
952\end{array}$ & $\begin{array}{r}26 \\
3,565 \\
- \\
2\end{array}$ & $\begin{array}{r}14,956 \\
9,652 \\
- \\
311\end{array}$ & $\begin{array}{r}33,305 \\
37,782 \\
49,613 \\
2,277\end{array}$ \\
\hline $\begin{array}{l}\text { TOTAL PINAL } \\
\text { DEHAND SECTORS }\end{array}$ & 12.133 & 6.014 & 41,809 & 11,201 & - & $23,3) 8$ & 3,593 & 24,919 & 122,977 \\
\hline $\begin{array}{l}\text { TRANSPORHATION } \\
\text { BLECTRICITY GEN. } \\
\text { PETROLEOM PRODOCTS } \\
\text { NATURAL GRS } \\
\text { SY NTHETICS }\end{array}$ & $\begin{array}{r}4.027 \\
= \\
-\end{array}$ & $\begin{array}{l}\overline{-} \\
\overline{-}\end{array}$ & $\begin{array}{l}\overline{-} \\
\overline{-}\end{array}$ & $\bar{z}$ & $\begin{array}{l}\overline{-} \\
\overline{-}\end{array}$ & $\begin{array}{l}2 \\
- \\
-\end{array}$ & $\begin{array}{r}273.546 \\
- \\
-\end{array}$ & $\begin{array}{r}-95,391 \\
- \\
-\end{array}$ & $\begin{array}{r}182,184 \\
= \\
-\end{array}$ \\
\hline $\begin{array}{l}\text { NET PUEL OSED } \\
\text { IN TRAYSPORHATION }\end{array}$ & 4.027 & - & - & - & - & 2 & 273,546 & $-95,391$ & 182,184 \\
\hline $\begin{array}{l}\text { TOTAL GROSS FLORS } \\
\text { IOSSES } \& \text { OMISSIONS }\end{array}$ & $\begin{array}{r}16.160 \\
934\end{array}$ & $\begin{array}{r}6,014 \\
0\end{array}$ & $\begin{array}{r}41,80,9 \\
-0\end{array}$ & $\begin{array}{r}11,201 \\
-468\end{array}$ & $\overline{-}$ & $\begin{array}{r}23,310 \\
-8 \div 4\end{array}$ & 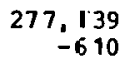 & $\begin{array}{r}24,919 \\
2,492\end{array}$ & $\begin{array}{r}305,161 \\
1,503\end{array}$ \\
\hline
\end{tabular}

\section{SOPPLY OP BDERG \\ POSS II POEL \\ HY DR OEL E CERIC \\ GEO. ESOLAA}

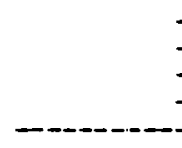

TOTAL SUPPLI

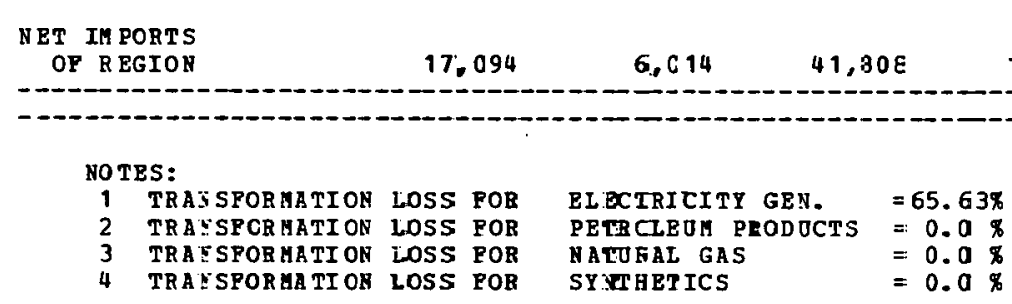


REGIONAL ENERGY BALANCE STATEMENT
PIES MID IID SCENARIO

\begin{tabular}{|c|c|c|c|c|c|c|c|c|c|c|}
\hline SECTOR & $\begin{array}{l}\text { DISTILLATE } \\
\text { OIL }\end{array}$ & $\begin{array}{l}\text { RESIDUAL } \\
\text { OII }\end{array}$ & $\begin{array}{l}\text { GASOLINE } \\
\text { (ALL UN }\end{array}$ & $\begin{array}{c}\text { OTHER } \\
\text { HYDRO- } \\
\text { CARBONS } \\
\text { TS IN } 10 * * 9\end{array}$ & $\begin{array}{c}\text { CRODE } \\
\text { OIL } \\
\text { BTO'S) }\end{array}$ & $\begin{array}{l}\text { NATURAL } \\
\text { GAS }\end{array}$ & $\mathrm{COAL}$ & ELECTRICITY & $\begin{array}{r}\text { SECTOR } \\
\text { TOTAL }\end{array}$ & \\
\hline $\begin{array}{l}\text { PINAL DEHAND SECTORS } \\
\text { RESIDENTIAL, COHM. } \\
\text { IND OS TRIAL } \\
\text { TRANSPORTATION } \\
\text { MISCELLANEOUS OSES }\end{array}$ & $\begin{array}{r}2,496 \\
1,340 \\
4,053 \\
654\end{array}$ & $\begin{array}{r}562 \\
2.437 \\
222 \\
372\end{array}$ & $\begin{array}{r}- \\
35,44 \overline{1} \\
-\end{array}$ & $\begin{array}{r}3,705 \\
5,064 \\
1,094 \\
39\end{array}$ & $\begin{array}{l}- \\
-\end{array}$ & $\begin{array}{r}7,714 \\
14,699 \\
91 \\
920\end{array}$ & $\begin{array}{r}27 \\
8,172 \\
- \\
2\end{array}$ & $\begin{array}{r}12,876 \\
10,974 \\
- \\
188\end{array}$ & $\begin{array}{r}27,380 \\
42,686 \\
40,901 \\
2,175\end{array}$ & $\begin{array}{r}23 \% \\
36 \% \\
34 \% \\
2 \%\end{array}$ \\
\hline $\begin{array}{l}\text { TOTAL PINAL } \\
\text { DEMAND SECTORS }\end{array}$ & 8,543 & 3,593 & 35,441 & 9,902 & - & 23,424 & 8,201 & 24.038 & 113,142 & $94 \%$ \\
\hline $\begin{array}{l}\text { TRANSPORHATION } \\
\text { BLECTRICITY GEN. } \\
\text { PETRCLEOM FRODOCTS } \\
\text { NATORAL GAS } \\
\text { SY NTHETICS }\end{array}$ & $\begin{array}{r}3,869 \\
- \\
-\end{array}$ & $\begin{array}{l}\overline{-} \\
\overline{-}\end{array}$ & $\begin{array}{l}\overline{-} \\
\overline{-}\end{array}$ & $\begin{array}{l}\bar{z} \\
\overline{-}\end{array}$ & $\begin{array}{l}\overline{-} \\
\overline{-}\end{array}$ & $\begin{array}{l}2 \\
- \\
-\end{array}$ & $\begin{array}{r}3.518 \\
- \\
-\end{array}$ & $\begin{array}{r}-2,633 \\
- \\
-\end{array}$ & $\begin{array}{r}4.756 \\
- \\
-\end{array}$ & $4 \%$ \\
\hline $\begin{array}{l}\text { NET POEL OSED } \\
\text { IN TRANSPORHATION }\end{array}$ & 3,869 & - & - & - & - & 2 & 3,518 & $-2,633$ & 4,756 & $4 \%$ \\
\hline $\begin{array}{l}\text { TOTAL GROSS FLOHS } \\
\text { LOSSES } \& \text { OMISSIONS }\end{array}$ & $\begin{array}{r}12,412 \\
717\end{array}$ & $\begin{array}{r}3,593 \\
0\end{array}$ & $\begin{array}{r}35,441 \\
-0\end{array}$ & $\begin{array}{r}9,902 \\
-413\end{array}$ & $\overline{-}$ & $\begin{array}{r}23,426 \\
-848\end{array}$ & $\begin{array}{r}11,719 \\
-25\end{array}$ & $\begin{array}{r}24,038 \\
2,404\end{array}$ & $\begin{array}{r}117,898 \\
1,833\end{array}$ & $\begin{array}{r}98 \% \\
2 \%\end{array}$ \\
\hline
\end{tabular}

\begin{tabular}{|c|c|c|c|c|c|c|c|c|c|}
\hline $\begin{array}{l}S \text { OPPLY OF ENERGY } \\
\text { POSS II POEL }\end{array}$ & - & - & - & - & - & - & - & - & \\
\hline HYDROELECTRIC & - & - & - & $\overline{-}$ & - & $\begin{array}{l}- \\
-\end{array}$ & - & $3,97 \overline{3}$ & $3,97 \overline{3}$ \\
\hline NOCL EAR & - & - & - & - & - & - & - & - & - \\
\hline TOTAL SOPPLY & - & - & - & - & - & - & - & 3,973 & 3,973 \\
\hline
\end{tabular}

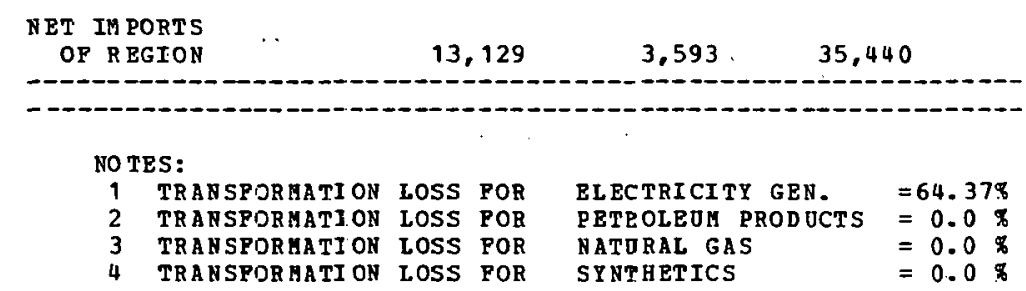


BEGIONAL ENERGY BALANCE STATEMENT

PIES IID MID SCENARIO
PIN

\begin{tabular}{|c|c|c|c|c|c|c|c|c|c|c|}
\hline SECTOR & $\begin{array}{l}\text { DI STILLATB } \\
\text { CIL. }\end{array}$ & $\begin{array}{l}\text { RESIDDAL } \\
\text { OIL }\end{array}$ & $\begin{array}{l}\text { GA.SOLINE } \\
\text { (ALL ONIT T }\end{array}$ & $\begin{array}{c}\text { OTHER } \\
\text { AYDRO- } \\
\text { CARBONS } \\
\text { TS IN } 10 * * 9\end{array}$ & $\begin{array}{c}\text { CROLE } \\
\text { OII } \\
\text { BTJ'S). }\end{array}$ & $\begin{array}{l}\text { NATOREL } \\
\text { GAS }\end{array}$ & $\operatorname{COAL}$ & ELECTRICITY & $\begin{array}{r}\text { SECT OR } \\
\text { TOTAL }\end{array}$ & \\
\hline $\begin{array}{l}\text { PINAL DEHAND SECTORS } \\
\text { RESID ENTIAL, COMA. } \\
\text { TND OSTRIAL } \\
\text { TRANS PORTATION } \\
\text { HISCE LLAGEOOS OSES }\end{array}$ & $\begin{array}{r}24,887 \\
10,331 \\
52,20 E \\
2,04 E\end{array}$ & $\begin{array}{r}7,607 \\
20,152 \\
838 \\
1,165\end{array}$ & $2413,67 \frac{-}{-}$ & $\begin{array}{r}24,985 \\
28,896 \\
85,026 \\
98\end{array}$ & $\begin{array}{l}- \\
- \\
-\end{array}$ & $\begin{array}{r}59,032 \\
72,567 \\
5,252 \\
2,554\end{array}$ & $\begin{array}{r}168 \\
25,484 \\
1 \\
6\end{array}$ & $\begin{array}{r}97,028 \\
46,841 \\
- \\
981\end{array}$ & $\begin{array}{r}213,757 \\
205,271 \\
384,0.76 \\
6,852\end{array}$ & $\begin{array}{r}19 \% \\
13 \% \\
35 \% \\
1 \%\end{array}$ \\
\hline $\begin{array}{l}\text { TCTAL PINGL } \\
\text { DEHAND SECTORS }\end{array}$ & 39,471 & 29,762 & $24 \cdot 0,674$ & 139,005 & - & $1 \equiv 9,415$ & 25,659 & 144,910 & 809,836 & $73 \%$ \\
\hline $\begin{array}{l}\text { THANSPORHATION } \\
\text { ELECTRICITY GEN. } \\
\text { PETR OLEDI PRODOCTS } \\
\text { NATURAL GAS } \\
\text { ST NTEETICS }\end{array}$ & $\begin{array}{r}23,421 \\
-4,26 \subseteq \\
= \\
-\end{array}$ & $\begin{array}{r}-520 \\
-\end{array}$ & $\begin{array}{r}- \\
-4,922 \\
-\end{array}$ & $\begin{array}{r}-2,090 \\
- \\
-\end{array}$ & $\begin{array}{r}11,743 \\
-\end{array}$ & $\begin{array}{r}2,830 \\
37 \\
- \\
-\end{array}$ & $\begin{array}{r}423,429 \\
-\end{array}$ & $\begin{array}{r}-153,797 \\
- \\
-\end{array}$ & $\begin{array}{r}292,8: 33 \\
27 \\
- \\
-\end{array}$ & $\begin{array}{l}26 \% \\
.0 \%\end{array}$ \\
\hline $\begin{array}{l}\text { MET POEL JSED } \\
\text { IN TRANSORHATION }\end{array}$ & 19,151 & -520 & $-4,922$ & $-2,090$ & 11,743 & 2,917 & 423,429 & $-153,797$ & 292,9 ^0 & $26 \%$ \\
\hline $\begin{array}{l}\text { TCTAL GROSS FLORS } \\
\text { LOSSES } \& \text { EUISSIONS }\end{array}$ & $\begin{array}{r}112,89 \bar{\epsilon} \\
6,52 \epsilon\end{array}$ & $\begin{array}{r}29,762 \\
0\end{array}$ & $\begin{array}{r}24), 674 \\
-0\end{array}$ & $\begin{array}{r}139,005 \\
-5,810\end{array}$ & $\begin{aligned} 11,743 \\
\Xi 86\end{aligned}$ & $\begin{array}{r}142,332 \\
-5,155\end{array}$ & $\begin{array}{r}447,088 \\
-984\end{array}$ & $\begin{array}{r}144,910 \\
14,492\end{array}$ & $\begin{array}{r}1,102,836 \\
9,654\end{array}$ & $\begin{array}{r}99 \% \\
1 \%\end{array}$ \\
\hline
\end{tabular}

\begin{tabular}{|c|c|c|c|c|c|c|c|c|c|}
\hline $\begin{array}{l}\text { SUPPLY OP ENERGY } \\
\text { POSS IL POBL }\end{array}$ & - & - & - & - & & & & & - \\
\hline HY DROEL ZCTRIC & - & - & - & - & - & - & - & $12,68 \overline{7}$ & 12.6371008 \\
\hline NOCL EAR & - & - & - & - & - & - & - & - & - \\
\hline GEO. \&SOIAR & - & - & - & - & - & - & - & - & - \\
\hline TOTAL SOPPLY & - & - & - & - & - & - & - & 12,687 & 12,637 \\
\hline
\end{tabular}

\begin{tabular}{l}
$\begin{array}{l}\text { NET IM PORTS } \\
\text { OF R BGION }\end{array}$ \\
\hline
\end{tabular}


REGIONAL ENERGY BALANCE STATEMENT

PNAL RNERGY BALANCE STA
PIES IID MID SCENARIO

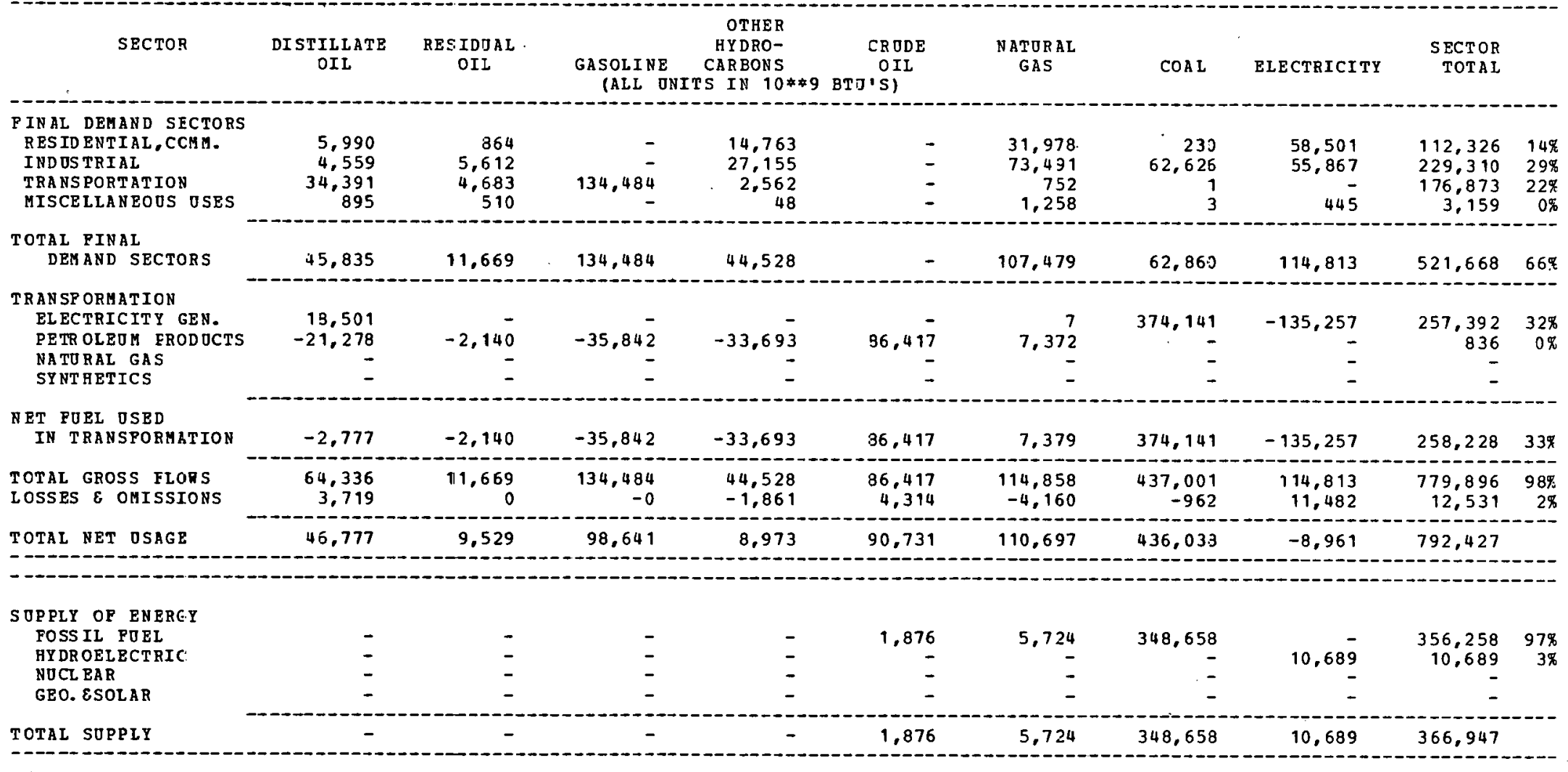

\begin{tabular}{l}
$\begin{array}{l}\text { NET IM PORTS } \\
\text { OF R BGION }\end{array}$ \\
\hdashline$\quad 46,777$
\end{tabular}


3EGIONAL 3NERGY BALANCZ STATEMEN=

PIES IID MID SCENA BIO

\begin{tabular}{|c|c|c|c|c|c|c|c|c|c|c|}
\hline SECTOR & $\begin{array}{c}\text { DISTILLATE } \\
\text { OIL }\end{array}$ & $\begin{array}{l}\text { RESTDUAL } \\
\text { OIL }\end{array}$ & $\begin{array}{l}\text { GASOI INE } \\
\text { (AIL ON }\end{array}$ & $\begin{array}{c}\text { OTHER } \\
\text { HYDRO- } \\
\text { CARBONS } \\
=\text { IN } 10 \star * 9\end{array}$ & $\begin{array}{c}\text { CROCE } \\
\text { OII } \\
\text { BTJ'S) }\end{array}$ & $\begin{array}{l}\text { N } R \text { TVR R RL } \\
\text { GAS }\end{array}$ & $2 O A L$ & ELECTRICITY & $\begin{array}{l}\text { SECTIOB } \\
\text { TOTIL }\end{array}$ & \\
\hline $\begin{array}{l}\text { FINAL DEMEND SECTORS } \\
\text { BESIDENTEAL, COUM. } \\
\text { INDOSTRIBL } \\
\text { TRANS PORTATION } \\
\text { MISCELLAEBOUS OSES }\end{array}$ & $\begin{array}{r}7,847 \\
10,485 \\
39,613 \\
1,074 \\
\end{array}$ & $\begin{array}{r}7.379 \\
26.582 \\
232 \\
740\end{array}$ & $\begin{array}{r}\overline{-} \\
\overline{-} \\
13+, 290 \\
-\end{array}$ & $\begin{array}{r}16,173 \\
50,557 \\
12,608 \\
52\end{array}$ & $\begin{array}{l}\overline{-} \\
-\end{array}$ & $\begin{array}{r}\equiv 7,675 \\
70,651 \\
1,462 \\
11,392\end{array}$ & $\begin{array}{r}417 \\
22,990 \\
1 \\
3\end{array}$ & $\begin{array}{r}60,234 \\
59.600 \\
- \\
415\end{array}$ & $\begin{array}{r}123,7 \geq 5 \\
240,8>5 \\
188,2-36 \\
3,6>6\end{array}$ & $\begin{array}{r}19 \% \\
36 \% \\
28 \% \\
1 \%\end{array}$ \\
\hline $\begin{array}{l}\text { TOTAL PINZL } \\
\text { DEMAND SECTORS }\end{array}$ & 59,019 & 28,933 & 134,290 & 79,390 & - & 111,180 & 23,411 & 120,249 & 556,472 & $84 \%$ \\
\hline $\begin{array}{l}\text { TRAN AP ORMRTION } \\
\text { EL ECTRI ITTY GEN. } \\
\text { PETR OLE IM PBODOCTS } \\
\text { NATURAL GAS } \\
\text { SY NT AETICS }\end{array}$ & $\begin{array}{r}18,196 \\
-22,995 \\
- \\
-\end{array}$ & $\begin{array}{r}-9,840 \\
- \\
-\end{array}$ & $\begin{array}{r}-42,55 \overline{-} \\
-\end{array}$ & $\begin{array}{r}-19,75 \overline{3} \\
- \\
-\end{array}$ & $91,=005$ & $\begin{array}{r}26,372 \\
4,602 \\
- \\
-\end{array}$ & $\begin{array}{r}95,904 \\
= \\
=\end{array}$ & $\begin{array}{r}-48,328 \\
- \\
-\end{array}$ & $\begin{array}{r}93,174 \\
754 \\
- \\
-\end{array}$ & $\begin{array}{r}14 \% \\
10 \%\end{array}$ \\
\hline $\begin{array}{l}\text { NET FOEL OSED } \\
\text { IN TRANSPORYATION }\end{array}$ & $-4,799$ & $-9,840$ & $-42, \leq 55$ & $-19,753$ & $91, \equiv 05$ & 30,974 & 35,904 & $-48,328$ & 93,938 & $14 \%$ \\
\hline $\begin{array}{l}\text { TOTAL GROES FLORS } \\
\text { LOSSES } \varepsilon \text { OMISSIONS }\end{array}$ & $\begin{array}{r}77,215 \\
4,464 \\
\end{array}$ & $\begin{array}{r}28,933 \\
0\end{array}$ & $\begin{array}{r}134, \approx 90 \\
-0\end{array}$ & $\begin{array}{r}79,390 \\
-3,318 \\
\end{array}$ & $\begin{array}{r}91,505 \\
4,558 \\
\end{array}$ & $\begin{array}{r}102,154 \\
-5,149 \\
\end{array}$ & $\begin{array}{r}120,315 \\
-265\end{array}$ & $\begin{array}{r}120,249 \\
12,026\end{array}$ & $\begin{array}{r}650,330 \\
12,315\end{array}$ & $\begin{array}{r}98 \% \\
2 \%\end{array}$ \\
\hline TOTAL NET DSAGE & 58,684 & 19,092 & 91,734 & $56,31 \mathrm{q}$ & $95, E \in 3$ & 137,005 & 120,049 & 83.947 & 662,675 & \\
\hline $\begin{array}{l}\text { SOPPLY OP ENERGY } \\
\text { FOSS IL FOEL } \\
\text { HYDR OELECTRIC } \\
\text { NOCL EAR } \\
\text { GEO. ESOLAR }\end{array}$ & $\begin{array}{l}\overline{-} \\
\overline{-}\end{array}$ & $\begin{array}{l}- \\
-\end{array}$ & $\begin{array}{l}- \\
-\end{array}$ & $\begin{array}{l}- \\
- \\
-\end{array}$ & $\begin{array}{l}\overline{-} \\
\overline{-}\end{array}$ & $\begin{array}{l}- \\
-\end{array}$ & $\begin{array}{l}\overrightarrow{-} \\
-\end{array}$ & $\frac{\overline{89}}{\overline{4}}$ & $\frac{-}{39}$ & $96 \%$ \\
\hline TOTAL SUPPLY & - & - & - & - & $=$ & - & - & 93 & 33 & \\
\hline
\end{tabular}

NET IM PORES

58,684

19,092

91,734

$56,31 \varepsilon$

NO TES:

$$
\begin{aligned}
& \text { TXANSPORMATION LCSS FOR ELECTRICITY GEN. }=6 \text {. } .8: \% \\
& \text { T2ANSPONAATION TCSS POR EETRDLEOM PRODOCTS }=C .8 \mathrm{~J} \% \\
& \begin{array}{lll}
\text { TRANSPORMATION LCSS POR } & \text { FATORAL GIS } & =\text { C. } \\
\text { TRANSPOBMATION LCSS POR } & \text { SYNTEETIC } &
\end{array}
\end{aligned}
$$


REGIONAL ENE RGY BALANCE STATEMENT

PIES MID MID SCENARIO

\begin{tabular}{|c|c|c|c|c|c|c|c|c|c|c|}
\hline SECTOR & $\begin{array}{l}\text { DISTILLATE } \\
\text { OIL }\end{array}$ & $\begin{array}{l}\text { RESIDUAL } \\
\text { OIL }\end{array}$ & $\begin{array}{l}\text { GASOLINE } \\
\text { (ALL UN }\end{array}$ & $\begin{array}{c}\text { OTHER } \\
\text { HYDRO- } \\
\text { CARBONS } \\
\text { TS IN } 10 * * 9\end{array}$ & $\begin{array}{c}\text { CRODE } \\
\text { OIL } \\
\text { BTU'S) }\end{array}$ & $\begin{array}{l}\text { NATURAL } \\
\text { GAS }\end{array}$ & $\operatorname{COAL}$ & ELECTRICITY & $\begin{array}{l}\text { SECTOR } \\
\text { TOTAL }\end{array}$ & \\
\hline $\begin{array}{l}\text { FINAL DEMAND SECTORS } \\
\text { RES ID ENTIAL, CCMM. } \\
\text { IND TS TRIAL } \\
\text { TRANSPORTATION } \\
\text { MISCELLANEOUS OSES }\end{array}$ & $\begin{array}{r}2,337 \\
1,602 \\
7,966 \\
990\end{array}$ & $\begin{array}{r}333 \\
2,090 \\
2,016 \\
564\end{array}$ & $\begin{array}{r}- \\
- \\
53,984\end{array}$ & $\begin{array}{r}5,944 \\
14,301 \\
2,123 \\
50\end{array}$ & $\begin{array}{l}- \\
\\
-\end{array}$ & $\begin{array}{r}12,665 \\
32,531 \\
371 \\
1,311\end{array}$ & $\begin{array}{r}106 \\
24,568 \\
- \\
3\end{array}$ & $\begin{array}{r}24,410 \\
25,050 \\
- \\
482\end{array}$ & $\begin{array}{r}45,795 \\
100,142 \\
66,460 \\
3,400\end{array}$ & $\begin{array}{r}17 \% \\
37 \% \\
24 \% \\
1 \%\end{array}$ \\
\hline $\begin{array}{l}\text { TOTAL PINAL } \\
\text { DEMAND SECTORS }\end{array}$ & 12,895 & 5,003 & 53.984 & 22.418 & - & 46.878 & 24.677 & 49.942 & 215.797 & $79 \%$ \\
\hline $\begin{array}{l}\text { TRANSFOREATION } \\
\text { ELECTRICITY GEN. } \\
\text { PETROLEOM FBODOCTS } \\
\text { NATORAL GAS } \\
\text { SY HT HEPICS }\end{array}$ & $\begin{array}{r}8,039 \\
- \\
-\end{array}$ & $\begin{array}{l}- \\
-\end{array}$ & $\begin{array}{l}- \\
-\end{array}$ & $\begin{array}{l}- \\
\overline{-}\end{array}$ & $\begin{array}{l}- \\
- \\
-\end{array}$ & $\begin{array}{r}1,517 \\
- \\
-\end{array}$ & $\begin{array}{r}72,950 \\
- \\
- \\
-\end{array}$ & $\begin{array}{r}-28,295 \\
- \\
-\end{array}$ & $\begin{array}{r}54,211 \\
- \\
-\end{array}$ & $20 \%$ \\
\hline $\begin{array}{l}\text { NET FOEL OSED } \\
\text { IN TRAHSPORMATION }\end{array}$ & 8,039 & - & - & - & - & 1,517 & 72,950 & $-28,295$ & 54,211 & $20 \%$ \\
\hline $\begin{array}{l}\text { TOTAL GROSS FLOHS } \\
\text { ICSSES } \& \text { OMISSIONS }\end{array}$ & $\begin{array}{r}20,934 \\
1,210\end{array}$ & $\begin{array}{r}5,003 \\
0\end{array}$ & $\begin{array}{r}53,984 \\
-0\end{array}$ & $\begin{array}{r}22,418 \\
-937\end{array}$ & - & $\begin{array}{l}48,395 \\
-1,753\end{array}$ & $\begin{array}{r}97,627 \\
-215\end{array}$ & $\begin{array}{r}49,942 \\
4,994\end{array}$ & $\begin{array}{r}270,008 \\
3,299\end{array}$ & $\begin{array}{r}99 \% \\
1 \%\end{array}$ \\
\hline
\end{tabular}

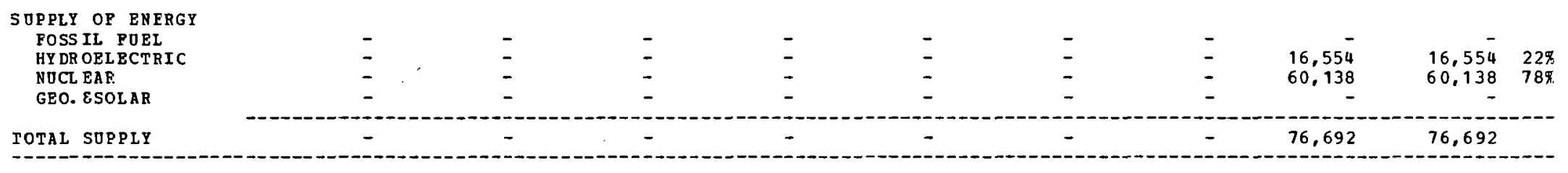

-

NET IM POETS
OP REGION

$\begin{array}{lllll}\text { NO TES: } & & & & \\ 1 & \text { TRANSFOR.ATION } & \text { LOSS POR } & \text { ELECTEICITY GEN. } & =65.71 \% \\ 2 & \text { TRANSPORAATION LOSS POR } & \text { PETROLEOY PRODOCTS } & =0.0 \% \\ 3 & \text { TRANSPORAATION LOSS POR } & \text { NATORAL GAS } & =0.0 \% \\ 4 & \text { TRANSFORAATION LOSS FOR } & \text { SYNTHTICS } & =0.0 \%\end{array}$


REGIONAL EFERGY BALANCE STATEHENT

PIES MID MID SCENARIO

\begin{tabular}{|c|c|c|c|c|c|c|c|c|c|c|}
\hline SECTOR & $\begin{array}{c}\text { DISTILLATE } \\
\text { DYL }\end{array}$ & $\begin{array}{l}\text { RESIDUAL } \\
\text { OIL }\end{array}$ & $\begin{array}{l}\text { GASOLINE } \\
\text { (ILL ONI }\end{array}$ & $\begin{array}{l}\text { OTHER } \\
\text { EYDRO- } \\
\text { CRRBONS } \\
\text { IS IN } 10 * \$ 9\end{array}$ & $\begin{array}{c}\text { CRODE } \\
\text { OIL } \\
\text { BTD'S) }\end{array}$ & $\begin{array}{c}\text { NATO?AL } \\
\text { GA? }\end{array}$ & $\operatorname{COAL}$ & ELECTRICITY & $\begin{array}{l}\text { SECTOE } \\
\text { TOTAI }\end{array}$ & \\
\hline $\begin{array}{l}\text { FINAL DEHAXD SECPORS } \\
\text { PES ID ENTIAL, COMR. } \\
\text { INDOSTRIAL } \\
\text { TRANS PORTITIOD } \\
\text { MISCELLAN } \geq O O S \text { OSES }\end{array}$ & $\begin{array}{r}3,747 \\
2,609 \\
10,450 \\
211\end{array}$ & $\begin{array}{r}552 \\
4,245 \\
146 \\
120\end{array}$ & $64,84 \overrightarrow{9}$ & $\begin{array}{r}6.996 \\
21.522 \\
2.461 \\
9\end{array}$ & $\begin{array}{l}- \\
-\end{array}$ & $\begin{array}{r}12,376 \\
37,24 c \\
17 \% \\
265\end{array}$ & $\begin{array}{r}176 \\
21.650 \\
- \\
-\end{array}$ & $\begin{array}{r}28,583 \\
38,455 \\
- \\
103\end{array}$ & $\begin{array}{r}52,930 \\
125,725 \\
78,083 \\
708\end{array}$ & $\begin{array}{r}15 \% \\
36 \% \\
22 \% \\
0 \%\end{array}$ \\
\hline $\begin{array}{l}\text { TOTAL FINAI } \\
\text { DEMAND SECTORS }\end{array}$ & 17,017 & 5,063 & 64,849 & 30,988 & - & 50,562 & 29.826 & 67,141 & 257,446 & 74.8 \\
\hline $\begin{array}{l}\text { TRANSP ORAATION } \\
\text { EL BCTRICITY GEN. } \\
\text { PETR OLEOI ERODOCTS } \\
\text { NATORAL GAS } \\
\text { SYNT HETICS }\end{array}$ & $\begin{array}{r}10,807 \\
- \\
- \\
-\end{array}$ & $\begin{array}{l}\overline{-} \\
\bar{z}\end{array}$ & $\begin{array}{l}- \\
\overline{-}\end{array}$ & $\begin{array}{l}\bar{E} \\
\overline{-}\end{array}$ & $\begin{array}{l}\overline{-} \\
\overline{-}\end{array}$ & $\begin{array}{l}5 \\
- \\
-\end{array}$ & $\begin{array}{r}121.351 \\
- \\
-\end{array}$ & $\begin{array}{r}-45,643 \\
- \\
- \\
-\end{array}$ & $\begin{array}{r}86,518 \\
= \\
=\end{array}$ & $25 \%$ \\
\hline $\begin{array}{l}\text { NET POEL UミED } \\
\text { IN TRANS?ORMATION }\end{array}$ & 10,807 & - & - & - & - & 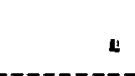 & 121,351 & $-45,643$ & 86,513 & $25 \%$ \\
\hline $\begin{array}{l}\text { TOTAL GROSI PLORS } \\
\text { L OSSES \& OYISSIOHS }\end{array}$ & $\begin{array}{r}27,824 \\
1,608\end{array}$ & $\begin{array}{r}5,063 \\
0\end{array}$ & $\begin{array}{r}64,849 \\
.-0\end{array}$ & $\begin{array}{r}30,988 \\
-1,295\end{array}$ & $\overline{-}$ & $\begin{array}{l}5 C, 566 \\
-1,83\end{array}$ & $\begin{array}{r}143,177 \\
-315\end{array}$ & $\begin{array}{r}57,141 \\
6,714\end{array}$ & $\begin{array}{r}343,965 \\
4,883\end{array}$ & $\begin{array}{r}99.8 \\
1 \%\end{array}$ \\
\hline $\begin{array}{l}\text { SOPPLY OP ENERGY } \\
\text { POSS IL PJEL } \\
\text { HYDROELEETRIC } \\
\text { NOCL EAR } \\
\text { GEO. ESOL QR }\end{array}$ & $\begin{array}{l}\overline{-} \\
\overline{-}\end{array}$ & $\begin{array}{l}\overline{-} \\
\overline{-}\end{array}$ & $\begin{array}{l}- \\
\overline{-}\end{array}$ & $\begin{array}{l}\bar{z} \\
\bar{z}\end{array}$ & $\begin{array}{l}\overline{-} \\
\overline{-}\end{array}$ & $\begin{array}{l}\overline{-} \\
\overline{-}\end{array}$ & $\begin{array}{r}31.526 \\
= \\
=\end{array}$ & $\begin{array}{r}17,456 \\
74,291 \\
-\end{array}$ & $\begin{array}{r}31,525 \\
17,455 \\
74,291 \\
-\end{array}$ & $\begin{array}{l}25 \% \\
14 \% \\
61 \%\end{array}$ \\
\hline TOTAL SOPPLY & - & - & - & - & - & - & 31,526 & 91,747 & 123,273 & \\
\hline
\end{tabular}

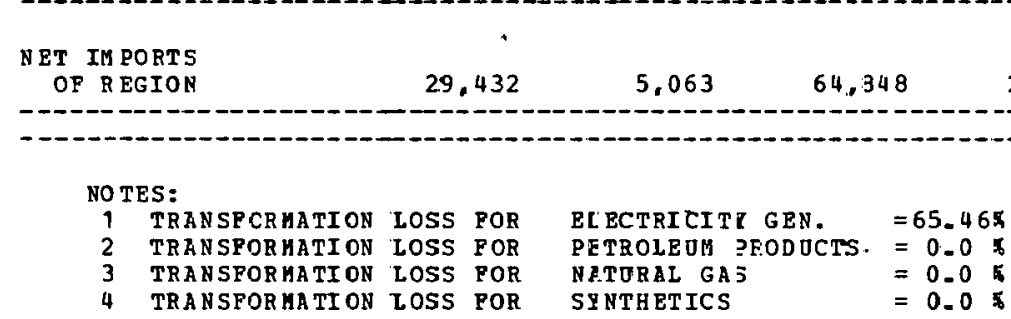


REGIONAL ENERGY BALANCE STATEMENT

PIES MID MID SCENARIO

\begin{tabular}{|c|c|c|c|c|c|c|c|c|c|c|}
\hline SECTOR & $\begin{array}{l}\text { DISTILLATE } \\
\text { OIL }\end{array}$ & $\begin{array}{l}\text { RESIDDAL } \\
\text { OIL }\end{array}$ & $\begin{array}{l}\text { GASOLINE } \\
\text { (ALL O }\end{array}$ & $\begin{array}{c}\text { OTHER } \\
\text { HYDRO- } \\
\text { CARBONS } \\
\text { TS IN 10**9 }\end{array}$ & $\begin{array}{c}\text { CR.ODE } \\
\text { OIL } \\
\text { BTOSS) }\end{array}$ & $\begin{array}{l}\text { NATURAL } \\
\text { GAS }\end{array}$ & $\operatorname{COAL}$ & ELECTRICITY & $\begin{array}{l}\text { SECTOR } \\
\text { TOTAL }\end{array}$ & \\
\hline 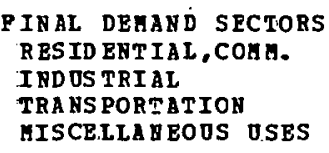 & $\begin{array}{r}5,513 \\
1,721 \\
23,961 \\
845\end{array}$ & $\begin{array}{r}534 \\
2,116 \\
3 \\
480\end{array}$ & 121,499 & $\begin{array}{r}13,522 \\
13,182 \\
10,330 \\
52\end{array}$ & $\begin{array}{l}\overline{-} \\
\bar{z}\end{array}$ & $\begin{array}{r}28,387 \\
35,614 \\
701 \\
1,465\end{array}$ & $\begin{array}{r}505 \\
24,940 \\
- \\
2\end{array}$ & $\begin{array}{r}60,015 \\
52,922 \\
- \\
541\end{array}$ & $\begin{array}{r}108,476 \\
130,495 \\
156,494 \\
3,385\end{array}$ & $\begin{array}{r}18 \% \\
21 \% \\
26 \% \\
1 \%\end{array}$ \\
\hline $\begin{array}{l}\text { TOTAL RINAL } \\
\text { DEHAND SECTORS }\end{array}$ & 32.040 & 3,133 & 121,499 & 37,086 & - & 66,167 & 25,447 & 113,478 & 398,850 & $66 \%$ \\
\hline $\begin{array}{l}\text { TRAYSPORHATION } \\
\text { ELECTRICITY GEN. } \\
\text { PETR OLEOA PRODOCTS } \\
\text { NATURAL GAS } \\
\text { SYNTEETICS }\end{array}$ & $\begin{array}{r}18,265 \\
- \\
- \\
-\end{array}$ & $\begin{array}{l}\overline{-} \\
\overline{-}\end{array}$ & $\begin{array}{l}- \\
-\end{array}$ & $\begin{array}{l}- \\
\overline{-}\end{array}$ & $\begin{array}{l}\overline{-} \\
\overline{-}\end{array}$ & $\begin{array}{r}4,238 \\
- \\
-\end{array}$ & $\begin{array}{r}280,128 \\
= \\
=\end{array}$ & $\begin{array}{r}-103,705 \\
- \\
-\end{array}$ & $\begin{array}{r}198,926 \\
- \\
-\end{array}$ & $33 \%$ \\
\hline $\begin{array}{l}\text { NET FORL USED } \\
\text { IH TRAESPORHATION }\end{array}$ & 18,265 & - & - & - & - & 4,238 & 280,128 & $-103,705$ & 198,926 & $33 \%$ \\
\hline $\begin{array}{l}\text { T JTAL GROSS PLORS } \\
\text { L } \text { OSSES \& OHISSIONS }\end{array}$ & $\begin{array}{r}50,305 \\
2,908\end{array}$ & $\begin{array}{r}3 . \cdot 33 \\
0\end{array}$ & $\begin{array}{r}121,499 \\
-0\end{array}$ & $\begin{array}{l}37,086 \\
-1,550\end{array}$ & - & $\begin{array}{l}70,405 \\
-2,550\end{array}$ & $\begin{array}{r}305,575 \\
-673\end{array}$ & $\begin{array}{r}113,478 \\
11,349\end{array}$ & $\begin{array}{r}597,776 \\
9,483\end{array}$ & $\begin{array}{r}98 \% \\
2 \%\end{array}$ \\
\hline TOTAL NET OSAGB & 53,213 & $3,: 33$ & 121,498 & 35,535 & - & 67,854 & 304.901 & 21,122 & 607,259 & \\
\hline $\begin{array}{l}\text { S DPPLY OP ENRBGI } \\
\text { POSS IL PUEL } \\
\text { HY DROBLECTRIC } \\
\text { NOCL BAR } \\
\text { GEO. ESOLAR }\end{array}$ & $\begin{array}{l}- \\
-\end{array}$ & $\overline{-}$ & $\begin{array}{l}- \\
\overline{-} \\
\overline{-}\end{array}$ & $\begin{array}{l}- \\
\overline{-} \\
\overline{-}\end{array}$ & $\begin{array}{r}1,789 \\
= \\
=\end{array}$ & $\begin{array}{r}1,827 \\
=\end{array}$ & $\begin{array}{r}18,544 \\
- \\
- \\
-\end{array}$ & $\begin{array}{r}- \\
6.820 \\
51.781 \\
-\end{array}$ & $\begin{array}{r}22,160 \\
6,820 \\
51,781 \\
-\end{array}$ & $\begin{array}{r}27 \% \\
8 \% \\
64 \%\end{array}$ \\
\hline TOTAL SOPPIY & - & - & - & - & 1,789 & 1,827 & 18,544 & 58,601 & 80,761 & \\
\hline
\end{tabular}

\section{NET IM PORTS}

53,213

3,133

121,498

35,535

$-1,789$

66,027

286,357

HO TES:

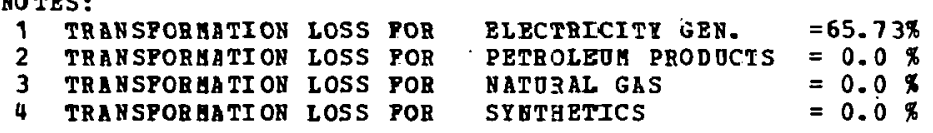


REGI JNAL ENERGY BALANCE STATZMENT

PIES MID MID SCENARI

\begin{tabular}{|c|c|c|c|c|c|c|c|c|c|c|}
\hline SECTOR & $\begin{array}{l}\text { IZSTELLATE } \\
\text { OIL }\end{array}$ & $\begin{array}{l}\text { FES IDTAL } \\
\text { OI }\end{array}$ & $\begin{array}{l}\text { GASOLINE } \\
\text { (ILL O }\end{array}$ & $\begin{array}{c}\text { DTHER } \\
\text { HYDRO- } \\
\text { CARBONS } \\
\text { TS IN } 10 * * 9\end{array}$ & $\begin{array}{c}\text { CRODE } \\
\text { OIL } \\
\text { BTO'S) }\end{array}$ & $\begin{array}{l}\text { NATORAL } \\
\text { GAS }\end{array}$ & $\operatorname{COAL}$ & ELECTRI CITY & $\begin{array}{r}\text { SECTCE } \\
\text { TOTAL }\end{array}$ & \\
\hline $\begin{array}{l}\text { PINAL DEMAYD SBCTORS } \\
\text { RESID ENTIAL, COHM. } \\
\text { INDOSTRIAL } \\
\text { TRA PSPORTATION } \\
\text { MISCE LLAREOOS OSES }\end{array}$ & $\begin{array}{r}3,450 \\
1,233 \\
1,063 \\
471\end{array}$ & $\begin{array}{r}312 \\
1,370 \\
3 \\
.267\end{array}$ & 77,093 & $\begin{array}{r}8,574 \\
22,996 \\
7,231 \\
22\end{array}$ & $\begin{array}{l}- \\
\overline{-} \\
\overline{-}\end{array}$ & $\begin{array}{r}17.33 \bar{z} \\
31 .+35 \\
+9 E \\
59 \Xi\end{array}$ & $\begin{array}{r}321 \\
25,676 \\
- \\
.1\end{array}$ & $\begin{array}{r}37,708 \\
44,621 \\
- \\
232\end{array}$ & $\begin{array}{r}68,19= \\
127,335 \\
98,89 \\
1,580\end{array}$ & $\begin{array}{r}17 \% \\
32 \% \\
25 \% \\
0 \%\end{array}$ \\
\hline $\begin{array}{l}\text { TOTAL PINAL } \\
\text { DENAND SECTORS }\end{array}$ & 18,222 & 1,952 & 77,093 & 38,823 & - & $50,36 c$ & 25,998 & 82,561 & 296,009 & $.74 \%$ \\
\hline $\begin{array}{l}\text { TRANSP ORHATION } \\
\text { EL BCTRICET GEN. } \\
\text { PETROLEO FRODUCTS } \\
\text { NA TORAL GAS } \\
\text { SYNT RETICS }\end{array}$ & $\begin{array}{r}13,289 \\
- \\
-\end{array}$ & $\begin{array}{l}\overline{-} \\
\overline{-}\end{array}$ & $\begin{array}{l}\bar{z} \\
\overline{-}\end{array}$ & $\begin{array}{l}\bar{z} \\
\overline{-}\end{array}$ & $\overline{-}$ & $\begin{array}{l}\epsilon \\
- \\
-\end{array}$ & $\begin{array}{r}137.895 \\
= \\
-\end{array}$ & $\begin{array}{r}-52,235 \\
= \\
-\end{array}$ & $\begin{array}{r}98,955 \\
- \\
-\end{array}$ & $25 \%$ \\
\hline $\begin{array}{l}\text { NET FOEL OSED } \\
\text { IN TRANSPORHATION }\end{array}$ & 13,289 & - & - & - & - & $\epsilon$ & 137,895 & $-52,235$ & 98,955 & $25 \%$ \\
\hline $\begin{array}{l}\text { TOTAL GROSS FLONS } \\
\text { LOSSES } \& \text { OIISSIONS }\end{array}$ & $\begin{array}{r}32,511 \\
7,879\end{array}$ & $\begin{array}{r}1,952 \\
0\end{array}$ & $\begin{array}{r}77.69 .3 \\
-0\end{array}$ & $\begin{array}{r}38,823 \\
-1,622\end{array}$ & $\overline{-}$ & $\begin{array}{l}50,36 e \\
-1,32 e\end{array}$ & $\begin{array}{r}163.893 \\
-361\end{array}$ & $\begin{array}{r}82,561 \\
8,25 \epsilon\end{array}$ & $\begin{array}{r}394,964 \\
6,328\end{array}$ & $\begin{array}{r}98 \% \\
2 \%\end{array}$ \\
\hline
\end{tabular}

\begin{tabular}{|c|c|c|c|c|c|c|c|c|c|c|}
\hline$S$ OPPLY OP ZNERGY & & & & & & & & & & \\
\hline FOSSIL FOEL & - & - & - & - & 3,908 & $1 \equiv .956$ & 747,394 & - & 765,253 & 99.8 \\
\hline HY DR OELECTRIC & - & - & - & - & - & - & - & 9,935 & 9,935 & 18 \\
\hline NOCL. EAR & - & - & - & - & - & - & - & - & 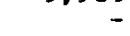 & \\
\hline GEO. ESOL 3R & - & - & - & - & - & - & - & - & - & \\
\hline TOTAL SOPPIY & - & - & - & - & $3,9 \mathrm{CB}$ & 13,956 & 747,394 & 9,935 & 775,193 & \\
\hline
\end{tabular}

\section{NET IM PORT}

OF REGION

34,390

1,952

77,092

37,200

$-3,9 c 8$

$34,585 \quad-583,862$

$28,647 \quad-373,90$

NoTES:
1 TRANSFORMATION LOSS POR
TR R NSPOR AATI ON LOSS PCR
TRANSPORYATION LOSS PCR
EIECTRICIT: GEN. $\quad=65.45$
PTROLEOM DRODOCTS $=0.0$

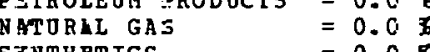


R3GIONAL ENERGY BALANCE STATEHENT
PIES MID MID SCENARIO

\begin{tabular}{|c|c|c|c|c|c|c|c|c|c|c|}
\hline SECTOR & $\begin{array}{l}\text { DISTILLATE } \\
\text { OIL }\end{array}$ & $\begin{array}{l}\text { RESIDOhI } \\
\text { OIL }\end{array}$ & $\begin{array}{l}\text { GASOLINE } \\
\text { (ALL ON }\end{array}$ & $\begin{array}{c}\text { OTHER } \\
\text { HYDRO- } \\
\text { CARBONS } \\
\text { CS IN } 10 * * 9\end{array}$ & $\begin{array}{c}\text { CRODE } \\
\text { OIL } \\
\text { BTO'S) }\end{array}$ & $\begin{array}{l}\text { NATURAL } \\
\text { GAS }\end{array}$ & COAL & ELECTRICITY & $\begin{array}{r}\text { SECTOR } \\
\text { TOTAL }\end{array}$ & \\
\hline $\begin{array}{l}\text { PIYAL DEMAND SECTOZS } \\
\text { RZSIDENTIAL, COH. } \\
\text { IRD USTRIAL } \\
\text { TRA NSPORTATION } \\
\text { MISCELLANBOUS OSES }\end{array}$ & $\begin{array}{r}5,748 \\
9,396 \\
12,338 \\
229\end{array}$ & $\begin{array}{r}452 \\
3.929 \\
1,124 \\
127\end{array}$ & $\begin{array}{r}- \\
- \\
60,269 \\
-\end{array}$ & $\begin{array}{r}5,619 \\
24,893 \\
6,383 \\
8\end{array}$ & 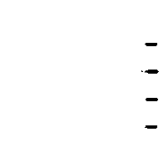 & $\begin{array}{r}14,300 \\
29,790 \\
785 \\
333\end{array}$ & $\begin{array}{r}372 \\
23,083 \\
7 \\
-\end{array}$ & $\begin{array}{r}22,751 \\
37,386 \\
- \\
123\end{array}$ & $\begin{array}{r}49,242 \\
128,497 \\
80,906 \\
819\end{array}$ & $\begin{array}{r}15 \% \\
40 \% \\
25 \% \\
0 \%\end{array}$ \\
\hline $\begin{array}{l}\text { TOTAL YINAL } \\
\text { DEHAND SECTORS }\end{array}$ & 27,710 & $5,65.2$ & 60,269 & 36,903 & - & 45,208 & 23,462 & 60,260 & 259,464 & $80 \%$ \\
\hline $\begin{array}{l}\text { T RAN SP ORHATION } \\
\text { EL ECTRICITY GEN. } \\
\text { PETR OLEUM PRODOCTS } \\
\text { UATORAL GAS } \\
\text { SY NTHETICS }\end{array}$ & $\begin{array}{r}6,569 \\
- \\
-\end{array}$ & $\begin{array}{l}\overline{-} \\
\overline{-}\end{array}$ & I & $\begin{array}{l}- \\
\overline{-}\end{array}$ & $\bar{z}$ & $\begin{array}{r}650 \\
- \\
-\end{array}$ & $\begin{array}{r}85,636 \\
= \\
=\end{array}$ & $\begin{array}{r}-31,739 \\
- \\
-\end{array}$ & $\begin{array}{r}61,116 \\
= \\
-\end{array}$ & $19 \%$ \\
\hline $\begin{array}{l}\text { NET FOEL OSED } \\
\text { IN TRANSPORGATIOF }\end{array}$ & 6,569 & - & - & - & - & 650 & 85,636 & -31.739 & 61,116 & $19 \%$ \\
\hline $\begin{array}{l}\text { TOTAL GROSS FLORS } \\
\text { IOSSES } 8 \text { OMISSIONS }\end{array}$ & $\begin{array}{r}34,279 \\
1,981\end{array}$ & $\begin{array}{r}5,652 \\
0\end{array}$ & $\begin{array}{r}60,269 \\
-0\end{array}$ & $\begin{array}{r}36,903 \\
-1,542\end{array}$ & - & $\begin{array}{l}45,858 \\
-1,661\end{array}$ & $\begin{array}{r}109,098 \\
-240\end{array}$ & $\begin{array}{r}60,260 \\
6,026\end{array}$ & $\begin{array}{r}320,580 \\
4,564\end{array}$ & $\begin{array}{r}99 \% \\
1 \%\end{array}$ \\
\hline $\begin{array}{l}\text { SOEPLY OP ENERGY } \\
\text { FOSS IL FUEL } \\
\text { RYDR OELECTRIC } \\
\text { NOCL EAR } \\
\text { GEO. ESOLAR }\end{array}$ & $\begin{array}{l}\bar{z} \\
\bar{z}\end{array}$ & $\begin{array}{l}\bar{z} \\
\overline{-}\end{array}$ & $\bar{z}$ & I & $\begin{array}{r}923 \\
-\end{array}$ & $\begin{array}{r}4,118 \\
= \\
-\end{array}$ & $\begin{array}{r}1,510,674 \\
= \\
-\end{array}$ & $\begin{array}{r}2,495 \\
51,792 \\
-\end{array}$ & $\begin{array}{r}1,515,715 \\
2,495 \\
51,792\end{array}$ & $\begin{array}{r}97 \% \\
0 \% \\
.3 \%\end{array}$ \\
\hline TOTAL SOPPLY & - & - & - & - & 923 & 4,118 & $1,510,674$ & 54,287 & $1,570,002$ & \\
\hline
\end{tabular}

\section{NET IM PORTS}

OP RBGION

36,260

5.652

60,268

35,360

$-923$

$40,078-1,401,816$

$-19,739-1,244,857$

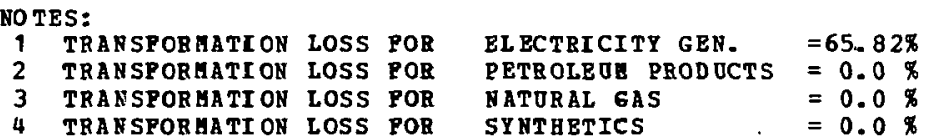

$\begin{array}{lll}\text { TRANSPORHATI ON LOSS POR } & \text { PETROLBUE PROD OCTS } & =0.0 \% \\ \text { TRANSPORATI ON LOSS POR } & \text { NATURAL GAS } & =0.0 \%\end{array}$ 
REG=ONAL 3NETGY BALARCE STATEMENT

PIES YID IID SCEKARIO

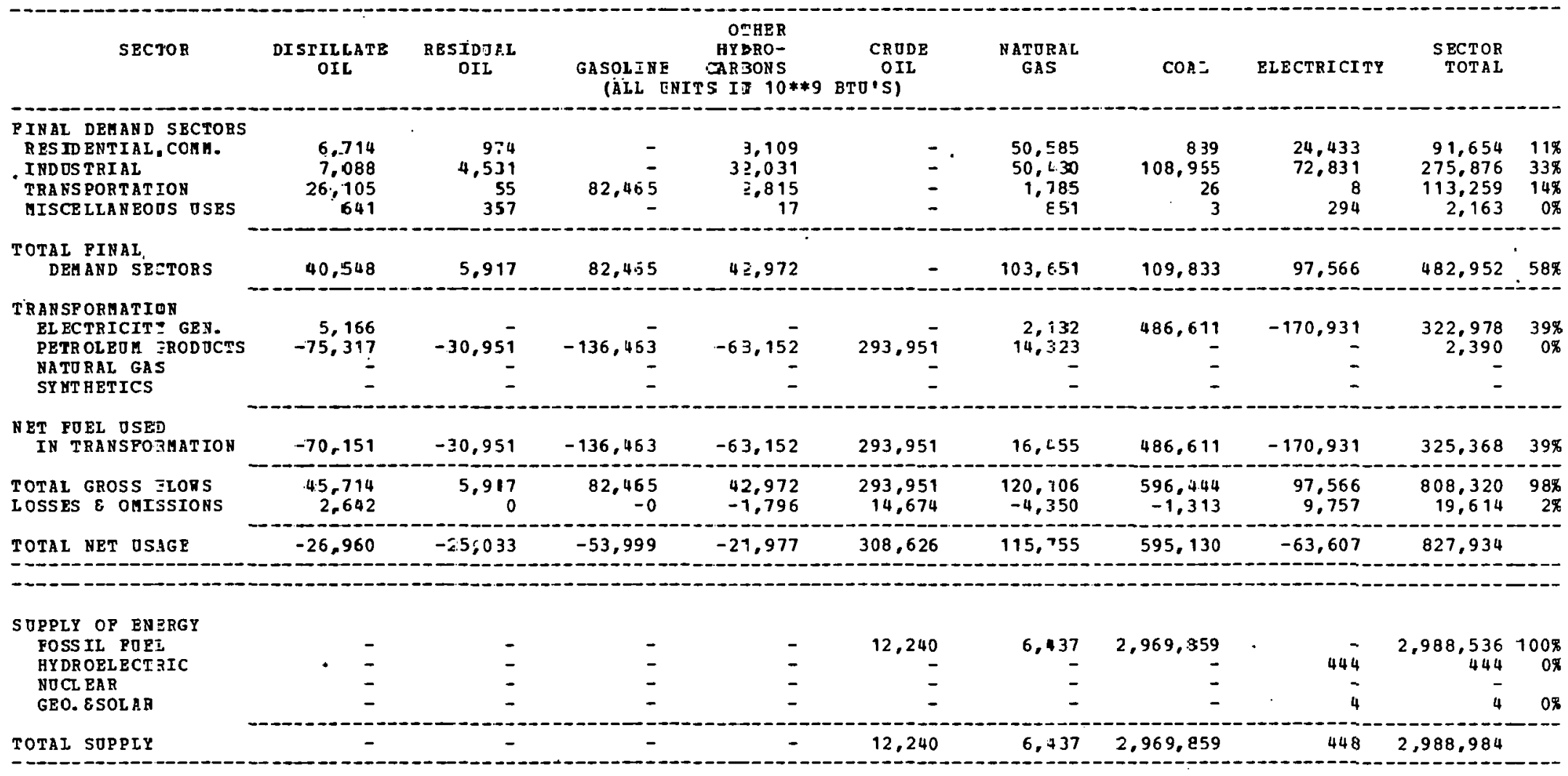

-

\begin{tabular}{l}
$\begin{array}{l}\text { NET IM PORTS } \\
\text { OP REGIOH }\end{array}$ \\
\hline
\end{tabular}


REGIONAL ENEPGY BALANCE STATEMENT

PIES MID MID SCEYARIO

\begin{tabular}{|c|c|c|c|c|c|c|c|c|c|c|}
\hline SECTOR & $\begin{array}{l}\text { DISTILIATE } \\
\text { OIL }\end{array}$ & $\begin{array}{l}\text { RESIDJAL } \\
\text { OIE }\end{array}$ & $\begin{array}{l}\text { GASOLINE } \\
\text { (ALL ONIT }\end{array}$ & $\begin{array}{c}\text { OTHER } \\
\text { HYDRO- } \\
\text { CARBONS } \\
\text { TS IN } 10 * * 9\end{array}$ & $\begin{array}{c}\text { CR ODE } \\
\text { OIL } \\
\text { BTO'S) }\end{array}$ & $\begin{array}{l}\text { NATURAL } \\
\text { GAS }\end{array}$ & $\operatorname{COAL}$ & ELECTRICITY & $\begin{array}{l}\text { SECTOR } \\
\text { TOTAL }\end{array}$ & \\
\hline $\begin{array}{l}\text { FINAL DEMAND SECTORS } \\
\text { RESIDENTIAL, COMH- } \\
\text { INDOSTRIAL } \\
\text { TRANSPORTATION } \\
\text { MISCELLANEOUS OSES }\end{array}$ & $\begin{array}{r}3,052 \\
895 \\
13.294 \\
840\end{array}$ & $\begin{array}{r}276 \\
521 \\
11 \\
+78\end{array}$ & $\begin{array}{r}\overline{-} \\
64,353 \\
-\end{array}$ & $\begin{array}{r}7,474 \\
2,650 \\
4,598 \\
39\end{array}$ & $\begin{array}{l}\overline{-} \\
\overline{-}\end{array}$ & $\begin{array}{r}27,085 \\
17.735 \\
382 \\
1,051\end{array}$ & $\begin{array}{r}253 \\
10,134 \\
- \\
3\end{array}$ & $\begin{array}{r}25,874 \\
31,590 \\
420\end{array}$ & $\begin{array}{r}64,014 \\
63,625 \\
82,638 \\
2,831\end{array}$ & $\begin{array}{l}23 \% \\
23 \% \\
29 \% \\
1 \%\end{array}$ \\
\hline $\begin{array}{l}\text { TOTAL PINAL } \\
\text { DEMAND SECTORS }\end{array}$ & 18,081 & 1,386 & 64.353 & 14,761 & - & 46,253 & 10,390 & 57,884 & 213,108 & $75 \%$ \\
\hline $\begin{array}{l}\text { TRANSFORMATICN } \\
\text { ELECTRICITY GEN. } \\
\text { PETR OLEOM PRODOCTS } \\
\text { NATURAL GAS } \\
\text { SYNTHETICS }\end{array}$ & $\begin{array}{r}9,345 \\
-1,571 \\
- \\
-\end{array}$ & $\begin{array}{r}16.695 \\
-672 \\
- \\
-\end{array}$ & $\begin{array}{r}- \\
-2,908 \\
- \\
-\end{array}$ & $\begin{array}{r}-1,349 \\
-\end{array}$ & 6,239 & $\begin{array}{r}4 \\
314 \\
- \\
-\end{array}$ & $\begin{array}{r}71,428 \\
- \\
-\end{array}$ & $\begin{array}{r}-33,396 \\
- \\
-\end{array}$ & $\begin{array}{r}64,076 \\
52 \\
- \\
-\end{array}$ & $\begin{array}{r}23 \% \\
0 \%\end{array}$ \\
\hline $\begin{array}{l}\text { NET FOBL OSED } \\
\text { IN TRANSORMATION }\end{array}$ & 7,773 & 16,022 & $-2,908$ & $-1,349$ & 6,239 & 318 & 71,428 & $-33,396$ & 64,128 & $23 \%$ \\
\hline $\begin{array}{l}\text { TDTAL GROSS FLOWS } \\
\text { IOSSES } \& \text { OMISSIONS }\end{array}$ & $\begin{array}{r}27,426 \\
1,585\end{array}$ & $\begin{array}{r}18, C 81 \\
0\end{array}$ & $\begin{array}{r}64,353 \\
-0\end{array}$ & $\begin{array}{r}14,761 \\
-617\end{array}$ & $\begin{array}{r}6,239 \\
311\end{array}$ & $\begin{array}{l}46,571 \\
-1,686\end{array}$ & $\begin{array}{r}81,818 \\
-180\end{array}$ & $\begin{array}{r}57,884 \\
5,789\end{array}$ & $\begin{array}{r}277,236 \\
5,202\end{array}$ & $\begin{array}{r}98 \pi \\
2 \pi\end{array}$ \\
\hline
\end{tabular}

$\begin{aligned} & \text { STPPLY OP. ENERGY } \\ & \text { FOSS IL POEL } \\ & \text { HYDROELCTRIC }\end{aligned}$
NOCL EAR
GEO. ESOLAR

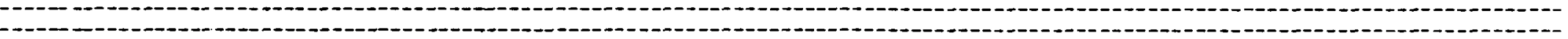

\section{NET IM PORTS \\ OF REGION}

27,440

17,408

61,444

12,794

$-8.649$

27,174

$-812,991$

$27,019 \quad-648,358$

$\begin{array}{lllll}\text { NOTES: } & & & \\ 1 & \text { TRANSFORHATI ON LOS } & \text { POR } & \text { ELECTRICITY GEN. } & =65.74 \% \\ 2 & \text { TRANSPORAATION LOSS POR } & \text { PETROLEOM PRODUCTS } & =0.79 \% \\ 3 & \text { TRANSPORHATI ON LOSS POR } & \text { NATURAL GAS } & =0.0 \% \\ 4 & \text { TRANSPORMATI ON LOSS FOR } & \text { SYNTHETICS } & =0.0 \%\end{array}$ 
REGIONAL ENERGY BALAHCE STATEMEN=

ORAL ENEEGY BALAHCE STA
PIES MID MID SCEHARIO

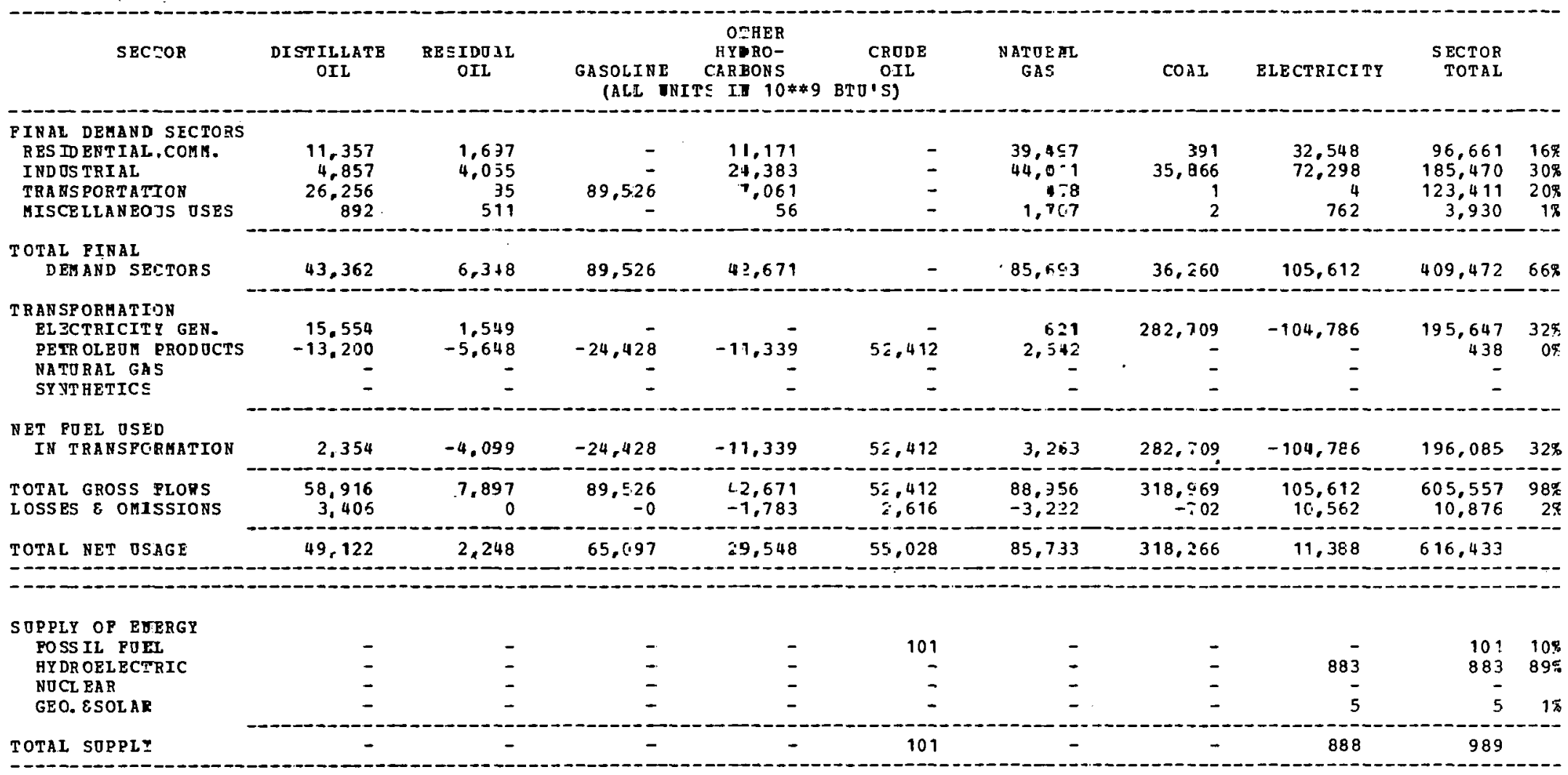

(1)

\section{NET IM PORTS}

49,122

65.097

$\Xi 9,548$

54.927

85.733

318,266

10,500

615,444

\begin{tabular}{|c|c|c|c|c|c|}
\hline \multicolumn{6}{|c|}{ NO TES: } \\
\hline 1 & TRAS SFOB MATI ON & Los & FOR & ELECTRICITY GEN. & $=65.112 \%$ \\
\hline & TRA S SFOB HATI ON & & POR & PELROLEUH PEODDCTS & $0.80 \%$ \\
\hline 3 & TRASSPORMATION & IDSS & PCF & NATORAL GAS & $=0.0 \%$ \\
\hline 4 & TRA SSFORMATI ON & IOSS & FCA & SYYTHEEICS & $=0.0 \mathrm{~g}$ \\
\hline
\end{tabular}


REGIONAL ENERGY BALANCE STATEMENT

PIES MID MID SCENARIO

\begin{tabular}{|c|c|c|c|c|c|c|c|c|c|c|}
\hline SECTOR & $\begin{array}{l}\text { DISTILIATE } \\
\text { OIL }\end{array}$ & $\begin{array}{l}\text { RESTDOAL } \\
\text { OIL }\end{array}$ & $\begin{array}{l}\text { GASOL INE } \\
\text { TALL ON }\end{array}$ & $\begin{array}{c}\text { OTHER } \\
\text { HYDRO- } \\
\text { CARBONS } \\
\text { TS IN } 10 * * 9\end{array}$ & $\begin{array}{c}\text { CRIDE } \\
\text { OIt } \\
\text { ETO'SI }\end{array}$ & $\begin{array}{l}\text { NATURAL } \\
\text { GAS }\end{array}$ & COAL & ELECTRICITY & $\begin{array}{r}\text { SECTOR } \\
\text { TOTAL }\end{array}$ & \\
\hline $\begin{array}{l}\text { FINAL DEMAND SPCTORS } \\
\text { EES ID ENTIAL, CCMA. } \\
\text { IND TS TRIAL } \\
\text { TRANSPORTATION } \\
\text { EISCELLANEOOS OSES }\end{array}$ & $\begin{array}{r}17.295 \\
9.397 \\
9.529 \\
850\end{array}$ & $\begin{array}{r}3,358 \\
4,729 \\
119 \\
489\end{array}$ & $\begin{array}{r}- \\
- \\
-\end{array}$ & $\begin{array}{r}8,199 \\
14,694 \\
6,475 \\
24\end{array}$ & $\begin{array}{l}\overline{-} \\
\overline{-}\end{array}$ & $\begin{array}{r}30,362 \\
24,266 \\
\quad 450 \\
593\end{array}$ & $\begin{array}{r}304 \\
31,028 \\
- \\
1\end{array}$ & $\begin{array}{r}17.052 \\
29.205 \\
13 \\
208\end{array}$ & $\begin{array}{r}76,570 \\
113,319 \\
72,807 \\
2,165\end{array}$ & $\begin{array}{r}12 \% \\
18 \% \\
11 \% \\
0 \%\end{array}$ \\
\hline $\begin{array}{l}\text { TCTAL FINAL } \\
\text { DEMAND SECTORS }\end{array}$ & 37.071 & 3,695 & 56,221 & 29,392 & - & 55,671 & 31,333 & 46,478 & 264,861 & $41 \%$ \\
\hline $\begin{array}{l}\text { TFAN SP ORMATICN } \\
\text { ELECTRICITY GEN. } \\
\text { PETR OIEUH PRODOCTS } \\
\text { NATORAL GAS } \\
\text { SYNT HETICS }\end{array}$ & $\begin{array}{r}8,043 \\
-55,830 \\
-\end{array}$ & $\begin{array}{r}32,676 \\
-23,892 \\
-\end{array}$ & $\begin{array}{r}-103,320 \\
-\end{array}$ & $\begin{array}{r}-47,958 \\
-\end{array}$ & $\begin{array}{r}221,680^{-} \\
-\end{array}$ & $\begin{array}{r}483 \\
11,174 \\
-\end{array}$ & $\begin{array}{r}518,414 \\
- \\
-\end{array}$ & $\begin{array}{r}-193,665 \\
- \\
-\end{array}$ & $\begin{array}{r}363,951 \\
1,854 \\
-\end{array}$ & $\begin{array}{r}57 \% \\
0 \%\end{array}$ \\
\hline $\begin{array}{l}\text { NET FOEL USED } \\
\text { IN TRANSFORMATION }\end{array}$ & $-47,787$ & 6,783 & $-103,320$ & $-47,958$ & $221, \epsilon 80$ & 11.657 & 518,414 & $-193,665$ & 365,805 & $57 \%$ \\
\hline $\begin{array}{l}\text { TOTAL GROSS FLORS } \\
\text { I.GSSES } \& \text { ORISSIONS }\end{array}$ & $\begin{array}{r}45,114 \\
2,608\end{array}$ & $\begin{array}{r}39,371 \\
0\end{array}$ & $\begin{array}{r}56,221 \\
-0\end{array}$ & $\begin{array}{l}29,392 \\
-1,228\end{array}$ & $\begin{array}{r}221,680 \\
11,066\end{array}$ & $\begin{array}{r}67,328 \\
-2,438\end{array}$ & $\begin{array}{r}549,747 \\
-1,210\end{array}$ & $\begin{array}{r}46,478 \\
4,648\end{array}$ & $\begin{array}{r}630,666 \\
13,445\end{array}$ & $\begin{array}{r}98 \% \\
2 \%\end{array}$ \\
\hline TOTAL NET OSAGE & $-8,107$ & $15,4.79$ & -47.099 & $-19,794$ & 232.746 & 64,890 & 548,536 & $-142,538$ & 644,111 & \\
\hline $\begin{array}{l}\text { SOPPLI OP ENRRGI } \\
\text { FOSS IL POEL } \\
\text { HYDR OEL ECTRIC } \\
\text { NOCL EAR } \\
\text { GEO. ESOLAR }\end{array}$ & $\begin{array}{l}- \\
\overline{-} \\
-\end{array}$ & $\begin{array}{l}- \\
\overline{-}\end{array}$ & $\begin{array}{l}- \\
\overline{-}\end{array}$ & $\begin{array}{l}\overline{-} \\
-\end{array}$ & $\begin{array}{r}94,570 \\
= \\
-\end{array}$ & $\begin{array}{r}17,462 \\
= \\
-\end{array}$ & $\begin{array}{r}2,384,616 \\
= \\
=\end{array}$ & $\begin{array}{r}5 \\
58 \\
27,342 \\
10\end{array}$ & $\begin{array}{r}2,496,648 \\
58 \\
27,342 \\
10\end{array}$ & $\begin{array}{r}99 \% \\
0 \% \\
1 \% \\
0 \%\end{array}$ \\
\hline TOTAL SUPPLY & - & - & - & - & 94,570 & 17,462 & $2,384,616$ & 27,410 & $2,524,058$ & \\
\hline
\end{tabular}

\begin{tabular}{|c|c|c|c|c|c|c|}
\hline \multicolumn{2}{|c|}{$\begin{array}{l}\text { NET IM PORTS } \\
\text { OF REGION }\end{array}$} & \multicolumn{2}{|c|}{$-8,1.07$} & 15,479 & \multicolumn{2}{|c|}{$-47,099$} \\
\hline \multicolumn{2}{|c|}{ NOTES: } & & & & & \\
\hline 1 & TR AN SFORMATI ON & Loss & FOR & ELECTRICI & T GEN. & $=65.27$ \\
\hline 2 & TRANSPORMATI ON & Loss & FOR & PETROLE OM & RRODUCTS & $=0.80 \%$ \\
\hline 3 & TR AN SFOR BA TI ON & Loss & FOR & NATORAL G & & $=0.0 \%$ \\
\hline 4 & TR AN SPOR MATI ON & Loss & POR & SY NTBETIC & & $=0.0$ \\
\hline
\end{tabular}


REGIONAL BNERGY BALANCE STATEMENT

ONAL ENERGY BALANCE
PIES MID MID SCENARIO

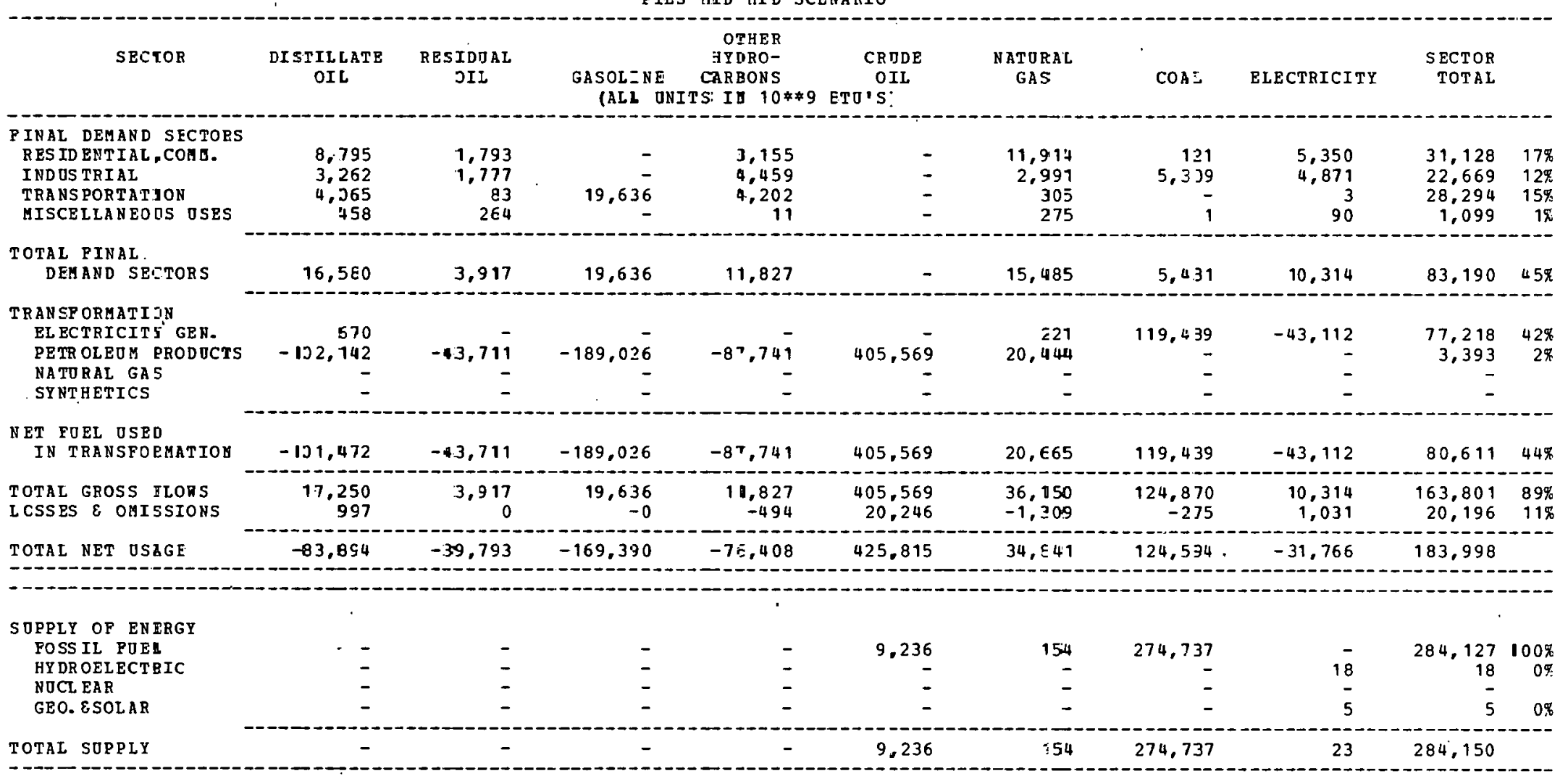

\section{NET IM PORTS}

OF REGION

$-83,894$

$-39,793$

$-169,390$

$-7 E, 408$

416,579

$34,687 \quad-150,142$

MO TES :

TRANSPORMATION LUSS POR TRANSPOR YATI ON LOSS POR TRANSPOR MATION LESS POR TRANSPORMATION LOSS POR

ELETTRIEITY GEN.

N. $=64.17 \%$

ETREOL PROEOCTS $=0.8 \mathrm{CX}$

$\begin{array}{ll}\text { SYNTHETICS } & =0.0 \\ & =0.0\end{array}$ 
PEGIONAL ENERGY BALANCE STATEMENT
PIES MID MID SCENARIO

\begin{tabular}{|c|c|c|c|c|c|c|c|c|c|c|}
\hline SECTOR & $\begin{array}{l}\text { DISTILLATE } \\
\text { OIL }\end{array}$ & $\begin{array}{l}\text { RESIDD.AL } \\
\text { OIL }\end{array}$ & $\begin{array}{l}\text { GASOLIN } \\
\text { (ALL }\end{array}$ & $\begin{array}{c}\text { OTHER } \\
\text { HYDRO- } \\
\text { CARBONS } \\
\text { TS IN } 10 * 49\end{array}$ & $\begin{array}{c}\text { CRODE } \\
\text { OIL } \\
\text { BTO'S) }\end{array}$ & $\begin{array}{l}\text { NATURAL } \\
\text { GAS }\end{array}$ & $\operatorname{COAL}$ & ELECTRICITY & $\begin{array}{l}\text { SECTOR } \\
\text { TOTAL }\end{array}$ & \\
\hline $\begin{array}{l}\text { FINAL DEHAND SBCTCRS } \\
\text { EESID ENTIAL; COMM. } \\
\text { IND OSTRIAL } \\
\text { TRANS PORTATION } \\
\text { MISCELLANEOUS OSES }\end{array}$ & $\begin{array}{r}13,139 \\
4,753 \\
6,038 \\
953\end{array}$ & $\begin{array}{r}3,437 \\
1,965 \\
52 \\
551\end{array}$ & $\begin{array}{r}- \\
\overline{-} \\
31,597 \\
-\end{array}$ & $\begin{array}{r}5,590 \\
4.034 \\
777 \\
23\end{array}$ & $\begin{array}{l}- \\
- \\
-\end{array}$ & $\begin{array}{r}28,558 \\
4,398 \\
410 \\
571\end{array}$ & $\begin{array}{r}189 \\
12,180 \\
-\end{array}$ & $\begin{array}{r}9,305 \\
8,445 \\
61 \\
191\end{array}$ & $\begin{array}{r}60,218 \\
35,775 \\
38,935 \\
2,290\end{array}$ & $\begin{array}{r}27 \% \\
16 \% \\
17 \% \\
1 \%\end{array}$ \\
\hline $\begin{array}{l}\text { TCTAL PINAL } \\
\text { DEMAND SECTORS }\end{array}$ & 24,883 & 6,035 & 31.597 & 10.424 & - & 33,937 & 12,370 & 18,002 & 137,218 & $62 \%$ \\
\hline $\begin{array}{l}\text { TRANSPORHATION } \\
\text { EL BCTRICITY GEN. } \\
\text { PETR OLEOM PRODUCTS } \\
\text { NATURAL GAS } \\
\text { SYNTHETICS }\end{array}$ & $\begin{array}{r}1,697 \\
- \\
-\end{array}$ & $\begin{array}{r}7.154 \\
- \\
-\end{array}$ & $\begin{array}{l}- \\
\overline{-}\end{array}$ & $\begin{array}{l}- \\
\overline{-}\end{array}$ & $\begin{array}{l}- \\
-\end{array}$ & $\begin{array}{r}386 \\
- \\
-\end{array}$ & $\begin{array}{r}120,940 \\
- \\
-\end{array}$ & $\begin{array}{r}-46,034 \\
- \\
-\end{array}$ & $\begin{array}{r}84,143 \\
= \\
-\end{array}$ & $38 \%$ \\
\hline $\begin{array}{l}\text { NET FUEL OSED } \\
\text { IN TRANSFORMATIO: }\end{array}$ & 1,697 & 7,154 & - & - & - & 386 & 120,940 & $-46,034$ & 84,143 & $38 \%$ \\
\hline $\begin{array}{l}\text { TOTAL GROSS FLOHS } \\
\text { LOSSES } \& \text { OHISSIONS }\end{array}$ & $\begin{array}{r}26,590 \\
1,536\end{array}$ & $\begin{array}{r}13,159 \\
0\end{array}$ & $\begin{array}{r}31,597 \\
-0\end{array}$ & $\begin{array}{r}10,424 \\
-435\end{array}$ & $\overline{-}$ & $\begin{array}{l}34,323 \\
-1,243\end{array}$ & $\begin{array}{r}133,310 \\
-293\end{array}$ & $\begin{array}{r}18,002 \\
1,800\end{array}$ & $\begin{array}{r}221,361 \\
1,364\end{array}$ & $\begin{array}{r}99 \% \\
1 \%\end{array}$ \\
\hline
\end{tabular}

\begin{tabular}{|c|c|c|c|c|c|c|c|c|c|c|}
\hline STPPLY OP ENERGY & & & & & & & & & & \\
\hline FOSSIL FOEL & - & - & - & - & 3,122 & - & 131,332 & - & 134,454 & $85 \%$ \\
\hline HY DR OEL ECTRIC & - & - & - & - & - & - & - & 32 & 32 & $0 \%$ \\
\hline NOCL EAR & - & - & - & - & - & - & - & 22,986 & 22,986 & $15 \%$ \\
\hline GEO. \& SOLAR & - & - & - & - & - & $\therefore$ & - & 8 & 8 & $0 \%$ \\
\hline TOTAL SUPPLT & - & - & - & - & 3,122 & - & 131,332 & 23,026 & 157,480 & \\
\hline
\end{tabular}

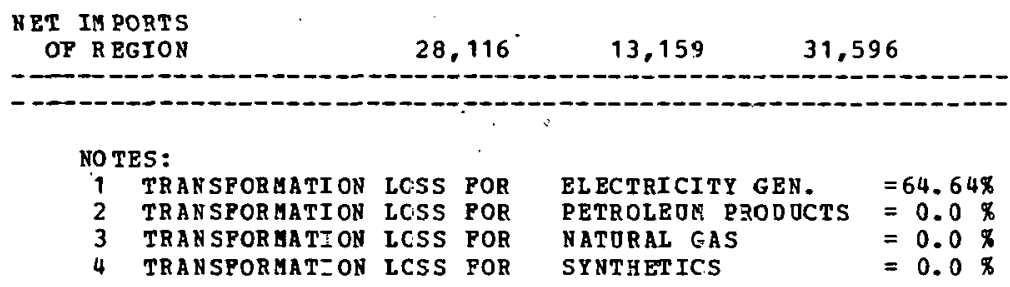


REGIONAL ENZREY BALANCE STATEMENT

ONAL ENSREY BALANCE STAT
PIES MIO MID STENARIO

\begin{tabular}{|c|c|c|c|c|c|c|c|c|c|c|}
\hline SECTOR & $\begin{array}{l}\text { DISTILLATE } \\
\text { DIL }\end{array}$ & $\begin{array}{l}\text { RESTDUAL } \\
\text { OIL }\end{array}$ & $\begin{array}{l}\text { GASOLIDE } \\
\text { (ALI O }\end{array}$ & $\begin{array}{l}\text { JTFER } \\
\text { HYDEO- } \\
\text { CARBCNS } \\
\text { CS IN } 10 * * 9\end{array}$ & $\begin{array}{c}\text { CRODE } \\
\text { OIL } \\
\text { BTO'SI }\end{array}$ & $\begin{array}{l}\text { NATORAI } \\
\text { GAS }\end{array}$ & $\operatorname{COAL}$ & ELECTRICI TY & $\begin{array}{l}\text { SECTOR } \\
\text { TOTAL }\end{array}$ & \\
\hline $\begin{array}{l}\text { PINAL DEHAND SECTORS } \\
\text { RESID ENTIAL, CONA. } \\
\text { IND OS TRIAL } \\
\text { TRANSPOBTATION } \\
\text { HISCELLANBODE OSES }\end{array}$ & $\begin{array}{l}0,865 \\
2,849 \\
2,571 \\
776\end{array}$ & $\begin{array}{r}3,058 \\
1,382 \\
17 \\
449\end{array}$ & 24,483 & $\begin{array}{r}4.346 \\
4.211 \\
538 \\
19\end{array}$ & $\bar{z}$ & $\begin{array}{r}22,884 \\
2,5 E 9 \\
2 \varepsilon 6 \\
614\end{array}$ & $\begin{array}{r}148 \\
7.047 \\
- \\
1\end{array}$ & $\begin{array}{r}7,720 \\
5,504 \\
16 \\
220\end{array}$ & $\begin{array}{r}49,021 \\
23,582 \\
27,917 \\
2,079\end{array}$ & $\begin{array}{l}+4 \% \\
.21 \% \\
25 \% \\
25\end{array}$ \\
\hline $\begin{array}{l}\text { TOTAL PINAL } \\
\text { DEAAND SECIORS }\end{array}$ & 17,061 & 1,906 & 24,489 & 9.114 & - & 26,373 & 7,195 & 13,460 & 102,599 & $33 x$ \\
\hline $\begin{array}{l}\text { PR AN SPORHATIOY } \\
\text { ELECTRICITY GEN. } \\
\text { PETR OI EOH ERODOCTS } \\
\text { NATERAL GAS: } \\
\text { SY NTHETICS }\end{array}$ & $\begin{array}{r}518 \\
- \\
-\end{array}$ & $\begin{array}{l}\bar{z} \\
\bar{z}\end{array}$ & $\begin{array}{l}\overline{-} \\
\overline{-}\end{array}$ & $\begin{array}{l}\overline{-} \\
-\end{array}$ & $\begin{array}{l}\overline{-} \\
\overline{-}\end{array}$ & $\begin{array}{r}289 \\
- \\
-\end{array}$ & $\begin{array}{r}10,51.0 \\
- \\
-\end{array}$ & $\begin{array}{r}-3,983 \\
- \\
- \\
-\end{array}$ & $\begin{array}{r}7,334 \\
- \\
-\end{array}$ & $7 \%$ \\
\hline $\begin{array}{l}\text { YET FOEI OSED } \\
\text { IN TRANSPORHATION }\end{array}$ & $\leq 18$ & - & - & - & - & 285 & 10,510 & $-3,983$ & 7,334 & $7 \%$ \\
\hline $\begin{array}{l}\text { ZOTAL GROSS FEORS } \\
\text { LOSSES } \varepsilon \text { OMISSIONS }\end{array}$ & $\begin{aligned} 17,5.79 \\
1,0.16\end{aligned}$ & $\begin{array}{r}4,906 \\
0\end{array}$ & $\begin{array}{r}24,489 \\
-0\end{array}$ & $\begin{array}{r}91114 \\
-380\end{array}$ & $\overline{-}$ & $\begin{aligned} 26,652 \\
-955\end{aligned}$ & $\begin{array}{r}17,7 \mathrm{C6} \\
-39\end{array}$ & $\begin{array}{r}13,460 \\
1,346\end{array}$ & $\begin{array}{r}109,933 \\
976\end{array}$ & $\begin{array}{r}99 \% \\
1 \%\end{array}$ \\
\hline TOTAL NET OSAGE & 18,595 & 4,905 & 24,488 & 8,733 & - & 25,696 & $17,6 \in 6$ & 10,823 & 110,909 & \\
\hline
\end{tabular}

\begin{tabular}{|c|c|c|c|c|c|c|c|c|c|c|}
\hline $\begin{array}{l}\text { S UPPLY OF EQERGI } \\
\text { POSS IL POEL }\end{array}$ & - & - & - & - & 5.411 & 13.671 & & & & \\
\hline HY DQOELECTEIC & - & - & - & - & 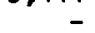 & - & 00,12 & 23 & 0.023 & $0 \%$ \\
\hline NOCI EAR & - & - & - & - & - & - & - & - & - & \\
\hline GEO. ESOLAR & - & - & - & - & - & - & - & 6 & 6 & $0 \%$ \\
\hline TOTAL SOPPLY & - & - & - & - & 5.411 & 13,691 & 59,122 & 29 & 78,253 & \\
\hline
\end{tabular}

20r.

NET. IM PORTS
OP REGION


REGIONAL ENERGY BALANCE STATEHENT

PIES MID MID SCENARIO

\begin{tabular}{|c|c|c|c|c|c|c|c|c|c|c|}
\hline SECTOR & $\begin{array}{l}\text { DISTILLATE } \\
\text { OIL }\end{array}$ & $\begin{array}{l}\text { RESIDJAL } \\
\text { OIL }\end{array}$ & $\begin{aligned} \text { GASOLINE } \\
\text { (ALL O }\end{aligned}$ & $\begin{array}{l}\text { OTHER } \\
\text { HYDBO- } \\
\text { CARBONS } \\
\text { TS IN } 10 * * 9\end{array}$ & $\begin{array}{c}\text { CRIDE } \\
\text { OIL } \\
\text { BTO'S) }\end{array}$ & $\begin{array}{l}\text { NATURAL } \\
\text { GAS }\end{array}$ & $\operatorname{COAL}$ & ELECTRICITY & $\begin{array}{r}\text { SECTOR } \\
\text { TOTAL }\end{array}$ & \\
\hline $\begin{array}{l}\text { FINAL DEHAND SECTORS } \\
\text { RESIDENTIAL, ZOMM. } \\
\text { INDOSTRIAL } \\
\text { TRANSPORTATIDN } \\
\text { MISCELLAKEOOS OSES }\end{array}$ & $\begin{array}{r}9,288 \\
3,155 \\
3,360 \\
306\end{array}$ & $\begin{array}{r}1,980 \\
3,598 \\
65 \\
177\end{array}$ & $\begin{array}{r}- \\
- \\
-\end{array}$ & $\begin{array}{r}3,129 \\
5,292 \\
3,282 \\
7\end{array}$ & $\overline{-}$ & $\begin{array}{r}11,558 \\
2,233 \\
186 \\
187\end{array}$ & $\begin{array}{r}122 \\
7,083 \\
- \\
-\end{array}$ & $\begin{array}{r}5,590 \\
4,916 \\
2 \\
58\end{array}$ & $\begin{array}{r}31,667 \\
26,277 \\
26,552 \\
735\end{array}$ & $\begin{array}{r}36 \% \\
30 \% \\
30 \% \\
1 \%\end{array}$ \\
\hline $\begin{array}{l}\text { TOTAL PINAL } \\
\text { DEMAND SECTORS }\end{array}$ & 16,109 & 5.820 & 19,657 & 11.710 & - & 14,164 & 7,205 & 10,566 & 85,231 & $97 \%$ \\
\hline $\begin{array}{l}\text { TRANSP ORMATICA } \\
\text { ELECTRICITY GEN. } \\
\text { PETROLEOA FRODOCTS } \\
\text { NATURAL GAS } \\
\text { SYNTHETICS }\end{array}$ & $\begin{array}{r}391 \\
- \\
-\end{array}$ & $\begin{array}{r}588 \\
- \\
-\end{array}$ & $\begin{array}{l}- \\
-\end{array}$ & $\begin{array}{l}- \\
-\end{array}$ & $\begin{array}{l}\overline{-} \\
\overline{-}\end{array}$ & $\begin{array}{r}227 \\
- \\
-\end{array}$ & $\begin{array}{r}1,114 \\
- \\
-\end{array}$ & $\begin{array}{r}-729 \\
- \\
-\end{array}$ & $\begin{array}{r}1,591 \\
- \\
- \\
-\end{array}$ & $2 \%$ \\
\hline $\begin{array}{l}\text { NET FOEL OSED } \\
\text { IN TRABSPORMATION }\end{array}$ & 391 & 588 & - & - & - & 227 & 1,114 & -729 & 1,591 & $2 \%$ \\
\hline $\begin{array}{l}\text { TOTAL GROSS FTONS } \\
\text { L OSSES E OMISSIONS }\end{array}$ & $\begin{array}{r}16,500 \\
953\end{array}$ & $\begin{array}{r}6.408 \\
0\end{array}$ & $\begin{array}{r}19,657 \\
-0\end{array}$ & $\begin{array}{r}11,710 \\
-489\end{array}$ & $\overline{-}$ & $\begin{array}{r}14,391 \\
-521\end{array}$ & $\begin{array}{r}8,3.19 \\
-18\end{array}$ & $\begin{array}{r}10,566 \\
1,056\end{array}$ & $\begin{array}{r}86,822 \\
981\end{array}$ & $\begin{array}{r}99 \% \\
1 \%\end{array}$ \\
\hline TOTAL NET OSAGE & 17,453 & 6.408 & 19.656 & 11,220 & - & 13,869 & 8,300 & 10,893 & 87,803 & \\
\hline
\end{tabular}

\begin{tabular}{|c|c|c|c|c|c|c|c|c|c|c|}
\hline $\begin{array}{l}\text { SOPPLY OF ENE.MGI } \\
\text { POSS IL POEL }\end{array}$ & - & - & - & - & - & - & 1,475 & - & 1,475 & $94 \%$ \\
\hline HY DROELECTRIC & - & - & - & - & - & - & - & 85 & 85 & $5 \%$ \\
\hline NOCL EAR & - & - & - & - & - & - & - & - & $\overline{-}$ & \\
\hline GEO. \&SOLAR & - & - & - & - & - & - & - & 5 & 5 & $0 \%$ \\
\hline TOTAL SOPPLY & - & - & - & - & - & - & 1,475 & 90 & 1.565 & \\
\hline
\end{tabular}

\section{NET IM PORTS}

OP B. BGION

17.453

6,408

19,656

11,220

13,369

6,825

10,803

86,238

\begin{tabular}{|c|c|c|c|c|c|}
\hline \\
\hline & TRAN SFORMA II ON & Loss & FOR & EL 3CTAICITY GEN. & $=68.58 \%$ \\
\hline & TRANSPORMACI ON & Loss & POR & PEZROLEOM PRODOCTS & $0.0 x$ \\
\hline 3 & TRANSEORHA GI ON & Loss & FOR & NA $\simeq$ ORAL GAS & $0.0 \%$ \\
\hline 4 & TRAN SPOBMAEI ON & Loss & POR & SYUTHETICS & $=0.0$ \\
\hline
\end{tabular}


BEGIONAL. ENERGY BALANCE STATEMENT

PIES MID MID SCENARIO

\begin{tabular}{|c|c|c|c|c|c|c|c|c|c|c|}
\hline SECTOR & $\underset{\text { OIL }}{\text { DESTIILATE }}$ & $\begin{array}{l}\text { BESIDOAX } \\
\text { OIL }\end{array}$ & $\begin{array}{l}\text { GASJLINZ } \\
\text { [ALL ] }\end{array}$ & $\begin{array}{c}\text { OTHES } \\
\text { HY DRO- } \\
\text { CARBONS } \\
\text { IS IN } 10 * \$ 9\end{array}$ & $\begin{array}{c}\text { CR JDE } \\
\text { OIL } \\
\text { ETU'Si }\end{array}$ & $\begin{array}{l}\text { NaTURAL } \\
\text { GAS }\end{array}$ & $\operatorname{COAL}$ & BLECTRICITY & $\begin{array}{l}\text { SECTOR } \\
\text { TCTAL }\end{array}$ & \\
\hline $\begin{array}{l}\text { PINAL DEIAND SECTORS } \\
\text { RESIDENTIAL, COAB. } \\
\text { IND USTPCAL } \\
\text { TRANSPCRTATION } \\
\text { MISCELLANEOOS OSES }\end{array}$ & $\begin{array}{r}60,272 \\
16,472 \\
28,730 \\
2,433\end{array}$ & $\begin{array}{r}12,377 \\
17,807 \\
586 \\
1,407\end{array}$ & $130,30 \frac{-}{-}$ & $\begin{array}{r}20,704 \\
41,978 \\
29,730 \\
60\end{array}$ & $\bar{z}$ & $\begin{array}{r}75,345 \\
19,1043 \\
1,683 \\
1,538\end{array}$ & $\begin{array}{r}818 \\
48,675 \\
4\end{array}$ & $\begin{array}{r}36,131 \\
27,131 \\
23 \\
445\end{array}$ & $\begin{array}{r}205,647 \\
171.106 \\
191.103 \\
5.887\end{array}$ & $\begin{array}{r}32 \% \\
27 \% \\
30 \% \\
1 \%\end{array}$ \\
\hline $\begin{array}{l}\text { TOTAL PIYAL } \\
\text { DEM ANO SECTORS }\end{array}$ & 107,957 & 32,177 & 130,301 & 92,472 & - & 97,609 & 49,497 & 63.730 & 573.743 & $89 \%$ \\
\hline $\begin{array}{l}\text { TRANSP ORHATION } \\
\text { BLECTRICITY GEN. } \\
\text { PETROL, ZOM PRODOCTS } \\
\text { NATORAE GAS } \\
\text { SYNT HETICS }\end{array}$ & $\begin{array}{r}2,313 \\
-16,762 \\
- \\
-\end{array}$ & $\begin{array}{r}4,992 \\
-7,173 \\
- \\
-\end{array}$ & $\begin{array}{r}-31,020 \\
-\end{array}$ & $\begin{array}{r}-14,39 \overline{-} \\
313,510\end{array}$ & $\begin{array}{r}66,554 \\
- \\
-\end{array}$ & $\begin{array}{r}1,368 \\
3,355 \\
-282,800\end{array}$ & $\begin{array}{r}54,537 \\
- \\
-\end{array}$ & $\begin{array}{r}-21,967 \\
- \\
- \\
-\end{array}$ & $\begin{array}{r}41,243 \\
556 \\
- \\
30,710\end{array}$ & $\begin{array}{l}6 \% \\
0 \%\end{array}$ \\
\hline $\begin{array}{l}\text { BET POEL OSED } \\
\text { IN THAISSPORMATION }\end{array}$ & $-14,449$ & $-2,18.1$ & $-311,020$ & 299,112 & 66,554 & $-278,077$ & $54,5.37$ & $-21,967$ & 72,509 & $11 \%$ \\
\hline $\begin{array}{l}\text { TOTAL GROSS FLOHS } \\
\text { LOSSES } \varepsilon \text { OHISSIONS }\end{array}$ & $\begin{array}{r}110,270 \\
6,375\end{array}$ & $\begin{array}{r}37,169 \\
0\end{array}$ & $\begin{array}{r}130,301 \\
-0\end{array}$ & $\begin{array}{l}405,982 \\
-16,970\end{array}$ & $\begin{array}{r}66,554 \\
3,322\end{array}$ & $\begin{array}{r}102,332 \\
-3,706\end{array}$ & $\begin{array}{r}104.034 \\
-229\end{array}$ & $\begin{array}{r}63,730 \\
6,373\end{array}$ & $\begin{array}{r}646,252 \\
-4,834\end{array}$ & $\begin{array}{r}101 \% \\
0 \%\end{array}$ \\
\hline $\begin{array}{l}\text { S OPPLY a? ENERGY } \\
\text { POSS IL POEL } \\
\text { HY DR OEL ECTRIC } \\
\text { NOCL EAR } \\
\text { GEO. ESOLAR }\end{array}$ & $\begin{array}{l}\overline{-} \\
\overline{-}\end{array}$ & $\begin{array}{l}- \\
-\end{array}$ & $\begin{array}{l}- \\
\overline{-}\end{array}$ & $\begin{array}{l}\overline{-} \\
\overline{-}\end{array}$ & $\overline{-}$ & $\begin{array}{l}\overline{-} \\
\overline{-}\end{array}$ & $\begin{array}{r}466 \\
- \\
-\end{array}$ & $\begin{array}{r}111 \\
- \\
29\end{array}$ & $\begin{array}{r}466 \\
111 \\
29\end{array}$ & $\begin{array}{l}77 \% \\
18 \%\end{array}$ \\
\hline TOTAL SOPPLY & - & - & - & - & - & - & 466 & 140 & 606 & \\
\hline
\end{tabular}

20-10

\section{IET IM PORTS}

OP REGEN

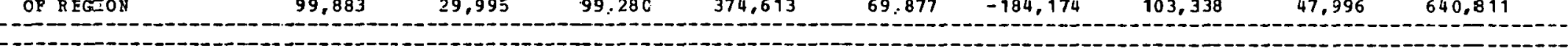

No TES :

TRANSPOBMATION LOSS POR

TRANSPORMATION LOSS POR

TRANSPORHATION LOSS POR

RLECTRICLTY GEN.

TRANSFOR MATI ON G.OSS FOR

HETS $=0.30 \%$

=0.3 
REGIONAL ENERGY BALANCE STATEMENT

PIES YID IID SCENAFIO

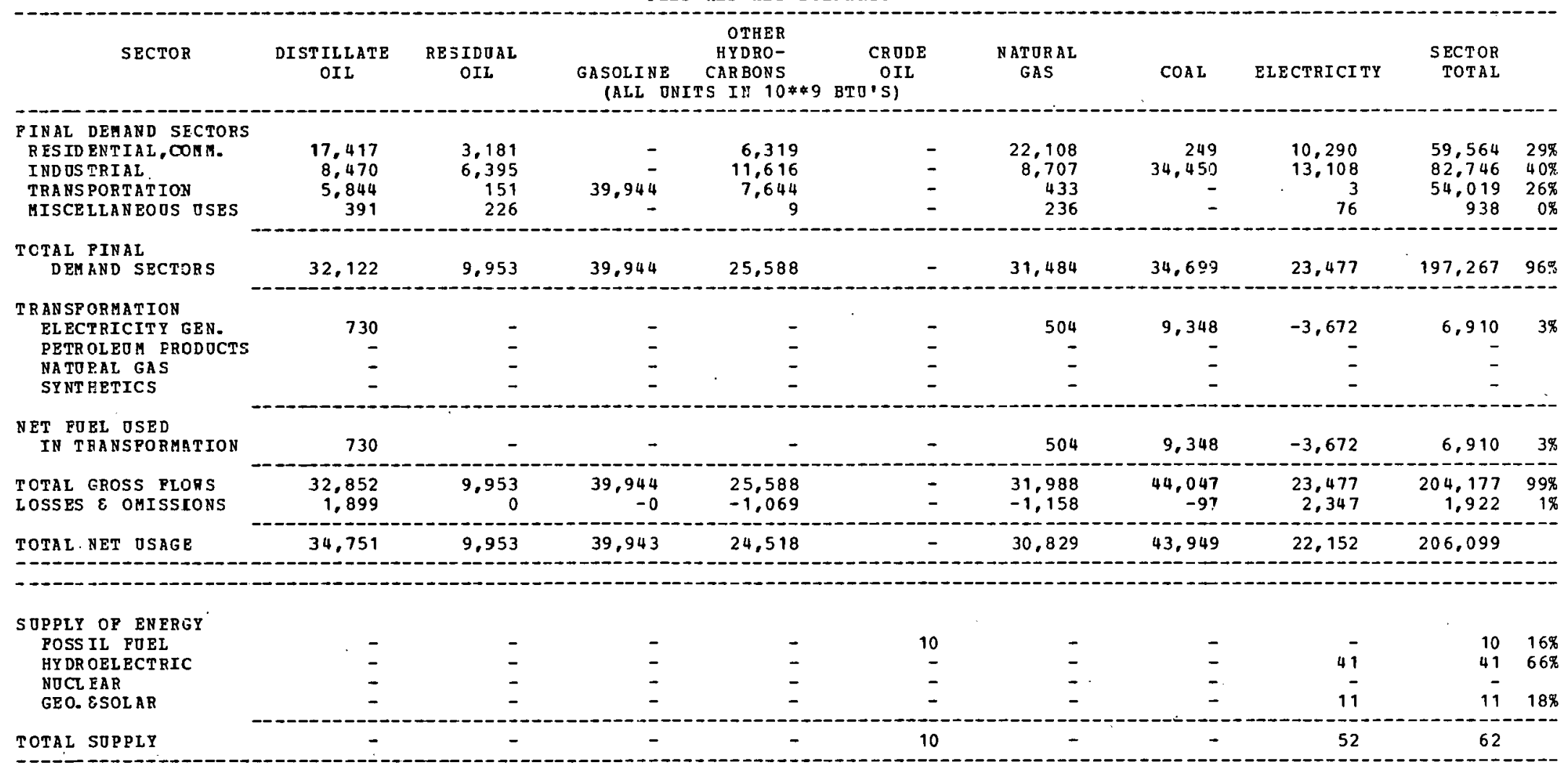

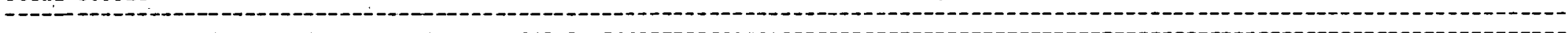

\section{NET IM PORTS}

OP REGION

34,751

9,953

39,943

24,518

$-10 \quad 30,829$

43,949

22,100

206,037

No TES

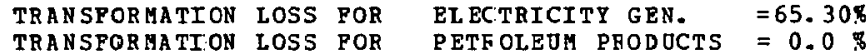

$$
\begin{aligned}
& \text { PETF OLEUM PHODOCTS }=0.0 \\
& \begin{array}{ll}
\text { TRANSPORMATION LOSS POR HATCRAL GAS } & =0.0 \\
\text { TRANSPORMATION LOSS FOR SYNTHTICS } & =0.0
\end{array}
\end{aligned}
$$


REGIOYAL ENERGY BALANCE STATEMENT

PIES MID MID SCENARID

\begin{tabular}{|c|c|c|c|c|c|c|c|c|c|c|}
\hline SECTOR. & $\begin{array}{l}\text { DI ST ILLATE } \\
\text { OIL }\end{array}$ & $\begin{array}{l}\text { RESIDDAI } \\
\text { OIL }\end{array}$ & $\begin{array}{l}\text { Gisol INE } \\
\text { iALL DNIJ }\end{array}$ & $\begin{array}{l}\text { OTHER } \\
\text { HYDRO- } \\
\text { CARBONS } \\
\text { S IN } 10 * \$ 9\end{array}$ & $\begin{array}{c}\text { CR ODE } \\
\text { OIL } \\
B=0 . S)\end{array}$ & $\begin{array}{l}\text { NATUFAL } \\
\text { GAS }\end{array}$ & COAL & ELECTRICITY & $\begin{array}{l}\text { SECTOR } \\
\text { TOIAL }\end{array}$ & \\
\hline $\begin{array}{l}\text { FINAL DEHAND SECTORS } \\
\text { RES ID ENEIAL,CCMM. } \\
\text { IND OS TREAL - } \\
\text { TRANSPORTATION } \\
\text { MISCRLEANEOUS OSES }\end{array}$ & $\begin{array}{r}19,477 \\
10,100 \\
27,665 \\
1,836\end{array}$ & $\begin{array}{r}1,66 \vdots \\
9,281 \\
221 \\
1,055\end{array}$ & $\begin{array}{r}- \\
\overline{-} \\
130,301\end{array}$ & $\begin{array}{r}19,270 \\
56,486 \\
6,668 \\
50\end{array}$ & $\begin{array}{l}- \\
- \\
-\end{array}$ & $\begin{array}{r}10 ., \leq 21 \\
33,: 56 \\
1, \in 48 \\
1, \leq 67\end{array}$ & $\begin{array}{r}649 \\
102,109 \\
-\end{array}$ & $\begin{array}{r}38,633 \\
62,146 \\
13 \\
435\end{array}$ & $\begin{array}{r}180, \in 13 \\
273, E 78 \\
166, E 16 \\
4, \in 50\end{array}$ & $\begin{array}{r}17 \% \\
26 \% \\
16 \% \\
0 \%\end{array}$ \\
\hline $\begin{array}{l}\text { TOTAL PIDAL } \\
\text { DEMAND SECTCRS }\end{array}$ & 59,078 & 12.224 & 130.301 & 82,474 & - & 137,592 & 102,761 & 101,227 & $625, E 57$ & $60 \%$ \\
\hline $\begin{array}{l}\text { TR R AN SPORIATION } \\
\text { BL ECTRICIT GEN. } \\
\text { PETR OL IFO ERODOCTS } \\
\text { NATORAL GAS } \\
\text { SY NT HEETCS }\end{array}$ & $\begin{array}{r}10,288 \\
-22,052 \\
- \\
-\end{array}$ & $\begin{array}{r}715 \\
-9,43 \pi \\
-\end{array}$ & $\begin{array}{r}-40,510 \\
- \\
-\end{array}$ & $\begin{array}{r}-18,943 \overline{-} \\
-\end{array}$ & $\begin{array}{r}87,561 \\
- \\
-\end{array}$ & $\begin{array}{r}1,542 \\
1,414 \\
-\end{array}$ & $\begin{array}{r}611.712 \\
= \\
-\end{array}$ & $\begin{array}{r}-219,278 \\
- \\
-\end{array}$ & $\begin{array}{r}405, \equiv 85 \\
733 \\
-\end{array}$ & $\begin{array}{r}39 \% \\
0 \%\end{array}$ \\
\hline $\begin{array}{l}\text { NET FOEL TSED } \\
\text { IN TRAUSFOBMATION }\end{array}$ & $-11,764$ & $-8,722$ & $-[0,310$ & $-18,9.43$ & 87,561 & $B, \equiv 6 \bar{i}$ & 611,712 & $-219,278$ & 406,718 & $39 \%$ \\
\hline $\begin{array}{l}\text { TOTAL GROSS FLORS } \\
\text { LOSSES } \& \text { OMISSIONS }\end{array}$ & $\begin{array}{r}6.9,366 \\
4,010\end{array}$ & $\begin{array}{r}12,939 \\
C\end{array}$ & $\begin{array}{r}730,301 \\
-0\end{array}$ & $\begin{array}{r}82,474 \\
-3,447\end{array}$ & $\begin{array}{r}87,561 \\
4,371\end{array}$ & $\begin{array}{r}143, \leq 54 \\
-5, \leq 14\end{array}$ & $\begin{array}{r}714,473 \\
-1,573\end{array}$ & $\begin{array}{r}101,227 \\
10,123\end{array}$ & $\begin{array}{r}1,031,: 75 \\
8,: 669\end{array}$ & $\begin{array}{r}99 \% \\
1 \%\end{array}$ \\
\hline TOTAL NEZ DSAGE & 51,324 & $3,50 \bar{z}$ & 89.490 & 60,083 & 91,932 & $13.3,73 \mathrm{c}$ & 712,899 & $-107,927$ & $1,040,044$ & \\
\hline $\begin{array}{l}\text { S OPPLY OF ENERGY } \\
\text { FOSS IL FOEL } \\
\text { HY DR OEEECT RIC } \\
\text { NDCL EAE } \\
\text { GEO. ESOLAR }\end{array}$ & $\begin{array}{l}- \\
-\end{array}$ & $\begin{array}{l}- \\
- \\
-\end{array}$ & $\begin{array}{l}- \\
- \\
-\end{array}$ & $\begin{array}{l}- \\
- \\
-\end{array}$ & $\begin{array}{l}\overline{-} \\
\overline{-}\end{array}$ & $\begin{array}{l}\overrightarrow{-} \\
\overrightarrow{-}\end{array}$ & $\begin{array}{l}- \\
-\end{array}$ & $\begin{array}{r}61 \overline{-} \\
9,582 \\
34\end{array}$ & $\begin{array}{r}E \overline{1} \\
9, \leq 82 \\
34\end{array}$ & $\begin{array}{r}6 \% \\
94 \% \\
0 \%\end{array}$ \\
\hline TOTAL SUPPLY & - & - & - & - & - & - & - & 10,227 & $10,-27$ & \\
\hline
\end{tabular}

\section{NET IM PORTS}

$3.50 \pi$

89.490

60.083

91,732

138,739

$7 \div 2,899$

$-118,154$

$1,029, E 17$

-

\section{NoTES:}

1 TRANSPCRMATI OA LOSS FOR

TRANSFORMATIOU LOSS FOR

TRANSPORMATION LDSS POA

ZLETRICITY GEY.

$=6+.50 \%$

-RANSFORMATIOA LOSS POR

政

$=3.6 \%$
$=3.6 \%$ 
REGIONAL ENERGY BALANCE STATEMENT

\begin{tabular}{|c|c|c|c|c|c|c|c|c|c|c|}
\hline SECTOR & $\begin{array}{l}\text { DISTILLATE } \\
\text { OIL }\end{array}$ & $\begin{array}{l}\text { RESILOAL } \\
\text { OIL }\end{array}$ & $\begin{array}{l}\text { GASOLINE } \\
\text { (ALL ON }\end{array}$ & $\begin{array}{l}\text { OTHER } \\
\text { HYDRO- } \\
\text { CARBONS } \\
\text { S IN } 10 * \$ 9\end{array}$ & $\begin{array}{c}\text { CR ODE } \\
\text { OIL } \\
\text { BTU'S) }\end{array}$ & $\begin{array}{l}\text { NATURAL } \\
\text { GAS }\end{array}$ & $\operatorname{COAL}$ & ELECTRICITY & $\begin{array}{r}\text { SECTOR } \\
\text { TOTAL }\end{array}$ & \\
\hline $\begin{array}{l}\text { PINAL DEMAND SECTORS } \\
\text { RES ID EMTIAL, COMH. } \\
\text { IND OSTRIAL } \\
\text { TRANSPORTATION } \\
\text { MISCELLANEOOS OSES }\end{array}$ & $\begin{array}{r}11,657 \\
4,896 \\
9,352 \\
1,529\end{array}$ & $\begin{array}{r}866 \\
3,033 \\
182 \\
884\end{array}$ & $\begin{array}{r}- \\
- \\
75,849 \\
-\end{array}$ & $\begin{array}{r}11,762 \\
11,125 \\
3,013 \\
45\end{array}$ & $\begin{array}{l}\overline{-} \\
\overline{-}\end{array}$ & $\begin{array}{r}67,797 \\
12,936 \\
1,370 \\
1,225\end{array}$ & $\begin{array}{r}390 \\
52.243 \\
- \\
3\end{array}$ & $\begin{array}{r}21,750 \\
22,998 \\
2 \\
378\end{array}$ & $\begin{array}{r}114,222 \\
107,231 \\
89,768 \\
4,064\end{array}$ & $\begin{array}{l}33 \% \\
31 \% \\
26 \% \\
1 \%\end{array}$ \\
\hline $\begin{array}{l}\text { TOTAL PINAL } \\
\text { DEMAND SECTORS }\end{array}$ & 27,434 & 4,965 & 75,849 & 25,945 & - & 83,328 & 52,636 & 45,128 & 315,285 & $91 \%$ \\
\hline $\begin{array}{l}\text { TRANSPORHATION } \\
\text { ELECTRICITY GEN. } \\
\text { PETRCLEUM PRODOCTS } \\
\text { NATURAL GAS } \\
\text { SY NTETICS }\end{array}$ & $\begin{array}{r}2.231 \\
- \\
-\end{array}$ & $\begin{array}{r}2.703 \\
- \\
-\end{array}$ & $\begin{array}{l}- \\
- \\
-\end{array}$ & $\begin{array}{l}- \\
- \\
-\end{array}$ & $\begin{array}{l}- \\
- \\
-\end{array}$ & $\begin{array}{r}968 \\
- \\
-\end{array}$ & $\begin{array}{r}37.633 \\
- \\
-\end{array}$ & $\begin{array}{r}-15,130 \\
- \\
-\end{array}$ & $\begin{array}{r}28,405 \\
- \\
-\end{array}$ & $8 \%$ \\
\hline $\begin{array}{l}\text { NET PUEL USED } \\
\text { IN TRANSFORMATION }\end{array}$ & 2,231 & 2,703 & - & - & - & 968 & 37,633 & $-15,130$ & 28,405 & $8 \%$ \\
\hline $\begin{array}{l}\text { TOTAL GROSS FLORS } \\
\text { LOSSES } \varepsilon \text { OMISSIONS }\end{array}$ & $\begin{array}{r}29,665 \\
1,715\end{array}$ & $\begin{array}{r}7,668 \\
0\end{array}$ & $\begin{array}{r}75,849 \\
-0\end{array}$ & $\begin{array}{r}25,945 \\
-1,084 \\
\end{array}$ & $\overline{-}$ & $\begin{array}{r}84,296 \\
-3,053\end{array}$ & $\begin{array}{r}90,269 \\
-193\end{array}$ & $\begin{array}{r}45,128 \\
\cdot 4,513\end{array}$ & $\begin{array}{r}343,690 \\
1,891\end{array}$ & $\begin{array}{r}99 \% \\
1 \%\end{array}$ \\
\hline TOTAL NET USAGE & 31,380 & 7,668 & 75,848 & 24,860 & - & 81,242 & 90,070 & 34,511 & 345,581 & \\
\hline $\begin{array}{l}\text { SOPPLY DF ENERGY } \\
\text { FOSS IL PUEL } \\
\text { HY DR OELECTRIC } \\
\text { NDCL EAR } \\
\text { GEO. ESOLAR }\end{array}$ & - & $\begin{array}{l}- \\
- \\
-\end{array}$ & $\begin{array}{l}- \\
-\end{array}$ & $\begin{array}{l}- \\
-\end{array}$ & $\begin{array}{l}17 \\
- \\
-\end{array}$ & $\begin{array}{l}\overline{-} \\
\overline{-} \\
\overline{-}\end{array}$ & $\bar{z}$ & $\begin{array}{r}-\overline{8} \\
\overrightarrow{21}\end{array}$ & $\begin{array}{r}17 \\
78 \\
- \\
21\end{array}$ & $\begin{array}{l}15 \% \\
67 \%\end{array}$ \\
\hline TOTAL SJPPLY & - & - & - & - & 17 & - & - & 99 & 116 & \\
\hline
\end{tabular}

\begin{tabular}{l}
$\begin{array}{l}\text { NET IM PORTS } \\
\text { OP REGION }\end{array}$ \\
\hline
\end{tabular}


REGIONF ENE RGY BALANCE STAEEMENT

PIES MID IID SCENARIO

\begin{tabular}{|c|c|c|c|c|c|c|c|c|c|c|}
\hline SECTOR & $\begin{array}{l}\text { DISTILLATE } \\
\text { OIL }\end{array}$ & $\underset{\text { JIL }}{\operatorname{RESIDDAL}}$ & $\begin{array}{l}\text { GASOLINE } \\
\text { (ALL ODI? }\end{array}$ & $\begin{array}{c}\text { OTHER } \\
\text { HYDRO- } \\
\text { CARBONS } \\
\text { TS IN } 10 * * 9\end{array}$ & $\begin{array}{l}\text { CRODE } \\
\text { OIL } \\
\text { BTO'S) }\end{array}$ & $\begin{array}{l}\text { NMTURAL } \\
\text { GAS }\end{array}$ & $\operatorname{COAL}$ & ELECTRICITY & $\begin{array}{l}\text { SECIDR } \\
\text { TOTAL }\end{array}$ & \\
\hline $\begin{array}{l}\text { PINAL DEMAND SFCTORS } \\
\text { RESID ENTLAL, COHM. } \\
\text { IND TSTRIAL } \\
\text { TRANSPORTATION } \\
\text { MISCELLATEOUS OSES }\end{array}$ & $\begin{array}{r}19,697 \\
9,363 \\
25,003 \\
2,527\end{array}$ & $\begin{array}{r}1,632 \\
5,623 \\
297 \\
1,458\end{array}$ & $130,16 \overline{-}$ & $\begin{array}{r}19.694 \\
37.325 \\
5,007 \\
67\end{array}$ & $\overline{-}$ & $\begin{array}{r}115,973 \\
36,870 \\
2,350 \\
7,767\end{array}$ & $\begin{array}{r}732 \\
57,806 \\
1 \\
4\end{array}$ & $\begin{array}{r}38,246 \\
43,405 \\
20 \\
559\end{array}$ & $\begin{array}{r}195,991 \\
231,332 \\
162,846 \\
6,389\end{array}$ & $\begin{array}{r}27 \% \\
32 \% \\
22 \% \\
1 \%\end{array}$ \\
\hline $\begin{array}{l}\text { TOTAL PINAL } \\
\text { DEMANE SECTORS }\end{array}$ & 56,587 & 10,010 & $1: 0,163$ & 62,093 & - & $156,9: 20$ & $\subseteq 8,543$ & 82,240 & 596,558 & $\varepsilon .1 \%$ \\
\hline $\begin{array}{l}\text { TBANSF ORMATION } \\
\text { EL ECTRI TITY GEN. } \\
\text { PETROLEIM ERODOCTS } \\
\text { NATORAL GAS } \\
\text { SY NT HETICS }\end{array}$ & $\begin{array}{r}2,817 \\
-4,141 \\
-\end{array}$ & $\begin{array}{r}2,369 \\
-504 \\
-\end{array}$ & $\begin{array}{r}-4,774 \\
-\end{array}$ & $\begin{array}{r}-2.027 \\
-\end{array}$ & $\begin{array}{r}11,397 \\
=\end{array}$ & $\begin{array}{r}1,911 \\
84 \\
-\end{array}$ & $\begin{array}{r}1 \leq 8,322 \\
- \\
-\end{array}$ & $\begin{array}{r}-71,299 \\
- \\
-\end{array}$ & $\begin{array}{r}134,022 \\
27 \\
- \\
-\end{array}$ & $\begin{array}{r}18 \% \\
0 \%\end{array}$ \\
\hline $\begin{array}{l}\text { NET FOEL OSEE } \\
\text { IN TRANSOHHATION }\end{array}$ & $-1,322$ & 1,864 & $-4,774$ & $-2,027$ & 11,391 & 1,995 & 198,322 & $-71,299$ & 134,149 & $18 \%$ \\
\hline $\begin{array}{l}\text { TOTAL GROSS FLORS } \\
\text { LOSSES } \varepsilon \text { ONISSIONS }\end{array}$ & $\begin{array}{r}59,403 \\
3,434\end{array}$ & $\begin{array}{r}12,379 \\
0\end{array}$ & $\begin{array}{r}130,163 \\
-0\end{array}$ & $\begin{array}{r}62,093 \\
-2,595\end{array}$ & $\begin{array}{r}11,391 \\
568\end{array}$ & $\begin{array}{r}158,515 \\
-5,75 \epsilon\end{array}$ & $\begin{array}{r}296,865 \\
-653\end{array}$ & $\begin{array}{r}82,240 \\
8,224\end{array}$ & $\begin{array}{r}730,707 \\
3,-222\end{array}$ & $\begin{array}{r}100 \% \\
0 \%\end{array}$ \\
\hline TOTAL NET OSAGE & 58,7 ar & 111.874 & 125,387 & 57,460 & 11,959 & $153,-59$ & 296,211 & 19,165 & $733, \simeq 29$ & \\
\hline
\end{tabular}

\begin{tabular}{|c|c|c|c|c|c|c|c|c|c|}
\hline $\begin{array}{l}\text { SOPPLY OF ENERGY } \\
\text { POSS IL POEL }\end{array}$ & - & - & - & - & 37,771 & $37, \varepsilon 37$ & 318,835 & - & 394,243 \\
\hline HY DR OELECT RIC & - & - & - & - & - & - & - & 140 & .40 \\
\hline NOCL EAE & - & - & - & - & - & - & - & - & - \\
\hline GE O. ESOLAR & - & - & - & - & - & - & - & 33 & $\Xi 3$ \\
\hline TOTAL SUPPLY & - & - & - & - & 37,771 & 37,837 & 318,835 & 173 & 394,616 \\
\hline
\end{tabular}

-

\begin{tabular}{l}
$\begin{array}{l}\text { NET IM POTTS } \\
\text { OP REGION }\end{array}$ \\
\hline
\end{tabular}


REGIONAL ENERGY BALANCE STATEMENT
PIZS MID MID SCENARIO

\begin{tabular}{|c|c|c|c|c|c|c|c|c|c|}
\hline SECTOR & $\begin{array}{l}\text { DISTILLATE } \\
\text { OIL }\end{array}$ & $\begin{array}{l}\text { BES =DUAL } \\
\text { OIL }\end{array}$ & $\begin{array}{l}\text { GASOLINE } \\
\text { (ALL O }\end{array}$ & $\begin{array}{c}\text { OTHER } \\
\text { HYDRO- } \\
\text { CARBONS } \\
\text { TS IN } 10 * * 9\end{array}$ & $\begin{array}{c}\text { CRODE } \\
\text { OIL } \\
\text { BTO' } 5 \text { ) }\end{array}$ & $\begin{array}{l}\text { NATURAL } \\
\text { GAS }\end{array}$ & COAL & ELECTRICITY & $\begin{array}{l}\text { SECTOR } \\
\text { TOTAL }\end{array}$ \\
\hline $\begin{array}{l}\text { PINAL DEHAND SECTORS } \\
\text { RES ID ENTIAL, COAM. } \\
\text { IND TS TRIAL } \\
\text { TRANS PORTATION } \\
\text { UISCELLANEOUS USES }\end{array}$ & $\begin{array}{r}1,930 \\
1,783 \\
5,384 \\
189\end{array}$ & $\begin{array}{r}438 \\
682 \\
- \\
104\end{array}$ & $22,56 \overline{-}$ & $\begin{array}{r}1.802 \\
611 \\
292 \\
4\end{array}$ & $\begin{array}{l}- \\
\overline{-}\end{array}$ & $\begin{array}{r}15,616 \\
11,295 \\
518 \\
316\end{array}$ & $\begin{array}{r}313 \\
11.841 \\
4 \\
1\end{array}$ & $\begin{array}{r}7,307 \\
12,638 \\
- \\
106\end{array}$ & $\begin{array}{l}27,406 \\
38,850 \\
28,767 \\
720\end{array}$ \\
\hline $\begin{array}{l}\text { TOTAL PINAL } \\
\text { DEMAND SECTORS }\end{array}$ & 9.286 & 1,224 & 22,569 & 2,709 & - & 27,745 & 12,159 & 20.051 & 95,743 \\
\hline $\begin{array}{l}\text { TBANSPOREATIOH } \\
\text { BLECTRICITY GEN. } \\
\text { PETROLEOA FRODOCTS } \\
\text { NATORAL GAS } \\
\text { SY HTEETICS }\end{array}$ & $\begin{array}{l}- \\
-\end{array}$ & $\begin{array}{r}630 \\
- \\
-\end{array}$ & $\begin{array}{l}- \\
-\end{array}$ & $\begin{array}{l}- \\
-\end{array}$ & $\begin{array}{l}- \\
\\
-\end{array}$ & $\begin{array}{r}667 \\
- \\
-\end{array}$ & $\begin{array}{r}184.620 \\
- \\
-\end{array}$ & $\begin{array}{r}-62,466 \\
- \\
- \\
-\end{array}$ & $\begin{array}{r}123,451 \\
- \\
-\end{array}$ \\
\hline $\begin{array}{l}\text { NET POEL OSBD } \\
\text { IN TRANSPORMATION }\end{array}$ & - & 630 & - & - & - & 667 & 184,620 & $-62,466$ & 123,451 \\
\hline $\begin{array}{l}\text { TOTAL GROSS PLOHS } \\
\text { LOSSES } \& \text { OMISSIO:SS }\end{array}$ & $\begin{array}{r}9,286 \\
536\end{array}$ & $\begin{array}{r}1,854 \\
0\end{array}$ & $\begin{array}{r}22,569 \\
-0\end{array}$ & $\begin{array}{r}2,709 \\
-113\end{array}$ & 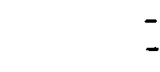 & $\begin{array}{r}28,412 \\
-1,029\end{array}$ & $\begin{array}{r}196,779 \\
-433\end{array}$ & $\begin{array}{r}20,051 \\
2,005\end{array}$ & $\begin{array}{r}219,194 \\
966\end{array}$ \\
\hline GOTAL NET OSAGE & 9,822 & 1.854 & 22,568 & 2,595 & - & 27,382 & 196,345 & $-40,409$ & 220,160 \\
\hline
\end{tabular}

\begin{tabular}{|c|c|c|c|c|c|c|c|c|c|c|}
\hline $\begin{array}{l}\text { SOPPLY OP ENERGY } \\
\text { FOSS II POEL }\end{array}$ & - & - & - & - & 37,020 & 144,986 & 967,050 & $\ddot{-}$ & $1,149,056$ & $100 \%$ \\
\hline HY DR OELECTRIC & - & - & - & - & - & - & - & 30 & 30 & $0 \%$ \\
\hline NOCL EAR & - & - & - & - & - & - & - & - & - & \\
\hline GEO. ESOLAR & - & - & - & - & - & - & - & - & - & \\
\hline TOTAL SOPPLY & - & - & - & - & 37.020 & 144,986 & 967.050 & 30 & $1,149,086$ & \\
\hline
\end{tabular}

144,98630020

\begin{tabular}{l}
$\begin{array}{l}\text { HPT IM PORTS } \\
\text { OP B EGION }\end{array}$ \\
\hline
\end{tabular}


REGIONAL ENERGY BALANCE STATEY $\Xi N T$

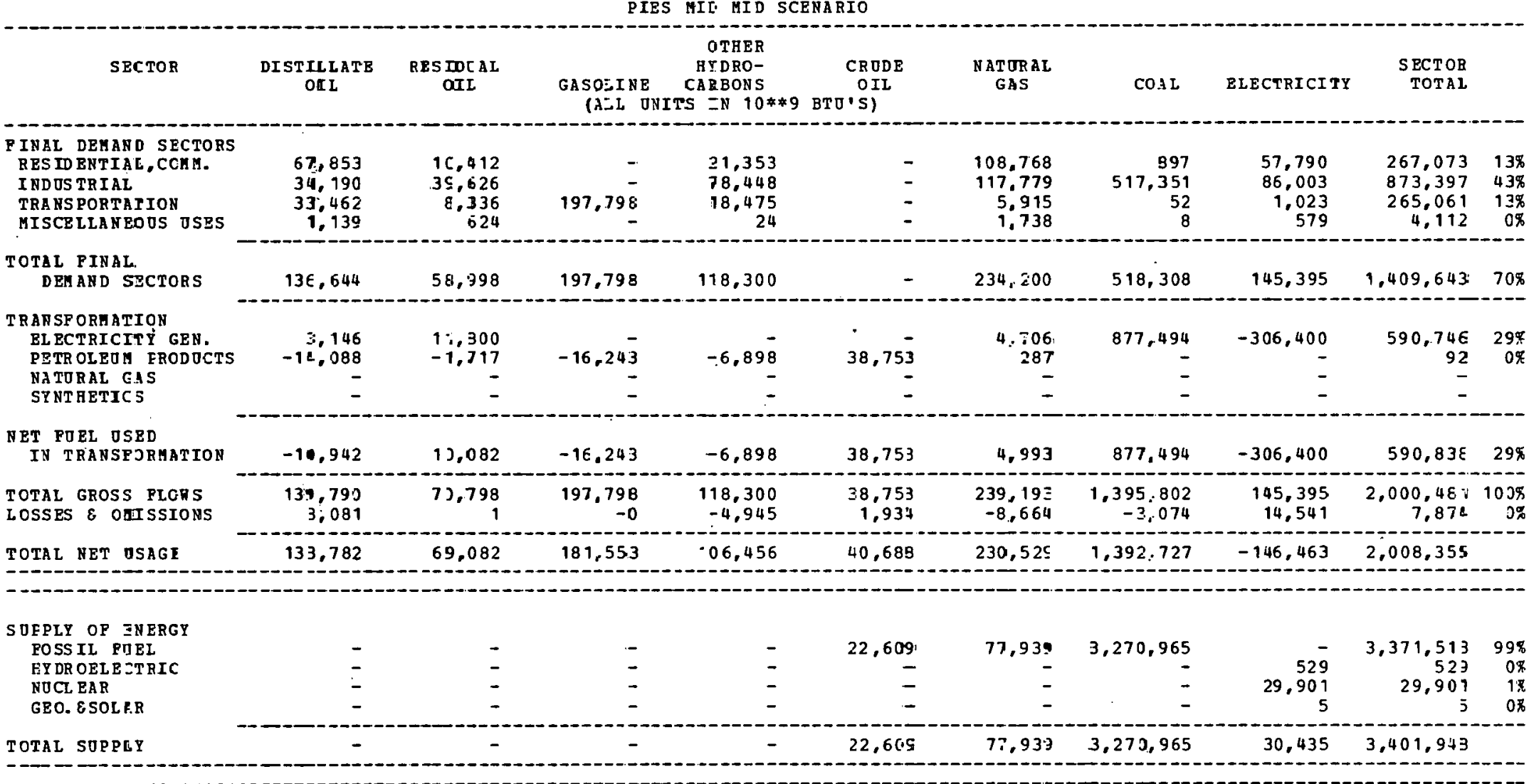

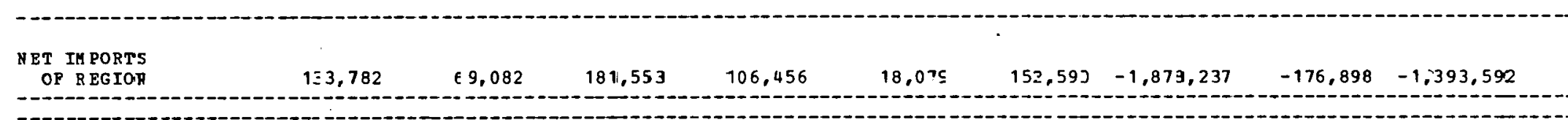

NOTES:
TRANSFORMATI ON LOSS POR TAANSPOR AA TI ON LOSS POR TEANSFORMATI ON LOSS FOR 
REGIONAL ENERGY BALANCE STATEMENT
PIES MID MID SCENARIO

\begin{tabular}{|c|c|c|c|c|c|c|c|c|c|c|}
\hline SECTOR & $\begin{array}{l}\text { DISTILLATE } \\
\text { OIL }\end{array}$ & $\begin{array}{l}\text { RES IDOAL } \\
\text { OIL }\end{array}$ & $\begin{array}{l}\text { GASOL INE } \\
\text { CALL ON }\end{array}$ & $\begin{array}{c}\text { OTHER } \\
\text { AYDRO- } \\
\text { CARBONS } \\
\text { TS IN } \quad 10 * * 9\end{array}$ & $\begin{array}{c}\text { CR ODE } \\
\text { OIL } \\
\text { BTU'S) }\end{array}$ & $\begin{array}{l}\text { NATURAL } \\
\text { GAS }\end{array}$ & $\operatorname{con} L$ & ELECTRICITY & $\begin{array}{r}\text { SECTOR } \\
\text { TOTAL }\end{array}$ & \\
\hline $\begin{array}{l}\text { PIHAL DEMAND SECTORS } \\
\text { RES ID ENTIAL, CCAM. } \\
\text { IND TS TRIAL } \\
\text { TRANSPORTATION } \\
\text { MISCELLANEOOS OSES }\end{array}$ & $\begin{array}{r}10,333 \\
6,155 \\
9.673 \\
492\end{array}$ & $\begin{array}{r}1.109 \\
5,138 \\
361 \\
283\end{array}$ & 48,699 & $\begin{array}{r}6,908 \\
23,060 \\
1.485 \\
12\end{array}$ & $\begin{array}{l}\overline{-} \\
-\end{array}$ & $\begin{array}{r}38,289 \\
18,085 \\
568 \\
369\end{array}$ & $\begin{array}{r}234 \\
100,508 \\
5 \\
1\end{array}$ & $\begin{array}{r}13,809 \\
21,079 \\
121 \\
122\end{array}$ & $\begin{array}{r}70,682 \\
174,023 \\
60,912 \\
1,279\end{array}$ & $\begin{array}{l}21 \% \\
53 \% \\
18 \% \\
0 \%\end{array}$ \\
\hline $\begin{array}{l}\text { TOTAL: PIBAL } \\
\text { DEHAND SECTORS }\end{array}$ & 26,653 & 6,891 & 48,699 & 31,465 & - & 57,309 & 100,748 & 35,131 & 306,896 & $93 \%$ \\
\hline $\begin{array}{l}\text { TRANSPORHATICN } \\
\text { EL ECTRICITY GEN. } \\
\text { PETROLEOM ERODOCTS } \\
\text { NATURAL GAS } \\
\text { SY NT HETICS }\end{array}$ & $\begin{array}{r}841 \\
- \\
-\end{array}$ & $\begin{array}{l}- \\
-\end{array}$ & $\begin{array}{l}- \\
- \\
-\end{array}$ & $\overline{-}$ & $\begin{array}{l}- \\
- \\
-\end{array}$ & $\begin{array}{r}850 \\
- \\
-\end{array}$ & $\begin{array}{r}33,377 \\
= \\
-\end{array}$ & $\begin{array}{r}-11,917 \\
- \\
-\end{array}$ & $\begin{array}{r}23,151 \\
- \\
- \\
\therefore \quad-\end{array}$ & $7 \%$ \\
\hline $\begin{array}{l}\text { NET PORL OSED } \\
\text { IN TRANSPORHATION }\end{array}$ & 841 & - & - & - & - & 850 & 33,377 & $-11,917$ & 23,151 & $7 \%$ \\
\hline $\begin{array}{l}\text { TOTAL GROSS FLORI } \\
\text { I OSSES \& OHISSIONS }\end{array}$ & $\begin{array}{r}27,494 \\
1,589\end{array}$ & $\begin{array}{r}6.891 \\
0\end{array}$ & $\begin{array}{r}48,699 \\
-0\end{array}$ & $\begin{array}{r}31,465 \\
-1,315\end{array}$ & $\overline{-}$ & $\begin{array}{l}58,159 \\
-2,106\end{array}$ & $\begin{array}{r}134,125 \\
-295\end{array}$ & $\begin{array}{r}35,131 \\
3,513\end{array}$ & $\begin{array}{r}330,047 \\
1,385\end{array}$ & $\begin{array}{r}100 \% \\
0 \%\end{array}$ \\
\hline TOTAL NET USAGE & 29,083 & 6,891 & 48,698 & 30,149 & - & 56,052 & 133,829 & 26,727 & 331,432 & \\
\hline $\begin{array}{l}\text { S OPPLY OP ENERGY } \\
\text { POSS IL POBI } \\
\text { HYDR OELECTRIC } \\
\text { HOCL EAR } \\
\text { GEO. ESOLAR }\end{array}$ & $\bar{z}$ & $\begin{array}{l}\bar{z} \\
\overline{-}\end{array}$ & $\begin{array}{l}\overline{-} \\
\overline{-}\end{array}$ & $\bar{z}$ & $\begin{array}{r}2,287 \\
- \\
-\end{array}$ & $\begin{array}{r}3,832 \\
- \\
-\end{array}$ & $\begin{array}{r}38,685 \\
- \\
-\end{array}$ & $\begin{array}{r}59 \\
\overline{12}\end{array}$ & $\begin{array}{r}44,804 \\
59 \\
\bar{y} \\
12\end{array}$ & $\begin{array}{r}100 \% \\
0 \% \\
0 \%\end{array}$ \\
\hline COTAL SUPPLY & - & - & - & - & 2,287 & 3,832 & 38,685 & 71 & 44,875 & \\
\hline
\end{tabular}

(1)

BET IM PORTS

29,083

6.891

48,698

30,149

$-2.287$

52,220

95,144

26,656

286,557

-

nOTES:

TRANSPOR AATI ON. LOSS POR TRANSPORMATI ON LOSS POR TRANSFORATIOR LOSS FOR TRANSPORMATIOI LOSS POR 
REGIDHAL ENERGI BALANCE STATZMENT

?IBS UID UID SCENARIO

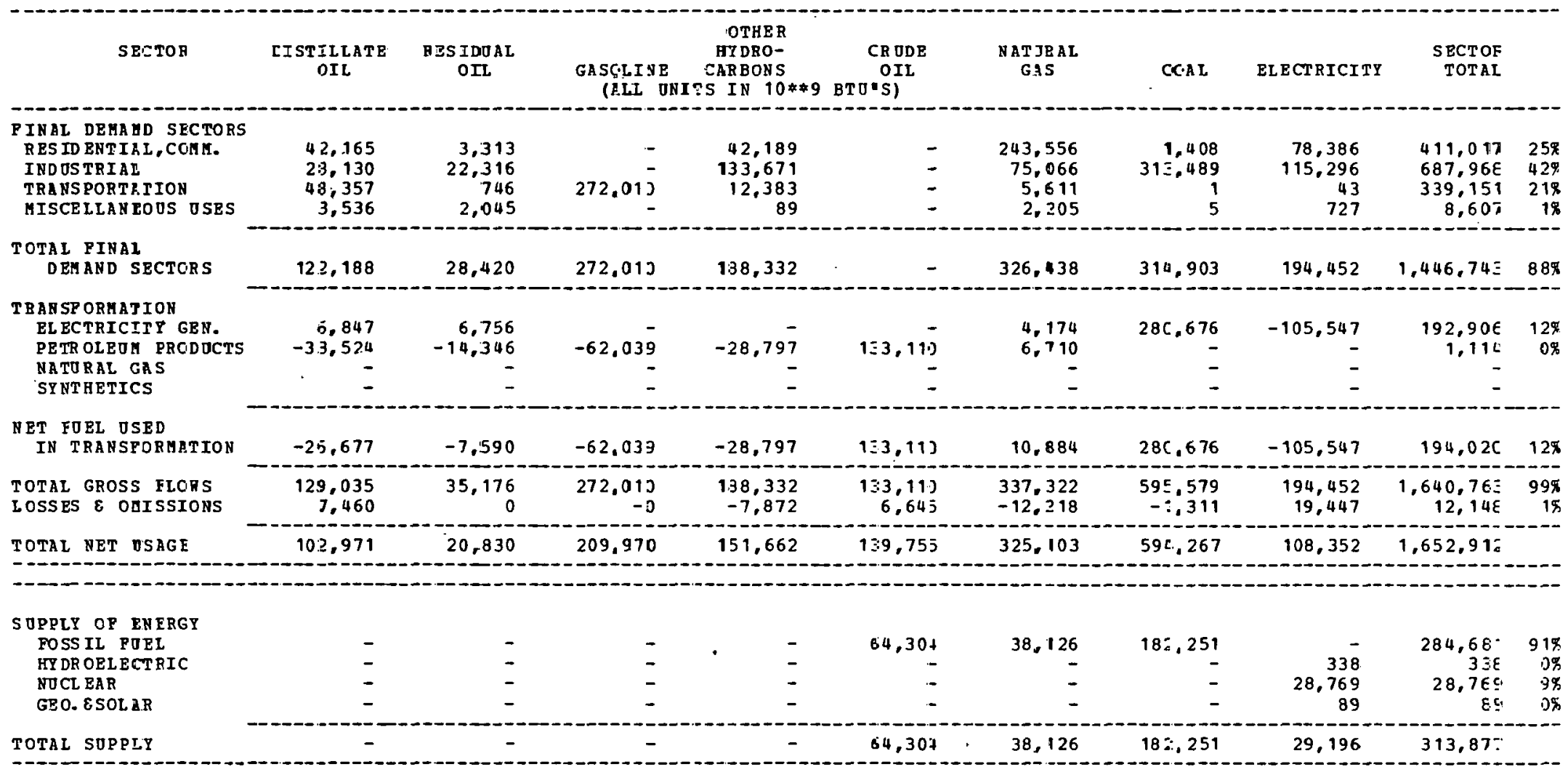

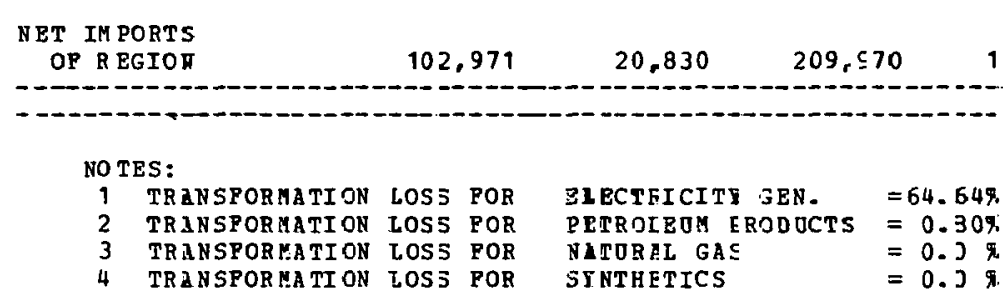


REGIONAL ENERGY BALANCE STATEMENT

PIES MID MID SCENAEIO

\begin{tabular}{|c|c|c|c|c|c|c|c|c|c|c|}
\hline SECTOR & $\begin{array}{l}\text { DISTILLATR } \\
\text { OIL }\end{array}$ & $\begin{array}{l}\text { RESIDOAL } \\
\text { JIL }\end{array}$ & $\begin{array}{l}\text { GASOLINE } \\
\text { (ALL ON. }\end{array}$ & $\begin{array}{c}\text { OTHER } \\
\text { HYDRO- } \\
\text { CARBONS } \\
\text { TS IN } 10 * * 9\end{array}$ & $\begin{array}{c}\text { CRODE } \\
\text { OIL } \\
\text { BTO'S) }\end{array}$ & $\begin{array}{l}\text { NATURAL } \\
\text { GAS }\end{array}$ & $\operatorname{COAL}$ & ELECTRI CITY & $\begin{array}{r}\text { SECTCR } \\
\text { TOTAL }\end{array}$ & \\
\hline $\begin{array}{l}\text { PINAL DEMAND SECTORS } \\
\text { RES IDEUTIAL, CCAM. } \\
\text { INDOSTRIAL } \\
\text { TRANSPORTATION } \\
\text { MISCELIANEOUS OSES }\end{array}$ & $\begin{array}{r}2,938 \\
1,419 \\
3,447 \\
149\end{array}$ & $\begin{array}{r}207 \\
1.773 \\
29 \\
86\end{array}$ & 19.263 & $\begin{array}{r}2,981 \\
6,132 \\
483 \\
4\end{array}$ & $\begin{array}{l}- \\
-\end{array}$ & $\begin{array}{r}16,962 \\
3,353 \\
217 \\
93\end{array}$ & $\begin{array}{r}97 \\
10,845 \\
-\end{array}$ & $\begin{array}{r}5,369 \\
7,278 \\
2 \\
31\end{array}$ & $\begin{array}{r}28,554 \\
30,800 \\
23,441 \\
363\end{array}$ & $\begin{array}{r}27 \% \\
29 \% \\
22 \% \\
0 \%\end{array}$ \\
\hline $\begin{array}{l}\text { TOTAL PINAL } \\
\text { DEMAND SECTORS }\end{array}$ & 7,953 & 2,095 & 19,263 & 9,600 & - & 20,625 & 10,942 & 12,680 & 83,158 & $79 \%$ \\
\hline $\begin{array}{l}\text { TRANSF ORMATION } \\
\text { BL ECTRICITY GEN. } \\
\text { PETROLEUM FRODOCTS } \\
\text { NA TORAL GAS } \\
\text { SY NT HETICS }\end{array}$ & $\begin{array}{r}398 \\
-88,000 \\
-\end{array}$ & $\begin{array}{r}223 \\
-37,659 \\
- \\
-\end{array}$ & $\begin{array}{r}-162,85 \overline{-} \\
-\end{array}$ & $\begin{array}{r}-75,59 \overline{2} \\
-\end{array}$ & $\begin{array}{r}349,413 \\
-\end{array}$ & $\begin{array}{r}273 \\
17,613 \\
- \\
-\end{array}$ & $\begin{array}{r}920 \\
- \\
-\end{array}$ & $\begin{array}{r}-566 \\
- \\
- \\
-\end{array}$ & $\begin{array}{r}1,248 \\
2,922 \\
- \\
-\end{array}$ & $\begin{array}{l}1 \% \\
3 \%\end{array}$ \\
\hline $\begin{array}{l}\text { NET PORL OSED } \\
\text { IN TRANSFORMATION }\end{array}$ & $-87,602$ & $-3 ?, 436$ & $-162,853$ & $-75,592$ & 349,413 & 17,886 & 920 & -566 & 4,170 & $4 \%$ \\
\hline $\begin{array}{l}\text { TOTAL GROSS FLOQS } \\
\text { LOSSES } 8 \text { OMISSIONS }\end{array}$ & $\begin{array}{r}B, 351 \\
482\end{array}$ & $\begin{array}{r}2,318 \\
0\end{array}$ & $\begin{array}{r}19,263 \\
-0\end{array}$ & $\begin{array}{r}9,600 \\
-401\end{array}$ & $\begin{array}{r}349,413 \\
17,443\end{array}$ & $\begin{array}{l}38,511 \\
-1,395\end{array}$ & $\begin{array}{r}11,862 \\
-26\end{array}$ & $\begin{array}{r}12,680 \\
1,268\end{array}$ & $\begin{array}{l}87,328 \\
17,371\end{array}$ & $\begin{array}{l}83 \% \\
17 \%\end{array}$ \\
\hline TOTAL NET USAGE & $-79,166$ & $-35,340$ & $-143,590$ & $-66,393$ & 356,856 & 37,116 & 11,835 & $13,3.82$ & 104,700 & \\
\hline $\begin{array}{l}\text { S OPPLY OP ENERG: } \\
\text { FOSS IL PUEL } \\
\text { HYDR OELECTRIC } \\
\text { NOCL EAR } \\
\text { GEO. ESOLAR }\end{array}$ & $\begin{array}{l}- \\
-\end{array}$ & $\begin{array}{l}- \\
-\end{array}$ & $\begin{array}{l}\bar{z} \\
\overline{-}\end{array}$ & $\begin{array}{l}- \\
-\end{array}$ & $\bar{z}$ & $\begin{array}{l}\overline{-} \\
-\end{array}$ & $\begin{array}{l}\overline{-} \\
\overline{-}\end{array}$ & $\begin{array}{r}\frac{-}{22} \\
\overline{6}\end{array}$ & $\frac{-}{22}$ & $79 \%$ \\
\hline TOTAL SUPPLY & - & - & - & - & - & - & - & 28 & 28 & \\
\hline
\end{tabular}

NET IM PORTS

OP REGION

$-79,166$

$-35,340$

$-143,590$

$-66.393$

366,856

37,116

11,835

13,354

104,672

NO TES :

TRARSPOBMATION LOSS POR ELECTRICITY GEN.

TRANSPBMATI ON LOSS POR PETROLEUM PRODOCTS $=0.80 \%$

TRANSPORHATI ON LOSS POR

NATURAL GAS

SY NTHETICS

$=0.0 \%$

$=0.0 \%$ 
RZGIONAL RIRR RGY BALANCE STATEMENT

\begin{tabular}{|c|c|c|c|c|c|c|c|c|c|c|}
\hline SECTOR & $\begin{array}{l}\text { XISTILLATE } \\
\text { OIL }\end{array}$ & $\begin{array}{c}\text { QESIDUAL } \\
\text { O=L }\end{array}$ & $\begin{array}{l}\text { GASDEINE } \\
\text { (AEI UNI }\end{array}$ & $\begin{array}{c}\text { OTHER } \\
\text { BYDRO- } \\
\text { CIRBONS } \\
\text { TS IN } 10 \$ \$ 9\end{array}$ & $\begin{array}{c}\text { CRODE: } \\
\text { CIL } \\
\text { BTO'S) }\end{array}$ & $\begin{array}{l}\text { NAZURAZ } \\
\text { CAS }\end{array}$ & $\operatorname{CJAL}$ & ELECTRICITY & $\begin{array}{l}\text { SECTOR } \\
\text { TOTAE }\end{array}$ & \\
\hline $\begin{array}{l}\text { PIUAL DEMAED SECTORS } \\
\text { RES ID ENTIZL, COHM. } \\
\text { IUD OS TRIAL } \\
\text { TRANS PORTATION } \\
\text { UISCE LLANBOOS OSES }\end{array}$ & $\begin{array}{r}14,165 \\
6,578 \\
15,625 \\
597\end{array}$ & $\begin{array}{r}859 \\
7.451 \\
176 \\
345\end{array}$ & $75,33 \overline{-}$ & $\begin{array}{r}11,743 \\
24,897 \\
2,503 \\
14\end{array}$ & $\begin{array}{l}- \\
- \\
-\end{array}$ & $\begin{array}{r}64.85 ? \\
13.765 \\
1.137 \\
375\end{array}$ & $\begin{array}{r}351 \\
55,568 \\
\overline{1}\end{array}$ & $\begin{array}{r}20,649 \\
24,337 \\
19 \\
122\end{array}$ & $\begin{array}{r}112,617 \\
133,595 \\
94,492 \\
1,454\end{array}$ & $\begin{array}{r}22 \% \\
26 \% \\
18 \% \\
0 \%\end{array}$ \\
\hline $\begin{array}{l}\text { TOTAL PINAI } \\
\text { DEMAND SECTORS }\end{array}$ & 36,965 & 8,831 & 75,035 & 39,157 & - & 80,125 & 56,920 & 45,127 & $342,16.1$ & $66 \%$ \\
\hline $\begin{array}{l}\text { TRANSP ORHAEICN } \\
\text { EL ECTRICITY GEN. } \\
\text { PETR OLEUY ERODOCTS } \\
\text { NATURAL SAS } \\
\text { SYNTHETIES }\end{array}$ & $\begin{array}{r}2,036 \\
-165,350 \\
-\end{array}$ & $\begin{array}{r}3,323 \\
-70,761 \\
-\end{array}$ & $\begin{array}{r}-305,79 \bar{c} \\
- \\
-\end{array}$ & $\begin{array}{r}-942,037 \\
-\end{array}$ & $\begin{array}{r}656,544 \\
-\end{array}$ & $\begin{array}{r}969 \\
33.096 \\
- \\
-\end{array}$ & $\begin{array}{r}205,360 \\
- \\
-\end{array}$ & $\begin{array}{r}-75,460 \\
- \\
- \\
-\end{array}$ & $\begin{array}{r}136,228 \\
5,493 \\
- \\
-\end{array}$ & $\begin{array}{r}26 \% \\
1 \%\end{array}$ \\
\hline $\begin{array}{l}\text { NBT FUEL OSED } \\
\text { IN TRANS?ORMATION }\end{array}$ & $-163,314$ & $-67,438$ & $-305,79 \subseteq$ & $-142,037$ & 656,544 & 34.065 & $20 \leq, 360$ & $-75,460$ & $141,7 \approx 1$ & $27 \%$ \\
\hline $\begin{array}{l}\text { TOTAL GROS.J FLOHS } \\
\text { LOSSES \& C CISSIONS }\end{array}$ & $\begin{array}{r}39,001 \\
2,254\end{array}$ & $\begin{array}{r}12,154 \\
0\end{array}$ & $\begin{array}{r}7 E, 0.35 \\
-c\end{array}$ & $\begin{array}{l}39,157 \\
-1,636\end{array}$ & $\begin{array}{r}656,544 \\
32,775\end{array}$ & $\begin{array}{r}11+, 197 \\
-+, 1360\end{array}$ & $\begin{array}{r}26 \bar{x}, 280 \\
-577\end{array}$ & $\begin{array}{r}45,127 \\
4,513\end{array}$ & $\begin{array}{r}483,8 E 2 \\
33,192\end{array}$ & $\begin{array}{r}94 \% \\
6 \%\end{array}$ \\
\hline TOTAL NET JSAGE & $-124,094$ & $-58,606$ & $-23 C, 95 c$ & $-104,516$ & 689,319 & 113.055 & 261,702 & $-25,819$ & 517.075 & \\
\hline
\end{tabular}

-

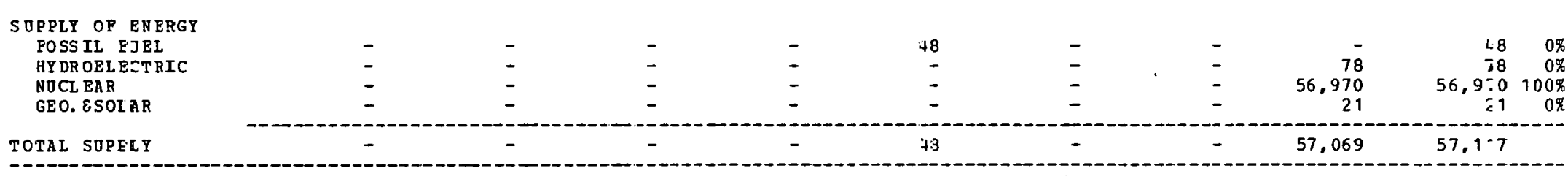

Torat

\begin{tabular}{|c|c|c|c|c|c|c|c|c|c|}
\hline $\begin{array}{l}\text { NET IM PORIS } \\
\text { OP REGION }\end{array}$ & $-124,094$ & $-5 \varepsilon, 606$ & -230.954 & $-104,516$ & 689,271 & 110.055 & $26 \%, 702$ & $-82,888$ & $459,9 \subseteq 8$ \\
\hline
\end{tabular}

\begin{tabular}{|c|c|c|c|c|c|}
\hline \\
\hline 1 & TEAN SPOR MA TI ON & Loss & POR & E. ECIRICIJY & 64 \\
\hline & TEANSPORHATI ON & LO:3S & POR & EETRCLEOM PRODUCAS & $=0.80$ \\
\hline & TEAN SEORMATION & Loss & POR & DATUGAL GAS & 0.0 \\
\hline 4 & TRAN SFORAATI ON & LOSS & FOR & SINTHETICS & 0.0 \\
\hline
\end{tabular}


3EGIONAL ENERGY BALANCE STATEMENT

PIES MID MID SCENARIO

\begin{tabular}{|c|c|c|c|c|c|c|c|c|c|c|}
\hline SECTOR & $\begin{array}{l}\text { IIISTILLATE } \\
\text { OII }\end{array}$ & $\begin{array}{l}\text { RES IDUAL } \\
\text { OIL }\end{array}$ & $\begin{array}{l}\text { GASOLINE } \\
\text { GALL D }\end{array}$ & $\begin{array}{c}\text { OTHER } \\
\text { HYDRO- } \\
\text { CARBONS } \\
\text { TS IN } 10 * \$ 9\end{array}$ & $\begin{array}{c}\text { CR UDE } \\
\text { OIL } \\
\text { BTO'S) }\end{array}$ & $\begin{array}{l}\text { NATURAL } \\
\text { GAS }\end{array}$ & $\operatorname{COAL}$ & ELECTRICITY & $\begin{array}{l}\text { SECTOR } \\
\text { TOTAL }\end{array}$ & \\
\hline $\begin{array}{l}\text { PINAL DEMAND SECTORS } \\
\text { BESID ENTIAL, COMM. } \\
\text { INDUSTRIAI } \\
\text { TRANS PORTATION } \\
\text { GISCELLANEOOS OSES }\end{array}$ & $\begin{array}{r}128,202 \\
21,471 \\
39,918 \\
5,342\end{array}$ & $\begin{array}{r}6,982 \\
22,164 \\
1,534 \\
3,089\end{array}$ & $\begin{array}{r}5 \\
88,390 \\
-\end{array}$ & $\begin{array}{r}62,718 \\
92.082 \\
20,087 \\
135\end{array}$ & $\begin{array}{l}- \\
-\end{array}$ & $\begin{array}{r}312,354 \\
52,082 \\
9,674 \\
3,385\end{array}$ & $\begin{array}{r}1,186 \\
240,975 \\
1 \\
9\end{array}$ & $\begin{array}{r}101,729 \\
91,439 \\
- \\
1,079\end{array}$ & $\begin{array}{r}613,171 \\
520,213 \\
456,004 \\
13,039\end{array}$ & $\begin{array}{r}34 \% \\
29 \% \\
25 \% \\
1 \%\end{array}$ \\
\hline $\begin{array}{l}\text { TOTAL PINAL } \\
\text { DEMAND SECTORS }\end{array}$ & 194.933 & 34,169 & 384,390 & 175,022 & - & 377,495 & 242,171 & 194,247 & $1,602,427$ & $89 \%$ \\
\hline $\begin{array}{l}\text { TPANSF ORMATICN } \\
\text { ELECTRICITY GEN. } \\
\text { PETROLEOM PRODOCTS } \\
\text { NATORAL GAS } \\
\text { SYNT BETICS }\end{array}$ & $\begin{array}{r}7,550 \\
-34,047 \\
- \\
-\end{array}$ & $\begin{array}{r}40,5107 \\
-14,570 \\
- \\
-\end{array}$ & $\begin{array}{r}-63,009 \\
- \\
-\end{array}$ & $\begin{array}{r}-29,247 \\
-\end{array}$ & $\begin{array}{r}- \\
135,190 \\
-\end{array}$ & $\begin{array}{r}4,571 \\
6,814 \\
- \\
-\end{array}$ & $\begin{array}{r}221,586 \\
- \\
-\end{array}$ & $\begin{array}{r}-94,360 \\
- \\
-\end{array}$ & $\begin{array}{r}179,854 \\
1,131 \\
-\end{array}$ & $\begin{array}{r}10 \% \\
0 \%\end{array}$ \\
\hline $\begin{array}{l}\text { NET POEL OSED } \\
\text { IN TRANSORMATION }\end{array}$ & $-26,497$ & 25,937 & -63.009 & $-29,247$ & 135,190 & 11,385 & 221,586 & $-94,360$ & 180,985 & $10 \%$ \\
\hline $\begin{array}{l}\text { TOTAL GROSS FLORS } \\
\text { L OSSES \& ONISSIONS }\end{array}$ & $\begin{array}{r}202 ; 483 \\
11,706\end{array}$ & $\begin{array}{r}74,676 \\
1\end{array}$ & $\begin{array}{r}384,390 \\
-1\end{array}$ & $\begin{array}{r}175,022 \\
-7,316\end{array}$ & $\begin{array}{r}135,190 \\
6,748\end{array}$ & $\begin{array}{l}388,880 \\
-14,086\end{array}$ & $\begin{array}{r}463,757 \\
-1,021\end{array}$ & $\begin{array}{r}194,247 \\
19,426\end{array}$ & $\begin{array}{r}1,783,412 \\
15,458\end{array}$ & $\begin{array}{r}99 \% \\
1 \%\end{array}$ \\
\hline $\begin{array}{l}\text { S OPPLY OP ENERGY } \\
\text { POSS IL POEL } \\
\text { HYDR OELECTRIC } \\
\text {. NDCL EAR } \\
\text { GEO. ESOLAR }\end{array}$ & $\begin{array}{l}- \\
-\end{array}$ & $\begin{array}{l}\overline{-} \\
-\end{array}$ & $\begin{array}{l}- \\
-\end{array}$ & $\begin{array}{l}- \\
-\end{array}$ & $\begin{array}{r}9,698 \\
- \\
-\end{array}$ & $\begin{array}{r}11,338 \\
= \\
-\end{array}$ & $\begin{array}{l}- \\
-\end{array}$ & $\begin{array}{r}- \\
338 \\
14,615 \\
89\end{array}$ & $\begin{array}{r}21,036 \\
338 \\
14,615 \\
89\end{array}$ & $\begin{array}{r}58 \% \\
1 \% \\
41 \% \\
0 \%\end{array}$ \\
\hline TOTAL SOPPLY & - & - & - & - & 9,598 & 11,338 & - & 15,042 & 36,078 & \\
\hline
\end{tabular}

\begin{tabular}{|c|c|c|c|c|c|c|c|c|c|}
\hline $\begin{array}{l}\text { NEE IM PORTS } \\
\text { OP REGION }\end{array}$ & 180,142 & 60.107 & 321,379 & 138,458 & 132,240 & 363,456 & 462,735 & 104,271 & $1,762,793$ \\
\hline
\end{tabular}

NO TES:

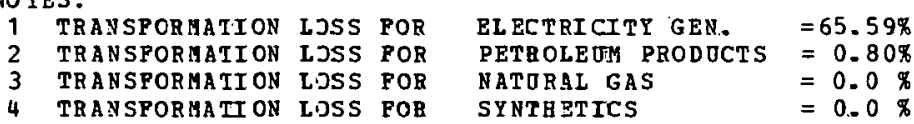

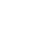


REGIONAL ENZRGY BALANCE STETEMENT
PIES MIO MID SCENARIO

\begin{tabular}{|c|c|c|c|c|c|c|c|c|c|c|}
\hline SECTOR & $\begin{array}{c}\text { DISTILLATE } \\
\text { JIL }\end{array}$ & $\begin{array}{l}\text { BESEDOAI } \\
\text { OIL }\end{array}$ & $\begin{array}{l}\text { GASOLI RE } \\
\text { (ALI ON }\end{array}$ & $\begin{array}{l}\text { TTERR } \\
\text { BIDBO- } \\
\text { CABBONS } \\
\text { TS IN } 10 * * 9\end{array}$ & $\begin{array}{c}\text { CRUDE } \\
\text { OIL } \\
\text { BTO'S) }\end{array}$ & $\begin{array}{l}\text { NATURAL } \\
\text { GAS }\end{array}$ & $\operatorname{COAL}$ & ELECTRICITY & $\begin{array}{r}\text { SECTOR } \\
\text { TOTAL }\end{array}$ & \\
\hline $\begin{array}{l}\text { FINAL DEHAND इECTORS } \\
\text { RES IDENTIAL,COMA. } \\
\text { IND OSTRIAL } \\
\text { TRANSPORTATIIN } \\
\text { MISCELLANEOOS OSES }\end{array}$ & $\begin{array}{r}22.806 \\
7.372 \\
5.279 \\
954\end{array}$ & $\begin{array}{r}1,107 \\
47.11 \overline{8} \\
21 \varepsilon \\
55 \bar{i}\end{array}$ & $\begin{array}{r}- \\
69,153 \\
-\end{array}$ & $\begin{array}{r}11.244 \\
-82.293 \\
1.977 \\
29\end{array}$ & $\begin{array}{l}- \\
- \\
-\end{array}$ & $\begin{array}{r}54,265 \\
10,8 \equiv 0 \\
9 \leq 0 \\
847\end{array}$ & $\begin{array}{r}210 \\
59,642 \\
-1\end{array}$ & $\begin{array}{r}17,261 \\
44,670 \\
= \\
212\end{array}$ & $\begin{array}{r}106,893 \\
251,858 \\
77,517 \\
2,595\end{array}$ & $\begin{array}{l}21 \% \\
50 \% \\
15 \% \\
1 \%\end{array}$ \\
\hline $\begin{array}{l}\text { TOTAL PINAL } \\
\text { DEMAND SECTORS }\end{array}$ & 36,201 & 49,988 & 69,153 & 95.543 & - & $66,8 \leq 2$ & $59,85.3$ & 62,143 & 438,863 & $38 \%$ \\
\hline $\begin{array}{l}\text { TR ANSPORMATIOH } \\
\text { BLECTRICITY'GEN, } \\
\text { PETH OLEOM FBODOCTS } \\
\text { NATORAL GAS } \\
\text { SY NTHETICS }\end{array}$ & $\begin{array}{r}2,360 \\
-46,566 \\
-\end{array}$ & $\begin{array}{r}25,676 \\
-13,928 \\
- \\
-\end{array}$ & $\begin{array}{r}-86,17 \overline{-} \\
-\end{array}$ & $\begin{array}{r}-40,00 \overline{1} \\
- \\
-\end{array}$ & $184,39 \overline{-}$ & $\begin{array}{r}1,377 \\
9,320 \\
-\end{array}$ & $\begin{array}{r}44,124 \\
= \\
-\end{array}$ & $\begin{array}{r}-24,484 \\
- \\
-\end{array}$ & $\begin{array}{r}50,053 \\
1,547 \\
-\end{array}$ & $\begin{array}{r}10 \pi \\
0 \%\end{array}$ \\
\hline $\begin{array}{l}\text { UET FORL OSED } \\
\text { IN TRANSFORGATION }\end{array}$ & $-44, \approx 06$ & $E, 743$ & $-86,176$ & -40.001 & 184,398 & 10,697 & 44,124 & $-24,484$ & 51,600 & $10 \%$ \\
\hline $\begin{array}{l}\text { TOTAL GROSS FEOHS } \\
\text { LOSSES } \varepsilon \text { OMISSIONS }\end{array}$ & $\begin{array}{r}38, \in 51 \\
2,=34\end{array}$ & 75,664 & $\begin{array}{r}69,15.3 \\
-0\end{array}$ & $\begin{array}{l}95.543 \\
-3.993\end{array}$ & $\begin{array}{r}184,898 \\
9,230\end{array}$ & $\begin{array}{l}77,589 \\
-2,810\end{array}$ & $\begin{array}{r}103,977 \\
-229\end{array}$ & $\begin{array}{r}62,143 \\
6,214\end{array}$ & $\begin{array}{r}490,463 \\
10,648\end{array}$ & $\begin{array}{r}93 \% \\
2 \pi\end{array}$ \\
\hline
\end{tabular}

\begin{tabular}{|c|c|c|c|c|c|c|c|c|c|c|}
\hline S OPPLT OF ENERGY & & & & & & & & & & \\
\hline POSS IL POEL & - & - & - & - & 48,220 & 9,130 & - & - & 57,410 & $78 \%$ \\
\hline HY DZ OELECTEIC & - & - & - & - & - & - & - & 1,125 & 1,125 & $2 \pi$ \\
\hline NOCT EAR & - & - & - & - & - & - & - & 15,377 & 15,377 & $21 \%$ \\
\hline GEO. ESOLAR & - & - & - & - & - & - & - & 29 & 29 & $0 \%$ \\
\hline TOTAL SOPPLY & - & - & - & - & 48,220 & 9,190 & - & 16,531 & 73,941 & \\
\hline
\end{tabular}

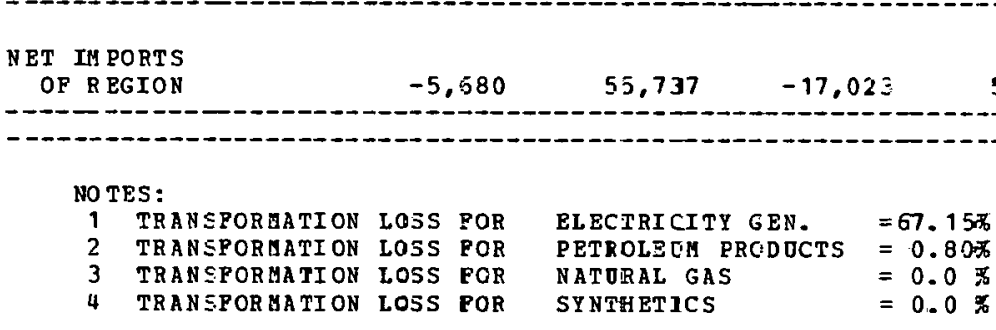


REGIONAL ENZRGY BALANCE STATEMENT

\begin{tabular}{|c|c|c|c|c|c|c|c|c|c|c|}
\hline SECTOR & $\begin{array}{l}\text { DISTILLATE } \\
\text { OIL }\end{array}$ & $\begin{array}{l}\text { RESIDUAL } \\
\text { C.IL }\end{array}$ & $\begin{array}{l}\text { GASOLINE } \\
\quad \begin{array}{l}\text { (ALI O }\end{array}\end{array}$ & $\begin{array}{c}\text { OTHER } \\
\text { HTDRO- } \\
\text { CAR BONS } \\
\text { S IN } 10 * \%\end{array}$ & $\begin{array}{c}\text { CQODE } \\
\text { OIL } \\
\text { BTO'S) }\end{array}$ & $\begin{array}{l}\text { NATURAL } \\
\text { GAS }\end{array}$ & COAL & ELECTRICITY & $\begin{array}{l}\text { SECTOR } \\
\text { TOTAL }\end{array}$ & \\
\hline $\begin{array}{l}\text { PINAL DEMAND SECTORS } \\
\text { RESID ENTIAL, CCMM. } \\
\text { INDOSTRIAL } \\
\text { TRANS PORTATION } \\
\text { MISCELLANEOOS OSES }\end{array}$ & $\begin{array}{r}31,348 \\
7,910 \\
9,911 \\
1,147\end{array}$ & $\begin{array}{r}1,564 \\
6,472 \\
317 \\
663\end{array}$ & $94,81 \bar{z}$ & $\begin{array}{r}15,433 \\
29,713 \\
2,959 \\
29\end{array}$ & $\begin{array}{l}- \\
- \\
-\end{array}$ & $\begin{array}{r}75,218 \\
15,801 \\
1,420 \\
722\end{array}$ & $\begin{array}{r}290 \\
70,770 \\
-\end{array}$ & $\begin{array}{r}24,124 \\
25,134 \\
- \\
231\end{array}$ & $\begin{array}{r}147,977 \\
155,800 \\
109,419 \\
2,793\end{array}$ & $\begin{array}{r}30 \% \\
32 \% \\
22 \% \\
1 \%\end{array}$ \\
\hline $\begin{array}{l}\text { TOTAL FINAL } \\
\text { DEMAND SECTOES }\end{array}$ & 50,316 & 9,016 & 94,812 & 48,134 & - & 93,169 & 79,061 & 49,489 & 415,989 & $85 \%$ \\
\hline $\begin{array}{l}\text { TRANSFORMATION } \\
\text { EL ECTRICITY GEM. } \\
\text { PETR OLEOH EROIOCTS } \\
\text { NATURAL GAS } \\
\text { SYNT HETICS }\end{array}$ & $\begin{array}{r}1,782 \\
-3,247 \\
-\end{array}$ & $\begin{array}{r}541 \\
-1.389 \\
- \\
-\end{array}$ & $\begin{array}{r}-6,010 \\
- \\
-\end{array}$ & $\begin{array}{r}-2,789 \\
-\end{array}$ & $\begin{array}{r}- \\
12,895 \\
-\end{array}$ & $\begin{array}{r}1,688 \\
650 \\
- \\
-\end{array}$ & $\begin{array}{r}103,116 \\
- \\
-\end{array}$ & $\begin{array}{r}-38,047 \\
- \\
-\end{array}$ & $\begin{array}{r}69,080 \\
\cdot 107 \\
-\end{array}$ & $\begin{array}{r}14 \% \\
0 \%\end{array}$ \\
\hline $\begin{array}{l}\text { NET POEL OSED } \\
\text { IN TRANSPORMATION }\end{array}$ & $-1,465$ & -848 & $-6,010$ & $-2,789$ & 12,895 & 2,338 & 103,116 & $-38,047$ & 69,187 & $14 \%$ \\
\hline $\begin{array}{l}\text { TOTAL GROSS FLORS } \\
\text { LOSSES } \& \text { OMISSIONS }\end{array}$ & $\begin{array}{r}52,098 \\
3,011\end{array}$ & $\begin{array}{r}9.557 \\
0\end{array}$ & $\begin{array}{r}94,812 \\
-0\end{array}$ & $\begin{array}{r}48,134 \\
-2,012\end{array}$ & $\begin{array}{r}12.895 \\
643\end{array}$ & $\begin{array}{r}95,499 \\
-3,459\end{array}$ & $\begin{array}{r}174.177 \\
-383\end{array}$ & $\begin{array}{r}49,489 \\
4,949\end{array}$ & $\begin{array}{r}485,176 \\
2,750\end{array}$ & $\begin{array}{r}998 \\
9 \%\end{array}$ \\
\hline $\begin{array}{l}\text { S OPPLY OP ENERGY } \\
\text { POSS IL POEL } \\
\text { HYDROELECTRIC } \\
\text { NOCL EAR } \\
\text { GEO. \&SOLAR }\end{array}$ & I & $\begin{array}{l}- \\
\overline{-} \\
-\end{array}$ & $\bar{z}$ & $\begin{array}{l}- \\
-\end{array}$ & $\begin{array}{r}41,980 \\
= \\
-\end{array}$ & $\begin{array}{r}39,506 \\
- \\
-\end{array}$ & $\begin{array}{l}\overline{-} \\
\overline{-}\end{array}$ & $\begin{array}{r}- \\
5,676 \\
859 \\
23\end{array}$ & $\begin{array}{r}81,486 \\
5,676 \\
859 \\
23\end{array}$ & $\begin{array}{r}938 \\
6 \% \\
1 \% \\
0 \%\end{array}$ \\
\hline TOTAL SUPPLY & - & - & - & - & 41,980 & 39,506 & - & 6,558 & 88,044 & \\
\hline
\end{tabular}

\begin{tabular}{l}
$\begin{array}{l}\text { NET IH PORTS } \\
\text { OP REGION }\end{array}$ \\
\hline
\end{tabular}


REGI ONAL ERERGI BALANCE STATEEENT

PIES YID HID SCENARIO

\begin{tabular}{|c|c|c|c|c|c|c|c|c|c|c|}
\hline SECTOR & $\begin{array}{l}\text { DISTELLATE } \\
\text { OIL }\end{array}$ & $\begin{array}{l}\text { BES IDOAL } \\
\text { OIL }\end{array}$ & $\begin{array}{l}\text { GASCLIIS } \\
\text { (2.LI ONI }\end{array}$ & $\begin{array}{c}\text { OTHER } \\
\text { HTY DRO- } \\
\text { CARBONS } \\
\text { CS IN } 10 * * 9\end{array}$ & $\begin{array}{c}\text { CR ODE } \\
\text { OIL } \\
\text { BTO'SI }\end{array}$ & $\begin{array}{l}\text { NATJRAL } \\
\text { GAS }\end{array}$ & $\operatorname{CoA} L$ & ELECTRICITY & $\begin{array}{l}\text { SECTOE } \\
\text { TOTAI }\end{array}$ & \\
\hline $\begin{array}{l}\text { PINAL DEHAND SECTORS } \\
\text { RESID ENTIAL, CCHA. } \\
\text { IND TS TRIAL } \\
\text { TRA RSPORTATION } \\
\text { HISCELLAMEOS OSES }\end{array}$ & $\begin{array}{r}27.339 \\
6.662 \\
5.857 \\
1.684\end{array}$ & $\begin{array}{r}1.387 \\
7.149 \\
.246 \\
974\end{array}$ & $82,55 \overline{-}$ & $\begin{array}{r}13,459 \\
19,744 \\
2,003 \\
42\end{array}$ & $\begin{array}{l}- \\
-\end{array}$ & $\begin{array}{r}66.520 \\
14.126 \\
362 \\
1,031\end{array}$ & $\begin{array}{r}253 \\
5 t .785 \\
- \\
3\end{array}$ & $\begin{array}{r}21.466 \\
21.897 \\
-\end{array}$ & $\begin{array}{r}130,42 \vdots \\
121,36 \vdots \\
91,62 z \\
4.075\end{array}$ & $\begin{array}{r}35 \pi \\
32 \% \\
24 \% \\
1 \%\end{array}$ \\
\hline $\begin{array}{l}\text { TOTAL PINAL } \\
\text { DEA AND SECTORS }\end{array}$ & 41,541 & 9,756 & 82,556 & 35,248 & - & 32, 1539 & 52,041 & 43,701 & 347,482 & $93 x$ \\
\hline $\begin{array}{l}\text { TRANSP ORHATION } \\
\text { EL ECTRICITY GEN, } \\
\text { PETR OLBOI ERODOCTS } \\
\text { NATORAL GAS } \\
\text { SYNTHETICS }\end{array}$ & $\begin{array}{r}1.396 \\
-3.771 \\
- \\
-\end{array}$ & $\begin{array}{r}2.544 \\
-1.614 \\
- \\
-\end{array}$ & $\begin{array}{r}- \\
-6,579 \\
-\end{array}$ & $\begin{array}{r}-3,239 \\
- \\
-\end{array}$ & $\begin{array}{r}- \\
14,974 \\
-\end{array}$ & $\begin{array}{r}967 \\
754 \\
- \\
-\end{array}$ & $\begin{array}{r}31.724 \\
- \\
-\end{array}$ & $\begin{array}{r}-12,728 \\
- \\
-\end{array}$ & $\begin{array}{r}23.903 \\
125 \\
- \\
-\end{array}$ & $\begin{array}{l}6 \% \\
0 \%\end{array}$ \\
\hline $\begin{array}{l}\text { NET FOEL OSBD } \\
\text { IN TRANSPORHATION }\end{array}$ & $-2,375$ & 930 & -6.579 & $-3,239$ & 14,974 & 1,721 & 39.724 & $-12,728$ & 24,028 & $6 \%$ \\
\hline $\begin{array}{l}\text { TOTAL GROSS FLORS } \\
\text { LOSSES } \& \text { OMISSIONS }\end{array}$ & $\begin{array}{r}42,937 \\
2,482\end{array}$ & $\begin{array}{r}12,300 \\
0\end{array}$ & $\begin{array}{r}82.556 \\
-0\end{array}$ & $\begin{array}{r}35,248 \\
-1,473\end{array}$ & $\begin{array}{r}14,974 \\
747\end{array}$ & $\begin{array}{l}84,360 \\
-3,355\end{array}$ & $\begin{array}{r}83,765 \\
-184\end{array}$ & $\begin{array}{r}43,701 \\
4,370\end{array}$ & $\begin{array}{r}371,510 \\
2,885\end{array}$ & $\begin{array}{r}99 \% \\
1 \%\end{array}$ \\
\hline $\begin{array}{l}\text { S OPPLY OP JNERGY } \\
\text { FOSS IL PDEL } \\
\text { HY DR OEL BCTRIC } \\
\text { NOCL EAR } \\
\text { GEO. ESOL.1B }\end{array}$ & $\begin{array}{l}\bar{z} \\
\overline{-}\end{array}$ & $\bar{z}$ & $\begin{array}{l}\overline{-} \\
\overline{-}\end{array}$ & $\begin{array}{l}\overline{-} \\
-\end{array}$ & $\begin{array}{r}42,433 \\
= \\
=\end{array}$ & $\begin{array}{r}25,365 \\
- \\
- \\
-\end{array}$ & $\begin{array}{l}- \\
- \\
-\end{array}$ & $\begin{array}{r}134 \\
8,299 \\
20\end{array}$ & $\begin{array}{r}67,793 \\
134 \\
8,29.9 \\
23\end{array}$ & $\begin{array}{r}89 \% \\
0 \% \\
11 \% \\
0 \%\end{array}$ \\
\hline TOTAL SUPPIY & - & - & - & - & $42,4 \geq 3=$ & 25.365 & - & 8,453 & 76.251 & \\
\hline
\end{tabular}

NET IM PORTE
OP REGIOY


REG IONAL ENE RGY BALANCE STATEMENT
PIES MID MID SCENARIO

\begin{tabular}{|c|c|c|c|c|c|c|c|c|c|c|}
\hline SECTOR & $\begin{array}{l}\text { DISTIL LATE } \\
\text { OIL }\end{array}$ & $\begin{array}{l}\text { EESIDUAL } \\
\text { OIL }\end{array}$ & $\begin{array}{l}\text { GASOLINE } \\
\text { (ALI O) }\end{array}$ & $\begin{array}{c}\text { OTHER } \\
\text { HYDRO- } \\
\text { CARBONS } \\
\text { TS IN } 10 * * 9\end{array}$ & $\begin{array}{c}\text { CRODE } \\
\text { OIL } \\
\text { BTD'S) }\end{array}$ & $\begin{array}{l}\text { NATURAL } \\
\text { GAS }\end{array}$ & COAL & ELECTRICITY & $\begin{array}{r}\text { SECTOR } \\
\text { TOTAL }\end{array}$ & \\
\hline $\begin{array}{l}\text { PINAL DEMAND SECTORS } \\
\text { RESIDENTIAL, COMM. } \\
\text { IND US TRIAL } \\
\text { TRANSPORTATION } \\
\text { MISCELLANEOOS OSES }\end{array}$ & $\begin{array}{r}20,560 \\
8,974 \\
13,300 \\
529\end{array}$ & $\begin{array}{r}4,265 \\
7.558 \\
167 \\
306\end{array}$ & $\begin{array}{r}- \\
- \\
-\end{array}$ & $\begin{array}{r}7.572 \\
13.598 \\
8,271 \\
13\end{array}$ & $\begin{array}{l}\text { - } \\
\overline{-}\end{array}$ & $\begin{array}{r}29,926 \\
10,464 \\
508 \\
318\end{array}$ & $\begin{array}{r}292 \\
40,500 \\
-\frac{1}{1}\end{array}$ & $\begin{array}{r}13,547 \\
15,745 \\
8 \\
104\end{array}$ & $\begin{array}{r}76,162 \\
96,839 \\
70,025 \\
1,271\end{array}$ & $\begin{array}{l}30 \% \\
38 \% \\
28 \% \\
1 \%\end{array}$ \\
\hline $\begin{array}{l}\text { TOTAL PINAL } \\
\text { DEHAND SBCTORS }\end{array}$ & 43,363 & 12,296 & 47,771 & 29,454 & - & 41,216 & 40,793 & 29,404 & 244.297 & $97 \%$ \\
\hline $\begin{array}{l}\text { TRAN SP ORMATION } \\
\text { BL ECTRICITY GEN. } \\
\text { PETR OLEOM PRODUCTS } \\
\text { NATURAL GAS } \\
\text { SY NT HETICS }\end{array}$ & $\begin{array}{r}1,367 \\
-12,611 \\
-\end{array}$ & $\begin{array}{r}477 \\
-5.396 \\
- \\
-\end{array}$ & $\begin{array}{r}-23,337 \\
-\end{array}$ & $\begin{array}{r}-10,833 \\
-\end{array}$ & $\begin{array}{r}50,072 \\
-\end{array}$ & $\begin{array}{r}631 \\
2,524 \\
-\end{array}$ & $\begin{array}{l}- \\
\overline{-}\end{array}$ & $\begin{array}{r}-661 \\
- \\
-\end{array}$ & $\begin{array}{r}1,814 \\
418 \\
-\end{array}$ & $\begin{array}{l}1 \% \\
0 \%\end{array}$ \\
\hline $\begin{array}{l}\text { NET POEI OSED } \\
\text { IN TRANSPORHATION }\end{array}$ & $-11,244$ & $-4,919$ & $-23,337$ & $-10,833$ & 50.072 & 3,155 & - & -661 & 2,232 & $1 \%$ \\
\hline $\begin{array}{l}\text { TOTAL GROSS FLORS } \\
\text { LOSSES \& OMISSIONS }\end{array}$ & $\begin{array}{r}44,730 \\
2,586\end{array}$ & $\begin{array}{r}12.773 \\
0\end{array}$ & $\begin{array}{r}47.771 \\
-0\end{array}$ & $\begin{array}{l}29,454 \\
-1,231\end{array}$ & $\begin{array}{r}50,072 \\
2,499\end{array}$ & $\begin{array}{l}44,371 \\
-1,607\end{array}$ & $\begin{array}{r}40,793 \\
-89\end{array}$ & $\begin{array}{r}29,404 \\
2,940\end{array}$ & $\begin{array}{r}246,529 \\
5,098\end{array}$ & $\begin{array}{r}98 \% \\
2 \%\end{array}$ \\
\hline
\end{tabular}

\begin{tabular}{|c|c|c|c|c|c|c|c|c|c|c|}
\hline SUPPLY OP ENERGS & & & & & & & & & & \\
\hline FOSS IL FOEL & $\bar{z}$ & - & - & - & 5 & $\because$ & - & $=\overline{0}$ & 5 & $7 \%$ \\
\hline HY DR OEL ECTRIC & - & - & - & - & - & 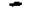 & - & 58 & 58 & $76 \%$ \\
\hline NOCL EAR & - & - & - & - & - & - & - & - & - & \\
\hline GEO. \&SOLAR & - & - & - & - & - & - & - & 13 & 13 & $17 \%$ \\
\hline TOTAL SOPPLY & - & - & - & - & 5 & - & - & 71 & 76 & \\
\hline
\end{tabular}

NET IM PORTS
OP BEGION

\section{NOTES:}

1 TRANSPOEMATI ON LOSS POR TRANSPOR MATI CN LOSS POR TRANSFOR MATI ON LOSS POR
EL ECTRICITY GEN. $\quad=73.29 \%$ MATORAL GAS SYNTHETICS 
REGIONAL ENE RGY BALANCE STATEIENT

IONAL ENE RGY BALANCE STAT
PIES HID MID SCENARIO

\begin{tabular}{|c|c|c|c|c|c|c|c|c|c|c|}
\hline SECTÓR & $\begin{array}{l}\text { DISTILLATE } \\
\text { JIL }\end{array}$ & $\begin{array}{l}\text { BESIEUAL } \\
\text { OIL }\end{array}$ & $\begin{array}{l}\text { GASOIINE } \\
\text { (AIL. ONIR }\end{array}$ & $\begin{array}{c}\text { OTHER } \\
\text { EYDRO- } \\
\text { CPRBONS } \\
\text { S IN } 10 * * 9\end{array}$ & $\begin{array}{c}\text { CR ODE } \\
\text { OII } \\
\text { BTO'S) }\end{array}$ & $\underset{\text { GAS }}{\text { NATURAI }}$ & $\operatorname{COAL}$ & ELECTRICITY & $\begin{array}{l}\text { SECTOL } \\
\text { TOTAL }\end{array}$ & \\
\hline $\begin{array}{l}\text { PINAL DEHADD SECTORS } \\
\text { RES ID ENTIAL, COAL. } \\
\text { IND USTRIAL } \\
\text { TRANSPORTATIOY } \\
\text { MISCELLAHEOOS OSES }\end{array}$ & $\begin{array}{r}23,647 \\
3,357 \\
7,500 \\
466\end{array}$ & $\begin{array}{r}3.571 \\
7.089 \\
211 \\
269\end{array}$ & $58, \equiv \underset{-}{-}$ & $\begin{array}{r}9,305 \\
23,143 \\
8,574 \\
11\end{array}$ & $\begin{array}{l}- \\
- \\
-\end{array}$ & $\begin{array}{r}.36,285 \\
12.07 \\
57 \varepsilon \\
285\end{array}$ & $\begin{array}{r}300 \\
38.380 \\
- \\
-\end{array}$ & $\begin{array}{r}14,716 \\
17,911 \\
3 \\
90\end{array}$ & $\begin{array}{r}87,824 \\
106,951 \\
75,281 \\
1,12\end{array}$ & $\begin{array}{r}32 \% \\
39 \% \\
27 \% \\
0 \%\end{array}$ \\
\hline $\begin{array}{l}\text { TOTAL PINAL } \\
\text { DEMAND SECTORS }\end{array}$ & 37,970 & 11.140 & $58 . \equiv 15$ & 41,033 & - & $4 \subseteq, 31 \subseteq$ & 38.680 & 32.720 & 271,177 & $98 \%$ \\
\hline $\begin{array}{l}\text { TRANSP ORMATION } \\
\text { EL ECTRICITY GEN. } \\
\text { PETR OLEOA PRODOCTS } \\
\text { NATORAL GAS } \\
\text { SY NTHETICS }\end{array}$ & $\begin{array}{r}1,051 \\
= \\
-\end{array}$ & $\begin{array}{r}3.736 \\
- \\
-\end{array}$ & $\begin{array}{l}\overline{-} \\
\bar{z}\end{array}$ & $\begin{array}{l}\overline{-} \\
\overline{-}\end{array}$ & $\begin{array}{l}\bar{z} \\
\bar{z}\end{array}$ & $\begin{array}{r}70: \\
-\end{array}$ & $\begin{array}{l}\overline{-} \\
\overline{-}\end{array}$ & $\begin{array}{r}-1,526 \\
= \\
-\end{array}$ & $\begin{array}{r}3,963 \\
- \\
-\end{array}$ & $1 \%$ \\
\hline $\begin{array}{l}\text { SET FOEL OSED } \\
\text { IN TRANSEORAATION }\end{array}$ & 1,051 & 3.736 & - & - & - & 702 & - & $-1,526$ & 3,963 & 18.8 \\
\hline $\begin{array}{l}\text { TOTAL GROSS FLONS } \\
\text { LOSSES } \varepsilon \text { OHISSIONS }\end{array}$ & $\begin{array}{r}41,021 \\
2,371\end{array}$ & $\begin{array}{r}14.876 \\
0\end{array}$ & $\begin{array}{r}58,315 \\
-0\end{array}$ & $\begin{array}{r}41,033 \\
-1,715\end{array}$ & $\overline{-}$ & $\begin{array}{l}5(1,021 \\
-\because, 81 .\end{array}$ & $\begin{array}{r}38,680 \\
-85\end{array}$ & $\begin{array}{r}32,720 \\
3.272\end{array}$ & $\begin{array}{r}275,143 \\
2,031\end{array}$ & $\begin{array}{r}99.5 \\
1 \%\end{array}$ \\
\hline $\begin{array}{l}\text { S OPPLY OP ENERGY } \\
\text { POSS IL PIEL } \\
\text { HYDROELEETRIC } \\
\text { NOCL EAR } \\
\text { GEO. ESOLAR }\end{array}$ & $\begin{array}{l}\overline{-} \\
\overline{-}\end{array}$ & $\begin{array}{l}- \\
-\end{array}$ & $\begin{array}{l}\overline{-} \\
\overline{-}\end{array}$ & $\begin{array}{l}- \\
-\end{array}$ & $\bar{z}$ & $\begin{array}{l}\overline{-} \\
\overline{-}\end{array}$ & $\begin{array}{l}\overline{-} \\
\overline{-}\end{array}$ & $\begin{array}{r}384 \\
25,406 \\
15\end{array}$ & $\begin{array}{r}-5 \\
384 \\
25.405 \\
15\end{array}$ & $\begin{array}{r}1 \% \\
98 \% \\
0 \%\end{array}$ \\
\hline TOTAL SOPPLY & - & - & - & - & - & - & - & 25,805 & 25,805 & \\
\hline
\end{tabular}

\section{NET IM PORTE}

OP RBGION

43,392

14,876

58,314

39,317

$-\quad 4 \varepsilon, 209$

38,594

8,661

251,355

BO TES:

1 TRENSPORAATION ZOSS FO

TRINSPOR UATI ON LOSS POR

TRBNSPORHATI ON IOSS POR

TRANSPORAATI ON IOSS POB

BL ECTRICIT! GEN

$=72.208$

ATURI GA

STNTHZTICS

$=0.0$
$=0.0$ 
REGIONAL ENERGY BALANCE STATEMENT

\begin{tabular}{|c|c|c|c|c|c|c|c|c|c|c|}
\hline SECTOR & $\begin{array}{l}\text { DIST ILLATE } \\
\text { CIL }\end{array}$ & $\begin{array}{l}\text { RES IDUAL } \\
\text { JIL }\end{array}$ & $\begin{array}{l}\text { GASOLINE } \\
\text { (ALL ONI }\end{array}$ & $\begin{array}{c}\text { OTHER } \\
\text { HYDRO- } \\
\text { CARBONS } \\
\text { TS IN } 10 * \$ 9\end{array}$ & $\begin{array}{c}\text { CRODE } \\
\text { OIL } \\
\text { BTO'S) }\end{array}$ & $\begin{array}{l}\text { NATURAL } \\
\text { GAS }\end{array}$ & COA L & ELECTRICITY & $\begin{array}{r}\text { SECTOR } \\
\text { TOTAL }\end{array}$ & \\
\hline $\begin{array}{l}\text { PINAL DEMAND SECTORS } \\
\text { RES ID ENTIAL, COMY. } \\
\text { IND OSTRIAL } \\
\text { TRANSPORTATION } \\
\text { MISCELLANEOOS OSES }\end{array}$ & $\begin{array}{r}226,309 \\
98,666 \\
105,896 \\
9,556\end{array}$ & $\begin{array}{r}60,019 \\
115,994 \\
1.719 \\
5,527\end{array}$ & $518,67 \overline{-}$ & $\begin{array}{r}90,806 \\
361,844 \\
94,343 \\
237\end{array}$ & - & $\begin{array}{r}457,432 \\
125,574 \\
40,018 \\
6,234\end{array}$ & $\begin{array}{r}3,174 \\
426,793 \\
2 \\
16\end{array}$ & $\begin{array}{r}157.822 \\
156,871 \\
656 \\
2.127\end{array}$ & $\begin{array}{r}995,562 \\
1,286,742 \\
761,307 \\
23,697\end{array}$ & $\begin{array}{r}29 \pi \\
379 \\
22 \pi \\
1 \%\end{array}$ \\
\hline $\begin{array}{l}\text { TOTAL PINAL } \\
\text { DEMAND SECTORS }\end{array}$ & 440,427 & 184,259 & 518,673 & 547,230 & - & 629,258 & 429,985 & 317,476 & $3,067,308$ & $88 \pi$ \\
\hline $\begin{array}{l}\text { TRANSP OEHATION } \\
\text { BLECTEICITY GEN. } \\
\text { PETROL EOA FRODOCTS } \\
\text { NATOREL GAS } \\
\text { SY NT HETICS }\end{array}$ & $\begin{array}{r}15,042 \\
-497,354 \\
-\end{array}$ & $\begin{array}{r}50,014 \\
-212,841 \\
- \\
-\end{array}$ & $\begin{array}{r}-920,411 \\
-\end{array}$ & $\begin{array}{r}-427,230 \\
-\end{array}$ & $\begin{array}{r}1,974,810 \\
-\end{array}$ & $\begin{array}{r}8,610 \\
99,550 \\
- \\
-\end{array}$ & $\begin{array}{r}376,721 \\
- \\
-\end{array}$ & $\begin{array}{r}-155,927 \\
- \\
-\end{array}$ & $\begin{array}{r}294,460 \\
16,524 \\
-\end{array}$ & $\begin{array}{l}8 \% \\
0 \%\end{array}$ \\
\hline $\begin{array}{l}\text { NET POEL OSED } \\
\text { IN TRANSFORMATION }\end{array}$ & $-482,312$ & $-162,827$ & -920.411 & $-427,230$ & $1,974.810$ & 108,160 & 376,721 & $-155,927$ & 310.984 & $9 \%$ \\
\hline $\begin{array}{l}\text { TOTAL GROSS FLOQS } \\
\text { ICSSES \& OMISSIONS }\end{array}$ & $\begin{array}{r}455,469 \\
26,332\end{array}$ & $\begin{array}{r}234,273 \\
5\end{array}$ & $\begin{array}{r}518,673 \\
-1\end{array}$ & $\begin{array}{l}547,230 \\
-22,875\end{array}$ & $\begin{array}{r}1,974,810 \\
98,585\end{array}$ & $\begin{array}{l}737,418 \\
-26,711\end{array}$ & $\begin{array}{r}806,706 \\
-1,776\end{array}$ & $\begin{array}{r}317,476 \\
31,750\end{array}$ & $\begin{array}{r}3,378,292 \\
105,309\end{array}$ & $\begin{array}{r}97 \pi \\
3 \pi\end{array}$ \\
\hline TOTAL NET USAGE & $-15,552$ & 21,437 & $-401,739$ & 97.124 & $2,073,395$ & 710,706 & 804,929 & 193,299 & $3,483,601$ & \\
\hline $\begin{array}{l}S \text { OPPLY OF ENERGI } \\
\text { POSS IL POEL } \\
\text { HYDR OEL ECTRIC } \\
\text { NOCL EAR } \\
\text { GEO. ESOLAR }\end{array}$ & $\begin{array}{l}- \\
-\end{array}$ & $\begin{array}{l}- \\
-\end{array}$ & $\begin{array}{l}\overline{-} \\
\overline{-}\end{array}$ & $\begin{array}{l}- \\
- \\
-\end{array}$ & $\begin{array}{l}- \\
-\end{array}$ & $\begin{array}{l}- \\
\overline{-}\end{array}$ & $\begin{array}{r}8,836 \\
- \\
-\end{array}$ & $\begin{array}{r}730 \\
105.761 \\
145\end{array}$ & $\begin{array}{r}8.836 \\
730 \\
105.761 \\
145\end{array}$ & $\begin{array}{r}8 \% \\
1 \% \\
92 \% \\
0 \%\end{array}$ \\
\hline TOTAL SOPPLY & - & - & - & - & - & - & 8,836 & 106,636 & 115,472 & \\
\hline
\end{tabular}

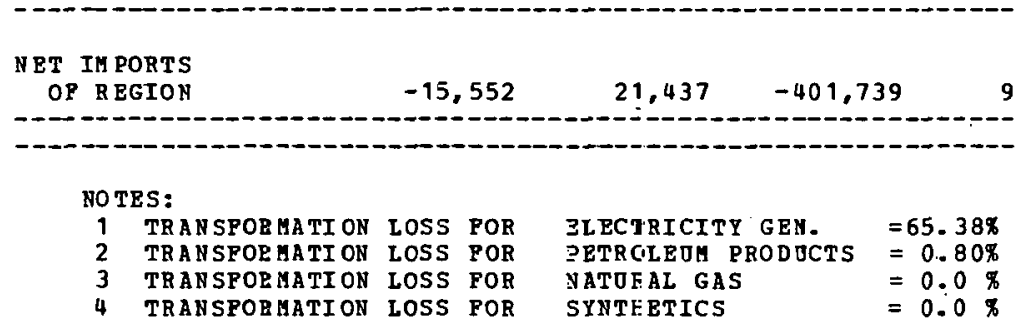




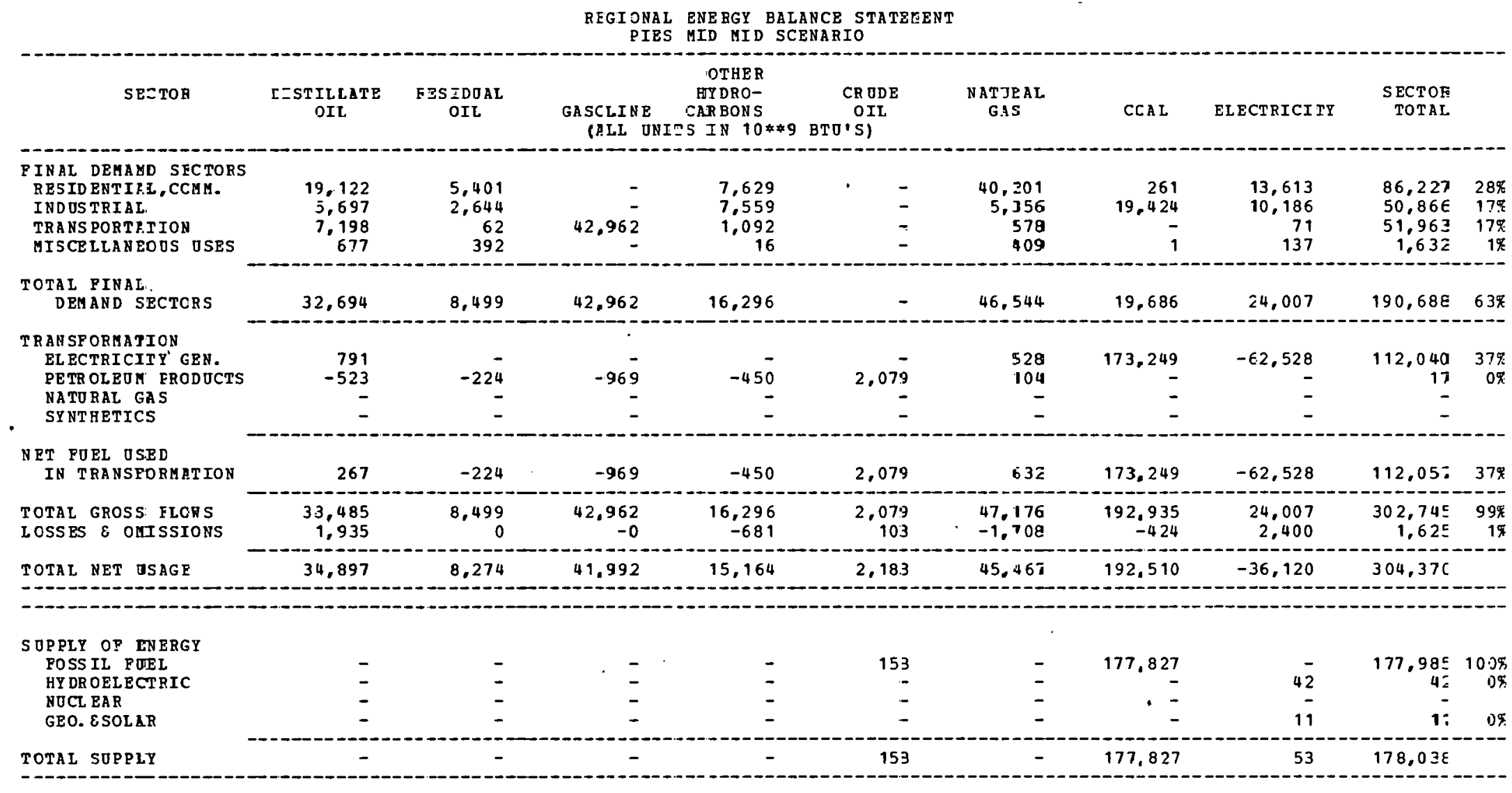

NET IM PORTS
OF REGIOI


REGIONAL ENE RGY BALANCE STATEMENT

\begin{tabular}{|c|c|c|c|c|c|c|c|c|c|c|}
\hline SECTOR & $\begin{array}{l}\text { DISTILLATE } \\
\text { OIL }\end{array}$ & $\begin{array}{l}\text { RES IDUAL } \\
\text { OIL }\end{array}$ & $\begin{array}{l}\text { GASOLINE } \\
\quad \text { (ALL ONI }\end{array}$ & $\begin{array}{c}\text { OTHER } \\
\text { HYDRO- } \\
\text { CARBONS } \\
\text { TS IN } 10 \$ 9\end{array}$ & $\begin{array}{c}\text { CR ODE } \\
\text { OIL } \\
\text { BTD'SI }\end{array}$ & $\begin{array}{l}\text { NATORAL } \\
\text { GAS }\end{array}$ & $\mathrm{COAL}$ & ELECTRICITY & $\begin{array}{r}\text { SECTOR } \\
\text { TOTAL }\end{array}$ & \\
\hline $\begin{array}{l}\text { PINAL DEMAND SECTORS } \\
\text { BESID ENTIAL, COMA. } \\
\text { INDUSTRIAL } \\
\text { TRANSPORTATION } \\
\text { GISCELLANEOOS OSES }\end{array}$ & $\begin{array}{r}12,824 \\
7,245 \\
8,308 \\
1,167\end{array}$ & $\begin{array}{r}2,424 \\
5,870 \\
32 \\
470\end{array}$ & $\begin{array}{r}- \\
43,519\end{array}$ & $\begin{array}{r}8,593 \\
30,376 \\
921 \\
36\end{array}$ & $\begin{array}{l}- \\
- \\
-\end{array}$ & $\begin{array}{r}34,090 \\
21,661 \\
418 \\
564\end{array}$ & $\begin{array}{r}154 \\
32,445 \\
- \\
1\end{array}$ & $\begin{array}{r}12,251 \\
14,883 \\
35 \\
202\end{array}$ & $\begin{array}{r}70,336 \\
112,480 \\
53,233 \\
2,440\end{array}$ & $\begin{array}{r}25 \% \\
40 \% \\
19 \% \\
1 \%\end{array}$ \\
\hline $\begin{array}{l}\text { TOTAL FINAL } \\
\text { DEMAND SECTORS }\end{array}$ & 29,544 & 8,796 & 43,519 & 39,926 & - & 56,733 & 32,600 & 27,371 & 238,489 & $85 \%$ \\
\hline $\begin{array}{l}\text { TBANSPORHATION } \\
\text { ELECTRICITY GEN. } \\
\text { PETR OLEOA FRODOCTS } \\
\text { NATURAL GAS } \\
\text { SY NTHETICS }\end{array}$ & $\begin{array}{r}2,139 \\
- \\
-\end{array}$ & $\begin{array}{r}1,844 \\
- \\
-\end{array}$ & $\begin{array}{l}- \\
\overline{-}\end{array}$ & $\bar{z}$ & $\overline{-}$ & $\begin{array}{r}310 \\
- \\
-\end{array}$ & $\begin{array}{r}52,412 \\
- \\
-\end{array}$ & $\begin{array}{r}-14,390 \\
= \\
-\end{array}$ & $\begin{array}{r}42,315 \\
- \\
-\end{array}$ & $15 \pi$ \\
\hline $\begin{array}{l}\text { BET POBL OSED } \\
\text { IN TRANSPORMATION }\end{array}$ & 2,139 & 1,844 & - & - & - & 310 & 52,412 & $-14,390$ & . 42,315 & $15 \%$ \\
\hline $\begin{array}{l}\text { TCTAL GROSS FLORS } \\
\text { LCSSES \& OMISSIONS }\end{array}$ & $\begin{array}{r}31,683 \\
1,831\end{array}$ & $\begin{array}{r}10,640 \\
0\end{array}$ & $\begin{array}{r}43,519 \\
-0\end{array}$ & $\begin{array}{l}39,926 \\
-1,668\end{array}$ & - & $\begin{array}{l}57,043 \\
-2,066\end{array}$ & $\begin{array}{r}85,012 \\
-187\end{array}$ & $\begin{array}{r}27,371 \\
2,737\end{array}$ & $\begin{array}{r}280,804 \\
646\end{array}$ & $\begin{array}{r}100 \% \\
0 \%\end{array}$ \\
\hline
\end{tabular}

\begin{tabular}{|c|c|c|c|c|c|c|c|c|c|c|}
\hline S UPPLY OF ENRRGY & & & & & & & & & & \\
\hline FOSS IL FUEL & - & - & - & - & - & - & 285 & - & 285 & $1 \%$ \\
\hline HY DROELECTRIC. & - & - & - & - & - & - & - & 87 & 87 & $0 \%$ \\
\hline NOCL BAR & - & - & - & - & - & - & - & 32,641 & 32,641 & $99 \%$ \\
\hline GEO. ESOLAR & - & - & - & - & - & - & - & 7 & 7 & $0 \%$ \\
\hline TOTAL SOPPLY & - & - & - & - & - & - & 285 & 32,735 & 33,020 & \\
\hline
\end{tabular}

\begin{tabular}{|c|c|c|c|c|c|c|c|c|c|}
\hline $\begin{array}{l}\text { NET IM PORTS } \\
\text { OP REGION }\end{array}$ & 33,514 & 10,640 & 43,518 & 38,257 & - & 54,976 & 84,539 & $-17,016$ & 248,430 \\
\hline
\end{tabular}

\footnotetext{
NOTES:

TRAHSPOBHATI ON LOSS ROR TRANSPOBATI TRANSPORHATI ON LOSS POR NATURAL GAS $\quad=0.0 \%$ TRANSPORHATI ON L.JSS POR SYNTHETICS
} 
REGIONAL EER FGY BALANCE STATEMENT

PIJS MED HI D SCEHARIO

\begin{tabular}{|c|c|c|c|c|c|c|c|c|c|c|}
\hline SECTOR & $\begin{array}{l}\text { DISIILLATE } \\
\text { OIL }\end{array}$ & $\begin{array}{c}\text { RE } \subseteq \text { IDUAL } \\
\text { OIL }\end{array}$ & $\begin{array}{l}\text { GASOIJNE } \\
\text { (ALL O }\end{array}$ & $\begin{array}{l}\text { OTHER } \\
\text { BYLYO- } \\
\text { CDREONS } \\
\text { TS IN 10**9 }\end{array}$ & $\begin{array}{c}\text { CRODE } \\
\text { OIL } \\
\text { BTO'S) }\end{array}$ & $\begin{array}{l}\text { NATURAL } \\
\text { GAS }\end{array}$ & $\cos 1$. & ELECTKICITY & $\begin{array}{r}\text { SECTOR } \\
\text { TOTAL }\end{array}$ & \\
\hline $\begin{array}{l}\text { PINAL DEHAND SECTORS } \\
\text { RESID ENTIAL, COMH. } \\
\text { IND OS TRIAL } \\
\text { TRANS PORTATION } \\
\text { MISCE LLANEOUS OSES }\end{array}$ & $\begin{array}{r}4,8.38 \\
2,635 \\
3,929 \\
539\end{array}$ & $\begin{array}{r}54 \\
1,155 \\
- \\
111\end{array}$ & 27,932 & $\begin{array}{r}6.170 \\
3,213 \\
468 \\
20\end{array}$ & $\begin{array}{l}\overline{-} \\
\overline{-}\end{array}$ & $\begin{array}{r}18,87 ? \\
6,354 \\
154 \\
1183\end{array}$ & $\begin{array}{r}26 \\
4,473 \\
- \\
-\end{array}$ & $\begin{array}{r}7.868 \\
5,817 \\
74\end{array}$ & $\begin{array}{r}37,868 \\
23,687 \\
32,475 \\
927\end{array}$ & $\begin{array}{l}33 \% \\
21 \% \\
29 \% \\
1 \%\end{array}$ \\
\hline $\begin{array}{l}\text { TOTAL PINAL } \\
\text { DEMAND SEITORS }\end{array}$ & 11,933 & 1,40 & 27,932 & 9,871 & - & 25,563 & 4,439 & 13,759 & 94,957 & $84 \%$ \\
\hline $\begin{array}{l}\text { TRANSF ORMATI-JN } \\
\text { BL BCTRICITY GEN. } \\
\text { PETR OLEUM PRODICTS } \\
\text { NATORAL GAS } \\
\text { SY NT BETICS }\end{array}$ & $\begin{array}{r}1,136 \\
- \\
-\end{array}$ & $\begin{array}{l}- \\
-\end{array}$ & $\begin{array}{l}\overline{-} \\
\overline{-}\end{array}$ & $\begin{array}{l}\overline{-} \\
\overline{-}\end{array}$ & $\begin{array}{l}\overline{-} \\
\overline{-}\end{array}$ & $\begin{array}{l}\bar{z} \\
\overline{-}\end{array}$ & $\begin{array}{r}22,154 \\
= \\
-\end{array}$ & $\begin{array}{r}-5,898 \\
- \\
-\end{array}$ & $\begin{array}{r}17,392 \\
- \\
-\end{array}$ & $15 \%$ \\
\hline $\begin{array}{l}\text { NET FOEL OSED } \\
\text { IN TRANSFORHATION }\end{array}$ & 1,136 & - & - & - & - & - & 22,154 & $-5,898$ & 17,392 & $15 \%$ \\
\hline $\begin{array}{l}\text { TOTAL GROSS ILORS } \\
\text { LOSSES } \varepsilon \text { OHISSIONS }\end{array}$ & $\begin{array}{r}13.069 \\
755\end{array}$ & $\begin{array}{r}1,41) 0 \\
0\end{array}$ & $\begin{array}{r}27,9 \cdot 32 \\
-0\end{array}$ & $\begin{array}{r}9,871 \\
-412\end{array}$ & $\overline{-}$ & $\begin{array}{r}25,5 \in 3 \\
-9 \div 5\end{array}$ & $\begin{array}{r}26,653 \\
-58\end{array}$ & $\begin{array}{r}13,759 \\
1,376\end{array}$ & $\begin{array}{r}112,349 \\
734\end{array}$ & $\begin{array}{r}99 \% \\
1 \%\end{array}$ \\
\hline $\begin{array}{l}\text { SOPPLY OP BNERGY } \\
\text { FOSS IL POEL } \\
\text { RY DR OELECT RIC } \\
\text { NOCL. EAR } \\
\text { GEO. ESOLAE }\end{array}$ & $\bar{z}$ & $\begin{array}{l}\overline{-} \\
\overline{-}\end{array}$ & $\begin{array}{l}\overline{-} \\
\overline{-}\end{array}$ & $\begin{array}{l}\overline{-} \\
\overline{-}\end{array}$ & $\begin{array}{l}\overline{-} \\
-\end{array}$ & $\begin{array}{l}\bar{z} \\
\bar{z}\end{array}$ & $\begin{array}{l}- \\
- \\
-\end{array}$ & $\begin{array}{r}- \\
11 \\
4,075 \\
-\end{array}$ & $\begin{array}{r}- \\
11 \\
4,075 \\
-\end{array}$ & $\begin{array}{r}0 \% \\
100 \%\end{array}$ \\
\hline TOTAL SUPPLY & - & - & - & - & - & - & - & 4,086 & $4.08 \epsilon$ & \\
\hline
\end{tabular}

NET IM PORTS

OP REGION

13,824

1,400

27,931

9,458

24,637

26,594

$5,151 \quad 108,997$

(1)

\section{NOTES:}
TRAASPORMETION LOSS POR
TRAYSFORMATI ON LOSS PO
TRAESPORHATI OY LOSS FOB
EL XTRICITY GEN.
$=74.68 \%$
DEODOCTS $=0.0 \%$
SY YTHETICS
$=0.0 \%$
$=0.0 \%$ 


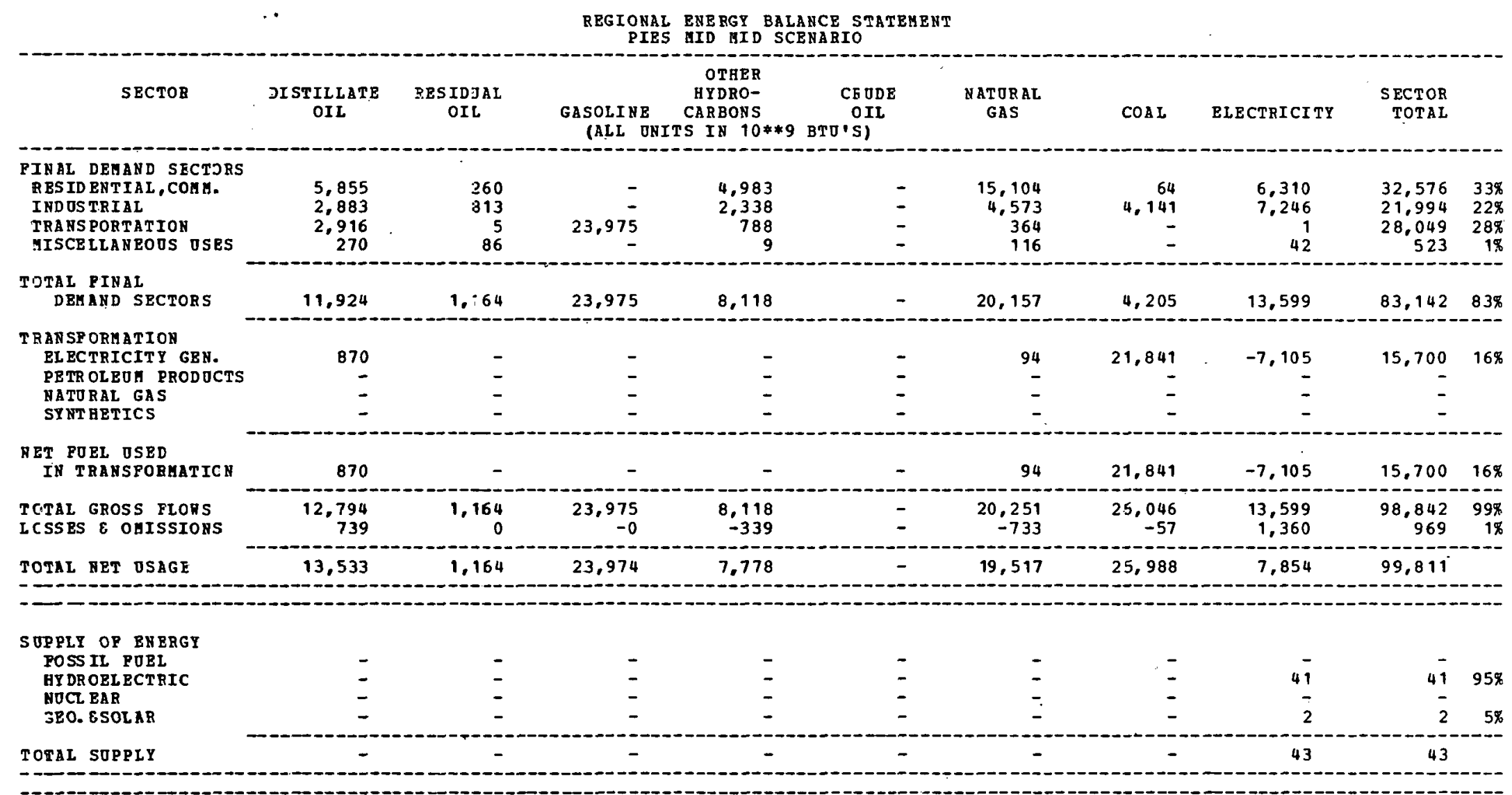

NET IU PORTS
OP RBGION


REGIONál EFE FGY BALANCE STATEMENT

PIES MID IID SCENARIO

\begin{tabular}{|c|c|c|c|c|c|c|c|c|c|c|}
\hline SECTOR & $\begin{array}{c}\text { DISJIL1ATE } \\
\text { OII }\end{array}$ & $\begin{array}{l}\text { RESIDUA: } \\
\text { OIL }\end{array}$ & $\begin{array}{l}\text { GASOLINE } \\
\text { (ALL O }\end{array}$ & $\begin{array}{c}\text { OTIER } \\
\text { GYDRO- } \\
\text { CLRBJNS } \\
\text { TS IN 10*\#9 }\end{array}$ & $\begin{array}{c}\text { CR EDE } \\
\text { OIL } \\
\text { BTO'S) }\end{array}$ & $\begin{array}{l}\text { NATORAI } \\
\text { GAS }\end{array}$ & $\operatorname{COAL}$ & ELECTRICITY & $\begin{array}{l}\text { SECTOR } \\
\text { TOTAL }\end{array}$ & \\
\hline $\begin{array}{l}\text { ZINAL DEMAND SECTORS } \\
\text { RESID ENTIAL, COHA. } \\
\text { INDUSTRIAL } \\
\text { TRANSPORTATION } \\
\text { MISCB LLABEOUS OSES }\end{array}$ & $\begin{array}{r}14,708 \\
5,578 \\
4.340 \\
153\end{array}$ & $\begin{array}{r}2,849 \\
2,848 \\
15 \\
262\end{array}$ & $35,5 \in \overline{0}$ & $\begin{array}{r}6.353 \\
5.261 \\
830 \\
11\end{array}$ & $\begin{array}{l}\overline{-} \\
\overline{-}\end{array}$ & $\begin{array}{r}28,047 \\
5,729 \\
471 \\
271\end{array}$ & $\begin{array}{r}229 \\
13,726 \\
- \\
-\end{array}$ & $\begin{array}{r}10,184 \\
11,136 \\
5 \\
90\end{array}$ & $\begin{array}{r}62,570 \\
44,278 \\
41,221 \\
1,087\end{array}$ & $\begin{array}{r}38 \% \\
27 \% \\
25 \% \\
1 \%\end{array}$ \\
\hline $\begin{array}{l}\text { TOTAL FINAL } \\
\text { DEMAND SECTORS }\end{array}$ & 25,279 & 5,974 & 35,560 & 12,455 & - & $34,5.13$ & 13,955 & 21,415 & 149,156 & ऽ $1 x$ \\
\hline $\begin{array}{l}\text { TRANSPORHATION } \\
\text { ELECTRICITI "GEA. } \\
\text { PETROLEOH ERODOCTS } \\
\text { NATORAL GAE } \\
\text { ST NTHETICS }\end{array}$ & $\begin{array}{r}3,319 \\
= \\
=\end{array}$ & $\begin{array}{r}1,033 \\
- \\
-\end{array}$ & $\begin{array}{l}\bar{z} \\
\overline{-}\end{array}$ & $\bar{z}$ & $\begin{array}{l}- \\
\overline{-}\end{array}$ & $\begin{array}{r}463 \\
- \\
-\end{array}$ & $\begin{array}{r}15,9.35 \\
= \\
-\end{array}$ & $\begin{array}{r}-7,055 \\
- \\
-\end{array}$ & $\begin{array}{r}13,692 \\
= \\
=\end{array}$ & $8 \pi$ \\
\hline $\begin{array}{l}\text { NBT PURL OSBE } \\
\text { IN TRANSPOEHATION }\end{array}$ & 3,319 & $1,0 \vdots 3$ & - & - & - & 460 & 15,935 & $-7,055$ & 13,692 & $8 \%$ \\
\hline $\begin{array}{l}\text { TOTAL GROSS FLORS } \\
\text { LOSSES \& OMISSIONS }\end{array}$ & $\begin{array}{r}28,598 \\
1,653\end{array}$ & $\begin{array}{r}7,007 \\
0\end{array}$ & $\begin{array}{r}35,550 \\
-0\end{array}$ & $\begin{array}{r}12,455 \\
-520\end{array}$ & - & $\begin{array}{l}34,578 \\
-1,-67\end{array}$ & $\begin{array}{r}29,890 \\
-65\end{array}$ & $\begin{array}{r}21,415 \\
2,141\end{array}$ & $\begin{array}{r}162,848 \\
1,941\end{array}$ & $\begin{array}{r}99 \% \\
1 \%\end{array}$ \\
\hline TOTAL NET OSAGE & 30.251 & 7,007 & 35,559 & 11,934 & - & $33,: 10$ & 29,824 & 16,501 & 164,789 & \\
\hline $\begin{array}{l}\text { SOPPLI OP ENZRGY } \\
\text { FOSS IL POEE } \\
\text { HY DROELECTIIC } \\
\text { NDCL. RAR } \\
\text { GEO. ESOLAR }\end{array}$ & $\begin{array}{l}\bar{z} \\
\overline{-}\end{array}$ & $\bar{z}$ & $\begin{array}{l}\overline{-} \\
\overline{-}\end{array}$ & $\begin{array}{l}\overline{-} \\
-\end{array}$ & $\overline{-}$ & $\begin{array}{l}\overline{-} \\
\overline{-}\end{array}$ & $\begin{array}{l}\overline{-} \\
-\end{array}$ & $\begin{array}{r}- \\
129 \\
48.877 \\
10\end{array}$ & $\begin{array}{r}129 \\
48,877 \\
10\end{array}$ & $\begin{array}{r}05 \\
100 \pi \\
05\end{array}$ \\
\hline TOTAL SUPPLY & - & - & - & - & - & - & - & 49,016 & 49,016 & \\
\hline
\end{tabular}

\section{NET IM PORTS}

OP REGIOY

30.251

7.007

35,559

11.934

33,710

29,824

$-32,514$

115,773

NOTES:
1 TRAYSPOHMATIOY LOSS POR
TRAEISPOFATI ON IOSS PO
TRA MSPCP MATI OH LDSS FOR
EL ENTRICITY GEN.
政
NAT JRAL GAS
$=0.0 \%$ 
REGIONAL ENBRGY BALANCE STATEMENT
PIES MID MID SCENARIO

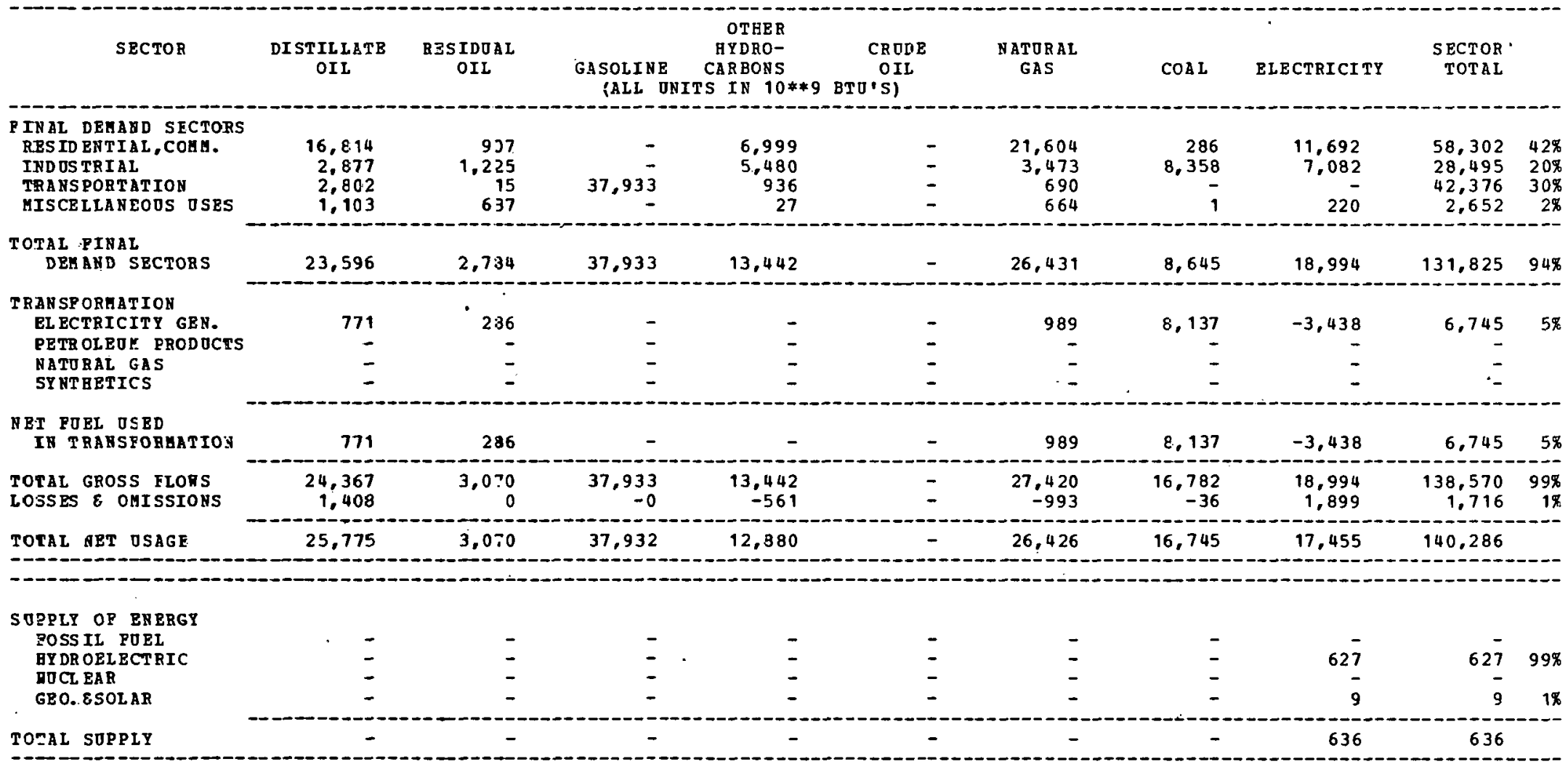

\begin{tabular}{l}
$\begin{array}{l}\text { N RT IM PORTS } \\
\text { OP REGION }\end{array}$ \\
\hline
\end{tabular}
HO TES:
TRANSFOBHATI ON LOSS POR TRAYSPORGATI ON LOSS PO
ELECTRICITY GEN.
$=66.24$
TRAYSPOPEATI Or LOSS POB
ATURAL Gas 
BEG IOHAL ENE RGY BALAICE STATEMENT

DIES EMD MID SCEVARTO

\begin{tabular}{|c|c|c|c|c|c|c|c|c|c|c|}
\hline SECEOR & $\underset{\text { OIL }}{\text { DISTILLATB }}$ & $\begin{array}{l}\text { RESIDOJLL } \\
\text { OII }\end{array}$ & $\begin{array}{l}\text { GASOLETE } \\
\text { (ALL O) }\end{array}$ & $\begin{array}{c}\text { OTHER } \\
\text { AYDRO- } \\
\text { CRR BONS } \\
\text { IS I } \quad 10 * * 9\end{array}$ & $\begin{array}{c}\text { CRODE } \\
\text { OIL } \\
\text { BTO'SI }\end{array}$ & $\begin{array}{l}\text { MATUEAL } \\
\text { GAS }\end{array}$ & COAI & ELECTRICITY & $\begin{array}{r}\text { SECTOR } \\
\text { TOTAL }\end{array}$ & \\
\hline $\begin{array}{l}\text { PINAL DEMAND SECTORS } \\
\text { RES ID ENTIAL, COBG. } \\
\text { IND OS TRIAL } \\
\text { TRAESPORTATION } \\
\text { MISCE LLANEOOS OSES }\end{array}$ & $\begin{array}{r}64.626 \\
12.804 \\
20.286 \\
1.888\end{array}$ & $\begin{array}{l}2,849 \\
8,0,09 \\
151 \\
1,092\end{array}$ & $148,53 \bar{z}$ & $\begin{array}{r}27.281 \\
44.299 \\
3.446 \\
47\end{array}$ & $\begin{array}{l}\overline{-} \\
\overline{-}\end{array}$ & $\begin{array}{r}81, * 63 \\
20,892 \\
2,521 \\
1,1 \leq 5\end{array}$ & $\begin{array}{r}1,112 \\
83,918 \\
- \\
3\end{array}$ & $\begin{array}{r}42,772 \\
32,178 \\
- \\
378\end{array}$ & $\begin{array}{r}219,803 \\
202,090 \\
174,941 \\
4,563\end{array}$ & $\begin{array}{r}30 \% \\
27 \% \\
24 \% \\
1 \%\end{array}$ \\
\hline $\begin{array}{l}\text { TOTAL PINAL } \\
\text { DEHAND SECTORS }\end{array}$ & 99.604 & 12,101 & 148,537 & 75,073 & - & 105,721 & 85,033 & 75,328 & 601,397 & $31 \%$ \\
\hline $\begin{array}{l}\text { TRAN SP ORMATION } \\
\text { EL ECTRICITY GEN. } \\
\text { PETR OLEOH IRODOCTS } \\
\text { NATURAL GAS } \\
\text { SY KT HETICS }\end{array}$ & $\begin{array}{r}4.319 \\
- \\
-\end{array}$ & $\begin{array}{l}- \\
\overline{-}\end{array}$ & $\begin{array}{l}- \\
\overline{-}\end{array}$ & $\begin{array}{l}\bar{z} \\
\bar{z}\end{array}$ & 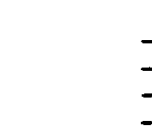 & $\begin{array}{r}1, .14 \\
- \\
-\end{array}$ & $\begin{array}{r}198,725 \\
- \\
-\end{array}$ & $\begin{array}{r}-72,936 \\
-\end{array}$ & $\begin{array}{r}131,822 \\
- \\
-\end{array}$ & $18 \%$ \\
\hline $\begin{array}{l}\text { NET POEL OSEJ } \\
\text { IN TRANSPOZMATION }\end{array}$ & 4,319 & - & - & - & - & $1,7 \cdot 4$ & 198,725 & $-72,936$ & 131.822 & $18 \%$ \\
\hline $\begin{array}{l}\text { TOTAL GROSS FLORS } \\
\text { LOSS } Z S \text { OUISSIONS }\end{array}$ & $\begin{array}{r}103,923 \\
6,008\end{array}$ & $i 2,131$ & $\begin{array}{r}148,537 \\
-0\end{array}$ & $\begin{array}{l}75,073 \\
-3,138\end{array}$ & - & $\begin{array}{r}107,435 \\
-3,8 \subseteq 1\end{array}$ & $\begin{array}{r}283,-758 \\
-\epsilon 25\end{array}$ & $\begin{array}{r}75,328 \\
7,533\end{array}$ & $\begin{array}{r}733,219 \\
5,886\end{array}$ & $\begin{array}{r}99 \% \\
1 \%\end{array}$ \\
\hline TOTAL NET OSAGE & $i 09,931$ & $\because 2,101$ & 148,536 & 71,934 & - & 103,503 & 283,132 & 9,925 & 739,105 & \\
\hline $\begin{array}{l}\text { S OPPLY OF ENERGY } \\
\text { POSS IL POEL } \\
\text { HY DROBLECTRIC } \\
\text { NOCL EAR } \\
\text { GEO. ESOLAF. }\end{array}$ & $\begin{array}{l}\overline{-} \\
\overline{-}\end{array}$ & $\begin{array}{l}\overline{-} \\
\overline{-}\end{array}$ & $\begin{array}{l}\overline{-} \\
\bar{z}\end{array}$ & $\begin{array}{l}\bar{z} \\
\overline{-}\end{array}$ & 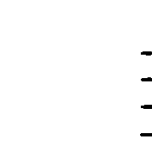 & $\begin{array}{l}\overline{-} \\
\overline{-}\end{array}$ & $\begin{array}{l}\overline{-} \\
\overline{-}\end{array}$ & $\begin{array}{r}131 \\
\overline{15}\end{array}$ & $\begin{array}{r}13 \overline{1} \\
3 \overline{5}\end{array}$ & $79 \%$ \\
\hline TOTAL SUPPLY & - & - & - & - & - & - & - & 166 & 166 & \\
\hline
\end{tabular}

NET IM PORTS

OP REGION

109.931

12,101

148,536

71,934

103,543

$283, \div 32$

9,759

738,939

NOTES:

TRA YSPORMATI ON LOSS POR

TRAYSPORMATI OH IOSS POR

TRAYSPORMATIOU IOSS POB

TRAYSPORMATIOR IOSS POR 
REGIONAL ENERGY BALANCE STATEMENT PIES MID MID SCENARI

\begin{tabular}{|c|c|c|c|c|c|c|c|c|c|c|}
\hline SECTOR & $\begin{array}{l}\text { DISTILLATE } \\
\text { OIL }\end{array}$ & $\begin{array}{l}\text { RESIDOAI } \\
\cdot \text { OIL }\end{array}$ & $\begin{array}{l}\text { GASOLINE } \\
\text { (ALL D }\end{array}$ & $\begin{array}{c}\text { OTHER } \\
\text { HYDRO- } \\
\text { CARBONS } \\
\text { TS IN } 10 * \%\end{array}$ & $\begin{array}{c}\text { CR UDE } \\
\text { OIL } \\
\text { BTO'S) }\end{array}$ & $\begin{array}{l}\text { NATORAL } \\
\text { GAS }\end{array}$ & $\operatorname{COAL}$ & ELECTRICITY & $\begin{array}{l}\text { SECTOR } \\
\text { TOTAL }\end{array}$ & \\
\hline $\begin{array}{l}\text { PIFAL DEHAND SECTOFS } \\
\text { RESIDENTIAL, CCMM. } \\
\text { INDOSTRIAL } \\
\text { TRANSPORTATION } \\
\text { MISCELLANEOOS OSES }\end{array}$ & $\begin{array}{r}28,994 \\
8,150 \\
7,376 \\
846\end{array}$ & $\begin{array}{r}1,187 \\
6,413 \\
154 \\
493\end{array}$ & $71.42 \overline{-}$ & $\begin{array}{r}12,710 \\
9,557 \\
2,155 \\
23\end{array}$ & $\begin{array}{l}- \\
\overline{-}\end{array}$ & $\begin{array}{r}42,295 \\
13,768 \\
1,355 \\
661\end{array}$ & $\begin{array}{r}452 \\
79,564 \\
- \\
1\end{array}$ & $\begin{array}{r}18,991 \\
31,125 \\
- \\
180\end{array}$ & $\begin{array}{r}104,629 \\
148,582 \\
82,468 \\
2,201\end{array}$ & $\begin{array}{l}28 \% \\
39 \% \\
22 \% \\
1 \%\end{array}$ \\
\hline $\begin{array}{l}\text { TOTAL FINAL } \\
\text { DEMAND SECTORS }\end{array}$ & 45,366 & 8,249 & 79,428 & 24,445 & - & 58,079 & 80,017 & 50,296 & 337,880 & $90 \%$ \\
\hline $\begin{array}{l}\text { TP.ANSPORMATION } \\
\text { EL ECTRICITY GEN. } \\
\text { PETROLOUM FRODOCTS } \\
\text { NATURAL GAS } \\
\text { SY NTHETICS }\end{array}$ & $\begin{array}{r}2,650 \\
- \\
-\end{array}$ & $\begin{array}{r}1,034 \\
= \\
-\end{array}$ & $\begin{array}{l}- \\
- \\
-\end{array}$ & $\begin{array}{l}- \\
\overline{-} \\
-\end{array}$ & $\begin{array}{l}- \\
\\
-\end{array}$ & $\begin{array}{r}1,086 \\
= \\
-\end{array}$ & $\begin{array}{r}47,514 \\
- \\
= \\
-\end{array}$ & $\begin{array}{r}-18,339 \\
- \\
-\end{array}$ & $\begin{array}{r}33,945 \\
- \\
- \\
-\end{array}$ & 9\% \\
\hline $\begin{array}{l}\text { NET POEL OSED } \\
\text { IN TRANSCORMATION }\end{array}$ & 2,650 & 1,036 & - & - & - & 1,086 & 47,514 & $-18,339$ & 33,945 & $9 \%$ \\
\hline $\begin{array}{l}\text { TOTAL GROSS FLOHS } \\
\text { LOSSES } \& \text { OHISSIONS }\end{array}$ & $\begin{array}{r}48,016 \\
2,775\end{array}$ & 9,283 & $\begin{array}{r}71,428 \\
-0\end{array}$ & $\begin{array}{r}24,445 \\
-1,021\end{array}$ & $\overline{-}$ & $\begin{array}{l}59,165 \\
-2,143\end{array}$ & $\begin{array}{r}127,531 \\
-280\end{array}$ & $\begin{array}{r}50,296 \\
5,030\end{array}$ & $\begin{array}{r}371,825 \\
4,360\end{array}$ & $\begin{array}{r}99 \% \\
1 \%\end{array}$ \\
\hline TOTAL NET OSAGE & 50,791 & $9,28=$ & 71,427 & 23,423 & - & 57,021 & 127,250 & 36,987 & 376,185 & \\
\hline
\end{tabular}

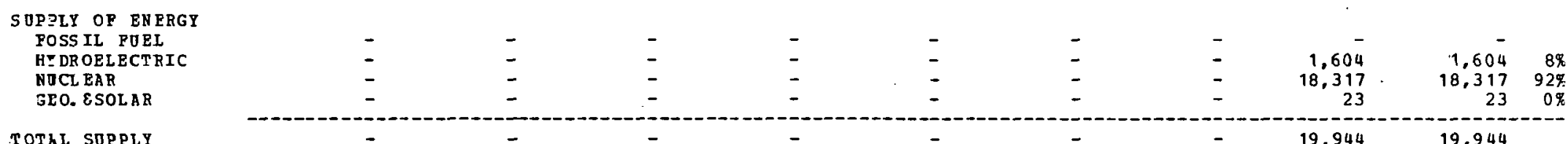

TOTAL SOPPL

19,944

\section{NET IM PORTS}

50,791

9,283

71,427

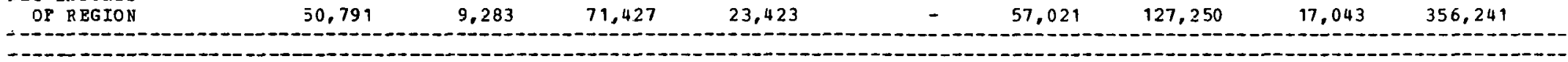

57,021

127,250

17,043

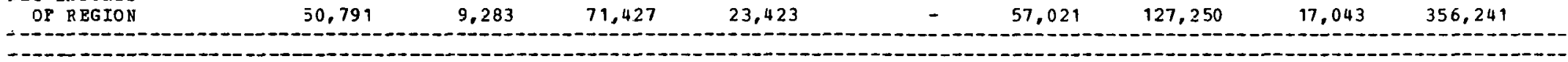

NOTES:

TRANSFORHATION LOSS POH TRANSFOR UATION LOSS FOA TRANSPORMATION LOSS PO TRANSPORMATION LOSS POA 
REGI JHAL ENERGY BALANCE STATEMENT

?IES MID HID .SCENRRIO

\begin{tabular}{|c|c|c|c|c|c|c|c|c|c|c|}
\hline SECTJR & $\begin{array}{l}\text { DISTILLATE } \\
\text { OIL }\end{array}$ & $\begin{array}{l}\text { RES IDUAL } \\
\text { GIL }\end{array}$ & $\begin{array}{l}\text { GASOLIN } \\
\text { (ALL JUIT }\end{array}$ & $\begin{array}{c}\text { OT:IER } \\
\text { HYDZO- } \\
\text { CAFBONS } \\
\text { PS IN } 10 * * 9\end{array}$ & $\begin{array}{l}\text { CR DDE } \\
\text { OIL } \\
\text { ETO'S) }\end{array}$ & $\begin{array}{l}\text { NATUR } 2 . I \\
\text { GAS }\end{array}$ & $\operatorname{COA} L$ & ELECTRICITY & $\begin{array}{l}\text { SECTOR } \\
\text { TOTAL }\end{array}$ & \\
\hline $\begin{array}{l}\text { FINAL DEHAND SECTORS } \\
\text { RESIDERTIAL, COHM. } \\
\text { INDUS TRIAL } \\
\text { TRANSPORTATION } \\
\text { MISCELLABEOUS OSES }\end{array}$ & $\begin{array}{r}12,633 \\
2,835 \\
4,164 \\
456\end{array}$ & $\begin{array}{r}562 \\
2,193 \\
39 \\
263\end{array}$ & $29.01 \overline{-}$ & $\begin{array}{l}5,321 \\
1.261 \\
1.310 \\
11\end{array}$ & $\begin{array}{l}- \\
\overline{-}\end{array}$ & $\begin{array}{r}15,621 \\
4,451 \\
95 E \\
275\end{array}$ & $\begin{array}{r}216 \\
23,47 \\
- \\
1\end{array}$ & $\begin{array}{r}8,145 \\
12,207 \\
- \\
91\end{array}$ & $\begin{array}{r}42,498 \\
46,434 \\
35,487 \\
1,097\end{array}$ & $\begin{array}{r}25 \% \\
29 \% \\
2.2 \% \\
1 \%\end{array}$ \\
\hline $\begin{array}{l}\text { TOTAL PINAL } \\
\text { DEMAND SECTORS }\end{array}$ & 20,088 & 3,047 & $29,01.6$ & 7,903 & - & $21,3 \geq 3$ & 23,654 & 20.443 & 725,516 & $78 \%$ \\
\hline $\begin{array}{l}\text { TRANSF ORHATICA } \\
\text { EL ECTRICITY GEN. } \\
\text { PETR OLBOH EMODOCTS } \\
\text { NATURAL GAS } \\
\text { SYNT HETICS }\end{array}$ & $\begin{array}{r}934 \\
- \\
-\end{array}$ & $\begin{array}{l}\overline{-} \\
\overline{-}\end{array}$ & $\begin{array}{l}- \\
- \\
-\end{array}$ & $\begin{array}{l}- \\
- \\
-\end{array}$ & $\begin{array}{l}- \\
- \\
-\end{array}$ & $\begin{array}{r}445 \\
- \\
-\end{array}$ & $\begin{array}{r}50,372 \\
- \\
-\end{array}$ & $\begin{array}{r}-18,442 \\
- \\
-\end{array}$ & $\begin{array}{r}33,309 \\
- \\
- \\
-\end{array}$ & $21 \%$ \\
\hline $\begin{array}{l}\text { NET FJEL OSED } \\
\text { IN TRANSFOEHATION }\end{array}$ & 934 & - & - & - & - & 445 & $50,3^{72}$ & $-18,442$ & 33,309 & $21 \%$ \\
\hline $\begin{array}{l}\text { TOTAL GROSS FLOHS } \\
\text { LOSSES E OUISSTONS }\end{array}$ & $\begin{array}{r}21,022 \\
1,215\end{array}$ & $\begin{array}{r}3,049 \\
0\end{array}$ & $\begin{array}{r}29,0 \text { i } \epsilon \\
-G\end{array}$ & $\begin{array}{r}7,903 \\
-330\end{array}$ & - & $\begin{array}{r}21,768 \\
-788\end{array}$ & $\begin{array}{r}74,066 \\
-163\end{array}$ & $\begin{array}{r}20.443 \\
2.044\end{array}$ & $\begin{array}{r}158,825 \\
1,977\end{array}$ & $\begin{array}{r}99 \% \\
1 \%\end{array}$ \\
\hline TOTAL NET USIGE & 22.237 & 3,049 & $29,0: 5$ & 7,572 & - & 20,977 & 73,902 & 4.045 & 160,802 & \\
\hline $\begin{array}{l}\text { S OPPLY OP EN TRGY } \\
\text { POSS IL POZE } \\
\text { HYDR OELECT EIC } \\
\text { NOCI EAR } \\
\text { GEO. ESOLAR }\end{array}$ & $\begin{array}{l}- \\
- \\
-\end{array}$ & $\begin{array}{l}- \\
-\end{array}$ & $\begin{array}{l}- \\
-\end{array}$ & $\begin{array}{l}\overline{-} \\
-\end{array}$ & $\begin{array}{l}\overline{-} \\
\overline{-}\end{array}$ & $\begin{array}{l}- \\
-\end{array}$ & $\begin{array}{l}- \\
-\end{array}$ & $\begin{array}{r}47 \overline{7} \\
\overline{9}\end{array}$ & $\begin{array}{r}47 \overline{7} \\
\overline{9}\end{array}$ & $98 \%$ \\
\hline TOTAL SUPPLY & - & - & - & - & - & - & - & 486 & 486 & \\
\hline
\end{tabular}

\section{NET IM PORTS}

22,237

$3,0<9$

29,015

7,572

$20, \subseteq 79$

73,902

3,559

160,316

MOTES: TRANSPORMAMION LOSS FOF
TRANSFORYATION LOSS FOR TRANSPOR YATI ON LESS FOR TRANSPOR YATI ON LISS POP 
REGIONAL ENERGY BALANCE STATEMENT

PIES MID MID SCENARIO

\begin{tabular}{|c|c|c|c|c|c|c|c|c|c|c|}
\hline SECTOR & $\begin{array}{l}\text { IISTILLATE } \\
\text { OIL }\end{array}$ & $\begin{array}{l}\text { BESIDCAL } \\
\text { OII. }\end{array}$ & $\begin{array}{l}\text { GASOLINE } \\
\text { GALL }\end{array}$ & $\begin{array}{c}\text { OTHER } \\
\text { HYDRO- } \\
\text { CARBONS } \\
\text { TS IN 10**9 }\end{array}$ & $\begin{array}{c}\text { CRODE } \\
\text { OIL } \\
\text { ETO'SI }\end{array}$ & $\begin{array}{l}\text { NATURAL } \\
\text { GAS }\end{array}$ & $\mathrm{COAL}$ & BLECTRICITY & $\begin{array}{r}\text { SECTOR } \\
\text { TOTAL }\end{array}$ & \\
\hline $\begin{array}{l}\text { PINAL DEMAND SECTORS } \\
\text { RESIDENTIAL, COMM. } \\
\text { ZNDOSTRIAI } \\
\text { ORANS PORTATION } \\
\text { GISCE LLANEOOS OSES }\end{array}$ & $\begin{array}{r}11,985 \\
10,434 \\
2,920 \\
437\end{array}$ & $\begin{array}{r}613 \\
6.417 \\
130 \\
253\end{array}$ & $30.21 \frac{-}{-}$ & $\begin{array}{r}4,974 \\
5,236 \\
2,552 \\
13\end{array}$ & - & $\begin{array}{r}15,408 \\
5,668 \\
1,341 \\
304\end{array}$ & $\begin{array}{r}112 \\
14,146 \\
- \\
-\end{array}$ & $\begin{array}{r}6,814 \\
11,044 \\
- \\
92\end{array}$ & $\begin{array}{r}39,906 \\
52,939 \\
37,159 \\
1,099\end{array}$ & $\begin{array}{l}22 \% \\
29 \% \\
20 \% \\
1 \%\end{array}$ \\
\hline $\begin{array}{l}\text { TOTAL PINAL } \\
\text { DEMAND SECTORS }\end{array}$ & 25,776 & 7,407 & 30,216 & 12,775 & - & 22,721 & 14,258 & 17,950 & 131,103 & $72 \%$ \\
\hline $\begin{array}{l}\text { TBANSP ORMATION } \\
\text { EL ECTRICITY GEN. } \\
\text { PETR OLEUM PRODOCTS } \\
\text { NATORAL GAS } \\
\text { SY NT HETICS }\end{array}$ & $\begin{array}{r}338 \\
-36,090 \\
- \\
-\end{array}$ & $\begin{array}{r}4,117 \\
-15,444 \\
- \\
-\end{array}$ & $\begin{array}{r}-66.789 \\
-\end{array}$ & $\begin{array}{r}-31.002 \\
- \\
-\end{array}$ & $\begin{array}{r}143,301 \\
- \\
-\end{array}$ & $\begin{array}{r}386 \\
7,223 \\
- \\
-\end{array}$ & $\begin{array}{r}57,975 \\
- \\
- \\
-\end{array}$ & $\begin{array}{r}-22,316 \\
- \\
-\end{array}$ & $\begin{array}{r}41,000 \\
1,199 \\
- \\
-\end{array}$ & $\begin{array}{r}23 \% \\
1 \%\end{array}$ \\
\hline $\begin{array}{l}\text { NET FOEL OSED } \\
\text { IN TRANSORMATION }\end{array}$ & $-35,252$ & $-11,327$ & $-6 \in, 789$ & $-31,002$ & 143,301 & 7,609 & 57.975 & $-22,316$ & 42,199 & $23 \%$ \\
\hline $\begin{array}{l}\text { TOTAL GROSS FLONS } \\
\text { LOSSES } \varepsilon \text { OMISSIONS }\end{array}$ & $\begin{array}{r}26,614 \\
1,538\end{array}$ & $\begin{array}{r}11,524 \\
0\end{array}$ & $\begin{array}{r}30,216 \\
-0\end{array}$ & $\begin{array}{r}12,775 \\
-534\end{array}$ & $\begin{array}{r}143,301 \\
7,753\end{array}$ & $\begin{array}{r}30,330 \\
-1,098\end{array}$ & $\begin{array}{r}72,233 \\
-159\end{array}$ & $\begin{array}{r}17,950 \\
1,795\end{array}$ & $\begin{array}{r}173,302 \\
8,696\end{array}$ & $\begin{array}{r}95 \% \\
5 \%\end{array}$ \\
\hline TOTAL NET OSAGE & $-7,937$ & $-3,920$ & $-36,573$ & $-18,761$ & 150,454 & 29,232 & 72,073 & $-2,570$ & 181,998 & \\
\hline
\end{tabular}

S TPPLY OP ENERGY
POSS IL PDEL
HYDRELECTRIC
NOCL EAR
GEOESOLAR

\begin{tabular}{l} 
YET IM PORTS \\
OP REGION \\
\hline
\end{tabular}


REGICNAL ENEBGY BALANCE STATEMETT

ENALS ENE BGY BALANCE
EIES MED HID SCENARIO

\begin{tabular}{|c|c|c|c|c|c|c|c|c|c|c|}
\hline SECTOR & $\begin{array}{l}\text { DISTILLATE } \\
\text { OIL }\end{array}$ & $\begin{array}{l}\text { RESIDUAL } \\
\text { JIL }\end{array}$ & $\begin{array}{l}\text { GASOLILE } \\
\text { (ALL U }\end{array}$ & $\begin{array}{c}\text { OTHER } \\
\text { AYLRO- } \\
\text { CAREONS } \\
\text { TS IY } 10 * * 9\end{array}$ & $\begin{array}{c}\text { CRODE } \\
\text { OILL } \\
\text { BTO'SI }\end{array}$ & $\begin{array}{l}\text { NATURAE } \\
\text { GAS }\end{array}$ & $\operatorname{COF} 1$ & ELECTEICITY & $\begin{array}{r}\text { SECTOR } \\
\text { TOTAL }\end{array}$ & \\
\hline $\begin{array}{l}\text { PINAL DEMAND SECEOPS } \\
\text { RES ID ENTIAL,CCHE. } \\
\text { INDOSTRIAL } \\
\text { TRANSPORTATION } \\
\text { MISCELLANEOES OSES }\end{array}$ & $\begin{array}{r}8,720 \\
1,264 \\
2,006 \\
400\end{array}$ & $\begin{aligned} 412 \\
4 \in 0 \\
2 \leq 1 \\
2 \equiv 1\end{aligned}$ & 19,924 & $\begin{array}{r}3.661 \\
777 \\
.095 \\
10\end{array}$ & $\begin{array}{l}- \\
\overline{-} \\
\overline{-}\end{array}$ & $\begin{array}{r}10,931 \\
1.162 \\
8: 11 \\
237\end{array}$ & $\begin{array}{r}-47 \\
2, \operatorname{cis} 9 \\
- \\
1\end{array}$ & $\begin{array}{r}5,772 \\
3,589 \\
- \\
80\end{array}$ & $\begin{array}{r}29,643 \\
9,861 \\
23,857 \\
961\end{array}$ & $\begin{array}{r}44 \% \\
15 \% \\
35 \% \\
1 \%\end{array}$ \\
\hline $\begin{array}{l}\text { TOTAL PINAL } \\
\text { DEMAND SECTORS }\end{array}$ & 12,390 & $1,1 \approx 4$ & $19,92 c$ & 5,543 & - & $13,1.4 .3$ & $2,: 57$ & 9,441 & 64,322 & $95 \%$ \\
\hline $\begin{array}{l}\text { TRAN SPORHATICN } \\
\text { EL ECTRICITIM" GEM. } \\
\text { PETROLEOM ERODOCTS } \\
\text { NATURAL GA } \\
\text { SYNT HETICS }\end{array}$ & $\begin{array}{r}3,182 \\
= \\
-\end{array}$ & $=$ & $\begin{array}{l}z \\
\bar{z}\end{array}$ & $\begin{array}{l}- \\
\overline{-}\end{array}$ & $\overline{-}$ & $\begin{array}{r}203 \\
- \\
-\end{array}$ & $\begin{array}{l}- \\
\bar{z}\end{array}$ & $\begin{array}{r}-942 \\
= \\
-\end{array}$ & $\begin{array}{r}2,443 \\
- \\
-\end{array}$ & $4 \%$ \\
\hline $\begin{array}{l}\text { NET FOEL OSE[ } \\
\text { IN TRANSPOEMATION }\end{array}$ & 3,182 & - & - & - & - & 203 & - & -942 & 2,443 & $4 \%$ \\
\hline $\begin{array}{l}\text { TOTAL GROSS ELONS } \\
\text { LOSSES \& OMI } \cong \text { SIOUS }\end{array}$ & $\begin{array}{r}15,572 \\
900\end{array}$ & $1,1<4$ & $\begin{array}{r}19,924 \\
-0\end{array}$ & $\begin{array}{r}5,543 \\
-231\end{array}$ & $\overline{-}$ & $\begin{array}{r}13,346 \\
-483\end{array}$ & $\begin{array}{r}2,757 \\
-6\end{array}$ & $\begin{array}{r}9,441 \\
944\end{array}$ & $\begin{array}{r}66,765 \\
1,123\end{array}$ & $\begin{aligned} 98 \% \\
2 \%\end{aligned}$ \\
\hline TOTAL NET OSEGE & 16,472 & $1,1=4$ & 19,923 & 5,311 & - & 12,862 & 2,150 & 9,443 & 67,888 & \\
\hline $\begin{array}{l}\text { SOPPLY OP ENERGY } \\
\text { POSS IL POEL } \\
\text { HY DROELECTEIC } \\
\text { NOCL EAR } \\
\text { GEO. } E \text { SOLAR }\end{array}$ & $\begin{array}{l}\overline{-} \\
\overline{-}\end{array}$ & $\begin{array}{l}\bar{z} \\
\overline{-}\end{array}$ & $\begin{array}{l}- \\
\overline{-} \\
-\end{array}$ & $\begin{array}{l}- \\
-\end{array}$ & $\begin{array}{l}- \\
\overline{-}\end{array}$ & $\begin{array}{l}- \\
\overline{-}\end{array}$ & $\begin{array}{l}\overline{-} \\
\overline{-}\end{array}$ & $\begin{array}{r}1,706 \\
13,913 \\
4\end{array}$ & $\begin{array}{r}1,706 \\
13,913 \\
4\end{array}$ & $\begin{array}{r}11 \% \\
89 \% \\
0 \%\end{array}$ \\
\hline TOTAL SOPPLY & - & - & - & - & - & - & - & 15,623 & 15,623 & \\
\hline
\end{tabular}

-

NET IM PORTS

OP REGION

16,472

1,124

19,923

5,311

$12, \varepsilon 62$

2,150

$-6,179$

52.265

\begin{tabular}{|c|c|c|c|c|c|}
\hline HOTES: & & & & \\
\hline 1 & TRANSPORMATION & Loss & POR & ELECTRICITY & $=: 2.17 \pi$ \\
\hline 2 & TRANSFORMAZI CN & LOSS & FOR & PETROLEUH PRODOCTS & $=0.0$ \\
\hline 3 & TRANSPOR YATION & LOSS & FOR & NAT'JRAL GAS & $=0.0$ \\
\hline 4 & TRANSPORMATI ON & LOSS & POR & SYNTHETICS & 0.0 \\
\hline
\end{tabular}


REGIONAL PNE RGY BALANCE STATEMENT

\begin{tabular}{|c|c|c|c|c|c|c|c|c|c|c|}
\hline SECTOR & $\begin{array}{l}\text { DISTILLATE } \\
\text { OIL }\end{array}$ & $\begin{array}{l}\text { RESIDOAL } \\
\text { OIL }\end{array}$ & $\begin{array}{l}\text { GASOLINE } \\
\text { (ALL ONIT }\end{array}$ & $\begin{array}{c}\text { OTHER } \\
\text { HYDRO- } \\
\text { CARBONS } \\
\text { IS IN } \quad 10 * * 9\end{array}$ & $\begin{array}{l}\text { CREDE } \\
\text { OIL } \\
\text { BTUSI }\end{array}$ & $\begin{array}{l}\text { NATURAL } \\
\text { GAS }\end{array}$ & COAL & ELECTRICITY & $\begin{array}{r}\text { SECTOR } \\
\text { TOTAL }\end{array}$ & \\
\hline $\begin{array}{l}\text { PINAL DEMAMD SECTORS } \\
\text { RESID ENTIAL, COMH. } \\
\text { INDUSTRIAL } \\
\text { TRANSPORTATION } \\
\text { IIISCELLANEOOS OSES }\end{array}$ & $\begin{array}{r}9,132 \\
2,673 \\
2,122 \\
442\end{array}$ & $\begin{array}{r}430 \\
1,130 \\
38 \\
256\end{array}$ & $21,46 \overline{-}$ & $\begin{array}{r}3,812 \\
1,800 \\
1,094 \\
11\end{array}$ & $\overline{-}$ & $\begin{array}{r}11,283 \\
1,583 \\
719 \\
272\end{array}$ & $\begin{array}{r}133 \\
4,345 \\
- \\
-\end{array}$ & $\begin{array}{r}5,677 \\
5,018 \\
- \\
89\end{array}$ & $\begin{array}{r}30,467 \\
16,549 \\
25,439 \\
1,070\end{array}$ & $\begin{array}{r}29 \% \\
16 \% \\
24 \% \\
1 \%\end{array}$ \\
\hline $\begin{array}{l}\text { TOTAL PINAL } \\
\text { DEHAND SECTORS }\end{array}$ & $14,3 \in 9$ & 1,854 & 21,466 & 6,717 & - & 13,857 & 4,478 & 10.784 & 73,525 & $71 \%$ \\
\hline $\begin{array}{l}\text { TRANSPORHATION } \\
\text { ELECTRICITY GEN. } \\
\text { PETROLEOH FRODOCTS } \\
\text { NATURAL GAS } \\
\text { SY NTHETICS }\end{array}$ & $\begin{array}{r}1,602 \\
- \\
-\end{array}$ & $\begin{array}{r}191 \\
- \\
-\end{array}$ & $\begin{array}{l}- \\
- \\
-\end{array}$ & $\begin{array}{l}- \\
- \\
-\end{array}$ & $\begin{array}{l}\overline{-} \\
\overline{-}\end{array}$ & $\begin{array}{r}231 \\
- \\
-\end{array}$ & $\begin{array}{r}43.978 \\
- \\
-\end{array}$ & $\begin{array}{r}-16,344 \\
- \\
-\end{array}$ & $\begin{array}{r}29,658 \\
- \\
-\end{array}$ & $28 \%$ \\
\hline $\begin{array}{l}\text { NET POEL OSED } \\
\text { IN TRANSPORHATION }\end{array}$ & 1,602 & 191 & - & - & - & 231 & 43,978 & $-16,344$ & 29,658 & $28 \%$ \\
\hline $\begin{array}{l}\text { TOTAL GROSS FLOHS } \\
\text { LOSSES } \varepsilon \text { OVISSIONS }\end{array}$ & $\begin{array}{r}15,971 \\
923\end{array}$ & $\begin{array}{r}2,045 \\
0\end{array}$ & $\begin{array}{r}21,466 \\
-0\end{array}$ & $\begin{array}{r}6,717 \\
-280\end{array}$ & $\overline{-}$ & $\begin{array}{r}14,088 \\
-510\end{array}$ & $\begin{array}{r}48,456 \\
-106\end{array}$ & $\begin{array}{r}10,784 \\
1,078\end{array}$ & $\begin{array}{r}103,183 \\
1,104\end{array}$ & $\begin{array}{r}99 \% \\
1 \%\end{array}$ \\
\hline $\begin{array}{l}\text { S UPPLY OP ENERGY } \\
\text { POSS IL POEL } \\
\text { GY DROEL OCTRIC } \\
\text { NOCL EAR } \\
\text { GEO. ESOLAR }\end{array}$ & $\begin{array}{l}- \\
-\end{array}$ & $\begin{array}{l}\overline{-} \\
\overline{-}\end{array}$ & $\begin{array}{l}- \\
- \\
-\end{array}$ & $\begin{array}{l}- \\
\overline{-}\end{array}$ & $\begin{array}{l}- \\
\overline{-}\end{array}$ & $\begin{array}{l}\overline{-} \\
\overline{-}\end{array}$ & $\begin{array}{l}\overline{-} \\
\overline{-}\end{array}$ & $\begin{array}{r}19 \overline{6} \\
581 \\
5\end{array}$ & $\begin{array}{r}19 \bar{~} \\
581 \\
5\end{array}$ & $\begin{array}{r}25 \% \\
74 \% \\
1 \%\end{array}$ \\
\hline TOTAL SOPPLY & - & - & - & - & - & - & - & 782 & 782 & \\
\hline
\end{tabular}

-

\section{NET IM PORTS}

16,834

2,045

21,465

6,436

13,577

48,349

$-5.263$

No TES :

TRANSPORMAZI ON LOSS POR TRANSPORAA TI ON LOSS POR TRANSPORAAEON LOSS POR

ELECTRICITY GEN. 
REGTOHLL EFERSY BALAECE STATEMENT

PIES MID MID SCEEARIO

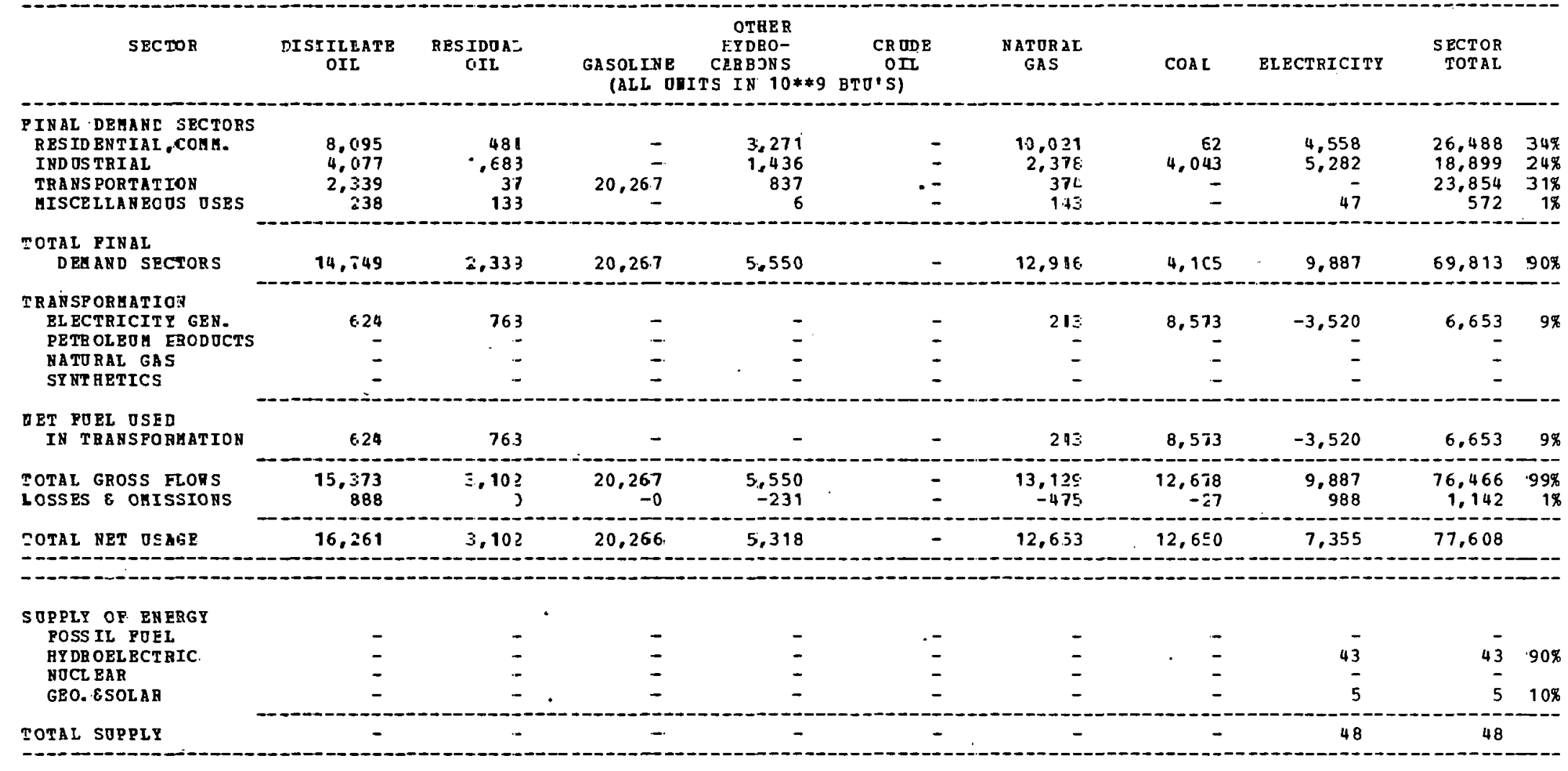

प्रET IM PORTS
OP REGION


REGIONAL ENERGY BALANCE STATEMENT
PIES MID MID SCENARID

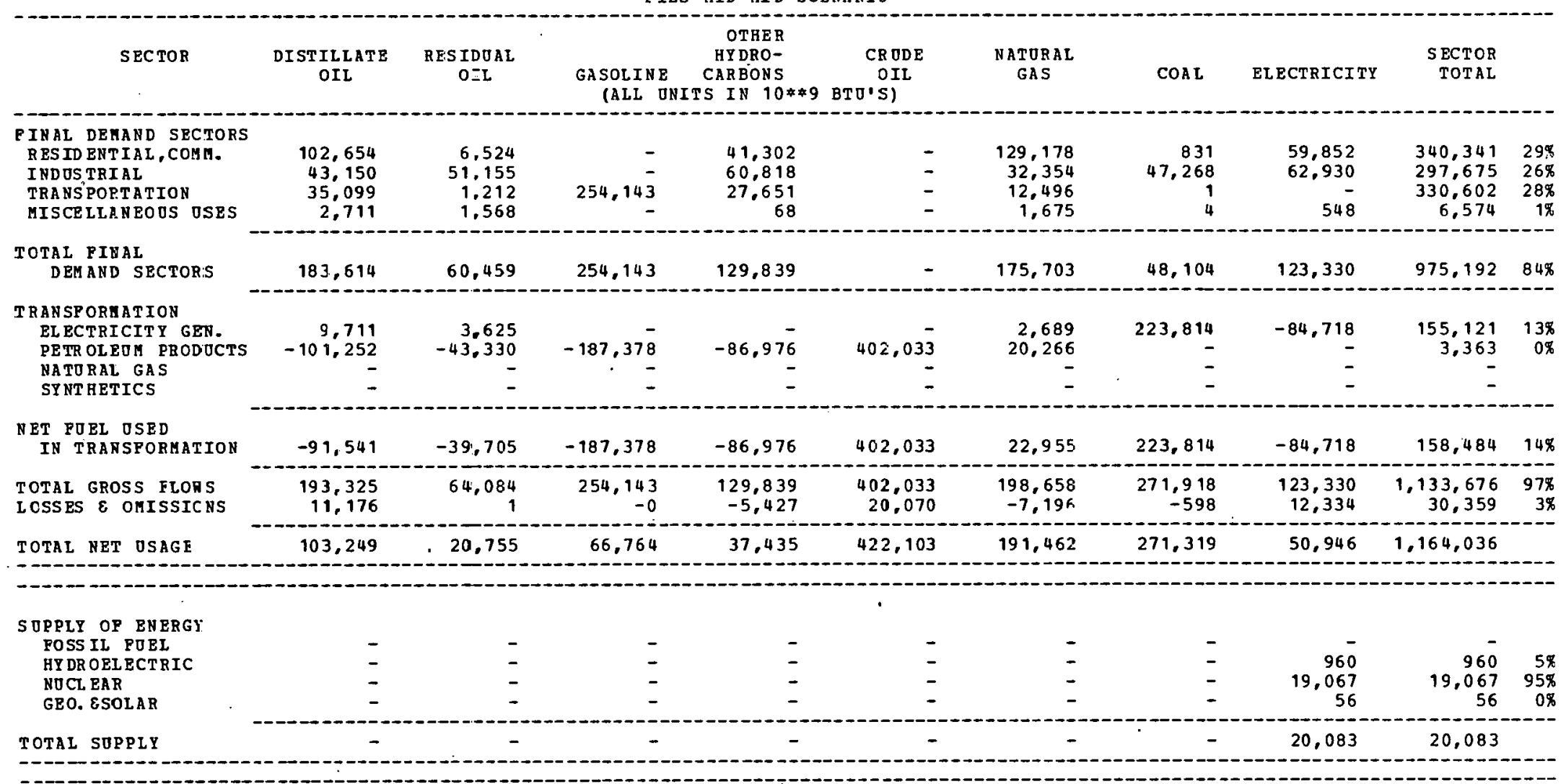

\begin{tabular}{|c|c|c|c|c|c|c|}
\hline \multicolumn{2}{|c|}{$\begin{array}{l}\text { NET IF PORTS } \\
\text { OP R BGION }\end{array}$} & \multicolumn{2}{|c|}{103,249} & 20,755 & \multicolumn{2}{|c|}{66.764} \\
\hline \multicolumn{7}{|c|}{ NoTES: } \\
\hline$i$ & TRAN SPORMATI ON & Loss & POR & EL BCTRICI 1 & Y GEN. & $=64.68$ \\
\hline 2 & TR AN SPOR MAT I ON & Loss & POR & PETROLEOM & PRODOCTS & $=0.80 \%$ \\
\hline 3 & TRAN SPOR MATION & LOS & POR & NATOZAL GA & & $=0.0$ \\
\hline 4 & TRANSPORMATI ON & Loss & POR & SYNTAETICS & & $=0.0$ \\
\hline
\end{tabular}


PEGIONAZ EYRRGY BALANCE STATEMENE

PIES MID MID SCENAFIO

\begin{tabular}{|c|c|c|c|c|c|c|c|c|c|c|}
\hline SECTOR & $\begin{array}{l}\text { DISTILLATE } \\
\text { OIL }\end{array}$ & $\begin{array}{l}\text { RESIDJAL } \\
\text { OIL }\end{array}$ & $\begin{array}{l}\text { GASOLINE } \\
\text { TALE OS }\end{array}$ & $\begin{array}{c}\text { OTHER } \\
\text { HYDRO- } \\
\text { CARBONS } \\
\text { S IN } 10 * 9\end{array}$ & $\begin{array}{c}\text { CRODZ } \\
\text { OIL } \\
\text { BTU'SI }\end{array}$ & $\begin{array}{l}\text { NATURAT. } \\
\text { SAS }\end{array}$ & $\operatorname{COAL}$ & ELECTRICITY & $\begin{array}{r}\text { SECTCR } \\
\text { TOTEL }\end{array}$ & \\
\hline $\begin{array}{l}\text { FINAL DEHARD SECTORS } \\
\text { RESIDENTIAL, COH. } \\
\text { IRD USTRIAL } \\
\text { TRANSPORTATION } \\
\text { IISCELLA HEOUS USES }\end{array}$ & $\begin{array}{l}5,685 \\
2,509 \\
5,150 \\
432\end{array}$ & $\begin{array}{r}529 \\
627 \\
35 \\
182\end{array}$ & $\begin{array}{r}- \\
20,665 \\
-\end{array}$ & $\begin{array}{r}3,919 \\
984 \\
1,851 \\
20\end{array}$ & $\overline{-}$ & $\begin{array}{r}8,033 \\
664 \\
58.5 \\
245\end{array}$ & $\begin{array}{r}36 \\
6,644 \\
-\end{array}$ & $\begin{array}{r}6,268 \\
2,294 \\
123\end{array}$ & $\begin{array}{r}24,475 \\
13,722 \\
28,281 \\
1,003\end{array}$ & $\begin{array}{r}35 \% \\
20 \% \\
41 \% \\
1 \%\end{array}$ \\
\hline $\begin{array}{l}\text { TOTAL PINAL } \\
\text { DEHARD SBCTORS }\end{array}$ & 13,776 & 1,373 & $20,56.5$ & 6,774 & - & 9,523 & 6.680 & 8,685 & $67,48: 1$ & $57 \%$ \\
\hline 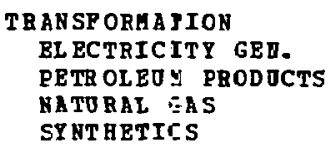 & $\begin{array}{r}407 \\
= \\
-\end{array}$ & $\begin{array}{l}- \\
-\end{array}$ & $\begin{array}{l}- \\
\overline{-}\end{array}$ & $\begin{array}{l}- \\
-\end{array}$ & $\begin{array}{l}- \\
\overline{-}\end{array}$ & $\begin{array}{r}12 \pm \\
-\end{array}$ & $\begin{array}{r}1,040 \\
- \\
-\end{array}$ & $\begin{array}{r}-476 \\
- \\
- \\
-\end{array}$ & $\begin{array}{r}1,093 \\
- \\
-\end{array}$ & 28 \\
\hline 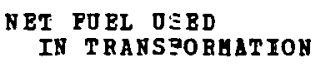 & 407 & - & - & $\dot{-}$ & - & 122 & 1.040 & -476 & 1,093 & $2 \%$ \\
\hline $\begin{array}{l}\text { TOTAL GROSS FLONS } \\
\text { LOSSES } 8 \text { OUISSIONS }\end{array}$ & $\begin{array}{r}14,183 \\
819\end{array}$ & $\begin{array}{r}1,373 \\
0\end{array}$ & $\begin{array}{r}20,665 \\
-0\end{array}$ & $\begin{array}{r}6,774 \\
-283\end{array}$ & - & $\begin{array}{r}9,650 \\
-34 \mathrm{c}\end{array}$ & $\begin{array}{r}7.720 \\
-17\end{array}$ & $\begin{array}{r}8,685 \\
868\end{array}$ & $\begin{array}{r}68,574 \\
1,038\end{array}$ & $\begin{array}{r}998 \\
1.8\end{array}$ \\
\hline TOTAL NET OSAGE & 15,002 & 1,373 & 20,664 & 6,490 & - & $9,30 \mathrm{C}$ & 7,702 & 9,077 & $69,6 i 2$ & \\
\hline $\begin{array}{l}\text { S OPPLY OP ENERGY } \\
\text { POSS IL PCEL } \\
\text { HYDR OELECTRIC } \\
\text { BDCL EAR } \\
\text { G30. ESOLAR }\end{array}$ & $\begin{array}{l}- \\
\overline{-}\end{array}$ & $\begin{array}{l}- \\
-\end{array}$ & $\begin{array}{l}- \\
\overline{-}\end{array}$ & $\begin{array}{l}- \\
\bar{z}\end{array}$ & $\begin{array}{l}- \\
- \\
-\end{array}$ & $\begin{array}{l}\bar{z} \\
\bar{z}\end{array}$ & $\begin{array}{l}- \\
- \\
-\end{array}$ & $\begin{array}{r}- \\
28 \\
104 \\
5\end{array}$ & $\begin{array}{r}-\overline{2 E} \\
104 \\
E\end{array}$ & $\begin{array}{r}20 \% \\
76 \pi \\
4 \%\end{array}$ \\
\hline TOTAL SOPPLT & - & - & - & - & - & - & - & 137 & 137 & \\
\hline
\end{tabular}

RET IM PORTS
OP REGION


REGIONAL ENERGY BALANCE STATEMENT
PIES MID MID SCENAEIO

\begin{tabular}{|c|c|c|c|c|c|c|c|c|c|}
\hline SECTOR & $\begin{array}{l}\text { DISTILLATE } \\
\text { OIL }\end{array}$ & $\begin{array}{l}\text { RESIDOAL } \\
\text { OIL }\end{array}$ & $\begin{array}{l}\text { GASOLINE } \\
\text { (ALL ONIT }\end{array}$ & $\begin{array}{c}\text { OTHER } \\
\text { HYDRO- } \\
\text { CARBONS } \\
\text { TS IN } 10 * * 9\end{array}$ & $\begin{array}{c}\text { CR ODE } \\
\text { OIL } \\
\text { BTO'S) }\end{array}$ & $\begin{array}{l}\text { NATURAL } \\
\text { GAS }\end{array}$ & $\operatorname{COAL}$ & ELECTRICITY & $\begin{array}{l}\text { SECTOR } \\
\text { TOTAL }\end{array}$ \\
\hline $\begin{array}{l}\text { PINAL DEMAND SECTORS } \\
\text { RESIDENTIAL, CCMM. } \\
\text { IND OSTFIAL } \\
\text { TRANSPORTATION } \\
\text { MISCELIANEOOS JSES }\end{array}$ & $\begin{array}{r}2,874 \\
2,511 \\
4,412 \\
350\end{array}$ & $\begin{array}{r}399 \\
1,229 \\
3 \\
124\end{array}$ & $15.49 \overline{-}$ & $\begin{array}{r}3,212 \\
1,079 \\
1,650 \\
20\end{array}$ & $\begin{array}{l}- \\
- \\
-\end{array}$ & $\begin{array}{r}6,018 \\
6,041 \\
324 \\
194\end{array}$ & $\begin{array}{r}15 \\
3,778 \\
- \\
-\end{array}$ & $\begin{array}{r}5,555 \\
4,091 \\
-\overline{2}\end{array}$ & $\begin{array}{r}18,073 \\
18,729 \\
21,879 \\
800\end{array}$ \\
\hline $\begin{array}{l}\text { TOTAL PINAL } \\
\text { DEMAND SECTORS }\end{array}$ & 10,147 & 1,755 & 15,490 & 5,961 & - & 12,577 & 3,793 & 9,758 & 59,481 \\
\hline $\begin{array}{l}\text { TRANSP ORHATION } \\
\text { EL ECTRICITY GEN. } \\
\text { PETR OLEUM FRODOCTS } \\
\text { NATURAL GAS } \\
\text { SY NT HETICS }\end{array}$ & $\begin{array}{r}361 \\
-4.026 \\
-\end{array}$ & $\begin{array}{r}-1.523 \\
- \\
-\end{array}$ & $\begin{array}{r}-7.030 \\
-\end{array}$ & $\begin{array}{r}-3,168 \\
- \\
-\end{array}$ & $\begin{array}{r}15.07 \overline{-} \\
\overline{-}\end{array}$ & $\begin{array}{r}110 \\
825 \\
- \\
-\end{array}$ & $\begin{array}{r}42,407 \\
- \\
- \\
-\end{array}$ & $\begin{array}{r}-13,369 \\
- \\
-\end{array}$ & $\begin{array}{r}29,509 \\
152 \\
- \\
-\end{array}$ \\
\hline $\begin{array}{l}\text { NET FOEL OSED } \\
\text { IN TRAYSPORHATION }\end{array}$ & $-3,665$ & $-1,523$ & $-7,030$ & $-3,168$ & 15,076 & 935 & 42,407 & $-13,369$ & 29,661 \\
\hline $\begin{array}{l}\text { TOTAL GROSS FLORS } \\
\text { LOSSES } 8 \text { OMISSIONS }\end{array}$ & $\begin{array}{r}10,508 \\
607\end{array}$ & $\begin{array}{r}1,755 \\
0\end{array}$ & $\begin{array}{r}15,490 \\
-0\end{array}$ & $\begin{array}{r}5,961 \\
-249\end{array}$ & $\begin{array}{r}15,076 \\
752\end{array}$ & $\begin{array}{r}13,512 \\
-489\end{array}$ & $\begin{array}{r}46,200 \\
-101\end{array}$ & $\begin{array}{r}9,758 \\
975\end{array}$ & $\begin{array}{r}89,142 \\
1,495\end{array}$ \\
\hline
\end{tabular}

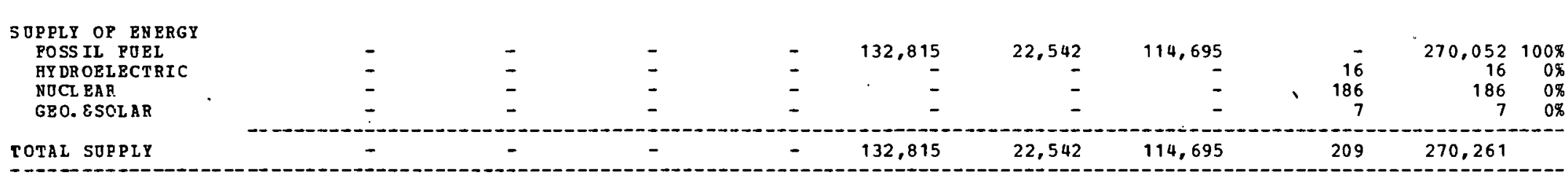

पET IM PORTS
OP R RGION


REGECNAL ENE RGY BALANCE STATEMENT
EIES MID MID SCENARIO

\begin{tabular}{|c|c|c|c|c|c|c|c|c|c|c|}
\hline SECTOR & $\begin{array}{c}\text { DISTILLATE } \\
\text { CIL }\end{array}$ & $\underset{O I E}{R E S I D N A L}$ & $\begin{array}{l}\text { GASOLIYE } \\
\text { (ALE ONIT }\end{array}$ & $\begin{array}{c}\text { OTHER } \\
\text { HZDRO- } \\
\text { CABBONS } \\
\text { IS IN } 10 * 9\end{array}$ & $\begin{array}{c}\text { CRODE } \\
\text { OIL } \\
\text { BTOSS) }\end{array}$ & $\begin{array}{l}\text { FATLRAL } \\
\text { GRS }\end{array}$ & $\cos 12$ & ELECTRICITY & $\begin{array}{l}\text { SECTOR } \\
\text { TOTAL }\end{array}$ & \\
\hline $\begin{array}{l}\text { PINAL DEHAND SECTORS } \\
\text { RESID ENTIAI, COHM. } \\
\text { IND OS TRIAL } \\
\text { TRANSPORTATION } \\
\text { MISCELLANEOOS USES }\end{array}$ & $\begin{array}{r}\square .243 \\
\therefore .999 \\
1 L .220 \\
624\end{array}$ & $\begin{array}{r}+31 \\
1.343 \\
116 \\
221\end{array}$ & $\begin{array}{r}- \\
- \\
-\end{array}$ & $\begin{array}{r}4,038 \\
6,856 \\
1,686 \\
31\end{array}$ & $\begin{array}{l}- \\
- \\
-\end{array}$ & $\begin{array}{r}14.254 \\
9.097 \\
235 \\
352\end{array}$ & $\begin{array}{r}28 \\
15.450 \\
1 \\
-\end{array}$ & $\begin{array}{r}7,504 \\
24,808 \\
- \\
175\end{array}$ & $\begin{array}{r}28,493 \\
61,053 \\
35,519 \\
1,403\end{array}$ & $\begin{array}{r}21 \% \\
4 \in \% \\
27 \% \\
1 \%\end{array}$ \\
\hline $\begin{array}{l}\text { TOTAL PINAI } \\
\text { DEMAND SECTORS }\end{array}$ & $26 \cdot, 086$ & 2,511 & 19,260 & 12,611 & - & $23 . \subseteq 38$ & 15,479 & 32,487 & 126,472 & $95 \%$ \\
\hline $\begin{array}{l}\text { TRANSFORMATION } \\
\text { ELECTRICITY GEN. } \\
\text { PETR OLEON ERODOCTS } \\
\text { NATURAL GAS } \\
\text { SYNTHETICS }\end{array}$ & $\begin{array}{r}1,186 \\
-16,015 \\
-\end{array}$ & $\begin{array}{r}-3.025 \\
- \\
-\end{array}$ & $\begin{array}{r}-15,87 \overline{-} \\
-\end{array}$ & $\begin{array}{r}-6,77 \overline{2} \\
- \\
-\end{array}$ & $\begin{array}{r}34,015 \\
-\end{array}$ & $\begin{array}{r}317 \\
2.125 \\
-\end{array}$ & $\begin{array}{l}- \\
-\end{array}$ & $\begin{array}{r}-463 \\
- \\
- \\
-\end{array}$ & $\begin{array}{r}1.040 \\
453 \\
- \\
-\end{array}$ & $\begin{array}{l}1 \% \\
0 \%\end{array}$ \\
\hline $\begin{array}{l}\text { NET FUEI OSED } \\
\text { IN TRANSFORMATION }\end{array}$ & $-3,829$ & $-3,025$ & $-15,875$ & $-6,772$ & 34,015 & $2,44 \bar{z}$ & - & -463 & $1,49 \equiv$ & $1 \%$ \\
\hline $\begin{array}{l}\text { TOTAL GROSS FLORS } \\
\text { LCSSES } \varepsilon \text { ONISSIONS }\end{array}$ & $\begin{array}{r}21,272 \\
1,229\end{array}$ & $\begin{array}{r}2,611 \\
0\end{array}$ & $\begin{array}{r}19, z 60 \\
-0\end{array}$ & $\begin{array}{r}12,611 \\
-527\end{array}$ & $\begin{array}{r}34,015 \\
1,693\end{array}$ & $\begin{array}{r}26,38 C \\
-955\end{array}$ & $\begin{array}{r}15,479 \\
-34\end{array}$ & $\begin{array}{r}32,487 \\
3,249\end{array}$ & $\begin{array}{r}127,965 \\
4,6 \in C\end{array}$ & $\begin{array}{r}95 \% \\
4 \%\end{array}$ \\
\hline
\end{tabular}

I0

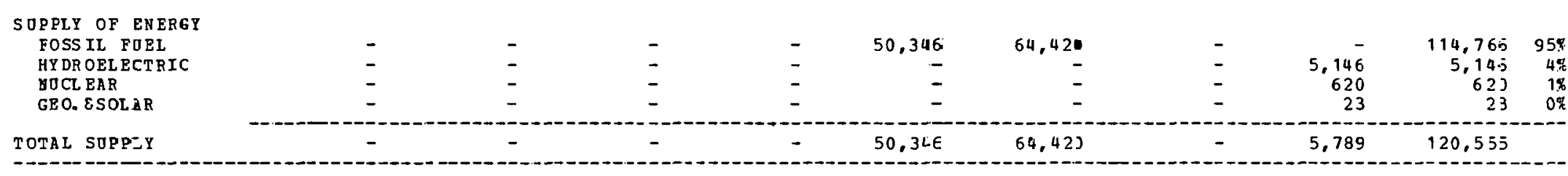

-

\section{NET IM POETS \\ OP REGION}

2,486

$-414$

$\Xi, 334$

$5,311-14,63^{\circ}$

$-33,995$

15,444

29,484

12,070

\section{NO TES:}

1 EEANSFORMATI ON LOSS FOR

2 TEANSPORMATI ON LOSS POR,

TEANSPORHATION LOJS FOR

E广ECTERICITY GEN

GEN. $=69 \ldots 15 \%$

TRANSPORMATIOK LOSS POR

FATURAL GAS

$=0.0 \%$ 
REG IONAL ENE FGY BALANCE STATEMENT
PIES MID MID SCENARIO

\begin{tabular}{|c|c|c|c|c|c|c|c|c|c|c|}
\hline SECTOR & $\begin{array}{l}\text { DI ST ILLATE } \\
\text { OIL }\end{array}$ & $\begin{array}{l}\text { FES IDJAL } \\
\text { OII }\end{array}$ & $\begin{array}{l}\text { GASOLINE } \\
\text { (ALL ONIT }\end{array}$ & $\begin{array}{c}\text { OTHER } \\
\text { HYDRO- } \\
\text { CARBONS } \\
\text { CS IN } 10 * \$ 9\end{array}$ & $\begin{array}{c}\text { CREDE } \\
\text { OIL } \\
\text { उTO'S) }\end{array}$ & $\begin{array}{l}\text { NATORAL } \\
\text { GAS }\end{array}$ & COAL & ELECTRICITY & $\begin{array}{r}\text { SECTOR } \\
\text { TOTAL }\end{array}$ & \\
\hline $\begin{array}{l}\text { FINAL DEMAND SECTORS } \\
\text { RESIDENTIAL, CCMM. } \\
\text { IND OSTRIAL } \\
\text { TRANS PORTATION } \\
\text { MISCELLANEOOS OSES }\end{array}$ & $\begin{array}{r}3,555 \\
6,297 \\
19.172 \\
412\end{array}$ & $\begin{array}{r}796 \\
12.459 \\
164 \\
146\end{array}$ & $25,44 \overline{-}$ & $\begin{array}{r}5,112 \\
16,851 \\
2,316 \\
17\end{array}$ & $\begin{array}{l}- \\
- \\
-\end{array}$ & $\begin{array}{r}18,624 \\
15,636 \\
366 \\
147\end{array}$ & $\begin{array}{r}31 \\
3,809 \\
1 \\
-\end{array}$ & $\begin{array}{r}10,476 \\
16,667 \\
- \\
107\end{array}$ & $\begin{array}{r}38,594 \\
71,719 \\
47,459 \\
829\end{array}$ & $\begin{array}{r}16 \% \\
29 \% \\
19 \% \\
0 \%\end{array}$ \\
\hline $\begin{array}{l}\text { TOTAL FINhL } \\
\text { DEM AND SECTORS }\end{array}$ & 29,436 & 13.565 & 25,440 & 24,296 & - & 34,773 & 3.841 & 27.250 & 158,601 & $64 \pi$ \\
\hline $\begin{array}{l}\text { TRANSP ORMATION } \\
\text { ELECTRICITY GEN. } \\
\text { PETR OLEOM FRODOCTS } \\
\text { NATURAL GAS } \\
\text { SY NTHETICS }\end{array}$ & $\begin{array}{r}995 \\
-95,092 \\
- \\
-\end{array}$ & $-28,730$ & $\begin{array}{r}-150,736 \\
-\end{array}$ & $\begin{array}{r}-64.303 \\
- \\
-\end{array}$ & $\begin{array}{r}= \\
322,987 \\
-\end{array}$ & $\begin{array}{r}267 \\
20,180 \\
- \\
-\end{array}$ & $\begin{array}{r}97.030 \\
- \\
-\end{array}$ & $\begin{array}{r}-30,650 \\
- \\
-\end{array}$ & $\begin{array}{r}67,642 \\
4,306 \\
- \\
-\end{array}$ & $\begin{array}{r}27 \% \\
2 \%\end{array}$ \\
\hline $\begin{array}{l}\text { NET POEL OSED } \\
\text { IN TRANSPORHATION }\end{array}$ & $-94,097$ & $-28,730$ & $-150,736$ & $-64,303$ & 322,987 & 20,447 & 97,030 & $-30,650$ & 71,948 & $29 \%$ \\
\hline $\begin{array}{l}\text { TOTAL GROSS FLORS } \\
\text { LOSSES } \varepsilon \text { OMISSIONS }\end{array}$ & $\begin{array}{r}30,431 \\
1.759\end{array}$ & $\begin{array}{r}1.3, \leq 65 \\
0\end{array}$ & $\begin{array}{r}25,440 \\
-0\end{array}$ & $\begin{array}{l}24,296 \\
-1,015\end{array}$ & $\begin{array}{r}322,987 \\
16,124\end{array}$ & $\begin{array}{l}55,220 \\
-2,000\end{array}$ & $\begin{array}{r}100,871 \\
-222\end{array}$ & $\begin{array}{r}27,250 \\
2,725\end{array}$ & $\begin{array}{r}230,549 \\
17,370\end{array}$ & $\begin{array}{r}93 \% \\
7 \%\end{array}$ \\
\hline TOTAL NET OSAGE & $-62,902$ & $-15,165$ & $-125,296$ & $-41,022$ & 339,111 & 53,220 & 100,648 & -674 & 247,920 & \\
\hline $\begin{array}{l}\text { S OPPLY OF ENRRGY } \\
\text { FOSS IL FORI } \\
\text { HYDROEL ECTRIC } \\
\text { NOCL EAR } \\
\text { GEO. ESOLAR }\end{array}$ & $\begin{array}{l}\bar{z} \\
\overline{-}\end{array}$ & $\begin{array}{l}- \\
-\end{array}$ & $\begin{array}{l}\overline{-} \\
-\end{array}$ & $\begin{array}{l}\overline{-} \\
\overline{-}\end{array}$ & $\begin{array}{r}381,417 \\
- \\
-\end{array}$ & $\begin{array}{r}84,179 \\
- \\
-\end{array}$ & $\begin{array}{r}1,399,003 \\
- \\
-\end{array}$ & $\begin{array}{r}7,820 \\
520 \\
19\end{array}$ & $\begin{array}{r}1,864,599 \\
7,820 \\
520 \\
19\end{array}$ & $\begin{array}{r}100 \% \\
0 \% \\
0 \% \\
0 \%\end{array}$ \\
\hline TOTAL SUPPLY & - & - & - & - & 381,497 & 84,179 & $1,399,003$ & 8,359 & $1,872,958$ & \\
\hline
\end{tabular}

\section{WET IM PORTS}

OF REGION

$-62,902$

$-15,165 \quad-125,296$

$-41.022$

$-42,305$

$-30,958-1,298,354$

$-9,033-1,625,037$

\section{NoTES: \\ TRANSFORMATI ON LOSS POR BLECTRIEITY GEN, \\ PETROLEOM PRODOCTS $=68.82$ \\ TRAYSPORART ON LOSS POR \\ DOCTS $=1.25 \%$ \\ TRANSPORMATI ON LOSS POR \\ NATURAL GA


REGIONAL ENE BGY BALANCE STATEMENT

PIES IID MID SCENARIO

\begin{tabular}{|c|c|c|c|c|c|c|c|c|c|c|}
\hline SECTOR & $\underset{\text { OIL }}{\text { DI STILE ATE }}$ & $\begin{array}{l}\text { RESIDJLLL } \\
\text { OIL }\end{array}$ & $\begin{array}{l}\text { GASOLIN) } \\
\text { (ALE }\end{array}$ & $\begin{array}{l}\text { OTHER } \\
\text { HYDRO- } \\
\text { CAR ZONS } \\
\text { SIT } 10 * \$ 9\end{array}$ & $\begin{array}{c}\text { CRIDE } \\
\text { OIL } \\
\text { BTU'SI }\end{array}$ & $\begin{array}{l}\text { NATOFAZ } \\
\text { GAS }\end{array}$ & $\cos 6$ & ELECTRI CI TY & $\begin{array}{r}\text { SECT OR } \\
\text { TOTAL }\end{array}$ & \\
\hline $\begin{array}{l}\text { PINAL DEMAND SECTORS } \\
\text { RESID ENTIAL, COHR. } \\
\text { IND OS TRIAL } \\
\text { TRANSPORTATION } \\
\text { MISCE LLANEOTS OSES }\end{array}$ & $\begin{array}{r}2,722 \\
2,610 \\
2,661 \\
.269\end{array}$ & $\begin{array}{r}352 \\
19.552 \\
- \\
96\end{array}$ & 14,053 & $\begin{array}{r}.9 .902 \\
11.054 \\
1.130 \\
11\end{array}$ & $\begin{array}{l}- \\
-\end{array}$ & $\begin{array}{r}4,556 \\
8.22 \\
242 \\
93\end{array}$ & $\begin{array}{r}13 \\
3,819 \\
- \\
-\end{array}$ & $\begin{array}{r}4.835 \\
1,826 \\
- \\
71\end{array}$ & $\begin{array}{r}15,380 \\
39,693 \\
18,096 \\
540\end{array}$ & $\begin{array}{r}9 \% \\
24 \% \\
11 \% \\
0 \%\end{array}$ \\
\hline $\begin{array}{l}\text { TOTAL FINAL } \\
\text { DEHAND SECTORS }\end{array}$ & 8,262 & 20,010 & 14,063 & 15.097 & - & $5,: 13$ & 3,832 & 6,732 & 73,709 & $44 \%$ \\
\hline $\begin{array}{l}\text { TRANSF ORMATION } \\
\text { BL ECTRICITT GEN. } \\
\text { PETROLEOM इRODOCTS } \\
\text { NATORAL GAS } \\
\text { SY ITHETICS }\end{array}$ & $\begin{array}{r}249 \\
-28,286 \\
-\end{array}$ & $\begin{array}{r}-12,1, \frac{-}{5} \\
- \\
-\end{array}$ & $\begin{array}{r}-52,34 \overline{6} \\
-\end{array}$ & $\begin{array}{r}-24,297 \\
-\end{array}$ & $\begin{array}{r}112,311 \\
-\end{array}$ & $\begin{array}{r}65 \\
5,6 \epsilon 1 \\
-38,360\end{array}$ & $\begin{array}{r}68,138 \\
- \\
80,060\end{array}$ & $\begin{array}{r}-21,347 \\
- \\
-\end{array}$ & $\begin{array}{r}47,105 \\
938 \\
- \\
41.760\end{array}$ & $\begin{array}{r}28 \% \\
1 \pi\end{array}$ \\
\hline $\begin{array}{l}\text { NET FUEL OSED } \\
\text { IN TRANSFOZMATION }\end{array}$ & -28.037 & $-12,135$ & $-52,346$ & $-24,297$ & 112,311 & $-32,5: 3$ & 148,198 & $-21,347$ & 89,803 & $53 \%$ \\
\hline $\begin{array}{l}\text { TOTAL GROSS FLORS } \\
\text { LOSS } E \text { \& OMISSIONS }\end{array}$ & $\begin{array}{r}8.511 \\
492\end{array}$ & $\begin{array}{r}20,010 \\
0\end{array}$ & $\begin{array}{r}14,063 \\
-0\end{array}$ & $\begin{array}{r}15,097 \\
-631\end{array}$ & $\begin{array}{r}112,311 \\
5,606\end{array}$ & $\begin{array}{r}11,+439 \\
-4: 4\end{array}$ & $\begin{array}{r}152,630 \\
-334\end{array}$ & $\begin{array}{r}6,732 \\
673\end{array}$ & $\begin{array}{r}163,512 \\
5,392\end{array}$ & $\begin{array}{r}97 \pi \\
3 \pi\end{array}$ \\
\hline $\begin{array}{l}\text { SOPPLY OP ENERGY } \\
\text { POSS IL POEL } \\
\text { HY DR OELECTRIC } \\
\text { NDCL EAR } \\
\text { GEO. ESOLAF }\end{array}$ & $\begin{array}{l}\overline{-} \\
\overline{-}\end{array}$ & $\begin{array}{l}E \\
-\end{array}$ & $\overline{-}$ & $\begin{array}{l}- \\
- \\
-\end{array}$ & $\begin{array}{r}40,922 \\
- \\
-\end{array}$ & $\begin{array}{r}21,581 \\
= \\
-\end{array}$ & $\begin{array}{r}524,512 \\
- \\
-\end{array}$ & $\begin{array}{r}7.008 \\
.129 \\
5\end{array}$ & $\begin{array}{r}587.015 \\
7.008 \\
129 \\
5\end{array}$ & $\begin{array}{r}99 \% \\
1 \% \\
0 \% \\
0 \%\end{array}$ \\
\hline TOTAL SOPPLT & - & - & - & - & 40,922 & $21,5: 31$ & 524,512 & 7,142 & 594,157 & \\
\hline
\end{tabular}

NET IM PORTS

$-19.282$

7,905

$-38,283$

76,995

$-48,355-372,816$

$-21,083$

-

\section{NOTES:}

1 TRAUSPOAMATI OH L.OSS POR

TRA IRSPORMA TI OR I.JSS POR

TRAOSPORMATI

TRAISFORAATI ON LIOSS POR

$\begin{array}{ll}\text { EIECTRICITY GEN. } & =68.81 \% \\ \text { PE:BOLEOM PEODUCTS } & =0.80 \%\end{array}$

NATJRAL GAS

$=0.80 \%$

$=0.0 \%$
$=52.16 \%$ 
REGIONAL ENE RGY BALANCE STATEHENT

PIES MID MID SCENARIO

\begin{tabular}{|c|c|c|c|c|c|c|c|c|c|c|}
\hline SECTOR & $\begin{array}{l}\text { DISTILLATE } \\
\text { OIL }\end{array}$ & $\begin{array}{l}\text { RES IDUAL } \\
\text { OIL }\end{array}$ & $\begin{array}{l}\text { GASOLINE } \\
\text { CALL ONIT }\end{array}$ & $\begin{array}{c}\text { OTHER } \\
\text { HYDRO- } \\
\text { CARBONS } \\
\text { S IN } 10 * * 9\end{array}$ & $\begin{array}{c}\text { CPODE } \\
\text { OII } \\
\text { BTU'S) }\end{array}$ & $\begin{array}{l}\text { NATURAL } \\
\text { GAS }\end{array}$ & COAL & ELECTRICITY & $\begin{array}{l}\text { SECTOR } \\
\text { TOTAL }\end{array}$ & \\
\hline $\begin{array}{l}\text { FINAL DEHAND SBCTORS } \\
\text { RESID BNTIAL, CCMA. } \\
\text { INDUS TRIAL } \\
\text { TRA } \\
\text { GISCE LORTATION } \\
\text { GIEOUS OSES }\end{array}$ & $\begin{array}{r}8,294 \\
3,523 \\
7,141 \\
450\end{array}$ & $\begin{array}{r}795 \\
909 \\
46 \\
191\end{array}$ & $29.47 \overline{-}$ & $\begin{array}{r}5,585 \\
1,723 \\
2,097 \\
16\end{array}$ & $\begin{array}{l}- \\
\overline{-}\end{array}$ & $\begin{array}{r}11,710 \\
685 \\
691 \\
195\end{array}$ & $\begin{array}{r}52 \\
7.037 \\
-\end{array}$ & $\begin{array}{r}9,169 \\
3,539 \\
- \\
109\end{array}$ & $\begin{array}{r}35,605 \\
17.416 \\
39.448 \\
961\end{array}$ & $\begin{array}{r}35 \% \\
17 \% \\
39 \% \\
1 \%\end{array}$ \\
\hline $\begin{array}{l}\text { TOTAL PINAL } \\
\text { DEHAND SECTORS }\end{array}$ & 19,408 & 1,941 & 29.473 & 9,421 & - & 13,281 & 7,089 & 12,817 & 93,430 & $93 \%$ \\
\hline $\begin{array}{l}\text { TR ARSPORHATIOR } \\
\text { BL BCTRICITY GEN. } \\
\text { PETROLEOA PRODOCTS } \\
\text { NATURAL GAS } \\
\text { SYHTHETICS }\end{array}$ & $\begin{array}{r}641 \\
- \\
-\end{array}$ & $\begin{array}{r}636 \\
- \\
-\end{array}$ & $\begin{array}{l}- \\
-\end{array}$ & $\begin{array}{l}\overline{-} \\
\overline{-}\end{array}$ & $\begin{array}{l}\overline{-} \\
-\end{array}$ & $\begin{array}{r}180 \\
- \\
-\end{array}$ & $\begin{array}{r}6,829 \\
= \\
=\end{array}$ & $\begin{array}{r}-2,871 \\
- \\
-\end{array}$ & $\begin{array}{r}5,415 \\
- \\
-\end{array}$ & $5 \%$ \\
\hline $\begin{array}{l}\text { N ZT POEL USED } \\
\text { IN TRANSPOREATION }\end{array}$ & 641 & E 36 & - & - & - & 180 & 6,829 & $-2,871$ & 5,415 & $5 \%$ \\
\hline $\begin{array}{l}\text { TOTAL GROSS FLORS } \\
\text { LOSSES E OHISSIONS }\end{array}$ & $\begin{array}{r}20,049 \\
1,159\end{array}$ & $\begin{array}{r}2,577 \\
0\end{array}$ & $\begin{array}{r}29,473 \\
-0\end{array}$ & $\begin{array}{r}9,421 \\
-393\end{array}$ & $\overline{-}$ & $\begin{array}{r}13,461 \\
-487\end{array}$ & $\begin{array}{r}13,918 \\
-30\end{array}$ & $\begin{array}{r}12,817 \\
1,281\end{array}$ & $\begin{array}{r}98,845 \\
1,528\end{array}$ & $\begin{array}{r}98 \% \\
2 \%\end{array}$ \\
\hline TOTAL NET USAGE & 21,208 & 2,577 & 29,472 & 9,027 & - & 12,973 & 13,887 & 11,227 & 100,373 & \\
\hline
\end{tabular}

\begin{tabular}{|c|c|c|c|c|c|c|c|c|c|c|}
\hline $\begin{array}{l}\text { SOPPLY OP BNBRGI } \\
\text { FOSS IL POEL } \\
\text { HYDROELECT RIC } \\
\text { HOCL EAR } \\
\text { GEO. ESOL AR }\end{array}$ & $\bar{z}$ & $\begin{array}{l}- \\
\overline{-} \\
-\end{array}$ & $\begin{array}{l}\overline{-} \\
\overline{-}\end{array}$ & $\begin{array}{l}\overline{-} \\
\overline{-}\end{array}$ & $\begin{array}{l}- \\
\overline{-}\end{array}$ & $\begin{array}{l}\overline{-} \\
\overline{-}\end{array}$ & $\begin{array}{l}\overline{-} \\
\overline{-}\end{array}$ & $\begin{array}{r}65 \\
153 \\
8\end{array}$ & $\begin{array}{r}- \\
65 \\
153 \\
8\end{array}$ & $\begin{array}{r}29 \% \\
68 \% \\
4 \%\end{array}$ \\
\hline TOTAL SOPPLY & - & - & - & - & - & - & - & 226 & 226 & \\
\hline
\end{tabular}

\begin{tabular}{l}
$\begin{array}{l}\text { RET IH PORTS } \\
\text { OP R RGION }\end{array}$ \\
\hline
\end{tabular}


REGIONAL ENERGY BALAICE STATEMENT

PIES KIID MID SCENARIO

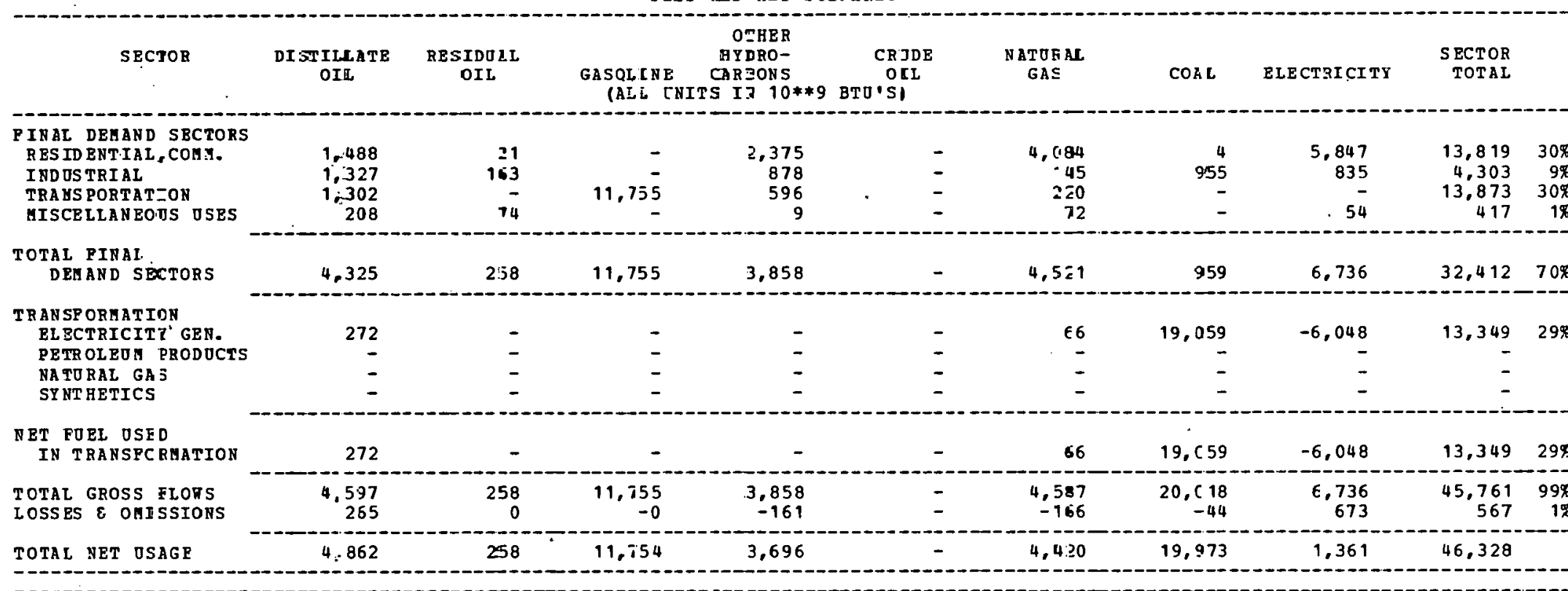

\begin{tabular}{|c|c|c|c|c|c|c|c|c|c|c|}
\hline & - & - & - & - & - & - & - & - & - & \\
\hline HY DR OEL BCERIC & - & - & - & - & - & - & - & 11 & 11 & $8 x$ \\
\hline NOCL EAR & - & - & - & - & - & - & - & 129 & 129 & 898 \\
\hline GEO. ESOLAR & - & - & - & - & - & - & - & 5 & 5 & $3 \pi$ \\
\hline TOTAL SOPPIT & - & - & - & - & - & - & - & 145 & 145 & \\
\hline
\end{tabular}

NET IM PORTS
OP REGION




\begin{tabular}{|c|c|c|c|c|c|c|c|c|c|c|}
\hline SECTOR & $\begin{array}{c}\text { DISTILLATE } \\
\text { OIL }\end{array}$ & $\begin{array}{l}\text { RESIDUAL } \\
\text { OIL }\end{array}$ & $\begin{array}{l}\text { GASOLINE } \\
\quad \text { (ALL ONI }\end{array}$ & $\begin{array}{c}\text { OTHER } \\
\text { HYDRO- } \\
\text { CARBONS } \\
\text { TS IN } 10 * \% 9\end{array}$ & $\begin{array}{l}\text { CR ODE } \\
\text { OII } \\
\text { BTO'S) }\end{array}$ & $\begin{array}{l}\text { NATORAL } \\
\text { GAS }\end{array}$ & COAL & ELECTRICITY & $\begin{array}{r}\text { SECTOR } \\
\text { TOTAL }\end{array}$ & \\
\hline $\begin{array}{l}\text { FIVAL DEHAND SECTORS } \\
\text { RIS IDENTIAL, COHA. } \\
\text { IRD OSTRIAL } \\
\text { TRANSPORTATION } \\
\text { IISCELIAEEOOS OSES }\end{array}$ & $\begin{array}{r}5,991 \\
4,747 \\
2,739 \\
401\end{array}$ & $\begin{array}{r}204 \\
1,300 \\
13 \\
156\end{array}$ & $\begin{array}{r}\overline{-} \\
30,128 \\
-\end{array}$ & $\begin{array}{r}5,310 \\
2,214 \\
939 \\
15\end{array}$ & $\bar{z}$ & $\begin{array}{r}12,281 \\
1,647 \\
366 \\
161\end{array}$ & $\begin{array}{r}32 \\
2,510 \\
- \\
-\end{array}$ & $\begin{array}{r}12,849 \\
4,261 \\
- \\
97\end{array}$ & $\begin{array}{r}37,167 \\
16,679 \\
34,185 \\
830\end{array}$ & $\begin{array}{l}41 \% \\
18 \% \\
37 \% \\
1 \%\end{array}$ \\
\hline $\begin{array}{l}\text { TOTAL PINAL } \\
\text { DEHAND SECTORS }\end{array}$ & 13,878 & $\cdot \quad 1,673$ & 30,128 & 8,978 & - & 14,455 & 2,542 & 17,207 & 88,861 & $97 \%$ \\
\hline $\begin{array}{l}\text { TRLNSPORHATION } \\
\text { FLECTRICITY GEN. } \\
\text { ERTROLBOA FBODOCTS } \\
\text { NATORAL GAS } \\
\text { SYNTHETICS }\end{array}$ & $\begin{array}{r}1.043 \\
- \\
-\end{array}$ & $\begin{array}{r}397 \\
- \\
-\end{array}$ & $\begin{array}{l}- \\
\overline{-} \\
-\end{array}$ & $\begin{array}{l}\overline{-} \\
-\end{array}$ & $\begin{array}{l}- \\
\overline{-}\end{array}$ & $\begin{array}{r}205 \\
- \\
-\end{array}$ & $\begin{array}{l}- \\
-\end{array}$ & $\begin{array}{r}-476 \\
- \\
-\end{array}$ & $\begin{array}{r}1,169 \\
- \\
-\end{array}$ & $1 \%$ \\
\hline $\begin{array}{l}\text { NBT FOEL OSED } \\
\text { IN TRABSFORHATION }\end{array}$ & 1,043 & 397 & - & - & - & 205 & - & -476 & 1,169 & 19 \\
\hline $\begin{array}{l}\text { TOTAL GROSS FLORS } \\
\text { LOSSES \& OHISSIONS }\end{array}$ & $\begin{array}{r}14,921 \\
862\end{array}$ & $\begin{array}{r}2,070 \\
10\end{array}$ & $\begin{array}{r}30,128 \\
-0 \\
\end{array}$ & $\begin{array}{r}8,978 \\
-375 \\
\end{array}$ & $\overline{-}$ & $\begin{array}{r}14,660 \\
-531\end{array}$ & $\begin{array}{r}2,542 \\
-5\end{array}$ & $\begin{array}{r}17,207 \\
1.720\end{array}$ & $\begin{array}{r}90,030 \\
1,671\end{array}$ & $\begin{array}{r}98 \% \\
2 \%\end{array}$ \\
\hline TOTAL NET OSAGE & 15,783 & 2,070 & 30,127 & 8,602 & - & 14,128 & 2,536 & 18,451 & 91,701 & \\
\hline $\begin{array}{l}\text { SOP PLY OP EHERGY } \\
\text { POSS IL POEL } \\
\text { HY DR ORL BCTRIC } \\
\text { HOCL EAR } \\
\text { GEO. ESOLAR }\end{array}$ & $\begin{array}{l}- \\
-\end{array}$ & $\overline{-}$ & $\begin{array}{l}- \\
- \\
-\end{array}$ & $=$ & $\begin{array}{l}- \\
\overline{-} \\
-\end{array}$ & I & $\bar{z}$ & $\begin{array}{r}28 \\
232 \\
11\end{array}$ & $\begin{array}{r}- \\
28 \\
232 \\
11\end{array}$ & $\begin{array}{r}10 \% \\
86 \% \\
4 \%\end{array}$ \\
\hline TOTAL SOPPLY & - & - & - & - & - & - & - & 271 & 271 & \\
\hline
\end{tabular}

-

\section{NET IM PORTS}

$2,070 \quad 30,127$

8,602

14,128

2,536

18,180

91,430

-

\section{YOTES:}

TRANSPORHATION LOSS POR TRABSPOR BATI ON LOSS PO

TRANSP OR HATION LOSS PO

EL. BCTRICITY GEN.

TRANSPORHATION LOSS POR 
REGIONAL BN $Z$ RGY BALANCE STATEMENT

PIES MID KID SCENARIO

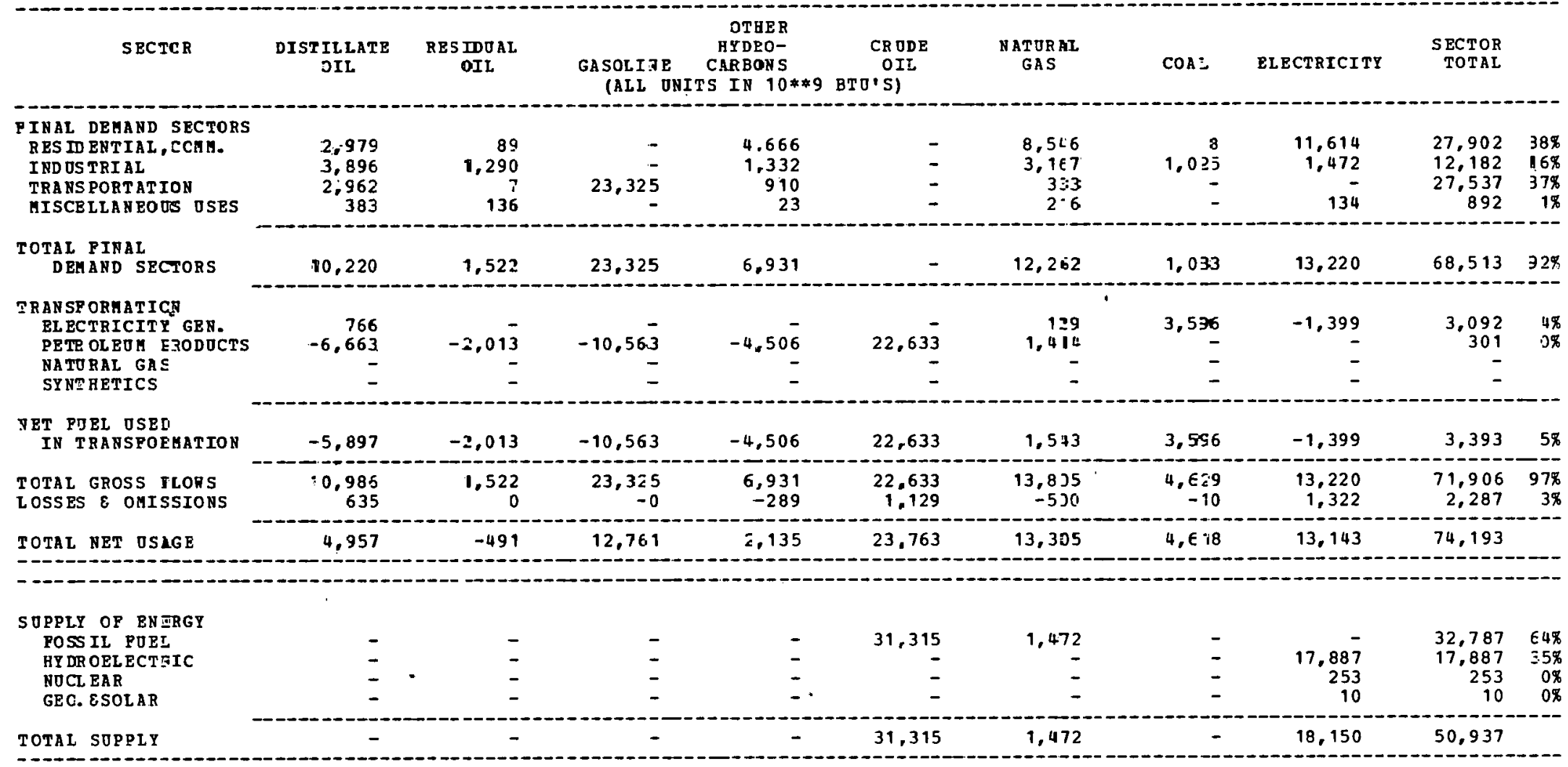

\section{NET IM PORTS}

OP REGION

4.957

$-491$

12,751

2,135

$-7,551$

$11, \varepsilon 33$

4,518

$-5,006$

23,256

nOTES:

TRANSPOR AATION LCSS POR TRANSPORMATI ON LCSS POR

TRANSPORHATI ON LCSS POB

TRANSFORMATI ON LCSS POR 
REGIONAL ENE RGY BALANCE STATEMENT

\begin{tabular}{|c|c|c|c|c|c|c|c|c|c|c|}
\hline SECTOR & $\begin{array}{l}\text { DISTILLATE } \\
\text { OIL }\end{array}$ & $\begin{array}{l}\text { RESIDJAL } \\
\text { OIL }\end{array}$ & $\begin{array}{l}\text { GASOLINE } \\
\text { (ALL ONIT }\end{array}$ & $\begin{array}{l}\text { OTHER } \\
\text { HYDRO- } \\
\text { CARBONS } \\
\text { TS IN } 10 * 49\end{array}$ & $\begin{array}{c}\text { CRODE } \\
\text { OIL } \\
\text { BTO'S) }\end{array}$ & $\begin{array}{l}\text { NATORAL } \\
\text { GAS }\end{array}$ & $\operatorname{COAL}$ & ELECTRICITY & $\begin{array}{r}\text { SECTOR } \\
\text { TOTAL }\end{array}$ & \\
\hline $\begin{array}{l}\text { PINAL DEMAND SECTORS } \\
\text { RES IDENTIAL, COMM. } \\
\text { IND OSTPIAI, } \\
\text { TRANS PORTATION } \\
\text { MISCELIANEOOS OSES }\end{array}$ & $\begin{array}{r}1,230 \\
1,046 \\
1,856 \\
87\end{array}$ & $\begin{array}{r}106 \\
296 \\
60 \\
99\end{array}$ & $8,15 \bar{z}$ & $\begin{array}{r}1,641 \\
526 \\
744 \\
3\end{array}$ & $\begin{array}{l}- \\
- \\
-\end{array}$ & $\begin{array}{r}5,205 \\
5,287 \\
188 \\
30\end{array}$ & $\begin{array}{r}13 \\
832 \\
-\end{array}$ & $\begin{array}{r}2,450 \\
1,953 \\
2 \\
13\end{array}$ & $\begin{array}{r}10,645 \\
9,940 \\
11,002 \\
152\end{array}$ & $\begin{array}{r}32 \% \\
30 \% \\
33 \% \\
0 \%\end{array}$ \\
\hline $\begin{array}{l}\text { TOTAL PINAL } \\
\text { DEHAND SECTORS }\end{array}$ & 4,219 & $4 \varepsilon, 1$ & 8,152 & 2,914 & - & 10.710 & 845 & 4,418 & 31.739 & $96 \%$ \\
\hline $\begin{array}{l}\text { TRANSPORMATION } \\
\text { EL ECTRICITY GEN. } \\
\text { PETROLEOM PRODOCTS } \\
\text { DATURAL GAS } \\
\text { SYNTEETICS }\end{array}$ & $\begin{array}{r}241 \\
-2,619 \\
- \\
-\end{array}$ & $\begin{array}{r}-1,120 \\
-\end{array}$ & $\begin{array}{r}-4,846 \\
- \\
-\end{array}$ & $\begin{array}{r}-2,249 \\
-\end{array}$ & $\begin{array}{r}- \\
10,399 \\
-\end{array}$ & $\begin{array}{r}533 \\
524 \\
- \\
-\end{array}$ & $\begin{array}{l}- \\
- \\
-\end{array}$ & $\begin{array}{r}-224 \\
- \\
-\end{array}$ & $\begin{array}{r}550 \\
87 \\
- \\
-\end{array}$ & $\begin{array}{l}2 \% \\
0 \%\end{array}$ \\
\hline $\begin{array}{l}\text { NET FOEL OSED } \\
\text { IN TRANSPORMATION }\end{array}$ & $-2,378$ & $-1,120$ & $-4,846$ & $-2,249$ & 10,399 & 1,057 & - & -224 & 637 & $2 \%$ \\
\hline $\begin{array}{l}\text { TOTAL GROSS FLORS. } \\
\text { LOSSES \& OMISSIONS }\end{array}$ & $\begin{array}{r}4,460 \\
257\end{array}$ & $\begin{array}{r}48 \hat{1} \\
3\end{array}$ & $\begin{array}{r}8,152 \\
-0\end{array}$ & $\begin{array}{r}2,914 \\
-121\end{array}$ & $\begin{aligned} 10,399 \\
519\end{aligned}$ & $\begin{array}{r}11.767 \\
-426\end{array}$ & $\begin{array}{r}845 \\
-1\end{array}$ & $\begin{array}{r}4,418 \\
441\end{array}$ & $\begin{array}{r}32,376 \\
668\end{array}$ & $\begin{array}{r}98 \% \\
2 \%\end{array}$ \\
\hline TOTAL NET OSAGE & 2,098 & -637 & 3,305 & 542 & 10,918 & 11.340 & 843 & 4,635 & 33.044 & \\
\hline
\end{tabular}

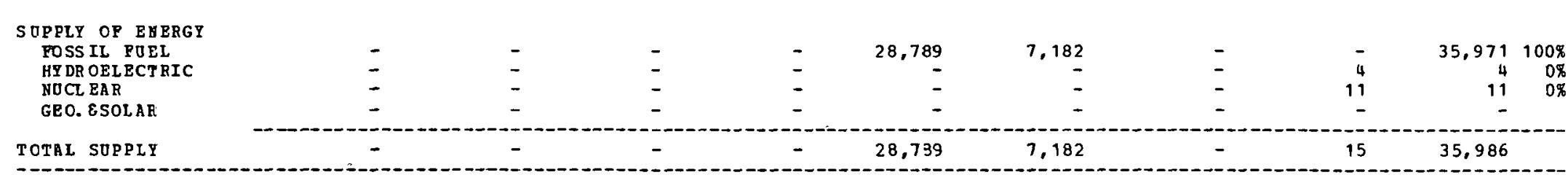

\begin{tabular}{l}
$\begin{array}{l}\text { NET IM PORTS } \\
\text { O? R BGION }\end{array}$ \\
\hline
\end{tabular}


REGIONAL ENE RGI BALANCZ STATEMEHT

\begin{tabular}{|c|c|c|c|c|c|c|c|c|c|}
\hline SECTCZ & $\begin{array}{c}\text { DI STILLETS } \\
\text { OIL }\end{array}$ & $\begin{array}{l}\text { BESIDUAL } \\
\text { CIL }\end{array}$ & $\begin{array}{l}\text { 3ASOLINE } \\
\text { (ALL O }\end{array}$ & $\begin{array}{c}\text { OTHER } \\
\text { HEDRD- } \\
\text { CAR ZOMS } \\
S=\$ 10 * *\end{array}$ & $\begin{array}{c}\text { CRULE } \\
\text { OIL } \\
\text { BTO'S) }\end{array}$ & $\begin{array}{l}\text { NATURAE } \\
\text { GAS }\end{array}$ & $\operatorname{COAL}$ & ELECTRICITY & $\begin{array}{r}\text { SECTOR } \\
\text { TOTAL }\end{array}$ \\
\hline $\begin{array}{l}\text { PINAL DEMAND SECTORS } \\
\text { RES ID ENTIAL, COMM. } \\
\text { IND US TRIAL } \\
\text { TRANSPORTATION } \\
\text { MISCE LLANEOOS OSES }\end{array}$ & $\begin{array}{r}4.075 \\
2.061 \\
6.314 \\
4.36\end{array}$ & $\begin{array}{l}215 \\
550 \\
174 \\
100\end{array}$ & $27,95 \overline{3}$ & $\begin{array}{r}5.815 \\
3.066 \\
1.951 \\
18\end{array}$ & $\begin{array}{l}- \\
- \\
-\end{array}$ & $\begin{array}{r}18,254 \\
5,836 \\
477 \\
168\end{array}$ & $\begin{array}{r}5 \% \\
537 \\
-\end{array}$ & $\begin{array}{r}8,438 \\
6,623 \\
7 \\
68\end{array}$ & $\begin{array}{r}36,854 \\
20,573 \\
36,876 \\
840\end{array}$ \\
\hline $\begin{array}{l}\text { TOTAL PINAL } \\
\text { DEHAND SECZORS }\end{array}$ & 12,936 & 7.039 & $27 ; 953$ & 10.850 & 1 & 24,735 & 2,494 & 15,136 & 95,143 \\
\hline $\begin{array}{l}\text { TR ANSF ORMATIOA } \\
\text { EL ECTRICITY GEN. } \\
\text { PETR OLEOM PRODOCTS } \\
\text { NA TURAL GAS } \\
\text { SY NTHETICS }\end{array}$ & $\begin{array}{r}1,558 \\
=\end{array}$ & - & $\begin{array}{l}\overline{-} \\
-\end{array}$ & $\begin{array}{l}\overline{-} \\
\overline{-}\end{array}$ & $\begin{array}{l}- \\
\\
-\end{array}$ & $\begin{array}{r}1,936 \\
- \\
-\end{array}$ & $\begin{array}{r}88,029 \\
- \\
-\end{array}$ & $\begin{array}{r}-23,150 \\
- \\
-\end{array}$ & $\begin{array}{r}68,383 \\
- \\
-\end{array}$ \\
\hline $\begin{array}{l}\text { NET PUEL OSED } \\
\text { IN TRANSPORMATION }\end{array}$ & $1,56 \varepsilon$ & - & - & - & - & $1,9 \Xi 6$ & 88,029 & $-23,150$ & 68,383 \\
\hline $\begin{array}{l}\text { TOTAL GROSS FRONS } \\
\text { LOSSES } \varepsilon \text { OMI SSIONS }\end{array}$ & $\begin{array}{r}14,504 \\
838\end{array}$ & $\begin{array}{r}1,039 \\
0\end{array}$ & $\begin{array}{r}27,953 \\
-3\end{array}$ & $\begin{array}{r}10.850 \\
-453\end{array}$ & $\begin{array}{l}- \\
-\end{array}$ & $\begin{array}{r}26.5: 1 \\
-966\end{array}$ & $\begin{array}{r}90,523 \\
-199\end{array}$ & $\begin{array}{r}15,136 \\
1,513\end{array}$ & $\begin{array}{r}163,526 \\
733\end{array}$ \\
\hline TOTAL NET OSAGE & 15,342 & 1,039 & 27,952 & 10.396 & - & 25,704 & 90,323 & $-6,500$ & 164.259 \\
\hline
\end{tabular}

SOPPLY OP ENERGY
$\begin{aligned} & \text { POSS IL FUEL } \\ & \text { HY DROELECTEIC }\end{aligned}$
$\begin{aligned} & \text { NOCL EAR } \\ & \text { GEO. ESOLAR }\end{aligned}$
TOTAL SOPPLY

\section{NRT IM PORTS}

OP BGION

1,039

$27,95.2$

16,396

$-14,776$

25,702

90,323

$-7,568$

148,413

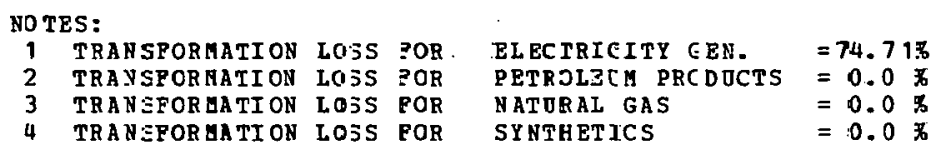


REGIONAL ENERGY BALANCE STATEMENT

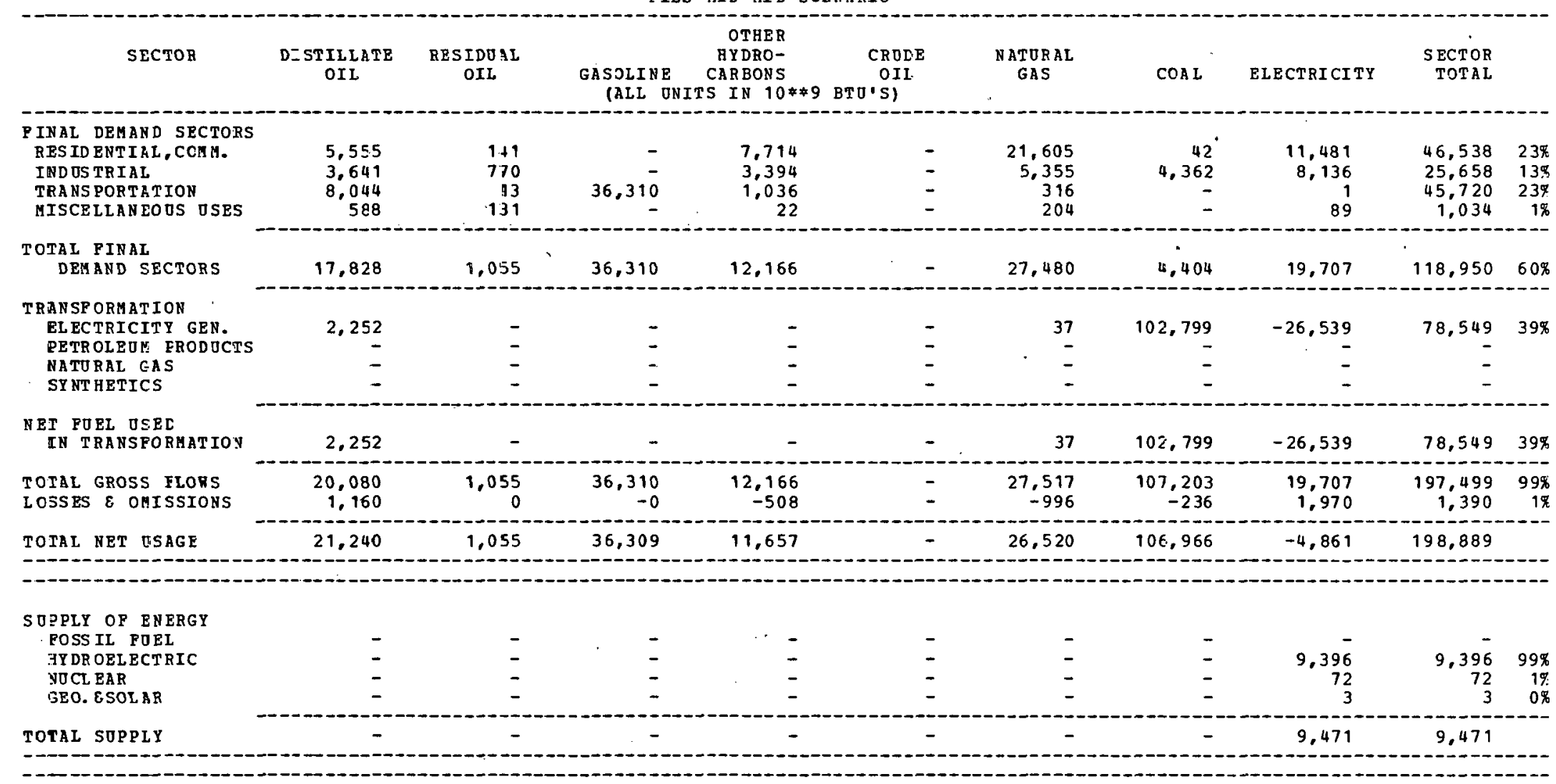

\section{NET IM PORTS}

OP BEGION

21,240

1,055

36,309

11,657

26,520

106,966

$-14.332$

189,418

พOTES:

1 TRANSPORMATION LOSS POR

TRANSPOR MATI ON LOSS POB

TRANSPORAAZION LOSS POR

TRANSPORAAIION LOSS FOR

RLECTRICITY GEN.

ETP OLECI GEN. $\quad=74.75 \%$

NATJRAL GAS

$=74.75 \%$

SYNTHETICS

$=0.0 \%$

$=0.0 \%$ 
REGIONAL ENERGY BALANCE STATEMENT

EIES MID MID SCENARIO

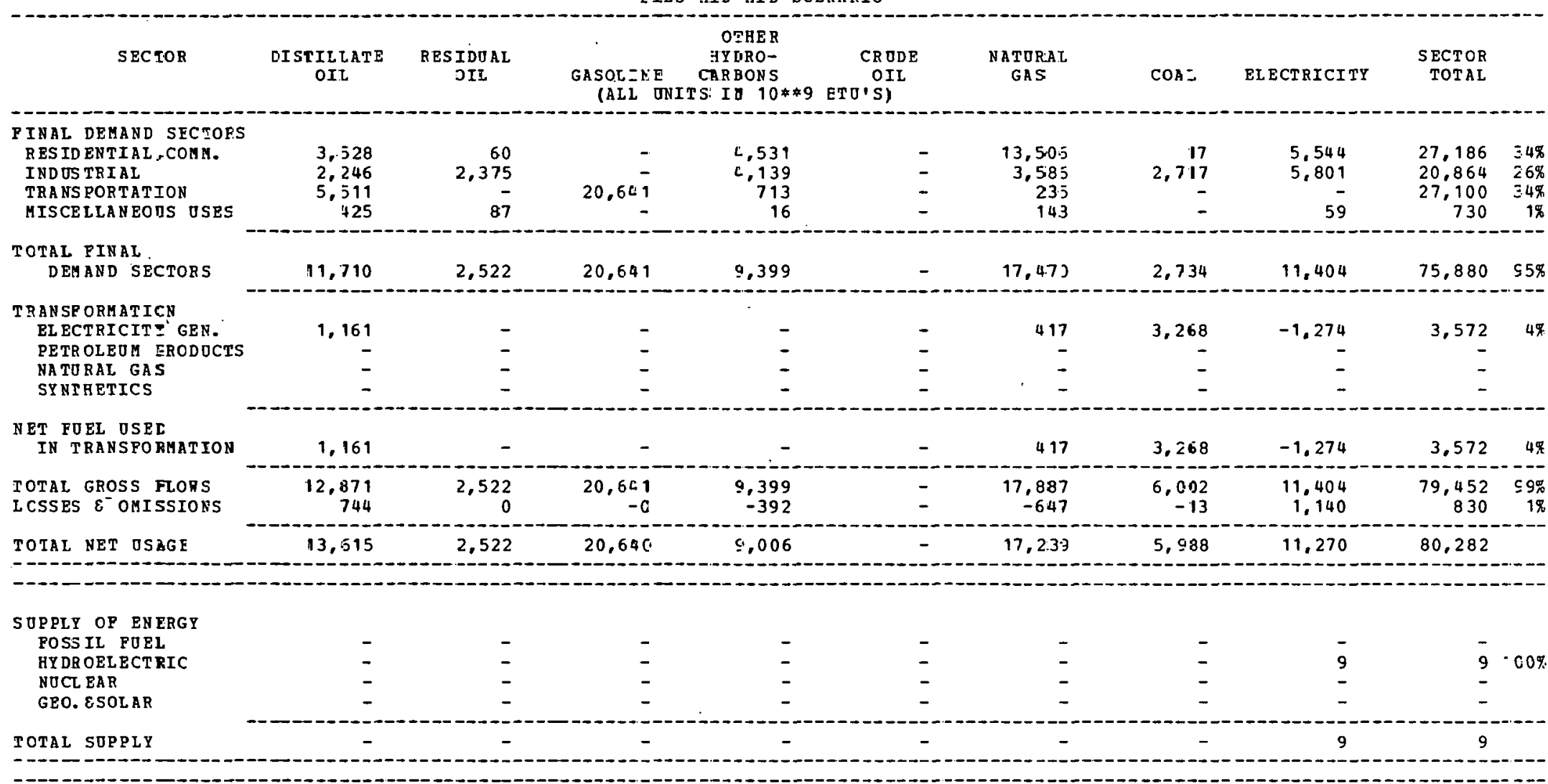

\begin{tabular}{l}
$\begin{array}{l}\text { NET IY PORTS } \\
\text { OP REGION }\end{array}$ \\
\hline
\end{tabular}


REGIONAL ENERGY BALANCE STATEMENT

PIES MID MID SCENARIO

\begin{tabular}{|c|c|c|c|c|c|c|c|c|c|c|}
\hline SECTOR & $\begin{array}{l}\text { DISTILLATE } \\
\text { OIL }\end{array}$ & $\begin{array}{l}\text { RESIDJAL } \\
\text { OIL }\end{array}$ & $\begin{array}{l}\text { GASOLIN } \\
\quad \text { (ALL }\end{array}$ & $\begin{array}{c}\text { OTHER } \\
\text { HYDRO- } \\
\text { CARBONS } \\
\text { TS IN } 10 * \$ 9\end{array}$ & $\begin{array}{c}\text { CRODE } \\
\text { OIL } \\
\text { BTO'S) }\end{array}$ & $\begin{array}{l}\text { NATURAL } \\
\text { GAS }\end{array}$ & $\cos L$ & ELECTRICITY & $\begin{array}{c}\text { SECTOR } \\
\text { TOTAL }\end{array}$ & \\
\hline $\begin{array}{l}\text { FINAL DEHAND SECTORS } \\
\text { RESIDENTIAL, COMM. } \\
\text { IND OS TRIAL } \\
\text { TRANSPORTATION } \\
\text { HISCELLANEOOS OSES }\end{array}$ & $\begin{array}{l}5,865 \\
3,014 \\
4,942 \\
555\end{array}$ & $\begin{array}{r}9 \overline{7} \\
88 \vdots \\
11 \overline{-}\end{array}$ & $34,38 \overline{-}$ & $\begin{array}{r}7.550 \\
4.835 \\
816 \\
21\end{array}$ & $\begin{array}{l}- \\
-\end{array}$ & $\begin{array}{r}22,517 \\
6,562 \\
270 \\
189\end{array}$ & $\begin{array}{r}32 \\
4,404 \\
- \\
-\end{array}$ & $\begin{array}{r}9,224 \\
8,238 \\
- \\
77\end{array}$ & $\begin{array}{r}45,286 \\
27,936 \\
40,409 \\
956\end{array}$ & $\begin{array}{r}37 \% \\
23 \% \\
33 \% \\
1 \%\end{array}$ \\
\hline $\begin{array}{l}\text { TOTAL FINAL } \\
\text { DEHAND SECTORS }\end{array}$ & 14,377 & 1,094 & 34,381 & 13,222 & - & 29,538 & 4,436 & 17,539 & 114,587 & $94 \%$ \\
\hline $\begin{array}{l}\text { TRAISPORMATION } \\
\text { ELECTRICITY GEN. } \\
\text { PETROLEOM FRODOCTS } \\
\text { NLTORAL GAS } \\
\text { SINTHETICS }\end{array}$ & $\begin{array}{r}3,025 \\
- \\
-\end{array}$ & $\bar{z}$ & $\begin{array}{l}- \\
-\end{array}$ & $\begin{array}{l}- \\
\overline{-} \\
-\end{array}$ & $\begin{array}{l}\overline{-} \\
\overline{-}\end{array}$ & $\begin{array}{r}1,066 \\
- \\
-\end{array}$ & $\begin{array}{r}4,313 \\
- \\
-\end{array}$ & $\begin{array}{r}-2,257 \\
- \\
-\end{array}$ & $\begin{array}{r}6,147 \\
- \\
-\end{array}$ & $5 \%$ \\
\hline $\begin{array}{l}\text { NET FORL OSRD } \\
\text { IS TRANSPORMATION }\end{array}$ & 3.025 & - & - & - & - & 1,066 & 4,313 & $-2,257$ & 6,147 & $5 \%$ \\
\hline $\begin{array}{l}\text { TOTEL GROSS FLONS } \\
\text { LOSEES E OHISSIOHS }\end{array}$ & $\begin{array}{r}17,402 \\
1,006\end{array}$ & $\begin{array}{r}1,094 \\
0\end{array}$ & $\begin{array}{r}34,381 \\
-0\end{array}$ & $\begin{array}{r}13,222 \\
-552\end{array}$ & $\overline{-}$ & $\begin{array}{l}30,604 \\
-1,108\end{array}$ & $\begin{array}{r}8,749 \\
-19\end{array}$ & $\begin{array}{r}17,539 \\
1,754\end{array}$ & $\begin{array}{r}120,734 \\
1,079\end{array}$ & $\begin{array}{r}99 \% \\
1 \%\end{array}$ \\
\hline TOTAL NET OSAGE & 18,408 & 1,094 & 34,380 & 12,669 & - & 29,495 & 8,729 & 17,036 & 121,813 & \\
\hline
\end{tabular}

SOPELY OP ENERGY
POSS IL POEL
MYDROELCTRIC
BUCL EAR
GEO. ESOLAR

\begin{tabular}{l}
$\begin{array}{l}\text { NET IM PORTS } \\
\text { OP REGION }\end{array}$ \\
\hdashline$\quad 18,408$
\end{tabular}


RBGIONAL ENERG BALANCE STATEMETT

PIES MIL MID SCENARIO

\begin{tabular}{|c|c|c|c|c|c|c|c|c|c|c|}
\hline SECTOR & $\begin{array}{l}\text { DISTILLATE } \\
\text { =IL }\end{array}$ & $\begin{array}{l}\text { RES ITIJAL } \\
\text { OIL }\end{array}$ & $\begin{array}{l}\text { SESOLINE } \\
\text { (ALL ONI }\end{array}$ & $\begin{array}{l}\text { CTHER } \\
\text { HSDRD- } \\
\text { CAEBOHS } \\
\text { TS IN } 10 * \$ 9\end{array}$ & $\begin{array}{c}\text { CRODE } \\
\text { OIL } \\
\text { BTO'S) }\end{array}$ & $\begin{array}{l}\text { NATURAL } \\
\text { GAS }\end{array}$ & $\mathrm{COAL}$ & ELECTRICITY & $\begin{array}{r}\text { SECTOR } \\
\text { TOTAL }\end{array}$ & \\
\hline $\begin{array}{l}\text { PINAL DEHAND SECTORS } \\
\text { RESID ENTIAL, COHM. } \\
\text { IRDOSTRIAL } \\
\text { TRANSPORTATIOA } \\
\text { ETSCELLAHEOS OSES }\end{array}$ & $\begin{array}{r}11.659 \\
6.524 \\
14.203 \\
1.4: 0\end{array}$ & $\begin{array}{r}245 \\
2,618 \\
- \\
289\end{array}$ & $\begin{array}{r}- \\
66,770 \\
-\end{array}$ & $\begin{array}{r}-4,745 \\
-0,955 \\
1,597 \\
54\end{array}$ & $\overline{-}$ & $\begin{array}{r}45,081 \\
9,999 \\
523 \\
483\end{array}$ & $\begin{array}{r}65 \\
5,837 \\
1 \\
1\end{array}$ & $\begin{array}{r}18,799 \\
13,365 \\
- \\
196\end{array}$ & $\begin{array}{r}90,595 \\
47,298 \\
83,094 \\
2,433\end{array}$ & $\begin{array}{l}32 \pi \\
17 \pi \\
29 \\
17\end{array}$ \\
\hline $\begin{array}{l}\text { TOTAL FINAL } \\
\text { DEHAND SECTORS }\end{array}$ & 31,796 & 3,152 & $66.77 a$ & 27,351 & - & 56,085 & 5,905 & 32,360 & 223,420 & $79 \%$ \\
\hline $\begin{array}{l}\text { TRANSPORMATION } \\
\text { ELRCTRICITY SEN. } \\
\text { PETROLEU PRODUCTS } \\
\text { HATORAL GAS } \\
\text { SY HT HETICS }\end{array}$ & $\begin{array}{r}4,321 \\
- \\
-\end{array}$ & $\begin{array}{l}\bar{z} \\
\overline{-}\end{array}$ & $\begin{array}{l}- \\
- \\
-\end{array}$ & I & $\begin{array}{l}\overline{-} \\
\overline{-}\end{array}$ & $\begin{array}{l}12 \\
- \\
-\end{array}$ & $\begin{array}{r}73,129 \\
- \\
-\end{array}$ & $\begin{array}{r}-19,634 \\
- \\
-\end{array}$ & $\begin{array}{r}57,828 \\
= \\
=\end{array}$ & $=0 x$ \\
\hline $\begin{array}{l}\text { RET PORL OSED } \\
\text { IN TRANSPOEAGTION }\end{array}$ & $4 ., 321$ & - & - & - & - & 12 & $73,12 c$ & $-19, \in 34$ & 57,828 & $=0 \pi$ \\
\hline $\begin{array}{l}\text { TOTAL GROSS PLONS } \\
\text { LOSSES } \& \text { OHISSIONS }\end{array}$ & $\begin{array}{r}3 E, 1: 7 \\
2,088\end{array}$ & $\begin{array}{r}3.152 \\
0\end{array}$ & $\begin{array}{r}66,770 \\
-0\end{array}$ & $\begin{array}{l}27,351 \\
-1,143\end{array}$ & - & $\begin{array}{l}56,093 \\
-2,032\end{array}$ & $\begin{array}{r}79,034 \\
-174\end{array}$ & $\begin{array}{r}32,360 \\
3,236\end{array}$ & $\begin{array}{r}281,248 \\
1,974\end{array}$ & $\leq 98$ \\
\hline $\begin{array}{l}\text { S JPPLY OP ENEFGY } \\
\text { POSS IL POEL } \\
\text { HYDR OELECTBI: } \\
\text { NDCL EAR } \\
\text { GEO. ESOLAR }\end{array}$ & $\begin{array}{l}\overline{-} \\
\overline{-}\end{array}$ & $\begin{array}{l}- \\
\overline{-} \\
-\end{array}$ & $\begin{array}{l}- \\
\overline{-} \\
\overline{-}\end{array}$ & $\begin{array}{l}\overline{-} \\
\overline{-}\end{array}$ & $\bar{E}$ & $=$ & $\begin{aligned} 12,63 & = \\
& = \\
& -\end{aligned}$ & $\begin{array}{r}6 \overline{3} \\
9,781 \\
-\end{array}$ & $\begin{array}{r}12,633 \\
63 \\
9,781 \\
-\end{array}$ & $\begin{array}{l}5.69 \\
09 \\
<49\end{array}$ \\
\hline TOTAL SOPPLY & - & - & - & - & - & - & 12,633 & 9,844 & 22,477 & \\
\hline
\end{tabular}

-

NET IM PORTS

OP REGION

38,205

3.152

66,769

26,207

54,065

66,226

6,118

250,745

\begin{tabular}{|c|c|c|c|c|c|}
\hline \multicolumn{6}{|c|}{ NO TES: } \\
\hline 1 & TRANSF JRAATI ON & LOSS & POR & ELECTRICITY & $=74.65 \%$ \\
\hline 2 & TRANSF JQHATI ON & oss & POR & PRTRQ & $0.0 \%$ \\
\hline 3 & TRAN SPOR MATI OH & Loss & POR & NATEEAL GAS & $=0.0 \%$ \\
\hline 4 & TRANSE JR AATI ON & Loss & POR & SYHTEZTICS & $=0.0 \%$ \\
\hline
\end{tabular}


REGIONAL ENERG BAIANCE STATEMENT

PIES MID MID SCENARIO

\begin{tabular}{|c|c|c|c|c|c|c|c|c|c|c|}
\hline SECTOR & $\begin{array}{l}\text { DISTILLATE } \\
\text { OIL }\end{array}$ & $\begin{array}{l}\text { RESIDUAL } \\
\text { OIL }\end{array}$ & $\begin{array}{l}\text { GASOLINE } \\
\text { (ALL O }\end{array}$ & $\begin{array}{l}\text { OTHER } \\
\text { HYDRO- } \\
\text { CABBONS } \\
\text { TS IN } 10 * 9\end{array}$ & $\begin{array}{l}\text { CRODE } \\
\text { OIL } \\
\text { BTO'S) }\end{array}$ & $\begin{array}{l}\text { NATURAL } \\
\text { GAS }\end{array}$ & $\operatorname{COAL}$ & ELECTRICITY & $\begin{array}{r}\text { SECTOR } \\
\text { TOTAL }\end{array}$ & \\
\hline $\begin{array}{l}\text { FINAL DEMAND SECTORS } \\
\text { RESID ENTIAL, COMM. } \\
\text { INDOSTRIAL } \\
\text { TRANSPORTATION } \\
\text { MISCE LLANEOUS USES }\end{array}$ & $\begin{array}{r}11,322 \\
6,123 \\
24,419 \\
1,164\end{array}$ & $\begin{array}{r}507 \\
6,399 \\
398 \\
239\end{array}$ & $73,65 \overline{-}$ & $\begin{array}{r}15,545 \\
15,634 \\
2,192 \\
63\end{array}$ & $\begin{array}{l}- \\
-\end{array}$ & $\begin{array}{r}48,316 \\
16,794 \\
555 \\
708\end{array}$ & $\begin{array}{r}131 \\
9,717 \\
1 \\
1\end{array}$ & $\begin{array}{r}21,834 \\
13,555 \\
17 \\
238\end{array}$ & $\begin{array}{r}97,655 \\
68,222 \\
101,241 \\
2,413\end{array}$ & $\begin{array}{r}28 \% \\
19 \% \\
29 \% \\
18\end{array}$ \\
\hline $\begin{array}{l}\text { TOTAL PINAL } \\
\text { DEHAND SECTORS }\end{array}$ & 43,028 & 7,543 & 73,659 & 33.434 & - & 66,373 & 9,850 & 35,644 & 269,531 & $77 \%$ \\
\hline $\begin{array}{l}\text { TRANSPORMATION } \\
\text { EL ECTRICITY GEN. } \\
\text { PETROLEOI PRODOCTS } \\
\text { NATORAL GAS } \\
\text { SYNTHETICS }\end{array}$ & $\begin{array}{r}3,105 \\
- \\
-\end{array}$ & $\begin{array}{l}- \\
-\end{array}$ & $\begin{array}{l}- \\
- \\
-\end{array}$ & $\begin{array}{l}- \\
\overline{-} \\
-\end{array}$ & $\begin{array}{l}- \\
-\end{array}$ & $\begin{array}{l}- \\
-\end{array}$ & $\begin{array}{r}102,275 \\
= \\
-\end{array}$ & $\begin{array}{r}-26,613 \\
- \\
-\end{array}$ & $\begin{array}{r}78,767 \\
- \\
-\end{array}$ & $22 \%$ \\
\hline $\begin{array}{l}\text { NET FOQL OSED } \\
\text { IN TRABSFORMATION }\end{array}$ & 3,105 & - & - & - & - & - & 102,275 & $-26,613$ & 78,767 & $22 \pi$ \\
\hline $\begin{array}{l}\text { TOTAL GROSS FLOH.S } \\
\text { LOSSES } \mathcal{E} \text { OMISSIONS }\end{array}$ & $\begin{array}{r}46,133 \\
2,667\end{array}$ & $\begin{array}{r}7.543 \\
0\end{array}$ & $\begin{array}{r}73.659 \\
-0\end{array}$ & $\begin{array}{l}33,434 \\
-1,397\end{array}$ & - & $\begin{array}{l}66,373 \\
-2,404\end{array}$ & $\begin{array}{r}112,125 \\
-246\end{array}$ & $\begin{array}{r}35,644 \\
3,564\end{array}$ & $\begin{array}{r}348,298 \\
2,183\end{array}$ & $\begin{array}{r}998 \\
9 \%\end{array}$ \\
\hline TOTAL NET OSAGE & 48,800 & 7,543 & 73,658 & 32,036 & - & 63,968 & 111,878 & 12,595 & 350,481 & \\
\hline $\begin{array}{l}\text { SOPPLY OP ENRRGY } \\
\text { FOSS IL PDEL } \\
\text { HYDR OELECTRIC } \\
\text { NOCL EAR } \\
\text { GEO. ESOLAR }\end{array}$ & $\begin{array}{l}\overline{-} \\
\overline{-}\end{array}$ & $\begin{array}{l}- \\
-\end{array}$ & $\begin{array}{l}\bar{z} \\
\overline{-}\end{array}$ & $\begin{array}{l}\overline{-} \\
\overline{-}\end{array}$ & $\begin{array}{l}- \\
\text { - }\end{array}$ & $\begin{array}{l}- \\
-\end{array}$ & $\begin{array}{l}\overline{-} \\
\overline{-}\end{array}$ & $\begin{array}{r}6 \overline{11} \\
13,082 \\
-\end{array}$ & $\begin{array}{r}611 \\
13,082 \\
-\end{array}$ & $\begin{array}{r}4 \% \\
96 \%\end{array}$ \\
\hline TOTAL SOPPLY & - & - & - & - & - & - & - & 13,693 & 13,693 & \\
\hline
\end{tabular}

-

NET IM PORTS
OP R BGION


REGIONAL ESERG BALANCE STATEMZNT

PIES MID MID SCENARIO

\begin{tabular}{|c|c|c|c|c|c|c|c|c|c|c|}
\hline SECTOB & $\begin{array}{l}\text { CISTILLATE } \\
\text { OIL }\end{array}$ & $\begin{array}{l}\text { EBSIDJAL } \\
\text { OIL }\end{array}$ & $\begin{array}{l}\text { GASOEINE } \\
\text { CAIL }\end{array}$ & $\begin{array}{c}\text { OTHER } \\
\text { IYDRO- } \\
\text { CBRBONS } \\
\text { TS IN } 10 * * 9\end{array}$ & $\begin{array}{c}\text { CRODE } \\
\text { OIL } \\
\text { BTO'S) }\end{array}$ & $\begin{array}{l}\text { NAEURA: } \\
\text { GAS }\end{array}$ & $\infty \mathrm{AL}$ & ELECTRICITY & $\begin{array}{l}\text { SECTOR } \\
\text { TOTAE }\end{array}$ & \\
\hline $\begin{array}{l}\text { PIVAL DEHAUD SECTORS } \\
\text { RESID ENTIAL,COHH. } \\
\text { IHD US TRIAI } \\
\text { TRANSPORTATION } \\
\text { GISCELLANEOUS OSES }\end{array}$ & $\begin{array}{r}4,475 \\
2,198 \\
6,216 \\
725\end{array}$ & $\begin{array}{r}263 \\
1,667 \\
130 \\
148\end{array}$ & $29.56 \overline{-}$ & $\begin{array}{r}6.173 \\
4.883 \\
742 \\
28\end{array}$ & $\begin{array}{l}- \\
- \\
-\end{array}$ & $\begin{array}{r}19,647 \\
7,341 \\
173 \\
247\end{array}$ & $\begin{array}{r}62 \\
3,584 \\
- \\
1\end{array}$ & $\begin{array}{r}9,315 \\
5,786 \\
6 \\
102\end{array}$ & $\begin{array}{r}39,935 \\
25,459 \\
36,833 \\
1,253\end{array}$ & $\begin{array}{r}28 \% \\
18 \% \\
25 \% \\
1 \%\end{array}$ \\
\hline $\begin{array}{l}\text { TOTAL PINAL } \\
\text { DEM AND SECTORS }\end{array}$ & 13,614 & 2,208 & 29.56 .1 & 11,826 & - & 27,415 & 3,647 & 15,209 & $103,48 \pi$ & $72 \%$ \\
\hline $\begin{array}{l}\text { TRANSP ORAATION } \\
\text { EL ECTRICITY GEN. } \\
\text { PETROLEOE PRODOCTS } \\
\text { RATORAL GAS } \\
\text { SY BTRETIES }\end{array}$ & $\begin{array}{r}1,728 \\
= \\
-\end{array}$ & $\begin{array}{l}- \\
-\end{array}$ & $\begin{array}{l}\overline{-} \\
\overline{-}\end{array}$ & $\bar{z}$ & I & $\begin{array}{l}- \\
- \\
-\end{array}$ & $\begin{array}{r}52,282 \\
- \\
-\end{array}$ & $\begin{array}{r}-13,645 \\
- \\
-\end{array}$ & $\begin{array}{r}40,365 \\
- \\
-\end{array}$ & $28 \%$ \\
\hline $\begin{array}{l}\text { NET POBL OSED } \\
\text { IH TRANSFORHATION }\end{array}$ & 1,728 & - & - & - & - & - & 52,282 & $-13,645$ & $40,36.5$ & $28 \%$ \\
\hline $\begin{array}{l}\text { TOTAL GROSS FLONS } \\
\text { LOSSES } \& \text { OEISSIOHS }\end{array}$ & $\begin{array}{r}15,342 \\
886\end{array}$ & $\begin{array}{r}2,208 \\
0\end{array}$ & $\begin{array}{r}29,569 \\
-0\end{array}$ & $\begin{array}{r}11,826 \\
-494\end{array}$ & $\overline{-}$ & $\begin{array}{r}27.415 \\
-993\end{array}$ & $\begin{array}{r}55,929 \\
-123\end{array}$ & $\begin{array}{r}15,209 \\
1,521\end{array}$ & $\begin{array}{r}143,845 \\
797\end{array}$ & $\begin{array}{r}99 \% \\
1 \%\end{array}$ \\
\hline TOTAL NET JSAGE & 16,228 & 2,208 & 29,560 & 11,331 & - & 26.42 .1 & 55,805 & 3.085 & 144,642 & \\
\hline
\end{tabular}

\begin{tabular}{|c|c|c|c|c|c|c|c|c|c|c|}
\hline SOPPLY OP INERGY & & & & & & & & & & \\
\hline POSSIL POEL & - & - & - & - & 263 & - & - & - & 26.3 & $4 \pi$ \\
\hline HY DR OBL ECTRIC & - & - & - & - & - & - & - & 122 & 122 & $2 \%$ \\
\hline BOCL EAR & - & - & - & - & - & - & - & 6,341 & 6.341 & $94 x$ \\
\hline GEO. \&SOLAR & - & - & - & - & - & - & - & - & - & \\
\hline TOTAL SUPPIY & - & - & - & - & 263 & - & - & 6.463 & 6,726 & \\
\hline
\end{tabular}

NET IM PORTS
OP R BGION

NO TES:

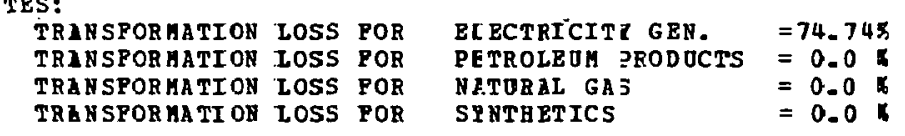


REGIONAL ENERGY BALANCE STATEMENT

PIES MID MID SCENARIO

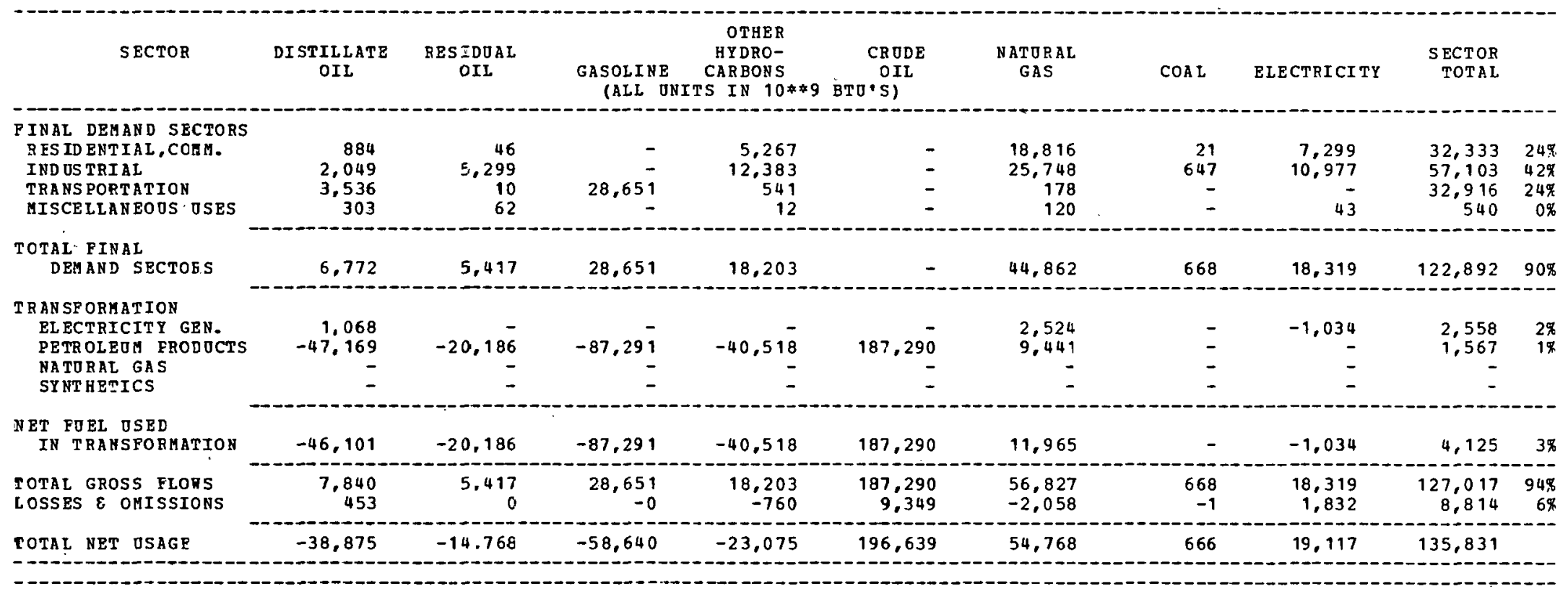

\begin{tabular}{|c|c|c|c|c|c|c|c|c|c|c|}
\hline $\begin{array}{l}5 \text { OPPLY OF ENERGY } \\
\text { FOSS IL FOEL }\end{array}$ & & & & & & & & & & \\
\hline $\begin{array}{l}\text { FOSS IL PUEL } \\
\text { HY DR ORL ECTRIC }\end{array}$ & $z$ & $\overline{-}$ & $=$ & - & 151,559 & 3,532 & $\overline{-}$ & $\overline{15}$ & & $\begin{array}{r}94 \% \\
0 \%\end{array}$ \\
\hline NOCL EAR & - & - & - & - & - & - & - & 9.373 & 9,373 & $6 \%$ \\
\hline GEO. \& SOLAR & - & - & - & - & - & - & - & - & - & \\
\hline
\end{tabular}

NET IM PORTS
OP R RGION


RZSICNAL ENZRGY BAIANCE STATEMENT
FIES MID MID SCENARIO

\begin{tabular}{|c|c|c|c|c|c|c|c|c|c|c|}
\hline SECTOR & $\begin{array}{l}\text { DISTLLATE } \\
\text { CII }\end{array}$ & $\begin{array}{l}\text { RES IDUAL } \\
\text { OIL }\end{array}$ & $\begin{array}{l}\text { GASOLIEE } \\
\text { (ALL ONI }\end{array}$ & $\begin{array}{c}\text { OTHER } \\
\text { HTDRO- } \\
\text { CA SBONS } \\
\text { IS IN 10**9 }\end{array}$ & $\begin{array}{c}\text { CRODE } \\
\text { OIL } \\
\text { BTO'S) }\end{array}$ & $\begin{array}{l}\text { WATCRAL } \\
\text { GFSS }\end{array}$ & $\cos L$ & ELECTRICISY & $\begin{array}{r}\text { SECTOR } \\
\text { TOTAI }\end{array}$ & \\
\hline $\begin{array}{l}\text { PINAL DEMANO SECTORS } \\
\text { RESID ENTIAE, COHM. } \\
\text { IND OS TRIAL } \\
\text { TRANS PORTATION } \\
\text { MISCE LLANEOUS OSES }\end{array}$ & $\begin{array}{r}1,916 \\
\vdots: 286 \\
E, 259 \\
666\end{array}$ & $\begin{array}{r}110 \\
12,253 \\
20 \\
137\end{array}$ & $\begin{array}{r}- \\
- \\
-\end{array}$ & $\begin{array}{r}11,136 \\
29,260 \\
1,393 \\
36\end{array}$ & $\overline{-}$ & $\begin{array}{r}40,425 \\
40,918 \\
459 \\
392\end{array}$ & $\begin{array}{r}48 \\
1,925 \\
- \\
-\end{array}$ & $\begin{array}{r}16,304 \\
16,908 \\
- \\
103\end{array}$ & $\begin{array}{r}69,939 \\
104,550 \\
70,424 \\
1,324\end{array}$ & $\begin{array}{r}24 \% \\
3 \in \% \\
24 \% \\
C \%\end{array}$ \\
\hline $\begin{array}{l}\text { TOTAL FINAL } \\
\text { DEMAND SZCTORS }\end{array}$ & $1 L, 127$ & 12,520 & 60,293 & 41,825 & - & 82,184 & 1,973 & 33,315 & 246,237 & $8 \in \mathscr{R}$ \\
\hline $\begin{array}{l}\text { TRANSFORHATION } \\
\text { EL BCTRICITY GEN. } \\
\text { PETROLEU PRODOCTS } \\
\text { NATORAL EAS } \\
\text { SYNTHETICS }\end{array}$ & $\begin{array}{r}2.304 \\
-11 \mathrm{e} .510 \\
- \\
-\end{array}$ & $\begin{array}{r}-49,360 \\
- \\
-\end{array}$ & $\begin{array}{r}- \\
-215,615 \\
-\end{array}$ & $\begin{array}{r}-100,083 \\
-\end{array}$ & $\begin{array}{r}- \\
462,619 \\
-\end{array}$ & $\begin{array}{r}20.918 \\
23.320 \\
- \\
-\end{array}$ & $\begin{array}{l}- \\
-\end{array}$ & $\begin{array}{r}-6,701 \\
- \\
- \\
-\end{array}$ & $\begin{array}{r}16,521 \\
3,870 \\
- \\
-\end{array}$ & $\begin{array}{l}6 \% \\
1 \%\end{array}$ \\
\hline $\begin{array}{l}\text { KET FOEL OSEL } \\
\text { IN TRANSETRMATION }\end{array}$ & $-114,206$ & $-49,360$ & -215.615 & $-100,083$ & $4 \in 2,619$ & 44,238 & - & $-6,701$ & 20,391 & $7 \%$ \\
\hline $\begin{array}{l}\text { TOTAL GROSS FLOHS } \\
\text { LOSSES } \varepsilon \text { OMISSIONS }\end{array}$ & $\begin{array}{r}16.431 \\
949\end{array}$ & $\begin{array}{r}12,520 \\
0\end{array}$ & $\begin{array}{r}60,293 \\
-3\end{array}$ & $\begin{array}{r}41,825 \\
-1,748\end{array}$ & $\begin{array}{r}462,619 \\
23,094\end{array}$ & $\begin{array}{r}126,422 \\
-4,579\end{array}$ & $\begin{array}{r}1.973 \\
-4\end{array}$ & $\begin{array}{r}33,315 \\
3,331\end{array}$ & $\begin{array}{r}266,62 \varepsilon \\
21,04 L\end{array}$ & $\begin{array}{r}93 \% \\
7 \%\end{array}$ \\
\hline
\end{tabular}

\begin{tabular}{|c|c|c|c|c|c|c|c|c|c|c|}
\hline $\begin{array}{l}\text { S UPPLY OP ENERGY } \\
\text { FOSS IL POEL }\end{array}$ & - & - & - & - & 237,375 & $969.76 i$ & - & - & $1.206 .8=6$ & $100 \%$ \\
\hline HY DR OEL ZCTRIC & - & - & - & - & 2010 & - & - & 28 & $2 \varepsilon$ & $0 \%$ \\
\hline NOCL EAR & - & - & - & - & - & - & - & - & - & \\
\hline GEO. \&SOL aR & - & - & - & - & - & - & - & - & - & \\
\hline
\end{tabular}

(1)

NET IM PORT:
OP REGIOS


REGIONAL ENERGY BALANCE STATEMENT

\begin{tabular}{|c|c|c|c|c|c|c|c|c|c|c|}
\hline SECTOR & $\begin{array}{l}\text { CISTILLATE } \\
\text { OIL }\end{array}$ & $\begin{array}{l}\text { RES IDEAL } \\
\text { OII }\end{array}$ & $\begin{array}{l}\text { GASOLINE } \\
\text { (ALL UNI }\end{array}$ & $\begin{array}{c}\text { OTHER } \\
\text { HYDRO- } \\
\text { CARBONS } \\
\text { TS IN } 10 * \$ 9\end{array}$ & $\begin{array}{c}\text { CRDDE } \\
\text { OII } \\
\text { ETO'S) }\end{array}$ & $\begin{array}{l}\text { NATORAL } \\
\text { GAS }\end{array}$ & $\operatorname{COAL}$ & ELECTRICITY & $\begin{array}{r}\text { SECTOR } \\
\text { TOTAL }\end{array}$ & \\
\hline $\begin{array}{l}\text { PINAL DEMAND SECTORS } \\
\text { RESIDENTIAL, CCHM. } \\
\text { IND USTRIAL } \\
\text { FRANSPORTATION } \\
\text { UISCELLANEOOS OSES }\end{array}$ & $\begin{array}{r}20,486 \\
9,391 \\
49,059 \\
5,290\end{array}$ & $\begin{array}{r}1,729 \\
19,233 \\
151 \\
1,086\end{array}$ & $192,94 \overline{-}$ & $\begin{array}{r}39,343 \\
99,167 \\
33,704 \\
263\end{array}$ & $\begin{array}{l}- \\
-\end{array}$ & $\begin{array}{r}124,817 \\
86,902 \\
6,882 \\
2,719\end{array}$ & $\begin{array}{r}159 \\
23,012 \\
3 \\
6\end{array}$ & $\begin{array}{r}55,117 \\
33,729 \\
22 \\
799\end{array}$ & $\begin{array}{r}241,651 \\
271,934 \\
282,763 \\
10,163\end{array}$ & $\begin{array}{l}20 \% \\
22 \% \\
23 \% \\
1 \%\end{array}$ \\
\hline $\begin{array}{l}\text { TOTAL FINAL } \\
\text { DEHAND SECTORS }\end{array}$ & 84,726 & 22,199 & 192,942 & 172,477 & - & 221,320 & 23,180 & 89,667 & 806,511 & $67 \%$ \\
\hline $\begin{array}{l}\text { TRANSP ORMATICN } \\
\text { EL ECTRICITY GEN. } \\
\text { PBTR OLEOM PRODOCTS } \\
\text { NATURAL GAS } \\
\text { SY NTHETICS }\end{array}$ & $\begin{array}{r}12,001 \\
-103,190 \\
- \\
-\end{array}$ & $\begin{array}{r}-44,160 \\
-\end{array}$ & $\begin{array}{r}-190,965 \\
-\end{array}$ & $\begin{array}{r}-88,641 \\
-\end{array}$ & $\begin{array}{r}409,729 \\
-\end{array}$ & $\begin{array}{r}21,604 \\
20,654 \\
- \\
-\end{array}$ & $\begin{array}{r}480,402 \\
= \\
-\end{array}$ & $\begin{array}{r}-130,509 \\
- \\
-\end{array}$ & $\begin{array}{r}383,498 \\
3,427 \\
- \\
-\end{array}$ & $\begin{array}{r}32 \% \\
0 \%\end{array}$ \\
\hline $\begin{array}{l}\text { NET FOEL DSED } \\
\text { IN TRANSFORHATION }\end{array}$ & $-91,189$ & $-44,1160$ & -190.965 & $-88,641$ & 409,729 & 42,258 & 480,402 & -130.509 & 386,925 & $32 \%$ \\
\hline $\begin{array}{l}\text { TOTAL GROSS FLORS } \\
\text { LOSSES } \& \text { OMISSIONS }\end{array}$ & $\begin{array}{r}96,727 \\
5,592\end{array}$ & $\begin{array}{r}22,199 \\
0\end{array}$ & $\begin{array}{r}192,942 \\
-0\end{array}$ & $\begin{array}{r}172,477 \\
-7,209\end{array}$ & $\begin{array}{r}409,729 \\
20,454\end{array}$ & $\begin{array}{r}263,578 \\
-9,547\end{array}$ & $\begin{array}{r}503,582 \\
-1,109\end{array}$ & $\begin{array}{r}89,667 \\
8,967\end{array}$ & $\begin{array}{r}1,193,436 \\
17,147\end{array}$ & $\begin{array}{r}99 \% \\
10\end{array}$ \\
\hline TOTAL NET OSAGE & -870 & $-21,960$ & 1,976 & 76,626 & 430,183 & 254,030 & $502,472^{\circ}$ & $-31,874$ & $1,210,583$ & \\
\hline $\begin{array}{l}\text { SOPPLY OF ENERGY } \\
\text { POSS IL POEL } \\
\text { HYDR OELECTRIC } \\
\text { NOCL EAR } \\
\text { GEO. ESOLAR }\end{array}$ & $=$ & $\begin{array}{l}- \\
-\end{array}$ & $\begin{array}{l}\overline{-} \\
\overline{-}\end{array}$ & $\begin{array}{l}\bar{z} \\
\overline{-}\end{array}$ & $\begin{array}{r}5,816 \\
= \\
=\end{array}$ & $\begin{array}{r}1,045 \\
- \\
-\end{array}$ & $\begin{array}{r}75,267 \\
= \\
=\end{array}$ & $\begin{array}{r}459 \\
- \\
-\end{array}$ & $\begin{array}{r}82,128 \\
459 \\
- \\
-\end{array}$ & $\begin{array}{r}99 \% \\
1 \%\end{array}$ \\
\hline TOTAL SOPPLY & - & - & - & - & 5,816 & 1,045 & 75,267 & 459 & 82,587 & \\
\hline
\end{tabular}

\section{RET IM PORTS}

$-870 \quad-21,960$

1,976

76,626

424,367

252,985

427,205

$-32,333 \quad 1,127,996$

-

\section{NO TES:}

1 TRANSPORMATI ON LOSS FOR ELECTRICITY GEN.

TRANSPORHATION LOSS POR PETROLENM PRODOCTS $=0.80 \%$

$\begin{array}{ll}\text { MATURAL GAS } & =0.80 \% \\ \text { SYUTELICS } & =0.0 \%\end{array}$

TRANSPORHATI ON LOSS POR SYUTHETICS 
REGIONAE RNERGY BALANCE STATEMENT

PIES IID MID SCENARIO

\begin{tabular}{|c|c|c|c|c|c|c|c|c|c|c|}
\hline SECTOR & $\begin{array}{l}\text { DISTILIATE } \\
\text { OIL }\end{array}$ & $\begin{array}{l}\text { RE SIDJEL } \\
\text { DIL }\end{array}$ & $\begin{array}{l}\text { GASOL } I \text { NE } \\
\text { (AL: }\end{array}$ & $\begin{array}{l}\text { OEHER } \\
\text { HYDRO- } \\
\text { CARBONS } \\
\text { IS IE } 10 * 49\end{array}$ & $\begin{array}{c}\text { CRJDE } \\
\text { OIL } \\
\text { ETO!S: }\end{array}$ & $\begin{array}{l}\text { NAT ORAL } \\
\text { GAS }\end{array}$ & $\operatorname{COA} \bar{I}$ & ELECTRICITY & $\begin{array}{r}\text { SECTOR } \\
\text { TOTAL }\end{array}$ & \\
\hline $\begin{array}{l}\text { PINAL DEMAND SECTORS } \\
\text { RES ID ENTIAL, COMH. } \\
\text { IND OS TRIAL } \\
\text { TRANS PORTATION } \\
\text { MSCELLANEOZS OSES }\end{array}$ & $\begin{array}{l}6,503 \\
1,233 \\
4,771 \\
1,193\end{array}$ & $\begin{array}{r}579 \\
48.8 \\
7 \\
24.5\end{array}$ & 37,332 & $\begin{array}{r}8,240 \\
6,665 \\
2,805 \\
46\end{array}$ & $\begin{array}{l}\overline{-} \\
\overline{-}\end{array}$ & $\begin{array}{r}22,927 \\
7,443 \\
487 \\
406\end{array}$ & $\begin{array}{r}30 \\
4,4 \frac{13}{1} \\
-\end{array}$ & $\begin{array}{r}10,481 \\
5,037 \\
6 \\
166\end{array}$ & $\begin{array}{r}48,760 \\
25,279 \\
45,458 \\
2,057\end{array}$ & $\begin{array}{l}23 \% \\
12 \% \\
22 \% \\
1 \%\end{array}$ \\
\hline $\begin{array}{l}\text { TOTAL PINAL } \\
\text { DEMAND SECTOBS }\end{array}$ & 13,700 & 1,319 & 37,332 & 17,756 & - & 31,263 & $4,4,14$ & 15,690 & 121,554 & $58 \%$ \\
\hline $\begin{array}{l}\text { TRANSPORMATICN } \\
\text { ELECTRICITI GEN. } \\
\text { PETROLEOM ERODOCTS } \\
\text { NATURAL GAS } \\
\text { ST RT HETICS }\end{array}$ & $\begin{array}{r}2,161 \\
= \\
-\end{array}$ & $\begin{array}{l}\overline{-} \\
\overline{-}\end{array}$ & $\begin{array}{l}- \\
\overline{-} \\
-\end{array}$ & $\begin{array}{l}- \\
\overline{-} \\
-\end{array}$ & 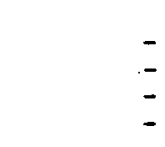 &. & $\begin{array}{r}114,3) 1 \\
= \\
=\end{array}$ & $\begin{array}{r}-29,570 \\
- \\
-\end{array}$ & $\begin{array}{r}87,590 \\
- \\
-\end{array}$ & $62 \%$ \\
\hline $\begin{array}{l}\text { NET FOEL OSRE } \\
\text { IN TRANSORATION }\end{array}$ & 2,161 & - & - & - & - & 6.93 & 114,331 & $-29,570$ & 87.590 & $42 \pi$ \\
\hline $\begin{array}{l}\text { TOTAL GROSS FLOKS } \\
\text { LOSSES. } \varepsilon \text { OMISSIONS }\end{array}$ & $\begin{array}{r}15,361 \\
916\end{array}$ & $\begin{array}{r}1,319 \\
0\end{array}$ & $\begin{array}{r}37,382 \\
-0\end{array}$ & $\begin{array}{r}17.756 \\
-742\end{array}$ & - & $\begin{array}{r}31,9.61 \\
-1,157\end{array}$ & $\begin{array}{r}118,745 \\
-259\end{array}$ & $\begin{array}{r}15,690 \\
1,569\end{array}$ & $\begin{array}{r}209,144 \\
324\end{array}$ & $\begin{array}{r}100 \% \\
0 \%\end{array}$ \\
\hline
\end{tabular}

(1)

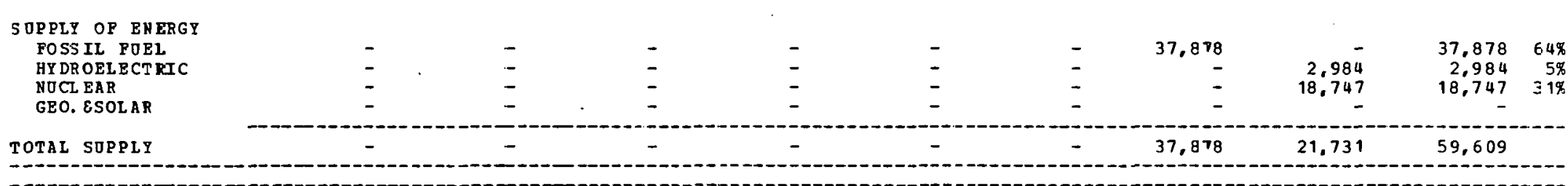

\begin{tabular}{l}
$\begin{array}{l}\text { NET IM PORTS } \\
\text { OP REGION }\end{array}$ \\
\hline
\end{tabular}


REGIONAL ENB RGY BALANCE STATEMENT

PIES MID MID SCENARIO

\begin{tabular}{|c|c|c|c|c|c|c|c|c|c|c|}
\hline SECTOR & $\begin{array}{l}\text { DISTILLATB } \\
\text { OIL }\end{array}$ & $\begin{array}{l}\text { RESIDOAL } \\
\text { OIL }\end{array}$ & $\begin{array}{l}\text { GASOLINE } \\
\text { (ALI D }\end{array}$ & $\begin{array}{c}\text { OTHER } \\
\text { HYDRO- } \\
\text { CARBONS } \\
\text { CS IN } 10 * * 9\end{array}$ & $\begin{array}{c}\text { CRODE } \\
\text { OIL } \\
\text { BTO'S] }\end{array}$ & $\begin{array}{l}\text { NATURAI } \\
\text { GAS }\end{array}$ & COAL & ELECTRICITY & $\begin{array}{l}\text { SECTOR } \\
\text { TOTAL }\end{array}$ & \\
\hline $\begin{array}{l}\text { P INAL DELAND SECTORS } \\
\text { RESID ENTIAL, COHH. } \\
\text { INDOS TRIAL } \\
\text { TRANS PORTATION } \\
\text { GISCELLABEOOS OSES }\end{array}$ & $\begin{array}{l}5,123 \\
2,581 \\
3,698 \\
224\end{array}$ & $\begin{array}{r}829 \\
1,663 \\
10 \\
72\end{array}$ & $20,17 \overline{-}$ & $\begin{array}{r}4,076 \\
9,427 \\
910 \\
8\end{array}$ & $\begin{array}{l}- \\
-\end{array}$ & $\begin{array}{r}14,546 \\
8,035 \\
309 \\
96\end{array}$ & $\begin{array}{r}55 \\
6,704 \\
- \\
-\end{array}$ & $\begin{array}{r}5,332 \\
6,515 \\
8 \\
36\end{array}$ & $\begin{array}{r}29,961 \\
34,925 \\
25,112 \\
436\end{array}$ & $\begin{array}{r}29 \% \\
34 \% \\
24 \% \\
0 \%\end{array}$ \\
\hline $\begin{array}{l}\text { TOTAL PINAL } \\
\text { DEHAYD SECTORS }\end{array}$ & 11,626 & 2,574 & 20,177 & 14,421 & - & 22,986 & 6,759 & 11,891 & 90.434 & $88 \%$ \\
\hline $\begin{array}{l}\text { TRANSP ORMATION } \\
\text { EL BCTRICITY GEN. } \\
\text { PETR OLEOM PRODOCTS } \\
\text { BATURAL GAS } \\
\text { SYRTEETICS }\end{array}$ & $\begin{array}{r}995 \\
-942 \\
- \\
-\end{array}$ & $\begin{array}{r}-403 \\
-\end{array}$ & $\begin{array}{r}- \\
-1,744 \\
- \\
-\end{array}$ & $\begin{array}{r}- \\
-809 \\
-\end{array}$ & $\begin{array}{r}- \\
3,743 \\
-\end{array}$ & $\begin{array}{r}109 \\
188 \\
- \\
-\end{array}$ & $\begin{array}{r}14,594 \\
= \\
=\end{array}$ & $\begin{array}{r}-4,093 \\
- \\
-\end{array}$ & $\begin{array}{r}11,605 \\
31 \\
-\end{array}$ & $\begin{array}{r}11 \% \\
0 \%\end{array}$ \\
\hline $\begin{array}{l}\text { NET POEL OSED } \\
\text { IN TRABSPOBHATION }\end{array}$ & 52. & -403 & $-1,744$ & -809 & 3,743 & 297 & 14,594 & -4.093 & 11.636 & $11 \%$ \\
\hline $\begin{array}{l}\text { TOTAL GROSS FLONS } \\
\text { LOSSES } \& \text { OHISSIONS }\end{array}$ & $\begin{array}{r}12,621 \\
729\end{array}$ & 2,574 & $\begin{array}{r}20.177 \\
-0\end{array}$ & $\begin{array}{r}14,421 \\
-602\end{array}$ & $\begin{array}{r}3,743 \\
186\end{array}$ & $\begin{array}{r}23,283 \\
-843\end{array}$ & $\begin{array}{r}21,353 \\
-47\end{array}$ & $\begin{array}{r}11.891 \\
1.189\end{array}$ & $\begin{array}{r}102,070 \\
612\end{array}$ & $\begin{array}{r}99 \% \\
1 \%\end{array}$ \\
\hline OTAL HET OSAGE & 12,407 & 2,170 & 18,432 & 13,008 & 3,930 & 22,440 & 21,305 & 8,987 & 102,682 & \\
\hline
\end{tabular}

S UPRLY OP RHERGI
POSS IL POEL
HYDROELCTRIC
NOCL EAR
GEO. ESOLAR

\begin{tabular}{l}
$\begin{array}{l}\text { MET IM PORTS } \\
\text { OP REGIOH }\end{array}$ \\
\hline
\end{tabular}


REG IONAL JNERGY BALANCE STATEMENT

PIES IIT IIID SCENARIC

\begin{tabular}{|c|c|c|c|c|c|c|c|c|c|c|}
\hline SBCTOR & $\begin{array}{c}\text { DISTILLATE } \\
\text { OIL }\end{array}$ & $\begin{array}{l}\text { RESIDDAL } \\
\text { OIL }\end{array}$ & $\begin{array}{l}\text { GASOLIAE } \\
\text { (AIL O }\end{array}$ & $\begin{array}{c}\text { CTHER } \\
\text { HYDRO- } \\
\text { DABBONS } \\
\text { TI IN } 10 * * 9\end{array}$ & $\begin{array}{l}\text { CEODE } \\
\text { OIL } \\
\text { BTO'S) }\end{array}$ & $\begin{array}{l}\text { NATURAL } \\
\text { GAS }\end{array}$ & CCRL & ELECTRICITY & $\begin{array}{l}\text { SECTOK } \\
\text { TOTAL }\end{array}$ & \\
\hline $\begin{array}{l}\text { PINAL DEHAND SECTORS } \\
\text { BES ID ENTIAL, COMN. } \\
\text { IND OSTRIAL } \\
\text { TRANSPORTAZYON } \\
\text { MISCE LLA EOOS OSES }\end{array}$ & $\begin{array}{r}54.200 \\
20.148 \\
42.747 \\
6.315\end{array}$ & $\begin{array}{r}9,082 \\
13,425 \\
199 \\
1,872\end{array}$ & $228,88 \overline{-}$ & $\begin{array}{r}17,523 \\
106,004 \\
\therefore 0,995 \\
259\end{array}$ & $\begin{array}{l}\overline{-} \\
-\end{array}$ & $\begin{array}{r}157,4.25 \\
83,736 \\
4,952 \\
3,136\end{array}$ & $\begin{array}{r}524 \\
67.319 \\
2 \\
7\end{array}$ & $\begin{array}{r}63,847 \\
41,492 \\
190 \\
1,069\end{array}$ & $\begin{array}{r}332,601 \\
332,174 \\
297,989 \\
12,718\end{array}$ & $\begin{array}{r}238 \\
238 \\
208 \\
17\end{array}$ \\
\hline $\begin{array}{l}\text { TOTAL PINAL } \\
\text { DEMAND SECTORS }\end{array}$ & 123,410 & 24,578 & 228,886 & $1: 4,781$ & - & 249,369 & 67,352 & 106.598 & 975,474 & $66 \%$ \\
\hline $\begin{array}{l}\text { TRANSPORHATION } \\
\text { BLECTRICITY' GEN. } \\
\text { PETR OLEOM PBODOCTS } \\
\text { NATURAL GAS } \\
\text { SYNTHETIC }\end{array}$ & $\begin{array}{r}6,179 \\
-237,154 \\
=\end{array}$ & $\begin{array}{r}9,300 \\
-101,489 \\
- \\
-\end{array}$ & $\begin{array}{r}-438,38 \bar{c} \\
\overline{-}\end{array}$ & $\begin{array}{r}-203,716 \\
-\end{array}$ & $941.648 \overline{-}$ & $\begin{array}{r}846 \\
47.468 \\
- \\
-\end{array}$ & 609. $\begin{array}{r}551 \\
- \\
-\end{array}$ & $\begin{array}{r}-186,717 \\
- \\
-\end{array}$ & $\begin{array}{r}439,259 \\
7,877 \\
-\end{array}$ & $\begin{array}{r}30 \% \\
1 \%\end{array}$ \\
\hline $\begin{array}{l}\text { NET FOEL OSED } \\
\text { IN TRANSFORATION }\end{array}$ & $-230,975$ & $-92,189$ & $-438,38 C$ & $-203,716$ & 949,648 & $48,3: 14$ & 609.651 & $-186,717$ & 447,136 & $30 \%$ \\
\hline $\begin{array}{l}\text { TOTAL GROSS PLORS } \\
\text { LOSSES } \varepsilon \text { OHISSIONS }\end{array}$ & $\begin{array}{r}129,589 \\
7.492\end{array}$ & $\begin{array}{r}33,878 \\
0\end{array}$ & $\begin{array}{r}228,38 \epsilon \\
-C\end{array}$ & $\begin{array}{r}174,781 \\
-7,306\end{array}$ & $\begin{array}{r}941,648 \\
47,008\end{array}$ & $\begin{array}{l}297,683 \\
-10,783\end{array}$ & $\begin{array}{r}677,503 \\
-1,492\end{array}$ & $\begin{array}{r}106,598 \\
10,660\end{array}$ & $\begin{array}{r}1,422,610 \\
45,580\end{array}$ & $\begin{array}{r}97 \pi \\
3 \pi\end{array}$ \\
\hline
\end{tabular}

-

\begin{tabular}{|c|c|c|c|c|c|c|c|c|c|c|}
\hline$S$ OPPLY OP EDERGT & & & & & & & & & & \\
\hline FOSS IL POEL & - & - & - & - & $77,85 \subseteq$ & 336 & $1,375,293$ & - & $1,447,488$ & $100 \%$ \\
\hline HY DR OELEC? RIC & - & - & - & - & - & - & $-\quad-$ & 848 & $848 ;$ & $0 \%$ \\
\hline NOCL EAR & - & - & - & - & - & - & - & - & - & \\
\hline GEO. E SỌLAR & - & - & - & - & - & - & - & 18 & 18 & $0 \%$ \\
\hline
\end{tabular}

\section{NET IM PORTS}

OP REGION

$-10 C, 072$

$-67,610-209,994$

$-36,241$

$916,79 ?$

286.564

$-699,282$

$-70,324$

19,836

NOTES:
TRANSPORMATION LOSS: POR TRANSPOR MATI ON IOSS POR
TRANSPORMATI ON LOSS POR
EIECTRICITY GEN. $\quad=70.17 \%$
PETROLEOT PRODOCTC $=0.00$
YINORAC PRODOCTS $=0.80 \%$
YEOTAL GAS
SPETHEICS
$=0.4 \%$ 
RESIONAL ENERGY BALANCE STATEMENT

\begin{tabular}{|c|c|c|c|c|c|c|c|c|c|c|}
\hline SECTOR & $\begin{array}{l}\text { DISTILLATE } \\
\text { OIL }\end{array}$ & $\begin{array}{l}\text { RESIDDAL } \\
\text { OIL }\end{array}$ & $\begin{array}{l}\text { GASOLINE } \\
\text { (ALL D }\end{array}$ & $\begin{array}{c}\text { OTHER } \\
\text { HYDRO- } \\
\text { CARBONS } \\
\text { TS IN } 10 * 4\end{array}$ & $\begin{array}{c}\text { CRODE } \\
\text { OIL } \\
\text { BTO'SI }\end{array}$ & $\begin{array}{l}\text { NATURAL } \\
\text { GAS }\end{array}$ & $\operatorname{COAL}$ & ELECTRICITY & $\begin{array}{l}\text { SECTOR } \\
\text { TOTAL }\end{array}$ & \\
\hline $\begin{array}{l}\text { PIHAL DEHAND SECTORS } \\
\text { BES ID ENTIAL, COHA. } \\
\text { IND OSTRIAL. } \\
\text { TRA NSPORTATION } \\
\text { MISCELLANEOUS OSES }\end{array}$ & $\begin{array}{r}6,270 \\
2,566 \\
7,597 \\
755\end{array}$ & $\begin{array}{r}785 \\
1.669 \\
21 \\
259\end{array}$ & $44.91 \frac{-}{-}$ & $\begin{array}{r}7,887 \\
9,744 \\
5,429 \\
27\end{array}$ & $\begin{array}{l}\overline{-} \\
\overline{-}\end{array}$ & $\begin{array}{r}24,079 \\
15,134 \\
866 \\
422\end{array}$ & $\begin{array}{r}106 \\
13,259 \\
- \\
-\end{array}$ & $\begin{array}{r}14,290 \\
24,060 \\
7 \\
164\end{array}$ & $\begin{array}{r}53,417 \\
66,432 \\
58,832 \\
1,627\end{array}$ & $\begin{array}{r}16 \% \\
20 \% \\
18 \% \\
0 \%\end{array}$ \\
\hline $\begin{array}{l}\text { TOTAL PINAL } \\
\text { JEHAND SECTORS }\end{array}$ & 17,188 & 2,734 & 44,912 & 23,087 & - & 40,501 & 13,365 & 38,521 & 180,308 & $54 \%$ \\
\hline $\begin{array}{l}\text { TRAYSPORHATION } \\
\text { EERCTRICITY GRN. } \\
\text { PZTR OLEU FRODOCTS } \\
\text { NATORAL GAS } \\
\text { SY NT HETICS }\end{array}$ & $\begin{array}{r}4.896 \\
= \\
=\end{array}$ & $\begin{array}{l}\overline{-} \\
\overline{-}\end{array}$ & $\begin{array}{l}I \\
I\end{array}$ & $\bar{z}$ & $\begin{array}{l}5 \\
-\end{array}$ & $\begin{array}{r}480 \\
-\end{array}$ & $\begin{array}{r}212,959 \\
- \\
-\end{array}$ & $\begin{array}{r}-68,557 \\
- \\
-\end{array}$ & $\begin{array}{r}149,778 \\
- \\
-\end{array}$ & $45 \%$ \\
\hline $\begin{array}{l}\text { NET FOEL OSBD } \\
\text { II TRASSORAATION }\end{array}$ & 4,896 & - & - & - & - & 480 & 212,959 & $-68,557$ & 149,778 & $45 \%$ \\
\hline $\begin{array}{l}\text { TOTAL GROSS PLOHS } \\
\text { LOSSES } E \text { OHISSIONS }\end{array}$ & $\begin{array}{r}22,084 \\
1,276\end{array}$ & $\begin{array}{r}2,73 c \\
0\end{array}$ & $\begin{array}{r}44,912 \\
-0\end{array}$ & $\begin{array}{r}23,087 \\
-965\end{array}$ & $\overline{-}$ & $\begin{array}{r}40,981 \\
-1,484\end{array}$ & $\begin{array}{r}226,324 \\
-498\end{array}$ & $\begin{array}{r}38,521 \\
3,852\end{array}$ & $\begin{array}{r}330,086 \\
2,181\end{array}$ & $\begin{array}{r}99 \% \\
1 \%\end{array}$ \\
\hline TOTHL NET USAGE & 23,360 & $2,73 L$ & 44,911 & 22,121 & - & 39,496 & 225,825 & $-26,183$ & 332,267 & \\
\hline $\begin{array}{l}\text { SOPPLY OP ENERGY } \\
\text { POSS IL POEL } \\
\text { HYDR OELECTRIC } \\
\text { NOCL BAR } \\
\text { GEO. ESOL AR }\end{array}$ & $\bar{z}$ & $\overline{-}$ & I & $\bar{z}$ & $\begin{array}{l}\overline{-} \\
-\end{array}$ & $\bar{z}$ & $\begin{array}{r}159 \\
- \\
-\end{array}$ & $\begin{array}{r}- \\
\overline{1}\end{array}$ & $\begin{array}{r}159 \\
4,848 \\
-1\end{array}$ & $\begin{array}{r}3 \% \\
97 \% \\
0 \%\end{array}$ \\
\hline TOTKL SUPPLY & - & - & - & - & - & - & 159 & 4,849 & 5,008 & \\
\hline
\end{tabular}

\section{NEI IMPORTS}

OP REGION

23,360

2,734

44,911

22,121

39,496

225,666

$-31,032$

327,259

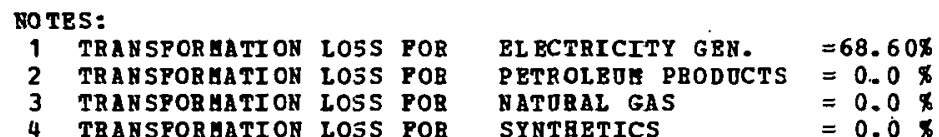

2 TRABSFORAATI ON LOSS FO

TRAYSPORHATIOY LOSS POB

WTOBAL GAS
SYNTBETICS

$=0.0 x$ 
REGIONAL ENE RGY BALANCE STATEMENT

IES MID IID SCENARIO

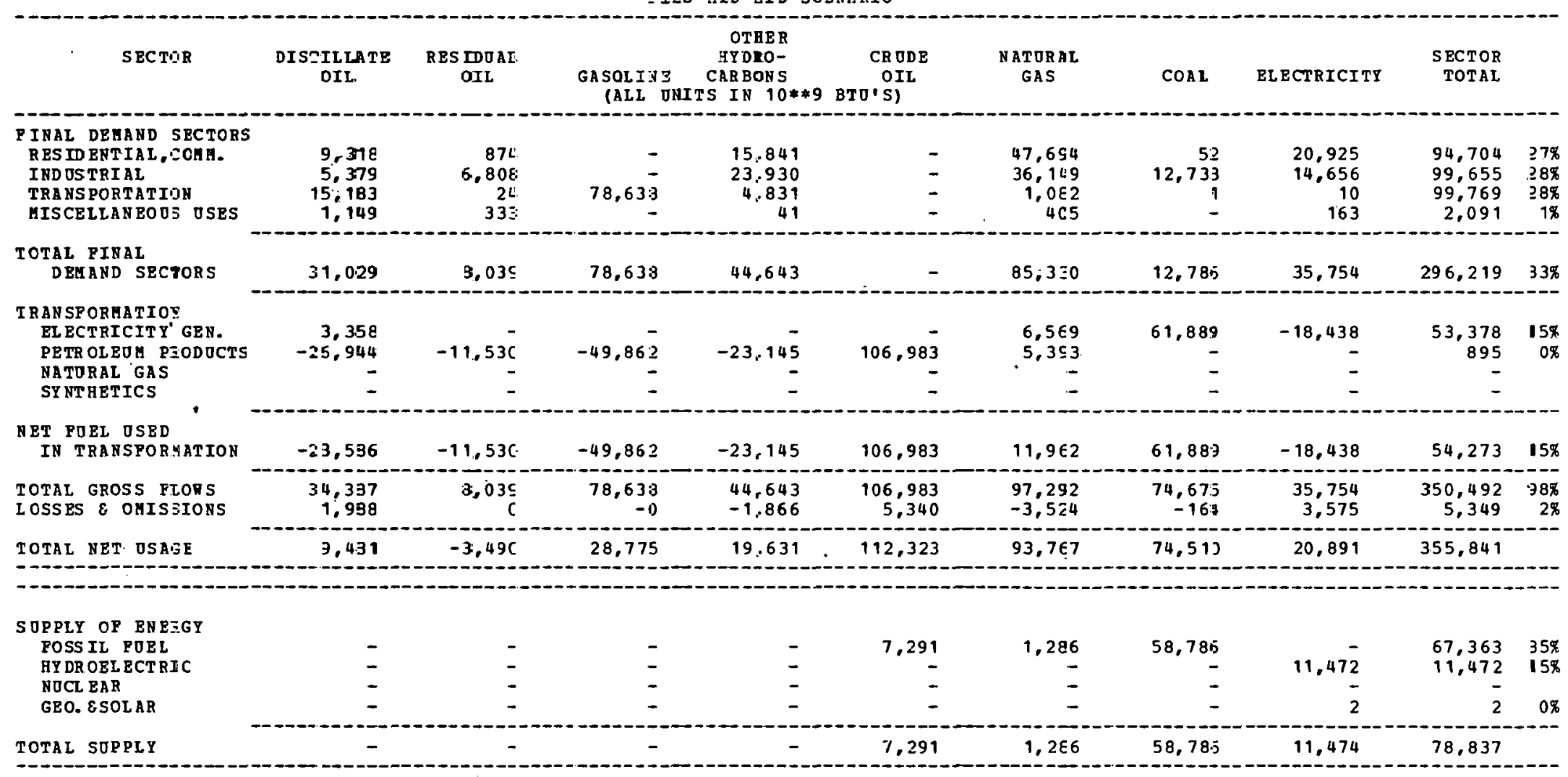

NET IM PORTS

$7,431-3: 49 C$

28,775

19.631

105,032

92,481

15,724

9,417

277,004

NOTES:

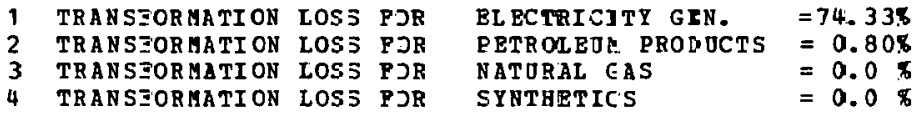


REGIONAL ENE PGY BALANCE STATEMENT
PIES MID YID SCENARIO

\begin{tabular}{|c|c|c|c|c|c|c|c|c|c|c|}
\hline SECTOR & $\begin{array}{l}\text { DISTILLATE } \\
\text { OIL }\end{array}$ & $\begin{array}{l}\text { RESIDDAL } \\
\text { OIL }\end{array}$ & $\begin{array}{l}\text { GASOLINE } \\
\text { CALI O }\end{array}$ & $\begin{array}{c}\text { OTHER } \\
\text { HYDRO- } \\
\text { CARBONS } \\
\text { TS IN } 10 * \$ 9\end{array}$ & $\begin{array}{c}\text { CR JDE } \\
\text { OIL } \\
\text { ETO'S) }\end{array}$ & $\begin{array}{l}\text { NATURAL } \\
\text { GAS }\end{array}$ & COAL & ELECTRICITY & $\begin{array}{l}\text { SECTOR } \\
\text { TOTAL }\end{array}$ & \\
\hline $\begin{array}{l}\text { ZINAL DEHAND SECTORS } \\
\text { RES IDENTIAL, CCMH. } \\
\text { IND OSTRIAL } \\
\text { ERANSPORTATION } \\
\text { WISCELLANEOUS OSES }\end{array}$ & $\begin{array}{r}9,427 \\
19,893 \\
31,135 \\
1,602\end{array}$ & $\begin{array}{r}3,532 \\
67,369 \\
- \\
1,488\end{array}$ & $81.43 \overline{-}$ & $\begin{array}{r}12,890 \\
64,732 \\
5,814 \\
33\end{array}$ & $\begin{array}{l}- \\
-\end{array}$ & $\begin{array}{r}47,934 \\
85,638 \\
2,441 \\
908\end{array}$ & $\begin{array}{r}4 \\
4,721 \\
1 \\
-\end{array}$ & $\begin{array}{r}25,133 \\
27,152 \\
- \\
290\end{array}$ & $\begin{array}{r}98,920 \\
269,505 \\
120,827 \\
4,321\end{array}$ & $\begin{array}{l}15 \% \\
42 \% \\
19 \% \\
1 \%\end{array}$ \\
\hline $\begin{array}{l}\text { TOTAL PINAL } \\
\text { DEMAND SECTORS }\end{array}$ & 62,057 & 72,389 & 81,436 & 83,469 & - & 136,921 & 4,726 & 52,575 & 493,573 & $77 \%$ \\
\hline $\begin{array}{l}\text { TEANSPORMATION } \\
\text { ELECTRICITY GEN. } \\
\text { PETROLEOM ERODOCTS } \\
\text { NATORAL GAS } \\
\text { SY NTHETICS }\end{array}$ & $\begin{array}{r}4,895 \\
- \\
-\end{array}$ & $\begin{array}{l}\overline{-} \\
\overline{-}\end{array}$ & $\begin{array}{l}- \\
\overline{-} \\
-\end{array}$ & $\begin{array}{l}- \\
\overline{-} \\
-\end{array}$ & $\begin{array}{l}- \\
\overline{-} \\
-\end{array}$ & $\begin{array}{r}25,092 \\
- \\
-\end{array}$ & $\begin{array}{r}194.976 \\
- \\
-\end{array}$ & $\begin{array}{r}-74,437 \\
- \\
-\end{array}$ & $\begin{array}{r}150,526 \\
- \\
-\end{array}$ & $239 i$ \\
\hline $\begin{array}{l}\text { NET FOEL OSED } \\
\text { IN TRANSPORMATION }\end{array}$ & 4,895 & - & - & - & - & 25,092 & 194,976 & $-74,437$ & 150,526 & $23 \%$ \\
\hline $\begin{array}{l}\text { TOTAL GROSS FLORS } \\
\text { L CSSES } \& \text { OMISSIONS }\end{array}$ & $\begin{array}{r}66,952 \\
3,870\end{array}$ & $72,3: 39$ & $\begin{array}{r}81,436 \\
-0\end{array}$ & $\begin{array}{l}83,469 \\
-3,489\end{array}$ & $\overline{-}$ & $\begin{array}{r}162,013 \\
-5,868\end{array}$ & $\begin{array}{r}199,702 \\
-439\end{array}$ & $\begin{array}{r}52,575 \\
5,258\end{array}$ & $\begin{array}{r}644,099 \\
-667\end{array}$ & $\begin{array}{r}100 \% \\
0 \%\end{array}$ \\
\hline TOTAL NET OSAGE & 70,822 & $72,3.90$ & 81,435 & 79,979 & - & 156,144 & 199,262 & $-16,603$ & 643.431 & \\
\hline $\begin{array}{l}\text { SOPPLY OF ENERGY } \\
\text { POSS IL FOEL } \\
\text { HY DROELECTRIC } \\
\text { NOCL, EAR } \\
\text { SBO. ESOLAR }\end{array}$ & $\begin{array}{l}5 \\
-\end{array}$ & I- & $\begin{array}{l}- \\
-\end{array}$ & $\begin{array}{l}- \\
-\end{array}$ & $\begin{array}{r}5,560 \\
- \\
-\end{array}$ & $\begin{array}{r}17.350 \\
- \\
-\end{array}$ & $\begin{array}{r}5,624 \\
- \\
-\end{array}$ & $\begin{array}{r}3,634 \\
21,263 \\
14\end{array}$ & $\begin{array}{r}28,534 \\
3,634 \\
21,263 \\
14\end{array}$ & $\begin{array}{r}53 \% \\
7 \% \\
40 \% \\
0 \%\end{array}$ \\
\hline TOTAL SOPPLY & - & - & - & - & 5.560 & 17,350 & 5,624 & 24,911 & 53,445 & \\
\hline
\end{tabular}

NET IM PORTS
OP REGION


BEG=ONAL ENERGY BALANCE STATEMENT

PIES MID MID.SCENARIO

\begin{tabular}{|c|c|c|c|c|c|c|c|c|c|c|}
\hline SECTOR & $\begin{array}{l}\text { DISTILLATE } \\
\text { OIL }\end{array}$ & $\begin{array}{l}\text { RESIDJAL } \\
\text { OIL }\end{array}$ & $\begin{array}{l}\text { GASOLINE } \\
\text { (ALE } \mathbb{E N I}\end{array}$ & $\begin{array}{c}\text { OZHER } \\
\text { HYDRO- } \\
\text { CARBONS } \\
\text { TS ID } 10 * 9\end{array}$ & $\begin{array}{c}\text { CRJDE } \\
\text { OIL } \\
\text { BTO'Si }\end{array}$ & $\begin{array}{l}\text { NATUFAL } \\
\text { GAS }\end{array}$ & $\operatorname{COAL}$ & ELECTRICITY & $\begin{array}{l}\text { SECTOR } \\
\text { TOTAL }\end{array}$ & \\
\hline $\begin{array}{l}\text { PINAL DEHAND SBCTOBS } \\
\text { RESID ENTIAL, COHA. } \\
\text { IND TSTRIAL } \\
\text { TRANSPORTATION } \\
\text { MISCELLANEOOS OSES }\end{array}$ & $\begin{array}{l}3,760 \\
3,589 \\
8,975 \\
1,128\end{array}$ & $\begin{array}{r}1,253 \\
11,048 \\
1,048\end{array}$ & $\begin{array}{r}- \\
36,839\end{array}$ & $\begin{array}{r}5,542 \\
2,829 \\
4,261 \\
21\end{array}$ & $\begin{array}{l}- \\
-\end{array}$ & $\begin{array}{r}22, c 18 \\
18,711 \\
1, \leq 23 \\
5.04\end{array}$ & $\begin{array}{r}2 \\
678 \\
- \\
-\end{array}$ & $\begin{array}{r}11,586 \\
3,809 \\
- \\
184\end{array}$ & $\begin{array}{r}44,161 \\
40,124 \\
51,968 \\
2,885\end{array}$ & $\begin{array}{r}31 \% \\
28 \% \\
37 \% \\
2 \%\end{array}$ \\
\hline $\begin{array}{l}\text { TOTAL FINAL } \\
\text { DEMAND SECTORS }\end{array}$ & 17,452 & 113,349 & $36,8] 9$ & 12,653 & - & $42, \in-16$ & 680 & 15,579 & 139,138 & $98 \%$ \\
\hline $\begin{array}{l}\text { TR AN SP ORHATION } \\
\text { BL ECTRICITE GEN. } \\
\text { PETR OLEOM FRODDCTS } \\
\text { NATORAL GAS } \\
\text { SYNTHETICS }\end{array}$ & $\begin{array}{r}1,450 \\
- \\
-\end{array}$ & $\bar{z}$ & $\begin{array}{l}\overline{-} \\
\overline{-}\end{array}$ & $\begin{array}{l}\overline{-} \\
\overline{-}\end{array}$ & $\begin{array}{l}\overline{-} \\
\overline{-}\end{array}$ & $\begin{array}{r}1,-75 \\
= \\
-\end{array}$ & $\begin{array}{l}\bar{z} \\
\bar{z}\end{array}$ & $\begin{array}{r}-1,043 \\
- \\
-\end{array}$ & $\begin{array}{r}2,182 \\
- \\
-\end{array}$ & $2 \%$ \\
\hline $\begin{array}{l}\text { NET POEL OSED } \\
\text { IN TRANSPORMATION }\end{array}$ & 1,450 & - & - & - & - & 1.75 & - & -1.043 & 2,182 & $2 \pi$ \\
\hline $\begin{array}{l}\text { TOTAL GROSS IELOHS } \\
\text { LOSSES } \& \text { OMISSIONS }\end{array}$ & $\begin{array}{r}18,902 \\
1,092\end{array}$ & $\begin{array}{r}13,349 \\
0\end{array}$ & $\begin{array}{r}36,809 \\
-0\end{array}$ & $\begin{array}{r}12,653 \\
-528\end{array}$ & $\begin{array}{l}- \\
-\end{array}$ & $\begin{array}{l}44,3 \subseteq 1 \\
-1,607\end{array}$ & $\begin{array}{r}680 \\
-1\end{array}$ & $\begin{array}{r}15,579 \\
1,558\end{array}$ & $\begin{array}{r}141,320 \\
512\end{array}$ & $\begin{array}{r}100 \% \\
0 \%\end{array}$ \\
\hline $\begin{array}{l}\text { S OPPLY OP ENIBRGY } \\
\text { FOSS IL POEZ } \\
\text { HYDR OELECTZIC } \\
\text { NOCL EAR } \\
\text { GEO. ESOLAR }\end{array}$ & $\bar{z}$ & $\bar{z}$ & $\begin{array}{l}\bar{z} \\
\bar{z}\end{array}$ & $\bar{z}$ & $\begin{array}{r}52,135 \\
= \\
=\end{array}$ & $\begin{array}{r}296,365 \\
- \\
-\end{array}$ & $\begin{array}{r}25,490 \\
= \\
=\end{array}$ & $5,94 \overline{1}$ & $\begin{array}{r}373,990 \\
5,941 \\
-\end{array}$ & $\begin{array}{r}98 \% \\
25\end{array}$ \\
\hline TOTAE SUPPLY & - & - & - & - & 52.135 & 296,365 & 25,490 & 5,945 & 379,935 & \\
\hline
\end{tabular}

NET IM PORTS

OP REGION

19.994

13,349

$36, \varepsilon 08$

$1: 2,124$

$-52,135$

$-253,581$

$-24, \varepsilon 11$

10,149

$-238,102$

NO TES:

1 TRANSPORMATI OY LOSS FOR

TRAFSPORHATI OY LOSS POB

TRANSPORMATIOY LOSS PO

TRANSPORMATI OH LOSS FOR

ELECTRICITY GEN.

PETROLEH PPODOCTS $=67.65 \%$

NATURAL GAS

$=0.0 \%$

STNTHETICS

$=0.0 \%$
$=0.0 \%$ 
3EGIONAL ENERG BALANCE STATEMENT

PIES MID MID SCENARIO

\begin{tabular}{|c|c|c|c|c|c|c|c|c|c|c|}
\hline SECTOR & $\begin{array}{l}\text { DISTILLATE } \\
\text { OIL }\end{array}$ & $\begin{array}{l}\text { RES IDOAL } \\
\text { OIL }\end{array}$ & $\begin{array}{l}\text { GASOLINE } \\
\text { \{ALI ONI }\end{array}$ & $\begin{array}{c}\text { OTHER } \\
\text { HYDRO- } \\
\text { CARBONS } \\
\text { TS IN } 10 * 9\end{array}$ & $\begin{array}{c}\text { CR DDE } \\
\text { OIL } \\
\text { BTO'S) }\end{array}$ & $\begin{array}{l}\text { NATORAL } \\
\text { GAS }\end{array}$ & COAL & ELECTRICITY & $\begin{array}{r}\text { SECTOR } \\
\text { TOTAL }\end{array}$ & \\
\hline $\begin{array}{l}\text { FINAL DEHAND SECTORS } \\
\text { RESID ENTIAL, COMM. } \\
\text { INDUSTRIAL } \\
\text { TRANSPORTATION } \\
\text { MISCELLANEOOS OSZS }\end{array}$ & $\begin{array}{r}7,432 \\
7,944 \\
17,206 \\
1,266\end{array}$ & $\begin{array}{r}1,308 \\
25,343 \\
1,176\end{array}$ & 96,927 & $\begin{array}{r}13,802 \\
116,937 \\
12,237 \\
24\end{array}$ & $\begin{array}{l}\overline{-} \\
\overline{-}\end{array}$ & $\begin{array}{r}56,115 \\
302,018 \\
5,666 \\
574\end{array}$ & $\begin{array}{r}5 \\
4,812 \\
- \\
-\end{array}$ & $\begin{array}{r}28,717 \\
22,708 \\
- \\
212\end{array}$ & $\begin{array}{r}107,379 \\
479,762 \\
132,036 \\
3,252\end{array}$ & $\begin{array}{r}11 \% \\
51 \% \\
14 \% \\
0 \%\end{array}$ \\
\hline $\begin{array}{l}\text { T JTAL FINAL } \\
\text { DEMAND SECTORS }\end{array}$ & 33,848 & 27,827 & 96,927 & 143.000 & - & 364.373 & 4,817 & 51,637 & 722,429 & $77 \%$ \\
\hline $\begin{array}{l}\text { T ZANSP ORMATION } \\
\text { EL ECTRICITY GEN. } \\
\text { PETR OLEOM ERODOCTS } \\
\text { NATURAL GAS } \\
\text { SYNT UETICS }\end{array}$ & $\begin{array}{r}4,808 \\
-173,904 \\
-\end{array}$ & $\begin{array}{r}-74,421 \\
-\end{array}$ & $\begin{array}{r}-321,829 \\
-\end{array}$ & $\begin{array}{r}-149,384 \\
-\end{array}$ & $\begin{array}{r}- \\
- \\
-\end{array}$ & $\begin{array}{r}70,884 \\
34,808 \\
- \\
-\end{array}$ & $\begin{array}{r}209,739 \\
- \\
-\end{array}$ & $\begin{array}{r}-94,431 \\
- \\
-\end{array}$ & $\begin{array}{r}191,000 \\
5,778 \\
-\end{array}$ & $\begin{array}{r}20 \% \\
1 \%\end{array}$ \\
\hline $\begin{array}{l}\text { NET POEL USED } \\
\text { IN TRANSFORMATION. }\end{array}$ & $-169,096$ & -74.421 & $-321,829$ & $-149,384$ & 690.508 & 105,692 & 209,739 & $-94,431$ & 196,778 & $21 \%$ \\
\hline $\begin{array}{l}\text { TOTAL GROSS FLORS } \\
\text { LOSSES } \varepsilon \text { OMISSIONS }\end{array}$ & $\begin{array}{r}38,556 \\
2,234\end{array}$ & $\begin{array}{r}27, \varepsilon 27 \\
0\end{array}$ & $\begin{array}{r}96,927 \\
-0\end{array}$ & $\begin{array}{r}143,000 \\
-5,977\end{array}$ & $\begin{array}{r}690,508 \\
34,471\end{array}$ & $\begin{array}{r}470,065 \\
-17,027\end{array}$ & $\begin{array}{r}214,556 \\
-472\end{array}$ & $\begin{array}{r}51,637 \\
5,164\end{array}$ & $\begin{array}{r}919,207 \\
18,393\end{array}$ & $\begin{array}{r}98 \% \\
2 \%\end{array}$ \\
\hline $\begin{array}{l}\text { S OPPLY OF EN ERGY } \\
\text { POSS IL POEL } \\
\text { HY DR OEL ECTRIC } \\
\text { NOCL EAR } \\
\text { GEO. ESOLAR }\end{array}$ & $\bar{z}$ & $\begin{array}{l}\overline{-} \\
\overline{-}\end{array}$ & $\begin{array}{l}- \\
-\end{array}$ & $\begin{array}{l}- \\
- \\
-\end{array}$ & $\begin{array}{r}86,493 \\
- \\
-\end{array}$ & $\begin{array}{r}11,162 \\
- \\
-\end{array}$ & $\begin{array}{r}35,142 \\
- \\
-\end{array}$ & $\begin{array}{r}6,686 \\
27.978 \\
14\end{array}$ & $\begin{array}{r}132,797 \\
6,686 \\
27,978 \\
14\end{array}$ & $\begin{array}{r}79 \% \\
4 \% \\
17 \% \\
0 \%\end{array}$ \\
\hline TOTAL SUPPLY & - & - & - & - & 86,493 & 11,162 & 35,142 & 34,678 & 167,475 & \\
\hline
\end{tabular}

\begin{tabular}{|c|c|c|c|c|c|c|c|c|c|}
\hline $\begin{array}{l}\text { HET IM PORTS } \\
\text { OF REGION }\end{array}$ & $-133,013$ & $-46,593$ & $-224,902$ & $-12,361$ & 638,486 & 441,876 & 173,941 & $-72,307$ & 770,125 \\
\hline
\end{tabular}

$\begin{array}{lllll}\text { NO TES: } & & & \\ 1 & \text { TRANSPORMATION LOSS } & \text { POR } & \text { ELECTRICITY GEN. } & =66.92 \% \\ 2 & \text { TRANSPORMATI ON LOSS POR } & \text { PETROLEOM PRODOCTS } & =0.80 \% \\ 3 & \text { TRANSPORATION LOSS POR } & \text { NATURAL GAS } & =0.0 \% \\ 4 & \text { TRANSPORATION LOSS POB } & \text { SYRTATICS } & =0.0 \%\end{array}$


REGIONAL EFERGY BALARCE STATEMEUT

PIES MED NID SCENARIO

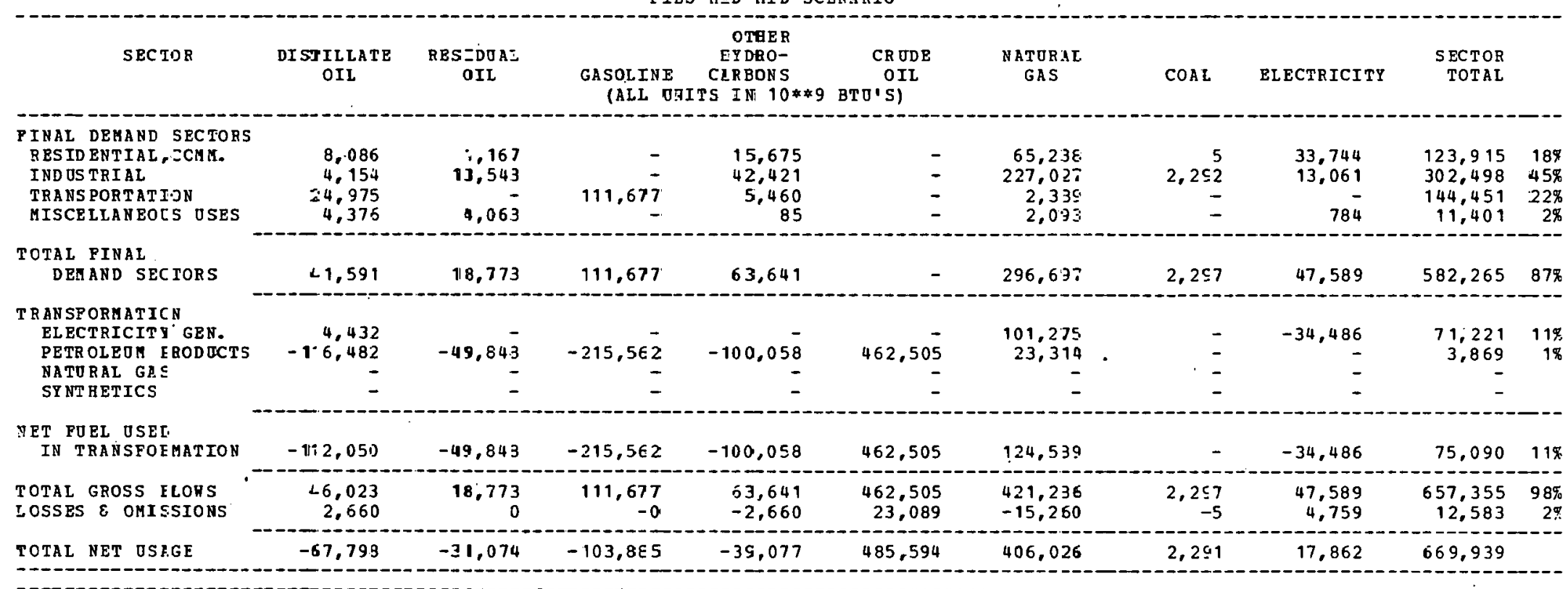

\begin{tabular}{|c|c|c|c|c|c|c|c|c|c|c|}
\hline SOPPLT OP EMERGY & & & & & & & & & & \\
\hline FOSS IL POEL & - & - & - & - & 481,862 & 897,942 & - & - & $1,379,804$ & $100 \%$ \\
\hline HY DE OELECTEIC & - & - & - & - & - & - & - & 29 & 29 & $0 \%$ \\
\hline NOCI EAR & - & - & - & - & - & - & - & $\overline{-}$ & - & \\
\hline GEO. ESOLAR & - & - & - & - & - & - & - & 12 & 12 & $0 \%$ \\
\hline TOTAL SUPPLY & - & - & - & - & 481,862 & 897,942 & - & 41 & $1,379,845$ & \\
\hline
\end{tabular}

NET IM PORTS

NOTES:

\begin{tabular}{|c|c|c|c|c|}
\hline & & & & \\
\hline $\begin{array}{l}\text { R A SPORMA TI ON } \\
\text { RAN SFOR MATI ON }\end{array}$ & $\begin{array}{l}\operatorname{loss} \\
\operatorname{Loss} \\
\operatorname{Los} 5\end{array}$ & $\begin{array}{l}\text { POR } \\
\text { POR } \\
\text { POR }\end{array}$ & $\begin{array}{l}\text { ELECTRICITY GEX. } \\
\text { PETEDLEUM PRCDUCTS } \\
\text { NATURAL GAS }\end{array}$ & \\
\hline AN SPORAATI ON & Loss & POR & SYNTAETICS & \\
\hline
\end{tabular}




\begin{tabular}{|c|c|c|c|c|c|c|c|c|c|c|}
\hline & & & $\begin{array}{r}\text { REGI ONAL } \\
\text { PIES }\end{array}$ & $\begin{array}{l}\text { ENE RGY BALA } \\
\text { MID HID SCE }\end{array}$ & $\begin{array}{l}\text { ANCE STATE } \\
\text { ENARIO }\end{array}$ & & & & & \\
\hline SECTOR & $\begin{array}{l}\text { DISTILLATE } \\
\text { OIL }\end{array}$ & $\begin{array}{l}\text { 9ES IDDAL } \\
\text { OIL }\end{array}$ & $\begin{array}{l}\text { GASOLINE } \\
\text { (ALL ONI? }\end{array}$ & $\begin{array}{c}\text { OTHER } \\
\text { HYDRO- } \\
\text { CARBONS } \\
\text { TS IN } 10 * \$ 9\end{array}$ & $\begin{array}{c}\text { CR ODE } \\
\text { OIL } \\
3 T 0 \cdot 5)\end{array}$ & $\begin{array}{l}\text { NATORAL } \\
\text { GAS }\end{array}$ & $\operatorname{COAL}$ & ELECTRICITY & $\begin{array}{l}\text { SECTOR } \\
\text { TOTAL }\end{array}$ & \\
\hline $\begin{array}{l}\text { PINAL DEHAND SECTORS } \\
\text { RESIDENTIAL, CONH. } \\
\text { INDOSTRIAI } \\
\text { TRANSPORTATION } \\
\text { MISCE LLAYEOOS OSBS }\end{array}$ & $\begin{array}{l}2,295 \\
1,835 \\
2,822 \\
1,165\end{array}$ & $\begin{array}{r}307 \\
5.459 \\
948 \\
1,081\end{array}$ & $\begin{array}{r}- \\
- \\
35,240 \\
-\end{array}$ & $\begin{array}{r}4,951 \\
7,753 \\
1,831 \\
54\end{array}$ & $\begin{array}{l}\overline{-} \\
\overline{-}\end{array}$ & $\begin{array}{r}16,711 \\
96,757 \\
585 \\
1,531\end{array}$ & $\begin{array}{r}1 \\
1,208 \\
- \\
-\end{array}$ & $\begin{array}{r}9,365 \\
7,906 \\
- \\
658\end{array}$ & $\begin{array}{r}33,630 \\
120,918 \\
41,426 \\
4,489\end{array}$ & $\begin{array}{r}14 \% \\
52 \% \\
18 \% \\
2 \%\end{array}$ \\
\hline $\begin{array}{l}\text { TOTAL PINAL } \\
\text { DEMAND SECTORS }\end{array}$ & 8,117 & 7,795 & 35,240 & 14,589 & - & 115,584 & 1,209 & 17,929 & 200,463 & $86 \%$ \\
\hline $\begin{array}{l}\text { TRANSPORHATICN } \\
\text { EL BCTRICITY GEN. } \\
\text { PETR OLEO F FODOZTS } \\
\text { NA TORAL GAS } \\
\text { SY NT HETICS }\end{array}$ & $\begin{array}{r}1,733 \\
-32,883 \\
-\end{array}$ & $\begin{array}{r}-14,024 \\
-\end{array}$ & $\begin{array}{r}-60,83 \overline{0} \\
-\end{array}$ & $\begin{array}{r}-28,35 \overline{-} \\
-\end{array}$ & $\begin{array}{r}130,580 \\
-\end{array}$ & $\begin{array}{r}39,718 \\
6,603 \\
- \\
-\end{array}$ & $\begin{array}{l}- \\
\overline{-}\end{array}$ & $\begin{array}{r}-13,378 \\
- \\
-\end{array}$ & $\begin{array}{r}28,073 \\
1,093 \\
- \\
-\end{array}$ & $\begin{array}{r}12 \% \\
0 \%\end{array}$ \\
\hline $\begin{array}{l}\text { NET POEL OSED } \\
\text { IN TRANSPOBHATION }\end{array}$ & $-31,150$ & $-14,024$ & $-60,830$ & $-28,352$ & 130,580 & 46,321 & - & $-13,378$ & 29,166 & $13 \%$ \\
\hline $\begin{array}{l}\text { TOTAL GROSS PLOHS } \\
\text { LOSSES \& OMISSIONS }\end{array}$ & $\begin{array}{r}9,850 \\
569\end{array}$ & $\begin{array}{r}7,795 \\
0\end{array}$ & $\begin{array}{r}35,240 \\
-0\end{array}$ & $\begin{array}{r}14,589 \\
-609\end{array}$ & $\begin{array}{r}130,580 \\
6,518\end{array}$ & $\begin{array}{r}161,905 \\
-5,864\end{array}$ & $\begin{array}{r}1.209 \\
-2\end{array}$ & $\begin{array}{r}17,929 \\
1,793\end{array}$ & $\begin{array}{r}229,629 \\
2,404\end{array}$ & $\begin{array}{r}99 \% \\
1 \%\end{array}$ \\
\hline TOTAL NET OSAGE & $-22,464$ & $-6,229$ & $-25,590$ & $-14,373$ & 137,099 & 156,040 & 1,206 & 6,344 & 232,033 & \\
\hline
\end{tabular}

\begin{tabular}{|c|c|c|c|c|c|c|c|c|c|c|}
\hline $\begin{array}{l}\text { SOPPLY OP ENEEGY } \\
\text { POSS IL POEL }\end{array}$ & - & - & - & - & 214,197 & 75,213 & - & - & 289,410 & $100 \pi$ \\
\hline HY DROELECTRIC & - & - & - & - & - & - & - & 11 & 11 & $0 \%$ \\
\hline NOCL EAR & - & - & - & - & - & - & - & $\overline{-}$ & $\overline{-}$ & \\
\hline GEO. \&SOLAR & - & - & - & - & - & - & - & 5 & 5 & $0 x$ \\
\hline T JTAL SOPPLY & - & - & - & - & 214,197 & 75,213 & - & 16 & 289,426 & \\
\hline
\end{tabular}

NET IM PORTS
OR REGION


REGIONLL ENERTY BALANCE STATEMENT

PIBS MID II D SCENARIO

\begin{tabular}{|c|c|c|c|c|c|c|c|c|c|c|}
\hline SECTOR & $\begin{array}{l}\text { DISTILIATE } \\
\text { OII }\end{array}$ & $\begin{array}{l}\text { RESIDUAL } \\
\text { CIIL }\end{array}$ & $\begin{array}{l}\text { GASOL INE } \\
\text { (ALL OUI }\end{array}$ & $\begin{array}{c}\text { OTAER } \\
\text { EYDSO- } \\
\text { CEBBDNS } \\
\text { TS IN } 10 * * 9\end{array}$ & $\begin{array}{c}\text { CR ODE } \\
\text { OIL } \\
\text { BTO' } 5 \text { ) }\end{array}$ & $\begin{array}{l}\text { NATORLL } \\
\text { GAS }\end{array}$ & COAL. & ELECTRICITY & $\begin{array}{r}\text { SECTOR } \\
\text { TOTAL }\end{array}$ & \\
\hline $\begin{array}{l}\text { PINAL DEHAND SECTORS } \\
\text { RESID ERTIAL, COMA. } \\
\text { IND TSTRIAL } \\
\text { TRARSPORTATION } \\
\text { GISCELLABEOUS OSES }\end{array}$ & $\begin{array}{r}2,184 \\
2,861 \\
14 . \varepsilon 75 \\
\equiv 81\end{array}$ & $\begin{array}{r}423 \\
7.557 \\
4.025 \\
35:\end{array}$ & $\begin{array}{r}- \\
34,16.8 \\
-\end{array}$ & $\begin{array}{r}4.883 \\
35.704 \\
6.394 \\
11\end{array}$ & $\begin{array}{l}- \\
-\end{array}$ & $\begin{array}{r}14,906 \\
124,234 \\
1,635 \\
275\end{array}$ & $\begin{array}{r}- \\
1,379 \\
-\end{array}$ & $\begin{array}{r}10,134 \\
12,602 \\
- \\
103\end{array}$ & $\begin{array}{r}32,530 \\
184,337 \\
61,097 \\
1,121\end{array}$ & $\begin{array}{r}10 \% \\
55 \% \\
18 \% \\
0 \%\end{array}$ \\
\hline $\begin{array}{l}\text { TOTAL PINAL } \\
\text { DEMAND SECTORS }\end{array}$ & $20, \triangleq 01$ & $1 \approx, 35 \%$ & 34,168 & 46,992 & - & 141,045 & 1,379 & 22,839 & 279,085 & $83 \%$ \\
\hline $\begin{array}{l}\text { TRANSPORMATIOV } \\
\text { BLECTRICITY GEN. } \\
\text { PETE OLEOM PRODOCTS } \\
\text { NATURAL GAS } \\
\text { SYNTHETICS }\end{array}$ & $\begin{array}{r}2,127 \\
-33,170 \\
=\end{array}$ & $\begin{array}{r}- \\
-8,36.5 \\
-\end{array}$ & $\begin{array}{r}-140,10.1 \\
- \\
-\end{array}$ & $\begin{array}{r}-.31,698 \\
-\end{array}$ & $\begin{array}{r}337,790 \\
-\end{array}$ & $\begin{array}{r}17,872 \\
28,815 \\
-\end{array}$ & $\begin{array}{r}44,148 \\
= \\
-\end{array}$ & $\begin{array}{r}-21.203 \\
- \\
-\end{array}$ & $\begin{array}{r}42,944 \\
3,271 \\
- \\
-\end{array}$ & $\begin{array}{r}13 \% \\
1 \%\end{array}$ \\
\hline $\begin{array}{l}\text { UET FOBL OSED } \\
\text { IN TRANSPORHATION }\end{array}$ & $-21,<43$ & $-\varepsilon, 36 . j$ & $-140,10.1$ & $--31,698$ & 337,790 & $46,68 \mathrm{i}$ & 44,148 & $-21,203$ & 46,215 & $14 \%$ \\
\hline $\begin{array}{l}\text { TOTAL GROSS FLORS } \\
\text { LOSSES } \& \text { OMISSIONS }\end{array}$ & $\begin{array}{l}22,428 \\
1,296\end{array}$ & 12,359 & $\begin{array}{r}34,168 \\
-0\end{array}$ & $\begin{array}{l}46,992 \\
-1,964\end{array}$ & $\begin{array}{r}337,790 \\
16,863\end{array}$ & $\begin{array}{r}187,734 \\
-6,8 i 30\end{array}$ & $\begin{array}{r}45,527 \\
-100\end{array}$ & $\begin{array}{r}22,839 \\
2,284\end{array}$ & $\begin{array}{r}325,300 \\
11,579\end{array}$ & $\begin{array}{r}97 \% \\
3 \%\end{array}$ \\
\hline
\end{tabular}

\begin{tabular}{|c|c|c|c|c|c|c|c|c|c|c|}
\hline SOPPLY OF BNERGT & & & & & & & & & & \\
\hline FOSS IL FOEL & - & - & - & - & 382,875 & $1,033,434$ & - & - & $1,416,359$ & $100 \%$ \\
\hline HY DR OELBCT EIC & - & - & - & - & - & - & - & 14 & 14 & $0 \%$ \\
\hline NOCL BAR & - & - & - & - & - & - & - & - & - & \\
\hline GEO. ESOLAR & - & - & - & - & - & - & - & 5 & 5 & $0 \pi$ \\
\hline TOTAL SOPPLY & - & - & - & - & 382,875 & $1,033,434$ & - & 19 & $1,416,378$ & \\
\hline
\end{tabular}

-

HET IU PORTS
OP REGION


3EA ECONONIC AREA 123

REGIONAL ENERGY BALANCE STATEMENT

\begin{tabular}{|c|c|c|c|c|c|c|c|c|c|c|}
\hline SECTOR & $\begin{array}{l}\text { DISTILLATE } \\
\text { OIL }\end{array}$ & $\begin{array}{l}\text { RESILUAL } \\
\text { OIL }\end{array}$ & $\begin{array}{l}\text { GASOLINE } \\
\text { (ALL ONI }\end{array}$ & $\begin{array}{c}\text { OTHER } \\
\text { HYDRO- } \\
\text { CARBONS } \\
\text { TS IN } 10 * * 9\end{array}$ & $\begin{array}{c}\text { CR DDE } \\
\text { OIL } \\
\text { BTO'S) }\end{array}$ & $\begin{array}{l}\text { NATORAL } \\
\text { GAS }\end{array}$ & $\operatorname{COAL}$ & ELECTRICITY & $\begin{array}{l}\text { SECTOR } \\
\text { TOTAL }\end{array}$ & \\
\hline $\begin{array}{l}\text { PINAL DEHAND SECEORS } \\
\text { RESID ENTIAL, CCHA. } \\
\text { IND OSTRIL } \\
\text { TRANSPORTATION } \\
\text { MISCELLANEOOS OSES }\end{array}$ & $\begin{array}{r}1,366 \\
1,387 \\
6,644 \\
349\end{array}$ & $\begin{array}{r}486 \\
2,926 \\
1,604 \\
323\end{array}$ & $\begin{array}{r}- \\
- \\
27,847 \\
-\end{array}$ & $\begin{array}{r}3,997 \\
3,879 \\
2,195 \\
8\end{array}$ & $\begin{array}{l}- \\
-\end{array}$ & $\begin{array}{r}11,568 \\
48,583 \\
541 \\
188\end{array}$ & $\begin{array}{r}- \\
856 \\
-\end{array}$ & $\begin{array}{r}9,340 \\
8,964 \\
- \\
76\end{array}$ & $\begin{array}{r}27,257 \\
66,595 \\
38,831 \\
944\end{array}$ & $\begin{array}{l}15 \% \\
36 \% \\
21 \% \\
1 \%\end{array}$ \\
\hline $\begin{array}{l}\text { TOTAL FINAL } \\
\text { DEMAND SECTORS }\end{array}$ & 10,246 & 5,339 & 27,847 & 10,079 & - & 60,880 & 856 & 18,380 & 133,627 & $72 \pi$ \\
\hline $\begin{array}{l}\text { TRAN SP ORHATION } \\
\text { EL ECTRICITY GEN. } \\
\text { PETR OLEO FRODUCTS } \\
\text { NATORAL GAS } \\
\text { SY NT HETICS }\end{array}$ & $\begin{array}{r}1,711 \\
= \\
-\end{array}$ & $\begin{array}{l}\overline{-} \\
\overline{-}\end{array}$ & $\begin{array}{l}\overline{-} \\
\overline{-}\end{array}$ & $\begin{array}{l}\bar{z} \\
\bar{z}\end{array}$ & $\begin{array}{l}\overline{-} \\
\overline{-}\end{array}$ & $\begin{array}{r}35,185 \\
= \\
=\end{array}$ & $\begin{array}{r}44,102 \\
- \\
-\end{array}$ & $\begin{array}{r}-26,731 \\
- \\
-\end{array}$ & $\begin{array}{r}54,267 \\
- \\
-\end{array}$ & $29 \%$ \\
\hline $\begin{array}{l}\text { NET PDEL OSED } \\
\text { IN TRANSPORHATION }\end{array}$ & 1,711 & - & - & - & - & 35,185 & 44,102 & $-26,731$ & 54,267 & $29 \pi$ \\
\hline $\begin{array}{l}\text { TOTAL GROSS FLORS } \\
\text { LOSSES E OMISSIONS }\end{array}$ & $\begin{array}{r}11.957 \\
691\end{array}$ & $\begin{array}{r}5,339 \\
0\end{array}$ & $\begin{array}{r}27,847 \\
-0\end{array}$ & $\begin{array}{r}10,079 \\
-421\end{array}$ & - & $\begin{array}{l}96,065 \\
-3,479\end{array}$ & $\begin{array}{r}44,958 \\
-99\end{array}$ & $\begin{array}{r}18,380 \\
1,838\end{array}$ & $\begin{array}{r}187,894 \\
-1,470\end{array}$ & $\begin{array}{r}101 \% \\
0 \%\end{array}$ \\
\hline
\end{tabular}

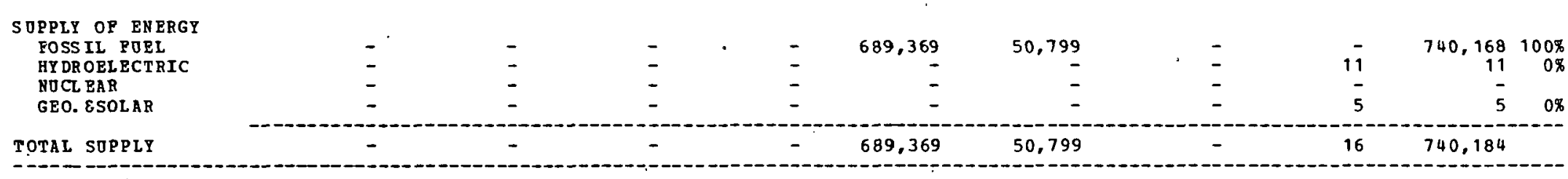

\begin{tabular}{|c|c|c|c|c|c|c|c|c|c|}
\hline $\begin{array}{l}\text { NET IM PORTS } \\
\text { OP REGION }\end{array}$ & $12,6.48$ & $5, \dot{339}$ & 27,846 & 9,657 & $-689,369$ & 41,786 & 44,858 & $-6,528$ & $-553,760$ \\
\hline
\end{tabular}

$\begin{array}{lllll}\text { NOTES: } & & & \\ 1 & \text { TRANSFORMATI ON } & \text { LOSS POR } & \text { ELECTRECITY GEN. } & =67.00 \% \\ 2 & \text { TRANSPORMATI ON } & \text { LOSS FOR } & \text { PETHOLEOM PRODOCTS } & =0.0 \% \\ 3 & \text { TRANSPORMATION } & \text { LOSS POR } & \text { NATURAI GAS } & =0.0 . \% \\ 4 & \text { TRANSPORMATION LOSS, POR } & \text { SYNTHEICS } & =0.0 \%\end{array}$


REGIONHAL ENE RGY BALANCE STATEMENT
PIES RID RID SCEHARIO

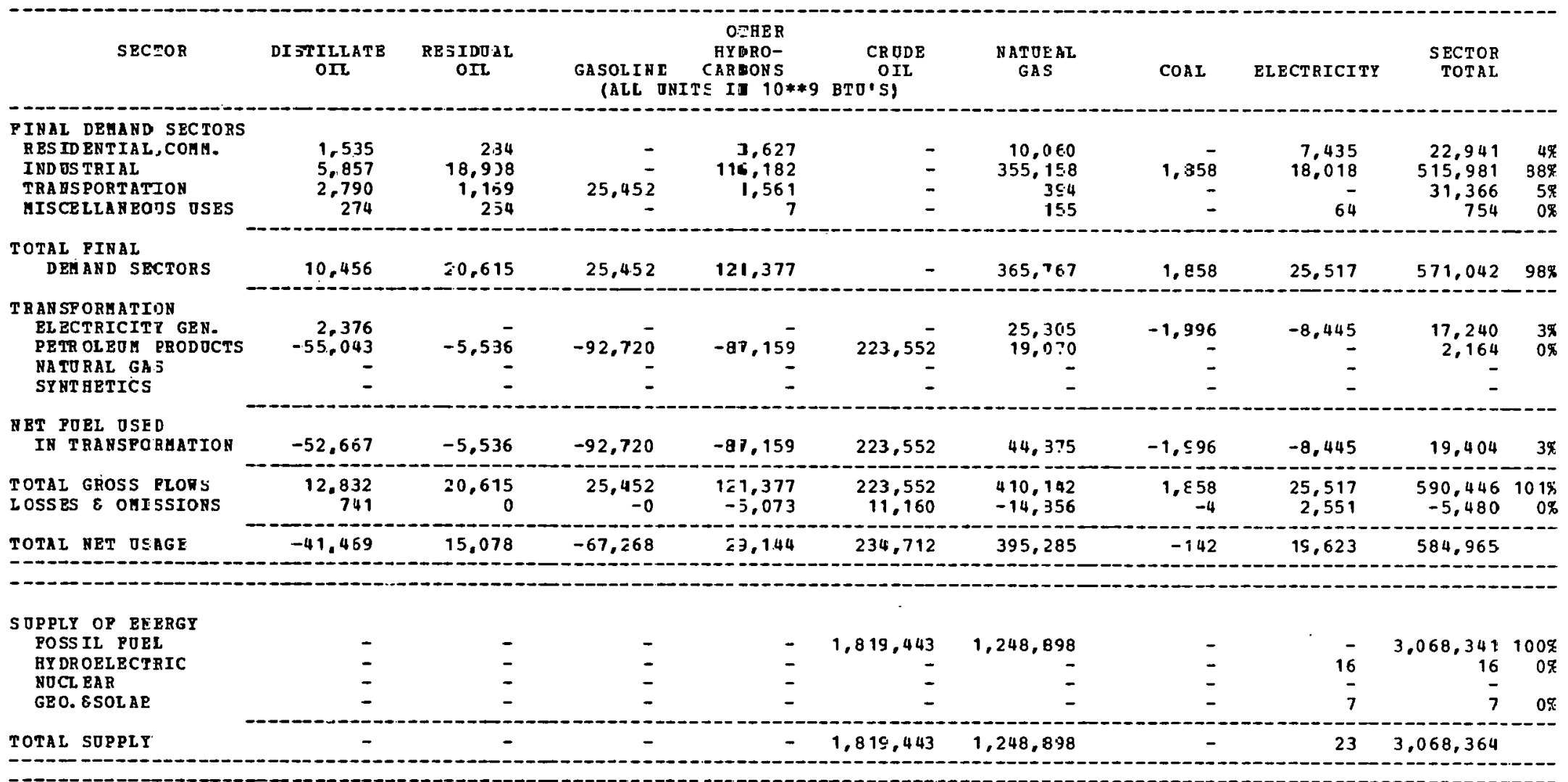

NET IM PORTS

พOTES:

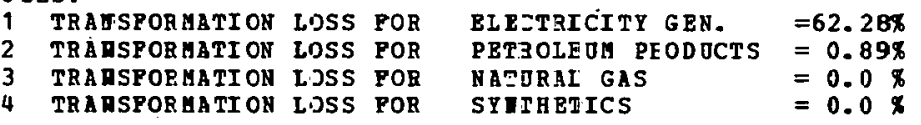


REGIONAL ENERGY BALANCE STATEMENT

PIES MID MID SCENARIO

\begin{tabular}{|c|c|c|c|c|c|c|c|c|c|c|}
\hline SECTOR & $\begin{array}{c}\text { DISTILLATE } \\
\text { OIL }\end{array}$ & $\begin{array}{l}\text { RES IDOAL } \\
\text { OIL }\end{array}$ & $\begin{array}{l}\text { GASOLINE } \\
\text { (ALL ONIT }\end{array}$ & $\begin{array}{c}\text { OTHER } \\
\text { HYDRO- } \\
\text { CARBONS } \\
\text { TS IN } 10 * \$ 9\end{array}$ & $\begin{array}{l}\text { CRUDE } \\
\text { OIL } \\
\text { BTO'SI }\end{array}$ & $\begin{array}{l}\text { NATURAL } \\
\text { GAS }\end{array}$ & $\operatorname{COAL}$ & ELECTRICITY & $\begin{array}{r}\text { SECTOR } \\
\text { TOTAL }\end{array}$ & \\
\hline $\begin{array}{l}\text { FINAL DEMAND SECTORS } \\
\text { RESID ENTIAL,CCMM. } \\
\text { INDUSTRIAL } \\
\text { TRANS PORTATION } \\
\text { MISCELLANEOUS OSES }\end{array}$ & $\begin{array}{r}1.370 \\
1,672 \\
3,808 \\
283\end{array}$ & $\begin{array}{r}274 \\
4.579 \\
804 \\
263\end{array}$ & 22,293 & $\begin{array}{r}3,180 \\
5,574 \\
1,095 \\
9\end{array}$ & $\begin{array}{l}\overline{-} \\
\overline{-}\end{array}$ & $\begin{array}{r}8,889 \\
72,114 \\
270 \\
198\end{array}$ & $\begin{array}{r}\overline{-} \\
- \\
-\end{array}$ & $\begin{array}{r}6,710 \\
8,059 \\
- \\
87\end{array}$ & $\begin{array}{r}20,423 \\
93,046 \\
28,270 \\
840\end{array}$ & $\begin{array}{r}12 \% \\
54 \% \\
16 \% \\
0 \%\end{array}$ \\
\hline $\begin{array}{l}\text { TOTAL PINAI } \\
\text { DEMAND SECTORS }\end{array}$ & $\begin{array}{r}7,133 \\
-\end{array}$ & 5,920 & 22,293 & 9,858 & - & 81,471 & 1,048 & 14,856 & 142.579 & $82 \%$ \\
\hline $\begin{array}{l}\text { T RANSP ORMATION } \\
\text { EL BCTRICITY GEN. } \\
\text { PETR OLEOM FRODOCTS } \\
\text { NATURAL GAS } \\
\text { SYNTHETICS }\end{array}$ & $\begin{array}{r}1,383 \\
-17,701 \\
-\end{array}$ & $\begin{array}{r}-1.780 \\
-\end{array}$ & $\begin{array}{r}- \\
-29,817 \\
-\end{array}$ & $\begin{array}{r}-28,029 \\
-\end{array}$ & $\begin{array}{r}71.891 \\
-\end{array}$ & $\begin{array}{r}42,392 \\
6,132 \\
-\end{array}$ & $\begin{array}{l}\overline{-} \\
\overline{-}\end{array}$ & $\begin{array}{r}-14,442 \\
- \\
-\end{array}$ & $\begin{array}{r}29,333 \\
696 \\
- \\
-\end{array}$ & $\begin{array}{r}17 \% \\
0 \%\end{array}$ \\
\hline
\end{tabular}

NET FOEL OSED
IN TRANSPORHATION

TOTAL GROSS FLORS

\begin{tabular}{|c|c|c|c|c|c|c|c|c|c|}
\hline$-16,318$ & $-1,780$ & $-29,817$ & $-28,029$ & 71,891 & 48,524 & - & $-14,442$ & 30,029 & $17 \%$ \\
\hline $\begin{array}{r}8,516 \\
492\end{array}$ & $\begin{array}{r}5,920 \\
0\end{array}$ & $\begin{array}{r}22,293 \\
-0\end{array}$ & $\begin{array}{r}9,858 \\
-412\end{array}$ & $\begin{array}{r}71,891 \\
3,588\end{array}$ & $\begin{array}{r}129,995 \\
-4,708\end{array}$ & $\begin{array}{r}1,048 \\
-2\end{array}$ & $\begin{array}{r}14,856 \\
1,485\end{array}$ & $\begin{array}{r}172,608 \\
443\end{array}$ & $\begin{array}{r}100 \% \\
0 \%\end{array}$ \\
\hline$-8,692$ & 4,139 & $-7,524$ & $-18,583$ & 75,480 & 125,286 & 1,045 & 1,899 & 173,052 & \\
\hline
\end{tabular}

TOTAL NET OSAGE

\begin{tabular}{rrr}
- & - & - \\
- & - & - \\
- & - & - \\
\hline- & - & -
\end{tabular}

\section{OPPLY OP ENERGY \\ POSS IL POEL \\ HYDR OELECTRIC \\ GPO BSOL}

OTAL SOPPIY

$\begin{array}{lr}- & 535,556 \\ - & - \\ - & -\end{array}$

72,361

535,556

72,361

61
-
-
-
61

\begin{tabular}{lrrr}
- & - & 607,917 & $100 \%$ \\
- & 9 & 9 & $0 \%$ \\
- & $\overline{4}$ & $\overline{4}$ & $0 \%$ \\
\hline- & 13 & 607,930
\end{tabular}

\section{NET IMPORTS}

OP REGION

$-8,692$

4,139

$-7,524$

$-18,583$

$-460,075$

52,925

1,045

1,886

$-434,877$

\section{NO TES :}
1 TRANSPORHATI ON LOSS POR
TRA TPORATI ON LOSS FOR
TRANSFORATION LOSS POB
EL ECTRICITY GEN.
. $=67.01 \%$
NATURAL GaS
$=0.89 \%$
NATURAL GAS
$=0.0 \%$ 
REG-IONAL ZNERGY BALANCE STATEYENT

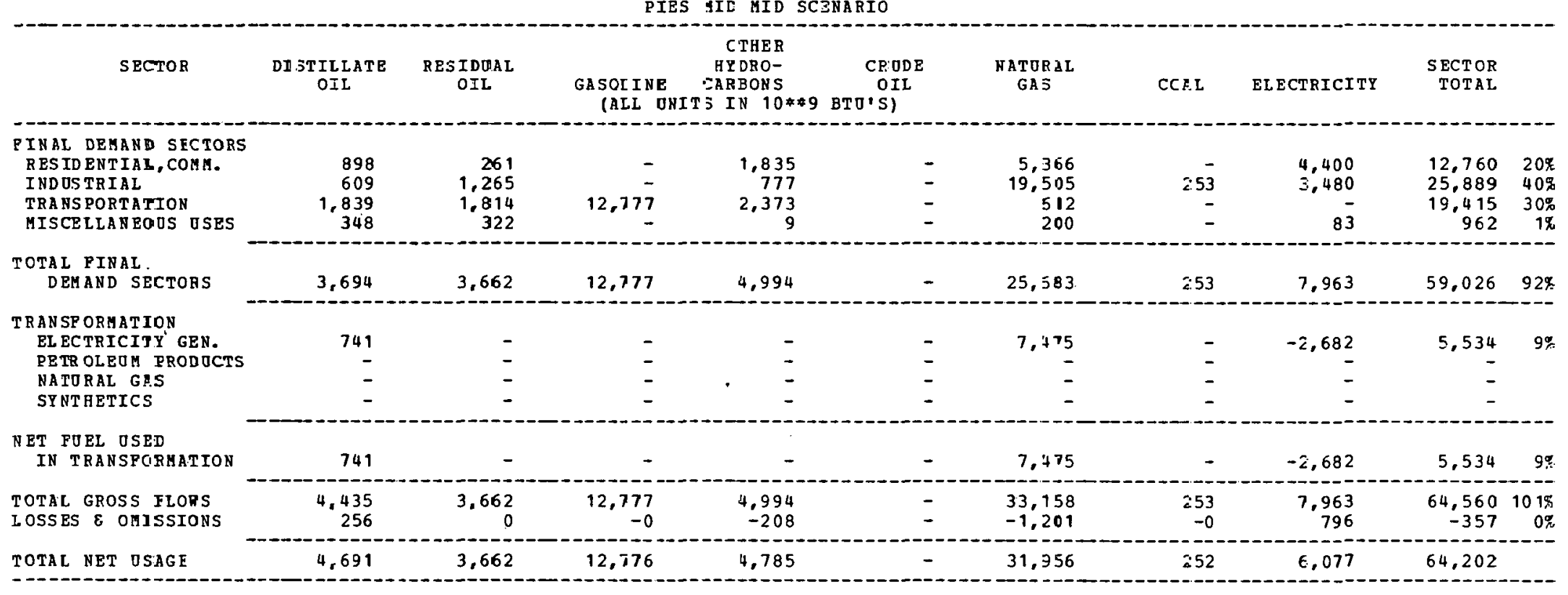

\begin{tabular}{|c|c|c|c|c|c|c|c|c|c|c|}
\hline 3 OPPLY OP EFIRGY & & & & & & & & & & \\
\hline POSSIL PORL & - & - & - & - & 60,000 & 50,230 & - & - & 110,230 & $100 \%$ \\
\hline HY DR OELECTRIC & - & - & - & - & - & - & - & 5 & 5 & $0 \%$ \\
\hline NOCL EAR & - & - & - & - & - & - & - & - & $=$ & \\
\hline GEO. $\varepsilon$ SOLAE & - & - & - & - & - & - & - & 2 & 2 & $0 \%$ \\
\hline TOTAL SUPPLY & - & - & - & - & 60,000 & 50,230 & - & 7 & 110,237 & \\
\hline
\end{tabular}

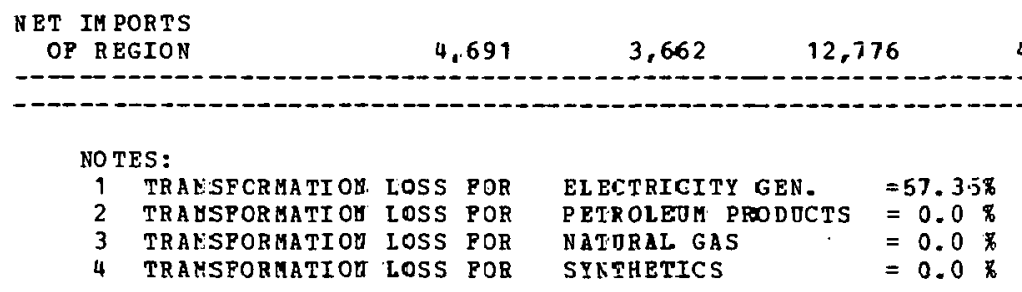


PEGIONAL ENERGY BALANCE STATENENT

PIES MID MID SCENARIO

\begin{tabular}{|c|c|c|c|c|c|c|c|c|c|c|}
\hline SECTOR & $\begin{array}{l}\text { DI STILLATE } \\
\text { OIL }\end{array}$ & $\begin{array}{l}\text { RESIDDAL } \\
\text { OIL }\end{array}$ & $\begin{array}{l}\text { GASOLINE } \\
\text { (ALL ONI }\end{array}$ & $\begin{array}{c}\text { OTHER } \\
\text { HYDRO- } \\
\text { CARBONS } \\
\text { TS IN } 10 * \$ 9\end{array}$ & $\begin{array}{c}\text { CR ODE } \\
\text { OIL } \\
\text { BTO'S) }\end{array}$ & $\begin{array}{l}\text { NATURAL } \\
\text { GAS }\end{array}$ & $\operatorname{COAL}$ & ELECTRICITY & $\begin{array}{r}\text { SECTOR } \\
\text { TOTAL }\end{array}$ & \\
\hline $\begin{array}{l}\text { PINAL DEMAND SECTORS } \\
\text { RESIDENTIAL, COMG. } \\
\text { IND USTRIAL } \\
\text { TRANSPORTATION } \\
\text { MISCEILANEOOS OSES }\end{array}$ & $\begin{array}{r}17,857 \\
9,554 \\
74,557 \\
4,248\end{array}$ & $\begin{array}{r}4,665 \\
\Xi 1,052 \\
52,226 \\
3,945\end{array}$ & $265,21 \overline{-}$ & $\begin{array}{r}38,216 \\
205,763 \\
68,879 \\
90\end{array}$ & $\begin{array}{l}\overline{-} \\
\overline{-}\end{array}$ & $\begin{array}{r}113,694 \\
482,257 \\
17,685 \\
2,091\end{array}$ & $\begin{array}{r}- \\
15,978 \\
1 \\
-\end{array}$ & $\begin{array}{r}94,955 \\
55,877 \\
- \\
811\end{array}$ & $\begin{array}{r}269,387 \\
800,481 \\
478,559 \\
11,175\end{array}$ & $\begin{array}{r}16 \% \\
47 \% \\
28 \% \\
1 \%\end{array}$ \\
\hline $\begin{array}{l}\text { TOTAL PINAL } \\
\text { DEMAND SECTORS }\end{array}$ & 106,216 & 91,888 & 265,211 & 312,948 & - & 615,717 & 15,979 & 151,643 & $1,559,602$ & $91 \%$ \\
\hline $\begin{array}{l}\text { TRANSP ORMATION } \\
\text { EL ECTRICITY GEN. } \\
\text { PETR OLEOM PRODOZTS } \\
\text { NATURAL. GAS } \\
\text { SYNTHETICS }\end{array}$ & $\begin{array}{r}14,119 \\
-12,609 \\
-\end{array}$ & $\begin{array}{r}-1.268 \\
-\end{array}$ & $\begin{array}{r}-21,24 \overline{0} \\
-\end{array}$ & $\begin{array}{r}-19,96 \overline{6} \\
-\end{array}$ & 51,210 & $\begin{array}{r}253,061 \\
4,368 \\
- \\
-\end{array}$ & $\begin{array}{l}- \\
-\end{array}$ & $\begin{array}{r}-88,046 \\
- \\
-\end{array}$ & $\begin{array}{r}179,134 \\
495 \\
- \\
-\end{array}$ & $\begin{array}{r}10 \% \\
0 \%\end{array}$ \\
\hline $\begin{array}{l}\text { NET POEL OSED } \\
\text { IN TRANSFOBMATION }\end{array}$ & 1,510 & $-1,268$ & $-21,240$ & $-19,966$ & 51,210 & 257,429 & - & $-88,046$ & 179,629 & $10 \%$ \\
\hline $\begin{array}{l}\text { TOTAL GROSS FLONS } \\
\text { LOSSES } \& \text { OHISSIONS }\end{array}$ & $\begin{array}{r}120,335 \\
6,957\end{array}$ & $\begin{array}{r}91,888 \\
2\end{array}$ & $\begin{array}{r}265.211 \\
-0\end{array}$ & $\begin{array}{r}312,948 \\
-13,081\end{array}$ & $\begin{array}{r}51,210 \\
2,556\end{array}$ & $\begin{array}{l}873,146 \\
-31,628\end{array}$ & $\begin{array}{r}15,979 \\
-35\end{array}$ & $\begin{array}{r}151,643 \\
15,165\end{array}$ & $\begin{array}{r}1,739,231 \\
-20,064\end{array}$ & $\begin{array}{r}101 \% \\
0 \%\end{array}$ \\
\hline
\end{tabular}

\begin{tabular}{|c|c|c|c|c|c|c|c|c|c|c|}
\hline $\begin{array}{l}\text { SOPPLY OP ENERGY } \\
\text { POSS IL FOEL }\end{array}$ & - & - & - & - & 190,892 & 103,121 & - & - & 294,013 & $91 \%$ \\
\hline HY DR OEL BCT RIC & - & - & - & - & . $\quad-$ & - & - & 1,229 & 1,229 & $0 \%$ \\
\hline NOCL EAR & - & - & - & - & - & - & - & 27,978 & 27,978 & $9 \%$ \\
\hline GEO. ESOL AR & - & - & - & - & - & - & - & 39 & 39 & $0 \%$ \\
\hline TOTAL SOPPIY & - & - & - & - & 190,892 & 103,121 & - & 29,246 & 323,259 & \\
\hline
\end{tabular}

\begin{tabular}{l}
$\begin{array}{l}\text { NET IM PORTS } \\
\text { OP R EGION }\end{array}$ \\
\hline
\end{tabular}


REGIONAL ZNERGY BALANCE STATEIZNT

ONAL INERGY BALANCE S
PIES MIE" MID SCENARIO

\begin{tabular}{|c|c|c|c|c|c|c|c|c|c|c|}
\hline SECTOR & $\begin{array}{l}\text { DI JTIELATE } \\
\text { O.IL }\end{array}$ & $\begin{array}{l}\text { RESIDUAL } \\
\text { OIL }\end{array}$ & $\begin{array}{l}\text { GASOLINE } \\
\text { (ALL OUIT }\end{array}$ & $\begin{array}{c}\text { OTHER } \\
\text { HYDRO- } \\
\text { =AEBONS } \\
3 \text { IN } 10 \neq \neq 9\end{array}$ & $\begin{array}{l}\text { CEODE } \\
\text { (IIL } \\
\text { BTU'S) }\end{array}$ & $\begin{array}{l}\text { NATORAL } \\
\text { GAS }\end{array}$ & $\operatorname{col} \mathrm{L}$ & ELECTRI CITY & $\begin{array}{l}\text { SECTOK } \\
\text { TOTAL }\end{array}$ & \\
\hline $\begin{array}{l}\text { PINAL DEHAND SECTORS } \\
\text { RESIDENTIAL., CCHH. } \\
\text { IND US TRIAL } \\
\text { TRANSPORTATION } \\
\text { MISCELLANEOOS ESES }\end{array}$ & $\begin{array}{l}2.973 \\
1,427 \\
8,824 \\
1,271\end{array}$ & $\begin{array}{l}718 \\
3,659 \\
2,771 \\
1,180\end{array}$ & $\begin{array}{r}- \\
\overline{-} \\
45,561 \\
-\end{array}$ & $\begin{array}{r}5,531 \\
6,821 \\
3,720 \\
52\end{array}$ & $\overline{-}$ & $\begin{array}{r}18,759 \\
48,450 \\
9.33 \\
1,1.59\end{array}$ & $\begin{array}{r}\overrightarrow{3} \\
- \\
-\end{array}$ & $\begin{array}{r}14,956 \\
8,785 \\
- \\
518\end{array}$ & $\begin{array}{r}43.937 \\
71.413 \\
61,805 \\
4.130\end{array}$ & $\begin{array}{r}18.8 \\
298 \\
258 \\
2.8\end{array}$ \\
\hline $\begin{array}{l}\text { TOTAL PINAL } \\
\text { DEMAND SECTORS }\end{array}$ & 14.495 & 8,328 & $45,56.1$ & $i 7,124$ & - & 69,251 & 2,261 & 24,259 & 181,289 & $72 \%$ \\
\hline $\begin{array}{l}\text { TRANSP ORHATION } \\
\text { ELECTRICITY GEN. } \\
\text { PETROLEOM FRODOCTS } \\
\text { NATORAL GRS } \\
\text { SYNT HETICS }\end{array}$ & $\begin{array}{r}2.259 \\
= \\
-\end{array}$ & $\begin{array}{l}\overline{-} \\
\overline{-}\end{array}$ & $\begin{array}{l}\bar{z} \\
\bar{z}\end{array}$ & $\bar{z}$ & $\overline{-}$ & $\begin{array}{r}49,854 \\
= \\
=\end{array}$ & $\begin{array}{r}53,386 \\
= \\
-\end{array}$ & $\begin{array}{r}-34,872 \\
- \\
-\end{array}$ & $\begin{array}{r}70,627 \\
= \\
=\end{array}$ & $28 \%$ \\
\hline $\begin{array}{l}\text { NET POEL OSED } \\
\text { IN TRASFOBMATION }\end{array}$ & 2.259 & - & - & - & - & 49,854 & 53,386 & $-34,872$ & 70,627 & $28 x$ \\
\hline $\begin{array}{l}\text { TOTAL GROSS FLOMS } \\
\text { LOSSES } \& \text { OHISSICNS }\end{array}$ & $\begin{array}{r}16.754 \\
968\end{array}$ & $\begin{array}{r}8,328 \\
0\end{array}$ & $\begin{array}{r}45,561 \\
-0\end{array}$ & $\begin{array}{r}17,124 \\
-715\end{array}$ & $\overline{-}$ & $\begin{array}{r}119,115 \\
-4,314\end{array}$ & $\begin{array}{r}55,647 \\
-122\end{array}$ & $\begin{array}{r}24,259 \\
2,426\end{array}$ & $\begin{array}{r}251,916 \\
-1,758\end{array}$ & $\begin{array}{r}1018 \\
0 \times\end{array}$ \\
\hline
\end{tabular}

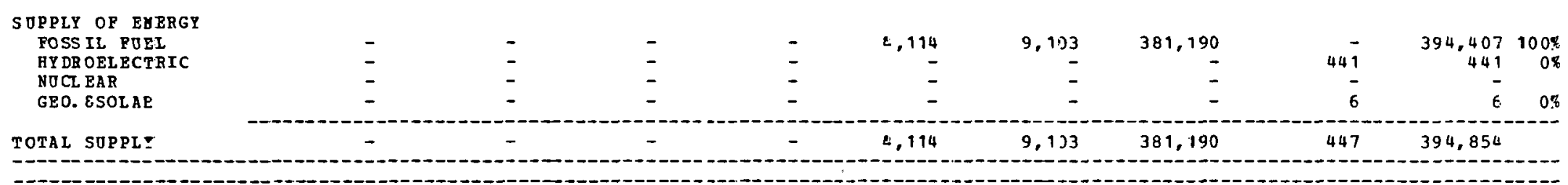

NET IM PORTS

OF REGION

17.722

8,328

45,560

96,408

$-2,114$

$105,697-325,665$

$-8,633$

$-144,696$

NO TES

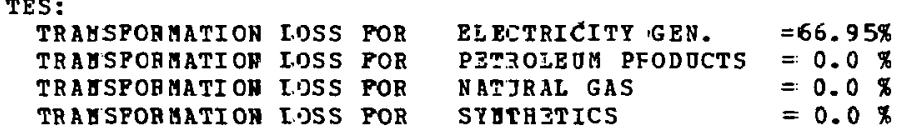


REGIONAL ENB RGY BALANCE STATEMENT

PIES MID MID SCENARID

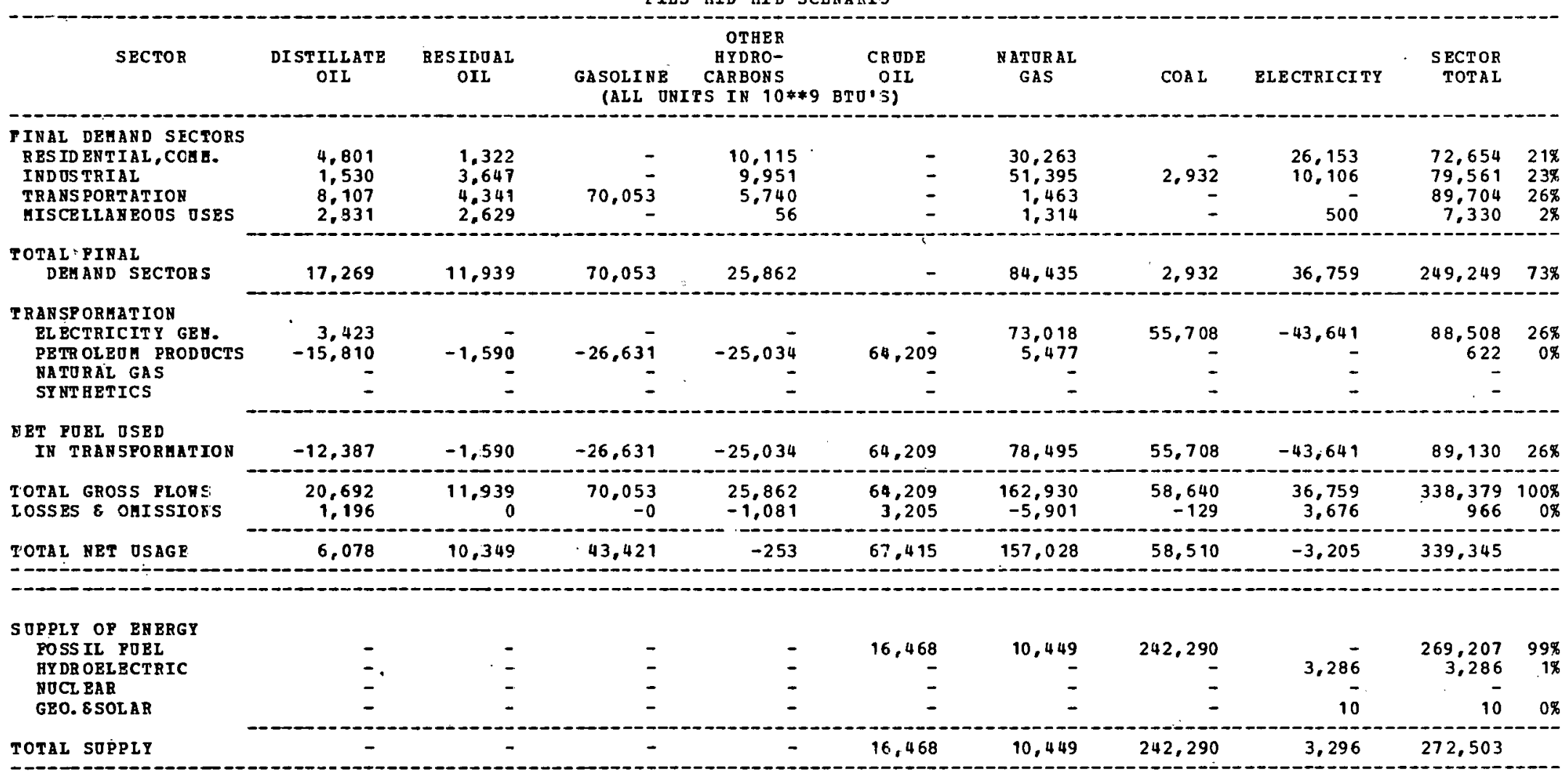

\begin{tabular}{l}
$\begin{array}{l}\text { RET IM POATS } \\
\text { OP R BGIOH }\end{array}$ \\
\hline
\end{tabular}


RBG.CONAL EN3RGY BALANCE STATEMENT

PIES UIJ MID SCBNARIO

\begin{tabular}{|c|c|c|c|c|c|c|c|c|c|c|}
\hline SECTOR & $\begin{array}{l}\text { DDSTILLATE } \\
\text { GIL }\end{array}$ & $\begin{array}{l}\text { RESIDDAL } \\
\text { OIL }\end{array}$ & $\begin{array}{l}\text { GASOLLEE } \\
\text { (ADL ONIT] }\end{array}$ & $\begin{array}{c}\text { JTHER } \\
\text { HYDRO- } \\
\text { CABBONS } \\
\text { IS IN } 10 * * 9\end{array}$ & $\begin{array}{c}\text { CRODE } \\
\text { OIL } \\
\text { BTO'SI }\end{array}$ & $\begin{array}{l}\text { NaTdE AL } \\
\text { Gis }\end{array}$ & $\operatorname{CAA} L$ & ELECTRICITY & $\begin{array}{l}\text { SECTOR } \\
\text { TOTAL. }\end{array}$ & \\
\hline $\begin{array}{l}\text { PINAL DEHANID SECTORS } \\
\text { RES IDENTIAL, COMA. } \\
\text { IND US TRIAL } \\
\text { TRANS PORTAEION } \\
\text { HISCELLANEOOS OSES }\end{array}$ & $\begin{array}{r}3,480 \\
3,210 \\
12,509 \\
823\end{array}$ & $\begin{array}{r}797 \\
10,590 \\
2,297 \\
765\end{array}$ & $\begin{array}{r}- \\
54,315 \\
-\end{array}$ & $\begin{array}{r}7,772 \\
30,204 \\
3,170 \\
15\end{array}$ & $\begin{array}{l}\overline{-} \\
\overline{-}\end{array}$ & $\begin{array}{r}22, c 86 \\
180, \div 06 \\
\div 72 \\
363\end{array}$ & $\begin{array}{r}- \\
7.233 \\
-\end{array}$ & $\begin{array}{r}17,223 \\
19,520 \\
= \\
134\end{array}$ & $\begin{array}{r}51,358 \\
301,463 \\
73,055 \\
2,100\end{array}$ & $\begin{array}{r}8 \% \\
47 \% \\
11 \% \\
0 \%\end{array}$ \\
\hline $\begin{array}{l}\text { TOTAL PINAL, } \\
\text { DEMAND SECTORS }\end{array}$ & 20.014 & 14,449 & 54,315 & 91,161 & - & 203,927 & 7,233 & 36,877 & 427,976 & $67 \%$ \\
\hline $\begin{array}{l}\text { TRARSPORHATION } \\
\text { ELECTRICIT GEN. } \\
\text { PETR OLEOA PRODOCTS } \\
\text { NATORAL GAS } \\
\text { SY RT BETICS }\end{array}$ & $\begin{array}{r}3,433 \\
-27.448 \\
- \\
-\end{array}$ & $\begin{array}{r}-2,760 \\
- \\
-\end{array}$ & $\begin{array}{r}-46,235 \\
-\end{array}$ & $\begin{array}{r}-43,46 \overline{-} \\
- \\
-\end{array}$ & $\begin{array}{r}111,477 \\
- \\
-\end{array}$ & $\begin{array}{r}75.939 \\
9.509 \\
- \\
-\end{array}$ & $\begin{array}{r}243,721 \\
- \\
-\end{array}$ & $\begin{array}{r}-106,926 \\
= \\
-\end{array}$ & $\begin{array}{r}216.167 \\
1,07 \mathrm{~g} \\
-\end{array}$ & $\begin{array}{r}34 \% \\
0 \%\end{array}$ \\
\hline $\begin{array}{l}\text { NET POBL OSZD } \\
\text { IR TRANSFORMATION }\end{array}$ & -26.015 & $-2,760$ & $-46,236$ & $-43,463$ & $111,47 ?$ & 85.448 & 243,721 & $-106,926$ & 217,245 & $34 \%$ \\
\hline $\begin{array}{l}\text { TOTAL GROSS FLONS } \\
\text { LOSSES \& OMISSIONS }\end{array}$ & $\begin{array}{r}23,447 \\
1,355\end{array}$ & $\begin{array}{r}14,449 \\
0\end{array}$ & $\begin{array}{r}54,315 \\
-1)\end{array}$ & $\begin{array}{l}91,161 \\
-3,810\end{array}$ & $\begin{array}{r}111,477 \\
5,565\end{array}$ & $\begin{array}{l}289,375 \\
-10,482\end{array}$ & $\begin{array}{r}250,954 \\
-552\end{array}$ & $\begin{array}{r}36,877 \\
3,688\end{array}$ & $\begin{array}{r}645,221 \\
-4,23 \epsilon\end{array}$ & $\begin{array}{r}101 \% \\
0 \%\end{array}$ \\
\hline
\end{tabular}

\begin{tabular}{|c|c|c|c|c|c|c|c|c|c|c|c|}
\hline $\begin{array}{l}\text { SOPPLY OP EYREGY } \\
\text { FOSS IL PUSL }\end{array}$ & . & - & - & - & - & 651,692 & 188,215 & 11.424 & - & 851,331 & $100 \%$ \\
\hline HZ DROBLBCTRIC & & - & - & - & - & - & - & - & 23 & $2 \equiv$ & Ox \\
\hline NDCL EAR & & - & - & - & - & - & - & - & - & - & \\
\hline GBO. \&SOL A & & - & - & - & - & - & - & - & 10 & $1 \mathrm{C}$ & $0 \%$ \\
\hline TOTAL SUPPIY & & - & - & - & - & 651,692 & 188,215 & 11,424 & 33 & $851,36 L$ & \\
\hline
\end{tabular}

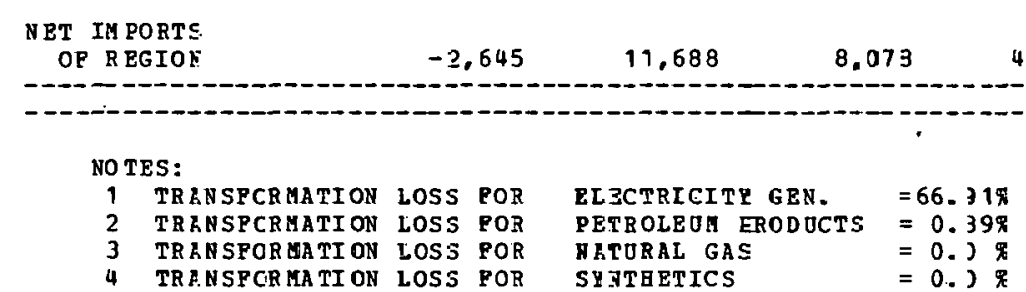


REGIONAL BNERGY BALANCE STATEMENT

\begin{tabular}{|c|c|c|c|c|c|c|c|c|c|c|}
\hline SECTOR & $\begin{array}{l}\text { DISTILLATB } \\
\text { OIL }\end{array}$ & $\begin{array}{l}\text { RES IDJAL } \\
\text { OIL }\end{array}$ & $\begin{array}{l}\text { GASOLIKE } \\
\text { (ALL ON }\end{array}$ & $\begin{array}{c}\text { OTHER } \\
\text { HYDRO- } \\
\text { CARBONS } \\
\text { TS IN } 10 * 9\end{array}$ & $\begin{array}{c}\text { ZRODE } \\
\text { OIL } \\
\text { BTU'S) }\end{array}$ & $\begin{array}{l}\text { NATURAL } \\
\text { GAS }\end{array}$ & $\operatorname{COAL}$ & ELECTRICITY & $\begin{array}{r}\text { SECTOR } \\
\text { TOTAL }\end{array}$ & \\
\hline $\begin{array}{l}\text { PINAL DEHAND SECTORS } \\
\text { RESID BNTIAL, CORA. } \\
\text { IND OS TRIAL } \\
\text { TRAUS PORTATION } \\
\text { GISCE LLANEOOS TSES }\end{array}$ & $\begin{array}{r}2,521 \\
3,680 \\
7,830 \\
921\end{array}$ & $\begin{array}{r}662 \\
12.496 \\
1.602 \\
855\end{array}$ & $32,12 \overline{-}$ & $\begin{array}{r}4,720 \\
11,008 \\
3,160 \\
17\end{array}$ & - & $\begin{array}{r}15,153 \\
43,154 \\
982 \\
406\end{array}$ & $\begin{array}{r}2,700 \\
-\end{array}$ & $\begin{array}{r}9,496 \\
8,588 \\
- \\
148\end{array}$ & $\begin{array}{r}32,552 \\
81,626 \\
45,694 \\
2,347\end{array}$ & $\begin{array}{r}12 \% \\
29 \% \\
16 \% \\
1 \%\end{array}$ \\
\hline $\begin{array}{l}\text { TOTAL FINAL } \\
\text { DEMAND SBCTORS }\end{array}$ & 14.952 & 15,615 & 32,120 & 18,905 & - & 59,695 & 2,700 & 18,232 & 162,219 & $58 \%$ \\
\hline $\begin{array}{l}\text { TRANSP ORMATION } \\
\text { BLECTRICITY GEN. } \\
\text { PETR OLEDH PRODDCTS } \\
\text { NATURAL GAS } \\
\text { SY NT AETICS }\end{array}$ & $\begin{array}{r}1.698 \\
-12,609 \\
-\end{array}$ & $\begin{array}{r}-1.268 \\
- \\
-\end{array}$ & $\begin{array}{r}-21,240 \\
- \\
-\end{array}$ & $\begin{array}{r}-19,96 \overline{-} \\
-\end{array}$ & $\begin{array}{r}51,210 \\
-\end{array}$ & $\begin{array}{r}7,041 \\
4,368 \\
- \\
-\end{array}$ & $\begin{array}{r}161,738 \\
- \\
-\end{array}$ & $\begin{array}{r}-56,452 \\
- \\
-\end{array}$ & $\begin{array}{r}114,025 \\
495 \\
- \\
-\end{array}$ & $\begin{array}{r}41 \% \\
0 \%\end{array}$ \\
\hline $\begin{array}{l}\text { IET PUBL USED } \\
\text { IN TRABSPORGATION }\end{array}$ & $-10,911$ & -1.268 & $-21,240$ & $-19,966$ & 51,210 & 11,409 & 161,738 & $-56,452$ & 114,520 & $41 \%$ \\
\hline $\begin{array}{l}\text { TOTAL GROSS FLOHS } \\
\text { BOSSES } \& \text { OHISSIOUS }\end{array}$ & $\begin{array}{r}16,650 \\
962\end{array}$ & $\begin{array}{r}15,615 \\
0\end{array}$ & $\begin{array}{r}32,120 \\
-0\end{array}$ & $\begin{array}{r}18,905 \\
-790\end{array}$ & $\begin{array}{r}51.210 \\
2.556\end{array}$ & $\begin{array}{l}71,104 \\
-2,575\end{array}$ & $\begin{array}{r}164,438 \\
-362\end{array}$ & $\begin{array}{r}18,232 \\
1,823\end{array}$ & $\begin{array}{r}276,739 \\
1,614\end{array}$ & $\begin{array}{r}99 \% \\
1 \%\end{array}$ \\
\hline TOTAL NET OSAGE & 5,003 & 14,347 & 10,879 & $-1,851$ & 53,766 & 68,528 & 164,075 & $-36,396$ & 278,354 & \\
\hline $\begin{array}{l}\text { SOPPLY OF ENERGY } \\
\text { POSS IL ZOEL } \\
\text { HY DR OELECTRIC } \\
\text { NOCL EAR } \\
\text { GEO. ESOL AR }\end{array}$ & $\bar{z}$ & $\begin{array}{l}- \\
-\end{array}$ & $\begin{array}{l}- \\
-\end{array}$ & $\begin{array}{l}- \\
-\end{array}$ & $\begin{array}{r}47.620 \\
- \\
- \\
-\end{array}$ & $\begin{array}{r}27,497 \\
- \\
-\end{array}$ & $\begin{array}{r}12,796 \\
- \\
-\end{array}$ & $\begin{array}{r}1,458 \\
- \\
4\end{array}$ & $\begin{array}{r}87.913 \\
1.458 \\
- \\
4\end{array}$ & $\begin{array}{r}98 \% \\
2 \%\end{array}$ \\
\hline TOTAL SUPPLY & - & - & - & - & 47,620 & 27.497 & 12,796 & 1,462 & 89,375 & \\
\hline
\end{tabular}

MET IH PORTS
OP REGION


REEIONAL' 3NE RGY BALANCE STATEMBNT
PIES IID GID SCENARIO

\begin{tabular}{|c|c|c|c|c|c|c|c|c|c|}
\hline SECTOR & $\begin{array}{l}\text { DI STILIATB } \\
\text { OIL }\end{array}$ & $\begin{array}{l}\text { RESIDUAL } \\
\text { OIL }\end{array}$ & $\begin{array}{l}\text { GASOIINE } \\
\text { (ALL ONIT }\end{array}$ & $\begin{aligned} & \text { C.THER } \\
& \text { HYDRO- } \\
& \text { ZAEBONS } \\
& \text { S IN } 10 * * 9\end{aligned}$ & $\begin{array}{c}\text { CR ODE } \\
\text { OIL } \\
\text { BTO!S) }\end{array}$ & $\begin{array}{l}\text { NATURAL } \\
\text { GAS }\end{array}$ & $\cos L$ & ELECTRICITY & $\begin{aligned} \text { SECTOK } \\
\text { TOTAL }\end{aligned}$ \\
\hline $\begin{array}{l}\text { PINAL DEHANE SECTORS } \\
\text { RESID BNTIAL, COHA. } \\
\text { INDUSTRIAL } \\
\text { TRANSPORTATION } \\
\text { MISCELLANEOOS DSES }\end{array}$ & $\begin{array}{r}.531 \\
7.752 \\
8.154 \\
554\end{array}$ & $\begin{array}{r}145 \\
32.198 \\
1.586 \\
514\end{array}$ & $28,39 \bar{z}$ & $\begin{array}{r}5,212 \\
13,728 \\
858 \\
14\end{array}$ & $\bar{z}$ & $\begin{array}{r}13,542 \\
159,603 \\
565 \\
320\end{array}$ & $\begin{array}{r}2 \\
2,515 \\
- \\
-\end{array}$ & $\begin{array}{r}10,851 \\
10,997 \\
- \\
140\end{array}$ & $\begin{array}{r}30,283 \\
226,793 \\
39,256 \\
1,542\end{array}$ \\
\hline $\begin{array}{l}\text { TOTAL FINAL } \\
\text { DEMAND SECTORS }\end{array}$ & 16,991 & 34.443 & 28,093 & 19,812 & - & 174,030 & 2,517 & 21,988 & 297,874 \\
\hline $\begin{array}{l}\text { TRARSF ORHATION } \\
\text { BLECTRICIT GEN. } \\
\text { PBTROLEOH FRODOCTS } \\
\text { NATORAL EAS } \\
\text { SY NT BETICS }\end{array}$ & $\begin{array}{r}2.047 \\
-33,108 \\
-\end{array}$ & $\begin{array}{r}- \\
-3.330 \\
- \\
-\end{array}$ & $\begin{array}{r}-55,77 i \\
-\end{array}$ & $\begin{array}{r}-52,426 \\
- \\
-\end{array}$ & $\begin{array}{r}134,466 \\
=\end{array}$ & $\begin{array}{r}13.840 \\
11.470 \\
- \\
-\end{array}$ & $\begin{array}{l}\overline{-} \\
\overline{-} \\
\overline{-}\end{array}$ & $\begin{array}{r}-5,218 \\
- \\
- \\
-\end{array}$ & $\begin{array}{r}10,669 \\
1,301 \\
- \\
-\end{array}$ \\
\hline $\begin{array}{l}\text { YET POEL OSPD } \\
\text { IN TRANSPORMATION }\end{array}$ & $-31,061$ & $-3,330$ & $-55,771$ & $-52,426$ & 134.465 & $25,31 \mathrm{c}$ & - & $-5,218$ & $11,97 c$ \\
\hline $\begin{array}{l}\text { TOTAL GROSS FLOHS } \\
\text { LOSSES } E \text { OHISSIONS }\end{array}$ & $\begin{array}{r}19,038 \\
1,100\end{array}$ & $\begin{array}{r}34,443 \\
0\end{array}$ & $\begin{array}{r}28,093 \\
-0\end{array}$ & $\begin{array}{r}19.812 \\
-828\end{array}$ & $\begin{array}{r}134,466 \\
6,712\end{array}$ & $\begin{array}{r}199, .34 C \\
-7,22 C\end{array}$ & $\begin{array}{r}2,517 \\
-5\end{array}$ & $\begin{array}{r}21,988 \\
2,199\end{array}$ & $\begin{array}{r}309,842 \\
1,958\end{array}$ \\
\hline TOTAL RET ZSAGI & $-12,969$ & 31,113 & -27.678 & $-33,442$ & 141,178 & 192,120 & 2,511 & 18,969 & 311,803 \\
\hline
\end{tabular}

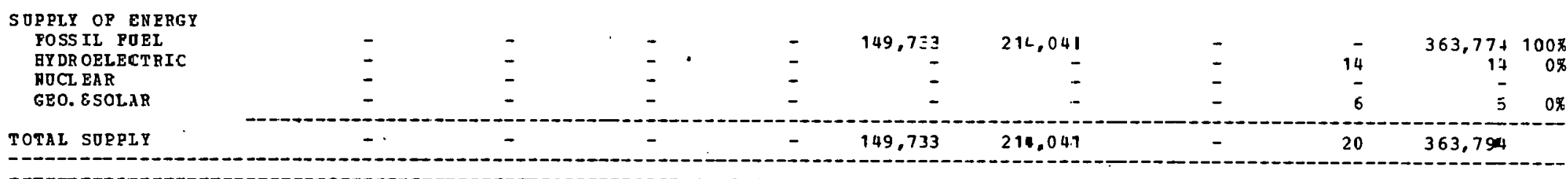

\section{NET IM PORTS}

OP R BGION

$-12,969$

31,113

$-27.678$

$-33,442$

$-8,554$

$-21,920$

2,511

18,949

$-51,9 \subseteq 0$

NO TES:

1 TBANSPORHATIOY LOSS POF TZANSPORAATIOU LOSS POF TFANSFOBNATI OV LOSS POE TEANSPOBAATIOT LOSS POE 
REGIONAL ENERGY BALANCE STATEMENT

PIES MID MID SCENARIO

\begin{tabular}{|c|c|c|c|c|c|c|c|c|c|c|}
\hline SECTOR & $\begin{array}{c}\text { DISTILLATE } \\
\text { OIL }\end{array}$ & $\begin{array}{l}\text { RESIDJAL } \\
\text { CIL }\end{array}$ & $\begin{array}{l}\text { GASOLINE } \\
\text { (ALL ONIT }\end{array}$ & $\begin{array}{c}\text { OTHER } \\
\text { HYDRO- } \\
\text { CARBONS } \\
\text { IS IN } 10 * \$ 9\end{array}$ & $\begin{array}{c}\text { CRODE } \\
\text { OIL } \\
\text { BTO'S) }\end{array}$ & $\begin{array}{l}\text { NATURAL } \\
\text { GAS }\end{array}$ & $\operatorname{COAL}$ & ELECTRICITY & $\begin{array}{r}\text { SECTOP } \\
\text { TOTAL }\end{array}$ & \\
\hline $\begin{array}{l}\text { PINAL DEMAND SECTORS } \\
\text { RESIDENTIAL, CCMM. } \\
\text { INDOSTRIAL } \\
\text { TRANSPORTATION } \\
\text { MISCELLANEOOS USES }\end{array}$ & $\begin{array}{r}686 \\
8,419 \\
8,503 \\
723\end{array}$ & $\begin{array}{r}231 \\
40,131 \\
4,041 \\
671\end{array}$ & $33,03 \overline{2}$ & $\begin{array}{r}6,147 \\
28,504 \\
1,938 \\
16\end{array}$ & $\begin{array}{l}\overline{-} \\
\overline{-}\end{array}$ & $\begin{array}{r}16,260 \\
144,625 \\
1,439 \\
363\end{array}$ & $\begin{array}{r}2 \\
2,744 \\
- \\
-\end{array}$ & $\begin{array}{r}13,470 \\
16,025 \\
- \\
147\end{array}$ & $\begin{array}{r}36,805 \\
240,448 \\
48,953 \\
1,920\end{array}$ & $\begin{array}{r}10 \% \\
66 \% \\
13 \% \\
1 \%\end{array}$ \\
\hline $\begin{array}{l}\text { TOTAL PINAL } \\
\text { DEMAND SECTORS }\end{array}$ & 18,331 & 45,074 & 33.032 & 36.605 & - & 162,696 & 2,746 & 29,642 & 328,126 & $90 \%$ \\
\hline $\begin{array}{l}\text { TRANSPORMATICN } \\
\text { ELECTRICITY GEN. } \\
\text { PETR OLEUM FRODOCTS } \\
\text { NATORAL GAS } \\
\text { SYNTHETICS }\end{array}$ & $\begin{array}{r}2,760 \\
- \\
-\end{array}$ & $\begin{array}{l}- \\
- \\
-\end{array}$ & $\begin{array}{l}\overline{-} \\
\overline{-}\end{array}$ & $\begin{array}{l}\overline{-} \\
\overline{-}\end{array}$ & $\begin{array}{l}- \\
- \\
-\end{array}$ & $\begin{array}{r}36,870 \\
- \\
-\end{array}$ & $\begin{array}{r}24,604 \\
- \\
-\end{array}$ & $\begin{array}{r}-21,110 \\
- \\
-\end{array}$ & $\begin{array}{r}43,124 \\
- \\
-\end{array}$ & $12 \%$ \\
\hline $\begin{array}{l}\text { YET FOEL DSED } \\
\text { IN TRANSFORMATION }\end{array}$ & 2,760 & - & - & - & - & 36,870 & 24,604 & $-21,110$ & 43,124 & $12 \%$ \\
\hline $\begin{array}{l}\text { TOTAL GROSS FLOHS } \\
\text { LOSSES } \varepsilon \text { OMISSIOBS }\end{array}$ & $\begin{array}{r}21,091 \\
1,299\end{array}$ & 45.074 & $\begin{array}{r}33,032 \\
-0\end{array}$ & $\begin{array}{l}36,605 \\
-1,530\end{array}$ & $\overline{-}$ & $\begin{array}{r}199,566 \\
-7,228\end{array}$ & $\begin{array}{r}27,350 \\
-60\end{array}$ & $\begin{array}{r}29,642 \\
2,964\end{array}$ & $\begin{array}{r}371,250 \\
-4,634\end{array}$ & $\begin{array}{r}101 \% \\
0 \%\end{array}$ \\
\hline TOTAL NET OSAGE & 22,310 & 45,075 & 33,031 & 35,074 & - & 192,337 & 27,289 & 11.496 & 366,615 & \\
\hline
\end{tabular}

\begin{tabular}{|c|c|c|c|c|c|c|c|c|c|c|}
\hline $\begin{array}{l}\text { SOPPLY OP ENERGY } \\
\text { FOSS IL POEL }\end{array}$ & - & - & - & - & 120,180 & 114,699 & - & - & 234,879 & $100 \%$ \\
\hline HY DR OELECTRIC & - & - & - & - & - & - & - & 18 & 18 & $0 \pi$ \\
\hline NOCL EAR & - & - & - & - & $\overline{-}$ & $\overline{-}$ & $\overrightarrow{-}$ & $\overline{8}$ & $\overline{8}$ & $0 \%$ \\
\hline GEU. ESOLAH & 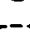 & 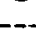 & - & $\vec{a}$ & 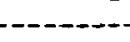 & 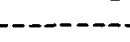 & 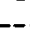 & $0^{\circ}$ & 8 & 00 \\
\hline TOTAL SUPPLY & - & - & - & - & 120,180 & 114,699 & - & 26 & 234,905 & \\
\hline
\end{tabular}

NET IM PORTS

45,075

33,031

35,074

$-120,180$

77,638

27,289

11,470

131,710

-

NOTES:

1 TRANSPORHATION LOSS POR

TRANSFORMATION LOSS POR

TRANSPORMLTI ON LOSS POR

TRANSPORAITI ON LOSS ?OR

BIECTRICITY GEN

EN. $\quad=67.14 \pi$

PRODJCTS $=0.0$

$=0.0 \%$
$=0.0 \%$

$=0.0 \%$ 
REGI OHAL EHERGY BALANCE STATENENT

\begin{tabular}{|c|c|c|c|c|c|c|c|c|c|c|}
\hline SECTOR & $\begin{array}{l}\text { DISTILLATE } \\
\text { OIL }\end{array}$ & $\begin{array}{l}\text { BESIDUAL } \\
\text { OIL. }\end{array}$ & $\begin{array}{l}\text { GASOIINE } \\
\text { (AIL ONIT }\end{array}$ & $\begin{array}{l}\text { OTRER } \\
\text { HYDRO- } \\
\text { CARBONS } \\
\text { IN } 10 * \$ 9\end{array}$ & $\begin{array}{c}\text { CRODE } \\
\text { OIL } \\
\text { BTO'S) }\end{array}$ & $\begin{array}{l}\text { VATUBEL } \\
\text { GAS }\end{array}$ & $\operatorname{COAL}$ & ELECTRICITY & $\begin{array}{r}\text { SECTOR } \\
\text { TOTAL }\end{array}$ & \\
\hline $\begin{array}{l}\text { PINAT, DEHAND SECTORS } \\
\text { RESID ENTIAL, COHM. } \\
\text { IND OSTRIAL } \\
\text { TRANS PORTATION } \\
\text { MISCE LLANEOUS OSES }\end{array}$ & $\begin{array}{l}2,453 \\
6.091 \\
7,491 \\
252\end{array}$ & $\begin{array}{r}515 \\
23,865 \\
288 \\
203\end{array}$ & $\begin{array}{r}- \\
34,217 \\
-\end{array}$ & $\begin{array}{r}4,363 \\
=5,070 \\
1,221 \\
7\end{array}$ & $\begin{array}{l}- \\
-\end{array}$ & $\begin{array}{r}11,7.38 \\
51,674 \\
454 \\
134\end{array}$ & $\begin{array}{r}52 \\
2,846 \\
- \\
-\end{array}$ & $\begin{array}{r}11,198 \\
20,471 \\
70\end{array}$ & $\begin{array}{r}30,319 \\
140,017 \\
43,671 \\
716\end{array}$ & $\begin{array}{r}128 \\
57.8 \\
18 . \\
0.8\end{array}$ \\
\hline $\begin{array}{l}\text { TOTAL PINAL } \\
\text { DEMAND SECTORS }\end{array}$ & 16,287 & $24,8.71$ & 34,217 & $\angle 0,661$ & - & 64,050 & $2,-398$ & 31,739 & 214,723 & $87 \pi$ \\
\hline $\begin{array}{l}\text { TRANSF ORHATION } \\
\text { ELECTRICITY GEN. } \\
\text { PETR OLEOU PRODOCTS } \\
\text { NATURAL GES } \\
\text { SINT HETICS }\end{array}$ & $\begin{array}{r}4.327 \\
-29,479 \\
-\end{array}$ & $\begin{array}{r}23,230 \\
-2,965 \\
- \\
-\end{array}$ & $\begin{array}{r}-49,55 \overline{-} \\
-\end{array}$ & $\begin{array}{r}-46,679 \\
-\end{array}$ & $\begin{array}{r}- \\
119,725 \\
-\end{array}$ & $\begin{array}{r}6,135 \\
10,213 \\
- \\
-\end{array}$ & $\begin{array}{r}2,759 \\
- \\
-\end{array}$ & $\begin{array}{r}-12,067 \\
- \\
-\end{array}$ & $\begin{array}{r}24,584 \\
1,158 \\
- \\
-\end{array}$ & $\begin{array}{r}10 \pi \\
0 \%\end{array}$ \\
\hline $\begin{array}{l}\text { NET FOBL OSED } \\
\text { IA TRANSPORAATION }\end{array}$ & $-25,152$ & 20,264 & $-49,65 ?$ & $-\$ 6,679$ & 119,725 & $16, \approx 48$ & 2,959 & $-12,067$ & 25,742 & $10 \%$ \\
\hline $\begin{array}{l}\text { TOTAL GROSS FLORS } \\
\text { LOSSES } \varepsilon \text { OMISSIONS }\end{array}$ & $\begin{aligned} 20,614 \\
\vdots, 191\end{aligned}$ & $\begin{array}{r}48,101 \\
1\end{array}$ & $\begin{array}{r}34,217 \\
-10\end{array}$ & $\begin{array}{l}40,661 \\
-1,699\end{array}$ & $\begin{array}{r}119,725 \\
5,976\end{array}$ & $\begin{array}{l}80,398 \\
-2,-12\end{array}$ & $\begin{array}{r}5.857 \\
-12\end{array}$ & $\begin{array}{r}31,739 \\
3,174\end{array}$ & $\begin{array}{r}240.465 \\
5,719\end{array}$ & $\begin{array}{r}98 \% \\
2 \%\end{array}$ \\
\hline
\end{tabular}

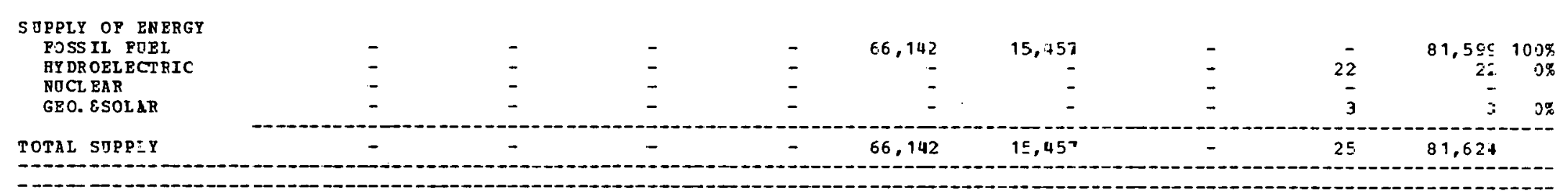

NET IM PORTE
OP REGIOY


REGIONAL ENERGY BALANCE STATEMENT

PIES MID MID SCENARIO

\begin{tabular}{|c|c|c|c|c|c|c|c|c|c|c|}
\hline SECTOR & $\begin{array}{l}\text { DISTILLATE } \\
\text { OIL }\end{array}$ & $\begin{array}{l}\text { RESIJסAL } \\
\text { OIL }\end{array}$ & $\begin{array}{l}\text { GASOLINE } \\
\text { (ALL ONIT }\end{array}$ & $\begin{array}{l}\text { OTHER } \\
\text { HYDRO- } \\
\text { CARBONS } \\
\text { S IN } 10 * * 9\end{array}$ & $\begin{array}{l}\text { CR ODE } \\
\text { OIL } \\
\text { BTO'S) }\end{array}$ & $\begin{array}{l}\text { NATURAL } \\
\text { GAS }\end{array}$ & COAL & ELECTRICITY & $\begin{array}{r}\text { SECTOR } \\
\text { TOTAL }\end{array}$ & \\
\hline $\begin{array}{l}\text { ?INAL DEYAND SECTORS } \\
\text { BESIDENTIAL, CCHY. } \\
\text { IND USTRIAL } \\
\text { TRANSPORTATION } \\
\text { MISCELLANEOUS OSES }\end{array}$ & $\begin{array}{r}2,356 \\
807 \\
14.227 \\
378\end{array}$ & $\begin{array}{r}202 \\
1.952 \\
755 \\
215\end{array}$ & $\begin{array}{r}- \\
- \\
45,521 \\
-\end{array}$ & $\begin{array}{r}4,923 \\
5,367 \\
1,442 \\
18\end{array}$ & $\begin{array}{l}\overline{-} \\
\overline{-}\end{array}$ & $\begin{array}{r}10,319 \\
31,706 \\
456 \\
475\end{array}$ & $\begin{array}{r}120 \\
5,055 \\
\overline{1}\end{array}$ & $\begin{array}{r}18,844 \\
19,383 \\
- \\
188\end{array}$ & $\begin{array}{r}36,764 \\
64,270 \\
62,401 \\
1,275\end{array}$ & $\begin{array}{r}20 \% \\
34 \% \\
33 \% \\
1 \%\end{array}$ \\
\hline $\begin{array}{l}\text { ZOTAL FINAL } \\
\text { DEHAND SECTORS }\end{array}$ & 17.768 & $\begin{array}{r}3.124 \\
\end{array}$ & 45,521 & 11,750 & - & 42,956 & 5,176 & 38,415 & 164,710 & $88 \%$ \\
\hline $\begin{array}{l}\text { בRANSF ORHATICN } \\
\text { EL ECTRICITY GEU. } \\
\text { PETROLEOM FRODOCTS } \\
\text { NATORAL GAS } \\
\text { SYNT HETICS }\end{array}$ & $\begin{array}{r}6,189 \\
-2,036 \\
- \\
-\end{array}$ & $\begin{array}{r}-204 \\
-\end{array}$ & $\begin{array}{r}- \\
-3.431 \\
- \\
-\end{array}$ & $\begin{array}{r}- \\
-3,225 \\
- \\
-\end{array}$ & $\begin{array}{r}- \\
8,27 \overline{2} \\
-\end{array}$ & $\begin{array}{r}17,005 \\
705 \\
- \\
-\end{array}$ & $\begin{array}{r}5,622 \\
- \\
-\end{array}$ & $\begin{array}{r}-9,254 \\
- \\
- \\
-\end{array}$ & $\begin{array}{r}19,562 \\
80 \\
- \\
-\end{array}$ & $\begin{array}{r}10 \% \\
0 \%\end{array}$ \\
\hline $\begin{array}{l}\text { FET FOEL JSED } \\
\text { IN TRANSPORGATION }\end{array}$ & 4,152 & -204 & $-3,431$ & $-3,225$ & 8,272 & 17,710 & 5,622 & $-9,254$ & 19,642 & 108 \\
\hline $\begin{array}{l}\text { TOTAL GROSS FLORS } \\
\text { LOSSES \& OMISSIONS }\end{array}$ & $\begin{array}{r}23,957 \\
1,385\end{array}$ & $\begin{array}{r}3,124 \\
0\end{array}$ & $\begin{array}{r}45,521 \\
-0\end{array}$ & $\begin{array}{r}11.750 \\
-491\end{array}$ & $\begin{array}{r}8,272 \\
412\end{array}$ & $\begin{array}{l}60,666 \\
-2,197\end{array}$ & $\begin{array}{r}10,798 \\
-23\end{array}$ & $\begin{array}{r}38,415 \\
3,841\end{array}$ & $\begin{array}{r}184,352 \\
2,927\end{array}$ & $\begin{array}{r}98 \% \\
2 \%\end{array}$ \\
\hline
\end{tabular}

\begin{tabular}{|c|c|c|c|c|c|c|c|c|c|c|}
\hline $\begin{array}{l}\text { SOPPLY OF ENERGY } \\
\text { FOSS }\end{array}$ & - & - & - & - & 37.797 & 34.737 & - & . & 72.534 & 739 \\
\hline HY DR OEL ECTRIC & - & - & - & - & - & - & - & 30 & $\begin{array}{r}12,334 \\
30\end{array}$ & $\begin{array}{r}0 \% \\
0 \%\end{array}$ \\
\hline NOCL EAR & - & - & - & - & - & - & - & 26,247 & 26,247 & $27 \%$ \\
\hline GEO. ESOLAR & - & - & - & - & - & - & - & - & - & \\
\hline TOTAL SUPPLY & - & - & - & - & 37,797 & 34,737 & - & 26,277 & 98,811 & \\
\hline
\end{tabular}

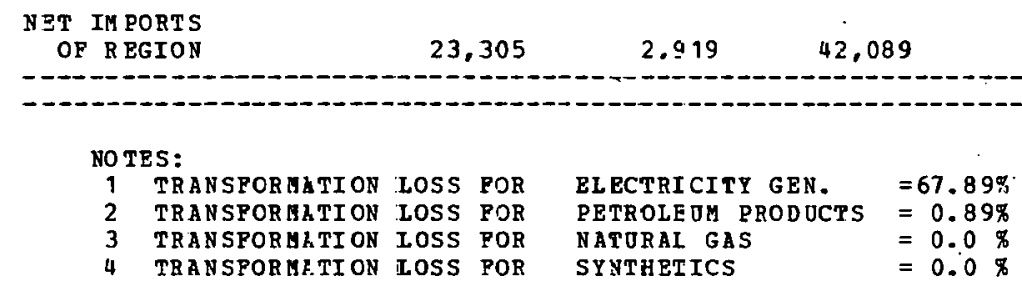


REGIONAL 3NERGY BALANCE STATE 1ENT

\begin{tabular}{|c|c|c|c|c|c|c|c|c|c|c|}
\hline SECTOR & $\begin{array}{l}\text { DI STIELATE } \\
\text { OIL }\end{array}$ & $\begin{array}{l}\text { RESIDUAL } \\
\text { OIL }\end{array}$ & $\begin{array}{l}\text { GASQLI IE } \\
\text { (ALL O }\end{array}$ & $\begin{array}{c}\text { OTHER } \\
\text { HEDRO- } \\
\text { ZAXBONS } \\
\text { S }-\mathbb{N} 10 * 99\end{array}$ & $\begin{array}{c}\text { CEODE } \\
\text { OIL } \\
\text { BTO'S) }\end{array}$ & $\begin{array}{l}\text { NATUR } .9 L \\
\text { GAS }\end{array}$ & $\cos \Delta \mathrm{L}$ & ELECTRICITY & $\begin{array}{l}\text { SECTOF } \\
\text { TOTAL }\end{array}$ & \\
\hline $\begin{array}{l}\text { PINAL DEMANE SECTORS } \\
\text { RESID ENTIAZ, CONM. } \\
\text { INDUS TRIAL } \\
\text { TRANSPORTATION } \\
\text { MISCELLANEOOS OSES }\end{array}$ & $\begin{array}{r}1.626 \\
796 \\
11,029 \\
270\end{array}$ & $\begin{array}{r}143 \\
2.697 \\
557 \\
553\end{array}$ & $\begin{array}{r}- \\
- \\
-\end{array}$ & $\begin{array}{r}3,522 \\
5,366 \\
1,216 \\
14\end{array}$ & $\begin{array}{l}\overline{-} \\
\bar{z}\end{array}$ & $\begin{array}{r}7,177 \\
34,290 \\
380 \\
383\end{array}$ & $\begin{array}{r}77 . \\
3,543 \\
1\end{array}$ & $\begin{array}{r}13,093 \\
17,089 \\
- \\
143\end{array}$ & $\begin{array}{l}25,638 \\
63,281 \\
46,152 \\
964\end{array}$ & $\begin{array}{r}14 \% \\
35 \% \\
26 \% \\
17\end{array}$ \\
\hline $\begin{array}{l}\text { TOTAL FINAL } \\
\text { DEMAND SECTORS }\end{array}$ & 13,721 & 3,350 & $32,57 \mathrm{C}$ & $-0,118$ & - & 42,230 & 3,721 & 30,325 & 136,035 & $76 \%$ \\
\hline $\begin{array}{l}\text { TRAN SP ORMATION } \\
\text { EL ECTRICIJY GZN. } \\
\text { PETR OLEOM FRODUCTS } \\
\text { NATORAL GES } \\
\text { SYNT HETICS }\end{array}$ & $\begin{array}{r}4,912 \\
-21,969 \\
-\end{array}$ & $\begin{array}{r}5,203 \\
-2,209 \\
-\end{array}$ & $\begin{array}{r}-37.20 \bar{\epsilon} \\
\overline{-}\end{array}$ & $\begin{array}{r}-54,787 \\
-\end{array}$ & 87,223 & $\begin{array}{r}1.960 \\
7.611 \\
-\end{array}$ & $\begin{array}{r}41,593 \\
- \\
-\end{array}$ & $\begin{array}{r}-13,362 \\
- \\
-\end{array}$ & $\begin{array}{r}35,306 \\
863 \\
- \\
-\end{array}$ & $\begin{aligned} 20 \% \\
0 \%\end{aligned}$ \\
\hline $\begin{array}{l}\text { NET FOEL OSED } \\
\text { IY TRANSFORHATION }\end{array}$ & $-17,057$ & 2,293 & $-37,0.06$ & $-34,787$ & $89,22 \vdots$ & 9,571 & 41,593 & $-18,362$ & 36,169 & $20 \%$ \\
\hline $\begin{array}{l}\text { TOTAL GROSS FLORS } \\
\text { LOSSES } \varepsilon \text { OMISSIONS }\end{array}$ & $\begin{array}{r}18,633 \\
1,077\end{array}$ & $\begin{array}{r}8,553 \\
0\end{array}$ & $\begin{array}{r}32,570 \\
-0\end{array}$ & $\begin{array}{r}10,118 \\
-422\end{array}$ & $\begin{array}{r}89,223 \\
4,452\end{array}$ & $\begin{array}{l}51 . \varepsilon 01 \\
-1 . \varepsilon 76\end{array}$ & $\begin{array}{r}45,314 \\
-99\end{array}$ & $\begin{array}{r}30,325 \\
3,032\end{array}$ & $\begin{array}{r}172,204 \\
6,165\end{array}$ & $\begin{aligned} 97 \% \\
3 \%\end{aligned}$ \\
\hline $\begin{array}{l}\text { S OPPLY OP ENERGY } \\
\text { FDSS IL FCEL } \\
\text { HY DR OELECTRIC } \\
\text { NOCL EAR } \\
\text { GEO. ESOLAR }\end{array}$ & $\begin{array}{l}\overline{-} \\
\bar{z}\end{array}$ & $\begin{array}{l}\overline{-} \\
\overline{-}\end{array}$ & $\begin{array}{l}\overline{-} \\
\overline{-}\end{array}$ & $\begin{array}{l} \pm \\
-\end{array}$ & $\begin{array}{r}186,195 \\
= \\
-\end{array}$ & $\begin{array}{r}18,232 \\
= \\
=\end{array}$ & $\begin{array}{l}\vec{z} \\
\overline{-}\end{array}$ & $\begin{array}{r}-\overline{3} \\
- \\
-\end{array}$ & $\begin{array}{r}204,42 \varepsilon \\
2 \Xi \\
-\end{array}$ & $\begin{array}{r}100 \% \\
0 \%\end{array}$ \\
\hline TOTAL SOPPLY & - & - & - & - & 186,195 & $18,23 \bar{\varepsilon}$ & - & 23 & $204,45^{-}$ & \\
\hline
\end{tabular}

-

NET IM PORTS

OP REGIOB

$-2,258$

5,343

$-4.436$

$-25,091$

$-92,517$

$31.59=$

45,214

14,972

$-26,0 \varepsilon^{\circ}$

\begin{tabular}{|c|c|c|c|c|c|}
\hline \multicolumn{6}{|c|}{ NOTES: } \\
\hline 1 & TRANSFORMATION & Loss & FOR & ELECTEICITE GEN. & $=65.79 \%$ \\
\hline 2 & TRINSPORMATI ON & IOSS & POR & PGTROREUM PRODUCTS & $=0.898$ \\
\hline 3 & TR IN SPOR UA TI ON & LOSS & POR & NATURLL GAS & $=0.0$ \\
\hline 4 & TR I N SPOR AA TI ON & IOSS & POR & STNTHETICS & $0 . .0$ \\
\hline
\end{tabular}


REGIONAL ENERGY BALANCE STATEMENT

PIES MID IID SCENARIO

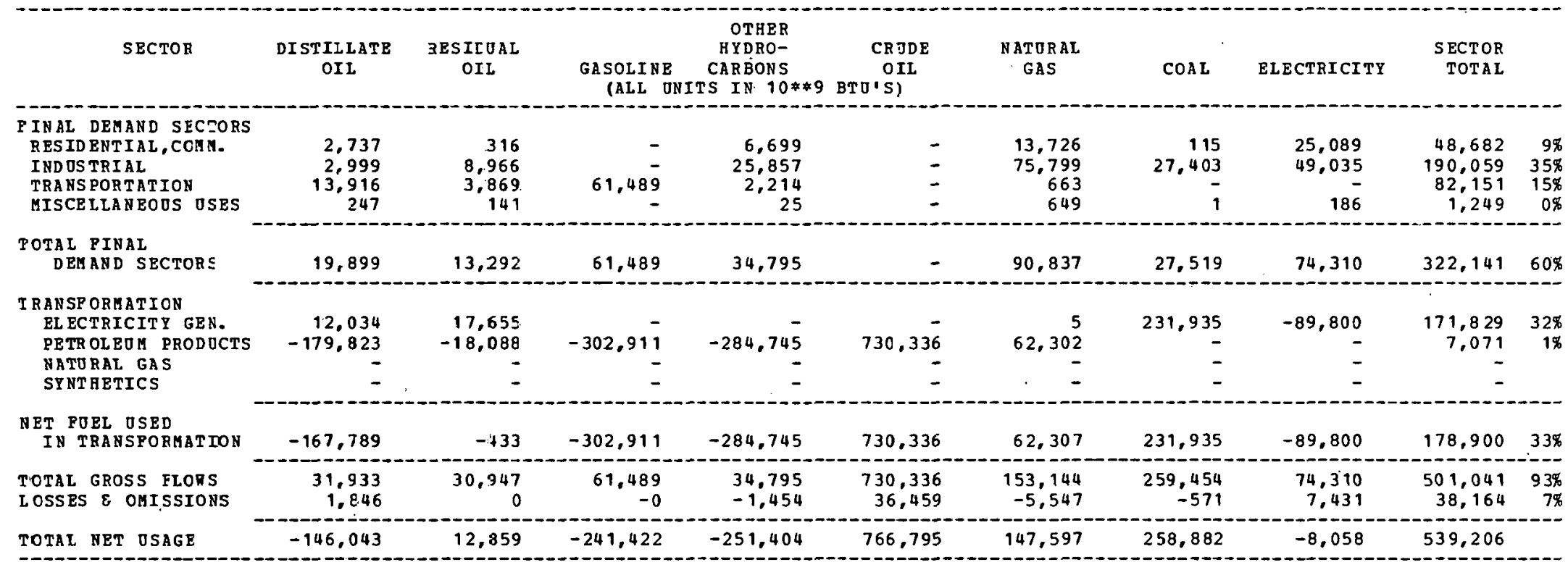

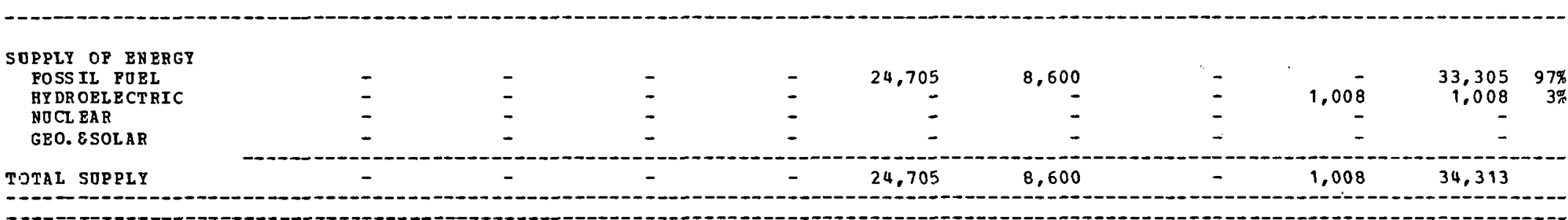

N3T IM PORTS
OP R BGION


REGIOJAL ENERGY BALANCE STATEHENT

PIES IID MID SCENARI

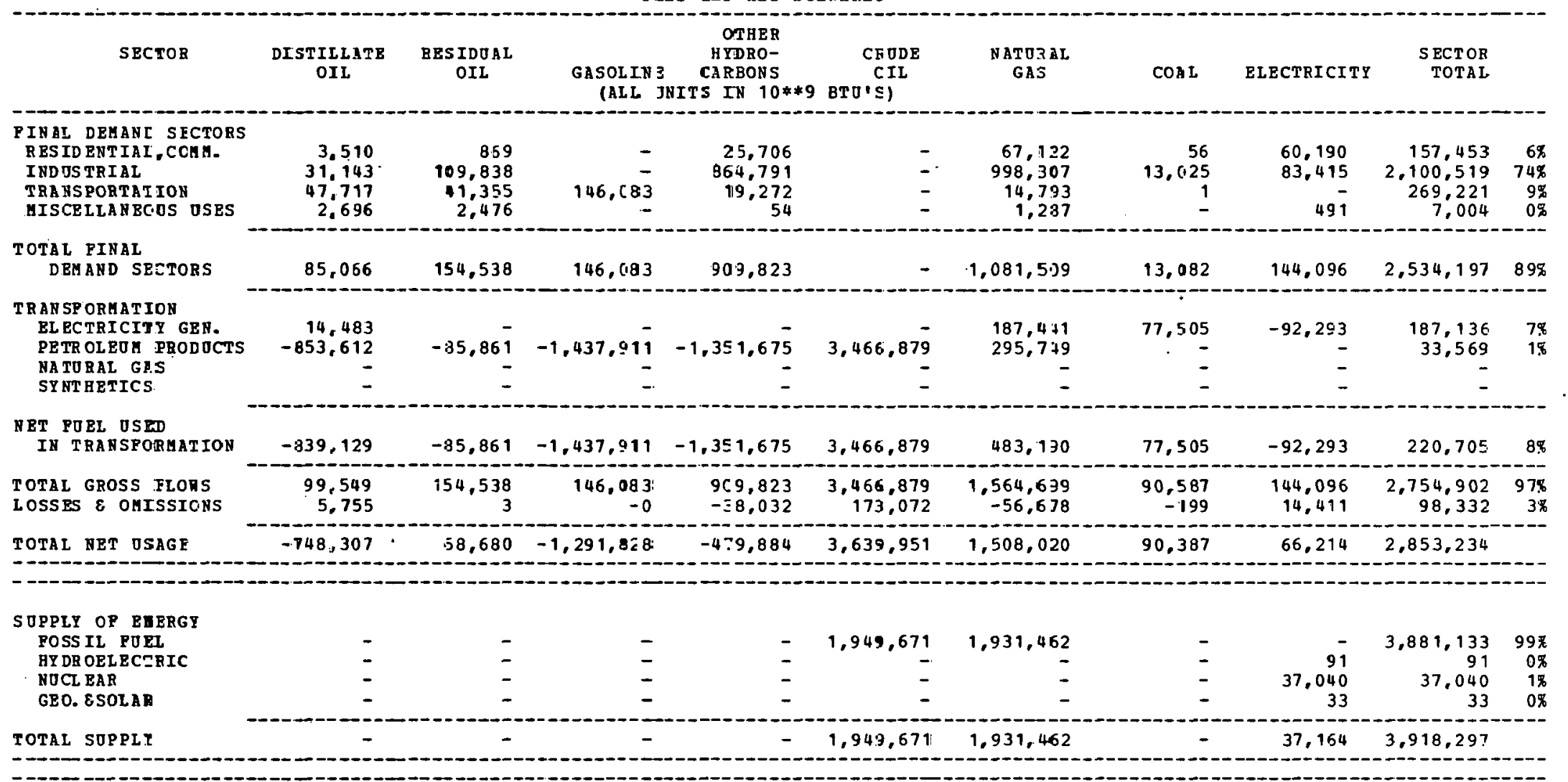

\section{$N B T$ IM PORTS}

$-748,307$

$68,680-1,291,32 \mathrm{e}$

$-479,884 \quad 1,69 \cdot 3,280$

$-423.441$

NOTES:

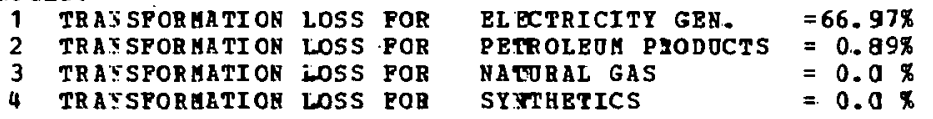


REGIONAL, ENE BGY BALANCE STATEMENT

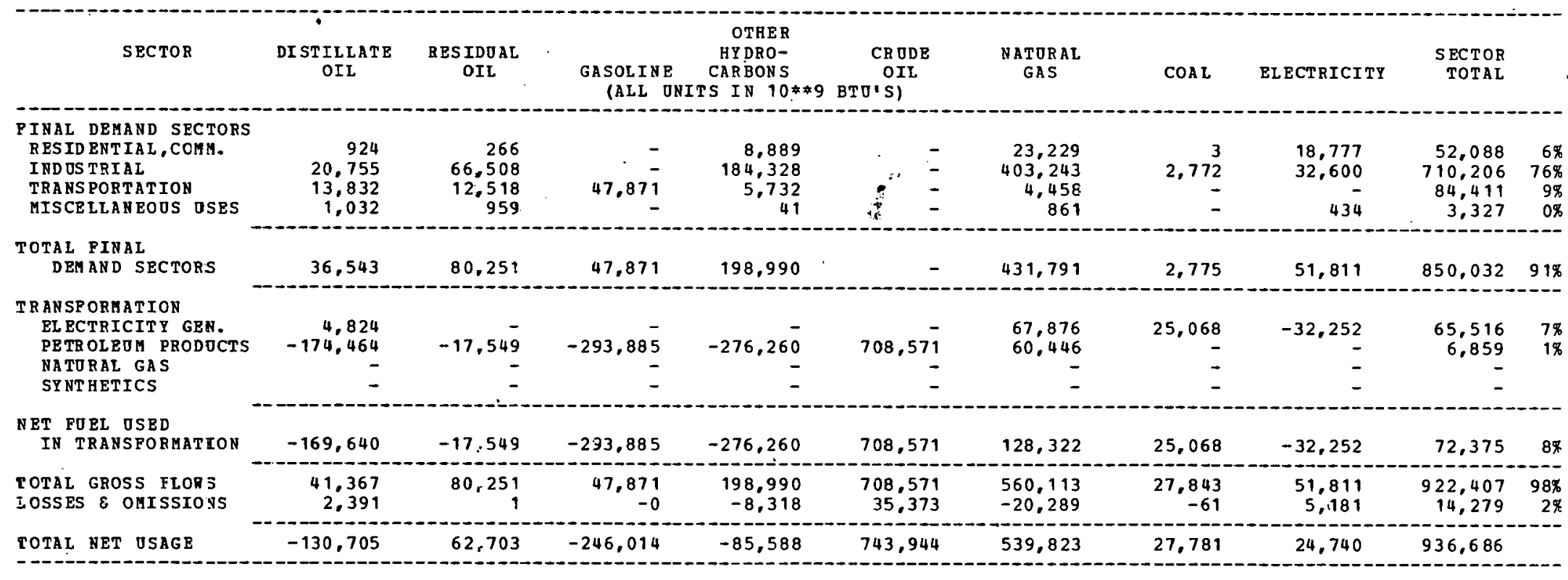

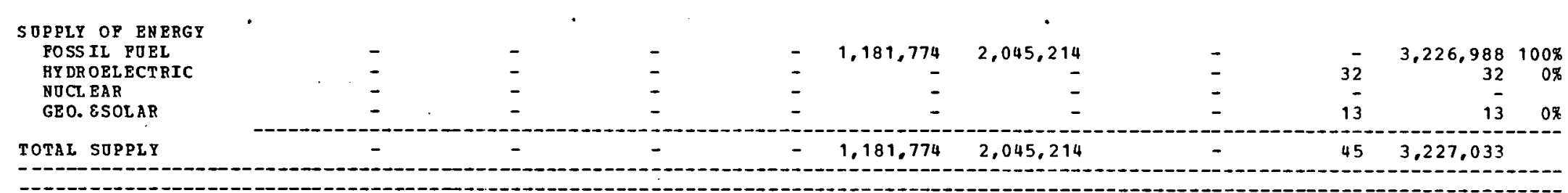

\section{ET IM PORTS}

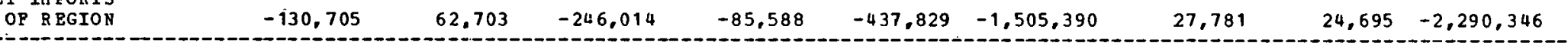

-

NOTES:

1 TRANSFORATION LOSS FOR

IRAIISPORAATION LOSS POR PETROLEOM PRODOCTS $=0.01 \%$

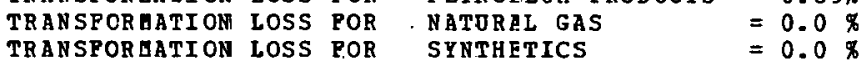

TRANSPORAATI ON LOSS P.OR 
REGICNAL ENE RGY BALANCE STATEMENT
PIES MID MID SCENARIO

\begin{tabular}{|c|c|c|c|c|c|c|c|c|c|c|}
\hline SECTOR & $\begin{array}{l}\text { DISTILLATE } \\
\text { OII }\end{array}$ & $\begin{array}{l}\text { RESIDDAL } \\
\text { OIL }\end{array}$ & $\begin{array}{l}\text { GASOEINE } \\
\quad(A E L O\end{array}$ & $\begin{array}{c}\text { OTHER } \\
\text { RTDRO- } \\
\text { CAEBONS } \\
\text { NITS IN } 10 * * 9\end{array}$ & $\begin{array}{c}\text { CQODE } \\
\text { OIL } \\
\text { BTO'S) }\end{array}$ & $\underset{\text { GaS }}{\text { NATURAL }}$ & $\operatorname{COAL}$ & ELECTRICITY & $\begin{array}{l}\text { SECTOR } \\
\text { TOTAL }\end{array}$ & \\
\hline $\begin{array}{l}\text { PINAL DEHANZ SECTORS } \\
\text { RESID BNTIAI, COBA. } \\
\text { INDUSTRIAL } \\
\text { TRANSPORTATION } \\
\text { MISCELLANECOS DSES }\end{array}$ & $\begin{array}{r}2,035 \\
6,340 \\
5,488 \\
391\end{array}$ & $\begin{array}{r}408 \\
19,701 \\
4,680 \\
363\end{array}$ & $33,10 \overline{-}$ & $\begin{array}{r}4,724 \\
402,518 \\
6,122 \\
8\end{array}$ & $\bar{z}$ & $\begin{array}{r}13,218 \\
381,187 \\
1,578 \\
183\end{array}$ & $5,25 \overline{6}$ & $\begin{array}{r}9,994 \\
25,500 \\
70\end{array}$ & $\begin{array}{r}30,379 \\
840,302 \\
50,972 \\
1,015\end{array}$ & $\begin{array}{r}3 \% \\
77 \% \\
5 \% \\
0 \%\end{array}$ \\
\hline $\begin{array}{l}\text { TOTAL PINAL } \\
\text { DEMAND SECTORS }\end{array}$ & 14,254 & 25,152 & 33,104 & 413,372 & - & 396,166 & 5,056 & 35,564 & 922,668 & $85 \%$ \\
\hline $\begin{array}{l}\text { TRANSP ORHATIOH } \\
\text { BLECTRICIIY GEN. } \\
\text { PETR OLEOH PBODOCTS } \\
\text { HATORAL GIS } \\
\text { SYNT HETIC: }\end{array}$ & $\begin{array}{r}3,311 \\
-658,913 \\
-\end{array}$ & $\begin{array}{r}-66.277 \\
-\end{array}$ & $\begin{array}{r}-1,109,341 \\
-\end{array}$ & $\begin{array}{r}-1,043,374 \\
- \\
-\end{array}$ & 2.676, 125 & $\begin{array}{r}56,714 \\
228,292 \\
-\end{array}$ & $\overline{-}$ & $\begin{array}{r}-19,781 \\
- \\
-\end{array}$ & $\begin{array}{r}40,244 \\
25,912 \\
-\end{array}$ & $\begin{array}{l}4 \% \\
2 \%\end{array}$ \\
\hline $\begin{array}{l}\text { NET POEL OSED } \\
\text { IA TRANSPCRHATION }\end{array}$ & $-655,602$ & $-66,277$ & $-1,109,341$ & $-1.043,374$ & $2,675,125$ & 285.006 & - & $-19,781$ & 66,156 & $6 \%$ \\
\hline $\begin{array}{l}\text { TOTAL GROSS FLONS } \\
\text { IOSSES \& OHESSIONS }\end{array}$ & $\begin{array}{r}17.565 \\
1,015\end{array}$ & $\begin{array}{r}25,152 \\
0\end{array}$ & $\begin{array}{r}33,104 \\
-6\end{array}$ & $\begin{array}{l}413,372 \\
-17,279\end{array}$ & $\begin{array}{r}2,676,125 \\
133,596\end{array}$ & $\begin{array}{l}681,1172 \\
-24, E=74\end{array}$ & $\begin{array}{r}5,056 \\
-11\end{array}$ & $\begin{array}{r}35,564 \\
3,556\end{array}$ & $\begin{array}{r}988,824 \\
96,204\end{array}$ & $\begin{array}{r}91 \% \\
\subseteq \%\end{array}$ \\
\hline TOTAL NET OSAGE & $-640,332$ & $-41,124$ & $-1,076,831$ & $-6+7,281$ & $2,809,721$ & 656.497 & 5,044 & 19,339 & $1,085,023$ & \\
\hline
\end{tabular}

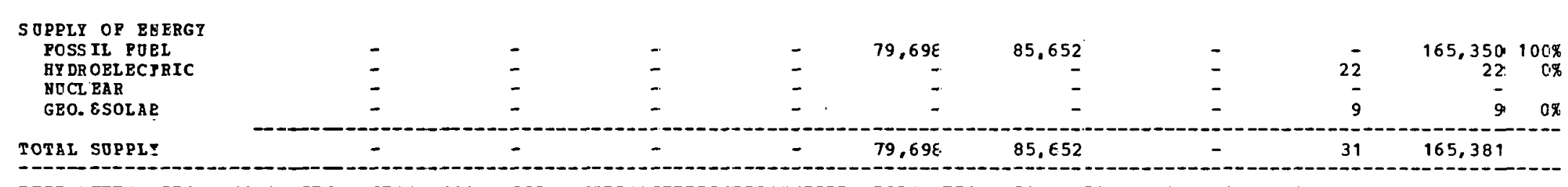

XET IM PORTS
OP B RGION

NO TES:

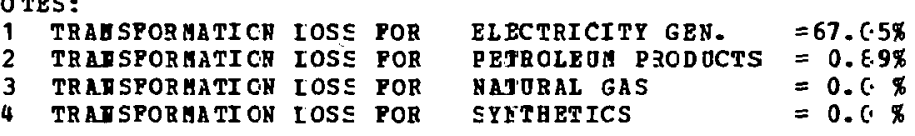


REGIONAL ENE RGY BALANCE STATEMENT PIES MID MID SCENARIO

\begin{tabular}{|c|c|c|c|c|c|c|c|c|c|c|}
\hline SECTOR & $\begin{array}{l}\text { DISTILLATE } \\
\text { OIL }\end{array}$ & $\begin{array}{l}\text { RESIDUAL } \\
\text { OIL }\end{array}$ & $\begin{array}{r}\text { GASOLINE } \\
\quad \text { (ALL U }\end{array}$ & $\begin{array}{c}\text { OTHER } \\
\text { HYDRO- } \\
\text { CARBONS } \\
\text { NITS IN } 10 * * 9\end{array}$ & $\begin{array}{c}\text { CRODE } \\
\text { OIL } \\
\text { BTU'S) }\end{array}$ & $\begin{array}{l}\text { NATURAL } \\
\text { GAS }\end{array}$ & $\operatorname{COAL}$ & ELECTRICITY & $\begin{array}{r}\text { SECTOR } \\
\text { TOTAL }\end{array}$ & \\
\hline $\begin{array}{l}\text { PINAL DEMAND SECTORS } \\
\text { RESIDENTIAL, COME. } \\
\text { INDUS TRIAL } \\
\text { TRANSPORTATION } \\
\text { MISCELLANEOUS USES }\end{array}$ & $\begin{array}{r}17,672 \\
21,408 \\
62,073 \\
4,209\end{array}$ & $\begin{array}{r}4.451 \\
67.382 \\
43.437 \\
3.908\end{array}$ & $\begin{array}{r}- \\
- \\
266,977 \\
-\end{array}$ & $\begin{array}{r}38,391 \\
1,221,455 \\
57,129 \\
80\end{array}$ & $\begin{array}{l}- \\
-\end{array}$ & $\begin{array}{r}112,271 \\
1,381,981 \\
14,646 \\
1,886\end{array}$ & $\begin{array}{r}- \\
26.462 \\
1 \\
-\end{array}$ & $\begin{array}{r}92,423 \\
101,273 \\
- \\
704\end{array}$ & $\begin{array}{r}265,208 \\
2,819,961 \\
444,255 \\
10,787\end{array}$ & $\begin{array}{r}7 \% \\
71 \% \\
11 \% \\
0 \%\end{array}$ \\
\hline $\begin{array}{l}\text { POTAL PINAL } \\
\text { DEMAND SECTORS }\end{array}$ & 105,362 & 119.178 & 266,977 & $1,317,047$ & - & $1,510,784$ & 26.463 & 194,400 & $3,540,211$ & $89 \%$ \\
\hline $\begin{array}{l}\text { TRANSP ORMATION } \\
\text { ELECTRICITY GEX- } \\
\text { PETROLEOM ERODOCTS } \\
\text { NATURAL GAS } \\
\text { SYNT HETICS }\end{array}$ & $\begin{array}{r}18,102 \\
-1,054,166 \\
-\end{array}$ & $\begin{array}{r}-106,034 \\
-\end{array}$ & $\begin{array}{r}-1,775,746 \\
-\end{array}$ & $\begin{array}{r}-1,669,249 \\
-\end{array}$ & $\begin{array}{r}4.281 .416 \\
-\end{array}$ & $\begin{array}{r}256,424 \\
365,234 \\
-\end{array}$ & $\begin{array}{r}181,978 \\
- \\
-\end{array}$ & $\begin{array}{r}-149,534 \\
= \\
-\end{array}$ & $\begin{array}{r}306,970 \\
49,455 \\
-\end{array}$ & $\begin{array}{l}8 \% \\
1 \%\end{array}$ \\
\hline $\begin{array}{l}\text { IET FOEL OSED } \\
\text { IN TRANSFORHATJON }\end{array}$ & $-1,036,064$ & $-106,034$ & $-1,775,746$ & $-1,669,249$ & $4,281,416$ & 621,658 & 181,978 & $-149,534$ & 348,425 & $9 \%$ \\
\hline $\begin{array}{l}\text { TOTAL GROSS PLOHS } \\
\text { LOSSES } \varepsilon \text { OMISSIONS }\end{array}$ & $\begin{array}{r}123,464 \\
7,137\end{array}$ & $\begin{array}{r}119,178 \\
2\end{array}$ & $\begin{array}{r}266,977 \\
-0\end{array}$ & $\begin{array}{r}1,317,047 \\
-55,054\end{array}$ & $\begin{array}{r}4,281,416 \\
213,735\end{array}$ & $\begin{array}{r}2,132,442 \\
-77,243\end{array}$ & $\begin{array}{r}238,441 \\
-459\end{array}$ & $\begin{array}{r}194,400 \\
19,442\end{array}$ & $\begin{array}{r}3,888,636 \\
107,559\end{array}$ & $\begin{array}{r}97 \% \\
3 \%\end{array}$ \\
\hline TOTAL NET DSAGE & $-923,564$ & 13,146 & $-1,508,769$ & $-407,256$ & $4,495,151$ & $2,055,198$ & 207,981 & 64,308 & $3,996,195$ & \\
\hline
\end{tabular}

-

\begin{tabular}{|c|c|c|c|c|c|c|c|c|c|c|}
\hline $\begin{array}{l}\text { S OPRLY OP ENERGY } \\
\text { FOSS IL FUEL }\end{array}$ & - & - & - & - & 834,995 & 720.812 & - & - & $1.555,807$ & $98 \%$ \\
\hline HY DR OELECTRIC & - & - & - & - & - & - & - & 120 & 120 & $0 \%$ \\
\hline NOCL EAR & - & - & - & - & - & - & - & 30,411 & 30,411 & $2 q$ \\
\hline GEO. ESOLAR & - & - & - & - & - & - & - & 50 & 50 & $0 \%$ \\
\hline
\end{tabular}

\begin{tabular}{|c|c|c|c|c|c|c|c|c|c|}
\hline $\begin{array}{l}\text { NET IM PORTS } \\
\text { OP R BGION }\end{array}$ & $-923,564$ & 13,146 & $-1,508,769$ & $-407,256$ & $3,660,156$ & $1,334,386$ & 207,981 & 33,727 & $2,409,807$ \\
\hline
\end{tabular}

\begin{tabular}{|c|c|c|c|c|c|}
\hline \multicolumn{6}{|c|}{ NOTES: } \\
\hline & TAANSFORMATION & Los: & POR & ELECTRICITY GEN. & $=67.24 \%$ \\
\hline & TRANSFORMATI ON & LOS & $P O B$ & PETBOLEOA PRODOCTS & $=0.89 \%$ \\
\hline 3 & TRAN SPOR HA TI ON & LOS & FOR & NATORAL GAS & $=0.0 \%$ \\
\hline 4 & TRANSFORMATI ON & LOS: & FOR & SYNTHEZICS & $=0.0 \%$ \\
\hline
\end{tabular}


REGIONAL ENERGY BALANCE STATEMENT

\begin{tabular}{|c|c|c|c|c|c|c|c|c|c|c|}
\hline SECTOR & $\begin{array}{l}\text { DISTILLATE } \\
\text { OII }\end{array}$ & $\underset{\text { OII }}{\text { RESIDUAL }}$ & $\begin{array}{l}\text { GASOLI } \\
\text { (ALI }\end{array}$ & $\begin{array}{c}\text { JTHER } \\
\text { HYDRO- } \\
\text { CABBONS } \\
\text { TS IN 10* }\end{array}$ & $\begin{array}{c}\text { CRUDE } \\
\text { OIL } \\
\text { BTO (S) }\end{array}$ & $\begin{array}{l}\text { NATUFAL } \\
\text { GAS }\end{array}$ & $\cos L$ & ELECTRICITY & $\begin{array}{l}\text { SECTOR: } \\
\text { TOTAL }\end{array}$ & \\
\hline $\begin{array}{l}\text { PINAL DEMANC SECTORS } \\
\text { RESID ENTIAL, CCAM. } \\
\text { IND OS TRIAL } \\
\text { TRANSPORTATION } \\
\text { MISCELLANEOOS OSES }\end{array}$ & $\begin{array}{r}7.690 \\
3.416 \\
19.067 \\
4.747\end{array}$ & $\begin{array}{l}1,789 \\
9,256 \\
8,210 \\
4,409\end{array}$ & $119,47 \overline{-}$ & $\begin{array}{r}17,128 \\
93,872 \\
10,928 \\
127\end{array}$ & $\begin{array}{l}- \\
- \\
-\end{array}$ & $\begin{array}{r}49.224 \\
171.823 \\
2.767 \\
2.836\end{array}$ & $\begin{array}{r}4.905 \\
-\end{array}$ & $\begin{array}{r}39,290 \\
20,647 \\
- \\
1,195\end{array}$ & $\begin{array}{r}115,121 \\
303,919 \\
160,446 \\
13,314\end{array}$ & $\begin{array}{r}16 \% \\
42 \% \\
22 \% \\
2 \%\end{array}$ \\
\hline $\begin{array}{l}\text { TOTAL PINAL } \\
\text { DEMAND SECTORS }\end{array}$ & 34,920 & 23,664 & 119.474 & 122.055 & - & 226.650 & 4.905 & 61,132 & $592,80 a$ & $82 \%$ \\
\hline $\begin{array}{l}\text { TRANSFORHATION } \\
\text { EIECTRICITY GEN. } \\
\text { PSTROLEUE FRODUCTS } \\
\text { NATURAL EAS } \\
\text { ST NTHETICS }\end{array}$ & $\begin{array}{r}5.592 \\
-2,240 \\
- \\
-\end{array}$ & $\begin{array}{r}-225 \\
-\end{array}$ & $\begin{array}{r}- \\
-3,77+ \\
-\end{array}$ & $\begin{array}{r}-3,547 \\
- \\
-\end{array}$ & $\begin{array}{r}9.099 \\
-\end{array}$ & $\begin{array}{r}97.810 \\
776 \\
- \\
-\end{array}$ & $\begin{array}{r}101,481 \\
= \\
-\end{array}$ & $\begin{array}{r}-67,714 \\
- \\
-\end{array}$ & $\begin{array}{r}137,269 \\
88 \\
-\end{array}$ & $\begin{aligned} 19 \% \\
0 \%\end{aligned}$ \\
\hline $\begin{array}{l}\text { NET PUEL OSED } \\
\text { IN TRANSERATION }\end{array}$ & 3,451 & -225 & $-3,774$ & $-3,547$ & 9,099 & 98,586 & 101.481 & -6.7 .714 & 137,357 & $19 \%$ \\
\hline $\begin{array}{l}\text { TOTAL GROSS FLOWS } \\
\text { LOSSBS \& ONISSIONS }\end{array}$ & $\begin{array}{r}40,512 \\
2,347\end{array}$ & $\begin{array}{r}23,664 \\
0\end{array}$ & $\begin{array}{r}119,474 \\
-3\end{array}$ & $\begin{array}{r}122,055 \\
-5,102\end{array}$ & $\begin{array}{r}9,099 \\
454\end{array}$ & $\begin{array}{r}325,236 \\
-11,781\end{array}$ & $\begin{array}{r}106,386 \\
-234\end{array}$ & $\begin{array}{r}61,132 \\
6,113\end{array}$ & $\begin{array}{r}730,157 \\
-8,201\end{array}$ & $\begin{array}{r}101 \% \\
0 \%\end{array}$ \\
\hline TOTAL NET OSAGE & 40,719 & 23.439 & 115.697 & 113,405 & 9.553 & 313.455 & 106,151 & -468 & 721,955 & \\
\hline $\begin{array}{l}\text { SUPPLY OF ENERGY } \\
\text { FOSS IL PUEL } \\
\text { HYDROELECTRIC } \\
\text { NOCL RAR } \\
\text { GEO. ESOL BR }\end{array}$ & $\begin{array}{l}\vec{z} \\
-\end{array}$ & $\begin{array}{l}- \\
-\end{array}$ & $\begin{array}{l}I \\
-\end{array}$ & $\begin{array}{l}\overline{-} \\
-\end{array}$ & $\begin{array}{r}2 \cdot 5,625 \\
- \\
-\end{array}$ & $\begin{array}{r}184,948 \\
- \\
-\end{array}$ & $\begin{array}{l}\text { - } \\
\text { - }\end{array}$ & $\begin{array}{r}1,230 \\
\overline{16}\end{array}$ & $\begin{array}{r}400,57 \equiv \\
1,230 \\
1 \epsilon\end{array}$ & $\begin{array}{r}100 \% \\
0 \% \\
0 \%\end{array}$ \\
\hline OTAL SUPPLY & - & - & - & - & 275,625 & 184,948 & - & 1,246 & $401,81 \leq$ & \\
\hline
\end{tabular}

-

\begin{tabular}{l} 
NET IM PORTS \\
OP REGIOU \\
\hline
\end{tabular}

\section{NoTES:}

TRANSPORMATION LOSS POR TRANSPORMATION LOSS POR TRAVPORATI ON LOSS POA 
REGIONAL ENERGY PALANCE STATEMENT

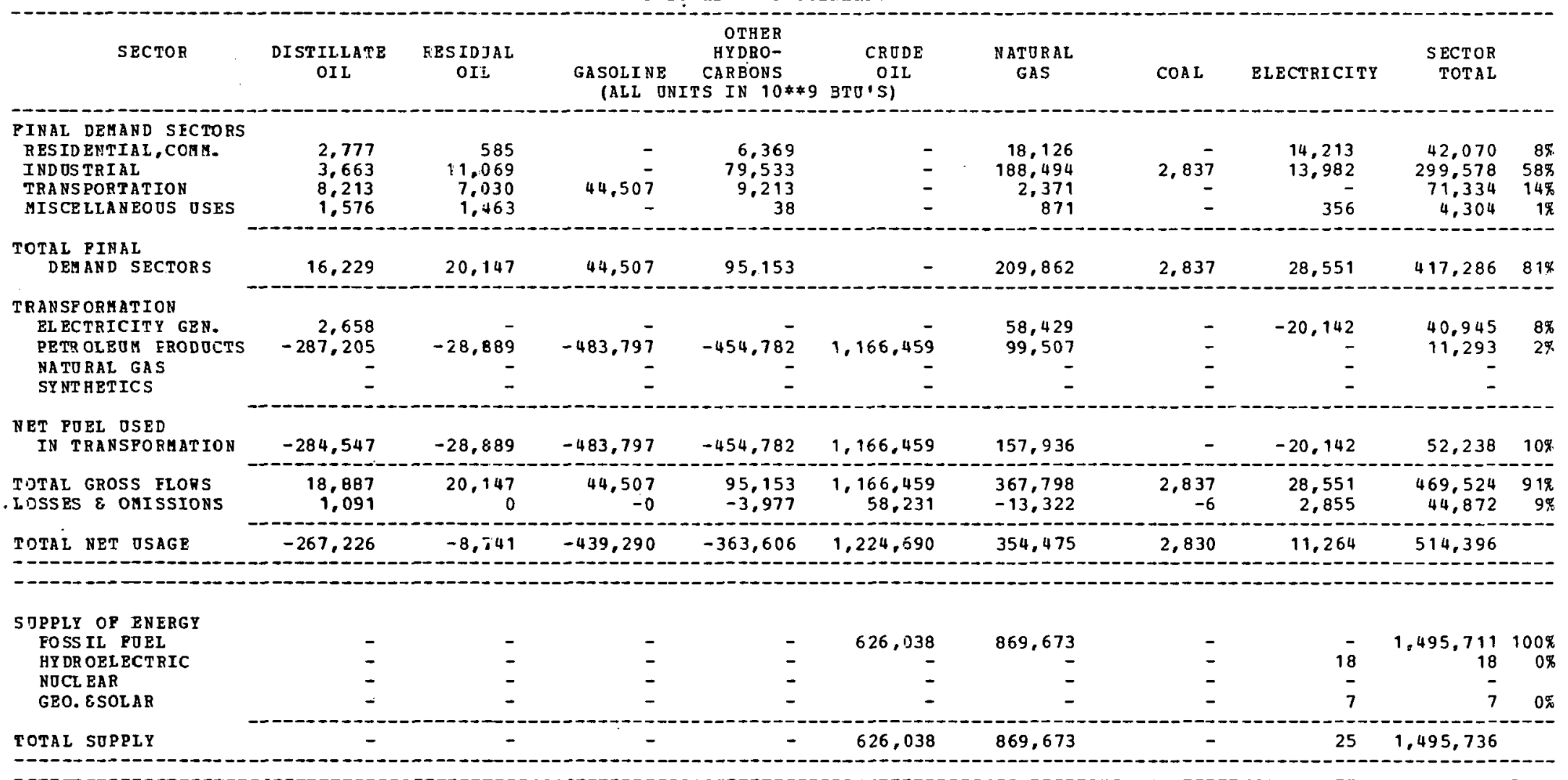

HET IMPORTS

OP REGION

$-267,226$

$-9,741 \quad-439,290$

$-363.606$

$598,652 \quad-515,197$

2,830

$11,239 \quad-981,339$

NOTES:

1 TRANSPORIATION LOSS POR ELECTRICITY GEN.

TRATSPORTATI ON LOSS POR

TRANSPOB GATI ON LOSS POR

TRANSPORHATI ON LOSS POR

政

SYNTHETICS

$=0.89 \%$
$=0.0 \%$

$=0.0 \%$ 
REGIONAL ENERGY BALANCE STATEMENT

PIES IID MID SCENARIO

\begin{tabular}{|c|c|c|c|c|c|c|c|c|c|c|}
\hline SECTOR & $\begin{array}{l}\text { DISTILLATE } \\
\text { OIL }\end{array}$ & $\begin{array}{l}\text { RESIDUAL } \\
\text { OIL }\end{array}$ & $\begin{array}{l}\text { GASOLIRI } \\
\text { (ALE }\end{array}$ & $\begin{array}{c}\text { ODHER } \\
\text { HYBRO- } \\
\text { CARBONS } \\
\text { TS ID } 10 * * 9\end{array}$ & $\begin{array}{c}\text { CR UDE } \\
\text { OIL } \\
\text { BTU'S\} }\end{array}$ & $\begin{array}{l}\text { NATURAL } \\
\text { GAS }\end{array}$ & $\cos 2$ & ELECTRICITY & $\begin{array}{r}\text { SECTOR } \\
\text { TOTAL }\end{array}$ & \\
\hline $\begin{array}{l}\text { PINAL DEMAND SECTORS } \\
\text { RESIDENTIAL, COHA. } \\
\text { INDOSTRIAL } \\
\text { TRANSPORTATION } \\
\text { MISCELILAOES OSES }\end{array}$ & $\begin{array}{r}2,724 \\
975 \\
4,958 \\
753\end{array}$ & $\begin{array}{r}586 \\
1.594 \\
4.884 \\
700\end{array}$ & $\begin{array}{r}- \\
43,355 \\
-\end{array}$ & $\begin{array}{r}6,202 \\
5,343 \\
6,389 \\
14\end{array}$ & $\begin{array}{l}- \\
-\end{array}$ & $\begin{array}{r}17, \leq 77 \\
25, E 55 \\
1, \in 47 \\
=35\end{array}$ & $\begin{array}{r}459 \\
-\end{array}$ & $\begin{array}{r}13,648 \\
6,727 \\
= \\
124\end{array}$ & $\begin{array}{r}40,737 \\
40,963 \\
61,233 \\
1,926\end{array}$ & $\begin{array}{r}26 \% \\
26 \% \\
40 \% \\
1 \%\end{array}$ \\
\hline $\begin{array}{l}\text { TOTAL PINAL } \\
\text { DEMAND SECTORS }\end{array}$ & 9,410 & 7,764 & $43,3.55$ & 17,948 & - & 45.414 & 469 & 20,499 & 144,859 & $94 \%$ \\
\hline $\begin{array}{l}\text { TRANSP ORMATI.YN } \\
\text { EL ECTRICITS GEN. } \\
\text { PETR OLEOH FRODOCTS } \\
\text { NATORAL GAS } \\
\text { SY NTHETICS }\end{array}$ & $\begin{array}{r}1,909 \\
-2,648 \\
- \\
-\end{array}$ & $\begin{array}{r}-26 \overline{-} \\
- \\
-\end{array}$ & $\begin{array}{r}-4,452 \\
-\end{array}$ & $\begin{array}{r}- \\
-4,194 \\
- \\
-\end{array}$ & 10,758 & $\begin{array}{r}11, \simeq 75 \\
\subseteq 17 \\
- \\
-\end{array}$ & $\begin{array}{l}- \\
\text { - } \\
\text { - }\end{array}$ & $\begin{array}{r}-4,558 \\
- \\
- \\
-\end{array}$ & $\begin{array}{r}9,326 \\
104 \\
- \\
-\end{array}$ & $\begin{array}{l}6 \% \\
0 \%\end{array}$ \\
\hline $\begin{array}{l}\text { NET PUEL OSEO } \\
\text { IN TRANSFOEMATION }\end{array}$ & -739 & -266 & $-4,452$ & $-4,194$ & 10,758 & $12, \varepsilon 92$ & - & $-4,558$ & 9,430 & $6 \%$ \\
\hline $\begin{array}{l}\text { TOTAL GROSS FLOHS } \\
\text { LOSSES \& OMISSIONS }\end{array}$ & $\begin{array}{r}11,319 \\
654\end{array}$ & $\begin{array}{r}7,764 \\
0\end{array}$ & $\begin{array}{r}43,355 \\
-15\end{array}$ & $\begin{array}{r}17,948 \\
-750\end{array}$ & $\begin{array}{r}10.758 \\
537\end{array}$ & $\begin{array}{l}58, \equiv a 6 \\
-2, ; 12\end{array}$ & $\begin{array}{r}469 \\
-1\end{array}$ & $\begin{array}{r}20.499 \\
2.050\end{array}$ & $\begin{array}{r}154,289 \\
378\end{array}$ & $\begin{array}{r}100 \% \\
0 \%\end{array}$ \\
\hline
\end{tabular}

\begin{tabular}{|c|c|c|c|c|c|c|c|c|c|c|}
\hline $\begin{array}{l}\text { S OPPLY OP ENERGY } \\
\text { FOSS IL POEL }\end{array}$ & - & - & - & - & 78.421 & $138.8=8$ & - & - & 217259 & 1008 \\
\hline HY DR OELECTRIC & - & - & - & - & 00 & 100,0 & - & 481 & 481 & $0 \%$ \\
\hline NOCL EAR & - & - & - & - & - & - & - & - & - & \\
\hline GEO. ESOLAR & - & - & - & - & - & - & - & 5 & 5 & $0 \pi$ \\
\hline
\end{tabular}

.324

7,497

38,892

13,003

$-67,125$

$-82,563$

467

17,505

$-63,077$

nOTES:

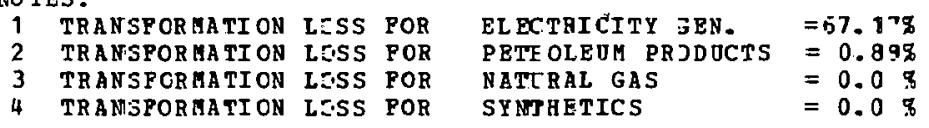


BEGIONAL ENE RGY BALANCE STATENENT

PIES MID UID SCENARIO

\begin{tabular}{|c|c|c|c|c|c|c|c|c|c|c|}
\hline SECTOR & $\begin{array}{l}\text { IISTILLATE } \\
\text { OIL }\end{array}$ & $\begin{array}{l}\text { RESIDUAL } \\
\text { OIL }\end{array}$ & $\begin{array}{l}\text { GASOLINE } \\
\text { IALL ONI }\end{array}$ & $\begin{array}{c}\text { OTHER } \\
\text { HYDRO- } \\
\text { CARBONS } \\
\text { TS IN } 10 * \$ 9\end{array}$ & $\begin{array}{c}\text { CR ODE } \\
\text { OIL } \\
\text { BTO'S) }\end{array}$ & $\begin{array}{l}\text { NATURAL } \\
\text { GAS }\end{array}$ & COAL & ELECTRICITY & $\begin{array}{r}\text { SECTOR } \\
\text { TOTAL }\end{array}$ & \\
\hline $\begin{array}{l}\text { PINAL DEHAND SECTORS } \\
\text { RESID ENTIAL,COHH. } \\
\text { INDOSTRIAL } \\
\text { TRANSPORTATION } \\
\text { EISCELLAKEOUS OSES }\end{array}$ & $\begin{array}{r}4,461 \\
1,874 \\
16,521 \\
2,297\end{array}$ & $\begin{array}{r}794 \\
4,829 \\
2,673 \\
2,124\end{array}$ & $\begin{array}{r}\overline{-} \\
59.109\end{array}$ & $\begin{array}{r}9.924 \\
12.106 \\
7,190 \\
61\end{array}$ & $\begin{array}{l}\overline{-} \\
\bar{z}\end{array}$ & $\begin{array}{r}32,052 \\
123,506 \\
1,762 \\
1,413\end{array}$ & $\begin{array}{r}1 \\
2,649 \\
- \\
-\end{array}$ & $\begin{array}{r}19,949 \\
6,994 \\
- \\
577\end{array}$ & $\begin{array}{r}67,181 \\
151,958 \\
97,255 \\
6,462\end{array}$ & $\begin{array}{r}19 \% \\
43 \% \\
27 \% \\
2 \%\end{array}$ \\
\hline $\begin{array}{l}\text { TOTAL PIMAL } \\
\text { DEHAND SECTORS }\end{array}$ & 25,143 & 10,420 & 69,109 & 29,281 & - & 158,733 & 2,650 & 27,520 & 322,856 & $91 \%$ \\
\hline $\begin{array}{l}\text { TRABSP OREATION } \\
\text { BLECTRICITY GEN. } \\
\text { PETBOLEOM FRODOCTS } \\
\text { NATURAL GAS } \\
\text { ST NT BETICS }\end{array}$ & $\begin{array}{r}2,563 \\
-76,541 \\
- \\
-\end{array}$ & $\begin{array}{r}- \\
-7,698 \\
- \\
-\end{array}$ & $\begin{array}{r}-128,933 \\
-\end{array}$ & $\begin{array}{r}-121,201 \\
-\end{array}$ & $\begin{array}{r}310,966 \\
-\end{array}$ & $\begin{array}{r}26,563 \\
26,519 \\
-\end{array}$ & $\begin{array}{l}\overline{-} \\
\overline{-}\end{array}$ & $\begin{array}{r}-9,305 \\
- \\
- \\
-\end{array}$ & $\begin{array}{r}19,821 \\
3,011 \\
- \\
-\end{array}$ & $\begin{array}{l}6 \% \\
1 \%\end{array}$ \\
\hline $\begin{array}{l}\text { BET FOEL OSED } \\
\text { IN TRANSPORMATICN }\end{array}$ & $-73,978$ & $-7,698$ & $-128,933$ & $-121,201$ & 310,866 & 53,082 & - & $-9,305$ & 22.832 & $6 \%$ \\
\hline $\begin{array}{l}\text { TCTAL GROSS FLORS } \\
\text { LGSSES \& OHISSIONS }\end{array}$ & $\begin{array}{r}27,706 \\
1,601\end{array}$ & $\begin{array}{r}10,420 \\
0\end{array}$ & $\begin{array}{r}69,109 \\
-0\end{array}$ & $\begin{array}{l}29,281 \\
-1,223\end{array}$ & $\begin{array}{r}310,866 \\
15,518\end{array}$ & $\begin{array}{r}211,815 \\
-7,672\end{array}$ & $\begin{array}{r}2,650 \\
-5\end{array}$ & $\begin{array}{r}27,520 \\
2,752\end{array}$ & $\begin{array}{r}345,688 \\
10,970\end{array}$ & $\begin{array}{r}97 \% \\
3 \%\end{array}$ \\
\hline
\end{tabular}

-

\begin{tabular}{|c|c|c|c|c|c|c|c|c|c|c|}
\hline $\begin{array}{l}\text { SUPPLY OP ENBBGY } \\
\text { FOSS IL POBL }\end{array}$ & - & - & $=$ & - & 296,251 & 469,726 & - & - & 765,977 & $100 \%$ \\
\hline HY DR OELBCT RIC & - & - & - & - & - & - & - & 357 & 357 & $0 \%$ \\
\hline NOCZ EAR & - & - & - & - & - & - & - & - & - & \\
\hline GRO. \&SOL AR & - & - & - & - & - & - & - & 7 & 7 & $0 \%$ \\
\hline TOTAL SUPPLY & - & - & - & - & 296,251 & 469,726 & - & 364 & 766,341 & \\
\hline
\end{tabular}

RET IM PORTS
OP REGION


REGIONAL ENE RGY BALANCE STATEHENT

PIES IID IID SCENARIO

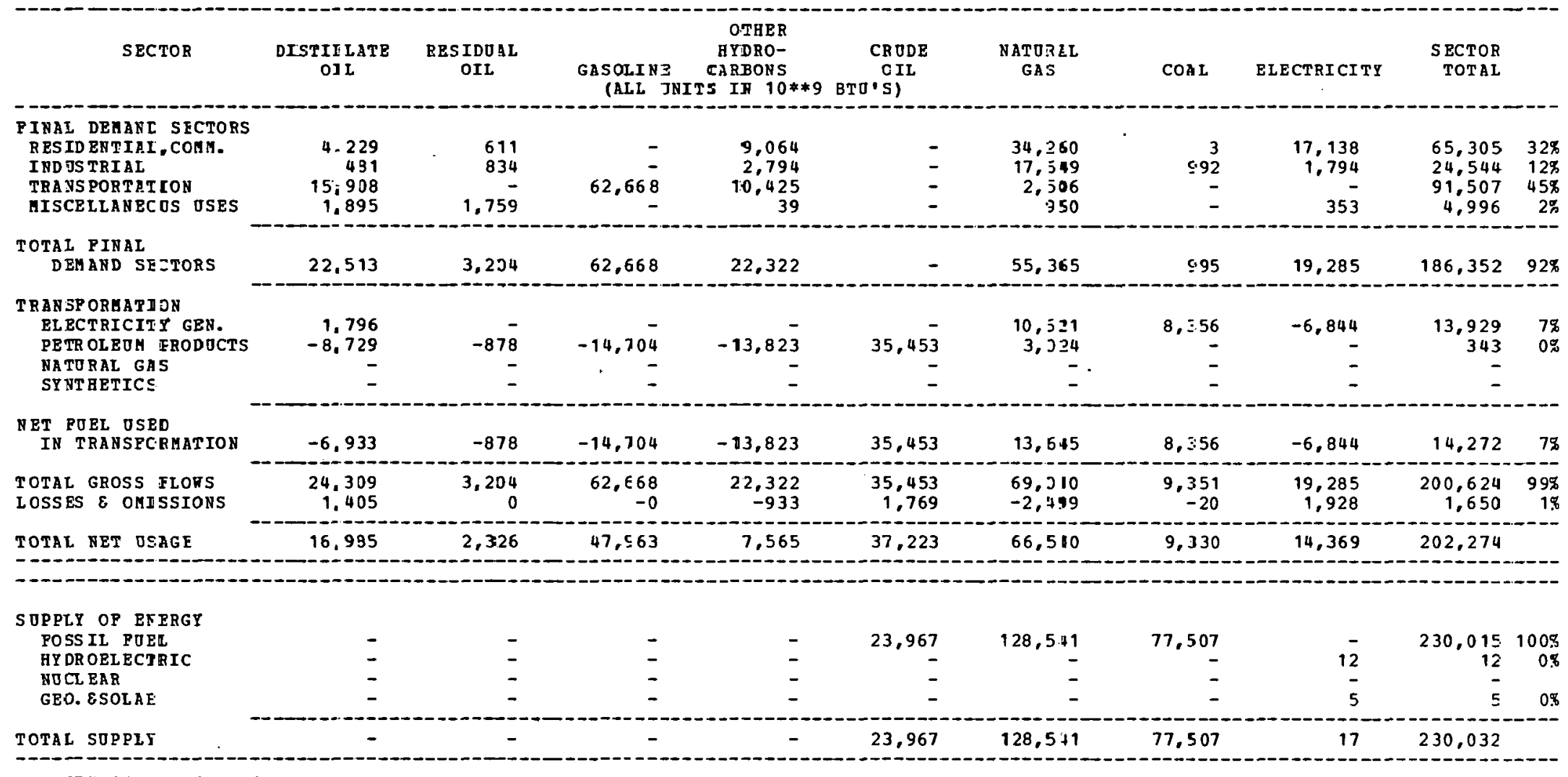

\begin{tabular}{l}
$\begin{array}{l}\text { NET IM PORTS } \\
\text { OP R RGIOU }\end{array}$ \\
\hline
\end{tabular}


REGIONAL ENERGY BALANCE STATEMENT

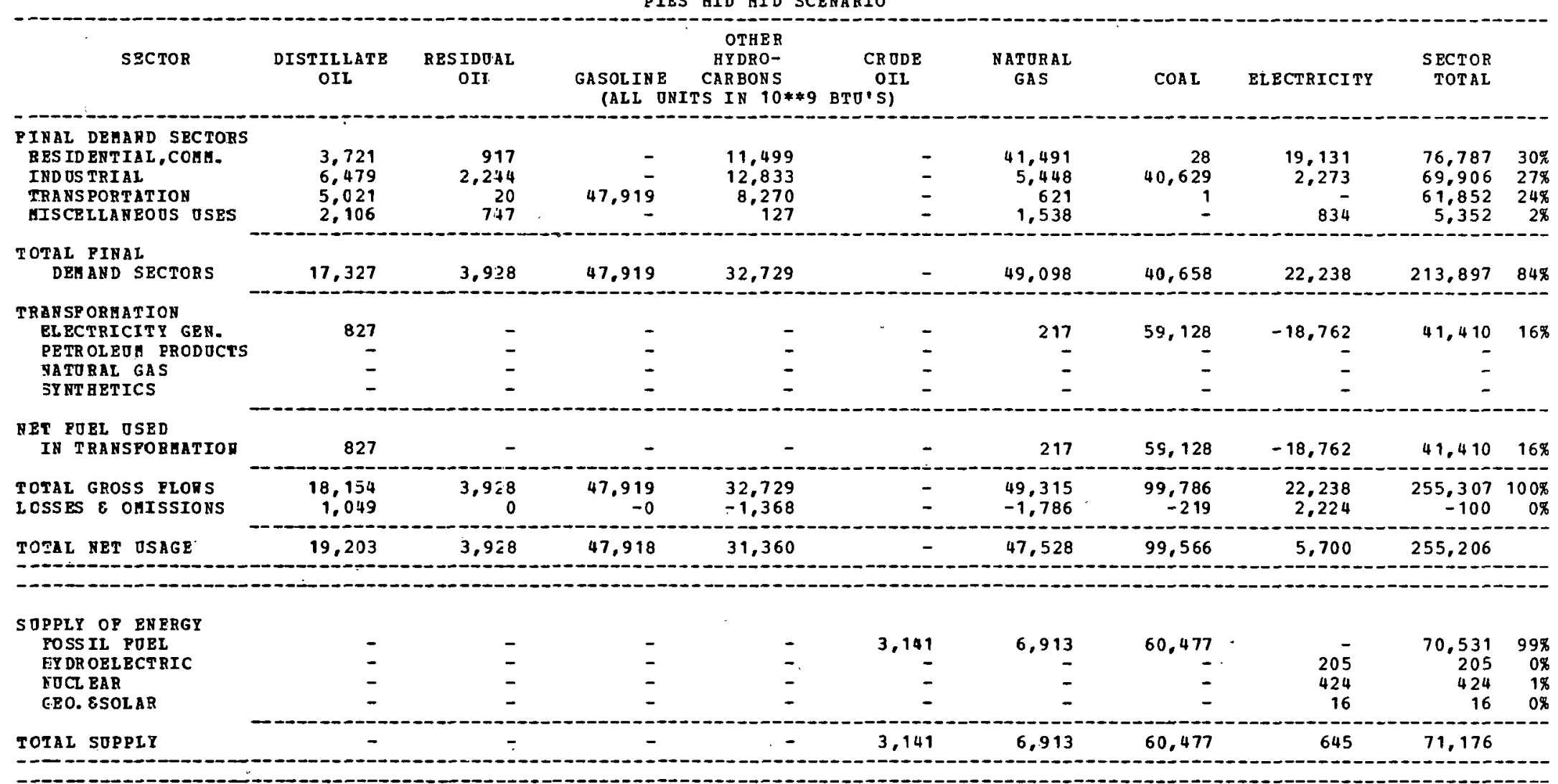

\begin{tabular}{l}
$\begin{array}{l}\text { NET IM PORTS } \\
\text { OP B BGION }\end{array}$ \\
\hline
\end{tabular}


REGIONAL BUEPGY BALANCE STATEMENT

PIES MID IID SCENARIO

\begin{tabular}{|c|c|c|c|c|c|c|c|c|c|c|}
\hline SECTOR & $\begin{array}{l}\text { DISTILLATE } \\
\text { OIl }\end{array}$ & $\begin{array}{l}\text { RESIDEAL } \\
\text { OIL }\end{array}$ & $\begin{array}{l}\text { GASOLINE } \\
\text { (ALL O }\end{array}$ & $\begin{array}{l}\text { OTARR } \\
\text { IYDZO- } \\
\text { CE BOHS } \\
\text { TS IN 10**9 }\end{array}$ & $\begin{array}{c}\text { CRODE } \\
\text { OIL } \\
\text { BTO'S) }\end{array}$ & $\begin{array}{l}\text { NATUR.AL } \\
\text { GAS }\end{array}$ & $\operatorname{COA} I$ & ELECTRICITY & $\begin{aligned} \text { SECTOR } \\
\text { TOTAL }\end{aligned}$ & \\
\hline $\begin{array}{l}\text { PINAL DEHAND SECTORS } \\
\text { RES ID ENTIAL, COHE. } \\
\text { INDOSTRIAL } \\
\text { TRANS PORTATION } \\
\text { MISCELLANEOOS OSES }\end{array}$ & $\begin{array}{r}12,334 \\
20,101 \\
17,338 \\
3,007\end{array}$ & $\begin{array}{r}3,052 \\
12.374 \\
44 \\
1.064\end{array}$ & $152,50 \overline{9}$ & $\begin{array}{r}36,662 \\
38,029 \\
51,086 \\
141\end{array}$ & $\begin{array}{l}- \\
\overline{-}\end{array}$ & $\begin{array}{r}133,618 \\
46,795 \\
3,852 \\
1,364\end{array}$ & $\begin{array}{r}\subseteq 3 \\
70,082 \\
1 \\
-\end{array}$ & $\begin{array}{r}63,398 \\
9,138 \\
- \\
895\end{array}$ & $\begin{array}{r}249,157 \\
196,719 \\
225,330 \\
6,471\end{array}$ & $\begin{array}{r}32 \% \\
25 \% \\
29 \% \\
1 \%\end{array}$ \\
\hline $\begin{array}{l}\text { TOTAL FIRAL } \\
\text { DEYAND SECTORS }\end{array}$ & 53,480 & $: 5,534$ & 152,509 & 125,918 & - & 185,629 & 70,176 & 73.431 & 677.677 & $87 \%$ \\
\hline $\begin{array}{l}\text { TR ANSP ORHATION } \\
\text { EL ECTRICITT GRE. } \\
\text { PETR OLEOA BRODOCTS } \\
\text { NATURAL GAS } \\
\text { SYNTHETICS }\end{array}$ & $\begin{array}{r}2,355 \\
-34,357 \\
-\end{array}$ & $\begin{array}{r}-70,531 \\
-\end{array}$ & $\begin{array}{r}-55,254 \\
- \\
-\end{array}$ & $\begin{array}{r}-23,571 \\
-\end{array}$ & $\begin{array}{r}118,394 \\
-\end{array}$ & $\begin{array}{r}711 \\
7.397 \\
- \\
-\end{array}$ & $\begin{array}{r}135,019 \\
= \\
-\end{array}$ & $\begin{array}{r}-43.239 \\
- \\
-\end{array}$ & $\begin{array}{r}95,446 \\
1,578 \\
- \\
-\end{array}$ & $\begin{array}{r}12 \% \\
0 \%\end{array}$ \\
\hline $\begin{array}{l}\text { NET FORL OSEZ } \\
\text { IN TRANSPOSHATION }\end{array}$ & $-.31, \exists 02$ & $-10,531$ & $-55,254$ & $-2 \equiv, 571$ & 118,394 & 8,103 & 135,019 & $-43,239$ & 97,024 & $12 \%$ \\
\hline $\begin{array}{l}\text { TOTAL GROSS ELONS } \\
\text { LOSSES } \& \text { OMI } \equiv S I O U S\end{array}$ & $\begin{array}{r}56,435 \\
3,262\end{array}$ & $\begin{array}{r}16,534 \\
0\end{array}$ & $\begin{array}{r}152,509 \\
-0\end{array}$ & $\begin{array}{r}125,918 \\
-5,263\end{array}$ & $\begin{array}{r}118,394 \\
5,910\end{array}$ & $\begin{array}{r}193,737 \\
-7,017\end{array}$ & $\begin{array}{r}205,935 \\
-451\end{array}$ & $\begin{array}{r}73,431 \\
7,343\end{array}$ & $\begin{array}{r}774,701 \\
3,783\end{array}$ & $\begin{array}{r}100 \% \\
0 \%\end{array}$ \\
\hline TOTAL NET USEGE & 24,840 & 6,003 & 97,254 & 97,083 & 124,304 & 186,719 & 204,743 & 37,535 & 778,485 & \\
\hline $\begin{array}{l}\text { S UPPLY OP ENERGY } \\
\text { FOSS IL POEI } \\
\text { HYDROELECT BIC } \\
\text { NOCL EAR } \\
\text { GEO. ESOLAR }\end{array}$ & $\overline{-}$ & $\begin{array}{l}\overline{-} \\
\overline{-}\end{array}$ & $\overline{-}$ & $\bar{z}$ & $\begin{array}{r}45,368 \\
= \\
=\end{array}$ & $\begin{array}{r}44,598 \\
= \\
-\end{array}$ & $\begin{array}{r}31,422 \\
=\end{array}$ & $\begin{array}{r}5,620 \\
1,390 \\
52\end{array}$ & $\begin{array}{r}121,788 \\
5,620 \\
1,390 \\
52\end{array}$ & $\begin{array}{r}95 \% \\
4 \% \\
1 \% \\
0 \%\end{array}$ \\
\hline TOTAL SUPPLY & - & - & - & - & 45,368 & 44,998 & 31,422 & 7,062 & 128,850 & \\
\hline
\end{tabular}

\begin{tabular}{|c|c|c|c|c|c|c|c|c|c|}
\hline $\begin{array}{l}\text { NET IM PORTS } \\
\text { OP REGION }\end{array}$ & 24,840 & 6,003 & 97.254 & 97,083 & 78,936 & 141,721 & 173,321 & 30,473 & 649,635 \\
\hline
\end{tabular}

\footnotetext{
YOTES:

TRAN SPORHATI ON LOSS POP TR AN JFORMATI ON LOSS POA TRAN SPR

4 TRAFSPORMATION LOSS POR SYNTHETICS

EL ECTRICITY JEN. $\quad=58.838$ PETEOLEJM PRJDUCTS $=1.2 .5 \%$

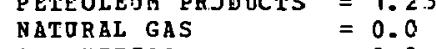


REGIONAL ENERGY BALANCE STATEMENT

\begin{tabular}{|c|c|c|c|c|c|c|c|c|c|c|}
\hline SECTOR & $\begin{array}{l}\text { DISTILLATE } \\
\text { OIL }\end{array}$ & $\begin{array}{l}\text { RES IDJAL } \\
\quad \text { OIL }\end{array}$ & $\begin{array}{l}\text { GASOLINE } \\
\text { IALL O }\end{array}$ & $\begin{array}{c}\text { OTHER } \\
\text { HYDRO- } \\
\text { CARBONS } \\
\text { TS IN } 10 * * 9\end{array}$ & $\begin{array}{c}\text { CR ODE } \\
\text { OIL } \\
\text { BTO'SI }\end{array}$ & $\begin{array}{l}\text { NATURAL } \\
\text { GAS }\end{array}$ & $\operatorname{COAL}$ & ELECTRICITY & $\begin{array}{l}\text { SECTOR } \\
\text { TOTAL }\end{array}$ & \\
\hline $\begin{array}{l}\text { PINAL DEMAND SRCTDRS } \\
\text { RESIDENTIAL, COMM. } \\
\text { IND USTRIAL } \\
\text { TRANSPORTATION } \\
\text { IISCELLANEOOS OSZS }\end{array}$ & $\begin{array}{r}2,176 \\
5,899 \\
3,055 \\
586\end{array}$ & $\begin{array}{r}474 \\
2,169 \\
8 \\
287\end{array}$ & $27.51 \overline{-}$ & $\begin{array}{r}5,926 \\
2,851 \\
5,572 \\
21\end{array}$ & $\begin{array}{l}\bar{z} \\
\overline{-}\end{array}$ & $\begin{array}{r}21,312 \\
32,181 \\
598 \\
216\end{array}$ & $\begin{array}{r}11 \\
6,361 \\
- \\
-\end{array}$ & $\begin{array}{r}9,761^{\circ} \\
1,876 \\
- \\
138\end{array}$ & $\begin{array}{r}39,660 \\
51,337 \\
36,743 \\
1,248\end{array}$ & $\begin{array}{r}12 \% \\
16 \% \\
11 \% \\
0 \%\end{array}$ \\
\hline $\begin{array}{l}\text { TOTAL PINAL } \\
\text { DEMAND SECTORS }\end{array}$ & 11,716 & 2,538 & 27,510 & 14,370 & - & 54,307 & 6,372 & 11,775 & 128,988 & $40 \%$ \\
\hline $\begin{array}{l}\text { TRANSP ORMATION } \\
\text { EL ECTRICITY GEN. } \\
\text { PETR OLEOM PRODOCTS } \\
\text { NATORAL GAS } \\
\text { SYNTHETICS }\end{array}$ & $\begin{array}{r}546 \\
-13,791 \\
- \\
-\end{array}$ & $\begin{array}{r}- \\
-2,564 \\
-\end{array}$ & $\begin{array}{r}- \\
-22,652 \\
- \\
-\end{array}$ & $\begin{array}{r}- \\
-16,542 \\
- \\
-\end{array}$ & $\begin{array}{r}52,132 \\
- \\
-50,000\end{array}$ & $\begin{array}{r}97 \\
3,994 \\
- \\
-61,200\end{array}$ & $\begin{array}{r}264,229 \\
- \\
127,936\end{array}$ & $\begin{array}{r}-85,995 \\
= \\
-\end{array}$ & $\begin{array}{r}178,877 \\
577 \\
- \\
16,736\end{array}$ & $\begin{array}{r}55 \% \\
0 \%\end{array}$ \\
\hline $\begin{array}{l}\text { UET FORL USED } \\
\text { IN TRANSFORMATION }\end{array}$ & $-13,245$ & $-2,554$ & $-22,652$ & $-16,542$ & 2,132 & $-57,108$ & 392,165 & $-85,995$ & 196.190 & $60 \%$ \\
\hline $\begin{array}{l}\text { TCTAL GROSS FLORS } \\
\text { LCSSES } \& \text { OMISSIONS }\end{array}$ & $\begin{array}{r}12,262 \\
708\end{array}$ & $\begin{array}{r}2,938 \\
0\end{array}$ & $\begin{array}{r}27,510 \\
-0\end{array}$ & $\begin{array}{r}14,370 \\
-600\end{array}$ & $\begin{array}{r}52,132 \\
2,602\end{array}$ & $\begin{array}{l}58,398 \\
-2,115\end{array}$ & $\begin{array}{r}398,537 \\
-877\end{array}$ & $\begin{array}{r}11,775 \\
1,177\end{array}$ & $\begin{array}{r}325,178 \\
895\end{array}$ & $\begin{array}{r}100 \% \\
0 \%\end{array}$ \\
\hline TOTAL NET DSAGE & -820 & 374 & 4,857 & $-2,772$ & 4,735 & $-4,916$ & 397,659 & $-73,042$ & 326,073 & \\
\hline
\end{tabular}

\begin{tabular}{|c|c|c|c|c|c|c|c|c|c|c|}
\hline S OPPLI OP ENERGY & & & & & & & & & & \\
\hline FOSS IL POEL & - & - & - & - & 159,955 & 389,369 & 830,848 & $\begin{array}{l}- \\
-\end{array}$ & $1,380,172$ & $100 \%$ \\
\hline HY DR OELECTRIC & - & - & - & - & - & - & - & 3,599 & 3.599 & of \\
\hline NOCL EAR & - & - & - & - & - & - & - & 190 & 190 & $0 \%$ \\
\hline GEO. ESOLAR & - & - & - & - & - & - & - & 8 & 8 & $0 \%$ \\
\hline TOTAL SUPPLY & - & - & - & - & 159,955 & 389,369 & 830,848 & 3,797 & $1,383,969$ & \\
\hline
\end{tabular}

-

NET IM PORTS
OP REGION

$\begin{array}{lllll}\text { NOTES: } & & & \\ 1 & \text { TRANSPORAATION } & \text { LOSS POR } & \text { ELECTRICITY GEN. } & =67.53 \% \\ 2 & \text { TRANSPORAATION LOSS POR } & \text { PETROLEOM PBODOCTS } & =1.03 \% \\ 3 & \text { TRANSPORHATION LOSS POR } & \text { NATORAL GAS } & =0.0 \% \\ 4 & \text { TRANSPORMATION LOSS POR } & \text { SYNTHETICS } & =13.08 \%\end{array}$


REGI JNAL ENERIYY BALANCE STATEMENT

PIFS MID :IID SCENARIO

\begin{tabular}{|c|c|c|c|c|c|c|c|c|c|c|}
\hline SECTJR & $\begin{array}{l}\text { DISTILIATE } \\
\text { OII }\end{array}$ & $\begin{array}{l}\text { RESIDUAE } \\
\text { =IL }\end{array}$ & $\begin{array}{l}\text { GASOLINE } \\
\text { (ALL OUI }\end{array}$ & $\begin{array}{c}\text { OT } \cong E R \\
\text { AYD } \cong O- \\
\text { CDEBONS } \\
\text { TS IN } 10 * \$ 9\end{array}$ & $\begin{array}{c}\text { CRODE } \\
\text { OIL } \\
\text { ETO'S) }\end{array}$ & $\begin{array}{l}\text { NATURBL } \\
\text { GAS }\end{array}$ & COAI & ELECTRICITY & $\begin{array}{r}\text { SECTOR } \\
\text { TOTAL }\end{array}$ & \\
\hline $\begin{array}{l}\text { PINAL DEMAND SECTORS } \\
\text { RESIDENTIAL, COMM. } \\
\text { IND DSTRIAL } \\
\text { TRANS PORTATION } \\
\text { MISCELLANEOE.S OSES }\end{array}$ & $\begin{array}{r}6,327 \\
15,297 \\
15,585 \\
740\end{array}$ & $\begin{array}{r}i, 784 \\
5.693 \\
543 \\
262\end{array}$ & $\begin{array}{r}- \\
30,145 \\
-\end{array}$ & $\begin{array}{r}4,889 \\
9,020 \\
883 \\
30\end{array}$ & $\begin{array}{l}- \\
\overline{-}\end{array}$ & $\begin{array}{r}18.579 \\
27.77 \% \\
303 \\
313\end{array}$ & $\begin{array}{r}13 \\
15,975 \\
1 \\
-\end{array}$ & $\begin{array}{r}12,115 \\
3,892 \\
- \\
172\end{array}$ & $\begin{array}{r}43,707 \\
77,660 \\
47,465 \\
1,517\end{array}$ & $\begin{array}{r}16 \% \\
29 \% \\
-18 \% \\
1 \%\end{array}$ \\
\hline $\begin{array}{l}\text { TCTAL PINAL } \\
\text { DELAND SECTORS }\end{array}$ & 37,949 & 8,293 & 30,145 & 14,822 & - & 46,972 & 15,989 & 16.179 & 170,349 & $64 \%$ \\
\hline $\begin{array}{l}\text { TRANSFORMATIOA } \\
\text { ELECTRICITS GEN. } \\
\text { PETR OLEUH PRODOCTS } \\
\text { NATTRAL GAS } \\
\text { SY NT HETICS }\end{array}$ & $\begin{array}{r}591 \\
-102,373 \\
- \\
-\end{array}$ & $\begin{array}{r}-\equiv 1,0 \overline{-} \\
-\end{array}$ & $\begin{array}{r}-163,07 \% \\
-\end{array}$ & $\begin{array}{r}- \\
-6 \subseteq, 565 \\
- \\
-\end{array}$ & $\begin{array}{r}- \\
349,415 \\
-\end{array}$ & $\begin{array}{r}158 \\
21,832 \\
- \\
-\end{array}$ & $\begin{array}{r}105,390 \\
= \\
=\end{array}$ & $\begin{array}{r}-33,099 \\
- \\
-\end{array}$ & $\begin{array}{r}73,040 \\
4,657 \\
- \\
-\end{array}$ & $\begin{array}{r}27 \% \\
2 \%\end{array}$ \\
\hline $\begin{array}{l}\text { NET FOEL OSED } \\
\text { IN TRANSPORHATION }\end{array}$ & $-102,282$ & $-31,0 \varepsilon 2$ & $-163,0: 0$ & $-6 \subseteq, 565$ & 349.415 & 21,993 & 105,390 & $-33,099$ & 77,697 & $29 \%$ \\
\hline $\begin{array}{l}\text { TOTAL GROSS FLONS } \\
\text { LCSSES } \& \text { OHISSIONS }\end{array}$ & $\begin{array}{r}38,540 \\
2,228\end{array}$ & $\begin{array}{r}3,293 \\
0\end{array}$ & $\begin{array}{r}30,145 \\
-0\end{array}$ & $\begin{array}{r}14,822 \\
-619\end{array}$ & $\begin{array}{r}349,415 \\
17,443\end{array}$ & $\begin{array}{l}68,9.62 \\
-2,493\end{array}$ & $\begin{array}{r}121.379 \\
-257\end{array}$ & $\begin{array}{r}16,179 \\
1,618\end{array}$ & $\begin{array}{r}248,046 \\
17,904\end{array}$ & $\begin{array}{r}93 \% \\
7 \%\end{array}$ \\
\hline $\begin{array}{l}\text { S OPPLY OP ENERGY } \\
\text { FOSS IL POEI } \\
\text { HYDROELECTEIC } \\
\text { NOCL BAR } \\
\text { GEO. ESOLAR }\end{array}$ & $\begin{array}{l}\overline{-} \\
\overline{-}\end{array}$ & $\begin{array}{l}\overline{-} \\
\overline{-}\end{array}$ & $\begin{array}{l}- \\
\overline{-} \\
\overline{-}\end{array}$ & $\begin{array}{l}\overline{-} \\
\overline{-}\end{array}$ & $\begin{array}{r}382,414 \\
= \\
-\end{array}$ & $\begin{array}{r}155,192 \\
- \\
-\end{array}$ & $\begin{array}{r}1,302,530 \\
= \\
=\end{array}$ & $\begin{array}{r}3,15 \overline{2} \\
308 \\
11\end{array}$ & $\begin{array}{r}1,840,106 \\
3,152 \\
308 \\
11\end{array}$ & $\begin{array}{r}100 \% \\
0 \% \\
0 \% \\
0 \%\end{array}$ \\
\hline TOTAL SUPPLY & - & - & - & - & 382,414 & $155,-92$ & $1,302,500$ & 3,471 & $1,843,577$ & \\
\hline
\end{tabular}

\begin{tabular}{l} 
N ET IM PORTS \\
OP REGION \\
\hline
\end{tabular}


REGIONAL ENERGY BALANCE STATEMENT

\begin{tabular}{|c|c|c|c|c|c|c|c|c|c|c|}
\hline SECTOR & $\begin{array}{l}\text { DISTILLATE } \\
\text { OIL }\end{array}$ & $\begin{array}{l}\text { RESIDUAL } \\
\text { OIL }\end{array}$ & $\begin{array}{l}\text { GASOLINE } \\
\text { (ALI ONI }\end{array}$ & $\begin{array}{c}\text { OTHER } \\
\text { HYDRO- } \\
\text { CARBONS } \\
\text { TS IN } 10 * 9\end{array}$ & $\begin{array}{c}\text { CRODE } \\
\text { OIL } \\
\text { BTO'S) }\end{array}$ & $\begin{array}{l}\text { NATURAL } \\
\text { GAS }\end{array}$ & COAL & ELECTRICITY & $\begin{array}{r}\text { SECTOR } \\
\text { TOTAL }\end{array}$ & \\
\hline $\begin{array}{l}\text { PINAL DEMAND SECTORS } \\
\text { RES ID ENTIAL, CCMM. } \\
\text { IND OS TRIAL } \\
\text { TRANSPORTATION } \\
\text { MISCELLANEOUS OSES }\end{array}$ & $\begin{array}{r}16,332 \\
26,010 \\
23,949 \\
5,002\end{array}$ & $\begin{array}{r}3,925 \\
28,773 \\
217 \\
1,776\end{array}$ & $116,88 \overline{-}$ & $\begin{array}{r}24,996 \\
52.771 \\
9.614 \\
209\end{array}$ & $\begin{array}{l}- \\
- \\
-\end{array}$ & $\begin{array}{r}83,162 \\
39,437 \\
1,003 \\
1,755\end{array}$ & $\begin{array}{r}110,62 \\
2 \\
1\end{array}$ & $\begin{array}{r}37,850 \\
13,715 \\
- \\
1,326\end{array}$ & $\begin{array}{r}166,357 \\
271,392 \\
151,671 \\
10,069\end{array}$ & $\begin{array}{r}23 \% \\
37 \% \\
21 \% \\
1 \%\end{array}$ \\
\hline $\begin{array}{l}\text { TCTAL FINAL } \\
\text { DEMAND SECTORS }\end{array}$ & 71,293 & 34,691 & 116,886 & 87,590 & - & 125,357 & 110,781 & 52,891 & 599,489 & $81 \%$ \\
\hline $\begin{array}{l}\text { TRANSFORMATION } \\
\text { ELECTRICITY GEN. } \\
\text { PETR OLEUM PBODUCTS } \\
\text { NATURAL GAS } \\
\text { SY NTHETICS }\end{array}$ & $\begin{array}{r}1,856 \\
-98,874 \\
-\end{array}$ & $\begin{array}{r}- \\
-29,873 \\
- \\
-\end{array}$ & $\begin{array}{r}-156,731 \\
-\end{array}$ & $\begin{array}{r}-66,860 \\
- \\
-\end{array}$ & $\begin{array}{r}335,834 \\
- \\
-50,000\end{array}$ & $\begin{array}{r}494 \\
20,983 \\
-\end{array}$ & $\begin{array}{r}242,792 \\
- \\
-\end{array}$ & $\begin{array}{r}-76,445 \\
- \\
-\end{array}$ & $\begin{array}{r}168,697 \\
4,476 \\
- \\
-50,000\end{array}$ & $\begin{array}{r}23 \% \\
1 \% \\
-6 \%\end{array}$ \\
\hline $\begin{array}{l}\text { NET FUEL OSED } \\
\text { IN TRANSFORMATION }\end{array}$ & $-97,018$ & $-29,873$ & $-156,731$ & $-66,860$ & 285,834 & 21,477 & 242,792 & $-76,445$ & 123,173 & $17 \%$ \\
\hline $\begin{array}{l}\text { TCTAL GROSS FLOHS } \\
\text { LCSSES } \& \text { OMISSIONS }\end{array}$ & $\begin{array}{r}73,149 \\
4,229\end{array}$ & $\begin{array}{r}34,671 \\
0\end{array}$ & $\begin{array}{r}116,886 \\
-0\end{array}$ & $\begin{array}{l}87,590 \\
-3,661\end{array}$ & $\begin{array}{r}335,834 \\
16,765\end{array}$ & $\begin{array}{r}146,834 \\
-5,318\end{array}$ & $\begin{array}{r}353,573 \\
-778\end{array}$ & $\begin{array}{r}52,891 \\
5,289\end{array}$ & $\begin{array}{r}772,662 \\
16,525\end{array}$ & $\begin{array}{r}105 \% \\
2 \%\end{array}$ \\
\hline TCTAL NET USAGE & $-21,496$ & 4,818 & $-39,846$ & 17.067 & 302,599 & 141,515 & 352,794 & $-18,264$ & 739,188 & \\
\hline $\begin{array}{l}\text { STPPLY OP ENERGY } \\
\text { FOSS IL FOEL } \\
\text { HYDR OELECTRIC } \\
\text { NUCL EAR } \\
\text { GEO. \&SOLAR }\end{array}$ & $\begin{array}{l}- \\
-\end{array}$ & $\begin{array}{l}- \\
-\end{array}$ & $\overline{-}$ & $\begin{array}{l}\overline{-} \\
-\end{array}$ & $\begin{array}{r}179,735 \\
- \\
-\end{array}$ & $\begin{array}{r}193,624 \\
- \\
-\end{array}$ & $\begin{array}{r}781,147 \\
- \\
-\end{array}$ & $\begin{array}{r}5.945 \\
966 \\
36\end{array}$ & $\begin{array}{r}1,154,506 \\
5,945 \\
966 \\
36\end{array}$ & $\begin{array}{r}99 \% \\
1 \% \\
0 \% \\
0 \%\end{array}$ \\
\hline TCTAL & & - & - & - & 179,735 & 193,624 & 781,147 & 6,947 & $1,161,453$ & \\
\hline
\end{tabular}

NET IH PORTS
OP R EGION


REGIOHAL BMERGY BALANCE STATERENT

PIES MID MI D SCENARIO

\begin{tabular}{|c|c|c|c|c|c|c|c|c|c|c|}
\hline SEC $=O R$ & $\begin{array}{c}\text { DI } \equiv \text { TILIATB } \\
\text { OII }\end{array}$ & $\begin{array}{l}\text { RE } \equiv I D O A L \\
\text { OIL }\end{array}$ & $\begin{array}{l}\text { GASOLIHE } \\
\text { (ALL UNIT }\end{array}$ & $\begin{array}{c}\text { OTHER } \\
\text { EYDRO- } \\
\text { CARBONS } \\
\text { TS IS 10**9 }\end{array}$ & $\begin{array}{c}\text { CRODE } \\
\text { OIL } \\
\text { BTO'S) }\end{array}$ & $\begin{array}{l}\text { NATUE AL } \\
\text { GAS }\end{array}$ & $\operatorname{COAL}$ & ELECTRICITY & $\begin{array}{r}\text { SECTOR } \\
\text { TOTAL }\end{array}$ & \\
\hline $\begin{array}{l}\text { FINAL DEMAND SECTORS } \\
\text { RES ID ENTIAL, COMH. } \\
\text { IND OSTRIAL } \\
\text { TRA TSPORTATION } \\
\text { MISCE LLANEOOS OSES }\end{array}$ & $\begin{array}{r}5,866 \\
1,919 \\
8,472 \\
231\end{array}$ & $\begin{array}{r}354 \\
533 \\
- \\
95\end{array}$ & $\begin{array}{r}- \\
34.457 \\
-\end{array}$ & $\begin{array}{r}3,929 \\
2,724 \\
2,218 \\
2\end{array}$ & $\begin{array}{l}- \\
- \\
-\end{array}$ & $\begin{array}{r}6,128 \\
6,204 \\
87 \\
-556\end{array}$ & $\begin{array}{r}56 \\
13,592 \\
1 \\
-\end{array}$ & $\begin{array}{r}17,355 \\
16,593 \\
- \\
117\end{array}$ & $\begin{array}{r}33,688 \\
41.565 \\
45,235 \\
701\end{array}$ & $\begin{array}{r}27 \% \\
33 \% \\
36 \% \\
1 \%\end{array}$ \\
\hline $\begin{array}{l}\text { TOTAL FINAL } \\
\text { DEMAND SEETORS }\end{array}$ & 16,488 & 982 & 34,457 & 8,873 & - & $12, \in 75$ & 13,649 & 34,065 & 121,189 & $97 \%$ \\
\hline $\begin{array}{l}\text { TRANSP ORMATIJN } \\
\text { EL ECTRICITS" GEN. } \\
\text { PETR OLEOM ERODOCTS } \\
\text { NATORAL GA } \\
\text {. SYNTHETICS }\end{array}$ & $\begin{array}{r}120 \\
- \\
-\end{array}$ & $\begin{array}{l}- \\
\overline{-} \\
-\end{array}$ & $\begin{array}{l}- \\
- \\
-\end{array}$ & $\begin{array}{l}- \\
-\end{array}$ & $\begin{array}{l}- \\
- \\
-\end{array}$ & $\begin{array}{l}4 \\
- \\
- \\
-\end{array}$ & $\begin{array}{l}- \\
-\end{array}$ & $\begin{array}{r}-39 \\
- \\
-\end{array}$ & $\begin{array}{l}85 \\
- \\
-\end{array}$ & $0 \%$ \\
\hline $\begin{array}{l}\text { NET POEL OSEE } \\
\text { IN TRANSFOEMATION }\end{array}$ & 120 & - & - & - & - & 4 & - & -39 & 85 & $0 \%$ \\
\hline $\begin{array}{l}\text { TOTAL GROSS ELORS } \\
\text { LCSSES } \varepsilon \text { OHI } \equiv \text { SIOUS }\end{array}$ & $\begin{array}{r}16,508 \\
960\end{array}$ & $\begin{array}{r}982 \\
0\end{array}$ & $\begin{array}{r}34,457 \\
-0\end{array}$ & $\begin{array}{r}8,873 \\
-370\end{array}$ & $\overline{-}$ & $\begin{array}{r}12,679 \\
-459\end{array}$ & $\begin{array}{r}13,6+9 \\
-30\end{array}$ & $\begin{array}{r}34,065 \\
3,406\end{array}$ & $\begin{array}{r}121,274 \\
3,506\end{array}$ & $\begin{array}{r}97 \% \\
3 \%\end{array}$ \\
\hline $\begin{array}{l}\text { SOPPLY OP ENERGY } \\
\text { FOSS IL PUEE } \\
\text { HYDR OELECTEIC } \\
\text { NOCL EAR } \\
\text { GEO. ESOLAR }\end{array}$ & $\begin{array}{l}- \\
-\end{array}$ & $\begin{array}{l}- \\
\overline{-} \\
-\end{array}$ & $\begin{array}{l}- \\
- \\
-\end{array}$ & $\begin{array}{l}- \\
-\end{array}$ & $\begin{array}{l}- \\
-\end{array}$ & $\begin{array}{l}- \\
-\end{array}$ & $\begin{array}{l}- \\
-\end{array}$ & $\begin{array}{r}- \\
14.706 \\
7 \\
-\end{array}$ & $\begin{array}{r}- \\
14,706 \\
7 \\
-\end{array}$ & $\begin{aligned} 0.0 \pi \\
0 \%\end{aligned}$ \\
\hline TOTAL SOPPLY & - & - & - & - & - & - & - & 14,713 & 14,713 & \\
\hline
\end{tabular}

\section{NET IM PORTS}

17,568

982

34.456

E.,502

$-\quad 12,219$

13,618

22.719

110,067

-

NO TES:

TRAN SPORMATION LCSS zOR

TRANSPORMATI ON LCSS ZOR

TR AN SFORHATI ON LCISS ?O

TRAN SPORHA TI ON LCSS ?OR

ELZCTRICITY GEN.

PETE JLEOIS PRCDOCIS $=63.55 \%$

NATLI ZAL GAS

$=0.0 \%$

SY NT IETICS

$=0.0 \%$ 
REGIONAL ENERGX BALANCE STATEMENT
PIES MID MID SCENARIO

\begin{tabular}{|c|c|c|c|c|c|c|c|c|c|c|}
\hline SECTOR & $\begin{array}{l}\text { DISTILLATE } \\
\text { OIL }\end{array}$ & $\begin{array}{l}\text { RESIDURLL } \\
\text { OIL }\end{array}$ & $\begin{array}{l}\text { GASOLINB } \\
\quad(A L L\end{array}$ & $\begin{array}{c}\text { OTHER } \\
\text { HYDRO- } \\
\text { CARBONS } \\
\text { TS IN } 10 * \$ 9\end{array}$ & $\begin{array}{c}\text { CRODE } \\
\text { OIL } \\
\text { BTO'SI }\end{array}$ & $\begin{array}{l}\text { NATURAL } \\
\text { GAS }\end{array}$ & $\operatorname{COAL}$ & ELECTRICITY & $\begin{array}{r}\text { SECTOR } \\
\text { TOTAL }\end{array}$ & \\
\hline $\begin{array}{l}\text { PINAL DEMAND SECTORS } \\
\text { RZSIDENTIAL, COMM. } \\
\text { IRD US TRIAL } \\
\text { TRA PSPORTATION } \\
\text { HISCE LLANEOOS OSES }\end{array}$ & $\begin{array}{r}3,139 \\
6,214 \\
13,819 \\
471\end{array}$ & $\begin{array}{r}6 \sqsubseteq 8 \\
2,5 \subseteq 5 \\
54 \\
1 \in 7\end{array}$ & $\begin{array}{r}- \\
- \\
25,052\end{array}$ & $\begin{array}{r}5,278 \\
4,761 \\
3,624 \\
19\end{array}$ & $\begin{array}{l}\overline{-} \\
\overline{-}\end{array}$ & $\begin{array}{r}19,024 \\
11,384 \\
510 \\
167\end{array}$ & $\begin{array}{r}36 \\
16,537 \\
1 \\
-\end{array}$ & $\begin{array}{r}10,435 \\
25,908 \\
- \\
123\end{array}$ & $\begin{array}{r}38,550 \\
67,399 \\
43,100 \\
947\end{array}$ & $\begin{array}{r}25 \% \\
44 \% \\
28 \% \\
1 \%\end{array}$ \\
\hline $\begin{array}{l}\text { TOTAL PINAL } \\
\text { DEMAND SECTORS }\end{array}$ & 23,643 & 3,454 & 25,052 & 13,682 & - & 31,085 & 16,574 & 36,466 & 149,996 & $97 \%$ \\
\hline $\begin{array}{l}\text { TRANSPORMATION } \\
\text { ELECTRICITY GEN. } \\
\text { PETR OLEOM PRODOCIS } \\
\text { BATURAL GAS } \\
\text { SY HTHETICS }\end{array}$ & $\begin{array}{r}1,331 \\
- \\
- \\
-\end{array}$ & $\begin{array}{l}- \\
\overline{-}\end{array}$ & $\begin{array}{l}- \\
-\end{array}$ & $\begin{array}{l}- \\
-\end{array}$ & $\begin{array}{l}- \\
-\end{array}$ & $\begin{array}{r}356 \\
- \\
-\end{array}$ & $\begin{array}{l}- \\
- \\
-\end{array}$ & $\begin{array}{r}-520 \\
- \\
-\end{array}$ & $\begin{array}{r}1,167 \\
- \\
-\end{array}$ & $1 \%$ \\
\hline $\begin{array}{l}\text { WET FOEL USED } \\
\text { IN TRANSPORMATIOS }\end{array}$ & 1,331 & - & - & - & - & 356 & - & -520 & 1,167 & $1 \%$ \\
\hline $\begin{array}{l}\text { TOTAL GROSS FLORS } \\
\text { LOSSES \& OMISSIONS }\end{array}$ & $\begin{array}{r}24,974 \\
1,443\end{array}$ & $\begin{array}{r}3.494 \\
0\end{array}$ & $\begin{array}{r}25,052 \\
-0\end{array}$ & $\begin{array}{r}13,682 \\
-571\end{array}$ & - & $\begin{array}{l}31,441 \\
-1,138\end{array}$ & $\begin{array}{r}16,574 \\
-36\end{array}$ & $\begin{array}{r}36,466 \\
3,646\end{array}$ & $\begin{array}{r}151,163 \\
3,343\end{array}$ & $\begin{array}{r}98 \% \\
2 \%\end{array}$ \\
\hline $\begin{array}{l}\text { SOFPLY OF EHERGY } \\
\text { FOSS IL PO } I L \\
\text { EYDROEL RCTRIC } \\
\text { NOCL EAR } \\
\text { GEO. ESOLAR }\end{array}$ & $\begin{array}{l}- \\
-\end{array}$ & $\begin{array}{l}- \\
\overline{-}\end{array}$ & $\begin{array}{l}- \\
-\end{array}$ & $\begin{array}{l}- \\
-\end{array}$ & $\begin{array}{l}- \\
\text { - } \\
-\end{array}$ & $\begin{array}{l}- \\
-\end{array}$ & $\begin{array}{l}- \\
-\end{array}$ & $\begin{array}{r}- \\
32.604 \\
696 \\
26\end{array}$ & $\begin{array}{r}- \\
32,604 \\
696 \\
26\end{array}$ & $\begin{array}{r}98 \% \\
2 \% \\
0 \%\end{array}$ \\
\hline TOTAL SUPPLT & - & - & - & - & - & - & - & 33,326 & 33,326 & \\
\hline
\end{tabular}

\begin{tabular}{l} 
NET IM PORTS \\
$\quad$ OP R EGION \\
\hline
\end{tabular}

\begin{tabular}{|c|c|c|c|c|c|}
\hline \multicolumn{6}{|c|}{ S: } \\
\hline 1 & TRAYSPORMATION & LOSS & POR & ELECTRICITY GBN. & $=69.18 x$ \\
\hline 2 & TRAUSPORMATI ON & LOSS & POR & PETROLE OA PRODUCT & \\
\hline 3 & TRARSPORMA TI ON & LOSS & FOR & NATORAL SAS & $=0.0$ \\
\hline 4 & TRA USPORMATI ON & Loss & POR & SYNTHETICS & $=0.0$ \\
\hline
\end{tabular}


REGICHAE BNERGY BALANCE STATEHEHT

EIES MID RID SCENARIO

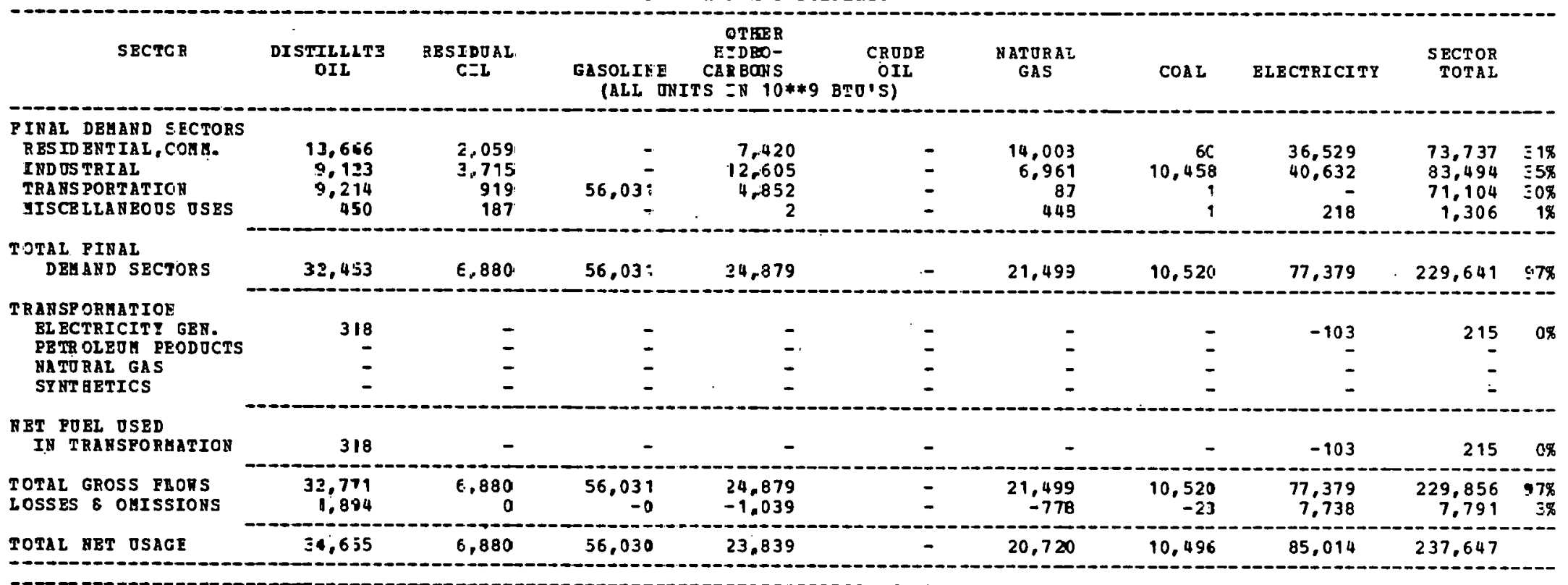

SUPPIY OF ENBRT
POSS IL POBL
HYDROELRCTRIC
NOCL BAR
GBO. SSOLAR

-

\section{RBT IH PORTS}

OP RBGION

$\$ 4,655$

$6.88 \mathrm{C}$

56,030

23,839

20,720

10,495

$-223,873$

$-71,240$

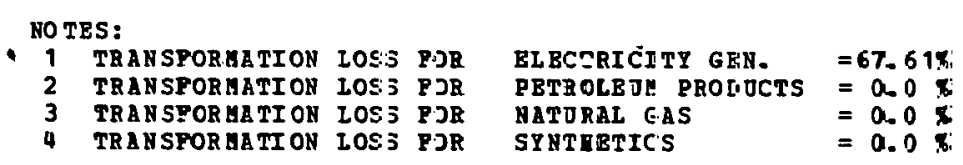


REGIONAL ENERGY BALLNCE STATEHENT PIES MID MID SCENARIO

\begin{tabular}{|c|c|c|c|c|c|c|c|c|c|c|}
\hline SECTOR & $\begin{array}{l}\text { DISTILLATE } \\
\text { OII }\end{array}$ & $\begin{array}{l}\text { BESILOUAL } \\
\text { OIL }\end{array}$ & $\begin{array}{l}\text { GASOLINE } \\
\text { (ALL DNI }\end{array}$ & $\begin{array}{c}\text { OTHER } \\
\text { HYDRO- } \\
\text { CARBONS } \\
\text { TS IN 10**9 }\end{array}$ & $\begin{array}{c}\text { CRIDE } \\
\text { OII } \\
\text { BTO'S) }\end{array}$ & $\begin{array}{l}\text { NATURAL } \\
\text { GAS }\end{array}$ & $\operatorname{COAL}$ & ELECTRICITY & $\begin{array}{r}\text { SECTOR } \\
\text { TOTAL }\end{array}$ & \\
\hline $\begin{array}{l}\text { PINAL DEHAND SECTORS } \\
\text { RESID BNTIAL, CCMA. } \\
\text { IND OS TRIAL } \\
\text { TRANS PORTATION } \\
\text { MISCELLAHEOUS OSES }\end{array}$ & $\begin{array}{r}45,989 \\
27,499 \\
21,811 \\
2,623\end{array}$ & $\begin{array}{r}8.110 \\
44.522 \\
11,211 \\
1,090\end{array}$ & $\begin{array}{r}- \\
\overline{-}\end{array}$ & $\begin{array}{r}23,396 \\
88,414 \\
54,274 \\
16\end{array}$ & $\begin{array}{l}\overline{-} \\
\overline{-}\end{array}$ & $\begin{array}{r}48,001 \\
27,790 \\
881 \\
2,364\end{array}$ & $\begin{array}{r}135 \\
17,279 \\
2 \\
6\end{array}$ & $\begin{array}{r}121,166 \\
71,230 \\
- \\
1,261\end{array}$ & $\begin{array}{r}246,797 \\
276,734 \\
254,770 \\
7,360\end{array}$ & $\begin{array}{r}28 \% \\
32 \% \\
29 \% \\
1 \%\end{array}$ \\
\hline $\begin{array}{l}\text { TOTAL PINAL } \\
\text { DEMAND SECTORS }\end{array}$ & 97,922 & 64.933 & 166,591 & 166,100 & - & 79,036 & 17,422 & 193,657 & 785,661 & $90 \%$ \\
\hline $\begin{array}{l}\text { T'RANSPOREATION } \\
\text { ELBCTRICITY GEN. } \\
\text { PETR OLEOM PRODOCTS } \\
\text { NATORAL GAS } \\
\text { SY NT HETICS }\end{array}$ & $\begin{array}{r}746 \\
-119,221 \\
-\end{array}$ & $\begin{array}{r}-142,211 \\
-\end{array}$ & $\begin{array}{r}-305,390 \\
-\end{array}$ & $\begin{array}{r}-207,407 \\
-\end{array}$ & $\begin{array}{r}772,877 \\
-\end{array}$ & $\begin{array}{r}3,126 \\
-\end{array}$ & $\begin{array}{r}45,648 \\
= \\
=\end{array}$ & $\begin{array}{r}-14,709 \\
- \\
-\end{array}$ & $\begin{array}{r}31,685 \\
1,774 \\
-\end{array}$ & $\begin{array}{l}4 \% \\
0 \%\end{array}$ \\
\hline $\begin{array}{l}\text { NET POBL OSBD } \\
\text { IN TRANSFORATION }\end{array}$ & $-118,475$ & $-142,211$ & $-305,390$ & $-207,407$ & 772,877 & 3,126 & 45,648 & $-14,709$ & 33.459 & 4\% \\
\hline $\begin{array}{l}\text { TOTAL GROSS FLOHS } \\
\text { LOSSES } \mathcal{E} \text { OMISSIONS }\end{array}$ & $\begin{array}{r}98,668 \\
5,704\end{array}$ & $\begin{array}{r}64,733 \\
1\end{array}$ & $\begin{array}{r}166,591 \\
-0\end{array}$ & $\begin{array}{r}166,100 \\
-6,943\end{array}$ & $\begin{array}{r}772,877 \\
38,583\end{array}$ & $\begin{array}{l}82,162 \\
-2,976\end{array}$ & $\begin{array}{r}63,070 \\
-138\end{array}$ & $\begin{array}{r}193,657 \\
19,367\end{array}$ & $\begin{array}{r}819,120 \\
53,598\end{array}$ & $\begin{array}{r}94 \% \\
6 \%\end{array}$ \\
\hline
\end{tabular}

-

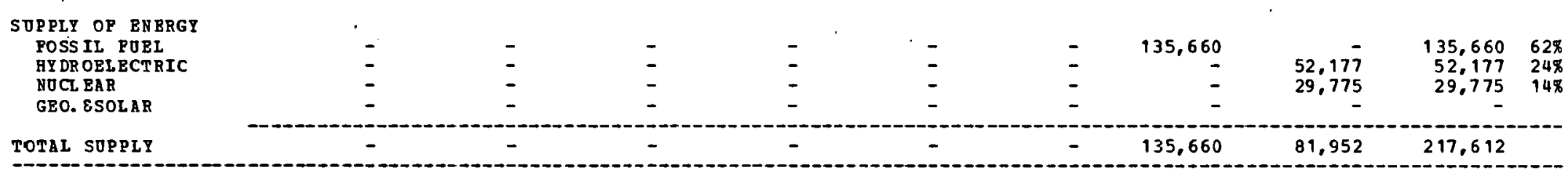

\begin{tabular}{l}
$\begin{array}{l}\text { NET IM PORTS } \\
\text { OP REGION }\end{array}$ \\
\hline
\end{tabular}


REGIONAL ENERGY BALANCE STATEMENT

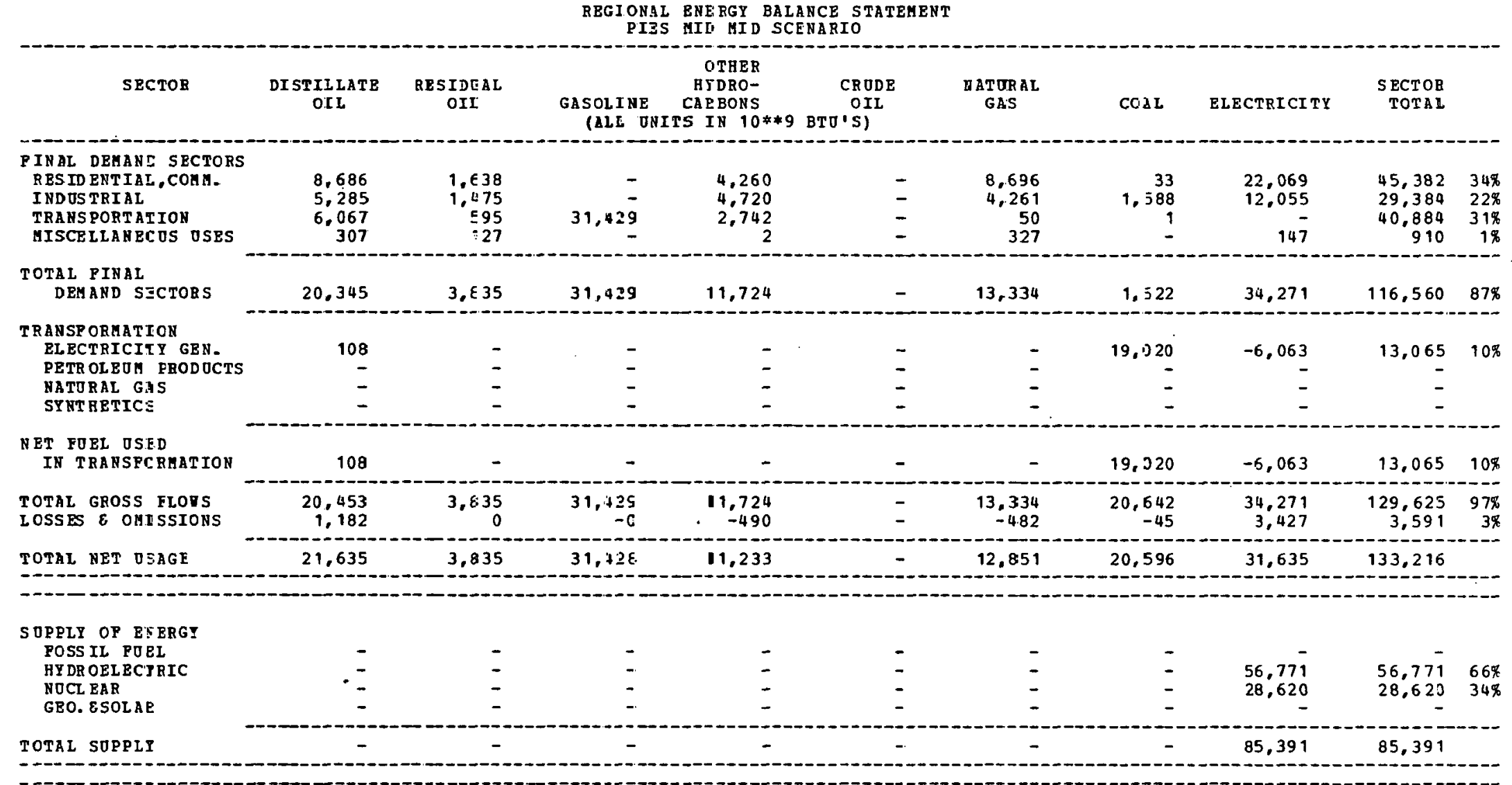

\begin{tabular}{l}
$\begin{array}{l}\text { NBT IH PORTS } \\
\text { OP REGION }\end{array}$ \\
\hline
\end{tabular}


REGIONAL ENERGY BALANCE STATEMENT
PIES MID MID SCENARIO

\begin{tabular}{|c|c|c|c|c|c|c|c|c|c|c|}
\hline SECTOR & $\begin{array}{l}\text { DISTILLATE } \\
\text { OIL }\end{array}$ & $\begin{array}{l}\text { RESIDJAL } \\
\text { OI }\end{array}$ & $\begin{array}{l}\text { GASOLINE } \\
\text { (ALL U }\end{array}$ & $\begin{array}{c}\text { OTHER } \\
\text { HYDRO- } \\
\text { CARBONS } \\
\text { C IN } 10 * * 9\end{array}$ & $\begin{array}{c}\text { CRUDE } \\
\text { OIL } \\
\text { BTU'S) }\end{array}$ & $\begin{array}{l}\text { NATURAL } \\
\text { GAS }\end{array}$ & $\operatorname{COA} L$ & ELECTRICITY & $\begin{array}{r}\text { SECTOR } \\
\text { TOTAL }\end{array}$ & \\
\hline $\begin{array}{l}\text { PINAL DEHAND SECTDRS } \\
\text { RESID ENTIAL, CCMM. } \\
\text { IND OS TRIAL } \\
\text { TRANSPORTATION } \\
\text { MISCE LLANEOOS OSES }\end{array}$ & $\begin{array}{r}40,492 \\
33,036 \\
31,446 \\
972\end{array}$ & $\begin{array}{r}8,727 \\
24,839 \\
2,659 \\
404\end{array}$ & $147,18 \overline{-}$ & $\begin{array}{r}18,302 \\
50,492 \\
14.272 \\
.6\end{array}$ & $\begin{array}{l}- \\
-\end{array}$ & $\begin{array}{r}36,119 \\
34,869 \\
345 \\
1,023\end{array}$ & $\begin{array}{r}264 \\
26,458 \\
2 \\
2\end{array}$ & $\begin{array}{r}90,927 \\
102,703 \\
- \\
454\end{array}$ & $\begin{array}{r}194,831 \\
272,389 \\
195,912 \\
2,861\end{array}$ & $\begin{array}{r}28 \% \\
40 \% \\
28 \% \\
0 \%\end{array}$ \\
\hline $\begin{array}{l}\text { TOTAL PINAL } \\
\text { DEMAND SECTORS }\end{array}$ & 105,946 & $\begin{array}{r}36,629 \\
-\end{array}$ & 147,188 & 83,072 & - & 72,348 & 26,726 & 194,084 & 665,993 & $97 \%$ \\
\hline $\begin{array}{l}\text { T } 3 \text { ANSPORMATION } \\
\text { EL ECTRICITY GEN_- } \\
\text { PETR OLEOM FRODOCTS } \\
\text { NATORAL GAS } \\
\text { SY NT HETICS }\end{array}$ & $\begin{array}{r}1,376 \\
-4.500 \\
- \\
-\end{array}$ & $\begin{array}{r}-5,367 \\
- \\
-\end{array}$ & $\begin{array}{r}-11,52 \overline{7} \\
-\end{array}$ & $\begin{array}{r}-7.828 \\
- \\
-\end{array}$ & 29.173 & $\begin{array}{r}118 \\
- \\
-\end{array}$ & $\begin{array}{r}1,331 \\
- \\
-\end{array}$ & $\begin{array}{r}-865 \\
- \\
-\end{array}$ & $\begin{array}{r}1,842 \\
67 \\
- \\
-\end{array}$ & $\begin{array}{l}0 \% \\
0 \%\end{array}$ \\
\hline $\begin{array}{l}\text { N } 3 T \text { FUEL USED } \\
\text { IN TRA NSPORMATION }\end{array}$ & $-3,124$ & $-5, \Xi 67$ & $-11,527$ & $-7,828$ & 29.173 & 118 & 1,331 & -865 & 1,909 & $0 \%$ \\
\hline $\begin{array}{l}\text { TOTAL GROSS FLOHS } \\
\text { LCSSES } \varepsilon \text { OHISSIONS }\end{array}$ & $\begin{array}{r}107,322 \\
6,204\end{array}$ & $\begin{array}{r}36, \epsilon 29 \\
0\end{array}$ & $\begin{array}{r}147,188 \\
-0\end{array}$ & $\begin{array}{l}83.072 \\
-3.472\end{array}$ & $\begin{array}{r}29,173 \\
1,456\end{array}$ & $\begin{array}{l}72,466 \\
-2,624\end{array}$ & $\begin{array}{r}28,057 \\
-61\end{array}$ & $\begin{array}{r}194,084 \\
19,410\end{array}$ & $\begin{array}{r}667,902 \\
20,912\end{array}$ & $\begin{array}{r}97 \% \\
3 \%\end{array}$ \\
\hline
\end{tabular}

\begin{tabular}{|c|c|c|c|c|c|c|c|c|c|c|}
\hline $\begin{array}{l}\text { SOPPLY OP ENERGY } \\
\text { POSS IL FOEL }\end{array}$ & - & - & - & - & - & - & - & _ & - & \\
\hline HY DR OEL ECT RIC & - & - & - & - & - & - & - & 138,502 & 138,502 & $95 \%$ \\
\hline NOCL EAR & - & - & - & - & - & - & - & 6,655 & 6.655 & $5 \%$ \\
\hline GEO. ESOL AR & - & - & - & - & - & - & - & - & - & \\
\hline TOTAL SOPPIY & - & - & - & - & - & - & - & 145,157 & 145,157 & \\
\hline
\end{tabular}

\section{UET IM PORTS}

109,026

31,261

135,660

71,770

30,629

69,841

27.995

67,472

543,657

NOTES :
1 TRAN SPORMATI ON LOSS POR TRANSPORMATI ON LOSS POR TRANSFORMATI ON LOSS FOR
ELECTRICITY GEN.
$=68.05 \%$
$0.23 \%$
NATORAL GAS $=0.0 \%$
TRANSFORMATI ON LOSS FOR
SYNTHETICS
$=0.0 \%$ 
REGLONAL ENERGY BALAICE STATEMENT

PIES RID MID SCEHARIO

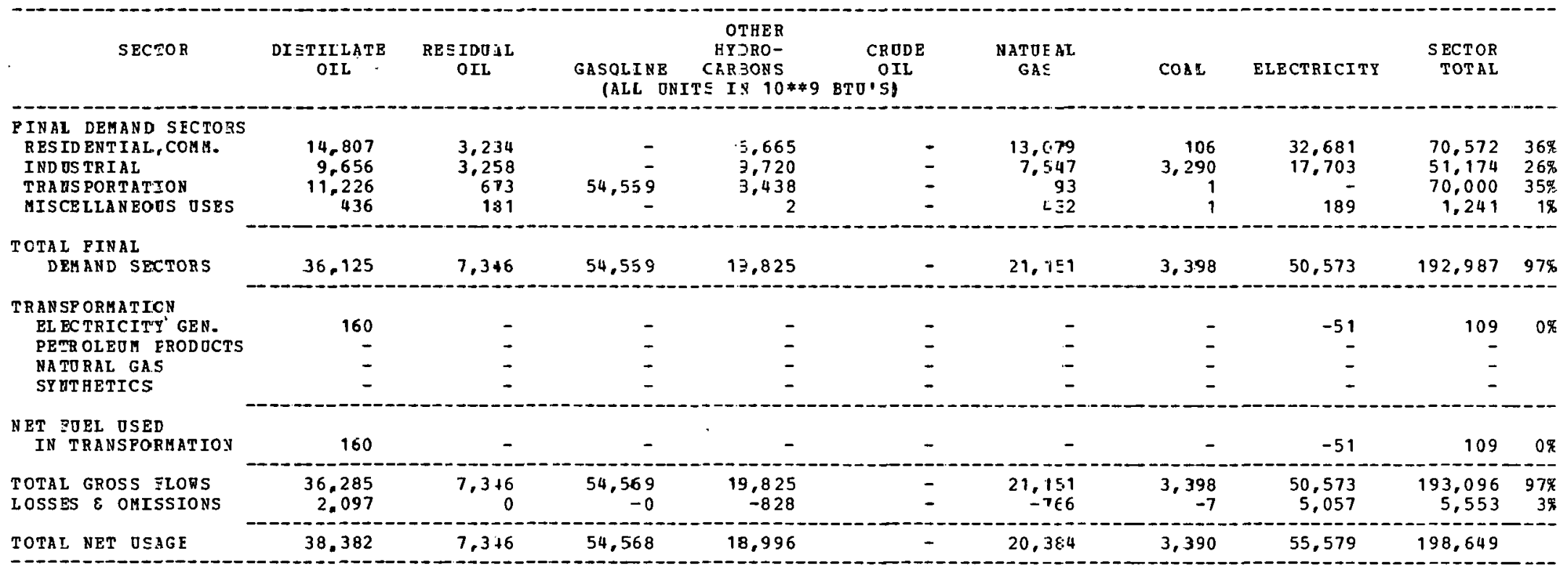

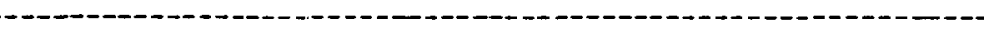

\section{SUPPEY OP ENERGY}

FOSS IL POEL

HY DR OELECIBIC

GOCLAR

GEO. ESOLAB

-
-
-
-

TOTAL SOPPLY

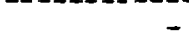

$-$

$\begin{array}{ll}- & - \\ - & - \\ - & - \\ - & -2\end{array}$

-
-
-

-

-
-
-

\begin{tabular}{lrrr}
- & - & - \\
- & 15,136 & 15,136 & $100 \%$ \\
- & - & - \\
\hline- & 15,136 & 15,136
\end{tabular}

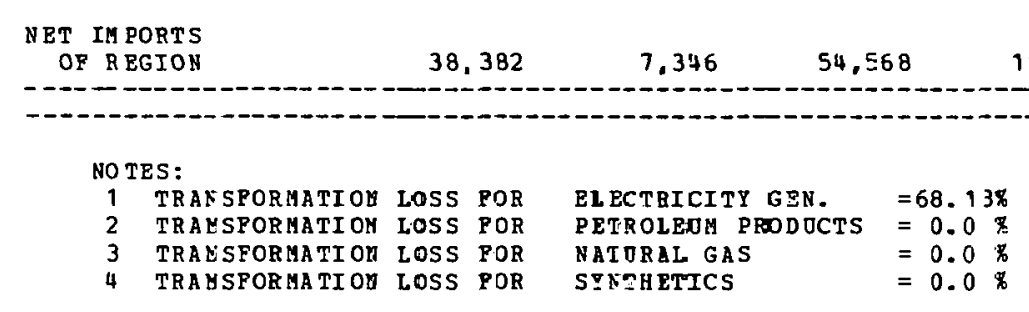


FEGIONAL ENERGY BALANCE STATEMENT

PIES MID MID SCENARIO

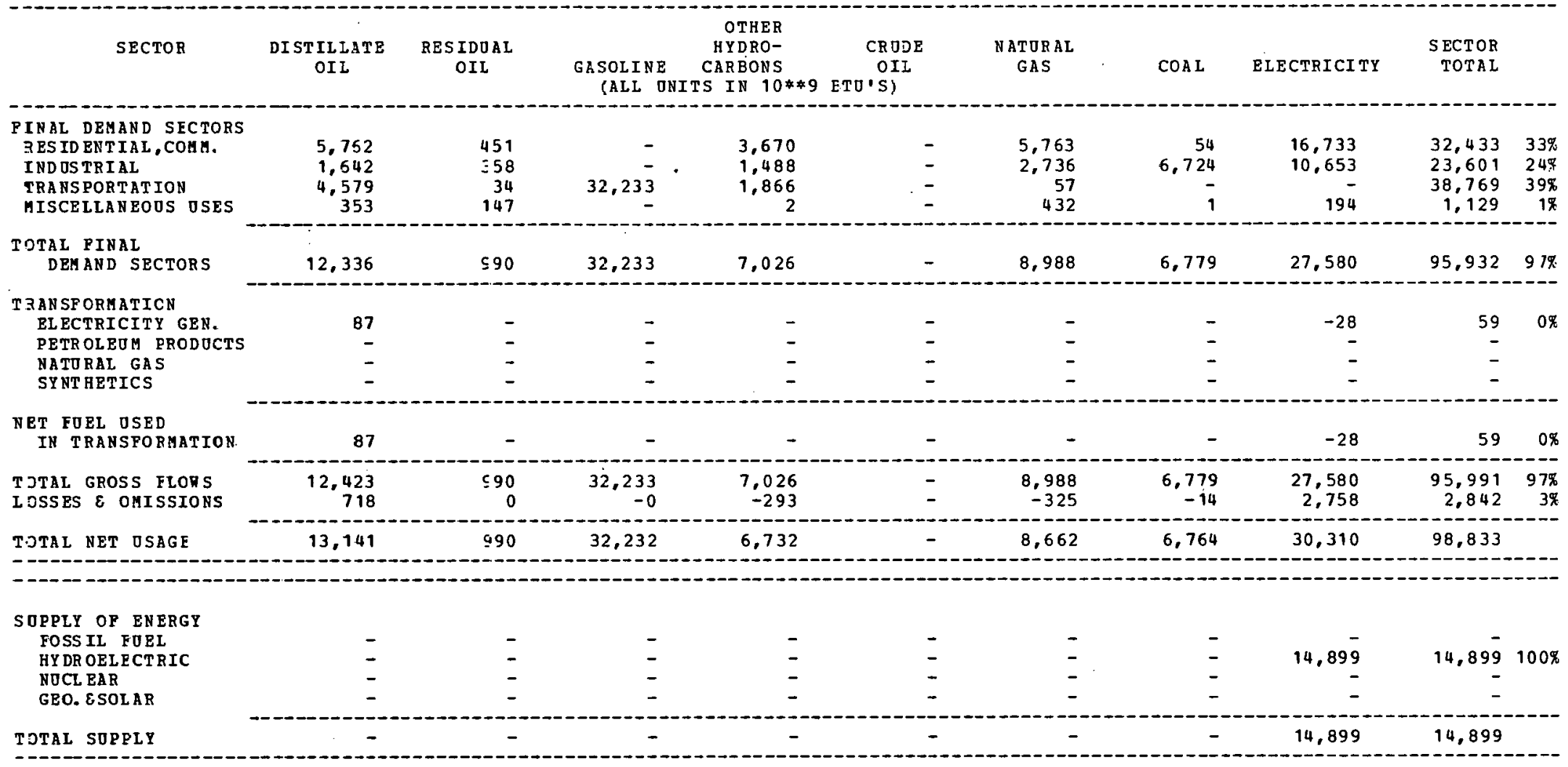

\section{NRT IM PORTS}

OP REGION

13,141

990

32,232

6.732

8,662

6,764

15,411

83,934

NO TES:

TRANSPORHATION LOSS POR ELECTRICITY GEV.

TRANSPORMATI ON LOSS POR PETBOLEOM PRODUCTS $=0.0 \%$

TRAH SFOR AATI ON LOSS POR

TRABSTORMATI ON LOSS POR

NATURAL GAS

SYNTAEIICS

$=0.0 \%$
$=0.0 \%$

$=0.0 \%$ 
REGIONAL 3NERGY BALANCE STATEMENT

ONAL
PIES MII RIY BALANCE S

\begin{tabular}{|c|c|c|c|c|c|c|c|c|c|c|}
\hline SECTOR & $\underset{0=L}{\text { DI.JTIELATE }}$ & $\begin{array}{l}\text { BESIDUAL } \\
\text { OIL }\end{array}$ & $\begin{array}{l}\text { GASOLINE } \\
\text { (ALL ONIT }\end{array}$ & $\begin{array}{c}\text { CTHER } \\
\text { HYDRO- } \\
\text { ZAFBONS } \\
5 \text { IN } 10 * \$ 9\end{array}$ & $\begin{array}{c}\text { CRUDE } \\
\text { CIL } \\
\text { BTD'S) }\end{array}$ & $\begin{array}{l}\text { NATURAL } \\
\text { GAS }\end{array}$ & COR.L & ELECTRI CI TY & $\begin{array}{l}\text { SECTOF } \\
\text { TOTAL }\end{array}$ & \\
\hline $\begin{array}{l}\text { PINAL DEMAND SECTORS } \\
\text { RES ID ENTIAL, CCHM. } \\
\text { IND OS TRIAL } \\
\text { TRANS PORTATION } \\
\text { HISCE LLANEOOS USES }\end{array}$ & $\begin{array}{r}3.122 \\
3.372 \\
7.077 \\
136\end{array}$ & $\begin{array}{r}40 \\
3,023 \\
- \\
38\end{array}$ & $29,94 \overline{-}$ & $\begin{array}{r}1,670 \\
2,086 \\
9,920 \\
1\end{array}$ & - & $\begin{array}{r}6,133 \\
19,852 \\
7105 \\
312\end{array}$ & $\begin{array}{r}2 \\
3,398 \\
- \\
-\end{array}$ & $\begin{array}{r}8,607 \\
10,842 \\
- \\
103\end{array}$ & $\begin{array}{r}19,574 \\
42,583 \\
47,650 \\
590\end{array}$ & $\begin{array}{r}14 \% \\
31 \% \\
348 \\
0 \%\end{array}$ \\
\hline $\begin{array}{l}\text { TOTAL PINAL } \\
\text { DEMAND SECTORS }\end{array}$ & 13.707 & 3,101 & 29,548 & 13,677 & - & 27,012 & 3,200 & 19,552 & 110,397 & $80 \%$ \\
\hline $\begin{array}{l}\text { TRANSP ORMATION } \\
\text { EL ECTRICITY GEN. } \\
\text { PETROLEUM PRODOCTS } \\
\text { NATORAL GAS } \\
\text { SYNTHETICS }\end{array}$ & $\begin{array}{r}12 \\
- \\
-\end{array}$ & $\begin{array}{l}- \\
-\end{array}$ & $\begin{array}{l}\overline{-} \\
\overline{-}\end{array}$ & - & $\begin{array}{l}\overline{-} \\
\overline{-}\end{array}$ & $\begin{array}{r}25,387 \\
- \\
-\end{array}$ & $\begin{array}{r}16,177 \\
- \\
-\end{array}$ & $\begin{array}{r}-13,705 \\
- \\
-\end{array}$ & $\begin{array}{r}27,871 \\
- \\
- \\
-\end{array}$ & $20 x$ \\
\hline $\begin{array}{l}\text { NET PUEL OSED } \\
\text { IN TRANSPCRMATION }\end{array}$ & 12 & - & - & - & - & 25,387 & 16,177 & $-13,705$ & 27,871 & $20 \%$ \\
\hline $\begin{array}{l}\text { TOTAL GROSS PLOHS } \\
\text { LOSSES } E \text { OMISSIONS }\end{array}$ & $\begin{array}{r}13.719 \\
793\end{array}$ & $\begin{array}{r}3,101 \\
0\end{array}$ & $\begin{array}{r}29,948 \\
-0\end{array}$ & $\begin{array}{r}13,677 \\
-571\end{array}$ & $\overline{-}$ & $\begin{array}{l}52,399 \\
-1,398\end{array}$ & $\begin{array}{r}19,577 \\
-43\end{array}$ & $\begin{array}{r}19,552 \\
1,955\end{array}$ & $\begin{array}{r}138,268 \\
235\end{array}$ & $\begin{array}{r}100 \% \\
0 \%\end{array}$ \\
\hline
\end{tabular}

$\begin{aligned} & \text { SOPPLY OF BNERGY } \\
& \text { FOSS IL FOEL } \\
& \text { HY DR OELECTRIC }\end{aligned}$
$\begin{aligned} & \text { NOCL EAR } \\
& \text { GEOESOLAR }\end{aligned}$
\begin{tabular}{l} 
TOTAL SOPPLY \\
\hline
\end{tabular}

\begin{tabular}{l}
$\begin{array}{l}\text { NET IM PORTS } \\
\text { OP R EGION }\end{array}$ \\
\hline
\end{tabular}


REGIONAL ENE RGY BALANCE STATEHENT
PIES IID MID SCENARIO

\begin{tabular}{|c|c|c|c|c|c|c|c|c|c|c|}
\hline SECTOB & $\begin{array}{l}\text { DISTILLATE } \\
\text { OIL }\end{array}$ & $\begin{array}{l}\text { RESIDJALL } \\
\text { OIL }\end{array}$ & $\begin{array}{l}\text { GASOLINE } \\
\text { (ALL ONI }\end{array}$ & $\begin{array}{c}\text { OTHER } \\
\text { HYDRO- } \\
\text { CARBONS } \\
\text { TS IN } 10 * \$ 9\end{array}$ & $\begin{array}{c}\text { CEODE } \\
\text { OIL } \\
\text { BTU'S) }\end{array}$ & $\begin{array}{l}\text { NATURAL } \\
\text { GAS }\end{array}$ & COA L & ELECTRICITY & $\begin{array}{r}\text { SECTOR } \\
\text { TOTAL }\end{array}$ & \\
\hline $\begin{array}{l}\text { PINAL DEHAND SECTORS } \\
\text { RES ID RNTIAL, CCML. } \\
\text { INDOSTRIAL } \\
\text { TRANSPORTATION } \\
\text { MISCE LLANEOOS USES }\end{array}$ & $\begin{array}{r}4,755 \\
2,996 \\
4.473 \\
224\end{array}$ & $\begin{array}{r}169 \\
3,730 \\
3 \\
69\end{array}$ & $\begin{array}{r}- \\
45,21 \overline{-} \\
-\end{array}$ & $\begin{array}{r}3,243 \\
6,102 \\
21,434 \\
4\end{array}$ & $\begin{array}{l}- \\
-\end{array}$ & $\begin{array}{r}11,560 \\
19,351 \\
1,534 \\
424\end{array}$ & $\begin{array}{r}5 \\
4,830 \\
- \\
-\end{array}$ & $\begin{array}{r}13,149 \\
10,192 \\
- \\
159\end{array}$ & $\begin{array}{r}32,881 \\
47,201 \\
72,6.59 \\
880\end{array}$ & $\begin{array}{r}12 \% \\
18 \% \\
28 \% \\
0 \%\end{array}$ \\
\hline $\begin{array}{l}\text { TOTAL PINAL } \\
\text { DEHAND SECTOBS }\end{array}$ & 12,448 & 3.371 & 45,215 & 30,783 & - & 32,869 & 4,835 & 23,500 & 153,621 & $58 \%$ \\
\hline $\begin{array}{l}\text { TR ANSP ORHATION } \\
\text { EL BCTRICITY GEN. } \\
\text { PETR OLEOM FRODOCTS } \\
\text { NATORAL GAS } \\
\text { SY HT HETICS }\end{array}$ & $\begin{array}{r}192 \\
- \\
- \\
-\end{array}$ & $\begin{array}{l}- \\
-\end{array}$ & $\begin{array}{l}- \\
\overline{-} \\
\bar{z}\end{array}$ & $\begin{array}{l}\overline{-} \\
\overline{-}\end{array}$ & $\begin{array}{l}- \\
\overline{-}\end{array}$ & $\begin{array}{r}15,592 \\
- \\
-\end{array}$ & $\begin{array}{r}148,387 \\
- \\
-\end{array}$ & $\begin{array}{r}-54,379 \\
- \\
-\end{array}$ & $\begin{array}{r}110,792 \\
- \\
-\end{array}$ & $42 \%$ \\
\hline $\begin{array}{l}\text { NET POEL USED } \\
\text { IN TRAKSPORHATION }\end{array}$ & 1,192 & - & - & - & - & 15,592 & 148,387 & $-54,379$ & 110,792 & $42 \%$ \\
\hline $\begin{array}{l}\text { T JTAL GROSS FLORS } \\
\text { I DSSES \& OHISSIONS }\end{array}$ & $\begin{array}{r}13,640 \\
788\end{array}$ & $\begin{array}{r}3,971 \\
0\end{array}$ & $\begin{array}{r}45,215 \\
-0\end{array}$ & $\begin{array}{r}30,783 \\
-1,286\end{array}$ & $\overline{-}$ & $\begin{array}{l}48,461 \\
-1,755\end{array}$ & $\begin{array}{r}153,222 \\
-337\end{array}$ & $\begin{array}{r}23,500 \\
2,350\end{array}$ & $\begin{array}{r}264.413 \\
-240\end{array}$ & $\begin{array}{r}100 \% \\
0 \%\end{array}$ \\
\hline
\end{tabular}

\begin{tabular}{|c|c|c|c|c|c|c|c|c|c|c|}
\hline \multicolumn{11}{|l|}{ S JPPLY OF EHERGT } \\
\hline POSS II POEL & - & - & - & - & 6,196 & - & - & - & 6,196 & $82 \%$ \\
\hline HY DR ORL ECT RIC & - & - & - & - & - & - & - & 280 & 280 & $4 \pi$ \\
\hline NOCL EAR & - & - & - & - & - & - & - & 30 & 30 & os \\
\hline GEO. ESOLAR & - & - & - & - & - & - & - & 1.076 & 1,076 & $14 \%$ \\
\hline TOTAL SOPPLY & - & - & - & - & 6,196 & - & - & 1,386 & 7,582 & \\
\hline
\end{tabular}

\begin{tabular}{l}
$\begin{array}{l}\text { IJT IM PORTS } \\
\text { OP REGION }\end{array}$ \\
\hline
\end{tabular}


REGIONAL EREAGY BALANCE STATELENT

PIRS UID UID SCENARIO

\begin{tabular}{|c|c|c|c|c|c|c|c|c|c|c|}
\hline SECTOR & $\begin{array}{l}\text { DISTILLATE } \\
\text { OIL }\end{array}$ & $\begin{array}{l}\text { RESIDOAL } \\
\text { OIL }\end{array}$ & $\begin{array}{l}\text { GASOITH } \\
\text { (ALI J) }\end{array}$ & $\begin{array}{c}\text { OTBER } \\
\text { HYDRO- } \\
\text { CARBONS } \\
\text { TS IN } 10 * * 9\end{array}$ & $\begin{array}{c}\text { CRUDE } \\
\text { OIL } \\
3 T 0.2)\end{array}$ & $\begin{array}{l}\text { NATUR LL } \\
\text { GAS }\end{array}$ & COAL & ELECTRICITY & $\begin{array}{r}\text { SECTOR } \\
\text { TOTAL }\end{array}$ & \\
\hline $\begin{array}{l}\text { PINAL DEHANE SBCTORS } \\
\text { RESTD BNTTAI, COHA. } \\
\text { IND TSTRIAL } \\
\text { TRAKSPORTATIOH } \\
\text { GISCBLLANECOS USBS }\end{array}$ & $\begin{array}{r}8,-492 \\
5,420 \\
37,370 \\
702\end{array}$ & $\begin{array}{r}1,753 \\
6,939 \\
- \\
178\end{array}$ & $166,26 \overline{-}$ & $\begin{array}{r}9.382 \\
19.636 \\
39.040 \\
5\end{array}$ & $\overline{-}$ & $\begin{array}{r}50,085 \\
75,074 \\
3,795 \\
1,559\end{array}$ & $\begin{array}{r}13 \\
14,248 \\
1 \\
-\end{array}$ & $\begin{array}{r}43,035 \\
19,002 \\
- \\
515\end{array}$ & $\begin{array}{r}112,740 \\
140,379 \\
246,472 \\
2,979\end{array}$ & $\begin{array}{r}17 \% \\
22 \% \\
38 \% \\
0 \%\end{array}$ \\
\hline $\begin{array}{l}\text { TOTAL FINAL } \\
\text { DEHARD SECTORS }\end{array}$ & 51,984 & 8,950 & 166,266 & 68.063 & - & 130,493 & $14, \approx 62$ & 62,552 & 502,570 & $78 \%$ \\
\hline 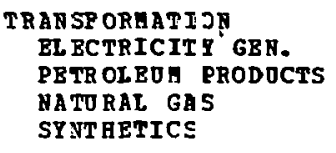 & $\begin{array}{r}17,930 \\
-2,346 \\
- \\
-\end{array}$ & $\begin{array}{r}22,696 \\
-2,799 \\
- \\
-\end{array}$ & $\begin{array}{r}-6,010 \\
- \\
-\end{array}$ & $\begin{array}{r}-4.08 \overline{2} \\
- \\
-\end{array}$ & $\begin{array}{r}- \\
15,211 \\
-\end{array}$ & $\begin{array}{r}25,032 \\
61 \\
-\end{array}$ & $\begin{array}{r}148, \text { E } 96 \\
- \\
-\end{array}$ & $\begin{array}{r}-72,813 \\
= \\
-\end{array}$ & $\begin{array}{r}141.541 \\
34 \\
- \\
-\end{array}$ & $\begin{array}{r}22 \% \\
0 \%\end{array}$ \\
\hline $\begin{array}{l}\text { NET POEL OSED } \\
\text { IN TRANSPCBMATION }\end{array}$ & 15,533 & $: 9,897$ & $-6,010$ & $-4,082$ & 15,211 & 25,1093 & $148,6.96$ & $-72,813$ & 141,575 & $22 \%$ \\
\hline $\begin{array}{l}\text { TOTAL GROSS FLORS } \\
\text { LOSSES } \varepsilon \text { OHISSIONS }\end{array}$ & $\begin{array}{r}69.914 \\
4.041\end{array}$ & $\begin{array}{r}31,646 \\
0\end{array}$ & $\begin{array}{r}166,266 \\
-0\end{array}$ & $\begin{array}{l}68,063 \\
-2,845\end{array}$ & $\begin{array}{r}15,211 \\
759\end{array}$ & $\begin{array}{r}155,586 \\
-5,535\end{array}$ & $\begin{array}{r}162,958 \\
-558\end{array}$ & $\begin{array}{r}62,552 \\
6,255\end{array}$ & $\begin{array}{r}644,145 \\
2,217\end{array}$ & $\begin{array}{r}100 \% \\
0 \%\end{array}$ \\
\hline TOTAL HET USAGE & 71,609 & 28,847 & $160, \approx 54$ & 61,135 & $1 \subseteq, 971$ & 149,950 & 162,599 & $-4,005$ & 646,363 & \\
\hline
\end{tabular}

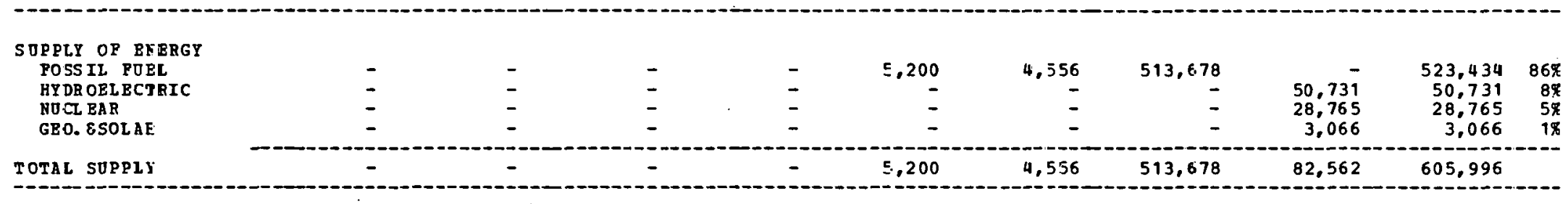

NET IM PORTS
OR R EGIOB


BEGIONAL BNBRGY BALANCE STATEMBNT

PIES MID UI D SCENARIO

\begin{tabular}{|c|c|c|c|c|c|c|c|c|c|c|}
\hline SBCTOR & $\begin{array}{l}\text { DISTILLATB } \\
\text { OIL }\end{array}$ & $\begin{array}{l}\text { RBSIDJAL } \\
\text { OIL }\end{array}$ & $\begin{array}{l}\text { GASOLINB } \\
\text { CALL ONI? }\end{array}$ & $\begin{array}{c}\text { OTHER } \\
\text { HYDRO- } \\
\text { CARBONS } \\
\text { IS IN } 10 * * 9\end{array}$ & $\begin{array}{c}\text { CRODE } \\
\text { OIL } \\
\text { BTOSI }\end{array}$ & $\begin{array}{l}\text { MATURAL } \\
\text { GAS }\end{array}$ & $\operatorname{COAL}$ & BLECTRICITY & $\begin{array}{r}\text { SECTOR } \\
\text { TOTAL }\end{array}$ & \\
\hline $\begin{array}{l}\text { PIVAL DBHAND SBCTOES } \\
\text { RESID BHTIAL, COHA. } \\
\text { IRD US TRIAL } \\
\text { TFARSPORTATIOH } \\
\text { GISCELLABEOOS OSBE }\end{array}$ & $\begin{array}{r}2,743 \\
1.241 \\
11.131 \\
357\end{array}$ & $\begin{array}{r}568 \\
936 \\
100\end{array}$ & $52.91 \frac{-}{-}$ & $\begin{array}{r}2,987 \\
2,002 \\
10,728 \\
3\end{array}$ & $\begin{array}{l}- \\
\overline{-} \\
\overline{-}\end{array}$ & $\begin{array}{r}16.025 \\
20,100 \\
1.042 \\
796\end{array}$ & $\begin{array}{r}4 \\
3,457 \\
1 \\
-\end{array}$ & $\begin{array}{r}13,943 \\
4,847 \\
- \\
267\end{array}$ & $\begin{array}{r}36,270 \\
32,583 \\
75,815 \\
1,523\end{array}$ & $\begin{array}{r}22 \% \\
20 \% \\
47 \% \\
1 \%\end{array}$ \\
\hline $\begin{array}{l}\text { TOTAL FIRAL } \\
\text { DEHAKD SBCTORS }\end{array}$ & 15,472 & 1,604 & 52,913 & 15,720 & - & 37,963 & 3,462 & 19.057 & 146,191 & $90 \%$ \\
\hline $\begin{array}{l}\text { TRLNSPORHATIOH } \\
\text { BLECTRICITY GBN. } \\
\text { PBTR OLBOA PRODOCTS } \\
\text { BATORAL GAS } \\
\text { ST BT BTICS }\end{array}$ & $\begin{array}{r}3,655 \\
- \\
-\end{array}$ & $\begin{array}{r}12,638 \\
= \\
-\end{array}$ & $\overline{-}$ & $\begin{array}{l}- \\
-\end{array}$ & $\begin{array}{l}- \\
\\
-\end{array}$ & $\begin{array}{r}7,312 \\
= \\
-\end{array}$ & $\begin{array}{l}\overline{-} \\
\overline{-}\end{array}$ & $\begin{array}{r}-8,272 \\
= \\
=\end{array}$ & $\begin{array}{r}15,333 \\
- \\
- \\
-\end{array}$ & $9 \%$ \\
\hline $\begin{array}{l}\text { YBT FOBL OSBD } \\
\text { I\& TEABSPORAATIOS' }\end{array}$ & 3,655 & 12,638 & - & - & - & 7,312 & - & $-8,272$ & 15,333 & $9 \%$ \\
\hline $\begin{array}{l}\text { TOTAL GROSS FLORS } \\
\text { LOSSBS } 8 \text { OHISSIOHS }\end{array}$ & $\begin{array}{r}19,127 \\
1,105\end{array}$ & $\begin{array}{r}14,242 \\
0\end{array}$ & $\begin{array}{r}52,913 \\
-0\end{array}$ & $\begin{array}{r}15,720 \\
-657\end{array}$ & - & $\begin{array}{l}45,275 \\
-1,639\end{array}$ & $\begin{array}{r}3.462 \\
-7\end{array}$ & $\begin{array}{r}19,057 \\
1,905\end{array}$ & $\begin{array}{r}161,524 \\
707\end{array}$ & $\begin{array}{r}100 \% \\
0 \%\end{array}$ \\
\hline $\begin{array}{l}\text { SOPPLI OP BNBRGI } \\
\text { POSS IL POBL } \\
\text { HY DROBLECTRIC } \\
\text { YOCL BAR } \\
\text { GBO. ESOLAR }\end{array}$ & $\bar{z}$ & $\begin{array}{l}\bar{z} \\
\bar{z}\end{array}$ & $\begin{array}{l}\bar{z} \\
\overline{-}\end{array}$ & $\begin{array}{l}\bar{z} \\
\bar{z}\end{array}$ & $\begin{array}{l}E \\
\overline{-}\end{array}$ & $=$ & $\begin{array}{l}\bar{z} \\
\bar{z}\end{array}$ & $\begin{array}{r}148 \\
934\end{array}$ & $\begin{array}{r}14 \overline{-} \\
934\end{array}$ & $14 x$ \\
\hline TOTAL SOPPLY & - & - & - & - & - & - & - & 1,082 & 1,082 & \\
\hline
\end{tabular}

\begin{tabular}{l} 
RBT IM PORTS \\
OP RBGIOB \\
\hline
\end{tabular}


BEGIONAE ENERGY BALAYCE SFATEMENT

PIES MLD IID SCENARIO

\begin{tabular}{|c|c|c|c|c|c|c|c|c|c|}
\hline SECEOR & $\begin{array}{l}\text { DI STILLATB } \\
\text { OIL }\end{array}$ & $\begin{array}{l}\text { RESIDEAL } \\
\text { DII }\end{array}$ & $\begin{array}{l}\text { GASOLINE: } \\
\text { (ALL OI }\end{array}$ & $\begin{array}{l}\text { OTHER } \\
\text { AYIRO- } \\
\text { CIREONS } \\
\text { TS IN } 10 * *\end{array}$ & $\begin{array}{c}\text { CRIDE } \\
\text { OIL } \\
\text { BTO'SI }\end{array}$ & $\begin{array}{l}\text { NATURAL } \\
\text { GAS }\end{array}$ & COAL & ELECTRICITY & $\begin{array}{r}\text { SECTOR } \\
\text { TOTAL }\end{array}$ \\
\hline $\begin{array}{l}\text { PINAL DEMAND SECTORS } \\
\text { RES ID ENTIAL,COBH. } \\
\text { IND TS TRIAL } \\
\text { TRANS PORTATION } \\
\text { HISCELLABOOS OSES }\end{array}$ & $\begin{array}{r}2,012 \\
1,530 \\
6,161 \\
671\end{array}$ & $\begin{array}{r}143 \\
1,165 \\
5,697 \\
189\end{array}$ & $121.36 \frac{-}{-}$ & $\begin{array}{r}7.730 \\
2.259 \\
2.690 \\
11\end{array}$ & $\begin{array}{l}- \\
\overline{-} \\
-\end{array}$ & $\begin{array}{r}51,276 \\
15,362 \\
3,908 \\
3,241\end{array}$ & 792 & $\begin{array}{r}28,057 \\
7,250 \\
5 \\
1,291\end{array}$ & $\begin{array}{r}89,218 \\
29,358 \\
160,827 \\
5,403\end{array}$ \\
\hline $\begin{array}{l}\text { TOTAL PINAL } \\
\text { DEMAND SECTORS }\end{array}$ & 10,374 & 3,194 & 121,366 & 33,690 & - & 73,737 & 792 & 36,603 & 284,806 \\
\hline $\begin{array}{l}\text { TRANSF ORMATION } \\
\text { ELECTRICITY GEN. } \\
\text { PETROLEU FRODOCTS } \\
\text { HATTRAL GAS } \\
\text { SYNT HETICS }\end{array}$ & $\begin{array}{r}3,375 \\
\div \\
-\end{array}$ & $\begin{array}{r}41.426 \\
- \\
- \\
-\end{array}$ & $\begin{array}{l}\overline{-} \\
\overline{-}\end{array}$ & $\begin{array}{l}\overline{-} \\
\overline{-}\end{array}$ & $\begin{array}{l}- \\
\overline{-}\end{array}$ & $\begin{array}{r}14,043 \\
- \\
-\end{array}$ & $\begin{array}{l}\overline{-} \\
-\end{array}$ & $\begin{array}{r}-20,533 \\
- \\
-\end{array}$ & $\begin{array}{r}38,811 \\
- \\
-\end{array}$ \\
\hline $\begin{array}{l}\text { NET FDEL USED } \\
\text { IN TRANSPOEHATION }\end{array}$ & 3,875 & 41,426 & - & - & - & 14,043 & - & $-20,533$ & 38,811 \\
\hline $\begin{array}{l}\text { TOTAL GROSS ILONS } \\
\text { IOSSES } \varepsilon \text { OMISSIONS }\end{array}$ & $\begin{array}{r}: 4,249 \\
823\end{array}$ & $\begin{array}{r}49,620 \\
1\end{array}$ & $\begin{array}{r}121,366 \\
-0\end{array}$ & $\begin{array}{r}33,690 \\
-1,408\end{array}$ & - & $\begin{array}{l}87,830 \\
-3,131\end{array}$ & $\begin{array}{r}7 \subseteq 2 \\
-1\end{array}$ & $\begin{array}{r}36,603 \\
3,660\end{array}$ & $\begin{array}{r}323,617 \\
-106\end{array}$ \\
\hline TOTAL NET OSEGE & $\cdot 5,072$ & 49,621 & 121,365 & $3 z, 281$ & - & 84,648 & 790 & 19,730 & 323,510 \\
\hline
\end{tabular}

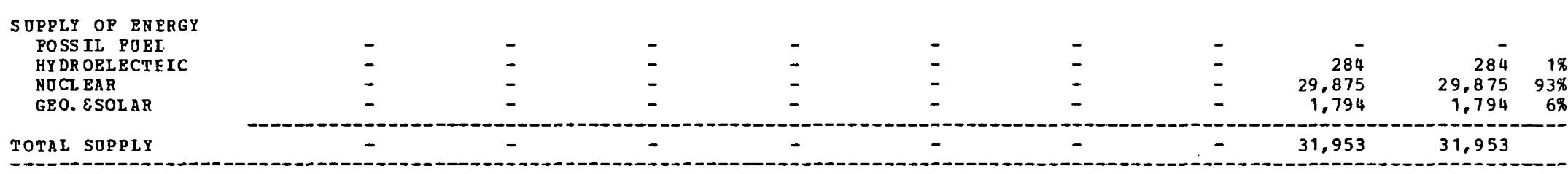

-

\begin{tabular}{|c|c|c|c|c|c|c|c|c|c|}
\hline OP REGION & 15,072 & 49,621 & 121,365 & 32,281 & - & $84,6+8$ & $7 \subseteq 0$ & $-12,222$ & 291,557 \\
\hline
\end{tabular}

\begin{tabular}{|c|c|c|c|c|c|}
\hline \multicolumn{6}{|c|}{ NOTES: } \\
\hline & TRAN SPOR GATION & $\operatorname{Los} \mathrm{S}$ & FOR & ELECTRICITY GEN. & $=65-40 \%$ \\
\hline 2 & TRANSPORMATION & LOES & POR & RETROLE OH PROJ OCTS & $=0.0 \mathrm{~g}$ \\
\hline 3 & TRAN SPORMATI ON & LoES & FOR & TYATUEAL GAS & $=0.0 \mathrm{~g}$ \\
\hline 4 & TRAN SPORMATI ON & LOSS & POR & SYNTHETICS & $=0.0$ \\
\hline
\end{tabular}


EEGIONAL ENERGY BALANCE STATEMENT

\begin{tabular}{|c|c|c|c|c|c|c|c|c|c|c|}
\hline SECTOR & $\begin{array}{l}\text { DISTILLATE } \\
\text { OIL }\end{array}$ & $\begin{array}{l}\text { RESIDDAL } \\
\text { OIL }\end{array}$ & $\begin{array}{l}\text { GASOLINE } \\
\text { CALL ONIT }\end{array}$ & $\begin{array}{l}\text { OTHER } \\
\text { GYDRO- } \\
\text { CARBONS } \\
\text { S IN } 10 * \% 9\end{array}$ & $\begin{array}{c}\text { CR gDE } \\
O I E \\
\text { BTU } S\end{array}$ & $\begin{array}{l}\text { NATURAL } \\
\text { GAS }\end{array}$ & $\angle O A L$ & BLECTRICITY & $\begin{array}{r}\text { SECTOR } \\
\text { TOTAL }\end{array}$ & \\
\hline $\begin{array}{l}\text { PENAL DEMAND SECTCRS } \\
\text { RESIDENTIAL, CONM. } \\
\text { INDUSTRIAL } \\
\text { TRANSPORTATION } \\
\text { MISCELLANEOUS OSES }\end{array}$ & $\begin{array}{r}12,885 \\
34,073 \\
97,429 \\
3,076\end{array}$ & $\begin{array}{r}1,000 \\
72,887 \\
51,545 \\
866\end{array}$ & $753,61 \frac{-}{-}$ & $\begin{array}{r}48,030 \\
269,760 \\
174,517 \\
27\end{array}$ & $\begin{array}{l}\overline{-} \\
\bar{z}\end{array}$ & $\begin{array}{r}326,449 \\
467,932 \\
30,039 \\
7,969\end{array}$ & $\begin{array}{r}8 \\
54,335 \\
3 \\
1\end{array}$ & $\begin{array}{r}185,554 \\
110,401 \\
356 \\
2,750\end{array}$ & $\begin{array}{r}573,926 \\
1,009,388 \\
1,107,502 \\
14,689\end{array}$ & $\begin{array}{l}18 \% \\
32 \% \\
36 \% \\
0 \%\end{array}$ \\
\hline $\begin{array}{l}\text { TOTAL FINAL } \\
\text { DEMAND SECTORS }\end{array}$ & 147.463 & 126,298 & 753,613 & 492,334 & - & 832,389 & 54,347 & 299,061 & $2,705,505$ & $87 \%$ \\
\hline $\begin{array}{l}\text { TEANSF ORMATION } \\
\text { ELECTRICITY GEN. } \\
\text { PETR OLEOM FRODOCTS } \\
\text { NATORAL GAS } \\
\text { SYNTHETICS }\end{array}$ & $\begin{array}{r}35,663 \\
-415,437 \\
- \\
-\end{array}$ & $\begin{array}{r}276,433 \\
-495,546 \\
- \\
-\end{array}$ & $\begin{array}{r}-1,064,15 \overline{-} \\
-\end{array}$ & $\begin{array}{r}-722,730 \\
60,020\end{array}$ & $\begin{array}{r}- \\
2,693,161 \\
-\end{array}$ & $\begin{array}{r}116,433 \\
10,893 \\
-54,140\end{array}$ & $\begin{array}{l}- \\
- \\
-\end{array}$ & $\begin{array}{r}-148,418 \\
- \\
-\end{array}$ & $\begin{array}{r}280,111 \\
6,183 \\
- \\
5,880\end{array}$ & $\begin{array}{l}9 \% \\
0 \%\end{array}$ \\
\hline $\begin{array}{l}\text { NET FOEL OSED } \\
\text { IN TRANSPORMATION }\end{array}$ & $-379,774$ & $-219,113$ & $-1,064,158$ & $-662,710$ & $2,693,161$ & 73,186 & - & $-148,418$ & 292,174 & $9 \%$ \\
\hline $\begin{array}{l}\text { TOTAL GROSS FLOHS } \\
\text { L CSSES } \& \text { OUISSIONS }\end{array}$ & $\begin{array}{r}183,126 \\
10,587\end{array}$ & $\begin{array}{r}402,731 \\
9\end{array}$ & $\begin{array}{r}753.613 \\
-2\end{array}$ & $\begin{array}{l}552,354 \\
-23,089\end{array}$ & $\begin{array}{r}2,693,161 \\
134,447\end{array}$ & $\begin{array}{l}959,715 \\
-34,763\end{array}$ & $\begin{array}{r}54.347 \\
-119\end{array}$ & $\begin{array}{r}299,061 \\
29,909\end{array}$ & $\begin{array}{r}2,997,679 \\
116,977\end{array}$ & $\begin{array}{r}96 \% \\
4 \%\end{array}$ \\
\hline TOTAL NET OSAGE & $-221,723$ & $-92,8) 5$ & -310.547 & $-193,465$ & $2,827,608$ & 870,811 & 54,227 & 180,552 & $3,114,657$ & \\
\hline
\end{tabular}

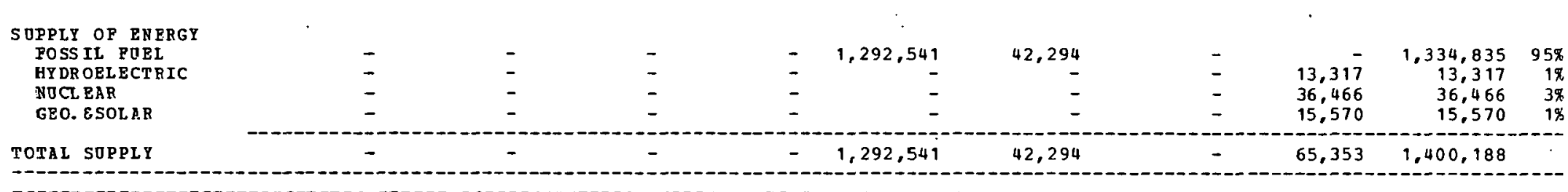

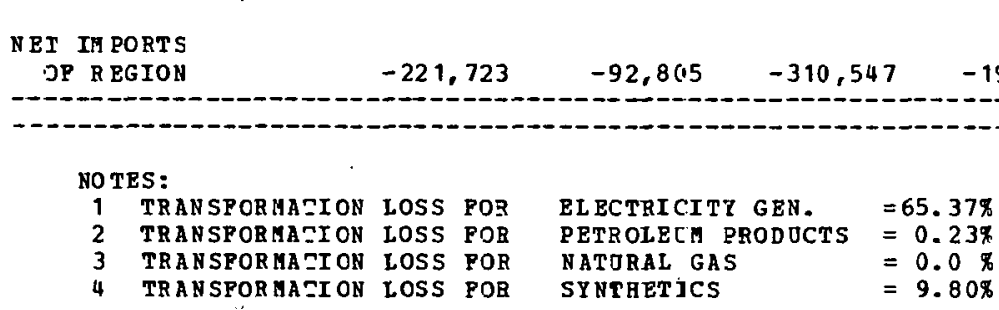


REGI:ONAL ENE RGY BALANCE STATEHENT

?IES MLD MID SCENRRIO

\begin{tabular}{|c|c|c|c|c|c|c|c|c|c|c|}
\hline SECTOR & $\begin{array}{l}\text { DI STILLATB } \\
\text { OIL }\end{array}$ & $\begin{array}{l}\text { RESLDUAL } \\
\text { DIL }\end{array}$ & $\begin{array}{l}\text { GASOLINE } \\
\text { (ALI OEIT }\end{array}$ & $\begin{array}{l}\text { OTBER } \\
\text { HYDZO- } \\
\text { CAFBONS } \\
\text { S IN } 10 * 9\end{array}$ & $\begin{array}{c}\text { CROJE } \\
\text { OIL } \\
\text { BTO'S) }\end{array}$ & $\begin{array}{l}\text { NATUR R.L } \\
\text { GAS }\end{array}$ & COAL. & BLECTRICITY & $\begin{array}{l}\text { SECTOR } \\
\text { TOTAL }\end{array}$ & \\
\hline $\begin{array}{l}\text { PINAL DEMAND SBCTORS } \\
\text { RESID ENTIAL, COMH. } \\
\text { INDOSTRIAL } \\
\text { TRANSPORTATION } \\
\text { MISCELLANEOOS OSES }\end{array}$ & $\begin{array}{r}1,245 \\
3,535 \\
12,954 \\
361\end{array}$ & $\begin{array}{r}83 \\
3,130 \\
\bar{z}, 028 \\
102\end{array}$ & $\begin{array}{r}- \\
\overline{-} \\
76,635 \\
-\end{array}$ & $\begin{array}{r}4,883 \\
6,890 \\
6,836 \\
4\end{array}$ & $\bar{z}$ & $\begin{array}{r}32,002 \\
22,931 \\
1,174 \\
940\end{array}$ & $\begin{array}{r}2.725 \\
1 \\
-\end{array}$ & $\begin{array}{r}17,075 \\
11,731 \\
84 \\
325\end{array}$ & $\begin{array}{r}55,328 \\
110,942 \\
99,762 \\
1,732\end{array}$ & $\begin{array}{r}19 \% \\
37 \% \\
34 \% \\
1 \%\end{array}$ \\
\hline $\begin{array}{l}\text { TCTAL PINAL } \\
\text { DERAND SECTORS }\end{array}$ & 18,095 & 5,343 & 76,685 & 18.613 & - & 117,087 & 2,726 & 29,215 & 267,764 & $90 \%$ \\
\hline $\begin{array}{l}\text { TR ANSF ORHATIOT } \\
\text { EL ECTRICITY GEN. } \\
\text { PETROLEU ORODUCTS } \\
\text { NATORAL GAS } \\
\text { SY HT HETICS }\end{array}$ & $\begin{array}{r}-51, \cos \\
-\end{array}$ & $\begin{array}{r}3,902 \\
-72,773 \\
- \\
-\end{array}$ & $\begin{array}{r}-156,276 \\
- \\
-\end{array}$ & $\begin{array}{r}-06.136 \\
-\end{array}$ & $\begin{array}{r}395,503 \\
- \\
-\end{array}$ & $\begin{array}{r}11,208 \\
1,59 \subseteq \\
-\end{array}$ & $\begin{array}{l}\bar{z} \\
\bar{z}\end{array}$ & $\begin{array}{r}-4,927 \\
- \\
-\end{array}$ & $\begin{array}{r}10,183 \\
908 \\
- \\
-\end{array}$ & $\begin{array}{l}3 \% \\
\partial \%\end{array}$ \\
\hline $\begin{array}{l}\text { DET FOEL OSED } \\
\text { IN TRANSPORHATION }\end{array}$ & $-51,609^{\circ}$ & $-68,871$ & $-156,276$ & $--06,136$ & 395,503 & 12,807 & - & $-4,927$ & 11,091 & $4 \%$ \\
\hline $\begin{array}{l}\text { TOTAL GROSS FEONS } \\
\text { lOSSES } \& \text { OHISIIONS }\end{array}$ & $\begin{array}{r}18,695 \\
1,(46\end{array}$ & $\begin{array}{r}9 \\
0\end{array}$ & $\begin{array}{r}76,685 \\
-0\end{array}$ & $\begin{array}{r}18,613 \\
-778\end{array}$ & $\begin{array}{r}395.503 \\
19.744\end{array}$ & $\begin{array}{r}129,89 L \\
-4,7 \cdot 35\end{array}$ & $\begin{array}{r}2,7 \div 6 \\
-6\end{array}$ & $\begin{array}{r}29,215 \\
2,921\end{array}$ & $\begin{array}{r}278,855 \\
18,222\end{array}$ & $\begin{array}{r}94 \pi \\
6 \%\end{array}$ \\
\hline TOTAL HET USAJE & $-41,867$ & $-63,527$ & $-79,591$ & $-88,301$ & 415.247 & 125,139 & 2,779 & 27,209 & 297,078 & \\
\hline $\begin{array}{l}\text { S OPPLI OF ENERGY } \\
\text { FOSS IL POEI } \\
\text { HYDR OELECTEIC } \\
\text { NOCL EAR } \\
\text { GEO. ESOLAR }\end{array}$ & $\bar{z}$ & - & $\begin{array}{l}\overline{-} \\
\bar{z}\end{array}$ & $\begin{array}{l}\overline{-} \\
\overline{-}\end{array}$ & $\begin{array}{r}825.466 \\
- \\
-\end{array}$ & $\begin{array}{r}29,458 \\
- \\
=\end{array}$ & $\begin{array}{l}\overline{-} \\
-\end{array}$ & $\begin{array}{r}24,04 \vec{\epsilon} \\
14,72 \overrightarrow{2} \\
1.432\end{array}$ & $\begin{array}{r}854,924 \\
24,046 \\
14,722 \\
1,432\end{array}$ & $\begin{array}{r}96 \% \\
3 \% \\
2 \% \\
0 \%\end{array}$ \\
\hline TOTAL SOPPIY & - & - & - & - & 825.466 & 29,458 & - & 40,200 & 895,124 & \\
\hline
\end{tabular}

\begin{tabular}{l} 
NET IIM PORTS \\
OP IEGION \\
\hline
\end{tabular}


REGIONAL ENERGY BALANCE STRTEMENT

\begin{tabular}{|c|c|c|c|c|c|c|c|c|c|c|}
\hline SECTOR & $\begin{array}{l}\text { DISTILLKTE } \\
\text { OIL }\end{array}$ & $\begin{array}{l}\text { RESIDJAL } \\
\text { OIL }\end{array}$ & $\begin{array}{l}\text { GASOLINE } \\
\text { (AIL ONIT }\end{array}$ & $\begin{array}{c}\text { OTHER } \\
\text { HYDRC- } \\
\text { CARBORS } \\
\text { S IN } 10 * 99\end{array}$ & $\begin{array}{c}\text { CRODE } \\
\text { OIL } \\
\text { BTO'S) }\end{array}$ & $\begin{array}{l}\text { NATURAL } \\
\text { GAS }\end{array}$ & $\mathrm{COAL}$ & ELECTRICI TY & $\begin{array}{r}\text { SECTOR } \\
\text { TOTAL }\end{array}$ & \\
\hline $\begin{array}{l}\text { PINAL DEHAND SECTORS } \\
\text { BESIDENTIAL, COMG. } \\
\text { IND OSTRIAL } \\
\text { TRANSPORTATION } \\
\text { MISCELLANEOOS OSES }\end{array}$ & $\begin{array}{r}821 \\
2,253 \\
9,204 \\
342\end{array}$ & $\begin{array}{r}50 \\
1,773 \\
1,273 \\
96\end{array}$ & $\begin{array}{r}- \\
\overline{-} \\
52,067 \\
-\end{array}$ & $\begin{array}{r}3,314 \\
2,269 \\
4,298 \\
2\end{array}$ & $\begin{array}{l}- \\
- \\
-\end{array}$ & $\begin{array}{r}21,261 \\
24,778 \\
737 \\
839\end{array}$ & $\begin{array}{r}1,781 \\
- \\
-\end{array}$ & $\begin{array}{r}10,885 \\
7,598 \\
46 \\
284\end{array}$ & $\begin{array}{r}36,331 \\
40.452 \\
67.625 \\
1.563\end{array}$ & $\begin{array}{r}24 \% \\
27 \% \\
45 \% \\
1 \%\end{array}$ \\
\hline $\begin{array}{l}\text { TOTAL FINAL } \\
\text { DEMAND SECTORS }\end{array}$ & 12,620 & 3,192 & 52,067 & 9,883 & - & 47,615 & 1,781 & 18,813 & 145,971 & $97 \%$ \\
\hline $\begin{array}{l}\text { TEANSPORHATION } \\
\text { R. FCTRICITY GEN. } \\
\text { PETROLEU FRODUCTS } \\
\text { NATURAL GRS } \\
\text { SY NT HETICS }\end{array}$ & $\overline{-}$ & $\begin{array}{l}\overline{-} \\
\overline{-}\end{array}$ & $\begin{array}{l}- \\
-\end{array}$ & $\begin{array}{l}\bar{z} \\
\overline{-}\end{array}$ & $\begin{array}{l}\overline{-} \\
\overline{-}\end{array}$ & $\begin{array}{r}7,217 \\
- \\
-\end{array}$ & $\begin{array}{l}\overline{-} \\
\overline{-}\end{array}$ & $\begin{array}{r}-2,297 \\
- \\
- \\
-\end{array}$ & $\begin{array}{r}4,920 \\
- \\
-\end{array}$ & $3 \%$ \\
\hline $\begin{array}{l}\text { NET FUEL OSED } \\
\text { IN TRANSPRMATION }\end{array}$ & - & - & - & - & - & 7,217 & - & $-2,297$ & 4,920 & $3 \%$ \\
\hline $\begin{array}{l}\text { TCTAL GROSS FLONS } \\
\text { LOSSES E OMISSIONS }\end{array}$ & $\begin{array}{r}12,620 \\
729\end{array}$ & $3,19 \frac{2}{0}$ & $\begin{array}{r}52.067 \\
-0\end{array}$ & $\begin{array}{r}9,883 \\
-413\end{array}$ & $\overline{-}$ & $\begin{array}{l}54,832 \\
-1,986\end{array}$ & $\begin{array}{r}1,781 \\
-3\end{array}$ & $\begin{array}{r}18,813 \\
1,881\end{array}$ & $\begin{array}{r}150,891 \\
207\end{array}$ & $\begin{array}{r}100 \% \\
0 \%\end{array}$ \\
\hline $\begin{array}{l}\text { S OPPLY OF ENERGY } \\
\text { FJSS IL PUEL } \\
\text { HY DR OEL ECTRIC } \\
\text { NJCL EAR } \\
\text { GEO. ESOLAF }\end{array}$ & $\begin{array}{l}\bar{z} \\
\bar{z}\end{array}$ & $\begin{array}{l}- \\
- \\
-\end{array}$ & $\begin{array}{l}- \\
- \\
-\end{array}$ & $\begin{array}{l}- \\
-\end{array}$ & $\begin{array}{l}- \\
-\end{array}$ & $\begin{array}{l}- \\
-\end{array}$ & $\begin{array}{l}- \\
-\end{array}$ & $\begin{array}{r}21,402 \\
- \\
921\end{array}$ & $\begin{array}{r}21,40 \frac{-}{-} \\
921\end{array}$ & $96 \%$ \\
\hline TOTAL SOPPLY & - & - & - & - & - & - & - & 22,323 & 22,323 & \\
\hline
\end{tabular}

\begin{tabular}{l}
$\begin{array}{l}\text { NET IM PORTS } \\
\text { OP R RGION }\end{array}$ \\
\hline
\end{tabular}


REGIJTAL ENERGY BALANCE STATEMENT

PIES MID MI D SCENARIO

\begin{tabular}{|c|c|c|c|c|c|c|c|c|c|c|}
\hline SECTOR & $\begin{array}{l}\text { DISEILLATB } \\
\text { OIL }\end{array}$ & $\begin{array}{l}\text { RESIDUAL } \\
\text { OIL }\end{array}$ & $\begin{array}{l}\text { GASOLINE } \\
\text { (ALE J }\end{array}$ & $\begin{array}{c}\text { OTZER } \\
\text { HYDZO- } \\
\text { CAFBCNS } \\
\text { TS IN } 10 * * 9\end{array}$ & $\begin{array}{c}\text { CROJE } \\
\text { OIL } \\
\text { BTU'S) }\end{array}$ & $\begin{array}{l}\text { NAEOREL } \\
\text { GAS }\end{array}$ & $\operatorname{COAL}$ & 3LECTRICITY & $\begin{array}{l}\text { SECTOR } \\
\text { TOTAL }\end{array}$ & \\
\hline $\begin{array}{l}\text { PINAL DEMAND SECTORS } \\
\text { RESIDENTIAL, CCMH, } \\
\text { IND US TRIAL } \\
\text { TRANS PORTATION } \\
\text { MISCELLANEOOS USES }\end{array}$ & $\begin{array}{r}1,533 \\
1,764 \\
12,840 \\
1,617\end{array}$ & $\begin{array}{r}113 \\
1,282 \\
2,606 \\
286\end{array}$ & $91,28 \overline{5}$ & $\begin{array}{r}5.814 \\
2.262 \\
8.757 \\
8\end{array}$ & $\begin{array}{l}- \\
\text { - }\end{array}$ & $\begin{array}{r}38,6 \div 3 \\
17,408 \\
1,505 \\
2.5016\end{array}$ & $\begin{array}{r}- \\
807 \\
1 \\
-\end{array}$ & $\begin{array}{r}21,144 \\
6.257 \\
138 \\
350\end{array}$ & $\begin{array}{r}67,227 \\
29,782 \\
117,132 \\
4,667\end{array}$ & $\begin{array}{r}29 \% \\
13 \% \\
51 \% \\
2 \%\end{array}$ \\
\hline $\begin{array}{l}\text { TOTAL FINAL } \\
\text { DEMAND SECTORS }\end{array}$ & 17,154 & 7,287 & 91,285 & 16.841 & - & $60,0 L_{2}$ & $81)$ & 28,389 & 218,808 & $36 \%$ \\
\hline $\begin{array}{l}\text { TRANSF ORMATIOY } \\
\text { EL ECTRICITY GEN. } \\
\text { PETR OLEUM FBOD UCTS } \\
\text { NATORAL GAS } \\
\text { SY NI HETICS }\end{array}$ & $\begin{array}{r}1,735 \\
- \\
-\end{array}$ & $\begin{array}{l}- \\
\overline{-}\end{array}$ & $\begin{array}{l}- \\
- \\
-\end{array}$ & $\begin{array}{l}\overline{-} \\
-\end{array}$ & $\begin{array}{l}\text { - } \\
-\end{array}$ & $\begin{array}{r}10,8 \subseteq 2 \\
- \\
- \\
-\end{array}$ & $\begin{array}{l}- \\
- \\
-\end{array}$ & $\begin{array}{r}-4,199 \\
- \\
-\end{array}$ & $\begin{array}{r}8,428 \\
- \\
-\end{array}$ & 4\%. \\
\hline $\begin{array}{l}\text { PET FOEL OSED } \\
\text { IN TRANSPORATION }\end{array}$ & 1,735 & - & - & - & - & 10,892 & - & $-4,199$ & 8,428 & $4 \%$ \\
\hline $\begin{array}{l}\text { TOTAL GROSS FLORS } \\
\text { LCSSES } \& \text { OMISSIONS }\end{array}$ & $\begin{array}{r}18,889 \\
1,092\end{array}$ & $\begin{array}{r}4,287 \\
0\end{array}$ & $\begin{array}{r}91,285 \\
-5\end{array}$ & $\begin{array}{r}16.841 \\
-703\end{array}$ & $\overline{-}$ & $\begin{array}{l}71,934 \\
-2,569\end{array}$ & $\begin{array}{r}813 \\
-1\end{array}$ & $\begin{array}{r}28,389 \\
2,939\end{array}$ & $\begin{array}{r}227.236 \\
655\end{array}$ & $\begin{array}{r}130 \% \\
0 \%\end{array}$ \\
\hline TOTAL NET USAGE & 19,981 & 4,287 & 91,284 & 16.137 & - & $6: 3,364$ & 809 & 27,029 & 227,891 & \\
\hline $\begin{array}{l}\text { S OFPLY OP ENEEGY } \\
\text { FOSS IL POEI } \\
\text { HYDF OELECTRIC } \\
\text { NOCL EAR } \\
\text { GEO. ESOLAR }\end{array}$ & $\overline{-}$ & $\begin{array}{l}\overline{-} \\
\overline{-} \\
-\end{array}$ & $\begin{array}{l}- \\
- \\
-\end{array}$ & $\begin{array}{l}\overline{-} \\
-\end{array}$ & $\begin{array}{r}30,357 \\
= \\
-\end{array}$ & $\begin{array}{r}31,, 666 \\
= \\
- \\
-\end{array}$ & $\begin{array}{l}- \\
- \\
-\end{array}$ & $\begin{array}{r}54,308 \\
10,339 \\
1,391\end{array}$ & $\begin{array}{r}61,023 \\
54,308 \\
10,339 \\
1,391\end{array}$ & $\begin{array}{r}+8 \% \\
+3 \% \\
8 \% \\
1 \%\end{array}$ \\
\hline TOTAL SUPPLY & - & - & - & - & 30,357 & 31), 666 & - & 66,038 & 127,061 & \\
\hline
\end{tabular}

-

NET IM PORTS
OP R EGION


R3GIONAL RNE RGY BALANCE STATEMENT
PIES MID MID SCENARIO

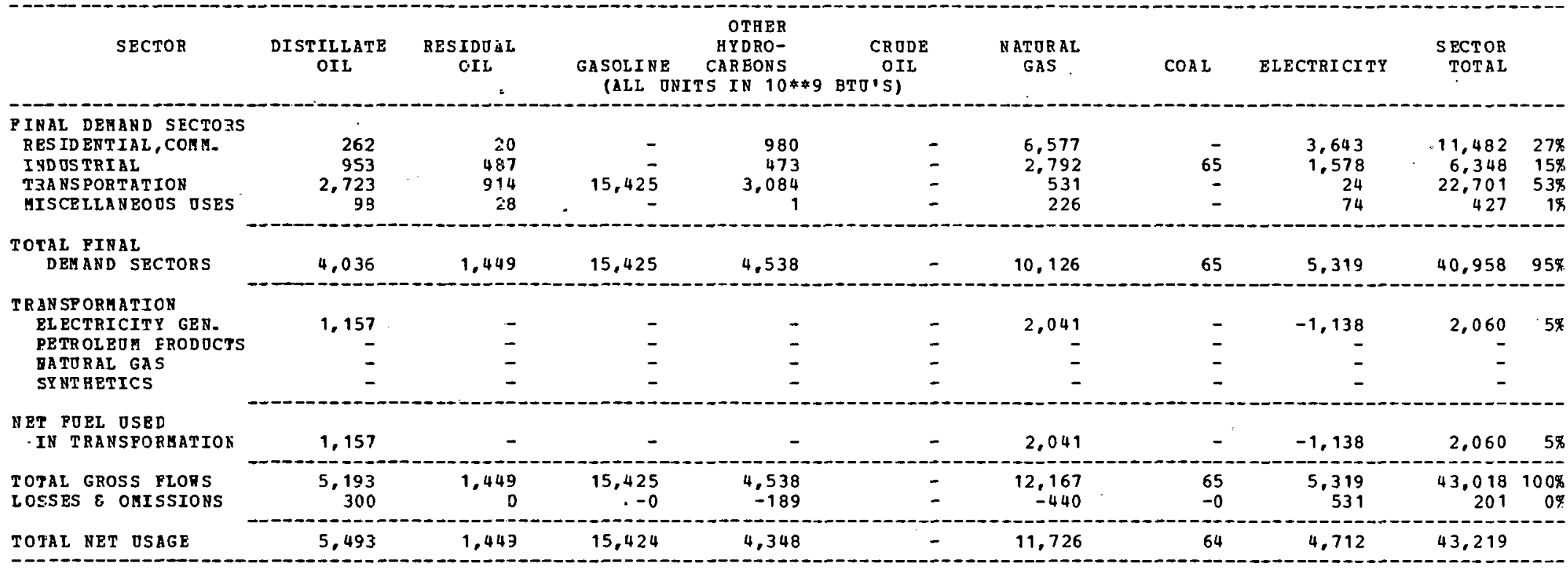

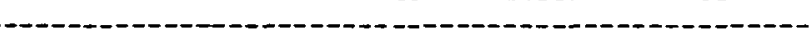

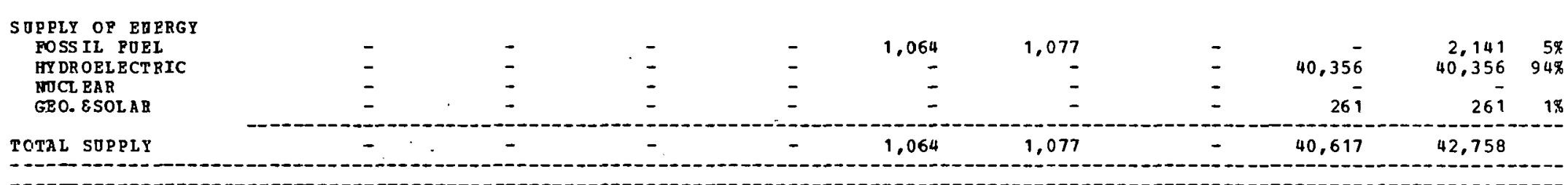

NET IM PORTS
OP REGION


REGICNA: ENERGY BALANCE STATEMEIT

ICNA
EIES MID RGY BALANCE STA

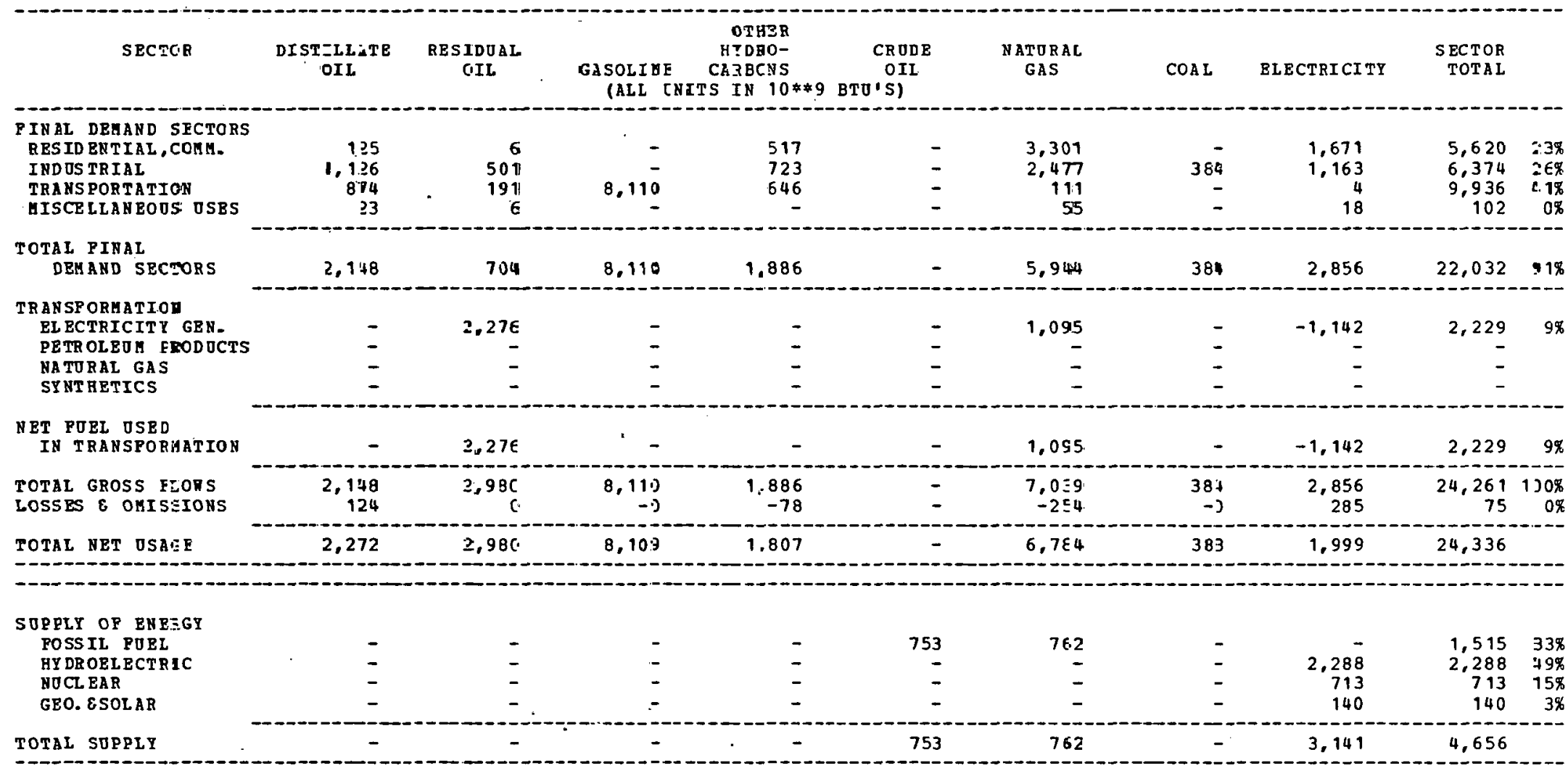

\section{NBT IM PORTS}

2,272

8,109

1.807

$-753$

$6,02 \pi$

393

$-1,141$

19,680

-

\section{NOTES:}

TRANSPORLATION LOSS FOR ELBCJRICITY GZN.

TRANSPORMATI ON LOSS EOR PETROLEOI PROJOCTS $=0.0 \%$

TRANSPORMATION LOSS EO

TRANSPORMATI ON LOSS EOR

I ATUEAL SA

$=0.0 \mathrm{~g}$ 
REGIONAL ENERGY BALANCE STATEMENT
PIES MID MID SCENARIO

\begin{tabular}{|c|c|c|c|c|c|c|c|c|c|c|}
\hline SECTOR & $\begin{array}{l}\text { DISTILLATE } \\
\text { OIL }\end{array}$ & $\begin{array}{l}\text { RES IDUAL } \\
\text { OIL }\end{array}$ & $\begin{array}{l}\text { GASOLINE } \\
\text { (ALL O }\end{array}$ & $\begin{array}{c}\text { OTHER } \\
\text { HYDRO- } \\
\text { CARBONS } \\
\text { TS IN } 10 * 9\end{array}$ & $\begin{array}{c}\text { CRODE } \\
\text { OIL } \\
\text { BTO'S) }\end{array}$ & $\begin{array}{l}\text { NATURAL } \\
\text { GAS }\end{array}$ & $\operatorname{COAL}$ & ELECTRICITY & $\begin{array}{r}\text { SECTOR } \\
\text { TOTAL }\end{array}$ & \\
\hline $\begin{array}{l}\text { FIMAL DEMAND SECTORS } \\
\text { RESIDENTIAL, COMM. } \\
\text { I NDOSTRIAL } \\
\text { TRANSPORTATION } \\
\text { MISCELLAFEOUS OSES }\end{array}$ & $\begin{array}{r}6,486 \\
13,644 \\
52,741 \\
1,838\end{array}$ & $\begin{array}{r}518 \\
51,585 \\
46,799 \\
517\end{array}$ & 374.745 & $\begin{array}{r}23,883 \\
164,132 \\
158,428 \\
18\end{array}$ & $\begin{array}{l}\overline{-} \\
\overline{-}\end{array}$ & $\begin{array}{r}162,484 \\
127,296 \\
27,282 \\
5,254\end{array}$ & $\begin{array}{r}2 \\
17,730 \\
2 \\
-\end{array}$ & $\begin{array}{r}92,748 \\
45,945 \\
242 \\
1,870\end{array}$ & $\begin{array}{r}286,121 \\
420,332 \\
660,239 \\
9,497\end{array}$ & $\begin{array}{l}18 \% \\
27 \% \\
42 \% \\
1 \%\end{array}$ \\
\hline $\begin{array}{l}\text { TOTAL PINAL } \\
\text { DEHAND SECTORS }\end{array}$ & 74,709 & 99,499 & 374.745 & 346.461 & - & 322,316 & 17,734 & 140,805 & $1,376,189$ & $87 \%$ \\
\hline $\begin{array}{l}\text { TRANSPORHATION } \\
\text { EL BCTRICITY GEN. } \\
\text { PETR OLEO FRODOCTS } \\
\text { NATORAL GAS } \\
\text { SY NT HETICS }\end{array}$ & $\begin{array}{r}7,739 \\
-257,471 \\
. \quad-\end{array}$ & $\begin{array}{r}131,908 \\
-307,119 \\
- \\
-\end{array}$ & $\begin{array}{r}-659,523 \\
- \\
-\end{array}$ & $\begin{array}{r}-447,920 \\
- \\
-\end{array}$ & $\begin{array}{r}1,669,114 \\
-\end{array}$ & $\begin{array}{r}54,019 \\
6,751 \\
- \\
-\end{array}$ & $\begin{array}{l}\bar{y} \\
\bar{y}\end{array}$ & $\begin{array}{r}-66,402 \\
- \\
- \\
-\end{array}$ & $\begin{array}{r}127,264 \\
3,832 \\
- \\
-\end{array}$ & $\begin{array}{l}8 \% \\
0 \%\end{array}$ \\
\hline $\begin{array}{l}\text { NET POEL USED } \\
\text { IN TRANSPORMATION }\end{array}$ & $-249,732$ & $-175,211$ & $-659,523$ & $-447,920$ & $1,669,114$ & 60,770 & - & $-66,402$ & 131,096 & $8 \%$ \\
\hline $\begin{array}{l}\text { TOTAL GROSS FLORS } \\
\text { LOSSES } \varepsilon \text { OMISSIONS }\end{array}$ & $\begin{array}{r}82,448 \\
4,766\end{array}$ & $\begin{array}{r}231,327 \\
5\end{array}$ & $\begin{array}{r}374,745 \\
-1\end{array}$ & $\begin{array}{r}346,461 \\
-14,482\end{array}$ & $\begin{array}{r}1,669,114 \\
83,325\end{array}$ & $\begin{array}{l}383,086 \\
-13,876\end{array}$ & $\begin{array}{r}17.734 \\
-39\end{array}$ & $\begin{array}{r}140,805 \\
14,081\end{array}$ & $\begin{array}{r}1,507,285 \\
73,779\end{array}$ & $\begin{array}{r}95 \% \\
5 \%\end{array}$ \\
\hline
\end{tabular}

SOPPLY OP ENERGY
$\begin{aligned} & \text { POSS IL FOEL } \\ & \text { HY DR OELECTRIC }\end{aligned}$
NDCL EAR
GEO. ESOLAR

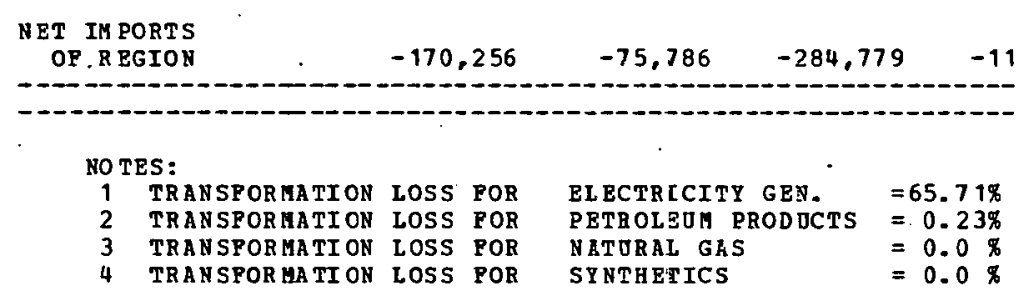


REGIOHAL ENERGY BALENCE STATEHENT

PIES UID MID SCEYARIO

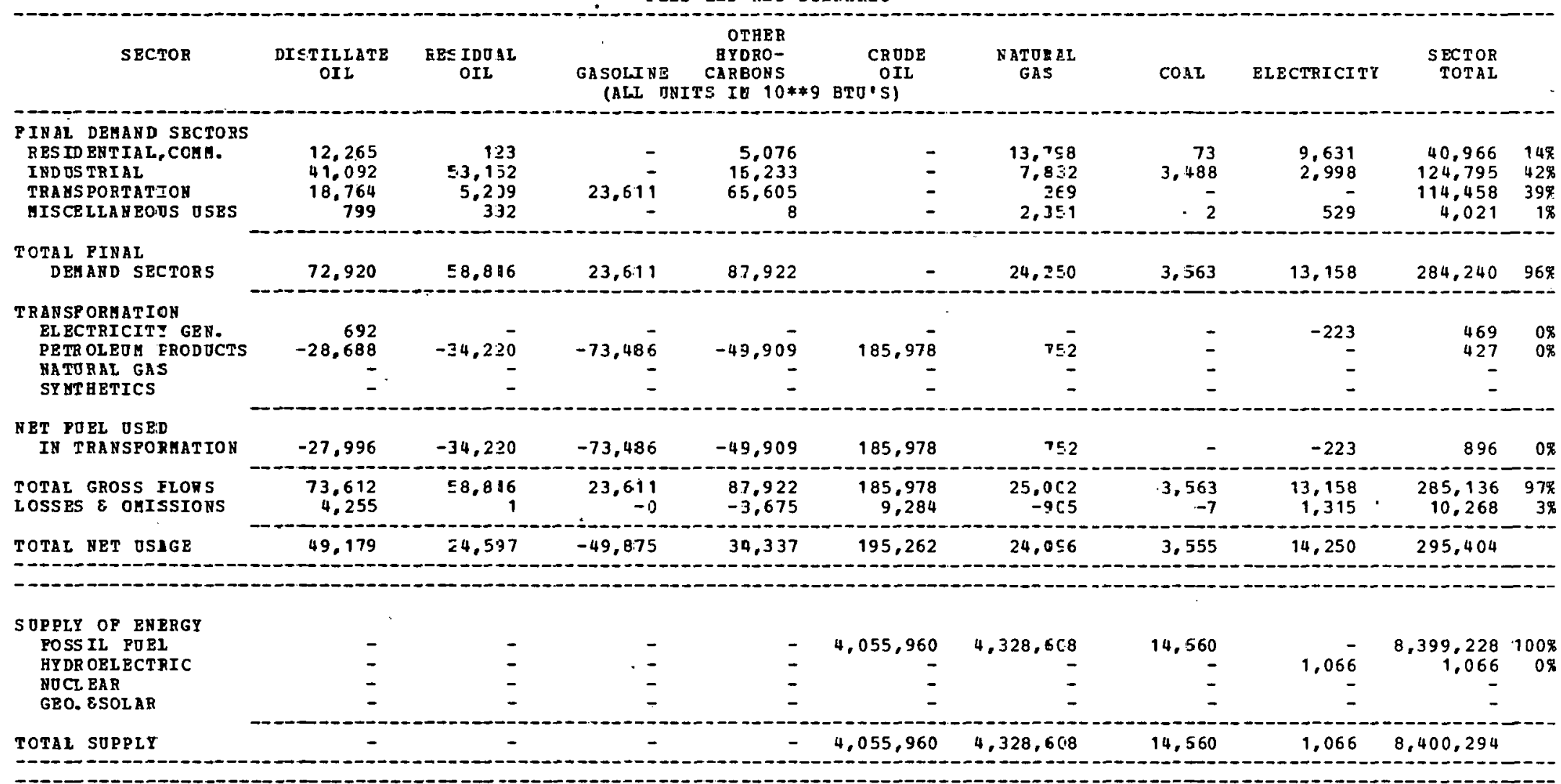

\begin{tabular}{l}
$\begin{array}{l}\text { NET IM PORTS } \\
\text { OP REGION }\end{array}$ \\
\hline
\end{tabular}


REGIONAL ENERGY BALANCE STATEMENT
PIES MID MID SCENARIO

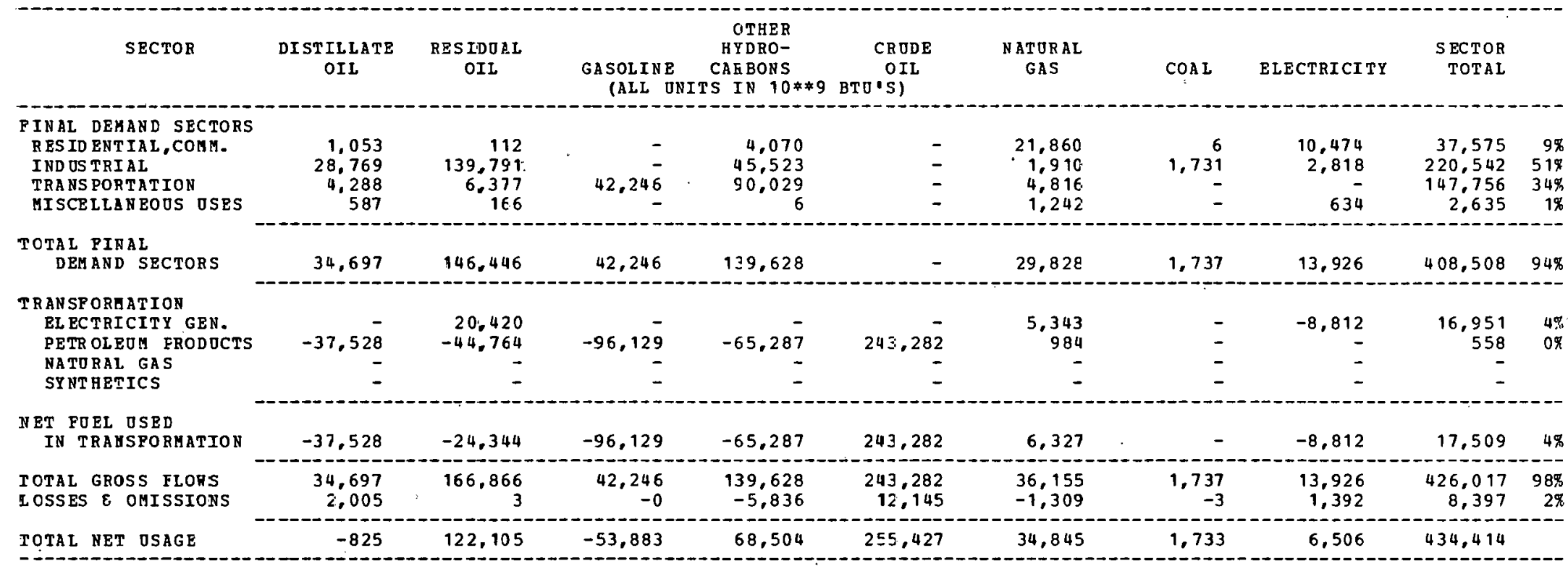

--

\section{OPQLY OP ENERGY \\ FOSS IL POEL \\ NOCL EAP. \\ GEO. \&SOLAR}

TOTAL SUPPLY

-

\begin{tabular}{ll}
- & - \\
- & - \\
- & - \\
\hdashline- & -
\end{tabular}

\begin{tabular}{rrrrr}
- & - & - & - \\
- & - & 108 & 108 & $14 \%$ \\
- & - & - & - & \\
\hline- & - & 793 & 683 & $86 \%$ \\
\hline & - & 791 & $79-$
\end{tabular}

\begin{tabular}{l}
$\begin{array}{l}\text { NET IM POETS } \\
\text { OP REGION }\end{array}$ \\
\hdashline$\quad-825$
\end{tabular}




\section{THIS PAGE}

\section{WAS INTENTIONALLY LEFT BLANK}


Census Region Tables for 1990 


\section{THIS PAGE}

\section{WAS INTENTIONALLY LEFT BLANK}


REGIONAL ENEFGI EALANCE STATEHENT

PIBS UID UID SCENARIO

\begin{tabular}{|c|c|c|c|c|c|c|c|c|c|c|}
\hline SECTOE & $\begin{array}{l}\text { DISTILLATE } \\
\text { OIL }\end{array}$ & $\begin{array}{l}\text { RESIDJAL } \\
\text { OIL. }\end{array}$ & $\begin{array}{l}\text { GASOLINE } \\
\text { (ALI ONI }\end{array}$ & $\begin{array}{c}\text { OTHER } \\
\text { HYDBO- } \\
\text { CAREONS } \\
\text { TS IN 10**9. }\end{array}$ & $\begin{array}{c}\text { CRODE } \\
\text { OIL } \\
\text { BTO'SI }\end{array}$ & $\begin{array}{l}\text { NATURAL } \\
\text { GAS }\end{array}$ & $\operatorname{COAL}$ & ELECTRICITY & $\begin{array}{l}\text { SECTOR } \\
\text { TOTAL }\end{array}$ & \\
\hline $\begin{array}{l}\text { PINLL CEHANI SFCTOFS } \\
\text { FESIDENTIAL, CCHA. } \\
\text { INDOSTRIAL } \\
\text { TRABSPORTATICN } \\
\text { FISCELLANECOS OSES }\end{array}$ & $\begin{array}{r}785,728 \\
25,173 \\
67,651 \\
11,955\end{array}$ & $\begin{array}{r}213,406 \\
244,429 \\
17,480 \\
8,344\end{array}$ & $\begin{array}{r}- \\
.850,879 \\
-\end{array}$ & $\begin{array}{r}121,355 \\
135,571 \\
84,680 \\
162\end{array}$ & $\begin{array}{l}- \\
-\end{array}$ & $\begin{array}{r}235,413 \\
93,991 \\
10,571 \\
14,237\end{array}$ & $\begin{array}{r}33 \\
3.140 \\
11 \\
-\end{array}$ & $\begin{array}{r}215,017 \\
124,109 \\
100 \\
3,144\end{array}$ & $\begin{array}{r}1,570,952 \\
626,413 \\
1,031,372 \\
. \quad 37,842\end{array}$ & $\begin{array}{r}42 \% \\
17 \% \\
27 \% \\
1 \%\end{array}$ \\
\hline $\begin{array}{l}\text { TCTAL PINAI } \\
\text { DEMAND SECTCRS }\end{array}$ & 890,507 & 483,659 & 850,879 & 341,768 & - & 354,212 & 3,184 & 342,370 & $3,266,579$ & $87 \%$ \\
\hline $\begin{array}{l}\text { TF ANSFCRMATICH } \\
\text { ELECTRICITY GEN. } \\
\text { PETROLEOH FHODOCTS } \\
\text { IATORAL GAS } \\
\text { SY HTEETICS }\end{array}$ & $\begin{array}{r}49,002 \\
-1,303,805 \\
-\end{array}$ & $\begin{array}{r}193,400 \\
-143,214 \\
- \\
-\end{array}$ & $\begin{array}{r}- \\
-1,457,324 \\
-\end{array}$ & $\begin{array}{r}- \\
-430,963 \\
59,830\end{array}$ & $\begin{array}{r}3,316,299 \\
- \\
-\end{array}$ & $\begin{array}{r}- \\
18,005 \\
-53,970\end{array}$ & $\begin{array}{r}218,106 \\
- \\
-\end{array}$ & $\begin{array}{r}-157,712 \\
- \\
-\end{array}$ & $\begin{array}{r}302,796 \\
-1,002 \\
5,860\end{array}$ & $\begin{array}{l}8 \% \\
0 \%\end{array}$ \\
\hline $\begin{array}{l}\text { XET FOFI OSEL } \\
\text { IN TRABSFOBUATICN }\end{array}$ & $-1,254,803$ & 50,185 & $-1,457,324$ & $-371,133$ & $3,316,299$ & $-35,964$ & 219,106 & $-157,712$ & 307,653 & $8 \%$ \\
\hline $\begin{array}{l}\text { TCTAL GROSS FLCRS } \\
\text { lCSSES E CBISSIONS }\end{array}$ & $\begin{array}{r}939,509 \\
58,4 ? 7\end{array}$ & $\begin{array}{r}677,059 \\
13\end{array}$ & $\begin{array}{r}850,879 \\
4\end{array}$ & $\begin{array}{l}401,598 \\
-1.5,840\end{array}$ & $\begin{array}{r}3,316,299 \\
137,577\end{array}$ & $\begin{array}{l}372,217 \\
-10,058\end{array}$ & $\begin{array}{r}221,290 \\
2,995\end{array}$ & $\begin{array}{r}342,370 \\
28,407\end{array}$ & $\begin{array}{r}3,575,235 \\
201,577\end{array}$ & $\begin{aligned} 95 x \\
\text { Ex }\end{aligned}$ \\
\hline $\begin{array}{l}\text { STEPLY OP ENEBGY } \\
\text { FOSS IL FOPI } \\
\text { GYDROELECTEIC } \\
\text { AOCL RAR } \\
\text { GEC. ESOLAB }\end{array}$ & $\bar{z}$ & $\begin{array}{l}- \\
-\end{array}$ & $\begin{array}{l}- \\
\overline{-}\end{array}$ & $\begin{array}{l}- \\
-\end{array}$ & $\begin{array}{l}\text { - } \\
\text { - }\end{array}$ & - & $\begin{array}{l}- \\
\text { - } \\
\text { - }\end{array}$ & $\begin{array}{r}- \\
20,890 \\
195,619 \\
6,830\end{array}$ & $\begin{array}{r}20 . \\
195,619 \\
6.830\end{array}$ & $\begin{array}{r}9 \% \\
88 \% \\
3 \%\end{array}$ \\
\hline TCTAL SUPPIY & - & - & - & - & - & - & - & 223,339 & 223,339 & \\
\hline
\end{tabular}

\section{IN FORTS}

$-305,818$

533,857

$-606,440$

$-45,206 \quad 3,453,877$

308,188

224.285

$-10,273 \quad 3,552,470$

\section{ROTES:}

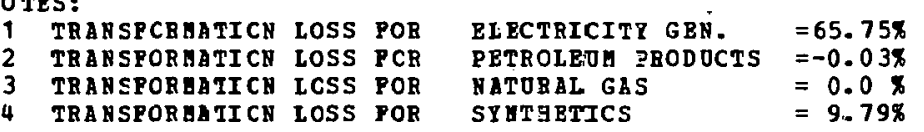


REGIOYAL 3NEFGP EALANCE STATEHZNT

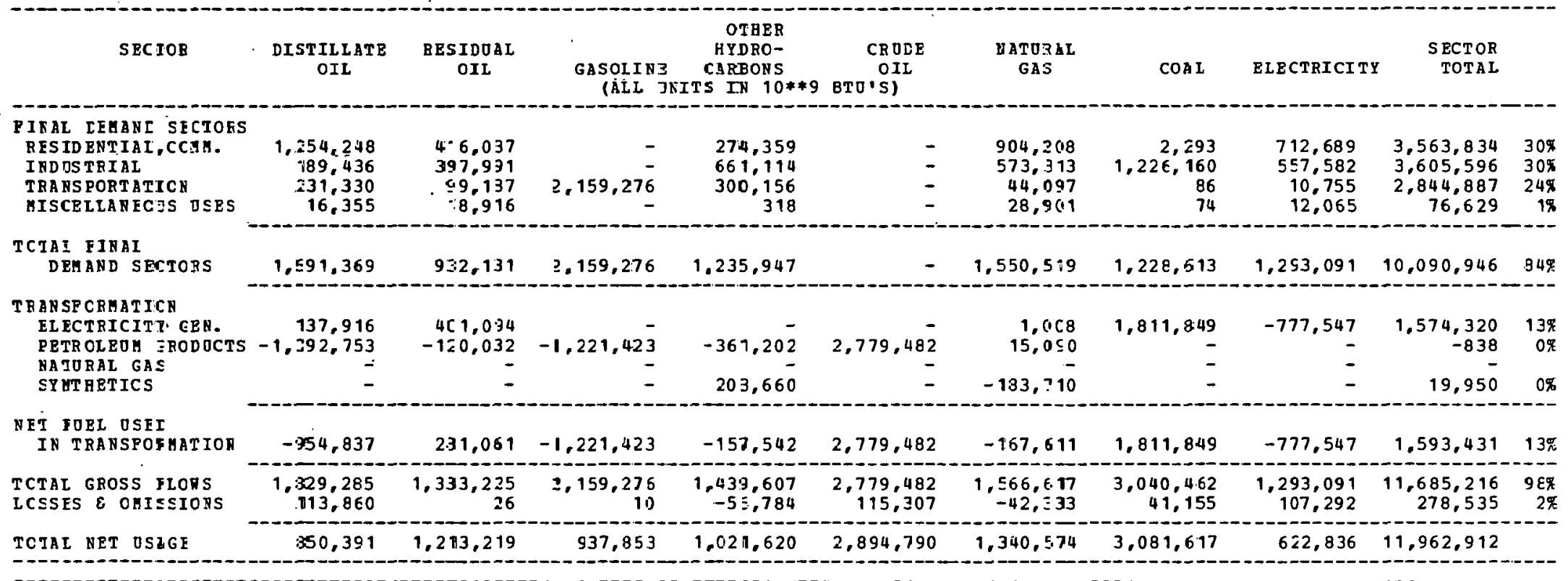

\begin{tabular}{|c|c|c|c|c|c|c|c|c|c|c|}
\hline SOEPLY OP ENIRGI & & & & & & & & & & \\
\hline FOSSIL FOEU & - & - & - & - & 41,899 & 77,109 & $2,933,168$ & - & $3,052,076$ & $83 \%$ \\
\hline HY LRCELFCTEIC & - & - & - & - & - & - & $: \quad-$ & 130,825 & 130,825 & $4 \%$ \\
\hline NOCL EAR & - & - & - & - & - & - & - & 508,517 & 508,517 & $14 \%$ \\
\hline GEC. $\varepsilon S O L A R$ & - & - & - & - & - & - & - & 6.832 & 6,832 & $0 \%$ \\
\hline TCTAL SUPPIY & - & - & - & - & 41,899 & 77,009 & $2,933,158$ & 646,174 & $3,698,250$ & \\
\hline
\end{tabular}

-

\section{NET IM PORTS}

$650,391 \quad 1,213,219$

$§ 37,863$

NOTBS:

\begin{tabular}{|c|c|c|c|c|}
\hline $\begin{array}{l}\text { IRAN SFCRMATICN } \\
\text { IRANSFCREATI CN } \\
\text { TRAN SPCBEATT CN }\end{array}$ & $\begin{array}{l}\text { LCS } \\
\text { LCS }\end{array}$ & & $\begin{array}{l}\text { ELECTRICITY EEN. } \\
\text { PETEOLE OM PRCDOCTS } \\
\text { NATOZAL GAS }\end{array}$ & \\
\hline & & & SYNT:AET & \\
\hline
\end{tabular}


REGIONAL ENEFGY BALANCE STATEMENT

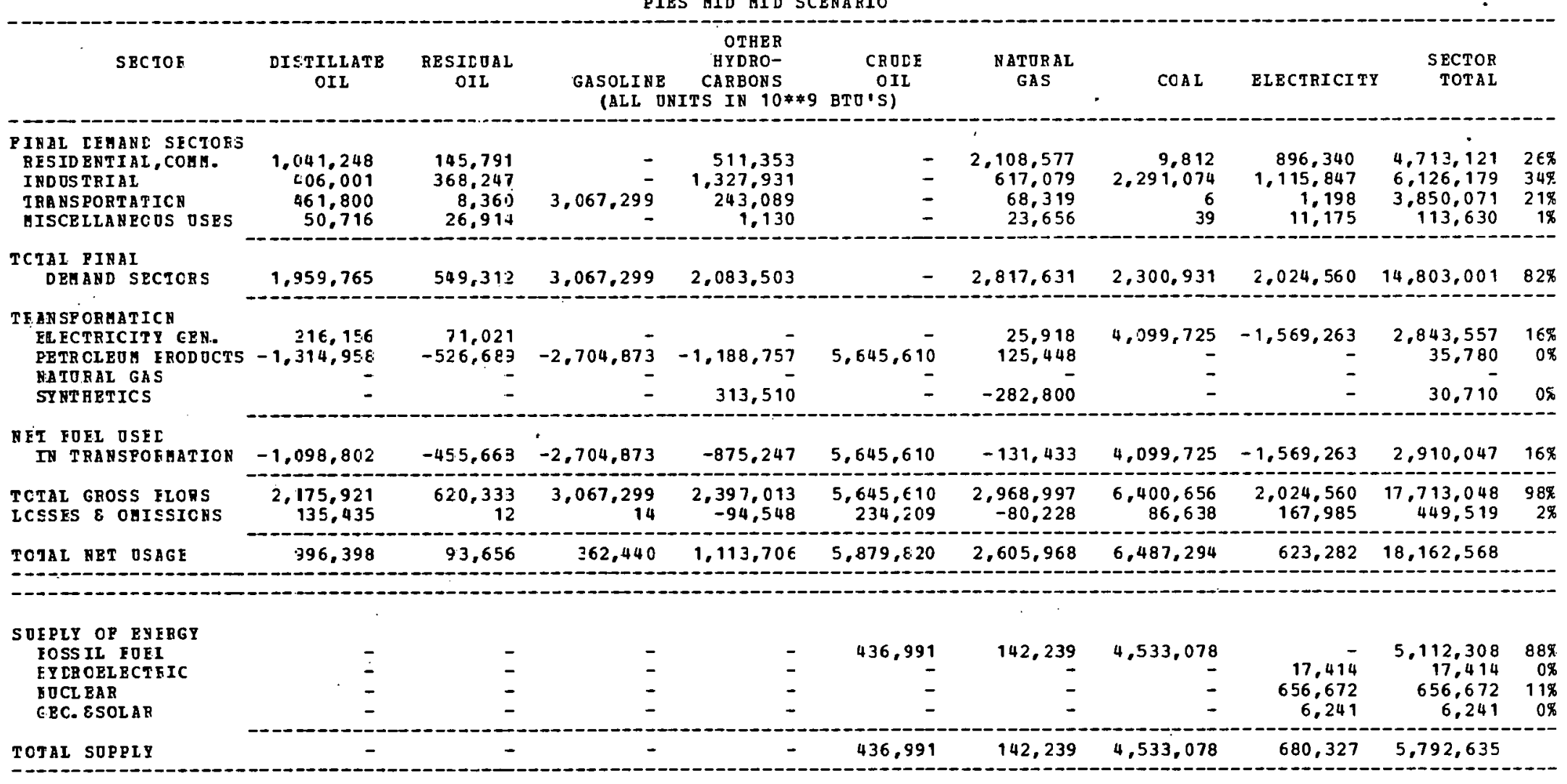

-

\section{NET III PORTS}

996,398

93,656

362,440

$1,113,706$

$5,442,829$

$2,463,729$

$1,954,216$

$-57,044 \quad 12,369,933$

-

NOTES:

1 TRANSFCRHATICN LOSS POB

TRATSPCRAATICH LOSS POR

TRAHSPORAATICN LOSS POR
TRABSPOBAATCN LOSS FOR
BLECTRICITY GEN.

PETROLEI $\quad=64.44 \%$

DRODOCTS $=0.62 \%$

ST $=0.0 \%$ 
REGTCNAL EREESY BALANCE STATEMEYT

\begin{tabular}{|c|c|c|c|c|c|c|c|c|c|c|}
\hline SECTOE & $\underset{\text { OII }}{\text { DISIILIIAE }}$ & $\begin{array}{l}\text { RESIDOAL } \\
\text { CIIL }\end{array}$ & $\begin{array}{l}\text { GASOL I.NE } \\
\text { (ALL OUI }\end{array}$ & $\begin{array}{c}\text { OTAER } \\
\text { HEDRO- } \\
\text { CARBONS } \\
\text { TS IN } 10 * 49\end{array}$ & $\begin{array}{c}\text { CR WDE } \\
\text { OII } \\
\text { ETD'S }\end{array}$ & $\begin{array}{l}\text { NATOR AL } \\
\text { GAS }\end{array}$ & COAL & BLECTRICITY & $\begin{array}{r}\text { SECTOR } \\
\text { TOTAL }\end{array}$ & \\
\hline $\begin{array}{l}\text { PIYLL DEHANC SECTOFS } \\
\text { RESIDENTIAL,CCHA. } \\
\text { INDOSTRIAL } \\
\text { TRANS PORTATICN } \\
\text { WISCELLANEOCS OSBS }\end{array}$ & $\begin{array}{r}333,456 \\
138,587 \\
257,162 \\
28,699\end{array}$ & $\begin{array}{r}17,705 \\
174,220 \\
i .656 \\
7,038\end{array}$ & $1.508,76 \overline{-}$ & $\begin{array}{r}295.269 \\
548.089 \\
119.979 \\
1.035\end{array}$ & $\begin{array}{l}- \\
\overline{-}\end{array}$ & $\begin{array}{c}706,245 \\
304,239 \\
31,484 \\
9,895\end{array}$ & $\begin{array}{r}1,304 \\
316,131 \\
5 \\
12\end{array}$ & $\begin{array}{r}440,963 \\
356,507 \\
99 \\
5,085\end{array}$ & $\begin{array}{r}1,764,842 \\
1,898,233 \\
1,530,151 \\
51,964\end{array}$ & $\begin{array}{r}23 \% \\
25 \% \\
25 \% \\
1 \%\end{array}$ \\
\hline $\begin{array}{l}\text { TCTAL FINAI } \\
\text { DEMAND SECIORS }\end{array}$ & 798,504 & $20 \pi, 619$ & 1.508 .763 & 964.372 & - & $1,051,8 \in 3$ & 317,515 & 802,554 & $5,645,190$ & $74 \%$ \\
\hline $\begin{array}{l}\text { TRANSFORHATIC } \\
\text { FLECTRICITY:ERN. } \\
\text { PETR OLEOH EECDOCTS } \\
\text { NATORAL GAS } \\
\text { SYNTHETICS }\end{array}$ & $\begin{array}{r}43,085 \\
-429,426 \\
= \\
-\end{array}$ & $\begin{array}{r}3,079 \\
-172,000 \\
-\end{array}$ & $\begin{array}{r}-883,331 \\
-\end{array}$ & $\begin{array}{r}-388.212 \\
-\end{array}$ & $\begin{array}{r}1.843,589 \\
-\end{array}$ & $\begin{array}{r}86,0 \in 9 \\
40,9 \in 7 \\
-135,150\end{array}$ & $\begin{array}{r}2,183,665 \\
- \\
282,607\end{array}$ & $\begin{array}{r}-632,977 \\
- \\
-\end{array}$ & $\begin{array}{r}1,682,922 \\
11,687 \\
147,419\end{array}$ & $\begin{array}{r}22 \% \\
0 \%\end{array}$ \\
\hline $\begin{array}{l}\text { NET FOFL OSEC } \\
\text { I TRANSFOFIATION }\end{array}$ & $-385,341$ & -168.9 .21 & $-883,331$ & $-388,212$ & $1,843,689$ & $-8,153$ & $2,466,275$ & $-632,977$ & $1,842,028$ & $24 \%$ \\
\hline $\begin{array}{l}\text { TCTAL GROSS FLORS } \\
\text { LCSSES \& CBISSIONS }\end{array}$ & $\begin{array}{r}847,539 \\
52,3 \geq 2\end{array}$ & $\begin{array}{r}204,698 \\
4\end{array}$ & $1.508,763$ & $\begin{array}{l}964,372 \\
-38,039\end{array}$ & $\begin{array}{r}1,843,689 \\
76,485\end{array}$ & $\begin{array}{r}1,178,899 \\
-31,856\end{array}$ & $\begin{array}{r}2,783,790 \\
37,681\end{array}$ & $\begin{array}{r}802,554 \\
66,591\end{array}$ & $\begin{array}{r}7,487,218 \\
163,256\end{array}$ & $\begin{array}{r}82 \% \\
2 \%\end{array}$ \\
\hline $\begin{array}{l}\text { SOFPLY OF ENEBGY } \\
\text { FOSS IL FUEI } \\
\text { HYDRCELECTEIC } \\
\text { NOCL FAR } \\
\text { GEC. ESOLAR }\end{array}$ & $\begin{array}{l}- \\
-\end{array}$ & 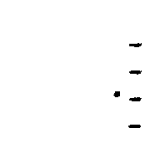 & $\begin{array}{l}- \\
\overline{-} \\
-\end{array}$ & $\begin{array}{l}- \\
- \\
-\end{array}$ & $\begin{array}{r}526, i 81 \\
- \\
-\end{array}$ & $\begin{array}{r}728,144 \\
- \\
-\end{array}$ & $\begin{array}{r}1,097,220 \\
= \\
=\end{array}$ & $\begin{array}{r}47,243 \\
146,041 \\
4,947\end{array}$ & $\begin{array}{r}2,351,545 \\
47,243 \\
146,041 \\
4,947\end{array}$ & $\begin{array}{r}92 \% \\
2 \% \\
6 \% \\
0 \%\end{array}$ \\
\hline TCTAL SOPPIY & - & - & - & - & 526,181 & 728,147 & $1,097,22 \mathrm{C}$ & 198,231 & $2,549,776$ & \\
\hline
\end{tabular}

\begin{tabular}{l}
$\begin{array}{l}\text { NET IM PORTS } \\
\text { CP R ZGION }\end{array}$ \\
\hline
\end{tabular}


REGIONAL ENE EGY EALANCE STATEMENT
PIES MID MID SCENARIO

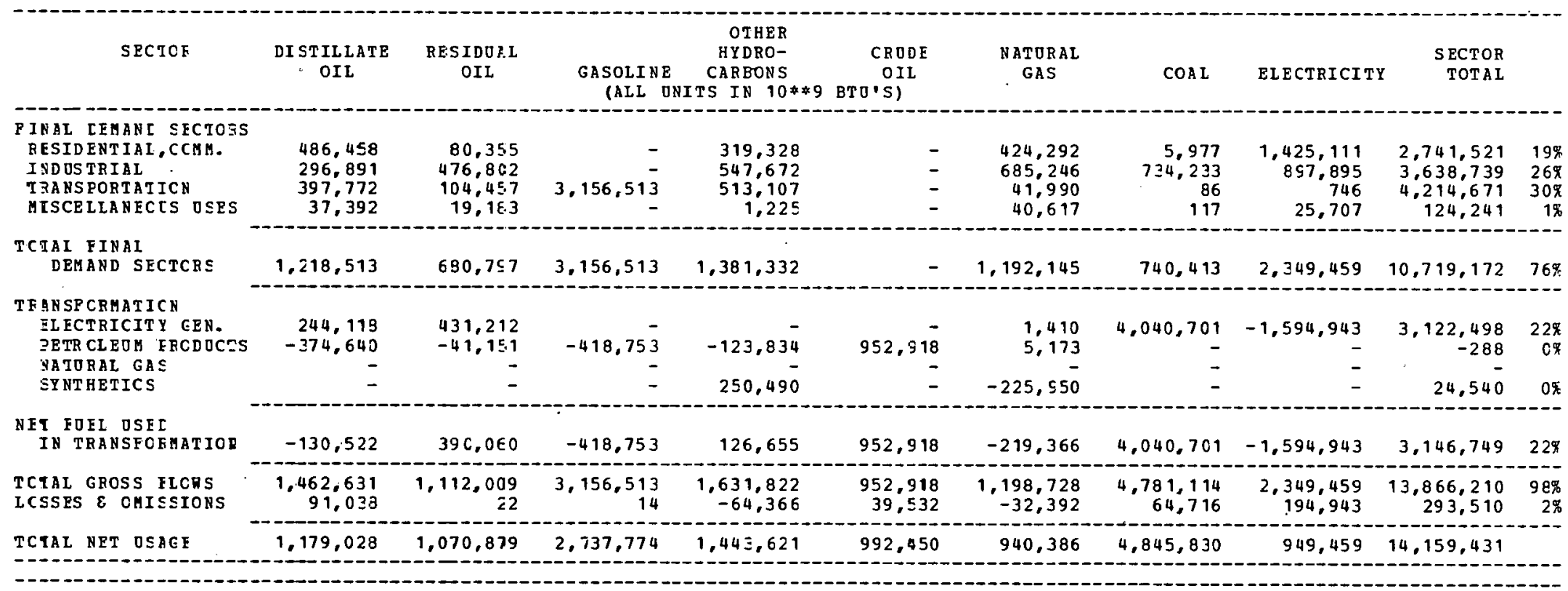

\begin{tabular}{|c|c|c|c|c|c|c|c|c|c|c|}
\hline SOEPLY OF ENERGY & & & & & & & & & & \\
\hline FOSSII FOEI & - & - & - & - & $1,058,827$ & 441,970 & $5,181,761$ & - & $6,682,558$ & $91 \%$ \\
\hline BY DRCELECTFIC & - & - & - & - & - & - & - & $\varepsilon 8,288$ & 88,288 & $1 \%$ \\
\hline DOCL EAR & - & - & - & - & - & - & - & 571,712 & 571,712 & $8 \%$ \\
\hline GEC. \&SOLAR & - & - & - & - & - & - & - & - & - & \\
\hline TCIAL SOPEIY & - & - & - & - & $1,058,827$ & 441,970 & $5,181,761$ & 660,000 & $7,342,558$ & \\
\hline
\end{tabular}

\section{NET IM FORTS}

CP R BGION

CP REGION

$1,179,028$

$1,070,879$

$2,737,774$

$1,443,621$

$-66.376$

$498,416 \cdot-335,930$

$289,459 \quad 6,816,873$

\section{NOTES:}
TRANSECRMATICN LOSS FOR
RANSFCRUATICN LOSS FOR ELECTRICITY GEN.
TRANSPCRAATICN LCSS POR
$=66.19 \%$
PETROLEOM FRODOCTS $=-0.03 \%$
TRAN SPCRAAI CN LCSS POR
NATORAL GAS
$=0.0 \%$ 
REGIONAL ENERGY PALANCE STATEMENT

\begin{tabular}{|c|c|c|c|c|c|c|c|c|c|c|}
\hline SECTCE & $\begin{array}{c}\text { DI ST ILLATE } \\
\text { כIL. }\end{array}$ & $\begin{array}{l}\text { RESIDOAL } \\
\text { OIL }\end{array}$ & $\begin{array}{l}\text { GASOLISE } \\
\text { (ALL ENG }\end{array}$ & $\begin{array}{c}\text { OTBER } \\
\text { BYDBO- } \\
\text { CARBONS } \\
\text { TS IN } 10 * 9\end{array}$ & $\begin{array}{c}\text { CRODE } \\
\text { OIL } \\
\text { BTU'S) }\end{array}$ & $\begin{array}{l}\text { NATORAL } \\
\text { GAS }\end{array}$ & $\cos 1$ & ELECTRICITY & $\begin{array}{l}\text { SECTOR } \\
\text { TOTAL }\end{array}$ & \\
\hline $\begin{array}{l}\text { FINIL CFHANL SECIOAS } \\
\text { RESIDRNTIAL,CCMM. } \\
\text { IND OSTRIAL } \\
\text { TRANSFORTATICN } \\
\text { MISCELLANEOCS USES }\end{array}$ & $\begin{array}{r}53,681 \\
33,391 \\
267,076 \\
7,631\end{array}$ & $\begin{array}{r}5,193 \\
51,658 \\
24,758 \\
5,064\end{array}$ & $1,141,509$ & $\begin{array}{r}125.715 \\
267.985 \\
69.433 \\
447\end{array}$ & $\begin{array}{l}- \\
\overline{-}\end{array}$ & $\begin{array}{r}208,3 \in 1 \\
558,2 \in 4 \\
6,643 \\
10,719\end{array}$ & $\begin{array}{r}2,091 \\
379,743 \\
4 \\
12\end{array}$ & $\begin{array}{r}594,815 \\
749,780 \\
- \\
5,559\end{array}$ & $\begin{array}{r}989,856 \\
2,040,826 \\
1,509,423 \\
31,432\end{array}$ & $\begin{array}{r}14 \% \\
29 \% \\
22 \% \\
0 \%\end{array}$ \\
\hline $\begin{array}{l}\text { TCTAL FINAL } \\
\text { DEHAND SECTCRS }\end{array}$ & $36.3,779$ & 36,673 & $1,141,509$ & 453,580 & - & 783,927 & 381,855 & $1,350,154$ & $4,571,537$ & $56 \pi$ \\
\hline $\begin{array}{l}\text { TR ANSFCRMATICN } \\
\text { FL ECTRICITY CEN. } \\
\text { PETR OLEOK FECDOCTS } \\
\text { NATURAL GAS } \\
\text { SY NTHETICS }\end{array}$ & $\begin{array}{r}173,210 \\
-373,753 \\
. \quad-\end{array}$ & $\begin{array}{r}38,296 \\
-58,847 \\
- \\
-\end{array}$ & $\begin{array}{r}-659,49 \overline{1} \\
-\end{array}$ & $\begin{array}{r}-560,96 \overline{2} \\
- \\
-\end{array}$ & $\begin{array}{r}1,557,011 \\
- \\
-39,608\end{array}$ & $\begin{array}{r}109,2 \approx \overline{4} \\
- \\
-\end{array}$ & $\begin{array}{r}2,926,090 \\
= \\
100,843\end{array}$ & $\begin{array}{r}-1,073,698 \\
- \\
-\end{array}$ & $\begin{array}{r}2,063,898 \\
13,170 \\
- \\
61,235\end{array}$ & $\begin{array}{r}30 \% \\
0 \%\end{array}$ \\
\hline $\begin{array}{l}\text { NET FUEL OSFC } \\
\text { IN TRANSPEATION }\end{array}$ & $-2(), 553$. & $-21), 551$ & -659.491 & -550.962 & 1.517 .403 & $109,2=4$ & $3,026,933$ & $-1,073,698$ & $2,138,303$ & $31 \%$ \\
\hline $\begin{array}{l}\text { TCIAL GROSS FLCWS } \\
\text { LCSSES \& OAISSIONS }\end{array}$ & $\begin{array}{r}5 \vdots 5,939 \\
33,423\end{array}$ & $\begin{array}{r}124,969 \\
2\end{array}$ & $\begin{array}{r}1,141,509 \\
5\end{array}$ & $\begin{array}{l}163.580 \\
-18.285\end{array}$ & $\begin{array}{r}1,557,011 \\
64,593\end{array}$ & $\begin{array}{l}893,211 \\
-24,1 \equiv 6\end{array}$ & $\begin{array}{r}3,408,783 \\
46,141\end{array}$ & $\begin{array}{r}1,350,154 \\
112,027\end{array}$ & $\begin{array}{r}6,709,840 \\
213,771\end{array}$ & $\begin{aligned} 37 \pi \\
3 \pi\end{aligned}$ \\
\hline TCTAL NET OSAEE & 195,649 & 65,123 & 482,022 & $-115,668$ & $1.581,997$ & 869,074 & $3,454,927$ & 388,483 & $6,923,612$ & \\
\hline $\begin{array}{l}\text { SOFFLY OF ENEGGY } \\
\text { FOSSIL FOEI } \\
\text { HY LROELECIEIC } \\
\text { NOCLEAR } \\
\text { GEO. ESOLAR }\end{array}$ & $\bar{z}$ & $\begin{array}{l}- \\
-\end{array}$ & $\begin{array}{l}\bar{z} \\
\bar{z}\end{array}$ & $\begin{array}{l}- \\
\overline{-} \\
-\end{array}$ & $\begin{array}{r}340,397 \\
- \\
-\end{array}$ & $\begin{array}{r}148,084 \\
- \\
-\end{array}$ & $\begin{array}{r}5,377,734 \\
- \\
-\end{array}$ & $\begin{array}{r}78,449 \\
487,609\end{array}$ & $\begin{array}{r}5,866,215 \\
78,449 \\
487,609 \\
-\end{array}$ & $\begin{array}{r}31 \% \\
1 \% \\
8 \%\end{array}$ \\
\hline TCTAI SOPEIY & - & - & - & - & 340,397 & $148,0 \varepsilon 4$ & $5,377,734$ & 566,058 & $6,432,273$ & \\
\hline
\end{tabular}

\begin{tabular}{l}
$\begin{array}{l}\text { NET IM FORTS } \\
\text { CP REGION }\end{array}$ \\
\hline
\end{tabular}


REGIONAL ENEKGY EALANCE STLTEMENT

PIES MID MID SCENARIO

\begin{tabular}{|c|c|c|c|c|c|c|c|c|c|c|}
\hline SECTOK & $\begin{array}{l}\text { IISTILLBTE } \\
\text { OIL }\end{array}$ & $\begin{array}{l}\text { RESIDUAL } \\
\text { OIL }\end{array}$ & $\begin{array}{l}\text { GASOLINE } \\
\text { (ALL O }\end{array}$ & $\begin{array}{c}\text { OTHER } \\
\text { HYDRO- } \\
\text { CARBONS } \\
\text { NITS IN } 10 \%\end{array}$ & $\begin{array}{c}\text { CROCE } \\
\text { OIL } \\
\text { BTO'S) }\end{array}$ & $\begin{array}{l}\text { NATORAL } \\
\text { GAS }\end{array}$ & $\operatorname{COAI}$ & BLECTRICITY & $\begin{array}{r}\text { SECTOR } \\
\text { TOTAL }\end{array}$ & \\
\hline $\begin{array}{l}\text { PINIL CEMANC SECTCRS } \\
\text { FESIDENTIAL, CCMA. } \\
\text { INDOSTRIAL } \\
\text { JRANSFCRTATICN } \\
\text { WISCELLANECS OSES }\end{array}$ & $\begin{array}{r}132,070 \\
241,318 \\
452,322 \\
46,641\end{array}$ & $\begin{array}{r}30,495 \\
906,069 \\
205,0153 \\
39,252\end{array}$ & $2,012,00 \overline{1}$ & $\begin{array}{r}292,401 \\
4,509,485 \\
269,683 \\
.848\end{array}$ & $\begin{array}{l}- \\
- \\
-\end{array}$ & $\begin{array}{r}823,210 \\
7,277,704 \\
90,588 \\
18,435\end{array}$ & $\begin{array}{r}26 \\
143,041 \\
4 \\
-\end{array}$ & $\begin{array}{r}678,058 \\
687,750 \\
- \\
9,769\end{array}$ & $\begin{array}{r}1,956,260 \\
13,770,367 \\
3,029,651 \\
114,945\end{array}$ & $\begin{array}{r}9 \% \\
64 \% \\
14 \% \\
1 \%\end{array}$ \\
\hline $\begin{array}{l}\text { CIAI FINAL } \\
\text { DEMAND SECTCRS }\end{array}$ & 872,351 & $1,180,869$ & $2,012,001$ & $5,072,417$ & - & $8,209,937$ & 148,071 & $1,375,577$ & $18,871,223$ & $88 \%$ \\
\hline $\begin{array}{l}\text { E ANSFCRMATICN } \\
\text { ELFCTRICITY GEN. } \\
\text { PETROLEO FRODOCTS } \\
\text { NATURAL GAS } \\
\text { SYNTHETICS }\end{array}$ & $\begin{array}{r}115,469 \\
-3,647,332 \\
= \\
-\end{array}$ & $\begin{array}{r}-331,450 \\
- \\
-\end{array}$ & $\begin{array}{r}-6,143,42 \bar{z} \\
-\end{array}$ & $\begin{array}{r}-6,070,25 \overline{-} \\
-\end{array}$ & $\begin{array}{r}15,066,55 \bar{z} \\
-248,511\end{array}$ & $\begin{array}{r}1,295,910 \\
1,262,458 \\
-\end{array}$ & $\begin{array}{r}1,969,673 \\
- \\
-\end{array}$ & $\begin{array}{r}-1,114,112 \\
- \\
-\end{array}$ & $\begin{array}{r}2,266,940 \\
136,540 \\
-248,511\end{array}$ & $\begin{array}{r}11 \% \\
1 \%\end{array}$ \\
\hline $\begin{array}{l}\text { AI FOFL OSEI } \\
\text { IN TRANSPCEATICN }\end{array}$ & $-3,531,863$ & $-331,450$ & $-6,143,428$ & $-6,070 \quad 59$ & $14,818,041$ & $2,558,368$ & $1,969,673$ & $-1,114,112$ & $2,154,969$ & $10 \%$ \\
\hline $\begin{array}{l}\text { ZCIAL GROSS FICRS } \\
\text { LCSSES \& CMISSIONS }\end{array}$ & $\begin{array}{r}987,820 \\
61,484\end{array}$ & $\begin{array}{r}1,180,869 \\
23\end{array}$ & $\begin{array}{r}2,012,001 \\
9\end{array}$ & $\begin{array}{r}5,072,417 \\
-200,078\end{array}$ & $\begin{array}{r}15,066,552 \\
625,040\end{array}$ & $\begin{array}{r}10,768,305 \\
-290,982\end{array}$ & $\begin{array}{r}2,117,744 \\
29,665\end{array}$ & $\begin{array}{r}1,375,577 \\
114,137\end{array}$ & $\begin{array}{r}21,274,7 C 3 \\
338,299\end{array}$ & $\begin{array}{r}100 \% \\
2 \%\end{array}$ \\
\hline TAI NET USAGE & $-2,598,028$ & 849,442 & $-4,131,417$ & $-1,197,920$ & $15,443,082$ & $10,477,322$ & $2,146,409$ & 375,602 & $21,364,492$ & \\
\hline
\end{tabular}

\begin{tabular}{|c|c|c|c|c|c|c|c|c|c|c|}
\hline SUEFLY OF ENERGY & & & & & & & & & & \\
\hline FOSS IL FOEI & - & - & - & - & $8,581,3 \in 9$ & $7,899,012$ & $1,189,171$ & - & $17,6 \in 9,552$ & $\begin{array}{r}98 \% \\
0 \%\end{array}$ \\
\hline HY LR CEL ECT FIC & - & - & - & - & . - & - & - & 32,832 & 32,832 & $=0 \%$ \\
\hline NOCLEAR & - & - & - & $\cdot-$ & - & - & - & 262,959 & 262,959 & $\begin{array}{l}1 \% \\
0 \%\end{array}$ \\
\hline GEC. \&SOLAR & - & - & - & - & - & - & - & 33,434 & 33,434 & $0 \%$ \\
\hline TCIAI SUPPLY & - & - & - & - & $8,581,369$ & $7,899,012$ & $1,189,171$ & 329,225 & $17,998,777$ & \\
\hline
\end{tabular}

NET IMPORTS
OF REGION


REG=ONAL ENEEGY BALANCE STATBMENT

EIES MID MID SCENARIO

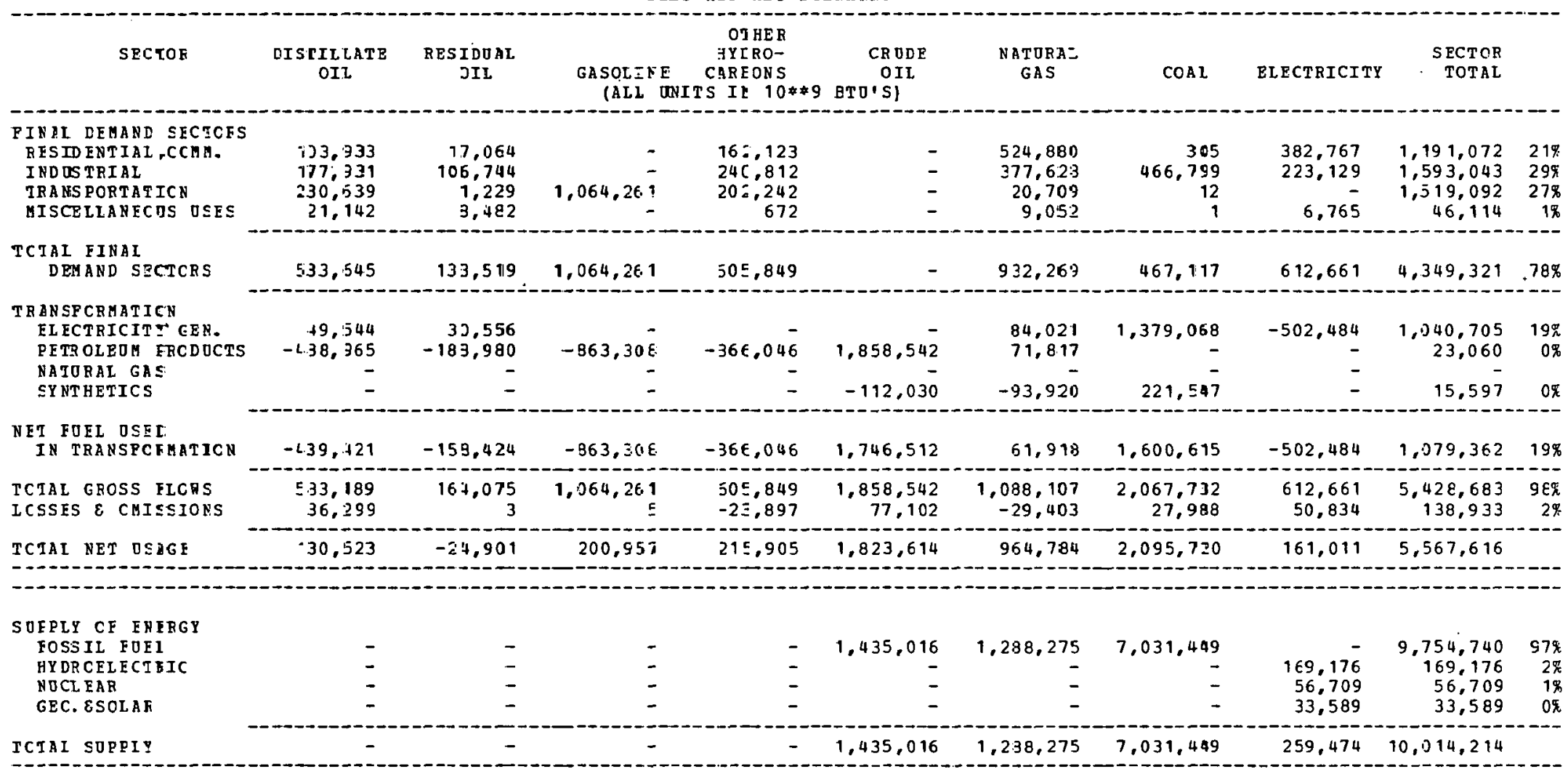

NET IY FORTS

CF REGION

\section{NOTES:}

TRAYSFCRMATICN LCSS FOR TRABSFCBMATICN ICSS POR TRARSFCREATICN LCSS YO TRAGSPORAATICN LCSS POR

EL 3CTRICITY GEN.

DETEDLEUM PRCDOCIS $\quad=67.448$

$\begin{array}{ll}\text { ETEDLEUM ERCD OCTS } & =1.198 \\ \text { ATUZALGAS } & =0.08\end{array}$

SYNTAETICS
$=7.048$ 
REGICNAL ENE FGY EALANCE STATEMENT
PIES MID MID SCENARIO

\begin{tabular}{|c|c|c|c|c|c|c|c|c|c|c|}
\hline SECTOF & $\begin{array}{l}\text { DIST ILLATE } \\
\text { OIL }\end{array}$ & $\begin{array}{l}\text { RESIDOAL } \\
\text { OIL }\end{array}$ & $\begin{array}{l}\text { GASOLINE } \\
\text { (ALL } 0\end{array}$ & $\begin{array}{c}\text { OTRER } \\
\text { HYDRO- } \\
\text { CARBONS } \\
\text { NITS IN } 10 * * 9\end{array}$ & $\begin{array}{c}\text { CRODE } \\
\text { OIL } \\
\text { BTO'S) }\end{array}$ & $\begin{array}{l}\text { NATURAL } \\
\text { GAS }\end{array}$ & $\operatorname{COAL}$ & ELECTRICITY & $\begin{array}{r}\text { SECTOR } \\
\text { TOTAL }\end{array}$ & \\
\hline 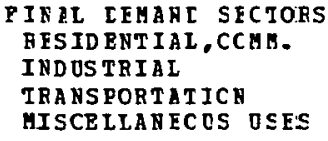 & $\begin{array}{r}202,303 \\
279,709 \\
306,828 \\
15,149\end{array}$ & $\begin{array}{r}28,9+9 \\
461,079 \\
140,670 \\
4,621\end{array}$ & $2,189,92 \overline{-}$ & $\begin{array}{r}191,697 \\
798,328 \\
620,630 \\
109\end{array}$ & $\overline{-}$ & $\begin{array}{r}643,843 \\
877,926 \\
90,104 \\
17,509\end{array}$ & $\begin{array}{r}404 \\
165,114 \\
14 \\
7\end{array}$ & $\begin{array}{r}797,821 \\
462,419 \\
901 \\
11,662\end{array}$ & $\begin{array}{r}1,865,017 \\
3,064,545 \\
3,349,069 \\
49,057\end{array}$ & $\begin{array}{r}20 \% \\
33 \% \\
37 \% \\
11\end{array}$ \\
\hline $\begin{array}{l}\text { TCTAL FINAI } \\
\text { DEHAND SECTCRS }\end{array}$ & 803,989 & 635.239 & $2,189,922$ & $1,610,764$ & - & $1,629,382$ & $16 \subseteq, 539$ & $1,292,803$ & $8,327,688$ & $91 \%$ \\
\hline $\begin{array}{l}\text { TRANSPCRHATICN } \\
\text { ELECTRICITY GEN. } \\
\text { PETR CIEOM FBODOCIS } \\
\text { NATORAL GAS } \\
\text { SYNTHETICS }\end{array}$ & $\begin{array}{r}82,121 \\
-1,055,554 \\
=\end{array}$ & $\begin{array}{r}411,944 \\
-1,033,933 \\
-\end{array}$ & $\begin{array}{r}-2,469,070 \\
-\end{array}$ & $\begin{array}{r}-1,694,959 \\
60,020\end{array}$ & $6,253,892$ & $\begin{array}{r}208,164 \\
22,138 \\
-54,300\end{array}$ & $\begin{array}{r}78,500 \\
- \\
-\end{array}$ & $\begin{array}{r}-280,395 \\
- \\
-\end{array}$ & $\begin{array}{r}500,334 \\
22,514 \\
5,720\end{array}$ & $\begin{array}{l}5 \% \\
0 \%\end{array}$ \\
\hline $\begin{array}{l}\text { NFT FOFL OSEL } \\
\text { IN TRANSPOFBATION }\end{array}$ & $-973,433$ & $-621,989$ & $-2,469,070$ & $-1,634,939$ & $6,253,892$ & 176,002 & 78,500 & $-280,395$ & 528,568 & $6 \%$ \\
\hline $\begin{array}{l}\text { TCIAL GROSS FLCRS } \\
\text { LCSSES E ONISSIONS }\end{array}$ & $\begin{array}{r}886,110 \\
55,154\end{array}$ & $\begin{array}{r}1,047,233 \\
21\end{array}$ & $2,189,922$ & $\begin{array}{r}1,670,784 \\
-65,902\end{array}$ & $\begin{array}{r}6,253,992 \\
259,444\end{array}$ & $\begin{array}{r}1,859,684 \\
-50,252\end{array}$ & $\begin{array}{r}244,039 \\
3,303\end{array}$ & $\begin{array}{r}1,292,803 \\
107,268\end{array}$ & $\begin{array}{r}8,856,256 \\
309,046\end{array}$ & $\begin{array}{r}97 \% \\
3 \%\end{array}$ \\
\hline
\end{tabular}

\begin{tabular}{|c|c|c|c|c|c|c|c|c|c|c|}
\hline SOEPLY OF FHERGY & & & & & & & & & & \\
\hline FOSSIL FOEI & - & - & - & - & $7,189,464$ & $6,960,551$ & 150,320 & - & $14,300,335$ & $93 \%$ \\
\hline BYDRCELECTEIC & - & - & - & - & - & - & - & 743,378 & 743,378 & $5 \%$ \\
\hline NOCL PAR & - & - & - & - & - & - & - & 307,890 & 307.890 & $2 \%$ \\
\hline SEC. \& SOL A R & - & $=$ & - & - & - & - & - & 75,492 & 75,492 & $0 \%$ \\
\hline TCTAL SUPPIY & - & - & - & - & $7,189,464$ & $6,960,551$ & 150,320 & $1,126,760$ & $15,427,095$ & \\
\hline
\end{tabular}

NET IM FORTS
CE REGION


THIS PAGE

\section{WAS INTENTIONALLY LEFT BLANK}


State Tables for 1990 
THIS PAGE

\section{WAS INTENTIONALLY LEFT BLANK}


REGICNAL ENE EGY EALANCE STATEMENT

\begin{tabular}{|c|c|c|c|c|c|c|c|c|c|c|}
\hline SECIOE & $\begin{array}{l}\text { CISTILLATE } \\
\text { OIL }\end{array}$ & $\begin{array}{l}\text { RESIDEAL } \\
\text { OII }\end{array}$ & $\begin{array}{l}\text { GASOLINE } \\
\quad \text { GLL O }\end{array}$ & $\begin{array}{l}\text { OTHER } \\
\text { HYDRO- } \\
\text { CAREONS } \\
\text { TS IN } 10 * 9\end{array}$ & $\begin{array}{c}\text { CRIDE } \\
\text { OIL } \\
\text { BTO'S) }\end{array}$ & $\begin{array}{l}\text { NATURAL } \\
\text { GAS }\end{array}$ & $\operatorname{COAL}$ & ELECTRICITY & $\begin{array}{l}\text { SECTOR } \\
\text { TOTAL }\end{array}$ & \\
\hline $\begin{array}{l}\text { FIKAL EEMANI SECTORS } \\
\text { BESIDENTIAL, CCAM. } \\
\text { IND OSTRIAL } \\
\text { TRANSPORTATICA } \\
\text { BISCELLANECES OSES }\end{array}$ & $\begin{array}{r}13,124 \\
13,785 \\
68,954 \\
3,195\end{array}$ & $\begin{array}{r}1,882 \\
19,416 \\
22,143 \\
1,679\end{array}$ & $301,63 \overline{2}$ & $\begin{array}{r}32,901 \\
75,090 \\
11,877 \\
144\end{array}$ & $\begin{array}{l}\overline{-} \\
\overline{-}\end{array}$ & $\begin{array}{r}49,993 \\
165,086 \\
2,590 \\
3,355\end{array}$ & $\begin{array}{r}261 \\
148,929 \\
1 \\
5\end{array}$ & $\begin{array}{r}154,986 \\
159,803 \\
- \\
1,591\end{array}$ & $\begin{array}{r}253,147 \\
582,109 \\
407,197 \\
9,969\end{array}$ & $\begin{array}{r}14 \% \\
32 \% \\
22 \% \\
1 \%\end{array}$ \\
\hline $\begin{array}{l}\text { TSTAI FINAL } \\
\text { DEMAND SBCTCRS }\end{array}$ & 99,058 & 45,120 & $30 \pi, 632$ & 120,012 & - & 221,024 & 149,196 & 316,380 & $1,252,422$ & $.68 \%$ \\
\hline $\begin{array}{l}\text { TEINSPCRMATICN } \\
\text { EL FCTRICITY EEN. } \\
\text { EETR OLEOM ERCDOCTS } \\
\text { NATURAL GAS } \\
\text { SYNTHETICS }\end{array}$ & $\begin{array}{r}40,582 \\
-106,853 \\
- \\
-\end{array}$ & $\begin{array}{r}-6,602 \\
- \\
-\end{array}$ & $\begin{array}{r}-176,238 \\
-\end{array}$ & $\begin{array}{r}-185,465 \\
-\end{array}$ & $\begin{array}{r}439.758 \\
-\end{array}$ & $\begin{array}{r}39,501 \\
. \quad-\end{array}$ & $\begin{array}{r}763,222 \\
- \\
-\end{array}$ & $\begin{array}{r}-274,979 \\
- \\
-\end{array}$ & $\begin{array}{r}528,825 \\
4,102 \\
-\end{array}$ & $\begin{array}{r}29 \% \\
0 \%\end{array}$ \\
\hline $\begin{array}{l}\text { NET FOEL OSEL } \\
\text { IN TRANSPOFUATION }\end{array}$ & $-66,271$ & $-6, \in 02$ & $-176,238$ & $-185,465$ & 439,758 & 39,501 & 763,222 & $-274,979$ & 532,927 & $29 \%$ \\
\hline $\begin{array}{l}\text { TCTAL GROSS FLCRS } \\
\text { LCSSES } \varepsilon \text { CMISSIONS }\end{array}$ & $\begin{array}{r}139,640 \\
8,691\end{array}$ & $\begin{array}{r}45,120 \\
0\end{array}$ & $\begin{array}{r}301,632 \\
1\end{array}$ & $\begin{array}{r}120,012 \\
-4,733\end{array}$ & $\begin{array}{r}439,758 \\
18,243\end{array}$ & $\begin{array}{r}260,525 \\
-7,039\end{array}$ & $\begin{array}{r}912,418 \\
12,350\end{array}$ & $\begin{array}{r}316,380 \\
26,251\end{array}$ & $\begin{array}{r}1,785,349 \\
53,765\end{array}$ & $\begin{array}{r}97 \% \\
3 \%\end{array}$ \\
\hline TCTAL NET OSAGE & 41,478 & 38,518 & 125,395 & $-70,186$ & 458.002 & 253,485 & 924,768 & 67,652 & $1,839,114$ & \\
\hline
\end{tabular}

\begin{tabular}{|c|c|c|c|c|c|c|c|c|c|c|}
\hline $\begin{array}{l}\text { SJFELY OF ENERGY } \\
\text { FOSSIL FOEI }\end{array}$ & - & - & - & - & 48,399 & 35,543 & 325,424 & - & 409,366 & $71 \%$ \\
\hline HYDRCELECTEIC & - & - & - & - & - & - & - & 36,011 & 36,011 & $E \mathbb{R}$ \\
\hline NOCL EAR & - & - & - & - & - & - & - & 132,701 & 132,701 & $23 x$ \\
\hline GEO. \&SOLAR & - & - & - & - & - & - & - & - & - & \\
\hline TOTAL SUPPIY & - & - & - & - & 48,399 & 35,543 & 325,424 & 168,712 & 578,078 & \\
\hline
\end{tabular}

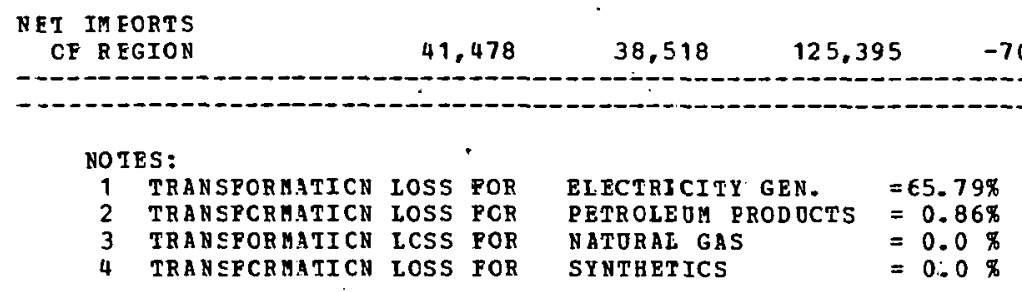


REGIONAL ERZEGY EALAMCE STATEMENT

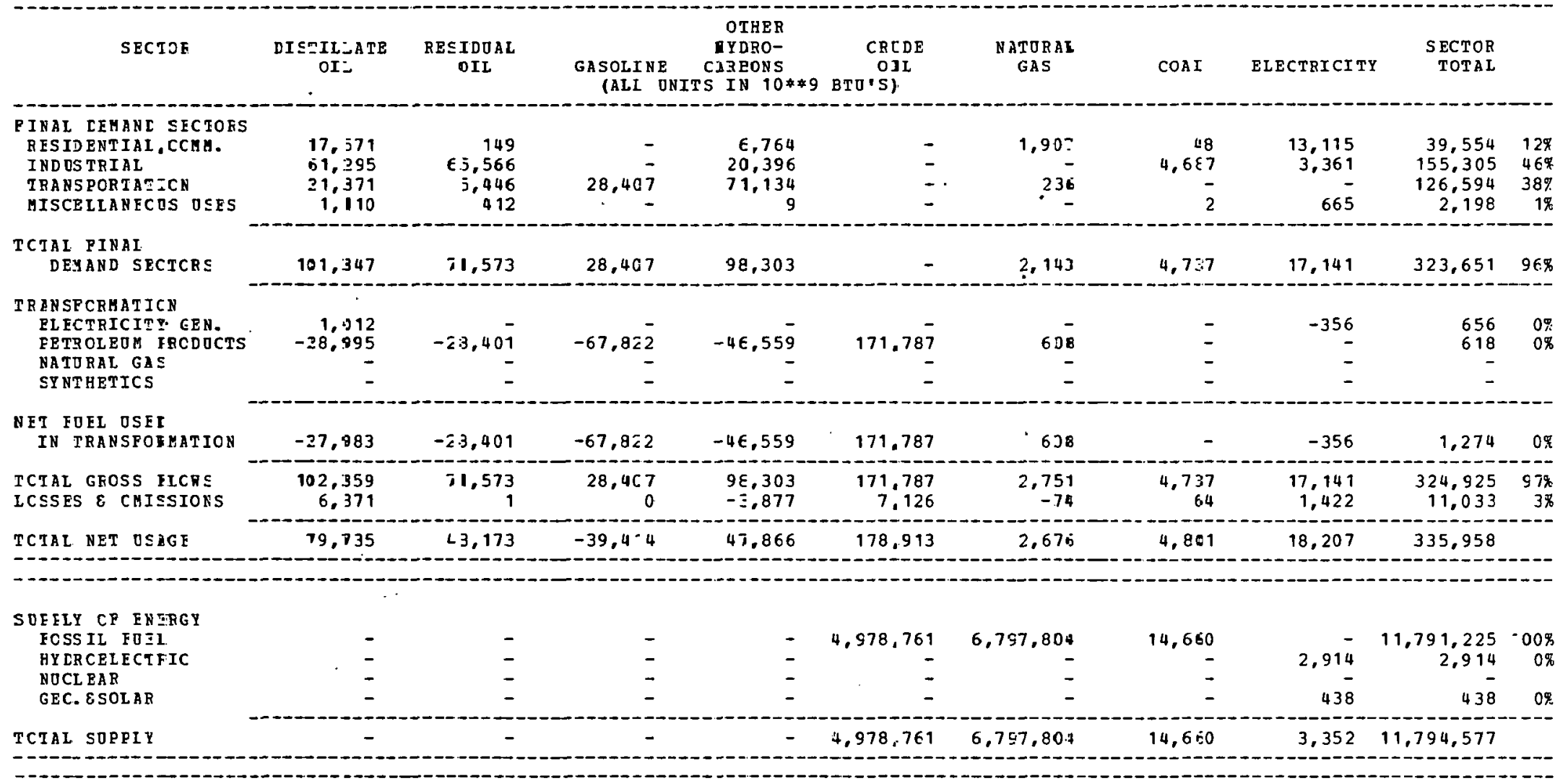

\section{NET IM FCBTS}
OF REGION
79,735
43,173
$-39,414$
$47,866 \quad-4,799,847 \quad-6,705,127$
$-9, \varepsilon 58$
$14,855-11,458,618$

TIES:

1 TRAYSFCRAATICN LOSS FO

TRANEPCRDATICN LOSS PCR

3 TRANEFORATIICN LCSS POR
4 TRAN EPCRAAICN LCSS FOR

ELECIRICITY EEN.

PRTAOLZUA PRCD OCTS $=0.36 \%$

$=0.0 \%$ 
REGICNAL ENEFGY EALANCE STATEMENT

CNAL ENEFGY EALANCE
PIES MID MID SCENARIO

\begin{tabular}{|c|c|c|c|c|c|c|c|c|c|}
\hline SECTCE & $\begin{array}{l}\text { DISTIILATE } \\
\text { OIL }\end{array}$ & $\begin{array}{l}\text { RESICOAL } \\
\text { OIL }\end{array}$ & $\begin{array}{l}\text { GASOLINE } \\
\text { (ALL ONI }\end{array}$ & $\begin{array}{c}\text { OTHER } \\
\text { HYDRC- } \\
\text { CARBONS } \\
\text { TS IN } 10 * * 9\end{array}$ & $\begin{array}{l}\text { CRODE } \\
\text { OIL } \\
\text { BTO'S) }\end{array}$ & $\begin{array}{l}\text { NATURAL } \\
\text { GAS }\end{array}$ & $\operatorname{COAL}$ & ELECTRICITY & $\begin{aligned} \text { SECTOR } \\
\text { TOTAL }\end{aligned}$ \\
\hline $\begin{array}{l}\text { ZINLI CEMANL SECTOES } \\
\text { RESIDENTIAI, CCAB. } \\
\text { IND OSTRIAL } \\
\text { TRANSPORTATICN } \\
\text { HISCELLANECS OSES }\end{array}$ & $\begin{array}{r}12,751 \\
8,079 \\
53,982 \\
1,176\end{array}$ & $\begin{array}{r}2.350 \\
9.282 \\
295\end{array}$ & $261,10 \overline{-}$ & $\begin{array}{r}15.586 \\
27.844 \\
56.087 \\
9\end{array}$ & $\begin{array}{l}\overline{-} \\
\overline{-}\end{array}$ & $\begin{array}{r}66.365 \\
113.842 \\
6.882 \\
2.027\end{array}$ & $\begin{array}{r}10 \\
20,817 \\
2 \\
-\end{array}$ & $\begin{array}{r}68,337 \\
28,554 \\
- \\
895\end{array}$ & $\begin{array}{r}165,399 \\
208,418 \\
378,058 \\
4,402\end{array}$ \\
\hline $\begin{array}{l}\text { TCTAI FINAL } \\
\text { DEMAND SECTORE }\end{array}$ & 75,988 & 11.927 & 251,105 & 99.526 & - & 189,116 & 20,829 & 97,786 & 756,277 \\
\hline $\begin{array}{l}\text { TF ANSFORHATICN } \\
\text { ELECTRICITY GEN, } \\
\text { FETROLEDA FBCDOCTS } \\
\text { NATORAL GAS } \\
\text { SYNTHETICS }\end{array}$ & $\begin{array}{r}32,837 \\
-67,346 \\
=\end{array}$ & $\begin{array}{r}30,556 \\
-65,967 \\
-\end{array}$ & $\begin{array}{r}- \\
-157,531 \\
- \\
-\end{array}$ & $\begin{array}{r}- \\
-108,141 \\
- \\
-\end{array}$ & $\begin{array}{r}- \\
399,008 \\
-\end{array}$ & $\begin{array}{r}32.093 \\
1.412 \\
- \\
-\end{array}$ & $\begin{array}{r}147,064 \\
- \\
-\end{array}$ & $\begin{array}{r}-85,487 \\
- \\
-\end{array}$ & $\begin{array}{r}157,063 \\
1,435 \\
- \\
-\end{array}$ \\
\hline $\begin{array}{l}\text { NET FOFL OSEL } \\
\text { IN TRANSFOELATION }\end{array}$ & $-34,509$ & $-35,411$ & $-157,531$ & $-108,141$ & 399,008 & 33,505 & 147,064 & $-85,487$ & 158,498 \\
\hline $\begin{array}{l}\text { TCTAL GROSS FLCRS } \\
\text { ICSSES E CBISSICNS }\end{array}$ & $\begin{array}{r}108,825 \\
6,773\end{array}$ & $\begin{array}{r}42 ;, 4 \varepsilon 3 \\
0\end{array}$ & $\begin{array}{r}261,105 \\
1\end{array}$ & $\begin{array}{l}99,52 \varepsilon \\
-3,925\end{array}$ & $\begin{array}{r}3 c, 008 \\
16,552\end{array}$ & $\begin{array}{r}222,621 \\
-6,015\end{array}$ & $\begin{array}{r}167,893 \\
2,272\end{array}$ & $\begin{array}{r}97,786 \\
8,113\end{array}$ & $\begin{array}{r}914,775 \\
23,773\end{array}$ \\
\hline TOTAL NET OSAGE & $48,2 \leq 2$ & $-23,4 \varepsilon 3$ & 103,575 & $-12,5,40$ & $4: 5,560$ & 216,605 & 170,165 & 20,412 & 938,548 \\
\hline $\begin{array}{l}\text { SOEPLY OF RNERG } \\
\text { FOSS IL FOEL } \\
\text { HYDROEL ECTEIC } \\
\text { NOCL BAR } \\
\text { GEC. \&SOLAR }\end{array}$ & $\overline{-}$ & $\begin{array}{l}- \\
\overline{-} \\
-\end{array}$ & $\begin{array}{l}- \\
- \\
-\end{array}$ & $\begin{array}{l}\overline{-} \\
\overline{-} \\
-\end{array}$ & $\begin{array}{r}4,948 \\
- \\
-\end{array}$ & $\begin{array}{r}1,727 \\
- \\
-\end{array}$ & $\begin{array}{r}558,252 \\
- \\
-\end{array}$ & $\begin{array}{r}50.535 \\
49,435 \\
6.141\end{array}$ & $\begin{array}{r}564,927 \\
50,535 \\
49,435 \\
6,141\end{array}$ \\
\hline TCIAL SOPPIY & - & - & - & - & 4,948 & 1,727 & 558,252 & 106,111 & 671.038 \\
\hline
\end{tabular}

\section{NET IM ECRTS}

48,252

103,575

$-12,540$

410,612

214,878

$-388,086$

$-85,698$

267,510

-

NOTES:

$\begin{array}{lllll}\text { TRANSFCRMATICN } & \text { LOSS POR } & \text { ELECIRICITY GEN. } & =64.75 \% \\ \text { TRANSPCRAATICN } & \text { LOSS } & \text { PCR } & \text { PETRDIEOM FRODOCTS } & =0.36 \% \\ \text { TRANSPOREATICN } & \text { LCSS POR } & \text { NATORAL GAS } & =0.0 \% \\ \text { TRANSPCRATICN } & \text { LCSS POR } & \text { STNTHETICS } & =0.0 \%\end{array}$

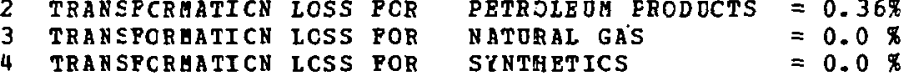


REGIONAL 3NE FGY EALANCZ STATEMENT

PIES MID MID SCENAZIO

\begin{tabular}{|c|c|c|c|c|c|c|c|c|c|c|}
\hline SECTOE & $\begin{array}{l}\text { DISTILLAIE } \\
\text { OIL }\end{array}$ & $\begin{array}{l}\text { RESIDOAL } \\
\text { OIL }\end{array}$ & $\begin{array}{l}\text { GASOLINE } \\
\quad \text { (ALI ONI }\end{array}$ & $\begin{array}{l}\text { OTHER } \\
\text { HYDRO- } \\
\text { CARBONS } \\
\text { TS IN } 10 * * 9\end{array}$ & $\begin{array}{c}\text { CRODE } \\
\text { OIL } \\
\text { BTO'S) }\end{array}$ & $\begin{array}{l}\text { NATJRAL } \\
\text { GAS }\end{array}$ & $\operatorname{COA} L$ & ELECTRICITY & $\begin{array}{l}\text { SECTCIR } \\
\text { TOTII }\end{array}$ & \\
\hline $\begin{array}{l}\text { FINAL CERANC SFCTOFS } \\
\text { RESIDENEIAL, CCAM. } \\
\text { IND OSTRIAL } \\
\text { TRANSPOFTATCN } \\
\text { WISCELLANECOS OSES }\end{array}$ & $\begin{array}{r}22,505 \\
55,573 \\
65,028 \\
3,53 E\end{array}$ & $\begin{array}{r}7,560 \\
198,648 \\
- \\
2,979\end{array}$ & $195,27 \overline{-}$ & $\begin{array}{r}29,945 \\
.158,331 \\
13,277 \\
58\end{array}$ & $\begin{array}{l}- \\
-\end{array}$ & $\begin{array}{r}99,017 \\
226,5-4 \\
5,741 \\
1,373\end{array}$ & $\begin{array}{r}6 \\
1 \cdot 076 \\
1 \\
-\end{array}$ & $\begin{array}{r}59,016 \\
66,315 \\
- \\
609\end{array}$ & $\begin{array}{r}218,0<9 \\
716,517 \\
279,3 \equiv 9 \\
8,557\end{array}$ & $\begin{array}{r}16 \% \\
53 \% \\
21 \% \\
1 \%\end{array}$ \\
\hline $\begin{array}{l}\text { TCIAI PINAL } \\
\text { DEMANC SECTCRS }\end{array}$ & 176,644 & 209,187 & $19 \leq, 292$ & 201,611 & - & 33.2 .705 & 11,083 & 125,940 & $1,222,462$ & $90 \%$ \\
\hline $\begin{array}{l}\text { TR ANSFCAMATICN } \\
\text { ELECTRIGITY GEN. } \\
\text { FETROLEOA FBCDOCTS } \\
\text { HATORAL GAS } \\
\text { SYNTHETICS }\end{array}$ & $\begin{array}{r}10,568 \\
-26,546 \\
-\end{array}$ & $\begin{array}{r}- \\
-1.640 \\
-\end{array}$ & $\begin{array}{r}- \\
-43,784 \\
- \\
-\end{array}$ & $\begin{array}{r}- \\
-46,076 \\
-\end{array}$ & $\begin{array}{r}109,25 \overline{-} \\
-106,383\end{array}$ & $\begin{array}{r}46,173 \\
9,813 \\
- \\
-\end{array}$ & $\begin{array}{r}290,287 \\
- \\
- \\
-\end{array}$ & $\begin{array}{r}-115,021 \\
- \\
-\end{array}$ & $\begin{array}{r}232,013 \\
1,019 \\
- \\
-106,383\end{array}$ & $\begin{array}{r}17 \% \\
0 \% \\
-7 \%\end{array}$ \\
\hline $\begin{array}{l}\text { VET FOEL OSEL } \\
\text { IN TRANSEOKHATION }\end{array}$ & $-15,978$ & $-1,640$ & $-43,7 \in 4$ & $-46,076$ & $2,8 \in \mathrm{g}$ & $55,99 ?$ & 290.287 & $-115,021$ & 126,643 & 98 \\
\hline $\begin{array}{l}\text { TCIAL GROSS FLORS } \\
\text { LCSSES \& CAISSIONS }\end{array}$ & $\begin{array}{r}197.212 \\
9.785\end{array}$ & $\begin{array}{r}209,187 \\
4\end{array}$ & $\begin{array}{r}195,292 \\
0\end{array}$ & $\begin{array}{r}201,611 \\
-7,952\end{array}$ & $\begin{array}{r}139,252 \\
4,5 \equiv 2\end{array}$ & $\begin{array}{l}38 E, 697 \\
-1 C, 503\end{array}$ & $\begin{array}{r}301.370 \\
4.079\end{array}$ & $\begin{array}{r}125,940 \\
10,449\end{array}$ & $\begin{array}{r}1,455,494 \\
10,395\end{array}$ & $\begin{array}{r}107.5 \\
18\end{array}$ \\
\hline TOYAL NET VSAGE & 140,451 & 207,551 & $151,5 C 8$ & 147,582 & $7.4 \mathrm{C1}$ & $37 \varepsilon, 194$ & 305.449 & $21,36 \varepsilon$ & $1,359,50^{7}$ & \\
\hline
\end{tabular}

\begin{tabular}{|c|c|c|c|c|c|c|c|c|c|c|}
\hline SOEELY OF ENERGY & - & - & & - & & & & & & \\
\hline EOSS IL FOEI & $\overline{-}$ & $\overline{-}$ & $=$ & $\overline{-}$ & 95,053 & 87,544 & 20.108 & - & $202,71^{\circ}$ & 799 \\
\hline $\begin{array}{l}\text { HY DROELECT BIC } \\
\text { NOCL EAR }\end{array}$ & $=$ & $=$ & $\overline{-}$ & - & - & - & - & $\begin{array}{l}14,969 \\
36,849\end{array}$ & 14,969 & $\begin{array}{r}58 \\
148\end{array}$ \\
\hline GEC. \&SOLAR & - & - & - & - & - & - & - & 3,061 & $3,06=$ & $\begin{array}{r}14 \pi \\
18\end{array}$ \\
\hline TCTAL SOPPIY & - & - & - & - & $\subseteq 5,059$ & 87.544 & 20,108 & 54,879 & $257,59 \mathrm{C}$ & \\
\hline
\end{tabular}

\section{NET IM PORTS}

OF R BGION

$14 C, 451$

207,551

151,503

147,582

$-27,65 ?$

290.650

285,341

$-33,510 \quad 1,101,917$

NO TES:
TRABSPCRMATICN IOSS POR
TRAISPCRAATICA LCSS POR
$\begin{array}{ll}\text { ELECTRICITY GEN. } & =66.86 \% \\ \text { PETROLE OM P BODOCTS } & =0.8 .6 \%\end{array}$
TRAISPORHATI CR LOSS POR
NAIURAL GAS
SYNTHETICS
$=* \# * * \%$ 
REGIONAL ENE EGY BALANCE STATEMENT
PIBS MID MID SCEMARIO

\begin{tabular}{|c|c|c|c|c|c|c|c|c|c|c|}
\hline SPCTOF & $\begin{array}{c}\text { DISTILIATE } \\
\text { OIL }\end{array}$ & $\begin{array}{l}\text { BESIIJAL } \\
\text { OIL }\end{array}$ & $\begin{array}{l}\text { GASOLIN } \\
\text { (ALL }\end{array}$ & $\begin{array}{c}\text { OTRER } \\
\text { RYDRO- } \\
\text { CARBONS } \\
\text { NITS IN } 10 * * 9\end{array}$ & $\begin{array}{c}\text { CRODE } \\
\text { OIL } \\
\text { BTO'S) }\end{array}$ & $\begin{array}{l}\text { NATURAL } \\
\text { GAS }\end{array}$ & $\operatorname{COAL}$ & ELECTRICITY & $\begin{array}{r}\text { SECTOR } \\
\text { TOTAL }\end{array}$ & \\
\hline 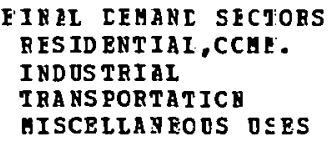 & $\begin{array}{r}26,273 \\
67,050 \\
199,261 \\
7,674\end{array}$ & $\begin{array}{r}1,792 \\
144,946 \\
112,943 \\
1,924\end{array}$ & $1,625,126$ & $\begin{array}{r}109,577 \\
518,710 \\
380,542 \\
64\end{array}$ & $\bar{z}$ & $\begin{array}{r}596,307 \\
875,692 \\
82,700 \\
16,470\end{array}$ & $\begin{array}{r}4 \\
88,194 \\
7 \\
-\end{array}$ & $\begin{array}{r}395,836 \\
219,737 \\
901 \\
7,725\end{array}$ & $\begin{array}{r}1,129,789 \\
1,914,329 \\
2,401,480 \\
33,857\end{array}$ & $\begin{array}{r}18 \% \\
31 \% \\
39 \% \\
1 \%\end{array}$ \\
\hline $\begin{array}{l}\text { TCTAL FIRAI } \\
\text { DEHAND SECTORS }\end{array}$ & 300,258 & 261,605 & $1,625,126$ & $1,008,893$ & - & $1,571,169$ & 88,205 & 624,199 & $5,479,455$ & $90 x$ \\
\hline $\begin{array}{l}\text { THANSPORBATICA } \\
\text { BLECTRICITY GEN. } \\
\text { PETROIEOA ERODOCTS } \\
\text { NATORAL GAS } \\
\text { SYNTERTICS }\end{array}$ & $\begin{array}{r}76,321 \\
-783.993 \\
-\end{array}$ & $\begin{array}{r}394,285 \\
-767,935 \\
-\end{array}$ & $-1,833,856$ & $\begin{array}{r}-1,258,899 \\
60,020\end{array}$ & $\begin{array}{r}4,644,964 \\
\overline{-}\end{array}$ & $\begin{array}{r}203,173 \\
16,442 \\
-54,300\end{array}$ & $\begin{array}{l}- \\
-\end{array}$ & $\begin{array}{r}-245,313 \\
- \\
-\end{array}$ & $\begin{array}{r}428,466 \\
16.723 \\
5,720\end{array}$ & $\begin{array}{l}7 \% \\
0 \%\end{array}$ \\
\hline $\begin{array}{l}\text { NET FOEL OSEL } \\
\text { IN TRANSPCEATION }\end{array}$ & $-707,672$ & $-373,550$ & $-1,833,856$ & $-1,198,879$ & $4,644,964$ & 165,315 & - & $-245,313$ & 450,909 & $7 \%$ \\
\hline $\begin{array}{l}\text { TCTAL GROSS FLCRS } \\
\text { LCSSES } \& \text { CHISSICHS }\end{array}$ & $\begin{array}{r}376,579 \\
23,439\end{array}$ & $\begin{array}{r}655,390 \\
13\end{array}$ & $\begin{array}{r}1.625,126 \\
7\end{array}$ & $\begin{array}{r}1,068,913 \\
-42,162\end{array}$ & $\begin{array}{r}4,644,964 \\
192,697\end{array}$ & $\begin{array}{r}1,790,784 \\
-48,390\end{array}$ & $\begin{array}{r}88,205 \\
1,193\end{array}$ & $\begin{array}{r}624,199 \\
51,792\end{array}$ & $\begin{array}{r}5,930,364 \\
178,590\end{array}$ & $\begin{array}{r}97 \% \\
3 \%\end{array}$ \\
\hline
\end{tabular}

T0TIL

\begin{tabular}{|c|c|c|c|c|c|c|c|c|c|c|}
\hline $\begin{array}{l}\text { SOFPLY OF ENERGY } \\
\text { FOSS IL FOEI } \\
\text { HYLROELECTEIC } \\
\text { NOCL EAR } \\
\text { GEC. ESOLAR }\end{array}$ & $\begin{array}{l}\text { - } \\
\overline{-}\end{array}$ & $\begin{array}{l}- \\
-\end{array}$ & $\begin{array}{l}- \\
\overline{-}\end{array}$ & I & $\begin{array}{r}2,210,703 \\
= \\
-\end{array}$ & $\begin{array}{r}162,747 \\
- \\
-\end{array}$ & $\begin{array}{l}\overline{-} \\
\overline{-}\end{array}$ & $\begin{array}{r}160,695 \\
158,812 \\
57,843\end{array}$ & $\begin{array}{r}2,373,450 \\
160,695 \\
158,812 \\
57,843\end{array}$ & $\begin{array}{r}86 \% \\
6 \% \\
6 \% \\
2 \%\end{array}$ \\
\hline TCTAL SOPPLY & - & - & - & - & $2,210,703$ & 162,747 & - & 377,350 & $2,750,800$ & \\
\hline
\end{tabular}

\begin{tabular}{l}
$\begin{array}{l}\text { BIT IH PORTS } \\
\text { OP R GGION }\end{array}$ \\
\hline
\end{tabular}


REGIONAL FNEZGG PALANCE STATEMENT

\begin{tabular}{|c|c|c|c|c|c|c|c|c|c|c|}
\hline SECTOK & $\underset{\text { OIL }}{D I S T I I L A T E}$ & $\begin{array}{l}\text { RES IDDJIL } \\
\text { OIL }\end{array}$ & $\begin{array}{l}\text { GASOLI V V } \\
\text { (ALL D }\end{array}$ & $\begin{array}{l}\text { OTHER } \\
\text { HYDRO- } \\
\text { CARBONS } \\
\text { I I } 10 * * 9\end{array}$ & $\begin{array}{c}\text { CRODE } \\
\text { OIL } \\
\text { BTO'S) }\end{array}$ & $\begin{array}{l}\text { NATURAL } \\
\text { GAS }\end{array}$ & $\cos I$ & EIECTRICITT & $\begin{array}{r}\text { SECTOR } \\
\text { TOTAL }\end{array}$ & \\
\hline $\begin{array}{l}\text { FINAL CRHANC SFCTORS } \\
\text { RESID BNTIAL, COBH. } \\
\text { INDOSTRIAL } \\
\text { TRA SPORTAIICN } \\
\text { HISCELLARPCS OSES }\end{array}$ & $\begin{array}{r}19.849 \\
50.674 \\
27.097 \\
6.483\end{array}$ & $\begin{array}{r}4,611 \\
-9,334 \\
73 \\
2,049\end{array}$ & $\begin{array}{r}- \\
- \\
248,699\end{array}$ & $\begin{array}{r}60,342 \\
71,833 \\
65,981 \\
279\end{array}$ & $\overline{-}$ & $\begin{array}{r}208,920 \\
26,159 \\
3,777 \\
2,550\end{array}$ & $\begin{array}{r}79 \\
164,468 \\
3 \\
-\quad\end{array}$ & $\begin{array}{r}109,508 \\
14,747 \\
- \\
2,131\end{array}$ & $\begin{array}{r}403,309 \\
347,207 \\
345,630 \\
13,492\end{array}$ & $\begin{array}{r}305 \\
265 \\
26 \% \\
1 \%\end{array}$ \\
\hline $\begin{array}{l}\text { TCIAL FINAI } \\
\text { DEHAND SE:TORS }\end{array}$ & 104,103 & 26.057 & 248,699 & 198,435 & - & 241,398 & 164,550 & 126,386 & $1,109,638$ & $82 \%$ \\
\hline 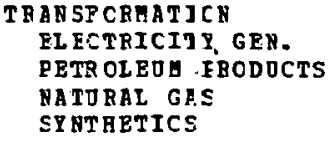 & $\begin{array}{r}4.387 \\
-43.017 \\
=\end{array}$ & $\begin{array}{r}-13,748 \\
- \\
-\end{array}$ & $\begin{array}{r}-72,138 \\
-\end{array}$ & $\begin{array}{r}-20,461 \\
- \\
-\end{array}$ & $\begin{array}{r}145,510 \\
-\end{array}$ & $\begin{array}{r}1,347 \\
6,127 \\
- \\
-\end{array}$ & $\begin{array}{r}321, L .71 \\
- \\
- \\
-\end{array}$ & $\begin{array}{r}-102,470 \\
- \\
-\end{array}$ & $\begin{array}{r}224,435 \\
2,272 \\
-\end{array}$ & $\begin{array}{r}17 \% \\
0 \%\end{array}$ \\
\hline $\begin{array}{l}\text { NET FOFI OSEL } \\
\text { IN TRANSFCFHATION }\end{array}$ & -38.630 & $-13,748$ & $-72,138$ & $-20,461$ & 145,510 & 7,174 & 321,471 & $-102,470$ & 226,707 & $17 \%$ \\
\hline $\begin{array}{l}\text { TCTAL GROSS FLCKS } \\
\text { LCSSES } \varepsilon \text { CHISSICNS }\end{array}$ & $\begin{array}{r}108.490 \\
6.752\end{array}$ & $\begin{array}{r}26,067 \\
0\end{array}$ & $\begin{array}{r}248,6,99 \\
1\end{array}$ & $\begin{array}{r}158,435 \\
-7,827\end{array}$ & $\begin{array}{r}145,510 \\
6,036\end{array}$ & $\begin{array}{r}248,572 \\
-6,716\end{array}$ & $\begin{array}{r}486,021 \\
6,578\end{array}$ & $\begin{array}{r}126,386 \\
10,486\end{array}$ & $\begin{array}{r}1,336,345 \\
15,312\end{array}$ & 99.8 \\
\hline TCTAL NET DSAGF & 72,225 & 12,319 & 176,562 & $1: 0,146$ & 151,546 & 241,856 & 492,599 & 34,402 & $1,351,657$ & \\
\hline
\end{tabular}

-

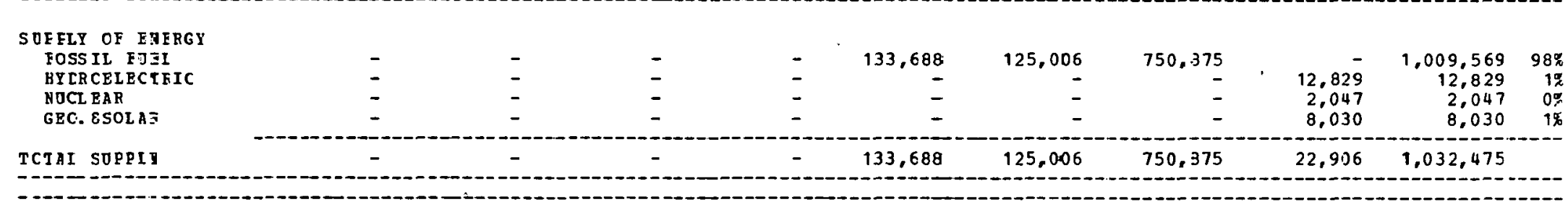

\section{-}

UO $7 \mathrm{BS}$ :

1 TRADSPCBMAICR IOSS POR ELECTRZCITY GEN. $=68.65 \%$

TRADSPCRMATICM LOSS POR PEIROLEOM P.TCDCTS $=1.50 \%$

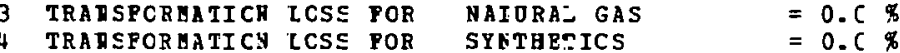


REGIONAL BNERGY PALANCE STATEHENT

PIES MID RG PALANCE STAT SCENARIO
PIES MID D

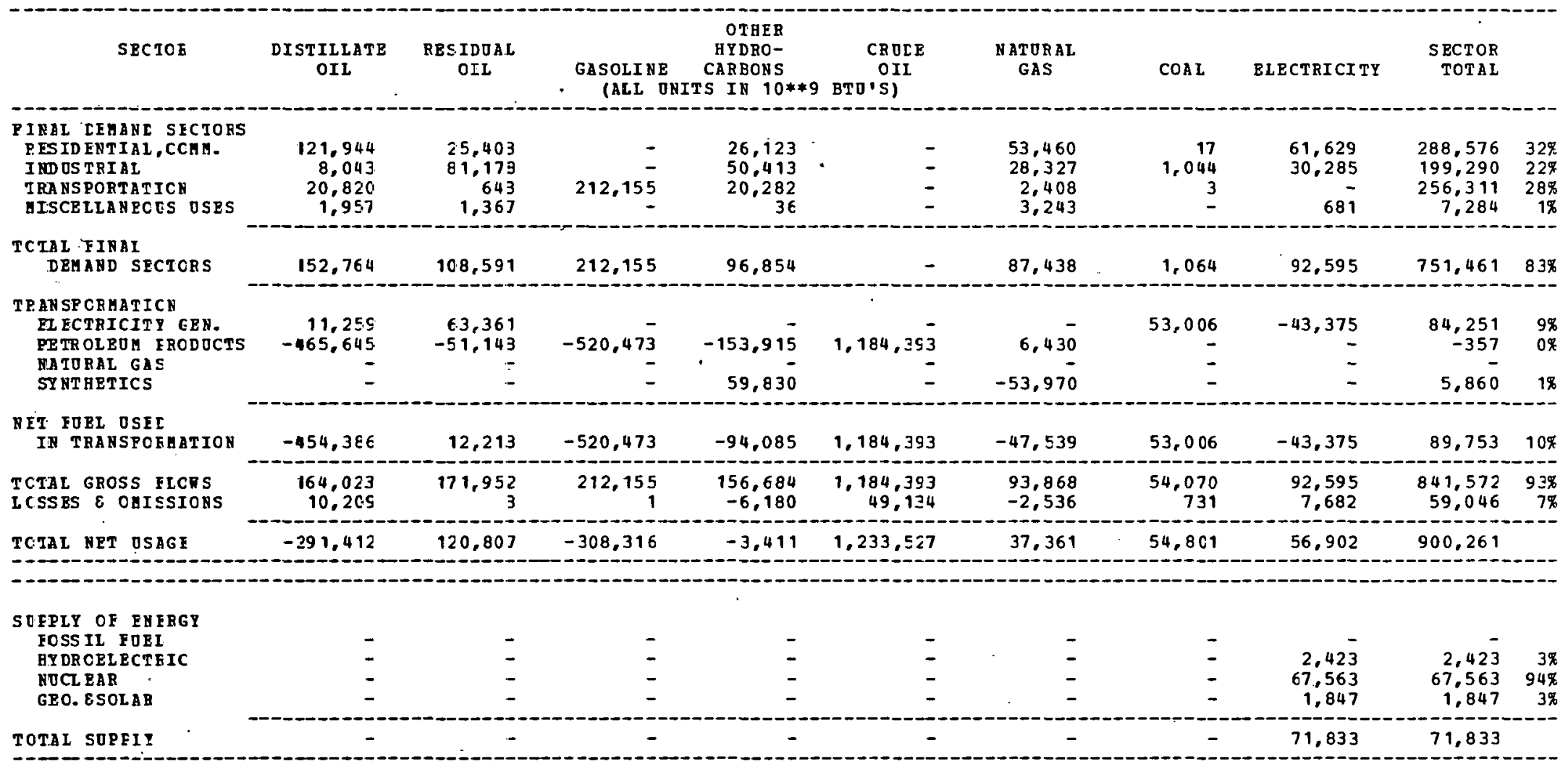

NET IM EORTS

OF REGIO:

\section{צOTES}

TRABSPCRMATICN LOSS POB TRABSPCR HATICN LOSS PGB TRARSPCRAATICN LCSS POE
ELECTRICLTY GEN. PETHOLEOI PBODOCTS

SATURAL TAS

\section{$=66.01$}

$=-0.03 \%$ $=0.0 \%$ $=9.79 \%$ 
REGIONAL ENE FGY FALANCE STATEMENT

PIES MID DCENARIO

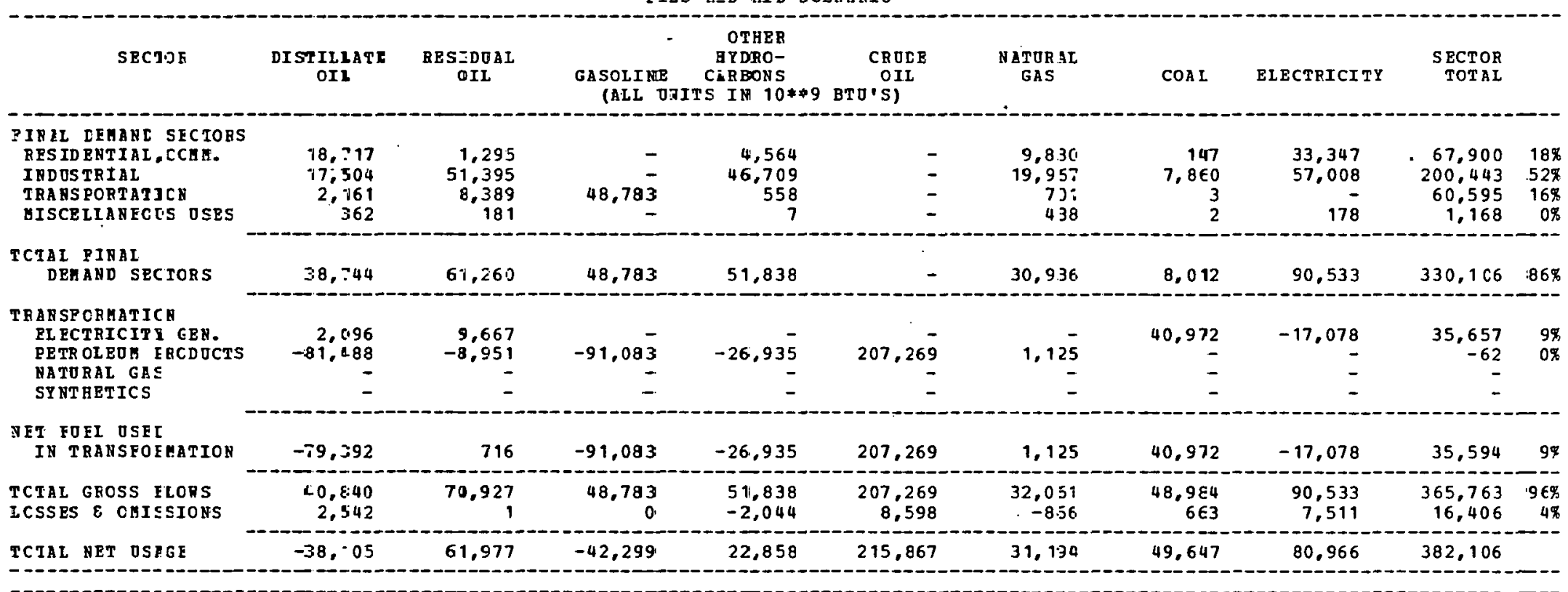

\section{S OEFLT OF EYERGY \\ FOSS IL FOEI \\ MYCR}

$\left(\frac{100}{10}\right.$

$\begin{array}{lll}- & - & - \\ - & - & - \\ - & - & -\end{array}$

YET II FCRTS

OP REGION

$-38, \cdot 05$

61,977

$-42,259$

22.858

215,867

31,194

49,647

80,966

NOTES:

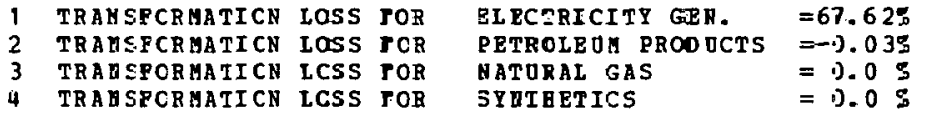

3 TRAMSPORMATICN LCSS POR
4 TRAMSPCRMAIICN LCSS FOR

YUTEETICS 
REGIONAL ENEFGY EAIANCE STATEMENT

PIES MID MID SCENARIO

\begin{tabular}{|c|c|c|c|c|c|c|c|c|c|}
\hline SECTOF & $\begin{array}{l}\text { DISTILLATE } \\
\text { OIL }\end{array}$ & $\begin{array}{l}\text { RESIDOF.L } \\
\text { OIL }\end{array}$ & $\begin{array}{l}\text { GASOLINE } \\
\quad \text { (ALL O }\end{array}$ & $\begin{array}{c}\text { OTHER } \\
\text { HYDRO- } \\
\text { CAREONS } \\
\text { CS IN } 10 * * 9\end{array}$ & $\begin{array}{c}\text { CROEE } \\
\text { OIL } \\
\text { BTO'S) }\end{array}$ & $\begin{array}{l}\text { NATURAL } \\
\text { GAS }\end{array}$ & $\operatorname{COAL}$ & ELECTRICITY & $\begin{array}{l}\text { SECTOR. } \\
\text { TOTAL }\end{array}$ \\
\hline $\begin{array}{l}\text { PINAL CEMAND SECTOBS } \\
\text { BESIDENTIAL,CCHH. } \\
\text { INDOSTRIAL } \\
\text { TBANSPORTATICH } \\
\text { MISCELLANECES OSES }\end{array}$ & $\begin{array}{r}32,186 \\
257 \\
5,209 \\
2,746\end{array}$ & $\begin{array}{r}12,161 \\
432 \\
8,266 \\
1,322\end{array}$ & $\begin{array}{r}- \\
- \\
-\end{array}$ & $\begin{array}{r}3,930 \\
1,143 \\
21 \\
43\end{array}$ & $\begin{array}{l}- \\
- \\
-\end{array}$ & $\begin{array}{r}15,978 \\
308 \\
2,290 \\
3,158\end{array}$ & $\begin{array}{r}55 \\
642 \\
1 \\
11\end{array}$ & $\begin{array}{r}19,673 \\
1,845 \\
34 \\
1,399\end{array}$ & $\begin{array}{r}83,983 \\
4,627 \\
60,295 \\
8,729\end{array}$ \\
\hline $\begin{array}{l}\text { TCIAI FINAI } \\
\text { DEMAND SECTCES }\end{array}$ & 40,398 & 22,211 & 44,494 & 5,137 & - & 21,734 & 709 & 22,951 & 157,634 \\
\hline $\begin{array}{l}\text { TEANSFORHATICN } \\
\text { ELFCTRICITY GEN. } \\
\text { FETRCLEOH FRCDOCTS } \\
\text { NATORAL GAS } \\
\text { SY NTETICS }\end{array}$ & $\begin{array}{r}1,985 \\
- \\
- \\
-\end{array}$ & $\begin{array}{r}8.338 \\
- \\
-\end{array}$ & $\begin{array}{l}\bar{z} \\
\overline{-}\end{array}$ & $\begin{array}{l}- \\
- \\
-\end{array}$ & $\begin{array}{l}- \\
\overline{-}\end{array}$ & $\begin{array}{l}\overline{-} \\
\overline{-}\end{array}$ & $\begin{array}{l}\overline{-} \\
\overline{-}\end{array}$ & $\begin{array}{r}-3,101 \\
- \\
- \\
-\end{array}$ & $\begin{array}{r}7,222 \\
- \\
-\end{array}$ \\
\hline $\begin{array}{l}\text { NET FOEL OSEL } \\
\text { IN TRANSFEYATIOY }\end{array}$ & 1,985 & $8,3] 8$ & - & - & - & - & - & $-3,101$ & 7,222 \\
\hline $\begin{array}{l}\text { TCIAL GFOSS FLCHS } \\
\text { LCSSES } \varepsilon \text { OUISSIONS }\end{array}$ & $\begin{array}{r}42,383 \\
2,638\end{array}$ & $\begin{array}{r}30,549 \\
0\end{array}$ & $\begin{array}{r}44,494 \\
0\end{array}$ & $\begin{array}{r}5,137 \\
-202\end{array}$ & 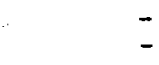 & $\begin{array}{r}21,734 \\
-587\end{array}$ & $\begin{array}{r}709 \\
9\end{array}$ & $\begin{array}{r}22,951 \\
1,904\end{array}$ & $\begin{array}{r}164,856 \\
3,762\end{array}$ \\
\hline TCIAL NET ESAGE & 45,021 & $3 c, 549$ & 44,494 & 4,934 & - & 21,146 & 718 & 21,754 & 168,618 \\
\hline
\end{tabular}

\begin{tabular}{|c|c|c|c|c|c|c|c|c|c|}
\hline $\begin{array}{l}\text { SOEPIY OF ENERGI } \\
\text { FOSSIL POEI }\end{array}$ & - & - & - & - & - & - & - & - & - \\
\hline HY DR OELECTEIC & - & - & - & - & - & - & - & - & - \\
\hline NOCL EAR & - & - & - & - & - & - & - & - & - \\
\hline GEC. ESOLAB & - & - & - & - & - & - & - & - & - \\
\hline
\end{tabular}

\section{NET IM FORTS}

OP REGION

45,021

30.549

44,494

4,934

21,146

718

21,754

168,618

\begin{tabular}{|c|c|c|c|c|c|}
\hline \multicolumn{6}{|c|}{ ES: } \\
\hline & TRANSFCRMATICN & LOSS & POR & ELBCTRICITY GEN. & $=69.96 \%$ \\
\hline 2 & TRANSFCRHAIICN & LOSS & FOR & PETROLEDH ERODOCTS & 0.0 \\
\hline 3 & IRAN SPCR AAIICN & LCSS & FOR & NATOEAL GAS & $=0.0$ \\
\hline 4 & TRA N SPOR AAIICN & LOSS & POR & SYNTETICS & $=0.0$ \\
\hline
\end{tabular}


REGI J YZL ENEFIY EALANCE STATEMENT

\begin{tabular}{|c|c|c|c|c|c|c|c|c|c|c|}
\hline SECT.OF & $\begin{array}{l}\text { DISTILIATE } \\
\text { OII }\end{array}$ & $\begin{array}{c}\text { RESIDUAL } \\
\text { III }\end{array}$ & $\begin{array}{l}\text { GASOLIN } 3 \\
\text { [ALL J }\end{array}$ & $\begin{array}{l}\text { OTEER } \\
\text { AYDEO- } \\
\text { CARBONS } \\
\text { S IN } 10 * 9\end{array}$ & $\begin{array}{c}\text { CRODE } \\
\text { OIL } \\
\text { BTO'S) }\end{array}$ & $\begin{array}{l}\text { NATORLL } \\
\text { GAS }\end{array}$ & $\operatorname{COAI}$ & ELECTRICITY & $\begin{array}{l}\text { SECTOR } \\
\text { TOTAL }\end{array}$ & \\
\hline $\begin{array}{l}\text { FINLL CEMANE SECTORS } \\
\text { RESIDENTIAL, CCHM. } \\
\text { INDOSTRIAL } \\
\text { TRANSPORTATICN } \\
\text { MISCEILANEOES OSES }\end{array}$ & $\begin{array}{r}74,451 \\
52,101 \\
37,420 \\
7,582\end{array}$ & $\begin{array}{r}1 E, 701 \\
9 C, C 06 \\
17, \in 87 \\
4,196\end{array}$ & 978,303 & $\begin{array}{r}104.051 \\
88.206 \\
256.027 \\
355\end{array}$ & $\begin{array}{l}- \\
-\end{array}$ & $\begin{array}{r}33,264 \\
114,881 \\
11,980 \\
7,045\end{array}$ & $\begin{array}{r}1,511 \\
60,597 \\
2 \\
16\end{array}$ & $\begin{array}{r}537,708 \\
110,209 \\
5,511\end{array}$ & $\begin{array}{r}767,686 \\
526,000 \\
1,351,424 \\
25,105\end{array}$ & $\begin{array}{r}22 \% \\
15 \% \\
38 \% \\
1 \%\end{array}$ \\
\hline $\begin{array}{l}\text { TCTAI FINAI } \\
\text { DEHAND SECICRS }\end{array}$ & 231,954 & $12 \Xi, 590$ & $\$ 78,309$ & 448.639 & - & $167,17 \mathrm{C}$ & 62,125 & 653,428 & $2,670,215$ & $75 \%$ \\
\hline $\begin{array}{l}\text { TE AN SPCRHATICU } \\
\text { ELECTRICITY GEN. } \\
\text { PETR CLEOM FBCDOCTS } \\
\text { NATCRAI GAS } \\
\text { SYNTAETICS }\end{array}$ & $\begin{array}{r}84,705 \\
-3,: 17 \\
-\end{array}$ & $\begin{array}{r}287, \approx 61 \\
-\equiv 64 \\
- \\
-\end{array}$ & $\begin{array}{r}-3,708 \overline{-} \\
-\end{array}$ & $\begin{array}{r}-1.096 \\
-\end{array}$ & $\begin{array}{r}8,438 \\
-\end{array}$ & $\begin{array}{l}\overline{-} \\
\overline{-}\end{array}$ & $\begin{array}{r}873,393 \\
-\end{array}$ & $\begin{array}{r}-423,330 \\
= \\
=\end{array}$ & $\begin{array}{r}821,939 \\
-2 \\
-\end{array}$ & $\begin{array}{r}23 \pi \\
0 \%\end{array}$ \\
\hline $\begin{array}{l}\text { NET FOFL OSEL } \\
\text { IN TRANSPOEAATION }\end{array}$ & 31,387 & $28 \epsilon, \varepsilon 96$ & $-3,70 B$ & -1.096 & 8,438 & 45 & 873,303 & $-423,330$ & $\varepsilon 21.936$ & $23 \pi$ \\
\hline $\begin{array}{l}\text { TCTAL GROSS FLORS } \\
\text { LCSSES E CUISSIONS }\end{array}$ & $\begin{array}{r}316,659 \\
19,709\end{array}$ & $\begin{array}{r}41 E, E 51 \\
8\end{array}$ & $\begin{array}{r}978,309 \\
4\end{array}$ & $\begin{array}{l}448: 639 \\
-17,696\end{array}$ & $\begin{array}{r}8,438 \\
350\end{array}$ & $\begin{array}{r}167,2=5 \\
-4,5 \cdot q\end{array}$ & $\begin{array}{r}935,429 \\
12,661\end{array}$ & $\begin{array}{r}653,428 \\
54,217\end{array}$ & $\begin{array}{r}3,492,154 \\
64,737\end{array}$ & $\begin{array}{r}38 \% \\
2 \%\end{array}$ \\
\hline TCIAL NET OSAGE & 333, C 51 & 415,494 & 974,604 & L29., 846 & 8,788 & 162,697 & 948,090 & 284,315 & $3,556,888$ & \\
\hline
\end{tabular}

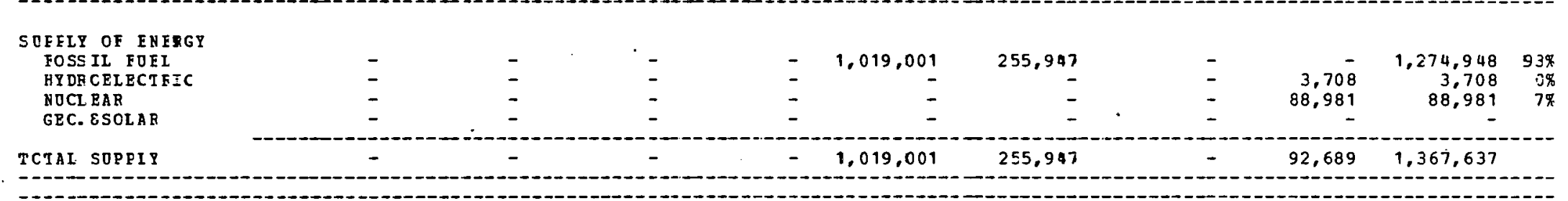

NET IMEORTS
OP FEGION


REGICNAL ENE FGY PALANCE STATEMENT

\begin{tabular}{|c|c|c|c|c|c|c|c|c|c|c|}
\hline SECTOR & $\begin{array}{l}\text { DISTILLATE } \\
\text { OIL }\end{array}$ & $\begin{array}{l}\text { RESIDDAL } \\
\text { OIL. }\end{array}$ & $\begin{array}{l}\text { GASOLINE } \\
\text { (ALI ONT }\end{array}$ & $\begin{array}{l}\text { OTHER } \\
\text { HYDRO- } \\
\text { CARBONS } \\
\text { S IN } 10 * \$ 9\end{array}$ & $\begin{array}{l}\text { CRODE } \\
\text { OIL } \\
\text { BTO'SI }\end{array}$ & $\begin{array}{l}\text { NATURAL } \\
\text { GAS }\end{array}$ & $\operatorname{COAL}$ & ELECTRICITY & $\begin{array}{r}\text { SECTOR } \\
\text { TOTAL }\end{array}$ & \\
\hline $\begin{array}{l}\text { PINAL CEHANC SFCICRS } \\
\text { E.FIDENTIAI, CCAM. } \\
\text { INDOSTRIAL } \\
\text { TRANSPORTATICN } \\
\text { NISCELLANEOCS OSES }\end{array}$ & $\begin{array}{r}49,106 \\
33,403 \\
84,795 \\
5,344\end{array}$ & $\begin{array}{r}12,967 \\
63,485 \\
1,000 \\
2,807\end{array}$ & $\begin{array}{r}- \\
- \\
495.762\end{array}$ & $\begin{array}{r}50,744 \\
72,234 \\
117,001 \\
228\end{array}$ & $\begin{array}{l}\overline{-} \\
\overline{-}\end{array}$ & $\begin{array}{r}80,147 \\
142,761 \\
5,347 \\
5,071\end{array}$ & $\begin{array}{r}182 \\
64,619 \\
1 \\
8\end{array}$ & $\begin{array}{r}218,244 \\
134,612 \\
-326\end{array}$ & $\begin{array}{r}411,390 \\
511,114 \\
703,906 \\
15,784\end{array}$ & $\begin{array}{r}18 \% \\
22 \% \\
31 \% \\
.1 \%\end{array}$ \\
\hline $\begin{array}{l}\text { TCIAL FINAL } \\
\text { DEMAND SECTCAS }\end{array}$ & 172,648 & 80,259 & 495,762 & 240,207 & - & 233,326 & 64,810 & 355,182 & $1,642,194$ & $72 \pi$ \\
\hline $\begin{array}{l}\text { TE ANSPORMATICN } \\
\text { FLECTRICITY GEN. } \\
\text { PETR OLEDY FRCDOCTS } \\
\text { NATORAL GAS } \\
\text { SY NTHETICS }\end{array}$ & $\begin{array}{r}48,894 \\
-10,476 \\
- \\
-\end{array}$ & $\begin{array}{r}15,636 \\
-1,150 \\
- \\
-\end{array}$ & $\begin{array}{r}-11,710 \\
-\end{array}$ & $\begin{array}{r}-3,463 \\
- \\
-\end{array}$ & $\begin{array}{r}- \\
26,648 \\
-\end{array}$ & $\begin{array}{r}144 \\
-\end{array}$ & $\begin{array}{r}839,975 \\
- \\
-\end{array}$ & $\begin{array}{r}-309,058 \\
- \\
-\end{array}$ & $\begin{array}{r}594,447 \\
-8 \\
- \\
-\end{array}$ & $\begin{aligned} 26 \% \\
0 \%\end{aligned}$ \\
\hline $\begin{array}{l}\text { DET FOEL OSEF } \\
\text { IN TRANSFOFATICN }\end{array}$ & 38,417 & 14,485 & $-11,710$ & $-3,463$ & 26,648 & 144 & 838,975 & $-309,058$ & 594,438 & $26 \pi$ \\
\hline $\begin{array}{l}\text { TCIAL GKOSS FLCHS } \\
\text { LCSSES \& CYISSIONS }\end{array}$ & $\begin{array}{r}221,542 \\
13,789\end{array}$ & 95,895 & $\begin{array}{r}495,762 \\
2\end{array}$ & $\begin{array}{r}240,207 \\
-9,474\end{array}$ & $\begin{array}{r}26,648 \\
1,105\end{array}$ & $\begin{array}{r}233,470 \\
-6,308\end{array}$ & $\begin{array}{r}903,785 \\
12,233\end{array}$ & $\begin{array}{r}355,182 \\
29,470\end{array}$ & $\begin{array}{r}2,236,641 \\
40,819\end{array}$ & $\begin{aligned} 9 \varepsilon \% \\
2 \%\end{aligned}$ \\
\hline TCIAL NET OSAGE & 224,854 & 94,746 & 484,053 & 227,269 & 27,754 & 227,161 & 916,018 & 75,594 & $2,277,452$ & \\
\hline $\begin{array}{l}\text { S UEFLY OF ENERGY } \\
\text { FOSS IL FDEI } \\
\text { HYDROELLCTEIC } \\
\text { HOCL EAR } \\
\text { GEC. ESOLAR }\end{array}$ & $\begin{array}{l}\bar{z} \\
\overline{-} \\
\overline{-}\end{array}$ & $\begin{array}{l}- \\
\overline{-} \\
\overline{-}\end{array}$ & $\begin{array}{l}- \\
- \\
-\end{array}$ & $\begin{array}{l}- \\
- \\
-\end{array}$ & $\begin{array}{l}- \\
- \\
-\end{array}$ & $\begin{array}{l}- \\
- \\
-\end{array}$ & $\begin{array}{l}- \\
- \\
-\end{array}$ & $\begin{array}{r}- \\
26,442 \\
85,132 \\
-\end{array}$ & $\begin{array}{r}26,442 \\
85,132 \\
-\end{array}$ & $\begin{array}{l}24 \% \\
76 \%\end{array}$ \\
\hline TCIAI SOPPIY & - & - & - & - & - & - & - & 111,574 & 111,574 & \\
\hline
\end{tabular}

NET IM FORTS
OP REGION


REGIGNAL EQZFGY DALANCE STATEMONT

P.I 3 S M-D MID SCENARIO

\begin{tabular}{|c|c|c|c|c|c|c|c|c|c|c|}
\hline SECIJE & $\begin{array}{l}\text { EISEILIATE } \\
\text { OIL }\end{array}$ & $\begin{array}{l}\text { RESIDOAL } \\
\text { OIL }\end{array}$ & $\begin{array}{l}\text { GASOLINE } \\
\text { (ALL ONI }\end{array}$ & $\begin{array}{c}\text { OTHER } \\
\text { IYDRO- } \\
\text { CAREONS } \\
\text { TS IN } 10 * * 9\end{array}$ & $\begin{array}{c}\text { CREDE } \\
\text { OlL } \\
\text { BTD'S) }\end{array}$ & $\begin{array}{l}\text { NATURAL } \\
\text { GAS }\end{array}$ & $\operatorname{COAI}$ & ELECTRICITY & $\begin{array}{r}\text { SECTOR } \\
\text { TOTAL }\end{array}$ & \\
\hline $\begin{array}{l}\text { ZINPL CEHANC SECTORS } \\
\text { RESIDENTIAL, SCMH. } \\
\text { INDOSTRIAL } \\
\text { TRANSPORTATISN } \\
\text { MISCELLANEOCS OSES }\end{array}$ & $\begin{array}{r}1,104 \\
31,719 \\
4,482 \\
630\end{array}$ & $\begin{array}{r}104 \\
156,787 \\
6,273 \\
157\end{array}$ & $\begin{array}{r}- \\
\overline{-} \\
46,748\end{array}$ & $\begin{array}{r}4,768 \\
511,652 \\
88,230 \\
6\end{array}$ & $\begin{array}{l}- \\
-\end{array}$ & $\begin{array}{r}21,315 \\
2,234 \\
5,957 \\
1,039\end{array}$ & $\begin{array}{r}3 \\
1,9 \varepsilon 5 \\
- \\
-\end{array}$ & $\begin{array}{r}11,569 \\
3,140 \\
- \\
670\end{array}$ & $\begin{array}{r}38,853 \\
247,517 \\
151,695 \\
2,502\end{array}$ & $\begin{array}{r}8 \% \\
152 \% \\
32 \% \\
1 \%\end{array}$ \\
\hline $\begin{array}{l}\text { TCTAI FINAI } \\
\text { DEAAND SECTCRS }\end{array}$ & 27,935 & $16], 325$ & 46,748 & 144,656 & - & 30,535 & $1,9 \varepsilon 8$ & 15,379 & 440,567 & $93 \%$ \\
\hline $\begin{array}{l}\text { TEANSFCRMATICA } \\
\text { ELECTRICITY, CEN. } \\
\text { FETROLEOM EACDOCTS } \\
\text { NATORAL GAS } \\
\text { SYNTHETICS }\end{array}$ & $\begin{array}{r}-75,289 \\
-\end{array}$ & $\begin{array}{r}17,659 \\
-73,747 \\
- \\
-\end{array}$ & $\begin{array}{r}-176,111 \\
-\end{array}$ & $\begin{array}{r}-120.89 \overline{-} \\
-\end{array}$ & $\begin{array}{r}5 \\
446.069 \\
-\end{array}$ & $\begin{array}{r}4.991 \\
1,575 \\
- \\
-\end{array}$ & $\begin{array}{l}- \\
- \\
-\end{array}$ & $\begin{array}{r}-7,993 \\
- \\
-\end{array}$ & $\begin{array}{r}14,657 \\
1,605 \\
- \\
-\end{array}$ & $\begin{array}{l}3 \% \\
0 \%\end{array}$ \\
\hline $\begin{array}{l}\text { NET FUEL USEL } \\
\text { IN TRANSFEMATION }\end{array}$ & $-75,289$ & $-56,0.88$ & $-176,111$ & $--20,896$ & 446,069 & $6,57 \mathrm{C}$ & - & $-7,993$ & 16,262 & $3 \%$ \\
\hline $\begin{array}{l}\text { ZCTAL GROSS FICRS } \\
\text { LCSSES \& CMISSIONS }\end{array}$ & $\begin{array}{r}\equiv 7,935 \\
2,361\end{array}$ & $\begin{array}{r}180,985 \\
3\end{array}$ & $\begin{array}{r}46,748 \\
0\end{array}$ & $\begin{array}{r}-44,656 \\
-5,705\end{array}$ & $\begin{array}{r}446,069 \\
18,505\end{array}$ & $\begin{array}{l}37,105 \\
-1,002\end{array}$ & $\begin{array}{r}1,9388 \\
26\end{array}$ & $\begin{array}{r}15,379 \\
1,276\end{array}$ & $\begin{array}{r}456,829 \\
15,464\end{array}$ & $\begin{array}{r}97 \% \\
3 \%\end{array}$ \\
\hline TCTAL NET OSAIE & $-34,992$ & 107,241 & $-129,36.2$ & 18,054 & 464,574 & $36,10 \bar{c}$ & 2,014 & 8,662 & 472,293 & \\
\hline
\end{tabular}

SOEFIY OP ENEGGY
$\begin{aligned} & \text { FOSS IL FUEI } \\ & \text { HYDEELECTFIC }\end{aligned}$
NOCLEAR
GEOESOLAR

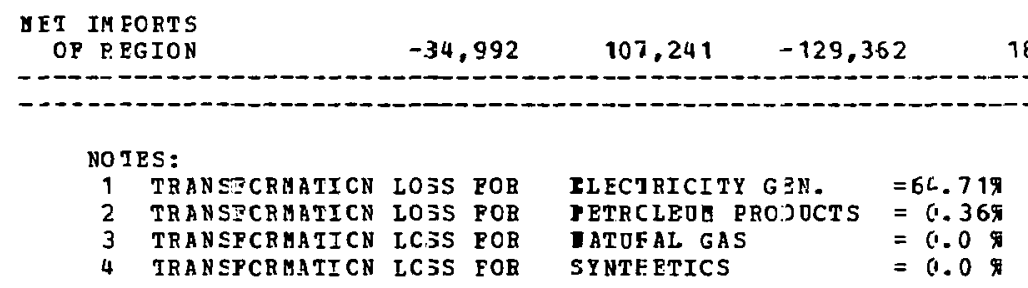


REGIONAL ENE FGY EALANCE STATEMENT
PIES MID MID SCENARIO

\begin{tabular}{|c|c|c|c|c|c|c|c|c|c|c|}
\hline SECTOE & $\begin{array}{l}\text { DISTILLATE } \\
\text { OIL }\end{array}$ & $\begin{array}{l}\text { RESIDDR.I } \\
\text { OIL }\end{array}$ & $\begin{array}{l}\text { GASOLINE } \\
\text { (ALL DNIT }\end{array}$ & $\begin{array}{l}\text { OIHER } \\
\text { HYDRO- } \\
\text { CAREONS } \\
\text { S IN } 10 * * 9\end{array}$ & $\begin{array}{c}\text { CRODE } \\
\text { OIL } \\
\text { BTO'SI }\end{array}$ & $\begin{array}{l}\text { NATORAL } \\
\text { GAS }\end{array}$ & $\operatorname{COAL}$ & ELECTRICI TY & $\begin{array}{r}\text { SECTOR } \\
\text { TOTAL }\end{array}$ & $\cdot$ \\
\hline $\begin{array}{l}\text { PIAAL CEHANC SECTOBS } \\
\text { RESIDENTIAL,CCHA. } \\
\text { INDOSTRIAL } \\
\text { TRANSPORTATICN } \\
\text { MISCELLANECES OSES }\end{array}$ & $\begin{array}{r}18,503 \\
7,488 \\
15,217 \\
807\end{array}$ & $\begin{array}{r}837 \\
2,603 \\
- \\
300\end{array}$ & $92,73 \frac{-}{-}$ & $\begin{array}{r}11,445 \\
8,529 \\
5,631 \\
3\end{array}$ & - & $\begin{array}{r}1,909 \\
- \\
144 \\
-\end{array}$ & $\begin{array}{r}87 \\
39,471 \\
1 \\
-\end{array}$ & $\begin{array}{r}52,657 \\
43,556 \\
- \\
411\end{array}$ & $\begin{array}{r}85,438 \\
101,647 \\
113,725 \\
1,521\end{array}$ & $\begin{array}{r}27 \% \\
32 \% \\
36 \% \\
0 \%\end{array}$ \\
\hline $\begin{array}{l}\text { TCIAI FINAI } \\
\text { DBMAND SECTCRS }\end{array}$ & 42,015 & $3,7<0$ & 92,732 & 25,608 & - & 2,053 & 39,559 & 96.624 & 302,331 & $97 \%$ \\
\hline $\begin{array}{l}\text { THANSPCRHATICN } \\
\text { ELECTRICITY GRN. } \\
\text { PETROLEOM FRCDOCTS } \\
\text { RATORAL GAS } \\
\text { SYNTHETICS }\end{array}$ & $\begin{array}{r}601 \\
- \\
-\end{array}$ & $\bar{z}$ & $\begin{array}{l}\bar{z} \\
\bar{z}\end{array}$ & $\begin{array}{l}\bar{z} \\
\bar{z}\end{array}$ & $\begin{array}{l}\bar{z} \\
\overline{-}\end{array}$ & $\begin{array}{l}\bar{z} \\
\bar{z}\end{array}$ & $\begin{array}{l}\overline{-} \\
\overline{-}\end{array}$ & $\begin{array}{r}-211 \\
- \\
-\end{array}$ & $\begin{array}{r}390 \\
- \\
-\end{array}$ & $0 \%$ \\
\hline $\begin{array}{l}\text { RET FOEL OSEL } \\
\text { IN TRANSPOEMATIOS }\end{array}$ & 601 & - & - & - & - & - & - & -211 & 390 & $0 \%$ \\
\hline $\begin{array}{l}\text { TCIAL GROSS FLCRS } \\
\text { LCSSES \& OMISSIONS }\end{array}$ & $\begin{array}{r}42,616 \\
2,652\end{array}$ & $\begin{array}{r}3,740 \\
0\end{array}$ & $\begin{array}{r}92,732 \\
0\end{array}$ & $\begin{array}{l}25,608 \\
-1,010\end{array}$ & $\overline{-}$ & $\begin{array}{r}2,053 \\
-55\end{array}$ & $\begin{array}{r}39.559 \\
535\end{array}$ & $\begin{array}{r}96,624 \\
8,017\end{array}$ & $\begin{array}{r}302,721 \\
10,140\end{array}$ & $\begin{array}{r}97 \% \\
3 \%\end{array}$ \\
\hline TCIAL NET OSAGE & 45,268 & $3,7<0$ & 92,732 & 24,597 & - & 1,997 & 40,054 & 104,430 & 312,861 & \\
\hline $\begin{array}{l}\text { SOEPLY OF ENERGI } \\
\text { FOSS IL FOEL } \\
\text { HYDROELECTEIC } \\
\text { NOCLEAR } \\
\text { GEO.ESOLAR }\end{array}$ & $\begin{array}{l}- \\
-\end{array}$ & $\begin{array}{l}z \\
-\end{array}$ & $\begin{array}{l}- \\
-\end{array}$ & $\begin{array}{l}\overline{-} \\
\overline{-}\end{array}$ & $\begin{array}{l}- \\
\overline{-} \\
-\end{array}$ & $\begin{array}{l}\overline{-} \\
\overline{-}\end{array}$ & - & $\begin{array}{r}49,42 \overline{1} \\
2,468\end{array}$ & $\begin{array}{r}49,42 \overline{1} \\
- \\
2,468\end{array}$ & $95 \%$ \\
\hline TCTAL SOPELY & - & - & - & - & - & - & - & 51,889 & 51,889 & \\
\hline
\end{tabular}

NET IN FORTS

45,268

3,740

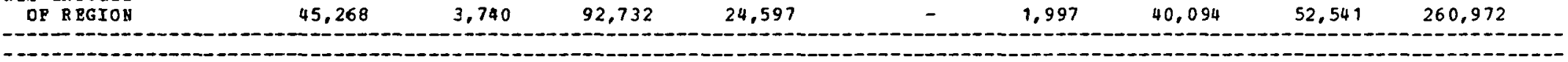

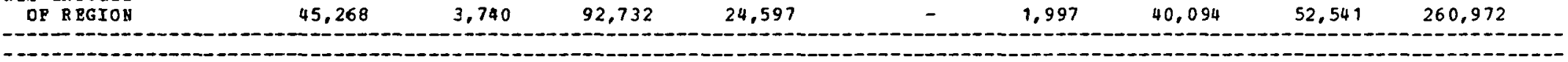

1,997

40,094

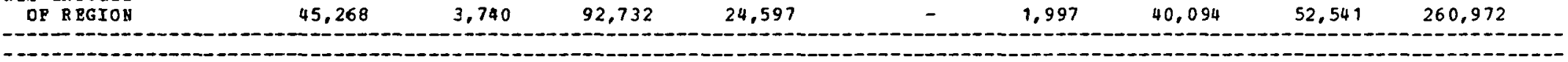

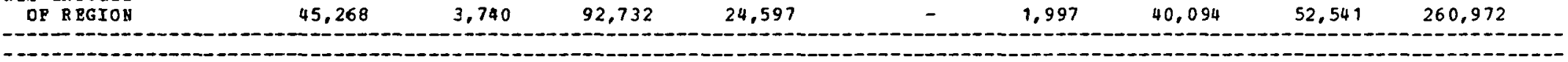

NO I PS:

TRANSPCRAATICR LOSS FOR

TRANSPORMATICN LOSS POR

TRANSPCRHATI CE ICSS FOR

TRANSPCRUATI CN ECSS POR

BLECTRICITY GEN.

BTRCLEOM PRODOCTS $=64.89 \%$

NATUFAL GAS

$=0.0 \%$

STUTHETECS

$=0.0 \%$ 
REGICNAL ENERG: RALANCE STATEMEYT

IES MID MD SCENARIO

\begin{tabular}{|c|c|c|c|c|c|c|c|c|c|c|}
\hline SECTOज & $\begin{array}{l}\text { DISTILLPTS } \\
\text { GII }\end{array}$ & $\underset{\text { aIL }}{3 E S \operatorname{LDALI}}$ & $\begin{array}{l}\text { JASOLINE } \\
\text { (ALL UN }\end{array}$ & $\begin{array}{c}\text { OTHER } \\
\text { HYDRD- } \\
\text { CAEBCJS } \\
\text { IS IY IO } 0 * 9\end{array}$ & $\begin{array}{c}\text { CRODE } \\
\text { OIL } \\
\text { BTOSS) }\end{array}$ & $\begin{array}{l}\text { NATURAL } \\
\text { GAS }\end{array}$ & COAL & ELECTRICITY & $\begin{array}{r}\text { SECTOR } \\
\text { TOTAL }\end{array}$ & . \\
\hline $\begin{array}{l}\text { PINAL IEHANE SECIOES } \\
\text { GFSID BNTIAI,CCMA. } \\
\text { INDOSTRIAL } \\
\text { TRANSPORTATICY } \\
\text { MISCEIIANECOS OSES }\end{array}$ & $\begin{array}{r}32:, 5 \vdots 0 \\
128,1 \div 0 \\
134,0 \div 3 \\
15,6 \div 2\end{array}$ & $\begin{array}{r}82.207 \\
75, .846 \\
1.636 \\
8.316\end{array}$ & $342,35 \overline{-}$ & $\begin{array}{r}131,-772 \\
385,738 \\
83, .272 \\
345\end{array}$ & $\begin{array}{l}- \\
-\end{array}$ & $\begin{array}{r}597,046 \\
158,470 \\
36,677 \\
7,350\end{array}$ & $\begin{array}{r}2,722 \\
409,144 \\
13\end{array}$ & $\begin{array}{r}236,627 \\
235,240 \\
1,015 \\
3.650\end{array}$ & $\begin{array}{r}1,372,104 \\
1,392,568 \\
998,978 \\
35,346\end{array}$ & $\begin{array}{r}30 \% \\
30 \% \\
22 \pi \\
1 \%\end{array}$ \\
\hline $\begin{array}{l}\text { TCTAL PINAI } \\
\text { DEMAND SECTCRS }\end{array}$ & $59 \leq, 3 \leq 5$ & 168,005 & $742,35 \bar{z}$ & 601,327 & - & 799,543 & $411,88 \bar{x}$ & 476,532 & $3,798,996$ & $E 2 \pi$ \\
\hline $\begin{array}{l}\text { TBANSPCRMATICN } \\
\text { ELECTRICITY ERN. } \\
\text { PETR OLEOM FAODOCTS } \\
\text { NA TORAL GAS } \\
\text { SYNTHETICS }\end{array}$ & $\begin{array}{r}45,389 \\
-620,966 \\
- \\
-\end{array}$ & $\begin{array}{r}24.901 \\
-248.695 \\
-\end{array}$ & $\begin{array}{r}-1,277,20 \overline{-} \\
-\end{array}$ & $\begin{array}{r}-561,31 \overline{6} \\
- \\
-\end{array}$ & 2,665,7855 & $\begin{array}{r}5,423 \\
59,235 \\
- \\
-\end{array}$ & $\begin{array}{r}933.260 \\
- \\
-\end{array}$ & $\begin{array}{r}-359,956 \\
- \\
-\end{array}$ & $\begin{array}{r}652,987 \\
16,894 \\
- \\
-\end{array}$ & $\begin{array}{r}14 \% \\
0 \%\end{array}$ \\
\hline $\begin{array}{l}\text { NET FOEL OSEL } \\
\text { IN TRANSFOEHATION }\end{array}$ & $-57^{\circ}, 5 c .7$ & $-223,794$ & $-1,277,20.7$ & $-56.1,316$ & $2,665,785$ & 64,653 & $933,26 C$ & $-359,956$ & 669,881 & $14 \%$ \\
\hline $\begin{array}{l}\text { TCTAL GROSS FLCRS } \\
\text { LCSSES } \varepsilon \text { CMISSIONS }\end{array}$ & $\begin{array}{r}648,7 \cdot 4 \\
40,3: 7\end{array}$ & $\begin{array}{r}192,906 \\
3\end{array}$ & $\begin{array}{r}742,35 \Sigma \\
\equiv\end{array}$ & $\begin{array}{l}601,327 \\
-23,718\end{array}$ & $\begin{array}{r}2,665,785 \\
110,590\end{array}$ & $\begin{array}{l}864,201 \\
-23,352\end{array}$ & $\begin{array}{r}1,345,142 \\
18,207\end{array}$ & $\begin{array}{r}476,532 \\
39,539\end{array}$ & $\begin{array}{l}4,468,877 \\
161,652\end{array}$ & $\begin{array}{r}57 \% \\
3 \%\end{array}$ \\
\hline TCTAL NET OSAGE & $6 E, 1 \varepsilon .5$ & $-55,785$ & $-534,852$ & 16,291 & $2,776,376$ & 840,843 & $1,363,345$ & 156,115 & $4,630,529$ & \\
\hline $\begin{array}{l}\text { STEPLY OF ENEESY } \\
\text { FOSSIL FOEI } \\
\text { HYDRCELFCTEI: } \\
\text { NOCL BAR } \\
\text { GEC. ESOLAR }\end{array}$ & $\begin{array}{l}- \\
-\end{array}$ & $\begin{array}{l}\bar{z} \\
\bar{z}\end{array}$ & $\begin{array}{l}\overline{-} \\
\overline{-}\end{array}$ & $\begin{array}{l}- \\
-\end{array}$ & $\begin{array}{r}154,475 \\
- \\
-\end{array}$ & $\begin{array}{r}11,782 \\
= \\
=\end{array}$ & $\begin{array}{r}2,107,574 \\
=\end{array}$ & $\begin{array}{r}1, \\
1,208 \\
275,745 \\
1,468\end{array}$ & $\begin{array}{r}2,273,831 \\
1,208 \\
275,745 \\
1,468\end{array}$ & $\begin{array}{r}\varepsilon 9 \% \\
0 \% \\
11 \% \\
0 \%\end{array}$ \\
\hline TCIAL SOPPIY & - & - & - & - & 154,475 & 11,782 & $2,107,574$ & 278,421 & $2,552,252$ & \\
\hline
\end{tabular}

NET IMEORTS

OF REGION

68,185

$-55,785 \quad-534,852$

$16,291 \quad 2,621,901$

829,065

$-744,224$

NOTES:

1 TRANSPCRMATICN LOSS FCR

TRANSFERMATCN LOSS PCA

TRANSFCR AATI ON LCSS FOR

$\quad=64.46 \%$

TRANSPORUATICN LCSS FOR 
REGIONAL ENEGGY PALANCE STATEMENT

PIES MID MID SCENARIC

\begin{tabular}{|c|c|c|c|c|c|c|c|c|c|c|}
\hline SECTOF & $\begin{array}{l}\text { DISTIILATE } \\
\text { OIL }\end{array}$ & $\begin{array}{l}\text { RESIDJAL } \\
\text { OIL }\end{array}$ & $\begin{array}{l}\text { GASOLINE } \\
\text { CALL ONI }\end{array}$ & $\begin{array}{c}\text { OTHER } \\
\text { HYDRO- } \\
\text { CARBONS } \\
\text { TS IN } 10 * 9\end{array}$ & $\begin{array}{c}\text { CAUDE } \\
\text { CIL } \\
\text { BTO'S) }\end{array}$ & $\begin{array}{l}\text { NATURAL } \\
\text { GAS }\end{array}$ & COAL & ELECTRICITY & $\begin{array}{l}\text { SECTOR } \\
\text { TOTAL }\end{array}$ & \\
\hline $\begin{array}{l}\text { FIRBL CEMANL SECTOKS } \\
\text { RESIDENTIAI, CCMM. } \\
\text { IND OS TRIAL } \\
\text { TRANSPORTATICN } \\
\text { UISCELIANECTS OSES }\end{array}$ & $\begin{array}{r}198,746 \\
107,104 \\
85,009 \\
6,641\end{array}$ & $\begin{array}{r}36,3 \varepsilon 4 \\
120,436 \\
1,931 \\
3,522\end{array}$ & $442.85 \overline{-}$ & $\begin{array}{r}70,345 \\
249,173 \\
95,164 \\
142\end{array}$ & $\begin{array}{l}- \\
-\end{array}$ & $\begin{array}{r}217,851 \\
105,310 \\
4,410 \\
2,957\end{array}$ & $\begin{array}{r}1,670 \\
358,670 \\
1 \\
4\end{array}$ & $\begin{array}{r}122,386 \\
163,334 \\
63 \\
1,332\end{array}$ & $\begin{array}{r}647,382 \\
1,114,027 \\
629,432 \\
14,598\end{array}$ & $\begin{array}{r}21 \% \\
36 \% \\
20 \% \\
0 \%\end{array}$ \\
\hline $\begin{array}{l}\text { TCTAI FINAI } \\
\text { DEMAND SFCTCRS }\end{array}$ & 397,500 & 162.273 & 442,854 & 414,824 & - & 330,528 & 370,345 & 287,115 & $2,405,439$ & $78 \%$ \\
\hline $\begin{array}{l}\text { T F ANSPCRMATICN } \\
\text { ELECTRICITY GEN. } \\
\text { ERTROLEOM ERCDUCTS } \\
\text { NATURAL GAS } \\
\text { ST NTHETICS }\end{array}$ & $\begin{array}{r}32,168 \\
-286,661 \\
- \\
-\end{array}$ & $\begin{array}{r}13,603 \\
-114,818 \\
- \\
-\end{array}$ & $\begin{array}{r}-589,663 \\
\overline{-}\end{array}$ & $\begin{array}{r}-259,149 \\
313,510\end{array}$ & $\begin{array}{r}1,230,745 \\
-\end{array}$ & $\begin{array}{r}3,165 \\
27,347 \\
-282,800\end{array}$ & $\begin{array}{r}805.079 \\
- \\
-\end{array}$ & $\begin{array}{r}-303,804 \\
- \\
-\end{array}$ & $\begin{array}{r}550,211 \\
7.801 \\
30.710\end{array}$ & $\begin{array}{r}18 \% \\
0 \%\end{array}$ \\
\hline $\begin{array}{l}\text { FET FOFL DSFE } \\
\text { IN TRANSFOFATION }\end{array}$ & $-254,493$ & $-101,215$ & $-589,663$ & 54.361 & $1,230,745$ & $-252,287$ & 805,079 & $-303,804$ & 588,722 & $19 \%$ \\
\hline $\begin{array}{l}\text { TCTAL GROSS FLCRS } \\
\text { LCSSES } \& \approx M I S S I O N S\end{array}$ & $\begin{array}{r}429,668 \\
26,743\end{array}$ & $\begin{array}{r}175,876 \\
3\end{array}$ & $\begin{array}{r}442,854 \\
2\end{array}$ & $\begin{array}{l}728,334 \\
-28,728\end{array}$ & $\begin{array}{r}1,230,745 \\
51,057\end{array}$ & $\begin{array}{r}361,040 \\
-9,756\end{array}$ & $\begin{array}{r}1,175,424 \\
15,910\end{array}$ & $\begin{array}{r}287,115 \\
23,823\end{array}$ & $\begin{array}{r}2,994,161 \\
79,055\end{array}$ & $\begin{array}{r}37 \% \\
3 \%\end{array}$ \\
\hline
\end{tabular}

\begin{tabular}{|c|c|c|c|c|c|c|c|c|c|c|}
\hline SOFPLY OF ENFRGY & & & & & & & & & & \\
\hline FOSSIL FOEI & - & - & - & - & 29,055 & 1,419 & 843,542 & - & 874,016 & $94 \%$ \\
\hline HY LR CELPCT IFIC & - & & - & - & - & - & - & 1,204 & 1,204 & \\
\hline NOCL EAR & - & - & - & - & - & - & - & 53,635 & 53,635 & $6 \%$ \\
\hline GEC. ESOLAR & - & - & - & - & - & - & - & 884 & 884 & $0 x$ \\
\hline =CTAI SOPPIY & - & - & - & - & 29,055 & 1,419 & 843,542 & 55,723 & 929,739 & \\
\hline
\end{tabular}

\section{BET IM FORTS}


REGIOHAL EREAGY EALENCE STATEQENT

\begin{tabular}{|c|c|c|c|c|c|c|c|c|c|c|}
\hline SECTOB & $\underset{\text { OIL }}{D I \leq T I I L A B}$ & $\begin{array}{l}\text { EESIDUAL } \\
\text { OIL }\end{array}$ & $\begin{array}{l}\text { GASOLINE } \\
\text { (ALI ONI? }\end{array}$ & $\begin{array}{c}\text { OIHER } \\
\text { AYDRO- } \\
\text { CAREONS } \\
\text { IS IB 10**9 }\end{array}$ & $\begin{array}{c}\text { CRODE } \\
\text { OII } \\
\text { 3TU'S) }\end{array}$ & $\begin{array}{l}\text { NATOREL } \\
\text { GAS }\end{array}$ & COA.I & ELECTRICITY & $\begin{array}{r}\text { SECTOR } \\
\text { TOTAL }\end{array}$ & \\
\hline $\begin{array}{l}\text { FIRAL CEHARE SECIOSS } \\
\text { RESID BNTIAL, CCHA. } \\
\text { IND TSTRIAL } \\
\text { TRAYSPORTATION } \\
\text { GISCELLANECOS OSES }\end{array}$ & $\begin{array}{r}44.179 \\
37,020 \\
50,504 \\
4,906\end{array}$ & $\begin{array}{r}7.38 \\
18,276 \\
915\end{array}$ & $254,1.08$ & $\begin{array}{r}54.725 \\
85,843 \\
5.653 \\
159\end{array}$ & $\begin{array}{l}\overline{-} \\
\overline{-}\end{array}$ & $\begin{array}{r}130,372 \\
37,582 \\
2,2 \varepsilon 4 \\
1,277\end{array}$ & $\begin{array}{r}135 \\
66,3: 47 \\
1 \\
1\end{array}$ & $\begin{array}{r}72,277 \\
72,332 \\
- \\
726\end{array}$ & $\begin{array}{r}302,426 \\
317,400 \\
313,550 \\
7,984\end{array}$ & $\begin{array}{r}25 \% \\
26 \% \\
25 \% \\
1 \%\end{array}$ \\
\hline $\begin{array}{l}\text { TCIAL FIMAL } \\
\text { DBHARD SECTCRS }\end{array}$ & 136.609 & $19,9 \geq 9$ & $254,1.08$ & 147,380 & - & 171,515 & 66,484 & 145,335 & 941,360 & $76 \%$ \\
\hline $\begin{array}{l}\text { TBANSPCRHATICB } \\
\text { EL BCTRICITE GEN. } \\
\text { PBTRCLED FRCDOCTS } \\
\text { MATORAL GAS } \\
\text { SY NT HETICS }\end{array}$ & $\begin{array}{r}6,690 \\
- \\
-\end{array}$ & $\begin{array}{l}\overline{-} \\
\overline{-}\end{array}$ & $\begin{array}{l}\overline{-} \\
\overline{-}\end{array}$ & $\begin{array}{l}\overline{-} \\
\overline{-}\end{array}$ & $\bar{z}$ & $\begin{array}{r}2.799 \\
- \\
-\end{array}$ & $\begin{array}{r}357,037 \\
= \\
-\end{array}$ & $\begin{array}{r}-92,829 \\
- \\
-\end{array}$ & $\begin{array}{r}273,097 \\
- \\
-\end{array}$ & $22 \%$ \\
\hline $\begin{array}{l}\text { BET FOBL OSET } \\
\text { IN TBASPOSGATIOR }\end{array}$ & 6.690 & - & - & - & - & 2,199 & $357,0: 37$ & $-92,829$ & 273.097 & 229 \\
\hline $\begin{array}{l}\text { TCTAL GROSS TLOHS } \\
\text { LCSSES \& OUISSIONS }\end{array}$ & $\begin{array}{r}143,299 \\
8,919\end{array}$ & $\begin{array}{r}19,9 \geq 9 \\
0\end{array}$ & $\begin{array}{r}254,108 \\
1\end{array}$ & $\begin{array}{r}147,380 \\
-5,813\end{array}$ & $\overline{-}$ & $\begin{array}{r}173,714 \\
-4,6,94\end{array}$ & $\begin{array}{r}423,5 \cdot 21 \\
5,732\end{array}$ & $\begin{array}{r}145,335 \\
12,059\end{array}$ & $\begin{array}{r}1,214,457 \\
16,205\end{array}$ & $\begin{array}{r}99 \% \\
1 \%\end{array}$ \\
\hline $\begin{array}{l}\text { SOFELY OF ENIRGY } \\
\text { FOSS IL FOEL } \\
\text { HY DR OEL BCTEIC } \\
\text { POCL BAR } \\
\text { GEO. ESOLAR }\end{array}$ & $\begin{array}{l}- \\
-\end{array}$ & $\begin{array}{l}- \\
\overline{-} \\
-\end{array}$ & $\begin{array}{l}\bar{z} \\
\overline{-}\end{array}$ & $\begin{array}{l}- \\
\overline{-}\end{array}$ & $\begin{array}{l}\bar{z} \\
\overline{-}\end{array}$ & $\begin{array}{l}\bar{z} \\
\bar{z}\end{array}$ & $\begin{array}{r}16,765 \\
= \\
=\end{array}$ & $\begin{array}{r}1,57 \overline{5} \\
26,140 \\
-\end{array}$ & $\begin{array}{r}16,765 \\
1,575 \\
26,1140 \\
-\end{array}$ & $\begin{array}{r}32 \% \\
4 \% \\
59 \%\end{array}$ \\
\hline TCTAI SOPPIY & - & - & - & - & - & - & 16,765 & 27,715 & 44,480 & \\
\hline
\end{tabular}

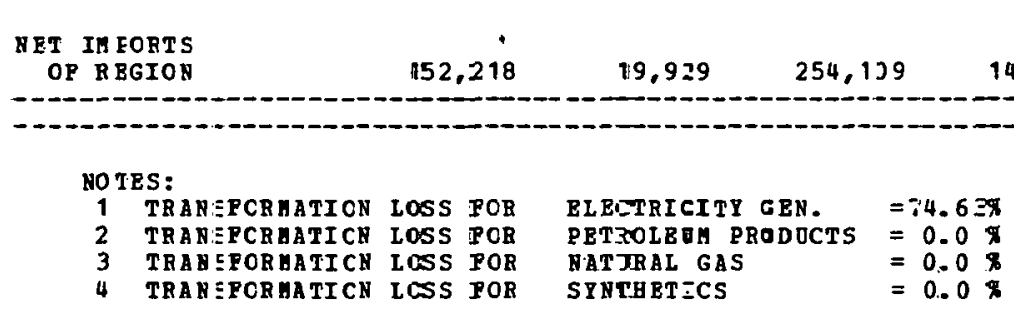


REGIONAL ENEGGY PALANCE STATEMENT

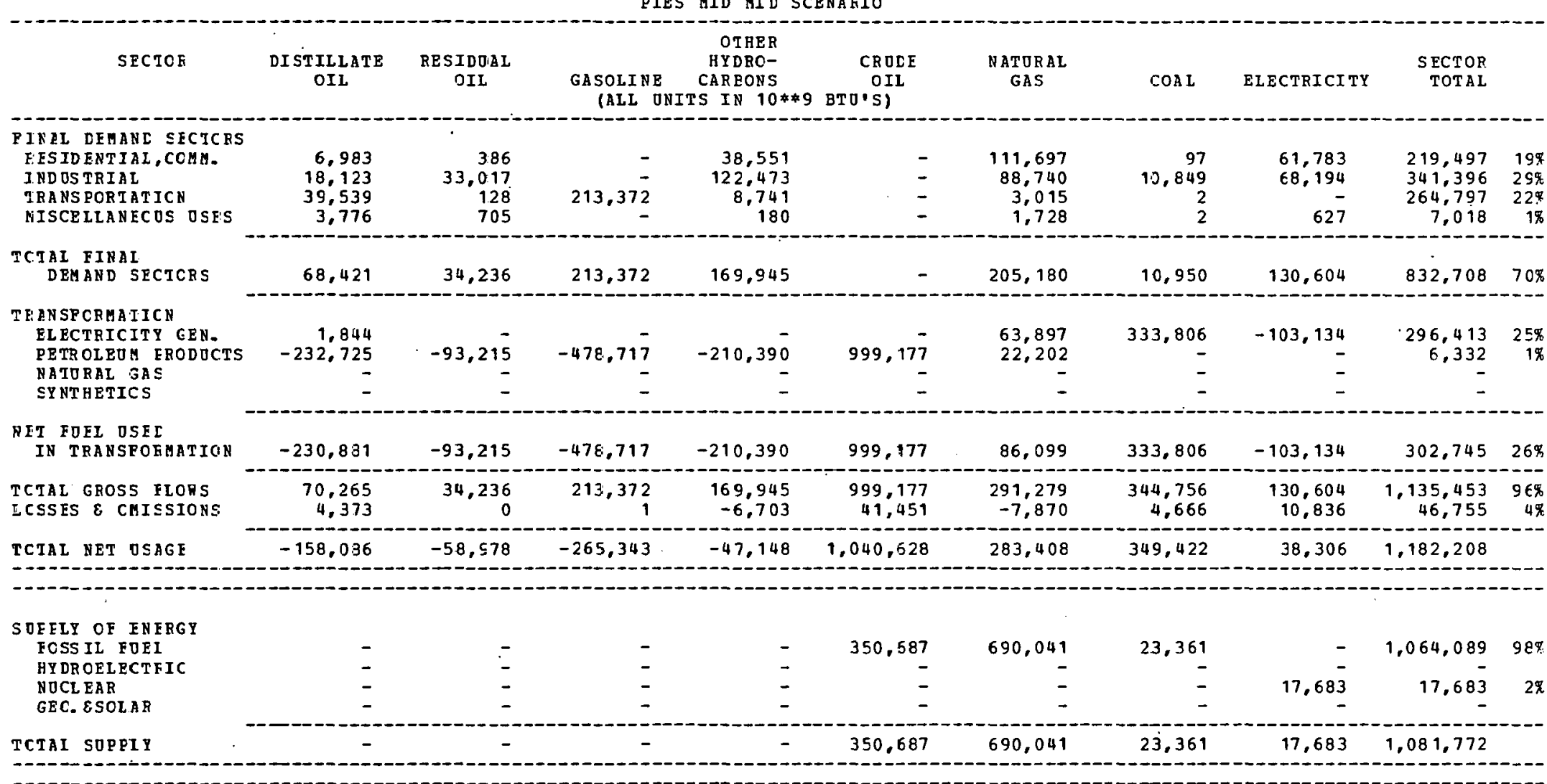

\section{NIT IM EORTS}

$-158,086$

$-58,978 \quad-265,343$

$-47,148$

689,941

$-406,632$

326,061

20,623

100,436

-

\section{NOTES:}

1 TRANSPORMATICN LOSS POR

TRANSPCRAATICN LOSS PO

TRANSPCREATICN LCSS POR

TRAN SPCRMATICN LCSS POR

BLECTRICITY GEN.

$=74.19 \%$

DRODOCTS $=0.62 \%$

$=0.0 \%$

SYNTHEICS $\quad=0.0 \%$ 
REGICHAL ENEGGY EALAUCE STBTEMENT

ICHAL ENEGGY EALAUCE STET
PIES NID MID SCEHARIO

\begin{tabular}{|c|c|c|c|c|c|c|c|c|c|}
\hline SECEOE & $\begin{array}{c}\text { DI } \equiv T \text { ILLLATE } \\
\text { OII }\end{array}$ & $\begin{array}{l}\text { RESIDJAL } \\
\text { OIL }\end{array}$ & $\begin{array}{l}\text { GASOILYE } \\
\text { (ALL ONI }\end{array}$ & $\begin{array}{l}\text { O:BER } \\
\text { EY } A \text { RO- } \\
\text { CARAONS } \\
\text { TS IL } 10 * * 9\end{array}$ & $\begin{array}{c}\text { CRIIE } \\
\text { OIL } \\
\text { BTO'S }\end{array}$ & $\begin{array}{l}\text { NATUF AI } \\
\text { GAS }\end{array}$ & $\operatorname{COAL}$ & ELECTRICITY & $\begin{array}{r}\text { SECTOR } \\
\text { TOTAL }\end{array}$ \\
\hline $\begin{array}{l}\text { FINAL TFMANL SECTORS } \\
\text { RFSIDENTIAL, CCAH. } \\
\text { IND OSTRIAL } \\
\text { TRANSPORTATICN } \\
\text { MISCELLANECOS OSES }\end{array}$ & $\begin{array}{r}13,078 \\
5,759 \\
65,696 \\
2,637\end{array}$ & $\begin{array}{r}999 \\
5,338 \\
39 \\
1,387\end{array}$ & $272,55 \overline{-}$ & $\begin{array}{r}3 \div .262 \\
4: .948 \\
1: .638 \\
127\end{array}$ & $\begin{array}{l}- \\
\overline{-} \\
-\end{array}$ & $\begin{array}{r}76,604 \\
104, \varepsilon 77 \\
1, c 84 \\
3,236\end{array}$ & $\begin{array}{r}620 \\
91,336 \\
2 \\
3\end{array}$ & $\begin{array}{r}122,348 \\
236,189 \\
- \\
1,951\end{array}$ & $\begin{array}{r}244,911 \\
491,447 \\
357,015 \\
9,341\end{array}$ \\
\hline $\begin{array}{l}\text { TCTAI FINAI } \\
\text { DEMAND SFETCRS }\end{array}$ & 97,170 & 7,763 & 272,556 & 95,975 & - & 185,807 & 91,951 & 360,488 & $1,102,714$ \\
\hline $\begin{array}{l}\text { TRANSPCRMATIEN } \\
\text { EL ECTRICIT S, GEN. } \\
\text { PETROLEOA ERCEOCTS } \\
\text { NATORAL GA: } \\
\text { SYNTHETICS }\end{array}$ & $\begin{array}{r}46,273 \\
-33,258 \\
- \\
-\end{array}$ & $\begin{array}{r}11,7 C 5 \\
-33,348 \\
- \\
-\end{array}$ & $\begin{array}{r}-171,261 \\
-\end{array}$ & $\begin{array}{r}-7 \equiv .26 \overrightarrow{6} \\
-\end{array}$ & $\begin{array}{r}357,45 \overline{8} \\
- \\
-39,608\end{array}$ & $\begin{array}{r}7,94 \overline{-} \\
- \\
-\end{array}$ & $\begin{array}{r}1,044,4: 36 \\
- \\
100,8+3\end{array}$ & $\begin{array}{r}-376,428 \\
- \\
-\end{array}$ & $\begin{array}{r}726,036 \\
2,266 \\
- \\
61,235\end{array}$ \\
\hline $\begin{array}{l}\text { NET FOEL USET } \\
\text { IN TRANSPOEATICN }\end{array}$ & $-36,985$ & $-21,543$ & $-171,261$ & $-7 \equiv .266$ & 317,850 & 7.942 & $1,145,3.29$ & $-376,428$ & 789,537 \\
\hline $\begin{array}{l}\text { TCTAL GROSS ELCHS } \\
\text { LCSSES E OHIESIOUS }\end{array}$ & $\begin{array}{r}733,443 \\
8,305\end{array}$ & $\begin{array}{r}19,468 \\
0\end{array}$ & $\begin{array}{r}272,556 \\
1\end{array}$ & $\begin{array}{l}96.975 \\
-. .825\end{array}$ & $\begin{array}{r}357,458 \\
14,829\end{array}$ & $\begin{array}{r}193,743 \\
-5,235\end{array}$ & $\begin{array}{r}7,237,230 \\
16,7+7\end{array}$ & $\begin{array}{r}360,488 \\
29,911\end{array}$ & $\begin{array}{r}1,892,251 \\
60,735\end{array}$ \\
\hline TCTAL NET OSEEE & 58,490 & $-13,379$ & 101,295 & 17,883 & 332,679 & 188,509 & $1,254,037$ & 13,971 & $1,952,986$ \\
\hline $\begin{array}{l}\text { SOEPLY CP ENFRGY } \\
\text { FOSSIL POEI } \\
\text { HYDRCELECT } \\
\text { NDCLEAR } \\
\text { GEO. ESOLAR }\end{array}$ & $\bar{z}$ & $\overline{-}$ & $\begin{array}{l}\bar{z} \\
\overline{-}\end{array}$ & $\begin{array}{l}\overline{-} \\
\overline{-}\end{array}$ & $\begin{array}{r}43,819 \\
- \\
-\end{array}$ & $\begin{array}{r}41,583 \\
= \\
-\end{array}$ & $\begin{array}{r}4,920,234 \\
- \\
-\end{array}$ & $\begin{array}{r}10,64 \overline{-} \\
- \\
-\end{array}$ & $\begin{array}{r}5.005,633 \\
10,645 \\
-\end{array}$ \\
\hline ICTAI SOPPIY & - & - & - & - & 43,819 & $41,58)$ & $L, 920,234$ & 10,645 & $5,016,278$ \\
\hline
\end{tabular}

\section{NET IMEORTS}

NET IMEORTS
CP R RGION

-

\section{NOTES:}

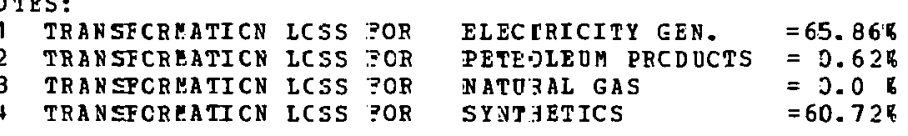


REGIONAL ENEEGY PAIANCE STATEMENT

\begin{tabular}{|c|c|c|c|c|c|c|c|c|c|c|}
\hline SECTOE & $\begin{array}{l}\text { DEISTILLATE } \\
\text { OIL }\end{array}$ & $\underset{\text { OII }}{\operatorname{RESIDUAL}}$ & $\begin{array}{l}\text { GASOLINE } \\
\text { /ALL O }\end{array}$ & $\begin{array}{c}\text { OTHER } \\
\text { HYDRO- } \\
\text { CARBONS } \\
\text { NITS IN } 10 * \$ 9\end{array}$ & $\begin{array}{l}\text { CRUDE } \\
\text { OIL } \\
\text { BTOיS) }\end{array}$ & $\begin{array}{l}\text { NATURAL } \\
\text { GAS }\end{array}$ & $\mathrm{COAL}$ & ELECTRICITY & $\begin{array}{r}\text { SECTOR } \\
\text { TOTAL }\end{array}$ & \\
\hline $\begin{array}{l}\text { PINLI LFMANL SFCIDHS } \\
\text { FESIDENTIAL, CCHM. } \\
\text { IND TSTRIAL } \\
\text { IRANSEORTATICN } \\
\text { WISCELLANECOS OSES }\end{array}$ & $\begin{array}{r}5,245 \\
85,870 \\
77,729 \\
5,550\end{array}$ & $\begin{array}{r}1,500 \\
35.1,800 \\
56,444 \\
4,670\end{array}$ & 259,431 & $\begin{array}{r}46,731 \\
1,407,802 \\
27,364 \\
107\end{array}$ & $\begin{array}{l}- \\
-\end{array}$ & $\begin{array}{r}113,122 \\
2,055,420 \\
21,463 \\
2,235\end{array}$ & $\begin{array}{r}11 \\
24,891 \\
1 \\
-\end{array}$ & $\begin{array}{r}105,656 \\
167,684 \\
1,270\end{array}$ & $\begin{array}{r}272,265 \\
4,093,467 \\
442,432 \\
13,832\end{array}$ & $\begin{array}{r}5 \% \\
78 \% \\
8 \% \\
0 \%\end{array}$ \\
\hline $\begin{array}{l}\text { TCTAL FINAI } \\
\text { DEMAND SPCICRS }\end{array}$ & 174,394 & 414,714 & 259,431 & $1,482,004$ & - & $2,192,240$ & 24,903 & 274,610 & $4,821,996$ & $91 \%$ \\
\hline $\begin{array}{l}\text { TRANSPCRHATICN } \\
\text { ELECTRICITY CEN. } \\
\text { PETRCLEM ERODOCTS } \\
\text { NATURAL GAS } \\
\text { SY NTHETICS }\end{array}$ & $\begin{array}{r}23,045 \\
-1,173,965 \\
- \\
-\end{array}$ & $\begin{array}{r}-72.537 \\
-\end{array}$ & $\begin{array}{r}-1,936,291 \\
- \\
-\end{array}$ & $\begin{array}{r}- \\
-2,037,664 \\
-\end{array}$ & $\begin{array}{r}4,831,540 \\
-\end{array}$ & $\begin{array}{r}238,867 \\
433,594 \\
- \\
-\end{array}$ & $\begin{array}{r}159,877 \\
- \\
- \\
-\end{array}$ & $\begin{array}{r}-152,158 \\
- \\
-\end{array}$ & $\begin{array}{r}309,631 \\
45,076 \\
- \\
-\end{array}$ & $\begin{array}{l}\epsilon \% \\
1 \%\end{array}$ \\
\hline $\begin{array}{l}\text { NET FOFI OSEL } \\
\text { IN TRANSOFEATION }\end{array}$ & $-1,150,920$ & -72.537 & $-1,936,291$ & $-2,037,664$ & $4,831,540$ & 672,861 & 199.877 & $-152,158$ & 354,707 & 79 \\
\hline $\begin{array}{l}\text { TCTAL GEOSS FLCHS } \\
\text { LCSSES } \& \text { OMISSIORS }\end{array}$ & $\begin{array}{r}197,439 \\
12,289\end{array}$ & $\begin{array}{r}414,+14 \\
8\end{array}$ & 259,431 & $\begin{array}{r}1,482,004 \\
-58,456\end{array}$ & $\begin{array}{r}4,831,540 \\
200,437\end{array}$ & $\begin{array}{r}2,865,101 \\
-77,421\end{array}$ & $\begin{array}{r}224,780 \\
3,042\end{array}$ & $\begin{array}{r}274,610 \\
22,785\end{array}$ & $\begin{array}{l}5,176,703 \\
102,686\end{array}$ & $\begin{array}{r}98 \% \\
2 \%\end{array}$ \\
\hline $\begin{array}{l}\text { SOEELY OF ENFRGY } \\
\text { FOSS IL FOEI } \\
\text { HYCROELPCTFIC } \\
\text { NOCLEAR } \\
\text { GEC. ESOLAR }\end{array}$ & $\begin{array}{l}- \\
-\end{array}$ & $\overline{-}$ & $\begin{array}{l}\bar{z} \\
-\end{array}$ & $\begin{array}{l}\overline{-} \\
-\end{array}$ & $\begin{array}{r}2,505,284 \\
- \\
-\end{array}$ & $\begin{array}{r}3,294,318 \\
- \\
-\end{array}$ & $\begin{array}{l}- \\
-\end{array}$ & $\begin{array}{r}379 \\
64,699 \\
6,675\end{array}$ & $\begin{array}{r}5,799,602 \\
379 \\
64,699 \\
6,675\end{array}$ & $\begin{array}{r}99 \% \\
0 \% \\
1 \% \\
0 \%\end{array}$ \\
\hline TCTAL SOPPIY & - & - & - & - & $2,505,284$ & $3,294,318$ & - & 71,753 & $5,871,355$ & \\
\hline
\end{tabular}

\begin{tabular}{l} 
BET IM FORTS \\
CF REGION \\
\hline
\end{tabular}

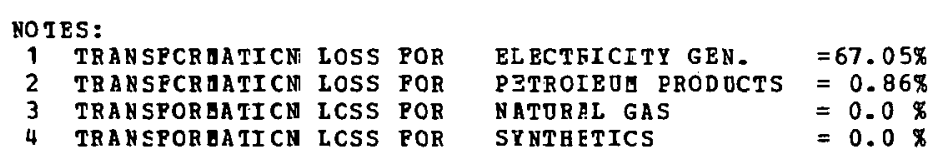


RZGICNAL ENE FGY EALANCE STATEHEUT

FIES MIJ MID SCENARIO

\begin{tabular}{|c|c|c|c|c|c|c|c|c|c|c|}
\hline SE:TOF & $\begin{array}{l}\text { DISTHLATE } \\
\text { OIL }\end{array}$ & $\begin{array}{l}\text { R3SIDVAL } \\
\text { OII }\end{array}$ & $\begin{array}{l}\text { GASO }=\text { INE } \\
\left(A^{2}=L O\right.\end{array}$ & $\begin{array}{c}\text { OTHER } \\
\text { HYDRO- } \\
\text { CA IBONS } \\
\text { CS IN } 10 * \$ 9\end{array}$ & $\begin{array}{c}\text { CRIDE } \\
\text { OIL } \\
\text { BTO'S) }\end{array}$ & $\begin{array}{l}\text { MATERAL } \\
\text { GAS }\end{array}$ & $\operatorname{COAL}$ & ELECTRICITY & $\begin{array}{r}\text { SECTOR } \\
\text { TOTAL }\end{array}$ & \\
\hline $\begin{array}{l}\text { PINAL LEMANL SECIOBS } \\
\text { RESIDENTIAI, CCAM. } \\
\text { INDOSTRIAL } \\
\text { TRANSPORTATICA } \\
\text { MISCELLANECOS OSES }\end{array}$ & $\begin{array}{r}76,547 \\
6,905 \\
8: 937 \\
1.379\end{array}$ & $\begin{array}{r}20,832 \\
82,206 \\
13,275 \\
563\end{array}$ & $\begin{array}{r}- \\
- \\
-\end{array}$ & $\begin{array}{r}1,102 \\
5,121 \\
7,098 \\
15\end{array}$ & $\bar{z}$ & $\begin{array}{r}1,824 \\
3,827 \\
604 \\
1,104\end{array}$ & $\begin{array}{r}6 \\
+92 \\
5 \\
-\end{array}$ & $\begin{array}{r}17,105 \\
26,600 \\
- \\
291\end{array}$ & $\begin{array}{r}127,416 \\
125,151 \\
118,012 \\
3,752\end{array}$ & $\begin{array}{r}29 \% \\
28 \% \\
26 \% \\
17\end{array}$ \\
\hline $\begin{array}{l}\text { TCTAI FINAL } \\
\text { DEMAND SECTCBS }\end{array}$ & 93.768 & 117.276 & 88.093 & 23,336 & - & 7,359 & 503 & 43,996 & 374,331 & 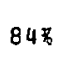 \\
\hline $\begin{array}{l}\text { TR ANSFCRHATICN } \\
\text { FLECTRICITY GEN. } \\
\text { PETR OLEOA ERODOCTS } \\
\text { NATORAL GAS } \\
\text { SY NTHETICS: }\end{array}$ & $\begin{array}{r}4,874 \\
-291,028 \\
=\end{array}$ & $\begin{array}{r}18,223 \\
-31,568 \\
- \\
-\end{array}$ & $\begin{array}{r}-325,296 \\
-\end{array}$ & $\begin{array}{r}-96,198 \\
-\end{array}$ & $\begin{array}{r}740.246 \\
- \\
-\end{array}$ & $\begin{array}{r}\overline{-} \\
\overline{-} \\
-\end{array}$ & $\begin{array}{r}25,186 \\
- \\
-\end{array}$ & $\begin{array}{r}-16,524 \\
- \\
- \\
-\end{array}$ & $\begin{array}{r}31,759 \\
-225 \\
-\end{array}$ & $\begin{array}{l}7 \% \\
0 \% \\
.\end{array}$ \\
\hline $\begin{array}{l}\text { NET FOEL OSEL } \\
\text { I TRANSOEMATICN }\end{array}$ & -286.154 & -13.745 & -325.296 & $-56,198$ & 740.246 & 4,019 & 25,186 & $-16,524$ & 31,534 & 79 \\
\hline $\begin{array}{l}\text { TCTAL GROSS FLORS } \\
\text { LCSSES } \varepsilon \text { CUISSIONS }\end{array}$ & $\begin{array}{r}98.642 \\
6: 139 \\
\end{array}$ & $\begin{array}{r}-35,4999 \\
2\end{array}$ & $\begin{array}{r}88,093 \\
0\end{array}$ & $\begin{array}{r}83,336 \\
-920\end{array}$ & $\begin{array}{r}740,246 \\
30,709\end{array}$ & $\begin{array}{r}11,378 \\
-307\end{array}$ & $\begin{array}{r}25.689 \\
347\end{array}$ & $\begin{array}{r}43,996 \\
3,650\end{array}$ & $\begin{array}{r}406,090 \\
39,62 \hat{z}\end{array}$ & $\begin{array}{r}91 \% \\
9 \%\end{array}$ \\
\hline TCIAL NET OSAGE & -186.246 & 103,533 & $-237,202$ & $-73,782$ & 770,955 & 11,070 & 26.036 & 31,122 & 445,487 & \\
\hline
\end{tabular}

\begin{tabular}{|c|c|c|c|c|c|c|c|c|c|c|}
\hline $\begin{array}{l}\text { SOFELY OP EFFRGI } \\
\text { FOSS II EOEL }\end{array}$ & - & - & - & & & & & - & - & \\
\hline HY DR OELECTEIC & - & - & 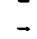 & $\overline{-}$ & - & $\overline{-}$ & $=$ & 3.636 & $3.63 \bar{\epsilon}$ & 18 \\
\hline NOCL EAR & - & - & - & - & - & - & - & 15,967 & 15,967 & $78 \%$ \\
\hline GEC. \&SOL $h \mathrm{~F}$ & - & - & - & - & - & - & - & 878 & 878 & 49 \\
\hline TCIAI SOPPIY & - & - & - & - & - & - & - & 20,481 & 20,489 & \\
\hline
\end{tabular}

\begin{tabular}{|c|c|c|c|c|c|}
\hline \multicolumn{2}{|c|}{$\begin{array}{l}\text { NET IM FORTS } \\
\text { OP REGION }\end{array}$} & -486.246 & $10.3,533$ & \multicolumn{2}{|c|}{$-237,202$} \\
\hline \multicolumn{6}{|c|}{ NOTES: } \\
\hline 1 & TRANSPORHATICN & LESS POR & ELECTRIGI? & SEN. & $=05.788$ \\
\hline 2 & TRANSFCBMATICH & LESS POR & PETE OLE JM & RJDOCTS & $=-0.03 \%$ \\
\hline 3 & TRANSPCRMATICN & LESS POR & NATCRAL GA & & $=0.0$ \\
\hline 4 & TRAN SPOREATI CN & LESS FOR & SYNI HETICS & & $=0.0$ \\
\hline
\end{tabular}


REGIONAL ENEEGY BALANCE STATEMENT
PIES BID GID SCENARIO

\begin{tabular}{|c|c|c|c|c|c|c|c|c|c|c|}
\hline SECTON & $\begin{array}{l}\text { DISTILLATE } \\
\text { OIL }\end{array}$ & $\begin{array}{l}\text { BZSIDOAL } \\
\text { OIL }\end{array}$ & $\begin{array}{l}\text { GASOLIN } \\
\text { (ALL }\end{array}$ & $\begin{array}{c}\text { OTHER } \\
\text { HYDRO- } \\
\text { CAREONS } \\
\text { TS IN 10**9 }\end{array}$ & $\begin{array}{c}\text { CRODE } \\
\text { OIL } \\
\text { BTU'SI }\end{array}$ & $\begin{array}{l}\text { NATURAL } \\
\text { GAS }\end{array}$ & $\operatorname{COAL}$ & ELECTRICITY & $\begin{array}{r}\text { SECTOR } \\
\text { TOTAL }\end{array}$ & \\
\hline $\begin{array}{l}\text { FIRIL DFHANC SECTORS } \\
\text { GESIDENTIAL , CCAH. } \\
\text { IND OSTRIAL } \\
\text { TRANSPORTAICR } \\
\text { GISCELLABEOS OSES }\end{array}$ & $\begin{array}{r}89,838 \\
39,469 \\
26,496 \\
7.441\end{array}$ & $\begin{array}{r}18,236 \\
49,145 \\
19,356 \\
3,718\end{array}$ & 302,464 & $\begin{array}{r}26,405 \\
39,721 \\
20,118 \\
126\end{array}$ & $\begin{array}{l}\overline{-} \\
\overline{-}\end{array}$ & $\begin{array}{r}88,997 \\
33,752 \\
5,370 \\
8,730\end{array}$ & $\begin{array}{r}289 \\
103,665 \\
20 \\
31\end{array}$ & $\begin{array}{r}97,506 \\
52,013 \\
712 \\
3,755\end{array}$ & $\begin{array}{r}321,271 \\
317,765 \\
374,536 \\
23,801\end{array}$ & $\begin{array}{r}26 \% \\
26 \% \\
31 \% \\
2 \%\end{array}$ \\
\hline $\begin{array}{l}\text { TCTAI FINAI } \\
\text { DEHAND SECTCRS }\end{array}$ & 163,244 & 90,455 & 302,464 & 86,370 & - & 136,849 & 104,005 & 153,986 & $1,037,373$ & $86 \%$ \\
\hline $\begin{array}{l}\text { TE ARSPORMATICY } \\
\text { BLECTRICITY GEN. } \\
\text { PBTR OLEOA ERODOCTS } \\
\text { HATORAL GAS } \\
\text { SYNTHETICS }\end{array}$ & $\begin{array}{r}8,808 \\
-135,328 \\
-\end{array}$ & $\begin{array}{r}49,122 \\
-14,865 \\
- \\
-\end{array}$ & $\begin{array}{r}-151,26 \overline{-} \\
-\end{array}$ & $\begin{array}{r}-44,732 \\
125,245\end{array}$ & 344,214 & $\begin{array}{r}1,410 \\
1,868 \\
-112,975\end{array}$ & $\begin{array}{r}138,640 \\
- \\
-\end{array}$ & $\begin{array}{r}-63,587 \\
- \\
-\end{array}$ & $\begin{array}{r}134,393 \\
-104 \\
- \\
12,270\end{array}$ & $\begin{array}{r}11 \% \\
0 \%\end{array}$ \\
\hline $\begin{array}{l}\text { BIT FOEL OSEL } \\
\text { IE TRABSPOEGATICN }\end{array}$ & $-126,520$ & 34,257 & $-151,262$ & 80,513 & 344,214 & $-109,696$ & 138,640 & -63.587 & 146,558 & $12 \%$ \\
\hline $\begin{array}{l}\text { TCTAL GROSS FIONS } \\
\text { LGSSES } 8 \text { OHISSIONS }\end{array}$ & $\begin{array}{r}172,052 \\
10,709\end{array}$ & $\begin{array}{r}139,577 \\
2\end{array}$ & $\begin{array}{r}302,464 \\
1\end{array}$ & $\begin{array}{r}21.1,615 \\
-8,347\end{array}$ & $\begin{array}{r}344,214 \\
14,279\end{array}$ & $\begin{array}{r}140,127 \\
-3,786\end{array}$ & $\begin{array}{r}242,645 \\
3,284\end{array}$ & $\begin{array}{r}153,986 \\
12,776\end{array}$ & $\begin{array}{r}1,184,036 \\
28,920\end{array}$ & $\begin{array}{r}98 \% \\
2 \%\end{array}$ \\
\hline $\begin{array}{l}\text { SOFFLY OF ENIBGY } \\
\text { FOSSIL FORI } \\
\text {-HYDR CELECTFIC } \\
\text { ROCL EAR } \\
\text { GBO. ESOLAR }\end{array}$ & $\begin{array}{l}\overline{-} \\
\overline{-}\end{array}$ & $\begin{array}{l}- \\
-\end{array}$ & $\begin{array}{l}- \\
- \\
-\end{array}$ & $\begin{array}{l}- \\
- \\
-\end{array}$ & $\begin{array}{r}17,935 \\
- \\
-\end{array}$ & $\begin{array}{r}70,532 \\
= \\
-\end{array}$ & $\begin{array}{r}87,175 \\
= \\
-\end{array}$ & $\begin{array}{r}3,710 \\
50,487 \\
-\end{array}$ & $\begin{array}{r}175,642 \\
3,710 \\
50,487 \\
-\end{array}$ & $\begin{array}{r}76 \% \\
2 \% \\
22 \%\end{array}$ \\
\hline TCTAL SUPPIP & - & - & - & - & 17,935 & 70,532 & 87,175 & 54,197 & 229,839 & \\
\hline
\end{tabular}

\begin{tabular}{l}
$\begin{array}{l}\text { YET IM FORTS } \\
\text { OP REGIOR }\end{array}$ \\
\hline
\end{tabular}


REGIONAL ENERGY BALANCE STATEMENT

PIES MID MID SCENARIO

\begin{tabular}{|c|c|c|c|c|c|c|c|c|c|c|}
\hline SEETOE & $\begin{array}{c}\text { DESTILIATE } \\
\text { OII }\end{array}$ & $\begin{array}{l}\text { RZSIDUAL } \\
\text { OIL }\end{array}$ & $\begin{array}{l}\text { GASOZINE } \\
\quad \text { (AEL }\end{array}$ & $\begin{array}{c}\text { OTHER } \\
\text { HEDRO- } \\
\text { CAEBONS } \\
\text { TS IN 10**9 }\end{array}$ & $\begin{array}{c}\text { CROLE } \\
\text { OIL } \\
\text { BTO'S) }\end{array}$ & $\begin{array}{l}\text { NATCRAL } \\
\text { GAS }\end{array}$ & $\cos \mathrm{L}$ & ELECTRICITY & $\begin{array}{r}\text { SECTOR } \\
\text { TOTAL }\end{array}$ & \\
\hline 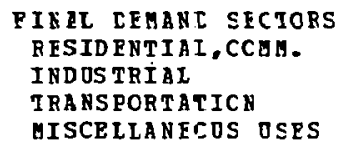 & $\begin{array}{r}455,710 \\
7.081 \\
26.842 \\
5, \geq 21\end{array}$ & $\begin{array}{r}140,197 \\
51,491 \\
3,265 \\
3,714\end{array}$ & $377,99 \overline{1}$ & $\begin{array}{r}61.383 \\
56.607 \\
54.942 \\
75\end{array}$ & $\begin{array}{l}\overline{-} \\
\overline{-}\end{array}$ & $\begin{array}{r}148,346 \\
39,429 \\
6,147 \\
6,870\end{array}$ & $\begin{array}{r}3 \\
582 \\
3 \\
-\end{array}$ & $\begin{array}{r}97,946 \\
42.284 \\
100 \\
1.448\end{array}$ & $\begin{array}{r}903,585 \\
197,574 \\
469,290 \\
17,428\end{array}$ & $\begin{array}{l}51 \% \\
11 \% \\
27 \% \\
1 \%\end{array}$ \\
\hline $\begin{array}{l}\text { TCIAI FINAI } \\
\text { DEMAND SECICRS }\end{array}$ & 494.954 & 198,667 & 377,991 & 173,007 & - & 200,792 & 588 & 141,778 & $1,587,877$ & $90 \%$ \\
\hline $\begin{array}{l}\text { TRANSPCRUATICN } \\
\text { ELECTRICITY GEN. } \\
\text { PETROLEOH ERCDOCTS } \\
\text { NATDRAL GAS } \\
\text { SYNTHETICS }\end{array}$ & $\begin{array}{r}25.350 \\
-58,206 \\
- \\
-\end{array}$ & $\begin{array}{r}78,184 \\
-6,393 \\
- \\
-\end{array}$ & $\begin{array}{r}-65,05 \overline{-} \\
- \\
-\end{array}$ & $\begin{array}{r}-\cdot 9.239 \\
-\end{array}$ & $\begin{array}{r}5 \\
148.049 \\
-\end{array}$ & ${ }^{80 \overline{-}}$ & $\begin{array}{r}86,650 \\
- \\
- \\
\cdots-\end{array}$ & $\begin{array}{r}-72,229 \\
- \\
-\end{array}$ & $\begin{array}{r}137,955 \\
-44 \\
- \\
-\end{array}$ & $\begin{array}{l}8 \% \\
0 \%\end{array}$ \\
\hline $\begin{array}{l}\text { WFT FOEI OSE } \\
\text { IN TRANSPOFHATICN }\end{array}$ & -32.856 & $\exists 1,790$ & $-65,059$ & $-i 9,239$. & 148,049 & 803 & 86,650 & $-72,229$ & 137,910 & $8 \%$ \\
\hline $\begin{array}{l}\text { TCIAL GROSS FLCFS } \\
\text { LCSSES } \& \text { CMISSIONS }\end{array}$ & $\begin{array}{r}520.304 \\
32,3 \varepsilon 5\end{array}$ & $\begin{array}{r}276,851 \\
5\end{array}$ & $\begin{array}{r}377.991 \\
1\end{array}$ & $\begin{array}{r}1: 3,007 \\
-6,824\end{array}$ & $\begin{array}{r}148,049 \\
6,141\end{array}$ & $\begin{array}{r}201,595 \\
-5,447\end{array}$ & $\begin{array}{r}87,338 \\
1,182\end{array}$ & $\begin{array}{r}141,778 \\
11,763\end{array}$ & $\begin{array}{r}1,725,832 \\
39,209\end{array}$ & $\begin{array}{r}98 \% \\
2 \pi\end{array}$ \\
\hline TOIAL NET OSAGE & 794,483 & 230,463 & 312,933 & $1<6.943$ & 154,190 & 196,148 & 88,520 & 81,312 & $1,764,996$ & \\
\hline $\begin{array}{l}\text { SOFELY OF EVERGY } \\
\text { FCSSIL FOEI } \\
\text { HY IROELECEFIC } \\
\text { NOCLEAR } \\
\text { GEC. ESOLAB }\end{array}$ & $\overline{-}$ & $\begin{array}{l}\bar{z} \\
\overline{-}\end{array}$ & $\begin{array}{l}\bar{z} \\
\bar{z}\end{array}$ & $\begin{array}{l}- \\
- \\
-\end{array}$ & $\begin{array}{l}- \\
-\end{array}$ & - & $\begin{array}{l}- \\
=\end{array}$ & $\begin{array}{r}7.938 \\
37,773 \\
2,829\end{array}$ & $\begin{array}{r}7.938 \\
37.773 \\
2.829\end{array}$ & $\begin{array}{r}1 \in 8 \\
78 \% \\
6 \%\end{array}$ \\
\hline TCTAI SUPPI: & - & - & - & - & - & - & - & 48,540 & 48,540 & \\
\hline
\end{tabular}

NET IM FORTS

194:- 483

290,463

312,533

146,943

154,190

$196,1+8$

88,520

$32,772 \quad 1,716,456$

-

\section{NOTES:}

1 TRAF SRCRHATICD LOSS FOR TRAESPCRMATICU LOSS PCR TRAESPCRMATICM IOSS POR TRAESPORMATICI LOSS FO 
REGIONAL ENEGGY EALANCE STATEMENT

PIES MID MID SCENARIO

\begin{tabular}{|c|c|c|c|c|c|c|c|c|c|c|}
\hline SECIOE & $\begin{array}{l}\text { DISTILLATE } \\
\text { OIL }\end{array}$ & $\begin{array}{l}\text { RESIDDAL } \\
\text { OIL }\end{array}$ & $\begin{array}{l}\text { GASOLINE } \\
\text { (ALL D }\end{array}$ & $\begin{array}{c}\text { OTHER } \\
\text { HYDRO- } \\
\text { CARBONS } \\
\text { TS IN } 10 * * 9\end{array}$ & $\begin{array}{c}\text { CRODE } \\
\text { OIL } \\
\text { BTO'S) }\end{array}$ & $\begin{array}{l}\text { NATORAL } \\
\text { GAS }\end{array}$ & COAI & EIECTRICITY & $\begin{array}{r}\text { SECTOR } \\
\text { TOTAL }\end{array}$ & \\
\hline $\begin{array}{l}\text { PINZL CEHANI SECTOES } \\
\text { FESIDENTIAL,CCAN. } \\
\text { INDOSTRIAL } \\
\text { TRLNSPORTATICN } \\
\text { HISCELLANECOS OSES }\end{array}$ & $\begin{array}{r}245,723 \\
56,951 \\
66,948 \\
11,154\end{array}$ & $\begin{array}{r}12,146 \\
94,442 \\
2,900 \\
5,921\end{array}$ & $748,50 \frac{-}{-}$ & $\begin{array}{r}122,207 \\
269,951 \\
27,924 \\
254\end{array}$ & $\begin{array}{l}\overline{-} \\
\overline{-}\end{array}$ & $\begin{array}{r}520,201 \\
112,857 \\
11,003 \\
5,331\end{array}$ & $\begin{array}{r}1,383 \\
510,752 \\
1 \\
10\end{array}$ & $\begin{array}{r}201,595 \\
257,012 \\
2,395\end{array}$ & $\begin{array}{r}1,103,255 \\
1,301,965 \\
857,278 \\
25,065\end{array}$ & $\begin{array}{l}29 \% \\
34 \% \\
22 \% \\
1 \%\end{array}$ \\
\hline $\begin{array}{l}\text { TCIMI FINAL } \\
\text { DEMAND SECTCRS }\end{array}$ & 380,776 & $115,40 \subseteq$ & 748,502 & 420,336 & - & 649,392 & 512,146 & 461,002 & $3,287,563$ & $8 E \%$ \\
\hline $\begin{array}{l}\text { TRADSPCRHATICH } \\
\text { ELECTRICITY GEN. } \\
\text { PITR OLEDH ERCDOCTS } \\
\text { NLTURAL GAS } \\
\text { SINTEETICS }\end{array}$ & $\begin{array}{r}47,178 \\
-84,933 \\
-\end{array}$ & $\begin{array}{r}26.535 \\
-34.018 \\
- \\
-\end{array}$ & $\begin{array}{r}-174.707 \\
-\end{array}$ & $\begin{array}{r}-76,781 \\
- \\
-\end{array}$ & $\begin{array}{r}364,649 \\
-\end{array}$ & $\begin{array}{r}7,671 \\
8,102 \\
- \\
-\end{array}$ & $\begin{array}{r}655,658 \\
- \\
-\end{array}$ & $\begin{array}{r}-261,272 \\
- \\
-\end{array}$ & $\begin{array}{r}475,770 \\
2,310 \\
- \\
-\end{array}$ & $\begin{array}{r}12 \% \\
0 \%\end{array}$ \\
\hline $\begin{array}{l}\text { NET FOEL DSFL } \\
\text { IIITANSOEHATION }\end{array}$ & $-37,755$ & $-7,48 \equiv$ & -174.707 & $-76,781$ & 364,649 & 15,773 & 655,658 & $-261,272$ & 478,080 & $12 \%$ \\
\hline $\begin{array}{l}\text { TCTAL GROSS FLORS } \\
\text { ICSSES } \varepsilon \text { OMISSIONS }\end{array}$ & $\begin{array}{r}427,954 \\
26,637\end{array}$ & $\begin{array}{r}141,944 \\
2\end{array}$ & $\begin{array}{r}748,502 \\
3\end{array}$ & $\begin{array}{r}420,336 \\
-16,579\end{array}$ & $\begin{array}{r}364,649 \\
15,127\end{array}$ & $\begin{array}{l}665,165 \\
-17,974\end{array}$ & $\begin{array}{r}1,167,804 \\
15,807\end{array}$ & $\begin{array}{r}461,002 \\
38,251\end{array}$ & $\begin{array}{r}3,765,643 \\
61,275\end{array}$ & $\begin{array}{r}98 \% \\
2 \%\end{array}$ \\
\hline
\end{tabular}

-

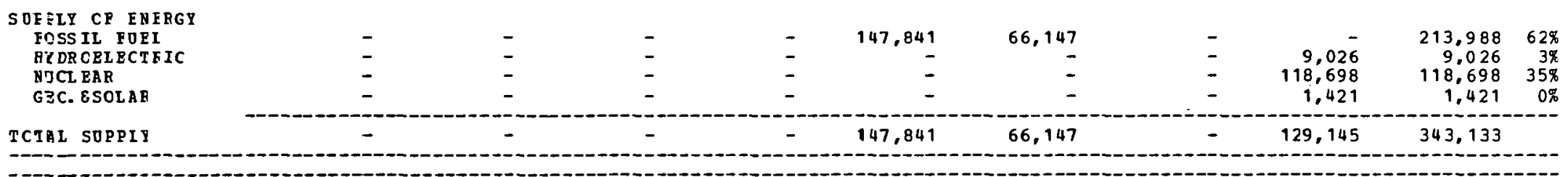

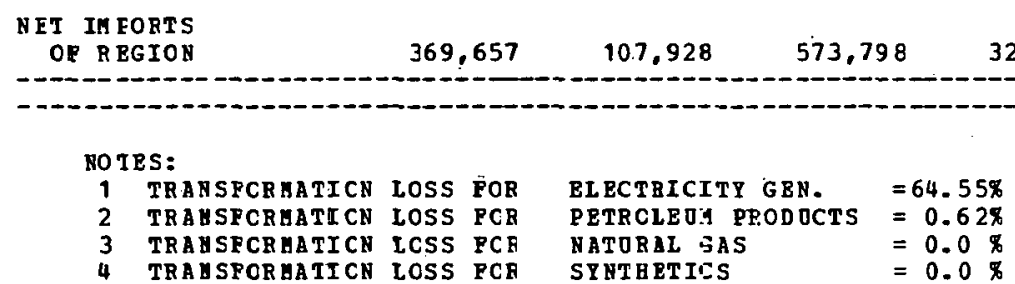


REGIOLAL EUEZTEY EALANCE STATEMENT

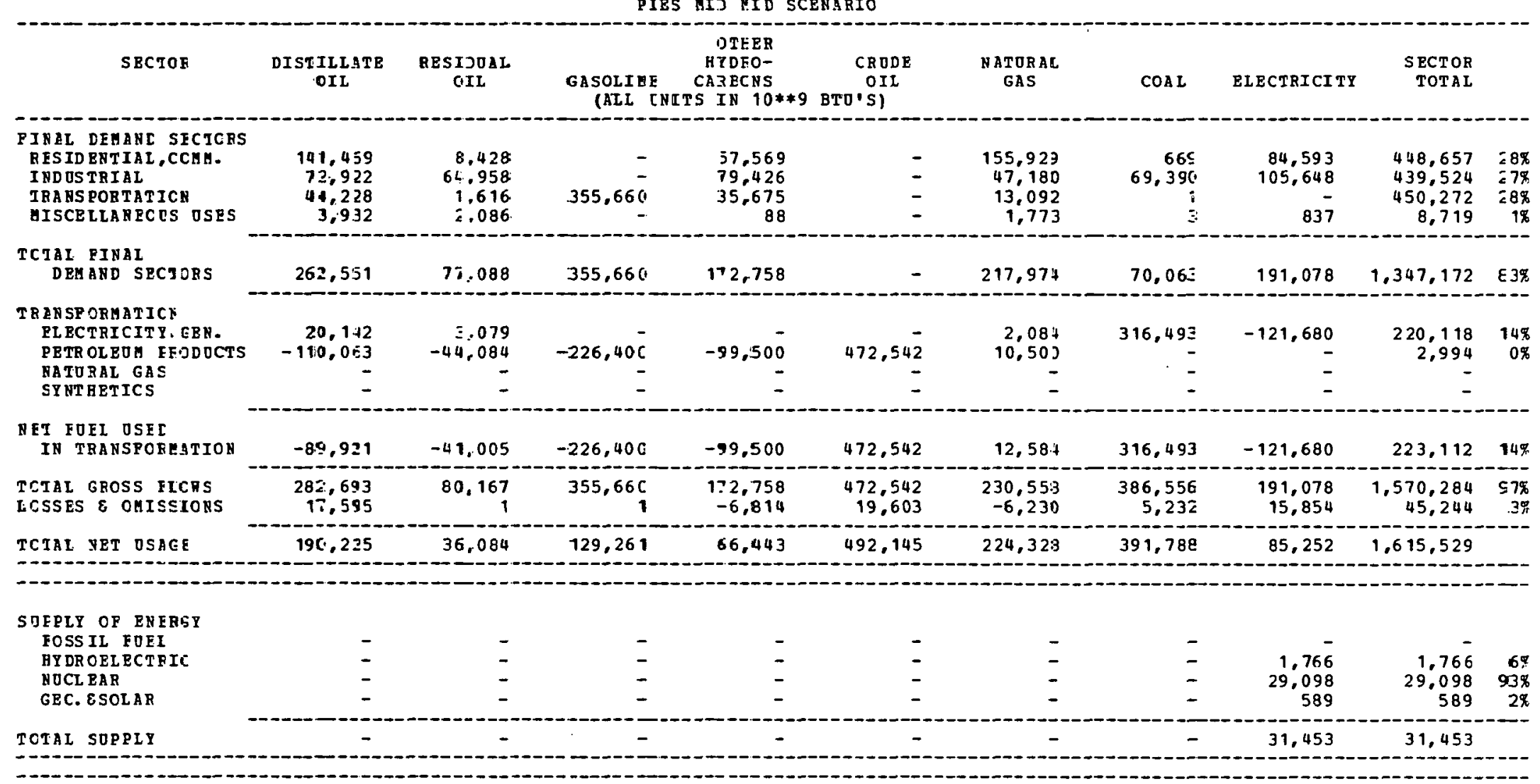

\begin{tabular}{l}
$\begin{array}{l}\text { NET IM FORTS } \\
\text { OP REGION }\end{array}$ \\
\hline
\end{tabular}


REG ICNAL ENEFGY EALANCE STATEMENT
PIES MID MID SCENARIO

\begin{tabular}{|c|c|c|c|c|c|c|c|c|c|c|}
\hline SECTOE & $\begin{array}{l}\text { DISTILLATE } \\
\text { OIL }\end{array}$ & $\begin{array}{l}\text { RESIDOAL } \\
\text { CIL }\end{array}$ & $\begin{array}{l}\text { GASOLINE } \\
\text { (ALL O: }\end{array}$ & $\begin{array}{c}\text { OTHER } \\
\text { HYDRO- } \\
\text { CARBONS } \\
\text { TS IN } 10 * * 9\end{array}$ & $\begin{array}{c}\text { CRODE } \\
\text { OII } \\
\text { BTO.5) }\end{array}$ & $\begin{array}{l}\text { NATORAL } \\
\text { GAS }\end{array}$ & $\operatorname{COAL}$ & ELECTRICITY & $\begin{array}{r}\text { SECTOR } \\
\text { TOTAL }\end{array}$ & \\
\hline $\begin{array}{l}\text { PINAL CEHANC SECTOFS } \\
\text { RESIDENTIAL, CCNH. } \\
\text { IND OSTRIAL } \\
\text { TRANSPORTATICN } \\
\text { MISCELLANECLS TSES }\end{array}$ & $\begin{array}{r}10,570 \\
5,181 \\
51,744 \\
1,290\end{array}$ & $\begin{array}{r}735 \\
13,945 \\
2,576 \\
680\end{array}$ & $203,18 \bar{z}$ & $\begin{array}{r}21,683 \\
36,387 \\
5,515 \\
65\end{array}$ & $\begin{array}{l}\overline{-} \\
\overline{-}\end{array}$ & $\begin{array}{r}30,090 \\
140,138 \\
1,294 \\
1,503\end{array}$ & $\begin{array}{r}302 \\
26,026 \\
\frac{1}{1}\end{array}$ & $\begin{array}{r}91,094 \\
125,233 \\
- \\
754\end{array}$ & $\begin{array}{r}154,474 \\
346,910 \\
264,311 \\
4,293\end{array}$ & $\begin{array}{r}14 \% \\
32 \% \\
24 \% \\
0 \%\end{array}$ \\
\hline $\begin{array}{l}\text { TCTAL FINAI } \\
\text { DEMAND SECTOFS }\end{array}$ & 68,785 & 17,936 & 203,182 & 63,650 & - & 173,025 & 26,329 & 217,081 & 769,988 & $70 \%$ \\
\hline $\begin{array}{l}\text { TFANSPCRMATICN } \\
\text { ELFCTRICITY EEN. } \\
\text { PETROLEO ERCDOCTS } \\
\text { NATORAL GAS } \\
\text { SYNT HETICS }\end{array}$ & $\begin{array}{r}27.865 \\
-161.365 \\
-\end{array}$ & $\begin{array}{r}26,551 \\
-9.970 \\
-\end{array}$ & $\begin{array}{r}-266,148 \\
-\end{array}$ & $\begin{array}{r}-280,082 \\
-\end{array}$ & 664,109 & 59,653 & $\begin{array}{r}354,601 \\
- \\
-\end{array}$ & $\begin{array}{r}-139,995 \\
- \\
-\end{array}$ & $\begin{array}{r}269,062 \\
6.196 \\
-\end{array}$ & $\begin{array}{r}25 \% \\
1 \%\end{array}$ \\
\hline $\begin{array}{l}\text { NET FOFL USEL } \\
\text { IN TRANSPOEMATION }\end{array}$ & $-133,500$ & 16.620 & -266.148 & $-280,082$ & 664.109 & 59,653 & 354,601 & $-139,995$ & 275,258 & $25 \%$ \\
\hline $\begin{array}{l}\text { TCIAL GROSS FLCRS } \\
\text { LCSSES E CMISSIONS }\end{array}$ & $\begin{array}{r}96,650 \\
6,015\end{array}$ & $\begin{array}{r}44.527 \\
0\end{array}$ & $\begin{array}{r}2.53,182 \\
0\end{array}$ & $\begin{array}{l}63,650 \\
-2,510\end{array}$ & $\begin{array}{r}664,109 \\
27,550\end{array}$ & $\begin{array}{r}232,678 \\
-6,287\end{array}$ & $\begin{array}{r}380,930 \\
5,156\end{array}$ & $\begin{array}{r}217,081 \\
18,012\end{array}$ & $\begin{array}{r}1,045,246 \\
47,938\end{array}$ & $\begin{array}{r}96 \% \\
4 \%\end{array}$ \\
\hline TCTAL NET OSAGE & $-58,699$ & 34,557 & $-62,965$ & $-218,943$ & 691,659 & 226,391 & 386,086 & $\$ 5,098$ & $1,093,184$ & \\
\hline
\end{tabular}

\begin{tabular}{|c|c|c|c|c|c|c|c|c|c|c|}
\hline SOEELY OF ENERGY & & & & & & & & & & \\
\hline FOSSIL FOEI & - & - & - & - & 247,340 & 70,961 & - & - & 318,301 & $77 x$ \\
\hline RY DR OELECTEIC & - & - & - & - & - & - & - & 1,121 & 1,121 & $0 \%$ \\
\hline NOCL BAR & - & - & - & - & - & - & - & 91,378 & 91,378 & $22 \%$ \\
\hline GEO. ESOLAR & - & - & - & - & - & - & - & - & - & \\
\hline ICTAL SOPPIY & - & - & - & - & 247,340 & 70,961 & - & 92,499 & 410,800 & \\
\hline
\end{tabular}

\begin{tabular}{l}
$\begin{array}{l}\text { TET IM PORTS } \\
\text { CF R RGION }\end{array}$ \\
\hline
\end{tabular}


REGICNAL ENEFGY PALANCE STATEMENT

FIES NID MID SCENARIO

\begin{tabular}{|c|c|c|c|c|c|c|c|c|c|c|}
\hline SE:TOF & $\begin{array}{l}\text { DISTIILATE } \\
\text { OII }\end{array}$ & $\begin{array}{c}\text { RESIDOAL } \\
\text { OIB }\end{array}$ & $\begin{array}{l}\text { GASOIINE } \\
\text { (AIL O }\end{array}$ & $\begin{array}{c}\text { OTHER } \\
\text { HIDRO- } \\
\text { CAREONS } \\
\text { TS }=N \quad 10 * * 9\end{array}$ & $\begin{array}{c}\text { CROLE } \\
\text { OIL } \\
\text { BTO'S) }\end{array}$ & $\begin{array}{l}\text { NATERAL } \\
\text { GAS }\end{array}$ & $\cos I$ & ELECTRICITY & $\begin{array}{r}\text { SECTOR } \\
\text { TOTAL }\end{array}$ & \\
\hline $\begin{array}{l}\text { PINEL CEMANC SFCTOES } \\
\text { RFSIDENTIA, CCMA. } \\
\text { INDOSTRIAL } \\
\text { TRANSPORTAIICN } \\
\text { UISCELLAMEOCS OSES }\end{array}$ & $\begin{array}{l}70,279 \\
32,025 \\
74,263 \\
11,451\end{array}$ & $\begin{array}{r}5,138 \\
25,854 \\
144 \\
2,140\end{array}$ & $413,72 \frac{-}{-}$ & $\begin{array}{r}38,896 \\
211,576 \\
54,325 \\
414\end{array}$ & $\begin{array}{l}- \\
-\end{array}$ & $\begin{array}{r}193.936 \\
109.143 \\
9.232 \\
3,458\end{array}$ & $\begin{array}{r}189 \\
109.794 \\
3 \\
6\end{array}$ & $\begin{array}{r}113,051 \\
67,264 \\
67 \\
1,761\end{array}$ & $\begin{array}{r}476,789 \\
555,655 \\
552,360 \\
19,230\end{array}$ & $\begin{array}{r}21 \% \\
25 \% \\
24 \% \\
1 \%\end{array}$ \\
\hline $\begin{array}{l}\text { TCTAL FINAI } \\
\text { DEMAND SECTCRS }\end{array}$ & $18 \varepsilon, 018$ & 33,576 & 413,726 & 355,211 & - & $316 . \Xi 69$ & 109,992 & 187,143 & $9,604,035$ & $71 \%$ \\
\hline $\begin{array}{l}\text { TRARSPCRMATICN } \\
\text { ELECTRICITY GEN. } \\
\text { PETROLEOA ERCDOCTS } \\
\text { NATORAL GAS } \\
\text { SY NTHETIC: }\end{array}$ & $\begin{array}{r}\overline{1}, 761 \\
-5 \bar{L}, 321 \\
-\end{array}$ & $\begin{array}{r}-21,757 \\
-\end{array}$ & $\begin{array}{r}-111,73 \overline{-} \\
-\end{array}$ & $\begin{array}{r}-49,107 \\
-\end{array}$ & $\begin{array}{r}233,220 \\
-\end{array}$ & $\begin{array}{r}13.681 \\
5.982 \\
=\end{array}$ & $\begin{array}{r}822,933 \\
- \\
-\end{array}$ & $\begin{array}{r}-213,765 \\
- \\
-\end{array}$ & $\begin{array}{r}630,610 \\
1,479 \\
-\end{array}$ & $\begin{array}{r}28 \% \\
0 \%\end{array}$ \\
\hline $\begin{array}{l}\text { NET FOEL OSEL } \\
\text { IN TRANSFOEHATION }\end{array}$ & $-46,560$ & -21.757 & -111.733 & $-49,107$ & 233,220 & 18,863 & 822.933 & $-213,765$ & $632,08 \mathrm{c}$ & $28 \%$ \\
\hline $\begin{array}{l}\text { TCTAL GROSS FLCRS } \\
\text { LCSSES } E \text { CNISSIONS }\end{array}$ & $\begin{array}{r}195,779 \\
12,185\end{array}$ & $\begin{array}{r}33,576 \\
0\end{array}$ & $\begin{array}{r}413,726 \\
1\end{array}$ & $\begin{array}{l}355,211 \\
-14,011\end{array}$ & $\begin{array}{r}233,220 \\
9,675\end{array}$ & $\begin{array}{r}335,232 \\
-9,05 \mathrm{~g}\end{array}$ & $\begin{array}{r}932.925 \\
12.627\end{array}$ & $\begin{array}{r}187,143 \\
15,527\end{array}$ & $\begin{array}{r}2,236,126 \\
26,94 \subseteq\end{array}$ & $\begin{aligned} 95 \% \\
1 \%\end{aligned}$ \\
\hline
\end{tabular}

\begin{tabular}{|c|c|c|c|c|c|c|c|c|c|c|}
\hline S TEFLY OF ENERGT & & & & & & & & & & \\
\hline FOSS IL FUEI & - & - & - & - & 70.5 & 76 & 169.573 & - & 170,352 & $80 \%$ \\
\hline HY CR OELICTFIC & - & - & - & - & - & - & - & 7,392 & $7,39 ?$ & $3 \%$ \\
\hline NOCL EAR & - & - & - & - & - & - & - & 35,366 & 35,366 & 179 \\
\hline GEC. $\varepsilon$ SOL $2 \mathrm{R}$ & - & - & - & - & - & - & - & - & - & \\
\hline TCTAI SUPPIY & - & - & - & - & $7 \mathrm{C5}$ & 70 & 169,573 & $42,75 \varepsilon$ & 213,11, & \\
\hline
\end{tabular}

NET IM FORT
CF REGIOE


RZGIONAL ENEFGY EALANCE STATEMENT

\begin{tabular}{|c|c|c|c|c|c|c|c|c|c|c|}
\hline SECICE & $\begin{array}{l}\text { DISTILLATE } \\
\text { OIL }\end{array}$ & $\begin{array}{l}\text { RESIDOAL } \\
\text { OIL }\end{array}$ & $\begin{array}{l}\text { GASOLINE } \\
\text { (ALL ONI }\end{array}$ & $\begin{array}{l}\text { OTHER } \\
\text { HYDRO- } \\
\text { CARBONS } \\
\text { TS IN } 10 * * 9\end{array}$ & $\begin{array}{c}\text { CRODE } \\
\text { OIL } \\
\text { BTO'S) }\end{array}$ & $\begin{array}{l}\text { NATORAL } \\
\text { GAS }\end{array}$ & $\operatorname{COAL}$ & ELECTRICITY & $\begin{array}{r}\text { SECTOR } \\
\text { TOTAL }\end{array}$ & \\
\hline $\begin{array}{l}\text { FIN LL LEMANC SFCTOES } \\
\text { RESIDENTIAL, CCAM. } \\
\text { INDOSTRIAL } \\
\text { TRANSPORTATICN } \\
\text { HISCELLANECS OSES }\end{array}$ & $\begin{array}{r}8,847 \\
23,081 \\
48.018 \\
1.690\end{array}$ & $\begin{array}{r}1.635 \\
17.139 \\
353 \\
535\end{array}$ & $74.02 \overline{-}$ & $\begin{array}{r}15,675 \\
29,987 \\
9,536 \\
63\end{array}$ & $\begin{array}{l}- \\
-\end{array}$ & $\begin{array}{r}53,289 \\
11,337 \\
1,021 \\
552\end{array}$ & $\begin{array}{r}57 \\
42,455 \\
3 \\
-\end{array}$ & $\begin{array}{r}32,144 \\
80,924 \\
- \\
461\end{array}$ & $\begin{array}{r}111,697 \\
204,923 \\
132,955 \\
3,301\end{array}$ & $\begin{array}{r}19 \% \\
35 \% \\
23 \% \\
1 \%\end{array}$ \\
\hline $\begin{array}{l}\text { TCTAL FINAL } \\
\text { DEMAND SECTCRS }\end{array}$ & 81,636 & 19,712 & 74.024 & 55,261 & - & 66,199 & 42,515 & 113,529 & 452.876 & $78 \%$ \\
\hline $\begin{array}{l}\text { TRANSPCRBATICN } \\
\text { ELECTRICITY GEN. } \\
\text { PRTR CLEOM FRCDOCTS } \\
\text { NATURAL GAS } \\
\text { SYNTETICS }\end{array}$ & $\begin{array}{r}3,747 \\
-104,771 \\
- \\
-\end{array}$ & $\begin{array}{r}-33,434 \\
- \\
-\end{array}$ & $\begin{array}{r}- \\
-175,696 \\
-\end{array}$ & $\begin{array}{r}-49,836 \\
- \\
-\end{array}$ & $\begin{array}{r}354,400 \\
-9,902\end{array}$ & $\begin{array}{r}941 \\
14,925 \\
- \\
-\end{array}$ & $\begin{array}{r}111,876 \\
- \\
25,211\end{array}$ & $\begin{array}{r}-36,590 \\
- \\
-\end{array}$ & $\begin{array}{r}79,974 \\
5,537 \\
- \\
15,309\end{array}$ & $\begin{array}{r}14 \% \\
1 \%\end{array}$ \\
\hline $\begin{array}{l}\text { NFI FOFL OSEL } \\
\text { IN TRANSFOFMATICN }\end{array}$ & $-101,024$ & $-33,4 \equiv 4$ & -175.696 & $-49,836$ & 344,498 & 15,866 & 137,087 & -36.590 & 100,820 & $17 \%$ \\
\hline $\begin{array}{l}\text { TCIAL GROSS FLCRS } \\
\text { LCSSES } E \text { CHISSIONS }\end{array}$ & $\begin{array}{r}85,383 \\
5,314\end{array}$ & $\begin{array}{r}19,712 \\
0\end{array}$ & $\begin{array}{r}74.024 \\
0\end{array}$ & $\begin{array}{l}55,261 \\
-2,179\end{array}$ & $\begin{array}{r}354,400 \\
14,702\end{array}$ & $\begin{array}{l}82,065 \\
-2,217\end{array}$ & $\begin{array}{r}179,602 \\
2,431\end{array}$ & $\begin{array}{r}113,529 \\
9,419\end{array}$ & $\begin{array}{r}553,696 \\
27,471\end{array}$ & $\begin{aligned} 95 \% \\
5 \%\end{aligned}$ \\
\hline TCTAL NET OSAEE & $-14,073$ & $-13,772$ & $-101,672$ & 3.244 & 359,201 & 79,847 & 182,033 & 86,358 & 581,167 & \\
\hline $\begin{array}{l}\text { SOFPLY OF ENFRGY } \\
\text { FOSS IL FOEI } \\
\text { HYLROELECTEIC } \\
\text { NOCLEAR } \\
\text { GEO. ESOLAR }\end{array}$ & $\begin{array}{l}- \\
-\end{array}$ & $\begin{array}{l}- \\
-\end{array}$ & $\begin{array}{l}\overline{-} \\
\overline{-}\end{array}$ & $\begin{array}{l}- \\
-\end{array}$ & $\begin{array}{r}185,769 \\
- \\
-\end{array}$ & $\begin{array}{r}74.576 \\
- \\
- \\
-\end{array}$ & $\begin{array}{r}2,116,247 \\
- \\
-\end{array}$ & $\begin{array}{r}- \\
44,583 \\
1,840 \\
7,213\end{array}$ & $\begin{array}{r}2,376,592 \\
44,583 \\
1,840 \\
7,213\end{array}$ & $\begin{array}{r}98 \% \\
2 \% \\
0 \% \\
0 \%\end{array}$ \\
\hline TCTAI SOPPLY & - & - & - & - & 185,769 & 74.576 & $2,116,247$ & 53,636 & $2,430,228$ & \\
\hline
\end{tabular}

\section{NET IM FORTS \\ CF REGION}

$-14,073$

$-13,772$

$-101,672$

3,244

173,432

$5,271-1,934,213$

$32,722-1,849,060$

\section{NOTES: \\ TRANSFCBAATICN LOSS POR TRANSPCBHATICN LOSS POR

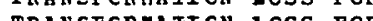 TRANSPORMAICM LCSS POR \\ ELECTRICITY GEN. $=68.61 \%$ \\ PETRCLETM PROD DCTS $=1.50 \%$ \\ NATUBAL GAS $\quad=0.0 \%$


REGIONAL ENEEGY PALANCE STATEMENT

\begin{tabular}{|c|c|c|c|c|c|c|c|c|c|c|}
\hline SECEOF & $\begin{array}{c}D I S T I L=A T E \\
\text { OI }\end{array}$ & $\begin{array}{l}\text { BESIDOAL } \\
\text { OIl }\end{array}$ & $\begin{array}{l}\text { GASOLIN } \\
\text { CALL }\end{array}$ & $\begin{array}{l}\text { OTHER } \\
\text { TYIRO- } \\
\text { CAREONS } \\
\text { TS IN } 10 * * 9\end{array}$ & $\begin{array}{c}\text { CREIEE } \\
\text { OIL } \\
\text { BTU'SI }\end{array}$ & $\begin{array}{l}\text { NATURAL } \\
\text { GAS }\end{array}$ & $\operatorname{COAI}$ & ELECTRICITY & $\begin{array}{r}\text { SECTOR } \\
\text { TOTAL }\end{array}$ & \\
\hline $\begin{array}{l}\text { FIN ZL CEMANL SECIORS } \\
\text { RESIDENTIAL,CCMU. } \\
\text { INDOSTRIAL } \\
\text { TRANSPORTATZCN } \\
\text { MISCELLANECES OSES }\end{array}$ & $\begin{array}{r}21,521 \\
18,527 \\
34,375 \\
2,579\end{array}$ & $\begin{array}{r}1,058 \\
10,909 \\
768 \\
481\end{array}$ & $145,20 \overline{0}$ & $\begin{array}{r}2 \varsigma, 550 \\
3 C, 170 \\
\epsilon, 356 \\
100\end{array}$ & $\bar{z}$ & $\begin{array}{r}73,520 \\
18,594 \\
1,608 \\
902\end{array}$ & $\begin{array}{r}172 \\
25,809 \\
1 \\
-\end{array}$ & $\begin{array}{r}45,913 \\
33,390 \\
32 \\
463\end{array}$ & $\begin{array}{r}171,734 \\
136,899 \\
189,030 \\
4,525\end{array}$ & $\begin{array}{r}26 \% \\
20 \% \\
28 \% \\
1 \%\end{array}$ \\
\hline $\begin{array}{l}\text { TCIAI FINAI } \\
\text { DEMAND SECTCRS }\end{array}$ & 77,102 & 13,216 & $145,2 \subseteq 0$ & $6 \epsilon, 176$ & - & 94,624 & 25,982 & 79,798 & 502,188 & $75 \%$ \\
\hline $\begin{array}{l}\text { TRANSFCRHATICN } \\
\text { ELECTRICITS EEN. } \\
\text { FETAOLEOM ERCDOCTS } \\
\text { NATORAL GAS } \\
\text { SYNIHETICS }\end{array}$ & $\begin{array}{r}3,380 \\
-2,338 \\
- \\
-\end{array}$ & $\begin{array}{r}-1.016 \\
-\end{array}$ & $\begin{array}{r}-5,2 \bar{i} \overline{1} \\
\overline{-}\end{array}$ & $\begin{array}{r}- \\
-\pi, 294 \\
-\end{array}$ & $\begin{array}{r}10,898 \\
- \\
-\end{array}$ & $\begin{array}{r}3,623 \\
242 \\
- \\
-\end{array}$ & $\begin{array}{r}205,225 \\
- \\
-\end{array}$ & $\begin{array}{r}-53,876 \\
- \\
-\end{array}$ & $\begin{array}{r}158,352 \\
69 \\
- \\
-\end{array}$ & $\begin{array}{r}24 \% \\
0 \%\end{array}$ \\
\hline $\begin{array}{l}\text { NET FUEL OSEI } \\
\text { IN TRANSFEMATION }\end{array}$ & 341 & -1.016 & $-5,221$ & $-\bar{z}, 294$ & 10,898 & 3,865 & 205,225 & $-53,876$ & 158,421 & $24 \%$ \\
\hline $\begin{array}{l}\text { TCIAL GKOSS FLCHS } \\
\text { LCSSES } \& \text { CHISSICNS }\end{array}$ & $\begin{array}{r}80, .582 \\
5,309\end{array}$ & $\begin{array}{r}13,216 \\
0\end{array}$ & $\begin{array}{r}145,290 \\
0\end{array}$ & $\begin{array}{l}6 E, 176 \\
-\frac{2}{2}, 610\end{array}$ & $\begin{array}{r}10.898 \\
452\end{array}$ & $\begin{array}{l}98,489 \\
-2,661\end{array}$ & $\begin{array}{r}231,207 \\
3,129\end{array}$ & $\begin{array}{r}79,798 \\
6,621\end{array}$ & $\begin{array}{r}560,609 \\
9,941\end{array}$ & $\begin{aligned} 99 \% \\
1 \%\end{aligned}$ \\
\hline CCTAL NET OSUGE & $82 . .753$ & 12,199 & 140.069 & $6: .271$ & 11,350 & $95,8: 27$ & 234,336 & 32,543 & 670,550 & \\
\hline
\end{tabular}

-

\begin{tabular}{|c|c|c|c|c|c|c|c|c|c|c|}
\hline $\begin{array}{l}\text { SOFELY CF ENIRGY } \\
\text { FOSSIL FOEI } \\
\text { HY LRCELECTIIC } \\
\text { NOCL EAR } \\
\text { GEC. ESOLAR }\end{array}$ & $\begin{array}{l}\overline{-} \\
\overline{-}\end{array}$ & $\begin{array}{l}\overline{-} \\
\overline{-}\end{array}$ & $\begin{array}{l}\bar{z} \\
\bar{z}\end{array}$ & $\begin{array}{l}- \\
-\end{array}$ & $\begin{array}{r}49.139 \\
- \\
-\end{array}$ & $\begin{array}{r}5,086 \\
- \\
=\end{array}$ & $\begin{array}{l}- \\
\overline{-}\end{array}$ & $\begin{array}{r}- \\
4,387 \\
36,642 \\
-\end{array}$ & $\begin{array}{r}54,225 \\
4,387 \\
36,642 \\
-\end{array}$ & $\begin{array}{r}57 \% \\
5 \% \\
38 \%\end{array}$ \\
\hline TCTAI SUPPIY & - & - & - & - & 49,139 & 5,086 & - & 41,029 & 95,254 & \\
\hline
\end{tabular}

NET IY FORTS
CP REGION


REGIONAL ENEEGY PALANCE STATEMENT

\begin{tabular}{|c|c|c|c|c|c|c|c|c|c|c|}
\hline SECTOE & $\begin{array}{c}\text { DI } \equiv \text { TILLATE } \\
\text { OIL }\end{array}$ & $\begin{array}{c}\text { RESIDJAL } \\
\text { OIL }\end{array}$ & $\begin{array}{l}\text { GASOLINB } \\
\text { (ALL ONI? }\end{array}$ & $\begin{array}{c}\text { OTHER } \\
\text { HYDRO- } \\
\text { CARBONS } \\
\text { TS IN } 10 * * 9\end{array}$ & $\begin{array}{c}\text { CROLE } \\
\text { OII } \\
\text { BTO'SI }\end{array}$ & $\begin{array}{l}\text { NATURAL } \\
\text { GAS }\end{array}$ & $\operatorname{COAL}$ & ELECTRICITY & $\begin{array}{r}\text { SECTOR } \\
\text { TOTAL }\end{array}$ & \\
\hline $\begin{array}{l}\text { PIBLL TFMANE SFCTORS } \\
\text { RESIDENTIAL, CCMA. } \\
\text { IRDOSTRIAL } \\
\text { TEANSPORTATICN } \\
\text { MISCELLANECOS OSES }\end{array}$ & $\begin{array}{r}8,182 \\
8,620 \\
11,846 \\
311 \\
\end{array}$ & $\begin{array}{r}93 \\
6.187 \\
\overline{77}\end{array}$ & $82,84 \overline{-}$ & $\begin{array}{r}4.787 \\
10,327 \\
34,440 \\
2\end{array}$ & $\begin{array}{l}- \\
-\end{array}$ & $\begin{array}{r}14,253 \\
45,009 \\
3,093 \\
590\end{array}$ & $\begin{array}{r}3 \\
8,954 \\
-\end{array}$ & $\begin{array}{r}23,887 \\
26,733 \\
- \\
266\end{array}$ & $\begin{array}{r}51,205 \\
105,830 \\
132,219 \\
1,246\end{array}$ & $\begin{array}{r}13 \% \\
26 \% \\
32 \% \\
0 \%\end{array}$ \\
\hline $\begin{array}{l}\text { TCJAL FINAI } \\
\text { DEMAND SECTORS }\end{array}$ & 28,959 & 6,357 & 82,840 & 49,556 & - & 62,945 & 8,957 & 50,886 & 290,500 & $71 \%$ \\
\hline $\begin{array}{l}\text { TRABSPCRMATICN } \\
\text { ELECTRICITY GEN. } \\
\text { PBTR OLEOM ERCDOCTS } \\
\text { UATORAL GAS } \\
\text { ST RTETICS }\end{array}$ & $\begin{array}{r}1,743 \\
- \\
-\end{array}$ & $\begin{array}{l}\bar{z} \\
=\end{array}$ & $\begin{array}{l}- \\
- \\
-\end{array}$ & $\begin{array}{l}- \\
-\end{array}$ & $\begin{array}{l}- \\
\overline{-} \\
-\end{array}$ & $\begin{array}{r}28,323 \\
- \\
-\end{array}$ & $\begin{array}{r}141,336 \\
- \\
-\end{array}$ & $\begin{array}{r}-58,389 \\
- \\
-\end{array}$ & $\begin{array}{r}113,013 \\
- \\
-\end{array}$ & $28 \%$ \\
\hline $\begin{array}{l}\text { NET FUFL DSFL } \\
\text { IN TRANSFOFATIOE }\end{array}$ & 1,743 & - & - & - & - & 28,323 & 141,336 & $-58,389$ & 113.013 & $28 \%$ \\
\hline $\begin{array}{l}\text { TCSAL GROSS FIORS } \\
\text { LCSSES } E \text { CMISSIONS }\end{array}$ & $\begin{array}{r}30,702 \\
1,910\end{array}$ & 6.357 & $\begin{array}{r}82,840 \\
0\end{array}$ & $\begin{array}{l}49,556 \\
-1,954\end{array}$ & $\overline{-}$ & $\begin{array}{l}91,268 \\
-2,466\end{array}$ & $\begin{array}{r}150,293 \\
2.034\end{array}$ & $\begin{array}{r}50,886 \\
4,222\end{array}$ & $\begin{array}{r}403,513 \\
3,747\end{array}$ & $\begin{array}{r}99 \% \\
1 \%\end{array}$ \\
\hline TCIAL NET OSAGE & 32,612 & 6,357 & 82,840 & 47,601 & - & 88,801 & 152,327 & $-3,280$ & 407,260 & \\
\hline
\end{tabular}

\begin{tabular}{|c|c|c|c|c|c|c|c|c|c|c|}
\hline SOEPLY OF ENERGT & & & & & & & & & & \\
\hline JOSSIL FOEI & - & - & - & - & 887 & - & - & - & 887 & $17 \%$ \\
\hline FY LROELECT FIC & - & - & - & - & - & - & - & 932 & 932 & $\begin{array}{r}18 \% \\
2 \%\end{array}$ \\
\hline $\begin{array}{l}\text { NOCL EAR } \\
\text { GEC. ESOLAR }\end{array}$ & $\overline{-}$ & - & - & $\overline{-}$ & $\overline{-}$ & $\overline{-}$ & $\because$ & $\begin{array}{r}122 \\
3,197\end{array}$ & $\begin{array}{r}122 \\
3,197\end{array}$ & $\begin{array}{r}2 \% \\
62 \%\end{array}$ \\
\hline TCTAL SUPPIY & - & - & - & - & 887 & - & - & 4,251 & 5,138 & \\
\hline
\end{tabular}

TCrab sop

\begin{tabular}{|c|c|c|c|c|c|c|c|c|c|}
\hline OF REGION & 32,612 & $6,35,7$ & 82,840 & 47,601 & -337 & 88,801 & 152,327 & $-7,531$ & 402,122 \\
\hline
\end{tabular}

\footnotetext{
NOTES: TRANSPCBHATICN IOSS PCR TR ANSPCRATICN IOSS PC TRAVPPORAIICR ICSS POR

BLECTRICITY GEN. $\quad=65.93 \%$

PBTROLEOH PROD OCTS $=0.0$

$\begin{array}{ll}\text { NATOEAL GAS } & =0.0 \\ & =0.0\end{array}$

$=0.0 \%$
} 
REGICNAL ENEFGY EALANCE STATERENT
PIES MID MID SCENARIO

\begin{tabular}{|c|c|c|c|c|c|c|c|c|c|c|}
\hline SBCTOS & $\begin{array}{l}\text { DI STILLLTE } \\
\text { EIL }\end{array}$ & $\begin{array}{l}\text { BESIDUAL } \\
\text { OIL }\end{array}$ & $\begin{array}{l}\text { GASOLINE: } \\
\text { (ALL UHI }\end{array}$ & $\begin{array}{c}\text { QTHER } \\
\text { HYDEO- } \\
\text { CABBCNS } \\
\text { TS IN } 10 * * 9\end{array}$ & $\begin{array}{c}\text { CROLE } \\
\text { OIL } \\
\text { BTD'S) }\end{array}$ & $\begin{array}{l}\text { NATURAL } \\
\text { GAS }\end{array}$ & $\operatorname{COAL}$ & ELECTRICITY & $\begin{array}{r}\text { SECTOR } \\
\text { TOTAL }\end{array}$ & \\
\hline $\begin{array}{l}\text { PINLL CEHANI SHCIOES } \\
\text { RESIDENTIAI,CCHA. } \\
\text { IND TSTRIAL } \\
\text { TRANS PORTATICH } \\
\text { BISCELIANECOS OSES }\end{array}$ & $\begin{array}{r}45,3 C 5 \\
1,6 \vdots 2 \\
=, 8 \leq 4 \\
5 \in 2\end{array}$ & $\begin{array}{r}10,733 \\
16,153 \\
- \\
392\end{array}$ & $\begin{array}{r}- \\
\frac{-}{6}, 606 \\
-\end{array}$ & $\begin{array}{r}8,145 \\
5,615 \\
506 \\
8\end{array}$ & $\begin{array}{l}\overline{-} \\
\overline{-}\end{array}$ & $\begin{array}{r}8,373 \\
6,570 \\
434 \\
747\end{array}$ & $23 \overline{2}$ & $\begin{array}{r}13,267 \\
11,709 \\
- \\
163\end{array}$ & $\begin{array}{r}89,823 \\
41,951 \\
68,400 \\
1,872\end{array}$ & $\begin{array}{r}318 \\
75 \% \\
24 \pi \\
18\end{array}$ \\
\hline $\begin{array}{l}\text { TCIAL FINAI } \\
\text { DEMAND SECTCRS }\end{array}$ & $54,3 \leq 3$ & 27,318 & 64,606 & 14,274 & - & 16,124 & 232 & 25,139 & 202,046 & $71:$ \\
\hline $\begin{array}{l}\text { TRARSPORHATICH: } \\
\text { EL ECTRICITY EER. } \\
\text { PETR OLEDH EBODOCTS } \\
\text { NATOBRL GAS } \\
\text { SY HTHETICS }\end{array}$ & $\begin{array}{r}\bar{z}, 955 \\
-46 \overline{\bar{j}}, 644 \\
- \\
-\end{array}$ & $\begin{array}{r}11,206 \\
-51,148 \\
-\end{array}$ & $\begin{array}{r}-520,47 \overline{2} \\
-\end{array}$ & $\begin{array}{r}-1 E 3,916 \\
-\end{array}$ & $\begin{array}{r}1,184,392 \\
-\end{array}$ & $\begin{array}{r}- \\
5 \\
-\end{array}$ & $\begin{array}{r}30,850 \\
= \\
=\end{array}$ & $\begin{array}{r}-15,294 \\
- \\
-\end{array}$ & $\begin{array}{r}29,757 \\
-357 \\
- \\
-\end{array}$ & $\begin{array}{l}108 \\
0.8\end{array}$ \\
\hline $\begin{array}{l}\text { NET FOEL OSEL } \\
\text { IN TRABSPCEBATION }\end{array}$ & $-462,649$ & $-39,942$ & $-520,472$ & $-1 \leq 3,916$ & $1,184,392$ & 6.430 & 30.850 & $-15,294$ & 29,399 & $10 \%$ \\
\hline $\begin{array}{l}\text { TOTAL GROSS FLORS } \\
\text { ICSSES \& CHISSIOAS }\end{array}$ & $\begin{array}{r}57,3408 \\
3,5 \in 9\end{array}$ & $\begin{array}{r}38,524 \\
0\end{array}$ & $\begin{array}{r}64,606 \\
0\end{array}$ & $\begin{array}{r}14,274 \\
-563\end{array}$ & $\begin{array}{r}1,184,392 \\
49,134\end{array}$ & $\begin{array}{r}22,554 \\
-609\end{array}$ & $\begin{array}{r}31,082 \\
420\end{array}$ & $\begin{array}{r}25,139 \\
2,085\end{array}$ & $\begin{array}{r}231,803 \\
54,039\end{array}$ & $\begin{array}{l}8: 12 \\
19 \%\end{array}$ \\
\hline TOTAL AET OSBGI & $-40+, 726$ & $-12,623$ & $-455,865$ & $-140,205$ & $1,233,526$ & 21,944 & 31,502 & 11,930 & 285,484 & \\
\hline $\begin{array}{l}\text { SOEFLY OF ENFEGY } \\
\text { FOSS IL FOEI } \\
\text { HY DROELECTEIC } \\
\text { NOCL EAR } \\
\text { GEO. ESOLAR }\end{array}$ & $\begin{array}{l}\overline{-} \\
\overline{-} \\
\overline{-}\end{array}$ & $\begin{array}{l}- \\
-\end{array}$ & $\begin{array}{l}- \\
-\end{array}$ & $\begin{array}{l}- \\
-\end{array}$ & - & $\begin{array}{l}- \\
-\end{array}$ & $\begin{array}{l}\overline{-} \\
-\end{array}$ & $\begin{array}{r}4,421 \\
42,903 \\
501\end{array}$ & $\begin{array}{r}4.421 \\
42,903 \\
501\end{array}$ & $\begin{array}{r}79 \\
975 \\
7 \%\end{array}$ \\
\hline TCTAL SUPPIY & - & - & - & - & - & - & - & 47,825 & 47,825 & \\
\hline
\end{tabular}

NET IMEORTS
OP REGIOA


REGIONAL ENEFG EALANCE STATEMENT
PIES GID MID SCENABIO

\begin{tabular}{|c|c|c|c|c|c|c|c|c|c|c|}
\hline SECTOK & $\begin{array}{l}\text { DISTILLATE } \\
\text { OIL }\end{array}$ & $\begin{array}{l}\text { RESIDDAL } \\
\text { OIL }\end{array}$ & $\begin{array}{l}\text { GASOLINE } \\
\text { (ALL O }\end{array}$ & $\begin{array}{c}\text { OTHER } \\
\text { HYDRO- } \\
\text { CARBONS } \\
\text { TS IN } 10 * 9\end{array}$ & $\begin{array}{c}\text { CRODE } \\
\text { CII } \\
\text { BTO'S) }\end{array}$ & $\begin{array}{l}\text { NATURAL } \\
\text { GAS }\end{array}$ & $\operatorname{COAL}$ & ELECTRICITY & $\begin{array}{r}\text { SECTOR } \\
\text { TOTAL }\end{array}$ & \\
\hline $\begin{array}{l}\text { TCTAL FINAI } \\
\text { DEHAND SECTCRS }\end{array}$ & 420.993 & 233,598 & 489,188 & 339.073 & - & 262,451 & 78,527 & 264.039 & $2,137,869$ & $87 \%$ \\
\hline $\begin{array}{l}\text { TRABSFCRUATICN } \\
\text { ELECTRICITY GER. } \\
\text { PETR OLEOM FRODICTS } \\
\text { HATORAL GAS } \\
\text { STNTHETICS }\end{array}$ & $\begin{array}{r}41,199 \\
-459,242 \\
-\end{array}$ & $\begin{array}{r}62,626 \\
-50,445 \\
- \\
-\end{array}$ & $\begin{array}{r}-513,31 \overline{-} \\
-\end{array}$ & $\begin{array}{r}-151,799 \\
101,830\end{array}$ & $1,168,108$ & $\begin{array}{r}532 \\
6,342 \\
-91,855\end{array}$ & $\begin{array}{r}228,867 \\
- \\
-\end{array}$ & $\begin{array}{r}-111,876 \\
- \\
-\end{array}$ & $\begin{array}{r}221,348 \\
=352 \\
- \\
9,975\end{array}$ & $\begin{array}{l}9 \% \\
0 \%\end{array}$ \\
\hline $\begin{array}{l}\text { WET FOEL OSEL } \\
\text { IN TRANSFOFMATICN }\end{array}$ & $-418,043$ & 12,181 & $-513,317$ & $-49,969$ & $1,168,108$ & $-84,981$ & 228,867 & $-111,876$ & 230,970 & $9 \%$ \\
\hline $\begin{array}{l}\text { TCIAL GROSS FLCRS } \\
\text { LCSSES E OMISSIOUS }\end{array}$ & $\begin{array}{r}462,192 \\
28,768\end{array}$ & $\begin{array}{r}346,224 \\
6\end{array}$ & $\begin{array}{r}489,188 \\
2\end{array}$ & $\begin{array}{r}440,903 \\
-17,391\end{array}$ & $\begin{array}{r}1,168,108 \\
48,459\end{array}$ & $\begin{array}{r}269,325 \\
-7,277\end{array}$ & $\begin{array}{r}307,394 \\
4,160\end{array}$ & $\begin{array}{r}264,039 \\
21,908\end{array}$ & $\begin{array}{r}2,369,192 \\
78,637\end{array}$ & $\begin{array}{r}978 \\
3 \%\end{array}$ \\
\hline TCIAL NET OSAGE & 31.718 & 295,785 & $-24,126$ & 271,712 & $1,216,567$ & 170,192 & 311,554 & 174,071 & $2,447,476$ & \\
\hline
\end{tabular}

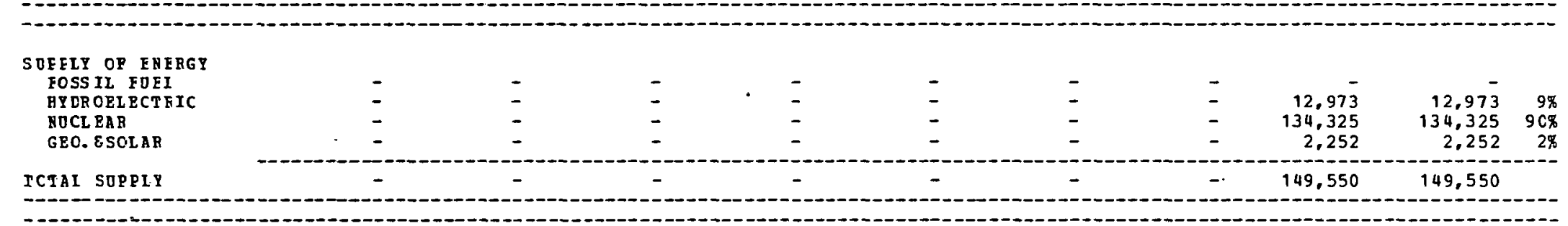

\section{NET IH EORTS}

31,718

295,785

$-24,126$

$271,712 \quad 1,216,567$

170,192

311.554

$24,521 \quad 2,297,926$

NOTES:
1 TRARSPCRAATICN LOSS FOR TRANSPCAHATICN LOSS POR TRARSPCFHATICN LCSS POR
TRANSPORAATICN LOSS POR
ELECTRICITY GEN.
PBTROIEOU PBODOCTS $=66.43 \%$
NATURAL GAS
$=-0.03 \%$ 
REGIONAL EN3 FGY BALANCE STATEMENT

PNAL EN3 FGY BALANCE SSAT
PIES MIJ MID SCENARI

\begin{tabular}{|c|c|c|c|c|c|c|c|c|c|c|}
\hline SECTCB & $\begin{array}{l}\text { DISTILLATB } \\
\text { OIL }\end{array}$ & $\begin{array}{l}\text { RESIDUAL } \\
\text { OIL }\end{array}$ & $\begin{array}{l}\text { GASOLINE } \\
\text { (ALI ONI }\end{array}$ & $\begin{array}{l}\text { DTHER } \\
\text { HEDRO- } \\
\text { CASBONS } \\
\text { C IN } 10 * 09\end{array}$ & $\begin{array}{c}\text { CRODE } \\
\text { OIL } \\
\text { BTO'S) }\end{array}$ & $\begin{array}{l}\text { NATURAL } \\
\text { GLS }\end{array}$ & COAL & ELECTRICITY & $\begin{array}{r}\text { SECTOZ } \\
\text { TOTAL }\end{array}$ & \\
\hline 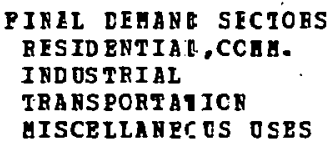 & $\begin{array}{r}8,238 \\
2,961 \\
29,341 \\
3,528\end{array}$ & $\begin{array}{r}998 \\
5,974 \\
- \\
2,968\end{array}$ & 123.520 & $\begin{array}{r}17,257 \\
6,969 \\
18,936 \\
63\end{array}$ & $\overline{-}$ & $\begin{array}{r}57.994 \\
148.9934 \\
4.581 \\
1.421\end{array}$ & $\begin{array}{r}3 \\
2,307 \\
-\end{array}$ & $\begin{array}{r}31,676 \\
7,292 \\
- \\
709\end{array}$ & $\begin{array}{r}116,166 \\
174,837 \\
176,378 \\
8,689\end{array}$ & $\begin{array}{r}15 \% \\
23 \% \\
23 \% \\
1 \%\end{array}$ \\
\hline $\begin{array}{l}\text { TCTAL FINAL } \\
\text { DEHAND SICTCBS }\end{array}$ & 44.068 & 9,940 & 123,520 & 43,225 & - & 212,930 & 2,710 & 39,677 & 476,070 & $62 \%$ \\
\hline 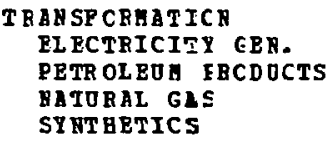 & $\begin{array}{r}3,331 \\
-45,518 \\
-\end{array}$ & $\begin{array}{r}-2,812 \\
-\end{array}$ & $\begin{array}{r}-75.076 \\
-\end{array}$ & $\begin{array}{r}-29.006 \\
-\end{array}$ & $\begin{array}{r}187,3.34 \\
\overline{-}\end{array}$ & $\begin{array}{r}20,890 \\
16,827 \\
- \\
-93,920\end{array}$ & $\begin{array}{r}237,641 \\
- \\
196,336\end{array}$ & $\begin{array}{r}-86,721 \\
= \\
-\end{array}$ & $\begin{array}{r}175,141 \\
1,748 \\
102,496\end{array}$ & $\begin{array}{r}230 \\
0 \% \\
13 \%\end{array}$ \\
\hline $\begin{array}{l}\text { NET FORL OSEL } \\
\text { IN TRABSPOEATION }\end{array}$ & $-42,187$ & $-2,812$ & $-7 \dot{5}, 076$ & $-: 9.006$ & $18 ? .334$ & $-56,202$ & 433.977 & $-86,721$ & 279,305 & $36 \%$ \\
\hline $\begin{array}{l}\text { TCIAL GROSS FICRS } \\
\text { LCSSES } \varepsilon \text { CATSSICHS }\end{array}$ & $\begin{array}{r}47,399 \\
2,950\end{array}$ & 9,940 & $\begin{array}{r}123,520 \\
0\end{array}$ & $\begin{array}{l}0.3,225 \\
-1,704\end{array}$ & $\begin{array}{r}182,334 \\
7,771\end{array}$ & $\begin{array}{r}250,647 \\
-6,773\end{array}$ & $\begin{array}{r}436,687 \\
5,910\end{array}$ & $\begin{array}{r}39,677 \\
3,292\end{array}$ & $\begin{array}{r}755,375 \\
11,447\end{array}$ & $\begin{array}{r}998 \\
1 \%\end{array}$ \\
\hline TCTAL NET OSAGE & 4,830 & 7,127 & 48.044 & $-§ 7.485$ & 195,106 & 149,954 & 442,597 & $-43,751$ & 766,823 & \\
\hline $\begin{array}{l}\text { SOFELY OF EEFRGY } \\
\text { FOSS IL PDFI } \\
\text { HY DROELECIEIC } \\
\text { NOCL BAR } \\
\text { GEO. ESOLAE }\end{array}$ & $\begin{array}{l}\overline{-} \\
\overline{-}\end{array}$ & $\begin{array}{l}\overline{-} \\
\overline{-} \\
-\end{array}$ & $\begin{array}{l}- \\
- \\
-\end{array}$ & $\begin{array}{l}- \\
-\end{array}$ & $\begin{array}{r}32 \%, 648 \\
- \\
-\end{array}$ & $\begin{array}{r}725,700 \\
- \\
-\end{array}$ & $\begin{array}{r}533,847 \\
- \\
-\end{array}$ & $\begin{array}{r}38 \overline{0} \\
1.841 \\
964\end{array}$ & $\begin{array}{r}1,587,195 \\
380 \\
1,841 \\
964\end{array}$ & $\begin{array}{r}100 \% \\
0 \% \\
0 \% \\
0 \%\end{array}$ \\
\hline TCTAL SOPPLY & - & - & - & - & $32 \pi, 648$ & 725,700 & 533,847 & 3,185 & $1,590,380$ & \\
\hline
\end{tabular}

\begin{tabular}{l}
$\begin{array}{l}\text { RET IM PORTS } \\
\text { OP REGION }\end{array}$ \\
\hline
\end{tabular}


REGIONAL ENERGY BALANCE STATEMENT

PIES MID MID SCENARIO

\begin{tabular}{|c|c|c|c|c|c|c|c|c|c|c|}
\hline SECTOK & $\begin{array}{l}\text { DISTILLATE } \\
\text { OIL }\end{array}$ & $\begin{array}{l}\text { RES I DUAL } \\
\text { OIL }\end{array}$ & $\begin{array}{l}\text { GASOLINE } \\
\text { (ALL }\end{array}$ & $\begin{array}{c}\text { OTHER } \\
\text { HYDRO- } \\
\text { CARBONS } \\
\text { TS IN } 10 * * 9\end{array}$ & $\begin{array}{c}\text { CRODE } \\
\text { OIL } \\
\text { BTU'S) }\end{array}$ & $\begin{array}{l}\text { NATURAL } \\
\text { GAS }\end{array}$ & COAL & ELECTRICITY & $\begin{array}{r}\text { SECTOR } \\
\text { TOTAL }\end{array}$ & \\
\hline $\begin{array}{l}\text { PJNAI DEHANC SECTCFS } \\
\text { EESIDENTIAL, CCAB. } \\
\text { INDOSTRIAL } \\
\text { TRANSPORTATICN } \\
\text { UISCELLANECOS OSES }\end{array}$ & $\begin{array}{r}667,256 \\
32,319 \\
59,544 \\
7,263\end{array}$ & $\begin{array}{r}300,054 \\
68,832 \\
40,007 \\
10,994\end{array}$ & $925.00 \bar{z}$ & $\begin{array}{r}136,564 \\
145,938 \\
205,382 \\
153\end{array}$ & $\begin{array}{l}\overline{-} \\
\overline{-}\end{array}$ & $\begin{array}{r}388,404 \\
168,068 \\
24,659 \\
15,036\end{array}$ & $\begin{array}{r}461 \\
165,701 \\
6 \\
32\end{array}$ & $\begin{array}{r}332,743 \\
189,927 \\
7,876 \\
6,478\end{array}$ & $\begin{array}{r}1,825,482 \\
770,785 \\
1,263,276 \\
39,956\end{array}$ & $\begin{array}{l}40 \% \\
17 \% \\
27 \% \\
1 \%\end{array}$ \\
\hline $\begin{array}{l}\text { TCTAL.FINAL } \\
\text { DEMAND SECTCRS }\end{array}$ & 766,382 & $420, \in 87$ & 925.002 & 488,037 & - & 596,167 & 166,200 & 537,024 & $3,899,499$ & $84 \pi$ \\
\hline $\begin{array}{l}\text { TEANSPCRHATICN } \\
\text { ELECTRICITY EEN. } \\
\text { PETR OLEOA IRODOCTS } \\
\text { NATORAL GAS } \\
\text { SYNTHETICS }\end{array}$ & $\begin{array}{r}75,342 \\
-192,884 \\
-\end{array}$ & $\begin{array}{r}292,575 \\
-21,187 \\
-\end{array}$ & $\begin{array}{r}- \\
-215,596 \\
-\end{array}$ & $\begin{array}{r}-63,75 \overline{-} \\
101,830\end{array}$ & $\begin{array}{r}- \\
490,512 \\
-\end{array}$ & $\begin{array}{r}267 \\
2,663 \\
-91,855\end{array}$ & $\begin{array}{r}561,619 \\
- \\
-\end{array}$ & $\begin{array}{r}-308,186 \\
- \\
-\end{array}$ & $\begin{array}{r}622,017 \\
-147 \\
- \\
9,975\end{array}$ & $\begin{array}{r}13 \% \\
0 \%\end{array}$ \\
\hline $\begin{array}{l}\text { NIT FOEL OSFL } \\
\text { IN TRANSPOEMATICN }\end{array}$ & $-117,542$ & 271,787 & $-215,596$ & 38,073 & 490,612 & $-88,924$ & 561,619 & $-308,186$ & 631,844 & $14 \pi$ \\
\hline $\begin{array}{l}\text { TCTAL GROSS FICRS } \\
\text { LCSSES } \& \text { CHISSICNS }\end{array}$ & $\begin{array}{r}841,724 \\
52,391\end{array}$ & $\begin{array}{r}713,662 \\
14\end{array}$ & $\begin{array}{r}925,002 \\
4\end{array}$ & $\begin{array}{l}589,867 \\
-23,266\end{array}$ & $\begin{array}{r}490.612 \\
20.353\end{array}$ & $\begin{array}{l}599,097 \\
-16,188\end{array}$ & $\begin{array}{r}727,819 \\
9,851\end{array}$ & $\begin{array}{r}537,024 \\
44,559\end{array}$ & $\begin{array}{r}4,531,491 \\
87,718\end{array}$ & $\begin{array}{r}98 \% \\
2 \%\end{array}$ \\
\hline $\begin{array}{l}\text { SOFPLY OP ENFEGI } \\
\text { FOSS IL FOEI } \\
\text { HYDR CELPCTEIC } \\
\text { WOCL EAR } \\
\text { GEC. ESOLAR }\end{array}$ & $\begin{array}{l}\overline{-} \\
\overline{-}\end{array}$ & $\begin{array}{l}\overline{-} \\
\overline{-}\end{array}$ & $\begin{array}{l}\overline{-} \\
\overline{-}\end{array}$ & $=$ & $\begin{array}{r}6,158 \\
- \\
-\end{array}$ & $\begin{array}{r}7,379 \\
- \\
-\end{array}$ & $\begin{array}{l}\overline{-} \\
\overline{-}\end{array}$ & $\begin{array}{r}113,55 \overline{3} \\
200,195 \\
4,580\end{array}$ & $\begin{array}{r}13,537 \\
113,553 \\
200,195 \\
4,580\end{array}$ & $\begin{array}{r}4 \pi \\
34 \% \\
60 \% \\
1 \%\end{array}$ \\
\hline TCTAI SOPPIY & - & - & - & - & 6,158 & 7,379 & - & $\vdots 18,328$ & 331,865 & \\
\hline
\end{tabular}

NET IM FORTS
CF REGION


REGICNAL ENEEGY EALANCE STATENENT

PIZS MII MID SCENARIO

\begin{tabular}{|c|c|c|c|c|c|c|c|c|c|c|}
\hline SECTOF & $\begin{array}{c}\text { DISTIELATE } \\
\text { OIL }\end{array}$ & $\begin{array}{l}\text { RESIDOAL } \\
\text { OIL }\end{array}$ & $\begin{array}{l}\text { GASOLINE } \\
\text { (ALL O }\end{array}$ & $\begin{array}{c}\text { QTHER } \\
\text { HYDRO- } \\
\text { ZAEEONS } \\
\text { IN } 10 * * 9\end{array}$ & $\begin{array}{c}\text { CEODE } \\
\text { OIL } \\
\text { BTO } S)\end{array}$ & $\begin{array}{l}\text { NATURAL } \\
\text { GAS }\end{array}$ & $\mathrm{COLI}$ & ELECTRICITY & $\begin{array}{l}\text { SECTOR } \\
\text { TOTAL }\end{array}$ & \\
\hline $\begin{array}{l}\text { FINIL CEHANC SECTOES } \\
\text { FESID ENTIAL, CCAM. } \\
\text { INDOSTRIAL } \\
\text { TRANS PORTAIICN } \\
\text { MISCELLANCCO USES }\end{array}$ & $\begin{array}{r}107.888 \\
56.400 \\
60.856 \\
4.112\end{array}$ & $\begin{array}{r}9,821 \\
83,874 \\
1,044 \\
2,158\end{array}$ & $483,51 \overline{-}$ & $\begin{array}{r}60,104 \\
96,570 \\
17,061 \\
198\end{array}$ & $\begin{array}{l}\overline{-} \\
\overline{-}\end{array}$ & $\begin{array}{r}31,749 \\
111,321 \\
2,397 \\
3,581\end{array}$ & 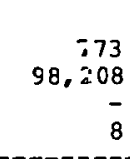 & $\begin{array}{r}232,898 \\
186,814 \\
2,685\end{array}$ & $\begin{array}{r}443,233 \\
633,687 \\
565,770 \\
12,742\end{array}$ & $\begin{array}{r}19 \% \\
27 \% \\
24 \% \\
1 \%\end{array}$ \\
\hline $\begin{array}{l}\text { TCIAL FINAL } \\
\text { DEMAND SECICRS }\end{array}$ & 229,256 & 96.897 & 483,912 & 173,933 & - & $150,1) 48$ & 98,589 & 422,397 & $1,655,432$ & $71 \%$ \\
\hline $\begin{array}{l}\text { TAANSFCBHAT ICN } \\
\text { ELECTRICITY GEN. } \\
\text { PETROIEOH ERCDOCTS } \\
\text { NATURAL GAS } \\
\text { SYHTHETICS }\end{array}$ & $\begin{array}{r}54.358 \\
- \\
-\end{array}$ & $\begin{array}{r}: 1,133 \\
- \\
-\end{array}$ & $\begin{array}{l}- \\
-\end{array}$ & $\begin{array}{l}- \\
-\end{array}$ & $\begin{array}{l}\overline{-} \\
\overline{-}\end{array}$ & $\begin{array}{l}- \\
\overline{-}\end{array}$ & $\begin{array}{r}881,079 \\
- \\
-\end{array}$ & $\begin{array}{r}-324,049 \\
- \\
-\end{array}$ & $\begin{array}{r}622,521 \\
- \\
-\end{array}$ & $27 \pi$ \\
\hline $\begin{array}{l}\text { NET FOEL DSEI } \\
\text { IN TRANSFOFHATIOY }\end{array}$ & 54,358 & 11,133 & - & - & - & - & 881,079 & $-324,049$ & 622,521 & $27 \%$ \\
\hline $\begin{array}{l}\text { TCTAL GROSS FLCRS } \\
\text { LCSSES \& OMISSIONS }\end{array}$ & $\begin{array}{r}283,614 \\
17,652\end{array}$ & $\begin{array}{r}1 J 8,030 \\
2\end{array}$ & $\begin{array}{r}483,912 \\
2\end{array}$ & $\begin{array}{r}173,933 \\
-5,860\end{array}$ & - & $\begin{array}{r}150,048 \\
-4,054\end{array}$ & $\begin{array}{r}980,068 \\
13,266\end{array}$ & $\begin{array}{r}422,397 \\
35,047\end{array}$ & $\begin{array}{r}2,277,953 \\
55,056\end{array}$ & $\begin{array}{r}9 \varepsilon \% \\
2 \%\end{array}$ \\
\hline $\begin{array}{l}\text { SOFELY CF ENERGY } \\
\text { FCSS IL FOEL } \\
\text { HY DRCELECTFIC } \\
\text { NOCLEAR } \\
\text { GEC. ESOLAR }\end{array}$ & $\begin{array}{l}- \\
\overline{-}\end{array}$ & $\begin{array}{l}\overline{-} \\
\overline{-}\end{array}$ & $\begin{array}{l}- \\
\overline{-}\end{array}$ & $\begin{array}{l}- \\
\overline{-}\end{array}$ & $\begin{array}{l}- \\
- \\
-\end{array}$ & $\begin{array}{l}\overline{-} \\
-\end{array}$ & $\begin{array}{l}- \\
-\end{array}$ & $\begin{array}{r}- \\
27,783 \\
111,676 \\
-\end{array}$ & $\begin{array}{r}- \\
27.783 \\
111.676\end{array}$ & $\begin{array}{l}20 \% \\
80 \%\end{array}$ \\
\hline TCTAI SOPPIY & - & - & - & - & - & - & - & 139,459 & 139,459 & \\
\hline
\end{tabular}

\begin{tabular}{l} 
NET IM FORTS \\
CF REGION \\
\hline
\end{tabular}


REGIONAL ENEFGY EALANCE STATEMENT

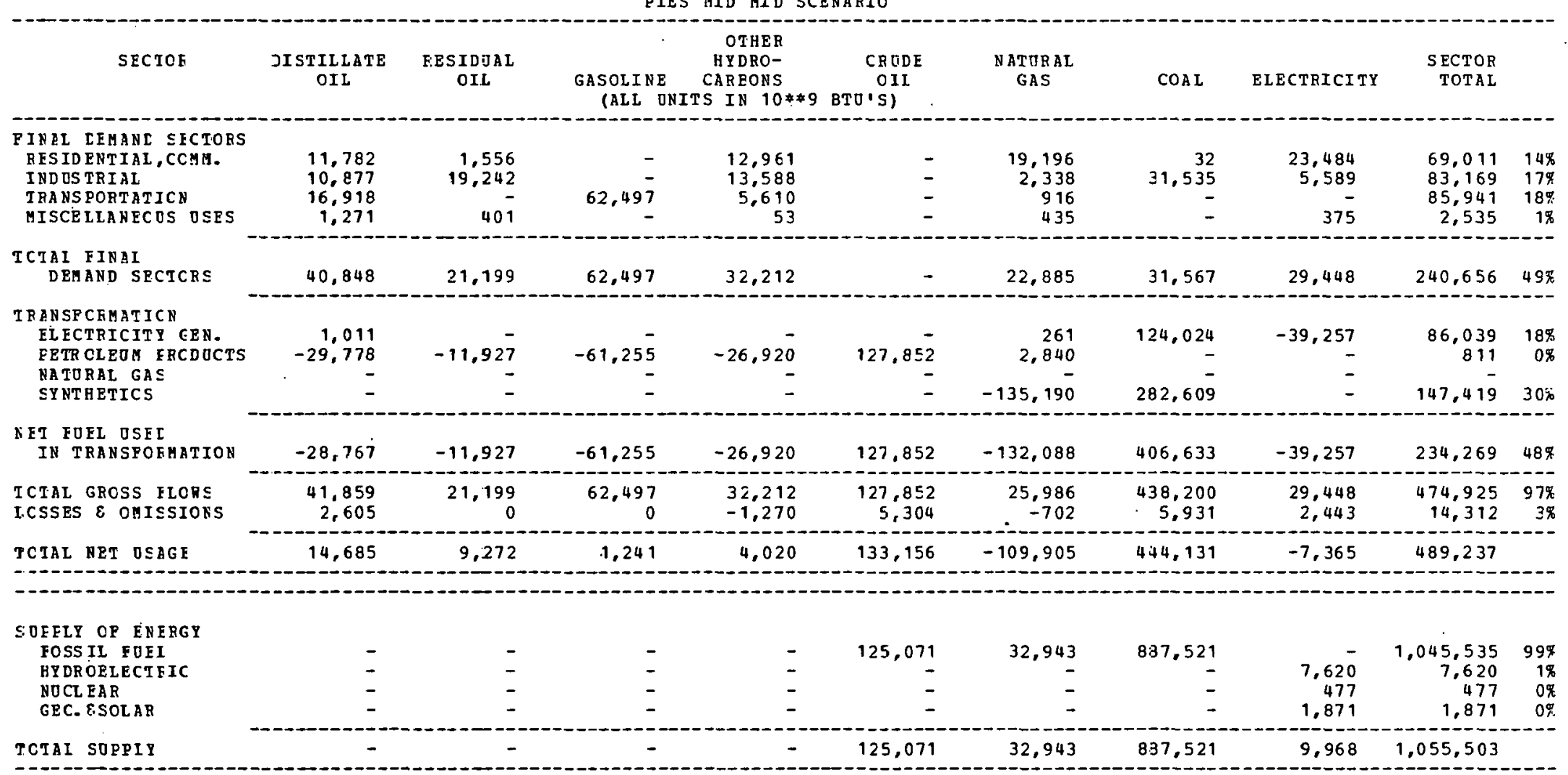

(2)

BET IM FORTS
CP RPGION


REGICNAL ENEGGY PALANCE STATEMENT

PIES UIL MID SCENARIO

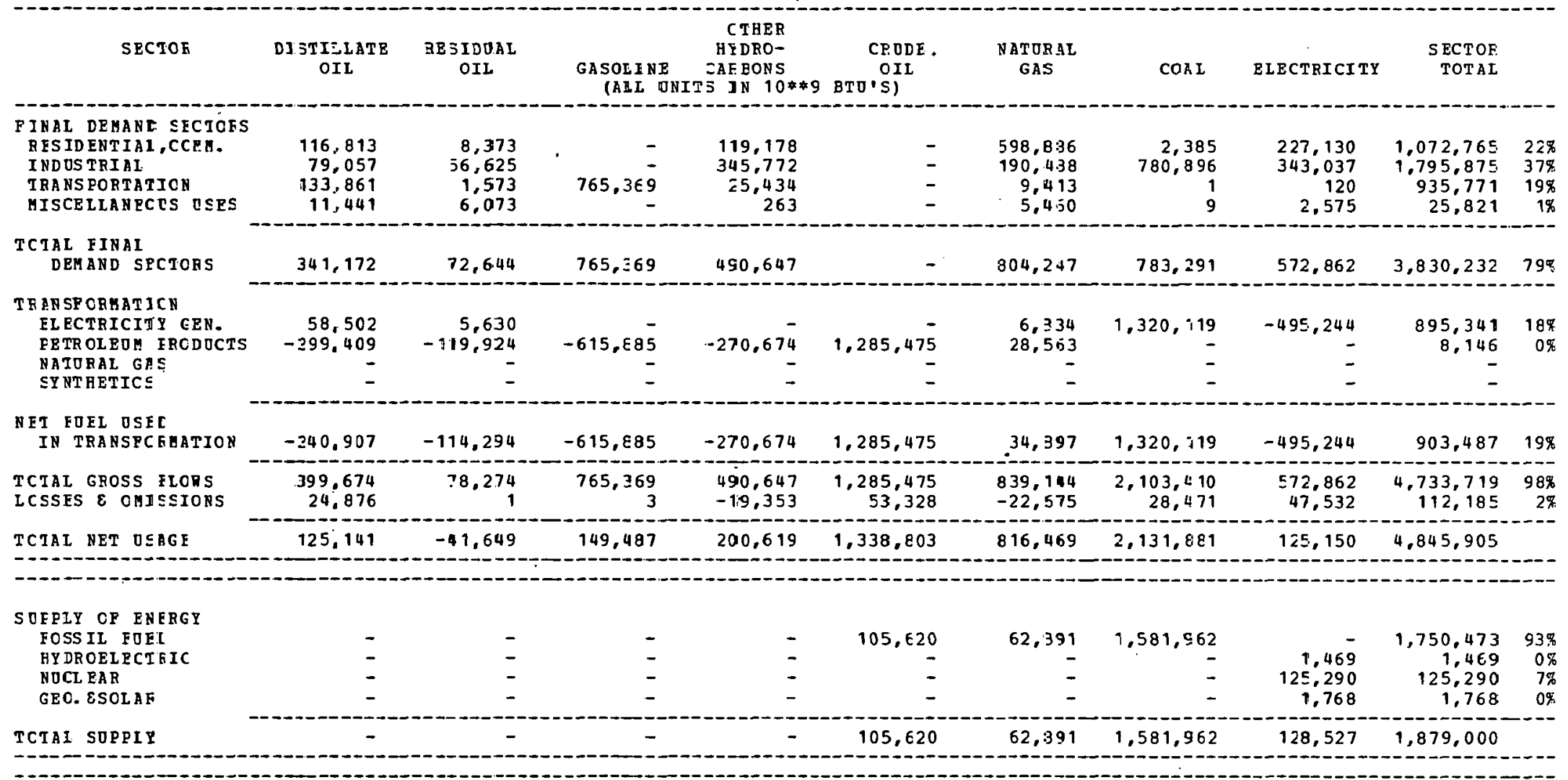

NET IM PORTS
CF REGION


REGICNAL ENEEGY BALANCE STATEMENT

\begin{tabular}{|c|c|c|c|c|c|c|c|c|c|c|}
\hline SBCTCE & $\begin{array}{l}\text { DISTILLATE } \\
\text { OIL }\end{array}$ & $\begin{array}{l}\text { RESIDULL } \\
\text { OIL }\end{array}$ & $\begin{array}{l}\text { GASOLINE } \\
\text { (ALL O }\end{array}$ & $\begin{array}{l}\text { OTHER } \\
\text { HYDRO- } \\
\text { CARBONS } \\
\text { TS IN } 10 * * 9\end{array}$ & $\begin{array}{c}\text { CRODE } \\
\text { OIL } \\
\text { BTO'S) }\end{array}$ & $\begin{array}{l}\text { NATURAL } \\
\text { GAS }\end{array}$ & $\operatorname{COAL}$ & ELECTRICITY & $\begin{array}{l}\text { SECTOR } \\
\text { TOTAL }\end{array}$ & \\
\hline $\begin{array}{l}\text { TCIAI FINAL } \\
\text { DEHAMD SECTORS }\end{array}$ & 92,053 & $67,8 ? 2$ & 274,213 & 229.589 & - & 836,249 & 9,413 & 127,858 & $1,637,247$ & $90 \%$ \\
\hline $\begin{array}{l}\text { TRENSPORHATICH } \\
\text { ELECTRICITY GEN. } \\
\text { PETR CLBOA FRCDOCTS } \\
\text { NATURAL GAS } \\
\text { SY NTHETICS }\end{array}$ & $\begin{array}{r}10,763 \\
-313,169 \\
-\end{array}$ & $\begin{array}{r}-125.436 \\
-\end{array}$ & $\begin{array}{r}-644,190 \\
- \\
-\end{array}$ & $\begin{array}{r}-283,114 \\
-\end{array}$ & $\begin{array}{r}1,344,553 \\
-142,128\end{array}$ & $\begin{array}{r}150,794 \\
29,876 \\
- \\
-\end{array}$ & $\begin{array}{r}25 \%, 248 \\
- \\
-\end{array}$ & $\begin{array}{r}-135,963 \\
- \\
-\end{array}$ & $\begin{array}{r}277,842 \\
8,520 \\
-142,128\end{array}$ & $\begin{array}{r}15 \% \\
0 \% \\
-7 \%\end{array}$ \\
\hline $\begin{array}{l}\text { RFT FOEL OSEL } \\
\text { IN TRASSOHEATIOA }\end{array}$ & $-302,406$ & -125.436 & $-644,190$ & $-283,114$ & $1,202,425$ & 180,670 & 252,248 & $-135,963$ & 144,234 & $8 \%$ \\
\hline $\begin{array}{l}\text { TCTAL GROSS FLONS } \\
\text { LCSSES E OHISSIORS }\end{array}$ & $\begin{array}{r}102,816 \\
6,399\end{array}$ & $\begin{array}{r}67,872 \\
1\end{array}$ & $\begin{array}{r}274,213 \\
1\end{array}$ & $\begin{array}{r}229,589 \\
-9,055\end{array}$ & $\begin{array}{r}1,344,553 \\
55,779\end{array}$ & $\begin{array}{r}1,016,919 \\
-27,479\end{array}$ & $\begin{array}{r}261,661 \\
3,541\end{array}$ & $\begin{array}{r}127,858 \\
10,608\end{array}$ & $\begin{array}{r}1,923,609 \\
39,796\end{array}$ & $\begin{array}{r}106 \% \\
2 \%\end{array}$ \\
\hline TCTAL NET OSAGE & $-203,953$ & $-57,552$ & $-369,975$ & $-62,580$ & $1,258,204$ & 989,440 & 265,202 & 2,503 & $1,821,278$ & \\
\hline
\end{tabular}

\begin{tabular}{|c|c|c|c|c|c|c|c|c|c|c|}
\hline $\begin{array}{l}\text { S OFPLY OF ENERGY } \\
\text { FOSS IL FOEI } \\
\text { HYDRCELBCTEIC } \\
\text { NOCL EAR } \\
\text { GEC. ESOLAR }\end{array}$ & $\bar{z}$ & $\begin{array}{l}\overline{-} \\
\overline{-}\end{array}$ & $\begin{array}{l}\overline{-} \\
\overline{-}\end{array}$ & - & $\begin{array}{r}759,987 \\
- \\
-\end{array}$ & $\begin{array}{r}1,154,593 \\
= \\
-\end{array}$ & $\begin{array}{r}103,063 \\
- \\
-\end{array}$ & $\begin{array}{r}10,12 \overline{-} \\
48,211 \\
3,106\end{array}$ & $\begin{array}{r}2,017,643 \\
10,123 \\
48,211 \\
3,106\end{array}$ & $\begin{array}{r}97 \% \\
0 \% \\
2 \% \\
0 \%\end{array}$ \\
\hline TCTAL SOPPII & - & - & - & - & 759,587 & $1,154,593$ & 103,063 & 61,440 & $2,079,083$ & \\
\hline
\end{tabular}

WE

NET IM PORTS
OP R RGIOH


REGIONAL ENEI:GY EALANCE STATEMENT

\begin{tabular}{|c|c|c|c|c|c|c|c|c|c|}
\hline SECIOR & $\begin{array}{c}\text { DISTILLATE } \\
\text { OII }\end{array}$ & $\begin{array}{l}\text { RESIDOAL } \\
\text { DIL }\end{array}$ & $\begin{array}{l}\text { GASOLIN } \\
\text { (AL } \dot{I}\end{array}$ & $\begin{array}{c}\text { OIRER } \\
\text { HYERO- } \\
\text { CAREONS } \\
\text { TS I: } 10 * \$ 9\end{array}$ & $\begin{array}{c}\text { CRJDE } \\
\text { OIL } \\
\text { BTO'S! }\end{array}$ & $\begin{array}{l}\text { NATUR AL. } \\
\text { GAS }\end{array}$ & COAL & ELECTRICITY & $\begin{array}{l}\text { SECTOR } \\
\text { TOTAL }\end{array}$ \\
\hline 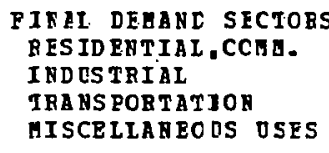 & $\begin{array}{r}70,638 \\
50,371 \\
44,715 \\
1,817\end{array}$ & $\begin{array}{r}13,703 \\
24,133 \\
2,703 \\
675\end{array}$ & 219.679 & $\begin{array}{r}2 \vdots, 237 \\
6: 539 \\
1 \vdots, 190 \\
.10\end{array}$ & $\begin{array}{l}\overline{-} \\
\overline{-}\end{array}$ & $\begin{array}{r}10,143 \\
337 \\
-\end{array}$ & $\begin{array}{r}234 \\
28,941 \\
3 \\
1\end{array}$ & $\begin{array}{r}152,824 \\
116,322 \\
- \\
798\end{array}$ & $\begin{array}{r}276,779 \\
287,306 \\
282,627 \\
3,301\end{array}$ \\
\hline $\begin{array}{l}\text { TCTAI FINAI } \\
\text { DEMAND SECTCRS }\end{array}$ & 157,541 & 41,214 & 219,679 & 111,976 & - & 10,480 & 29,179 & 269,944 & 850,013 \\
\hline 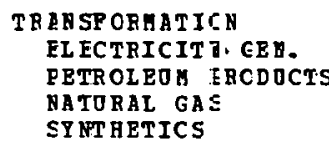 & $\begin{array}{r}2,328 \\
-76,782 \\
-\end{array}$ & $\begin{array}{r}-45,323 \\
-\end{array}$ & $\begin{array}{r}-109,428 \\
-\end{array}$ & $\begin{array}{r}-7 \Xi, 120 \\
-\end{array}$ & 277.169 & $\begin{array}{r}981 \\
- \\
-\end{array}$ & $\begin{array}{r}22,622 \\
- \\
-\end{array}$ & $\begin{array}{r}-8,037 \\
- \\
-\end{array}$ & $\begin{array}{r}16,913 \\
997 \\
- \\
-\end{array}$ \\
\hline $\begin{array}{l}\text { NET FOEL OSET } \\
\text { IN TRANSPOEHATION }\end{array}$ & $-74,454$ & $-45,823$ & $-109,428$ & $-75,120$ & 277,169 & 981 & 22,632 & $-8,037$ & 17,910 \\
\hline $\begin{array}{l}\text { TCTAL GRCSS ILCRS } \\
\text { ICSSES } \varepsilon \text { CMISSIORS }\end{array}$ & $\begin{array}{r}169,369 \\
10,573\end{array}$ & $\begin{array}{r}41,214 \\
0\end{array}$ & 219,679 & $\begin{array}{r}111,976 \\
-4,416\end{array}$ & $\begin{array}{r}277,169 \\
11,498\end{array}$ & $\begin{array}{r}11,461 \\
-3: 09\end{array}$ & $\begin{aligned} 51,801 \\
7.01\end{aligned}$ & $\begin{array}{r}269,944 \\
22,398\end{array}$ & $\begin{array}{r}867,923 \\
40,446\end{array}$ \\
\hline TCIAL NET OSZGE & 133,560 & $-4,608$ & 110,252 & 32,439 & 288,667 & 11,151 & $52,5: 2$ & 284,305 & 908,369 \\
\hline
\end{tabular}

133,560

-

\begin{tabular}{|c|c|c|c|c|c|c|c|c|c|c|}
\hline $\begin{array}{l}\text { SOFELY OF FNERGY } \\
\text { FOSS IL FUEI }\end{array}$ & - & - & - & - & - & - & - & - & - & \\
\hline HYDROELECTEIC & - & - & - & - & - & - & - & 176,148 & 176,148 & $82 \%$ \\
\hline NOCL PAR & - & - & - & - & - & - & - & 32,248 & 32,248 & $15 \%$ \\
\hline GEC. \&SOLAR & - & - & - & - & - & - & - & 6.894 & 6,894 & 38 \\
\hline TCTAL SUPPIY & - & - & - & - & - & - & - & 215,290 & 215,290 & \\
\hline
\end{tabular}

YET IMPORTS
CP RPGION

\section{NOTES:}

\begin{tabular}{|c|c|c|c|c|}
\hline IRA N & $\begin{array}{l}\text { Los } \\
\text { tcs }\end{array}$ & $\begin{array}{l}\text { TOR } \\
\text { YOR } \\
\text { TOR } \\
\text { TOR }\end{array}$ & $\begin{array}{l}\text { ZLECERICITY GED. } \\
\text { ZETROLEOY PRODDCTS } \\
\text { IATUEAL GAS } \\
\text { SY NTEETICS }\end{array}$ & $=0.0$ \\
\hline
\end{tabular}


REGIONAL BNEEGY EALANCE STKTEMENT

\begin{tabular}{|c|c|c|c|c|c|c|c|c|c|c|}
\hline SECTOR & $\begin{array}{l}\text { DISTILLATE } \\
\text { OIL }\end{array}$ & $\begin{array}{l}\text { BESIDOAL } \\
\text { OIL. }\end{array}$ & $\begin{array}{l}\text { GASOLINE } \\
\text { (ALL ONI }\end{array}$ & $\begin{array}{c}\text { OTBER } \\
\text { HYDRO- } \\
\text { CARBONS } \\
\text { TS IN } 10 * * 9\end{array}$ & $\begin{array}{c}\text { CROLE } \\
\text { OIL } \\
\text { BTO'S) }\end{array}$ & $\begin{array}{l}\text { NATURAL } \\
\text { GAS }\end{array}$ & $\operatorname{COAL}$ & EIECTRICITY & $\begin{array}{r}\text { SECTOR } \\
\text { TOTAL }\end{array}$ & \\
\hline $\begin{array}{l}\text { PJNAL CEMANI SECTCES } \\
\text { FFS IDENTIAI, CCAM. } \\
\text { INDOS TRIAL } \\
\text { IRA NSORTATICN } \\
\text { VISCELIANECOS OSES }\end{array}$ & $\begin{array}{r}275,338 \\
112,764 \\
110,130 \\
5,762\end{array}$ & $\begin{array}{r}41,602 \\
158,358 \\
25,0.05 \\
2,8: 81\end{array}$ & $\begin{array}{r}- \\
\overline{-} \\
745,086\end{array}$ & $\begin{array}{r}74,300 \\
279,261 \\
55,178 \\
98\end{array}$ & $\begin{array}{l}\overline{-} \\
\overline{-}\end{array}$ & $\begin{array}{r}344,497 \\
326,434 \\
13,557 \\
7,413\end{array}$ & $\begin{array}{r}1,699 \\
982,082 \\
77 \\
28\end{array}$ & $\begin{array}{r}228,270 \\
257,632 \\
2,856 \\
3,270\end{array}$ & $\begin{array}{r}965,706 \\
2,116,531 \\
951,889 \\
19,452\end{array}$ & $\begin{array}{r}20 \% \\
43 \% \\
19 \% \\
0 \%\end{array}$ \\
\hline $\begin{array}{l}\text { TCTAL FINAL } \\
\text { DEHAND SECTORS }\end{array}$ & 503,994 & 227.846 & 745,086 & 408,837 & - & $691,901$. & 983,886 & 492,028 & $4,053,578$ & $83 \%$ \\
\hline $\begin{array}{l}\text { TF LNSPCRHATICN } \\
\text { RL ECTRICITY GBN. } \\
\text { PBTROLEOH ERODOCTS } \\
\text { NATURAL GAS } \\
\text { SY BTEETICS }\end{array}$ & $\begin{array}{r}21,375 \\
-440,627 \\
- \\
-\end{array}$ & $\begin{array}{r}45,493 \\
-48,400 \\
- \\
-\end{array}$ & $\begin{array}{r}-492,510 \\
-\end{array}$ & $\begin{array}{r}-145,646_{-}^{-} \\
-\end{array}$ & $\begin{array}{r}1,120,761 \\
-\end{array}$ & $\begin{array}{r}209 \\
6,084 \\
- \\
-\end{array}$ & $\begin{array}{r}1,021,363 \\
- \\
-\end{array}$ & $\begin{array}{r}-357,485 \\
- \\
-\end{array}$ & $\begin{array}{r}730,955 \\
-337 \\
- \\
-\end{array}$ & $\begin{array}{r}15 \% \\
0 \%\end{array}$ \\
\hline $\begin{array}{l}\text { GFT FOEL OSEL } \\
\text { IN TRANSPOEATICR }\end{array}$ & $-419,252$ & $-2,907$ & -492.510 & $-145,646$ & $1,120,761$ & 6,293 & $1,021,363$ & $-\$ 57,485$ & 730,617 & $15 \pi$ \\
\hline $\begin{array}{l}\text { TCTAL GROSS FLCRS } \\
\text { LCSSES E CHISSIONS }\end{array}$ & $\begin{array}{r}525,369 \\
32,700\end{array}$ & $\begin{array}{r}273,3: 39 \\
5\end{array}$ & $\begin{array}{r}745,086 \\
3\end{array}$ & $\begin{array}{l}408,837 \\
-16,126\end{array}$ & $\begin{array}{r}1,120,761 \\
46,495\end{array}$ & $\begin{array}{l}698,194 \\
-18,866\end{array}$ & $\begin{array}{r}2,005,249 \\
27,142\end{array}$ & $\begin{array}{r}492,028 \\
40,825\end{array}$ & $\begin{array}{r}4,784,533 \\
112,179\end{array}$ & $\begin{array}{r}98 \% \\
2 \%\end{array}$ \\
\hline $\begin{array}{l}\text { SOFELY OP ENEBGY } \\
\text { FOSS IL FOEL } \\
\text { HYDROELECTEIC } \\
\text { HOCL BAR } \\
\text { GEC. ESOLAR }\end{array}$ & $\bar{z}$ & $\begin{array}{l}\overline{-} \\
\overline{-}\end{array}$ & $\begin{array}{l}\overline{-} \\
\overline{-}\end{array}$ & $\begin{array}{l}\overline{-} \\
\overline{-}\end{array}$ & $\begin{array}{r}35,741 \\
= \\
-\end{array}$ & $\begin{array}{r}69.630 \\
- \\
-\end{array}$ & $\begin{array}{r}2,933,168 \\
= \\
-\end{array}$ & $\begin{array}{r}- \\
4.299 \\
173.997 \\
-\end{array}$ & $\begin{array}{r}3,038,539 \\
4,299 \\
173,997 \\
-\end{array}$ & $\begin{array}{r}94 \% \\
0 \% \\
5 \%\end{array}$ \\
\hline TCTAL SOPPIY & - & - & - & - & 35,741 & 69,630 & $2,933,168$ & 178,296 & $3,216,835$ & \\
\hline
\end{tabular}

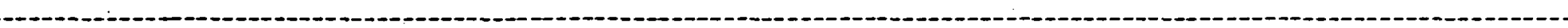

\section{WET IH FORTS}

$117,441 \quad 224,944$

\section{ROTES:}

TRAASPCRALTION LOSS POR TRANSFCBUATICN LOSS FOR TRAKSPCRATICN IOSS POR 
REGIONAL ENEFGY BALANCE STATEM ZNT

PIZS VIE HID SCENARIO

\begin{tabular}{|c|c|c|c|c|c|c|c|c|c|c|}
\hline SECTOK & $\begin{array}{c}\text { DI STILLATB } \\
\text { OIL }\end{array}$ & $\begin{array}{l}\text { BESIDUAL } \\
\text { OIL }\end{array}$ & $\begin{array}{l}\text { GASOLINE } \\
\text { (ALL ONIT }\end{array}$ & $\begin{array}{c}\text { C THER } \\
\text { HYDRO- } \\
\text { ZAE.BONS } \\
5 \text { IN } 10 * * 9\end{array}$ & $\begin{array}{c}\text { CEODE } \\
\text { OIL } \\
\text { BTO'S) }\end{array}$ & $\begin{array}{l}\text { NATURAL } \\
\text { GAS }\end{array}$ & $\cos \mathrm{L}$ & ELECTRICITY & $\begin{array}{r}\text { SECTOF } \\
\text { TOTAL }\end{array}$ & \\
\hline 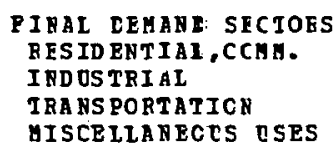 & $\begin{array}{r}58,725 \\
810 \\
4.863 \\
2.405\end{array}$ & $\begin{array}{r}15,983 \\
6,025 \\
297 \\
1,678\end{array}$ & $\begin{array}{r}\overline{-} \\
66,6.51 \\
-\end{array}$ & $\begin{array}{r}9,324 \\
15,991 \\
929 \\
22\end{array}$ & $\begin{array}{l}\overline{-} \\
\overline{-}\end{array}$ & $\begin{array}{r}21,019 \\
8,553 \\
613 \\
1,620\end{array}$ & $\begin{array}{r}5 \\
658 \\
- \\
-\end{array}$ & $\begin{array}{r}14,736 \\
7,064 \\
4 \\
414\end{array}$ & $\begin{array}{r}119,792 \\
39,111 \\
73,353 \\
6,139\end{array}$ & $\begin{array}{r}47.8 \\
15 \% \\
29 \% \\
2 \%\end{array}$ \\
\hline $\begin{array}{l}\text { TCIAL FINAL } \\
\text { DEHAND SECTCAS }\end{array}$ & 66,803 & 23,983 & $66, E 51$ & 26,266 & - & 31,815 & 663 & 22,214 & 238,395 & 938 \\
\hline $\begin{array}{l}\text { TA ANSFCABATICN } \\
\text { FLECTRICIJY. GEN. } \\
\text { PETROLBOA FRCDOCTS } \\
\text { NATORAL GES } \\
\text { SYNTHETICS }\end{array}$ & $\begin{array}{r}2,296 \\
-23,282 \\
-\end{array}$ & $\begin{array}{r}2.426 \\
-2.557 \\
- \\
-\end{array}$ & $\begin{array}{r}-26,0.24 \\
-\end{array}$ & $\begin{array}{r}- \\
-7,695 \\
- \\
-\end{array}$ & $\begin{array}{r}5 \subseteq, 219 \\
- \\
-\end{array}$ & $\begin{array}{r}321 \\
-\end{array}$ & $\begin{array}{r}12,-16 \\
- \\
- \\
-\end{array}$ & $\begin{array}{r}-\epsilon, 060 \\
= \\
-\end{array}$ & $\begin{array}{r}11,378 \\
-18 \\
- \\
-\end{array}$ & $\begin{array}{l}4 \% \\
0 \%\end{array}$ \\
\hline $\begin{array}{l}\text { RET FOEL OSEI } \\
\text { IN TRANSFCEHATION }\end{array}$ & $-20,986$ & -131 & $-26, c 24$ & $-7,695$ & $5 \subseteq, 219$ & 321 & 12,716 & $-\epsilon .060$ & 11,359 & $4 \%$ \\
\hline $\begin{array}{l}\text { TCTAL GROSS FLCHS } \\
\text { LCSSES } \varepsilon \text { CMJSIONS }\end{array}$ & $\begin{array}{r}69,099 \\
4,300\end{array}$ & $\begin{array}{r}26,409 \\
0\end{array}$ & $\begin{array}{r}66, E 51 \\
0\end{array}$ & $\begin{array}{l}26,266 \\
-1,036\end{array}$ & $\begin{aligned} 5 \subseteq, 219 \\
z, 456\end{aligned}$ & $\begin{array}{r}32,136 \\
-368\end{array}$ & $\begin{array}{r}13, \equiv 79 \\
181\end{array}$ & $\begin{array}{r}22,214 \\
1,843\end{array}$ & $\begin{array}{r}249,773 \\
6,878\end{array}$ & $\begin{array}{r}97 \% \\
3 \%\end{array}$ \\
\hline
\end{tabular}

\begin{tabular}{|c|c|c|c|c|c|c|c|c|c|c|}
\hline SOEELY OF EFERGY & & & & & & & & & & \\
\hline FOSSIL FOEI & - & - & - & - & - & - & - & - & - & \\
\hline BY DROELECTRIC & - & - & - & - & - & - & - & 448 & 448 & $2 \%$ \\
\hline ROCL EAR & - & - & - & - & - & - & - & 21,452 & 21,452 & $96 \%$ \\
\hline GEO. ESOLAF & - & - & - & - & - & - & - & 443 & 443 & $2 \%$ \\
\hline TOTAI SOPPIY & - & - & - & - & - & - & - & 22,343 & 22,343 & \\
\hline
\end{tabular}

\section{NET IK FORTS}

CP REGION

50,117

23,852

40,627

17,534

61,676

31,268

13,560

$-4,345$

234,290

YOTES:
TRANSPCRAATICN LOSS POR
TRAN SPCRAAIICE ICSS POR
$\begin{array}{ll}\text { ELECTRI ZITY JEN. } & =55.25 \% \\ \text { PETEOLE TH PR DDOCTS } & =-0.038\end{array}$
TRAN SPORMATICN LCSS POR
NATMRAL GAS
SYNTHETICS
$=0.08$
$=0.0 \%$ 
REGIONAL ENEFGY PAIANCE STATEHENT

PIES MID MID SCENARIO

\begin{tabular}{|c|c|c|c|c|c|c|c|c|c|c|}
\hline SECTOE & $\begin{array}{l}\text { DISTILLATE } \\
\text { OIL }\end{array}$ & $\begin{array}{l}\text { RESIJUAL } \\
\text { OIL }\end{array}$ & $\begin{array}{l}\text { GhSOL INE } \\
\text { (ALIU }\end{array}$ & $\begin{array}{c}\text { CTHER } \\
\text { HYDRO- } \\
\text { CARBONS } \\
\text { S IN } 10 * 4\end{array}$ & $\begin{array}{c}\text { CRODE } \\
\text { OIL } \\
\text { BTU'SI }\end{array}$ & $\begin{array}{l}\text { NATURAL } \\
\text { GAS }\end{array}$ & $\operatorname{COAL}$ & ELECTRICITY & $\begin{array}{l}\text { SECTOR } \\
\text { TOTAL. }\end{array}$ & \\
\hline $\begin{array}{l}\text { FINAL DEYANC SECICES } \\
\text { EFSIDENTIAI, CCMA. } \\
\text { INDOSTRIAL } \\
\text { TRANSPORTATICN } \\
\text { MISCELLANECS OSES }\end{array}$ & $\begin{array}{r}32.835 \\
24.759 \\
30.369 \\
2.035\end{array}$ & $\begin{array}{r}1.289 \\
45,760 \\
16,920 \\
1,069\end{array}$ & $\begin{array}{r}\overline{-} \\
257.457\end{array}$ & $\begin{array}{r}30,093 \\
83,624 \\
7,570 \\
119\end{array}$ & $\begin{array}{l}\overline{-} \\
\overline{-}\end{array}$ & $\begin{array}{r}22,413 \\
113,954 \\
1,124 \\
2,412\end{array}$ & $\begin{array}{r}454 \\
79.310 \\
- \\
4\end{array}$ & $\begin{array}{r}116,667 \\
149,632 \\
- \\
1,615\end{array}$ & $\begin{array}{r}203,751 \\
497,039 \\
313,440 \\
7,254\end{array}$ & $\begin{array}{r}15 \% \\
37 \% \\
23 \% \\
1 \%\end{array}$ \\
\hline $\begin{array}{l}\text { PCIAI FINAI } \\
\text { DEMAND SECICRS }\end{array}$ & 89,998 & 65.038 & 257,457 & 121,406 & - & 139,903 & 79,768 & 267,914 & $1,021,484$ & $76 \%$ \\
\hline $\begin{array}{l}\text { CRANSPCRMATICN } \\
\text { ELECTRICITY GEM. } \\
\text { FETROLEOA FBCDECTS } \\
\text { NATURAL GAS } \\
\text { SYNTHETICS }\end{array}$ & $\begin{array}{r}39,335 \\
- \\
-\end{array}$ & $\begin{array}{r}17.674 \\
- \\
=\end{array}$ & $\begin{array}{l}\overline{-} \\
\overline{-} \\
-\end{array}$ & $\begin{array}{l}- \\
-\end{array}$ & $\begin{array}{l}- \\
\bar{z}\end{array}$ & - & $\begin{array}{r}393,756 \\
- \\
-\end{array}$ & $\begin{array}{r}-154,941 \\
= \\
-\end{array}$ & $\begin{array}{r}295,824 \\
- \\
-\end{array}$ & $22 \%$ \\
\hline $\begin{array}{l}\text { VET FOEL OSEL } \\
\text { IN TRANSFOFYATION }\end{array}$ & 39,335 & 17,674 & - & - & - & - & 393,756 & $-154,941$ & 295.824 & $22 \%$ \\
\hline $\begin{array}{l}\text { TCTAL GROSS FICWS } \\
\text { lCSSES } \& \text { CMISSIOYS }\end{array}$ & $\begin{array}{r}129,333 \\
8,050\end{array}$ & $\begin{array}{r}32.712 \\
1\end{array}$ & 257,457 & $\begin{array}{r}121,406 \\
-4,788\end{array}$ & $\overline{-}$ & $\begin{array}{r}139,903 \\
-3,780\end{array}$ & $\begin{array}{r}473,524 \\
6,409\end{array}$ & $\begin{array}{r}267,914 \\
22,229\end{array}$ & $\begin{array}{r}1,317,308 \\
28,123\end{array}$ & $\begin{array}{r}9 E \% \\
2 \%\end{array}$ \\
\hline TCTAL NET OSAGE & 137,383 & 82.713 & 257,458 & 116,617 & - & 136,122 & 479,933 & 135,202 & $1,345,431$ & \\
\hline $\begin{array}{l}\text { SOFELY OF ENEFGY } \\
\text { FOSS IL FOEI } \\
\text { HYDRCELECTEIC } \\
\text { NOCL BAR } \\
\text { GEC. ESOLAB }\end{array}$ & $\begin{array}{l}- \\
- \\
-\end{array}$ & $\overline{-}$ & $\begin{array}{l}\overline{-} \\
\overline{-}\end{array}$ & $\begin{array}{l}\overline{-} \\
\overline{-}\end{array}$ & $\begin{array}{l}- \\
\overline{-}\end{array}$ & $\begin{array}{l}- \\
\text { - } \\
\text { - }\end{array}$ & $\begin{array}{l}- \\
\overline{-}\end{array}$ & $\begin{array}{r}15,761 \\
140,961 \\
-\end{array}$ & $\begin{array}{r}15,761 \\
140,961 \\
-\end{array}$ & $\begin{array}{l}10 \% \\
90 \%\end{array}$ \\
\hline TCTAI SOPELY & - & - & - & - & - & - & - & 156,722 & 156,722 & \\
\hline
\end{tabular}

\begin{tabular}{|c|c|c|c|c|c|c|c|c|c|}
\hline $\begin{array}{l}\text { EET IM FORTS } \\
\text { OP R EGION }\end{array}$ & 137,383 & 82,713 & 257.458 & 116,617 & - & 136,122 & 479,933 & $-21,519$ & $1,188,709$ \\
\hline
\end{tabular}

NOTES:

TRANSPCRRATICN LOSS FOR TRANSFCREATICN LOSS POR TRANSPCREATICN LCSS POR 
REGIOHAL FUE:GY EALAACR STATELENT

PIBS IID MID SCENARIO

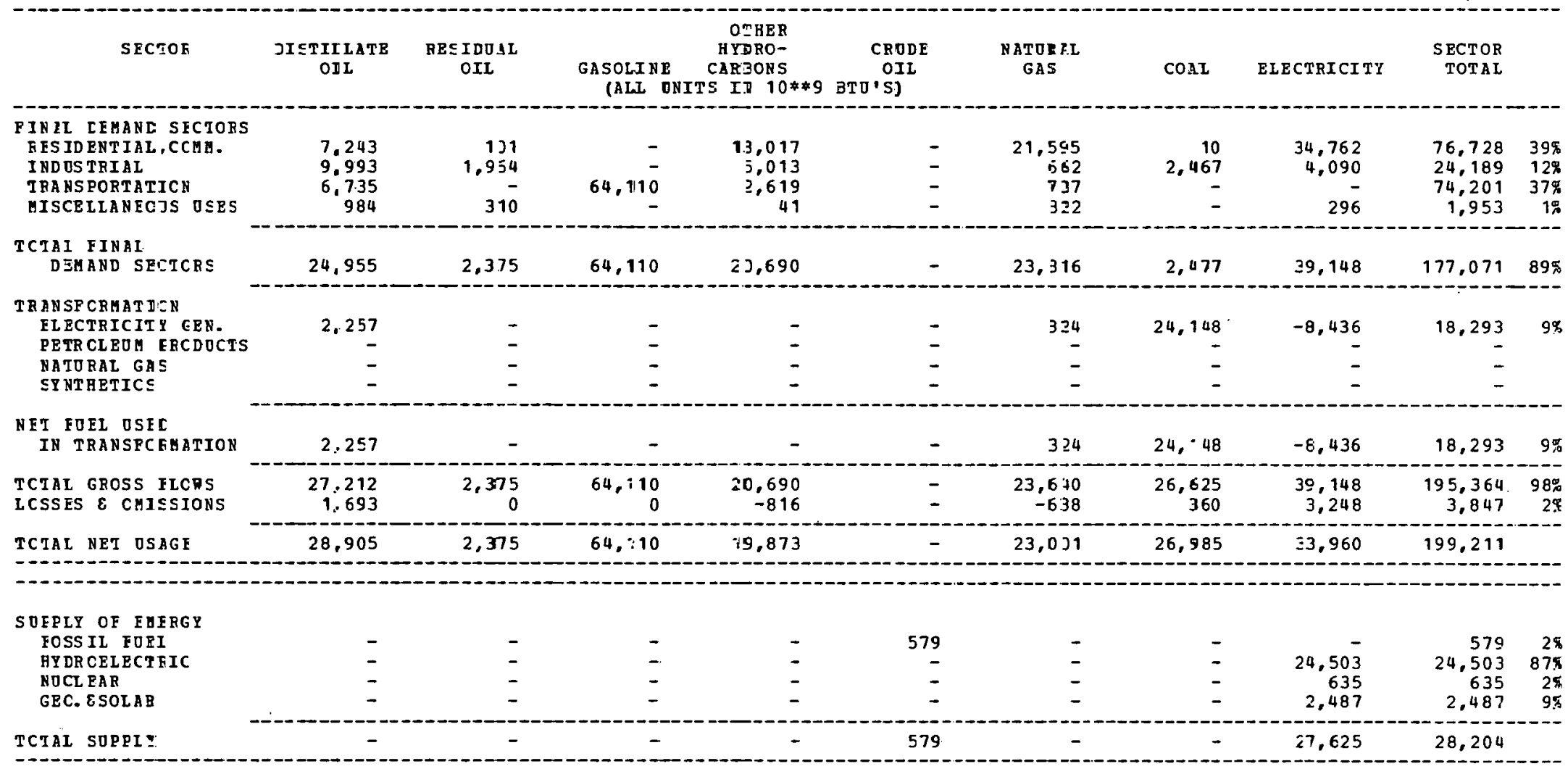

NET IM FORTS
OF REGION


REGICNAL ENEFGY EALANCE STATEMENT

PIES MID MID SCENARIC

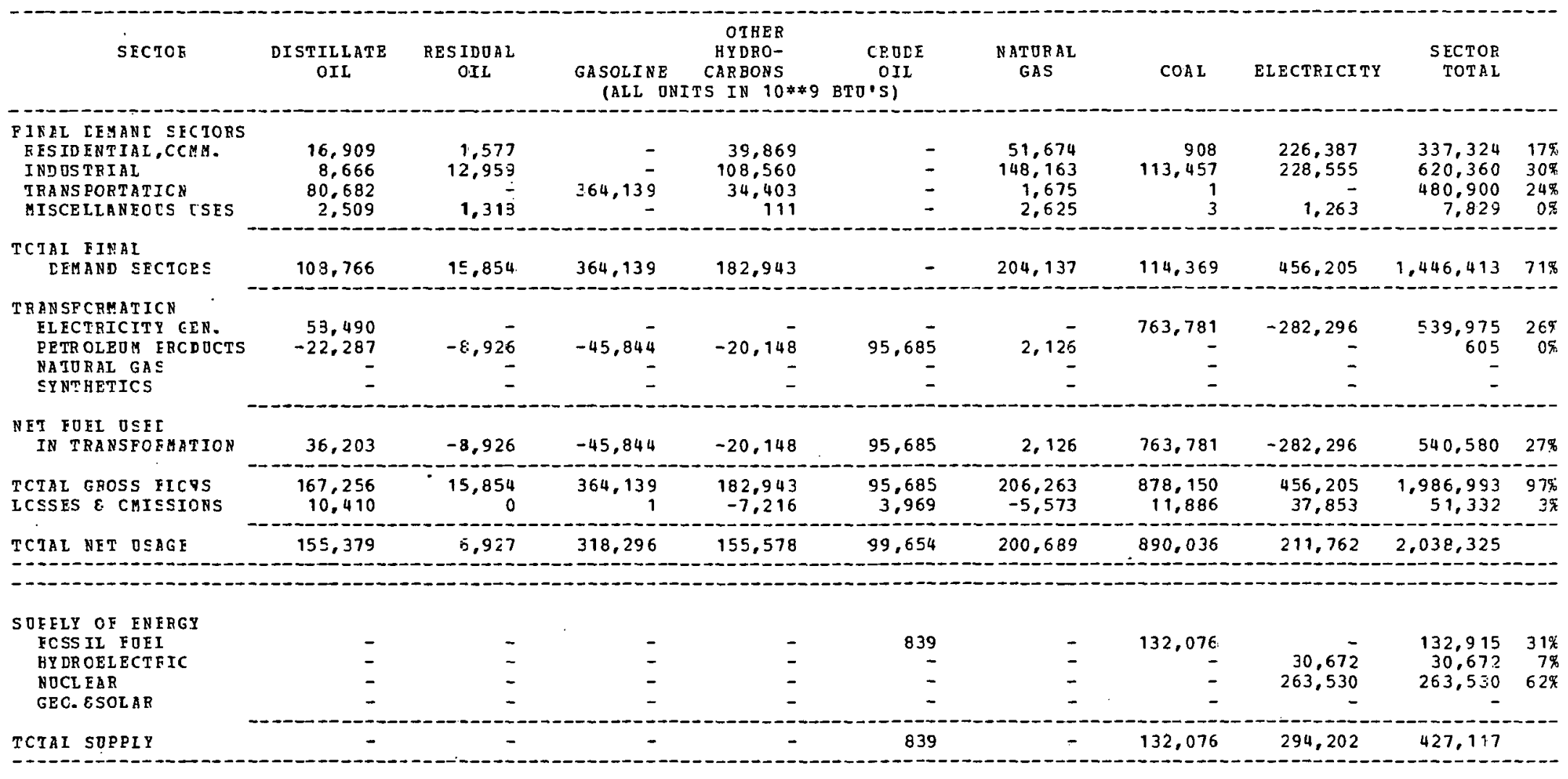

-

MET IM FORTS
OF RFGION

\footnotetext{
NOTES:

1 TRANSFCRMATICN LOSS FOR TRANSPCRMATICN LOSS FCR TRAN SPCRMATICN LCSS POR

ELECTRICITY GEN. $\quad=65.67 \%$

PETFCLEOM PRODOCTS $=0.62 \%$

NATCRAL GAS

TRANSPORMAIICN LOSS PCB
} 
REGI ZNAL ENEFGY EAIANCE STATZMENT IES MID MID SCENARIO

\begin{tabular}{|c|c|c|c|c|c|c|c|c|c|c|}
\hline SE:IO $\mathrm{Fi}$ & $\begin{array}{c}\text { LESTELLATE } \\
\text { OIL }\end{array}$ & $\begin{array}{l}\text { FESIDDAL } \\
\text { OIL }\end{array}$ & $\begin{array}{l}\text { GASCLINE } \\
\text { GALL }\end{array}$ & 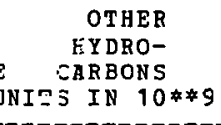 & $\begin{array}{c}\text { CRODE } \\
\text { OII } \\
\text { BTONS) }\end{array}$ & $\begin{array}{l}\text { NATJRAI. } \\
\text { GAS }\end{array}$ & CCAL & ELECTRICITY & $\begin{array}{l}\text { SECTOF } \\
\text { TOTAI }\end{array}$ & \\
\hline $\begin{array}{l}\text { PIN EL CEMEND SECTOES } \\
\text { RESIDENTIAI, CCMH. } \\
\text { INDOSTRIAL } \\
\text { TRANSPORTATICN } \\
\text { MISCELLANECOS OSES }\end{array}$ & $\begin{array}{r}8 c, 568 \\
8:, 582 \\
26:, 764 \\
25,346\end{array}$ & $\begin{array}{r}18,358 \\
297,133 \\
148,509 \\
24,596\end{array}$ & $1,283,055$ & $\begin{array}{r}178,481 \\
2,772,578 \\
207,614 \\
540\end{array}$ & $\begin{array}{l}- \\
-\end{array}$ & $\begin{array}{r}472.466 \\
4,311,399 \\
53.496 \\
11.382\end{array}$ & $\begin{array}{r}- \\
102,670 \\
2 \\
-\end{array}$ & $\begin{array}{r}433,367 \\
407,684 \\
- \\
6,118\end{array}$ & $\begin{array}{r}1,187,840 \\
7,975,046 \\
1,954,550 \\
72,082\end{array}$ & $\begin{array}{r}9 \% \\
62 \% \\
15 \% \\
i \pi\end{array}$ \\
\hline $\begin{array}{l}\text { TCTAL PINAL } \\
\text { DEHAND SECTCRS }\end{array}$ & $45 \subseteq, 260$ & 185,396 & $1,283,065$ & $\Xi, 159,213$ & - & $4,848,743$ & 102,672 & 847,169 & $11,189,518$ & $87 \%$ \\
\hline $\begin{array}{l}\text { TF ADSFCRHATICN } \\
\text { ELECTRICIII, ERN. } \\
\text { PETROLEOM ERODOCTS } \\
\text { NATORAL GAS } \\
\text { STNTHETICS }\end{array}$ & $\begin{array}{r}71,093 \\
-2,13 \equiv, 652 \\
-\end{array}$ & $\begin{array}{r}-131,336 \\
- \\
-\end{array}$ & $\begin{array}{r}-3,519,163 \\
- \\
-\end{array}$ & $\begin{array}{r}-\Sigma, 703,405 \\
- \\
-\end{array}$ & $\begin{array}{r}8,781,20 \div \\
-\end{array}$ & $\begin{array}{r}360,070 \\
788,773 \\
- \\
-\end{array}$ & $\begin{array}{r}1,227,261 \\
= \\
-\end{array}$ & $\begin{array}{r}-710,970 \\
- \\
-\end{array}$ & $\begin{array}{r}1,447,454 \\
81,923 \\
-\end{array}$ & $\begin{aligned} & 11 \% \\
& 1 \%\end{aligned}$ \\
\hline $\begin{array}{l}\text { NET FOEL OSFI } \\
\text { IN TRANSFOFHATION }\end{array}$ & $-2,06 \tilde{z}, 559$ & $-131,836$ & $-3,519,163$ & $-\equiv, 703,405$ & $8,781,207$ & $1,648,843$ & $1,227,261$ & $-710,970$ & $1,529,377$ & $12 \%$ \\
\hline $\begin{array}{l}\text { TCTBL GROSS ELCRS } \\
\text { LCSSES } \& \text { CMISIIONS }\end{array}$ & $\begin{array}{r}530,353 \\
33,010\end{array}$ & $\begin{array}{r}489,396 \\
9\end{array}$ & $1,283,365$ & $\begin{array}{l}\Xi .159,213 \\
-124,613\end{array}$ & $\begin{array}{r}8,781,20 i \\
364,290\end{array}$ & $\begin{array}{r}6,497,586 \\
-175,578\end{array}$ & $\begin{array}{r}1,329,933 \\
18,301\end{array}$ & $\begin{array}{r}847,169 \\
70,292\end{array}$ & $\begin{array}{r}12,718,895 \\
185,420\end{array}$ & $\begin{array}{r}99 \% \\
1 \%\end{array}$ \\
\hline TCTAL NET OSAGE & $-1,570,289$ & 357,569 & $-2,236,292$ & $-668,805$ & $9,14 \bar{\zeta}, 49 \varepsilon$ & $6,322,0.07$ & $1,347,934$ & 206,491 & $12,904,316$ & \\
\hline $\begin{array}{l}\text { SOFELY OF EEFBGI } \\
\text { FCSS IL FOEI } \\
\text { HYDRCELBCIFIC } \\
\text { NOCLEAR } \\
\text { GEO. \& SOLAE }\end{array}$ & $\overline{-}$ & $\begin{array}{l}- \\
-\end{array}$ & $\begin{array}{l}\overline{ } \\
\bar{z}\end{array}$ & $\begin{array}{l}\overline{-} \\
\overline{-}\end{array}$ & $\begin{array}{r}5,221,039 \\
= \\
=\end{array}$ & $\begin{array}{r}3,362,557 \\
= \\
-\end{array}$ & $\begin{array}{r}1,066,000 \\
= \\
-\end{array}$ & $\begin{array}{r}7,361 \\
113,200 \\
20,592\end{array}$ & $\begin{array}{r}9,649,596 \\
7,361 \\
113,200 \\
20,592\end{array}$ & $\begin{array}{r}99 \% \\
0 \% \\
1 \% \\
0 \%\end{array}$ \\
\hline TCTAI SUPPLE & - & - & - & - & $5,221,039$ & $3,362,557$ & $1,066,000$ & 141,153 & $9,790,749$ & \\
\hline
\end{tabular}

\section{NET IMEORTS}

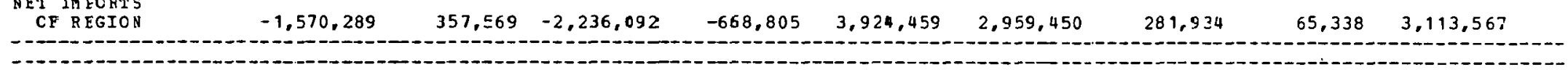

NOIES:

1 TRAMSFCPMATICV LOSS FOR

2 TRANSFCEMAICN LOSS POR

TRA MSFCPMATICN LESS PO

TRA RSFCRUATICN LCSS POR

EIEะTBICITY GEN.

PETRCLEOM FECDOCTS $=0.85 \%$

$\begin{array}{ll}\text { STTIRAL GAS } & =0.0 \% \\ \text { STETITICS } & =0.0 \%\end{array}$ 
REGICNAL ENE FGP EALANCE STATEMENT
PIES MID MID SCENARIO

\begin{tabular}{|c|c|c|c|c|c|c|c|c|c|c|}
\hline SECTCA & $\begin{array}{l}\text { DISTILLATE } \\
\text { OIL }\end{array}$ & $\begin{array}{l}\text { RESI DOAL } \\
\text { OIL }\end{array}$ & $\begin{array}{l}\text { GASOLINE } \\
\text { (ALL ONI }\end{array}$ & $\begin{array}{c}\text { OTHER } \\
\text { HYDRO- } \\
\text { CARBONS } \\
\text { TS IN } 10 * * 9\end{array}$ & $\begin{array}{c}\text { CRIDE } \\
\text { OIL } \\
\text { BTO'S) }\end{array}$ & $\begin{array}{l}\text { NATURAL } \\
\text { GAS }\end{array}$ & COAI & ELECTRICITY & $\begin{array}{r}\text { SECTOR } \\
\text { TOTAL }\end{array}$ & \\
\hline $\begin{array}{l}\text { PIRAL CEMANC SECTOES } \\
\text { RESIDENTIAL, CCH. } \\
\text { IND OSTRIAL } \\
\text { TRANSPORTATICH } \\
\text { MISCELLANECS OSES }\end{array}$ & $\begin{array}{r}17,842 \\
32,989 \\
23,647 \\
6,118\end{array}$ & $\begin{array}{r}4,008 \\
34,062 \\
63 \\
1,934\end{array}$ & $\begin{array}{r}\overline{-} \\
132,613 \\
-\end{array}$ & $\begin{array}{r}29,116 \\
68,462 \\
10,008 \\
218\end{array}$ & $\begin{array}{l}- \\
\overline{-}\end{array}$ & $\begin{array}{r}93,973 \\
14,009 \\
775 \\
1,602\end{array}$ & $\begin{array}{r}56 \\
132,338 \\
2 \\
1\end{array}$ & $\begin{array}{r}44,725 \\
13,381 \\
- \\
1,643\end{array}$ & $\begin{array}{r}189,720 \\
295,241 \\
167,108 \\
11,516\end{array}$ & $\begin{array}{r}28 \% \\
44 \% \\
25 \% \\
2 \%\end{array}$ \\
\hline $\begin{array}{l}\text { TCTAI FINAI } \\
\text { DEHAND SPCICRS }\end{array}$ & 80.596 & 40,067 & 132,613 & 107,804 & - & 110,359 & 132,397 & 59.749 & 663,585 & $98 \%$ \\
\hline $\begin{array}{l}\text { TRANSPCRMATICN } \\
\text { ELECTRICITY GEN. } \\
\text { FBTR CLEM ERCDOCTS } \\
\text { NATORAL GAS } \\
\text { SY NTHETICS }\end{array}$ & $\begin{array}{r}1,973 \\
-101,967 \\
-\end{array}$ & $\begin{array}{r}-32,5 \varepsilon 8 \\
-\end{array}$ & $\begin{array}{r}-170,993 \\
- \\
-\end{array}$ & $\begin{array}{r}-48,503 \\
- \\
-\end{array}$ & $\begin{array}{r}344,91 \overline{-} \\
-102,12 \overline{-}\end{array}$ & $\begin{array}{r}495 \\
14,525 \\
- \\
-\end{array}$ & $\begin{array}{r}127,109 \\
- \\
-\end{array}$ & $\begin{array}{r}-40,621 \\
- \\
-\end{array}$ & $\begin{array}{r}88,956 \\
5,388 \\
-102,128\end{array}$ & $\begin{array}{r}138 \\
1 \% \\
-14 \%\end{array}$ \\
\hline $\begin{array}{l}\text { NET FOFI OSEL } \\
\text { IN TRANSFOEBATICN }\end{array}$ & $-99,994$ & $-32,588$ & $-170,993$ & $-48,503$ & 242,786 & 15,020 & 127,109 & $-40,621$ & $-7,783$ & or \\
\hline $\begin{array}{l}\text { TCTAL GROSS FLCRS } \\
\text { ICSSES \& OHISSIONS }\end{array}$ & $\begin{array}{r}82,569 \\
5,139\end{array}$ & $\begin{array}{r}40.067 \\
0\end{array}$ & $\begin{array}{r}132,613 \\
0\end{array}$ & $\begin{array}{r}107.804 \\
-4,252\end{array}$ & $\begin{array}{r}344,914 \\
14,308\end{array}$ & $\begin{array}{r}125,379 \\
-3,388\end{array}$ & $\begin{array}{r}259,506 \\
3,512\end{array}$ & $\begin{array}{r}59,749 \\
4,957\end{array}$ & $\begin{array}{r}757,929 \\
20,279\end{array}$ & $\begin{array}{r}112 \% \\
3 \%\end{array}$ \\
\hline TCTAL NET OSAGF & $-14,258$ & 7,479 & $-38,379$ & 55,048 & 257,094 & 121,991 & 263,018 & 24,085 & 676.081 & \\
\hline $\begin{array}{l}\text { SOFFLY OP EYFRGP } \\
\text { FOSSIL FORI } \\
\text { BYDRCELECTEIC } \\
\text { NOCLEAR } \\
\text { GEC. } \delta \text { SOLAR }\end{array}$ & $\begin{array}{l}- \\
-\end{array}$ & - & $\begin{array}{l}- \\
- \\
-\end{array}$ & $\begin{array}{l}- \\
- \\
-\end{array}$ & $\begin{array}{r}120,101 \\
- \\
-\end{array}$ & $\begin{array}{r}58,582 \\
- \\
-\end{array}$ & $\begin{array}{r}514,500 \\
- \\
-\end{array}$ & $\begin{array}{r}6,499 \\
969 \\
3,797\end{array}$ & $\begin{array}{r}793,183 \\
6,499 \\
965 \\
3,797\end{array}$ & $\begin{array}{l}99 \% \\
1 \% \\
0 \% \\
0 \%\end{array}$ \\
\hline TCTAI SOPPIY & - & - & - & - & 120,101 & 58,582 & 614,500 & 11,265 & 804,448 & \\
\hline
\end{tabular}

\begin{tabular}{l}
$\begin{array}{l}\text { NET IM FORTS } \\
\text { CP REGION }\end{array}$ \\
\hdashline$-14,258$
\end{tabular}


R3G̈GINAL BNEEGT EALANCE STATEHENT

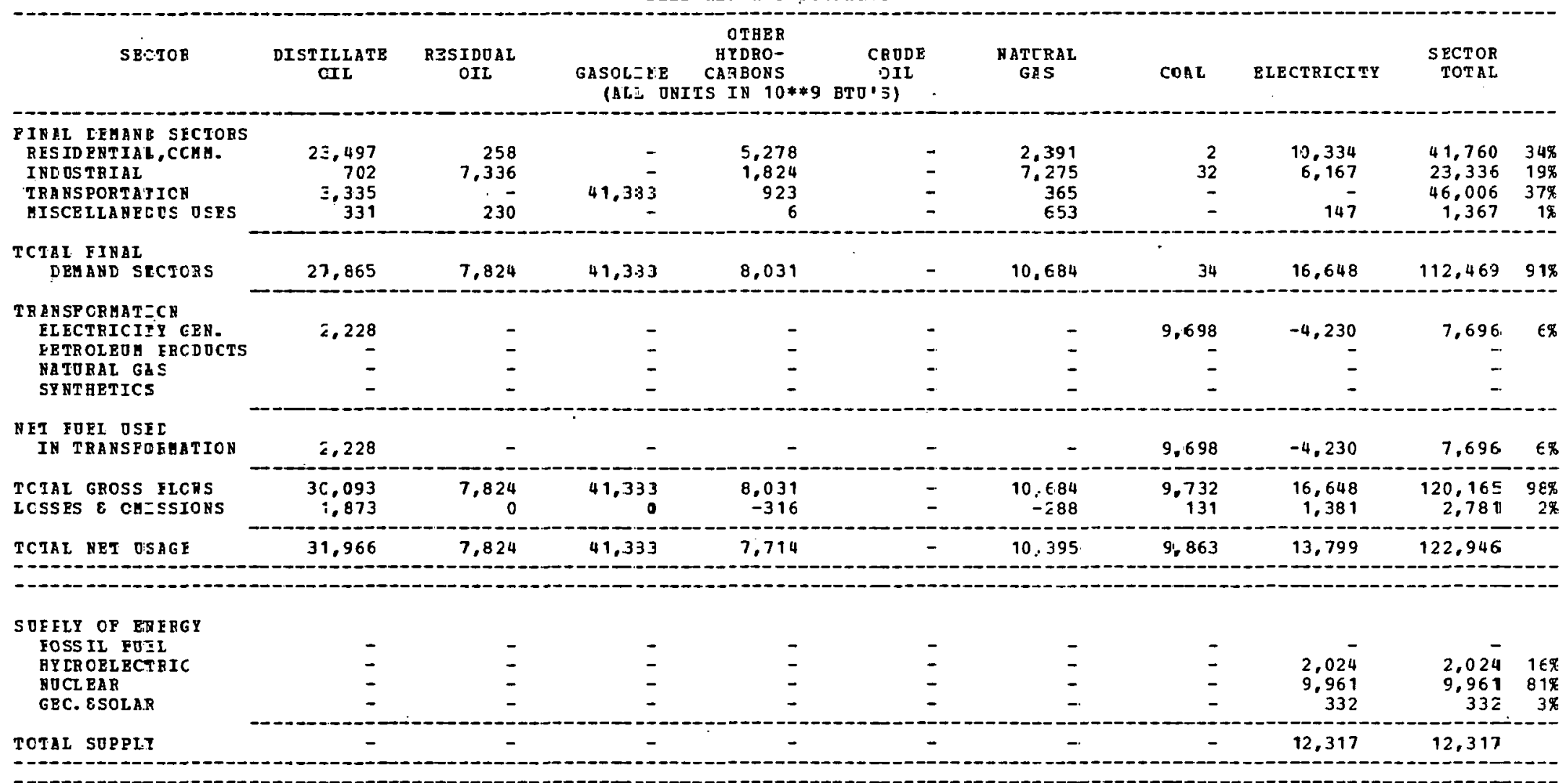

\begin{tabular}{l}
$\begin{array}{l}\text { NET IM FORTS } \\
\text { CP RBGIOF }\end{array}$ \\
\hline
\end{tabular}


REGIONAL RHEFGY EALANCE STATEMENT
PIES HID MID SCENARIO

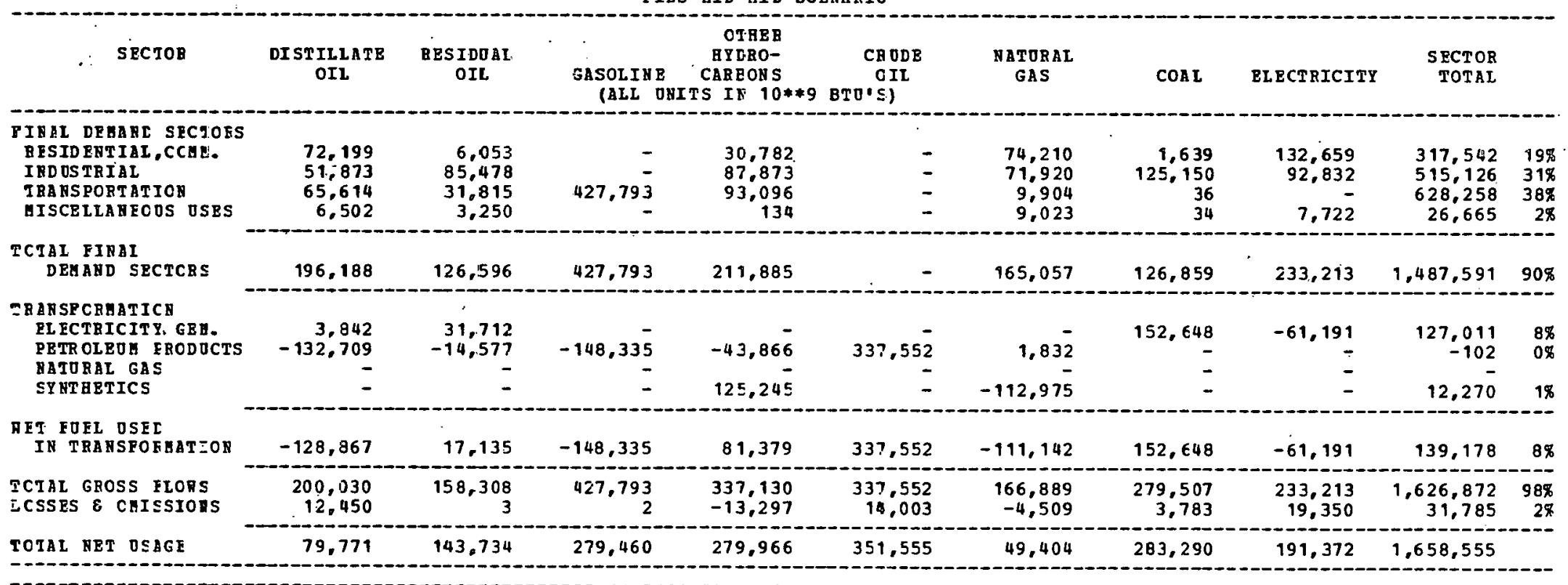

\begin{tabular}{|c|c|c|c|c|c|c|c|c|c|c|}
\hline SOEELY OP ENERGY & & & & & & & & & & \\
\hline FOSSIL FOEI & - & - & - & - & 166 & 3,189 & $1,230,700$ & - & $1,234,055$ & $92 \%$ \\
\hline HY DR OEIECTEIC & - & - & - & - & - & - & - & 10,884 & 10,884 & $1 \%$ \\
\hline NOCLEAR & - & - & - & - & - & - & - & 94,475 & 94,475 & $7 \%$ \\
\hline GBC. ESOLAR & - & - & - & - & - & - & - & - & 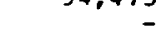 & \\
\hline TCTAI SOPEIY & - & - & - & - & 166 & 3,189 & $1,230,700$ & 105,359 & $1,339,414$ & \\
\hline
\end{tabular}

\begin{tabular}{l}
$\begin{array}{l}\text { GET IM FORTS } \\
\text { CP REGION }\end{array}$ \\
\hline
\end{tabular}


RBGI ONAL 3RETGY EALANCE STATEIBHT
PIES MDD BD SCENARIO

\begin{tabular}{|c|c|c|c|c|c|c|c|c|c|c|}
\hline SBCTOE & $\begin{array}{c}\text { D1STIELATE } \\
\text { OEL }\end{array}$ & $\begin{array}{l}\text { RESI JUAL } \\
\text { OIL }\end{array}$ & $\begin{array}{l}\text { GASOL.INB } \\
\text { (AI.L OHI }\end{array}$ & $\begin{array}{c}\text { OIBER } \\
\text { AYDRO- } \\
\text { CARBONS } \\
\text { TS IN } 10 * * 9\end{array}$ & $\begin{array}{c}\text { CE ODE } \\
\text { CII } \\
\text { BTO'S) }\end{array}$ & $\begin{array}{l}\text { HATUßÁ } \\
\text { GAS }\end{array}$ & $\operatorname{COAL}$ & ELBCTRICITY & $\begin{array}{r}\text { SECTOR } \\
\text { TOTAL }\end{array}$ & \\
\hline 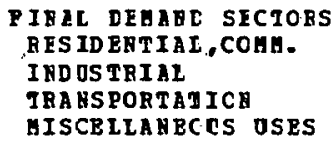 & $\begin{array}{r}86.717 \\
69.274 \\
36.999 \\
3.918\end{array}$ & $\begin{array}{r}13.201 \\
69.617 \\
13.300 \\
1.453\end{array}$ & $269,96 \overline{2}$ & $\begin{array}{r}41,351 \\
143,031 \\
65,534 \\
20\end{array}$ & $\begin{array}{l}- \\
\overline{-}\end{array}$ & $\begin{array}{r}14,181 \\
374 \\
-\end{array}$ & $41, \begin{array}{r}115 \\
07 \\
4 \\
4\end{array}$ & $\begin{array}{r}224,477 \\
135,859 \\
1,804\end{array}$ & $\begin{array}{r}380,042 \\
460,088 \\
386,673 \\
7,199\end{array}$ & $\begin{array}{r}28 \% \\
34 \% \\
29 \% \\
1 \%\end{array}$ \\
\hline $\begin{array}{l}\text { TCTAI FINAL } \\
\text { DEHAND SEZTORS }\end{array}$ & 196.908 & 97.571 & 269,962 & $24.5,936$ & - & 15,055 & 41,430 & 366,140 & $1.234,002$ & $92 \%$ \\
\hline 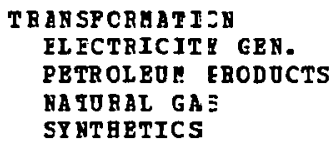 & $\begin{array}{r}2.460 \\
-.20 .495 \\
-\end{array}$ & $\begin{array}{r}-1: 8,027 \\
-\end{array}$ & $\begin{array}{r}-281,053 \overline{-} \\
-\end{array}$ & $\begin{array}{r}-19.3,485 \\
-\end{array}$ & $\begin{array}{r}713,903 \\
- \\
-\end{array}$ & $\begin{array}{r}- \\
2,527 \\
-\end{array}$ & $\begin{array}{r}55,878 \\
- \\
-\end{array}$ & $\begin{array}{r}-18,696 \\
- \\
-\end{array}$ & $\begin{array}{r}39,642 \\
2,570 \\
- \\
-\end{array}$ & $\begin{array}{l}3 \% \\
0 \%\end{array}$ \\
\hline $\begin{array}{l}\text { DET FOEL OSFE } \\
\text { IN TRANSPOBEATICN }\end{array}$ & -118.035 & $-1.18,027$ & $-281,853$ & $-193,485$ & 713,903 & 2,527 & 55,8778 & $-18,696$ & 42,212 & $3 \%$ \\
\hline $\begin{array}{l}\text { TCTAL GROSS ELORS } \\
\text { LCSSES \& OHI SSIOHS }\end{array}$ & $\begin{array}{r}199,368 \\
12,409\end{array}$ & $\begin{array}{r}57,571 \\
1\end{array}$ & $\begin{array}{r}269,962 \\
1\end{array}$ & $\begin{array}{r}246,936 \\
-9,740\end{array}$ & $\begin{array}{r}713,903 \\
29,616\end{array}$ & $\begin{array}{r}17,582 \\
-6.75\end{array}$ & $\begin{array}{r}97,308 \\
1,317\end{array}$ & $\begin{array}{r}366,140 \\
30,380\end{array}$ & $\begin{array}{r}1,27 \epsilon, 214 \\
63,510\end{array}$ & $\begin{array}{r}95 \% \\
5 \%\end{array}$ \\
\hline TCIAL NET OSJGE & 91,282 & -20.454 & $-11,889$ & 43,710 & 743,519 & 17,106 & 98,625 & 377,824 & $1,339,724$ & \\
\hline $\begin{array}{l}\text { SOFELY OF BNIIRGI } \\
\text { FOSS IL FOEI } \\
\text { GYDROELECTHIC } \\
\text { YOCL PAR } \\
\text { GBO. ESOLAB }\end{array}$ & $\overline{-}$ & $\begin{array}{l}\overline{-} \\
\overline{-}\end{array}$ & $\begin{array}{l}\overline{-} \\
\overline{-}\end{array}$ & $\begin{array}{l}- \\
\overline{-}\end{array}$ & - & $\begin{array}{l}\overline{-} \\
\overline{-}\end{array}$ & $\begin{array}{r}135,660 \\
= \\
=\end{array}$ & $\begin{array}{r}- \\
403,345 \\
116,793 \\
9,351\end{array}$ & $\begin{array}{r}135,660 \\
403,345 \\
116,793 \\
9,351\end{array}$ & $\begin{array}{r}20 \% \\
61 \% \\
18 \% \\
1 \%\end{array}$ \\
\hline TCTAL SOPPIY & - & - & - & - & - & - & 135,650 & 529,489 & 665,149 & \\
\hline
\end{tabular}

\section{QET II FORTS}

OP REGION

91,282

$-20,4 \leq 4$

$-11,889$

$4 \equiv .710$

743.519

17, 106

$-37,034$

$-151,664$

674,575

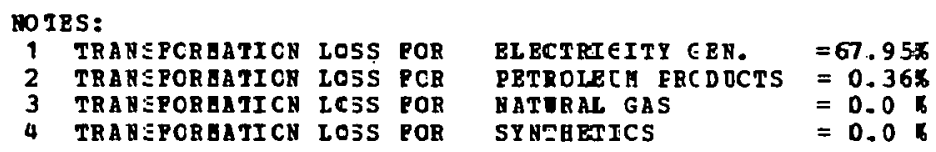


REGIONAL ENEFGY EALANCE STATEMENT

PIBS MID MID SCENARID

\begin{tabular}{|c|c|c|c|c|c|c|c|c|c|c|}
\hline SECTOF & $\begin{array}{l}\text { DISTILLATE } \\
\text { OIL }\end{array}$ & $\underset{O I I L}{R E S I D J A L}$ & $\begin{array}{l}\text { GASOLINE } \\
\text { (ALL O }\end{array}$ & $\begin{array}{c}\text { OTHER } \\
\text { HYDRO- } \\
\text { CAREONS } \\
\text { TS IN } 10 * 4\end{array}$ & $\begin{array}{c}\text { CRODE } \\
\text { OIL } \\
\text { BTU'SI }\end{array}$ & $\begin{array}{l}\text { NATURAL } \\
\text { GAS }\end{array}$ & $\operatorname{COAL}$ & ELECTRICITY & $\begin{array}{r}\text { SECTOR } \\
\text { TOTAL }\end{array}$ & \\
\hline $\begin{array}{l}\text { ZINAL CEMANL SFCTORS } \\
\text { RESIDENTIAI, CCMS. } \\
\text { INDOSTRIAL } \\
\text { TRANSPORTATICN } \\
\text { MISCELLANECOS OSES }\end{array}$ & $\begin{array}{r}9,238 \\
11,125 \\
34,852 \\
868\end{array}$ & $\begin{array}{r}1,832 \\
7.227 \\
- \\
432\end{array}$ & $117.54 \overline{-}$ & $\begin{array}{r}8,655 \\
31,592 \\
1,655 \\
15\end{array}$ & $\begin{array}{l}\overline{-} \\
-\end{array}$ & $\begin{array}{r}67,704 \\
75,882 \\
2,377 \\
1,159\end{array}$ & $\begin{array}{r}927 \\
194,182 \\
23 \\
3\end{array}$ & $\begin{array}{r}36,409 \\
112,930 \\
- \\
516\end{array}$ & $\begin{array}{r}124,765 \\
432,938 \\
156,447 \\
2,993\end{array}$ & $\begin{array}{r}10 \% \\
35 \% \\
13 \% \\
0 \%\end{array}$ \\
\hline $\begin{array}{l}\text { TCTAL FINAI } \\
\text { DEMAND SECTCRS }\end{array}$ & $56, c 83$ & 9.491 & 117,540 & 41,917 & - & 147,122 & 195,135 & - 149,855 & 717,143 & $59 \%$ \\
\hline $\begin{array}{l}\text { TRANSPCEHATICE } \\
\text { FLECTRICITY GEY. } \\
\text { PETR CLPOM ERCDJCTS } \\
\text { NATURAI GAS } \\
\text { SYNTHETICS }\end{array}$ & $\begin{array}{r}95 \\
-11,320 \\
-\end{array}$ & $\begin{array}{r}669 \\
-1,243 \\
- \\
-\end{array}$ & $\begin{array}{r}-12,65 \overline{-} \\
- \\
-\end{array}$ & $\begin{array}{r}-3,741 \\
- \\
-\end{array}$ & 28,795 & $\begin{array}{r}15 \overline{6} \\
- \\
-\end{array}$ & $\begin{array}{r}721,328 \\
- \\
-\end{array}$ & $\begin{array}{r}-238,608 \\
- \\
-\end{array}$ & $\begin{array}{r}483,484 \\
-8 \\
- \\
-\end{array}$ & $\begin{array}{r}39 \% \\
0 \%\end{array}$ \\
\hline $\begin{array}{l}\text { SET FOEL OSFL } \\
\text { IN TRANSFOFATION }\end{array}$ & $-11,225$ & -574 & $-12,653$ & $-3,741$ & 28,795 & 156 & 721,328 & $-238,608$ & 483,475 & $39 \%$ \\
\hline $\begin{array}{l}\text { TCTAL GROSS FLOHS } \\
\text { LCSSES \& OHISSIONS }\end{array}$ & $\begin{array}{r}56,178 \\
3,496\end{array}$ & $\begin{array}{r}10,160 \\
0\end{array}$ & $\begin{array}{r}117,540 \\
0\end{array}$ & $\begin{array}{r}41,917 \\
-1,653\end{array}$ & $\begin{array}{r}28,795 \\
1,194\end{array}$ & $\begin{array}{r}147,278 \\
-3,979\end{array}$ & $\begin{array}{r}916,463 \\
12,405\end{array}$ & $\begin{array}{r}149,855 \\
12,434\end{array}$ & $\begin{array}{r}1,200,627 \\
23,898\end{array}$ & $\begin{array}{r}98 \% \\
2 \%\end{array}$ \\
\hline
\end{tabular}

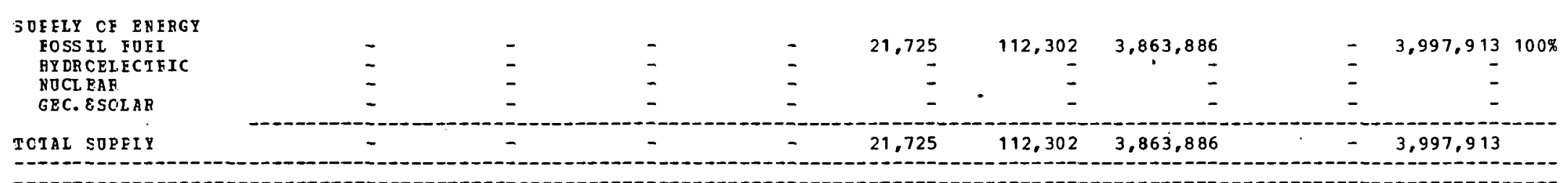

NET IM EORTS

48,353

8,916

104,886

36,521

8,265

$30,996 \quad-2,935,017$

$-76,318 \quad-2,773,396$

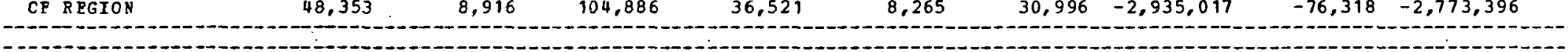

\begin{tabular}{|c|c|c|c|c|c|}
\hline \multicolumn{6}{|c|}{ NO IES: } \\
\hline $\begin{array}{l}1 \\
2\end{array}$ & TRANSPCRHATICN & $\begin{array}{l}\text { Los } \\
\text { Los }\end{array}$ & $\begin{array}{l}\text { POR } \\
\text { PCR }\end{array}$ & ELECTBICITY GEN. & $\begin{array}{l}=66.96 \% \\
=-0.03 \%\end{array}$ \\
\hline 3 & TRANSPCRMATI CN & LCSS & POR & NATURAL GAS & $=0.0 \%$ \\
\hline 4 & TRAN SPCRHATI CN & LCSS & FOR & SYNTH $3 T$ ICS & $=0.0 \%$ \\
\hline
\end{tabular}


RESI JRAL EHEFGY EALANCE STATEMENT

?-ES EID MID SCENARIO

\begin{tabular}{|c|c|c|c|c|c|c|c|c|c|c|}
\hline SECTOF & $\begin{array}{c}\text { DISTIYLATE } \\
\text { OIL }\end{array}$ & $\begin{array}{c}\text { FES IDOAL } \\
\text { OIL }\end{array}$ & $\begin{array}{l}\text { GASOLI SE } \\
\text { (ALL OKI }\end{array}$ & $\begin{array}{c}\text { OIHER } \\
\text { HYDRO- } \\
\text { CARBONS } \\
\text { TS IN } 10 * 9\end{array}$ & $\begin{array}{c}\text { CROCE } \\
\text { OIL } \\
\text { BTO'SI }\end{array}$ & $\begin{array}{l}\text { NATUEAL } \\
\text { GAS }\end{array}$ & $\cos I$ & ELECTRTCITY & $\begin{array}{r}\text { SECTOR } \\
\text { TOTAL }\end{array}$ & \\
\hline $\begin{array}{l}\text { FIRPI CEMANL SECTOFS } \\
\text { KFSIDENTIAI, CCMH. } \\
\text { INDOSTRIAL } \\
\text { TRA ISFORTATICN } \\
\text { MISCELLANECES OSES }\end{array}$ & $\begin{array}{r}58.436 \\
34.759 \\
41.959 \\
5.808\end{array}$ & $\begin{array}{r}6,631 \\
20,838 \\
3 \geq 0 \\
3,032\end{array}$ & $\begin{array}{r}- \\
- \\
368,222 \\
.-\end{array}$ & $\begin{array}{r}67.651 \\
77.297 \\
11.295 \\
126\end{array}$ & $\begin{array}{l}- \\
- \\
-\end{array}$ & $\begin{array}{r}174,593 \\
49,954 \\
6,816 \\
2,5 \leq 8\end{array}$ & $\begin{array}{r}1,552 \\
221,512 \\
- \\
3\end{array}$ & $\begin{array}{r}108,602 \\
117,224 \\
- \\
1,223\end{array}$ & $\begin{array}{r}517,615 \\
521,744 \\
428,612 \\
12,800\end{array}$ & $\begin{array}{l}29 \% \\
25 \% \\
24 \% \\
1 \%\end{array}$ \\
\hline $\begin{array}{l}\text { TCTAI FINAI } \\
\text { DEMAND SECICRS }\end{array}$ & 240,962 & $\equiv 0,9 \geqq 1$ & $368,22 ?$ & 155,369 & - & 233,521 & 223,267 & 227,049 & $1,480,771$ & $83 \%$ \\
\hline $\begin{array}{l}\text { TE ANSFORMATICN } \\
\text { ELECTRICIT' } \\
\text { PETRCEN. } \\
\text { NATORAL GACACDOCTS } \\
\text { SYBTHETICS }\end{array}$ & $\begin{array}{r}28.949 \\
-23.048 \\
- \\
-\end{array}$ & $\begin{array}{r}352 \\
-9,231 \\
- \\
-\end{array}$ & $\begin{array}{r}-47,4.15 \\
- \\
-\end{array}$ & $\begin{array}{r}- \\
-23,836 \\
-\end{array}$ & $\begin{array}{r}98,95 \overline{4} \\
- \\
-\end{array}$ & $\begin{array}{r}3,325 \\
2,1 \leq 8 \\
-\end{array}$ & $\begin{array}{r}385,6.09 \\
- \\
-\end{array}$ & $\begin{array}{r}-148,987 \\
- \\
-\end{array}$ & $\begin{array}{r}269,248 \\
627 \\
- \\
-\end{array}$ & $\begin{aligned} 15 \% \\
0 \%\end{aligned}$ \\
\hline $\begin{array}{l}\text { NET FUFL USE: } \\
\text { IN TRANSFEATICN }\end{array}$ & 5.901 & $-8,879$ & $-47,41 \mathrm{~J}$ & $-20,836$ & 98,954 & $5,5 \div 3$ & 385,609 & $-148,987$ & 269,875 & $15 \%$ \\
\hline $\begin{array}{l}\text { TCTAL GEOSS FLONS } \\
\text { LCSSES } \varepsilon \text { CMI:SIONS }\end{array}$ & $\begin{array}{r}-69.911 \\
16.800\end{array}$ & $\begin{array}{r}31,333 \\
0\end{array}$ & $\begin{array}{r}368,222 \\
1\end{array}$ & $\begin{array}{r}156,369 \\
-6,167\end{array}$ & $\begin{array}{r}98,954 \\
4,105\end{array}$ & $\begin{array}{r}239,4<4 \\
-6,470\end{array}$ & $\begin{array}{r}608,876 \\
8,241\end{array}$ & $\begin{array}{r}227,049 \\
18,839\end{array}$ & $\begin{array}{r}1,750,646 \\
35,350\end{array}$ & $\begin{array}{r}98 \% \\
2 \%\end{array}$ \\
\hline
\end{tabular}

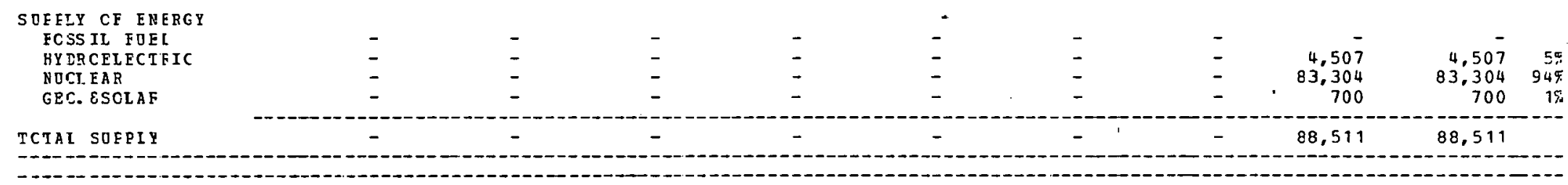

\begin{tabular}{l} 
NET IM FCRTS \\
CF REGION \\
\hdashline
\end{tabular}


REGICNAI ENEFGY EALANCE STLTEMENT

PIES MID MID SCENARIO

\begin{tabular}{|c|c|c|c|c|c|c|c|c|c|c|}
\hline SECTOF & $\begin{array}{l}\text { DISTILLATE } \\
\text { OIL }\end{array}$ & $\begin{array}{l}\text { RESIDUAL } \\
\text { OIL }\end{array}$ & $\begin{array}{l}\text { GASOLINE } \\
\text { (ALL ONIT }\end{array}$ & $\begin{array}{l}\text { OTHER } \\
\text { HYDRO- } \\
\text { CARBORS } \\
\text { TS IN } 10 * * 9\end{array}$ & $\begin{array}{c}\text { CRODE } \\
\text { OIl } \\
\text { BTU'S) }\end{array}$ & $\begin{array}{l}\text { NATURAL } \\
\text { GAS }\end{array}$ & $\operatorname{COA} \mathrm{L}$ & ELECTRICITY & $\begin{array}{r}\text { SECTOR } \\
\text { TOTAL }\end{array}$ & \\
\hline $\begin{array}{l}\text { PIYLL LEMANC SFCTCES } \\
\text { FESIDFNTIAL,CCMM. } \\
\text { IND TSTRIAL } \\
\text { TBANSORTATICN } \\
\text { MISCELLANECTS OSES }\end{array}$ & $\begin{array}{r}9,721 \\
44,039 \\
21,491 \\
1,029\end{array}$ & $\begin{array}{r}2,4 \in 2 \\
12,1 \in 3 \\
7 \in 0 \\
3 \varepsilon 4\end{array}$ & $\begin{array}{r}- \\
- \\
48,728 \\
-\end{array}$ & $\begin{array}{r}7,915 \\
16,861 \\
1,623 \\
35\end{array}$ & $\begin{array}{l}- \\
\overline{-} \\
-\end{array}$ & $\begin{array}{r}28,177 \\
18,346 \\
436 \\
310\end{array}$ & $\begin{array}{r}10 \\
55,589 \\
1 \\
-\end{array}$ & $\begin{array}{r}19,833 \\
7,942 \\
. \\
-249\end{array}$ & $\begin{array}{r}68,138 \\
154,940 \\
73,019 \\
1,947\end{array}$ & $\begin{array}{r}13 \% \\
29 \% \\
14 \% \\
0 \%\end{array}$ \\
\hline $\begin{array}{l}\text { TCIAI FINAI } \\
\text { DEMAND SECTCBS }\end{array}$ & 76,280 & 15,709 & 48,728 & 26,434 & - & 47,269 & 55,600 & 28,024 & 298,044 & $5 \in q$ \\
\hline $\begin{array}{l}\text { TEANSFCRMAT ICN } \\
\text { FLECTRICITY CEN. } \\
\text { PETROLEO ERCDOCTS } \\
\text { NATORAL CAS } \\
\text { SYNTHETICS }\end{array}$ & $\begin{array}{r}925 \\
-126,344 \\
- \\
-\end{array}$ & $\begin{array}{r}-40,379 \\
-\end{array}$ & $\begin{array}{r}-211,873 \\
-\end{array}$ & $\begin{array}{r}-60,098 \\
-\end{array}$ & $\begin{array}{r}427.274 \\
-\end{array}$ & $\begin{array}{r}232 \\
17.998 \\
- \\
-\end{array}$ & $\begin{array}{r}292,571 \\
- \\
-\end{array}$ & $\begin{array}{r}-91,995 \\
- \\
- \\
-\end{array}$ & $\begin{array}{r}201,733 \\
6,677 \\
- \\
-\end{array}$ & $\begin{aligned} 38 \% \\
1 \%\end{aligned}$ \\
\hline $\begin{array}{l}\text { NET FOEL OSEL } \\
\text { IN TRANSFEMATICN }\end{array}$ & $-125,419$ & $-40,379$ & $-211,873$ & $-60,098$ & 427,374 & 18,230 & $29 \hat{z}, 571$ & $-91,995$ & 208,410 & $39 \%$ \\
\hline $\begin{array}{l}\text { TCTAL GROSS FLCWS } \\
\text { LCSSES \& CUISSICNS }\end{array}$ & $\begin{array}{r}77,205 \\
4,805\end{array}$ & $\begin{array}{r}15,709 \\
0\end{array}$ & $\begin{array}{r}48,728 \\
0\end{array}$ & $\begin{array}{l}26,434 \\
-1,042\end{array}$ & $\begin{array}{r}427,374 \\
17,729\end{array}$ & $\begin{array}{r}65,499 \\
-1,769\end{array}$ & $\begin{array}{r}348,171 \\
4,712\end{array}$ & $\begin{array}{r}28,024 \\
2,325\end{array}$ & $\begin{array}{r}506,454 \\
26,761\end{array}$ & $\begin{aligned} 95 \% \\
5 x\end{aligned}$ \\
\hline CTAL NET OSACE & $-44,3 \geq 4$ & $-24,6,70$ & $-163,145$ & $-34,70 E$ & 445,104 & 63,729 & 352,883 & $-61,645$ & 533,215 & \\
\hline
\end{tabular}

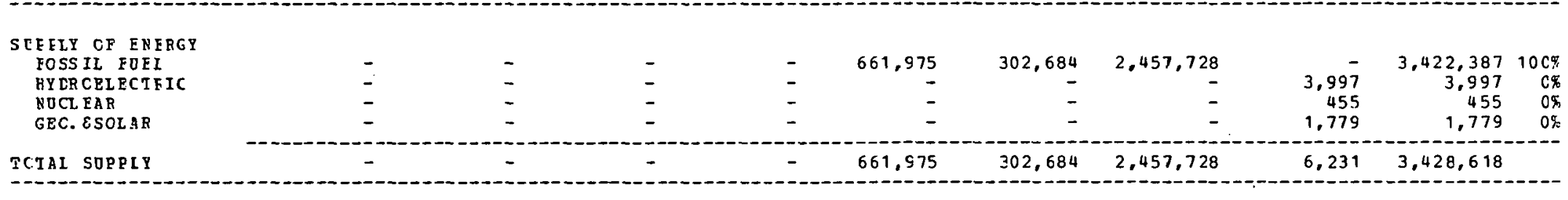

\section{NET IM FOETS}

CP REGION

$-44,334$

$-24,670$

$-163,145$

$-238,954-2,104,844$

$-67,876-2,895,402$
NO IES:
1 TRANSFCRMATICN IOSS POR TRANSPCBYATICN IOSS PCR
TRANSFCRMITICN LCSS PO
ELECTRICITY GEN. $\quad=68.68 \%$
PETROLEOM PRODOCTS $=1.50 \%$
$\begin{array}{ll}\text { NATURAI GAS } & =0.0 \mathrm{q}\end{array}$
4 TRANSFCRMATICN LOSS FOR SYNTHETICS 


\section{THIS PAGE}

\section{WAS INTENTIONALLY \\ LEFT BLANK}


BEA Region Tables for 1990 


\section{THIS PAGE}

\section{WAS INTENTIONALLY LEFT BLANK}


RZGIONAL ENE GGY BALANCE STATEMENT

PIBS MID MID SCENARIO

\begin{tabular}{|c|c|c|c|c|c|c|c|c|c|c|}
\hline SECTOR & $\begin{array}{l}\text { DISTILLATE } \\
\text { OIL }\end{array}$ & $\begin{array}{l}\text { RESIDUAL } \\
\text { OIL }\end{array}$ & $\begin{array}{l}\text { GASOLINE } \\
\text { (ALI O }\end{array}$ & $\begin{array}{c}\text { OTRER } \\
\text { HYDRO- } \\
\text { CARBONS } \\
\text { TS IN 10**9 }\end{array}$ & $\begin{array}{c}\text { CRODE } \\
\text { OIL } \\
\text { BTO'S) }\end{array}$ & $\begin{array}{l}\text { NATURAL } \\
\text { GAS }\end{array}$ & $\operatorname{COAL}$ & ELECTRICITY & $\begin{array}{r}\text { SECTOR } \\
\text { TOTAL }\end{array}$ & \\
\hline $\begin{array}{l}\text { PINAL CEHANC SICTOBS } \\
\text { RESID ENTIAL, CCUA. } \\
\text { INDOSTRIAL } \\
\text { TRANSPORTATICN } \\
\text { MISCELLABCOS OSES }\end{array}$ & $\begin{array}{r}23,923 \\
3,291 \\
2,725 \\
504\end{array}$ & $\begin{array}{r}6,174 \\
42.357 \\
7,602 \\
352\end{array}$ & $28,44 \overline{2}$ & $\begin{array}{r}3,581 \\
1,181 \\
4,064 \\
4\end{array}$ & $\begin{array}{l}- \\
\overline{-}\end{array}$ & $\begin{array}{r}585 \\
2,341 \\
346 \\
225\end{array}$ & $\begin{array}{r}2 \\
137 \\
3 \\
-\end{array}$ & $\begin{array}{r}5,298 \\
12,623 \\
- \\
73\end{array}$ & $\begin{array}{r}39,563 \\
61,930 \\
43,182 \\
1,158\end{array}$ & $\begin{array}{r}23 \% \\
36 \% \\
25 \% \\
1 \%\end{array}$ \\
\hline $\begin{array}{l}\text { TCTAL FINAL } \\
\text { DEHAYE SECTCRS }\end{array}$ & 30,443 & 56.485 & 28.442 & 8.830 & - & 3,497 & 142 & 17,994 & 145,833 & $84 \%$ \\
\hline $\begin{array}{l}\text { TA ARSPORHATICN } \\
\text { ELECTRICITY GEN. } \\
\text { PETR OLEOM FRODOCES } \\
\text { HATURAL GAS } \\
\text { SY TTETICS }\end{array}$ & $\begin{array}{r}1,938 \\
-145,514 \\
-\end{array}$ & $\begin{array}{r}1,4: 44 \\
-15,984 \\
-\end{array}$ & $\begin{array}{r}-162,64 \overline{8} \\
- \\
-\end{array}$ & $\begin{array}{r}-48,099 \\
- \\
-\end{array}$ & $\begin{array}{r}370,123 \\
- \\
-\end{array}$ & $\begin{array}{r}\overline{-} \\
- \\
-\end{array}$ & $\begin{array}{r}10,301 \\
- \\
-\end{array}$ & $\begin{array}{r}-4,764 \\
- \\
- \\
-\end{array}$ & $\begin{array}{r}8,889 \\
-112 \\
- \\
-\end{array}$ & $\begin{array}{l}5 \% \\
0 \%\end{array}$ \\
\hline $\begin{array}{l}\text { MET FOEL OSEL } \\
\text { IN TRASSFCEBATIOU }\end{array}$ & $-143,576$ & $-14,570$ & $-162,648$ & $-48,099$ & 370,123 & 2,009 & 10,301 & $-4,764$ & 8,776 & $5 \%$ \\
\hline $\begin{array}{l}\text { TCEAL GROSS FLOHS } \\
\text { LOSSES } \& \text { CMISSIONS }\end{array}$ & $\begin{array}{r}32,381 \\
2,015\end{array}$ & 57,899 & 28,442 & $\begin{array}{r}8,830 \\
-348\end{array}$ & $\begin{array}{r}370,123 \\
15,354\end{array}$ & $\begin{array}{r}5,506 \\
-148\end{array}$ & $\begin{array}{r}10,443 \\
141\end{array}$ & $\begin{array}{r}17,994 \\
1,493\end{array}$ & $\begin{array}{r}154,722 \\
18,508\end{array}$ & $\begin{array}{l}89 \% \\
11 \%\end{array}$ \\
\hline
\end{tabular}

-

\section{SOFELY OF ERERGY}

IOSS II FOEI -

EYDR OEL ECT FIC

DOCL EAR

GEO. \& SOLAR

TCIAI SOPPII

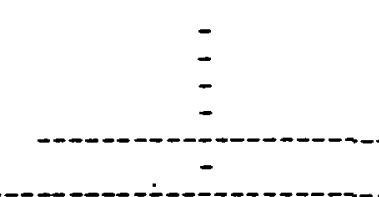

$\begin{array}{lll}- & - & - \\ - & - & - \\ - & - & -\end{array}$

-

RET IH FORTS
CP REGION


REGI JNAL ENERGY BALANCE STATEMERT

PIES MID MID SCENARIO

\begin{tabular}{|c|c|c|c|c|c|c|c|c|c|c|}
\hline SECTOR & $\begin{array}{l}\text { EISIILIATE } \\
\text { OII }\end{array}$ & $\begin{array}{l}\text { RES IDUAL } \\
\text { CIL }\end{array}$ & $\begin{array}{l}\text { GASOLINE } \\
\text { (ALL DUI }\end{array}$ & 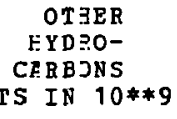 & $\begin{array}{c}\text { CRODE } \\
\text { OII } \\
\text { ETO'S) }\end{array}$ & $\begin{array}{l}\text { NATORAL } \\
\text { GAS }\end{array}$ & COA 5 & ELECTRICITY & $\begin{array}{r}\text { SECTOR } \\
\text { TOTAL }\end{array}$ & \\
\hline $\begin{array}{l}\text { PINAL CEMAND SECTORS } \\
\text { RESID BNTIAL,CCMA. } \\
\text { INDOSTRIAL } \\
\text { TRANSPORTATICN } \\
\text { MISCEILANECOS OSBS }\end{array}$ & $\begin{array}{r}57,-535 \\
3,-88 \\
6, \vdots 12 \\
\leq 17\end{array}$ & $\begin{array}{r}15,62.7 \\
4: 203 \\
5,67.3 \\
643\end{array}$ & $66,17 \overline{-}$ & $\begin{array}{r}8,342 \\
4,825 \\
3,050 \\
12\end{array}$ & $\begin{array}{l}- \\
-\end{array}$ & $\begin{array}{r}2,050 \\
2,655 \\
27 \bar{c} \\
946\end{array}$ & $\begin{array}{r}4 \\
373 \\
2 \\
-\end{array}$ & $\begin{array}{r}13,079 \\
15,310 \\
- \\
232\end{array}$ & $\begin{array}{r}96,534 \\
68,170 \\
81,486 \\
2,747\end{array}$ & $\begin{array}{r}30 \% \\
21 \% \\
26 \% \\
1 \%\end{array}$ \\
\hline $\begin{array}{l}\text { TCTAI FINAL } \\
\text { DEMAND SECTCRS }\end{array}$ & $\in 8, C 52$ & 63,145 & 66,177 & 16.229 & - & 5,933 & 379 & 28,621 & 248,937 & $78 \%$ \\
\hline $\begin{array}{l}\text { TRANSPORMATICY } \\
\text { ELECTRICIT GEN. } \\
\text { PETB OLEOM EAODOCTS } \\
\text { NATURAL GAS } \\
\text { SY NTHETICS }\end{array}$ & $\begin{array}{r}3,: 07 \\
-3,8, ; 36 \\
- \\
-\end{array}$ & $\begin{array}{r}16,803 \\
-41,553 \\
-\end{array}$ & $\begin{array}{r}-422,884 \\
- \\
-\end{array}$ & $\begin{array}{r}-125,057 \\
- \\
-\end{array}$ & $\begin{array}{r}962.319 \\
- \\
-\end{array}$ & $\begin{array}{r}5.22 \overline{-} \\
- \\
-\end{array}$ & $\begin{array}{r}16,394 \\
- \\
-\end{array}$ & $\begin{array}{r}-12,381 \\
- \\
-\end{array}$ & $\begin{array}{r}24,019 \\
-291 \\
- \\
-\end{array}$ & $\begin{array}{l}8 \% \\
0 \%\end{array}$ \\
\hline $\begin{array}{l}\text { NET FDEL OSEI } \\
\text { IX TRANSPEYATION }\end{array}$ & $-5.5, \cdot 29$ & $-24,749$ & $-422,824$ & $-125,057$ & 962,319 & $5,2 \geq 0$ & $16,3 \varepsilon 4$ & $-12,381$ & 23,727 & $7 \%$ \\
\hline $\begin{array}{l}\text { TOTAL GRCSS FLCRS } \\
\text { ICSSES \& OHISSIONS }\end{array}$ & $\begin{array}{r}71,659 \\
4.460\end{array}$ & $\begin{array}{r}79,955 \\
1\end{array}$ & $\begin{array}{r}66,177 \\
0\end{array}$ & $\begin{array}{r}1 \epsilon, 229 \\
-640\end{array}$ & $\begin{array}{r}962.319 \\
39,922\end{array}$ & $\begin{array}{r}11,157 \\
-331\end{array}$ & $\begin{array}{r}16,763 \\
2 \therefore 6\end{array}$ & $\begin{array}{r}28,621 \\
2,374\end{array}$ & $\begin{array}{r}272.956 \\
46.044\end{array}$ & $\begin{array}{l}86 \% \\
14 \%\end{array}$ \\
\hline $\begin{array}{l}\text { SOPELY OP ENYRGY } \\
\text { FOSS IL FOEI } \\
\text { HY DZOELECTIIC } \\
\text { NOCL EAR } \\
\text { GEO. ESOLAR }\end{array}$ & $\begin{array}{l}- \\
-\end{array}$ & $\begin{array}{l}\overline{-} \\
-\end{array}$ & $\begin{array}{l}- \\
- \\
-\end{array}$ & $\begin{array}{l}- \\
-\end{array}$ & $\begin{array}{l}- \\
-\end{array}$ & $\begin{array}{l}\text { - } \\
\text { - }\end{array}$ & $\begin{array}{l}\text { - } \\
\text { - }\end{array}$ & $\begin{array}{r}- \\
3,064 \\
15,967 \\
571\end{array}$ & $\begin{array}{r}- \\
3.064 \\
15.967 \\
571\end{array}$ & $\begin{array}{r}16 \% \\
81 \% \\
3 \%\end{array}$ \\
\hline TOTAL SUPPLY & - & - & - & - & - & - & - & 19,602 & 19,602 & \\
\hline
\end{tabular}

\begin{tabular}{l}
$\begin{array}{l}\text { NET IM PORTS } \\
\text { OP R RGION }\end{array}$ \\
\hline
\end{tabular}


R3GIONAL ENEGGY EALANCE STATEMENT

PIES MID MID SCENARIO

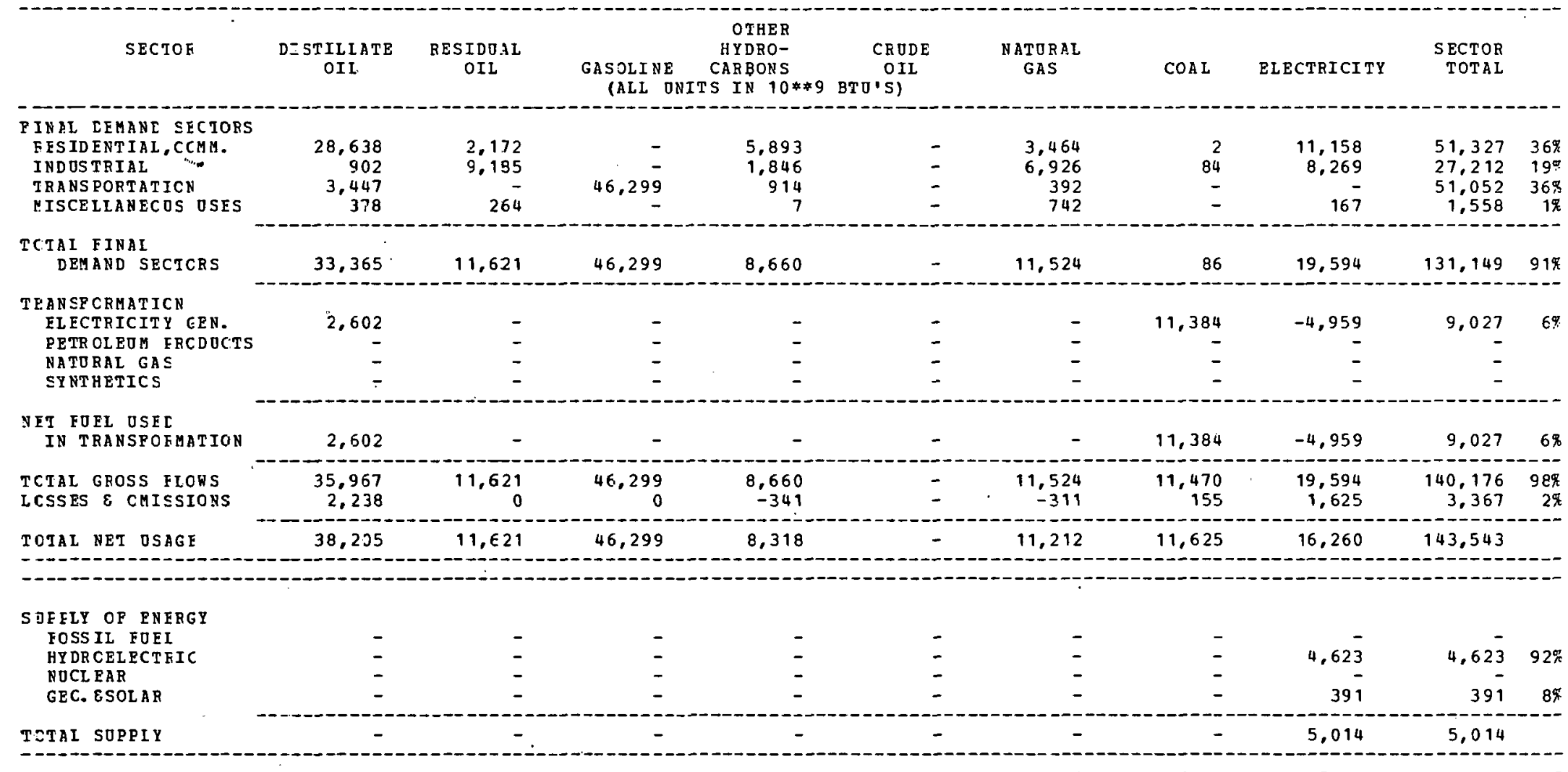

\section{NET IM FORTS}

OF REGION

38,205

11,621

46,299

8,318

11,212

11,625

11,246

138,529

\begin{tabular}{|c|c|c|c|c|c|}
\hline \\
\hline $\begin{array}{l}1 \\
2\end{array}$ & $\begin{array}{l}\text { TRANSFCRMATI CN } \\
\text { TRANSFCRMATI CN }\end{array}$ & Loss & $\begin{array}{ll}\text { POR } \\
\text { FOR }\end{array}$ & $\begin{array}{l}\text { ELECTRECITY GEN. } \\
\text { PETROLZOM PRODOCTS }\end{array}$ & $\begin{array}{l}=64.54 \pi \\
=0.0 \%\end{array}$ \\
\hline & TR A N SPORMA TI CN & LCSS & FOR & NATURA= GAS & $=0.0$ \\
\hline 4 & TRA N SFOR MA TI ON & Loss & POR & SYNTHETICS & $=0.0$ \\
\hline
\end{tabular}


REGI JNAL ZNE FGY BALANCE STATIMENT

?IES MID MID.SCENARIO

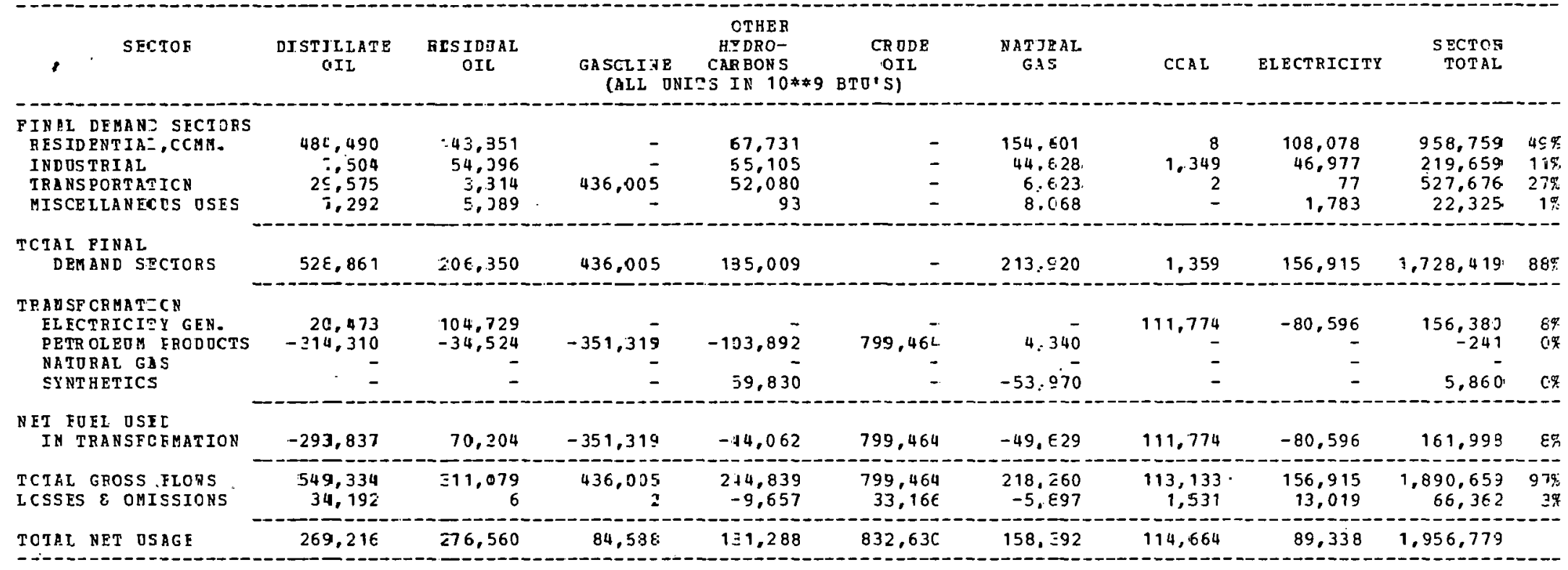

(5)

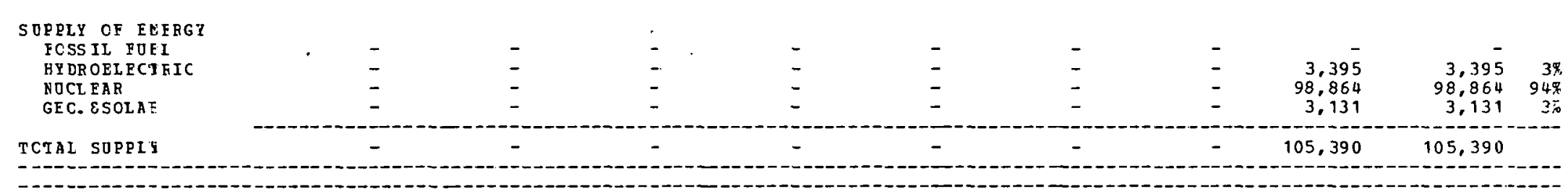

\begin{tabular}{l}
$\begin{array}{l}\text { NET IMFORTS } \\
\text { CF REGION }\end{array}$ \\
\hline
\end{tabular}


REGIONAL ENE FGY EALANCE STATEMENT

PIES MID MID SCENARIO

\begin{tabular}{|c|c|c|c|c|c|c|c|c|c|c|}
\hline SECTOK & $\begin{array}{l}\text { DISTILLATE } \\
\text { OII }\end{array}$ & $\begin{array}{l}\text { RESIDJAL } \\
\text { OII }\end{array}$ & $\begin{array}{l}\text { GASOLINE } \\
\text { (ALL ON }\end{array}$ & $\begin{array}{c}\text { OTHER } \\
\text { HYDRO- } \\
\text { CARBONS } \\
\text { TS IN } 10 * *\end{array}$ & $\begin{array}{c}\text { CRODE } \\
\text { OIL } \\
\text { BTO'S) }\end{array}$ & $\begin{array}{l}\text { NATURAL } \\
\text { GAS }\end{array}$ & $\operatorname{COAL}$ & ELECTRICITY & $\begin{array}{r}\text { SECTOR } \\
\text { TOTAL }\end{array}$ & \\
\hline $\begin{array}{l}\text { FINAL LEMANC SECTORS } \\
\text { RESIDENTIAL, CCMM- } \\
\text { INDOSTRIAL } \\
\text { IRANSEORTATICN } \\
\text { MISCELLAUECS OSES }\end{array}$ & $\begin{array}{r}150,844 \\
7,483 \\
20,606 \\
2,450\end{array}$ & $\begin{array}{r}36,368 \\
76,238 \\
515 \\
1,710\end{array}$ & $212,14 \overline{-}$ & $\begin{array}{r}27,822 \\
43,672 \\
16,342 \\
39\end{array}$ & $\begin{array}{l}\overline{-} \\
\overline{-}\end{array}$ & $\begin{array}{r}58,598 \\
25,715 \\
1,956 \\
3,468\end{array}$ & $\begin{array}{r}13 \\
922 \\
3 \\
-\end{array}$ & $\begin{array}{r}60,461 \\
32,176 \\
20 \\
717\end{array}$ & $\begin{array}{r}334,606 \\
186,206 \\
251,688 \\
8,384\end{array}$ & $\begin{array}{r}36 \% \\
20 \% \\
27 \% \\
1 \%\end{array}$ \\
\hline $\begin{array}{l}\text { TCTAI FINAL } \\
\text { DEMAND SECTORS }\end{array}$ & 181,383 & 115,431 & 212,146 & 87,875 & - & 89,737 & 938 & 93,374 & 780,884 & $85^{\not 4}$ \\
\hline $\begin{array}{l}\text { THANSFORMATICN } \\
\text { FLECTRICITY GEN. } \\
\text { PETR OL BOM FRODOCTS } \\
\text { NATURAL GAS } \\
\text { SY NTETICS }\end{array}$ & $\begin{array}{r}17.607 \\
-465,645 \\
-\end{array}$ & $\begin{array}{r}50,410 \\
-51,148 \\
- \\
-\end{array}$ & $\begin{array}{r}-520,47 \overline{3} \\
-\end{array}$ & $\begin{array}{r}-153,915 \\
-\end{array}$ & $\begin{array}{r}1,184,393 \\
-\end{array}$ & 6,430 & $\begin{array}{r}53,452 \\
- \\
-\end{array}$ & $\begin{array}{r}-42,118 \\
- \\
-\end{array}$ & $\begin{array}{r}79,351 \\
-357 \\
- \\
-\end{array}$ & $\begin{array}{l}9 \% \\
0 \%\end{array}$ \\
\hline $\begin{array}{l}\text { NET FOEL OSEL } \\
\text { I TRANSFCFHATION }\end{array}$ & $-448,038$ & -738 & $-520,473$ & $-153,915$ & $1,184,393$ & 6,430 & 53,452 & $-42,118$ & 78,993 & $9 \%$ \\
\hline $\begin{array}{l}\text { TCTAL GROSS FLONS } \\
\text { LCSSES } \varepsilon \text { CMISSIONRS }\end{array}$ & $\begin{array}{r}198,990 \\
12,385\end{array}$ & $\begin{array}{r}165,341 \\
3\end{array}$ & 212,146 & $\begin{array}{r}87,875 \\
-3,466\end{array}$ & $\begin{array}{r}1,184,393 \\
49,134\end{array}$ & $\begin{array}{l}96,167 \\
-2,598\end{array}$ & $\begin{array}{r}54,390 \\
736\end{array}$ & $\begin{array}{r}93,374 \\
7,747\end{array}$ & $\begin{array}{r}860,235 \\
63,943\end{array}$ & $\begin{array}{r}93 \% \\
7 \%\end{array}$ \\
\hline $\begin{array}{l}\text { SUFELY OF ENERGY } \\
\text { FOSS IL EOFI } \\
\text { HYDROELECTEIC } \\
\text { NOCLEAR } \\
\text { GEC. ESOLAR }\end{array}$ & $\begin{array}{l}\overline{-} \\
\overline{-} \\
-\end{array}$ & $\begin{array}{l}- \\
\overline{-} \\
-\end{array}$ & $\begin{array}{l}\bar{y} \\
\overline{-}\end{array}$ & $\begin{array}{l}- \\
- \\
-\end{array}$ & $\begin{array}{l}- \\
-\end{array}$ & $\begin{array}{l}\overline{-} \\
-\end{array}$ & $\begin{array}{l}- \\
- \\
-\end{array}$ & $\begin{array}{r}- \\
6,888 \\
80,788 \\
1,862\end{array}$ & $\begin{array}{r}- \\
6,888 \\
80,788 \\
1,862\end{array}$ & $\begin{array}{r}8 \% \\
90 \% \\
2 \%\end{array}$ \\
\hline TCTAL SOPPLY & - & - & - & - & - & - & - & 89,538 & 89,538 & \\
\hline
\end{tabular}

NET IMECRTS

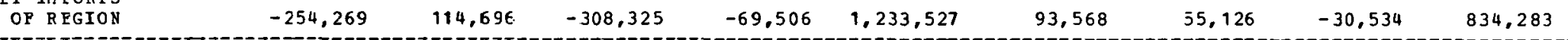

-

NOTES:

1 TRANSPCRMATICN LOSS FOR

TRANSFORMATICN LOSS POR

TRANSFOREATICN ICSS POR

TRANSFORLATICN LCSS POR
ELECTRICITY GEN.

$\begin{array}{ll} & =65.33 \% \\ \text { BCTRICITY GEN. } & =0.03 \%\end{array}$

$\begin{array}{ll}\text { SINTHETICS } & =0.0 \% \\ & =0.0 \%\end{array}$ 
REGIONAL EYEFGY EALANCE STATEMENT

PIES MJD MID SCENARIO

\begin{tabular}{|c|c|c|c|c|c|c|c|c|c|c|}
\hline SECTOE & $\begin{array}{l}\text { DISIILDATE } \\
\text { OII }\end{array}$ & $\begin{array}{l}\text { RESIDUAL } \\
\text { GIL }\end{array}$ & $\begin{array}{l}\text { GASOLINE } \\
\text { (ALL OH }\end{array}$ & $\begin{array}{c}\text { OTHER } \\
\text { P } \text { YDRO- } \\
\text { CLREDNS } \\
\text { TS IN } 10 * * 9\end{array}$ & $\begin{array}{c}\text { CRUDE } \\
\text { OII } \\
\text { BTण'S) }\end{array}$ & $\begin{array}{l}\text { NRTORAI } \\
\text { GAS }\end{array}$ & $\operatorname{COAL}$ & ELECTRICITY & $\begin{array}{l}\text { SECTOR } \\
\text { TOTAL }\end{array}$ & \\
\hline $\begin{array}{l}\text { FINAL DEMANL SECTORS } \\
\text { RESIDENTIAL, CCIM- } \\
\text { INDOSTRIAL } \\
\text { TRANSPORTATICN } \\
\text { MISCELLANECOS OSES }\end{array}$ & $\begin{array}{r}57,630 \\
3, c 83 \\
4,826 \\
\leq 76\end{array}$ & $\begin{array}{r}21.017 \\
6.755 \\
676 \\
., 403\end{array}$ & $\begin{array}{r}\overline{-} \\
78,26 \overline{3} \\
-\end{array}$ & $\begin{array}{r}11.620 \\
14.148 \\
3.803 \\
20\end{array}$ & $\begin{array}{l}- \\
- \\
-\end{array}$ & $\begin{array}{r}30,613 \\
11,655 \\
455 \\
1,992\end{array}$ & $\begin{array}{r}26 \\
10,905 \\
1 \\
4\end{array}$ & $\begin{array}{r}24,529 \\
17,762 \\
840 \\
824\end{array}$ & $\begin{array}{r}145,435 \\
67,312 \\
88,868 \\
5,219\end{array}$ & $\begin{array}{r}42 \% \\
79 \% \\
25 \% \\
2 \%\end{array}$ \\
\hline $\begin{array}{l}\text { TCIAI FINAL } \\
\text { DEMAND SECTORS }\end{array}$ & $56, \leq 15$ & $3 \mp .851$ & 78,263 & 29.591 & - & 44,723 & 10,936 & 43.955 & 306,834 & $89 \%$ \\
\hline $\begin{array}{l}\text { CR PNSFCRAATICA } \\
\text { ELECTRICITY GEN. } \\
\text { PETPOLEOM FRCDOCTS } \\
\text { NATORAL GAS } \\
\text { SYNTHETICS }\end{array}$ & $\begin{array}{r}6, i 71 \\
-11,641 \\
-\end{array}$ & $\begin{array}{r}7,920 \\
-1,278 \\
-\end{array}$ & $\begin{array}{r}-13,012 \\
-\end{array}$ & $\begin{array}{r}-3.847 \\
-\end{array}$ & $\begin{array}{r}29,609 \\
- \\
-\end{array}$ & $\begin{array}{r}7 \\
16 \mathrm{C} \\
- \\
-\end{array}$ & $\begin{array}{r}33,832 \\
= \\
=\end{array}$ & $\begin{array}{r}-16,172 \\
- \\
-\end{array}$ & $\begin{array}{r}31,758 \\
-8 \\
- \\
-\end{array}$ & $\begin{array}{l}3 \% \\
3 \%\end{array}$ \\
\hline $\begin{array}{l}\text { UFT FIEL OSEL } \\
\text { IN TRANSPOFHATION }\end{array}$ & $-5,470$ & $\epsilon .641$ & $-13,012$ & -3.847 & 29,609 & 167 & 33,832 & $-16,172$ & 31,749 & $9 \pi$ \\
\hline $\begin{array}{l}\text { TCTAL GROSS FLCRS } \\
\text { lCSSES } \varepsilon \text { CMISSIONS }\end{array}$ & $\begin{array}{r}72,686 \\
4,524\end{array}$ & $\begin{array}{r}45,771 \\
0\end{array}$ & $\begin{array}{r}78,263 \\
0\end{array}$ & $\begin{array}{l}29.591 \\
-1.167\end{array}$ & $\begin{array}{r}29,609 \\
1,228\end{array}$ & $\begin{array}{l}44,890 \\
-1,213\end{array}$ & $\begin{array}{r}44,758 \\
605\end{array}$ & $\begin{array}{r}43,955 \\
3,647\end{array}$ & $\begin{array}{r}338,592 \\
7.626\end{array}$ & $\begin{array}{r}93 \% \\
2 \%\end{array}$ \\
\hline TOTAL NET OSAGE & 55,569 & 35,493 & $65,25.1$ & 24.575 & 30,838 & 43,677 & 45,373 & $31: 430$ & $\$ 46,209$ & \\
\hline
\end{tabular}

\begin{tabular}{|c|c|c|c|c|c|c|c|c|c|c|}
\hline $\begin{array}{l}\text { SOFELI CF EHFRGY } \\
\text { FCSSIL FUEL. }\end{array}$ & - & - & - & - & - & - & - & - & - & \\
\hline HY CROELECTEIC & - & - & - & - & - & - & - & 11,723 & 11.723 & $34 \pi$ \\
\hline NOCLEAR & - & - & - & - & - & - & - & 22,298 & 22,298 & $55 \%$ \\
\hline GEO. \&SCLAR & - & - & - & - & - & - & - & 432 & 432 & $1 \%$ \\
\hline TOTAL SUPRLY & - & - & - & - & - & - & - & 34,453 & 34,453 & \\
\hline
\end{tabular}

\section{VET IM ECRTS}

55,569

$3 \subseteq, 493$

$65,25.1$

24.575

30,838

43,677

45,373

$-3,022$

NOTES:

\begin{tabular}{|c|c|c|c|c|}
\hline TRAD & & EOB & IY G $\Xi N$. & \\
\hline & & & & \\
\hline CRMATICN & $\bar{\Xi} 0 \mathrm{SS}$ & EOR & УATUEAL GAS & $(1.0$ \\
\hline TR ANSFORMATICN & ¿0sS & EOB & SYNTEETICS & $=0.0$ \\
\hline
\end{tabular}


RZGIONAL ENEFGY EALANCE STATEMENT

PIES MID MID SCENARIO

\begin{tabular}{|c|c|c|c|c|c|c|c|c|c|c|}
\hline SECTOF & $\begin{array}{l}\text { DISTILLATE } \\
\text { OIL }\end{array}$ & $\begin{array}{l}\text { RESIDUAL } \\
\text { OIL }\end{array}$ & $\begin{array}{l}\text { GASOLINE } \\
\text { (ALL D }\end{array}$ & $\begin{array}{c}\text { OTHER } \\
\text { HYDRO- } \\
\text { CARBONS } \\
\text { IS IN } 10 * 9\end{array}$ & $\begin{array}{c}\text { CRODE } \\
\text { OIL } \\
\text { BIO'S) }\end{array}$ & $\begin{array}{l}\text { NATORAL } \\
\text { GAS }\end{array}$ & $\operatorname{COAL}$ & ELECTRICITY & $\begin{array}{l}\text { SECTOR } \\
\text { TOTAL }\end{array}$ & \\
\hline 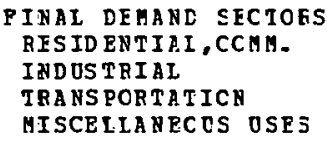 & $\begin{array}{r}53,762 \\
3,116 \\
4,248 \\
509\end{array}$ & $\begin{array}{r}22,481 \\
5,232 \\
1,352 \\
770\end{array}$ & 76,739 & $\begin{array}{r}11,318 \\
9,615 \\
6,809 \\
9\end{array}$ & $\begin{array}{l}- \\
- \\
-\end{array}$ & $\begin{array}{r}31,501 \\
16,580 \\
817 \\
889\end{array}$ & $29, \begin{array}{r}35 \\
354 \\
-\end{array}$ & $\begin{array}{r}26,171 \\
21,564 \\
302 \\
423\end{array}$ & $\begin{array}{r}145,268 \\
85,461 \\
90,267 \\
2,601\end{array}$ & $\begin{array}{l}34 \% \\
20 \% \\
21 \% \\
1 \%\end{array}$ \\
\hline $\begin{array}{l}\text { TCIAL FINAI } \\
\text { DEMAND SECTCRS }\end{array}$ & 61,635 & 29.835 & 76.739 & 27,751 & - & 49,787 & 29,390 & 48,460 & 323,597 & $76 \%$ \\
\hline $\begin{array}{l}\text { TRANSP ORMATICN } \\
\text { ELECTRICITY GEN. } \\
\text { PETR OLEON ERODOCTS } \\
\text { NATORAL GAS } \\
\text { SYNTHETICS }\end{array}$ & $\begin{array}{r}6,624 \\
-116,411 \\
- \\
-\end{array}$ & $\begin{array}{r}41,084 \\
-12,787 \\
- \\
-\end{array}$ & $\begin{array}{r}-130,118 \\
- \\
-\end{array}$ & $\begin{array}{r}-38,47 \overline{9} \\
\overline{-} \\
101,830\end{array}$ & $\begin{array}{r}- \\
296,098 \\
-\end{array}$ & $\begin{array}{r}8 \\
1,607 \\
- \\
-91,855\end{array}$ & $\begin{array}{r}66,433 \\
- \\
- \\
-\end{array}$ & $\begin{array}{r}-37,564 \\
- \\
-\end{array}$ & $\begin{array}{r}76,585 \\
. \quad-89 \\
- \\
9,975\end{array}$ & $\begin{array}{r}18 \% \\
0 \%\end{array}$ \\
\hline $\begin{array}{l}\text { NEI FOEL OSEL } \\
\text { IN TRANSFOFHATION }\end{array}$ & $-109,787$ & 28,297 & $-130,118$ & 63,351 & 296,098 & $-90,239$ & 66,433 & $-37,564$ & 86,470 & $20 \%$ \\
\hline $\begin{array}{l}\text { TCIAL GFOSS FICNS } \\
\text { ICSSES E OMISSIONS }\end{array}$ & $\begin{array}{r}68,259 \\
4,248\end{array}$ & $\begin{array}{r}70,9: 9 \\
19\end{array}$ & $\begin{array}{r}76,739 \\
0\end{array}$ & $\begin{array}{r}129,581 \\
-5,111\end{array}$ & $\begin{array}{r}296,098 \\
12,283\end{array}$ & $\begin{array}{l}51,402 \\
-1,389\end{array}$ & $\begin{array}{r}95,823 \\
1,297\end{array}$ & $\begin{array}{r}48,460 \\
4,020\end{array}$ & $\begin{array}{r}410,157 \\
15,351\end{array}$ & $\begin{array}{r}96 \% \\
4 \%\end{array}$ \\
\hline TCIAL NET OSAGE & $-43,903$ & 58,133 & $-53,378$ & 85,990 & 308,381 & $-41,841$ & 97,120 & 14,916 & 425,419 & \\
\hline $\begin{array}{l}\text { SOEFLY OF ENERGY } \\
\text { EOSS IL FOEI } \\
\text { HY DROELECTRIC } \\
\text { NOCL EAR } \\
\text { 3EO. ESOLAR }\end{array}$ & $\begin{array}{l}- \\
- \\
-\end{array}$ & $\begin{array}{l}\overline{-} \\
\overline{-}\end{array}$ & $\begin{array}{l}- \\
\text { - }\end{array}$ & $\begin{array}{l}\overline{-} \\
\overline{-}\end{array}$ & $\begin{array}{l}- \\
-\end{array}$ & $\begin{array}{l}\text { - } \\
\text { - }\end{array}$ & $\begin{array}{l}- \\
-\end{array}$ & $\begin{array}{r}10.495 \\
68.026 \\
413\end{array}$ & $\begin{array}{r}- \\
10,495 \\
68,026 \\
413\end{array}$ & $\begin{array}{r}13 \% \\
86 \% \\
1 \%\end{array}$ \\
\hline TCTAL SOPPIY & - & - & - & - & - & - & - & 78,934 & 78,934 & \\
\hline
\end{tabular}

VET IMPORTS

$-43,903$

58,133

$-53,378$

85,990

308,381

$-41,841$

97,120

$-64,017$

346,485

NOTES:

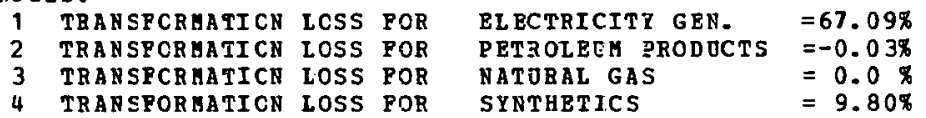


REGIONAL ENEFGE BALANCE STATEMENT
PIZS MIL MID SCENARIO

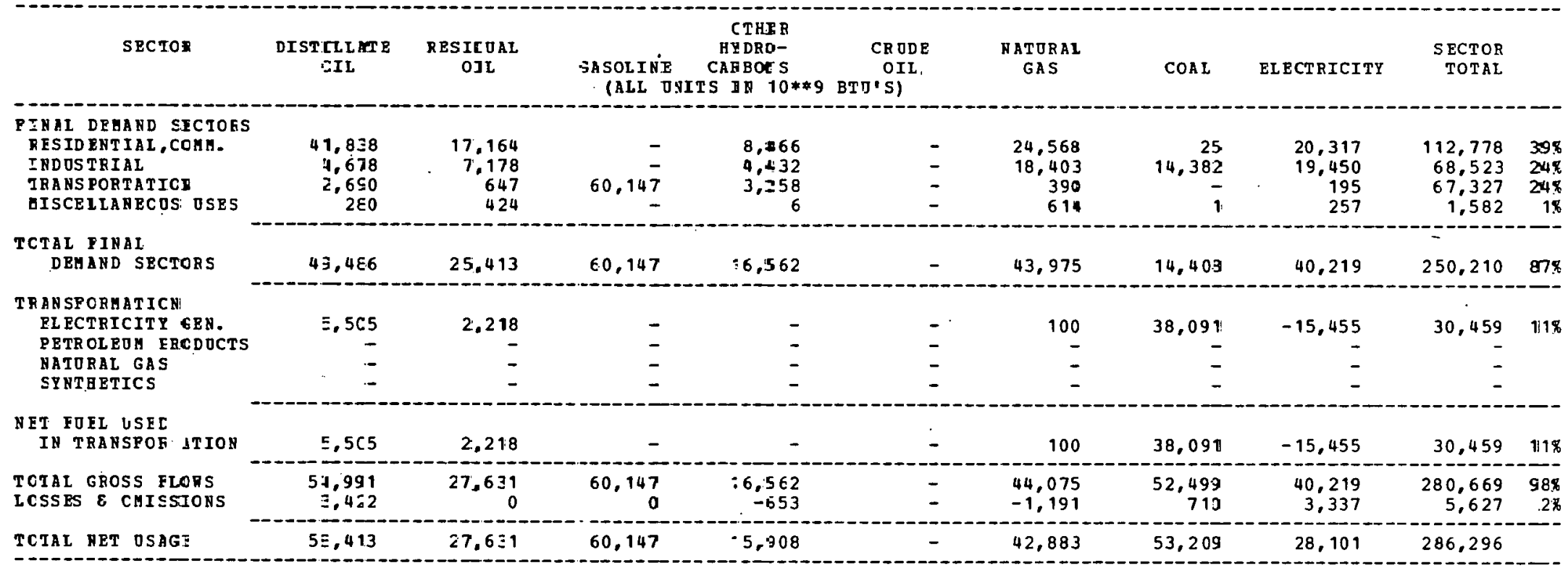

SDFEI OP ENERGI
$\begin{aligned} & \text { FOSSIL FOEI } \\ & \text { HYDROELECTEIC }\end{aligned}$
NOCI EAR
GEO. ESOLAR

NET IM PORTS
OP REGION


REGIONAL ENEFGY BALANCE STATEMENT

PIES MID MID SCENARIO

\begin{tabular}{|c|c|c|c|c|c|c|c|c|c|c|}
\hline SECTOE & $\begin{array}{l}\text { DISTILLATE } \\
\text { OIL }\end{array}$ & $\begin{array}{l}\text { RESIDCAL } \\
\text { OIL }\end{array}$ & $\begin{array}{l}\text { GASOLINE } \\
\text { CALL O }\end{array}$ & $\begin{array}{c}\text { OTHER } \\
\text { HYDRO- } \\
\text { CARBONS } \\
\text { TS IN } 10 * * 9\end{array}$ & $\begin{array}{c}\text { CR DDE } \\
\text { OIL } \\
\text { BTO'SI }\end{array}$ & $\begin{array}{l}\text { NATURAL } \\
\text { GAS }\end{array}$ & COAL & ELECTRICITY & $\begin{array}{l}\text { SECTCR } \\
\text { TOTAL }\end{array}$ & \\
\hline $\begin{array}{l}\text { PINAL DEHANI SECTOES } \\
\text { BESTDENTIAI, CCMH. } \\
\text { INDOSTRIAL } \\
\text { TRANSPORTATICN } \\
\text { MISCELLANECES OSES }\end{array}$ & $\begin{array}{r}59,901 \\
5,192 \\
6,630 \\
460\end{array}$ & $\begin{array}{r}24,137 \\
10,6.18 \\
672 \\
6.80\end{array}$ & $88.07 \overline{3}$ & $\begin{array}{r}12,798 \\
18,319 \\
3,146 \\
9\end{array}$ & $\begin{array}{l}\overline{-} \\
\overline{-}\end{array}$ & $\begin{array}{r}36,089 \\
49,043 \\
392 \\
981\end{array}$ & $\begin{array}{r}45 \\
49,632 \\
1 \\
2\end{array}$ & $\begin{array}{r}29,573 \\
32,432 \\
1,402 \\
414\end{array}$ & $\begin{array}{r}162,543 \\
157,236 \\
100,316 \\
2,546\end{array}$ & $\begin{array}{r}30 \% \\
29 \% \\
19 \% \\
0 \%\end{array}$ \\
\hline $\begin{array}{l}\text { TCTAL PINAI } \\
\text { DEMAND SECTCRS }\end{array}$ & 72,183 & $36,: 07$ & 88,073 & 34,272 & - & 78,505 & 49,680 & 63,821 & 422,641 & $79 \%$ \\
\hline $\begin{array}{l}\text { TFANSPCRHATICN } \\
\text { BLFCTRICITY GEN. } \\
\text { PETROLEOM ERCDOCTS } \\
\text { NATORAL GAS } \\
\text { SYNTHETICS }\end{array}$ & $\begin{array}{r}8,310 \\
-73,853 \\
- \\
-\end{array}$ & $-8,912$ & $\begin{array}{r}-82,550 \\
-\end{array}$ & $\begin{array}{r}-24,412 \\
-\end{array}$ & $\begin{array}{r}187,852 \\
-\end{array}$ & $\begin{array}{r}10 \\
1,019 \\
- \\
-\end{array}$ & $\begin{array}{r}137,819 \\
- \\
-\end{array}$ & $\begin{array}{r}-48,541 \\
- \\
- \\
-\end{array}$ & $\begin{array}{r}97,598 \\
-55 \\
- \\
-\end{array}$ & $\begin{array}{r}18 \% \\
0 \%\end{array}$ \\
\hline $\begin{array}{l}\text { NET FORL OSEL } \\
\text { IN TRANSOEMATION }\end{array}$ & $-65,543$ & $-8,712$ & $-82,550$ & $-24,412$ & 187,852 & 1,029 & 137,819 & $-48,541$ & 97,542 & $18 \%$ \\
\hline $\begin{array}{l}\text { T_TAL GROSS FLCHS } \\
\text { L CSSES } \varepsilon \text { OMISSIONS }\end{array}$ & $\begin{array}{r}80,493 \\
5,010\end{array}$ & $\begin{array}{r}36,707 \\
0\end{array}$ & $\begin{array}{r}88,073 \\
0\end{array}$ & $\begin{array}{r}34,272 \\
-1,351\end{array}$ & $\begin{array}{r}187,852 \\
7,793\end{array}$ & $\begin{array}{l}79,534 \\
-2,149\end{array}$ & $\begin{array}{r}187,499 \\
2,537\end{array}$ & $\begin{array}{r}63,821 \\
5,295\end{array}$ & $\begin{array}{r}520,239 \\
17,136\end{array}$ & $\begin{array}{r}97 \% \\
3 \%\end{array}$ \\
\hline
\end{tabular}

\begin{tabular}{|c|c|c|c|c|c|c|c|c|c|c|}
\hline $\begin{array}{c}\text { SOEFLY OP ENERGY } \\
\text { FOSSIL FOEI }\end{array}$ & - & - & - & - & 17.501 & 8.224 & - & - & 25,725 & 268 \\
\hline HY DR OELECTRIC & - & - & - & - & - & 0.224 & - & 71,719 & 71,719 & $73 \%$ \\
\hline NOCL EAR & - & - & - & - & - & - & - & - & - & \\
\hline GEO. ESOLAR & - & - & - & - & - & - & - & 519 & 519 & $1 \%$ \\
\hline
\end{tabular}

NET IM PORTS
CF REGION


REGIONAL ENE FG BALANCE STATEUENT

PIES WID ID SCENARIO

\begin{tabular}{|c|c|c|c|c|c|c|c|c|c|}
\hline SECTOK & $\begin{array}{c}\text { DISTIDLATE } \\
\text { O]L }\end{array}$ & $\begin{array}{l}\text { RESIDDAL } \\
\text { OIL }\end{array}$ & $\begin{array}{l}\text { GASOLINZ } \\
\text { (ALL }\end{array}$ & $\begin{array}{c}\text { OTHER } \\
\text { HYDRO- } \\
\text { CAREONS } \\
\text { TS IN } 10 * * 9\end{array}$ & $\begin{array}{c}\text { CRODE } \\
\text { OIL } \\
\text { BTO'S) }\end{array}$ & $\begin{array}{l}\text { YATOZAL } \\
\text { GAS }\end{array}$ & COAL & ELECTRICITY & $\begin{array}{l}\text { SECTOR } \\
\text { TOTAL }\end{array}$ \\
\hline $\begin{array}{l}\text { PINLL CEHANC SECTOES } \\
\text { RESID BNTIAL, CCAU. } \\
\text { INDOSTRIAL } \\
\text { TRANSPORTATICN } \\
\text { MISCELLANECTS OSES }\end{array}$ & $\begin{array}{r}11.033 \\
5.016 \\
4.708 \\
231\end{array}$ & $\begin{array}{r}1,597 \\
7.357 \\
459 \\
116\end{array}$ & $\begin{array}{r}- \\
30,479 \\
-\end{array}$ & $\begin{array}{r}3.038 \\
10.846 \\
1,018 \\
4\end{array}$ & $\begin{array}{l}- \\
-\end{array}$ & $\begin{array}{r}13,9: 6 \\
18,735 \\
249 \\
302\end{array}$ & $\begin{array}{r}67 \\
56, \varepsilon 78 \\
4 \\
1\end{array}$ & $\begin{array}{r}9,087 \\
13,332 \\
154 \\
136\end{array}$ & $\begin{array}{r}38,728 \\
112,314 \\
37,081 \\
790\end{array}$ \\
\hline $\begin{array}{l}\text { TCTAI FINAL } \\
\text { DEHAKD SECTCRS }\end{array}$ & 20,988 & 9,479 & 30,479 & 14,906 & - & 33,402 & 56,550 & 22,709 & 188,913 \\
\hline $\begin{array}{l}\text { TRANSPORHATIEN } \\
\text { RLECTRICITY GEN. } \\
\text { PETROLEOH ERODOCTS } \\
\text { MATORAL GAE } \\
\text { SYNTHETICS }\end{array}$ & $\begin{array}{r}435 \\
-39.242 \\
- \\
-\end{array}$ & $\begin{array}{r}-4.310 \\
- \\
-\end{array}$ & $\begin{array}{r}-43,96 \overline{3} \\
- \\
-\end{array}$ & $\begin{array}{r}-12.971 \\
- \\
-\end{array}$ & 99,814 & $54 \overline{-}$ & $\begin{array}{r}10,963 \\
- \\
-\end{array}$ & $\begin{array}{r}-3,746 \\
- \\
-\end{array}$ & $\begin{array}{r}7,652 \\
-29 \\
-\end{array}$ \\
\hline $\begin{array}{l}\text { NET FOFL OSEC } \\
\text { IN TRALSPOFAATION }\end{array}$ & $-38,807$ & -4.310 & $-43,863$ & $-12,971$ & 99,814 & 541 & 10,563 & $-3,746$ & 7.622 \\
\hline $\begin{array}{l}\text { TCTAL GROSS FLONS } \\
\text { LCSSES } \varepsilon \text { CMISSIOHS }\end{array}$ & $\begin{array}{r}21.423 \\
1.333\end{array}$ & $\begin{array}{r}9,479 \\
0\end{array}$ & $\begin{array}{r}30,479 \\
0\end{array}$ & $\begin{array}{r}14,906 \\
-587\end{array}$ & $\begin{array}{r}99,814 \\
4,140\end{array}$ & $\begin{array}{r}33,743 \\
-9 \div 7\end{array}$ & $\begin{array}{r}67,913 \\
919\end{array}$ & $\begin{array}{r}22,709 \\
1,884\end{array}$ & $\begin{array}{r}196,565 \\
6,772\end{array}$ \\
\hline TCTAL NET OSAGE & -16.485 & 5,158 & $-13,383$ & 1,347 & 103,955 & 33,026 & $68, \varepsilon 32$ & 20,847 & 203,308 \\
\hline
\end{tabular}

\begin{tabular}{|c|c|c|c|c|c|c|c|c|c|}
\hline $\begin{array}{l}\text { SOEELY OF ERERGY } \\
\text { FOSSIL FOFI }\end{array}$ & - & - & - & - & 9.499 & 10.301 & 16.170 & - & 35.970 \\
\hline HYDROEL BCTEIC & - & - & - & - & 3040 & 0.01 & 10. & 830 & $\begin{array}{l}33,9 \\
830\end{array}$ \\
\hline NOCL EAR & - & - & - & - & - & - & - & - & - \\
\hline GEC. ESOLAR & - & - & - & - & - & - & - & - & - \\
\hline TCTAL SUPPLY & - & - & - & - & $s, 499$ & 10,301 & 16,170 & 830 & 36,800 \\
\hline
\end{tabular}

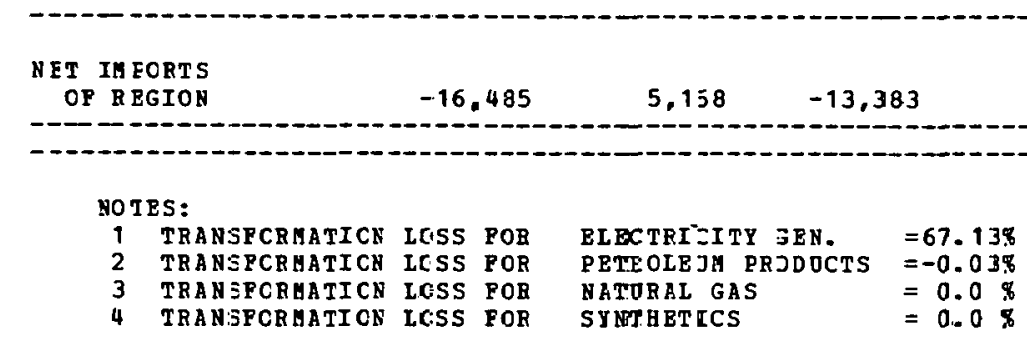


REGIONAL ENEFGY PALANCE STATEMENT

\begin{tabular}{|c|c|c|c|c|c|c|c|c|c|c|}
\hline SECTOF & $\begin{array}{l}\text { DISTILLATE } \\
\text { OIL }\end{array}$ & $\begin{array}{l}\text { RESIDUAL } \\
\text { OIL. }\end{array}$ & $\begin{array}{l}\text { GASOLINE } \\
\text { (ALL D }\end{array}$ & $\begin{array}{c}\text { OTHER } \\
\text { YYDRO- } \\
\text { CAREONS } \\
\text { TS IN 10**9 }\end{array}$ & $\begin{array}{c}\text { CRODE } \\
\text { OIL } \\
\text { BTOSI }\end{array}$ & $\begin{array}{l}\text { NATURAL } \\
\text { GAS }\end{array}$ & $\operatorname{COAL}$ & ELECTRICITY & $\begin{array}{r}\text { SECTOR } \\
\text { TOTAL }\end{array}$ & \\
\hline $\begin{array}{l}\text { FINZL TFMANL SECTCRS } \\
\text { FESIDENTIAL, CCMM. } \\
\text { JNDOSTRIAL } \\
\text { JRANSPORTATICN } \\
\text { VISCELLANECOS OSES }\end{array}$ & $\begin{array}{r}10,559 \\
4,374 \\
3,854 \\
191\end{array}$ & $\begin{array}{r}1,620 \\
3,632 \\
1,203 \\
96\end{array}$ & $\begin{array}{r}- \\
- \\
-\end{array}$ & $\begin{array}{r}2,832 \\
4,601 \\
2,675 \\
3\end{array}$ & $\begin{array}{l}- \\
-\end{array}$ & $\begin{array}{r}13,184 \\
11,766 \\
658 \\
249\end{array}$ & $\begin{array}{r}64 \\
31,825 \\
1 \\
1\end{array}$ & $\begin{array}{r}8,749 \\
9,622 \\
35 \\
111\end{array}$ & $\begin{array}{r}37,000 \\
65,820 \\
36,815 \\
651\end{array}$ & $\begin{array}{r}22 \% \\
40 \% \\
22 \pi \\
0 \%\end{array}$ \\
\hline $\begin{array}{l}\text { TCTAL FINAL } \\
\text { CEMAND SECTCRS }\end{array}$ & 18,978 & 6.551 & 28,389 & 10,111 & - & 25,857 & 31,891 & 18,509 & 140,286 & $85 x$ \\
\hline $\begin{array}{l}\text { TE ANSPCRMATICN } \\
\text { ELECTRICITY GEN. } \\
\text { FETRCLEOM ERCDOCTS } \\
\text { NATURAL GAS } \\
\text { SYNTHETICS }\end{array}$ & $\begin{array}{r}538 \\
- \\
-\end{array}$ & $\begin{array}{r}403 \\
- \\
-\end{array}$ & $\begin{array}{l}- \\
-\end{array}$ & $\begin{array}{l}- \\
- \\
-\end{array}$ & $\begin{array}{l}- \\
-\end{array}$ & $\begin{array}{l}- \\
-\end{array}$ & $\begin{array}{r}32,279 \\
- \\
-\end{array}$ & $\begin{array}{r}-10,942 \\
- \\
-\end{array}$ & $\begin{array}{r}22,278 \\
- \\
-\end{array}$ & $13 \%$ \\
\hline $\begin{array}{l}\text { DIT FOFL OSEL } \\
\text { IN TRANSFOFHATICN }\end{array}$ & 538 & 403 & - & - & - & - & 32,279 & $-10,942$ & 22,278 & $13 x$ \\
\hline $\begin{array}{l}\text { TCTAL GFOSS FLCFS } \\
\text { ICSSPS \& OMISSIONS }\end{array}$ & $\begin{array}{r}19,516 \\
1,214\end{array}$ & $\begin{array}{r}5,9: 54 \\
0\end{array}$ & $\begin{array}{r}28,389 \\
0\end{array}$ & $\begin{array}{r}10,111 \\
-398\end{array}$ & $\overline{-}$ & $\begin{array}{r}25,857 \\
-698\end{array}$ & $\begin{aligned} & 64, 170 \\
& 868\end{aligned}$ & $\begin{array}{r}18,509 \\
1,535\end{array}$ & $\begin{array}{r}162,564 \\
2,521\end{array}$ & $\begin{aligned} 98 \% \\
2 \%\end{aligned}$ \\
\hline
\end{tabular}

-

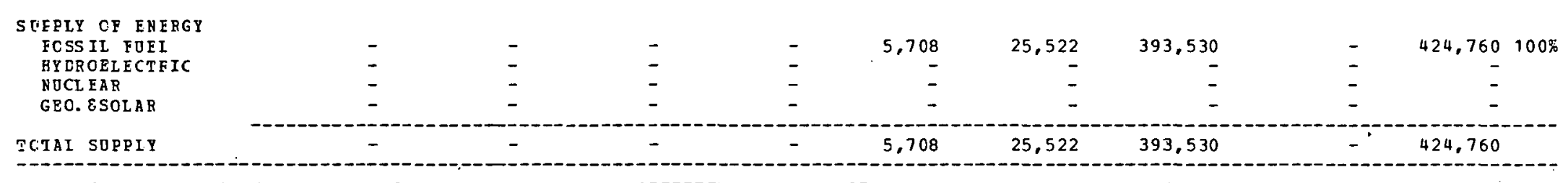

\title{
HIT IMFORTS
OP REGION
}

20,730

6,954

28,389

9.712

$-5,708$

$-363-328,491$

9,102

$-259,674$

-

\section{NOTES:}

1 TRANSPCRMRTICN LOSS POR

TR ANS PORMETICN LOSS FOR

TRANSPORMETI CN ICSS FOR

ELECTRICITY GEN.

PETROLEUM PROD OCTS $=0.0 \%$

NATURAL GLS

$=0.0 \%$

C.

\begin{abstract}
SYNTHBICS $=0.0$
\end{abstract}


REG =ONAL ZNE IGY PALANCE STATEMENT
PIES YID MID SCENARIO

\begin{tabular}{|c|c|c|c|c|c|c|c|c|c|c|}
\hline SECTOE & $\begin{array}{c}\text { GISTIL SATE } \\
\text { OIE }\end{array}$ & $\underset{\text { JI }}{\operatorname{RZSIDDA}}$ & $\begin{array}{l}\text { GASOL=NE } \\
\text { (ALI O }\end{array}$ & $\begin{array}{c}\text { OERER } \\
\text { AYERO- } \\
\text { CAREONS } \\
\text { TS IE } 10 * 9\end{array}$ & $\begin{array}{c}\text { CROLE } \\
\text { OIL } \\
\text { BTO'SI }\end{array}$ & $\begin{array}{l}\text { NATURA: } \\
\text { GAS: }\end{array}$ & COAL & ELECTRICITY & $\begin{array}{r}\text { SECTOR } \\
\text { TOTAL }\end{array}$ & \\
\hline $\begin{array}{l}\text { FINAL CEMANC SECTOFS } \\
\text { RESIDENTIAL, CCMA. } \\
\text { INDOSTRIAL } \\
\text { TRANSPORTATICN } \\
\text { MISCE LLANECOS OSES }\end{array}$ & $\begin{array}{r}24,768 \\
2,+11 \\
3,726 \\
267\end{array}$ & $\begin{array}{r}3,9 \geq 4 \\
3,3 \leq 9 \\
250 \\
3 \leq 7\end{array}$ & $40,23 \frac{-}{-}$ & $\begin{array}{r}5,540 \\
5,280 \\
1,205 \\
6\end{array}$ & $\begin{array}{l}- \\
\overline{-}\end{array}$ & $\begin{array}{r}16,574 \\
9,165 \\
165 \\
564\end{array}$ & $\begin{array}{r}29 \\
15,645 \\
1 \\
1\end{array}$ & $\begin{array}{r}12,674 \\
12,243 \\
445 \\
232\end{array}$ & $\begin{array}{r}68,519 \\
48,073 \\
46,069 \\
1,427\end{array}$ & $\begin{array}{r}38 \% \\
26 \% \\
25 \% \\
1 \%\end{array}$ \\
\hline $\begin{array}{l}\text { TCTAI FINAL } \\
\text { DEMAND SEGICRS }\end{array}$ & 31,172 & $\because 2,920$ & 40,236 & $1 \overline{2}, 031$ & - & 26,469 & $15,6^{7} 6$ & 25,594 & 164,088 & $90 \%$ \\
\hline $\begin{array}{l}\text { TRANSFCRMATICN } \\
\text { FLECTRICIT\& CEN. } \\
\text { PETRCLEOM ERCDOCTS } \\
\text { NATORAL GAE } \\
\text { SYNTHETICS }\end{array}$ & $\begin{array}{r}2,755 \\
- \\
-\end{array}$ & $\begin{array}{l}- \\
\overline{-}\end{array}$ & $\begin{array}{l}- \\
- \\
-\end{array}$ & $\begin{array}{l}\overline{-} \\
\overline{-}\end{array}$ & $\begin{array}{l}- \\
- \\
-\end{array}$ & $\begin{array}{r}212 \\
- \\
-\end{array}$ & $\begin{array}{r}19,253 \\
- \\
-\end{array}$ & $\begin{array}{r}-7,480 \\
- \\
-\end{array}$ & $\begin{array}{r}14,740 \\
- \\
-\end{array}$ & $8 \%$ \\
\hline $\begin{array}{l}\text { NET FOEL OSEI } \\
\text { IN TRANSFOFATION }\end{array}$ & 2,755 & - & - & - & - & 212 & 19,253 & $-7,480$ & 14,740 & $8 \%$ \\
\hline $\begin{array}{l}\text { TCTAL GROSS FLCWS } \\
\text { ICSSES } \varepsilon \text { CMISSIONS }\end{array}$ & $\begin{array}{r}33,927 \\
2,111\end{array}$ & 12,9 च & $\begin{array}{r}40,236 \\
0\end{array}$ & $\begin{array}{r}12.031 \\
-474\end{array}$ & $\begin{array}{l}- \\
-\end{array}$ & $\begin{array}{r}26,691 \\
-720\end{array}$ & $\begin{array}{r}34,929 \\
472\end{array}$ & $\begin{array}{r}25,594 \\
2,123\end{array}$ & $\begin{array}{r}178,828 \\
3,513\end{array}$ & $\begin{array}{r}98 \% \\
2 \%\end{array}$ \\
\hline
\end{tabular}

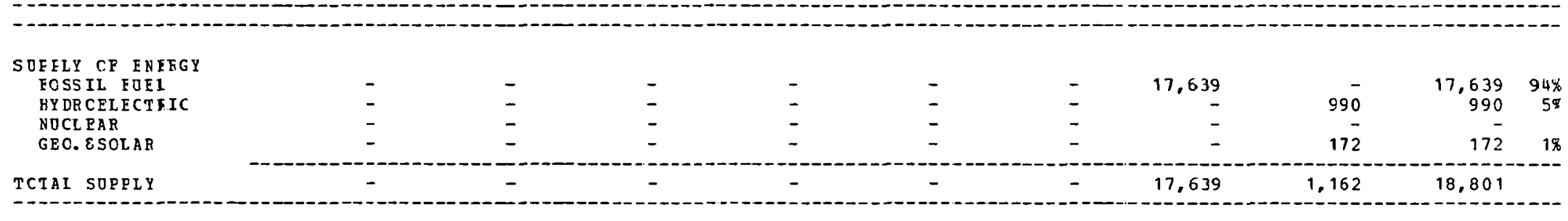

NET IMFCRTS
OF REGION


REGIONAL ENEFGY EALANCE STATEMENT

PIES MID MID SCENARIO

\begin{tabular}{|c|c|c|c|c|c|c|c|c|c|c|}
\hline SECTOE & $\begin{array}{l}\text { DISTILLATE } \\
\text { OIL }\end{array}$ & $\begin{array}{l}\text { RESIDOAL } \\
\text { OIL }\end{array}$ & $\begin{array}{l}\text { GASOLINE } \\
\quad \text { (ALL UNI }\end{array}$ & $\begin{array}{c}\text { OTHER } \\
\text { HYDRO- } \\
\text { CARBONS } \\
\text { TS IN 10**9 }\end{array}$ & $\begin{array}{c}\text { CREDE } \\
\text { OIL } \\
\text { BTO'S) }\end{array}$ & $\begin{array}{l}\text { NATURAL } \\
\text { GAS }\end{array}$ & $\operatorname{COAL}$ & ELECTRICITY & $\begin{array}{r}\text { SECTOR } \\
\text { TOTAL }\end{array}$ & \\
\hline $\begin{array}{l}\text { FJ IL IEMANL SFCTCES } \\
\text { EESIDENTIAL, CCMH. } \\
\text { INDOSTRIAL } \\
\text { TRANSPORTATICN } \\
\text { MISCELLANECS OSES }\end{array}$ & $\begin{array}{r}15,374 \\
6,230 \\
6,795 \\
425\end{array}$ & $\begin{array}{r}1,957 \\
6,357 \\
662 \\
213\end{array}$ & $\begin{array}{r}- \\
- \\
-\end{array}$ & $\begin{array}{r}4,420 \\
5,488 \\
1,480 \\
7\end{array}$ & $\begin{array}{l}- \\
- \\
-\end{array}$ & $\begin{array}{r}19,687 \\
13,050 \\
362 \\
555\end{array}$ & $\begin{array}{r}97 \\
13,852 \\
- \\
2\end{array}$ & $\begin{array}{r}12,352 \\
14,959 \\
15 \\
250\end{array}$ & $\begin{array}{r}53,887 \\
59,936 \\
53,765 \\
1,452\end{array}$ & $\begin{array}{r}31 \% \\
34 \% \\
31 \% \\
1 \%\end{array}$ \\
\hline $\begin{array}{l}\text { TCTAI FINAL } \\
\text { DEMAND SECTORS }\end{array}$ & 28,824 & $9,1: 89$ & 44,451 & 11,395 & - & 33,654 & 13,951 & 27,576 & 169,040 & $97 \%$ \\
\hline $\begin{array}{l}\text { TRANSFORMATICN } \\
\text { ELECTRICITY CEN. } \\
\text { FETROLEUM FECDOCTS } \\
\text { NATORAL GAS } \\
\text { SY NTHETICS }\end{array}$ & $\begin{array}{r}633 \\
- \\
-\end{array}$ & $\begin{array}{l}- \\
- \\
-\end{array}$ & $\begin{array}{l}- \\
- \\
-\end{array}$ & $\begin{array}{l}\overline{-} \\
\overline{-}\end{array}$ & $\begin{array}{l}\overline{-} \\
\overline{-}\end{array}$ & $\begin{array}{l}\overline{-} \\
-\end{array}$ & $\begin{array}{r}2,547 \\
- \\
-\end{array}$ & $\begin{array}{r}-1,021 \\
- \\
-\end{array}$ & $\begin{array}{r}2,159 \\
- \\
-\end{array}$ & $1 \%$ \\
\hline $\begin{array}{l}\text { NET FOFL OSEL } \\
\text { IN TRANSFOFHATION }\end{array}$ & 633 & - & - & - & - & - & 2,547 & $-1,021$ & 2,159 & $1 \%$ \\
\hline $\begin{array}{l}\text { TCTAL GROSS FLCRS } \\
\text { ICSSES } E \text { CMISSIONS }\end{array}$ & $\begin{array}{r}29,457 \\
1,833\end{array}$ & 9,789 & $\begin{array}{r}44,451 \\
.0\end{array}$ & $\begin{array}{r}11,395 \\
-449\end{array}$ & $\overline{-}$ & $\begin{array}{r}33,654 \\
-909\end{array}$ & $\begin{array}{r}16,498 \\
223\end{array}$ & $\begin{array}{r}27,576 \\
2,288\end{array}$ & $\begin{array}{r}171,199 \\
2,986\end{array}$ & $\begin{array}{r}98 \% \\
28\end{array}$ \\
\hline $\begin{array}{l}\text { SOEEIY OF ENFRGY } \\
\text { FOSSIL FOEI } \\
\text { HYDRCELECTEIC } \\
\text { NOCLEAR } \\
\text { GEC. ESOLAR }\end{array}$ & $\begin{array}{l}- \\
\overline{-} \\
-\end{array}$ & $\begin{array}{l}- \\
\overline{-}\end{array}$ & $\begin{array}{l}- \\
- \\
-\end{array}$ & $\begin{array}{l}\check{-} \\
-\end{array}$ & $\begin{array}{l}\overline{-} \\
\overline{-}\end{array}$ & $\begin{array}{l}- \\
\overline{-}\end{array}$ & $\begin{array}{r}66,530 \\
= \\
=\end{array}$ & $\begin{array}{r}30 \overline{8} \\
37,293 \\
-\end{array}$ & $\begin{array}{r}66,530 \\
308 \\
37,293 \\
-\end{array}$ & $\begin{array}{r}64 \% \\
0 \% \\
36 \%\end{array}$ \\
\hline TCIAI SUPPIY & - & - & - & - & - & - & 66,530 & 37,601 & 104,131 & \\
\hline
\end{tabular}

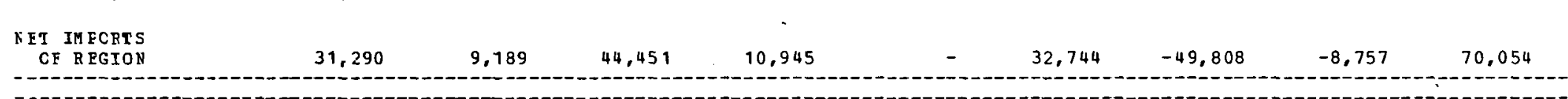

\begin{tabular}{|c|c|c|c|c|c|}
\hline \multicolumn{6}{|c|}{ NOTES: } \\
\hline 1 & TRANSFCRMATICN & LOSS & POR & ELECTRICITY GEN. & $=67.89 \%$ \\
\hline 2 & TRANSFOR DATICN & LOSS & FOR & PETROIEOM PRODOCTS & $=0.0 \%$ \\
\hline 3 & TRANSPCR DATICN & LCSS & FOR & NATORAL GAS & $=0.0 \%$ \\
\hline 4 & TRAN SPORDATI CN & LosS & FOR & STNTHETICS & 0.0 \\
\hline
\end{tabular}


FEGIDNAL EHEFGY EALANCE STATZEENT
PIES MIJ MID. SCENARIO

\begin{tabular}{|c|c|c|c|c|c|c|c|c|c|c|}
\hline SE $=10 \mathrm{~F}$ & $\begin{array}{l}\text { LISTELLATE } \\
\text { OIL }\end{array}$ & $\begin{array}{l}\text { FESIDOAL } \\
\text { OIL }\end{array}$ & $\begin{array}{l}\text { GASCLINE } \\
\text { CALL ONI }\end{array}$ & $\begin{aligned} & \text { JTHER } \\
& \text { F TDRO- } \\
& \text { TRBONS } \\
&-5 \text { IN } 10 * * 9\end{aligned}$ & $\begin{array}{c}\text { CRODE } \\
\text { OIL } \\
\text { BTJ'S) }\end{array}$ & $\begin{array}{l}\text { NATJEAL } \\
\text { G.AS }\end{array}$ & CCAL & ELECTRICITY & $\begin{array}{l}\text { SECTOF } \\
\text { TOTAL }\end{array}$ & \\
\hline $\begin{array}{l}\text { PIN IL CEMANC SFCIORS } \\
\text { RESIDENTIAI, CCMM. } \\
\text { INDOSTRIAI } \\
\text { TRANSPORTATICN } \\
\text { HISCELLANECUS USES }\end{array}$ & $\begin{array}{r}695.040 \\
5: 104 \\
9 \div 991 \\
\div 041\end{array}$ & $\begin{array}{r}269,322 \\
181,770 \\
65,349 \\
10,395\end{array}$ & $1,001,16 \overline{-}$ & $\begin{array}{r}1+0,496 \\
237,357 \\
228,629 \\
150\end{array}$ & $\begin{array}{l}- \\
- \\
-\end{array}$ & $\begin{array}{r}392.557 \\
150.566 \\
28 .: 84 \\
14.6 .78\end{array}$ & $\begin{array}{r}424 \\
115,910 \\
7 \\
31\end{array}$ & $\begin{array}{r}348,299 \\
181,868 \\
4,740 \\
6,003\end{array}$ & $\begin{array}{r}1,845,938 \\
978,575 \\
1,421,266 \\
38,298\end{array}$ & $\begin{array}{r}37 \% \\
20 \% \\
29 \% \\
1 \%\end{array}$ \\
\hline $\begin{array}{l}\text { TCTAI FINAL, } \\
\text { DEMAND SECICRS }\end{array}$ & $84 \epsilon, 176$ & $5: 26,836$ & $1,001,156$ & 646,632 & - & $585 . \subseteq 85$ & 116,372 & 540,910 & $4,284,077$ & $87 x$ \\
\hline $\begin{array}{l}\text { TFAMSPCRMATICN } \\
\text { PLFCTRICIOY GRN. } \\
\text { PETR OI EOM ERCDOCTS } \\
\text { NATURAL GAS } \\
\text { SYNTBETICS }\end{array}$ & $\begin{array}{r}7 \epsilon, 876 \\
-26 \equiv, 671 \\
-\end{array}$ & $\begin{array}{r}\Xi 17,151 \\
-28,963 \\
- \\
-\end{array}$ & $\begin{array}{r}-294,71 \varepsilon \\
- \\
-\end{array}$ & $\begin{array}{r}-E: 7,15 \overline{-} \\
- \\
-\end{array}$ & $\begin{array}{r}- \\
670,66 \vdots \\
\\
\vdots\end{array}$ & $\begin{array}{r}E 59 \\
3, E 41 \\
- \\
-\end{array}$ & $\begin{array}{r}440,124 \\
- \\
-\end{array}$ & $\begin{array}{r}-277,120 \\
- \\
-\end{array}$ & $\begin{array}{r}557,690 \\
-202 \\
- \\
-\end{array}$ & $\begin{array}{r}11 \% \\
0 \%\end{array}$ \\
\hline $\begin{array}{l}\text { NET FOEL OSEL } \\
\text { IN TRANSPEGATION }\end{array}$ & $-186,795$ & $: 288,188$ & $-294,718$ & $-\equiv 7,155$ & 670,663 & 4,300 & 440,124 & $-277,120$ & 557.487 & $11 \%$ \\
\hline $\begin{array}{l}\text { TCTAL GROSS FLCRS } \\
\text { LCSSES E CMISSICNS }\end{array}$ & $\begin{array}{r}323,052 \\
57,453\end{array}$ & $\begin{array}{r}843.987 \\
16\end{array}$ & $1,001,166$ & $\begin{array}{l}6 \Xi 6,632 \\
-\equiv 6,294\end{array}$ & $\begin{array}{r}670,663 \\
27,822\end{array}$ & $\begin{array}{l}590,285 \\
-15,950\end{array}$ & $\begin{array}{r}556,+96 \\
7,532\end{array}$ & $\begin{array}{r}540,910 \\
44,881\end{array}$ & $\begin{array}{r}4,841,767 \\
95,466\end{array}$ & $\begin{aligned} 92 \% \\
2 \%\end{aligned}$ \\
\hline TCTAL NET OEAGE & 716,834 & 815,040 & 706,452 & $5 \equiv 3,182$ & 698,485 & 574,334 & 564,328 & 308,671 & $4,937,030$ & \\
\hline
\end{tabular}

\begin{tabular}{|c|c|c|c|c|c|c|c|c|c|c|}
\hline S OEELY CF EDERGY & & & & & & & & & & \\
\hline FOSSIL FOII & - & - & - & - & - & - & - & - & - & \\
\hline HY CR OELBCTFIC & - & - & - & - & - & - & - & 27,492 & 27,492 & $21 \%$ \\
\hline NOCL EAR & - & - & - & - & - & - & - & 101,138 & $101,13 \varepsilon$ & $76 \%$ \\
\hline GEO. \&SOLAE & - & - & - & - & - & - & - & 4,851 & 4.851 & 4,5 \\
\hline TOTAL SOPPIY & - & - & - & - & - & - & - & 133,481 & 133,481 & \\
\hline
\end{tabular}

\section{RET IM FORTS}

OF REGION

$? 16.834$

815,040

706,452

j도 3,182

698,485

574,334

564,628

$175,190 \quad 4,803,549$

NOTES:

1 TRANSFCRMATICN LESS FOR TR ANISFORMATICN LESS FCR TRAN'SFCR TRANSPOBMATICN LESS POR

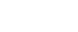


REGIONAL ENEEGY EALANCE STATEMENT
PIES MID MI D SCENARIO

\begin{tabular}{|c|c|c|c|c|c|c|c|c|c|c|}
\hline SECTOE & $\begin{array}{l}\text { DIST İLLATE } \\
\text { OII }\end{array}$ & $\begin{array}{l}\text { BESIDUAL } \\
\text { OIL }\end{array}$ & $\begin{array}{l}\text { GASOLINE } \\
\text { (ALL ON. }\end{array}$ & $\begin{array}{c}\text { OTHER } \\
\text { HYDRO- } \\
\text { CARBONS } \\
\text { TS IN 10**9 }\end{array}$ & $\begin{array}{c}\text { CRCDE } \\
\text { OIL } \\
\text { BTO'S) }\end{array}$ & $\begin{array}{l}\text { NATURAL } \\
\text { GAS }\end{array}$ & $\operatorname{COAL}$ & ELECTRICITY & $\begin{array}{r}\text { SECTOR } \\
\text { TOTAL }\end{array}$ & \\
\hline $\begin{array}{l}\text { FIR LL CEHANC SECTORS } \\
\text { RESIDENTIAL, CCBA. } \\
\text { IND OSTRIAL } \\
\text { TRANSPORTATICN } \\
\text { MISCELLANBCOS OSES }\end{array}$ & $\begin{array}{r}225,822 \\
69,383 \\
54,528 \\
4,850\end{array}$ & $\begin{array}{r}41,127 \\
175,077 \\
24,946 \\
3,933\end{array}$ & $\begin{array}{r}- \\
500,665 \\
-\end{array}$ & $\begin{array}{r}54,005 \\
256,859 \\
34,246 \\
85\end{array}$ & $\begin{array}{l}- \\
-\end{array}$ & $\begin{array}{r}207,662 \\
163,010 \\
8,243 \\
6,831\end{array}$ & $\begin{array}{r}887 \\
338,725 \\
32 \\
22\end{array}$ & $\begin{array}{r}169,369 \\
177,089 \\
1,055 \\
2,680\end{array}$ & $\begin{array}{r}698,872 \\
1,180,143 \\
623,715 \\
18,451\end{array}$ & $\begin{array}{r}24 \% \\
41 \% \\
22 \% \\
1 \%\end{array}$ \\
\hline $\begin{array}{l}\text { TCTAL FIHAI } \\
\text { DBHAND SECTORS }\end{array}$ & 354,583 & 245,133 & 500,665 & 345,195 & - & 385,746 & 339,666 & 350,193 & $2,521,181$ & $87 \%$ \\
\hline $\begin{array}{l}\text { TRANSFCRHATICN } \\
\text { ELECTRICITY GEN. } \\
\text { PBTR OLEDM ERODOCTS } \\
\text { NATORAL GAS } \\
\text { SY RTHETICS }\end{array}$ & $\begin{array}{r}30,223 \\
-665,465 \\
-\end{array}$ & $\begin{array}{r}50,487 \\
-73,097 \\
- \\
-\end{array}$ & $\begin{array}{r}-743,82 \overline{1} \\
-\end{array}$ & $\begin{array}{r}-219,96 \overline{-} \\
101,830\end{array}$ & $\begin{array}{r}1,692,646 \\
-\end{array}$ & $\begin{array}{r}12 \\
9,189 \\
-91,855\end{array}$ & $\begin{array}{r}299,409 \\
- \\
-\end{array}$ & $\begin{array}{r}-124,475 \\
- \\
-\end{array}$ & $\begin{array}{r}255,656 \\
-511 \\
- \\
9,975\end{array}$ & $\begin{array}{l}9 \% \\
0 \%\end{array}$ \\
\hline $\begin{array}{l}\text { WET FOEL OSEL } \\
\text { IN TRANSPOFHATION }\end{array}$ & $-635,242$ & $-22,610$ & $-743,821$ & $-118,134$ & $1,692,646$ & $-82,653$ & 299,409 & $-124,475$ & 265,119 & $9 \%$ \\
\hline $\begin{array}{l}\text { TCTAL GROSS FLCRS } \\
\text { LCSSES \& OBISSIONS }\end{array}$ & $\begin{array}{r}384,806 \\
23,951\end{array}$ & $\begin{array}{r}295,620 \\
5\end{array}$ & $\begin{array}{r}500,665 \\
2\end{array}$ & $\begin{array}{l}447,025 \\
-17,632\end{array}$ & $\begin{array}{r}1,692,646 \\
70,219\end{array}$ & $\begin{array}{l}394,947 \\
-10,672\end{array}$ & $\begin{array}{r}639,075 \\
8,650\end{array}$ & $\begin{array}{r}350,193 \\
29,056\end{array}$ & $\begin{array}{r}2,786,812 \\
103,582\end{array}$ & $\begin{array}{r}9 \in \% \\
4 \%\end{array}$ \\
\hline $\begin{array}{l}\text { SOFPLY OF EAEBGY } \\
\text { FOSS IL FOEI } \\
\text { HYDROELECTEIC } \\
\text { HOCL EAR } \\
\text { GEC. \&SOLAR }\end{array}$ & $\begin{array}{l}- \\
-\end{array}$ & $\begin{array}{l}- \\
-\end{array}$ & $\begin{array}{l}\overline{-} \\
\overline{-}\end{array}$ & $\begin{array}{l}- \\
- \\
-\end{array}$ & - & $\begin{array}{l}\overline{-} \\
\overline{-}\end{array}$ & $\begin{array}{r}113,572 \\
- \\
-\end{array}$ & $\begin{array}{r}3,559 \\
171,795 \\
618\end{array}$ & $\begin{array}{r}113,572 \\
3,559 \\
171,795 \\
618\end{array}$ & $\begin{array}{r}39 \% \\
1 \% \\
59 \% \\
0 \%\end{array}$ \\
\hline TCTAL SOPPII & - & - & - & - & - & - & 113,572 & 175,972 & 289,544 & \\
\hline
\end{tabular}

\begin{tabular}{l}
$\begin{array}{l}\text { BET IM FORTS } \\
\text { OP REGION }\end{array}$ \\
\hline
\end{tabular}


REGIONAL RNEFGY BALANCR STATEMENT
PIES GID MID SCENARIO

\begin{tabular}{|c|c|c|c|c|c|c|c|c|c|c|}
\hline SECIOE & $\begin{array}{l}\text { DISTILLATE } \\
\text { OIL }\end{array}$ & R.ESIMUAL & $\begin{array}{l}\text { GASOLIN } \\
\text { (ALL JI }\end{array}$ & $\begin{array}{c}\text { OTHER } \\
\text { HYDRO- } \\
\text { CARBONS } \\
\text { IS IN } 10 * 9\end{array}$ & $\begin{array}{c}\text { CRODE } \\
\text { OIL } \\
\text { BTO'S) }\end{array}$ & $\begin{array}{l}\text { HATUR RL } \\
\text { GAS }\end{array}$ & $\operatorname{COAL}$ & ELECTRICITY & $\begin{array}{l}\text { SECTOR } \\
\text { TOTAL }\end{array}$ & \\
\hline $\begin{array}{l}\text { PINLL LEHANE SECTORS } \\
\text { RESIDENTIAI, COMN. } \\
\text { INDOSTRIAI } \\
\text { TRANSPORTATICN } \\
\text { HISCELLANPCDS OSES }\end{array}$ & $\begin{array}{r}43.361 \\
17.899 \\
23.775 \\
736\end{array}$ & $\begin{array}{r}6.170 \\
-5,883 \\
1.896 \\
367\end{array}$ & 120,290 & $\begin{array}{r}11,982 \\
16,233 \\
4,131 \\
13\end{array}$ & $\begin{array}{l}- \\
- \\
-\end{array}$ & $\begin{array}{r}54,7: 9 \\
42,370 \\
9,008 \\
937\end{array}$ & $\begin{array}{r}273 \\
104,271 \\
15 \\
4\end{array}$ & $\begin{array}{r}35,653 \\
42,427 \\
556 \\
408\end{array}$ & $\begin{array}{r}152,158 \\
239,023 \\
151,671 \\
2,465\end{array}$ & $\begin{array}{r}22 \% \\
35 \% \\
22 \% \\
0 \%\end{array}$ \\
\hline $\begin{array}{l}\text { TCTAI FINAI } \\
\text { DEMAND SECTORS }\end{array}$ & 85.771 & 24,316 & 120,290 & 32,359 & - & 98,974 & 104,563 & 79,044 & 545,317 & $80 \pi$ \\
\hline $\begin{array}{l}\text { TAANSPCREATIEN } \\
\text { BLECTRICITY GEN. } \\
\text { PETROIROM ERCDOCTS } \\
\text { NATORAL GAS } \\
\text { SYHTHETICS }\end{array}$ & $\begin{array}{r}2.325 \\
= \\
-\end{array}$ & $\begin{array}{r}137 \\
- \\
-\end{array}$ & $\begin{array}{l}\overline{-} \\
\overline{-}\end{array}$ & $\begin{array}{l}- \\
\overline{-}\end{array}$ & $\bar{z}$ & $\begin{array}{l}\bar{z} \\
\overline{-}\end{array}$ & $\begin{array}{r}184,927 \\
- \\
-\end{array}$ & $\begin{array}{r}-61,813 \\
- \\
-\end{array}$ & $\begin{array}{r}125,576 \\
- \\
-\end{array}$ & $18 \%$ \\
\hline $\begin{array}{l}\text { NET FOEL OSEL } \\
\text { IN TRANSPOSHATION }\end{array}$ & 2.325 & 137 & - & - & - & - & 184,927 & $-61,813$ & 125,576 & $18 \pi$ \\
\hline $\begin{array}{l}\text { TCTAL GROSS ELONS } \\
\text { LCSSES } \varepsilon \text { OHI } \Xi S I O N S\end{array}$ & $\begin{array}{r}88.096 \\
5.483\end{array}$ & $\begin{array}{r}24.453 \\
0\end{array}$ & $\begin{array}{r}120,290 \\
0\end{array}$ & $\begin{array}{r}32,359 \\
-1,276\end{array}$ & $\overline{-}$ & $\begin{array}{l}98,974 \\
-2,674\end{array}$ & $\begin{array}{r}289,490 \\
3,918\end{array}$ & $\begin{array}{r}79,044 \\
6,558\end{array}$ & $\begin{array}{r}670,893 \\
12,010\end{array}$ & $\begin{array}{r}98 \% \\
2 \pi\end{array}$ \\
\hline CTAL NET OSAGE & 93.579 & 24,453 & 120,290 & 31,082 & - & 96,269 & 293,408 & 23,789 & 682,903 & \\
\hline
\end{tabular}

SOFELT CP ENERGT
FOSS IL FOE
HYDROELCTIC
NOCLEAR
GEOESOLAR

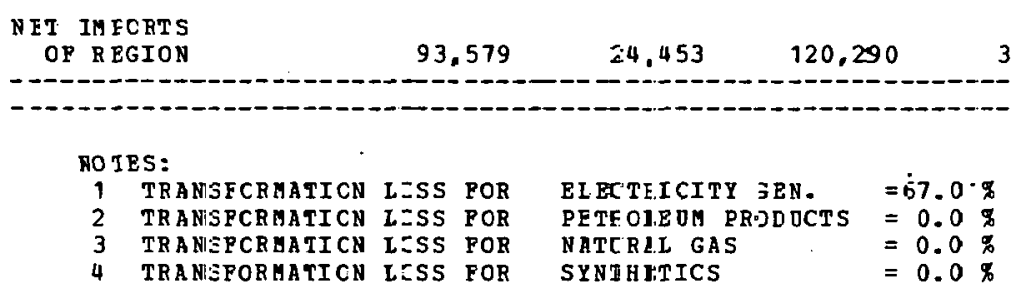


REGICNAI ENE EGY PALANCE STATEMENT
PIES MID BID SCENARIO

\begin{tabular}{|c|c|c|c|c|c|c|c|c|c|c|}
\hline SECTOA & $\begin{array}{l}\text { DISTILLATE } \\
\text { OIL }\end{array}$ & $\begin{array}{l}\text { RESIDJAL } \\
\text { OIL }\end{array}$ & $\begin{array}{l}\text { GASOLINE } \\
\text { (AIL ONI }\end{array}$ & $\begin{array}{c}\text { OTHER } \\
\text { HYDRO- } \\
\text { CARBONS } \\
\text { TS IN } 10 \$ 9\end{array}$ & $\begin{array}{c}\text { CRODE } \\
\text { OIL } \\
\text { BTO'S) }\end{array}$ & $\begin{array}{l}\text { NATURAL } \\
\text { GAS }\end{array}$ & $\operatorname{COAL}$ & BLECTRICITY & $\begin{array}{r}\text { SECTOR } \\
\text { TOTAL }\end{array}$ & \\
\hline $\begin{array}{l}\text { PIKLL EEHANE SECTORS } \\
\text { BFSID BNTIAL, CCHA. } \\
\text { INDOSTRIAL } \\
\text { TEANSPORTATICN } \\
\text { GISCELLAHECOS OSES }\end{array}$ & $\begin{array}{r}58,622 \\
34,329 \\
19,924 \\
3,995\end{array}$ & $\begin{array}{r}10,760 \\
39,967 \\
11,779 \\
1,997\end{array}$ & $198,19 \overline{-}$ & $\begin{array}{r}17,327 \\
33,925 \\
11,095 \\
68\end{array}$ & $\begin{array}{l}- \\
-\end{array}$ & $\begin{array}{r}55,965 \\
30,153 \\
2,991 \\
4,717\end{array}$ & $\begin{array}{r}224 \\
97,673 \\
16 \\
17\end{array}$ & $\begin{array}{r}67,361 \\
50,768 \\
565 \\
2,028\end{array}$ & $\begin{array}{r}210,259 \\
286,815 \\
244,566 \\
12,822\end{array}$ & $\begin{array}{r}24 \% \\
33 \% \\
28 \% \\
1 \%\end{array}$ \\
\hline $\begin{array}{l}\text { TCJAL EINAI } \\
\text { DEMAND SECTCRS }\end{array}$ & 116,870 & 64,503 & 198,196 & 62,415 & - & 93,826 & 97,930 & 120,722 & 754,462 & $87 \%$ \\
\hline 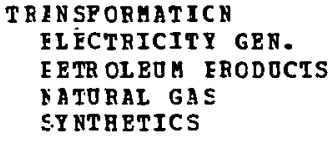 & $\begin{array}{r}7,409 \\
-135,328 \\
-\end{array}$ & $\begin{array}{r}29,147 \\
-14,865 \\
- \\
-\end{array}$ & $\begin{array}{r}-151,26 \overline{-} \\
-\end{array}$ & $\begin{array}{r}-44,73 \overline{2} \\
125,24 \overline{5}\end{array}$ & $\begin{array}{r}344,214 \\
-\end{array}$ & $\begin{array}{r}1,410 \\
1,868 \\
-112,975\end{array}$ & $\begin{array}{r}68,434 \\
- \\
-\end{array}$ & $\begin{array}{r}-33,906 \\
- \\
- \\
-\end{array}$ & $\begin{array}{r}72,494 \\
-104 \\
- \\
12,270\end{array}$ & $\begin{array}{l}8 \% \\
0 \%\end{array}$ \\
\hline $\begin{array}{l}\text { NET FOEL OSEL } \\
\text { IN TRA TSPOFATTIOB }\end{array}$ & $-127,919$ & $1.4,282$ & $-151,262$ & 80,513 & 344,214 & $-109,696$ & 68.434 & $-33,906$ & 84,659 & $10 \%$ \\
\hline $\begin{array}{l}\text { TCTAL GROSS FLCRS } \\
\text { ICSSES } \varepsilon \text { OHISSIORS }\end{array}$ & $\begin{array}{r}124,279 \\
7,735\end{array}$ & $\begin{array}{r}93,650 \\
1\end{array}$ & $\begin{array}{r}198,196 \\
0\end{array}$ & $\begin{array}{r}187,660 \\
-7,402\end{array}$ & $\begin{array}{r}344,214 \\
14,279\end{array}$ & $\begin{array}{l}97,104 \\
-2,623\end{array}$ & $\begin{array}{r}166,364 \\
2,251\end{array}$ & $\begin{array}{r}120,722 \\
10,016\end{array}$ & $\begin{array}{r}839,226 \\
24,260\end{array}$ & $\begin{array}{r}97 \% \\
3 \%\end{array}$ \\
\hline TIAL NET OSAGE & $-3,313$ & 78,786 & 46,934 & 135,525 & 358,093 & $-18,494$ & 168,615 & 96.832 & 863,382 & \\
\hline
\end{tabular}

SOFPLY OF ENFRG
FOSS IL FOEL
GYDROERCTEIC
UOCLEAR

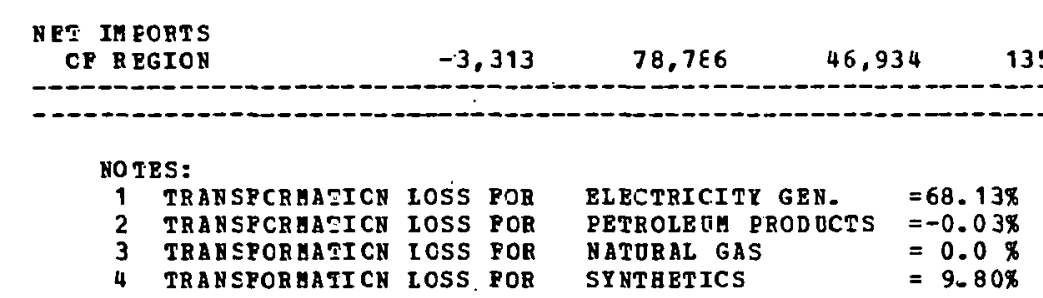


REGIJTAL EREFGY EALANCE STATBMENT

PIES MID MID SCENARIO

\begin{tabular}{|c|c|c|c|c|c|c|c|c|c|c|}
\hline SECTOK & $\begin{array}{l}\text { DISTILLATE } \\
\text { DIL }\end{array}$ & $\begin{array}{l}\text { RESCDOAL } \\
\underset{D L}{ }\end{array}$ & $\begin{array}{l}\text { GASOLIN: } \\
\text { TALL }\end{array}$ & $\begin{array}{c}\text { OT EER } \\
\text { HYDSO- } \\
\text { CAF BONS } \\
\text { IN } 10 * * 9\end{array}$ & $\begin{array}{c}\text { CBOJE } \\
\text { OIE } \\
\text { BTO'S) }\end{array}$ & $\begin{array}{l}\text { NATURAL. } \\
\text { GAS }\end{array}$ & $\operatorname{COAL}$ & ELECTRICITY & $\begin{array}{r}\text { SECTOR } \\
\text { TOTAL }\end{array}$ & \\
\hline $\begin{array}{l}\text { FIHAL DEMANC EFCTORS } \\
\text { BESIDENTIAL, CCAB. } \\
\text { INDOSTRIAL } \\
\text { TRANSPORTATICA } \\
\text { GISCELLANECE OSES }\end{array}$ & $\begin{array}{r}85,107 \\
8,621 \\
20,682 \\
9,326\end{array}$ & $\begin{array}{r}21,338 \\
15,730 \\
23,447 \\
+, 660\end{array}$ & 261,827 & $\begin{array}{r}21.327 \\
11.182 \\
42.840 \\
162\end{array}$ & $\begin{array}{l}\overline{-} \\
\overline{-}\end{array}$ & $\begin{array}{r}68,742 \\
7,536 \\
8,294 \\
11,459\end{array}$ & $\begin{array}{r}575 \\
7,363 \\
3 \\
4 ?\end{array}$ & $\begin{array}{r}93,000 \\
16,068 \\
69 \\
6,149\end{array}$ & $\begin{array}{r}290,090 \\
66,509 \\
362,162 \\
31,798\end{array}$ & $\begin{array}{r}33 \% \\
7 \% \\
+1 \% \\
4 \%\end{array}$ \\
\hline $\begin{array}{l}\text { TCTAL PINAL } \\
\text { DEMAND SECTCRS }\end{array}$ & 123,736 & 73,184 & 261,827 & 75.511 & - & 96,031 & 7,984 & 115,286 & 750,559 & $.35 \%$ \\
\hline $\begin{array}{l}\text { TR ANSPCRMATICS } \\
\text { ELECTRICITY GEN. } \\
\text { PETROLEOH FGCDOCTS } \\
\text { NAIURAL GAS } \\
\text { SYNTHETICS }\end{array}$ & $\begin{array}{r}5.045 \\
- \\
-\end{array}$ & $\begin{array}{r}41,288 \\
= \\
-\end{array}$ & $\bar{E}$ & $\begin{array}{l}\overline{-} \\
\overline{-}\end{array}$ & $\begin{array}{l}- \\
\overline{-}\end{array}$ & $\begin{array}{l}- \\
- \\
-\end{array}$ & $\begin{array}{r}136,481 \\
=\end{array}$ & $\begin{array}{r}-59,105 \\
- \\
-\end{array}$ & $\begin{array}{r}123,709 \\
- \\
-\end{array}$ & \\
\hline $\begin{array}{l}\text { NET FOEL OSEL } \\
\text { IN TRANSPEITION }\end{array}$ & 5,045 & 41,298 & - & - & - & - & 136,481 & $-59,105$ & 123,709 & $14 \%$ \\
\hline $\begin{array}{l}\text { TCTAL GROSS FIORS } \\
\text { LCSSES } \varepsilon \text { CMISIIONS }\end{array}$ & $\begin{array}{r}123,731 \\
3,015\end{array}$ & $\begin{array}{r}111,472 \\
2\end{array}$ & 261,827 & $\begin{array}{l}75.511 \\
-2.978\end{array}$ & $\begin{array}{l}- \\
-\end{array}$ & $\begin{array}{l}96,031 \\
-2,594\end{array}$ & $\begin{array}{r}144,465 \\
1,955\end{array}$ & $\begin{array}{r}115,286 \\
9,565\end{array}$ & $\begin{array}{r}874,268 \\
13,966\end{array}$ & $\begin{array}{r}38 \% \\
2 \%\end{array}$ \\
\hline TOTAL NET OSAGE & 135,736 & 111,474 & 261,823 & 72,532 & - & 93,436 & 146,4210 & 65,746 & 888,234 & \\
\hline $\begin{array}{l}\text { SOFELY OF FNEGGY } \\
\text { FOSS IL FOEI } \\
\text { HYLRCEL RCISIC } \\
\text { NOCL EAR } \\
\text { GEC. ESOLAR }\end{array}$ & $\bar{z}$ & $\begin{array}{l}\overline{-} \\
\overline{-}\end{array}$ & $\begin{array}{l}\overline{-} \\
\overline{-}\end{array}$ & $\begin{array}{l}- \\
-\end{array}$ & $\begin{array}{l}- \\
\text { - } \\
\text { - }\end{array}$ & $\begin{array}{l}- \\
-\end{array}$ & $\begin{array}{l}\overline{-} \\
\overline{-}\end{array}$ & $\begin{array}{r}- \\
50,487 \\
-\end{array}$ & $\begin{array}{r}- \\
50.487 \\
-\end{array}$ & $100 \%$ \\
\hline CIAL SOPPIY & - & - & - & - & - & - & - & 50,487 & 50,487 & \\
\hline
\end{tabular}

\begin{tabular}{l} 
NET IM FORTS \\
CF REGION \\
\hline
\end{tabular}

\begin{tabular}{|c|c|c|c|c|c|}
\hline & \multirow{2}{*}{\multicolumn{5}{|c|}{ TPANSPCPNATTCN }} \\
\hline & & & & EI BCTRICITY GEN. & \\
\hline 2 & TRANSTCRAATICN & Loss & POR & PETROLE ON PROL OCTS & \\
\hline 3 & TRAN SPCRHATI CN & LosS & POR & NATUEAL GAS & $=0.0$ \\
\hline 4 & TRANSPORMAIICN & LosS & POR & SYNTE $3 T I C S$ & $=0.0$ \\
\hline
\end{tabular}


FEGIONAL ENEEGY EALANCE STATEMENT
PIES MID MID SCENARIO

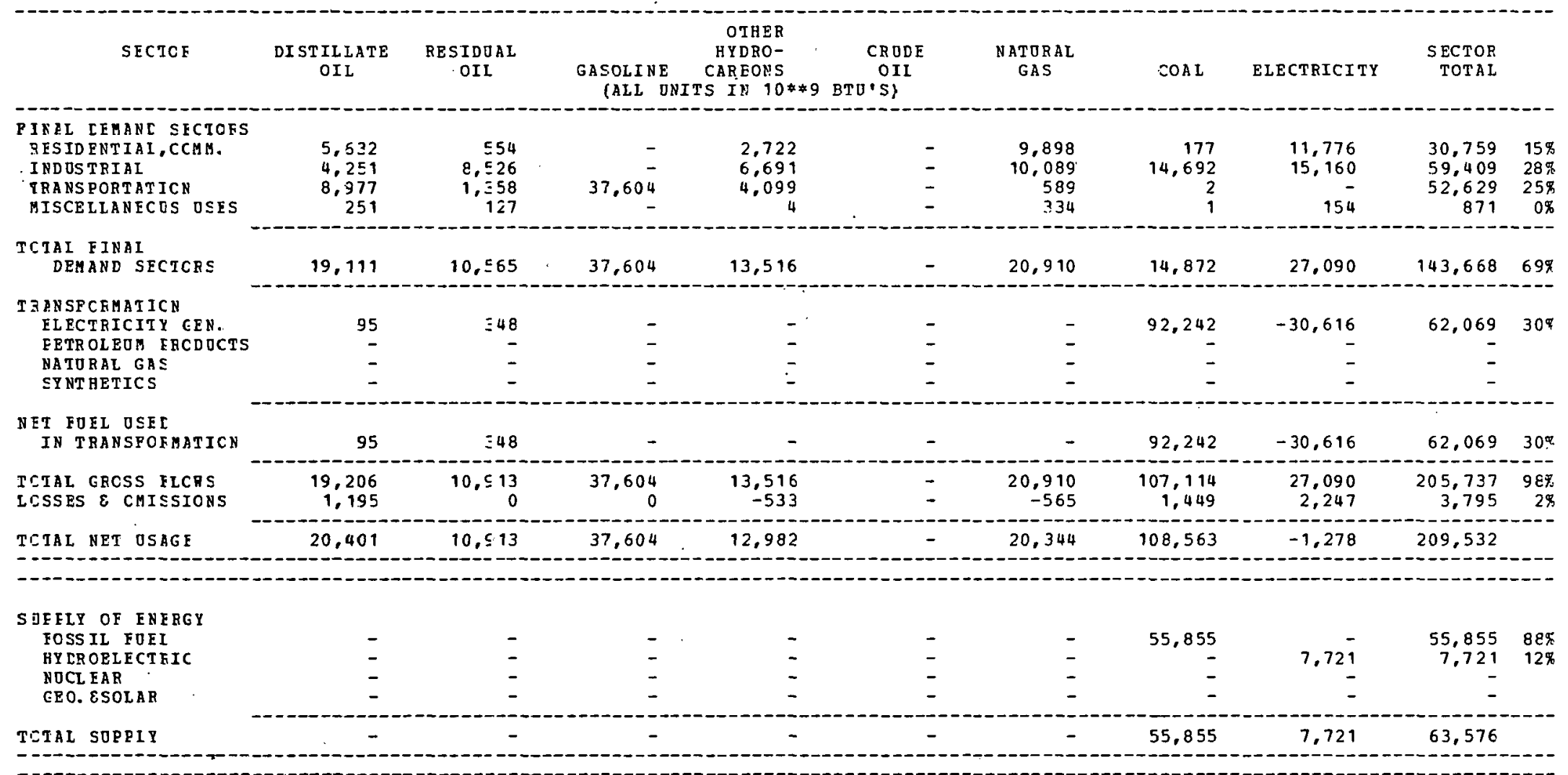

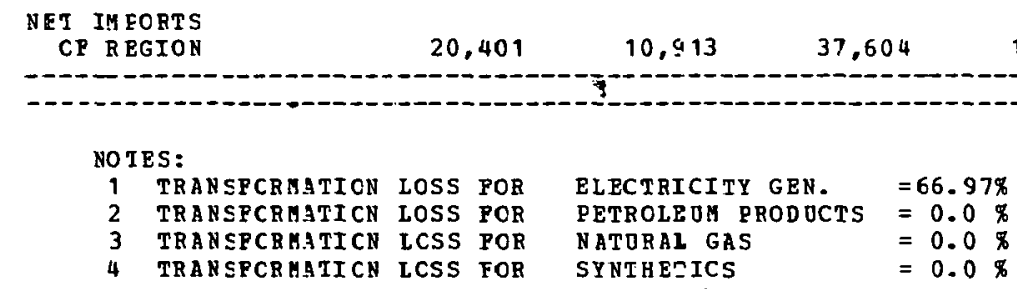


REGIONAL ENE FGY EALANCE STITEMENT
PIES MID MID SCENARIO

\begin{tabular}{|c|c|c|c|c|c|c|c|c|c|c|}
\hline SECIOE & $\begin{array}{l}\text { IISTIL ¿ATE } \\
\text { OI } \bar{i}\end{array}$ & $\begin{array}{l}\text { RESIDUAL } \\
\text { JIE }\end{array}$ & $\begin{array}{l}\text { GASOL }=\square E \\
\text { (ALL ON }\end{array}$ & $\begin{array}{c}\text { OTHER } \\
\text { AYIRO- } \\
\text { CARBONS } \\
\text { TS ID } 10 * * 9\end{array}$ & $\begin{array}{c}\text { CRUDE } \\
\text { OIL } \\
\text { ETU'S! }\end{array}$ & $\begin{array}{l}\text { NATURAL } \\
\text { GAS }\end{array}$ & $\cos =$ & ELECTRICITY & $\begin{array}{r}\text { SECTOR } \\
\text { TOTAL }\end{array}$ & \\
\hline $\begin{array}{l}\text { PINAL LEMANC SFCTOES } \\
\text { RESIDENTIAL, CCGM. } \\
\text { INDOSTRIAI. } \\
\text { TRANSPORTATICN } \\
\text { MISCELLANECOS OSES }\end{array}$ & $\begin{array}{r}12,342 \\
14,758 \\
17,141 \\
335\end{array}$ & $\begin{array}{r}902 \\
23,910 \\
2,335 \\
167\end{array}$ & $74,48 \overline{-}$ & $\begin{array}{r}5.440 \\
27.648 \\
6.794 \\
6\end{array}$ & $\begin{array}{l}\overline{-} \\
-\end{array}$ & $\begin{array}{r}12,195 \\
24,763 \\
722 \\
438\end{array}$ & $\begin{array}{r}279 \\
54,878 \\
18 \\
1\end{array}$ & $\begin{array}{r}21,708 \\
30,247 \\
- \\
210\end{array}$ & $\begin{array}{r}52,866 \\
175,904 \\
101,498 \\
1,157\end{array}$ & $\begin{array}{l}15 \% \\
50 \% \\
29 \% \\
0 \%\end{array}$ \\
\hline $\begin{array}{l}\text { TCTAL FINAI. } \\
\text { DEMAND SECTCRS }\end{array}$ & $+4,276$ & 27,314 & 74.488 & 39,888 & - & 38,118 & 55,176 & 52,165 & 331,425 & $94 \%$ \\
\hline $\begin{array}{l}\text { TRANSFCRMATICN } \\
\text { FLECTRICIT G GEY. } \\
\text { PETROLEOM ERCDOCTS } \\
\text { NATRRAL GAE } \\
\text { SYNTHETICS }\end{array}$ & $\begin{array}{r}577 \\
- \\
-\end{array}$ & $\begin{array}{l}\overline{-} \\
\overline{-}\end{array}$ & $\begin{array}{l}\bar{z} \\
\overline{-}\end{array}$ & $\begin{array}{l}\overline{-} \\
\overline{-}\end{array}$ & $\bar{z}$ & $\begin{array}{l}- \\
-\end{array}$ & $\begin{array}{r}22,252 \\
- \\
-\end{array}$ & $\begin{array}{r}-7,588 \\
- \\
-\end{array}$ & $\begin{array}{r}15,351 \\
= \\
=\end{array}$ & $4 \pi$ \\
\hline $\begin{array}{l}\text { NFT FUEL OSE } \\
\text { IN TRANPOEHATION }\end{array}$ & 577 & - & - & - & - & - & 22,252 & $-7,588$ & 15,351 & $4 \%$ \\
\hline $\begin{array}{l}\text { TCIAL GROSS EICRS } \\
\text { LCSSES } \varepsilon \text { OMIESIOUS }\end{array}$ & $\begin{array}{r}+4,753 \\
2,798\end{array}$ & $\begin{array}{r}27,314 \\
0\end{array}$ & $\begin{array}{r}74,488 \\
0\end{array}$ & $\begin{array}{l}39,888 \\
-1,573\end{array}$ & $\overline{-}$ & $\begin{aligned} 38,118 \\
-7,030\end{aligned}$ & $\begin{array}{r}77,438 \\
1,048\end{array}$ & $\begin{array}{r}52,165 \\
4,328\end{array}$ & $\begin{array}{r}346,776 \\
5,572\end{array}$ & $\begin{array}{r}98 \% \\
2 \%\end{array}$ \\
\hline
\end{tabular}

-

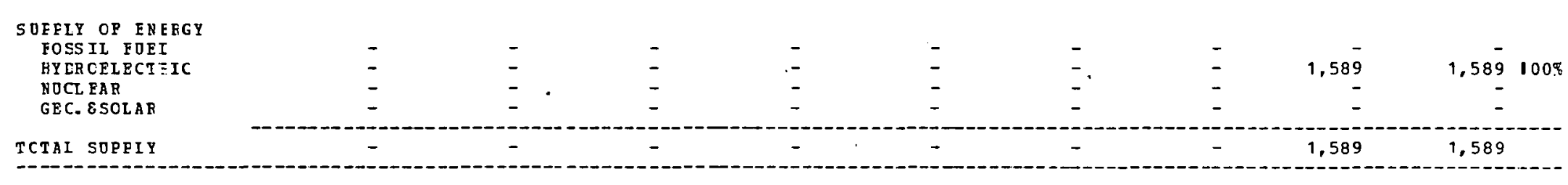

NET IM FORTS
CF REGION


REGIONAL ENEFGY EALANCE STATEMENT

PIES MID MID SCENARIO

\begin{tabular}{|c|c|c|c|c|c|c|c|c|c|}
\hline SECTOF & $\begin{array}{l}\text { DISTILLATE } \\
\text { OIL }\end{array}$ & $\begin{array}{l}\text { RESIDUAL } \\
\text { OIL }\end{array}$ & $\begin{array}{l}\text { GASOLINE } \\
\text { (ALL O }\end{array}$ & $\begin{array}{c}\text { OTRER } \\
\text { HYDRO- } \\
\text { CARBONS } \\
\text { S IN } 10 * 9\end{array}$ & $\begin{array}{c}\text { CRUDE } \\
\text { OIL } \\
\text { BTU'S) }\end{array}$ & $\begin{array}{l}\text { NATURAL } \\
\text { GAS }\end{array}$ & COAL & ELECTRICITY & $\begin{array}{l}\text { SECTOR } \\
\text { TOTAL }\end{array}$ \\
\hline $\begin{array}{l}\text { FINAL IEMANI SECTORS } \\
\text { RESIDENTIAL, CCMM. } \\
\text { INDOSTRIAL } \\
\text { TRANSPORTATICN } \\
\text { MISCELIANECCS OSES }\end{array}$ & $\begin{array}{r}15,621 \\
16,187 \\
16,918 \\
1,016\end{array}$ & $\begin{array}{r}1,431 \\
22,289 \\
5,065 \\
538\end{array}$ & $90.82 \overline{-}$ & $\begin{array}{r}6,545 \\
25,542 \\
14,823 \\
19\end{array}$ & $\begin{array}{l}- \\
\end{array}$ & $\begin{array}{r}16,268 \\
24,520 \\
1,576 \\
1,372\end{array}$ & $\begin{array}{r}353 \\
36,734 \\
6 \\
5\end{array}$ & $\begin{array}{r}29,652 \\
24,847 \\
- \\
901\end{array}$ & $\begin{array}{r}69,870 \\
150,119 \\
129,213 \\
3,821\end{array}$ \\
\hline $\begin{array}{l}\text { TCTAI FINAI } \\
\text { DEMAND SECTCRS }\end{array}$ & 49,742 & 29,293 & 90,825 & 46,929 & - & 43,736 & 37,098 & 55,400 & 353,023 \\
\hline $\begin{array}{l}\text { TEANSFORMATICN } \\
\text { ELECTRICITY GEN. } \\
\text { FETROLEUM FRCIOCTS } \\
\text { NATURAL GAS } \\
\text { STNTEETICS }\end{array}$ & $\begin{array}{r}490 \\
- \\
-\end{array}$ & $\begin{array}{r}3,610 \\
- \\
-\end{array}$ & $\begin{array}{l}\bar{z} \\
\bar{z}\end{array}$ & $\begin{array}{l}\bar{z} \\
\overline{-}\end{array}$ & $\begin{array}{l}- \\
\end{array}$ & $\begin{array}{l}- \\
-\end{array}$ & $\begin{array}{r}67,936 \\
- \\
-\end{array}$ & $\begin{array}{r}-23,689 \\
- \\
- \\
. \quad-\end{array}$ & $\begin{array}{r}48,347 \\
= \\
-\end{array}$ \\
\hline $\begin{array}{l}\text { NET FOFL OSEL } \\
\text { IN TRANSOEMATION }\end{array}$ & 490 & 3,610 & - & - & - & - & 67,936 & $-23,689$ & 48,347 \\
\hline $\begin{array}{l}\text { TCTAL GFOSS FLCRS } \\
\text { LCSSES } \mathcal{O} \text { OMISSIONS }\end{array}$ & $\begin{array}{r}50,232 \\
3,126\end{array}$ & $\begin{array}{r}32,903 \\
0\end{array}$ & $\begin{array}{r}90,825 \\
0\end{array}$ & $\begin{array}{r}46,929 \\
-1,851\end{array}$ & - & $\begin{array}{l}43,736 \\
-1,181\end{array}$ & $\begin{array}{r}105,034 \\
1,421\end{array}$ & $\begin{array}{r}55,400 \\
4,596\end{array}$ & $\begin{array}{r}401,370 \\
6,113\end{array}$ \\
\hline TCTAL NET OSAGE & 53,358 & 32,903 & 90,825 & 45,077 & - & 42,554 & 106,455 & 36,307 & 407,483 \\
\hline $\begin{array}{l}\text { SOEELY OP ENERGY } \\
\text { FOSS IL FOEI } \\
\text { HY DROELECTEIC } \\
\text { NOCLEAR } \\
\text { GEC. ESOLAR }\end{array}$ & $\begin{array}{l}\overline{-} \\
\overline{-}\end{array}$ & $\begin{array}{l}\overline{-} \\
\overline{-}\end{array}$ & $\bar{z}$ & $\begin{array}{l}- \\
- \\
-\end{array}$ & $\overline{-}$ & $\begin{array}{l}- \\
- \\
-\end{array}$ & $\begin{array}{l}- \\
-\end{array}$ & $\begin{array}{r}1.568 \\
66.488 \\
-\end{array}$ & $\begin{array}{r}1,568 \\
66,488 \\
-\end{array}$ \\
\hline TCTAI SOPPIY & - & - & - & - & - & - & - & 68,056 & 68,056 \\
\hline
\end{tabular}

\section{NET IM FORTS}

$53,358 \quad 32,903$

90,825

45.077

- $\quad 42,554$

106,455

339.427

-

\section{NOTES:}

TRANSFCRMATICN LOSS POR

TRANSFCRMATICN LOSS FC

TRANSPCRHATICN LCSS POR

TRANSFCRMATI CN LCSS FOR

ELECTRICITY GEN

=67.12\%

NATURAL GAS

$=67.12 \%$
$=0.0 \%$

SY HTH ETICS

$=0.0 \%$
$=0.0 \%$ 
REGICNAL ENZFGI ERLANCE STATEMEAT

\begin{tabular}{|c|c|c|c|c|c|c|c|c|c|c|}
\hline SECTGE & $\begin{array}{l}\text { DIST=LLITE } \\
\text { OIL }\end{array}$ & $\begin{array}{l}\text { RESIDUAL } \\
\text { CIL }\end{array}$ & $\begin{array}{l}\text { GASOLIEE } \\
\text { (ALL UNC? }\end{array}$ & $\begin{array}{c}\text { DTHSR } \\
\text { HYDRO- } \\
\text { ChIBCNS } \\
\text { TS IN } 10 * 9\end{array}$ & $\begin{array}{l}\text { CRDDE } \\
\text { OIL } \\
\text { BTOCS) }\end{array}$ & $\begin{array}{l}\text { NATORAL } \\
\text { GAS }\end{array}$ & $\operatorname{COAL}$ & ELECTRICITY & $\begin{array}{r}\text { SECTOR } \\
\text { TOTAL }\end{array}$ & \\
\hline $\begin{array}{l}\text { FINAL CEMANC SFCTCRS } \\
\text { RESIDENTIAL, CCHM. } \\
\text { INDOSTRIAL } \\
\text { TRANSPORTATICN } \\
\text { MISCELLANECOS USES }\end{array}$ & $\begin{array}{r}18,239 \\
8,414 \\
11,836 \\
1,901\end{array}$ & $\begin{array}{r}1,453 \\
2 \equiv .067 \\
\subseteq, 970 \\
951\end{array}$ & $106,64 \overline{-}$ & $\begin{array}{r}8.169 \\
19.969 \\
29.398 \\
49\end{array}$ & $\begin{array}{l}- \\
- \\
-\end{array}$ & $\begin{array}{r}17,129 \\
9,223 \\
3,147 \\
2,764\end{array}$ & $\begin{array}{r}384 \\
-8,036 \\
\varepsilon \\
11\end{array}$ & $\begin{array}{r}33,741 \\
19,028 \\
- \\
3,513\end{array}$ & $\begin{array}{r}79,175 \\
97,737 \\
161,006 \\
9,189\end{array}$ & $\begin{array}{l}z 0 \% \\
255 \% \\
41 \% \\
2 \%\end{array}$ \\
\hline $\begin{array}{l}\text { TCTAI FINAI } \\
\text { DEMAND SECICRS }\end{array}$ & 40,450 & 35.441 & $106,64 i$ & 57.585 & $=$ & 32,263 & $-8,43 c$ & 56,282 & 347,107 & $\varepsilon 8 \%$ \\
\hline $\begin{array}{l}\text { TRANSFCEMATICL } \\
\text { ELEC TRICITY CEN. } \\
\text { PETROLEOM FECDOCTS } \\
\text { NATURAL GAS } \\
\text { SYNTHETICS }\end{array}$ & $\begin{array}{r}2,7+6 \\
-132,739 \\
-\end{array}$ & $\begin{array}{r}1 \epsilon, 007 \\
-16,577 \\
- \\
-\end{array}$ & $\begin{array}{r}-148,33 \overline{5} \\
-\end{array}$ & $\begin{array}{l}-43,36 \bar{j} \\
.125,245\end{array}$ & $\begin{array}{r}337,552 \\
-\end{array}$ & $\begin{array}{r}1,83 \overline{-} \\
-112,975\end{array}$ & $\begin{array}{r}9,96 \leq \\
- \\
-\end{array}$ & $\begin{array}{r}-9,155 \\
- \\
-\end{array}$ & $\begin{array}{r}19,563 \\
-102 \\
- \\
12,270\end{array}$ & $\begin{array}{l}5 \% \\
0 \%\end{array}$ \\
\hline $\begin{array}{l}\text { NFT FOFL OSEL } \\
\text { IN TRANSFCFATICN }\end{array}$ & $-129,953$ & 1,430 & $-148,335$ & 31,379 & 337,552 & $-111,142$ & $9.96 \mathrm{E}$ & $-9,155$ & 31,730 & $8 \%$ \\
\hline $\begin{array}{l}\text { TCTAL GRCSS FICRS } \\
\text { LCSSES } \& \text { CMISSIONS }\end{array}$ & $\begin{array}{r}43,196 \\
2,638\end{array}$ & 51,448 & $106,64 ?$ & $\begin{array}{r}192.830 \\
-7.211\end{array}$ & $\begin{array}{r}337,552 \\
14,003\end{array}$ & $\begin{array}{r}34,095 \\
-921\end{array}$ & $\begin{array}{r}\therefore 8,40 c \\
384\end{array}$ & $\begin{array}{r}56,282 \\
4,669\end{array}$ & $\begin{array}{r}378,940 \\
13,615\end{array}$ & $\begin{array}{c}\leq 7 \% \\
3 \%\end{array}$ \\
\hline TCIAL NET OSACE & $-26,8 \geq 4$ & $3 \epsilon, 872$ & $-41,68 ?$ & 131,752 & 351,555 & $-79,800$ & 28,788 & 51,796 & 372,452 & \\
\hline
\end{tabular}

\begin{tabular}{|c|c|c|c|c|c|c|c|c|c|}
\hline SUEFLY CF ENEEGY & & & & & & & & - & \\
\hline FCSSIL FOEI & - & - & - & - & - & - & - & - & - \\
\hline HY DRCEIECIE & - & - & - & - & $\rightarrow$ & - & - & 57 & 57 \\
\hline NOCLEAR & - & - & - & - & - & - & - & 27,987 & 27,987 \\
\hline GEC. \&SOLAR & - & - & - & - & - & - & - & - & - \\
\hline TCTAL SOPPIY & - & - & - & - & - & - & - & 28,044 & 28,044 \\
\hline
\end{tabular}

\begin{tabular}{l} 
NET IMFCRTS \\
CF REGION \\
\hline
\end{tabular}


REGICNAL ENEFGY BALANCE STATEMENT

PIES MID GID SCENARIO

\begin{tabular}{|c|c|c|c|c|c|c|c|c|c|c|}
\hline SECTOF & $\begin{array}{l}\text { DISTILLATE } \\
\text { OIL }\end{array}$ & $\begin{array}{l}\text { RESIDUEL } \\
\text { GIL }\end{array}$ & $\begin{array}{l}\text { GASOLINE } \\
\text { (ALI ON }\end{array}$ & $\begin{array}{l}\text { OTHER } \\
\text { HYDRO- } \\
\text { CARBONS } \\
\text { TS IN } 10 * * 9\end{array}$ & $\begin{array}{c}\text { CROLE } \\
\text { OIL } \\
\text { BIO DS }\end{array}$ & $\begin{array}{l}\text { NATURAL } \\
\text { GAS }\end{array}$ & COAL & ELECTRICITY & $\begin{array}{l}\text { SECTOR } \\
\text { TOTAL }\end{array}$ & \\
\hline $\begin{array}{l}\text { FIXIL TEMANI SECIOES } \\
\text { RESIDENTIAI, CCHM. } \\
\text { INDOSTRIAL } \\
\text { TRANSPORTATICN } \\
\text { MISCELLANECOS OSES }\end{array}$ & $\begin{array}{r}35,494 \\
14,591 \\
11,885 \\
1,868\end{array}$ & $\begin{array}{r}3.454 \\
20,776 \\
2 \equiv 1 \\
931\end{array}$ & $\begin{array}{r}\overline{-} \\
\overline{-} \\
156,887\end{array}$ & $\begin{array}{r}19,527 \\
23,280 \\
3,708 \\
92\end{array}$ & $\begin{array}{l}5 \\
-\end{array}$ & $\begin{array}{r}10,672 \\
26,284 \\
631 \\
1,615\end{array}$ & $\begin{array}{r}255 \\
21.436 \\
- \\
4\end{array}$ & $\begin{array}{r}78,174 \\
46,561 \\
- \\
1,265\end{array}$ & $\begin{array}{r}147,576 \\
152,928 \\
173,342 \\
5,825\end{array}$ & $\begin{array}{r}20 \% \\
21 \% \\
238 \\
1 \%\end{array}$ \\
\hline $\begin{array}{l}\text { TCTAL FINAL } \\
\text { DEMAND SPCTCRS }\end{array}$ & 63,838 & $25,4.42$ & 156,887 & 46,607 & - & 39,202 & 21,695 & 126,000 & 479,671 & $65 \%$ \\
\hline $\begin{array}{l}\text { TEANSFORHATICN } \\
\text { FLECTRICITY ERN. } \\
\text { PETR CLEOM FECDOCTS } \\
\text { MATORAL GAS } \\
\text { SYNTHETICS }\end{array}$ & $\begin{array}{r}16,231 \\
- \\
-\end{array}$ & $\begin{array}{l}- \\
- \\
-\end{array}$ & $\begin{array}{l}- \\
- \\
-\end{array}$ & $\begin{array}{l}- \\
\overline{-}\end{array}$ & $\begin{array}{l}- \\
\\
-\end{array}$ & - & $\begin{array}{r}349,436 \\
- \\
-\end{array}$ & $\begin{array}{r}-124,959 \\
- \\
-\end{array}$ & $\begin{array}{r}240,708 \\
- \\
-\end{array}$ & $33 \%$ \\
\hline $\begin{array}{l}\text { NIT FOEL OSEL } \\
\text { IN TRANSFCFHATION }\end{array}$ & 16,231 & - & - & - & - & - - & 349,436 & $-124,959$ & 240,708 & $33 \%$ \\
\hline $\begin{array}{l}\text { TCIAL GROSS FLORS } \\
\text { LOSSES E OMISSIONS }\end{array}$ & $\begin{array}{r}80,069 \\
4,983\end{array}$ & $\begin{array}{r}25,442 \\
0\end{array}$ & $\begin{array}{r}156,887 \\
0\end{array}$ & $\begin{array}{l}46,607 \\
-1,838\end{array}$ & $\overline{-}$ & $\begin{array}{l}39,202 \\
-1,059\end{array}$ & $\begin{array}{r}371,131 \\
5,023\end{array}$ & $\begin{array}{r}126,000 \\
10,454\end{array}$ & $\begin{array}{r}720,379 \\
17,565\end{array}$ & $\begin{array}{r}98 \% \\
2 \%\end{array}$ \\
\hline TETAL NET OSAGE & 85,052 & $25,4,42$ & 156,887 & 44,768 & - & 38,142 & 376,154 & 11,495 & 737,944 & \\
\hline $\begin{array}{l}\text { SOEELY OF ENERGI } \\
\text { FOSS IL FOEI } \\
\text { HYDROELECTEIC } \\
\text { NUCLEAR } \\
\text { GEC. ESOLAR }\end{array}$ & $\begin{array}{l}\overline{-} \\
\overline{-}\end{array}$ & :- & $\begin{array}{l}\overline{-} \\
\overline{-}\end{array}$ & $\begin{array}{l}- \\
- \\
-\end{array}$ & $\begin{array}{l}- \\
-\end{array}$ & $\begin{array}{l}- \\
-\end{array}$ & $\begin{array}{l}\overline{-} \\
\overline{-}\end{array}$ & $\begin{array}{r}5,415 \\
16,340 \\
-\end{array}$ & $\begin{array}{r}5.415 \\
16.340 \\
-\end{array}$ & $\begin{array}{l}25 \% \\
75 \%\end{array}$ \\
\hline TCTAI SUPPLI & - & - & - & - & - & - & - & 21,755 & 21,755 & \\
\hline
\end{tabular}

\begin{tabular}{l} 
XET IM FORTS \\
CE R EGIOH \\
\hline
\end{tabular}

\begin{tabular}{|c|c|c|c|c|c|}
\hline \\
\hline 1 & TRANSPCR AATICN & LOSS & POR & ELBCTEICITY GEN. & $=65.83 \%$ \\
\hline 2 & TRANSPORAATICN & IOSS & POB & PQTROIEOH PRODOCTS & $.0 \%$ \\
\hline 3 & TRANSFOREATICN & LCSS & FOR & NATURAI GAS & 0.0 \\
\hline 4 & TRANSPORHATICN & LCSS & POR & SYNTHETICS & $=0.0$ \\
\hline
\end{tabular}


REGIORAL FYEFGY PALANCE STATELENT
?IES RID MID SCENARIO

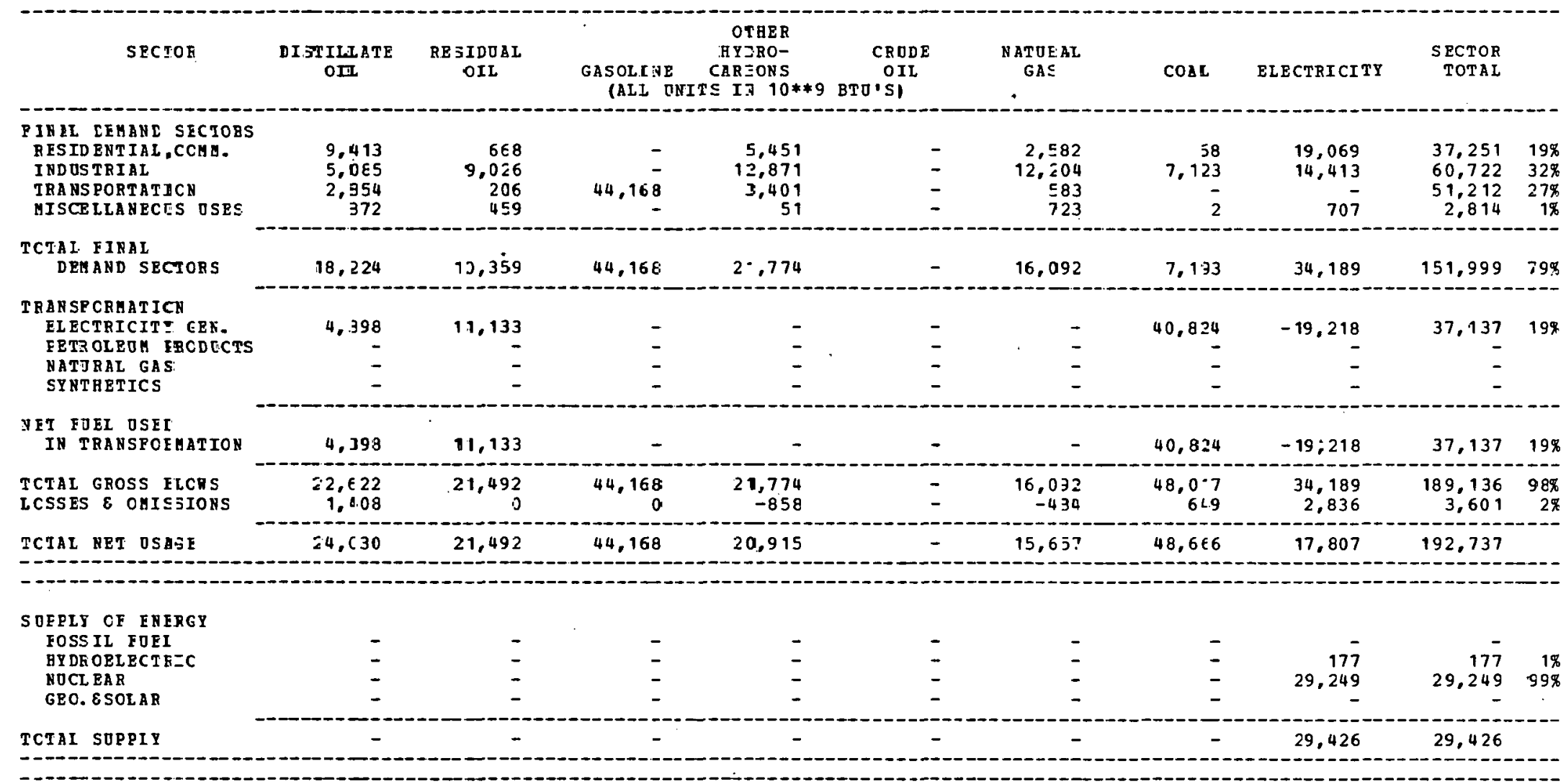

NET II FORTS
OP REGION


REGICNAL ENEFGY EALANCE STATEMENT

ICNAL ENE FGY FALANCE S
PIES MID MID SCENARIO

\begin{tabular}{|c|c|c|c|c|c|c|c|c|c|c|}
\hline SECTOE & $\begin{array}{l}\text { DISTILLATE } \\
\text { OIL }\end{array}$ & $\begin{array}{l}\text { RESIDJAI } \\
\text { OI: }\end{array}$ & $\begin{array}{l}\text { GASOLINE } \\
\text { (ALL ONI }\end{array}$ & $\begin{array}{c}\text { OTHER } \\
\text { HYDRO- } \\
\text { CAREONS } \\
\text { TS IN } 10 * \$ 9\end{array}$ & $\begin{array}{c}\text { CRODE } \\
\text { OIL } \\
\text { BTO'SI }\end{array}$ & $\begin{array}{l}\text { NATURAL } \\
\text { GAS }\end{array}$ & $\operatorname{COA} \mathbf{L}$ & ELECTRICITY & $\begin{array}{r}\text { SECTOR } \\
\text { TOTAL }\end{array}$ & \\
\hline $\begin{array}{l}\text { PIN PL CFHANL SFCTORS } \\
\text { RESIDENTIAI, CCMA. } \\
\text { INDOSTRIAL } \\
\text { TRANSPORTATICN } \\
\text { MISCELLANECS OSES }\end{array}$ & $\begin{array}{r}23,172 \\
13,706 \\
15,782 \\
455\end{array}$ & $\begin{array}{r}2,1748 \\
18,370 \\
268 \\
238\end{array}$ & $\begin{array}{r}- \\
105,428 \\
-\end{array}$ & $\begin{array}{r}12,889 \\
20,848 \\
3,072 \\
18\end{array}$ & $\overline{-}$ & $\begin{array}{r}7,183 \\
25,367 \\
500 \\
415\end{array}$ & $\begin{array}{r}176 \\
25,337 \\
- \\
1\end{array}$ & $\begin{array}{r}49,440 \\
48,299 \\
238\end{array}$ & $\begin{array}{r}94,908 \\
152,427 \\
125,050 \\
1,365\end{array}$ & $\begin{array}{r}19 \% \\
30 \% \\
25 \% \\
0 \%\end{array}$ \\
\hline $\begin{array}{l}\text { TCTAL FINAL } \\
\text { DEMAND SECTCRS }\end{array}$ & 53,115 & 21,424 & 105,428 & 36,827 & - & 33,465 & 25,514 & 97,977 & 373,750 & $74 x$ \\
\hline $\begin{array}{l}\text { TRANSPCRMLICN } \\
\text { ELECTRICITY GEN. } \\
\text { PETROLEOM FRCDOCTS } \\
\text { NATORAL GAS } \\
\text { SYNTBETICS }\end{array}$ & $\begin{array}{r}12,269 \\
- \\
-\end{array}$ & $\begin{array}{l}\overline{-} \\
\overline{-}\end{array}$ & $\begin{array}{l}- \\
\overline{-} \\
-\end{array}$ & $\begin{array}{l}- \\
- \\
-\end{array}$ & $\begin{array}{l}- \\
\overline{-}\end{array}$ & $\begin{array}{l}\overline{-} \\
\overline{-}\end{array}$ & $\begin{array}{r}166,455 \\
- \\
-\end{array}$ & $\begin{array}{r}-61,331 \\
= \\
=\end{array}$ & $\begin{array}{r}117,393 \\
- \\
-\end{array}$ & $23 \%$ \\
\hline $\begin{array}{l}\text { NET FOEL USEL } \\
\text { IN TRANSPCEATION }\end{array}$ & 12,269 & - & - & - & - & - & 166,455 & $-61,331$ & 117,393 & $23 \%$ \\
\hline $\begin{array}{l}\text { TCTAL GROSS FLCRS } \\
\text { LCSSES } \varepsilon \text { OMISSIONS }\end{array}$ & $\begin{array}{r}65,384 \\
4,069\end{array}$ & $\begin{array}{r}21,+24 \\
0\end{array}$ & $\begin{array}{r}105,428 \\
0\end{array}$ & $\begin{array}{r}36.827 \\
-1,452\end{array}$ & $\overline{-}$ & $\begin{array}{r}33,465 \\
-904\end{array}$ & $\begin{array}{r}191,969 \\
2,598\end{array}$ & $\begin{array}{r}97,977 \\
8,129\end{array}$ & $\begin{array}{r}491,143 \\
12,441\end{array}$ & $\begin{array}{r}92 \% \\
2 \%\end{array}$ \\
\hline TCIAL NET DSAGE & 69,453 & $21,+24$ & 105,428 & 35,374 & - & 32,560 & 194,567 & 44,775 & 503,584 & \\
\hline $\begin{array}{l}\text { SOFELY OF ENERGI } \\
\text { FOSSIL FOEI } \\
\text { GYDROELECTEIC } \\
\text { NOCLEAR } \\
\text { GEC. ESOLAR }\end{array}$ & - & $\overline{-}$ & $\begin{array}{l}- \\
\overline{-} \\
-\end{array}$ & - & $\begin{array}{l}\overline{-} \\
\overline{-}\end{array}$ & $\begin{array}{l}- \\
\text { - }\end{array}$ & $\begin{array}{l}\overline{-} \\
\overline{-} \\
\overline{-}\end{array}$ & $\begin{array}{r}- \\
23,997 \\
23,239\end{array}$ & $\begin{array}{r}- \\
2,997 \\
23,239 \\
-\end{array}$ & $\begin{array}{l}11 \% \\
89 \%\end{array}$ \\
\hline TCTAI SUPPIY & - & - & - & - & - & - & - & 26,236 & 26,236 & \\
\hline
\end{tabular}

\begin{tabular}{l} 
XET IM FORTS \\
CF REGION \\
\hline
\end{tabular}
NO IES:
1 TZANSFCRNATICN LOSS POR TRANSPCRMATICN LOSS FOR TRANSPCREATICN LCSS FOR
ELECTRICITY GEN. $\quad=65.68 \%$ RTPOLO PRODCTS $=0.0 \%$ NATIRAI GAS $\quad=0.0 \%$
4 TRANSPCRUATICN LCSS POR 
REGIONAL BDEETY PALANCE STATEHENT

PI3S MED IID SCENARIO

\begin{tabular}{|c|c|c|c|c|c|c|c|c|c|c|}
\hline SECTOE & $\begin{array}{l}\text { DISTILIATE } \\
\text { OII }\end{array}$ & $\begin{array}{l}\text { RESIDOAL } \\
\text { OIL }\end{array}$ & $\begin{array}{l}\text { GASOLINE } \\
\text { (ALI DWI }\end{array}$ & $\begin{array}{c}\text { OT IER } \\
\text { IYD } 30- \\
\text { CA3BJNS } \\
\text { TS IN 10*\$9 }\end{array}$ & $\begin{array}{c}\text { CRUDE } \\
\text { OIL } \\
\text { BTO'S) }\end{array}$ & $\begin{array}{l}\text { NATURAL } \\
\text { GAS }\end{array}$ & $\operatorname{COAI}$ & ELECTRICITY & $\begin{array}{r}\text { SECTOR } \\
\text { TOTAL }\end{array}$ & \\
\hline 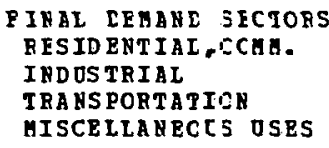 & $\begin{array}{r}30.989 \\
: 8,879 \\
27.954 \\
617\end{array}$ & $\begin{array}{r}2,821 \\
29,036 \\
1,478 \\
323\end{array}$ & $\begin{array}{r}- \\
143,4 \subseteq 1 \\
-\end{array}$ & $\begin{array}{r}17.729 \\
38.838 \\
5.657 \\
25\end{array}$ & $\begin{array}{l}- \\
-\end{array}$ & $\begin{array}{r}9,913 \\
48,012 \\
. \quad 944 \\
559\end{array}$ & $\begin{array}{r}2 \geq 3 \\
39,0 \geq 6 \\
- \\
1\end{array}$ & $\begin{array}{r}69,656 \\
70,273 \\
319\end{array}$ & $\begin{array}{r}131,141 \\
244,063 \\
179,524 \\
1,846\end{array}$ & $\begin{array}{r}17 \% \\
32 \% \\
23 \% \\
0 \%\end{array}$ \\
\hline $\begin{array}{l}\text { TCTAI,FINAL } \\
\text { DEEAND SECTCRS }\end{array}$ & 78,239 & 33,658 & 143,451 & 62,249 & - & 59,430 & $39,2 \in 0$. & 140,248 & 556,574 & $72 \%$ \\
\hline $\begin{array}{l}\text { TRANSPCRMATICN } \\
\text { ELECTRICITY GEN. } \\
\text { PETROLEOA ERCDOCTS } \\
\text { NATORAL GAS } \\
\text { SYNTERTICS }\end{array}$ & $\begin{array}{r}18,071 \\
- \\
-\end{array}$ & $\begin{array}{l}- \\
- \\
-\end{array}$ & $\begin{array}{l}- \\
\overline{-}\end{array}$ & $\begin{array}{l}- \\
-\end{array}$ & $\begin{array}{l}\overline{-} \\
\overline{-}\end{array}$ & $\begin{array}{l}- \\
\overline{-} \\
-\end{array}$ & $\begin{array}{r}284,5=0 \\
= \\
-\end{array}$ & $\begin{array}{r}-103,679 \\
- \\
-\end{array}$ & $\begin{array}{r}198,912 \\
- \\
-\end{array}$ & $26 \%$ \\
\hline $\begin{array}{l}\text { RET FOEL OSEL } \\
\text { IN TRANSOEMATION }\end{array}$ & $: 8,071$ & - & - & - & - & - & 284,520 & $-103,679$ & 198,912 & $26 \pi$ \\
\hline $\begin{array}{l}\text { TCIAL GROSS FLORS } \\
\text { LCSSES } E \text { OMISSIONS }\end{array}$ & $\begin{array}{r}56,309 \\
5,994\end{array}$ & $\begin{array}{r}33,658 \\
0\end{array}$ & $\begin{array}{r}143,451 \\
0\end{array}$ & $\begin{array}{l}52,249 \\
-2,455\end{array}$ & $\overline{-}$ & $\begin{array}{l}59,430 \\
-1,635\end{array}$ & $\begin{array}{r}323,780 \\
4,382\end{array}$ & $\begin{array}{r}140,248 \\
11,636\end{array}$ & $\begin{array}{r}755,486 \\
17,954\end{array}$ & $\begin{array}{r}98 \% \\
2 \%\end{array}$ \\
\hline $\begin{array}{l}\text { SOFELY OP. PYERGY } \\
\text { FOSS IL POEI } \\
\text { HYDROELECTEIC } \\
\text { NOCL BAR } \\
\text { GEO. ESOLAB }\end{array}$ & $\begin{array}{l}- \\
\overline{-}\end{array}$ & $\begin{array}{l}- \\
-\end{array}$ & $\begin{array}{l}- \\
\overline{-} \\
-\end{array}$ & $\begin{array}{l}- \\
- \\
-\end{array}$ & $\begin{array}{l}\text { - } \\
\text { - }\end{array}$ & $\begin{array}{l}- \\
-\end{array}$ & $\begin{array}{l}- \\
-\end{array}$ & $\begin{array}{r}- \\
10,102 \\
84,715 \\
-\end{array}$ & $\begin{array}{r}10,102 \\
84,715 \\
-\end{array}$ & $\begin{array}{l}11 \% \\
89 \%\end{array}$ \\
\hline YCTAL SOPPIY & - & - & - & - & - & - & - & 94,817 & 94,817 & \\
\hline
\end{tabular}

\begin{tabular}{l}
$\begin{array}{l}\text { NET IM FORTS } \\
\text { OF REGION }\end{array}$ \\
\hline \\
\hline
\end{tabular}


REGIONAL ENE FGY BALAHCE STATEMENT

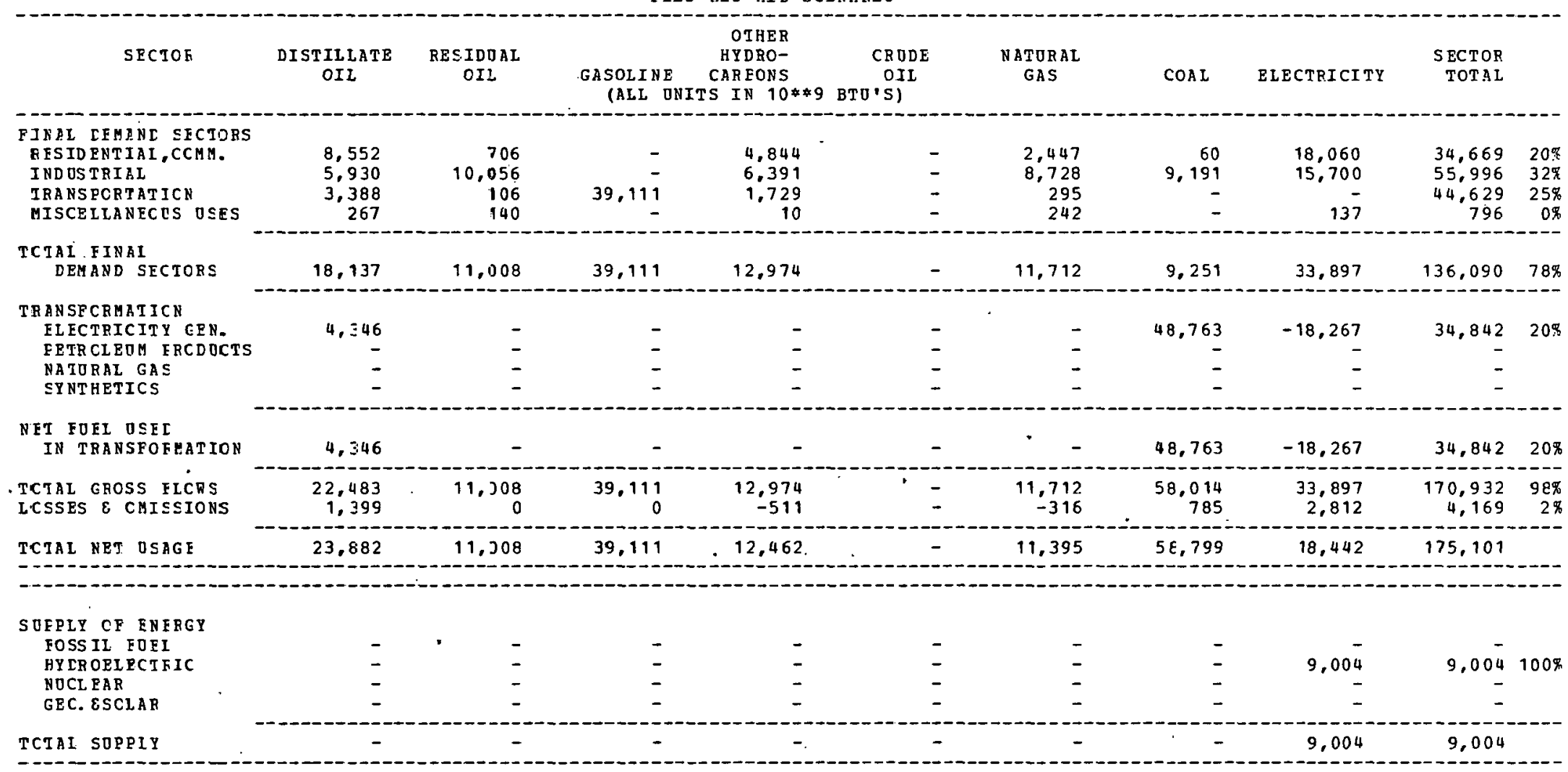

-

\section{NET IM FORTS}

23,882

11,008

39,111

12,462

11,395

$5 \varepsilon, 799$

9,438

166,097

NOTES:

TRANSFCRMATICN LOSS POR
TZANEFCRATICN LOSS PCR
TBANSPORATICN LCSS POR

TZANSPCREATICN LCSS POR

ELECTRICITY GEN:

PETROLE PRODOCTS $=0.0$

NATJRAL GAS 
REGIONAL EUERGY BALANCE STATEMENT

ONAL ELEFGY EALANCE SIA
PIES RID MID SCEMARIO

\begin{tabular}{|c|c|c|c|c|c|c|c|c|c|}
\hline SECTOE & $\begin{array}{l}\text { DISJILLATE } \\
\text { OYI }\end{array}$ & $\begin{array}{l}\text { RESIDOA: } \\
\text { OII }\end{array}$ & $\begin{array}{l}\text { GASOLINE } \\
\text { (ALL O) }\end{array}$ & $\begin{array}{l}\text { OTHER } \\
\text { FYDEO- } \\
\text { CERBDNS } \\
\text { TS IN } 10 * \$ 9\end{array}$ & $\begin{array}{c}\text { CR D D F } \\
\text { OIC } \\
\text { BTU'S) }\end{array}$ & $\begin{array}{l}\text { NRTURAI } \\
\text { GAS }\end{array}$ & COAL & ELECTRICITY & $\begin{aligned} \text { SECTOR } \\
\text { TOTAL }\end{aligned}$ \\
\hline $\begin{array}{l}\text { FINAI LEMANL EECTOES } \\
\text { RESIDENTIAL,CCMA. } \\
\text { INDOSTRIAL } \\
\text { TRANSPORTATICN } \\
\text { MISCELLANECOS OSES }\end{array}$ & $\begin{array}{r}10,287 \\
7,466 \\
10,992 \\
243\end{array}$ & $\begin{array}{r}361 \\
12,615 \\
2.742 \\
12.3\end{array}$ & $\begin{array}{r}- \\
80,805 \\
-\end{array}$ & $\begin{array}{r}9.434 \\
34.008 \\
1.248 \\
9\end{array}$ & - & $\begin{array}{r}6,697 \\
47,782 \\
18 \Xi \\
22 \epsilon\end{array}$ & $\begin{array}{r}144 \\
31,424 \\
- \\
-\end{array}$ & $\begin{array}{r}35,333 \\
51,713 \\
- \\
129\end{array}$ & $\begin{array}{r}62,256 \\
185,008 \\
95,970 \\
735\end{array}$ \\
\hline $\begin{array}{l}\text { TCTAL FINAL } \\
\text { DEMAND SECECRS }\end{array}$ & 28,988 & 15,845 & 80.805 & 44.699 & - & 54,882 & 31,568 & 87,175 & $343,9.69$ \\
\hline $\begin{array}{l}\text { SRANSFCRMATICE } \\
\text { ELECTRICITY GEN. } \\
\text { PETEOLEOM ERCDOCTS } \\
\text { NATORAL GAS } \\
\text { SYNTHETICS }\end{array}$ & $\begin{array}{r}11,191 \\
- \\
-\end{array}$ & $\begin{array}{r}572 \\
- \\
-\end{array}$ & $\begin{array}{l}\overline{-} \\
\overline{-}\end{array}$ & $\begin{array}{l}\bar{z} \\
\overline{-}\end{array}$ & $\begin{array}{l}\overline{-} \\
\overline{-}\end{array}$ & $\begin{array}{l}\overline{-} \\
-\end{array}$ & $\begin{array}{r}110,905 \\
- \\
-\end{array}$ & $\begin{array}{r}-42,251 \\
- \\
-\end{array}$ & $\begin{array}{r}80,417 \\
- \\
- \\
-\end{array}$ \\
\hline $\begin{array}{l}\text { NET FUEL OSEL } \\
\text { IN TRANSEFAATICN }\end{array}$ & 1,191 & 572 & - & - & - & - & 110,905 & $-42,251$ & 80,417 \\
\hline $\begin{array}{l}\text { TCTAL GROSS ELCNS } \\
\text { ICSSES E CMISSIONS }\end{array}$ & $\begin{array}{l}10,17 c \\
2,500\end{array}$ & $1 E, 418$ & $\begin{array}{r}80,805 \\
0\end{array}$ & $\begin{array}{l}44,699 \\
-1,763\end{array}$ & $\overline{-}$ & $\begin{array}{l}54,888 \\
-1,4 \notin 3\end{array}$ & $\begin{array}{r}142,473 \\
1,923\end{array}$ & $\begin{array}{r}87,175 \\
7,233\end{array}$ & $\begin{array}{r}424,386 \\
8,417\end{array}$ \\
\hline TCTAL NET OSAGE & $+2,679$ & $1 E, 418$ & 80,805 & 42,935 & - & 53,404 & 144,401 & 52,157 & 432,803 \\
\hline
\end{tabular}

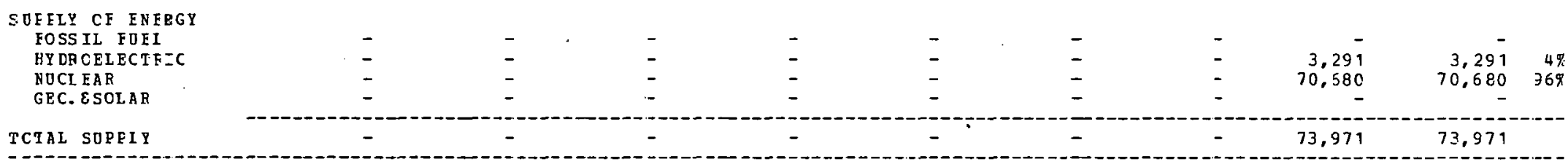

\section{NOTES:}

\begin{tabular}{|c|c|c|c|c|}
\hline & & & & \\
\hline CRMATICN & Loss & PCF & EETROLEUE PRODOCTS & $=0.0$ \\
\hline TRANSECRMAIICN & LCSS & FOF & SATUZAL GAS & $=0.0$ \\
\hline TRANSEORMA & & FOF & SYNTHETICS & 0.0 \\
\hline
\end{tabular}


PEGICNAL ENEFGY EALANCE STATEMENT

\begin{tabular}{|c|c|c|c|c|c|c|c|c|c|c|}
\hline SECICF & $\begin{array}{l}\text { DISTILLATE } \\
\text { OIL }\end{array}$ & $\begin{array}{l}\text { RESIDUAL } \\
\text { OIL }\end{array}$ & $\begin{array}{l}\text { GASOLINE } \\
\text { (ALL O }\end{array}$ & $\begin{array}{c}\text { OTHER } \\
\text { HYDRO- } \\
\text { CARBONS } \\
\text { TS IN } 10 * 9\end{array}$ & $\begin{array}{c}\text { CROLE } \\
\text { OIL } \\
\text { BTU'S) }\end{array}$ & $\begin{array}{l}\text { NATURAL } \\
\text { GAS }\end{array}$ & $\operatorname{COA} \mathbf{L}$ & ELECTRICITY & $\begin{array}{l}\text { SECTOR } \\
\text { TOTAL }\end{array}$ & \\
\hline $\begin{array}{l}\text { FIBDL LEMANL SECTORS } \\
\text { KESIDENTIAL, CCMM. } \\
\text { INDOSTRIAL } \\
\text { TZANSPORTATICN } \\
\text { MISCELLANECCS OSES }\end{array}$ & $\begin{array}{l}8,034 \\
4,621 \\
6,678 \\
652\end{array}$ & $\begin{array}{r}365 \\
7,233 \\
3,169 \\
3<2\end{array}$ & $62,15 \overline{-}$ & $\begin{array}{r}7,288 \\
21,591 \\
1,411 \\
42\end{array}$ & $\begin{array}{l}- \\
\overline{-} \\
-\end{array}$ & $\begin{array}{r}5,765 \\
25,342 \\
209 \\
824\end{array}$ & $\begin{array}{r}111 \\
18,355 \\
- \\
2\end{array}$ & $\begin{array}{r}29,655 \\
29,058 \\
- \\
572\end{array}$ & $\begin{array}{r}51,218 \\
106,200 \\
73,606 \\
2,434\end{array}$ & $\begin{array}{r}17 \% \\
35 \% \\
24 \% \\
1 \%\end{array}$ \\
\hline $\begin{array}{l}\text { TCIAL FINAI } \\
\text { CEMAND SECTCRS }\end{array}$ & 19,985 & $11,0 \& 9$ & 62,159 & 30,332 & - & 32,140 & $18,468^{\circ}$ & 59,285 & 233,458 & $76 \%$ \\
\hline $\begin{array}{l}\text { TRANSFCEMATICN } \\
\text { FLECTEICITY GEN. } \\
\text { PETRCLEOM ERCDOCES } \\
\text { YATORAL GAS } \\
\text { SYNTRETICS }\end{array}$ & $\begin{array}{r}7,668 \\
- \\
-\end{array}$ & $\begin{array}{r}733 \\
- \\
-\end{array}$ & $\begin{array}{l}- \\
\overline{-}\end{array}$ & $\begin{array}{l}- \\
- \\
-\end{array}$ & $\begin{array}{l}- \\
\overline{-}\end{array}$ & $\begin{array}{l}- \\
\overline{-}\end{array}$ & $\begin{array}{r}91,709 \\
- \\
-\end{array}$ & $\begin{array}{r}-34,391 \\
- \\
-\end{array}$ & $\begin{array}{r}65,719 \\
- \\
- \\
-\end{array}$ & $22 g$ \\
\hline $\begin{array}{l}\text { NEI FOEI OSEL } \\
\text { IN TRANSOEMATICD }\end{array}$ & 7,658 & $7 \equiv 3$ & - & - & - & - & $91,7 \mathrm{Cg}$ & $-34,391$ & 65,719 & $22 \pi$ \\
\hline $\begin{array}{l}\text { TCTAL GROSS FLCRS } \\
\text { LCSSES \& CHISSIONS }\end{array}$ & $\begin{array}{r}27,653 \\
1,721\end{array}$ & $\begin{array}{r}11,8 \div 2 \\
0\end{array}$ & $\begin{array}{r}62,159 \\
0\end{array}$ & $\begin{array}{l}30,332 \\
-1,196\end{array}$ & $\overline{-}$ & $\begin{array}{r}32,140 \\
-868\end{array}$ & $\begin{array}{r}110,177 \\
1,491\end{array}$ & $\begin{array}{r}59,285 \\
4,919\end{array}$ & $\begin{array}{r}299,177 \\
6,067\end{array}$ & $\begin{array}{r}98 \% \\
2 \%\end{array}$ \\
\hline TCIAL NET OSAGE & 29,374 & $11,8=2$ & 62,159 & 29,135 & - & 31,271 & 111,668 & 29,813 & 305,244 & \\
\hline $\begin{array}{l}\text { SOEPLY OP ENERGY } \\
\text { FOSS IL FOEI } \\
\text { HY LROELECTEIC } \\
\text { IOCLEAR } \\
\text { GEC. ESOLAR }\end{array}$ & $\begin{array}{l}- \\
-\end{array}$ & $\begin{array}{l}- \\
- \\
-\end{array}$ & $\begin{array}{l}- \\
-\end{array}$ & $\begin{array}{l}- \\
-\end{array}$ & $\begin{array}{l}\overline{-} \\
\overline{-}\end{array}$ & $\begin{array}{l}\text { - } \\
\text { - }\end{array}$ & $\begin{array}{l}- \\
- \\
-\end{array}$ & $\begin{array}{r}8,949 \\
16,340 \\
-\end{array}$ & $\begin{array}{r}8,949 \\
16,340 \\
-\end{array}$ & $\begin{array}{l}35 \% \\
65 \%\end{array}$ \\
\hline TCTAL SUPPIY & - & - & - & - & - & - & - & 25,289 & 25,289 & \\
\hline
\end{tabular}

\section{NET IM ECRTS}

29,374

$11,8=2$

62,159

29,135

$31,271 \quad 111,668$

$4,524 \quad 279,955$

WII

NOTES: TRANSFCRMATICN LOSS FOB TRANSFCRMATICN LOSS POB TRANSPCBHATICN LCSS FO TRANSPORUA:ICN LCSS FO 
REGICNAL EJPEGY EALAMCE STATEMZNT
EIZS

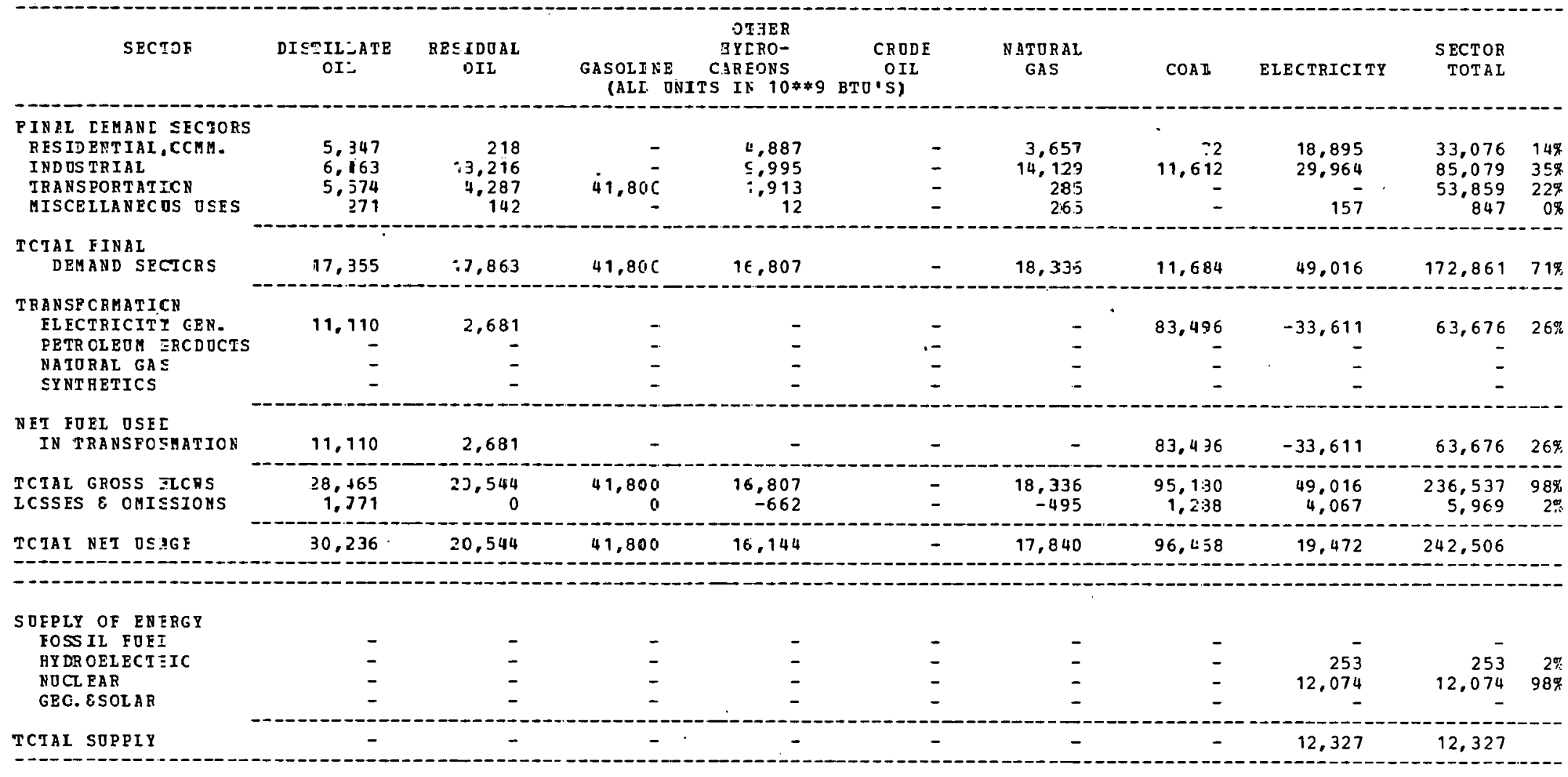

\begin{tabular}{l} 
NET IM PORTS \\
OF REGION \\
\hline
\end{tabular}

\begin{tabular}{|c|c|c|c|c|}
\hline \multicolumn{5}{|c|}{ NOTES: } \\
\hline 1 & TRANSPORAATICN & LOSS FOR & ELEETRICI TY GEN. & $=65.458$ \\
\hline 2 & TRANSFORYAIICN & LaSS FCR & PETBCLEUM PRODOCTS & $:=0.0 \mathrm{~s}$ \\
\hline 3 & TRANSFOR YA II CN & LOSS FCR & NATORAL GAS & $=0.0 \%$ \\
\hline 4 & TRAN $S$ FOR MAIICN & LESS FOR & SYNIHET ICS & $=0.0 \%$ \\
\hline
\end{tabular}


RGgIONAL ENERg baLANCE STATEMENT

PIES BID MID SCENARIO
PALY ENANCE

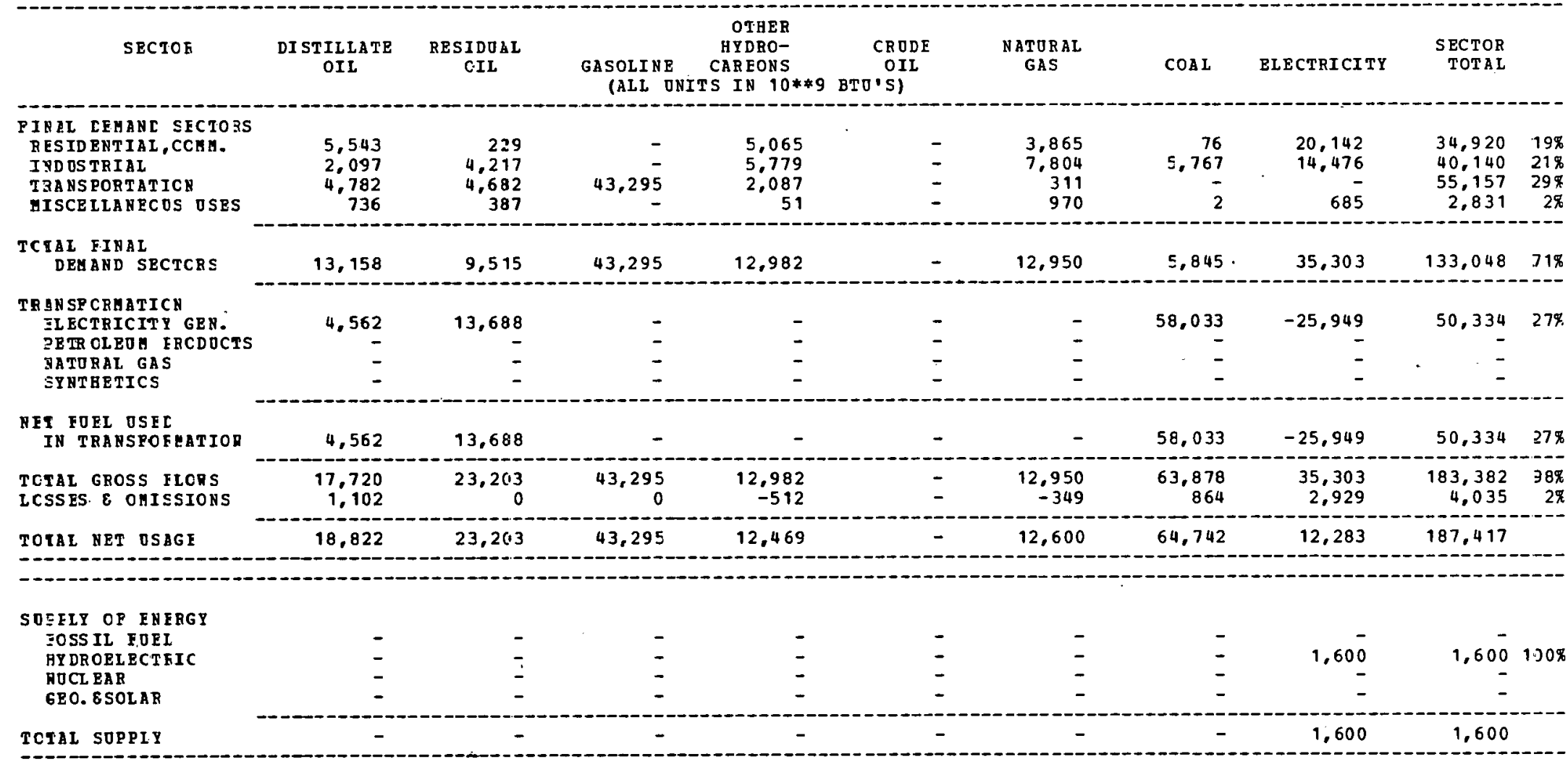

NET IM FORTS

18,822

23,263

43,295

12,469

12,600

64,742

10,683

185,817

MOTES:

TRANSFCRHATICN LOSS FO? TRANSFORAATICN LOSS PCO TRAMSPOBAATICN LCSS FO TRAYSPOBUATICH LOSS POR
ELECTRICITY GRN.

$\quad=65.98 \%$

PETROLECA PRODDCTS $=0.0 \%$

$\begin{array}{ll}\text { SATURAL GAS } & =0.0 \% \\ \text { SYNTHETJCS } & =0.0 \%\end{array}$ 
REGI TYRL ENEFIY EALANCE STATEHENT
P.ES MID :I D SCENARIO

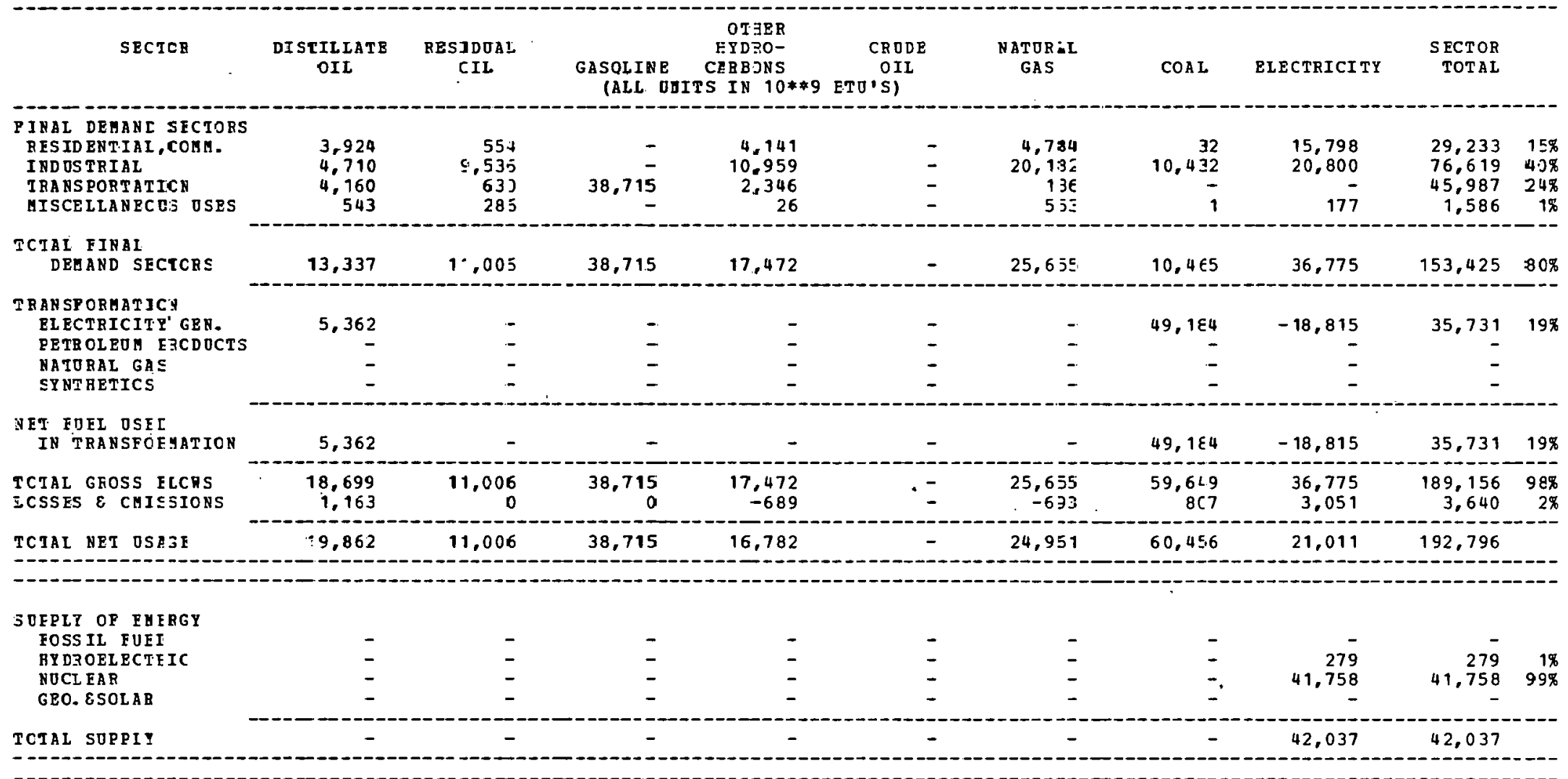

\section{NET IY PORTS}

OF REGION

19,362

11.006

$38,7 i \leq$

$1 \epsilon, 782$

24.9161

60,456

$-21,025$

\section{NoTES}

TRAMSFORAATICN LCSS POB

TRAN SFORAATICN LCSS PO

4 TRANSFORMATICN LCSS FOR SYYPIETICS

ELBCTRICITY GEN.

NATURAL GAS

$=0.0 \%$
$=0.0 \%$ 
REGIONAL ENE EGY PALANCE STATEHENT

PIES HID MID SCENARIO

\begin{tabular}{|c|c|c|c|c|c|c|c|c|c|c|}
\hline SECTOE & $\begin{array}{l}\text { DISTILLATE } \\
\text { OIL }\end{array}$ & $\begin{array}{l}\text { RESIDOAL } \\
\text { OIL }\end{array}$ & $\begin{array}{l}\text { GASOLINE } \\
\text { (ALL O }\end{array}$ & $\begin{array}{c}\text { OTAER } \\
\text { HYDBO- } \\
\text { CAREONS } \\
\text { TS IN } 10 * \$ 9\end{array}$ & $\begin{array}{c}\text { CRODP } \\
\text { OIL } \\
\text { BTO'S) }\end{array}$ & $\begin{array}{l}\text { NATURAL } \\
\text { GAS }\end{array}$ & $\operatorname{COAL}$ & ELECTRICITY & $\begin{array}{r}\text { SECTOR } \\
\text { TOTAL }\end{array}$ & \\
\hline $\begin{array}{l}\text { PINIL LEMANI SFCIORS } \\
\text { RESIDENTIAI, CCAB. } \\
\text { INOOSTRIAL } \\
\text { TRANSPORTATICN } \\
\text { HISCELLAHEOS OSES }\end{array}$ & $\begin{array}{r}3,343 \\
3,379 \\
4,945 \\
435\end{array}$ & $\begin{array}{r}765 \\
8.162 \\
354 \\
228\end{array}$ & $\begin{array}{r}- \\
- \\
36.917 \\
-\end{array}$ & $\begin{array}{r}3,772 \\
7,608 \\
8,252 \\
19\end{array}$ & $\begin{array}{l}- \\
-\end{array}$ & $\begin{array}{r}5,501 \\
11,999 \\
390 \\
422\end{array}$ & $\begin{array}{r}13 \\
5,479 \\
- \\
-\end{array}$ & $\begin{array}{r}15,046 \\
13,138 \\
- \\
173\end{array}$ & $\begin{array}{r}28,440 \\
49,765 \\
50,858 \\
1,277\end{array}$ & $\begin{array}{r}17 \% \\
30 \% \\
30 \% \\
1 \%\end{array}$ \\
\hline $\begin{array}{l}\text { TCTAL FHAAI } \\
\text { JEHAND SECTCRS }\end{array}$ & 12,102 & 9,509 & 36.917 & 19,651 & - & 18,312 & 5,492 & 28,357 & 130,340 & $78 \%$ \\
\hline $\begin{array}{l}\text { TR ASSFCEHATICN } \\
\text { FI ECTRICITY GEN. } \\
\text { PRTROLEU FBODOCTS } \\
\text { NATORAL GAS } \\
\text { ST NTHETICS }\end{array}$ & $\begin{array}{r}3.663 \\
-7.566 \\
- \\
-\end{array}$ & $\begin{array}{r}13,188 \\
-831 \\
- \\
-\end{array}$ & $\begin{array}{r}-8,45 \overline{7} \\
-\end{array}$ & $\begin{array}{r}- \\
-2,501 \\
- \\
-\end{array}$ & $\begin{array}{r}19,246 \\
- \\
-\end{array}$ & $\begin{array}{r}104 \\
-\end{array}$ & $\begin{array}{r}33,860 \\
= \\
=\end{array}$ & $\begin{array}{r}-17,232 \\
- \\
-\end{array}$ & $\begin{array}{r}33,479 \\
-5 \\
- \\
-\end{array}$ & $\begin{array}{r}20 \% \\
0 \%\end{array}$ \\
\hline $\begin{array}{l}\text { BET FOEL USEL } \\
\text { IS TRASSFOEHATION }\end{array}$ & $-3,903$ & 12,356 & -8.457 & $-2,501$ & 19,246 & 104 & 33,860 & $-17,232$ & 33,473 & $20 \%$ \\
\hline $\begin{array}{l}\text { TOTAL GROSS FLCRS } \\
\text { LCSSES \& OHISSIONS }\end{array}$ & $\begin{array}{r}15,765 \\
981\end{array}$ & $\begin{array}{r}22,697 \\
0\end{array}$ & $\begin{array}{r}36,917 \\
0\end{array}$ & $\begin{array}{r}19,651 \\
-775\end{array}$ & $\begin{array}{r}19.246 \\
798\end{array}$ & $\begin{array}{r}18,416 \\
-497\end{array}$ & $\begin{array}{r}39,352 \\
532\end{array}$ & $\begin{array}{r}28,357 \\
2,352\end{array}$ & $\begin{array}{r}163,819 \\
3,393\end{array}$ & $\begin{array}{r}98 \% \\
2 \%\end{array}$ \\
\hline
\end{tabular}

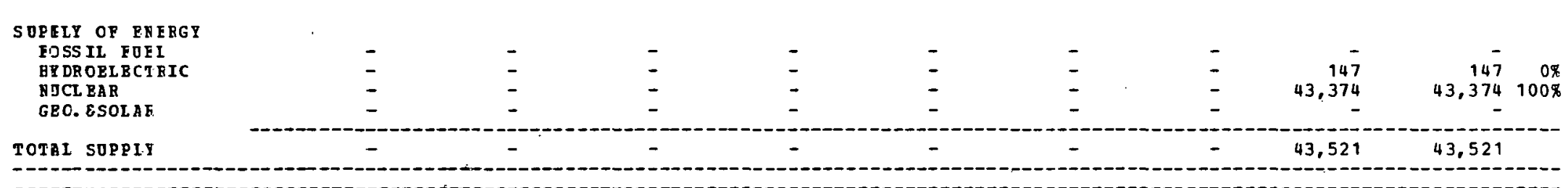

NPT IH EORTS

28,459

16,374

20,044

17,918

39,884

$-30.043$

123,685

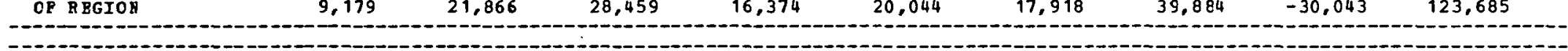

NOTES:

\begin{tabular}{|c|c|c|c|c|}
\hline $\begin{array}{l}\text { TRAN SPCRBATI CN } \\
\text { TBAE SPOB BATI CN } \\
\text { TRABSPORATT CN }\end{array}$ & $\begin{array}{l}\text { LOSS } \\
\text { LOSS } \\
\text { LCSS } \\
\text { LOSS }\end{array}$ & $\begin{array}{l}\text { POR } \\
\text { POR } \\
\text { POR }\end{array}$ & $\begin{array}{l}\text { ELBCTRICITY GEN. } \\
\text { PETROLEOB PBODOCTS } \\
\text { NATURAL GAS } \\
\text { SYTHETICS }\end{array}$ & $\begin{array}{l}=66.02 \% \\
=-0.03 \% \\
=0.0 \% \\
=0.0 \%\end{array}$ \\
\hline
\end{tabular}


REG IONAL EFEE EY BALANCE STATEMENT

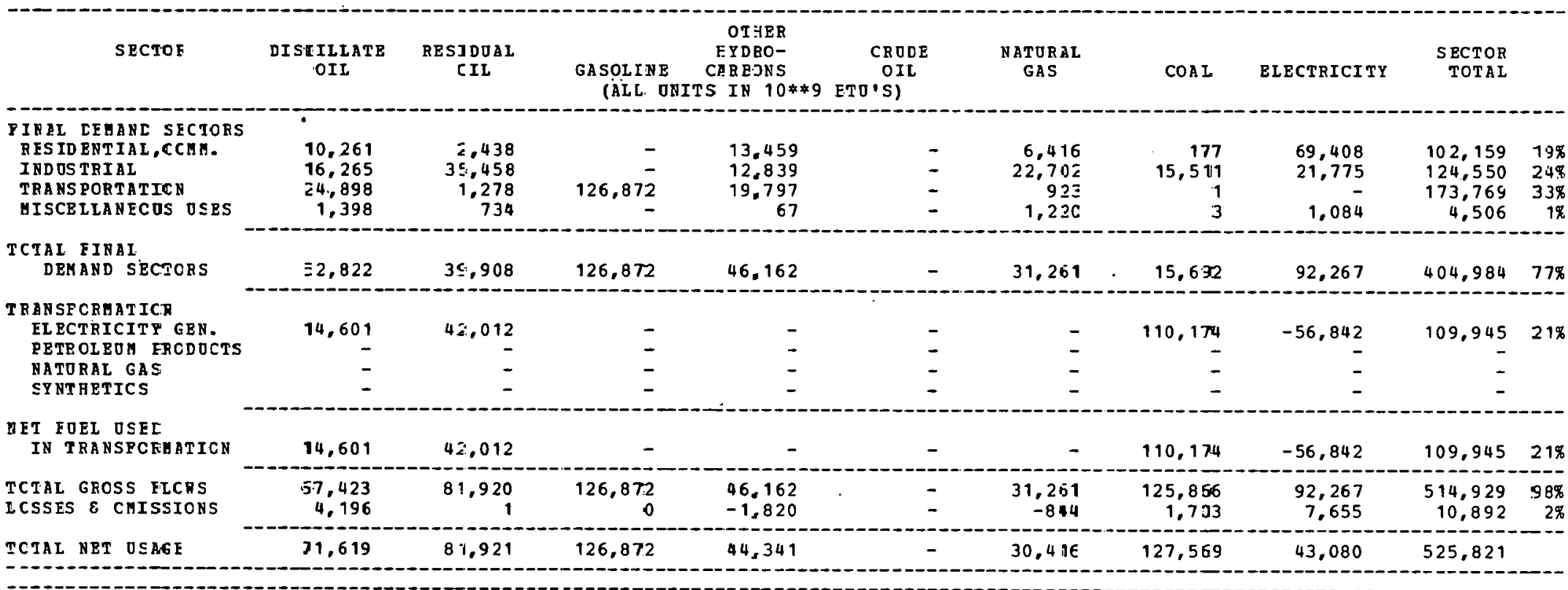

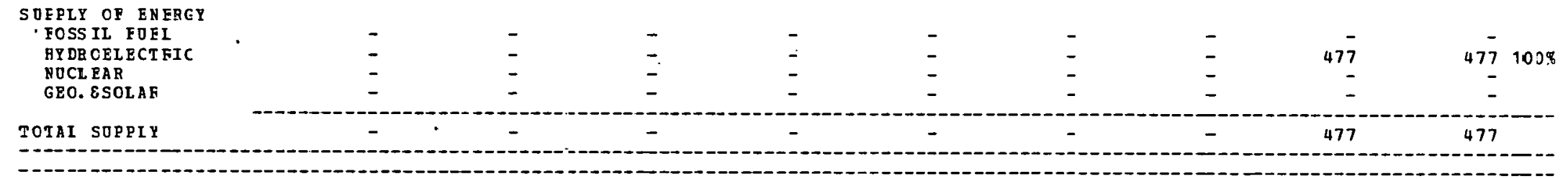

\section{NET IU FORTS}

CP REGION

NOTES :
TRANS?CRUATICN LOSS FOR TRANSPORHATICN LCES PCR TRANEFCRMATICN LOSS POR TRANCFORAATICN LOSS FOR 
REGIONAL ENEFGY EALANCE STATEMENT

IONAL ENEFGY EALANCE STA
PIES MID MID SCENARIO

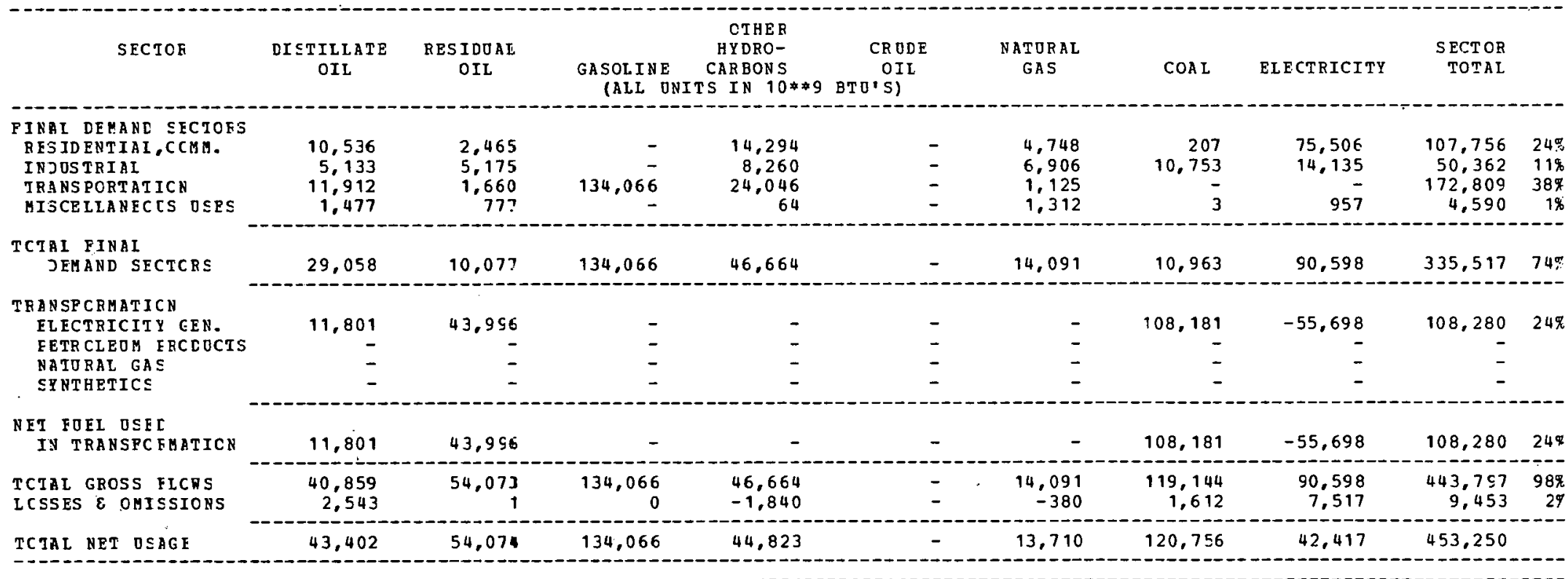

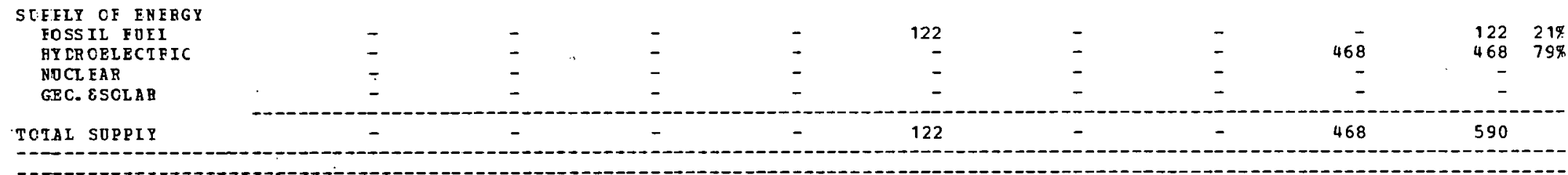

\begin{tabular}{l} 
NET IM FORTS \\
CF REGION \\
\hline
\end{tabular}




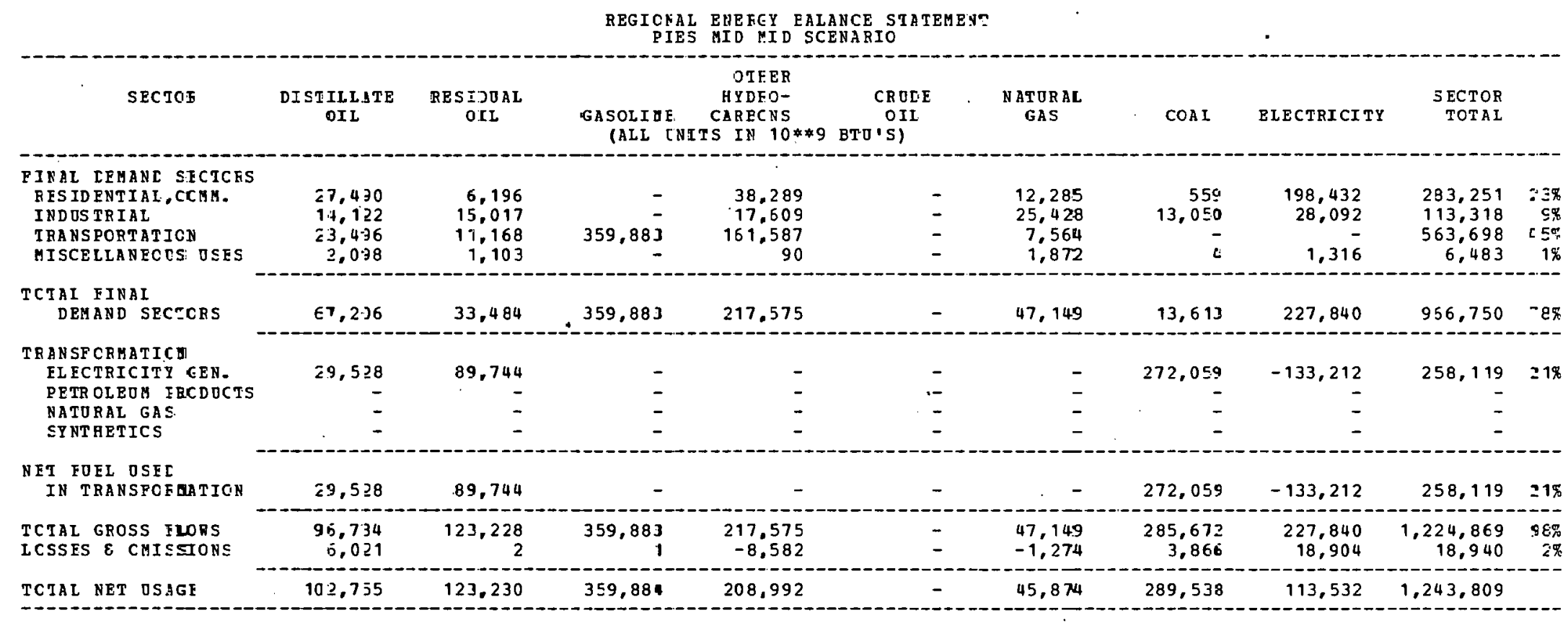

\begin{tabular}{|c|c|c|c|c|c|c|c|c|c|c|}
\hline SOFPLY CP ENIDGY & & & & & & & & & & \\
\hline FOSSIL FOEL & - & - & - & - & 106,397 & 2,107 & - & - & 108,504 & $59 \%$ \\
\hline HY DR OELECTECC & - & - & - & - & - & - & - & 1,177 & 1,177 & $1 \%$ \\
\hline NOCI EAR & - & - & - & - & - & - & - & 74.003 & 74,003 & $40 \%$ \\
\hline GEC. \&SOLAR & - & - & - & - & - & - & - & - & - & \\
\hline TOIAL SUPPIY & - & - & - & - & 106,397 & 2,107 & - & 75,180 & 183,684 & \\
\hline
\end{tabular}

\begin{tabular}{l}
$\begin{array}{l}\text { NET IM PCRTS } \\
\text { CF REGION }\end{array}$ \\
\hline
\end{tabular}


REGIONAL ENEFGY EALANCE STATEMENT
PIES MID MID SCENARIO

\begin{tabular}{|c|c|c|c|c|c|c|c|c|c|c|}
\hline SECTOF & $\begin{array}{l}\text { DISTILLATE } \\
\text { OIL }\end{array}$ & $\begin{array}{l}\text { RES IDUAL } \\
\text { OIL }\end{array}$ & $\begin{array}{l}\text { GASOLIN } \\
\text { IALL }\end{array}$ & $\begin{array}{c}\text { OTHER } \\
\text { HYDRO- } \\
\text { CARBONS } \\
\text { TS IN } 10 * * 9\end{array}$ & $\begin{array}{c}\text { CRODE } \\
\text { OII } \\
\text { BTO'S! }\end{array}$ & $\begin{array}{l}\text { NATURAL } \\
\text { GAS }\end{array}$ & $\operatorname{COAL}$ & ELECTRICITY & $\begin{array}{l}\text { SECTCR } \\
\text { TOTAL }\end{array}$ & \\
\hline $\begin{array}{l}\text { FINAL CEMANE SFCTOES } \\
\text { EFSIDENTIAL,CCMH. } \\
\text { IND OSTRIAL } \\
\text { FRANSPCRTATICN } \\
\text { UISCELIANECCS OSIS }\end{array}$ & $\begin{array}{r}21,620 \\
18,146 \\
24,608 \\
1,634\end{array}$ & $\begin{array}{r}4,669 \\
19,607 \\
2,135 \\
885\end{array}$ & $292.02 \overline{-}$ & $\begin{array}{r}30,998 \\
23,163 \\
30,935 \\
69\end{array}$ & $\begin{array}{l}\overline{-} \\
-\end{array}$ & $\begin{array}{r}9,576 \\
30,876 \\
1,446 \\
1,512\end{array}$ & $\begin{array}{r}452 \\
17,267 \\
1 \\
3\end{array}$ & $\begin{array}{r}157,295 \\
29,938 \\
- \\
994\end{array}$ & $\begin{array}{r}224,610 \\
138,997 \\
351,152 \\
5,147\end{array}$ & $\begin{array}{r}22 \% \\
14 \% \\
359 \\
1 \%\end{array}$ \\
\hline $\begin{array}{l}\text { TCIAI FINAI } \\
\text { DEMAND SECTCRS }\end{array}$ & 66,058 & $\begin{array}{r}27,296 \\
-\end{array}$ & 292,027 & 85,165 & - & $\begin{array}{r}43,410 \\
\end{array}$ & 17,723 & 188,227 & 719,906 & $71 \%$ \\
\hline $\begin{array}{l}\text { TE IN SPCRMATICN } \\
\text { ELECTRICITY GEN. } \\
\text { FETROLEOM ERCEUCTS } \\
\text { NATURAL GAS } \\
\text { SYNTHETICS }\end{array}$ & $\begin{array}{r}24,418 \\
- \\
-\end{array}$ & $\begin{array}{r}97,320 \\
- \\
-\end{array}$ & $\begin{array}{l}- \\
\overline{-}\end{array}$ & $\begin{array}{l}- \\
-\end{array}$ & $\begin{array}{l}- \\
-\end{array}$ & $\begin{array}{l}- \\
-\end{array}$ & $\begin{array}{r}285,595 \\
- \\
-\end{array}$ & $\begin{array}{r}-138,232 \\
- \\
-\end{array}$ & $\begin{array}{r}269,101 \\
- \\
-\end{array}$ & $27 \%$ \\
\hline $\begin{array}{l}\text { NET FOEI OSFC } \\
\text { IN TRANSFCFMATION }\end{array}$ & 24,418 & $97, \equiv 20$ & - & - & - & - & 285,595 & $-138,232$ & 269,101 & $27 \%$ \\
\hline $\begin{array}{l}\text { TCIAL GROSS FLCHS } \\
\text { LCSSES } \& \text { CMISSIONS }\end{array}$ & $\begin{array}{r}90,476 \\
5,631\end{array}$ & $\begin{array}{r}124, \epsilon 16 \\
2\end{array}$ & $\begin{array}{r}292,027 \\
1\end{array}$ & $\begin{array}{r}85,165 \\
-3,359\end{array}$ & - & $\begin{array}{r}43,410 \\
-1,173\end{array}$ & $\begin{array}{r}303,318 \\
4,105\end{array}$ & $\begin{array}{r}188,227 \\
15,617\end{array}$ & $\begin{array}{r}989.007 \\
20,826\end{array}$ & $\begin{array}{r}98 \% \\
2 \%\end{array}$ \\
\hline $\begin{array}{l}\text { SDEELY OF ENERGY } \\
\text { FOSSIL FOEL } \\
\text { HYDROELECTEIC } \\
\text { NOCLEAR } \\
\text { GZC. ESOLAR }\end{array}$ & $\begin{array}{l}- \\
- \\
-\end{array}$ & $\overline{-}$ & $\begin{array}{l}- \\
\overline{-} \\
-\end{array}$ & $\begin{array}{l}- \\
\overline{-} \\
-\end{array}$ & $\begin{array}{r}18,785 \\
5 \\
-\end{array}$ & $\begin{array}{r}463 \\
- \\
-\end{array}$ & $\begin{array}{l}- \\
- \\
-\end{array}$ & $\begin{array}{r}972 \\
14,978 \\
-\end{array}$ & $\begin{array}{r}19,248 \\
972 \\
14,978 \\
-\end{array}$ & $\begin{array}{r}55 \% \\
3 \% \\
43 \%\end{array}$ \\
\hline TCTAL SUPPIY & - & - & - & - & $18,7.85$ & 463 & - & 15,950 & 35,198 & \\
\hline
\end{tabular}

-

\section{NミT IM FCRTS}

CF REGION

96,107

124,618

292,028

81,805

$-18,785$

41,773

307,423

49,662

$974,635^{\circ}$

No TES:

\begin{tabular}{|c|c|c|c|c|}
\hline N & LOSS & FOR & ECTRICITY GEN. & \\
\hline & LOSS & & PRODOCTS & \\
\hline & LCSS & PO & NATURAL GAS & 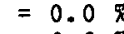 \\
\hline & LCSS & POR & SYNTHEIICS & $=0.0$ \\
\hline
\end{tabular}


REGIONAL ENSFGY EALANCE STATEMENM

EIES MIJ RID SCENARIO

\begin{tabular}{|c|c|c|c|c|c|c|c|c|c|c|}
\hline SECTCIE & $\begin{array}{l}\text { DISTILLATE } \\
\text { OIL }\end{array}$ & $\begin{array}{l}\text { RESJDUAL } \\
\text { CIL }\end{array}$ & $\begin{array}{l}\text { GaSOLIEE } \\
\text { (ALL UNIT }\end{array}$ & $\begin{array}{l}\text { OIHER } \\
\text { HTDKO- } \\
\text { CARBCNS } \\
S=N \quad 10 * \$ 9\end{array}$ & $\begin{array}{c}\text { CRODE } \\
\text { OIL } \\
\text { BEU }\end{array}$ & $\begin{array}{l}\text { NATURAL } \\
\text { GAS }\end{array}$ & $\operatorname{COAL}$ & ELECTRICITY & $\begin{array}{l}\text { SECTOR } \\
\text { TOTAL }\end{array}$ & \\
\hline $\begin{array}{l}\text { FINAL LEMANL CECTOFS } \\
\text { RESIDENTIAL, CCMM. } \\
\text { INDOSTRIAL } \\
\text { IRANSPORTATICN } \\
\text { MISCE LIANECOS OSES }\end{array}$ & $\begin{array}{r}3,51) 4 \\
4,3.56 \\
3,436 \\
7.49\end{array}$ & $\begin{array}{r}831 \\
\varepsilon .414 \\
511 \\
394\end{array}$ & $44,08 \bar{z}$ & $\begin{array}{r}4,704 \\
3,959 \\
7.395 \\
31\end{array}$ & $\begin{array}{l}- \\
-\end{array}$ & $\begin{array}{r}1,589 \\
5,392 \\
345 \\
673\end{array}$ & $\begin{array}{r}67 \\
3,361 \\
- \\
1\end{array}$ & $\begin{array}{r}25,002 \\
5,776 \\
- \\
436\end{array}$ & $\begin{array}{r}35,697 \\
31,258 \\
55,830 \\
2,284\end{array}$ & $\begin{array}{l}20 \% \\
17 \% \\
\equiv 1 \% \\
1 \%\end{array}$ \\
\hline $\begin{array}{l}\text { TCIAI FINAI } \\
\text { CEMAND SECTERS }\end{array}$ & 112,1105 & $1 C .150$ & 44,082 & 16,089 & - & 8,003 & 3,425 & 31,214 & 125,069 & E9\% \\
\hline $\begin{array}{l}\text { THANSPCEMATICS } \\
\text { ELECTRICITY EEN. } \\
\text { FETROLEOM EEEDOCTS } \\
\text { NATORAL GAS } \\
\text { SYNTHETICS }\end{array}$ & $\begin{array}{r}4,022 \\
-3,317 \\
-\end{array}$ & $\begin{array}{r}16.637 \\
-364 \\
- \\
-\end{array}$ & $\begin{array}{r}-3.70 \varepsilon \\
- \\
-\end{array}$ & $\begin{array}{r}- \\
-1,096 \\
-\end{array}$ & $\begin{array}{r}- \\
8,438 \\
-\end{array}$ & $\begin{array}{r}4 \overline{5} \\
- \\
-\end{array}$ & $\begin{array}{r}57,474 \\
- \\
-\end{array}$ & $\begin{array}{r}-26,504 \\
- \\
-\end{array}$ & $\begin{array}{r}51,629 \\
-2 \\
-\end{array}$ & $\begin{array}{l}-99 \% \\
0 \%\end{array}$ \\
\hline $\begin{array}{l}\text { NET FDEL OSET } \\
\text { IN TBANSFOFPATICN }\end{array}$ & 704 & 16.272 & $-3,70 \varepsilon$ & $-1,096$ & 8,438 & 45 & 57,474 & $-26,504$ & 51,626 & $29 \%$ \\
\hline $\begin{array}{l}\text { TCIAL GROSS FICRS } \\
\text { LESSES } \& \text { CMISSIONS }\end{array}$ & $\begin{array}{r}16.127 \\
4,003\end{array}$ & $\begin{array}{r}26,787 \\
0\end{array}$ & $\begin{array}{r}44.08 \pi \\
G\end{array}$ & $\begin{array}{r}16.089 \\
-634\end{array}$ & $\begin{array}{r}8,438 \\
350\end{array}$ & $\begin{array}{r}8,045 \\
-217\end{array}$ & $\begin{array}{r}60,903 \\
824\end{array}$ & $\begin{array}{r}31,214 \\
2,589\end{array}$ & $\begin{array}{r}17 \epsilon, \epsilon \mathcal{E} \varepsilon \\
3,916\end{array}$ & $\begin{aligned} \subseteq 8 \% \\
2 \%\end{aligned}$ \\
\hline TETAL NET OSAGE & 13,813 & 26,423 & 40,373 & 14,357 & 8,788 & 3,828 & 61,727 & 7,299 & 180,612 & \\
\hline
\end{tabular}

\begin{tabular}{|c|c|c|c|c|c|c|c|c|c|}
\hline $\begin{array}{l}\text { SDEFLY OF FNEFGY } \\
\text { FCSS IL FOEI }\end{array}$ & - & - & - & - & - & - & - & - & - \\
\hline HYDROELECIEIE & - & - & - & - & - & - & - & 494 & $4941 \mathrm{COD}$ \\
\hline NUCL EAR & - & - & - & - & - & - & - & - & - \\
\hline GEC. \&SCLAR & - & - & - & - & - & - & - & - & - \\
\hline TCTAI SUPPIY & - & - & - & - & - & - & - & 494 & 494 \\
\hline
\end{tabular}

NET IM ECETS

13,813

26,423

40,373

$-4,357$

8,788

$7,92: 3$

61,727

6,805

180,118

NOTES:

\begin{tabular}{|c|c|c|c|c|}
\hline TRANSFCRMATICN & & & EEECTEICIIY GEN. & $=66 \cdot(8 \%$ \\
\hline CRMATIC & LOSE & $\mathbf{F C R}$ & PZTFCLEEM PRODDCTS & $=-0 . c 3 \%$ \\
\hline TRANSFORHA I ICN & LCSE & FCR & NATORIL GAS & $=0.0 \%$ \\
\hline
\end{tabular}

4 TRANSFCRHAIICN LOSS FCR

INT HET IC 3 
REGIONAL ENEKGY EALANCE STATEHENT

PIES MID MID SCENARIO

\begin{tabular}{|c|c|c|c|c|c|c|c|c|c|c|}
\hline SECTOE & $\begin{array}{l}\text { DISTILLATE } \\
\text { OIL }\end{array}$ & $\begin{array}{l}\text { RESIDUAL } \\
\text { OIL }\end{array}$ & $\begin{array}{l}\text { GASOLIN } \\
\text { (ALL }\end{array}$ & $\begin{array}{c}\text { OTAER } \\
\text { AYDRO- } \\
\text { CARBONS } \\
\text { S IN } 10 * 9\end{array}$ & $\begin{array}{c}\text { CROLE } \\
\text { OII } \\
\text { BTO'SI }\end{array}$ & $\begin{array}{l}\text { NATURAL } \\
\text { GAS }\end{array}$ & $\operatorname{COAI}$ & BLECTRICITY & $\begin{array}{r}\text { SECTOR } \\
\text { TOTAL }\end{array}$ & \\
\hline $\begin{array}{l}\text { PIEAL CEHANE SECTOFS } \\
\text { RESIDENTIAE, CCMA. } \\
\text { IKDOSTRIAL } \\
\text { TEANSPORTATICN } \\
\text { IISCELLANECS OSES }\end{array}$ & $\begin{array}{l}2,622 \\
6,747 \\
3,306 \\
717\end{array}$ & $\begin{array}{r}469 \\
12,459 \\
1,237 \\
377\end{array}$ & 40,446 & $\begin{array}{r}4,273 \\
28,816 \\
13,858 \\
41\end{array}$ & $\begin{array}{l}- \\
\overline{-}\end{array}$ & $\begin{array}{r}1,570 \\
35,918 \\
675 \\
590\end{array}$ & $\begin{array}{r}57 \\
7.915 \\
\overline{2}\end{array}$ & $\begin{array}{r}20.208 \\
20.758 \\
- \\
784\end{array}$ & $\begin{array}{r}29,199 \\
112,613 \\
59,522 \\
2,511\end{array}$ & $\begin{array}{r}12 \% \\
45 \% \\
24 \% \\
1 \%\end{array}$ \\
\hline $\begin{array}{l}\text { TCIAI FINAI } \\
\text { DEMAND SECTCRS }\end{array}$ & 13,392 & 14,542 & 40,446 & 46,988 & - & 38,753 & 7.974 & 41,750 & 203,845 & $81 \%$ \\
\hline $\begin{array}{l}\text { TRINSPCRHATICN } \\
\text { ELECTRICITY GEN. } \\
\text { ERTROLEOA ERCDOCTS } \\
\text { FATORAL GAS } \\
\text { SYNTEETICS }\end{array}$ & $\begin{array}{r}5,355 \\
- \\
-\end{array}$ & $\begin{array}{l}- \\
- \\
-\end{array}$ & $\begin{array}{l}- \\
\overline{-}\end{array}$ & $\begin{array}{l}- \\
- \\
-\end{array}$ & $\begin{array}{l}- \\
-\end{array}$ & $\begin{array}{l}- \\
- \\
-\end{array}$ & $\begin{array}{r}61,872 \\
- \\
-\end{array}$ & $\begin{array}{r}-23,115 \\
- \\
-\end{array}$ & $\begin{array}{r}44,112 \\
- \\
=\end{array}$ & $18 \%$ \\
\hline $\begin{array}{l}\text { NEI FOEL OSEL } \\
\text { IN TRANSPOEMATION }\end{array}$ & 5,355 & - & - & - & - & - & 61,872 & $-23,115$ & 44,112 & $18 \%$ \\
\hline $\begin{array}{l}\text { TCJAL GROSS FLCHS } \\
\text { LCSSES E OHISSIONS }\end{array}$ & $\begin{array}{r}18,747 \\
1,166\end{array}$ & 14,542 & $\begin{array}{r}40,446 \\
0\end{array}$ & $\begin{array}{l}46,988 \\
-1,853\end{array}$ & - & $\begin{array}{l}38,753 \\
-1,047\end{array}$ & $\begin{array}{r}69,846 \\
945\end{array}$ & $\begin{array}{r}41,750 \\
3,464\end{array}$ & $\begin{array}{r}247,957 \\
2,676\end{array}$ & $\begin{array}{r}99 \% \\
17 \%\end{array}$ \\
\hline TCIAL NET OSAGE & 19,913 & 14,542 & 40,446 & 45,134 & - & 37,705 & 70,791 & 22,099 & 250,633 & \\
\hline
\end{tabular}

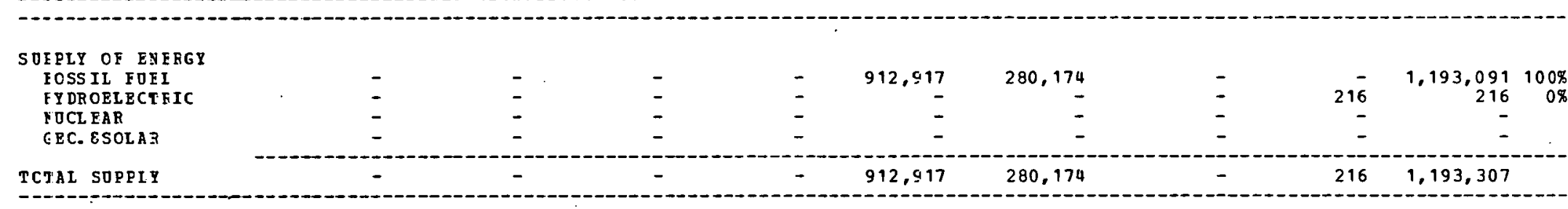

PPPI

\begin{tabular}{|c|c|c|c|c|c|}
\hline \multicolumn{2}{|c|}{$\begin{array}{l}\text { NET IM FORTS } \\
\text { OF REGION }\end{array}$} & 19,913 & 14,542 & \multicolumn{2}{|c|}{40,446} \\
\hline \multicolumn{6}{|c|}{ NOTES: } \\
\hline 1 & TRANSFCRAAIICN & LOSS FOR & EL ECTRICIT & GEN. & $=65.62 \%$ \\
\hline 2 & TRANSFCBMAIICN & LJSS FOR & PETROLEOM & RODOCTS & \\
\hline 3 & TRAHSPCRHAJI CN & LESS POR & NATURAL GA & & $=0.0$ \\
\hline 4 & TRANSPORHAII CN & LJSS FOR & SYNTHETICS & & $=0.0$ \\
\hline
\end{tabular}


RBGIONAI ENEFGI EALANCE STATEMENT

PIZS BIL MID SCENARIO
PII

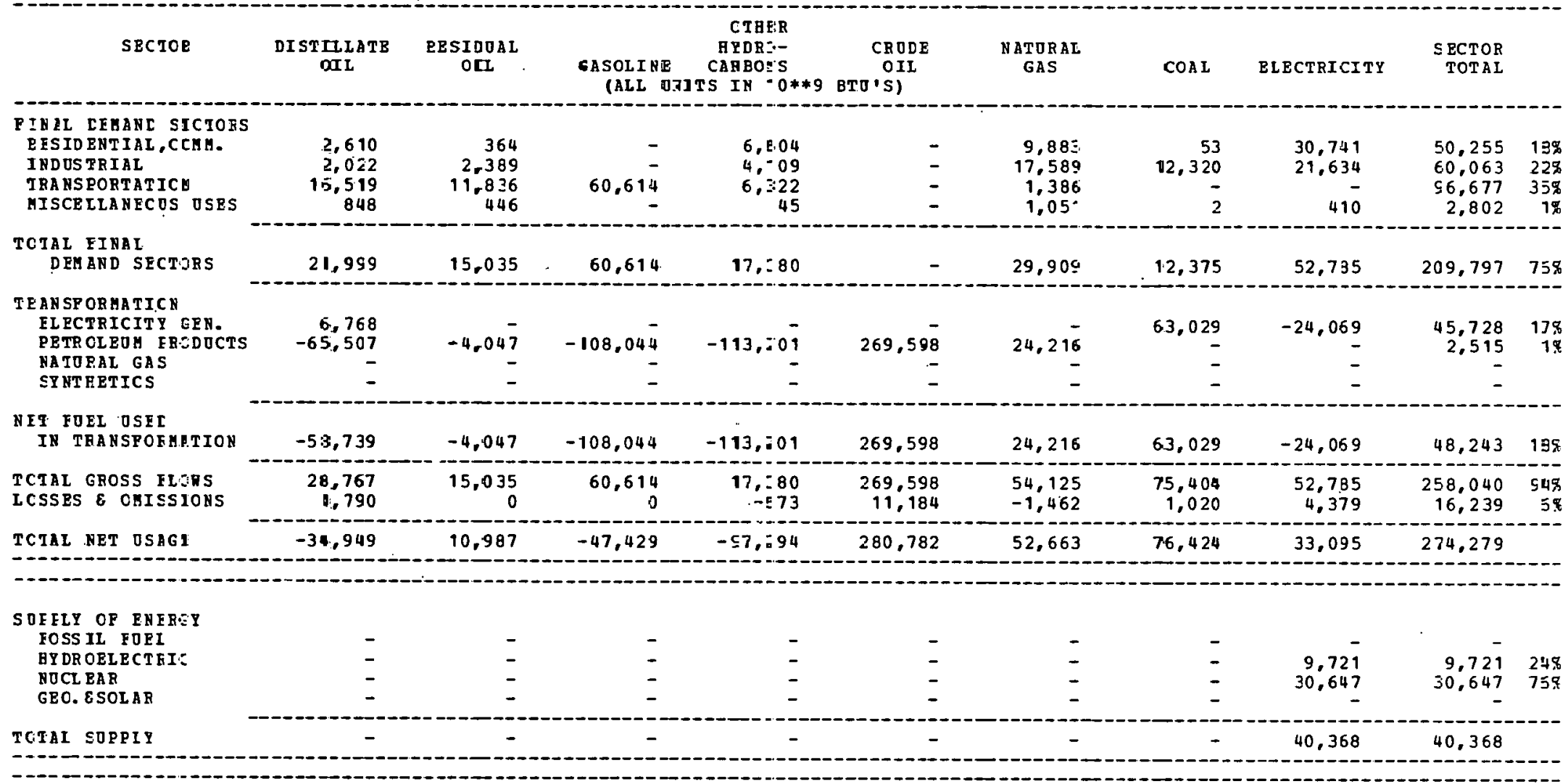

NET IM PORTS

$-34,949$

10,987

$-47,429$

$-\$ 7,: 94$

280,782

52,663

76.424

$-7,272$

$2 \Xi 3,911$

\section{NOJES:}

1 TRANSECRHATICN LOSS POR TRANSPCRAATICN LCSS PCR TRANSPCRAATI CN LOSS POB TRANSPCRMATICN LOSS POB 
REGIONAL ENEFGY EALANCE STATEMENT

PIES MID MID SCENARIO

\begin{tabular}{|c|c|c|c|c|c|c|c|c|c|c|}
\hline SECTCE & $\begin{array}{l}\text { DISTILLATE } \\
\text { OIL }\end{array}$ & $\begin{array}{l}\text { RES IJ ס AL } \\
\text { OIL }\end{array}$ & $\begin{array}{l}\text { GA SOL IN } \\
\text { (ALL }\end{array}$ & $\begin{array}{c}\text { OTHER } \\
\text { HYDRO- } \\
\text { CARBONS } \\
\text { TS IN 10**9 }\end{array}$ & $\begin{array}{c}\text { CRODE } \\
\text { OIL } \\
\text { BTO.S) }\end{array}$ & $\begin{array}{l}\text { NATORAL } \\
\text { GAS }\end{array}$ & COAI & ELECTRICITY & $\begin{array}{l}\text { SECTOR } \\
\text { TOTAL }\end{array}$ & \\
\hline $\begin{array}{l}\text { PINAL CEYAND SECTOKS } \\
\text { RESIDENTIAI, CCGM. } \\
\text { INDOSTRIAL } \\
\text { TRANSPORTATICN } \\
\text { HISCELLANECOS OSES }\end{array}$ & $\begin{array}{r}3,996 \\
3,379 \\
4,678 \\
445\end{array}$ & $\begin{array}{r}938 \\
5.076 \\
30 \\
234\end{array}$ & $44,85 \overline{-}$ & $\begin{array}{r}4,565 \\
4.253 \\
3,479 \\
19\end{array}$ & - & $\begin{array}{r}6,747 \\
10,983 \\
159 \\
423\end{array}$ & $\begin{array}{r}13 \\
6.272 \\
\overline{1}\end{array}$ & $\begin{array}{r}18,145 \\
14,244 \\
- \\
192\end{array}$ & $\begin{array}{r}34,404 \\
44,207 \\
53,198 \\
1,314\end{array}$ & $\begin{array}{l}21 \% \\
26 \% \\
32 \% \\
1 \%\end{array}$ \\
\hline $\begin{array}{l}\text { TCTAL EINAI } \\
\text { DEMAND SECTCRS }\end{array}$ & 12,498 & 6,278 & 44,852 & 12,316 & - & 18,312 & 6,286 & 32,581 & 133,123 & $79 \%$ \\
\hline $\begin{array}{l}\text { TEANSFCRAATICN } \\
\text { ELECTRICITY GEN. } \\
\text { FETROLEUM FECDOCTS } \\
\text { NATORAL GAS } \\
\text { SYNTHETICS }\end{array}$ & $\begin{array}{r}4,202 \\
- \\
-\end{array}$ & $\begin{array}{l}\overline{-} \\
\overline{-}\end{array}$ & $\begin{array}{l}\overline{-} \\
\overline{-}\end{array}$ & $\begin{array}{l}- \\
-\end{array}$ & $\begin{array}{l}- \\
- \\
-\end{array}$ & $\begin{array}{l}- \\
-\end{array}$ & $\begin{array}{r}43,248 \\
= \\
-\end{array}$ & $\begin{array}{r}-16,340 \\
- \\
-\end{array}$ & $\begin{array}{r}31,110 \\
- \\
=\end{array}$ & $19 \pi$ \\
\hline $\begin{array}{l}\text { NET FOEL DSEL } \\
\text { IN TRANSFCFBATION }\end{array}$ & 4,202 & - & - & - & - & - & 43,248 & $-16,340$ & 31,110 & $19 \%$ \\
\hline $\begin{array}{l}\text { TCTAL GROSS FLCFS } \\
\text { ICSSES \& OMISSIOHS }\end{array}$ & $\begin{array}{r}16,700 \\
1,039\end{array}$ & $\begin{array}{r}6,278 \\
0\end{array}$ & $\begin{array}{r}44,852 \\
0\end{array}$ & $\begin{array}{r}12,316 \\
-485\end{array}$ & $\overline{-}$ & $\begin{array}{r}18,312 \\
-494\end{array}$ & $\begin{array}{r}49,534 \\
670\end{array}$ & $\begin{array}{r}32,581 \\
2,703\end{array}$ & $\begin{array}{r}164,233 \\
3,433\end{array}$ & $\begin{aligned} 98 \% \\
2 \%\end{aligned}$ \\
\hline TCTAL NET OSAEE & 17,739 & $\epsilon, 278$ & 44,852 & 11,830 & - & 17,817 & 50,204 & 18,944 & 167,666 & \\
\hline
\end{tabular}

\begin{tabular}{|c|c|c|c|c|c|c|c|c|c|}
\hline $\begin{array}{l}\text { SUEFLY OF ENFRG: } \\
\text { FOSS IL FOEI }\end{array}$ & - & - & - & - & - & - & - & - & - \\
\hline HY DR OEL BCTFIC & - & - & - & - & - & - & - & 1,947 & $1,947 \quad 100 \%$ \\
\hline NOCL EAR & - & - & - & - & - & - & - & - & - \\
\hline GEC. ESOLAR & - & - & - & - & - & - & - & - & - \\
\hline TCIAL SOPEIY & - & - & - & - & - & - & - & 1,947 & 1,947 \\
\hline
\end{tabular}

NET IM FORTS

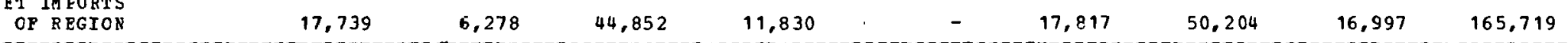

-

NOTES:
1 TRANSFCRMATICN LOSS POR TRANSPCRMATICN LOSS POR TRANSFCRMATICN ICSS POR TRANSFCRAAIICN LCSS POR
ELECTRICITY GEN.
$=65.56 \%$
PETR JEOA PRODOCTS $=0.0 \%$
SYNTIETICS
$=0.0 \%$
$=0.0 \%$ 
3EGIONAL EHEFGY EALANCE STATEMENT
PIES MID MID SCENARIO

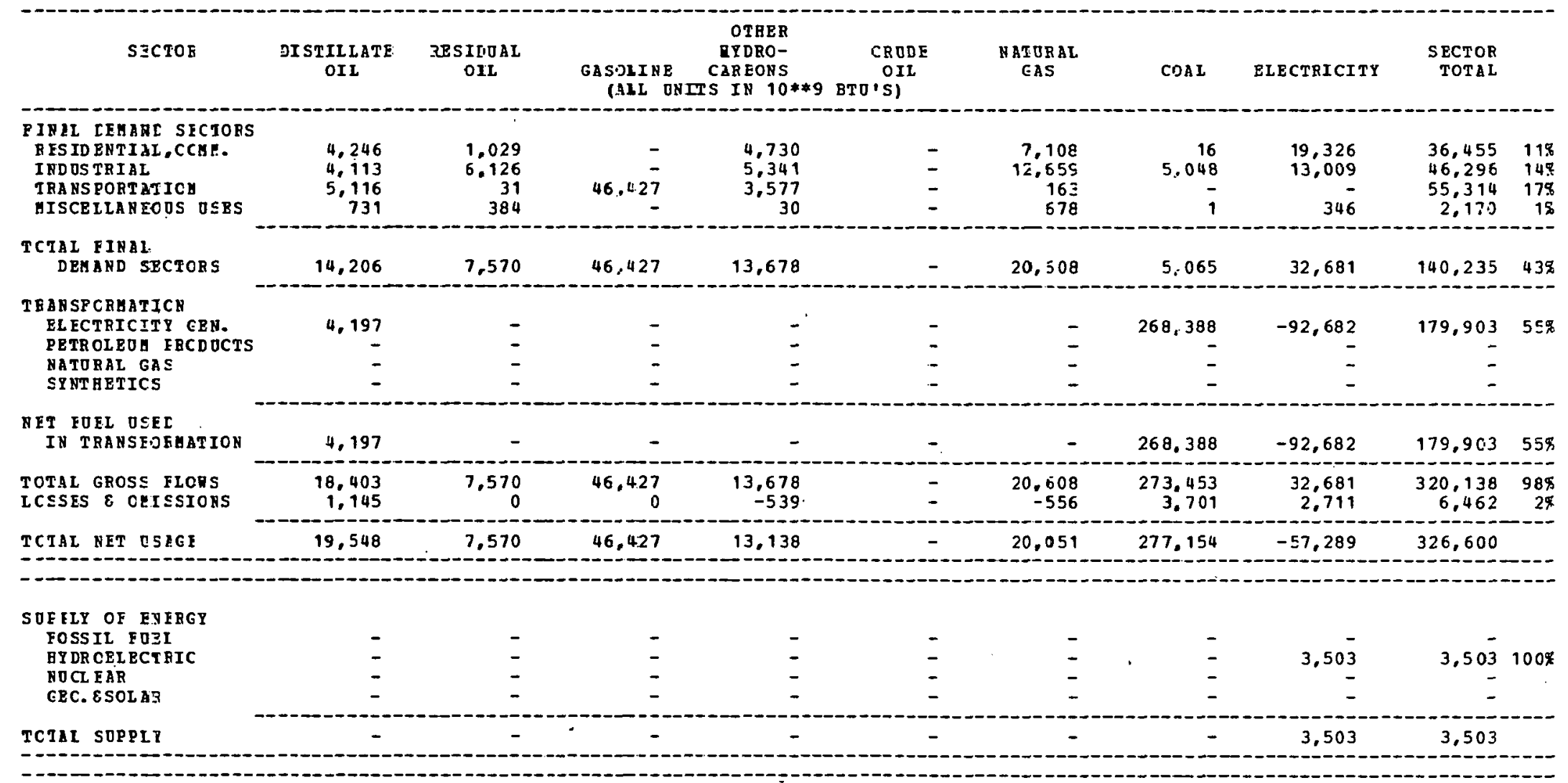

\section{NET IM FORTS}

CF REGION:

19,548

7.570

46,427

13,138

$20 . C 51$

277,154

$-60,792$

323,097

(1)

NoTES:

1 TRAJSPCRAATICN LCSS POR

TRAJSPCRAATICN LCSS POR ELECTRECITY GBN.

TRADSFAB LOS FOR

TRABSPOBAATION LOSS POR

$\begin{array}{ll} & =66 . C 0 \% \\ \text { ITY GEN. } & =0 . \mathrm{C} \%\end{array}$

SYNTHEPICS

$=0.6 \%$
$=0.6 \%$ 
REGICNAL ENEFGY EALANCE STATEMENT

PIES MID MID SCENARID

\begin{tabular}{|c|c|c|c|c|c|c|c|c|c|c|}
\hline SECTOF & $\begin{array}{l}\text { DISTILLATE } \\
\text { OII }\end{array}$ & $\begin{array}{l}\text { RES IDUAL } \\
\text { OEI }\end{array}$ & $\begin{array}{l}\text { GASOLINE } \\
\text { (ALL O }\end{array}$ & $\begin{array}{c}\text { OTHER } \\
\text { HYDRO- } \\
\text { CARBONS } \\
\text { TS IN } 10 * * 9\end{array}$ & $\begin{array}{c}\text { CRODE } \\
\text { DIL } \\
\text { BTO'S) }\end{array}$ & $\begin{array}{l}\text { NATORAL } \\
\text { GAS }\end{array}$ & COAL & ELECTRICITY & $\begin{array}{l}\text { SECTCR } \\
\text { TOTAL }\end{array}$ & \\
\hline $\begin{array}{l}\text { IN I DEUAND SFCICES } \\
\text { FESIDEYTIAI, CCMY: } \\
\text { INDOSTRIAL } \\
\text { TRANSPORTATICN } \\
\text { MISCELLANEOS OSES }\end{array}$ & $\begin{array}{r}2,693 \\
1,848 \\
4,125 \\
704\end{array}$ & $\begin{array}{r}543 \\
3,325 \\
199 \\
370\end{array}$ & 37,904 & $\begin{array}{r}3,929 \\
6,701 \\
1,099 \\
34\end{array}$ & $\begin{array}{l}- \\
\overline{-}\end{array}$ & $\begin{array}{r}5,573 \\
14,157 \\
67 \\
727\end{array}$ & $\begin{array}{r}18 \\
10,311 \\
- \\
1\end{array}$ & $\begin{array}{r}15,886 \\
14,646 \\
= \\
214\end{array}$ & $\begin{array}{r}28,642 \\
50,988 \\
43,394 \\
2,050\end{array}$ & $\begin{array}{r}19 \% \\
33 \% \\
28 \% \\
1 \%\end{array}$ \\
\hline $\begin{array}{l}\text { TCTAI FINAL } \\
\text { DEMAND SECTCRS }\end{array}$ & 9,370 & 4.437 & 37,904 & 11,763 & - & 20,524 & 10,330 & 30,746 & 125,074 & $81 \%$ \\
\hline $\begin{array}{l}\text { TEANSPCRMATICN } \\
\text { ELFCTRICITY GEN. } \\
\text { FETROLEOM FECDOCTS } \\
\text { NATORAL GAS } \\
\text { SYNTHETICS }\end{array}$ & $\begin{array}{r}3,942 \\
= \\
-\end{array}$ & $\begin{array}{l}\bar{z} \\
\bar{z}\end{array}$ & $\begin{array}{l}\overline{-} \\
\overline{-}\end{array}$ & $\begin{array}{l}\overline{-} \\
\overline{-}\end{array}$ & $\begin{array}{l}\overline{-} \\
\overline{-}\end{array}$ & $\begin{array}{l}\overline{-} \\
\overline{-}\end{array}$ & $\begin{array}{r}36,713 \\
= \\
-\end{array}$ & $\begin{array}{r}-14,020 \\
- \\
- \\
-\end{array}$ & $\begin{array}{r}26,635 \\
- \\
-\end{array}$ & 17\%: \\
\hline $\begin{array}{l}\text { NET FOEL OSEL } \\
\text { IN TRANSOFHATICN }\end{array}$ & 3,942 & - & - & - & - & - & 36,713 & $-14,020$ & 26,635 & $17 \%$ \\
\hline $\begin{array}{l}\text { TCTAL CROSS FICRS } \\
\text { ICSSES } \& \text { CMISSIONS }\end{array}$ & $\begin{array}{r}13,312 \\
828\end{array}$ & $\begin{array}{r}4.437 \\
0\end{array}$ & $\begin{array}{r}37,904 \\
0\end{array}$ & $\begin{array}{r}11,7 \in 3 \\
-463\end{array}$ & $\begin{array}{l}- \\
-\end{array}$ & $\begin{array}{r}20,524 \\
-554\end{array}$ & $\begin{array}{r}47.043 \\
636\end{array}$ & $\begin{array}{r}30,746 \\
2,551\end{array}$ & $\begin{array}{r}151,709 \\
2,998\end{array}$ & $\begin{array}{r}9 \varepsilon \% \\
2 \%\end{array}$ \\
\hline TCTAL NET OSAGE & 14,140 & $4.4 \geqq 7$ & 37,904 & 11,299 & - & $19,96 \mathrm{c}$ & 47,679 & 19,277 & 154,707 & \\
\hline $\begin{array}{l}\text { SOFELY CF ENEFGY } \\
\text { FOSS IL FUEI } \\
\text { HYDRCELECTEIC. } \\
\text { NOCLEAR } \\
\text { GEC. ESOLAR }\end{array}$ & $\begin{array}{l}\bar{z} \\
\bar{z}\end{array}$ & $\begin{array}{l}- \\
- \\
-\end{array}$ & $\begin{array}{l}\bar{z} \\
\overline{-}\end{array}$ & $\begin{array}{l}- \\
\overline{-} \\
\overline{-}\end{array}$ & $\begin{array}{l}\overline{-} \\
\overline{-}\end{array}$ & $\begin{array}{l}\overline{-} \\
\overline{-}\end{array}$ & $\begin{array}{l}\overline{-} \\
\overline{-}\end{array}$ & $\begin{array}{r}- \\
3,846 \\
-\end{array}$ & $\begin{array}{r}- \\
3,846 \\
-\end{array}$ & $100 \%$ \\
\hline TCTAL SOPPIY & - & - & - & - & - & - & - & 3,846 & 3,846 & \\
\hline
\end{tabular}

NET IM FORTS

$4,437 \quad 37,904$

11,299

19,969

47,679

15,431

150,861

-

NOTES:
1 TRANSFCPAATICN LOSS POR
TRANSFCBMATICN LOSS FOR
TRANSFCBHATICN LCSS FCR
TRANSFCBMATICN LOSS FOR
ZLECTRICITY GEU.
FRODDCTS $=65.51 \%$
NATUEAL GAS
$=0.0$
Y YTE.ET ICS
$=0.0 \%$ 
REGIONAL 3NEFGY EALANCE STATEMZNT

\begin{tabular}{|c|c|c|c|c|c|c|c|c|c|c|}
\hline SECICE & $\begin{array}{l}\text { DISTIILATZ } \\
0=L\end{array}$ & $\begin{array}{l}\text { RESIDUAL } \\
\text { OIL }\end{array}$ & $\begin{array}{l}\text { GASCLINE } \\
\text { (ALL JNIT }\end{array}$ & $\begin{array}{c}\text { OTHER } \\
\text { HYDRO- } \\
\text { CAREONS } \\
\text { IS IN } 10 * 9\end{array}$ & $\begin{array}{c}\text { CRODE } \\
\text { OII } \\
\text { BTO'S) }\end{array}$ & $\begin{array}{l}\text { NATUSBL } \\
\text { GAS }\end{array}$ & CCA I & ELECTRICITY & $\begin{array}{r}\text { SECTOR } \\
\text { TOTAL }\end{array}$ & \\
\hline $\begin{array}{l}\text { FINAI IEMANI SFCTORS } \\
\text { RESIDENTIAL, CCMM. } \\
\text { INDDSTRIAL } \\
\text { TRANSPORTATICN } \\
\text { MISCELIANECIS OSES }\end{array}$ & $\begin{array}{r}30.050 \\
14.570 \\
57.836 \\
2.506\end{array}$ & $\begin{array}{r}8.525 \\
27.096 \\
845 \\
1,316\end{array}$ & $280.97 \overline{-}$ & $\begin{array}{r}28,902 \\
36,590 \\
96.643 \\
100\end{array}$ & $\begin{array}{l}- \\
\overline{-} \\
-\end{array}$ & $\begin{array}{r}47,984 \\
71,206 \\
4,420 \\
2,294\end{array}$ & $\begin{array}{r}115 \\
32,605 \\
1 \\
4\end{array}$ & $\begin{array}{r}131,467 \\
62,101 \\
- \\
1,248\end{array}$ & $\begin{array}{r}247,043 \\
244,168 \\
440,724 \\
7,468\end{array}$ & $\begin{array}{r}20 \% \\
20 \% \\
35 \% \\
1 \%\end{array}$ \\
\hline $\begin{array}{l}\text { TCTAI FINAI } \\
\text { DEMAND SECTCRS }\end{array}$ & $: 04.962$ & $§ 7,7 a 2$ & 280,979 & 162,235 & - & 125,904 & 32,725 & 194,816 & 939,403 & $75 \%$ \\
\hline $\begin{array}{l}\text { TE ANSFCRMATICN } \\
\text { ELECTRICITI GEN. } \\
\text { FETRCLEOM FECDOCTS } \\
\text { NATURAL GAS } \\
\text { SYNTHETICS }\end{array}$ & $\begin{array}{r}25.017 \\
-2.910 \\
- \\
-\end{array}$ & $\begin{array}{r}-319 \\
-\end{array}$ & $\begin{array}{r}-3,253 \\
- \\
-\end{array}$ & $\begin{array}{r}- \\
-962 \\
-\end{array}$ & $\begin{array}{r}7,40 \overline{2} \\
- \\
-\end{array}$ & $\stackrel{-}{10}$ & $\begin{array}{r}413,776 \\
- \\
-\end{array}$ & $\begin{array}{r}-150,278 \\
- \\
-\end{array}$ & $\begin{array}{r}288,515 \\
-2 \\
- \\
-\end{array}$ & $\begin{array}{r}23 \% \\
0 \%\end{array}$ \\
\hline $\begin{array}{l}\text { WET EUEL OSET } \\
\text { IN TRANSECSMATICN }\end{array}$ & 22,106 & -319 & $-3,253$ & -962 & 7,402 & 10 & 413,776 & $-150,278$ & 288,512 & $23 \%$ \\
\hline $\begin{array}{l}\text { TCIAI GFOSS ILCWS } \\
\text { LCSSES \& CMISSIONS }\end{array}$ & $\begin{array}{r}129,979 \\
8.090\end{array}$ & $\begin{array}{r}\equiv 7,782 \\
0\end{array}$ & $\begin{array}{r}280,973 \\
1\end{array}$ & $\begin{array}{r}162,235 \\
-6,399\end{array}$ & $\begin{array}{r}7,402 \\
307\end{array}$ & $\begin{array}{r}125,944 \\
-3,263\end{array}$ & $\begin{array}{r}446,501 \\
6,543\end{array}$ & $\begin{array}{r}194,816 \\
16,164\end{array}$ & $\begin{array}{r}1,227,918 \\
20,805\end{array}$ & $\begin{array}{r}98 \% \\
2 \%\end{array}$ \\
\hline
\end{tabular}

\begin{tabular}{|c|c|c|c|c|c|c|c|c|c|}
\hline $\begin{array}{l}\text { SOEELY OF ENIEGGY } \\
\text { FOSSIL FOEI }\end{array}$ & - & - & - & - & - & - & - & - & - \\
\hline HY LR CELECIFIC & - & - & - & - & - & - & - & 12,187 & $12,187 \quad 100 \%$ \\
\hline NOCL EAR & - & - & - & - & - & - & - & - & - \\
\hline GEC. \&SOLAR & - & - & - & - & - & - & - & - & - \\
\hline TCTAI SOPEIY & - & - & - & - & - & - & - & 12,187 & 12,187 \\
\hline
\end{tabular}

\begin{tabular}{l} 
NET IM FORTS \\
CF REGION \\
\hline
\end{tabular}


REGICNAL ENE FGY EALANCE STITEMENT

\begin{tabular}{|c|c|c|c|c|c|c|c|c|c|c|}
\hline SECTOF & $\begin{array}{l}\text { DISTILLATE } \\
\text { OIL }\end{array}$ & $\begin{array}{l}\text { RESIDUEL } \\
\text { OIL }\end{array}$ & $\begin{array}{l}\text { GASOLINE } \\
\text { (ALL D }\end{array}$ & $\begin{array}{l}\text { OTHER } \\
\text { HYDRO- } \\
\text { CAREONS } \\
\text { TS IN } 10 * 9\end{array}$ & $\begin{array}{c}\text { CROJE } \\
\text { OII } \\
\text { BTO'S) }\end{array}$ & $\begin{array}{l}\text { NATURAL } \\
\text { GAS }\end{array}$ & $\operatorname{COAI}$ & ELECTRICITY & $\begin{array}{r}\text { SECTOR } \\
\text { TOTAL }\end{array}$ & \\
\hline $\begin{array}{l}\text { PIYAL LEMANL SECTOKS } \\
\text { GESIDENTIAL, CCMM. } \\
\text { INDOSTRIAL } \\
\text { IZANS PORTATICH } \\
\text { MISCELLANECTS OSES }\end{array}$ & $\begin{array}{r}6,757 \\
5,756 \\
36,113 \\
1,037\end{array}$ & $\begin{array}{r}9: 9 \\
7,1 \in 2 \\
4,3: 2 \\
5<5\end{array}$ & $\begin{array}{r}\overline{-} \\
146,710\end{array}$ & $\begin{array}{r}15,963 \\
31,633 \\
2,653 \\
46\end{array}$ & $\overline{-}$ & $\begin{array}{r}24,431 \\
65,763 \\
578 \\
1,057\end{array}$ & $\begin{array}{r}147 \\
64.111 \\
1 \\
1\end{array}$ & $\begin{array}{r}74,941 \\
66,991 \\
- \\
533\end{array}$ & $\begin{array}{r}123,158 \\
241,416 \\
190,377 \\
3,219\end{array}$ & $\begin{array}{r}14 \% \\
28 \% \\
22 \% \\
0 \%\end{array}$ \\
\hline $\begin{array}{l}\text { TCIAI FINAL } \\
\text { DEMAND SECICRS }\end{array}$ & 49,663 & 12,948 & 146,710 & 50,295 & - & 91,829 & 64.260 & 142,465 & 558,170 & $6 \in F$ \\
\hline $\begin{array}{l}\text { TR BNSFORMATICN } \\
\text { ELECTRICITY GEN. } \\
\text { IETROLEOM ERCDOCCS } \\
\text { VATORAL GAS } \\
\text { SYNTHETICS }\end{array}$ & $\begin{array}{r}18.274 \\
-19,161 \\
-\end{array}$ & $\begin{array}{r}-1,18 \overline{3} \\
- \\
-\end{array}$ & $\begin{array}{r}- \\
-31,603 \\
- \\
-\end{array}$ & $\begin{array}{r}- \\
-33,25 \overline{7} \\
-\end{array}$ & $\begin{array}{r}- \\
78, \equiv 57 \\
-\end{array}$ & $\begin{array}{r}7.083 \\
- \\
-\end{array}$ & $\begin{array}{r}394,524 \\
- \\
-\end{array}$ & $\begin{array}{r}-141,064 \\
- \\
-\end{array}$ & $\begin{array}{r}271,734 \\
735 \\
- \\
-\end{array}$ & $\begin{array}{r}32 \% \\
0 \%\end{array}$ \\
\hline $\begin{array}{l}\text { NEI FUEL OSEL } \\
\text { IN TRANSFFATICA }\end{array}$ & -887 & $-1,1 \notin 3$ & $-31,603$ & $-33,257$ & 78.357 & 7,083 & 394,524 & $-141,064$ & 272,469 & $32 \%$ \\
\hline $\begin{array}{l}\text { TCTAL GROSS FLCFS } \\
\text { LCSSES } \& \text { OMISSIONS }\end{array}$ & $\begin{array}{r}67.937 \\
4.228\end{array}$ & $\begin{array}{r}12,9<8 \\
0\end{array}$ & $\begin{array}{r}146.710 \\
0\end{array}$ & $\begin{array}{l}50,295 \\
-1,983\end{array}$ & $\begin{array}{r}78,357 \\
3,271\end{array}$ & $\begin{array}{l}98,912 \\
-2,672\end{array}$ & $\begin{array}{r}458,784 \\
6,210\end{array}$ & $\begin{array}{r}142,465 \\
11,820\end{array}$ & $\begin{array}{r}830,639 \\
20,875\end{array}$ & $\begin{array}{r}98 \% \\
2 \%\end{array}$ \\
\hline TCIAL NET OSAGE & 53,004 & $11,7 \in 4$ & 115,107 & 15,054 & 82,128 & 96,239 & 464,994 & 13,221 & 851,515 & \\
\hline $\begin{array}{l}\text { SOEELY CF ENFAGY } \\
\text { FOSS IL FOEL } \\
\text { JY OROELFCT FIC } \\
\text { YOCL EAR } \\
\text { GEC. ESOLAR }\end{array}$ & $\begin{array}{l}- \\
- \\
=\end{array}$ & $\begin{array}{l}\overline{-} \\
\overline{-}\end{array}$ & $\begin{array}{l}\overline{-} \\
\overline{-}\end{array}$ & $\begin{array}{l}- \\
\overline{-}\end{array}$ & $\begin{array}{r}1,653 \\
- \\
-\end{array}$ & $\begin{array}{r}4,417 \\
- \\
-\end{array}$ & $\begin{array}{r}312,234 \\
- \\
-\end{array}$ & $\begin{array}{r}10,532 \\
- \\
-\end{array}$ & $\begin{array}{r}318,304 \\
10,532 \\
-\end{array}$ & $\begin{array}{r}97 \% \\
3 \%\end{array}$ \\
\hline TCTAI SOPPIY & - & - & - & - & 1,553 & 4,417 & 312,234 & 10,532 & 328,836 & \\
\hline
\end{tabular}

\section{NET IM FORTS}

53,004 $11,7 \in 4$

115,107

15,054

80,475

91,822

152,760

$2,689 \quad 522,679$
NO TES:
1 TRANSFCRMAEICN LOSS POR ELECTRICITT GEN. $\quad=65.83 \%$

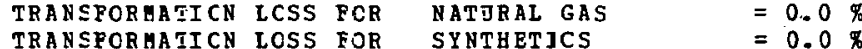


REGICNAL ZNEFGY EALANCE SIATEMZNT

PIES IID MID. SCENARIC

\begin{tabular}{|c|c|c|c|c|c|c|c|c|c|c|}
\hline SECICE & $\begin{array}{l}\text { DISTIILATE } \\
\text { OIL }\end{array}$ & $\begin{array}{l}\text { RESIJDAL } \\
\text { OLL }\end{array}$ & $\begin{array}{l}\text { GASOI,INE } \\
\text { (ALI ONIT }\end{array}$ & $\begin{aligned} & \text { CTHER } \\
& \text { HYDRO- } \\
& \text { AFBONS } \\
& 5 \text { IN } 10 * * 9\end{aligned}$ & $\begin{array}{c}\text { CEOLE } \\
\text { CIL } \\
\text { BTO'SS) }\end{array}$ & $\begin{array}{l}\text { NATURAL } \\
\text { GAS }\end{array}$ & COF.L & ELECTRICITY & $\begin{array}{l}\text { SECTOR } \\
\text { TOTAL }\end{array}$ & \\
\hline $\begin{array}{l}\text { PINAL CEMARE SECTORS } \\
\text { FESIDENTIAI, CCHH. } \\
\text { IND OSTRIAL } \\
\text { TRANS PORTAIICN } \\
\text { MISCELLANECTS OSES }\end{array}$ & $\begin{array}{r}8,779 \\
13,796 \\
42,390 \\
1,237\end{array}$ & $\begin{array}{r}1,415 \\
38,013 \\
216 \\
778\end{array}$ & 147.054 & $\begin{array}{r}17,455 \\
63,186 \\
13,134 \\
50\end{array}$ & $\begin{array}{l}- \\
-\end{array}$ & $\begin{array}{r}32,102 \\
77,439 \\
1,235 \\
1.154\end{array}$ & $\begin{array}{r}270 \\
29.784 \\
1 \\
1\end{array}$ & $\begin{array}{r}76.868 \\
76,307 \\
- \\
492\end{array}$ & $\begin{array}{r}136,889 \\
298,585 \\
204,180 \\
3,712\end{array}$ & $\begin{array}{r}17 \% \\
37 \% \\
25 \% \\
0 \%\end{array}$ \\
\hline $\begin{array}{l}\text { TCIAI FINAI } \\
\text { DEMAND SECTCES }\end{array}$ & 66,202 & 40.422 & 147.154 & $\$ 3,825$ & - & 112,040 & 30,056 & 153,667 & 643,366 & $79 \%$ \\
\hline $\begin{array}{l}\text { TRANSFCRMATICN } \\
\text { ELECTRICITY GEN. } \\
\text { PETROLEO ERCEOCTS } \\
\text { NATURAL GBS } \\
\text { SYNTHETICS }\end{array}$ & $\begin{array}{r}18,828 \\
-22,287 \\
- \\
-\end{array}$ & $\begin{array}{r}-8,926 \\
- \\
-\end{array}$ & $\begin{array}{r}-45.84 \overline{4} \\
-\end{array}$ & $\begin{array}{r}- \\
-50,148 \\
-\end{array}$ & $\begin{array}{r}95.685 \\
-\end{array}$ & $\begin{array}{r}19,11) 2 \\
2,126 \\
=\end{array}$ & $\begin{array}{r}197,919 \\
- \\
-\end{array}$ & $\begin{array}{r}-80,728 \\
- \\
-\end{array}$ & $\begin{array}{r}155,121 \\
605 \\
- \\
-\end{array}$ & $\begin{array}{r}19 \% \\
0 \%\end{array}$ \\
\hline $\begin{array}{l}\text { NET FOFL OSFI } \\
\text { IN TRANSPOFMATION }\end{array}$ & $-3,459$ & $-8,926$ & $-45,8: 44$ & $-\tau 0,148$ & 95,685 & 21,228 & 197,919 & $-80,728$ & $155,72 \epsilon$ & $19 \pi$ \\
\hline $\begin{array}{l}\text { TCTAL GROSS FLCRS } \\
\text { LCSSES } \varepsilon \text { CHISSICNS }\end{array}$ & $\begin{array}{r}85,030 \\
5,292\end{array}$ & $\begin{array}{r}40,422 \\
0\end{array}$ & $\begin{array}{r}147,: \leq 4 \\
0\end{array}$ & $\begin{array}{l}53,825 \\
-3,700\end{array}$ & $\begin{array}{r}95,685 \\
3,969\end{array}$ & $\begin{array}{r}133,258 \\
-3,601\end{array}$ & $\begin{array}{r}227,975 \\
3,085\end{array}$ & $\begin{array}{r}153,667 \\
12,750\end{array}$ & $\begin{array}{r}799,092 \\
17,797\end{array}$ & $\begin{aligned} 98 \% \\
2 \%\end{aligned}$ \\
\hline TCTAL NET DSAGE & 68,035 & 31.496 & 101.310 & $6.9,976$ & 99,654 & 129,657 & 231,060 & 85,689 & 816.890 & \\
\hline $\begin{array}{l}\text { SOFELY CF EDERGY } \\
\text { FOSSII FOEI } \\
\text { HYDRCELECEIC } \\
\text { NOCLEAR } \\
\text { GEC. \&SOLAR }\end{array}$ & $\begin{array}{l}\overline{-} \\
\overline{-}\end{array}$ & $\begin{array}{l}- \\
\overline{-} \\
-\end{array}$ & $\begin{array}{l}- \\
\bar{z} \\
-\end{array}$ & $\begin{array}{l}- \\
- \\
-\end{array}$ & $\begin{array}{l}- \\
\overline{-} \\
-\end{array}$ & $\begin{array}{l}- \\
\bar{z} \\
\bar{z}\end{array}$ & $\begin{array}{l}- \\
\overline{-}\end{array}$ & $\begin{array}{r}719 \\
916 \\
479\end{array}$ & $\begin{array}{r}719 \\
916 \\
479\end{array}$ & $\begin{array}{l}34 \% \\
43 \pi \\
23 \pi\end{array}$ \\
\hline TCIAI SOPPIY & - & - & - & - & - & - & - & 2,114 & 2,114 & \\
\hline
\end{tabular}

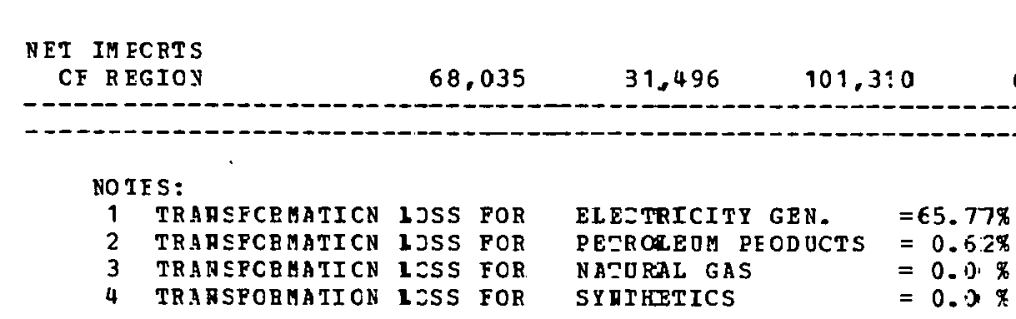


REGIONAL ENEFGY EALANCE STATEMENT

ONAL ENEEGY EALANCE STA
PIES MID UID SCENARIO

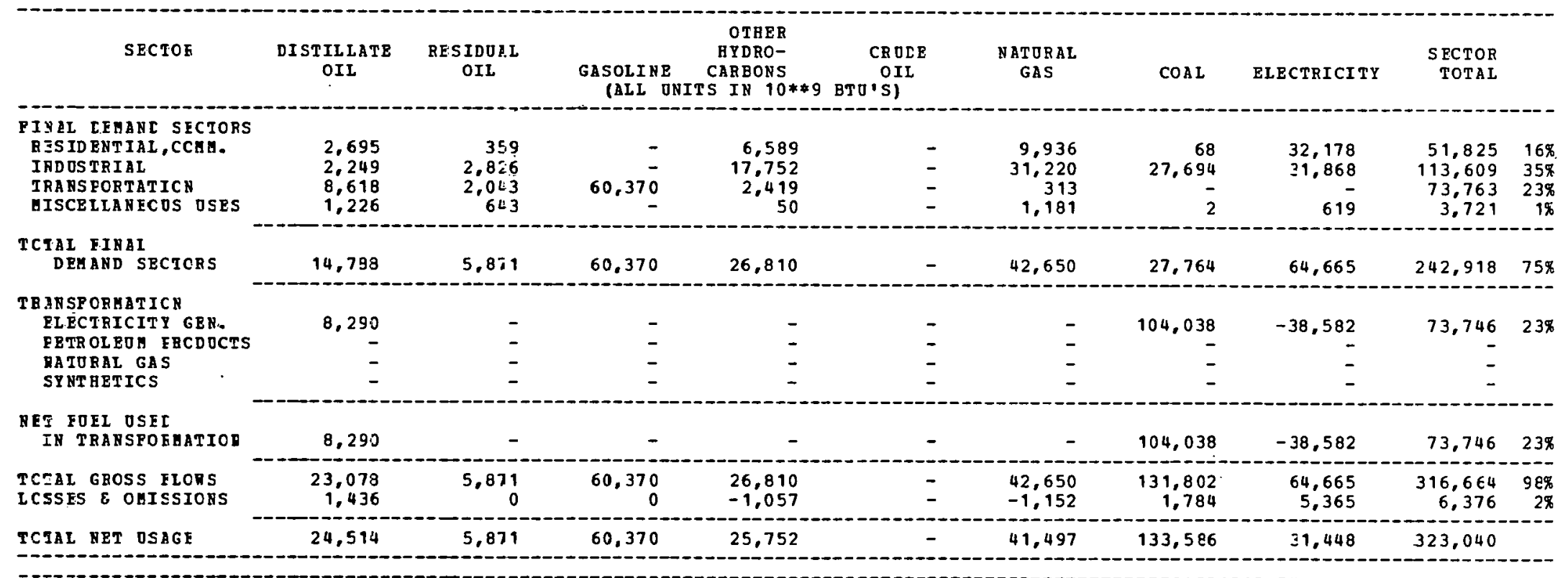

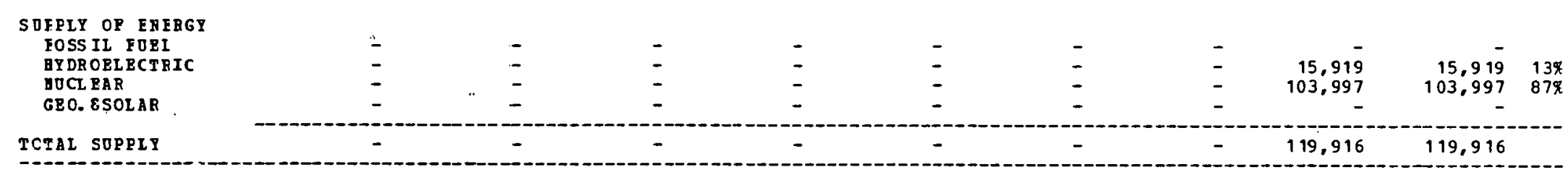

\begin{tabular}{l} 
BEE IN PORTS \\
CP REGIOR \\
\hline
\end{tabular}


REGIONAL EFEFGT RALANCE STATEMENT

PIES IID YID SCENARIO

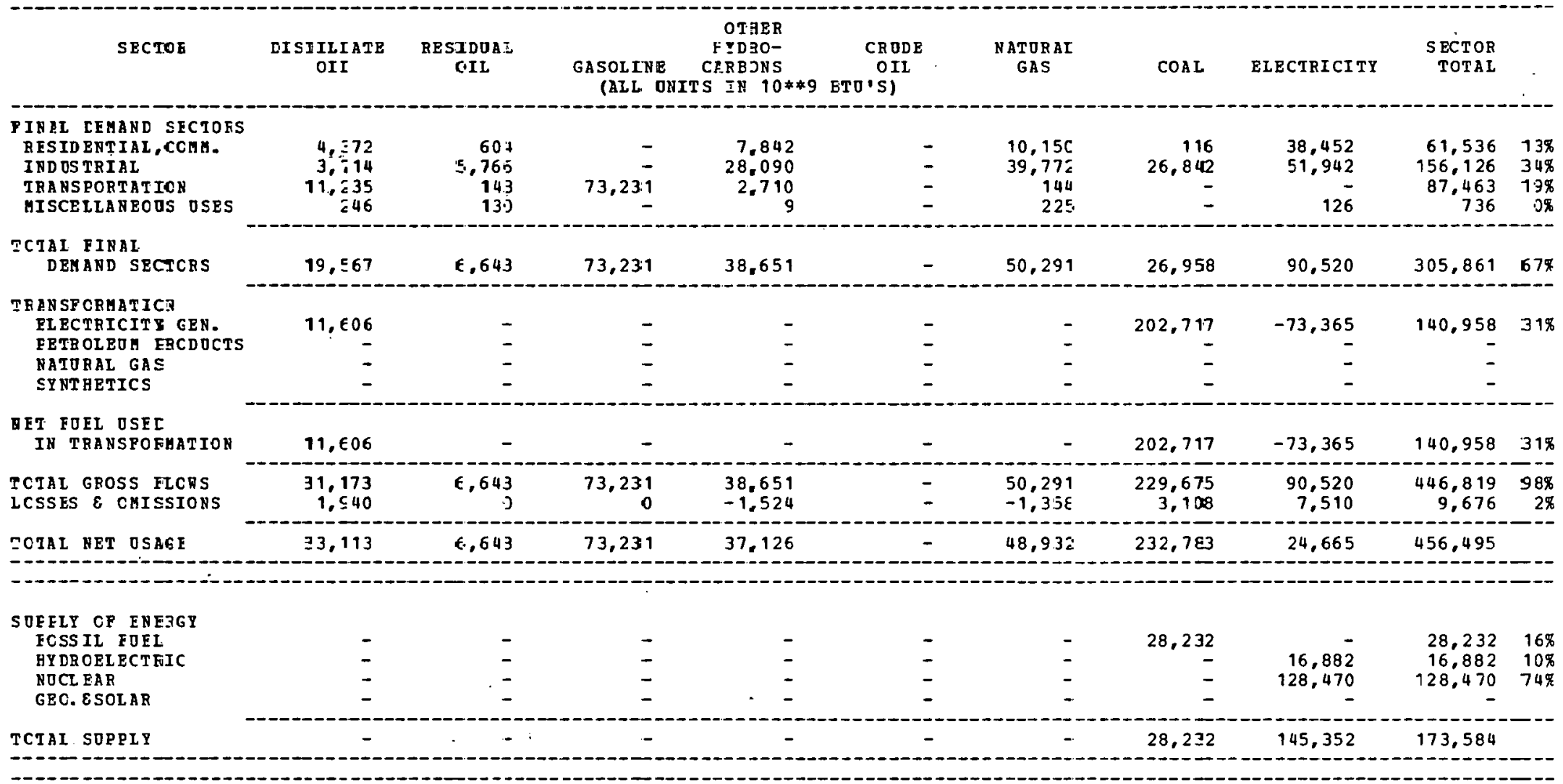

\section{RET IN ECRTS}

CF REGION

$\equiv 3, \cdot 13$

6,643

73,231

37,126

$-\quad 48,93 \hat{2}$

$204,551 \quad-120,686$

282,911

\section{NOTES:}

1 TRANSZCRMATICN LOSS FOR

TRANS?CRMATICN LOES EOR

TRAN SICRAATICN LCES BOR

TRAN SZORMATI CN LCES BOF

BIECERICETY GEY.

$=65.77 \%$

A

SY NTEETIES

$=0.0 \mathrm{~g}$

$=0.0 \%$
$=0.0 \%$ 
RESIONAL ENE FGY PALANCE STATEMENT
PIES MID MID SCENARIO

\begin{tabular}{|c|c|c|c|c|c|c|c|c|c|c|}
\hline SECTOE & $\begin{array}{c}\text { DISTILLATE } \\
\text { OIL }\end{array}$ & $\begin{array}{l}\text { RESIDOAL } \\
\text { OIL }\end{array}$ & $\begin{array}{l}\text { GASOLINE } \\
\cdot \text { (ALL ONI }\end{array}$ & $\begin{array}{l}\text { OTHER } \\
\text { HYDRO- } \\
\text { CARBONS } \\
\text { S IN } 10 * 9\end{array}$ & $\begin{array}{c}\text { CROLE } \\
\text { OII } \\
\text { BTU'S) }\end{array}$ & $\begin{array}{l}\text { NATURAL } \\
\text { GAS }\end{array}$ & COA I & ELECTRICITY & $\begin{array}{l}\text { SECTOR } \\
\text { TOTAL }\end{array}$ & \\
\hline $\begin{array}{l}\text { PIEAL CFHANC SECTORS } \\
\text { EESID ENTIAL,CCHA. } \\
\text { INDOSTRIAL } \\
\text { TRANSPORTATION } \\
\text { MISCE LLANEOOS OSES }\end{array}$ & $\begin{array}{r}6,358 \\
2,403 \\
25,511 \\
1,014\end{array}$ & $\begin{array}{r}579 \\
2,894 \\
3 \\
533\end{array}$ & $135.91 \overline{-}$ & $\begin{array}{r}14,999 \\
15,858 \\
10,642 \\
50\end{array}$ & $\begin{array}{l}\overline{-} \\
\overline{-}\end{array}$ & $\begin{array}{r}22,298 \\
32,891 \\
534 \\
1,245\end{array}$ & $\begin{array}{r}334 \\
29,989 \\
- \\
1\end{array}$ & $\begin{array}{r}80,004 \\
65,450 \\
- \\
653\end{array}$ & $\begin{array}{r}124,571 \\
149,485 \\
172,604 \\
3,496\end{array}$ & $\begin{array}{r}18 \% \\
22 \% \\
25 \% \\
1 \%\end{array}$ \\
\hline $\begin{array}{l}\text { TCTAI INAL } \\
\text { DEMAND SECTCRS }\end{array}$ & 35,286 & 4,008 & 135,914 & 41,549 & - & 56,968 & 30,324 & 146,107 & 450,156 & $66 \%$ \\
\hline $\begin{array}{l}\text { TBARSFORMATICN } \\
\text { ELECTRICITY GEN. } \\
\text { PBTRCLEO FBCDOCTS } \\
\text { NATORAL GAS } \\
\text { SY HTHETICS }\end{array}$ & $\begin{array}{r}18,732 \\
- \\
-\end{array}$ & $\begin{array}{l}- \\
- \\
-\end{array}$ & $\begin{array}{l}- \\
-\end{array}$ & $\overline{-}$ & $\begin{array}{l}\overline{-} \\
-\end{array}$ & $\begin{array}{l}\overline{-} \\
\overline{-}\end{array}$ & $\begin{array}{r}303,056 \\
- \\
-\end{array}$ & $\begin{array}{r}-110,227 \\
- \\
-\end{array}$ & $\begin{array}{r}211,561 \\
- \\
-\end{array}$ & $31 \%$ \\
\hline $\begin{array}{l}\text { MET FOEL OSEI } \\
\text { IH TRANSPOEHATION }\end{array}$ & 18,732 & - & - & - & - & - & 303,056 & $-110,227$ & 211,561 & $31 \%$ \\
\hline $\begin{array}{l}\text { TCIAL GROSS FLORS } \\
\text { LCSSBS } 8 \text { OHISSIONS }\end{array}$ & $\begin{array}{r}54,018 \\
3,362\end{array}$ & $\begin{array}{r}4,008 \\
0\end{array}$ & $\begin{array}{r}135,914 \\
0\end{array}$ & $\begin{array}{r}41,549 \\
-1,638\end{array}$ & $\overline{-}$ & $\begin{array}{l}56,968 \\
-1,539\end{array}$ & $\begin{array}{r}333,380 \\
4,512\end{array}$ & $\begin{array}{r}146,107 \\
12,123\end{array}$ & $\begin{array}{r}661,717 \\
16,820\end{array}$ & $\begin{array}{r}98 \% \\
2 \%\end{array}$ \\
\hline $\begin{array}{l}\text { SOEPLY OP EYERGY } \\
\text { IOSS IL FOPI } \\
\text { EYDRORLECYEIC } \\
\text { IOCL EAR } \\
\text { GEO.ESOLAB }\end{array}$ & $\begin{array}{l}\bar{z} \\
\overline{-}\end{array}$ & $\begin{array}{l}- \\
- \\
-\end{array}$ & $\begin{array}{l}\overline{-} \\
\overline{-}\end{array}$ & $\begin{array}{l}\overline{-} \\
\overline{-}\end{array}$ & $\begin{array}{r}1,652 \\
- \\
-\end{array}$ & $\begin{array}{r}1,415 \\
- \\
-\end{array}$ & $\begin{array}{r}19,609 \\
= \\
-\end{array}$ & $\begin{array}{r}6,853 \\
89,544 \\
-\end{array}$ & $\begin{array}{r}22,676 \\
6,853 \\
89,544 \\
-\end{array}$ & $\begin{array}{r}19 \% \\
6 \% \\
75 \%\end{array}$ \\
\hline TCJAL SOPPIY & - & - & - & - & 1,652 & 1,415 & 19.609 & 96,397 & 119.073 & \\
\hline
\end{tabular}

\section{NET II FORTS}

CIP R BGION

57,380

4,008

135,914

39.910

$-1,652$

54,013

318,283

$-48,393$

559,464

NOTES:

TRANSFORAATICN LOSS POR TRARSPCRAATICN LOSS PCR

TRAASPCRAATICN LCSS POB

EL. BCTRICITY. GEY.

(CITY $=65.75 \%$

MTURAL GAS

$=0.0 \%$

TRAASPCR HA TI CA LOSS POR

SYNTHET ICS 
REGIDNAL EMERGY PALANCE STATEMENT

?IES MID UID SCENARIO

\begin{tabular}{|c|c|c|c|c|c|c|c|c|c|c|}
\hline SECICE & $\begin{array}{l}\text { DISSILLATE: } \\
\text { JIL }\end{array}$ & $\begin{array}{l}\text { RESIDUAI } \\
\text { OIL }\end{array}$ & $\begin{array}{l}\text { GASOLISE } \\
\text { (ALL O }\end{array}$ & $\begin{array}{c}\text { OTBER } \\
\text { HYDEO- } \\
\text { CAREONS } \\
\text { TS IN } 10 * * 9\end{array}$ & $\begin{array}{c}\text { CRODE } \\
\text { OII } \\
\text { BIO'S) }\end{array}$ & $\begin{array}{l}\text { NATURAL } \\
\text { GAS }\end{array}$ & $\operatorname{COAL}$ & ELECTRICITY & $\begin{array}{l}\text { SECTOR } \\
\text { TOTAL }\end{array}$ & \\
\hline $\begin{array}{l}\text { PIBAL LEHANC IFCTORS } \\
\text { RESIDENTIAL, CCMA. } \\
\text { INDOSTRIAL } \\
\text { TRANSPORTATICN } \\
\text { MISCELLAFCOE OSES }\end{array}$ & $\begin{array}{r}3,997 \\
1,691 \\
14,997 \\
564\end{array}$ & $\begin{array}{r}335 \\
1.81 \frac{5}{E} \\
29 \epsilon\end{array}$ & $86.55 \%$ & $\begin{array}{r}9.543 \\
26.091 \\
8.073 \\
22\end{array}$ & $\begin{array}{l}- \\
-\end{array}$ & $\begin{array}{r}13,989 \\
39,1 \equiv 6 \\
409 \\
5<2\end{array}$ & $\begin{array}{r}213 \\
28,255 \\
- \\
1\end{array}$ & $\begin{array}{r}50,371 \\
54,662 \\
- \\
287\end{array}$ & $\begin{array}{r}78,438 \\
143,647 \\
110,041 \\
1,692\end{array}$ & $\begin{array}{r}17 \% \\
31 \% \\
23 \% \\
0 \%\end{array}$ \\
\hline $\begin{array}{l}\text { TCTAI FINAI: } \\
\text { DEHAND SECTCRS }\end{array}$ & 21,239 & $2,44 \epsilon$ & $86,55 \exists$ & 43,729 & - & $46,0 \leq 6$ & 28,469 & 105,320 & 333,818 & $71 \%$ \\
\hline $\begin{array}{l}\text { TRANSPCRHATICI } \\
\text { FLECTRICITY GEN. } \\
\text { PETROIEOH FICDOCTS } \\
\text { NATURAL GAS } \\
\text { SYNTHETICS }\end{array}$ & $\begin{array}{r}13,533 \\
= \\
=\end{array}$ & $\begin{array}{l}- \\
\overline{-}\end{array}$ & $\begin{array}{l}\overline{-} \\
\overline{-}\end{array}$ & $\begin{array}{l}- \\
\overline{-} \\
-\end{array}$ & $\begin{array}{l}\overline{-} \\
\overline{-}\end{array}$ & $\bar{z}$ & $\begin{array}{r}177,172 \\
- \\
-\end{array}$ & $\begin{array}{r}-65,458 \\
- \\
-\end{array}$ & $\begin{array}{r}125,217 \\
-\end{array}$ & $37 \%$ \\
\hline $\begin{array}{l}\text { NET FOEL OSEC } \\
\text { IN TRASSPOEATION }\end{array}$ & 13,533 & - & - & - & - & - & 177,172 & $-65,458$ & 125,217 & $27 \%$ \\
\hline $\begin{array}{l}\text { TCTAL GROSS FEORS } \\
\text { LOSSES \& OHISSIONS }\end{array}$ & $\begin{array}{r}34,7+2 \\
2,152\end{array}$ & $2,44 \epsilon$ & $\begin{array}{r}86,55 \% \\
0\end{array}$ & $\begin{array}{r}43,729 \\
-1,724\end{array}$ & $\overline{-}$ & $\begin{array}{l}46,056 \\
-1,244\end{array}$ & $\begin{array}{r}205,641 \\
2,783\end{array}$ & $\begin{array}{r}105,320 \\
8,738\end{array}$ & $\begin{array}{r}459,035 \\
10,715\end{array}$ & $\begin{array}{r}98 \% \\
2 \%\end{array}$ \\
\hline $\begin{array}{l}\text { SOEFLY OF ENESGY } \\
\text { FOSS IL FOEL } \\
\text { HYDRCELECTEIC } \\
\text { NOCL EAR } \\
\text { GEO. ESOLAR }\end{array}$ & $\begin{array}{l}\bar{z} \\
\bar{z}\end{array}$ & $\begin{array}{l}- \\
\overline{-}\end{array}$ & $\begin{array}{l}- \\
\bar{z}\end{array}$ & $\begin{array}{l}\bar{z} \\
\bar{z}\end{array}$ & $\begin{array}{r}3,658 \\
- \\
=\end{array}$ & $\begin{array}{r}10,811 \\
= \\
=\end{array}$ & $\begin{array}{r}302,001 \\
- \\
-\end{array}$ & $\begin{array}{r}9.67 \overline{-} \\
-\end{array}$ & $\begin{array}{r}816,470 \\
9.674 \\
-\end{array}$ & $\begin{array}{r}89 \% \\
1 \%\end{array}$ \\
\hline TCTAI SOPPIY & - & - & - & - & 3,658 & 10,811 & 302,001 & 9,674 & 826,144 & \\
\hline
\end{tabular}

\begin{tabular}{l} 
NET IM FCRTS \\
CF R RGION \\
\hline
\end{tabular}

\begin{tabular}{|c|c|c|c|c|c|}
\hline \multicolumn{6}{|c|}{ NOIES: } \\
\hline & TRANSECRAATICN & LOS: & F JR & EL ECTRICITY GEN. & $=65.67 \%$ \\
\hline & TRANSEORMATICN & $\operatorname{Los} 5$ & P JR & FETROLEOY FROL OCTS & $=0.08$ \\
\hline 3 & TR AN SFCB BRTI CN & ICS5 & F.JR & NATURAL EAS & $=0.0 \%$ \\
\hline 4 & TRAN SPORUATICN & $\operatorname{tcs} 5$ & PJR & SYNTHETICS & $=0.0 \%$ \\
\hline
\end{tabular}


REGICNAL ENEEGY EALANCE STATEMENT

PIES MID MID SCENARIO

\begin{tabular}{|c|c|c|c|c|c|c|c|c|c|c|}
\hline SECTCE & $\begin{array}{l}\text { DISTILLATE } \\
\text { OIL }\end{array}$ & $\begin{array}{l}\text { RESIDUAL } \\
\text { OIL }\end{array}$ & $\begin{array}{l}\text { GASCLINE } \\
\quad \text { (ALL O }\end{array}$ & $\begin{array}{l}\text { OTHER } \\
\text { HYDRO- } \\
\text { CAREONS } \\
\text { TS IN } 10 * \$ 9\end{array}$ & $\begin{array}{c}\text { CROCE } \\
\text { OIL } \\
\text { BTO'S) }\end{array}$ & $\begin{array}{l}\text { NATURAL } \\
\text { GAS }\end{array}$ & $\operatorname{COAL}$ & ELECTRICITY & $\begin{array}{r}\text { SECTOR } \\
\text { TOTAL }\end{array}$ & \\
\hline $\begin{array}{l}\text { FIEAL CEMANL SECTOES } \\
\text { RESIDENTIAL, CCMM. } \\
\text { IEDOSTRIAL } \\
\text { TEANSPCRTATICN } \\
\text { MISCELIANECOS OSES }\end{array}$ & $\begin{array}{r}6,138 \\
7,544 \\
13,293 \\
263\end{array}$ & $\begin{array}{r}470 \\
4,627 \\
1,319 \\
134\end{array}$ & $\begin{array}{r}- \\
- \\
-\end{array}$ & $\begin{array}{r}5,928 \\
31,259 \\
7,473 \\
7\end{array}$ & - & $\begin{array}{r}12,623 \\
34,906 \\
735 \\
293\end{array}$ & $\begin{array}{r}235 \\
26.062 \\
4 \\
-\end{array}$ & $\begin{array}{r}28,271 \\
44,683 \\
- \\
148\end{array}$ & $\begin{array}{r}53,665 \\
149.081 \\
88,708 \\
845\end{array}$ & $\begin{array}{r}14 \% \\
39 \% \\
23 \% \\
0 \%\end{array}$ \\
\hline $\begin{array}{l}\text { TCEAI FINAI } \\
\text { DEMAND SECICRS }\end{array}$ & 27,238 & 6.550 & 65,884 & 44,667 & - & 48,557 & 26,301 & 73.102 & 292.299 & $76 \%$ \\
\hline $\begin{array}{l}\text { TEINSPCRMATICN } \\
\text { FLECTRICITY CEN. } \\
\text { PETROLEOM FBCDOCIS } \\
\text { HATORAL GAS } \\
\text { SY NTHETICS }\end{array}$ & $\begin{array}{r}6,900 \\
- \\
-\end{array}$ & $\begin{array}{l}- \\
- \\
-\end{array}$ & $\begin{array}{l}\overline{-} \\
\overline{-}\end{array}$ & $\overline{-}$ & $\begin{array}{l}- \\
-\end{array}$ & $\begin{array}{l}- \\
- \\
-\end{array}$ & $\begin{array}{r}120.416 \\
- \\
-\end{array}$ & $\begin{array}{r}-43,245 \\
- \\
-\end{array}$ & $\begin{array}{r}84,071 \\
- \\
- \\
-\end{array}$ & $22 \pi$ \\
\hline $\begin{array}{l}\text { NET FUEL USEL } \\
\text { IN TRANSFEHATIOS }\end{array}$ & 6,900 & - & - & - & - & - & 120,416 & $-43,245$ & 84.071 & $22 \%$ \\
\hline $\begin{array}{l}\text { TEEAL GRCSS FLCRS } \\
\text { LESSES \& OMISSIONS }\end{array}$ & $\begin{array}{r}34,138 \\
2,124\end{array}$ & $\begin{array}{r}6,550 \\
10\end{array}$ & $\begin{array}{r}65,884 \\
0\end{array}$ & $\begin{array}{r}44,667 \\
-1,769\end{array}$ & - & $\begin{array}{l}48,557 \\
-1,312\end{array}$ & $\begin{array}{r}146,717 \\
1,985\end{array}$ & $\begin{array}{r}73,102 \\
6,065\end{array}$ & $\begin{array}{r}376,370 \\
7,102\end{array}$ & $\begin{array}{r}98 \% \\
2 \%\end{array}$ \\
\hline TCIAI NET OSAGE & 36,262 & 6,550 & 65,884 & 42,905 & - & 47,244 & 148,702 & 35,922 & 383,472 & \\
\hline
\end{tabular}

\begin{tabular}{|c|c|c|c|c|c|c|c|c|c|c|}
\hline SDFELY OP ENERGY & & & & & & & & & & \\
\hline $\begin{array}{l}\text { FCSSIL FOEI } \\
\text { QY CROELECTEIC }\end{array}$ & $\overline{-}$ & - & - & $\overline{-}$ & 166 & 3,189 & $1,675,532$ & $2.46 \overline{0}$ & $\begin{array}{r}1.678 .887 \\
2.460\end{array}$ & $\begin{array}{r}95 \% \\
0 \%\end{array}$ \\
\hline DOCLEAR & - & - & - & - & - & - & - & 89,562 & $\begin{array}{r}89,562 \\
8,500\end{array}$ & $5 \%$ \\
\hline GEC. ESCLAR & - & - & - & - & - & - & - & - & - & \\
\hline TCTAI SOFPIY & - & - & - & - & 166 & 3,189 & $1,675,532$ & 92,022 & $1,770,909$ & \\
\hline
\end{tabular}

\begin{tabular}{l} 
NET IM ECRTS \\
CF REGION \\
\hline
\end{tabular}


REGICNAL EDEEGY EALANCE STATEMZNT

\begin{tabular}{|c|c|c|c|c|c|c|c|c|c|c|}
\hline SECJOF & DISEILIATE & $\underset{\text { OIL }}{R E S I D J A L}$ & $\begin{array}{l}\text { GASOLINE } \\
\text { (ALI ONI }\end{array}$ & $\begin{array}{l}\text { OTHER } \\
\text { HYIRO- } \\
\text { CIREONS } \\
\text { TS IL } 10 * \$ 9\end{array}$ & $\begin{array}{l}\text { CREDE } \\
\text { OIL } \\
\text { BTO'S) }\end{array}$ & $\begin{array}{l}\text { NATURAL } \\
\text { GAS }\end{array}$ & COA $\mathrm{L}$ & ELECTEICITY & $\begin{array}{r}\text { SECTOR } \\
\text { TOTAL }\end{array}$ & \\
\hline $\begin{array}{l}\text { PINAL CEMANC SECTORS } \\
\text { RFSIDENTIAI.COHH. } \\
\text { IND OS TRIAL } \\
\text { TRANSPORTATICN } \\
\text { UISCBLLANECES OSES }\end{array}$ & $\begin{array}{r}7.928 \\
7,910 \\
27.498 \\
760\end{array}$ & $\begin{array}{r}963 \\
5.162 \\
56 \\
390\end{array}$ & $88,04 \overline{-}$ & $\begin{array}{r}E, 313 \\
3 \epsilon, 012 \\
=.883 \\
17\end{array}$ & $\begin{array}{l}\overline{-} \\
\overline{-}\end{array}$ & $\begin{array}{r}45,567 \\
51,679 \\
1,517 \\
784\end{array}$ & $\begin{array}{r}5: 8 \\
118,060 \\
17 \\
2\end{array}$ & $\begin{array}{r}27,683 \\
85,498 \\
9 \\
368\end{array}$ & $\begin{array}{r}90,072 \\
304,312 \\
120,024 \\
2,321\end{array}$ & $\begin{array}{r}9 \% \\
32 \% \\
13 \% \\
0 \%\end{array}$ \\
\hline $\begin{array}{l}\text { TCTAI FINAI } \\
\text { IEMANC SECICRS }\end{array}$ & 43,196 & 5,571 & 88,644 & $4 \div .225$ & - & 99,533 & 118,597 & 113.558 & 516,729 & $54 \%$ \\
\hline $\begin{array}{l}\text { T F DNSFCRMATICN } \\
\text { ELEETRICIYI GEN. } \\
\text { ERTROLEOM FRCDUCTS } \\
\text { NATJRAL GAS } \\
\text { SYNTERTICS }\end{array}$ & $\begin{array}{r}5,778 \\
-71,794 \\
- \\
-\end{array}$ & $\begin{array}{r}-27.927 \\
-\end{array}$ & $\begin{array}{r}-145,000 \\
-\end{array}$ & $\begin{array}{r}-65,26 \overline{7} \\
- \\
-\end{array}$ & $\begin{array}{r}303,2.4 \overline{7} \\
-39.608\end{array}$ & $\begin{array}{r}119 \\
6.61 .5 \\
- \\
-\end{array}$ & $\begin{array}{r}509,694 \\
- \\
- \\
100,843\end{array}$ & $\begin{array}{r}-176,553 \\
- \\
-\end{array}$ & $\begin{array}{r}339,038 \\
1.873 \\
- \\
61.235\end{array}$ & $\begin{array}{r}36 \% \\
0 \% \\
6 \%\end{array}$ \\
\hline $\begin{array}{l}\text { NET FOFL OSFI } \\
\text { IN TRASSCEMATION }\end{array}$ & $-66,016$ & $-=7,927$ & $-145,000$ & $-6 \vdots, 267$ & 263,639 & $6,73 j$ & 610,537 & $-176,553$ & 402,146 & $42 \%$ \\
\hline $\begin{array}{l}\text { ICTAL GROSS FLCRS } \\
\text { LCSSES E CMISSIONS }\end{array}$ & $\begin{array}{r}18,974 \\
3,348\end{array}$ & $\begin{array}{r}5,571 \\
0\end{array}$ & $\begin{array}{r}88,0<4 \\
0\end{array}$ & $\begin{array}{l}4:, 225 \\
-\because, 862\end{array}$ & $\begin{array}{r}303,247 \\
12,580\end{array}$ & $\begin{array}{r}106,273 \\
-2,871\end{array}$ & $\begin{array}{r}729,134 \\
9,869\end{array}$ & $\begin{array}{r}113.558 \\
9,422\end{array}$ & $\begin{array}{r}918,875 \\
30,186\end{array}$ & $\begin{array}{r}57 \% \\
3 \%\end{array}$ \\
\hline $\begin{array}{l}\text { SOEFLY OF ENFEG } \\
\text { FOSS IL FORI } \\
\text { HYCROELECTFIC } \\
\text { NOCLEAR } \\
\text { GEC. ESOLAR }\end{array}$ & $\begin{array}{l}- \\
-\end{array}$ & $\begin{array}{l}\overline{-} \\
\overline{-}\end{array}$ & $\begin{array}{l}- \\
\overline{-} \\
-\end{array}$ & $\begin{array}{l}- \\
\overline{-}\end{array}$ & $\begin{array}{r}6,720 \\
- \\
-\end{array}$ & $\begin{array}{r}4,987 \\
+\quad- \\
-\end{array}$ & $\begin{array}{r}3,293,955 \\
- \\
-\end{array}$ & $\begin{array}{r}54 \overline{3} \\
34\end{array}$ & $\begin{array}{r}3,305,662 \\
543 \\
- \\
34\end{array}$ & $\begin{array}{r}-00 \% \\
0 \%\end{array}$ \\
\hline TOTAL SOPPIT & - & - & - & - & 6.720 & 4,987 & $3,293,955$ & 577 & $3,306,239$ & \\
\hline $\begin{array}{l}\text { NET IM EORTS } \\
\text { CF REGION }\end{array}$ & $-19,771$ & $-21,356$ & $-56,956$ & $-17,905$ & 269,499 & 98,414 & -2.554 .9 .51 & $-54,149$ & $-2,357,176$ & \\
\hline
\end{tabular}

NoTES:

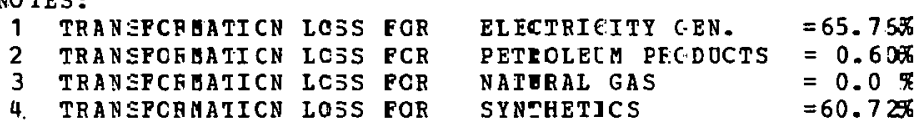


REGIONAL ENEFGY EALANCE STATEMENT

PIES MID MID SCENARIO

\begin{tabular}{|c|c|c|c|c|c|c|c|c|c|c|}
\hline SECTCE & $\begin{array}{l}\text { CISTILLATE } \\
\text { OIL }\end{array}$ & $\begin{array}{l}\text { RESIDOAL } \\
\text { OII }\end{array}$ & $\begin{array}{l}\text { GRSOLINE } \\
\text { CALL ON }\end{array}$ & $\begin{array}{l}\text { OTHER } \\
\text { HYDRO- } \\
\text { CARBONS } \\
\text { TS IN } 10 * 9\end{array}$ & $\begin{array}{c}\text { CRJDE } \\
\text { OIL } \\
\text { BTO.S) }\end{array}$ & $\begin{array}{l}\text { NATURAL } \\
\text { GAS }\end{array}$ & $\operatorname{COAL}$ & ELECTRICITY & $\begin{array}{l}\text { SECTCR } \\
\text { TOTAL }\end{array}$ & \\
\hline $\begin{array}{l}\text { FINAL CEMANC SECICFS } \\
\text { FESIDENTIAL, CCMM. } \\
\text { INDOSTRIAL } \\
\text { TRANSPORTATICN } \\
\text { HISCELLANECOS OSES }\end{array}$ & $\begin{array}{r}3,643 \\
1,260 \\
15,438 \\
1,058\end{array}$ & $\begin{array}{l}\vdots 14 \\
860 \\
12 \\
556\end{array}$ & $74,25 \overline{1}$ & $\begin{array}{r}8,549 \\
3,509 \\
5,671 \\
41\end{array}$ & $\begin{array}{l}- \\
- \\
-\end{array}$ & $\begin{array}{r}21,911 \\
17,009 \\
349 \\
972\end{array}$ & $\begin{array}{r}171 \\
13,097 \\
-\end{array}$ & $\begin{array}{r}34,997 \\
37,841 \\
- \\
545\end{array}$ & $\begin{array}{r}69,585 \\
73,576 \\
95,721 \\
3,173\end{array}$ & $\begin{array}{l}21 \% \\
22 \% \\
28 \% \\
1 \%\end{array}$ \\
\hline $\begin{array}{l}\text { TCTAI FINAL } \\
\text { DEMAND SECTCRS }\end{array}$ & 21,399 & 1,742 & 74,251 & 17,770 & - & 40,241 & 13,269 & 73,383 & 242.055 & $72 \%$ \\
\hline $\begin{array}{l}\text { T3 BNSFCRMATICN } \\
\text { ELECTRICITY GEN. } \\
\text { FETROLEOM FRCDOCTS } \\
\text { NATURAL GAS } \\
\text { SY NTHETICS }\end{array}$ & $\begin{array}{r}9,420 \\
-1,523 \\
- \\
-\end{array}$ & $\begin{array}{r}9, \epsilon \cdot 32 \\
-6 \cdot 10 \\
- \\
-\end{array}$ & $\begin{array}{r}- \\
-3,132 \\
-\end{array}$ & $\begin{array}{r}- \\
-1.376 \\
- \\
-\end{array}$ & $\begin{array}{r}- \\
6.538 \\
-\end{array}$ & $\begin{array}{r}145 \\
- \\
-\end{array}$ & $\begin{array}{r}113,352 \\
- \\
- \\
-\end{array}$ & $\begin{array}{r}-45,324 \\
- \\
-\end{array}$ & $\begin{array}{r}87,080 \\
41 \\
- \\
-\end{array}$ & $\begin{array}{r}26 \% \\
0 \%\end{array}$ \\
\hline $\begin{array}{l}\text { NEI FUFL OSEI } \\
\text { IN TRANSFOFYATICN }\end{array}$ & 7,897 & $9,(122$ & $-3,132$ & $-1,376$ & 6.538 & 145 & 113,352 & $-45,324$ & 87,121 & $26 \%$ \\
\hline $\begin{array}{l}\text { TCTAL GROSS FLCHS } \\
\text { LESSES } \varepsilon \text { CMISSIONS }\end{array}$ & $\begin{array}{r}30,819 \\
1.918\end{array}$ & $\begin{array}{r}11,374 \\
0\end{array}$ & $\begin{array}{r}74,251 \\
0\end{array}$ & $\begin{array}{r}17,770 \\
-700\end{array}$ & $\begin{array}{r}6.538 \\
271\end{array}$ & $\begin{array}{l}40,386 \\
-1,091\end{array}$ & $\begin{array}{r}126, \in 21 \\
1,713\end{array}$ & $\begin{array}{r}73,383 \\
6,088\end{array}$ & $\begin{array}{r}329,176 \\
8,200\end{array}$ & $\begin{array}{r}98 \% \\
2 \%\end{array}$ \\
\hline
\end{tabular}

-

\begin{tabular}{|c|c|c|c|c|c|c|c|c|c|c|}
\hline $\begin{array}{l}\text { SDEFLY CF ENEFGY } \\
\text { FCSSIL FOEI }\end{array}$ & - & - & - & - & 13,992 & 13,719 & 992,258 & - & $1,019,969$ & $100 \pi$ \\
\hline HY LRCELECTEIC & - & - & - & - & - & - & - & 3,259 & 3,259 & $0 \%$ \\
\hline NOCL EAR & - & - & - & - & - & - & - & - & - & \\
\hline GEC. \&SOLAR & - & - & - & - & - & - & - & - & - & \\
\hline
\end{tabular}

-

NET IMFORTS
CF REGION


REGICNAL EFEFGY EALANCE STATEMEUT

PIES HID UID SCENATIO

\begin{tabular}{|c|c|c|c|c|c|c|c|c|c|}
\hline SECTOK & $\begin{array}{l}\text { DISJILIATE } \\
\text { OII }\end{array}$ & $\begin{array}{l}\text { RESIDOAI } \\
\text { GIIL }\end{array}$ & $\begin{array}{l}\text { GASOLYNE } \\
\text { GALL DDIT }\end{array}$ & $\begin{array}{l}\text { OTHER } \\
\text { FYDRO- } \\
\text { CIRBSNS } \\
\text { TS IN } 10 * * 9\end{array}$ & $\begin{array}{c}\text { CR UTE } \\
\text { OII } \\
\text { ETO'SI }\end{array}$ & $\begin{array}{l}\text { NATURAL } \\
\text { GAS }\end{array}$ & $\operatorname{COAL}$ & ELECTRICITY & $\begin{array}{l}\text { SECTOR } \\
\text { TOTAL }\end{array}$ \\
\hline $\begin{array}{l}\text { FINAL CEMANL SECTORS } \\
\text { RESIDENTIAL, CCMH. } \\
\text { INDOSTRIAL } \\
\text { TRANSPCRTATICN } \\
\text { MISCELLANECS OSES }\end{array}$ & $\begin{array}{r}12,000 \\
6,057 \\
<8,692 \\
1,014\end{array}$ & $\begin{array}{r}1,723 \\
2,773 \\
81 \\
534\end{array}$ & 97,736 & $\begin{array}{r}12.110 \\
29.588 \\
6.586 \\
52\end{array}$ & $\begin{array}{l}- \\
\overline{-} \\
-\end{array}$ & $\begin{array}{r}31,964 \\
43,41 \subseteq \\
348 \\
1,3\urcorner 4\end{array}$ & $\begin{array}{r}255 \\
44.131 \\
1 \\
2\end{array}$ & $\begin{array}{r}40,828 \\
90,814 \\
4 \\
860\end{array}$ & $\begin{array}{r}99,286 \\
218,882 \\
132,848 \\
3,836\end{array}$ \\
\hline $\begin{array}{l}\text { TCIAI FINAI } \\
\text { DEMAND SPCTCRS }\end{array}$ & $17, \in 63$ & 7,117 & 97,736 & 48.336 & - & 77,105 & 44,339 & 132,506 & 454,852 \\
\hline $\begin{array}{l}\text { C R PNSFCRMATICR } \\
\text { ELECTRICITY EEN. } \\
\text { PETR CLEUM ERCDOCTS } \\
\text { NATURAL GAS } \\
\text { SYNTHETICS }\end{array}$ & $\begin{array}{r}16, \in 17 \\
-12, ; 93 \\
- \\
-\end{array}$ & $\begin{array}{r}894 \\
-E, 124 \\
-\end{array}$ & $\begin{array}{r}-26,316 \\
-\end{array}$ & $\begin{array}{r}-11.565 \\
- \\
-\end{array}$ & $\begin{array}{r}- \\
- \\
-\end{array}$ & $\begin{array}{r}154 \\
1,220 \\
- \\
-\end{array}$ & $\begin{array}{r}308,161 \\
- \\
-\end{array}$ & $\begin{array}{r}-113.017 \\
- \\
-\end{array}$ & $\begin{array}{r}212,809 \\
348 \\
- \\
-\end{array}$ \\
\hline $\begin{array}{l}\text { VET FOEL DSEL } \\
\text { IN TRANSFOFBATICN }\end{array}$ & $3, \varepsilon 24$ & $-4,230$ & $-26,316$ & $-i 1.565$ & 54,926 & 1,374 & 308,167 & $-113,017$ & 213,157 \\
\hline $\begin{array}{l}\text { TCIAL GRCSS FICHS } \\
\text { LCSSES } \& \text { OMISSIONS }\end{array}$ & $\begin{array}{r}54,280 \\
4, C 00\end{array}$ & $\begin{array}{r}3,011 \\
0\end{array}$ & $\begin{array}{r}97,736 \\
0\end{array}$ & $\begin{array}{r}48.336 \\
-1.906\end{array}$ & $\begin{array}{r}54,926 \\
2,278\end{array}$ & $\begin{array}{l}78,479 \\
-2,120\end{array}$ & $\begin{array}{r}352,553 \\
4,772\end{array}$ & $\begin{array}{r}132,506 \\
10,994\end{array}$ & $\begin{array}{r}E 68,009 \\
18,019\end{array}$ \\
\hline TCTAL NET OSAGE & 55,487 & $\overline{2}, 886$ & 71,420 & 34,864 & 57,205 & $76,35 \varepsilon$ & 357,322 & 30,483 & 686.029 \\
\hline $\begin{array}{l}\text { SUEPLY OF ENEKGY } \\
\text { FCSSIL FOEI } \\
\text { HYLEOELECTEIC } \\
\text { NOCLEAR } \\
\text { GEC. ESOLAR }\end{array}$ & $\begin{array}{l}- \\
- \\
-\end{array}$ & $\overline{-}$ & $\begin{array}{l}- \\
-\end{array}$ & $\begin{array}{l}- \\
\overline{-} \\
-\end{array}$ & $\begin{array}{r}94 \\
- \\
-\end{array}$ & $\begin{array}{l}\text { - } \\
\text { - }\end{array}$ & $\begin{array}{l}- \\
- \\
-\end{array}$ & $1,34 \overline{8}$ & $\begin{array}{r}94 \\
1,348 \\
43\end{array}$ \\
\hline TCIAI SOPPLY & - & - & - & - & 94 & - & - & 1,391 & 1,485 \\
\hline
\end{tabular}

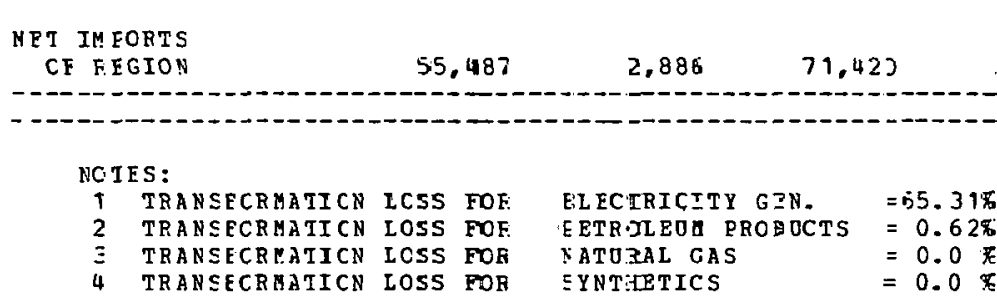


REGICNAL ENEGGP EALANCE STATEMENT

PIES MID MID SCENARIO

\begin{tabular}{|c|c|c|c|c|c|c|c|c|c|c|}
\hline SECTOE & $\begin{array}{l}\text { DISTILLATE } \\
\text { OIL }\end{array}$ & $\begin{array}{l}\text { RES IDUAL } \\
\text { OIL }\end{array}$ & $\begin{array}{l}\text { GASOLINE } \\
\text { (ALI ONI }\end{array}$ & $\begin{array}{c}\text { OTHEB } \\
\text { HYDRO- } \\
\text { CARBONS } \\
\text { TS IN } 10 * 9\end{array}$ & $\begin{array}{c}\text { CR OCE } \\
\text { OIL } \\
\text { BTO'SI }\end{array}$ & $\begin{array}{l}\text { NATURAL } \\
\text { GAS }\end{array}$ & COAL & ELECTRICITY & $\begin{array}{r}\text { SECTOR } \\
\text { TOTAL }\end{array}$ & \\
\hline $\begin{array}{l}\text { FIVIL CEMANI SECTCES } \\
\text { RESIDENTIAI, CCHM. } \\
\text { INDOSTRIAL } \\
\text { TFANSPORTATICN } \\
\text { HISCELILNECOS OSES }\end{array}$ & $\begin{array}{r}18,762 \\
12,923 \\
9,439 \\
998\end{array}$ & $\begin{array}{r}3,387 \\
5,061 \\
125 \\
528\end{array}$ & $61.53 \overline{5}$ & $\begin{array}{r}8,954 \\
16,621 \\
6,641 \\
24\end{array}$ & $\overline{-}$ & $\begin{array}{r}27,309 \\
24,926 \\
374 \\
508\end{array}$ & $\begin{array}{r}198 \\
35,530 \\
- \\
1\end{array}$ & $\begin{array}{r}20,252 \\
39,142 \\
13 \\
255\end{array}$ & $\begin{array}{r}78,862 \\
134,203 \\
78,127 \\
2,314\end{array}$ & $\begin{array}{r}12 \% \\
2 C \% \\
12 \% \\
0 \%\end{array}$ \\
\hline $\begin{array}{l}\text { TCJAI FINAI } \\
\text { DEMANC SECTCRS }\end{array}$ & $42 ; 122$ & 9,101 & 61,535 & 32,240 & - & 53,117 & 35,729 & 59,662 & 293,506 & $43 \%$ \\
\hline $\begin{array}{l}\text { TF 1NSPCRMATICN } \\
\text { FIECTRICITY EEN. } \\
\text { ERTR OLBOS EBCDOCTS } \\
\text { UATORAL GAS } \\
\text { SYNTHETICS }\end{array}$ & $\begin{array}{r}9,521 \\
-54,110 \\
- \\
-\end{array}$ & $\begin{array}{r}11,409 \\
-21,673 \\
-\end{array}$ & $\begin{array}{r}-111,30 \overline{5} \\
- \\
-\end{array}$ & $\begin{array}{r}-48,5.17 \\
-\end{array}$ & 232,314 & $\begin{array}{r}329 \\
5,162 \\
- \\
-\end{array}$ & $\begin{array}{r}526,825 \\
- \\
-\end{array}$ & $\begin{array}{r}-190,696 \\
- \\
-\end{array}$ & $\begin{array}{r}357,388 \\
1,471 \\
-\end{array}$ & $\begin{array}{l}53 \% \\
.0 \%\end{array}$ \\
\hline $\begin{array}{l}\text { NET FOEI OSEL } \\
\text { JN TRANSPOFATICS }\end{array}$ & $-44,589$ & $-10,264$ & $-111,305$ & $-48,917$ & 232,314 & 5,491 & 526,825 & $-190,696$ & 358,859 & $53 \%$ \\
\hline $\begin{array}{l}\text { TCIAL GROSS FLCHS } \\
\text { LCSSES \& CMISSIONS }\end{array}$ & $\begin{array}{r}51,643 \\
3,214\end{array}$ & $\begin{array}{r}20,510 \\
0\end{array}$ & $\begin{array}{r}61,535 \\
0\end{array}$ & $\begin{array}{r}32,240 \\
-1,271\end{array}$ & $\begin{array}{r}232,314 \\
9,637\end{array}$ & $\begin{array}{l}58,608 \\
-1,583\end{array}$ & $\begin{array}{r}562,554 \\
7,614\end{array}$ & $\begin{array}{r}59,662 \\
4,950\end{array}$ & $\begin{array}{r}652,365 \\
22,562\end{array}$ & $\begin{array}{r}97 \% \\
3 \%\end{array}$ \\
\hline TCTAL NET OSAGE & 747 & $-1,162$ & $-49,769$ & $-17,948$ & 241,952 & 57,024 & 570,168 & -126.083 & 674.927 & \\
\hline
\end{tabular}

\begin{tabular}{|c|c|c|c|c|c|c|c|c|c|c|}
\hline SOFELY OF EAERG & & & & & & & & & & \\
\hline FOSSIL FOEI & - & - & - & - & 103,383 & 13,526 & $2,644,846$ & - & $2,761,755$ & $99 \%$ \\
\hline QY DR OELPCIFIC & - & - & - & - & - & - & - & 222 & 222 & $0 \%$ \\
\hline DOCLEAR & - & - & - & - & - & - & - & 41,726 & 41,726 & 18 \\
\hline GEO. \&SOLAR & - & - & - & - & - & - & - & 83 & 83 & $0 \%$ \\
\hline TOTAI SOPRIY & - & - & - & - & 103,383 & 13,526 & $2,644,846$ & 42,031 & $2,803,786$ & \\
\hline
\end{tabular}

\begin{tabular}{l} 
NEE IMFORTS \\
CF REGION \\
\hline
\end{tabular}

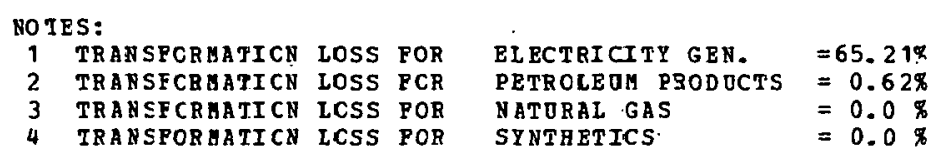


REGIONAL ENEFGY EALANCE STATEMEN

\begin{tabular}{|c|c|c|c|c|c|c|c|c|c|c|}
\hline SECICE & $\begin{array}{l}\text { DI STILLATE } \\
\text { JIL }\end{array}$ & $\begin{array}{l}\text { RESIDUAI } \\
\text { OIL }\end{array}$ & $\begin{array}{l}\text { GASOLITE } \\
\text { (ALI ONI }\end{array}$ & $\begin{array}{c}\text { JTHER } \\
\text { HYDEO- } \\
\text { CAREONS } \\
\text { TS IN } 10 * * 9\end{array}$ & $\begin{array}{c}\text { CROCE } \\
\text { OIL } \\
\text { BTO'S) }\end{array}$ & $\begin{array}{l}\text { NATURAI } \\
\text { GAS }\end{array}$ & $\operatorname{COAL}$ & ELECTRICITY & $\begin{array}{r}\text { SECTOR } \\
\text { TOTAL }\end{array}$ & \\
\hline 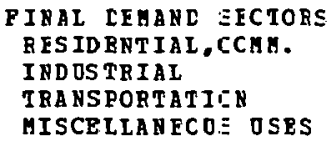 & $\begin{array}{r}7,696 \\
3,611 \\
4,067 \\
530\end{array}$ & $\begin{array}{l}1.84 \mathrm{C} \\
1.67 \mathrm{C} \\
10 \mathrm{C} \\
28\end{array}$ & $21,7 \overline{-}$ & $\begin{array}{r}3,505 \\
4,000 \\
5,380 \\
11\end{array}$ & $\begin{array}{l}- \\
-\end{array}$ & $\begin{array}{r}11,448 \\
3,362 \\
3 \leq 1 \\
2 \leq 1\end{array}$ & $\begin{array}{r}80 \\
4,917 \\
- \\
-\end{array}$ & $\begin{array}{r}6,086 \\
6,016 \\
3 \\
110\end{array}$ & $\begin{array}{r}32,655 \\
23,527 \\
31,658 \\
1,163\end{array}$ & $\begin{array}{r}17 \% \\
12 \% \\
16 \% \\
1 \%\end{array}$ \\
\hline $\begin{array}{l}\text { TCTAL EINAI } \\
\text { DEMAND SECTCRS }\end{array}$ & 17,904 & $3,90 \subseteq$ & 21,773 & 12.896 & - & $15,3 c 2$ & 4,997 & 12,215 & 89,003 & $.16 \%$ \\
\hline 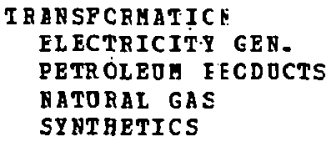 & $\begin{array}{r}1,278 \\
-98,996 \\
-\end{array}$ & $\begin{array}{r}-33.65 \mathrm{I} \\
- \\
-\end{array}$ & $\begin{array}{r}- \\
-203,635 \\
-\end{array}$ & $\begin{array}{r}-29.495 \\
-\end{array}$ & $\begin{array}{r}- \\
425,026 \\
-\end{array}$ & $\begin{array}{r}1 \equiv 3 \\
9,42.4 \\
- \\
-\end{array}$ & $\begin{array}{r}125,162 \\
- \\
-\end{array}$ & $\begin{array}{r}-45,095 \\
- \\
-\end{array}$ & $\begin{array}{r}81,478 \\
2,693 \\
- \\
-\end{array}$ & $\begin{array}{r}+2 \% \\
1 \%\end{array}$ \\
\hline $\begin{array}{l}\text { XET FUEL OSEL } \\
\text { IN TRANSPEBTICN }\end{array}$ & $-97,718$ & $-39,65 i$ & $-203,635$ & $-89,495$ & 425,026 & $9,5: 7$ & 125,162 & -45.095 & 84,171 & $+3 \%$ \\
\hline $\begin{array}{l}\text { TCIAL GROSS FLCNS } \\
\text { ICSSES } \varepsilon \text { ORISSIONS }\end{array}$ & $\begin{array}{r}19,182 \\
1,193\end{array}$ & 3,909 & $\begin{array}{r}21,779 \\
j\end{array}$ & $\begin{array}{r}12.896 \\
-508\end{array}$ & $\begin{array}{r}425,026 \\
17,632\end{array}$ & $\begin{array}{r}24,879 \\
-672\end{array}$ & $\begin{array}{r}130,161 \\
1,761\end{array}$ & $\begin{array}{r}12,215 \\
1,013\end{array}$ & $\begin{array}{r}173,174 \\
20,420\end{array}$ & $\begin{array}{l}39 x \\
11 x\end{array}$ \\
\hline TCIAL NET DSAGE & $-78, \in 20$ & $-35,741$ & $-181,856$ & -77.107 & 442,658 & 24,2017 & 131,922 & $-\Xi 1,866$ & 193.595 & \\
\hline $\begin{array}{l}\text { SOEPLY OP ENESGY } \\
\text { FOSS IL FOEI } \\
\text { BY DEOELECTEIC } \\
\text { ROCL EAR } \\
\text { GEC. ESOLAR }\end{array}$ & $\begin{array}{l}\overline{-} \\
\overline{-}\end{array}$ & I- & $\begin{array}{l}- \\
-\end{array}$ & - & $\begin{array}{r}10,631 \\
- \\
-\end{array}$ & $\begin{array}{r}119 \\
- \\
-\end{array}$ & $\begin{array}{r}304,718 \\
- \\
-\end{array}$ & $\frac{\overline{2}}{3 \overline{8}}$ & $\begin{array}{r}315,468 \\
23 \\
- \\
38\end{array}$ & $\begin{array}{r}100 \% \\
0 \% \\
0 \%\end{array}$ \\
\hline TCTAI SOPPLY & - & - & - & - & 10,631 & $11 \subseteq$ & 304,718 & 61 & 315,529 & \\
\hline
\end{tabular}

\section{BET IM EORTS}

$-78,620$

$-35,741$

$-181,856$

$-77.107$

432,027

$24,08 \varepsilon \quad-172,755$

\section{NOTES:}

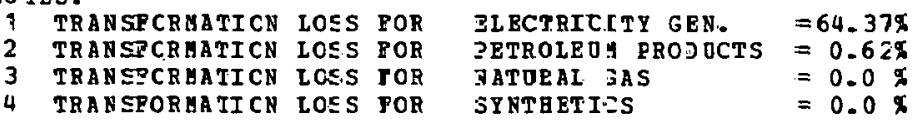


REGIONAL ENEEGY PALANCE STATEMENT

ONAL ENERG PALANCE
PIES MID MID SCENARIO

\begin{tabular}{|c|c|c|c|c|c|c|c|c|c|c|}
\hline SECTOE & $\begin{array}{l}\text { DISTILLATE } \\
\text { OIL }\end{array}$ & $\begin{array}{l}\text { RESIDDIL } \\
\text { OIL }\end{array}$ & $\begin{array}{l}\text { GASOLINE } \\
\text { (ALL ONI }\end{array}$ & $\begin{array}{l}\text { OTHER } \\
\text { HYDRO- } \\
\text { CARBONS } \\
\text { TS IN } 10 * * 9\end{array}$ & $\begin{array}{c}\text { CROLE } \\
\text { OIL } \\
\text { BTO'S) }\end{array}$ & $\begin{array}{l}\text { NATURAL } \\
\text { GAS }\end{array}$ & COAL & ELECTRICITY & $\begin{array}{r}\text { SECTOR } \\
\text { TOTAL }\end{array}$ & \\
\hline $\begin{array}{l}\text { FINAL CEBANC SICTORS } \\
\text { RESIDENTIAL, CCMB. } \\
\text { INDOSTRIAL } \\
\text { TRANS PORTATION } \\
\text { MISCELLANECCS OSES }\end{array}$ & $\begin{array}{r}14,112 \\
7,330 \\
6,104 \\
1,033\end{array}$ & $\begin{array}{r}3,379 \\
2,3+1 \\
49 \\
549\end{array}$ & $\begin{array}{r}- \\
-495 \\
-\end{array}$ & $\begin{array}{r}6,113 \\
4,787 \\
816 \\
22\end{array}$ & - & $\begin{array}{r}27,080 \\
5,013 \\
353 \\
448\end{array}$ & $\begin{array}{r}124 \\
13,722 \\
- \\
1\end{array}$ & $\begin{array}{r}10,319 \\
11,711 \\
61 \\
218\end{array}$ & $\begin{array}{r}61,127 \\
44,904 \\
41,878 \\
2,271\end{array}$ & $\begin{array}{r}26 \% \\
10 \% \\
179 \\
1 \%\end{array}$ \\
\hline $\begin{array}{l}\text { TCTAI FINAL } \\
\text { CEMAND SECTCRS }\end{array}$ & 28,579 & 6,318 & 34,495 & 11,738 & - & 32,894 & 13,847 & 22,309 & 150,180 & $63 \%$ \\
\hline $\begin{array}{l}\text { TF ANSFCRHATICN } \\
\text { ELECTRICITY CEN. } \\
\text { PETROLEOA FBCDOCTS } \\
\text { NATURAL GAS } \\
\text { SY NTHETICS }\end{array}$ & $\begin{array}{r}2,367 \\
- \\
-\end{array}$ & $\begin{array}{r}2,556 \\
- \\
-\end{array}$ & $\begin{array}{l}- \\
- \\
-\end{array}$ & $\begin{array}{l}- \\
\overline{-}\end{array}$ & $\overline{-}$ & $\begin{array}{r}243 \\
- \\
-\end{array}$ & $\begin{array}{r}126,735 \\
- \\
-\end{array}$ & $\begin{array}{r}-46,897 \\
- \\
-\end{array}$ & $\begin{array}{r}85,004 \\
- \\
- \\
-\end{array}$ & $35 \%$ \\
\hline $\begin{array}{l}\text { NET FOEL OSEI } \\
\text { IN TRANSFOEMATICN }\end{array}$ & 2,367 & 2,556 & - & - & - & 243 & 126,735 & $-46,897$ & 85,004 & $35 \%$ \\
\hline $\begin{array}{l}\text { TCTAL GROSS FLCNS } \\
\text { LCSSES } 8 \text { CMISSIONS }\end{array}$ & $\begin{array}{r}30,946 \\
1,926\end{array}$ & $\begin{array}{r}8,874 \\
0\end{array}$ & $\begin{array}{r}34,495 \\
0\end{array}$ & $\begin{array}{r}11,738 \\
-462\end{array}$ & - & $\begin{array}{r}33,137 \\
-895\end{array}$ & $\begin{array}{r}140,582 \\
1,902\end{array}$ & $\begin{array}{r}22,309 \\
1,851\end{array}$ & $\begin{array}{r}235,184 \\
4,322\end{array}$ & $\begin{array}{r}98 \% \\
28\end{array}$ \\
\hline TOTAL NET OSAGE & 32,872 & 8,874 & 34,495 & 11,275 & - & 32,241 & 142,484 & $-22,736$ & 239.506 & \\
\hline $\begin{array}{l}\text { SOFELY OF ENFRGY } \\
\text { FOSSIL FOEL } \\
\text { HY IR CELECTEIC } \\
\text { NOCLEAR } \\
\text { GEC. ESOLAR }\end{array}$ & $\overline{-}$ & $\begin{array}{l}- \\
- \\
-\end{array}$ & $\begin{array}{l}- \\
\vdots\end{array}$ & $\begin{array}{l}- \\
-\end{array}$ & $\begin{array}{r}3,588 \\
- \\
-\end{array}$ & $\begin{array}{l}- \\
\text { - }\end{array}$ & $\begin{array}{r}145,664 \\
- \\
-\end{array}$ & $\begin{array}{r}4 \overline{44} \\
35,080 \\
69\end{array}$ & $\begin{array}{r}149,252 \\
44 \\
35,080 \\
69\end{array}$ & $\begin{array}{r}81 \% \\
0 \% \\
19 \% \\
0 \%\end{array}$ \\
\hline TCTAL SOPPIY & - & - & - & - & 3,588 & - & 145,664 & 35,193 & 184,445 & \\
\hline
\end{tabular}

\begin{tabular}{l} 
RET IMFGRTS \\
CP RPGION \\
\hline
\end{tabular}

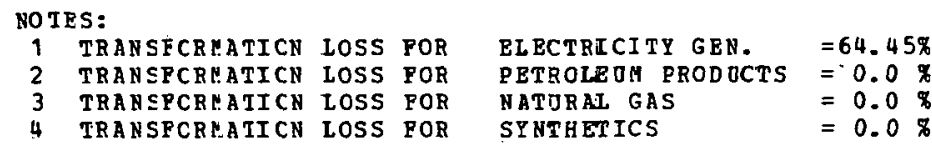


REGTORAL ENEFGY EALANCE STATEMENT

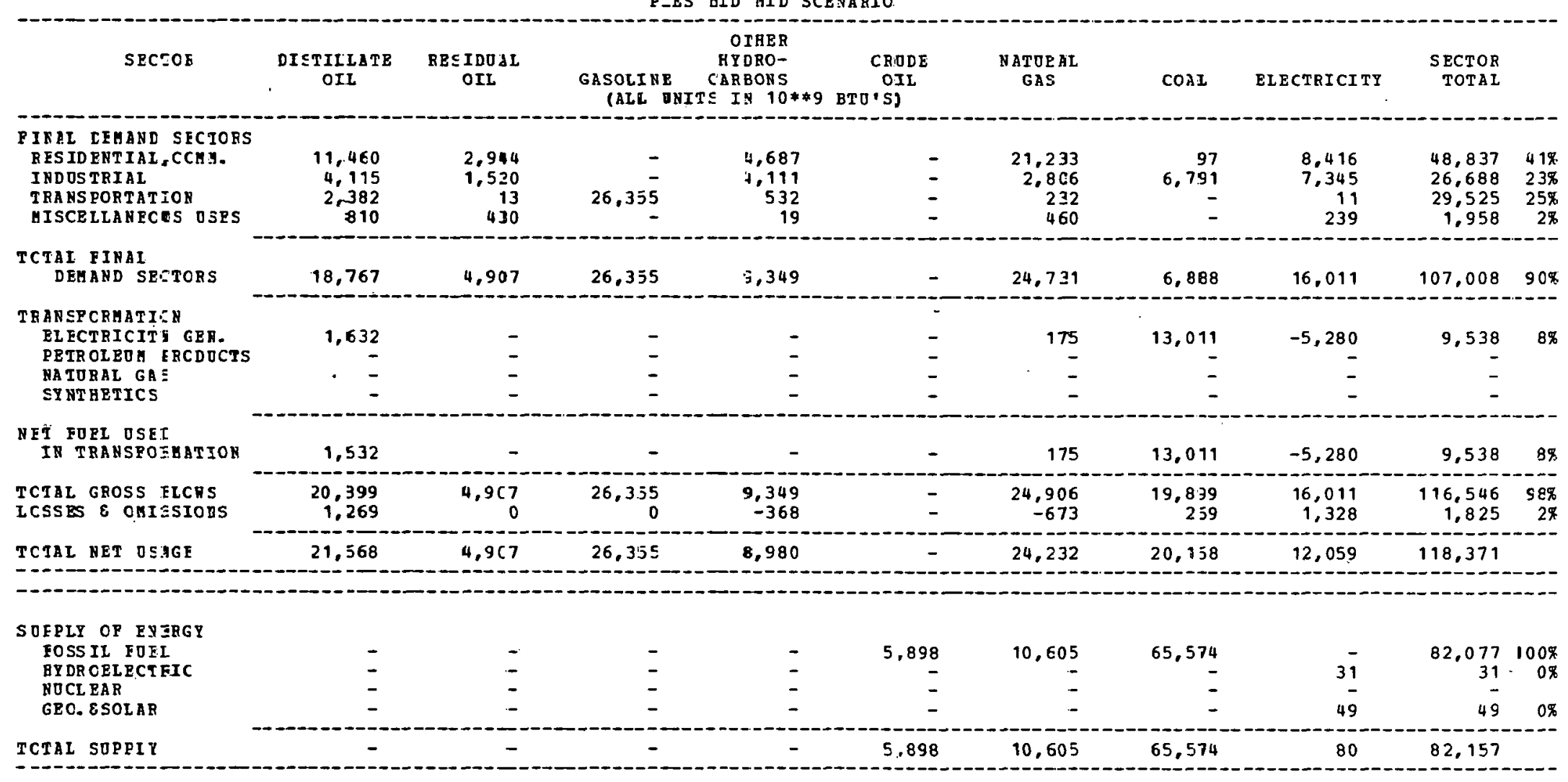

-

NET IMEORTS
OP REGION


REGIONAL ENEFGY EAIANCE STATEMENT

PIES MID MID SCENARIO

\begin{tabular}{|c|c|c|c|c|c|c|c|c|c|c|}
\hline SECICE & $\begin{array}{l}\text { DISTILLATE } \\
\text { OIL }\end{array}$ & $\begin{array}{l}\text { RESIDOAL } \\
\text { OIL }\end{array}$ & $\begin{array}{l}\text { GASOLINE } \\
\text { (ALL ONIT }\end{array}$ & $\begin{array}{c}\text { OTHER } \\
\text { HYDRO- } \\
\text { CARBONS } \\
\text { TS IN } 10 * * 9\end{array}$ & $\begin{array}{c}\text { CRUDE } \\
\text { OIL } \\
\text { BTO'S) }\end{array}$ & $\begin{array}{l}\text { NATURAL } \\
\text { GAS }\end{array}$ & $\operatorname{COAL}$ & ELECTRICITY & $\begin{array}{r}\text { SECTOR } \\
\text { TOTAL }\end{array}$ & \\
\hline $\begin{array}{l}\text { FINAL LEMANL SECIOAS } \\
\text { RESIDENTIAL, CCIM. } \\
\text { INDOSTRIAI } \\
\text { TRANSPORTATICN } \\
\text { MISCELLANECES OSES }\end{array}$ & $\begin{array}{r}9,572 \\
3,558 \\
3,632 \\
354\end{array}$ & $\begin{array}{r}1,954 \\
3,735 \\
56 \\
137\end{array}$ & 21,390 & $\begin{array}{r}3,405 \\
5,152 \\
3,264 \\
7\end{array}$ & $\begin{array}{l}- \\
\overline{-} \\
-\end{array}$ & $\begin{array}{r}10,780 \\
2,219 \\
151 \\
157\end{array}$ & $\begin{array}{r}79 \\
5,754 \\
- \\
-\end{array}$ & $\begin{array}{r}6,193 \\
5,877 \\
71 \\
71\end{array}$ & $\begin{array}{r}32,383 \\
26,145 \\
28,504 \\
776\end{array}$ & $\begin{array}{r}35 \% \\
28 \% \\
319 \\
1 \%\end{array}$ \\
\hline $\begin{array}{l}\text { TCTAI FINAI } \\
\text { DEMAND SECTCRS }\end{array}$ & $17, \$ 16$ & 5,972 & 21,390 & 11,828 & - & 13,307 & 5,833 & $12,142^{\circ}$ & 87.808 & $95 \%$ \\
\hline $\begin{array}{l}\text { TEANSPCRMATICN } \\
\text { ELECTRICITY GEN. } \\
\text { EETROLEOM ERCDOCTS } \\
\text { NATURAL GAS } \\
\text { STNTEETICS }\end{array}$ & $\begin{array}{r}1,235 \\
- \\
-\end{array}$ & $\begin{array}{r}210 \\
- \\
-\end{array}$ & $\begin{array}{l}- \\
-\end{array}$ & $\begin{array}{l}- \\
- \\
-\end{array}$ & $\begin{array}{l}\overline{-} \\
\overline{-}\end{array}$ & $\begin{array}{r}132 \\
- \\
-\end{array}$ & $\begin{array}{r}3,369 \\
5 \\
=\end{array}$ & $\begin{array}{r}-1,756 \\
- \\
-\end{array}$ & $\begin{array}{r}3,190 \\
- \\
-\end{array}$ & $3 \%$ \\
\hline $\begin{array}{l}\text { NET FOFL OSEL } \\
\text { IN TRANSFOFHATION }\end{array}$ & 1,235 & 210 & - & - & - & 132 & 3,369 & $-1,756$ & 3,190 & $3 \%$ \\
\hline $\begin{array}{l}\text { TCTAL GFOSS FICWS } \\
\text { LCSSES } \varepsilon \text { OMISSIONS }\end{array}$ & $\begin{array}{r}18,551 \\
1,154\end{array}$ & $\begin{array}{r}6,202 \\
0\end{array}$ & $\begin{array}{r}21,390 \\
0\end{array}$ & $\begin{array}{r}11,828 \\
-466\end{array}$ & $\overline{-}$ & $\begin{array}{r}13,439 \\
-363\end{array}$ & $\begin{array}{r}9,202 \\
124\end{array}$ & $\begin{array}{r}12,142 \\
1,007\end{array}$ & $\begin{array}{r}90,998 \\
1,457\end{array}$ & $\begin{array}{l}98 \% \\
2 \%\end{array}$ \\
\hline
\end{tabular}

\begin{tabular}{|c|c|c|c|c|c|c|c|c|c|c|}
\hline SUEPLY OF ENERGY & & & & & & & & & & \\
\hline FOSSIL FOEI & - & - & - & - & - & - & 1,636 & - & 1,636 & $93 \%$ \\
\hline HY DR CEL F CTFIC & - & - & - & - & - & - & - & 90 & 90 & $5 \%$ \\
\hline NOCL EAR & - & - & - & - & - & - & - & - & - & \\
\hline GEO. ESOLAR & - & - & - & - & - & - & - & 37 & 37 & $2 \%$ \\
\hline TCTAI SOPEIY & - & - & - & - & - & - & 1,636 & 127 & 1,763 & \\
\hline
\end{tabular}

UET IM EORTS
CP REGION


REGICHAL ENZFGQ PALANCE STETEMENT

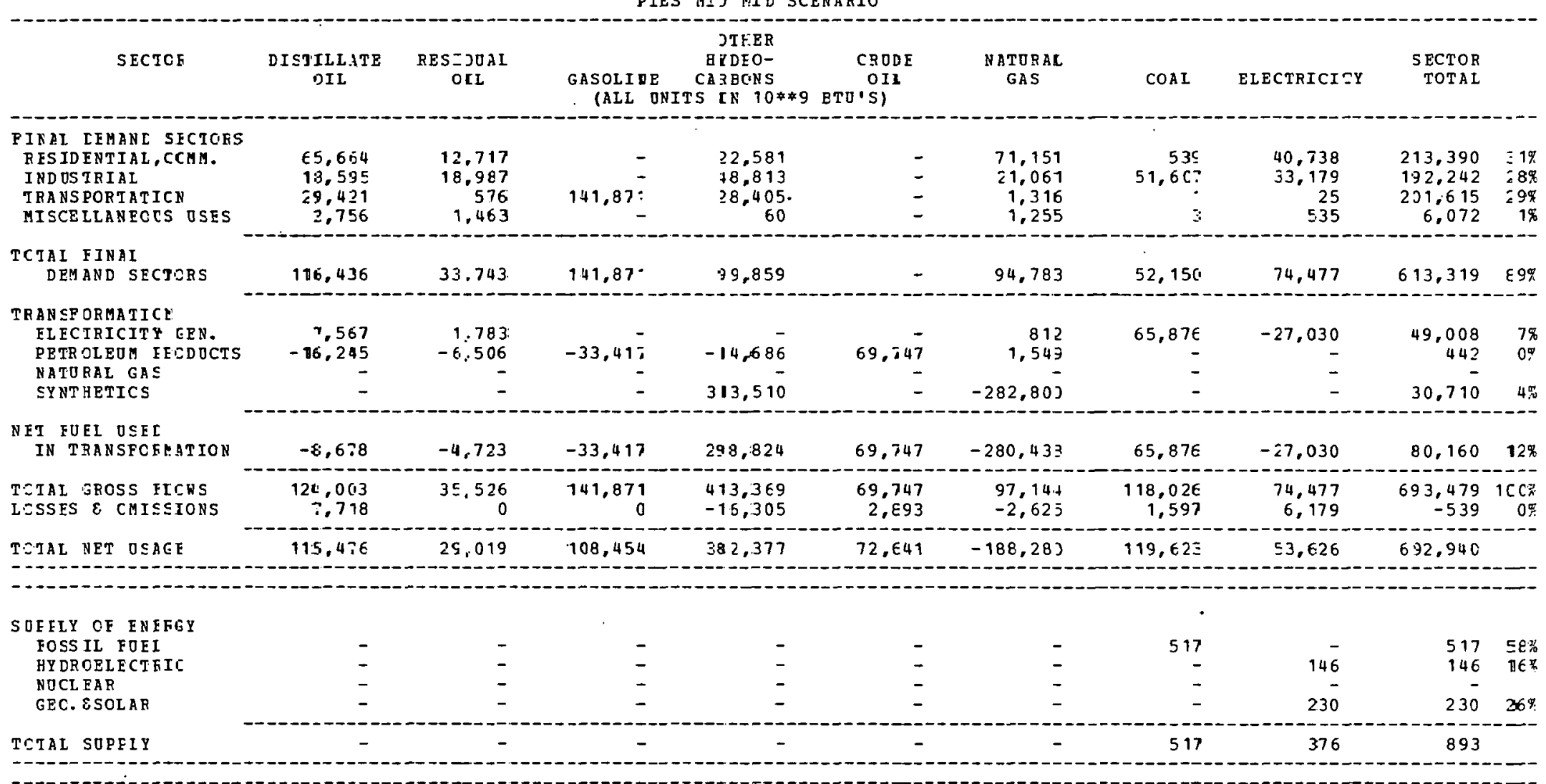

NET IM $=$ CRTS
CF REGION

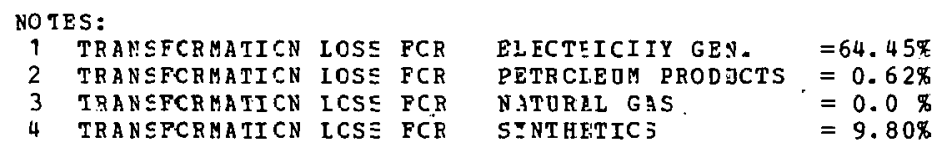


REGIONAL ENEFGY EALANCE STATEMENT

PIES MID MID SCENARIO

\begin{tabular}{|c|c|c|c|c|c|c|c|c|c|c|}
\hline SECTCE & $\begin{array}{l}\text { DISTILLATE } \\
\text { OIL }\end{array}$ & $\begin{array}{l}\text { RESIDUAL } \\
\text { OIL. }\end{array}$ & $\begin{array}{l}\text { GASOLIN } \\
\text { (ALL }\end{array}$ & $\begin{array}{c}\text { OTHER } \\
\text { HYDRO- } \\
\text { CARBONS } \\
\text { TS IN } 10 * 9\end{array}$ & $\begin{array}{c}\text { CROLE } \\
\text { OIL } \\
\text { BTO'S) }\end{array}$ & $\begin{array}{l}\text { NATURAL } \\
\text { GAS }\end{array}$ & $\operatorname{COAL}$ & ELECTRICITY & $\begin{array}{r}\text { SECT OR } \\
\text { TOTAL }\end{array}$ & \\
\hline $\begin{array}{l}\text { FINIL LEMANE SECIOFS } \\
\text { RESIDENTIAI, COMM. } \\
\text { IND OS TPIAL } \\
\text { ERA PSPRTATICN } \\
\text { UISCELLANECCS OSES }\end{array}$ & $\begin{array}{r}18,370 \\
9,906 \\
5,879 \\
433\end{array}$ & $\begin{array}{r}3,161 \\
6,968 \\
153 \\
229\end{array}$ & 42,226 & $\begin{array}{r}6,694 \\
13,944 \\
7,796 \\
9\end{array}$ & $\begin{array}{l}- \\
-\end{array}$ & $\begin{array}{r}20,383 \\
9,376 \\
361 \\
190\end{array}$ & $\begin{array}{r}157 \\
37.173 \\
- \\
-\end{array}$ & $\begin{array}{r}11,209 \\
16,414 \\
3 \\
89\end{array}$ & $\begin{array}{r}59,974 \\
93,781 \\
56,423 \\
950\end{array}$ & $\begin{array}{r}279 \\
428 \\
25 \% \\
0 \%\end{array}$ \\
\hline $\begin{array}{l}\text { TCTAI FINAI } \\
\text { DEMAND SECICRS }\end{array}$ & 34,588 & 10.516 & 42,226 & 28,443 & - & 30,310 & 37,330 & 27,715 & 211,128 & $94 \%$ \\
\hline $\begin{array}{l}\text { TFINSFCRMATICN } \\
\text { FLECTRICITY GEN. } \\
\text { EETROLEOM FCDOCTS } \\
\text { NATURAL GAS } \\
\text { SY NTHETICS }\end{array}$ & $\begin{array}{r}2.795 \\
- \\
-\end{array}$ & $\begin{array}{l}- \\
- \\
-\end{array}$ & $=$ & $\begin{array}{l}\overline{-} \\
\overline{-}\end{array}$ & $\begin{array}{l}- \\
\overline{-}\end{array}$ & $\begin{array}{r}302 \\
- \\
-\end{array}$ & $\begin{array}{r}14,139 \\
= \\
-\end{array}$ & $\begin{array}{r}-6,143 \\
- \\
- \\
-\end{array}$ & $\begin{array}{r}11,093 \\
- \\
-\end{array}$ & $5 q$ \\
\hline $\begin{array}{l}\text { NET FOEI OSEL } \\
\text { IN TRANSFCFATION }\end{array}$ & 2,795 & - & - & - & - & 302 & 14,139 & $-6,143$ & 11,093 & $5 \pi$ \\
\hline $\begin{array}{l}\text { TCTAL GKOSS FLCRS } \\
\text { LCSSES \& CMISSICNS }\end{array}$ & $\begin{array}{r}37,383 \\
2,326\end{array}$ & $\begin{array}{r}10,516 \\
0\end{array}$ & $\begin{array}{r}42,226 \\
0\end{array}$ & $\begin{array}{l}28,443 \\
-1,121\end{array}$ & $\overline{-}$ & $\begin{array}{r}30,612 \\
-827\end{array}$ & $\begin{array}{r}51,469 \\
696\end{array}$ & $\begin{array}{r}27,715 \\
2,299\end{array}$ & $\begin{array}{r}.222,221 \\
3,374\end{array}$ & $\begin{array}{r}99 \% \\
1 \% .\end{array}$ \\
\hline TCIAL NET USAEE & 39.709 & 10,516 & 42,226 & 27.321 & - & 29,784 & 52,165 & 23.871 & 225,595 & \\
\hline $\begin{array}{l}\text { SOFPLY CF ENERGY } \\
\text { FOSS IL FOEI } \\
\text { OYDROELECTFIC } \\
\text { OOCL EAR } \\
\text { GEC. ESOLAR }\end{array}$ & $\begin{array}{l}\overline{-} \\
\overline{-}\end{array}$ & $\begin{array}{l}\overline{-} \\
\overline{-}\end{array}$ & $\begin{array}{l}- \\
\overline{-}\end{array}$ & $\begin{array}{l}\overline{-} \\
\overline{-}\end{array}$ & $\begin{array}{l}11 \\
- \\
-\end{array}$ & $\begin{array}{l}- \\
-\end{array}$ & $\begin{array}{l}- \\
-\end{array}$ & $\begin{array}{l}\overline{5} \\
\overline{5} \\
8 \overline{5}\end{array}$ & $\begin{array}{l}11 \\
55 \\
- \\
85\end{array}$ & $\begin{array}{r}7 \% \\
3 E x\end{array}$ \\
\hline TCEAI SOPRIY & - & - & - & - & 11 & - & - & 140 & 151 & \\
\hline
\end{tabular}

\begin{tabular}{|c|c|c|c|c|c|c|c|c|c|}
\hline CF REGION & 39,709 & 10,516 & 42,226 & 27,321 & -11 & 29,784 & 52,165 & 23,731 & 225,444 \\
\hline
\end{tabular}

\section{NOTES:}

1 TRANSFCRMATICN LCSS FOZ TRANSEBAATICA LOSS POA TRANCPCBHATCN LCSS POB TRABSPOBDATTCH LCSS POR

ELECTRICITY GEN.

$=64.36 \%$

TITOAT GAS $=0.0$

SYTTHET JCS 
REG-CNAL 3NE FGY EALANCE STITEMENT

\begin{tabular}{|c|c|c|c|c|c|c|c|c|c|c|}
\hline SECTOF & $\begin{array}{l}\text { [ISTILLATE } \\
\text { OIL }\end{array}$ & $\begin{array}{l}\text { RESIDUAL } \\
\text { OIL }\end{array}$ & $\begin{array}{l}\text { GASOL }=N E \\
\text { (ALI U }\end{array}$ & $\begin{array}{l}\text { OTHER } \\
\text { HYERO- } \\
\text { CAREONS } \\
\text { TS IN } 10 * \$ 9\end{array}$ & $\begin{array}{l}\text { CRDDE } \\
\text { OIL } \\
\text { ETO'S: }\end{array}$ & $\begin{array}{l}\text { NATURAL } \\
\text { GAS }\end{array}$ & $\operatorname{COA}=$ & ELECTRICITY & $\begin{array}{r}\text { SECTOR } \\
\text { TOTAL }\end{array}$ & \\
\hline $\begin{array}{l}\text { PINAL CEMANL SECIOES } \\
\text { RESIDENTIAL, CCMM. } \\
\text { INDOSTRIAL } \\
\text { TRANSPORTATICN } \\
\text { MISCELLANECES OSES }\end{array}$ & $\begin{array}{r}20,734 \\
12,078 \\
29,034 \\
2,097\end{array}$ & $\begin{array}{r}1,672 \\
10,005 \\
203 \\
1,112\end{array}$ & $\begin{array}{r}- \\
\overline{-} \\
139.911\end{array}$ & $\begin{array}{r}20,733 \\
65,174 \\
5,990 \\
50\end{array}$ & $\begin{array}{l}- \\
\overline{-} \\
-\end{array}$ & $\begin{array}{r}93,075 \\
37,097 \\
1,199 \\
1,049\end{array}$ & $\begin{array}{r}418 \\
114,637 \\
- \\
1\end{array}$ & $\begin{array}{r}44.228 \\
77.601 \\
13 \\
523\end{array}$ & $\begin{array}{r}180,860 \\
320,592 \\
176,350 \\
4,832\end{array}$ & $\begin{array}{r}16 \% \\
29 \% \\
16 \% \\
0 \%\end{array}$ \\
\hline $\begin{array}{l}\text { TCTAI FINAI } \\
\text { DEMAND SECTCRS }\end{array}$ & 53,943 & 12,992 & 139,911 & 95,947 & - & 132,423 & 115,056 & 122.365 & 682.634 & $61 \%$ \\
\hline $\begin{array}{l}\text { TRANSPCRMATICN } \\
\text { ELECTRICITT EEN. } \\
\text { PETROLEOM GRCDUCIS } \\
\text { NATORAL GAS } \\
\text { SYNTHETICS }\end{array}$ & $\begin{array}{r}14.007 \\
-21.373 \\
- \\
-\end{array}$ & $\begin{array}{r}256 \\
-8,560 \\
- \\
-\end{array}$ & $\begin{array}{r}- \\
-43,964 \\
-\end{array}$ & $\begin{array}{r}-19,322 \\
- \\
-\end{array}$ & $\begin{array}{r}- \\
91.762 \\
-\end{array}$ & $\begin{array}{r}972 \\
2.039 \\
- \\
-\end{array}$ & $\begin{array}{r}622,9 \cdot 34 \\
- \\
-\end{array}$ & $\begin{array}{r}-222,963 \\
- \\
-\end{array}$ & $\begin{array}{r}415,176 \\
581 \\
- \\
-\end{array}$ & $\begin{array}{r}37 \% \\
0 \%\end{array}$ \\
\hline $\begin{array}{l}\text { NET FOFL OSFI } \\
\text { IN TRANSPOFHATION }\end{array}$ & $-7,366$ & $-8,304$ & $-43,964$ & $-19,322$ & 91.762 & 3,011 & 622,934 & $-222,963$ & 415,757 & $37 \%$ \\
\hline $\begin{array}{l}\text { TCIAL GROSS FLCRS } \\
\text { LCSSES E CMISSIONS }\end{array}$ & $\begin{array}{r}77,950 \\
4,851 \\
\end{array}$ & $\begin{array}{r}13,248 \\
0\end{array}$ & $\begin{array}{r}139,911 \\
0\end{array}$ & $\begin{array}{l}95,947 \\
-\Xi .784\end{array}$ & $\begin{array}{r}91.762 \\
3.806\end{array}$ & $\begin{array}{r}135,431 \\
-3,657\end{array}$ & $\begin{array}{r}737,950 \\
9,938\end{array}$ & $\begin{array}{r}122,365 \\
10,153\end{array}$ & $\begin{array}{r}1,098,391 \\
21,357\end{array}$ & $\begin{array}{r}98 \% \\
2 \%\end{array}$ \\
\hline
\end{tabular}

SUEELY CP EN IREY

FOSS IL FOEI

HY LR OEL ECT EIC

GEC. ESOLA

TCIAI SUPPIY

$\begin{array}{lll}- & - & - \\ - & - & - \\ - & - & -\end{array}$

$\begin{array}{llll}- & - & - & - \\ - & - & - & - \\ - & - & - & -\end{array}$

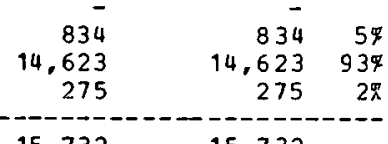

$-$

$-$

- $\quad 15,732$

15,732

\begin{tabular}{l} 
NET IM FORTS \\
CF REGION \\
\hline
\end{tabular}


REGIONAL ENEFGY RALANCE STATELENT.

PIES MID UID SCENARIO

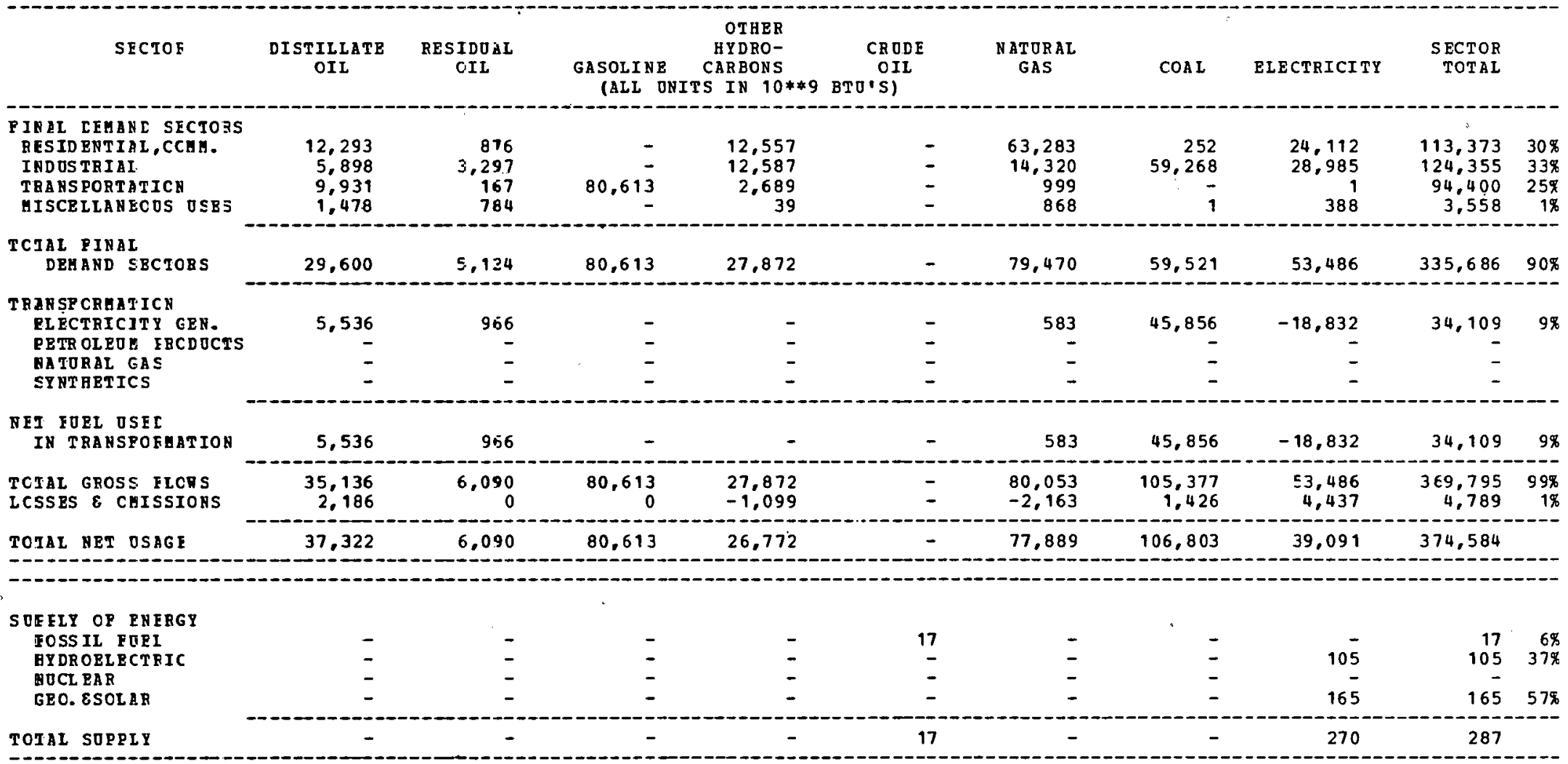

RET IM FORTS

OP RBGION

37,322

6,030

80,613

26.772

$-17$

77,889

106,803

38,821

374,297

\section{HOTES:}

1 TRANSFCRHATION LOSS PO TRANSPORAATICN LOSS PO TBANSPOBVATI CN ICSS PO TRARSPORDATI ON LOSS POR

BLECTRICITY GEN.

PETROLE'TH PBODOCTS $=64.43 \%$

NATUBAL GAS

$=0.0 \%$

SY YTH BTICS

$=0.0 \%$
$=0.0 \%$ 
REGIONAL ENEFGT EALANCE STATEMENT

PIJS MIL GID SCENARIO

\begin{tabular}{|c|c|c|c|c|c|c|c|c|c|c|}
\hline SECTOF & $\begin{array}{c}\text { DISTELLTE } \\
\text { GIL }\end{array}$ & $\begin{array}{l}\text { OESIDJAL } \\
\text { OIL }\end{array}$ & $\begin{array}{l}\text { SASOLI NE } \\
\text { (ALL OY }\end{array}$ & $\begin{array}{c}\text { CTHBR } \\
\text { HYDRO- } \\
\text { CAEBOAS } \\
\text { TS IX } 10 * \% 9\end{array}$ & $\begin{array}{c}\text { CRODE } \\
\text { OIL } \\
\text { BTO'SI }\end{array}$ & $\begin{array}{l}\text { NATORAL } \\
\text { GAS }\end{array}$ & $\operatorname{COAL}$ & ELECTRICI TY & $\begin{array}{l}\text { SECTOR } \\
\text { TOTAL }\end{array}$ & \\
\hline $\begin{array}{l}\text { PINAL TEHANC SECTORS } \\
\text { BES IDENTIAL, CCAM. } \\
\text { INDOSTRIAL } \\
\text { TRANSPORTATICD } \\
\text { GISCELLANEOCS USES }\end{array}$ & $\begin{array}{l}21,414 \\
11,525 \\
27.032 \\
2,871\end{array}$ & $\begin{array}{r}1.684 \\
7.254 \\
286 \\
1.521\end{array}$ & $\begin{array}{r}\overline{-} \\
142,95 \overline{1} \\
-\end{array}$ & $\begin{array}{r}-21,567 \\
46,+15 \\
4,590 \\
67\end{array}$ & $\begin{array}{l}- \\
-\end{array}$ & $\begin{array}{r}111,363 \\
42,849 \\
1,805 \\
1,441\end{array}$ & $\begin{array}{r}484 \\
910.870 \\
- \\
3\end{array}$ & $\begin{array}{r}43,547 \\
55,802 \\
21 \\
675\end{array}$ & $\begin{array}{r}200,159 \\
274,715 \\
176,785 \\
6,578\end{array}$ & $\begin{array}{r}258 \\
34.8 \\
22.8 \\
1 \%\end{array}$ \\
\hline $\begin{array}{l}\text { TCTAL FINAL } \\
\text { DEMAND SECTCRS }\end{array}$ & 62,842 & 10.745 & 142,951 & 72,339 & - & 157,458 & 111,357 & 100,045 & 658,237 & 8.7 .8 \\
\hline $\begin{array}{l}\text { TRARSFCRHATICN } \\
\text { ELECTRICITY EEN. } \\
\text { FETR OLEOM FREDOCTS } \\
\text { NATOBAL GAS } \\
\text { STNTHETICS }\end{array}$ & $\begin{array}{r}3,855 \\
-2,823 \\
- \\
-\end{array}$ & $\begin{array}{r}846 \\
-310 \\
- \\
-\end{array}$ & $\begin{array}{r}-3,155 \\
-\end{array}$ & $\begin{array}{r}-833 \\
-\end{array}$ & $7,18 \overline{-}$ & $\begin{array}{r}1,033 \\
39 \\
- \\
-\end{array}$ & $\begin{array}{r}211,364 \\
- \\
-\end{array}$ & $\begin{array}{r}-76,962 \\
- \\
-\end{array}$ & $\begin{array}{r}145,136 \\
-2 \\
- \\
-\end{array}$ & $\begin{aligned} 18.8 \\
3.8\end{aligned}$ \\
\hline $\begin{array}{l}\text { NIT FOEL USEL } \\
\text { IN TRANSFOFITION }\end{array}$ & 6.032 & 535 & $-3,155$ & -933 & 7,130 & 1,072 & $211,3 \in 4$ & $-76,962$ & 145,133 & $13 \%$ \\
\hline $\begin{array}{l}\text { TCTAL GROSS FLCRS } \\
\text { LCSSES } \varepsilon \text { CMISSIONS }\end{array}$ & $\begin{array}{r}71,697 \\
+, 4 \in 2\end{array}$ & $\begin{array}{r}11,591 \\
0\end{array}$ & $\begin{array}{r}142,951 \\
0\end{array}$ & $\begin{array}{l}72,239 \\
-2,: 37\end{array}$ & $\begin{array}{r}7,190 \\
297\end{array}$ & $\begin{array}{r}158,530 \\
-4,28\end{array}$ & $\begin{array}{r}322,721 \\
4,368\end{array}$ & $\begin{array}{r}100,045 \\
8,301\end{array}$ & $\begin{array}{r}803,373 \\
10,273\end{array}$ & $\begin{array}{r}99 \% \\
1.8\end{array}$ \\
\hline
\end{tabular}

\begin{tabular}{|c|c|c|c|c|c|c|c|c|c|c|}
\hline $\begin{array}{l}\text { SOEELY CP FNEBSY } \\
\text { FOSS IL FOEL }\end{array}$ & & - & & & & & & & & \\
\hline HYDRCELECTEIT: & - & - & - & $\begin{array}{l}- \\
-\end{array}$ & 31.638 & $29,30 ?$ & 353.629 & $\overline{-}$ & 420,594 & 1038 \\
\hline NOCL EAR & - & - & - & - & $\overline{-}$ & $\overline{-}$ & $\overline{-}$ & $\begin{array}{l}170 \\
-\end{array}$ & $\begin{array}{r}170 \\
-\end{array}$ & 3.8 \\
\hline GEC. \&SOLAR & - & - & - & - & - & - & - & 268 & 268 & $3 \%$ \\
\hline TCTAL SUPPIY & - & - & - & - & 37,658 & $29,30 \%$ & 353,629 & 438 & 421,032 & \\
\hline
\end{tabular}

MET IMFORTS
OP REGION


BEGIONAL ENEFGY EALANCE STATEMENT
PIES MID MID SCENARIO

\begin{tabular}{|c|c|c|c|c|c|c|c|c|c|c|}
\hline SECTOE & $\begin{array}{l}\text { DISTILLATE } \\
\text { OIL }\end{array}$ & $\begin{array}{l}\text { RESIDOAL } \\
\text { OIL }\end{array}$ & $\begin{array}{l}\text { GASOLINI } \\
\text { (ALL }\end{array}$ & $\begin{array}{c}\text { OTHER } \\
\text { HYDRO- } \\
\text { CARBONS } \\
\text { TS IN } 10 * * 9\end{array}$ & $\begin{array}{c}\text { CRODE } \\
\text { OIE } \\
\text { BTU'S) }\end{array}$ & $\begin{array}{l}\text { NATURAL } \\
\text { GAS }\end{array}$ & COA L & ELECTRICITY & $\begin{array}{l}\text { SECTOR } \\
\text { TOTAL }\end{array}$ & \\
\hline 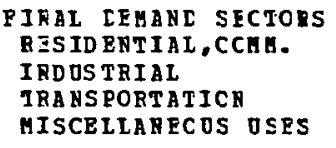 & $\begin{array}{l}2,175 \\
2,389 \\
6,293 \\
233\end{array}$ & $\begin{array}{l}477 . \\
8 \subseteq 4 \\
1: 6\end{array}$ & $25,73 \overline{-}$ & $\begin{array}{r}1.901 \\
660 \\
453 \\
4\end{array}$ & - & $\begin{array}{r}15,537 \\
12,675 \\
657 \\
310\end{array}$ & $\begin{array}{r}205 \\
13,723 \\
2 \\
1\end{array}$ & $\begin{array}{r}8,722 \\
16,986 \\
- \\
139\end{array}$ & $\begin{array}{r}29,017 \\
47,326 \\
33,143 \\
803\end{array}$ & $\begin{array}{r}12 \% \\
19 \% \\
14 \% \\
0 \%\end{array}$ \\
\hline $\begin{array}{l}\text { TCTAL FINAI } \\
\text { DEAABD SECICRS }\end{array}$ & 11,089 & 1,487 & 25,738 & 3,018 & - & 29,179 & 13,931 & 25.847 & 110,289 & $45 \%$ \\
\hline $\begin{array}{l}\text { TEANSFCRHATICN } \\
\text { ELECTRICITY GEH. } \\
\text { PETRCLEOH ERCDOCTS } \\
\text { HATORAL GAS } \\
\text { SYRTHETICS }\end{array}$ & $\begin{array}{l}\bar{z} \\
\overline{-}\end{array}$ & $\begin{array}{r}669 \\
- \\
-\end{array}$ & - & $\begin{array}{l}\overline{-} \\
\overline{-}\end{array}$ & $\begin{array}{l}- \\
\overline{-}\end{array}$ & $\begin{array}{l}\check{-} \\
-\end{array}$ & $\begin{array}{r}190,852 \\
- \\
-\end{array}$ & $\begin{array}{r}-63,275 \\
- \\
-\end{array}$ & $\begin{array}{r}128,246 \\
- \\
-\end{array}$ & $53 \%$ \\
\hline $\begin{array}{l}\text { HEI FOEL OSEL } \\
\text { IN TRABSPOBEATIOY }\end{array}$ & - & 669 & - & - & - & - & 190,852 & $-63,275$ & 128,246 & $53 \%$ \\
\hline $\begin{array}{l}\text { TCIAL GROSS FLCRS } \\
\text { LCSSES E OHISSIONS }\end{array}$ & $\begin{array}{r}11.089 \\
690\end{array}$ & $\begin{array}{r}2,156 \\
0\end{array}$ & $\begin{array}{r}25,738 \\
0\end{array}$ & $\begin{array}{r}3,018 \\
-119\end{array}$ & $\overline{-}$ & $\begin{array}{r}29,179 \\
-788\end{array}$ & $\begin{array}{r}204,783 \\
2,771\end{array}$ & $\begin{array}{r}25,847 \\
2,1144\end{array}$ & $\begin{array}{r}238,535 \\
4,699\end{array}$ & $\begin{array}{r}9 \varepsilon \% \\
2 \%\end{array}$ \\
\hline TOTAL HET OSAGE & 11,779 & 2,156 & 25,738 & 2,898 & - & 28,390 & 207,554 & $-35,283$ & 243,234 & \\
\hline
\end{tabular}

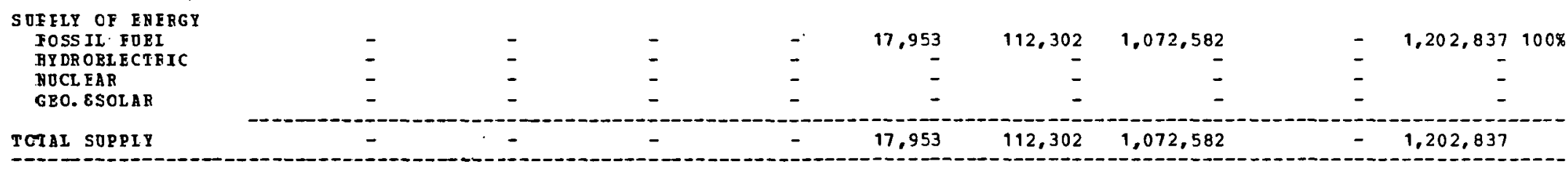

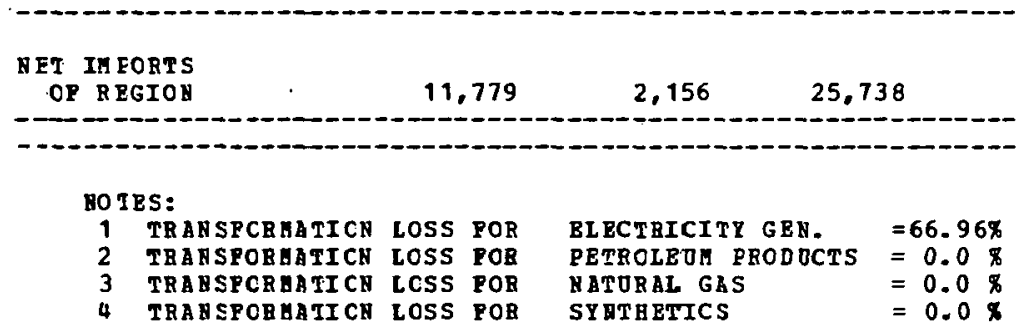


REGIONLL EREFTY EALANCE STATEMENT

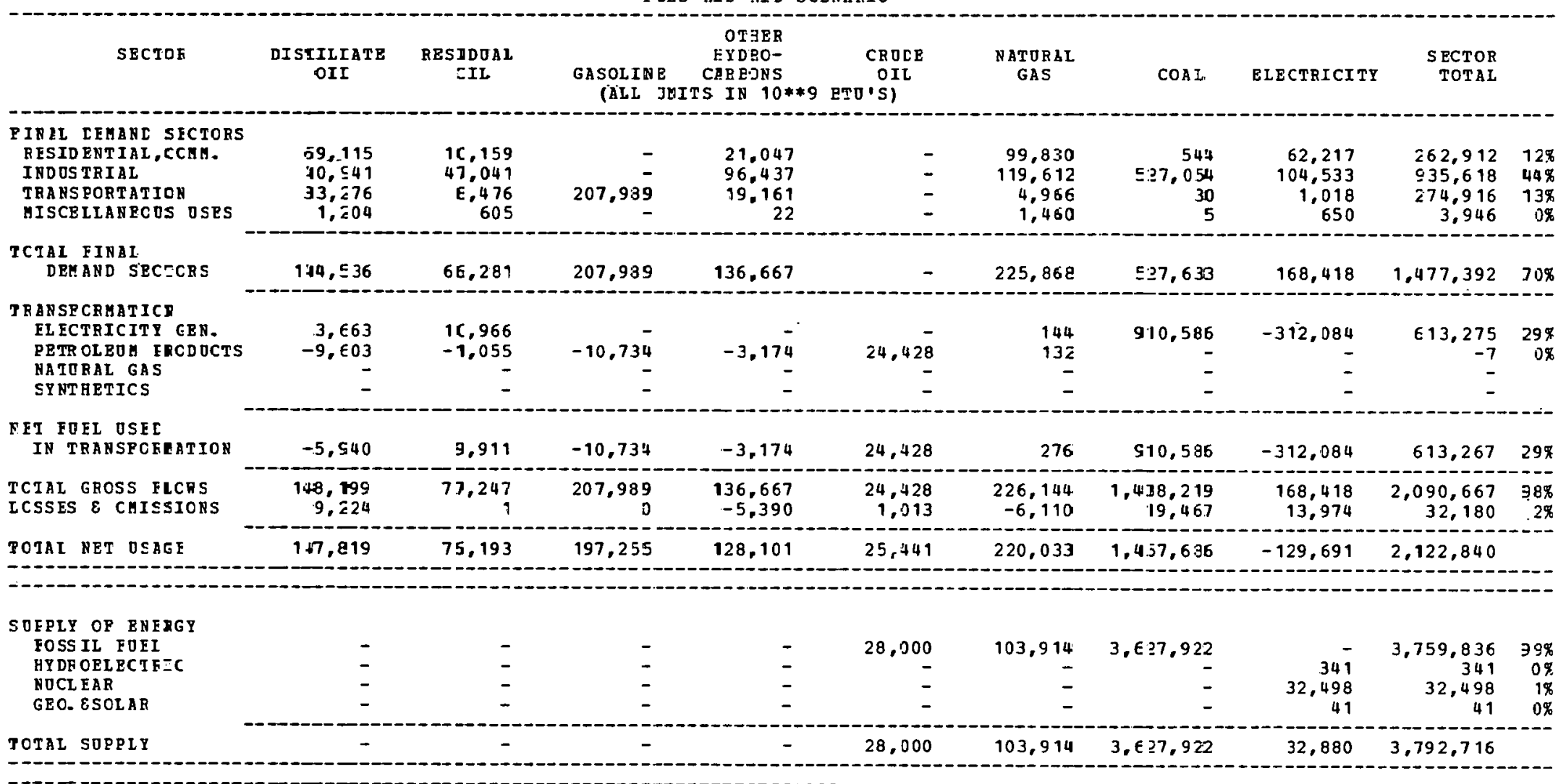

\section{PT IH FORTS \\ CP PEGION}

$177, E 19$

7E. 193

197,255

128,101

\section{NOTES:}

TRAN SPCRMATICN LOSS FOR TRANSPCRMATICN LOSS FCB TRANSTCRMATICN LCSS FO 
REGIONAL ENE EGY EALANCE STATEMENT

PIES MID MID SCENARIO

\begin{tabular}{|c|c|c|c|c|c|c|c|c|c|c|}
\hline SECICF & $\begin{array}{c}\text { LISTILLATE } \\
\text { OIL }\end{array}$ & $\begin{array}{l}\text { BESIDOAL } \\
\text { OIL }\end{array}$ & $\begin{array}{l}\text { GASOLIN } \\
\text { (ALL }\end{array}$ & $\begin{array}{c}\text { OTHEE } \\
\text { HYDRO- } \\
\text { CARBONS } \\
\text { TS IN } 1.0 * 9\end{array}$ & $\begin{array}{c}\text { CR ODF } \\
\text { OIL } \\
\text { BTO'S) }\end{array}$ & $\begin{array}{l}\text { NATURAL } \\
\text { GAS }\end{array}$ & COAL & ELECTRICITY & $\begin{array}{r}\text { SECTOK } \\
\text { TOTAL }\end{array}$ & \\
\hline $\begin{array}{l}\text { PINAL CEMANE SFCTCES } \\
\text { BESIDENTIAI, CCMM. } \\
\text { INDOSTRIAI } \\
\text { TRANSEORTATICA } \\
\text { WISCELIANECOS OSES }\end{array}$ & $\begin{array}{r}10,829 \\
6,692 \\
10,159 \\
532\end{array}$ & $\begin{array}{r}1,107 \\
5,149 \\
372 \\
281\end{array}$ & 52,071 & $\begin{array}{r}7,304 \\
24,637 \\
1,521 \\
11\end{array}$ & $\begin{array}{l}- \\
\\
-\end{array}$ & $\begin{array}{r}35,799 \\
17,744 \\
472 \\
296\end{array}$ & $\begin{array}{r}148 \\
96,470 \\
3 \\
-\end{array}$ & $\begin{array}{r}15,186 \\
24,935 \\
126 \\
139\end{array}$ & $\begin{array}{r}70,373 \\
175,626 \\
64,715 \\
1,259\end{array}$ & $\begin{array}{r}20 \% \\
51 \% \\
19 \% \\
0 \%\end{array}$ \\
\hline $\begin{array}{l}\text { TCTAL FINAI } \\
\text { DEMAND SECICRS }\end{array}$ & 28,203 & 6,903 & 52,071 & 33,473 & - & 54,311 & 96,621 & 40,386 & 311,973 & $91 \%$ \\
\hline $\begin{array}{l}\text { TBANSFCEMATICN } \\
\text { ELCTRICITY CEN. } \\
\text { FETRCLEOM ERCDOCTS } \\
\text { NATURAL GAS } \\
\text { SYNTHETICS }\end{array}$ & $\begin{array}{r}3,1 \equiv 6 \\
- \\
-\end{array}$ & $\begin{array}{l}\overline{-} \\
\bar{z}\end{array}$ & $\begin{array}{l}- \\
\\
-\end{array}$ & $\begin{array}{l}\overline{-} \\
-\end{array}$ & $\begin{array}{l}- \\
\\
-\end{array}$ & $\begin{array}{r}339 \\
- \\
-\end{array}$ & $\begin{array}{r}39,479 \\
- \\
-\end{array}$ & $\begin{array}{r}-14,710 \\
- \\
-\end{array}$ & $\begin{array}{r}28,244 \\
- \\
- \\
-\end{array}$ & 89 \\
\hline $\begin{array}{l}\text { NET EOEL OSEI } \\
\text { IN TRANSFOEMATICN }\end{array}$ & $3,1 \equiv \epsilon$ & - & - & - & - & 339 & 39.479 & $-14,710$ & 28,244 & $8 \%$ \\
\hline $\begin{array}{l}\text { TCIAL GFOSS FICRS } \\
\text { LCSSES } \& \text { CMISSIONS }\end{array}$ & $\begin{array}{r}31,339 \\
1,950\end{array}$ & $\begin{aligned} 6,90.3 \\
. j\end{aligned}$ & $\begin{array}{r}52,071 \\
0\end{array}$ & $\begin{array}{l}33,473 \\
-1,320\end{array}$ & $\overline{-}-$ & $\begin{array}{l}54,650 \\
-1,476\end{array}$ & $\begin{array}{r}136,100 \\
1,842\end{array}$ & $\begin{array}{r}40,386 \\
3,350\end{array}$ & $\begin{array}{r}340,217 \\
4,347\end{array}$ & $99 \%$ \\
\hline TCIAL NET DSAGE & $33,2 \varepsilon 9$ & $6,90.3$ & 52,071 & 32,152 & - & 53,173 & 137,942 & 29,026 & 344,564 & \\
\hline
\end{tabular}

\begin{tabular}{|c|c|c|c|c|c|c|c|c|c|c|}
\hline S TEFLY CF EDERGY & & & & & & & & & & \\
\hline FOSSIL FOEI & - & - & - & - & 2,246 & 2,969 & 42,907 & - & 48,122 & $100 \%$ \\
\hline HY CR CELECTFIC & - & - & - & - & - & - & - & 61 & 61 & 0 Q⿻日木 \\
\hline $\begin{array}{l}\text { NOCLEAR } \\
\text { GRO.\&SOLAE }\end{array}$ & $\overline{-}$ & - & - & - & - & - & - & $\overline{96}$ & $\overline{96}$ & $0 \%$ \\
\hline TCIAI SOPPIY & - & - & - & - & 2,246 & 2,969 & 42,907 & 157 & 48,279 & \\
\hline
\end{tabular}

NET IM FCRTS
CF REGION


REGICNAL ETEFGY EBLANCE STATEMZTT

CNAL EERFGY ERLANCE STA
FIZS MID MID SCENARIO

\begin{tabular}{|c|c|c|c|c|c|c|c|c|c|c|}
\hline SECJ JE & $\begin{array}{c}\text { DISEILLATE } \\
\text { OIj }\end{array}$ & $\begin{array}{l}\text { RESIDUAL } \\
\text { OIL }\end{array}$ & $\begin{array}{l}\text { GASOLI KE } \\
\text { (ALI, ONIT }\end{array}$ & $\begin{array}{c}\text { OTJER } \\
\text { MYERO- } \\
\text { CIREONS } \\
\text { TS IE 10**9 }\end{array}$ & $\begin{array}{c}\text { CRLCE } \\
\text { OIL } \\
\text { BTO'S) }\end{array}$ & $\begin{array}{l}\text { NATURAL: } \\
\text { GAS }\end{array}$ & $\operatorname{COA} 1$ & ELECTFICITY & $\begin{array}{r}\text { SECTOR } \\
\text { TOTAL }\end{array}$ & \\
\hline $\begin{array}{l}\text { PINLL CEMAYC SECTOFS } \\
\text { RESIDENTIAL,CCMH. } \\
\text { INDOSTRIAL } \\
\text { TRANSPORTATICN } \\
\text { MISCELLANECOS OSES }\end{array}$ & $\begin{array}{r}44,293 \\
32,575 \\
49,314 \\
3,338\end{array}$ & $\begin{array}{r}3.341 \\
23,234 \\
641 \\
2,037\end{array}$ & $287,8 \equiv \overline{-}$ & $\begin{array}{r}44,851 \\
16 C, 002 \\
1 C, 339 \\
85\end{array}$ & $\begin{array}{l}- \\
-\end{array}$ & $\begin{array}{r}226,207 \\
83,431 \\
3,832 \\
1,731\end{array}$ & $\begin{array}{r}901 \\
335,761 \\
1 \\
4\end{array}$ & $\begin{array}{r}86,449 \\
142,348 \\
42 \\
828\end{array}$ & $\begin{array}{r}406,042 \\
777,351 \\
351,900 \\
8,522\end{array}$ & $\begin{array}{r}23 \% \\
43 \% \\
20 \% \\
0 \%\end{array}$ \\
\hline $\begin{array}{l}\text { TCTAL PINAL } \\
\text { DEYAND SECTCRE }\end{array}$ & 129,920 & $27,2 \subseteq 3$ & 287,831 & $21 \leq, 277$ & - & $315,2.03$ & 336,657 & 229.667 & $1,543,815$ & $26 \%$ \\
\hline $\begin{array}{l}\text { TRANSFCRHAT ICN } \\
\text { ELECTRICITE GBN. } \\
\text { PETR OLBOM ERCDOCTS } \\
\text { NATURAL GAS } \\
\text { STNTRETICS }\end{array}$ & $\begin{array}{r}23, ? 97 \\
-32,191 \\
=\end{array}$ & $\begin{array}{r}2,414 \\
-0,3,014 \\
-\end{array}$ & $\begin{array}{r}- \\
-66,834 \\
- \\
-\end{array}$ & $\begin{array}{r}- \\
-2 c, 373 \\
- \\
-\end{array}$ & $\begin{array}{r}- \\
139.486 \\
-\end{array}$ & $\begin{array}{r}2,504 \\
3,097 \\
- \\
-\end{array}$ & $\begin{array}{r}309,766 \\
- \\
-\end{array}$ & $\begin{array}{r}-120,340 \\
- \\
-\end{array}$ & $\begin{array}{r}217,641 \\
883 \\
- \\
-\end{array}$ & $\begin{aligned} & 12 \% \\
& 0 \%\end{aligned}$ \\
\hline $\begin{array}{l}\text { NET FOFL OSFC } \\
\text { IN TRAYSCFHATION }\end{array}$ & $-9,194$ & $-10,600$ & $-66,834$ & $-2 c .373$ & 139.496 & 5,603 & 309,756 & $-120,340$ & 218,524 & $12 \%$ \\
\hline $\begin{array}{l}\text { TCTAL GROSS FLCRS } \\
\text { ICSSES } \varepsilon \text { CMISSIONS }\end{array}$ & $\begin{array}{r}: 53,2917 \\
9,536\end{array}$ & $\begin{array}{r}31,667 \\
0\end{array}$ & $287,83^{\circ}$ & $\begin{array}{r}215,277 \\
-8,491\end{array}$ & $\begin{array}{r}139.496 \\
5.787\end{array}$ & $\begin{array}{r}320,803 \\
-8,663\end{array}$ & $\begin{array}{r}646,433 \\
8,750\end{array}$ & $\begin{array}{r}229,667 \\
19,056\end{array}$ & $\begin{array}{r}1,762,339 \\
25,971\end{array}$ & $\begin{array}{r}95 \% \\
1 \%\end{array}$ \\
\hline
\end{tabular}

-

\begin{tabular}{|c|c|c|c|c|c|c|c|c|c|c|}
\hline $\begin{array}{l}\text { SOEPLY OF ENERGY } \\
\text { FOSSIL FOEE }\end{array}$ & - & - & - & - & 64,530 & 29,531 & 202,140 & - & 296,201 & $87 \%$ \\
\hline HY EROELECT SIC & - & - & - & - & - & - & - & 450 & 450 & $c \%$ \\
\hline NOCL EAR & - & - & - & - & - & - & - & 43,905 & 43,905 & $13 \%$ \\
\hline GEC. ESOLAR & - & - & - & - & - & - & - & 708 & 708 & $0 \%$ \\
\hline
\end{tabular}

NFI IM FORTS
OP R RGION


REGIONAL ENERGY BALANCE ऽTATEMENT
PIES MID MID SCENARIC

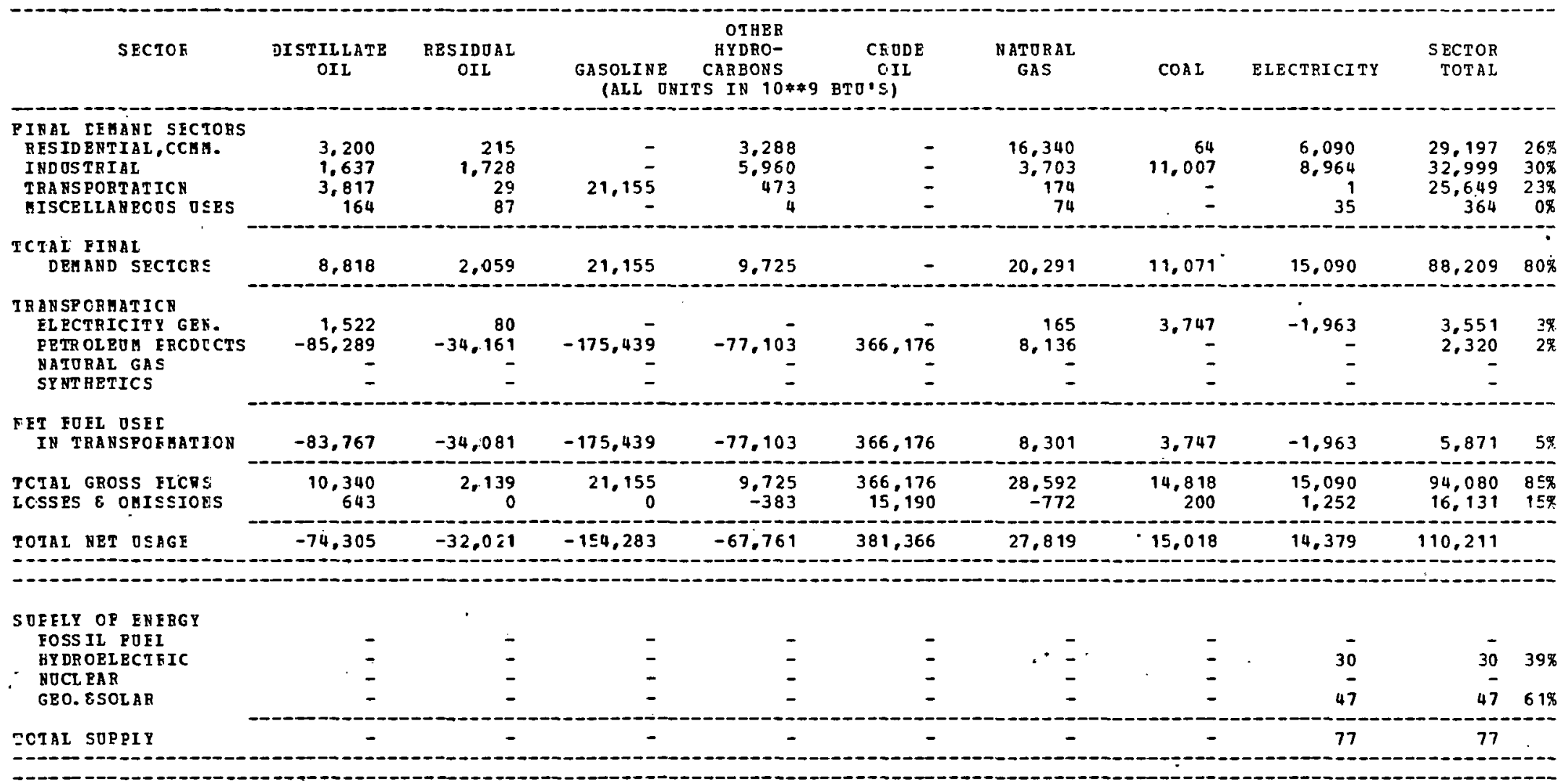

\begin{tabular}{l} 
GET IM FORTS \\
OF R RGION \\
\hline
\end{tabular}


REGI OYAL ENEAGY EALANCE SIATEHENT
PIES MID GID SCENARIO

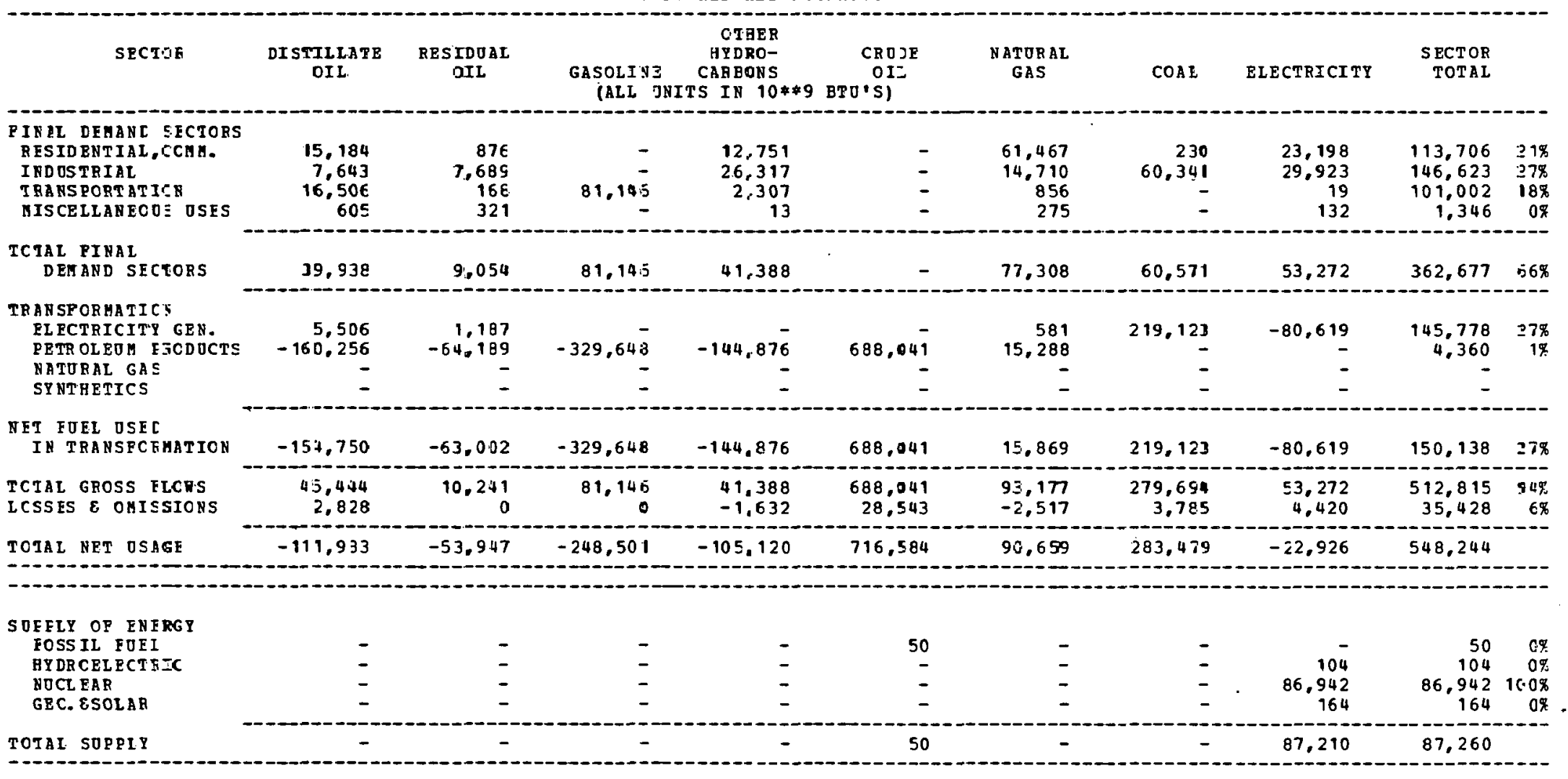

NET IM EORTS

CP REGION

$-111,933$

$-53,947$

$-248,501$

$-105,120$

716,534

90,659

283,479

$-110,136$

NOIES:

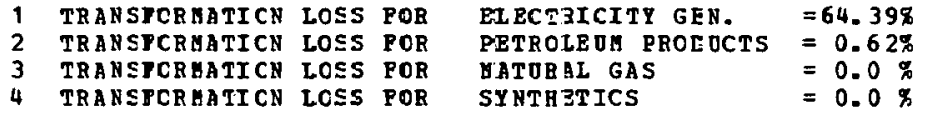


REGIONAL ENEEGY EALANCE STATEMENT
PIES MID GI DCENARIO

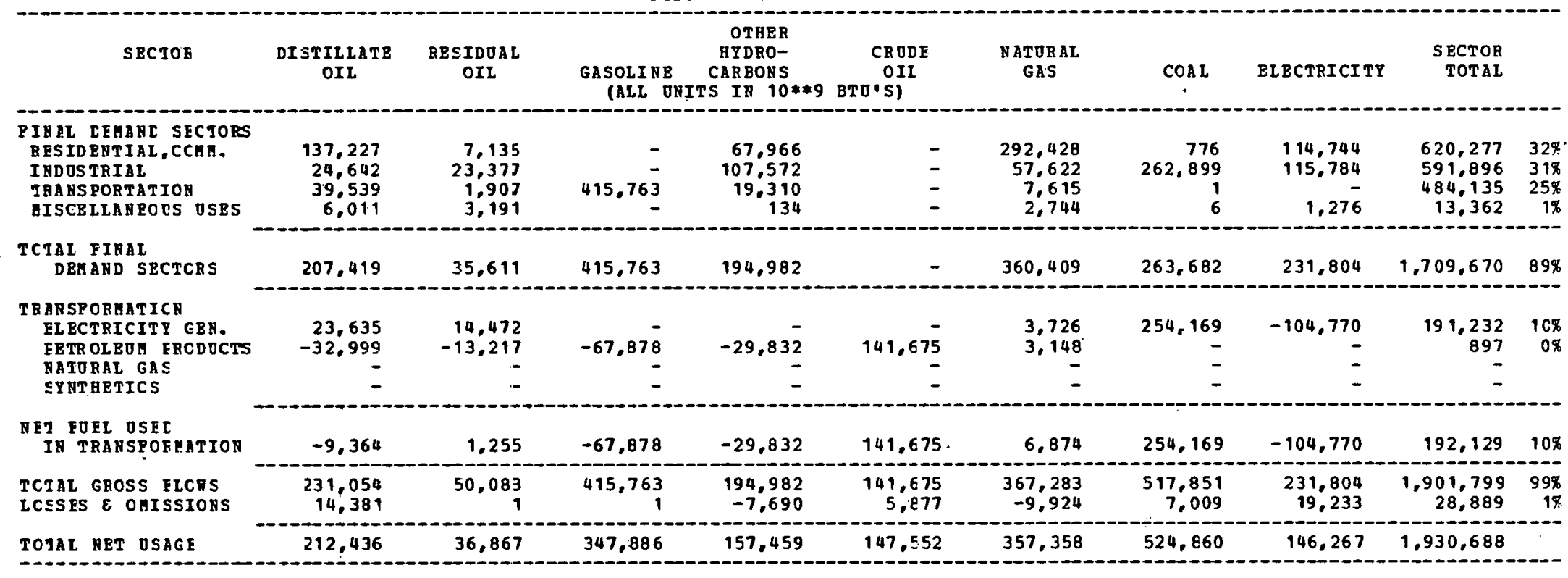

\begin{tabular}{|c|c|c|c|c|c|c|c|c|c|c|}
\hline $\begin{array}{l}\text { SOEPLY OP ENERGY } \\
\text { TOSSIL FOEL. }\end{array}$ & - & - & - & - & 9,972 & 8,782 & - & - & 18,754 & $44 \pi$ \\
\hline EYDROELECTEIC & - & - & - & - & & - & - & 454 & 454 & 19 \\
\hline SOCL EAR & - & - & - & - & - & - & - & 22,303 & 22,303 & 539 \\
\hline GRC. ESOLAR & - & - & - & - & - & - & - & 715 & 715 & $2 \pi$ \\
\hline TOTAL SOPPIY & - & - & - & - & 9,972 & 8,782 & - & 23,472 & 42,226 & \\
\hline
\end{tabular}

\section{NET IN PORTS \\ CP R BGIOY}

212,436

36,867

347,886

157.459

137,580

348,576

524,860

$122,795 \quad 1,888,462$

\section{YOTES: \\ 1 TRARSPCRAATI ON LOSS POB TRANSPOREATION LOSS POB TRANSPORGATICH IESS POB \\ BLECTRICITY GBN. \\ GBN. $\quad=64.608$ \\ $\begin{array}{ll}\text { PETROLEOH PROD OCTS } & =0.62 \% \\ \text { MATORAL GAS } & =0.0 \%\end{array}$ \\ 4 TRAYSFOREATICH LOSS FOR \\ FATORAL GAS \\ $=0.0 \%$
$=0.0 \%$}


RBGICHAL ERE RGI PALARCE STATEHE:

FIRS UID MID SCENARIO

\begin{tabular}{|c|c|c|c|c|c|c|c|c|c|c|}
\hline SBCTCA & $\begin{array}{c}\text { DISTILLETE } \\
\text { OIL }\end{array}$ & $\begin{array}{c}\text { RBS1DOAL } \\
r=L\end{array}$ & $\begin{array}{l}\text { GASOLIEE } \\
\text { (ALL OHI }\end{array}$ & $\begin{array}{l}\text { OTHER } \\
\text { BIDEO- } \\
\text { CARBOHS } \\
\text { TS IN } 10 * * 9\end{array}$ & $\begin{array}{c}\text { CR ODE } \\
\text { OII } \\
\text { BTO'SI }\end{array}$ & $\begin{array}{l}\text { NATURAI } \\
\text { GAS }\end{array}$ & COAL & ELECTRICITY & $\begin{array}{r}\text { SECTOR } \\
\text { TOTAL }\end{array}$ & \\
\hline $\begin{array}{l}\text { PIBIL DEHAHE SECTOBS } \\
\text { BESID BNTIAL, COHA. } \\
\text { IHDOSTRIAL } \\
\text { IRAHS PORTATICA } \\
\text { GISCELLABEOUS OSES }\end{array}$ & $\begin{array}{r}25,356 \\
8,513 \\
5,318 \\
1,142\end{array}$ & $\begin{array}{r}1,168 \\
52,160 \\
214 \\
606\end{array}$ & 77.784 & $\begin{array}{r}12,673 \\
90,230 \\
1,876 \\
29\end{array}$ & $\overline{-}$ & $\begin{array}{r}52,962 \\
11,901 \\
733 \\
693\end{array}$ & $\begin{array}{r}14 \Xi \\
67.50 \% \\
\overline{1}\end{array}$ & $\begin{array}{r}20,102 \\
60,770 \\
- \\
262\end{array}$ & $\begin{array}{r}112,404 \\
291,101 \\
85,950 \\
2,738\end{array}$ & $\begin{array}{r}20 \% \\
52 \% \\
15 \% \\
0 \%\end{array}$ \\
\hline $\begin{array}{l}\text { TCTAL PINAL } \\
\text { DBHABD SBCTORS }\end{array}$ & 40,369 & 54,148 & 77.784 & 104.808 & - & 66,299 & $67,65:$ & 81,134 & 492,193 & $\varepsilon 8 \%$ \\
\hline $\begin{array}{l}\text { TRARSPORAATICE: } \\
\text { BL BCTRICITY GBN. } \\
\text { PBTR OLEO FEODOCTS } \\
\text { BATORA GAS } \\
\text { SY BT BETICS }\end{array}$ & $\begin{array}{r}8,255 \\
-45,132 \\
-\end{array}$ & $\begin{array}{r}0.531 \\
-18,077 \\
-\end{array}$ & $\begin{array}{r}-92,836 \\
\overline{-}\end{array}$ & $\begin{array}{r}-40.800 \\
-\end{array}$ & $\begin{array}{r}193.768 \\
-\end{array}$ & $\begin{array}{r}1,144 \\
4,305 \\
-\end{array}$ & $\begin{array}{r}57.276 \\
\overline{-}\end{array}$ & $\begin{array}{r}-26,761 \\
= \\
-\end{array}$ & $\begin{array}{r}49,443 \\
1,228 \\
-\end{array}$ & $\begin{array}{l}9 \% \\
0 \%\end{array}$ \\
\hline $\begin{array}{l}\text { BET FOEL OSEC } \\
\text { IB TRABSPOREATION }\end{array}$ & $-36,877$ & -8.546 & $-92,836$ & $-40,800$ & 193.768 & 5,449 & 57,270 & $-26,761$ & 50,671 & $9 \%$ \\
\hline $\begin{array}{l}\text { TCTAL GROSS FIONS } \\
\text { IOSSES } 8 \text { OHISSIONS }\end{array}$ & $\begin{array}{r}48.624 \\
3.0 \pm 6\end{array}$ & $6 \equiv .679$ & 77,786 & $\begin{array}{r}104.808 \\
-4.134\end{array}$ & $\begin{array}{r}193,768 \\
8,038\end{array}$ & $\begin{array}{l}71,748 \\
-1,939\end{array}$ & $\begin{array}{r}124,925 \\
1,690\end{array}$ & $\begin{array}{r}81,134 \\
6,732\end{array}$ & $\begin{array}{r}542,864 \\
13,416\end{array}$ & $\begin{array}{r}98 \% \\
2 \%\end{array}$ \\
\hline
\end{tabular}

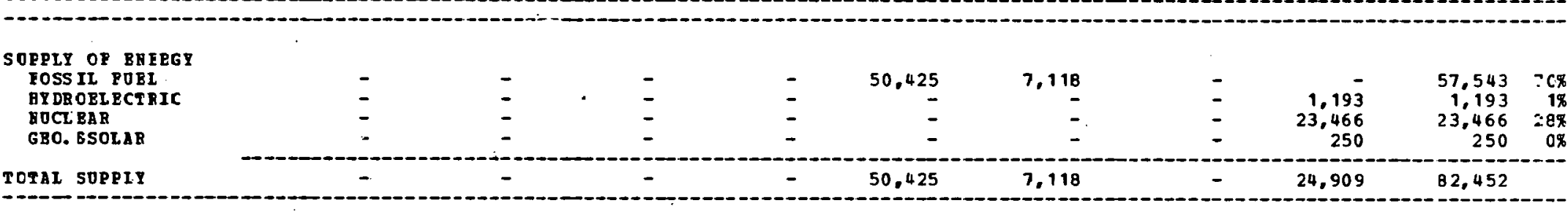

-

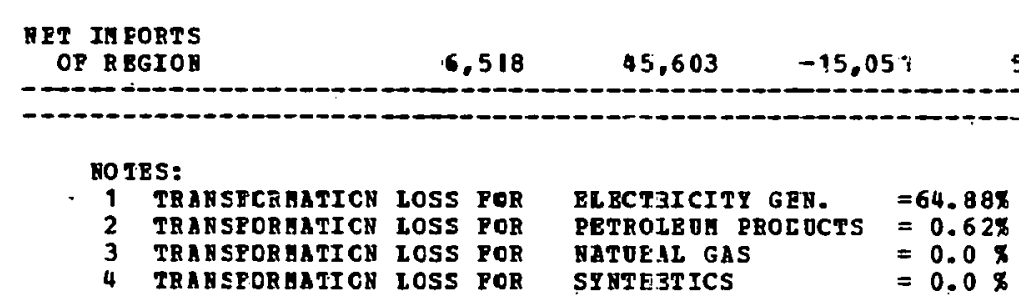


REGIONAL BNERGY EALANCE STATEHENT

PIES MID IID SCENARIO

\begin{tabular}{|c|c|c|c|c|c|c|c|c|c|}
\hline SECTOE & $\begin{array}{l}\text { DISTILLATE } \\
\text { OIL }\end{array}$ & $\begin{array}{l}\text { RESIDOAL: } \\
\text { OIL }\end{array}$ & $\begin{array}{l}\text { GASOLIN) } \\
\text { (ALL }\end{array}$ & $\begin{array}{c}\text { OTAER } \\
\text { HYDRO- } \\
\text { CARBOWS } \\
\text { TS IN 10**9 }\end{array}$ & $\begin{array}{c}\text { CR ODE } \\
\text { OII } \\
\text { BTO'SI) }\end{array}$ & $\begin{array}{l}\text { NATURAL } \\
\text { GAS }\end{array}$ & $\operatorname{COAI}$ & ELECTRICITY & $\begin{array}{l}\text { SECTOR } \\
\text { TOTAL }\end{array}$ \\
\hline 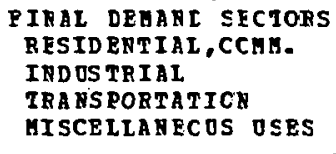 & $\begin{array}{r}34.507 \\
9.427 \\
10,266 \\
1.382\end{array}$ & $\begin{array}{r}1,646 \\
7.139 \\
313 \\
734\end{array}$ & $105,49 \overline{1}$ & $\begin{array}{r}17,209 \\
36,951 \\
2,861 \\
31\end{array}$ & $\begin{array}{l}- \\
-\end{array}$ & $\begin{array}{r}72,669 \\
18,059 \\
1,124 \\
626\end{array}$ & $\begin{array}{r}194 \\
78.310 \\
-\end{array}$ & $\begin{array}{r}27,946 \\
31.764 \\
- \\
293\end{array}$ & $\begin{array}{r}154,171 \\
181,650 \\
120,055 \\
3,067\end{array}$ \\
\hline $\begin{array}{l}\text { TCTAL PIRAL } \\
\text { DBHAND SBCTORS }\end{array}$ & 55,582 & 9,832 & 105,491 & 57.052 & - & 92,478 & 78,505 & 60.003 & 458,943 \\
\hline $\begin{array}{l}\text { TEARSPORHATICN } \\
\text { BLECTRICITY GBN. } \\
\text { PETROLRO FRCDOCTS } \\
\text { RATORAL GAS } \\
\text { SY NTHETICS }\end{array}$ & $\begin{array}{r}6,093 \\
-3,147 \\
= \\
=\end{array}$ & $\begin{array}{r}193 \\
-1,260 \\
-\end{array}$ & $\begin{array}{r}-6.474 \\
- \\
-\end{array}$ & $\begin{array}{r}-2.845 \\
- \\
-\end{array}$ & $\begin{array}{r}13,513 \\
- \\
-\end{array}$ & $\begin{array}{r}1.634 \\
300 \\
- \\
-\end{array}$ & $\begin{array}{r}109.161 \\
- \\
-\end{array}$ & $\begin{array}{r}-41,580 \\
- \\
-\end{array}$ & $\begin{array}{r}75,501 \\
85 \\
- \\
-\end{array}$ \\
\hline $\begin{array}{l}\text { BFT FOEL OSEL } \\
\text { IN TRABSFOABTION }\end{array}$ & 2,945 & $-1,067$ & $-6,474$ & $-2,845$ & 13,513 & 1,934 & 109,161 & $-41,580$ & 75,586 \\
\hline $\begin{array}{l}\text { TOTAL GROSS FLCRS } \\
\text { ICSSES } \& \text { CMISSIORS }\end{array}$ & $\begin{array}{r}61,675 \\
3,838\end{array}$ & $\begin{array}{r}10,025 \\
0\end{array}$ & $\begin{array}{r}105,491 \\
0\end{array}$ & $\begin{array}{l}57.052 \\
-2.250\end{array}$ & $\begin{array}{r}13,513 \\
560\end{array}$ & $\begin{array}{l}94,412 \\
-2,551\end{array}$ & $\begin{array}{r}187,666 \\
2,540\end{array}$ & $\begin{array}{r}60,003 \\
4,978\end{array}$ & $\begin{array}{r}534,529 \\
7,117\end{array}$ \\
\hline TOIAL NET OSAGE & 62,366 & 8,764 & 99.016 & 51,956 & 14.074 & 91,861 & 190,206 & 23,401 & 549.647 \\
\hline $\begin{array}{l}\text { S JFELY OP BHERGY } \\
\text { FOSS IL POEI } \\
\text { GYDROBLECTEIC } \\
\text { HDCL BAR } \\
\text { GBO. ESOLAR }\end{array}$ & $\overline{-}$ & $\begin{array}{l}\overline{-} \\
\overline{-}\end{array}$ & $\begin{array}{l}- \\
\end{array}$ & $\overline{-}$ & $\begin{array}{r}43,336 \\
= \\
=\end{array}$ & $\begin{array}{r}30,600 \\
= \\
-\end{array}$ & - & $\begin{array}{r}5,725 \\
1,311 \\
185\end{array}$ & $\begin{array}{r}73.936 \\
5.725 \\
1.311 \\
185\end{array}$ \\
\hline TCTAL SOPPLI & - & - & - & - & 43,336 & 30,600 & - & 7,221 & 81,157 \\
\hline
\end{tabular}

\section{SET IN FORTS}

99,016

51,956

$-29,261$

61,261

190,206

16,180

460,490

-

MOTES:

1 TRANSFCRMATICN LOSS POR TRABSFOBGATICM LOSS POR

TRAASPORHATICM LCSS POR

TRA BSPORAATI CN LOSS POR

ELECTRICITY GBN.

ETCTATCITY $\quad=64.49 \%$

PETROL3OA PRODOCTS $=0.62 \%$

$=0.0 \%$

SYNABTICS 
REGIORAL BRERGT BALARCE STATEKENT

PIBS MID HI D SCEVARI

\begin{tabular}{|c|c|c|c|c|c|c|c|c|c|c|}
\hline SBCTOB & $\begin{array}{c}\text { DISTI:LATB } \\
\text { OLL }\end{array}$ & $\begin{array}{l}\text { RESIDDAL } \\
\text { OIL }\end{array}$ & $\begin{array}{l}\text { GASOLI ME } \\
\text { (ALL OHI? }\end{array}$ & $\begin{array}{l}\text { OTABR } \\
\text { BYDRO- } \\
\text { CAEBOHS } \\
\text { TS J日 10**9 }\end{array}$ & $\begin{array}{c}\text { CRODB } \\
\text { OII } \\
\text { BTOSII }\end{array}$ & $\begin{array}{l}\text { NATUR AL } \\
\text { GAS }\end{array}$ & $\operatorname{CCh~I}$ & BLECTRICI TY & $\begin{array}{l}\text { SECTOR } \\
\text { TOTAL }\end{array}$ & \\
\hline $\begin{array}{l}\text { PIRLL DEHABD SECIOBS } \\
\text { RESID BHTIAL.CCBA. } \\
\text { IRDOSTRIAL } \\
\text { TRARSPORTATICR } \\
\text { GISCBLLABOOS OSBS }\end{array}$ & $\begin{array}{r}29.516 \\
7.676 \\
5.715 \\
1.989\end{array}$ & $\begin{array}{r}1,424 \\
7.785 \\
2.48 \\
1.056\end{array}$ & $90 .: \frac{\overline{-}}{-}$ & $\begin{array}{r}14.720 \\
21.268 \\
2.009 \\
43\end{array}$ & $\overline{-}$ & $\begin{array}{r}62,854 \\
15,024 \\
731 \\
879\end{array}$ & $\begin{array}{r}165 \\
54,580 \\
- \\
2\end{array}$ & $\begin{array}{r}24,376 \\
27,209 \\
- \\
419\end{array}$ & $\begin{array}{r}133,065 \\
133.542 \\
98,887 \\
4,388\end{array}$ & $\begin{array}{r}338 \\
338 \\
248 \\
18\end{array}$ \\
\hline $\begin{array}{l}\text { TCTAL FINAL } \\
\text { DEHAKD SECTORS }\end{array}$ & 44,896 & 10,513 & 90,124 & $\equiv 8,040$ & - & 79.558 & 54.247 & 52,004 & 369,882 & $91 \%$ \\
\hline 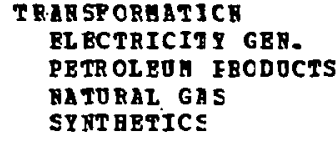 & $\begin{array}{r}5.251 \\
-3.655 \\
- \\
-\end{array}$ & $\begin{array}{r}909 \\
-1.464 \\
-\end{array}$ & $\begin{array}{r}-7,518 \\
-\end{array}$ & $\begin{array}{r}-3,304 \\
- \\
-\end{array}$ & $\begin{array}{r}15,603 \\
-\end{array}$ & $\begin{array}{r}774 \\
348 \\
-\end{array}$ & $\begin{array}{r}39,974 \\
- \\
-\end{array}$ & $\begin{array}{r}-16,653 \\
- \\
-\end{array}$ & $\begin{array}{r}30,255 \\
99 \\
- \\
-\end{array}$ & $\begin{array}{l}79 \\
0.8\end{array}$ \\
\hline $\begin{array}{l}\text { HET FOBL OSEC } \\
\text { IN TRARSPEBAATIOA }\end{array}$ & 1.595 & -555 & $-7,518$ & $-3,304$ & 15,693 & 1,122 & 39,974 & $-16,653$ & 30,354 & $7 \%$ \\
\hline $\begin{array}{l}\text { TCTAL GROSS ELORS } \\
\text { ICSSES } 8 \text { OEIESTONS }\end{array}$ & $\begin{array}{r}50,147 \\
3,121\end{array}$ & $\begin{array}{r}11.422 \\
0\end{array}$ & $\begin{array}{r}90,124 \\
0\end{array}$ & $\begin{array}{l}38,040 \\
-1,500\end{array}$ & $\begin{array}{r}15,693 \\
651\end{array}$ & $\begin{array}{l}80,680 \\
-2,180\end{array}$ & $\begin{array}{r}94,721 \\
1,382\end{array}$ & $\begin{array}{r}52,004 \\
4,314\end{array}$ & $\begin{array}{r}400,23 \epsilon \\
5,689\end{array}$ & $\begin{array}{r}99 \% \\
1 \%\end{array}$ \\
\hline TOTAL RET ESBGE & 49,613 & 9,958 & 82,605 & 33,235 & 16.344 & 78,500 & 96,0103 & 39,665 & 405.925 & \\
\hline $\begin{array}{l}\text { SOPPLY CF ENIFGY } \\
\text { FOSS IL FOBI } \\
\text { BY DROELBCTSIC } \\
\text { MOCL BAR } \\
\text { GEO. ESOLAR }\end{array}$ & $\begin{array}{l}- \\
\overline{-}\end{array}$ & $\begin{array}{l}\text { - } \\
-\end{array}$ & $\begin{array}{l}- \\
-\end{array}$ & - & $\begin{array}{r}44.064 \\
= \\
-\end{array}$ & $\begin{array}{r}19,647 \\
- \\
-\end{array}$ & $\begin{array}{l}- \\
\overline{-}\end{array}$ & $\begin{array}{r}159 \\
12,666 \\
160\end{array}$ & $\begin{array}{r}63.711 \\
159 \\
12.666 \\
160\end{array}$ & $\begin{array}{r}839 \\
0 \% \\
17 \% \\
0 \%\end{array}$ \\
\hline TOTAL SUPRIY & - & - & - & - & 44,064 & 19,647 & - & 12,985 & 76,696 & \\
\hline
\end{tabular}

\section{AET IN FORTS}

49.613

9,958

82,605

33,235

$-27,719$

58,853

96.003

$26,680 \quad 329,229$

-

yoTes :

TRARSPCRYATI ON LESS POR TRABSPCRMATION LESS POB TRARSPOBMATICN IESS POR TRARSPOBATI CII LESS POR

BLBCTRICITY SBN.

=64.50

GASDUCTS $=0.62 \mathrm{2}$

N.ATLRAL GAS

$=0.0$

$=0.0 \%$ 
REGIONAL ENERGY PALANCE STATEMENT

\begin{tabular}{|c|c|c|c|c|c|c|c|c|c|c|}
\hline SECTOE & $\begin{array}{l}\text { DISTILLATE } \\
\text { OIL }\end{array}$ & $\begin{array}{l}\text { RESIDDAL } \\
\text { OIL }\end{array}$ & $\begin{array}{l}\text { GASOLINE } \\
\quad \text { (ALI O }\end{array}$ & $\begin{array}{l}\text { OTBER } \\
\text { HYDRO- } \\
\text { CARBONS } \\
\text { IS IN } 10 * 9\end{array}$ & $\begin{array}{c}\text { CRODE } \\
\text { OIL } \\
\text { BTO'S) }\end{array}$ & $\begin{array}{l}\text { NATURAL } \\
\text { GAS }\end{array}$ & $\operatorname{COAL}$ & ELECTRICITY & $\begin{array}{r}\text { SECTOR } \\
\text { TOTAL }\end{array}$ & \\
\hline $\begin{array}{l}\text { PINIL CEHANL SECIORS } \\
\text { RESIDENTIAL, CCHH. } \\
\text { INDOSTRIAL } \\
\text { TRANSPORTATION } \\
\text { HISCELLANECOS OSES }\end{array}$ & $\begin{array}{r}22,723 \\
10,609 \\
14,374 \\
622\end{array}$ & $\begin{array}{r}4,485 \\
8,147 \\
177 \\
331\end{array}$ & 52.504 & $\begin{array}{r}8.341 \\
15.967 \\
8.530 \\
13\end{array}$ & $\begin{array}{l}- \\
\overline{-} \\
-\end{array}$ & $\begin{array}{r}28,645 \\
11,698 \\
428 \\
271\end{array}$ & $\begin{array}{r}196 \\
44,606 \\
- \\
=\end{array}$ & $\begin{array}{r}15.529 \\
20.012 \\
8 \\
129\end{array}$ & $\begin{array}{r}79,919 \\
111.039 \\
76.021 \\
1.366\end{array}$ & $\begin{array}{r}28 \% \\
39 \% \\
27 \% \\
0 \%\end{array}$ \\
\hline $\begin{array}{l}\text { TCTAI FINAL } \\
\text { DEHAND SECTCRS }\end{array}$ & 48,328 & 13,140 & 52,504 & 32,851 & - & 41,042 & 44.802 & 35,678 & 268,345 & $95 \%$ \\
\hline $\begin{array}{l}\text { TRANSPORHATICN } \\
\text { ELECTRICITY GEN. } \\
\text { PETROLEOM ERCDOCTS } \\
\text { MATORAL GAS } \\
\text { SYNTHETICS }\end{array}$ & $\begin{array}{r}3,676 \\
-12,222 \\
- \\
-\end{array}$ & $\begin{array}{r}170 \\
-4.895 \\
- \\
-\end{array}$ & $\begin{array}{r}-25,141 \\
-\end{array}$ & $\begin{array}{r}-11,049 \\
-\end{array}$ & $\begin{array}{r}- \\
52,474 \\
-\end{array}$ & $\begin{array}{r}389 \\
1,166 \\
-\end{array}$ & $\begin{array}{r}6,796 \\
- \\
-\end{array}$ & $\begin{array}{r}-3,927 \\
- \\
-\end{array}$ & $\begin{array}{r}7.104 \\
333 \\
- \\
-\end{array}$ & $\begin{array}{l}3 \% \\
0 \%\end{array}$ \\
\hline $\begin{array}{l}\text { NET FOEL OSEL } \\
\text { IN TRANSFORATION }\end{array}$ & $-8,546$ & $-4,725$ & $-25,141$ & $-11,049$ & 52,474 & 1,555 & 6.796 & -3.927 & 7.437 & $3 \%$ \\
\hline $\begin{array}{l}\text { TCIAL GROSS FLCHS } \\
\text { ICSSES \& OHISSIOHS }\end{array}$ & $\begin{array}{r}52,004 \\
3,236\end{array}$ & $\begin{array}{r}13.310 \\
0\end{array}$ & $\begin{array}{r}52.504 \\
0\end{array}$ & $\begin{array}{r}32,851 \\
-1.295\end{array}$ & $\begin{array}{r}52,474 \\
2,176\end{array}$ & $\begin{array}{l}42,597 \\
-1,151\end{array}$ & $\begin{array}{r}51,598 \\
698\end{array}$ & $\begin{array}{r}35.678 \\
2.960\end{array}$ & $\begin{array}{r}275.782 \\
6.626\end{array}$ & $\begin{aligned} 98 \% \\
2 \%\end{aligned}$ \\
\hline TOTAL NET OSAGE & 43,018 & 8,414 & 27.363 & 20,506 & 54,651 & 41,445 & 52,296 & 34,711 & 282,408 & \\
\hline $\begin{array}{l}\text { S OEFLY OF BHERGY } \\
\text { FOSS IL EOEL } \\
\text { HYDRCELBCTEIC } \\
\text { NOCL EAR } \\
\text { GEO. ESOLAR }\end{array}$ & $\bar{z}$ & - & I & $\overline{-}$ & $\begin{array}{l}6 \\
- \\
-\end{array}$ & I & $\begin{array}{l}\bar{z} \\
\overline{-}\end{array}$ & $\begin{array}{r}7 \overline{7} \\
\overline{110}\end{array}$ & $\begin{array}{r}6 \\
77 \\
110\end{array}$ & $\begin{array}{r}3 \% \\
40 \%\end{array}$ \\
\hline TCTAL SUPPIY & - & - & - & - & 6 & - & - & 187 & 193 & \\
\hline
\end{tabular}

\begin{tabular}{|c|c|c|c|c|c|c|c|c|c|}
\hline $\begin{array}{l}\text { RET IN FORTS } \\
\text { OP REGION }\end{array}$ & 43,018 & 8,414 & 27,363 & 20,506 & 54,645 & 41,445 & 52,296 & 34.524 & 282,215 \\
\hline
\end{tabular}

NOTRS:

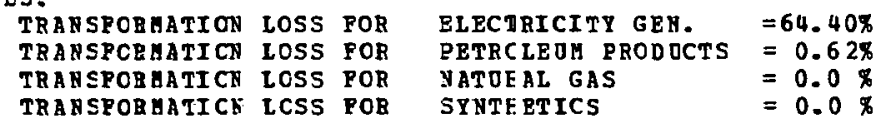


REGIONAL EMERGY PALARCE STATEMBET

PIZS UID MID SCENARIO

\begin{tabular}{|c|c|c|c|c|c|c|c|c|c|}
\hline SECTOE & $\begin{array}{l}\text { DISTILLATE } \\
\text { OII }\end{array}$ & 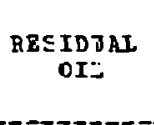 & $\begin{array}{l}\text { GASOLINE } \\
\text { (ALI ONII }\end{array}$ & $\begin{array}{c}\text { OTHER } \\
\text { EYDRO- } \\
\text { CARBDNS } \\
\text { TS IN } 10 * * 9\end{array}$ & $\begin{array}{c}\text { CR DDE } \\
\text { OIL } \\
\text { BTO'S) }\end{array}$ & $\begin{array}{l}\text { NATURAL } \\
\text { GAS }\end{array}$ & $\operatorname{COAI}$ & BLECTRICITY & $\begin{array}{l}\text { SECTOR } \\
\text { TOTAL }\end{array}$ \\
\hline $\begin{array}{l}\text { PINIL FEHANC SECTORS } \\
\text { BESIDENTIAL, CCHA. } \\
\text { INDOSTRIAL } \\
\text { TRANSPORTATIEN } \\
\text { MISCELLANECTS OSES }\end{array}$ & $\begin{array}{r}25,252 \\
9,734 \\
7,773 \\
509\end{array}$ & $\begin{array}{r}3.583 \\
7.696 \\
215 \\
270\end{array}$ & $62,67 \overline{-}$ & $\begin{array}{r}10.019 \\
28.248 \\
8,546 \\
11\end{array}$ & $\begin{array}{l}- \\
-\end{array}$ & $\begin{array}{r}33,952 \\
13.527 \\
552 \\
22 ?\end{array}$ & $\begin{array}{r}195 \\
40,9 \pm 1 \\
- \\
-\end{array}$ & $\begin{array}{r}16,270 \\
22,407 \\
3 \\
105\end{array}$ & $\begin{array}{r}89,273 \\
122,537 \\
79,166 \\
1,122\end{array}$ \\
\hline $\begin{array}{l}\text { TCTAL FINAI } \\
\text { DEHAND SECTCRS }\end{array}$ & $42,6,68$ & 11,764 & 62,675 & 46,824 & - & $48,25 \epsilon$ & 41,126 & 38,785 & 292,098 \\
\hline $\begin{array}{l}\text { TRANSPCRHATICY } \\
\text { ELECTRICITE ERN. } \\
\text { PETROLEOA ESCDOCTS } \\
\text { NATORAL GAS } \\
\text { SYNTAETICS }\end{array}$ & $\begin{array}{r}3,917 \\
= \\
=\end{array}$ & $\begin{array}{r}1,335 \\
= \\
=\end{array}$ & $\bar{z}$ & $\begin{array}{l}\overline{-} \\
\bar{z}\end{array}$ & $\bar{E}$ & $\begin{array}{r}42 \Xi \\
\vdots \\
-\end{array}$ & $\begin{array}{r}7,388 \\
= \\
-\end{array}$ & $\begin{array}{r}-4,606 \\
- \\
- \\
-\end{array}$ & $\begin{array}{r}8,457 \\
= \\
-\end{array}$ \\
\hline $\begin{array}{l}\text { NET FOEL OSEL } \\
\text { IN TRANSCEYATION }\end{array}$ & 3,597 & 1,335 & - & - & - & $42 \vdots$ & $7,3 \varepsilon 8$ & $-4,606$ & 8,457 \\
\hline $\begin{array}{l}\text { TCTAL GROSS FICHS } \\
\text { LCSSES } \varepsilon \text { OMISSIONS }\end{array}$ & $\begin{array}{r}46,5: 85 \\
2,899\end{array}$ & $\begin{array}{r}13.6 .97 \\
3\end{array}$ & $\begin{array}{r}62,675 \\
0\end{array}$ & $\begin{array}{l}4 E, 824 \\
-1,846\end{array}$ & - & $\begin{array}{l}48,6,7 \subseteq \\
-1,315\end{array}$ & $\begin{array}{r}48,514 \\
6 \subseteq 6\end{array}$ & $\begin{array}{r}38.785 \\
3,218\end{array}$ & $\begin{array}{r}300,555 \\
3,612\end{array}$ \\
\hline TOTAL NET OSAISE & 49.484 & 13.093 & 62,675 & 44,977 & - & $47.35 \equiv$ & 49,170 & 37,397 & 304,167 \\
\hline $\begin{array}{l}\text { SOFELI OP ENESGY } \\
\text { FOSS IL FOEL } \\
\text { RYDROEL BCTFIC } \\
\text { NOCL EAR } \\
\text { GEO. ESOLAE }\end{array}$ & $\begin{array}{l}\overline{-} \\
\overline{-}\end{array}$ & $\begin{array}{l}\overline{-} \\
\overline{-}\end{array}$ & $\begin{array}{l}\bar{z} \\
\overline{-}\end{array}$ & $\begin{array}{l}\overline{-} \\
\bar{z}\end{array}$ & $\begin{array}{l}- \\
\end{array}$ & $\begin{array}{l}- \\
- \\
-\end{array}$ & $\begin{array}{l}\overline{-} \\
\overline{-} \\
-\end{array}$ & $\begin{array}{r}410 \\
38.772 \\
119\end{array}$ & $\begin{array}{r}4- \\
410 \\
38772 \\
119\end{array}$ \\
\hline TCTAL SOPPIY & - & - & - & - & - & - & - & 39,301 & 39,301 \\
\hline
\end{tabular}

HET IN PORTS

13.097

62,675

44.977

47.355

49,170

$-1,903$

264.866

-

NO IES

TRANSPCRMATICN IOSS FOR TRARSFORAATICN LOSS FO

TRANSPCRHATI CN ICES ECR
TRAN SPORHATI CN LOSS FOR

ZLECTRJ CITI GEN.

PRTROLF PROJOCTS

SYNTERTICS

$=0.0 x$

$=0.0 \%$ 
REGIONAL ENEFGY EALANCE STATEMENT

\begin{tabular}{|c|c|c|c|c|c|c|c|c|c|c|}
\hline SECTOE & $\begin{array}{l}\text { DISTILLATR } \\
\text { OIL }\end{array}$ & $\begin{array}{l}\text { RESIDUBL } \\
\text { OIL }\end{array}$ & $\begin{array}{l}\text { GASOLINE } \\
\text { /ALI ONI }\end{array}$ & $\begin{array}{c}\text { OTHER } \\
\text { HYDRO- } \\
\text { CAREONS } \\
\text { IS IN } 10 * * 9\end{array}$ & $\begin{array}{c}\text { CRODE } \\
\text { OIL } \\
\text { BTO'S) }\end{array}$ & $\begin{array}{l}\text { NATURAL } \\
\text { GAS }\end{array}$ & COA L & ELECTRICITY & $\begin{array}{r}\text { SECTOR } \\
\text { TOTAL }\end{array}$ & \\
\hline 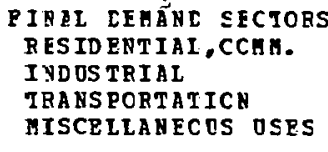 & $\begin{array}{r}244,217 \\
114,532 \\
105,609 \\
10,301\end{array}$ & $\begin{array}{r}60,632 \\
121,162 \\
1,7 \in 6 \\
5.46 .6\end{array}$ & $\begin{array}{r}- \\
558,174 \\
-\end{array}$ & $\begin{array}{r}97.990 \\
432.022 \\
97.766 \\
227\end{array}$ & $\begin{array}{l}\overline{-} \\
\overline{-}\end{array}$ & $\begin{array}{r}429,145 \\
142,743 \\
33,953 \\
4,844\end{array}$ & $\begin{array}{r}2,064 \\
462,849 \\
2 \\
9\end{array}$ & $\begin{array}{r}176.266 \\
196.073 \\
653 \\
2.396\end{array}$ & $\begin{array}{r}1,010,314 \\
1,469,361 \\
797,923 \\
23,243\end{array}$ & $\begin{array}{r}27 \% \\
39 \% \\
21 \% \\
1 \%\end{array}$ \\
\hline $\begin{array}{l}\text { TCTAL FINAL } \\
\text { DEMAND SPCICRS }\end{array}$ & 474,659 & $189,0<6$ & 558,174 & 628,005 & - & 610,685 & 464,924 & 375,388 & $3,300,841$ & $88 \%$ \\
\hline $\begin{array}{l}\text { TR ANSPCRHATICN } \\
\text { ELECTRICITY GEN. } \\
\text { PETR OLEOM ERCDUCTS } \\
\text { BATORAL GAS } \\
\text { ST HT HETICS }\end{array}$ & $\begin{array}{r}38,744 \\
-494,725 \\
-\end{array}$ & $\begin{array}{r}17,8 \in 9 \\
-198,1 \leq 6 \\
-\end{array}$ & $\begin{array}{r}- \\
-1,017,651 \\
-\end{array}$ & $\begin{array}{r}-447,245 \\
- \\
-\end{array}$ & $\begin{array}{r}2,124,041 \\
-\end{array}$ & $\begin{array}{r}4,272 \\
47,197 \\
- \\
-\end{array}$ & $\begin{array}{r}433,195 \\
- \\
-\end{array}$ & $\begin{array}{r}-175,366 \\
- \\
-\end{array}$ & $\begin{array}{r}318,714 \\
13,461 \\
-\end{array}$ & $\begin{array}{l}8 \% \\
0 \%\end{array}$ \\
\hline $\begin{array}{l}\text { NEF FOEL OSEL } \\
\text { IN TRABSPOEGATIOA }\end{array}$ & $-455,981$ & $-180,287$ & $-1,017,651$ & $-447,245$ & 2.124 .041 & 51,469 & 433.195 & $-175,366$ & 332,175 & $9 \%$ \\
\hline $\begin{array}{l}\text { TCEAL GROSS FLORS } \\
\text { LCSSES \& OHISSIOHS }\end{array}$ & $\begin{array}{r}513,403 \\
31,955\end{array}$ & $\begin{array}{r}206,875 \\
4\end{array}$ & $\begin{array}{r}558,174 \\
2\end{array}$ & $\begin{array}{l}628,005 \\
-24,771\end{array}$ & $\begin{array}{r}2,124,041 \\
88,716\end{array}$ & $\begin{array}{l}662,154 \\
-17,892\end{array}$ & $\begin{array}{r}898,119 \\
12,156\end{array}$ & $\begin{array}{r}375,388 \\
31,147\end{array}$ & $\begin{array}{r}3,633,096 \\
120,719\end{array}$ & $\begin{array}{r}97 \% \\
3 \%\end{array}$ \\
\hline $\begin{array}{l}\text { SOFFLY OF FNFRGY } \\
\text { JOSS IL FOEI } \\
\text { EYDROELBCTRIC } \\
\text { IOCL EAR } \\
\text { CEO. ESOLAR }\end{array}$ & $\begin{array}{l}\bar{z} \\
\bar{z}\end{array}$ & $\begin{array}{l}- \\
-\end{array}$ & $\begin{array}{l}- \\
-\end{array}$ & $\begin{array}{l}\overline{-} \\
\overline{-}\end{array}$ & $\begin{array}{l}- \\
- \\
-\end{array}$ & $\begin{array}{l}- \\
\overline{-}\end{array}$ & $\begin{array}{r}9.800 \\
- \\
-\end{array}$ & $\begin{array}{r}- \\
910 \\
161.404 \\
1,157\end{array}$ & $\begin{array}{r}9,800 \\
910 \\
161,404 \\
1,157\end{array}$ & $\begin{array}{r}6 \% \\
1 \% \\
93 \% \\
1 \%\end{array}$ \\
\hline TOTAL SUPEIY & - & - & - & - & - & - & 9,800 & 163,471 & 173,271 & \\
\hline
\end{tabular}

\section{RET IM EORTS} CF R BGION 50,633 8,723

$\begin{array}{lllll}\text { MOTES: } & & & \\ 1 & \text { TRANSPCRAATICN } & \text { LOSS POR } & \text { ELECTRICITI GEN. } & =64.51 \% \\ 2 & \text { TRANSPORAATICN } & \text { LOSS PCR } & \text { PETROLEOA PRODOCTS } & =0.62 \% \\ 3 & \text { TRARSPCRATICN } & \text { LOSS POR } & \text { NATURAL GAS } & =0.0 \% \\ 4 & \text { TRANSPORAATICN LOSS FOR } & \text { SYNTHETICS } & =0.0 \%\end{array}$


REGIONAL ENEFGY BALANCE STATENFNT

ONAL ENEEGY BALANCE
PIES GID MID SCENARIO

\begin{tabular}{|c|c|c|c|c|c|c|c|c|c|c|}
\hline SECTOE & $\begin{array}{c}\text { DISTILLATE } \\
\text { OEL }\end{array}$ & $\begin{array}{l}\text { BESIDOAL } \\
\text { OIL }\end{array}$ & $\begin{array}{l}\text { GASCITNE } \\
\text { (AIL ONIT }\end{array}$ & $\begin{array}{c}\text { OTHER } \\
\text { HYDRO- } \\
\text { EAR3ONS } \\
\text { I } 5 \text { IN } 10 * 49\end{array}$ & $\begin{array}{l}\text { CEODE } \\
\text { OII } \\
\text { BTO'S) }\end{array}$ & $\begin{array}{l}\text { NATURAL } \\
\text { GAS }\end{array}$ & $\operatorname{COAL}$ & ELECTRICITY & $\begin{array}{r}\text { SECTOR } \\
\text { TOTAL }\end{array}$ & \\
\hline $\begin{array}{l}\text { PINAL CFHARE SECTORS } \\
\text { RES IDENTIAI, CCHA. } \\
\text { INDOSTRIAL } \\
\text { TRABSPORTATICA } \\
\text { MISCELIANBCOS OSES }\end{array}$ & $\begin{array}{r}21.391 \\
7.069 \\
7.370 \\
827\end{array}$ & $\begin{array}{r}5.694 \\
2.862 \\
60 \\
439\end{array}$ & $47.4 \subseteq \overline{9}$ & $\begin{array}{r}8,464 \\
8,802 \\
1,114 \\
18\end{array}$ & z- & $\begin{array}{r}38,928 \\
5,818 \\
4: 33 \\
351\end{array}$ & 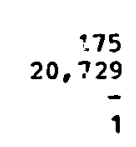 & $\begin{array}{r}15,782 \\
12,831 \\
74 \\
175\end{array}$ & $\begin{array}{l}90,334 \\
58,111 \\
56.600 \\
1,821\end{array}$ & $\begin{array}{r}27 \% \\
18 \% \\
17 \% \\
1 \%\end{array}$ \\
\hline $\begin{array}{l}\text { TCTAL FIMAI } \\
\text { DEMAND SECTORS }\end{array}$ & 36,657 & 9,055 & $47,4 \subseteq 9$ & $.88,398$ & - & 45,490 & 20,905 & 28,862 & 206,866 & $62 \pi$ \\
\hline $\begin{array}{l}\text { TBARSPORHATICH } \\
\text { ELECTRICITY GBN. } \\
\text { PETR OLEOH EBODOCTS } \\
\text { NATDRAL GMS } \\
\text { SY NTHETICS }\end{array}$ & $\begin{array}{r}2,918 \\
-507 \\
- \\
-\end{array}$ & $\begin{array}{r}-203 \overline{-} \\
- \\
-\end{array}$ & $\begin{array}{r}-1.0<4 \\
- \\
-\end{array}$ & $\begin{array}{r}-45 \overline{8} \\
- \\
-\end{array}$ & $2,27 \overline{9}$ & $\begin{array}{r}363 \\
48 \\
- \\
-\end{array}$ & $\begin{array}{r}181.551 \\
- \\
-\end{array}$ & $\begin{array}{r}-65.844 \\
- \\
-\end{array}$ & $\begin{array}{r}118,988 \\
13 \\
- \\
-\end{array}$ & $\begin{array}{r}36 \% \\
0 \%\end{array}$ \\
\hline $\begin{array}{l}\text { NET FOEL OSEL } \\
\text { IR TRANSPCEABTIOH }\end{array}$ & 2,410 & -203 & $-1,1) \otimes 4$ & -458 & 2,179 & 411 & 181,551 & $-65,844$ & 119,001 & $36 \%$ \\
\hline $\begin{array}{l}\text { TCTAL GROSS FLORS } \\
\text { LCSSES \& OHISSIONS }\end{array}$ & $\begin{array}{r}39,575 \\
\ddot{2}, 463\end{array}$ & $\begin{array}{r}9.055 \\
0\end{array}$ & $47,+95$ & $\begin{array}{r}18.398 \\
-725\end{array}$ & $\begin{array}{r}2,179 \\
90\end{array}$ & $\begin{array}{l}45,901 \\
-1,240\end{array}$ & $\begin{array}{r}202,456 \\
2,740\end{array}$ & $\begin{array}{r}28,862 \\
2,394\end{array}$ & $\begin{array}{r}325,867 \\
5.723\end{array}$ & $\begin{array}{r}98 \% \\
28\end{array}$ \\
\hline TOTAL NET OSAGE & 41.530 & 8,851 & $46,4.54$ & 17.213 & $2.27 \mathrm{C}$ & 44,661 & 205,196 & -34.587 & 331,591 & \\
\hline
\end{tabular}

SOFFLY OP EIFRGI
FOSS IL FOEI
HYDROELECRIC
NOCL EAR
GEO. ESOLAR
TOTAI SOPPLT

I SOPPLT

$1,530 \quad 8,851$

46,457

17,213

2,089

44.561

7,964

$-34,733$

NOTES:

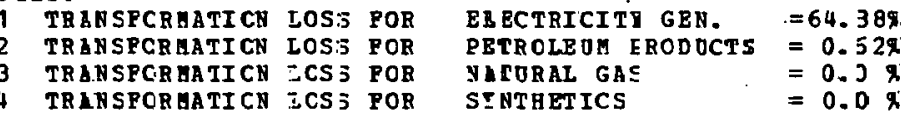

3 TRANSPGRAATICN ZCS 3 POR

TRLASPORAATICN ICS S POR

SINTHET ICS

$=0.0 \%$ 
RBGIONAL EREEGY EALANCB STATEMENT

PIBS UID UI D SCENARIO

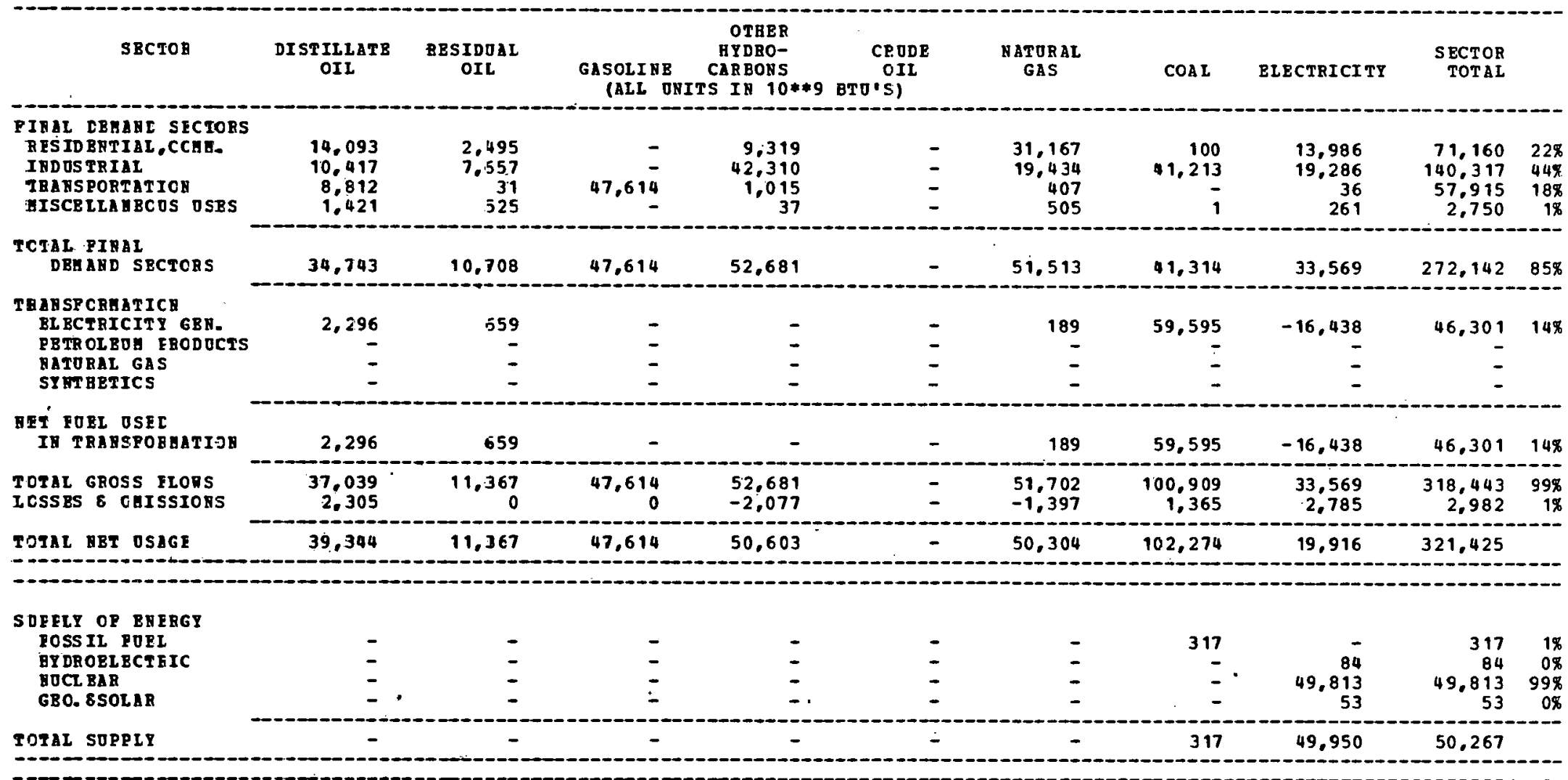

\section{B3T In PORTS}

39,344

11,367

47,614

50,603

50,304

101,957

$-30,033$

271,158

-

BOTBS:

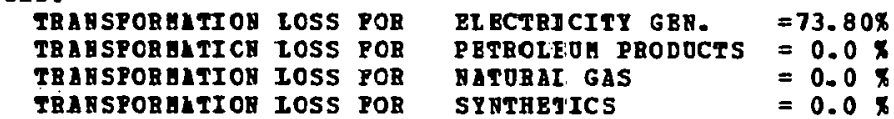


REGIOHEL BNEAGY RALANCB STATEHENT

PIES UID YID SCENARIO

\begin{tabular}{|c|c|c|c|c|c|c|c|c|c|}
\hline SBCTOB & $\begin{array}{l}\text { DI SEILILATB } \\
\text { OII }\end{array}$ & $\begin{array}{l}\text { RES IDUAL } \\
\text { CIL }\end{array}$ & $\begin{array}{l}\text { GASOLINE } \\
\text {;GLL OI }\end{array}$ & $\begin{array}{l}\text { OTBBR } \\
\text { FYDZO- } \\
\text { CEBBDNS } \\
\text { S IN } 10 * * 9\end{array}$ & $\begin{array}{c}\text { CR ODE } \\
\text { OIL } \\
\text { BTO'S) }\end{array}$ & $\begin{array}{l}\text { NATURLI } \\
\text { GAS }\end{array}$ & $\operatorname{COAL}$ & ELECTRICITY & $\begin{array}{l}\text { SECTOR } \\
\text { TOTAL }\end{array}$ \\
\hline 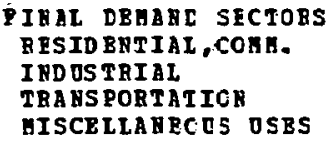 & $\begin{array}{r}5, \quad \vdots 82 \\
4, E 23 \\
4, \quad=20 \\
6,37\end{array}$ & $\begin{array}{r}95 \\
\because, 646 \\
- \\
119\end{array}$ & $\begin{array}{r}- \\
30,782 \\
-\end{array}$ & $\begin{array}{r}6.649 \\
4.636 \\
463 \\
21\end{array}$ & - & $\begin{array}{r}16,088 \\
3,47 \pi \\
159 \\
163\end{array}$ & $\begin{array}{r}16 \\
7,612 \\
- \\
-\end{array}$ & $\begin{array}{r}9,021 \\
7,642 \\
94\end{array}$ & $\begin{array}{r}37.251 \\
29.636 \\
35.624 \\
1.034\end{array}$ \\
\hline $\begin{array}{l}\text { TCTAL FIRAL } \\
\text { DBHAND SECTORS }\end{array}$ & $i 4.862$ & 1,860 & 30,782 & 11.769 & - & 19.88? & $7,6 \pm .8$ & 16.757 & 103.545 \\
\hline $\begin{array}{l}\text { TRARSECRUATICB } \\
\text { PLECTRICITY GRR. } \\
\text { PBTR OLBOY ERCDOCTS } \\
\text { BATDRAL GAS } \\
\text { SY RTETICS }\end{array}$ & $\begin{array}{r}455 \\
- \\
-\end{array}$ & $\overline{-}$ & $\begin{array}{l}\bar{z} \\
\bar{z}\end{array}$ & $\bar{z}$ & - & $\overline{-}$ & $\begin{array}{r}23,7 \subseteq 3 \\
- \\
-\end{array}$ & $\begin{array}{r}-6,147 \\
- \\
- \\
-\end{array}$ & $\begin{array}{r}18,101 \\
- \\
-\end{array}$ \\
\hline $\begin{array}{l}\text { AFT FOBL OSEI } \\
\text { IN TRANSPOEMATION }\end{array}$ & 455 & - & - & - & - & - & 23.793 & $-6,147$ & 18,101 \\
\hline $\begin{array}{l}\text { TCTAL GROSS FLORS } \\
\text { LCSSES \& OMISSIONS }\end{array}$ & $\begin{array}{r}15,317 \\
953\end{array}$ & $\begin{array}{r}1.860 \\
0\end{array}$ & $\begin{array}{r}30,782 \\
0\end{array}$ & $\begin{array}{r}1.1 .769 \\
-464\end{array}$ & $\overline{-}$ & $\begin{array}{r}19,887 \\
-537\end{array}$ & $\begin{array}{r}31,421 \\
425\end{array}$ & $\begin{array}{r}16,757 \\
1,390\end{array}$ & $\begin{array}{r}121,646 \\
1.767\end{array}$ \\
\hline TOTAL HET OSBGE & 16,270 & 1,860 & 30,782 & $1 \therefore, 304$ & - & 19,349 & 31,846 & 12,000 & 123,413 \\
\hline $\begin{array}{l}\text { SOPPLY OF EYIEGY } \\
\text { FOSS IL PORE } \\
\text { HY DR OELBCTEIC } \\
\text { HOCL, BAR } \\
\text { GEC. ESOLAR }\end{array}$ & $\overline{\check{z}}$ & $\bar{z}$ & $\begin{array}{l}\bar{z} \\
\overline{-}\end{array}$ & $\bar{z}$ & - & $\begin{array}{l}\overline{-} \\
\overline{-}\end{array}$ & $\begin{array}{l}\text { - } \\
\text { - }\end{array}$ & $\begin{array}{r}\overrightarrow{-} \\
7,688 \\
-\end{array}$ & $\begin{array}{r}\overline{-} \\
7.688 \\
-\end{array}$ \\
\hline TCTAL SUPPIY & - & - & - & - & - & - & - & 7,688 & 7,688 \\
\hline
\end{tabular}

\section{NET IN PORTS}

OP R BGION

16,270

1,860

30,732

11,304

19,349

31,846

4,312

115,725

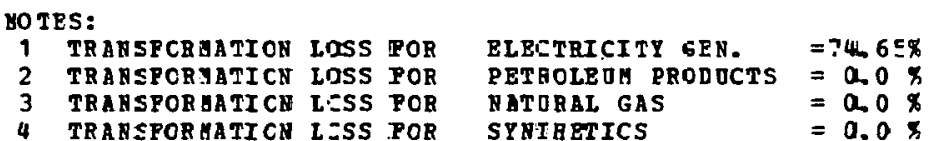

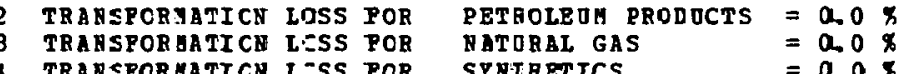


REGIONAL ENBBG EALANCE STATEHENT
PIES UID HID SCENARIO

\begin{tabular}{|c|c|c|c|c|c|c|c|c|c|c|}
\hline SBCTOR & $\begin{array}{l}\text { DISTILLATB } \\
\text { OIL }\end{array}$ & $\begin{array}{l}\text { RESIDOAL } \\
\text { OIL }\end{array}$ & $\begin{array}{l}\text { GASOLI NE } \\
\text { (ALL }\end{array}$ & $\begin{array}{c}\text { OTRER } \\
\text { HYDRO- } \\
\text { CABBONS } \\
\text { TS IN 10**9 }\end{array}$ & $\begin{array}{c}\text { CRODE } \\
\text { OIL } \\
\text { BTU'SI }\end{array}$ & $\begin{array}{l}\text { MATURAL } \\
\text { GAS }\end{array}$ & $\cos L$ & BLECTRICITY & $\begin{array}{r}\text { SECTOR } \\
\text { TOTAL }\end{array}$ & \\
\hline 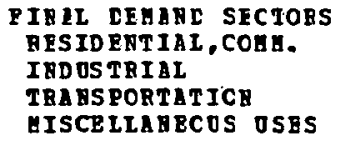 & $\begin{array}{r}6,425 \\
4,287 \\
3,111 \\
294\end{array}$ & $\begin{array}{r}258 \\
1.153 \\
3 \\
85\end{array}$ & $26,33 \overline{-}$ & $\begin{array}{r}5.397 \\
3.296 \\
1,042 \\
9\end{array}$ & $\begin{array}{l}\overline{-} \\
\overline{-}\end{array}$ & $\begin{array}{r}13.343 \\
2,792 \\
447 \\
93\end{array}$ & $\begin{array}{r}41 \\
6.065 \\
- \\
-\end{array}$ & $\begin{array}{r}7,205 \\
8,900 \\
1 \\
49\end{array}$ & $\begin{array}{r}32,679 \\
26,493 \\
30,935 \\
530\end{array}$ & $\begin{array}{r}30 \% \\
24 \% \\
28 \% \\
0 \%\end{array}$ \\
\hline $\begin{array}{l}\text { TCTAL FIHAL } \\
\text { DBHABD SBCTCRS }\end{array}$ & 14.117 & 1,509 & 26,331 & 9.744 & - & 16,675 & 6,106 & 16,155 & 90,637 & $83 \%$ \\
\hline $\begin{array}{l}\text { TEABSPCRHATICY } \\
\text { BLECTRICITY GEY. } \\
\text { PETROLBO ERODOCTS } \\
\text { MATORAL GAS } \\
\text { STHTHBTICS }\end{array}$ & $\begin{array}{r}754 \\
- \\
-\end{array}$ & $\begin{array}{l}\overline{-} \\
\overline{-}\end{array}$ & I & $\begin{array}{l}- \\
-\end{array}$ & $\begin{array}{l}- \\
\overline{-}\end{array}$ & $\begin{array}{r}56 \\
- \\
-\end{array}$ & $\begin{array}{r}23,342 \\
= \\
=\end{array}$ & $\begin{array}{r}-7.555 \\
- \\
- \\
-\end{array}$ & $\begin{array}{r}16,597 \\
- \\
-\end{array}$ & $15 \%$ \\
\hline $\begin{array}{l}\text { AIT FOBL USFC } \\
\text { IR TBABSPOEATIOH }\end{array}$ & 754 & - & - & . - & - & 56 & 23,342 , & $-7,555$ & 16,597 & $15 \%$ \\
\hline $\begin{array}{l}\text { TOTAL GROSS FLORS } \\
\text { LOSSBS } 8 \text { OHISSIOUS }\end{array}$ & $\begin{array}{r}14.871 \\
925\end{array}$ & $\begin{array}{r}1,509 \\
0\end{array}$ & $\begin{array}{r}26,331 \\
0\end{array}$ & $\begin{array}{r}9,7.44 \\
-384\end{array}$ & $\overline{-}$ & $\begin{array}{r}16,731 \\
-452\end{array}$ & $\begin{array}{r}29,448 \\
398\end{array}$ & $\begin{array}{r}16,155 \\
1,340\end{array}$ & $\begin{array}{r}107,234 \\
1,828\end{array}$ & $\begin{array}{r}98 \% \\
2 \%\end{array}$ \\
\hline
\end{tabular}

(1)

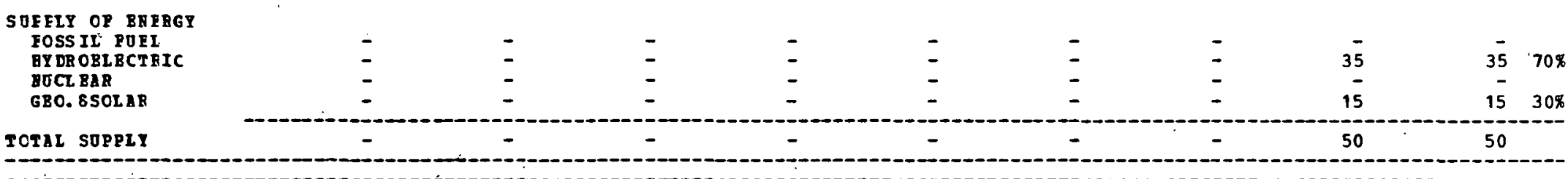

TOTAL SOPRLY

\section{BRI IM POATS}

OP RBGIOR

15,796

1,509

26,331

9,359

16,278

29,846

9,890

109,012

\section{vores: TRABSPOBABTICR IOSS POB TrA.SPORGATICK LOSS POB TRa \\ BLECTRECITY GBR. $\quad=68.72 x$ \\ PETHOLBOH PBODOCTS $=0.0$ \\ ATURAI GAS $=0.0$}




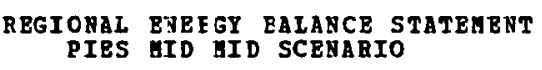

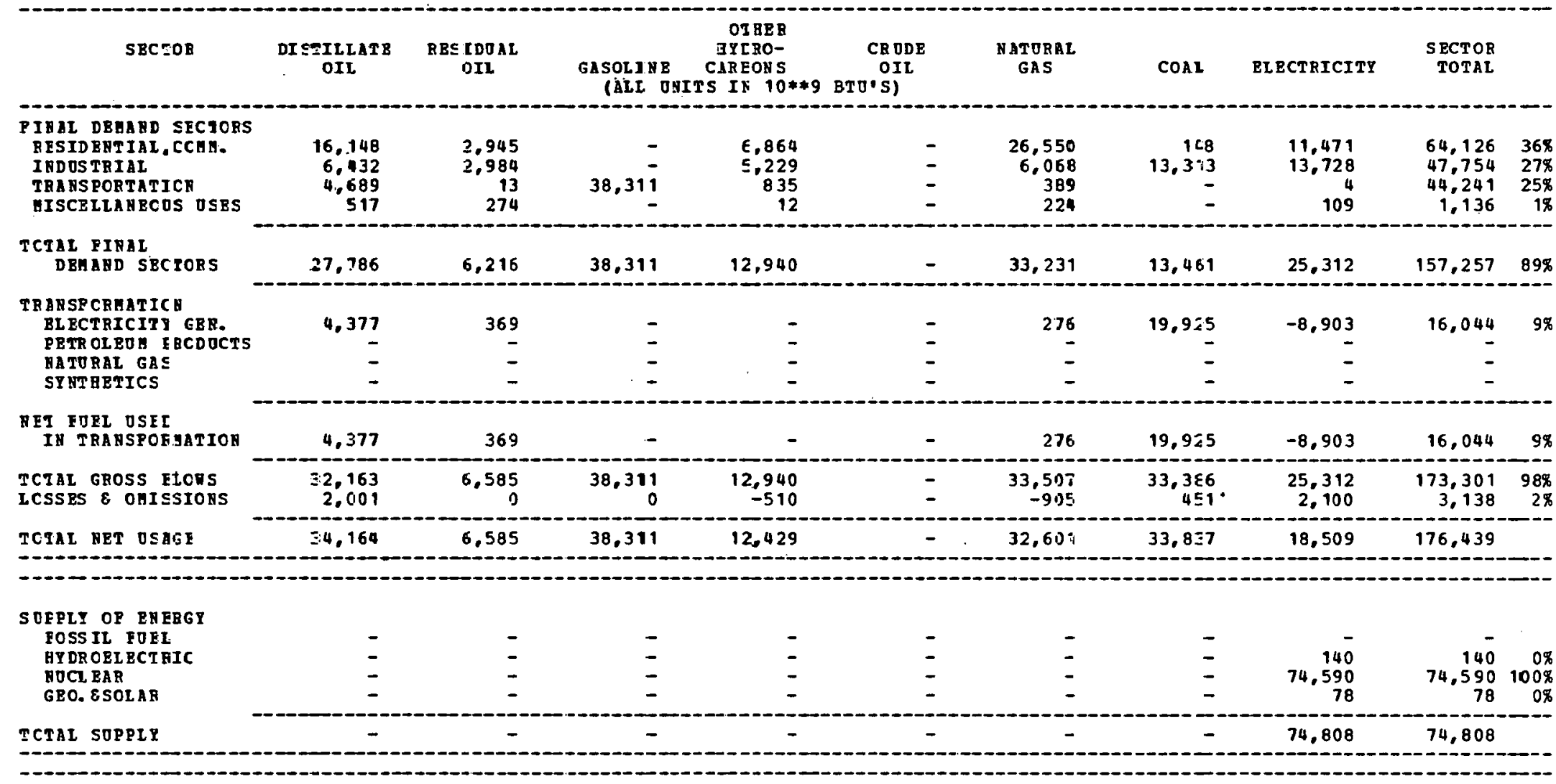

\begin{tabular}{l}
$\begin{array}{l}\text { QRT IM PORTS } \\
\text { OP B BGION }\end{array}$ \\
\hline
\end{tabular}


REGIONAL ENERGY PALANCE STATEMENT

IONAL ENERGY PALANCE ST
PIES AID GID SCENARIO

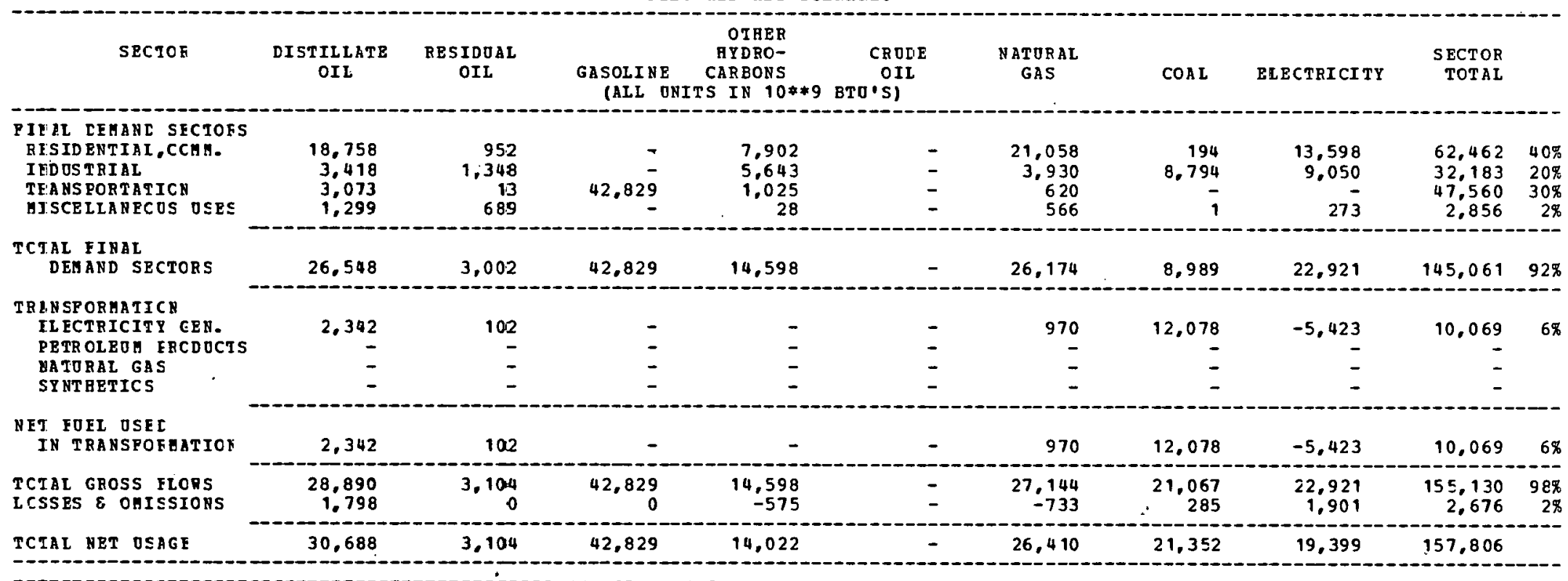

\begin{tabular}{|c|c|c|c|c|c|c|c|c|c|c|}
\hline $\begin{array}{l}\text { SOFFLY OF ENERGY } \\
\text { FOSS IL FOEI }\end{array}$ & - & - & - & - & - & - & - & - & - & \\
\hline QY DR OELECT FIC & - & - & - & - & - & - & - & 665 & 665 & $90 \%$ \\
\hline DOCL EAR & - & - & - & - & - & - & - & - & - & ron \\
\hline GEO. ESOLAR & - & - & - & - & - & - & - & 71 & 71 & $10 \%$ \\
\hline TCTAL SOPPIY & - & - & - & - & - & - & - & 736 & 736 & \\
\hline
\end{tabular}

\section{RES IM PORTS}

OP REGION

30,688

3.104

42,829

14,022

26,410

21,352

18,663

NOTES:

\begin{tabular}{|c|c|c|c|c|}
\hline $\begin{array}{l}\text { TRANSPORHA } \\
\text { TRABSFCRMA } \\
\text { TRAMSPOR }\end{array}$ & $\begin{array}{l}\text { LOS } \\
\text { LOS } \\
\text { LOS } \\
\text { LOS }\end{array}$ & $\begin{array}{l}\text { FOR } \\
\text { FOR } \\
\text { FOR } \\
\text { POR }\end{array}$ & $\begin{array}{l}\text { ELBCTRICITY GEN. } \\
\text { PETROLEUH PRODOCTS } \\
\text { HATURAL GAS } \\
\text { SYNTHETICS }\end{array}$ & $\begin{array}{l}=64.99 \% \\
=0.0 \% \\
=0.0 \% \\
=0.0 \%\end{array}$ \\
\hline
\end{tabular}


RBGIORAL RMEFGY EALANCE STATEHENT
PIBS GID MID SCEMARIO

\begin{tabular}{|c|c|c|c|c|c|c|c|c|c|c|}
\hline SECTOF & $\underset{\text { OIL }}{\operatorname{DISTIFLTE}}$ & $\begin{array}{l}\text { RESIDOIL } \\
\text { OIL }\end{array}$ & $\begin{array}{l}\text { GA SOLI N } \\
\text { (ALI }\end{array}$ & $\begin{array}{c}\text { OTRER } \\
\text { BYDRO- } \\
\text { CAREONS } \\
\text { TS IT } 10 * 49\end{array}$ & $\begin{array}{c}\text { CRODE } \\
\text { OII } \\
\text { BTOSI) }\end{array}$ & $\begin{array}{l}\text { NATORLL } \\
\text { GAS }\end{array}$ & COAL & ELECTRICITT & $\begin{array}{r}\text { SECTOR } \\
\text { TOTAL }\end{array}$ & \\
\hline 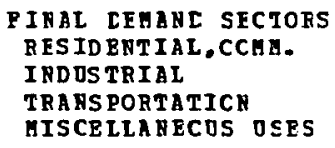 & $\begin{array}{r}69.452 \\
14.458 \\
21.116 \\
2.026\end{array}$ & $\begin{array}{r}2,973 \\
7,878 \\
170 \\
1.075\end{array}$ & $161.54 \overline{-}$ & $\begin{array}{r}29.695 \\
53.089 \\
3.034 \\
45\end{array}$ & $\begin{array}{l}\overline{-} \\
\overline{-}\end{array}$ & $\begin{array}{r}76,934 \\
22,553 \\
1,316 \\
397\end{array}$ & $\begin{array}{r}730 \\
91,102 \\
-\end{array}$ & $\begin{array}{r}48,096 \\
38,955 \\
= \\
427\end{array}$ & $\begin{array}{r}227,810 \\
228,155 \\
187,647 \\
4,472\end{array}$ & $\begin{array}{r}28 \% \\
28 \% \\
23 \% \\
1 \%\end{array}$ \\
\hline $\begin{array}{l}\text { TCTAI PINAL } \\
\text { DEMAND SECTORS }\end{array}$ & $: 07.052$ & $\cdot 2.016$ & 161,541 & $8.5,863$ & - & 102,300 & $91, \varepsilon 34$ & 87,478 & 648,084 & $81 \%$ \\
\hline $\begin{array}{l}\text { TRANSPORHATICN } \\
\text { FL RCTRICITY GEN. } \\
\text { PETR CLEOA FRCDOCTS } \\
\text { NA YORAL GAS } \\
\text { SYNTERTICS }\end{array}$ & $\begin{array}{r}9.120 \\
- \\
=\end{array}$ & $\overline{-}$ & - & $\begin{array}{l}- \\
-\end{array}$ & $\begin{array}{l}\overline{-} \\
\text { - }\end{array}$ & $\begin{array}{r}1,135 \\
- \\
-\end{array}$ & $\begin{array}{r}208, \pi 48 \\
- \\
-\end{array}$ & $\begin{array}{r}-77,810 \\
- \\
-\end{array}$ & $\begin{array}{r}140,593 \\
- \\
-\end{array}$ & $18 \%$ \\
\hline $\begin{array}{l}\text { NET FOEL OSEL } \\
\text { IN TRANSCCEATION }\end{array}$ & 9,120 & - & - & - & - & 1.235 & $208,-48$ & -77.810 & 140,593 & $18 \%$ \\
\hline $\begin{array}{l}\text { TCIAI GROSS FLCRS } \\
\text { LCSS ES CHISSIONS }\end{array}$ & $\begin{array}{r}: 16,172 \\
7,230\end{array}$ & $\begin{array}{r}12,016 \\
0\end{array}$ & $\begin{array}{r}161,541 \\
0\end{array}$ & $\begin{array}{l}85,863 \\
-3,386\end{array}$ & $\overline{-}$ & $\begin{array}{r}103,335 \\
-2,792\end{array}$ & $\begin{array}{r}300,(82 \\
4,(61)\end{array}$ & $\begin{array}{r}87,478 \\
7,258\end{array}$ & $\begin{array}{r}788,677 \\
12,373\end{array}$ & $\begin{array}{r}98 \% \\
2 \%\end{array}$ \\
\hline
\end{tabular}

-

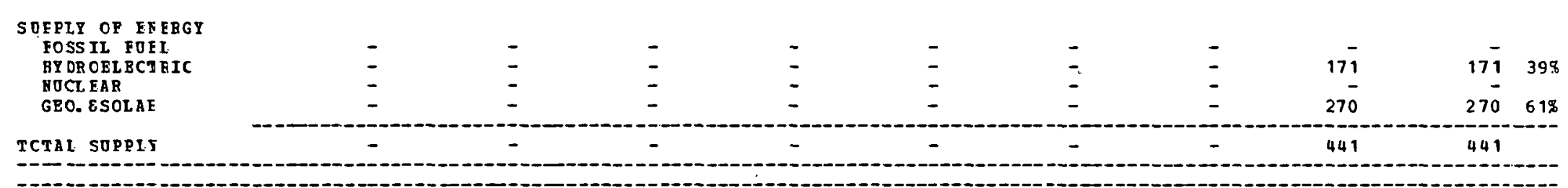

NET IM FORTS
OF REGION


REGICNAL ENERGY PALANCE STATEHENT

PIES HID HID SCENARIO

\begin{tabular}{|c|c|c|c|c|c|c|c|c|c|c|}
\hline SECTOK, & $\begin{array}{l}\text { DISTILLATE } \\
\text { OIL }\end{array}$ & $\begin{array}{l}\text { RESIDOAL } \\
\text { OIL }\end{array}$ & $\begin{array}{l}\text { GASOLINE } \\
\text { [ALL ONI? }\end{array}$ & $\begin{array}{c}\text { OTHER } \\
\text { HYDRO- } \\
\text { CARBONS } \\
\text { TS IN } 10 * 9\end{array}$ & $\begin{array}{c}\text { CRODE } \\
\text { OIL } \\
\text { BTO'S) }\end{array}$ & $\begin{array}{l}\text { NATURAL } \\
\text { GAS }\end{array}$ & $\operatorname{COAL}$ & ELECTRICITY & $\begin{array}{r}\text { SECTOR } \\
\text { TOTAL }\end{array}$ & \\
\hline $\begin{array}{l}\text { FINAL CEMANE SECIOORS } \\
\text { RESIDERTIAL,CCAR. } \\
\text { INDOSTRIAL } \\
\text { TRANSPORTATICR } \\
\text { MISCELIANECOS OSES }\end{array}$ & $\begin{array}{r}31,434 \\
9,517 \\
7,534 \\
960\end{array}$ & $\begin{array}{r}1,242 \\
6.970 \\
159 \\
510\end{array}$ & $\begin{array}{r}\overline{-} \\
78,228 \\
=\end{array}$ & $\begin{array}{r}13,948 \\
11,603 \\
2,330 \\
23\end{array}$ & $\begin{array}{l}\text { - } \\
\overline{-}\end{array}$ & $\begin{array}{r}40,557 \\
15,169 \\
1,201 \\
530\end{array}$ & $\begin{array}{r}298 \\
90,157 \\
- \\
-\end{array}$ & $\begin{array}{r}21,630 \\
39,870 \\
214\end{array}$ & $\begin{array}{r}109,109 \\
173,286 \\
89,452 \\
2,237\end{array}$ & $\begin{array}{r}26 \% \\
41 \% \\
21 \% \\
1 \%\end{array}$ \\
\hline $\begin{array}{l}\text { TCTAI. FINAI } \\
\text { DEHABD SECTCRS }\end{array}$ & 49,445 & 8.881 & 78,228 & 27,904 & - & 57.457 & 90,455 & 61,714 & 374,084 & $88 \%$ \\
\hline $\begin{array}{l}\text { TRANSPORMATICN } \\
\text { ELECTRICITY GEN. } \\
\text { FETROLEOH FRCDOCTS } \\
\text { NATORAL GAS } \\
\text { SYNTHETICS }\end{array}$ & $\begin{array}{r}6,369 \\
- \\
-\end{array}$ & $\begin{array}{r}369 \\
- \\
-\end{array}$ & $\begin{array}{l}\bar{z} \\
\overline{-}\end{array}$ & $\begin{array}{l}\overline{-} \\
\overline{-}\end{array}$ & $\begin{array}{l}- \\
\overline{-}\end{array}$ & $\begin{array}{r}699 \\
- \\
-\end{array}$ & $\begin{array}{r}56,911 \\
= \\
=\end{array}$ & $\begin{array}{r}-22,916 \\
- \\
-\end{array}$ & $\begin{array}{r}41,432 \\
- \\
-\end{array}$ & $10 \%$ \\
\hline $\begin{array}{l}\text { UET FOEL OSEC } \\
\text { IN TRANSFOFMATICN }\end{array}$ & 6,369 & 369 & - & - & - & 699 & 56.911 & $-22,916$ & 41,432 & $10 \%$ \\
\hline $\begin{array}{l}\text { TCTAL GROSS FLCRS } \\
\text { ICSSES E OHISSIOUS }\end{array}$ & $\begin{array}{r}55,814 \\
3,474\end{array}$ & $\begin{array}{r}9.250 \\
0\end{array}$ & $\begin{array}{r}78,228 \\
0\end{array}$ & $\begin{array}{r}27,904 \\
-1,100\end{array}$ & - & $\begin{array}{l}58,156 \\
-1,571\end{array}$ & $\begin{array}{r}147,366 \\
1,994\end{array}$ & $\begin{array}{r}61,714 \\
5,120\end{array}$ & $\begin{array}{r}415,516 \\
7,917\end{array}$ & $\begin{array}{r}98 \% \\
2 \%\end{array}$ \\
\hline ZCTAL NET OSAGE & 59,288 & 9.250 & 78,228 & 26,803 & - & 56,584 & 149,360 & 43,918 & 423,433 & \\
\hline
\end{tabular}

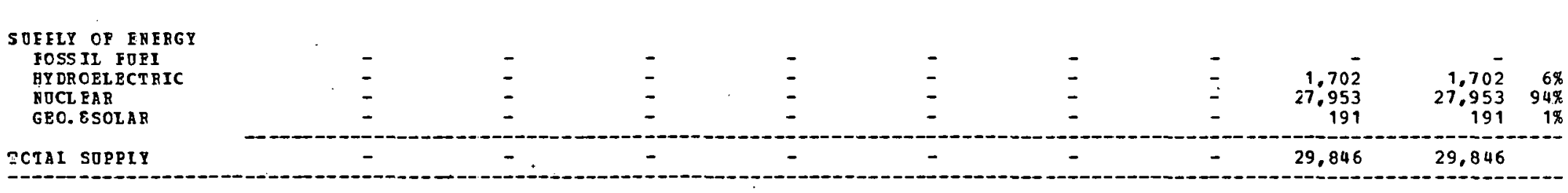

\begin{tabular}{l}
$\begin{array}{l}\text { MET IM FORTS } \\
\text { CP R EGION }\end{array}$ \\
\hline
\end{tabular}


REGIONAL EREGIY PALARCE SJATEHZNT
PISS MID GID SCENARIO

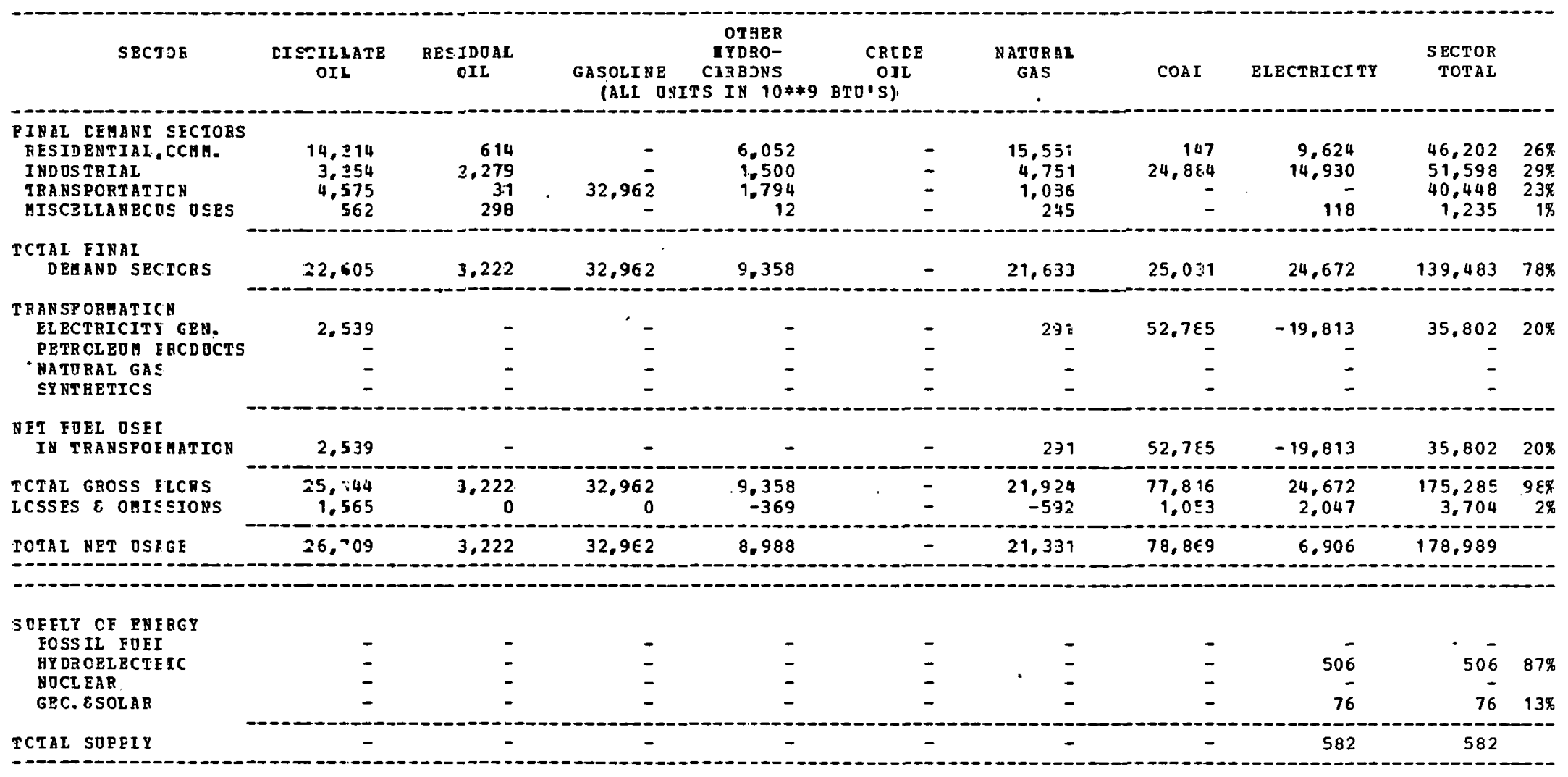

NET IM FORTS

26,709

3,222

32,962

8,988

21,331

$78,8 E 9$

6,324

178,407

\section{NOTES:}

1 TRANSPCR AATICN LOSS TOZ TRANSPCRAATICN LOSS TO TRANSPORHATICN LCSS FO TRANSPORAATICN LCSS TO 
REGIONAL BNEEGY BALANCE STATEMENT

\begin{tabular}{|c|c|c|c|c|c|c|c|c|c|c|}
\hline SECTOK & $\begin{array}{l}\text { DISTILLATE } \\
\text { OIL }\end{array}$ & $\begin{array}{l}\text { RESIDOAL } \\
\text { OIL }\end{array}$ & $\begin{array}{l}\text { GASOLINE } \\
\text { (ALL O }\end{array}$ & $\begin{array}{l}\text { OTHER } \\
\text { AYDRO- } \\
\text { CARBONS } \\
\text { TS IN } 10 * * 9\end{array}$ & $\begin{array}{c}\text { CRODE } \\
\text { OIl } \\
\text { BTO'S) }\end{array}$ & $\begin{array}{l}\text { NATORAL } \\
\text { GAS }\end{array}$ & $\mathrm{COAL}$ & BLECTRICITY & $\begin{array}{r}\text { SECTOR } \\
\text { TOTAL }\end{array}$ & \\
\hline $\begin{array}{l}\text { PIRAL CEMANC SECTOES } \\
\text { RESIDENTIAL, CCHH. } \\
\text { IRDOSTRIAL } \\
\text { TRA RSPORTATIOR } \\
\text { GISCELLABOOS OSES }\end{array}$ & $\begin{array}{r}12,228 \\
11,844 \\
2.654 \\
420\end{array}$ & $\begin{array}{r}591 \\
6.296 \\
134 \\
223\end{array}$ & $31,18 \overline{-}$ & $\begin{array}{r}5,141 \\
5,313 \\
2,777 \\
11\end{array}$ & $\begin{array}{l}\overline{-} \\
\overline{-}\end{array}$ & $\begin{array}{r}13,890 \\
6,104 \\
1,196 \\
212\end{array}$ & $\begin{array}{r}69 \\
14.754 \\
-\end{array}$ & $\begin{array}{r}7,196 \\
13,856 \\
- \\
94\end{array}$ & $\begin{array}{r}39.115 \\
58.167 \\
37.949 \\
960\end{array}$ & $\begin{array}{l}21 \% \\
31 \% \\
20 \% \\
1 \%\end{array}$ \\
\hline $\begin{array}{l}\text { TCTAL PINAL } \\
\text { DBHAND SECTCRS }\end{array}$ & 27.146 & 7.244 & 31,188 & $.13,242$ & - & 21,402 & 14,823 & 21,146 & 136.191 & $72 \%$ \\
\hline $\begin{array}{l}\text { TAANSPCRHATICN } \\
\text { PLECTRICITY GBN. } \\
\text { PBTR OLBOH ERCDOCTS } \\
\text { MATORAL GAS } \\
\text { SY RTEETICS }\end{array}$ & $\begin{array}{r}2,256 \\
-34,978 \\
-\end{array}$ & $\begin{array}{r}1,471 \\
-14,010 \\
- \\
-\end{array}$ & $\begin{array}{r}-71,95 \overline{1} \\
- \\
-\end{array}$ & $\begin{array}{r}-31,621 \\
-\end{array}$ & $\begin{array}{r}- \\
150,175 \\
- \\
-\end{array}$ & $\begin{array}{r}230 \\
3.337 \\
-\end{array}$ & $\begin{array}{r}61,257 \\
- \\
-\end{array}$ & $\begin{array}{r}-23,180 \\
- \\
-\end{array}$ & $\begin{array}{r}42,034 \\
952 \\
- \\
-\end{array}$ & $\begin{array}{r}22 \% \\
1 \%\end{array}$ \\
\hline $\begin{array}{l}\text { MEI FOEL OSEL } \\
\text { IN TRABSFOFHATIOI }\end{array}$ & $-32,722$ & $-12,539$ & $-71,951$ & $-31,621$ & 150,175 & 3.567 & 61,257 & $-23,180$ & 42,986 & $23 \%$ \\
\hline $\begin{array}{l}\text { TCTAL GROSS FLOQS } \\
\text { LOSSES E OHISSIONS }\end{array}$ & $\begin{array}{r}29,402 \\
1,830\end{array}$ & $\begin{array}{r}8,715 \\
0\end{array}$ & $\begin{array}{r}31,188 \\
0\end{array}$ & $\begin{array}{r}13.242 \\
-522\end{array}$ & $\begin{array}{r}150,175 \\
6,230\end{array}$ & $\begin{array}{r}24,969 \\
-674\end{array}$ & $\begin{array}{r}76,080 \\
1,029\end{array}$ & $\begin{array}{r}21,146 \\
1,754\end{array}$ & $\begin{array}{r}179,177 \\
9,647\end{array}$ & $\begin{aligned} 95 \% \\
5 \%\end{aligned}$ \\
\hline
\end{tabular}

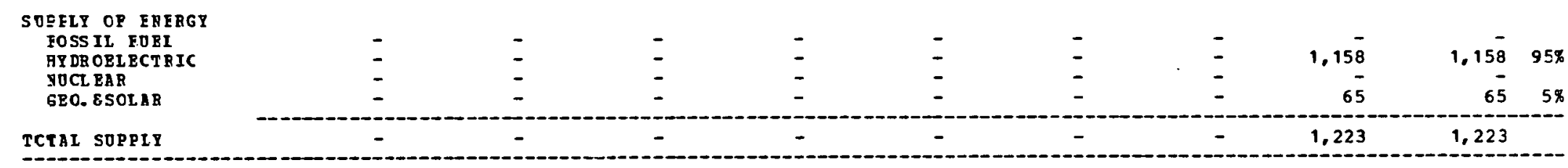

\section{BET III PORTS}

OF RBGION

$-3,745$

$-40,762$

$-18,901$

156.405

24,294

77. 109

$-1,502$

187.602

MOTES:

1 TRANSPCR ARTICN LOSS POR

TRAASPCRAATICN LOSS POR

TRABSPORBATICR LOSS POR

TRABSPORGATICH LOSS POR

ELECTRICITY GEV.

$=64.468$
0.028

PBDOLEE PRODOCTS $=0.62 \%$

$\begin{array}{ll}\text { RATURAL GAS } & =0.0 \% \\ \text { SYRTBRTICS } & =0.0 \%\end{array}$ 
RBGIONAR BNE BGY BALANCE STATEMENT
PIBS GID YID SCENARIO

\begin{tabular}{|c|c|c|c|c|c|c|c|c|c|c|}
\hline SECTIER & $\begin{array}{l}\text { DISFILLATE } \\
\text { OIL }\end{array}$ & $\begin{array}{l}\text { RES IDUAI } \\
\text { OLL }\end{array}$ & $\begin{array}{l}\text { GASOLIAB } \\
\text { (ALL DNI }\end{array}$ & $\begin{array}{c}\text { OTBER } \\
\text { HYDBO- } \\
\text { CAFBONS } \\
\text { TS I\$ } 10 * * 9\end{array}$ & $\begin{array}{c}\text { CRODE } \\
\text { OIL } \\
\text { BIO'S) }\end{array}$ & $\begin{array}{l}\text { N ATOR AL. } \\
\text { GAS }\end{array}$ & $\operatorname{COAL}$ & 3LECTRICITY & $\begin{array}{r}\text { SECTOR } \\
\text { TOTAL }\end{array}$ & \\
\hline $\begin{array}{l}\text { FIRAL DEMANE SFCTORS } \\
\text { RESIDERTIAL,ECHA. } \\
\text { IHDOSTRIAL } \\
\text { TRABSPORTATIOR } \\
\text { GISCELLABBCOS OSBS }\end{array}$ & $\begin{array}{r}10,087 \\
1,431 \\
2,236 \\
504\end{array}$ & $\begin{array}{r}459 \\
486 \\
2 \% \\
26 ?\end{array}$ & 23.281 & $\begin{array}{r}4,282 \\
897 \\
1,503 \\
11\end{array}$ & $\begin{array}{l}\overline{-} \\
\overline{-}\end{array}$ & $\begin{array}{r}11.145 \\
1,258 \\
912 \\
219\end{array}$ & $\begin{array}{r}104 \\
2.707 \\
-\end{array}$ & $\begin{array}{r}7,004 \\
4,340 \\
- \\
106\end{array}$ & $\begin{array}{r}33,081 \\
11,116 \\
27,953 \\
1,107\end{array}$ & $\begin{array}{r}12 \% \\
14 \% \\
35 \% \\
1 \%\end{array}$ \\
\hline $\begin{array}{l}\text { TCTAL PIRAL } \\
\text { DEHAHD SECTCRS }\end{array}$ & 14,258 & 1,233 & 23,281 & 6.693 & - & 13,534 & 2,803 & 11.450 & 73,257 & $73 \%$ \\
\hline 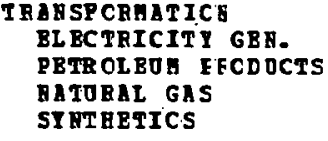 & $\begin{array}{r}4,0.33 \\
- \\
-\end{array}$ & $\begin{array}{l}\overline{-} \\
\overline{-}\end{array}$ & $\begin{array}{l}\overline{-} \\
\overline{-}\end{array}$ & $\begin{array}{l}- \\
-\end{array}$ & $\ddot{-}$ & $\begin{array}{r}125 \\
\overline{-}\end{array}$ & $\begin{array}{r}2.181 \\
= \\
=\end{array}$ & $\begin{array}{r}-2,303 \\
- \\
- \\
-\end{array}$ & $\begin{array}{r}4,036 \\
- \\
-\end{array}$ & $5 \%$ \\
\hline $\begin{array}{l}\text { DET POBL OSFI } \\
\text { IH THABSFOFATIOR }\end{array}$ & 4.033 & - & - & - & - & 125 & 2,181 & $-2,303$ & 4.036 & $5 \%$ \\
\hline $\begin{array}{l}\text { TCTAL GROSS FLCRS } \\
\text { LOSSBS \& OHISSIORS }\end{array}$ & $\begin{array}{r}18,291 \\
1,138\end{array}$ & $\begin{array}{r}1.233 \\
0\end{array}$ & $\begin{array}{r}23,281 \\
\text { i }\end{array}$ & $\begin{array}{r}6,693 \\
-264\end{array}$ & - & $\begin{array}{r}13,659 \\
-369\end{array}$ & $\begin{array}{r}4,989 \\
67\end{array}$ & $\begin{array}{r}11.450 \\
950\end{array}$ & $\begin{array}{r}77,293 \\
1,523\end{array}$ & $\begin{array}{r}38 \% \\
2 \%\end{array}$ \\
\hline TCTAL EBT OSAGE & 19,429 & 11,233 & 23,281 & 6.428 & - & 13,289 & 5.055 & 10,097 & 78.816 & \\
\hline $\begin{array}{l}\text { S OFELT OP BHEGGI } \\
\text { FOSS IL POEL } \\
\text { OY DRCELBCTEIC } \\
\text { AOCL EAR } \\
\text { GEO. ESOLAR }\end{array}$ & $\begin{array}{l}- \\
-\end{array}$ & $\overline{-}$ & $\begin{array}{l}- \\
\overline{-}\end{array}$ & $\vec{z}$ & $\begin{array}{l}- \\
\overline{-}\end{array}$ & $\begin{array}{l}\bar{z} \\
\bar{z}\end{array}$ & $\begin{array}{l}\overline{-} \\
\bar{I}\end{array}$ & $\begin{array}{r}1.810 \\
21.232 \\
35\end{array}$ & $\begin{array}{r}1.810 \\
21.232 \\
35\end{array}$ & $\begin{array}{r}8 \% \\
72 \% \\
0 \%\end{array}$ \\
\hline TOTAL SOPPLY & - & - & - & - & - & - & - & 23,077 & 23,077 & \\
\hline
\end{tabular}

NBT IMPORTS

OP. REGION

19.429

11,233

23,281

6.428

13,2 ह9

5,055

$-12,979$

55,739

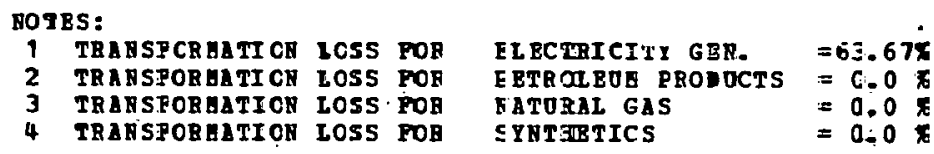


REGIOHAL BNE FGY EALANCE STATEMENT

PIES MID HID SCENARIO

\begin{tabular}{|c|c|c|c|c|c|c|c|c|c|c|}
\hline SECTOR & $\begin{array}{l}\text { DISTILLATE } \\
\text { OIL }\end{array}$ & $\begin{array}{l}\text { RESIDULL } \\
\text { OIL }\end{array}$ & $\begin{array}{l}\text { GASOLINE } \\
\text { (ALL }\end{array}$ & $\begin{array}{c}\text { OTEER } \\
\text { HYDRO- } \\
\text { CARBONS } \\
\text { TS IN } 10 * * 9\end{array}$ & $\begin{array}{c}\text { CRODE } \\
\text { OIL } \\
\text { BTU.S) }\end{array}$ & $\begin{array}{l}\text { NATURAL } \\
\text { GAS }\end{array}$ & COAL & ELECTRICITY & $\begin{array}{r}\text { SECTOR } \\
\text { TOTAL }\end{array}$ & \\
\hline 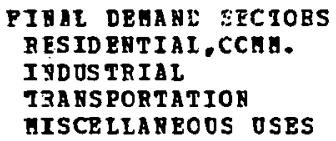 & $\begin{array}{r}10,098 \\
3,011 \\
2,083 \\
528\end{array}$ & $\begin{array}{r}456 \\
1,160 \\
61 \\
281\end{array}$ & $23,99 \overline{3}$ & $\begin{array}{r}4,266 \\
1,912 \\
1.442 \\
11\end{array}$ & $\overline{-}$ & $\begin{array}{r}11,016 \\
1,797 \\
778 \\
235\end{array}$ & $\begin{array}{r}89 \\
4,529 \\
- \\
-\end{array}$ & $\begin{array}{r}6.543 \\
6.189 \\
.111\end{array}$ & $\begin{array}{r}32,468 \\
18,598 \\
28,337 \\
1,166\end{array}$ & $\begin{array}{r}28 \% \\
16 \% \\
25 \% \\
1 \%\end{array}$ \\
\hline $\begin{array}{l}\text { TCIAL RINAL } \\
\text { DBHAYD SECTORS }\end{array}$ & 15,720 & 1,938 & 23,993 & 7,631 & - & 13,826 & 4,618 & 12,843 & 80,569 & $70 \%$ \\
\hline 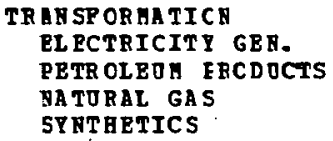 & $\begin{array}{r}2,240 \\
- \\
-\end{array}$ & $\begin{array}{r}68 \\
- \\
-\end{array}$ & $\begin{array}{l}\overline{-} \\
\overline{-}\end{array}$ & $\overline{-}$ & $\begin{array}{l}- \\
\overline{-}\end{array}$ & $\begin{array}{r}140 \\
- \\
-\end{array}$ & $\begin{array}{r}46,674 \\
= \\
-\end{array}$ & $\begin{array}{r}-17,514 \\
= \\
-\end{array}$ & $\begin{array}{r}31,608 \\
- \\
-\end{array}$ & $28 \%$ \\
\hline $\begin{array}{l}\text { NET FOEL OSEC } \\
\text { IN TRANSFOEHATIOS }\end{array}$ & 2,240 & 68 & - & - & - & 140 & 46,674 & $-17,514$ & 31,608 & $28 \%$ \\
\hline $\begin{array}{l}\text { TCIAL GROSS FLORS } \\
\text { LCSSBS \& ORISSIORS }\end{array}$ & $\begin{array}{r}17,960 \\
1,117\end{array}$ & $\begin{array}{r}2,006 \\
0\end{array}$ & $\begin{array}{r}23,993 \\
0\end{array}$ & $\begin{array}{r}7.631 \\
-300\end{array}$ & $\overline{-}$ & $\begin{array}{r}13.966 \\
-377\end{array}$ & $\begin{array}{r}51,292 \\
694\end{array}$ & $\begin{array}{r}12,843 \\
1,065\end{array}$ & $\begin{array}{r}112,177 \\
2,199\end{array}$ & $\begin{array}{r}98 \% \\
2 \%\end{array}$ \\
\hline
\end{tabular}

\begin{tabular}{|c|c|c|c|c|c|c|c|c|c|c|}
\hline $\begin{array}{l}\text { SOFFLY OP ERERGY } \\
\text { FOSS IL FEEI }\end{array}$ & - & - & - & - & - & - & - & - & - & \\
\hline BY DR OBL BCT BIC & - & - & - & - & - & - & - & 210 & 210 & $18 \%$ \\
\hline NOCL BAR & - & - & - & - & - & - & - & 886 & 886 & $78 \%$ \\
\hline GBO. ESOLER & - & - & - & - & - & - & - & 40 & 40 & $4 \%$ \\
\hline TCTAL SOPPII & - & - & - & - & - & - & - & 1,136 & 1,136 & \\
\hline
\end{tabular}

FET. II FORTS
OF R BGIOB


REGLONAL ESESGT BALARCB STATEMERT

PWAL ENE SGI EALARCB
PIBS UID HID SCERARIO

\begin{tabular}{|c|c|c|c|c|c|c|c|c|c|c|}
\hline SBCTOE & $\begin{array}{l}\text { DI STILLATE } \\
\text { OIX }\end{array}$ & $\begin{array}{l}\text { RESIDOLL } \\
\text { DIL }\end{array}$ & $\begin{array}{l}\text { GA SOLI IE } \\
\text { (ALE O }\end{array}$ & $\begin{array}{c}\text { OTHER } \\
\text { BIDRO- } \\
\text { CARBONS } \\
\text { TS ID } 10 * * 9\end{array}$ & $\begin{array}{c}\text { CRODE } \\
\text { OIL } \\
\text { BTOיSI }\end{array}$ & $\begin{array}{l}\text { NATORAL } \\
\text { GAS }\end{array}$ & $\cos I$ & ELECTRICITY & $\begin{array}{r}\text { SECTOR } \\
\text { TOTAL }\end{array}$ & \\
\hline 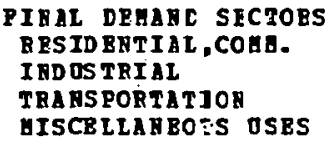 & $\begin{array}{r}8,780 \\
4.786 \\
2.633 \\
274\end{array}$ & $\begin{array}{r}4.2 \\
1.86 .3 \\
5.3 \\
165\end{array}$ & $22,23 \overline{-}$ & $\begin{array}{r}3,590 \\
1,640 \\
1,192 \\
6\end{array}$ & $\overline{-}$ & $\begin{array}{r}9,564 \\
2,819 \\
437 \\
119\end{array}$ & $\begin{array}{r}40 \\
432 \\
- \\
-\end{array}$ & $\begin{array}{r}5,119 \\
6,955 \\
57\end{array}$ & $\begin{array}{r}27,585 \\
22,365 \\
26,548 \\
601\end{array}$ & $\begin{array}{r}32 \% \\
26 \% \\
31 \% \\
1 \%\end{array}$ \\
\hline $\begin{array}{l}\text { TCTAL FINAL } \\
\text { DBHAND SBCTOBS }\end{array}$ & 16,473 & 2,553 & 22,233 & 6.428 & - & 12,939 & $4,3+2$ & 12,131 & 77.099 & $89 \%$ \\
\hline 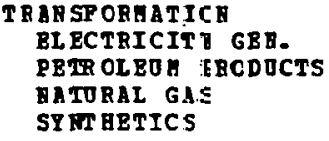 & $\begin{array}{r}1,266 \\
= \\
=\end{array}$ & $\begin{array}{r}273 \\
- \\
-\end{array}$ & E & $\begin{array}{l}\bar{z} \\
\overline{-}\end{array}$ & $\begin{array}{l}- \\
\overline{-} \\
-\end{array}$ & $\begin{array}{r}132 \\
- \\
-\end{array}$ & $\begin{array}{r}10,436 \\
= \\
=\end{array}$ & $\begin{array}{r}-4,305 \\
- \\
-\end{array}$ & $\begin{array}{r}7,802 \\
- \\
-\end{array}$ & $9 \%$ \\
\hline $\begin{array}{l}\text { BET FOBL OSPE } \\
\text { IR TRABSPOEHATIOF }\end{array}$ & 1,266 & 273 & - & - & - & 132 & 10.436 & $-4,305$ & 7,802 & $9 \%$ \\
\hline $\begin{array}{l}\text { TCTAX, GROSS ELONS } \\
\text { LOSSES } E \text { OUISSIOUS }\end{array}$ & $\begin{array}{r}17,739 \\
1,104\end{array}$ & $\begin{array}{r}2,8=6 \\
0\end{array}$ & $\begin{array}{r}22,233 \\
0\end{array}$ & $\begin{array}{l}6.428 \\
-253\end{array}$ & $\begin{array}{l}- \\
-\end{array}$ & $\begin{array}{r}13,071 \\
-353\end{array}$ & $\begin{array}{r}14.778 \\
2.30\end{array}$ & $\begin{array}{r}12,131 \\
1,006\end{array}$ & $\begin{array}{r}84,901 \\
1,704\end{array}$ & $\begin{array}{r}98 \% \\
28\end{array}$ \\
\hline TOTAL RET OSAGE & 18.843 & $2,8=6$ & 22,233 & 6.174 & - & 12,717 & 14,978 & 8,832 & 86.605 & \\
\hline $\begin{array}{l}\text { SOEFIY OP EYIRGY } \\
\text { FOSS IL POBI } \\
\text { HYDROBLBCIBIC } \\
\text { YOCL BRR } \\
\text { GBO. 8SOLAR }\end{array}$ & $\begin{array}{l}\bar{z} \\
\overline{-}\end{array}$ & $\bar{z}$ & $\bar{z}$ & $\bar{z}$ & $\bar{E} \overline{-}$ & $=$ & $\bar{z}$ & $\frac{4}{37}$ & $\frac{49}{37}$ & $43 \%$ \\
\hline TOTAL SOPPIY & - & - & - & - & - & - & - & 86 & 86 & \\
\hline
\end{tabular}

\section{RBT INPORTS}

OP R BGIOH

18,843

2,826

22.233

6,174

12,717

14.978

8,746

86,519

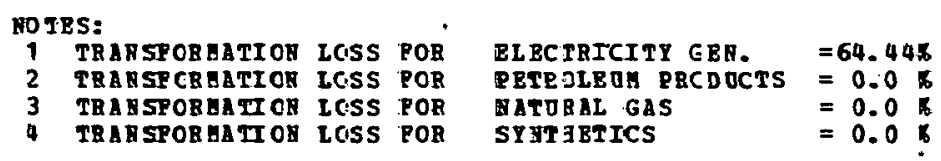


REGIONAL BNEFGY EALANCE STATEMENT

PIES MID HID SCENARIO

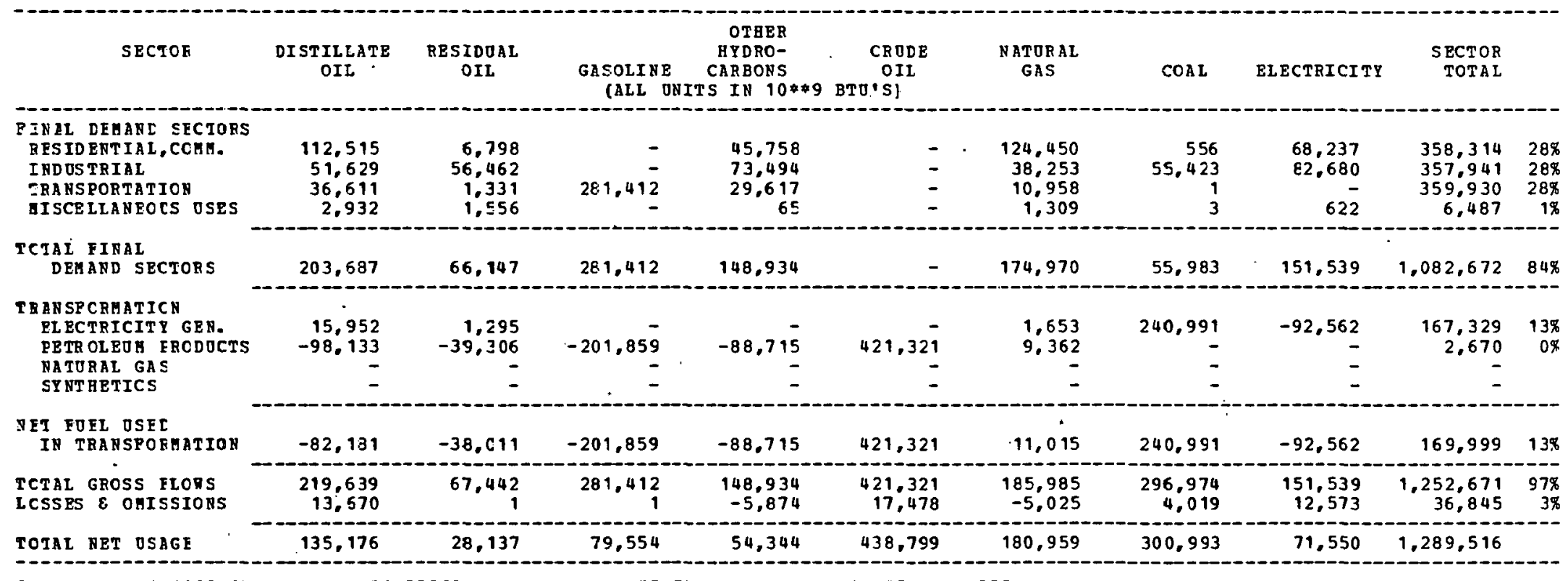

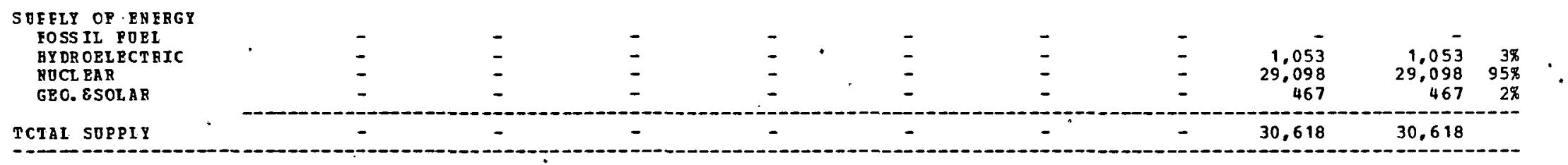

-

\section{HET IN PORTS}

\begin{tabular}{l} 
OF REGION \\
\hline
\end{tabular}

-

พo TES:

1 TRANSPCRMATICN LOSS POR TRANSPCRMATICN IOSS POR TRANSPORMATICN LOSS POR TRANSFORHATICN LOSS POR
ELECTRICITY GRN.

( $=64.38 \%$

PETROLEOU PRODOCTS $=0.62 \pi$

$\begin{array}{ll}\text { NATURAL GAS } & =0.0 \% \\ \text { SYNTETICS } & =0.0 \%\end{array}$ 
REGI.JTAL ERE RGY PALANCE STATEMENT
?IES BID IID SCENARIO

\begin{tabular}{|c|c|c|c|c|c|c|c|c|c|}
\hline SECTJF & $\begin{array}{c}\text { DISEILLATB } \\
\text { OIL }\end{array}$ & $\begin{array}{l}\text { RESIDDAL } \\
\text { OIL }\end{array}$ & $\begin{array}{l}\text { GASOLI IE } \\
\text { CALL ONIT }\end{array}$ & $\begin{array}{c}\text { OTBER } \\
\text { HIY DRO- } \\
\text { CARBONS } \\
\text { IS IN } \quad 10 * * 9\end{array}$ & $\begin{array}{c}\text { CRODE } \\
\text { OIL } \\
\text { BTU'SI }\end{array}$ & $\begin{array}{l}\text { NATUREL. } \\
\text { GAS }\end{array}$ & $\operatorname{COAI}$ & ELECTRICITY & $\begin{array}{r}\text { SECTOR } \\
\text { TOTAL }\end{array}$ \\
\hline 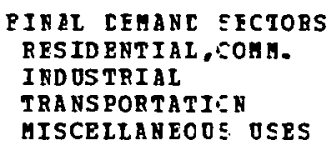 & $\begin{array}{l}6,146 \\
3,150 \\
5,594 \\
495\end{array}$ & $\begin{array}{r}554 \\
740 \\
50 \\
189\end{array}$ & $22,92 \overline{-}$ & $\begin{array}{r}4,355 \\
1.351 \\
2.412 \\
19\end{array}$ & $\begin{array}{l}- \\
- \\
-\end{array}$ & $\begin{array}{r}8,1 \equiv 4 \\
5: 7 \\
6: 9 \\
2 C 4\end{array}$ & $\begin{array}{r}23 \\
9.39 ? \\
- \\
-\end{array}$ & $\begin{array}{r}7,340 \\
2.691 \\
141\end{array}$ & $\begin{array}{r}26,552 \\
17,901 \\
31,603 \\
1,048\end{array}$ \\
\hline $\begin{array}{l}\text { TCTAL FINAL } \\
\text { DEMAND SECIORS }\end{array}$ & $: 5,335$ & 1,533 & $22,92.3$ & 8.137 & - & $9,5 \equiv 4$ & 9,415 & 10,172 & 77,104 \\
\hline $\begin{array}{l}\text { T RANSPCRHATICY } \\
\text { EL ECTRICITI GEN. } \\
\text { PETR OLEOM FGCDOCTS } \\
\text { MA TORAL GAS } \\
\text { SY NTRETICS }\end{array}$ & $\begin{array}{r}620 \\
- \\
-\end{array}$ & $\begin{array}{l}- \\
-\end{array}$ & $\begin{array}{l}- \\
- \\
-\end{array}$ & $\begin{array}{l}- \\
\overline{-} \\
-\end{array}$ & $\begin{array}{l}- \\
\overline{-} \\
-\end{array}$ & $\begin{array}{l}95 \\
- \\
-\end{array}$ & $\begin{array}{r}1,903 \\
- \\
-\end{array}$ & $\begin{array}{r}-875 \\
= \\
-\end{array}$ & $\begin{array}{r}1,743 \\
= \\
-\end{array}$ \\
\hline $\begin{array}{l}\text { NET FOEL OSEL } \\
\text { IN TRANSPOEATION }\end{array}$ & 620 & - & - & - & - & $\$ 5$ & 1,903 & -875 & 1,743 \\
\hline $\begin{array}{l}\text { TCTAL GROSS FLCRS } \\
\text { LCSSES \& OHISEIORS }\end{array}$ & $\begin{array}{r}15,0 J 5 \\
976\end{array}$ & $\begin{array}{r}1.533 \\
0\end{array}$ & 22,928 & $\begin{array}{r}8,137 \\
-320\end{array}$ & - & $\begin{array}{r}9,629 \\
-2 \in 0\end{array}$ & $\begin{aligned} 11,318 \\
153\end{aligned}$ & $\begin{array}{r}10,172 \\
844\end{array}$ & $\begin{array}{r}78,847 \\
1,412\end{array}$ \\
\hline TCTAL NET OSAEE & $: 7,0] 1$ & 1,533 & 22,928 & 7.816 & - & $9,3 \in 8$ & 11,471 & 10,141 & 80,259 \\
\hline
\end{tabular}

\begin{tabular}{|c|c|c|c|c|c|c|c|c|c|c|}
\hline SOEELY OP ENFBGY & & & & & & & & & & \\
\hline FOSS IL POEI & - & - & - & - & - & - & - & - & - & \\
\hline HY LR CELECTEIC & - & - & - & - & - & - & - & 277 & 277 & $35 \%$ \\
\hline YOCL BAR & - & - & - & - & - & - & - & 103 & 103 & $\because \Xi$ \\
\hline GEC. \&SOLAR & - & - & - & - & - & - & - & 416 & 416 & $\$ 2 \%$ \\
\hline TCTAL SOPPIY & - & - & - & - & - & - & - & 796 & 796 & \\
\hline
\end{tabular}

NET IM FORTS
OP REGION


REGIONAL ENE BGY PALANCE STATEMENT

PIES MID MID SCENARIO

\begin{tabular}{|c|c|c|c|c|c|c|c|c|c|c|}
\hline SECIOK & $\begin{array}{l}\text { DISTILLATE } \\
\text { OIL }\end{array}$ & $\begin{array}{l}\text { RESIDOAZ } \\
\text { OIL }\end{array}$ & $\begin{array}{l}\text { GASOEINE } \\
\text { GALL ONIT }\end{array}$ & $\begin{array}{c}\text { OTHER } \\
\text { AYDRO- } \\
\text { CARBONS } \\
\text { TS IN } 10 * * 9\end{array}$ & $\begin{array}{c}\text { CRODE } \\
\text { OII } \\
\text { BTU'SI }\end{array}$ & $\begin{array}{l}\text { NATORAL } \\
\text { GAS }\end{array}$ & $\operatorname{COAL}$ & ELECTRICITY & $\begin{array}{r}\text { SECTOR } \\
\text { TOTAL }\end{array}$ & \\
\hline $\begin{array}{l}\text { PINAL CEMANC SFCTOES } \\
\text { EESIDENTIAL, COMH. } \\
\text { INDOSTRIAL } \\
\text { TRANSPORTATION } \\
\text { GISCELLAHEOC OSES }\end{array}$ & $\begin{array}{r}2,870 \\
3,757 \\
4,790 \\
350\end{array}$ & $\begin{array}{r}391 \\
1.079 \\
3 \\
111\end{array}$ & $\begin{array}{r}- \\
16.305 \\
-\end{array}$ & $\begin{array}{r}3.388 \\
1,291 \\
2,081 \\
18\end{array}$ & $\begin{array}{l}- \\
\overline{-} \\
\overline{-}\end{array}$ & $\begin{array}{r}5,985 \\
2,371 \\
313 \\
148\end{array}$ & $\begin{array}{r}9 \\
7,857 \\
-\end{array}$ & $\begin{array}{r}6,197 \\
4,611 \\
113\end{array}$ & $\begin{array}{r}18,839 \\
20.966 \\
23,492 \\
740\end{array}$ & $\begin{array}{r}19 \% \\
21 \% \\
23 \% \\
1 \%\end{array}$ \\
\hline $\begin{array}{l}\text { TCIAL FINAL } \\
\text { DEHAND SECTORS. }\end{array}$ & 11,767 & 1,583 & 16,305 & 6,778 & - & 8,817 & 7,866 & 10,921 & 64,037 & $64 \%$ \\
\hline $\begin{array}{l}\text { TEANSPORMATICH } \\
\text { RLECTRICIT GEN. } \\
\text { PETR OLEO FRODOCTS } \\
\text { RATORAL GAS } \\
\text { SYNTHETICS }\end{array}$ & $\begin{array}{r}364 \\
-4.041 \\
- \\
-\end{array}$ & $\begin{array}{r}-1,483 \\
- \\
-\end{array}$ & $\begin{array}{r}-7.676 \\
- \\
-\end{array}$ & $\begin{array}{r}- \\
-2,93 \overline{5} \\
-\end{array}$ & $\begin{array}{r}15.825 \\
-\end{array}$ & $\begin{array}{r}107 \\
464 \\
- \\
-\end{array}$ & $\begin{array}{r}47,954 \\
- \\
-\end{array}$ & $\begin{array}{r}-15,172 \\
- \\
-\end{array}$ & $\begin{array}{r}33,253 \\
152 \\
- \\
-\end{array}$ & $\begin{array}{r}33 \% \\
0 \%\end{array}$ \\
\hline $\begin{array}{l}\text { NET FOFL USEE } \\
\text { IN TRAYSPOEGATIOY }\end{array}$ & $-3,677$ & $-1,48.3$ & $-7,576$ & $-2,935$ & 15,825 & 571 & 47.954 & $-15,172$ & 33.405 & $33 \%$ \\
\hline $\begin{array}{l}\text { TOTAL GROSS ELCRS } \\
\text { LCSSES \& OHISSIOHS }\end{array}$ & $\begin{array}{r}12.131 \\
755\end{array}$ & $\begin{array}{r}1,58.3 \\
j\end{array}$ & $\begin{array}{r}16,305 \\
0\end{array}$ & $\begin{array}{r}6,778 \\
-267\end{array}$ & $\begin{array}{r}15.825 \\
656\end{array}$ & $\begin{array}{r}9,388 \\
-253\end{array}$ & $\begin{array}{r}55.820 \\
755\end{array}$ & $\begin{array}{r}10,921 \\
906\end{array}$ & $\begin{array}{r}97,442 \\
2,552\end{array}$ & $\begin{array}{r}97 \% \\
3 \%\end{array}$ \\
\hline
\end{tabular}

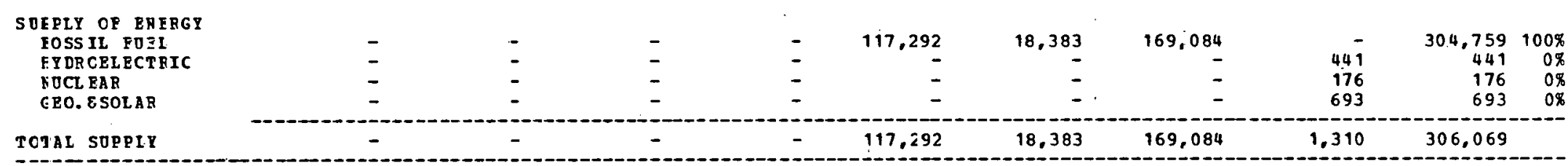

8,844

99

8,628

$3,575 \quad-100,809$

$-9,248 \quad-112,508$

$-4,654 \quad-206,073$

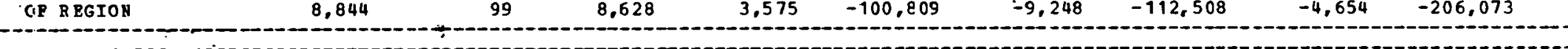

NOTBS:

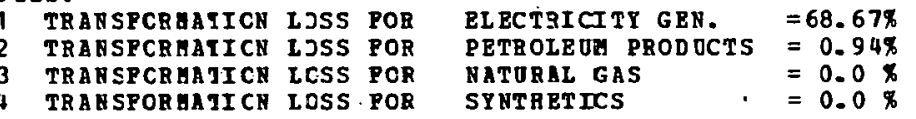

TRARSCRAATCA LJSS POR TRABSPORATIICH LOSS POR 
REGIONAL BNERGY EALARCE STATEHENT

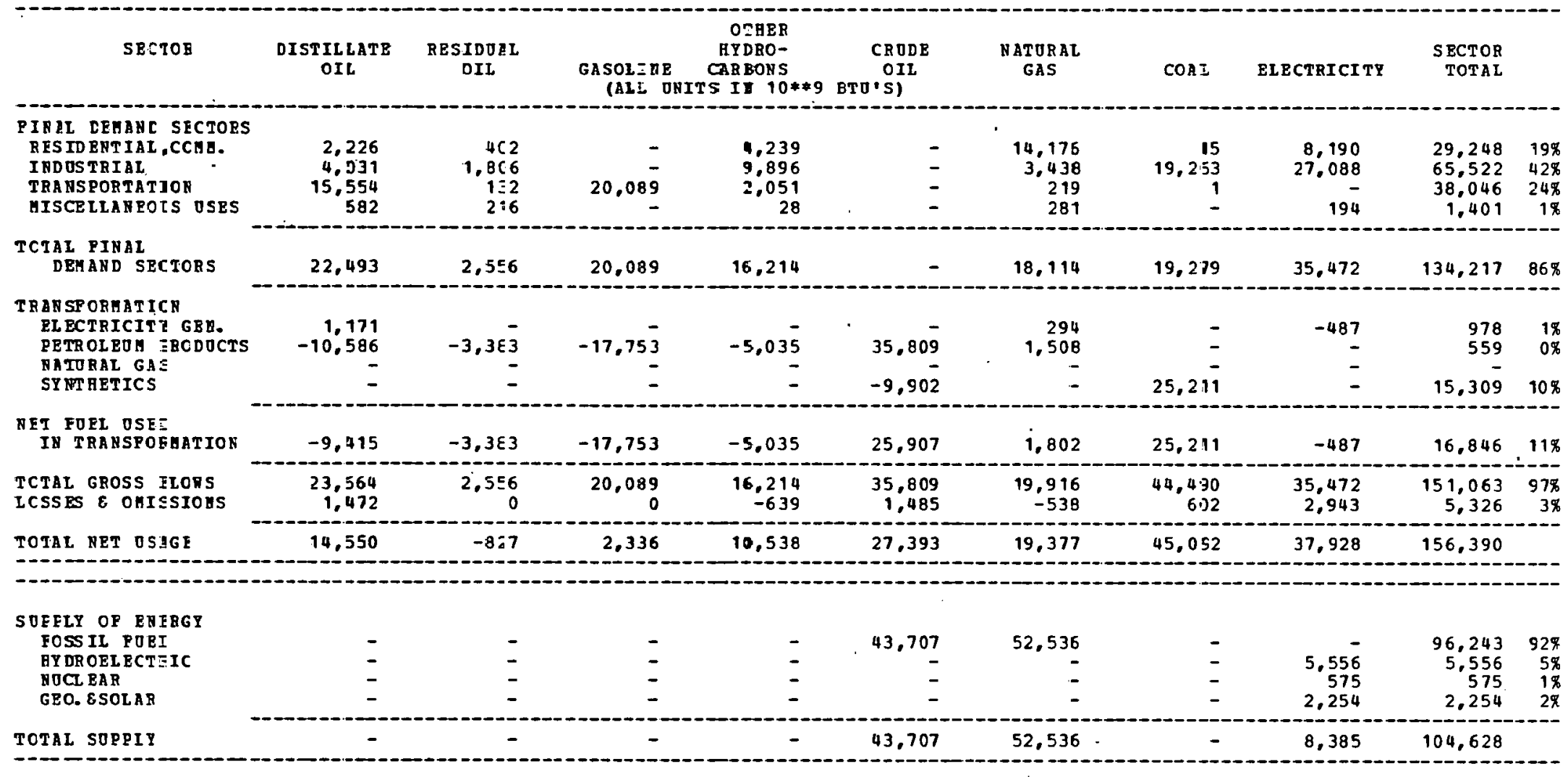

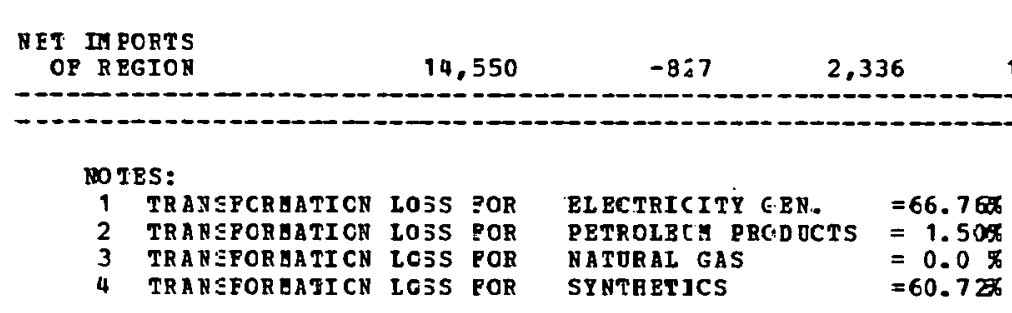


REGIONAL BNB BGY FALANCB STATEMENT

PIBS MID MI D SCEMARIO

\begin{tabular}{|c|c|c|c|c|c|c|c|c|c|c|}
\hline SECTOR & $\begin{array}{l}\text { DISTILLATB } \\
\text { OIL }\end{array}$ & $\begin{array}{l}\text { RBSIDOAL } \\
\text { OIL }\end{array}$ & $\begin{array}{l}\text { GASOLINB } \\
\text { (ALL OHI }\end{array}$ & $\begin{array}{c}\text { OTBER } \\
\text { RYDRO- } \\
\text { CARBONS } \\
\text { TS IN } 10 * * 9\end{array}$ & $\begin{array}{c}\text { CRODE } \\
\text { OII } \\
\text { BTO'S) }\end{array}$ & $\begin{array}{l}\text { NATURAL } \\
\text { GAS }\end{array}$ & $\cos 1$ & ELECTRICITY & $\begin{array}{r}\text { SECTOR } \\
\text { TOTAL }\end{array}$ & \\
\hline 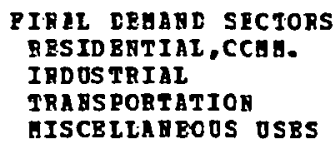 & $\begin{array}{r}3,807 \\
15,288 \\
18,458 \\
455\end{array}$ & $\begin{array}{r}792 \\
13.996 \\
157 \\
144\end{array}$ & 28,539 & $\begin{array}{r}5,765 \\
18,914 \\
2,876 \\
16\end{array}$ & $\begin{array}{l}\overline{-} \\
\overline{-}\end{array}$ & $\begin{array}{r}19,761 \\
6,165 \\
349 \\
123\end{array}$ & $\begin{array}{r}19 \\
8,872 \\
1 \\
-\end{array}$ & $\begin{array}{r}12,211 \\
25,268 \\
- \\
121\end{array}$ & $\begin{array}{r}42,355 \\
88,503 \\
50,380 \\
859\end{array}$ & $\begin{array}{r}15 \% \\
318 \\
18 \% \\
0 \%\end{array}$ \\
\hline $\begin{array}{l}\text { TCTAL FIMAL } \\
\text { DBHAKD SBCTOBS }\end{array}$ & 38,008 & 15,089 & 28,539 & 27.571 & - & 26,398 & 8,892 & 37,600 & 182,097 & $64 \%$ \\
\hline 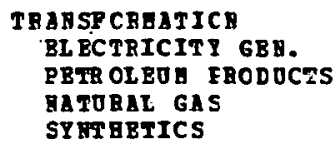 & $\begin{array}{r}1,241 \\
-100,517 \\
-\end{array}$ & $\begin{array}{r}-32,124 \\
-\end{array}$ & $\begin{array}{r}-168,563 \\
-\end{array}$ & $\begin{array}{r}-47 ; 813 \\
-\end{array}$ & $\begin{array}{r}340.011 \\
-\end{array}$ & $\begin{array}{r}312 \\
14,319 \\
-\end{array}$ & $\begin{array}{r}109,721 \\
- \\
-\end{array}$ & $\begin{array}{r}-34,872 \\
= \\
=\end{array}$ & $\begin{array}{r}76,402 \\
5,312 \\
= \\
=\end{array}$ & $\begin{array}{r}27 \% \\
2 \%\end{array}$ \\
\hline $\begin{array}{l}\text { BET FORL OSEL } \\
\text { IE TRABSPOBATIOR }\end{array}$ & $-99,276$ & $-32,12: 4$ & $-168,563$ & $-47,813$ & 340.011 & 14,631 & 109.721 & $-34,872$ & 81,714 & $29 \%$ \\
\hline $\begin{array}{l}\text { TOTAL GROSS FLORS } \\
\text { LOSSES E OAISSIOHS }\end{array}$ & $\begin{array}{r}39,249 \\
2,442\end{array}$ & $\begin{array}{r}15,089 \\
0\end{array}$ & $\begin{array}{r}28,539 \\
0\end{array}$ & $\begin{array}{l}27.571 \\
-1.087\end{array}$ & $\begin{array}{r}340,011 \\
14,105\end{array}$ & $\begin{array}{l}41,029 \\
-1,108\end{array}$ & $\begin{array}{r}118,613 \\
1,605\end{array}$ & $\begin{array}{r}37,600 \\
3,119\end{array}$ & $\begin{array}{r}263,811 \\
19,078\end{array}$ & $\begin{array}{r}93 \% \\
7 \%\end{array}$ \\
\hline $\begin{array}{l}\text { SOPELI OP BAFBGY } \\
\text { FOSS IL FOBL } \\
\text { GT OROBLECTEIC } \\
\text { YOCL BAR } \\
\text { GEC. } 8 \text { SOLAR }\end{array}$ & $\overline{-}$ & $\begin{array}{l}\overline{-} \\
\overline{-}\end{array}$ & $\bar{z}$ & $\begin{array}{l}- \\
- \\
-\end{array}$ & $\begin{array}{r}329,324 \\
- \\
-\end{array}$ & $\begin{array}{r}68,648 \\
- \\
= \\
-\end{array}$ & $\begin{array}{r}2.062,414 \\
= \\
-\end{array}$ & $\begin{array}{r}7.814 \\
610 \\
2,389\end{array}$ & $\begin{array}{r}2,460,386 \\
7,814 \\
610 \\
2,389\end{array}$ & $\begin{array}{r}100 \% \\
0 \% \\
0 \% \\
0 \%\end{array}$ \\
\hline TCTAI SOPPIY & - & - & - & - & 329,324 & 68,648 & $2,062,414$ & 10,813 & $2,471,199$ & \\
\hline
\end{tabular}

MOIBS:

TRAXSPCRUATIOR IOSS POR TRABSPORAATICY IOSS POR TRABSPOBAATI OR IOSS POB TRABSPOREATI OR IOSS POR
BLBCTRICITI.GBN. $\quad=68.66 \pi$

PBTOLBOA PROD DCTS $=1.50 \%$

$\begin{array}{ll}\text { GTOAAL GAS } & =0.0 x \\ \text { SYBTB BTICS } & =0.0\end{array}$ 
RBGIOMAL BRSFGY EALAMCE STATBMETT

OMAL RESFG EALANCE STA
PIBS N-D MID SCEMATO

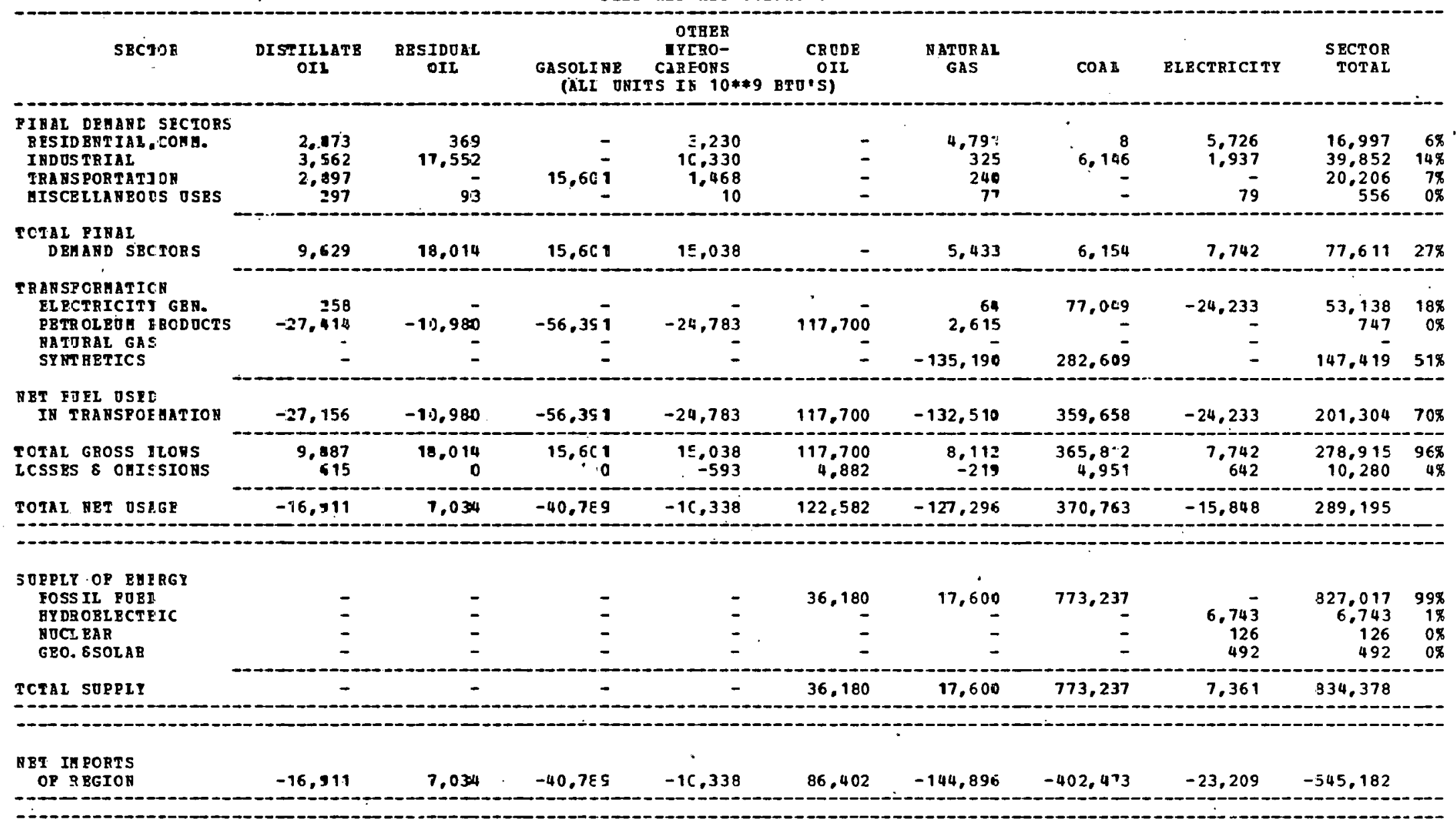

\section{HoTES:}

1 TRABSFCRAATICN LCSS POR TRANSPORAATICR LOSS POR

TRAYSPORAATICN LCSS POR
TRAGSPORAATICN LCSS POR

BLECTRICITY GBY:

=68.687

$\begin{array}{ll}\text { MATC3AL GAS } & =0.628 \\ \text { SYODOCS } & =0.0\end{array}$

SYATAETICS

$=0.01$
$=52.168$ 
REGIONAL EREAGY BALANCE STATEMENT
PIES IID IID SCENARIO

\begin{tabular}{|c|c|c|c|c|c|c|c|c|c|c|}
\hline SBCTOE & $\begin{array}{l}\text { DISTILLATB } \\
\text { OIL }\end{array}$ & $\begin{array}{l}\text { RESIDOLL } \\
\text { OII }\end{array}$ & $\begin{array}{l}\text { GASOLIHE } \\
\text { (ALL ON! }\end{array}$ & $\begin{array}{c}\text { OTHER } \\
\text { HYDRO- } \\
\text { CARBONS } \\
\text { TS IN } 10 * * 9\end{array}$ & $\begin{array}{c}\text { CRODE } \\
\text { OIL } \\
\text { BTO :S) }\end{array}$ & $\begin{array}{l}\text { NaTURAL } \\
\text { GAS }\end{array}$ & COAL & BLECTRICITY & $\begin{array}{r}\text { SECTOR } \\
\text { TOTAL }\end{array}$ & \\
\hline $\begin{array}{l}\text { PIRAL CBHABC SECTORS } \\
\text { RESIDERTIAL, CCHH. } \\
\text { IRDOSTRIAL } \\
\text { TRABSPORTATIOA } \\
\text { GISCELLABOOS OSBS }\end{array}$ & $\begin{array}{l}8,622 \\
4,449 \\
7,578 \\
491\end{array}$ & $\begin{array}{r}7 \varepsilon 1 \\
1,125 \\
63 \\
188\end{array}$ & 31,543 & $\begin{array}{l}5,974 \\
2,159 \\
2,641 \\
14\end{array}$ & z- & $\begin{array}{r}11,328 \\
659 \\
715 \\
158\end{array}$ & $\begin{array}{r}33 \\
9,965 \\
- \\
-\end{array}$ & $\begin{array}{r}10,223 \\
4,092 \\
- \\
121\end{array}$ & $\begin{array}{r}36,961 \\
22,441 \\
42,540 \\
972\end{array}$ & $\begin{array}{r}33 \% \\
20 \% \\
38 \% \\
1 \%\end{array}$ \\
\hline $\begin{array}{l}\text { TCYAI FIRAL } \\
\text { DBAABD SBCTORS }\end{array}$ & $-21,140$ & $2,1 \leq 7$ & 31.543 & 10,780 & - & 12,860 & 9,998 & 14,436 & 102,914 & $93 \%$ \\
\hline 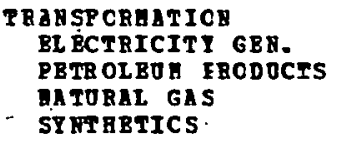 & $\begin{array}{r}891 \\
- \\
-\end{array}$ & $\begin{array}{r}227 \\
- \\
-\end{array}$ & $\begin{array}{l}- \\
= \\
-\end{array}$ & $\begin{array}{l}\overline{-} \\
\overline{-}\end{array}$ & $\begin{array}{l}- \\
- \\
-\end{array}$ & $\begin{array}{r}134 \\
= \\
-\end{array}$ & $\begin{array}{r}7,516 \\
- \\
-\end{array}$ & $\begin{array}{r}-3,106 \\
= \\
=\end{array}$ & $\begin{array}{r}5,662 \\
- \\
-\end{array}$ & $5 \%$ \\
\hline $\begin{array}{l}\text { BET FOEL OSEC } \\
\text { IA TRABSPOEBATIOD }\end{array}$ & 891 & $2 \div 7$ & - & - & - & 134 & 7,516 & $-3,106$ & 5,662 & $5 \%$ \\
\hline $\begin{array}{l}\text { TCIAL GROSS FLONS } \\
\text { LOSSBS } 8 \text { OUISSIOAS }\end{array}$ & $\begin{array}{r}22,031 \\
1 ;: 371\end{array}$ & $\begin{array}{r}2,3 \varepsilon 4 \\
0\end{array}$ & $\begin{array}{r}31,543 \\
0\end{array}$ & $\begin{array}{r}10,780 \\
-425\end{array}$ & $\overline{-}$ & $\begin{array}{r}12.994 \\
--151\end{array}$ & $\begin{aligned} 17.514 \\
.237\end{aligned}$ & $\begin{array}{r}14,436 \\
1,197\end{array}$ & $\begin{array}{r}108,576 \\
2,030\end{array}$ & $\begin{array}{r}98 \% \\
28\end{array}$ \\
\hline TOFAL ABT OSAGE & 23,402 & $2,3 \varepsilon 4$ & 31,543 & 10,354 & - & 12,642 & 17,751 & 12,527 & 110,606 & \\
\hline
\end{tabular}

\begin{tabular}{|c|c|c|c|c|c|c|c|c|c|c|}
\hline $\begin{array}{l}\text { SOEELT OP BRERGY } \\
\text { EOSS IL POBL } \\
\text { EY DR OBLBCTEIC } \\
\text { OOCL BAR } \\
\text { GBC. \&SOLAR. }\end{array}$ & $\begin{array}{l}\overline{-} \\
\overline{-}\end{array}$ & $\begin{array}{l}- \\
-\end{array}$ & $\begin{array}{l}\overline{-} \\
\overline{-}\end{array}$ & $\begin{array}{l}\text { - } \\
\overline{-}\end{array}$ & $\begin{array}{l}\overline{-} \\
\overline{-}\end{array}$ & $\overline{-}$ & $\begin{array}{l}\text { - } \\
\text { - }\end{array}$ & $\begin{array}{l}41 \overline{6} \\
145 \\
586\end{array}$ & $\begin{array}{l}416 \\
145 \\
586\end{array}$ & $\begin{array}{l}36 \% \\
13 \% \\
51 \%\end{array}$ \\
\hline TOTAL SOPPLY & - & - & - & - & - & - & - & 1,147 & 1,147 & \\
\hline
\end{tabular}

\section{BET In EORTS
OP R BGIOA}

23.402

2,384

31,543

10,354

12,642

17,751

11,380

BOTES:

1 TRAR SPCBAATION LOSS POR TRARSPCRAATION LOSS POB

3 TBABSPOR HATI ON TOSS POR

BL BCTRICITY GBR.

$=64.58 \%$

$\begin{array}{ll}\text { MATORAL GAS } & =0.0 \% \\ \text { SYYTHETCS } & =0.0 \%\end{array}$

SYETHBTICS 
REGIONAL BEBFG RALARCE STATEMEUT

PORAL BEBFGY PALARCE STA
PIBS WID IID SCEMARIO

\begin{tabular}{|c|c|c|c|c|c|c|c|c|c|c|}
\hline SBCTOR & $\begin{array}{l}\text { DISJILIATB } \\
\text { OII. }\end{array}$ & $\begin{array}{l}\text { RBSIDUALL } \\
\text { OIL }\end{array}$ & $\begin{array}{l}\text { GASOLIM] } \\
\text { (ALL }\end{array}$ & $\begin{array}{l}\text { OTZER } \\
\text { EYDZO- } \\
\text { CAREONS } \\
\text { TS IN } 10 * * 9\end{array}$ & $\begin{array}{c}\text { CRUDB } \\
\text { OII } \\
\text { BTU'SI. }\end{array}$ & $\begin{array}{l}\text { NATORAL } \\
\text { GAS }\end{array}$ & $\cos I$ & ELECTRICI TY & $\begin{array}{r}\text { SECTOR } \\
\text { TOTAL }\end{array}$ & \\
\hline $\begin{array}{l}\text { PIRLL CEHARE SECTORS } \\
\text { RESID BNTIAL, CCHH. } \\
\text { INDOSTRIAL } \\
\text { TRANSPORTATIOR } \\
\text { HISCELLABBOES OSBS }\end{array}$ & $\begin{array}{r}1,219 \\
1,695 \\
1,379 \\
: 25\end{array}$ & $\begin{array}{r}27 \\
135 \\
71\end{array}$ & $12.42 \overline{-}$ & $\begin{array}{r}2.516 \\
1.034 \\
768 \\
8\end{array}$ & $\bar{z}$ & $\begin{array}{r}4,12 \vdots \\
47 \\
217 \\
59\end{array}$ & $\begin{array}{r}2 \\
6=1 \\
- \\
-\end{array}$ & $\begin{array}{r}6,582 \\
871 \\
59\end{array}$ & $\begin{array}{r}14.666 \\
4.403 \\
14.785 \\
422\end{array}$ & $\begin{array}{r}.29 \% \\
9 \% \\
29 \% \\
1 \%\end{array}$ \\
\hline $\begin{array}{l}\text { TCTAL PINAL } \\
\text { DBEAND SECEORS }\end{array}$ & 4.718 & 233 & 12,421 & 4,326 & - & 4,446 & 623 & 7,512 & 34.276 & $68 \%$ \\
\hline $\begin{array}{l}\text { TRANSPORHATICY } \\
\text { BLECTRICITY GBR. } \\
\text { PBTROLEU EACDOCTS } \\
\text { NATORAL GAS } \\
\text { SYNTERTICS }\end{array}$ & $\begin{array}{r}268 \\
- \\
-\end{array}$ & $\begin{array}{l}\overline{-} \\
\overline{-}\end{array}$ & $\begin{array}{l}\overline{-} \\
\bar{z}\end{array}$ & $\begin{array}{l}\overline{-} \\
\overline{-}\end{array}$ & $\overline{-}$ & $\begin{array}{r}6 i \\
- \\
-\end{array}$ & $\begin{array}{r}21,552 \\
- \\
- \\
-\end{array}$ & $\begin{array}{r}-6,859 \\
- \\
-\end{array}$ & $\begin{array}{r}15,023 \\
- \\
-\end{array}$ & $30 \%$ \\
\hline $\begin{array}{l}\text { RET FORL OSEL } \\
\text { IN TRANSPOEATION }\end{array}$ & 268 & - & - & - & - & 62 & $21,5 \leq 2$ & $-6,859$ & 15,023 & $30 \%$ \\
\hline $\begin{array}{l}\text { TCTAL GROSS FICRS } \\
\text { ICSSES \& OUISSIONS }\end{array}$ & 4.586 & 23) & $\begin{array}{r}12.421 \\
0\end{array}$ & $\begin{array}{r}4,326 \\
-170\end{array}$ & $\overline{-}$ & $\begin{array}{r}4,508 \\
-121\end{array}$ & $\begin{array}{r}22,175 \\
3 \mathrm{CO}\end{array}$ & $\begin{array}{r}7.512 \\
623\end{array}$ & $\begin{array}{r}49,259 \\
941\end{array}$ & $\begin{array}{r}98 \% \\
2 \%\end{array}$ \\
\hline
\end{tabular}

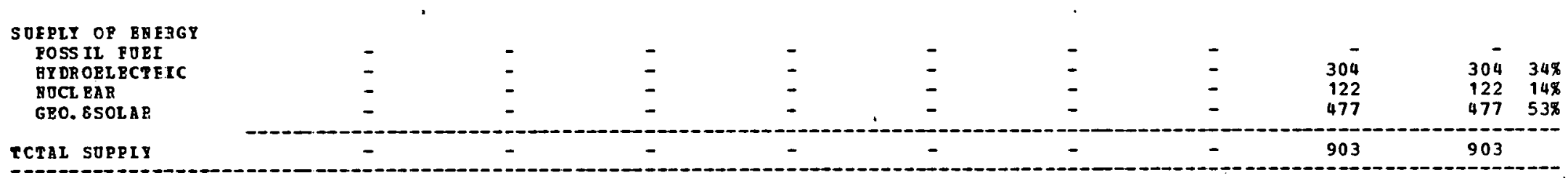

\section{YET II PORTS}

5,296

230

$12,4 \div 1$

4,155

4,386

22,475

373

49,337

-

SOTES:

TRAYSPCRAATI OR LCSS TOR

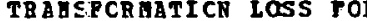
TRAYSPOR BATICR LCSS POR TRA YSPORAATI CI LOSS TOR

BLECTRICITY GER.

MATURAL GAS

$=0.0 .5$

SYUTERTICS 
REGIONAL ENERGY EALANCE STATEMENT
PIES HID GID SCENARIO

\begin{tabular}{|c|c|c|c|c|c|c|c|c|c|c|}
\hline SECTOE & $\begin{array}{l}\text { DISTILLATE } \\
\text { OIL }\end{array}$ & $\begin{array}{l}\text { RESIDOAL } \\
\text { OIL }\end{array}$ & $\begin{array}{l}\text { GASOLINE } \\
\quad \text { GALL O }\end{array}$ & $\begin{array}{c}\text { OTHER } \\
\text { HYDRO- } \\
\text { CARBONS } \\
\text { TS IN } 10 * * 9\end{array}$ & $\begin{array}{c}\text { CRODE } \\
\text { OIL } \\
\text { BTO'S) }\end{array}$ & $\begin{array}{l}\text { NATURAL } \\
\text { GAS }\end{array}$ & $\mathrm{CCAL}$ & ELECTRICITY & $\begin{array}{l}\text { SECTOR } \\
\text { TOTAL }\end{array}$ & \\
\hline $\begin{array}{l}\text { PINLL CEHANL SECTOES } \\
\text { BESIDENTIAL, CCHH. } \\
\text { INDOSTRIAL } \\
\text { TRANSPORTATION } \\
\text { MISCELLAHECS OSES }\end{array}$ & $\begin{array}{r}5.954 \\
6.176 \\
2.641 \\
426\end{array}$ & $\begin{array}{r}199 \\
1,581 \\
17 \\
148\end{array}$ & $\begin{array}{r}\overline{-} \\
31.423 \\
-\end{array}$ & $\begin{array}{r}6,058 \\
2,867 \\
1,163 \\
14\end{array}$ & $\begin{array}{l}- \\
- \\
-\end{array}$ & $\begin{array}{r}11.644 \\
1.079 \\
364 \\
128\end{array}$ & $\begin{array}{r}18 \\
2,678 \\
- \\
-\end{array}$ & $\begin{array}{r}14.094 \\
4.909 \\
- \\
107\end{array}$ & $\begin{array}{r}37,967 \\
19,290 \\
35,608 \\
823\end{array}$ & $\begin{array}{r}39 \% \\
20 \% \\
37 \% \\
1 \%\end{array}$ \\
\hline $\begin{array}{l}\text { TCTAL FINAI } \\
\text { DEMAND SECTORS }\end{array}$ & 15,197 & 1,945 & 31.423 & 10,102 & - & 13,215 & 2,696 & 19.110 & 93,688 & $97 \%$ \\
\hline $\begin{array}{l}\text { THANSPCRHATICN } \\
\text { ELECTRICITY GEN. } \\
\text { PETR OLEOH ERODOCTS } \\
\text { NATORAL GAS } \\
\text { SY NTHETICS }\end{array}$ & $\begin{array}{r}1,114 \\
= \\
=\end{array}$ & $\begin{array}{r}142 \\
- \\
-\end{array}$ & $\begin{array}{l}\overline{-} \\
\overline{-}\end{array}$ & $\begin{array}{l}- \\
- \\
-\end{array}$ & $\begin{array}{l}- \\
\overline{-}\end{array}$ & $\begin{array}{r}161 \\
- \\
-\end{array}$ & $\begin{array}{r}874 \\
- \\
-\end{array}$ & $\begin{array}{r}-800 \\
- \\
-\end{array}$ & $\begin{array}{r}1,491 \\
- \\
-\end{array}$ & $2 \%$ \\
\hline $\begin{array}{l}\text { TET FOEL OSEL } \\
\text { IN TRANSOFEATIOS }\end{array}$ & 1,114 & 142 & - & - & - & 161 & 874 & -800 & 1,491 & $2 \%$ \\
\hline $\begin{array}{l}\text { TCTAL GROSS FLCRS } \\
\text { LCSSES \& OBISSIOHS }\end{array}$ & $\begin{array}{r}16,311 \\
1,015\end{array}$ & $\begin{array}{r}2,087 \\
.0\end{array}$ & $\begin{array}{r}31,423 \\
0\end{array}$ & $\begin{array}{r}10,102 \\
-398\end{array}$ & - & $\begin{array}{r}13,376 \\
-361\end{array}$ & $\begin{array}{r}3,570 \\
48\end{array}$ & $\begin{array}{r}19,110 \\
1,585\end{array}$ & $\begin{array}{r}95,179 \\
1,889\end{array}$ & $\begin{array}{r}98 \% \\
2 \%\end{array}$ \\
\hline $\begin{array}{l}\text { SOFPLY OF ERFRGY } \\
\text { FDSS IL POEL } \\
\text { HYDR OELBCTEIC } \\
\text { HOCL EAR } \\
\text { GEO. ESOLAR. }\end{array}$ & $\begin{array}{l}\bar{z} \\
\overline{-}\end{array}$ & $\begin{array}{l}\overline{-} \\
-\end{array}$ & $\begin{array}{l}\overline{-} \\
-\end{array}$ & $\begin{array}{l}\overline{-} \\
\overline{-}\end{array}$ & $\begin{array}{l}- \\
\overline{-} \\
-\end{array}$ & 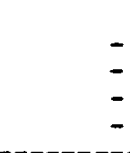 & $\begin{array}{l}\overline{-} \\
\overline{-}\end{array}$ & $\begin{array}{r}549 \\
217 \\
864\end{array}$ & $\begin{array}{l}549 \\
217 \\
864\end{array}$ & $\begin{array}{l}34 \% \\
13 \% \\
53 \%\end{array}$ \\
\hline TOTAL SUPPLY & - & - & - & - & - & - & - & 1,630 & 1,630 & \\
\hline
\end{tabular}

(1)

\section{RET III PORTS}

OP R RGIOR

17,326

$2,08 ?$

31,423

9,703

13,014

3.618

18.265

95.438

NoTES:

TRARSPORAATLON LOSS POR TRAY SPCBHATICN LOSS FOR TRAASPORMATION LOSS POB

$\begin{array}{ll}\text { ELECTAICETY GEN. } & =65.08 \% \\ \text { PETROLEOU PBODOCTS } & =0.0 \%\end{array}$

$=0.0 \%$ 
REGIOUAL ERERGY BALANCE STATEEENT

\begin{tabular}{|c|c|c|c|c|c|c|c|c|c|c|}
\hline SEC $=O B$ & $\underset{\text { OIL }}{\text { DIETIILATE }}$ & $\begin{array}{l}\text { RESIDOIL } \\
\text { OIL }\end{array}$ & $\begin{array}{l}\text { GASOLI A } \\
\text { (ALL }\end{array}$ & $\begin{array}{c}\text { OMRRR } \\
\text { HYRO- } \\
\text { CARBONS } \\
\text { TS: } \mathrm{DI} \quad 10 * *\end{array}$ & $\begin{array}{c}\text { CRODE } \\
\text { OIL } \\
\text { BTOSS) }\end{array}$ & $\begin{array}{l}\text { FATUEAL } \\
\text { GAS }\end{array}$ & COAI & ELECTRICITY & $\begin{array}{l}\text { SECTOR } \\
\text { TOTAL }\end{array}$ & \\
\hline 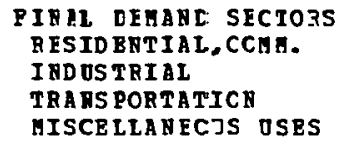 & $\begin{array}{r}2.890 \\
5.366 \\
3.199 \\
375\end{array}$ & $\begin{array}{r}31 \\
1,3) 4 \\
7 \\
118\end{array}$ & 25,069 & $\begin{array}{r}5.025 \\
1,618 \\
1,139 \\
19\end{array}$ & $\bar{E}$ & $\begin{array}{r}8,716 \\
1,190 \\
320 \\
161\end{array}$ & $\begin{array}{r}4 \\
1,537 \\
- \\
-\end{array}$ & $\begin{array}{r}13,220 \\
1,602 \\
- \\
134\end{array}$ & $\begin{array}{r}29.946 \\
12.617 \\
29.734 \\
807\end{array}$ & $\begin{array}{r}38 \% \\
16 \% \\
37 \% \\
1 \%\end{array}$ \\
\hline $\begin{array}{l}\text { TCTAL FINAL } \\
\text { DEHAND SECTORS }\end{array}$ & 11.830 & 1.520 & 25,069 & 7.801 & - & 10.387 & 1,541 & 14,956 & 73.104 & $92 \pi$ \\
\hline 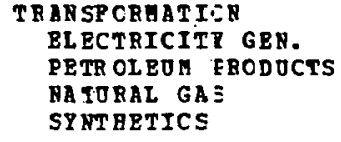 & $\begin{array}{r}720 \\
-7.043 \\
-\end{array}$ & $\begin{array}{r}-2.251 \\
-\end{array}$ & $-11,812$ & $\begin{array}{r}-3.350 \\
- \\
-\end{array}$ & $\begin{array}{r}23.826 \\
- \\
-\end{array}$ & $\begin{array}{r}124 \\
1.1303 \\
-\end{array}$ & $\begin{array}{r}4,065 \\
- \\
-\end{array}$ & $\begin{array}{r}-1,558 \\
- \\
-\end{array}$ & $\begin{array}{r}3,351 \\
372 \\
- \\
-\end{array}$ & $\begin{array}{l}48 \\
08\end{array}$ \\
\hline $\begin{array}{l}\text { NET FOFL DSEC } \\
\text { IN TRABSFEHATION }\end{array}$ & $-6,323$ & -2.251 & $-11,812$ & -3.350 & 23,826 & 1.127 & 4,065 & $-1,558$ & 3,723 & $5 \%$ \\
\hline $\begin{array}{l}\text { TOTAI GROSS FLONS } \\
\text { LCSSES \& CHISSIONS }\end{array}$ & $\begin{array}{r}12,550 \\
781\end{array}$ & $\begin{array}{r}1,520 \\
0\end{array}$ & $\begin{array}{r}25,069 \\
0\end{array}$ & $\begin{array}{r}7,801 \\
-307\end{array}$ & $\begin{array}{r}23.926 \\
988\end{array}$ & $\begin{aligned} 11,514 \\
-311\end{aligned}$ & $\begin{array}{r}5, \epsilon 06 \\
75\end{array}$ & $\begin{array}{r}14,956 \\
1,240\end{array}$ & $\begin{array}{r}76,827 \\
2,467\end{array}$ & $\begin{array}{r}97 \% \\
3 \%\end{array}$ \\
\hline COTAL RET OSBGE & 6,287 & -731 & 13.257 & 4.142 & 24,814 & 11,203 & $5, \epsilon 81$ & 14,638 & 79.295 & \\
\hline
\end{tabular}

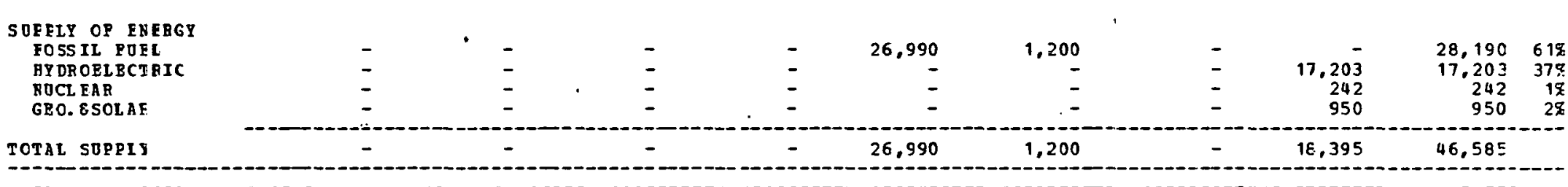

\begin{tabular}{l}
$\begin{array}{l}\text { NET IH PORTS } \\
\text { OP R RGION }\end{array}$ \\
\hline
\end{tabular}


REGIONAL ENERGY EALANCE STATEMENT

\begin{tabular}{|c|c|c|c|c|c|c|c|c|c|c|}
\hline SECTOR & $\begin{array}{l}\text { DISTILLATE } \\
\text { OIL }\end{array}$ & $\begin{array}{l}\text { RESIDDAL } \\
\text { OIL }\end{array}$ & $\begin{array}{l}\text { GASOLIN } \\
\text { (ALL }\end{array}$ & $\begin{array}{c}\text { OTHER } \\
\text { HYDRO- } \\
\text { CARBONS } \\
\text { TS IN } 10 * * 9\end{array}$ & $\begin{array}{c}\text { CRODE } \\
\text { OIL } \\
\text { BTO'S) }\end{array}$ & $\begin{array}{l}\text { NATURAL } \\
\text { GAS }\end{array}$ & $\cos L$ & ELECTRICITY & $\begin{array}{r}\text { SECTOR } \\
\text { TOTAL }\end{array}$ & \\
\hline $\begin{array}{l}\text { PINAL CEMAHE SECTORS } \\
\text { RFSIDENTIAL, CCAH. } \\
\text { INDOSTRIAL } \\
\text { TRANSPORTATICN } \\
\text { GISCELLANECOS OSES }\end{array}$ & $\begin{array}{r}1,208 \\
1,677 \\
1,891 \\
88\end{array}$ & $\begin{array}{r}90 \\
418 \\
64 \\
18\end{array}$ & $8,16 \overline{-}$ & $\begin{array}{r}1.609 \\
761 \\
959 \\
3\end{array}$ & $\begin{array}{l}\overline{-} \\
\overline{-}\end{array}$ & $\begin{array}{r}4.080 \\
2,884 \\
247 \\
23\end{array}$ & $\begin{array}{r}8 \\
1,791 \\
- \\
-\end{array}$ & $\begin{array}{r}2,453 \\
2,354 \\
2 \\
14\end{array}$ & $\begin{array}{r}9.448 \\
9.885 \\
11.327 \\
146\end{array}$ & $\begin{array}{r}29 \% \\
31 \% \\
35 \% \\
0 \%\end{array}$ \\
\hline $\begin{array}{l}\text { TCTAL FINAI } \\
\text { DEMAND. SECTORS }\end{array}$ & 4,864 & 590 & 8,164 & 3,332 & - & 7,234 & 1,799 & 4,823 & 30,806 & $95 \%$ \\
\hline $\begin{array}{l}\text { TEARSPCRMATICN } \\
\text { ELECTRICITY GEN. } \\
\text { PETROLEO ERODOCTS } \\
\text { RATURAL GAS } \\
\text { SY NTETICS }\end{array}$ & $\begin{array}{r}20 \\
-2,538 \\
- \\
-\end{array}$ & $\begin{array}{r}-1,0.16 \\
-\end{array}$ & $\begin{array}{r}-5.221 \\
-\end{array}$ & $\begin{array}{r}-2,294 \\
- \\
-\end{array}$ & $\begin{array}{r}10,898 \\
-\end{array}$ & $\begin{array}{r}780 \\
242 \\
- \\
-\end{array}$ & $\begin{array}{l}- \\
-\end{array}$ & $\begin{array}{r}-232 \\
- \\
-\end{array}$ & $\begin{array}{r}568 \\
69 \\
- \\
-\end{array}$ & $\begin{array}{l}2 \% \\
0 \%\end{array}$ \\
\hline $\begin{array}{l}\text { BET FOEL OSEE } \\
\text { IN TRANSPOBAATICN }\end{array}$ & $-2,518$ & -1.016 & $-5,221$ & $-2,294$ & 10,898 & 1,022 & - & -232 & 637 & $2 \%$ \\
\hline $\begin{array}{l}\text { TGTAI GROSS FLCHS } \\
\text { LCSSES \& ONISSIONS }\end{array}$ & $\begin{array}{r}4,884 \\
303\end{array}$ & $\begin{array}{r}590 \\
0\end{array}$ & $\begin{array}{r}8,164 \\
0\end{array}$ & $\begin{array}{r}3,332 \\
-131\end{array}$ & $\begin{array}{r}10,898 \\
452\end{array}$ & $\begin{array}{r}8,256 \\
-223\end{array}$ & $\begin{array}{r}1.799 \\
24\end{array}$ & $\begin{array}{r}4.823 \\
400\end{array}$ & $\begin{array}{r}31,443 \\
826\end{array}$ & $\begin{array}{r}97 \% \\
3 \%\end{array}$ \\
\hline
\end{tabular}

I

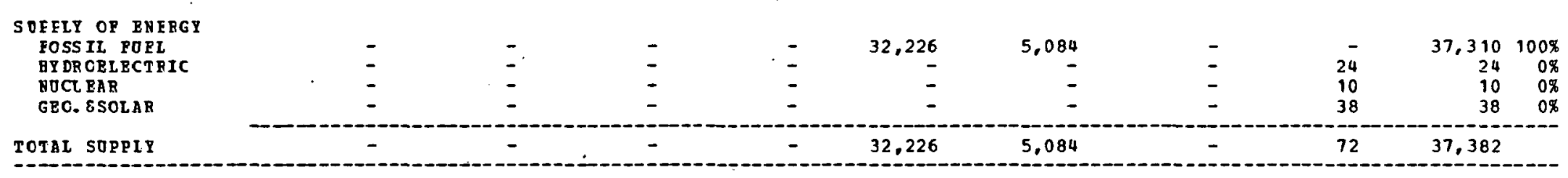

-

sT In EORTS

2,649

2,942

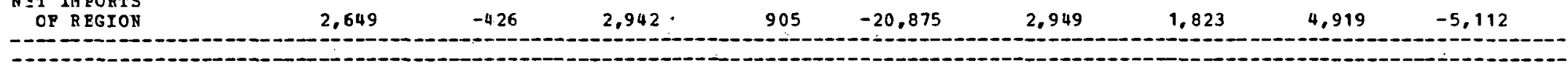

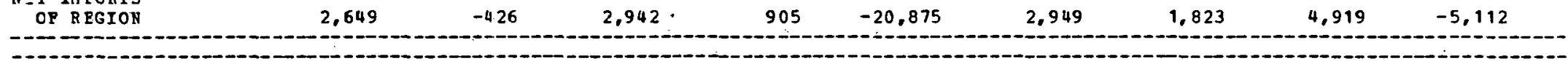

1,823

4,919

$-5,112$

$\begin{array}{lllll}\text { MOTES: } & & & \\ 1 & \text { TRANSFCRHATICN } & \text { LOSS POR } & \text { ELECTRICITY GEN. } & =71.00 \% \\ 2 & \text { TRANSPORATICN } & \text { LOSS POR } & \text { PETROLEOH PROD OCTS } & =0.62 \% \\ 3 & \text { TRANSPORAATICN LOSS POR } & \text { NATORAL GAS } & =0.0 \% \\ 4 & \text { TRANSPORHATCN LOSS POR } & \text { SYNTHEIICS } & =0.0 \%\end{array}$


REGIDIAL EYERGY EALANCE STATEHENT

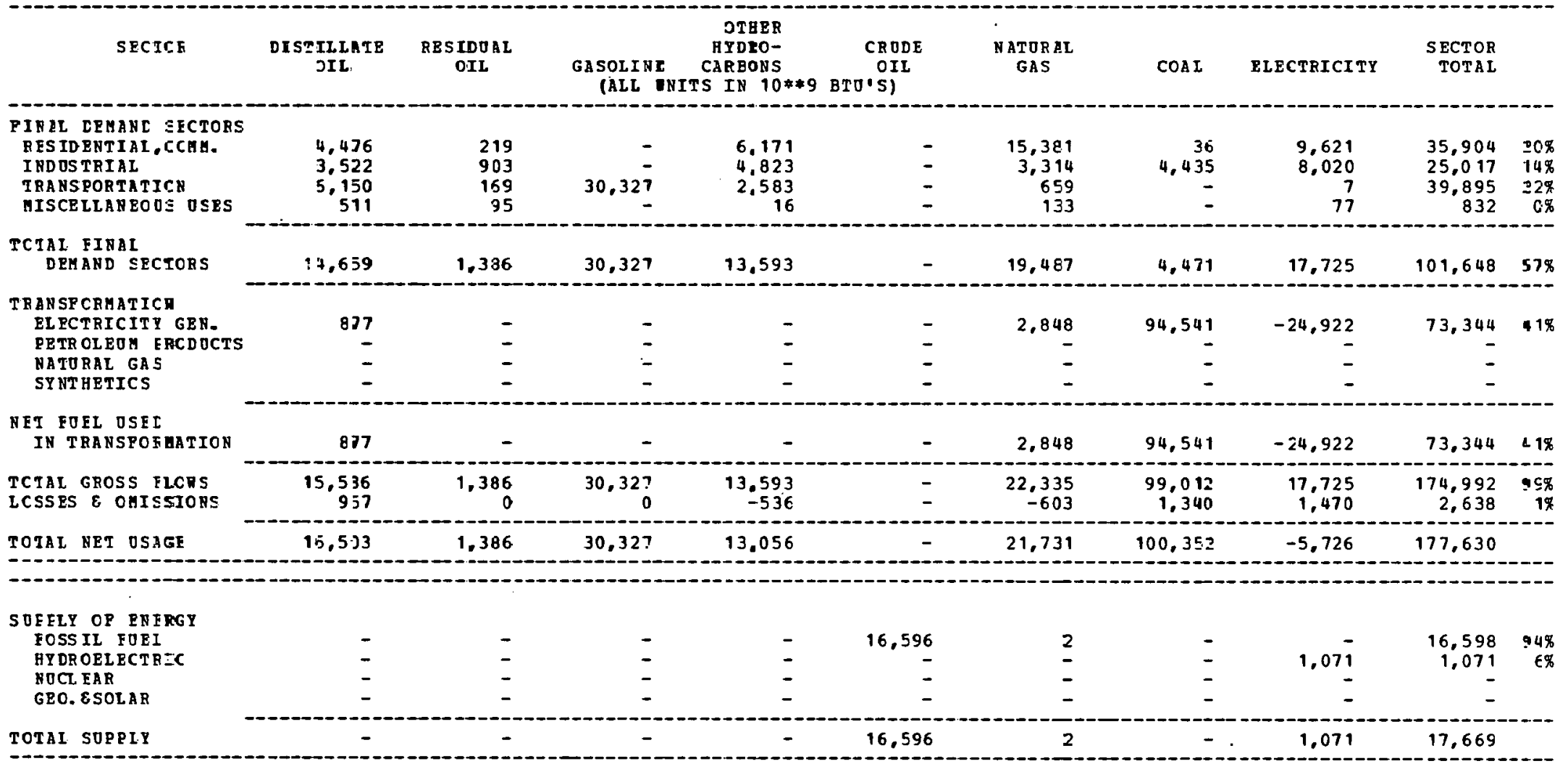

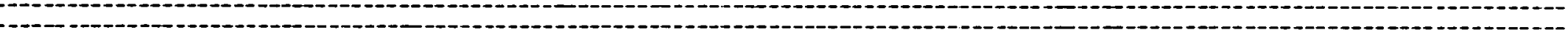

\section{NET IM RORTS}

OP REGION

$16,5,33$

1,386

30,327

13.056

21.78

100,352

$-6.797$

159,961

No TES:

TRANSFCB HATICN LOS S POR
TRANSFCRMATCN LOSS POR

TRANSFCRHATICN LOSS POR
TRANSFORAATIGN LOSS POR

TRANSFORUATICN LOSS POR

EI ECTZICITY GEN,

N.ATOBAL.GAS

SYNTRETICS 
REGIONAL ENERGY BALANCE STATEHENT

PIES UID UID SCENARIO

\begin{tabular}{|c|c|c|c|c|c|c|c|c|c|c|}
\hline SECTOF & $\begin{array}{l}\text { DISTILLATE } \\
\text { OIL }\end{array}$ & $\begin{array}{l}\text { RESIDDAL } \\
\text { OII }\end{array}$ & $\begin{array}{l}\text { GASOLIRE } \\
\text { (ALL }\end{array}$ & $\begin{array}{c}\text { OTBER } \\
\text { AYDRO- } \\
\text { CAREONS } \\
\text { TS IN } 10 * * 9\end{array}$ & $\begin{array}{c}\text { CRंDDE } \\
\text { OIL } \\
\text { BTJ'S) }\end{array}$ & $\begin{array}{l}\text { NATURAI } \\
\text { GAS }\end{array}$ & $\operatorname{COAL}$ & ELECTRICITY & $\begin{array}{r}\text { SECTOR } \\
\text { TOTAL }\end{array}$ & \\
\hline 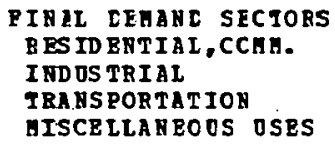 & $\begin{array}{l}5,753 \\
5,657 \\
8,344 \\
626\end{array}$ & $\begin{array}{r}137 \\
1,179 \\
13 \\
127\end{array}$ & $38,05 \overline{-}$ & $\begin{array}{r}7,948 \\
4.886 \\
1,228 \\
21\end{array}$ & $\begin{array}{l}- \\
\overline{-}\end{array}$ & $\begin{array}{r}18,032 \\
2,806 \\
387 \\
163\end{array}$ & $\begin{array}{r}24 \\
7.143 \\
-\end{array}$ & $\begin{array}{r}12,618 \\
9.484 \\
1 \\
102\end{array}$ & $\begin{array}{r}44,552 \\
31,195 \\
48,027 \\
1,039\end{array}$ & $\begin{array}{r}21 \% \\
15 \% \\
23 \% \\
0 \%\end{array}$ \\
\hline $\begin{array}{l}\text { TCTAL FINAL } \\
\text { DBHAND SECTORS }\end{array}$ & 20,460 & 1,455 & 38,054 & 14,083 & - & 21,388 & 7,167 & 22,205 & 124,813 & $59 \%$ \\
\hline 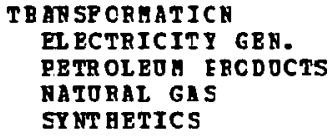 & $\begin{array}{r}1.426 \\
- \\
-\end{array}$ & $\begin{array}{l}- \\
\overline{-} \\
-\end{array}$ & $\begin{array}{l}- \\
-\end{array}$ & $\begin{array}{l}- \\
\overline{-}\end{array}$ & $\bar{E}$ & $\begin{array}{l}34 \\
- \\
-\end{array}$ & $\begin{array}{r}110,403 \\
= \\
=\end{array}$ & $\begin{array}{r}-28,289 \\
= \\
-\end{array}$ & $\begin{array}{r}83,574 \\
= \\
=\end{array}$ & $39 \%$ \\
\hline $\begin{array}{l}\text { YET FORL OSEL } \\
\text { IN TRARSPOEHATION }\end{array}$ & 1,426 & - & - & - & - & 34 & 110,403 & $-28,289$ & 83,574 & $39 \%$ \\
\hline $\begin{array}{l}\text { TOTAL GROSS FLORS } \\
\text { LOSSES } \& \text { OAISSIORS }\end{array}$ & $\begin{array}{r}21,886 \\
1,362\end{array}$ & $\begin{array}{r}1,456 \\
0\end{array}$ & $\begin{array}{r}38,054 \\
0\end{array}$ & $\begin{array}{r}14.083 \\
-555\end{array}$ & - & $\begin{array}{r}21,422 \\
-578\end{array}$ & $\begin{array}{r}117,570 \\
1,591\end{array}$ & $\begin{array}{r}22,205 \\
1,842\end{array}$ & $\begin{array}{r}208,387 \\
3,661\end{array}$ & $\begin{array}{r}98 \% \\
2 \%\end{array}$ \\
\hline TOJAL HET OSAGE & 23,248 & 1,456 & 38,054 & 13,527 & - & 20,843 & 119,161 & $-4,241$ & 212,048 & \\
\hline $\begin{array}{l}\text { S OEFLY OP ENFBGY } \\
\text { IOSS IL POEI } \\
\text { EY DROELECTEIC } \\
\text { YOCL EAR } \\
\text { GEO. ESOLAR, }\end{array}$ & $\begin{array}{l}- \\
-\end{array}$ & $\begin{array}{l}- \\
- \\
-\end{array}$ & - & $\begin{array}{l}\overline{-} \\
\overline{-}\end{array}$ & $\begin{array}{l}\overline{-} \\
\overline{-}\end{array}$ & $\begin{array}{l}\overline{-} \\
\overline{-}\end{array}$ & $\begin{array}{l}- \\
-\end{array}$ & $\begin{array}{r}9,103 \\
67 \\
261\end{array}$ & $\begin{array}{r}- \\
9.103 \\
67 \\
261\end{array}$ & $\begin{array}{r}97 \% \\
1 \% \\
3 \%\end{array}$ \\
\hline TOTAL SOPPLY & - & - & - & - & - & - & - & 9,431 & 9,431 & \\
\hline
\end{tabular}

IBY IM PORTS
OP R RGIOR

NoTES:

1 TRATSPCRAATICR LOSS POR TRAMSPORMATICH LOSS POB

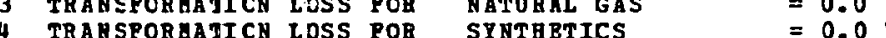

BLECTRICITY GBN. $=74.711$

PBTROLEOB PRODOCTS $=0.0$ NATURAL GAS $\quad=0.0$ 
BBGIONAL BHZBGT EALARCE STATEHEIG

PIBS UIJ EID SCENARIO

\begin{tabular}{|c|c|c|c|c|c|c|c|c|c|c|}
\hline SBCTOR & $\begin{array}{l}\text { DISTILLATE } \\
\text { OII }\end{array}$ & $\begin{array}{l}\text { BESIJOALL } \\
\text { CIL }\end{array}$ & $\begin{array}{l}\text { GASOLIZF } \\
\text { (ALL }\end{array}$ & $\begin{array}{c}\text { OTBER } \\
\text { RTDEO- } \\
\text { CARBCYS } \\
\text { IS IN 10**9 }\end{array}$ & $\begin{array}{c}\text { CRODE } \\
\text { OIL } \\
\text { BTO'S) }\end{array}$ & $\begin{array}{l}\text { MATORAL } \\
\text { GAS }\end{array}$ & $\operatorname{COAL}$ & BLECTRICITY & $\begin{array}{r}\text { SECTOR } \\
\text { TOTAL }\end{array}$ & \\
\hline $\begin{array}{l}\text { PIRAL DEAARD SYCTORS } \\
\text { RESID BRTIAL,COHA. } \\
\text { IRDOSTRIAL } \\
\text { TRAYSPORTATIOA } \\
\text { HISCBLIABOOS OSES }\end{array}$ & $\begin{array}{r}3,734 \\
3,579 \\
5,7.57 \\
457\end{array}$ & $\begin{array}{r}58 \\
2,520 \\
- \\
87\end{array}$ & $22.01 \overline{-}$ & $\begin{array}{r}4.728 \\
4.726 \\
963 \\
15\end{array}$ & 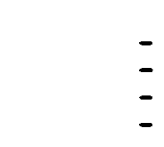 & $\begin{array}{r}11,107 \\
1,868 \\
333 \\
119\end{array}$ & $\begin{array}{r}10 \\
409 \\
- \\
-\end{array}$ & $\begin{array}{r}6,102 \\
6,961 \\
- \\
69\end{array}$ & $\begin{array}{r}25,801 \\
23,863 \\
29.078 \\
757\end{array}$ & $\begin{array}{r}11 \% \\
\vdots 8 \% \\
\vdots 5 \% \\
1 \%\end{array}$ \\
\hline $\begin{array}{l}\text { TOYAI FINAL } \\
\text { DBEARD SBCIORS }\end{array}$ & 13,637 & 2,665 & 22,015 & 10.432 & - & 13,427 & 4.221 & 13,132 & 79.499 & $94 \%$ \\
\hline 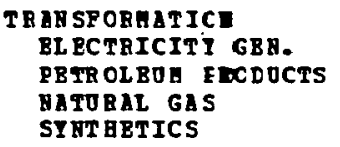 & $\begin{array}{r}650 \\
- \\
-\end{array}$ & $\begin{array}{l}\overline{-} \\
\overline{-}\end{array}$ & $\begin{array}{l}- \\
\overline{-}\end{array}$ & $\begin{array}{l}\overline{-} \\
\overline{-}\end{array}$ & $\begin{array}{l}\overline{-} \\
\overline{-}\end{array}$ & $\begin{array}{r}613 \\
- \\
-\end{array}$ & $\begin{array}{r}3,509 \\
- \\
-\end{array}$ & $\begin{array}{r}-1,288 \\
= \\
-\end{array}$ & $\begin{array}{r}3,484 \\
= \\
=\end{array}$ & $4 \%$ \\
\hline $\begin{array}{l}\text { FET FOEL OSFE } \\
\text { IB TRABSOHETIOH }\end{array}$ & 650 & - & - & - & - & 613 & 3,509 & $-1,288$ & 3,484 & $4 \%$ \\
\hline $\begin{array}{l}\text { TOTAL GROSS FLORS } \\
\text { LOSSES } 8 \text { OBISSIORS }\end{array}$ & $\begin{array}{r}14,2.57 \\
897\end{array}$ & 2,665 & $\begin{array}{r}22.015 \\
0\end{array}$ & $\begin{array}{r}10,432 \\
-411\end{array}$ & $\overline{-}$ & $\begin{array}{r}14,0400 \\
-379\end{array}$ & $\begin{array}{r}7,730 \\
104\end{array}$ & $\begin{array}{r}13,132 \\
1,089\end{array}$ & $\begin{array}{r}82,983 \\
1,290\end{array}$ & $\begin{array}{r}98 \% \\
2 \%\end{array}$ \\
\hline TOSAX RBT OSAGE & 15,134 & 2,665 & 22,015 & 10.020 & - & 13,660 & 7,834 & 12,933 & 84,273 & \\
\hline
\end{tabular}

-

\section{SOFFLY OP ERFEGY \\ YOSS IL POEI}

GY DROBL
BOCL BAR

GBO. ESOLAR

TOTAL SUPPIY

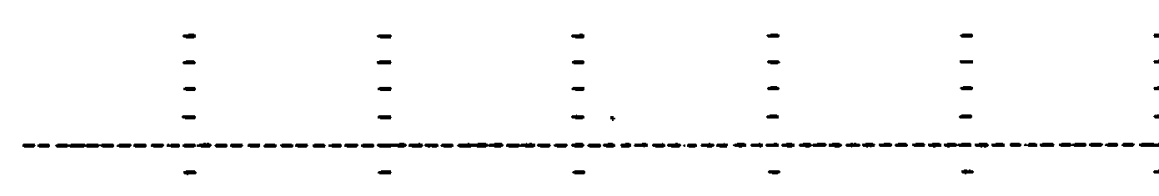

\begin{tabular}{llll}
- & - & - & - \\
- & - & - & - \\
- & - & - & - \\
\hline- & - & - & - \\
\hline
\end{tabular}

\section{NBT IH PORTS \\ OP R BGIOH}

15,174

2,665

22.015

10.020

13,660

7.834

12,933

84,273

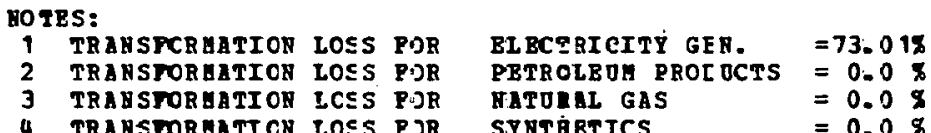

TRABSFORGATION ICES PJP

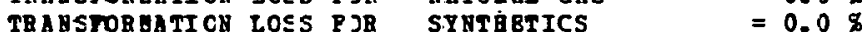


REGIONAL BNERGY FALANCE STATEHENT

PIES UID HID SCENARIO

\begin{tabular}{|c|c|c|c|c|c|c|c|c|c|c|}
\hline SBCTOE & $\begin{array}{l}\text { DISTILLATE } \\
\text { OIL }\end{array}$ & $\begin{array}{l}\text { RESIDDAL } \\
\text { OIL }\end{array}$ & $\begin{array}{l}\text { GASOLINE } \\
\text { (ALI O }\end{array}$ & $\begin{array}{c}\text { OTHER } \\
\text { HYDRO- } \\
\text { CARBONS } \\
\text { TS IN 10**9 }\end{array}$ & $\begin{array}{c}\text { CROCE } \\
\text { OIL } \\
\text { BTO'SI }\end{array}$ & $\begin{array}{l}\text { NATUR AL } \\
\text { GAS }\end{array}$ & $\operatorname{COAL}$ & ELECTRICITY & $\begin{array}{r}\text { SECTOR } \\
\text { TOTAL }\end{array}$ & \\
\hline 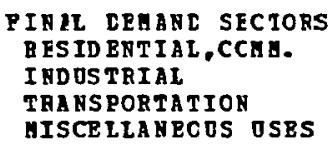 & $\begin{array}{l}6.431 \\
4.923 \\
4.911 \\
644\end{array}$ & $\begin{array}{r}97 \\
1.292 \\
125\end{array}$ & $37.33 \frac{-}{-}$ & $\begin{array}{r}8.026 \\
7,282 \\
1.197 \\
21\end{array}$ & $\begin{array}{l}\overline{-} \\
\overline{-}\end{array}$ & $\begin{array}{r}18,965 \\
3,368 \\
387 \\
166\end{array}$ & $\begin{array}{r}19 \\
6,642 \\
-\end{array}$ & $\begin{array}{r}10,438 \\
10,250 \\
- \\
95\end{array}$ & $\begin{array}{r}43,978 \\
33,757 \\
43,747 \\
1,046\end{array}$ & $\begin{array}{r}34 \% \\
26 \% \\
34 \% \\
1 \%\end{array}$ \\
\hline $\begin{array}{l}\text { TCTAL PIRAI } \\
\text { DEMAND SECTORS }\end{array}$ & 16.909 & 1.511 & 37,332 & 16,446 & - & 22,886 & 6,661 & 20,783 & 122,528 & $94 \pi$ \\
\hline $\begin{array}{l}\text { TRARSFCRHATICN } \\
\text { EL ECTRICITY GBN. } \\
\text { EETROLEOA EBCDOCTS } \\
\text { RATORAL GAS } \\
\text { SYNTHETICS }\end{array}$ & $\begin{array}{r}1,693 \\
- \\
-\end{array}$ & $\begin{array}{l}- \\
\overline{-}\end{array}$ & $\begin{array}{l}\overline{-} \\
\overline{-}\end{array}$ & $\begin{array}{l}\overline{-} \\
\overline{-}\end{array}$ & $\begin{array}{l}- \\
\overline{-}\end{array}$ & $\begin{array}{r}1,568 \\
- \\
-\end{array}$ & $\begin{array}{r}4,632 \\
= \\
=\end{array}$ & $\begin{array}{r}-2,214 \\
- \\
=\end{array}$ & $\begin{array}{r}5.679 \\
- \\
-\end{array}$ & $4 \%$ \\
\hline 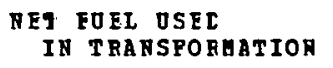 & 1,693 & - & - & - & - & 1,568 & 4,632 & $-2,214^{\circ}$ & 5,679 & $4 \%$ \\
\hline $\begin{array}{l}\text { TOJAL GROSS FLORS } \\
\text { LCSSES \& OHISSIONS }\end{array}$ & $\begin{array}{r}18,602 \\
1,157\end{array}$ & $\begin{array}{r}1,511 \\
0\end{array}$ & $\begin{array}{r}37.332 \\
0\end{array}$ & $\begin{array}{r}16,446 \\
-648\end{array}$ & $\overline{-}$ & $\begin{array}{r}24.454 \\
-660\end{array}$ & $\begin{array}{r}11,293 \\
152\end{array}$ & $\begin{array}{r}20,783 \\
1,724\end{array}$ & $\begin{array}{r}128,207 \\
1,725\end{array}$ & $\begin{array}{r}99 \% \\
1 \%\end{array}$ \\
\hline
\end{tabular}

\begin{tabular}{|c|c|c|c|c|c|c|c|c|c|}
\hline SDFPLY OP ENEBGY & & & & & & & & & \\
\hline JOSSIL POEL & - & - & - & - & - & - & - & - & - \\
\hline GY DR OEL BCT RIC & - & - & - & - & - & - & - & 49 & 49 \\
\hline JUCL EAR & - & - & - & - & - & - & - & - & - \\
\hline GEO. ESOLAR & - & - & - & - & - & - & - & - & - \\
\hline TOEAL SUPPLY & - & - & - & - & - & - & - & 49 & 49 \\
\hline
\end{tabular}

-AL SUPPLY

\section{NET II FORTS \\ OP REGION}

19,759

1.511

37,332

15.797

23,793

11,445

20,244

129,883

\begin{tabular}{|c|c|c|c|c|c|}
\hline & TRARSPORHAEICN & Loss & Fos & ELECTRICITY GEN.: & $=71.95 \%$ \\
\hline & TRA YSPORAATI CN & LoSS & FOR & NATORAL GAS & $=0.0 \%$ \\
\hline 4 & CRAYSPOB AAPT ON & LCs & POR & SYNTERTJCS & 0.0 \\
\hline
\end{tabular}


REGIONAL ENB $3 G Y$ RALANCE STATEMENT

\begin{tabular}{|c|c|c|c|c|c|c|c|c|c|c|}
\hline SBCTOE & $\begin{array}{l}\text { DI STILLATB } \\
\text { OIL }\end{array}$ & $\begin{array}{l}\text { RESIDOAL } \\
\text { OIL }\end{array}$ & $\begin{array}{l}\text { GASOLINE } \\
\text { (ALE CHIT }\end{array}$ & $\begin{array}{c}\text { OTBER } \\
\text { GYDRO- } \\
\text { CARBONS } \\
\text { CS IJ 10**9 }\end{array}$ & $\begin{array}{c}\text { CRODE } \\
\text { OIL } \\
\text { BTO'S }\end{array}$ & $\begin{array}{l}\text { NATUEAL } \\
\text { GAS }\end{array}$ & $\cos t$ & ELECTRICITY & $\begin{array}{r}\text { SECTOR } \\
\text { TOTAL }\end{array}$ & \\
\hline 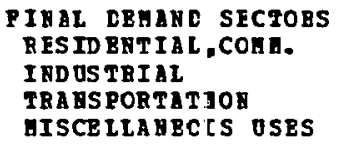 & $\begin{array}{r}12,774 \\
7,335 \\
14: 381 \\
1.550\end{array}$ & $\begin{array}{r}239 \\
2,946 \\
289\end{array}$ & $\begin{array}{r}\overline{-} \\
\overline{-}\end{array}$ & $\begin{array}{r}15,684 \\
15,973 \\
1,567 \\
51\end{array}$ & $\begin{array}{l}- \\
-\end{array}$ & $\begin{array}{r}37.904 \\
5.184 \\
535 \\
402\end{array}$ & $\begin{array}{r}41 \\
8,655 \\
1 \\
1\end{array}$ & $\begin{array}{r}21,227 \\
16,730 \\
- \\
229\end{array}$ & $\begin{array}{r}87.869 \\
56,823 \\
89.119 \\
2.522\end{array}$ & $\begin{array}{r}29 \% \\
19 \% \\
30 \% \\
1 \%\end{array}$ \\
\hline $\begin{array}{l}\text { TOTAL FIYAL } \\
\text { DBHARD SBCTORS }\end{array}$ & 36,040 & 3.474 & 72,635 & 33,275 & - & 44,025 & 8,638 & 38,186 & 236,333 & $79 \%$ \\
\hline $\begin{array}{l}\text { TRARSPORMATIEA } \\
\text { BLECTRICITI GBY. } \\
\text { PBTROLBO ERCDUCTS } \\
\text { BATORAL GAS } \\
\text { SI BT BETICS }\end{array}$ & $\begin{array}{r}2,418 \\
= \\
=\end{array}$ & $\begin{array}{l}- \\
-\end{array}$ & $\bar{z}$ & $\begin{array}{l}\overline{-} \\
-\end{array}$ & $\overline{-}$ & $\begin{array}{r}18 \\
- \\
-\end{array}$ & $\begin{array}{r}78,538 \\
= \\
-\end{array}$ & $\begin{array}{r}-20.616 \\
- \\
-\end{array}$ & $\begin{array}{r}60,358 \\
= \\
=\end{array}$ & $20 \%$ \\
\hline $\begin{array}{l}\text { RET FOEL OSET } \\
\text { IY TRABSPOEUATIOR }\end{array}$ & 2,418 & - & - & - & - & 18 & 78,538 & $-20,616$ & 60,358 & $20 \%$ \\
\hline $\begin{array}{l}\text { TCYAI GROSS ELORS } \\
\text { LCSSES } 8 \text { OHIESIOHS }\end{array}$ & $\begin{array}{r}38,458 \\
2,393\end{array}$ & $\begin{array}{r}3,474 \\
0\end{array}$ & $\begin{array}{r}72,635 \\
0\end{array}$ & $\begin{array}{r}33,275 \\
-1,312\end{array}$ & $\overline{-}$ & $\begin{array}{r}44,043 \\
-1,190\end{array}$ & $\begin{array}{r}87,236 \\
1,130\end{array}$ & $\begin{array}{r}38,186 \\
3,168\end{array}$ & $\begin{array}{r}296,691 \\
4,240\end{array}$ & $\begin{array}{r}99 \% \\
1 \%\end{array}$ \\
\hline
\end{tabular}

\begin{tabular}{|c|c|c|c|c|c|c|c|c|c|}
\hline $\begin{array}{l}\text { SOEPLY OP BRTEGT } \\
\text { POSS IL POEI } \\
\text { HY IR OELBCTEIC } \\
\text { HOCL BAR } \\
\text { GBC. } 8 \text { SOLAR }\end{array}$ & $\begin{array}{l}\overline{-} \\
\overline{-}\end{array}$ & $\begin{array}{l}\overline{-} \\
\overline{-}\end{array}$ & $\bar{z}$ & $\bar{z}$ & I & $\begin{array}{l}- \\
-\end{array}$ & $\begin{array}{r}16,765 \\
= \\
=\end{array}$ & $18,45 \overline{3}$ & $\begin{array}{r}16,765 \\
37 \\
18,452 \\
-\end{array}$ \\
\hline TCTAI SOPPII & - & - & - & - & - & - & 16,765 & 18,489 & 35,254 \\
\hline
\end{tabular}

\begin{tabular}{l}
$\begin{array}{l}\text { RET IH RORTS } \\
\text { OP R BGIOR }\end{array}$ \\
\hline
\end{tabular}




\begin{tabular}{|c|c|c|c|c|c|c|c|c|c|c|}
\hline & & & $\begin{array}{l}\text { REGIONAL } \\
\text { PIES }\end{array}$ & $\begin{array}{l}\text { ENE FGY EAL } \\
\text { MID HID SC }\end{array}$ & $\begin{array}{l}\text { ANCE STAT } \\
\text { ENARIO }\end{array}$ & & & & & \\
\hline SBCTOF & $\begin{array}{l}\text { DISTILLATE } \\
\text { OIL }\end{array}$ & $\begin{array}{l}\text { RESIDUAL } \\
\text { OIL }\end{array}$ & $\begin{array}{l}\text { GASOLINE } \\
\text { |ALL ONIT }\end{array}$ & $\begin{array}{c}\text { OTHER } \\
\text { HYDRO- } \\
\text { CARBONS } \\
\text { TS IN } 10 * \$ 9\end{array}$ & $\begin{array}{c}\text { CRODE } \\
\text { OIL } \\
\text { BTO'SI }\end{array}$ & $\begin{array}{l}\text { NATURAL } \\
\text { GAS }\end{array}$ & $\cos L$ & ELECTRICITY & $\begin{array}{l}\text { SECTOR } \\
\text { TOTAL }\end{array}$ & \\
\hline $\begin{array}{l}\text { PINAL CEHAHC SECTCRS } \\
\text { EESIDENTIAL, CCMA- } \\
\text { INDUSTRIAL } \\
\text { TRANSPORTATION } \\
\text { GISCELLANEOOS OSES }\end{array}$ & $\begin{array}{r}12,641 \\
10,762 \\
25,186 \\
1,247\end{array}$ & $\begin{array}{r}510 \\
9.080 \\
407 \\
233\end{array}$ & $81.81 \overline{-}$ & $\begin{array}{r}16,880 \\
22,881 \\
1,898 \\
56\end{array}$ & 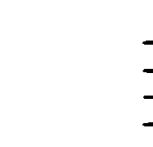 & $\begin{array}{r}41.551 \\
9.251 \\
499 \\
561\end{array}$ & $\begin{array}{r}86 \\
16,588 \\
1 \\
-\quad\end{array}$ & $\begin{array}{r}25,276 \\
17,330 \\
17 \\
264\end{array}$ & $\begin{array}{r}96,944 \\
85,892 \\
109,818 \\
2,361\end{array}$ & $\begin{array}{r}25 \% \\
22 \% \\
29 \% \\
1 \%\end{array}$ \\
\hline $\begin{array}{l}\text { TCTAL FINAL } \\
\text { DEMAND SECTCRS }\end{array}$ & 49.836 & 10.230 & 81,810 & 41,715 & - & 51,862 & 16,675 & 42,887 & 295,015 & $77 \%$ \\
\hline 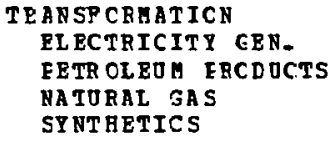 & $\begin{array}{r}1,394 \\
- \\
-\end{array}$ & $\begin{array}{l}\overline{-} \\
\overline{-}\end{array}$ & $\bar{z}$ & $\begin{array}{l}\overline{-} \\
\overline{-}\end{array}$ & 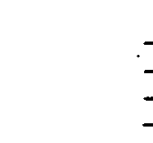 & $\bar{z}$ & $\begin{array}{r}109,842 \\
= \\
-\end{array}$ & $\begin{array}{r}-28,129 \\
= \\
-\end{array}$ & $\begin{array}{r}83,107 \\
- \\
-\end{array}$ & $22 \%$ \\
\hline $\begin{array}{l}\text { RIT FOEL OSEI } \\
\text { IN TRANSPOBAATION }\end{array}$ & 1,394 & - & - & - & - & - & 109,842 & $-28,129$ & 83,107 & $22 \pi$ \\
\hline $\begin{array}{l}\text { TCTAL GROSS FLONS } \\
\text { LCSSES } 8 \text { OHISSIONS }\end{array}$ & $\begin{array}{r}51,230 \\
3,188\end{array}$ & $\begin{array}{r}10.230 \\
0\end{array}$ & $\begin{array}{r}81,810 \\
0\end{array}$ & $\begin{array}{r}41,715 \\
-1,645\end{array}$ & 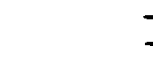 & $\begin{array}{r}51,862 \\
-1,401\end{array}$ & $\begin{array}{r}126,517 \\
1,712\end{array}$ & $\begin{array}{r}42,887 \\
3,558\end{array}$ & $\begin{array}{r}378,122 \\
5,413\end{array}$ & $\begin{array}{r}99 \% \\
1 \%\end{array}$ \\
\hline TOTAL NET OSAGE & 54,418 & 10,230 & 81,810 & 40,069 & - & 50,460 & 128,229 & 18,316 & 383,535 & \\
\hline
\end{tabular}

\begin{tabular}{|c|c|c|c|c|c|c|c|c|c|c|}
\hline $\begin{array}{l}\text { SOFPIY OP ENFRGY } \\
\text { FOSS IL POEI } \\
\text { RYDROELPCTAIC } \\
\text { HOCL EAR } \\
\text { GBO. ESOLAR }\end{array}$ & $\begin{array}{l}\overline{-} \\
\overline{-}\end{array}$ & $\begin{array}{l}\bar{z} \\
\overline{-}\end{array}$ & - & $\begin{array}{l}\text { - } \\
\text { - }\end{array}$ & $\begin{array}{l}- \\
-\end{array}$ & $\begin{array}{l}\overline{-} \\
\overline{-}\end{array}$ & $\bar{z}$ & $\begin{array}{r}5 \overline{1} \\
24,679 \\
-\end{array}$ & $\begin{array}{r}59 \overline{1} \\
24.679 \\
-\end{array}$ & $\begin{array}{c}28 \\
98 \%\end{array}$ \\
\hline TCTAL SUPPIY & - & - & - & - & - & - & - & 25,270 & 25,270 & \\
\hline
\end{tabular}

XET IM PORTS
OP REGION

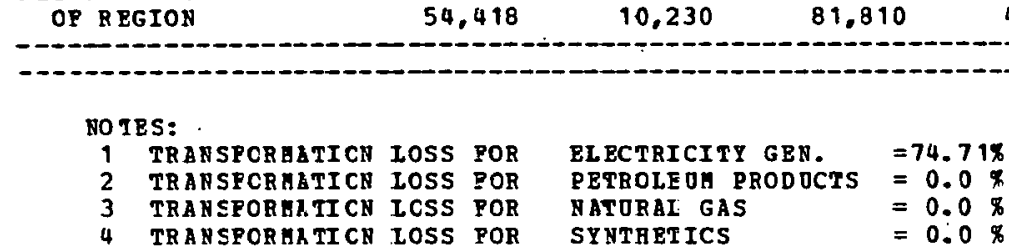


REGTONAL ENEEGX EALANCE STATEMENT

\begin{tabular}{|c|c|c|c|c|c|c|c|c|c|c|}
\hline SECTOG & $\begin{array}{l}\text { DIST ILLATR } \\
=I L\end{array}$ & $\begin{array}{l}\text { RESTrOELL } \\
\text { OII }\end{array}$ & $\begin{array}{l}\text { SASOLINU } \\
\text { (ALL }\end{array}$ & $\begin{array}{l}\text { CTAER } \\
\text { HYDRO- } \\
\text { CAEBONS } \\
\text { TS IN 10*\%9 }\end{array}$ & $\begin{array}{c}\text { CRODE } \\
\text { OII } \\
\text { BTU SI }\end{array}$ & $\begin{array}{l}\text { FATORAB } \\
\text { GAS }\end{array}$ & COAI & ELECTRICITY & $\begin{array}{r}\text { SECT OR } \\
\text { TOTAL }\end{array}$ & \\
\hline $\begin{array}{l}\text { PINAL CEHANE SHCTORS } \\
\text { QESIDENTIAI, COHH. } \\
\text { INDOSTRIAL } \\
\text { IRANSPORTATICS } \\
\text { MISCELLABOOS OSES }\end{array}$ & $\begin{array}{l}4,9 \equiv 6 \\
4,046 \\
5.313 \\
773\end{array}$ & $\begin{array}{r}259 \\
2.455 \\
1=3 \\
164\end{array}$ & $32.47 \overline{7}$ & $\begin{array}{r}6.523 \\
7.176 \\
.27 \\
25\end{array}$ & $\begin{array}{l}- \\
-\end{array}$ & $\begin{array}{r}16,645 \\
4,223 \\
233 \\
201\end{array}$ & $\begin{array}{r}39 \\
6.651 \\
- \\
-\end{array}$ & $\begin{array}{r}10.596 \\
7.497 \\
5 \\
115\end{array}$ & $\begin{array}{r}39,098 \\
32,088 \\
40,078 \\
1,258\end{array}$ & $\begin{array}{l}25 \% \\
25 \% \\
25 \% \\
1 \%\end{array}$ \\
\hline $\begin{array}{l}\text { TCTAL PIBAI } \\
\text { DEMARD SECTCRS }\end{array}$ & $15,0 \in 8$ & $3,0: 1$ & 32.477 & 14.751 & - & 21,302 & 6.690 & 18,213 & 112.522 & $71 \%$ \\
\hline $\begin{array}{l}\text { T3ANSPORAATICA } \\
\text { EL RCTRICITY GEN. } \\
\text { PETROLEOA ERCDOCTS } \\
\text { NATORAL GAS } \\
\text { SYNTHETICS }\end{array}$ & $\begin{array}{r}9 \in 7 \\
\overline{-} \\
-\end{array}$ & $\begin{array}{l}\overline{-} \\
\overline{-}\end{array}$ & $\begin{array}{l}- \\
-\end{array}$ & $\begin{array}{l}\overline{-} \\
\overline{-}\end{array}$ & $\begin{array}{l}\overline{-} \\
\overline{-}\end{array}$ & $\bar{z}$ & $\begin{array}{r}56,149 \\
- \\
-\end{array}$ & $\begin{array}{r}-14,468 \\
- \\
-\end{array}$ & $\begin{array}{r}42,648 \\
= \\
-\end{array}$ & 27.8 \\
\hline $\begin{array}{l}\text { NET FOYL OSEL } \\
\text { IN TRANSPOEATION }\end{array}$ & 9E7 & - & - & - & - & - & 56,149 & $-14,468$ & 42,648 & $27 \%$ \\
\hline $\begin{array}{l}\text { TCTAL GROSS FLORS } \\
\text { LCSSES E ONISSIONS }\end{array}$ & $\begin{array}{r}13,0 \equiv 5 \\
:, 0 \in 0\end{array}$ & $\begin{aligned} 3: 0 \% 1 \\
0\end{aligned}$ & $\begin{array}{r}32,477 \\
0\end{array}$ & $\begin{array}{r}-4,751 \\
-581\end{array}$ & $\overline{-}$ & $\begin{array}{r}21,302 \\
-575\end{array}$ & $\begin{array}{r}62,839 \\
850\end{array}$ & $\begin{array}{r}18,213 \\
1,511\end{array}$ & $\begin{array}{r}155,170 \\
2,264\end{array}$ & $\begin{array}{r}998 \\
18\end{array}$ \\
\hline TOTAL YET OSAGE & $1 E ., 0 \leq 5$ & $3,0 \geq 1$ & 32.477 & $\cdot 4,169$ & - & 20,726 & 63,689 & 5,256 & 157,434 & \\
\hline
\end{tabular}

\begin{tabular}{|c|c|c|c|c|c|c|c|c|c|c|}
\hline SOEPLY OP FNEFSY & & & & & & & & & & \\
\hline FOSS IL FOYI & - & - & - & - & 296 & - & - & - & 296 & $2 \pi$ \\
\hline HY DROELECTEIS & - & - & - & - & - & - & - & 111 & 111 & 18 \\
\hline NOCL EAR & - & - & - & - & - & - & - & 11,963 & 11,963 & 97: \\
\hline GEO. ESOLAR & - & - & - & - & - & - & - & - & - & \\
\hline TOTAL SOPPIY & - & - & - & - & 296 & - & - & 12,074 & 12,370 & \\
\hline
\end{tabular}

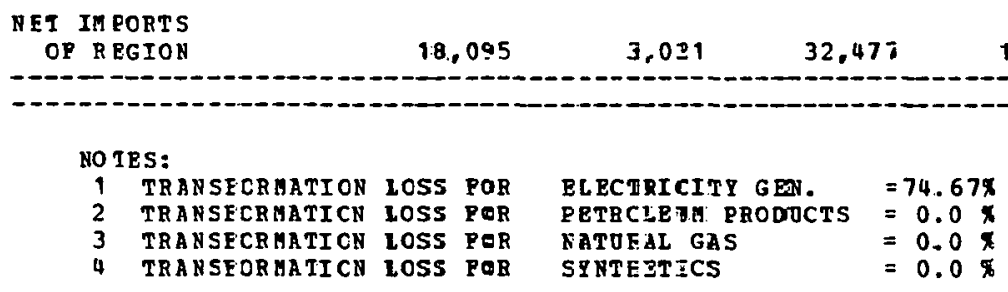


REGICNAL ENEEGY EALANCE STATEHENT
PIES MID MID SCENARIO

\begin{tabular}{|c|c|c|c|c|c|c|c|c|c|c|}
\hline SECTOF & $\underset{\text { OIL }}{\text { DISTILLATE }}$ & $\begin{array}{l}\text { RESIDDAL } \\
\text { OIL }\end{array}$ & $\begin{array}{l}\text { GASOLINE } \\
\text { (ALI ON? }\end{array}$ & $\begin{array}{c}\text { OTHER } \\
\text { HYDRO- } \\
\text { CARBONS } \\
\text { TS IN } 10 * * 9\end{array}$ & $\begin{array}{c}\text { CROCE } \\
\text { OII } \\
\text { BTO'SI }\end{array}$ & $\begin{array}{l}\text { NATORAL } \\
\text { GAS }\end{array}$ & COAL & ELECTRICITY & $\begin{array}{r}\text { SECTOR } \\
\text { TOTAL }\end{array}$ & \\
\hline 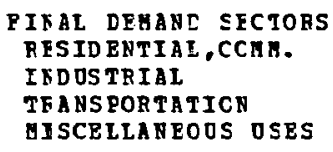 & $\begin{array}{r}902 \\
3,431 \\
3,129 \\
278\end{array}$ & $\begin{array}{r}41 \\
5,918 \\
9 \\
52\end{array}$ & 29.629 & $\begin{array}{r}5,307 \\
16,480 \\
468 \\
10\end{array}$ & $\begin{array}{l}- \\
-\end{array}$ & $\begin{array}{r}14,914 \\
14,504 \\
160 \\
84\end{array}$ & $\begin{array}{r}13 \\
1,094 \\
- \\
-\end{array}$ & $\begin{array}{r}7.579 \\
14.214 \\
- \\
42\end{array}$ & $\begin{array}{r}28,756 \\
55,641 \\
33,395 \\
466\end{array}$ & $\begin{array}{r}22 \% \\
42 \% \\
25 \% \\
0 \%\end{array}$ \\
\hline $\begin{array}{l}\text { TCIAL FINAI } \\
\text { DEMAND SECTORS }\end{array}$ & 7,740 & 6,020 & 29,629 & 22.265 & - & 29,662 & 1,107 & 21,835 & 118,258 & $90 \pi$ \\
\hline $\begin{array}{l}\text { TRLASPCRHATICN } \\
\text { FLRCTRICITY GRN. } \\
\text { FETROLEO ERODOCTS } \\
\text { HATURAL GAS } \\
\text { STHT RETICS }\end{array}$ & $\begin{array}{r}19 \\
-48,000 \\
- \\
-\end{array}$ & $\begin{array}{r}-19,226 \\
-\end{array}$ & $\begin{array}{r}-98,737 \\
-\end{array}$ & $\begin{array}{r}-43,394 \\
-\end{array}$ & $\begin{array}{r}\overline{-} \\
206,083 \\
-\end{array}$ & $\begin{array}{r}3.713 \\
4,579 \\
-\end{array}$ & $\begin{array}{l}\overline{-} \\
\overline{-}\end{array}$ & $\begin{array}{r}-1,081 \\
- \\
-\end{array}$ & $\begin{array}{r}2,651 \\
1,305 \\
- \\
-\end{array}$ & $2 \%$ \\
\hline $\begin{array}{l}\text { REY FOEL OSEL } \\
\text { JN TRARSORATION }\end{array}$ & $-47,981$ & -19.226 & $-98,737$ & $-43,394$ & 206.083 & 8,292 & - & -1.081 & 3,956 & $3 x$ \\
\hline $\begin{array}{l}\text { TCTAL GROSS FLCRS } \\
\text { LCSSES } \& \text { OHISSIONS }\end{array}$ & $\begin{array}{r}7.759 \\
482\end{array}$ & $\begin{array}{r}6,020 \\
0\end{array}$ & $\begin{array}{r}29,629 \\
0\end{array}$ & $\begin{array}{r}22,265 \\
-878\end{array}$ & $\begin{array}{r}206,083 \\
8,549\end{array}$ & $\begin{array}{l}37,954 \\
-1,025\end{array}$ & $\begin{array}{r}1,107 \\
14\end{array}$ & $\begin{array}{r}21,835 \\
1,811\end{array}$ & $\begin{array}{r}122,214 \\
8,955\end{array}$ & $\begin{array}{r}93 \pi \\
79\end{array}$ \\
\hline $\begin{array}{l}\text { SOFELY OP ENERGY } \\
\text { FOSS IL PUEI } \\
\text { UY DROELECT } \\
\text { OOCL BAR } \\
\text { GEO. \&SOLAR }\end{array}$ & $\begin{array}{l}\overline{-} \\
\overline{-}\end{array}$ & $\begin{array}{l}\text { I } \\
\text { - }\end{array}$ & $\begin{array}{l}- \\
\overline{-} \\
-\end{array}$ & - & $\begin{array}{r}133,433 \\
- \\
- \\
-\end{array}$ & $\begin{array}{r}2,500 \\
- \\
-\end{array}$ & $\begin{array}{l}\text { - } \\
\text { - }\end{array}$ & 17.683 & $\begin{array}{r}135,933 \\
17,683 \\
-\end{array}$ & $12 x$ \\
\hline TOEAL SUPPIY & - & - & - & - & 133.433 & 2,500 & - & 17,683 & 153,616 & \\
\hline
\end{tabular}

NOTES:

TRANSPCRMATICN LOSS FOR TRANSPCRIATICN IOSS POR TRAN SPCRAATI CN LOSS POR TRANSPOREATICN LOSS POR
BLECTRICITY GEN.

DTROLEOA PRODOCTS $=0.62 \%$

MATORAL GAS

$=0.62 \%$

$=0.0 \%$ 
REGIONAL ENE BGY PALAYCE STATEMENT

\begin{tabular}{|c|c|c|c|c|c|c|c|c|c|c|}
\hline SECTOE & $\begin{array}{l}\text { DISTrLaldTE } \\
\text { OIL }\end{array}$ & $\begin{array}{l}\text { RESIDOAL } \\
\text { OIL }\end{array}$ & $\begin{array}{l}\text { GASOLIYY } \\
\text { (ALL ONIT }\end{array}$ & $\begin{array}{c}\text { OTHER } \\
\text { HYDRO- } \\
\text { CAR3ONS } \\
\text { TS I } 10 * * 9\end{array}$ & $\begin{array}{c}\text { CRODE } \\
\text { OIL } \\
\text { BTO'SI }\end{array}$ & $\begin{array}{l}\text { NATURAL } \\
\text { GAS }\end{array}$ & $\operatorname{COAL}$ & ELECTRICI TY & $\begin{array}{r}\text { SECTOR } \\
\text { TOTAL }\end{array}$ & \\
\hline $\begin{array}{l}\text { PIREL CEAANC SECTORS } \\
\text { RESIDERTIAL, COHA. } \\
\text { INDOSTRIAL } \\
\text { TRARSPORTATION } \\
\text { MISCELLANEOOS OSES }\end{array}$ & $\begin{array}{r}1,975 \\
5,417 \\
7,480 \\
633\end{array}$ & $\begin{array}{r}100 \\
74,188 \\
19 \\
118\end{array}$ & 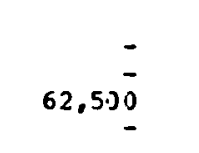 & $\begin{array}{r}11.260 \\
37.981 \\
1.164 \\
30\end{array}$ & $\bar{z}$ & $\begin{array}{r}32,314 \\
23,001 \\
399 \\
283\end{array}$ & $\begin{array}{r}27 \\
3.081 \\
- \\
-\end{array}$ & $\begin{array}{r}17.377 \\
22,255 \\
- \\
104\end{array}$ & $\begin{array}{r}63,053 \\
105,923 \\
71.562 \\
1.168\end{array}$ & $\begin{array}{r}22 \% \\
37 \% \\
25 \% \\
0 \%\end{array}$ \\
\hline $\begin{array}{l}\text { TCTAI FINAI } \\
\text { DEHAND SECTORS }\end{array}$ & 15,505 & 14.425 & 62,530 & 50,435 & - & 55,997 & 3,108 & 39,736 & 241.706 & $84 \%$ \\
\hline $\begin{array}{l}\text { TRANSP ORHATICN } \\
\text { ELECTRICITI GBN. } \\
\text { PETR CLEOA IRODOCTS } \\
\text { NATORAL GAS } \\
\text { SYNT BETICS }\end{array}$ & $\begin{array}{r}512 \\
-112,921 \\
-\end{array}$ & $\begin{array}{r}-45,229 \\
-\end{array}$ & $\begin{array}{r}-232.279 \\
- \\
-\end{array}$ & $\begin{array}{r}-102,08 \overline{-} \\
-\end{array}$ & $\begin{array}{r}484,813 \\
- \\
-\end{array}$ & $\begin{array}{r}30,768 \\
10,772 \\
-\end{array}$ & $\begin{array}{l}- \\
-\end{array}$ & $\begin{array}{r}-9.082 \\
- \\
-\end{array}$ & $\begin{array}{r}22,198 \\
3,072 \\
-\end{array}$ & $\begin{array}{l}8 \% \\
1 \%\end{array}$ \\
\hline $\begin{array}{l}\text { NET FUEL OSEL } \\
\text { IN TRABSPOEBATIOR }\end{array}$ & -112.409 & $-45,229$ & -232.279 & -102.084 & 484,813 & 41,540 & - & -9.082 & 25,270 & $9 \%$ \\
\hline $\begin{array}{l}\text { TCTAL GROSS ILCHS } \\
\text { lOSSES } \& \text { OUISSIONS }\end{array}$ & $\begin{array}{r}16.017 \\
996\end{array}$ & $\begin{array}{r}14.425 \\
0\end{array}$ & $\begin{array}{r}62,530 \\
0\end{array}$ & $\begin{array}{r}51, .435 \\
-1,989\end{array}$ & $\begin{array}{r}484,813 \\
20,112 \\
\end{array}$ & $\begin{array}{r}97,537 \\
-2,635\end{array}$ & $\begin{array}{r}3.108 \\
42\end{array}$ & $\begin{array}{r}39,736 \\
3,297\end{array}$ & $\begin{array}{r}266,976 \\
19,824\end{array}$ & $\begin{array}{r}93 \% \\
7 \%\end{array}$ \\
\hline
\end{tabular}

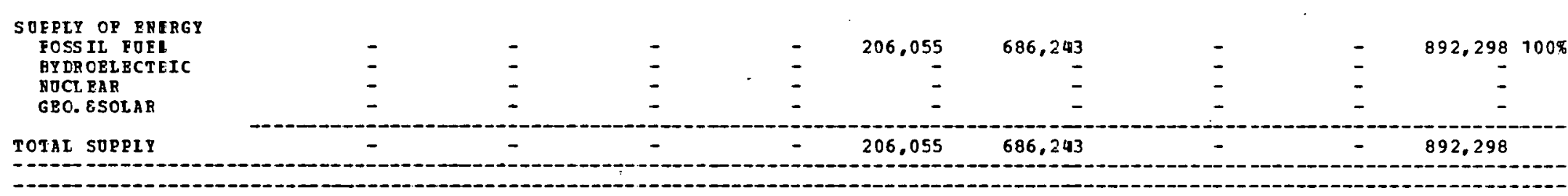

\section{NET IM FORTS}

OP R RGIO

$-95,907$

$-30,803$

$-169.778$

$-53,638$

298,870

$-591,340$

3. 150

33.951

NOTES:

TRANSFCRUATICN LOSS POR TRANSPORHATICN LOSS POR

TRANSPCRSATI CN LOSS POR

BLRCTRICITY CEN.

Deciricini cen. $=\$ 0.97 \%$

PETROLEOH PRODOCTS $=0.6=\%$

TRANSPCRMATICN LDSS POR RATJRAL GAS
TRANSFORMATICN LOSS FOR SYNTHETCS

$=0.0 \pi$

$=0.0 \pi$ 
REGIOHAL EHE FGY EALANCE STATEMENT

PIES UID MID SCERARIO

\begin{tabular}{|c|c|c|c|c|c|c|c|c|c|c|}
\hline SBCTCE & $\begin{array}{l}\text { DISTILLATE } \\
\text { OIL }\end{array}$ & $\begin{array}{l}\text { RESIDDAL } \\
\text { OIL }\end{array}$ & $\begin{array}{l}\text { GASOLI IBE } \\
\text { (ALL OH }\end{array}$ & $\begin{array}{l}\text { OTHER } \\
\text { HYDRO- } \\
\text { CARBOHS } \\
\text { S IN } 10 * * 9\end{array}$ & $\begin{array}{c}\text { CRODE } \\
\text { OIL } \\
\text { BTO'S) }\end{array}$ & $\begin{array}{l}\text { NATURAL } \\
\text { GAS }\end{array}$ & COAL & BLECTRICITY & $\begin{array}{l}\text { SECTOR } \\
\text { TOTAL }\end{array}$ & \\
\hline $\begin{array}{l}\text { TCTAL FIRAL } \\
\text { DBHABD SBCTORS }\end{array}$ & 95,689 & 27,049 & 209.259 & 214,815 & - & 189,620 & 38,226 & 106,541 & 881,199 & $67 \%$ \\
\hline $\begin{array}{l}\text { TRARSPOREATICY } \\
\text { RLBCTRICITY GER. } \\
\text { PETR OLBOA FEODOCTS } \\
\text { RATORAL GAS } \\
\text { SY HTERTICS }\end{array}$ & $\begin{array}{r}5.969 \\
-100,011 \\
-\end{array}$ & $\begin{array}{r}-40,058 \\
-\end{array}$ & $\begin{array}{r}-205,723- \\
-\end{array}$ & $\begin{array}{r}-90,41 \overline{-} \\
-\end{array}$ & $\begin{array}{r}429.386 \\
-\end{array}$ & $\begin{array}{r}31,778 \\
9,541 \\
-\end{array}$ & $\begin{array}{r}515,939 \\
=\end{array}$ & $\begin{array}{r}-141,121 \\
- \\
-\end{array}$ & $\begin{array}{r}412,565 \\
2,723 \\
- \\
-\end{array}$ & $\begin{array}{r}31 x \\
0 x\end{array}$ \\
\hline $\begin{array}{l}\text { AET FOEL DSEL } \\
\text { IB TRABSPOBATIOH }\end{array}$ & $-94,042$ & $-0,058$ & $-205,723$ & -90.412 & 429,386 & 41,319 & 515,939 & -141.121 & 415.288 & $31 \%$ \\
\hline $\begin{array}{l}\text { TOTAL GROSS FLONS } \\
\text { LCSSBS } 8 \text { OBISSIORS }\end{array}$ & $\begin{array}{r}101,658 \\
6,327\end{array}$ & $\begin{array}{r}27,049 \\
0\end{array}$ & $\begin{array}{r}209,259 \\
0\end{array}$ & $\begin{array}{r}214,815 \\
-8,473\end{array}$ & $\begin{array}{r}429,386 \\
17,813\end{array}$ & $\begin{array}{r}230,939 \\
-6.240\end{array}$ & $\begin{array}{r}554,165 \\
7,501\end{array}$ & $\begin{array}{r}106,541 \\
8,840\end{array}$ & $\begin{array}{r}1,296,487 \\
25,769\end{array}$ & $\begin{array}{r}98 \% \\
2 \%\end{array}$ \\
\hline TOTAL ABT OSAGY & 7,974 & $-13,008$ & 3.536 & 115,929 & 447,199 & 224.698 & 561,665 & $-25,739$ & $1,322,256$ & \\
\hline $\begin{array}{l}\text { SOEFLY OP BHERGY } \\
\text { FOSS IL POEL } \\
\text { GYDROELBCTEIC } \\
\text { GOCL BAR } \\
\text { GBO. 8SOLAR }\end{array}$ & E & $\begin{array}{l}\overline{-} \\
\overline{-}\end{array}$ & $\bar{z}$ & $\begin{array}{l}\overline{-} \\
\overline{-}\end{array}$ & $\begin{array}{r}5,286 \\
- \\
-\end{array}$ & $\begin{array}{r}482 \\
- \\
-\end{array}$ & $\begin{array}{r}99,890 \\
= \\
-\end{array}$ & $\begin{array}{r}419 \\
-\end{array}$ & $\begin{array}{r}105,658 \\
419 \\
- \\
-\end{array}$ & $\begin{array}{r}100 \% \\
0 \%\end{array}$ \\
\hline TCQAI SOPPIY & - & - & - & - & 5,286 & 482 & 99,890 & 419 & 106,077 & \\
\hline
\end{tabular}

\section{BET IH PORTS}

OP RBGIOI

7,974

$-13,008$

3,536

MOTES:

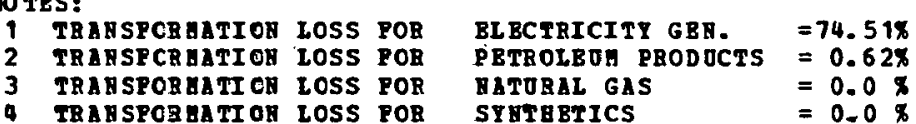


RBG IORAL EGERG BALAMCE STATEAENT

TORAL BER RGT EALAHCE STA
PIES IID MI D SCEHARIO

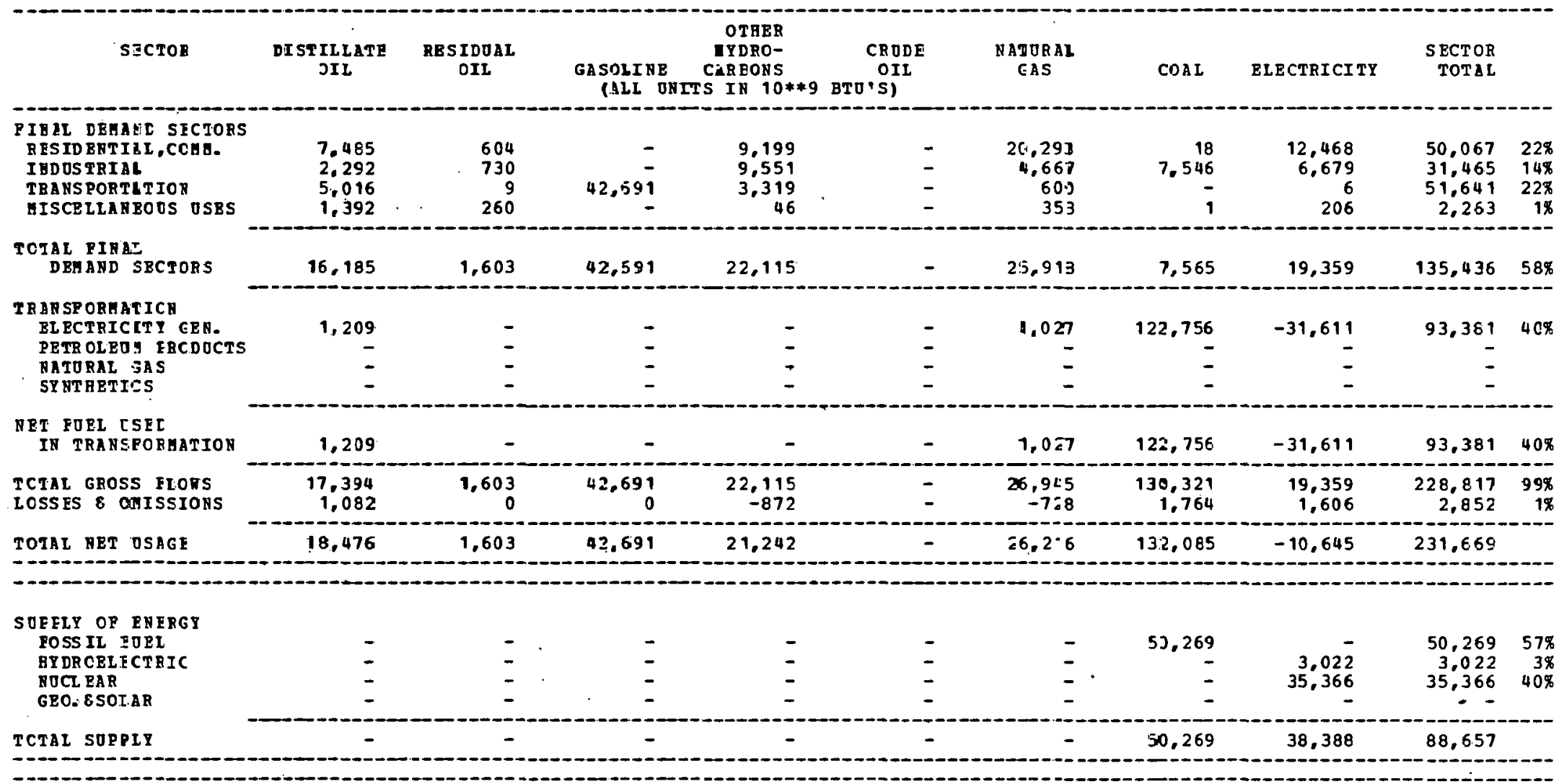

\section{NET IN FORES}

42,691

21,242

26.216

$\varepsilon \uparrow, 816$

$-49.033$

143,012

-

NOTES:

1 T3ARSPCRATICE LOS 5 PO

TIANSPCRHATICU LOSS POR

TRARSPCR DATICI LOSS POB

TRA SPORAATI C LCSS FOR

BLECTRICITY GER.

PETROLEUA PRODOCAS $=7 \$ .71 \%$

TATUBAL GAS

$=-0.6 \%$

SYRT.HETICS

$=0.6 \%$
$=3.0 \%$ 
REGIONAL ENEEGY BALANCE STATEMENT

PIBS MID HID SCENARIO
PIAL EALARCE ST

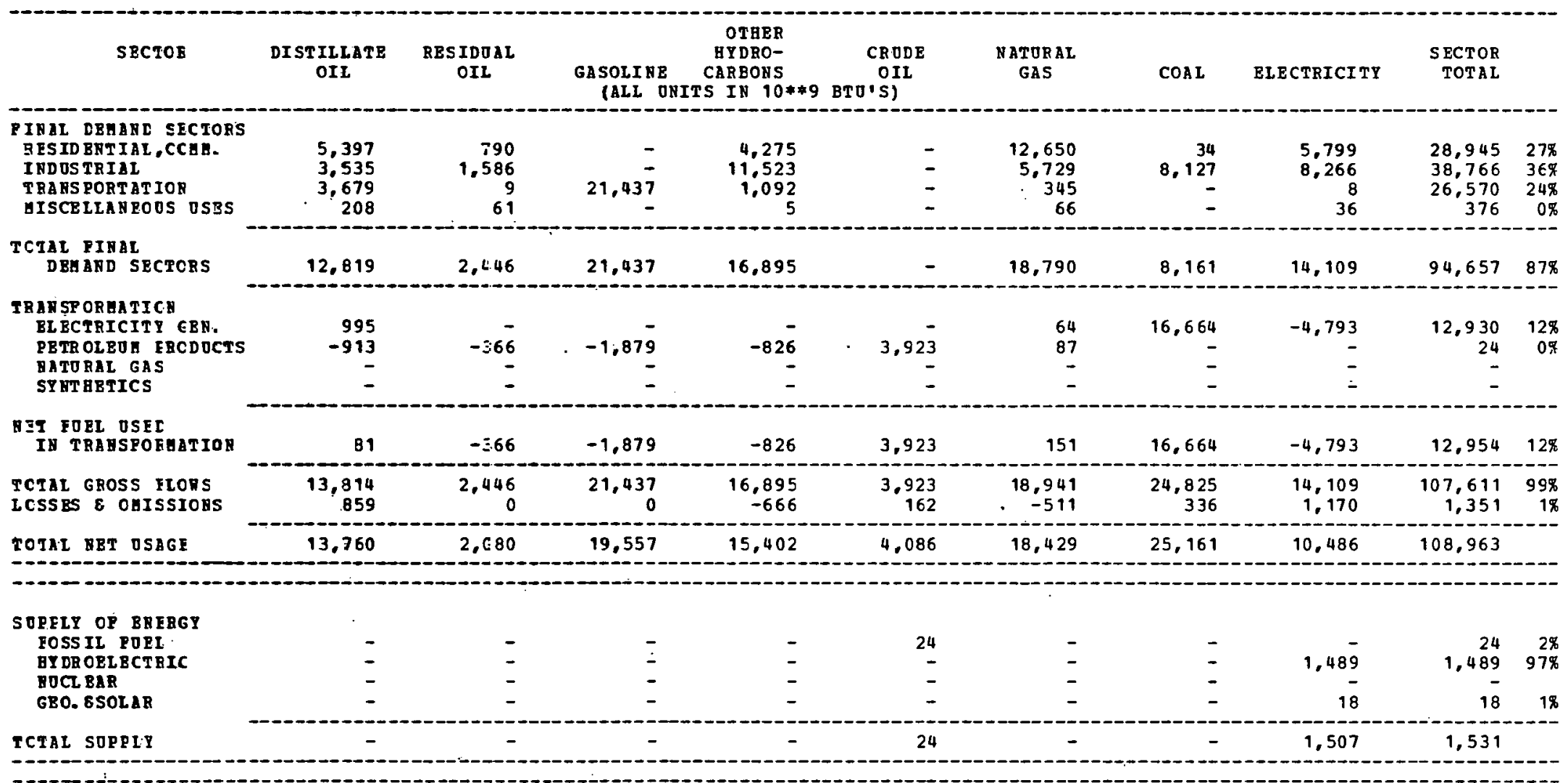

BET III PORTS

OP R BGION

13,760

2,080

19,557

15,402

4,062

18,429

25,161

$8,979 \quad 107,432$
BOTES:
TRARSFCRUETICN LOSS POR
TRANSPORAITICN LOSS POA
BL3CTRICITY GEN.
PETROLEOM PRODOCTS $=0.62 \%$
$\begin{array}{ll}\text { SYTTERTICS } & =0.0 \% \\ & =0.0 \%\end{array}$ 
RBGIONAL BYE FGY EALANCE STATEMENT

PIES MID UID SCENARIO

\begin{tabular}{|c|c|c|c|c|c|c|c|c|c|c|}
\hline SECTOR & $\begin{array}{l}\text { DISTILIATB } \\
\text { DIL. }\end{array}$ & $\begin{array}{l}\text { RESIDJAL } \\
\text { OIL }\end{array}$ & $\begin{array}{l}\text { GASOLIR } \\
\text { (ALL }\end{array}$ & $\begin{array}{c}\text { OTHER } \\
\text { HYDRO- } \\
\text { CAREONS } \\
\text { ITS IN } 10 * * 9\end{array}$ & $\begin{array}{c}\text { CRODE } \\
\text { OIL } \\
\text { BTU'S) }\end{array}$ & $\begin{array}{l}\text { NATUR AL } \\
\text { GAS }\end{array}$ & $\operatorname{COA} L$ & ELECTRICITY & $\begin{array}{r}\text { SECTOR } \\
\text { TOTAL }\end{array}$ & \\
\hline 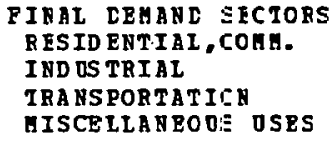 & $\begin{array}{r}58,534 \\
30,207 \\
42,749 \\
7,031\end{array}$ & $\begin{array}{r}9,166 \\
15,889 \\
196 \\
1,903\end{array}$ & $244.64 \%$ & $\begin{array}{r}50.027 \\
135,372 \\
20.219 \\
246\end{array}$ & $\begin{array}{l}\overline{-} \\
-\end{array}$ & $\begin{array}{r}137,0 \varepsilon 5 \\
78,4 \in 9 \\
4,5 \varepsilon 4 \\
2,6 C 8\end{array}$ & $\begin{array}{r}335 \\
83,69.7 \\
? \\
\frac{2}{5}\end{array}$ & $\begin{array}{r}71,565 \\
52,853 \\
193 \\
1,249\end{array}$ & $\begin{array}{r}326,712 \\
396,484 \\
312,592 \\
13,042\end{array}$ & $\begin{array}{l}21 \% \\
25 \% \\
20 \% \\
1 \%\end{array}$ \\
\hline $\begin{array}{l}\text { TCTAL FIRAI } \\
\text { DEHAND SECJORS }\end{array}$ & 138,521 & 27,154 & 244,647 & 205.864 & - & 222,716 & 84,035 & 125,860 & $1,048,830$ & $57 \%$ \\
\hline $\begin{array}{l}\text { TR ARSFORHATICS } \\
\text { BLECTRICITY GRN. } \\
\text { PRTR OLEOH FEODOCTS } \\
\text { NATURAL GAS } \\
\text { SY BTHETICS }\end{array}$ & $\begin{array}{r}5,3783 \\
-229,848 \\
-\end{array}$ & $\begin{array}{r}3,323 \\
-92,062 \\
-\end{array}$ & $\begin{array}{r}-472,793 \\
-\end{array}$ & $\begin{array}{r}-207.789 \\
- \\
-\end{array}$ & $\begin{array}{r}- \\
986,824 \\
-\end{array}$ & $\begin{array}{r}5: 5 \\
21,9: 7 \\
- \\
-\end{array}$ & $\begin{array}{r}647,775 \\
- \\
-\end{array}$ & $\begin{array}{r}-195,505 \\
- \\
-\end{array}$ & $\begin{array}{r}461,492 \\
6,254 \\
- \\
-\end{array}$ & $\begin{array}{r}29 \% \\
0 \%\end{array}$ \\
\hline $\begin{array}{l}\text { DET FORL OSEL } \\
\text { IN TRABSPOBATION }\end{array}$ & $-22.4,465$ & $-8 E, 739$ & -472.793 & $-207,789$ & 986,324 & $22,4 \div 2$ & 647,775 & $-195,505$ & 467,746 & $30 \pi$ \\
\hline $\begin{array}{l}\text { TCTAL GROSS FLORS } \\
\text { LCSSES } \& \text { OMISSIONS }\end{array}$ & $\begin{array}{r}143,904 \\
8,557\end{array}$ & $\begin{array}{r}39,477 \\
0\end{array}$ & $\begin{array}{r}244,649 \\
1\end{array}$ & $\begin{array}{r}205,864 \\
-8,120\end{array}$ & $\begin{array}{r}986,324 \\
40,938\end{array}$ & $\begin{array}{r}245,1 \varepsilon .8 \\
-6,6: 5\end{array}$ & $\begin{array}{r}731,812 \\
9,905\end{array}$ & $\begin{array}{r}125,860 \\
10,443\end{array}$ & $\begin{array}{r}1,516,576 \\
.55,500\end{array}$ & $\begin{array}{r}\exists \in \mathscr{W} \\
4 \%\end{array}$ \\
\hline
\end{tabular}

\begin{tabular}{|c|c|c|c|c|c|c|c|c|c|c|}
\hline SOFELY OF ENEBGY & & & & & & & & & & \\
\hline FOSS IL FOEI & - & - & - & - & 82,617 & 2.61 & $1,525,377$ & - & $1,608,255$ & $100 \%$ \\
\hline AYDROELECTEIC & - & - & - & - & - & - & - & 867 & 867 & $0 \%$ \\
\hline NOCL EAR & - & - & - & - & - & - & - & - & - & \\
\hline GEO. ESOLAR & - & - & - & - & - & - & - & 146 & 146 & $0 \%$ \\
\hline ICTAL SOPPIY & - & - & - & - & 82,617 & 251 & $1,525,377$ & 1,013 & $1,609,268$ & \\
\hline
\end{tabular}

RET IN PORTS
OP R RGION


REGIONAL RNE FGY EALANCE ST ATEMENT

\begin{tabular}{|c|c|c|c|c|c|c|c|c|c|c|}
\hline SECTOE & $\begin{array}{l}\text { DISTILLATE } \\
\text { OIL }\end{array}$ & $\begin{array}{l}\text { RESIDOLL } \\
\text { OIL }\end{array}$ & $\begin{array}{l}\text { GASOLINE } \\
\text { (ALL O }\end{array}$ & $\begin{array}{l}\text { OTHER } \\
\text { HYDRO- } \\
\text { CARBONS } \\
\text { CS IN } 10 * \$ 9\end{array}$ & $\begin{array}{c}\text { CROEE } \\
\text { OIL } \\
\text { BTU'S) }\end{array}$ & $\begin{array}{l}\text { NATORAL } \\
\text { GAS }\end{array}$ & $\operatorname{COAL}$ & ELECTRICITY & $\begin{array}{r}\text { SECTOR } \\
\text { TOTAL }\end{array}$ & \\
\hline $\begin{array}{l}\text { PIYAL EEMAND SFCTOSS } \\
\text { HESIDENTIAI, CCMM. } \\
\text { INDUSTRIAL } \\
\text { TRANSPORTATICN } \\
\text { MISCELIANEOCS OSPS }\end{array}$ & $\begin{array}{r}6.987 \\
4,038 \\
7,998 \\
910\end{array}$ & $\begin{array}{r}8(13 \\
2,45.1 \\
\vdots 1 \\
2 \varepsilon 7\end{array}$ & $\begin{array}{r}- \\
- \\
49,796\end{array}$ & $\begin{array}{r}8,604 \\
12,622 \\
5,819 \\
29\end{array}$ & 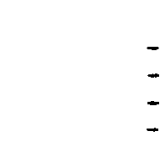 & $\begin{array}{r}20,540 \\
12,631 \\
827 \\
379\end{array}$ & $\begin{array}{r}69 \\
19,292 \\
- \\
-\end{array}$ & $\begin{array}{r}17.471 \\
28,450 \\
+\quad 7 \\
209\end{array}$ & $\begin{array}{r}54,474 \\
79,484 \\
64.468 \\
1,814\end{array}$ & $\begin{array}{r}15 \% \\
22 \% \\
18 \% \\
0 \%\end{array}$ \\
\hline $\begin{array}{l}\text { TCTAI FINAI } \\
\text { DEXAND SECICRS }\end{array}$ & 19,933 & $3,5 \in 2$ & 49,796 & 27,074 & - & 34,377 & $19,3 \in 1$ & 46,137 & 200,240 & $55 \%$ \\
\hline $\begin{array}{l}\text { TRANSPCRMATICN } \\
\text { ELECTRICITY GEN. } \\
\text { PETROLEOM ERCLOCTS } \\
\text { HATURAL GAS } \\
\text { SY NTETICS }\end{array}$ & $\begin{array}{r}4,313 \\
- \\
- \\
-\end{array}$ & $\begin{array}{l}- \\
\overline{-} \\
-\end{array}$ & $\begin{array}{l}- \\
- \\
-\end{array}$ & $\begin{array}{l}- \\
\overline{-} \\
-\end{array}$ & $\dot{-}$ & $\begin{array}{r}661 \\
- \\
- \\
-\end{array}$ & $\begin{array}{r}223,610 \\
- \\
-\end{array}$ & $\begin{array}{r}-71,237 \\
- \\
-\end{array}$ & $\begin{array}{r}157,352 \\
- \\
-\end{array}$ & 439 \\
\hline $\begin{array}{l}\text { NET FOEL OSEL } \\
\text { IN TRANSFEMATIOU }\end{array}$ & 4,318 & - & - & - & - & 661 & 223,610 & $-71,237$ & 157.352 & $43 \%$ \\
\hline $\begin{array}{l}\text { TCEAL GROSS FLCWS } \\
\text { LCSSES \& CMISSIONS }\end{array}$ & $\begin{array}{r}24,251 \\
1,509\end{array}$ & $\begin{array}{r}3.562 \\
0\end{array}$ & $\begin{array}{r}49,796 \\
0\end{array}$ & $\begin{array}{l}27,074 \\
-1,067\end{array}$ & $\begin{array}{l}- \\
-\end{array}$ & $\begin{array}{r}35,038 \\
-946\end{array}$ & $\begin{array}{r}242,971 \\
3,288\end{array}$ & $\begin{array}{r}46,137 \\
3,828\end{array}$ & $\begin{array}{r}357,592 \\
6,612\end{array}$ & $\begin{array}{r}98 \% \\
2 \%\end{array}$ \\
\hline TCEAL NET OSAGE & 25,760 & 3,562 & 49,796 & $2 \epsilon, 006$ & - & 34.091 & $24 \epsilon, 259$ & $-21,271$ & 364,204 & \\
\hline $\begin{array}{l}\text { SOFPLY OF ENERGY } \\
\text { IOSS IL FOEI } \\
\text { FY DRCELECTEIC } \\
\text { FOCL EAR } \\
\text { GEO.ESOLAZ }\end{array}$ & $\begin{array}{l}- \\
\overline{-}\end{array}$ & $\begin{array}{l}- \\
-\end{array}$ & $\begin{array}{l}- \\
-\end{array}$ & $\begin{array}{l}\overline{-} \\
\overline{-}\end{array}$ & $\begin{array}{l}- \\
\\
-\end{array}$ & $\begin{array}{l}- \\
- \\
-\end{array}$ & $\begin{array}{r}176 \\
- \\
-\end{array}$ & $\begin{array}{r}\overline{-} \\
\overline{8}\end{array}$ & $\begin{array}{r}176 \\
4,686 \\
-8\end{array}$ & $\begin{array}{r}4 \% \\
9 \in q\end{array}$ \\
\hline CTAL SOPPIY & - & - & - & - & - & - & 176 & 4,694 & 4,870 & \\
\hline
\end{tabular}

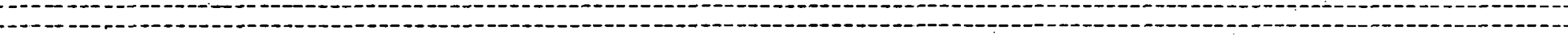

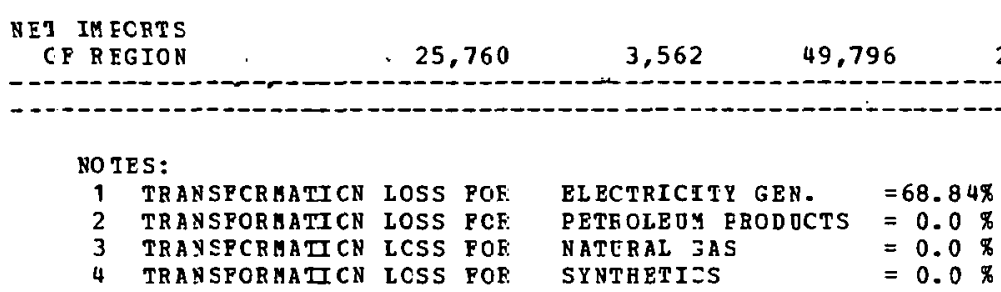


REG ZCNA
PIE: ENE YGGY BID MID. SCENARIO

\begin{tabular}{|c|c|c|c|c|c|c|c|c|c|c|}
\hline SECTOR & $\begin{array}{l}\text { DISTILLATE } \\
\text { OIL }\end{array}$ & $\begin{array}{l}\text { RESIDJTAL } \\
\text { OIL }\end{array}$ & $\begin{array}{l}\text { GASOL } \approx N B \\
\text { (AL } \approx N C ?\end{array}$ & $\begin{array}{l}\text { OSHER } \\
\text { HYDRO- } \\
\text { ARBONS } \\
\text { S IR } 10 * 9\end{array}$ & $\begin{array}{c}\text { CRICE } \\
\text { OIL } \\
\text { BTO'SI }\end{array}$ & $\begin{array}{l}\text { NATORAL } \\
\text { GAS }\end{array}$ & $\operatorname{cosin}$ & ELECTRICITY & $\begin{array}{r}\text { SECTOR } \\
\text { TOTAL }\end{array}$ & \\
\hline $\begin{array}{l}\text { FINAL CEHANC SECTORS } \\
\text { RESIDERTIAL,CCMA. } \\
\text { INDOSTRIAL } \\
\text { TRANSPORTATICN } \\
\text { MISCELLANECES OSES }\end{array}$ & $\begin{array}{r}10,483 \\
8,587 \\
16,070 \\
1,299\end{array}$ & $\begin{array}{r}896 \\
8,947 \\
25 \\
344\end{array}$ & $\begin{array}{r}\overline{-} \\
87,516 \\
-\end{array}$ & $\begin{array}{r}17,240 \\
30,452 \\
\Xi, 223 \\
39\end{array}$ & $\begin{array}{l}- \\
\overline{-}\end{array}$ & $\begin{array}{r}41,856 \\
27,336 \\
1,212 \\
347\end{array}$ & $\begin{array}{r}33 \\
21,320 \\
1 \\
-\end{array}$ & $\begin{array}{r}24,199 \\
18,955 \\
\times \quad 10 \\
194\end{array}$ & $\begin{array}{r}94,707 \\
116,097 \\
110,057 \\
2,223\end{array}$ & $\begin{array}{l}24 \% \\
30 \% \\
28 \% \\
1 \%\end{array}$ \\
\hline $\begin{array}{l}\text { TCTAL FINAL } \\
\text { DEMAND SEETCRS }\end{array}$ & 36,439 & 10,212 & 87,516 & 52,954 & - & $70,7 \leq 1$ & 21,354 & 43,358 & 323,084 & $83 \%$ \\
\hline $\begin{array}{l}\text { TA ANSFCRAATICN } \\
\text { ELECTRICIT GEN. } \\
\text { FETROLEO ERCDUCTS } \\
\text { NATORAL GAS } \\
\text { SYRTEETICS. }\end{array}$ & $\begin{array}{r}1,759 \\
-26,114 \\
- \\
-\end{array}$ & $\begin{array}{r}-10,459 \\
- \\
-\end{array}$ & $\begin{array}{r}- \\
-53,776 \\
-\end{array}$ & $\begin{array}{r}-23,607 \\
\cdot-\end{array}$ & $\begin{array}{r}- \\
112,115 \\
-\end{array}$ & $\begin{array}{r}9,6 \in 1 \\
2,4 \subseteq 1 \\
= \\
-.\end{array}$ & $\begin{array}{r}67,357 \\
- \\
- \\
-\end{array}$ & $\begin{array}{r}-20,597 \\
- \\
-\end{array}$ & $\begin{array}{r}58,680 \\
710 \\
- \\
-\end{array}$ & $\begin{array}{r}15 \% \\
0 \%\end{array}$ \\
\hline $\begin{array}{l}\text { NET FOEL OSEE } \\
\text { IN TRANSOEMATIOY }\end{array}$ & $-24,355$ & $-10,459$ & $-53,716$ & $-23,607$ & 112,115 & 12,152 & 67,857 & $-20,597$ & 59,390 & $15 \%$ \\
\hline $\begin{array}{l}\text { TCTAL GROSS FLCRS } \\
\text { LCSSZS } E \text { OUIESIONS }\end{array}$ & $\begin{array}{r}38,198 \\
2,377\end{array}$ & $\begin{array}{r}: 0,212 \\
0\end{array}$ & $\begin{array}{r}87,516 \\
0\end{array}$ & $\begin{array}{l}52,954 \\
-2,088\end{array}$ & $\begin{array}{r}112,115 \\
4,651\end{array}$ & $\begin{array}{l}82,903 \\
-2,240\end{array}$ & $\begin{array}{r}89,711 \\
1,2<14\end{array}$ & $\begin{array}{r}43,358 \\
3,597\end{array}$ & $\begin{array}{r}382,474 \\
7,512\end{array}$ & $\begin{array}{r}98 \% \\
2 \pi\end{array}$ \\
\hline $\begin{array}{l}\text { S OFPLY OP ENERGY } \\
\text { FOSS IL FOEL } \\
\text { HYDROELECIFIC } \\
\text { NDCLEAR } \\
\text { GEC. ESOLAE }\end{array}$ & $\begin{array}{l}\overline{-} \\
\overline{-}\end{array}$ & $\begin{array}{l}- \\
\overline{-}\end{array}$ & $\begin{array}{l}- \\
- \\
-\end{array}$ & $\begin{array}{l}- \\
- \\
-\end{array}$ & $\begin{array}{r}6,420 \\
- \\
-\end{array}$ & $\begin{array}{r}311 \\
- \\
-\end{array}$ & $\begin{array}{r}78.015 \\
- \\
-\end{array}$ & $\begin{array}{r}- \\
11,124 \\
265 \\
138\end{array}$ & $\begin{array}{r}85,34 \epsilon \\
11,124 \\
265 \\
13 \varepsilon\end{array}$ & $\begin{array}{r}88 \% \\
11 \% \\
0 \% \\
0 \%\end{array}$ \\
\hline TCTAL SOPPIY & - & - & - & - & 6,420 & 911 & 78,015 & 11,527 & 96,873 & \\
\hline
\end{tabular}

NET IM PORTS
OF REGION
NOTES:


REGIONAL ENEFGY EALANCE STATEMENT
PIES MID MID SCENARIO

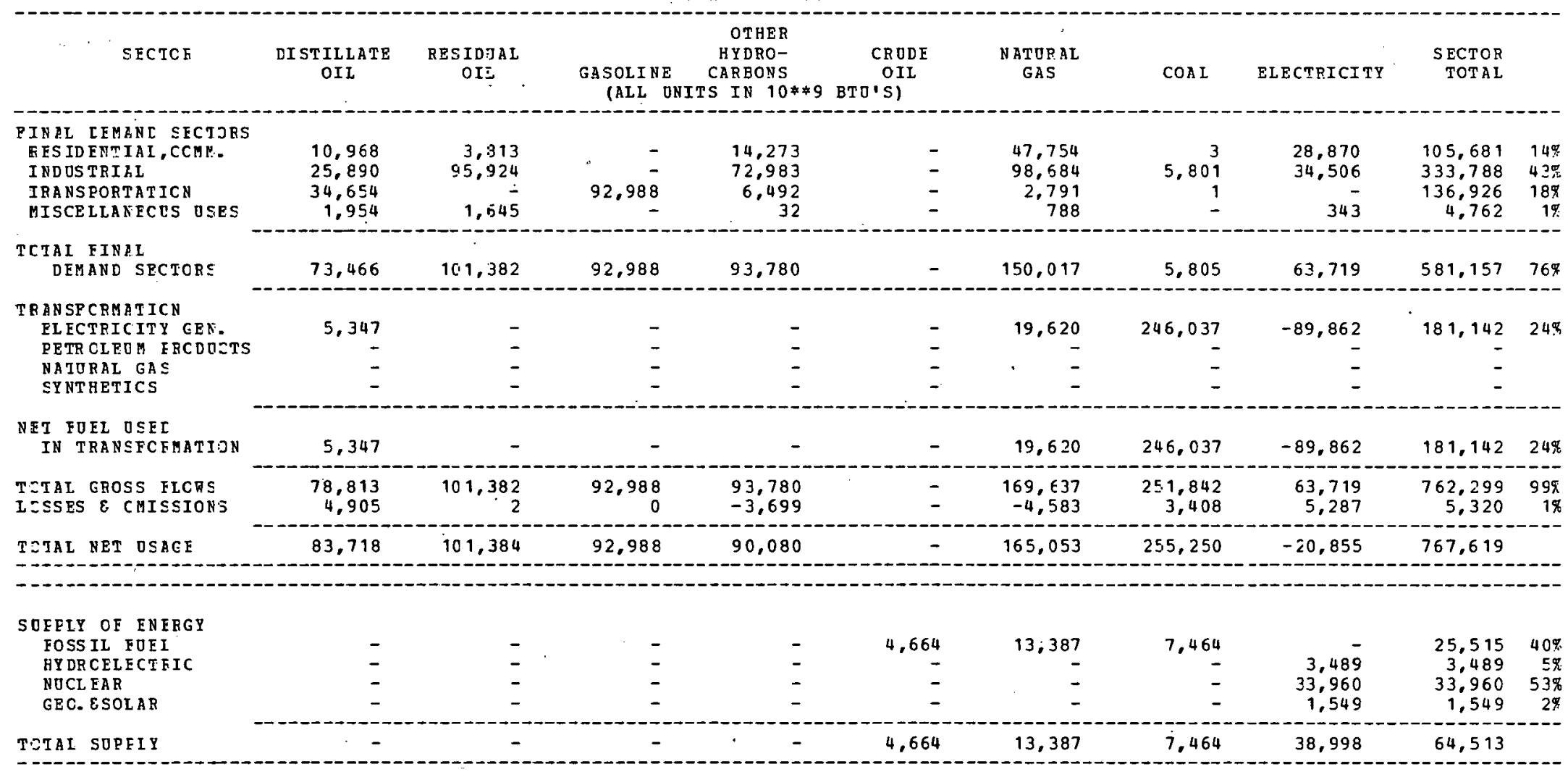

\section{$N$ ET IM FORTS}

OF

83,718

101.384

92,988

90,080

$-4,664$

151,666

247,786

$-59,853$

\begin{tabular}{|c|c|c|c|c|c|}
\hline \\
\hline 1 & TRANSFCRMATICN & LOSS & & ELECTRICITY GEN. & $=66.84 \%$ \\
\hline 2 & TRANSFCRMATICN & Loss & FCR & PETRCLEOM PRODOCTS & $0.0 \%$ \\
\hline 3 & TRANSPCRAATI CN & LCSS & FOR & NATORAR GAS & $0.0 \%$ \\
\hline 4 & TRANSFORMATI CN & LCSS & FOR & SYNTHETICS & $=0.0$ \\
\hline
\end{tabular}


REGIONAL ENZFGY EAIANCE STATEMENT

PIES MI $\supset$ AID SCENARIO

\begin{tabular}{|c|c|c|c|c|c|c|c|c|c|}
\hline SECTOR & $\begin{array}{c}\text { DIST.CLLATE } \\
\text { DIL }\end{array}$ & $\begin{array}{l}\text { RESIDUAL } \\
\text { OLL }\end{array}$ & $\begin{array}{l}\text { GASOLIDE } \\
\text { (ALL O }\end{array}$ & $\begin{array}{l}\text { DTFER } \\
\text { BYDEO- } \\
\text { CA BBONS } \\
\text { IS IN } 10 * \$ 9\end{array}$ & $\begin{array}{c}\text { CRODE } \\
\text { OIL } \\
\text { BTO'S) }\end{array}$ & $\begin{array}{l}\text { NATORAC } \\
\text { GAS }\end{array}$ & $\operatorname{COA} \mathbf{3}$ & EIECTRICITY & $\begin{aligned} \text { SECTOR } \\
\text { TOTAL }\end{aligned}$ \\
\hline $\begin{array}{l}\text { PINIL CFMANL SFCTORS } \\
\text { RESIDENTIAL,CCMM. } \\
\text { INDOSTRIAL } \\
\text { TRANSPORTATICN } \\
\text { MISCELLANECE OSES }\end{array}$ & $\begin{array}{r}4.779 \\
4,693 \\
1.056 \\
1,494\end{array}$ & $\begin{array}{r}1,509 \\
15,7.33 \\
1,258\end{array}$ & 45,419 & $\begin{array}{r}6,636 \\
3,180 \\
5,501 \\
, \quad 22\end{array}$ & $\begin{array}{l}- \\
- \\
-\end{array}$ & $\begin{array}{r}23,911 \\
21,284 \\
2,521 \\
492\end{array}$ & $\begin{array}{r}2 \\
819 \\
-\end{array}$ & $\begin{array}{r}14,640 \\
4,373 \\
24 \overline{1}\end{array}$ & $\begin{array}{r}51,477 \\
50,262 \\
64,497 \\
3,507\end{array}$ \\
\hline $\begin{array}{l}\text { TCTAI FINAI } \\
\text { DEMAND SECTCRS }\end{array}$ & 22,022 & 18,550 & 45,419 & 15.339 & - & 48,308 & 851 & 19,254 & 169,743 \\
\hline $\begin{array}{l}\text { TEANSFCRMATICS } \\
\text { ELECTRICITY GEN. } \\
\text { FETRCLEUM FSCLOCTS } \\
\text { NATURAL GAS } \\
\text { SYNTHETICS }\end{array}$ & $\begin{array}{r}1,616 \\
- \\
-\end{array}$ & $\begin{array}{l}- \\
\overline{-}\end{array}$ & $\begin{array}{l}- \\
-\end{array}$ & $\begin{array}{l}- \\
- \\
-\end{array}$ & $\begin{array}{l}- \\
- \\
-\end{array}$ & $\begin{array}{r}1,388 \\
- \\
-\end{array}$ & $\begin{array}{r}4,6: 2 \\
- \\
-\end{array}$ & $\begin{array}{r}-2,571 \\
- \\
-\end{array}$ & $\begin{array}{r}5,125 \\
- \\
-\end{array}$ \\
\hline $\begin{array}{l}\text { NET FOEL OSEL } \\
\text { IN TRANSFOF }\end{array}$ & $1,61 \epsilon$ & - & - & - & - & $1,3 \varepsilon 8$ & $4,6] 2$ & $-2,571$ & 5,125 \\
\hline $\begin{array}{l}\text { TCTAL GROSS FLCRS } \\
\text { LCSSES E OMISEIONS }\end{array}$ & $\begin{array}{r}23,638 \\
1,471\end{array}$ & $\begin{array}{r}13,55 \mathrm{C} \\
0\end{array}$ & $\begin{array}{r}45,419 \\
0\end{array}$ & $\begin{array}{r}15.339 \\
-605\end{array}$ & - & $\begin{array}{l}49,6 \subseteq 6 \\
-1,342\end{array}$ & $5,5+3$ & $\begin{array}{r}19,254 \\
1,597\end{array}$ & $\begin{array}{r}174,868 \\
1,196\end{array}$ \\
\hline TCTAL NET OSAEE & 25,109 & $1.3,550$ & 45,417 & 14,733 & - & $48,3 \leq 3$ & 5,613 & 18,280 & 176,064 \\
\hline $\begin{array}{l}\text { SOEPLY CF ENEEGY } \\
\text { FOSSIL FUEI } \\
\text { HYDFCELECTEJC } \\
\text { NOCLEAR } \\
\text { GEC. ESOLAR }\end{array}$ & $\begin{array}{l}\overline{-} \\
\overline{-} \\
-\end{array}$ & $\begin{array}{l}\overline{-} \\
\overline{-}\end{array}$ & $\begin{array}{l}- \\
- \\
-\end{array}$ & $\begin{array}{l}- \\
\overline{-}\end{array}$ & $\begin{array}{r}45,374 \\
= \\
-\end{array}$ & $\begin{array}{r}214,048 \\
- \\
-\end{array}$ & $\begin{array}{r}33,8 \geq 3 \\
= \\
=\end{array}$ & $\begin{array}{r}5,691 \\
894 \\
467\end{array}$ & $\begin{array}{r}293,251 \\
5,691 \\
894 \\
467\end{array}$ \\
\hline PCTAI SOPEIY & - & - & - & - & 45,374 & $294,048:$ & 33,827 & 7,052 & $\Xi 00,303$ \\
\hline
\end{tabular}

\begin{tabular}{|c|c|c|c|c|c|c|c|c|c|}
\hline $\begin{array}{l}\text { MET IM FORTS } \\
\text { CP PEGION }\end{array}$ & 25,109 & $1 E, 550$ & 45,419 & 14,733 & $-45,374$ & $-165,694$ & $-28,210$ & 11,228 & $-124,238$ \\
\hline
\end{tabular}

\begin{tabular}{|c|c|c|c|c|}
\hline TRANSTCRMATICH & $\begin{aligned} 20=8 \\
10=0\end{aligned}$ & res & CLECIRICITY GZN. & $=66.5$ \\
\hline TR A N STCR A A TI CN & $\mathrm{L} C \equiv \mathrm{S}$ & FOR & BATUEAL GAS & 0.0 \\
\hline TR A N SPCRMATICN & $I C \equiv S$ & FOR & SYNTEETICS & 0.0 \\
\hline
\end{tabular}


REGICNAL ENEFGY EALANCE STATEHENT
PIES MID MID SCENARIO

\begin{tabular}{|c|c|c|c|c|c|c|c|c|c|c|}
\hline SECTOF & $\begin{array}{l}\text { DISTILLATE } \\
\text { OOL }\end{array}$ & $\begin{array}{l}\text { RESI IJKL } \\
\text { OIL }\end{array}$ & $\begin{array}{l}\text { GASOLINE } \\
\text { (ALL ONI? }\end{array}$ & $\begin{array}{c}\text { OTHER } \\
\text { HYDRO- } \\
\text { CARBONS } \\
\text { TS IN } 10 * \$ 9\end{array}$ & $\begin{array}{c}\text { CRODE } \\
\text { OIL } \\
\text { BTU'S) }\end{array}$ & $\begin{array}{l}\text { NATURAL } \\
\text { GAS }\end{array}$ & $\operatorname{COAL}$ & ELECTRICITY & $\begin{array}{r}\text { SECTOR } \\
\text { TOTAL }\end{array}$ & \\
\hline $\begin{array}{l}\text { FIRAL LEMANI SECTOSS } \\
\text { RESIDENTIAL, CCHM. } \\
\text { INDOSTRIAL } \\
\text { TBANSPORTATICN } \\
\text { MISCELIANECOS OSPS }\end{array}$ & $\begin{array}{r}8,257 \\
10.913 \\
19,275 \\
1,459\end{array}$ & $\begin{array}{r}1,332 \\
38,003 \\
1,227\end{array}$ & $\begin{array}{r}\overline{-} \\
\overline{-} \\
-\end{array}$ & $\begin{array}{r}14,796 \\
122,398 \\
12,247 \\
21\end{array}$ & $\begin{array}{l}- \\
-\end{array}$ & $\begin{array}{r}54,386 \\
348,814 \\
5,725 \\
486\end{array}$ & $\begin{array}{r}3 \\
6.057 \\
- \\
-\end{array}$ & $\begin{array}{r}31,655 \\
27,553 \\
- \\
240\end{array}$ & $\begin{array}{r}110,429 \\
553,738 \\
144,461 \\
3,433\end{array}$ & $\begin{array}{r}12 \% \\
61 \% \\
16 \% \\
0 \%\end{array}$ \\
\hline $\begin{array}{l}\text { TCIAI FINAI } \\
\text { IEMAND SECTCRS }\end{array}$ & 39,904 & $40,5 \in 2$ & 107,214 & 149,462 & - & 409,411 & 6.060 & 59.448 & 812,061 & $89 \%$ \\
\hline $\begin{array}{l}\text { TR ANSFCRMATICN } \\
\text { ELECTRICITY GEN. } \\
\text { PETR OLETM ERCDOCTS } \\
\text { AATORAL GAS } \\
\text { SYNTHETICS }\end{array}$ & $\begin{array}{r}4,989 \\
-168,547 \\
-\end{array}$ & $\begin{array}{r}-67,5 c 9 \\
- \\
-\end{array}$ & $\begin{array}{r}-346,70 \overline{1} \\
- \\
-\end{array}$ & $\begin{array}{r}-152,371 \\
- \\
-\end{array}$ & $\begin{array}{r}723,634 \\
-142,128\end{array}$ & $\begin{array}{r}55,424 \\
16,079 \\
- \\
-\end{array}$ & $\begin{array}{r}264.665 \\
- \\
- \\
-\end{array}$ & $\begin{array}{r}-107,603 \\
- \\
-\end{array}$ & $\begin{array}{r}217,475 \\
4,585 \\
- \\
-142,128\end{array}$ & $\begin{array}{r}24 \% \\
1 \% \\
-15 \%\end{array}$ \\
\hline $\begin{array}{l}\text { NET FUEL OSFL } \\
\text { IN TRANSOFATIOD }\end{array}$ & $-163,558$ & $-67,509$ & $-346,701$ & $-152,371$ & 581,506 & 71,503 & 264,665 & $-107,603$ & 79,932 & $9 \%$ \\
\hline $\begin{array}{l}\text { TCEAL GROSS FLCRS } \\
\text { LCSSES \& CUISSIONS }\end{array}$ & $\begin{array}{r}44.893 \\
2,794\end{array}$ & $\begin{array}{r}40,562 \\
0\end{array}$ & $\begin{array}{r}107,214 \\
.0\end{array}$ & $\begin{array}{r}149,462 \\
-5,895\end{array}$ & $\begin{array}{r}723,634 \\
30,020\end{array}$ & $\begin{array}{l}480,914 \\
-12,995\end{array}$ & $\begin{array}{r}270,725 \\
3,664\end{array}$ & $\begin{array}{r}59,448 \\
4,932\end{array}$ & $\begin{array}{r}1,034,121 \\
22,522\end{array}$ & $\begin{array}{r}113 \% \\
2 \%\end{array}$ \\
\hline
\end{tabular}

\begin{tabular}{|c|c|c|c|c|c|c|c|c|c|c|}
\hline SOFELY OP ENERGY & & & & & & & & & & \\
\hline TOSSIL FOEI & - & - & - & - & 80,627 & 7,902 & 46,638 & - & 135,167 & 728 \\
\hline EY DR OELECT FIC & - & - & - & - & - - & - & - & 6,436 & 6,436 & $3 \%$ \\
\hline NUCLEAR & - & - & - & - & - & - & - & 45,035 & 45,035 & $24 \%$ \\
\hline GEC. \&SOLAR & - & - & - & - & - & - & - & 1,445 & 1,445 & $1 \%$ \\
\hline TCIAI SUPPIY & - & - & - & - & $80, \in 27$ & 7,902 & 46,638 & 52,916 & 188,083 & \\
\hline
\end{tabular}

-

\begin{tabular}{|c|c|c|c|c|c|c|c|c|c|}
\hline CPREGION & $-120,859$ & $-26,945$ & $-239,486$ & $-8,804$ & 530,899 & 460.017 & 227,751 & $-96,138$ & 726,432 \\
\hline
\end{tabular}

NOTES:

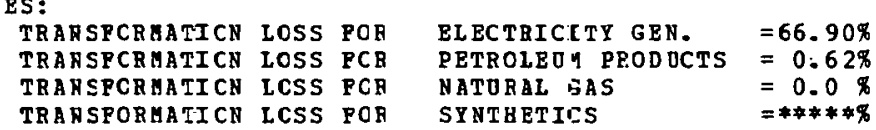

3 TRARSPCRMATICN LCSS PCA NATURAL SAS 
REGICNAL ENEFG FALANCE STATEMENT.
PIES MID HID SCENARIO

\begin{tabular}{|c|c|c|c|c|c|c|c|c|c|c|}
\hline SECTOE & $\begin{array}{c}\text { DISTHLATB } \\
\text { OII }\end{array}$ & $\begin{array}{l}\text { EESIJUAL } \\
\text { OIL }\end{array}$ & $\begin{array}{l}\text { CASOLI HE } \\
\text { (ALL DAIT }\end{array}$ & $\begin{array}{c}\text { CTHER } \\
\text { HYDR:- } \\
\text { CAEEO:S } \\
\text { TS IN } 0 * * 9\end{array}$ & $\begin{array}{c}\text { CRODE } \\
\text { OIL } \\
\text { BTO'SI }\end{array}$ & $\begin{array}{l}\text { NATURAI } \\
\text { GAS }\end{array}$ & $2 O A L$ & ELECTRICITY & $\begin{array}{r}\text { SECTOR } \\
\text { TOTAL }\end{array}$ & \\
\hline 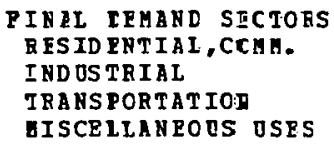 & $\begin{array}{r}\equiv, 946 \\
\equiv, 6 \notin 7 \\
27.8 .19 \\
5.028\end{array}$ & $\begin{array}{r}1,163 \\
20,063 \\
- \\
4.231\end{array}$ & 023,395 & $\begin{array}{r}16,781 \\
43,023 \\
5,442 \\
78\end{array}$ & $\begin{array}{l}\overline{-} \\
\overline{-}\end{array}$ & $\begin{array}{r}6 \Xi, 094 \\
269,306 \\
2,378 \\
1,761\end{array}$ & $\begin{array}{r}4 \\
2,978 \\
- \\
-\end{array}$ & $\begin{array}{r}37,122 \\
15,397 \\
- \\
881\end{array}$ & $\begin{array}{r}127,110 \\
356,454 \\
159,034 \\
11,979\end{array}$ & $\begin{array}{r}17 \% \\
43 \% \\
22 \% \\
2 \%\end{array}$ \\
\hline $\begin{array}{l}\text { TCTAL PINAI } \\
\text { DEMAND SECTCRS }\end{array}$ & $4 \pi, 4 \notin 0$ & 25,457 & 123,395 & 65,324 & - & 336,539 & 2,982 & 53,400 & 654,577 & 8998 \\
\hline $\begin{array}{l}\text { TRANSP ORAATICN } \\
\text { ELECTRICITY GRN. } \\
\text { PETROLEOH FRODOCTS } \\
\text { NATORAL GAS } \\
\text { SYNTHETICS }\end{array}$ & $\begin{array}{r}4,482 \\
-112,893 \\
-\end{array}$ & $\begin{array}{r}- \\
-45,218 \\
-\end{array}$ & $\begin{array}{r}-232,22 \bar{z} \\
\overline{-}\end{array}$ & $\begin{array}{r}-102,059 \\
-\end{array}$ & $\begin{array}{r}- \\
484.693 \\
-\end{array}$ & $\begin{array}{r}79,923 \\
10,770 \\
- \\
-\end{array}$ & $\begin{array}{r}13,013 \\
- \\
-\end{array}$ & $\begin{array}{r}-31,593 \\
- \\
-\end{array}$ & $\begin{array}{r}65,825 \\
3,071 \\
-\end{array}$ & $\begin{array}{l}9 \% \\
0 \%\end{array}$ \\
\hline $\begin{array}{l}\text { NET FOEL OSFL } \\
\text { IN TRANSPOERATION }\end{array}$ & $-10 \varepsilon, 411$ & $-45,218$ & $-232,22 \pi$ & $-102, .059$ & 484.693 & 90,693 & 13.013 & $-31,593$ & 68,896 & $9 \%$ \\
\hline $\begin{array}{l}\text { TETAL GROSS IIORS } \\
\text { LOSSES \& CMISSIONS }\end{array}$ & $\begin{array}{r}5:, 952 \\
j, 234\end{array}$ & $\begin{array}{r}25,457 \\
0\end{array}$ & $123,39 \frac{5}{C}$ & $\begin{array}{r}65.324 \\
-2.576\end{array}$ & $\begin{array}{r}484.693 \\
20.107\end{array}$ & $\begin{array}{r}427,232 \\
-11,544\end{array}$ & $\begin{array}{r}15,995 \\
21 \epsilon\end{array}$ & $\begin{array}{r}53,400 \\
4,430\end{array}$ & $\begin{array}{r}723,473 \\
13,868\end{array}$ & $\begin{aligned} \subseteq 2 \% \\
2 \%\end{aligned}$ \\
\hline
\end{tabular}

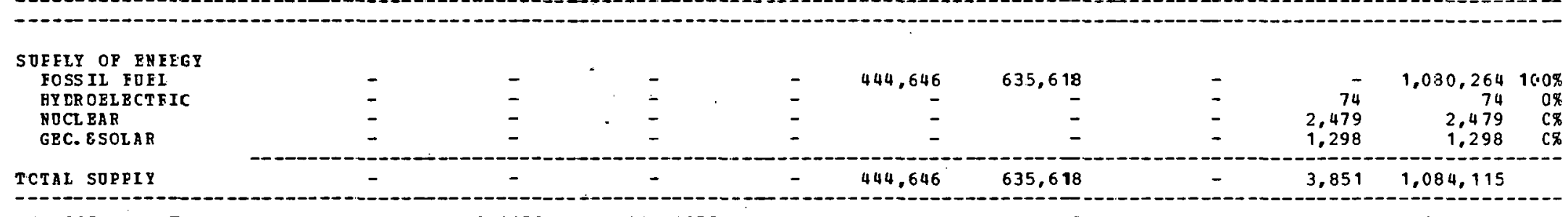

\section{NET II FORTS}

OF REGTON

$-57,696$

$-19,760 \quad-108,826$

$-39.311$

60.154

16,211

22.386

$-346,772$

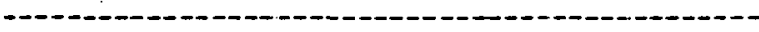

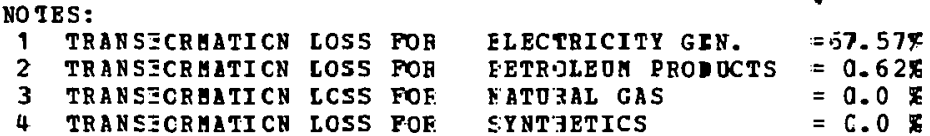


REGIONAL ENERGY EALANCE STATEMENT
PIES MID MI D SCENARIO

\begin{tabular}{|c|c|c|c|c|c|c|c|c|c|c|}
\hline SECTOE & $\begin{array}{l}\text { DISTILLATE } \\
\text { OIL }\end{array}$ & $\begin{array}{l}\text { RESIDUAL } \\
\text { OII }\end{array}$ & $\begin{array}{l}\text { GASOLINE } \\
\text { (ALL ON }\end{array}$ & $\begin{array}{l}\text { OTHER } \\
\text { HYDRO- } \\
\text { CAREONS } \\
\text { IS IN } 10 * \%\end{array}$ & $\begin{array}{c}\text { CREDE } \\
\text { OIL } \\
\text { BTO'S) }\end{array}$ & $\begin{array}{l}\text { NATORAL } \\
\text { GAS }\end{array}$ & COAI & ELECTRICITY & $\begin{array}{r}\text { SECTOR } \\
\text { TOTAL }\end{array}$ & \\
\hline $\begin{array}{l}\text { PINAL LEMANC SECTORS } \\
\text { EFSIDENTIAI, CCMM. } \\
\text { INDOSTRIAE } \\
\text { IRANSPORTATICN } \\
\text { UISCELIANECOS OSES }\end{array}$ & $\begin{array}{l}2,366 \\
2,572 \\
2,625 \\
1,245\end{array}$ & $\begin{array}{r}269 \\
8,494 \\
780 \\
1,048\end{array}$ & $\begin{array}{r}- \\
- \\
36,629 \\
-\end{array}$ & $\begin{array}{r}4,987 \\
9,325 \\
1,596 \\
45\end{array}$ & $\begin{array}{l}- \\
- \\
-\end{array}$ & $\begin{array}{r}15,251 \\
118,222 \\
513 \\
1,177\end{array}$ & $\begin{array}{r}1 \\
1,879 \\
-\end{array}$ & $\begin{array}{r}9,292 \\
10,002 \\
- \\
676\end{array}$ & $\begin{array}{r}32,166 \\
150,494 \\
42,143 \\
4,191\end{array}$ & $\begin{array}{r}12 \% \\
58 \% \\
16 \% \\
2 \%\end{array}$ \\
\hline $\begin{array}{l}\text { TCTAI FINAI } \\
\text { DEMAND SECTCRS }\end{array}$ & 8,808 & 10,591 & 36,629 & 15,953 & - & 135,163 & 1,880 & 19,970 & 228,994 & $89 \%$ \\
\hline $\begin{array}{l}\text { TEANSPCRMATICN } \\
\text { FLECTRICITY GEN. } \\
\text { PETROLEOM ERCDOCTS } \\
\text { NATORAL GAS } \\
\text { STNTBETICS }\end{array}$ & $\begin{array}{r}1,707 \\
-31,860 \\
- \\
-\end{array}$ & $\begin{array}{r}-12.717 \\
-\end{array}$ & $\begin{array}{r}-65,483 \\
-\end{array}$ & $\begin{array}{r}-28,911 \\
-\end{array}$ & $\begin{array}{r}136.765 \\
- \\
-\end{array}$ & $\begin{array}{r}31,632 \\
3,075 \\
- \\
-\end{array}$ & $\begin{array}{r}4,866^{\circ} \\
- \\
-\end{array}$ & $\begin{array}{r}-12,245 \\
- \\
- \\
-\end{array}$ & $\begin{array}{r}25,960 \\
868 \\
- \\
-\end{array}$ & $\begin{array}{r}10 \% \\
0 \%\end{array}$ \\
\hline $\begin{array}{l}\text { VET FOFL OSER } \\
\text { IN TRANSPOFMATION }\end{array}$ & $-30,153$ & $-12, .717$ & $-65,483$ & $-28,911$ & 136,765 & 34,707 & 4,866 & $-12,245$ & 26,828 & $10 \%$ \\
\hline $\begin{array}{l}\text { TCTAL GROSS FLCRS } \\
\text { LCSSES \& CMISSIONS }\end{array}$ & $\begin{array}{r}10.515 \\
654\end{array}$ & $\begin{array}{r}10,591 \\
0\end{array}$ & $\begin{array}{r}36,629 \\
0\end{array}$ & $\begin{array}{r}15,953 \\
-629\end{array}$ & $\begin{array}{r}136,765 \\
5,673\end{array}$ & $\begin{array}{r}169,870 \\
-4,590\end{array}$ & $\begin{array}{r}6,746 \\
91\end{array}$ & $\begin{array}{r}19,970 \\
1,656\end{array}$ & $\begin{array}{r}255,822 \\
2,857\end{array}$ & $\begin{array}{l}99 \% \\
1 \%\end{array}$ \\
\hline $\begin{array}{l}\text { SJEPLY OP ENFRGY } \\
\text { FOSS IL FOEI } \\
\text { HYDRCELECTEIC } \\
\text { NOCL BAR } \\
\text { GEO.ESOLAR }\end{array}$ & $\begin{array}{l}- \\
- \\
-\end{array}$ & $\begin{array}{l}- \\
- \\
-\end{array}$ & $\begin{array}{l}- \\
-\end{array}$ & I- & $\begin{array}{r}190,214 \\
= \\
-\end{array}$ & $\begin{array}{r}54,315 \\
= \\
-\end{array}$ & $\begin{array}{l}- \\
- \\
-\end{array}$ & $\begin{array}{r}25 \\
927 \\
485\end{array}$ & $\begin{array}{r}244,52 \mathrm{c} \\
28 \\
927 \\
485\end{array}$ & $\begin{array}{r}99 \% \\
0 \% \\
0 \% \\
0 \%\end{array}$ \\
\hline TニTAL SOPEIY & - & - & - & - & 190,214 & 54,315 & - & $1,440$. & 245,969 & \\
\hline
\end{tabular}

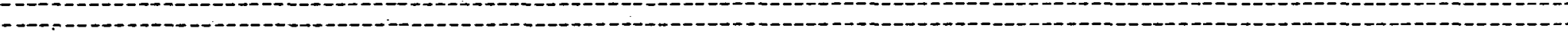

\section{NET IM FORTS}

OP RBGION

$-20,690$

$-13,587$

$-47,775$

110,965

$6,837.7,941$

12,711

NO IRS:
TRANSFCRMATICN LOSS FOR
TBANSPCRMATICN LOSS FOR
TRANSPCREATICN LOSS FOR
TBANSPOR DATICN LCSS FOR
ELBCTRECITY GEN.
THOLE PRODUCTS
SYNTHETICS

$=67.95 \%$
$=0.62 \%$
$=0.0 \%$
$=0.0 \%$


REGIONAL JNEEGT EALANCB STATEHENT

PIES IID MI D SCENARIC

\begin{tabular}{|c|c|c|c|c|c|c|c|c|c|c|}
\hline SECIOE & $\underset{\text { DIST }}{\substack{\text { DILIATZ } \\
\text { DIST }}}$ & $\begin{array}{l}\text { RESIDDAL } \\
\text { OIL }\end{array}$ & $\begin{array}{l}\text { GASOIINZ } \\
\text { (ALI JNI }\end{array}$ & $\begin{array}{c}\text { OTHER } \\
\text { HYDRO- } \\
\text { CARBONS } \\
\text { CS IN } 10 * * 5\end{array}$ & $\begin{array}{c}\text { CEOLE } \\
\text { CIL } \\
\text { BTO'SI }\end{array}$ & $\begin{array}{l}\text { NATUZBL } \\
\text { GAS }\end{array}$ & $\operatorname{COA} L$ & ELECTRICITY & $\begin{array}{l}\text { SECTOR } \\
\text { TOTAL }\end{array}$ & \\
\hline $\begin{array}{l}\text { PIRAL LEHANI SFCTORS } \\
\text { RESIDENTIAI, CCHA. } \\
\text { INDDSTRIAL } \\
\text { TRAYSPORTATION } \\
\text { UISCELIANECOS OSES }\end{array}$ & $\begin{array}{r}2.267 \\
3,430 \\
14.701 \\
373\end{array}$ & $\begin{array}{r}374 \\
11.123 \\
4.178 \\
314\end{array}$ & $\begin{array}{r}- \\
35,908 \\
-\end{array}$ & $\begin{array}{r}4,967 \\
33,197 \\
6,994 \\
8\end{array}$ & $\begin{array}{l}- \\
-\end{array}$ & $\begin{array}{r}13,587 \\
140,373 \\
1,313 \\
201\end{array}$ & $\begin{array}{r}- \\
1,751 \\
-\end{array}$ & $\begin{array}{r}10,167 \\
14,375 \\
= \\
103\end{array}$ & $\begin{array}{r}31,462 \\
204,749 \\
63,594 \\
999\end{array}$ & $\begin{array}{r}9 \% \\
57 \% \\
18 \% \\
0 \%\end{array}$ \\
\hline $\begin{array}{l}\text { TCTAI. FINAI } \\
\text { DZMAND SECTORS }\end{array}$ & 20,771 & 15.989 & 35,908 & 45,166 & - & $156,5 ? 4$ & 1,751 & 24,645 & 300,804 & $83 \%$ \\
\hline $\begin{array}{l}\text { TRANSPORHATICN } \\
\text { EL ZCTRICITY GEN. } \\
\text { PETROLEOA ERCDOCTS } \\
\text { RATURAL GAE } \\
\text { SY HTEETICS }\end{array}$ & $\begin{array}{r}2.069 \\
-74.896 \\
-\end{array}$ & $\begin{array}{r}-4,627 \\
- \\
-\end{array}$ & $\begin{array}{r}-123,530 \\
- \\
-\end{array}$ & $\begin{array}{r}-129,998 \\
- \\
-\end{array}$ & $\begin{array}{r}308,240 \\
- \\
-\end{array}$ & $\begin{array}{r}13,974 \\
27,587 \\
- \\
-\end{array}$ & $\begin{array}{r}56,483 \\
- \\
- \\
-\end{array}$ & $\begin{array}{r}-24,012 \\
- \\
-\end{array}$ & $\begin{array}{r}48,514 \\
2,876 \\
- \\
-\end{array}$ & $\begin{array}{r}139 \\
1 \%\end{array}$ \\
\hline $\begin{array}{l}\text { NET TOEL OSEE } \\
\text { IN TRANSFOEMATION }\end{array}$ & $-72,827$ & $-4,627$ & $-123,530$ & $-129,998$ & 308,240 & 41,661 & 56,483 & $-24,012$ & 51,390 & $14 \pi$ \\
\hline $\begin{array}{l}\text { TCTAL GROSS FLORS } \\
\text { LCSSES \& OHISSIONS }\end{array}$ & $\begin{array}{r}22.840 \\
1.421\end{array}$ & $\begin{array}{r}5,989 \\
0\end{array}$ & $\begin{array}{r}35,908 \\
0\end{array}$ & $\begin{array}{l}45,166 \\
-1,781\end{array}$ & $\begin{array}{r}308,240 \\
12,787\end{array}$ & $\begin{array}{r}198,235 \\
-5,356\end{array}$ & $\begin{array}{r}58,234 \\
788\end{array}$ & $\begin{array}{r}24,645 \\
2,044\end{array}$ & $\begin{array}{r}352,194 \\
. \quad 9,904\end{array}$ & $\begin{array}{r}975 \\
37\end{array}$ \\
\hline $\begin{array}{l}\text { SOFPLY OP PNERGI } \\
\text { FOSS IL FOEI. } \\
\text { RYDROFLPCTEIC } \\
\text { ROCL EAR } \\
\text { GEC. \&SOLAR }\end{array}$ & $\begin{array}{l}\overline{-} \\
\overline{-}\end{array}$ & $\begin{array}{l}- \\
-\end{array}$ & $\begin{array}{l}- \\
- \\
-\end{array}$ & $\begin{array}{l}\overline{-} \\
\overline{-} \\
-\end{array}$ & $\begin{array}{r}333,664 \\
- \\
-\end{array}$ & $\begin{array}{r}770,585 \\
- \\
- \\
-\end{array}$ & $\begin{array}{l}- \\
\text { - }\end{array}$ & $\begin{array}{r}- \\
35 \\
1,144 \\
599\end{array}$ & $\begin{array}{r}1,104,249 \\
35 \\
1,144 \\
599\end{array}$ & $\begin{array}{r}100 \% \\
0 \% \\
0 \% \\
0 \%\end{array}$ \\
\hline TOTAL SOPPIY & - & - & - & - & 333,664 & 770,585 & - & 1,778 & $1,106,027$ & \\
\hline
\end{tabular}

烈

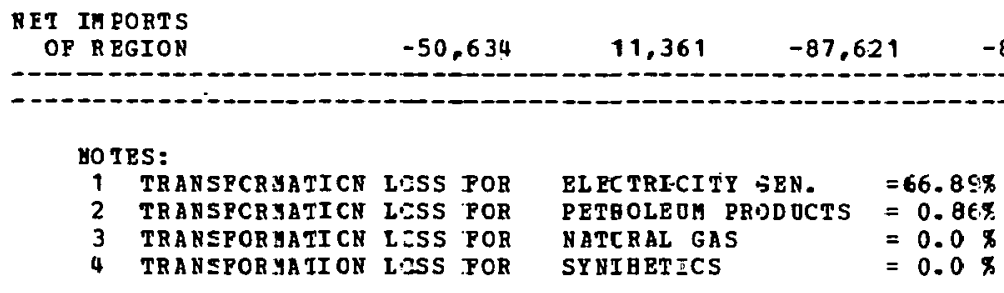


REGIONAL ENEFGY PALANCE STATEMENT

PIES MID MID SCENARIO

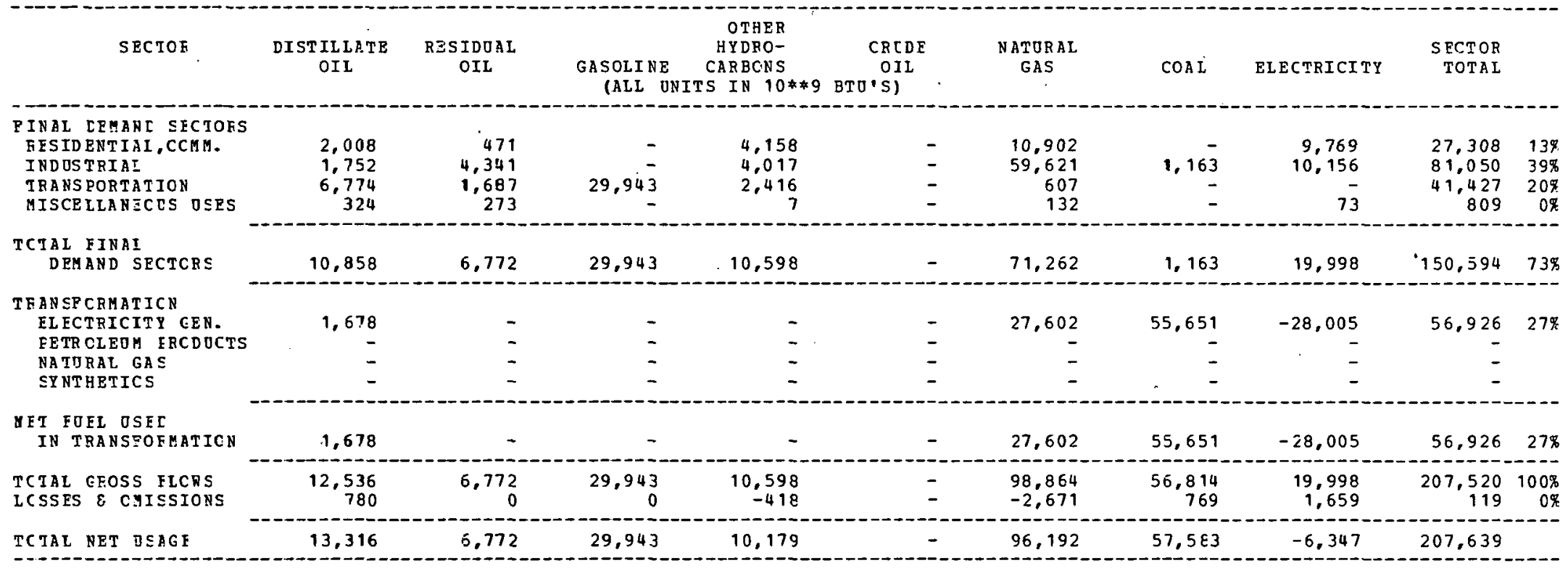

\begin{tabular}{|c|c|c|c|c|c|c|c|c|c|c|}
\hline $\begin{array}{l}\text { STEFLY OP ENERGY } \\
\text { FOSS IL FOEI }\end{array}$ & - & - & - & - & 577297 & $30 \cdot 1014$ & & & & \\
\hline HYDRCELECTEIC & - & - & - & - & 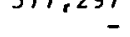 & 39,194 & - & 28 & $\begin{array}{r}616,491 \\
28\end{array}$ & $100 \%$ \\
\hline NOCL EAR & - & - & - & - & - & - & - & 928 & 928 & $0 \%$ \\
\hline GRO. ESOLAR & - & - & - & - & - & - & - & 486 & 486 & $0 \%$ \\
\hline
\end{tabular}

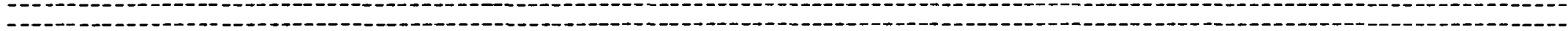

\begin{tabular}{l} 
NET IM FORTS \\
OF R EGION \\
\hline
\end{tabular}

NOIES:

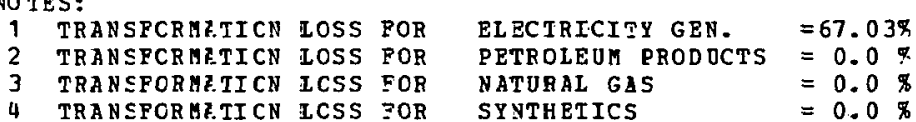


REGIDHAL ENEFFY EALANCE STATEMENT

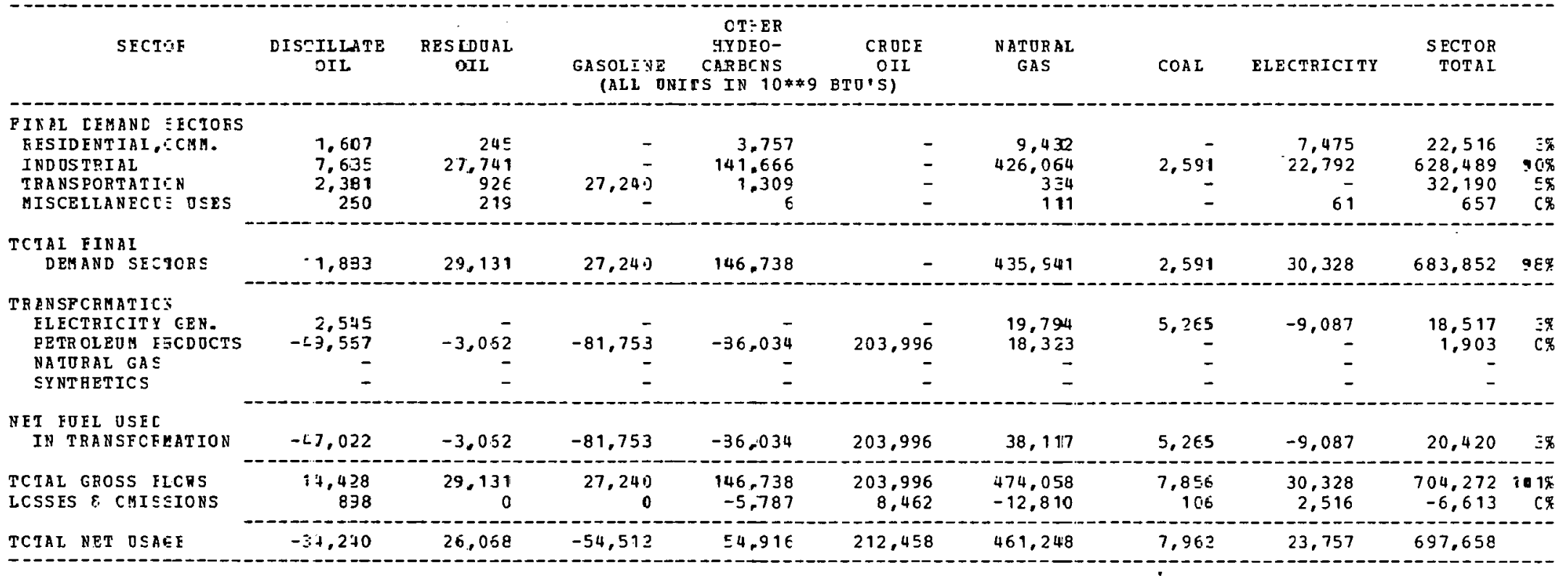

\begin{tabular}{|c|c|c|c|c|c|c|c|c|c|c|}
\hline $\begin{array}{l}\text { SOEFLY OF ENESEY } \\
\text { FOSS IL FUEI }\end{array}$ & - & - & - & - & $1,533,551$ & 963,600 & . & - & $2,497,151$ & $10 \mathrm{c} \%$ \\
\hline HY LR OELECTEIC & - & - & - & - & - & - & - & 42 & 42 & C9 \\
\hline NOCL EAR & - & - & - & - & - & - & - & 1,408 & 1,408 & C. \\
\hline GEC. $\varepsilon$ SOLAR & - & - & - & - & - & - & - & 738 & 738 & cit \\
\hline
\end{tabular}

-

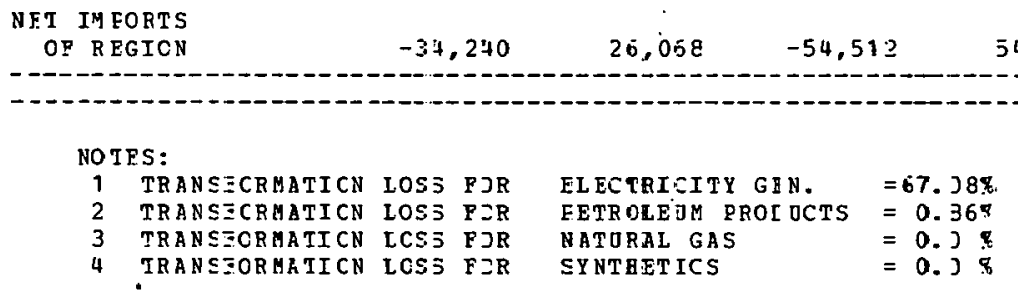


REGIONAL ENEFGY EALANCE STAIEMENT
PIES MID MID SCENARIO

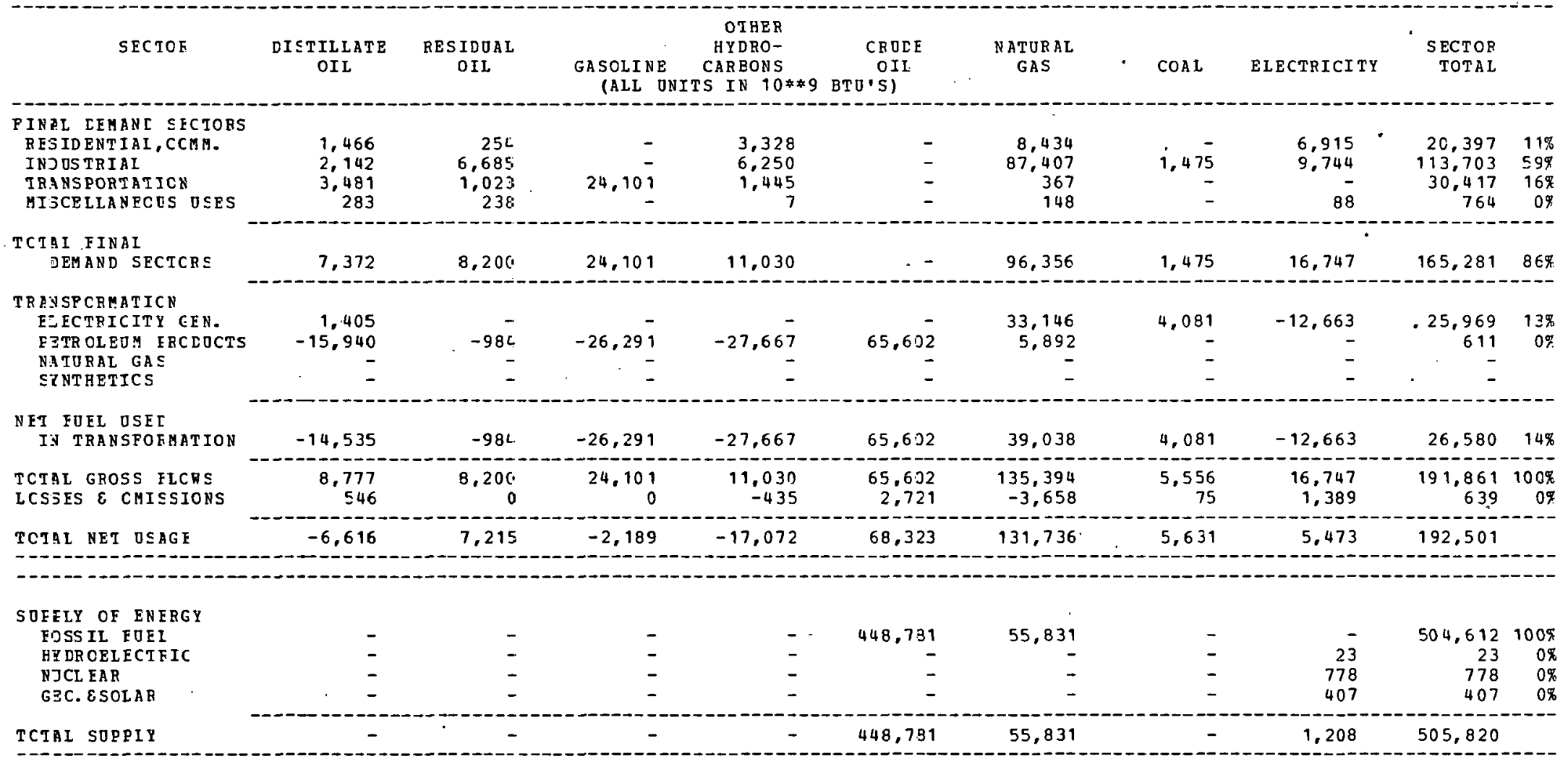

\begin{tabular}{l}
$\begin{array}{c}\text { NET IM FORTS } \\
\text { OP REGION }\end{array}$ \\
\hline
\end{tabular}


REGIOVIL EIREFGY EALANCE STATEMENT

PIES MID ID SCENARIO

\begin{tabular}{|c|c|c|c|c|c|c|c|c|c|c|}
\hline SECTOK & $\begin{array}{l}\text { DISUILLATE } \\
\text { OIL }\end{array}$ & $\begin{array}{l}\text { RESIDJAL } \\
=\mathrm{IL}\end{array}$ & $\begin{array}{l}\text { GASOLINE } \\
\text { (ALL D }\end{array}$ & $\begin{array}{c}\text { OT }=E R \\
\text { AYDEO- } \\
\text { CPREONS } \\
\text { TS IN } 10 * \$ 9\end{array}$ & $\begin{array}{c}\text { CRODE } \\
\text { OIL } \\
\text { BTO'S) }\end{array}$ & $\begin{array}{l}\text { MATURAL } \\
\text { GAS }\end{array}$ & $\operatorname{COAL}$ & ELECTRICITY & $\begin{array}{l}\text { SECTOR } \\
\text { TOTAL }\end{array}$ & \\
\hline $\begin{array}{l}\text { PINAL CEMANE SICTORS } \\
\text { RESIDENTIAI,CCMH. } \\
\text { INDOSTRIAL } \\
\text { IRANSPORTATICN } \\
\text { MISCELLANECS OSES }\end{array}$ & $\begin{array}{r}1,098 \\
755 \\
2,385 \\
450\end{array}$ & $\begin{array}{r}295 \\
i, 784 \\
\overline{4}, 483 \\
379\end{array}$ & 15,459 & $\begin{array}{r}2.153 \\
867 \\
3.441 \\
8\end{array}$ & $\begin{array}{l}\overline{-} \\
\overline{-}\end{array}$ & $\begin{array}{r}5,760 \\
23,267 \\
894 \\
181\end{array}$ & $\begin{array}{r}- \\
- \\
-\end{array}$ & $\begin{array}{r}5,406 \\
3,938 \\
- \\
99\end{array}$ & $\begin{array}{r}14,712 \\
30,942 \\
24,662 \\
1,117\end{array}$ & $\begin{array}{r}19 \% \\
40 \% \\
32 \% \\
1 \%\end{array}$ \\
\hline $\begin{array}{l}\text { TCTAI FINAL } \\
\text { DEMAND SECECRS }\end{array}$ & $4, \in 88$ & 4,941 & 15,459 & 6,469 & - & $30,10 z$ & 331 & 9.443 & 71,433 & $92 \%$ \\
\hline $\begin{array}{l}\text { TRAN SP ORNATICR } \\
\text { FLECTRICITY GEN. } \\
\text { PETROLEOH ERCDOCTS } \\
\text { NATURAL GAS } \\
\text { SYNTHETICS }\end{array}$ & $\begin{array}{r}792 \\
- \\
-\end{array}$ & $\begin{array}{l}\overline{-} \\
\overline{-}\end{array}$ & $\begin{array}{l}- \\
\overline{-} \\
-\end{array}$ & $\begin{array}{l}- \\
\overline{-} \\
-\end{array}$ & $\overline{-}$ & $\begin{array}{r}5,888 \\
- \\
- \\
-\end{array}$ & $\begin{array}{r}2,3 \pi \\
- \\
-\end{array}$ & $\begin{array}{r}-2,938 \\
- \\
-\end{array}$ & $\begin{array}{r}6,043 \\
- \\
-\end{array}$ & EF \\
\hline $\begin{array}{l}\text { BET FOFL OSEL } \\
\text { IN TRANSPOFHATION }\end{array}$ & 792 & - & - & - & - & $5,88 \varepsilon$ & $2,3 \mathrm{Cl}$ & -2.938 & 6.043 & $8 \%$ \\
\hline $\begin{array}{l}\text { TCTAL GROSS FLCRS } \\
\text { LCSSES \& CMISSIONS }\end{array}$ & $\begin{array}{r}5.480 \\
\vdots 41\end{array}$ & 4,941 & $\begin{array}{r}15,459 \\
0\end{array}$ & $\begin{array}{r}6.469 \\
-255\end{array}$ & - & $\begin{array}{r}35,990 \\
-972\end{array}$ & $\begin{array}{r}2,632 \\
35\end{array}$ & $\begin{array}{r}9.443 \\
783\end{array}$ & $\begin{array}{r}77,476 \\
-67\end{array}$ & $\begin{array}{l}\pi 00 \% \\
0 \%\end{array}$ \\
\hline $\begin{array}{l}\text { SOEELY OF FNERGY } \\
\text { FOSS IL FUEI } \\
\text { HYLROELECTEIC } \\
\text { NOCLEAR } \\
\text { GEC. ESOLAR }\end{array}$ & $\overline{-}$ & $\begin{array}{l}\bar{I} \\
\overline{-}\end{array}$ & $\begin{array}{l}\overline{-} \\
-\end{array}$ & $\begin{array}{l}\overline{-} \\
\overline{-}\end{array}$ & $\begin{array}{r}50,652 \\
- \\
-\end{array}$ & $\begin{array}{r}38,755 \\
- \\
-\end{array}$ & $\begin{array}{l}\overline{-} \\
\overline{-}\end{array}$ & $\begin{array}{r}13 \\
438 \\
230\end{array}$ & $\begin{array}{r}89,407 \\
13 \\
438 \\
230\end{array}$ & $\begin{array}{l}99 \% \\
0 \% \\
0 \% \\
0 \%\end{array}$ \\
\hline TCTAI SUPPIY & - & - & - & - & 50,652 & 38,755 & - & $68 i$ & 90,088 & \\
\hline
\end{tabular}

-

\section{STET IM FORTS}

5,821

15,459

6,213

$-50.652$

$-3,73^{7}$

$2,6 \leqslant 7$

$6.607 \quad-12.679$

-

\section{NO TES:}

TRANSECRMATICN LOSS FOB

TRANSZCRMATICN LOSS POT

TRANS?CRMATICN LCSS PO

ZLECTRICIIY GEN.

TRAN SPGRMA II CN LCSS TOR 
REGICNAL ENE FGY EALANCE STATEHENT

PIES MID MID SCENARIO

\begin{tabular}{|c|c|c|c|c|c|c|c|c|c|c|}
\hline SECTOE & $\begin{array}{l}\text { DISTILLATE } \\
\text { OIL }\end{array}$ & $\begin{array}{l}\text { RESIDUAL } \\
\text { OIL }\end{array}$ & $\begin{array}{l}\text { GASOLINE } \\
\text { (ALL ONIT }\end{array}$ & $\begin{array}{c}\text { OTHER } \\
\text { HYDRO- } \\
\text { CARBONS } \\
\text { TS IN } 10 * * 9\end{array}$ & $\begin{array}{c}\text { CRTDE } \\
\text { OIL } \\
\text { BTO'S) }\end{array}$ & $\begin{array}{l}\text { NATORAL } \\
\text { GAS }\end{array}$ & COAL & ELECTRICITY & $\begin{array}{r}\text { SECTOR } \\
\text { TOTAL }\end{array}$ & \\
\hline $\begin{array}{l}\text { FINAL CEMARL SECIORS } \\
\text { RESID FNTIAL, CCAB. } \\
\text { IND OSTRIAL } \\
\text { TRA PSORTATICN } \\
\text { IISCELIANECOS OSES }\end{array}$ & $\begin{array}{r}20,420 \\
12,652 \\
82,097 \\
4,961 \\
\end{array}$ & $\begin{array}{r}4,932 \\
45,100 \\
53,232 \\
4,175\end{array}$ & $300,22 \overline{-}$ & $\begin{array}{r}41,898 \\
248,873 \\
74,422 \\
83\end{array}$ & $\begin{array}{l}- \\
-\end{array}$ & $\begin{array}{r}113,670 \\
580,419 \\
19,248 \\
1,772\end{array}$ & $\begin{array}{r}21,239 \\
1 \\
-\end{array}$ & $\begin{array}{r}108,400 \\
70,069 \\
- \\
920\end{array}$ & $\begin{array}{r}289,320 \\
978,352 \\
529,220 \\
11,911\end{array}$ & $\begin{array}{l}15 \% \\
50 \% \\
27 \% \\
1 \%\end{array}$ \\
\hline $\begin{array}{l}\text { TCTAI FINAI } \\
\text { DEMAND SECTCRS }\end{array}$ & 120,130 & 107.439 & 300,220 & 365,276 & - & 715,109 & 21,240 & 179,389 & $1,808,803$ & $92 \%$ \\
\hline $\begin{array}{l}\text { TR.ANSPCRHATICN } \\
\text { ELECTRICITY EBN. } \\
\text { PBTR OLEOH ERCDOCTS } \\
\text { NATORAL GAS } \\
\text { SY HTRETICS }\end{array}$ & $\begin{array}{r}15,054 \\
-11,354 \\
-\end{array}$ & $\begin{array}{r}-731 \\
- \\
-\end{array}$ & $\begin{array}{r}-18,72 \overline{-} \\
-\end{array}$ & $\begin{array}{r}-19,708 \\
- \\
-\end{array}$ & $\begin{array}{r}46,730 \\
- \\
-\end{array}$ & $\begin{array}{r}197.894 \\
4.197 \\
-\end{array}$ & $\begin{array}{r}43,714 \\
- \\
-\end{array}$ & $\begin{array}{r}-84,312 \\
- \\
-\end{array}$ & $\begin{array}{r}172,350 \\
436 \\
- \\
-\end{array}$ & $\begin{array}{l}9 \% \\
0 \%\end{array}$ \\
\hline $\begin{array}{l}\text { NET FOEL OSEC } \\
\text { IN TRANSPOFUATION }\end{array}$ & 3,700 & $-7 \cdot 31$ & $-18,728$ & $-19,708$ & 46,730 & 202,091 & 43,714 & $-84,312$ & 172,786 & $9 \%$ \\
\hline $\begin{array}{l}\text { TCTAL GROSS FICRS } \\
\text { LCSSES } \varepsilon \text { CHISSIOHS }\end{array}$ & $\begin{array}{r}135,184 \\
8,414\end{array}$ & $\begin{array}{r}107,439 \\
2\end{array}$ & $\begin{array}{r}300,220 \\
1\end{array}$ & $\begin{array}{l}365,276 \\
-14,408\end{array}$ & $\begin{array}{r}46,730 \\
1,938\end{array}$ & $\begin{array}{l}917,200 \\
-24,784\end{array}$ & $\begin{array}{r}64,954 \\
879\end{array}$ & $\begin{array}{r}179,389 \\
14,884\end{array}$ & $\begin{array}{r}1,981,589 \\
-13,072\end{array}$ & $\begin{array}{r}101 \% \\
0 \%\end{array}$ \\
\hline
\end{tabular}

\begin{tabular}{|c|c|c|c|c|c|c|c|c|c|c|}
\hline $\begin{array}{l}\text { SOEPLY OF ERFRGY } \\
\text { FOSSIL FOEI } \\
\text { GYDROELBCTEIC } \\
\text { NOCL EAR } \\
\text { FEO. ESOLAR }\end{array}$ & $\begin{array}{l}\overline{-} \\
\overline{-}\end{array}$ & $\begin{array}{l}- \\
\overline{-} \\
-\end{array}$ & $\begin{array}{l}- \\
-\end{array}$ & $\begin{array}{l}\overline{-} \\
\overline{-}\end{array}$ & $\begin{array}{r}161,010 \\
- \\
-\end{array}$ & $\begin{array}{r}79,041 \\
- \\
- \\
-\end{array}$ & $\begin{array}{l}\overline{-} \\
\overline{-}\end{array}$ & $\begin{array}{r}1,331 \\
44,754 \\
4,360\end{array}$ & $\begin{array}{r}240,051 \\
1,331 \\
44,754 \\
4,360\end{array}$ & $\begin{array}{r}83 \% \\
0 \% \\
15 \% \\
2 \%\end{array}$ \\
\hline TCIAL SUPPIY & - & - & - & - & 161,010 & 79,041 & - & 50,445 & 290,496 & \\
\hline
\end{tabular}

-

\section{MET III FORTS}

$132,244 \quad 106,739$

281,493

331,159

813,374

65,833

$59,516 \quad 1,678,020$

NOIES:

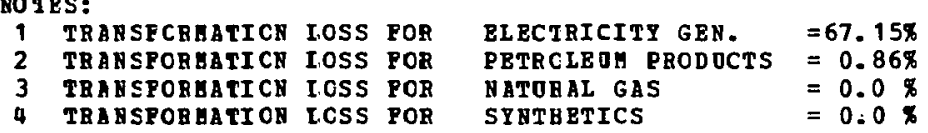


REGICNAL ENERGT BALANCE STATEMEYT

\begin{tabular}{|c|c|c|c|c|c|c|c|c|c|c|}
\hline SECTCE & $\underset{\text { OIL }}{\text { DISTILLLT }}$ & $\begin{array}{c}\text { RESIDOAL } \\
C=L\end{array}$ & $\begin{array}{l}\text { GASOLISE } \\
\text { (ALL UNI }\end{array}$ & $\begin{array}{c}\text { OT HER } \\
\text { EEDRO- } \\
\text { CAEBODS } \\
Z S=N \quad 10 * 99\end{array}$ & $\begin{array}{c}\text { CR OLE } \\
\text { OII } \\
\text { BIO'S) }\end{array}$ & $\begin{array}{l}\text { NATURA } \\
\text { GAS }\end{array}$ & $\operatorname{COAL}$ & ELECTRICITY & $\begin{array}{l}\text { SECTOR } \\
\text { TOTAL }\end{array}$ & \\
\hline $\begin{array}{l}\text { PINAL DEHANL SECTOES } \\
\text { RESIDENTIAL, COHH. } \\
\text { INDOSTRIAL } \\
\text { TRANSPORTATICN } \\
\text { MISCELLANECES OSES }\end{array}$ & $\begin{array}{l}3.4 .59 \\
1,917 \\
9,5,52 \\
1,5.30\end{array}$ & $\begin{aligned} 762 \\
5,631 \\
\vdots, 282 \\
i, 262\end{aligned}$ & $52.84 \overline{2}$ & $\begin{array}{r}7,335 \\
9,178 \\
4.631 \\
46\end{array}$ & 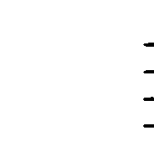 & $\begin{array}{r}19,179 \\
62,044 \\
1,187 \\
904\end{array}$ & $\begin{array}{r}3,402 \\
- \\
-\end{array}$ & $\begin{array}{r}17,080 \\
11,641 \\
- \\
557\end{array}$ & $\begin{array}{r}47,815 \\
93,813 \\
71,437 \\
4,269\end{array}$ & $\begin{array}{l}=E x \\
\equiv 2 \pi \\
=5 \% \\
1 \%\end{array}$ \\
\hline $\begin{array}{l}\text { TCTAI FINAI } \\
\text { DEMAND SECTCRS }\end{array}$ & 16,378 & 10,937 & 52,842 & 21,190 & - & 83,307 & $3,4 C 2$ & 29,278 & 217,334 & $.5 \%$ \\
\hline $\begin{array}{l}\text { TBANSPORHATICE } \\
\text { ELECTRICITY ERN. } \\
\text { PETROLEOH ERCDOCTS } \\
\text { NATORAL GAS } \\
\text { SYNTHETICS }\end{array}$ & $\begin{array}{r}2,457 \\
- \\
-\end{array}$ & $\begin{array}{l}- \\
\overline{-} \\
-\end{array}$ & $\begin{array}{l}\vdots \\
\vdots\end{array}$ & $\begin{array}{l}- \\
-\end{array}$ & 7 & $\begin{array}{r}38,980 \\
- \\
-\end{array}$ & $\begin{array}{r}67,36 ? \\
- \\
-\end{array}$ & $\begin{array}{r}-35,921 \\
- \\
-\end{array}$ & $\begin{array}{r}72,883 \\
- \\
-\end{array}$ & $25 x$ \\
\hline $\begin{array}{l}\text { NET FOFL OSFC } \\
\text { IN TRA SSFCFOATICN }\end{array}$ & 2,457 & - & - & - & - & 38,980 & $E 7,367$ & $-35,921$ & 72,883 & $25 \%$ \\
\hline $\begin{array}{l}\text { TCTAL GROSS FUCRS } \\
\text { ICSSES } E \text { CMISSIONS }\end{array}$ & $\begin{array}{r}1.3,835 \\
1,1.72\end{array}$ & $\begin{array}{r}10,937 \\
6\end{array}$ & 52,842 & $\begin{array}{r}21,190 \\
-835\end{array}$ & $\overline{-}$ & $\begin{array}{r}122,287 \\
-3,304\end{array}$ & $\begin{array}{r}70,769 \\
957\end{array}$ & $\begin{array}{r}29,278 \\
2,429\end{array}$ & $\begin{array}{r}290,217 \\
419\end{array}$ & $\begin{array}{r}100 \% \\
C \%\end{array}$ \\
\hline TCTAL NET OSAEE & 25,007 & 10,937 & 52,842 & 20.354 & - & $118,9 \& 2$ & $\because 1,725$ & $-4,213$ & 290,636 & \\
\hline
\end{tabular}

-

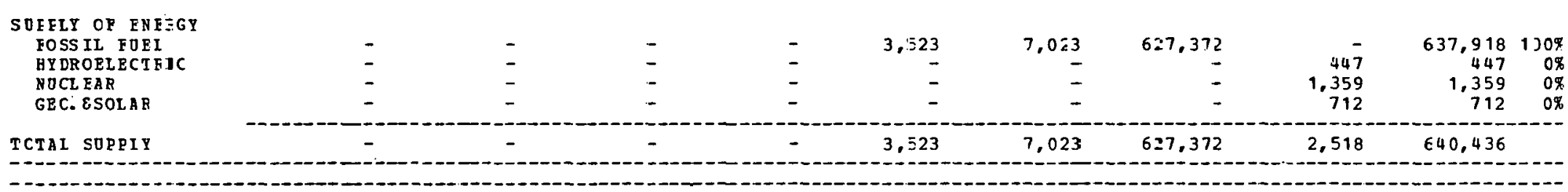

MET IY FORTS
CF FEGION


REGIONAL BNE IGY PALANCE STATEMENT
PIES MID GID SCENARIO.

\begin{tabular}{|c|c|c|c|c|c|c|c|c|c|c|}
\hline SBCTOE & $\begin{array}{l}\text { DISTILLATE } \\
\text { OIL }\end{array}$ & $\begin{array}{l}\text { RESIDUAL } \\
\text { OIL }\end{array}$ & $\begin{array}{l}\text { GASOLINE } \\
\text { (ALL O }\end{array}$ & $\begin{array}{c}\text { OTHER } \\
\text { AYDRO- } \\
\text { CARBONS } \\
\text { TS IN } 10 *\end{array}$ & $\begin{array}{c}\text { CRODE } \\
\text { OIL } \\
\text { BTO'S) }\end{array}$ & $\begin{array}{l}\text { NATORAL } \\
\text { GAS }\end{array}$ & $\operatorname{COAL}$ & ELECTRICITY & $\begin{array}{r}\text { SECTOR } \\
\text { TOTAL }\end{array}$ & \\
\hline $\begin{array}{l}\text { PIVIL TEHANC SECTOES } \\
\text { RESIDENTIAL, CCAB. } \\
\text { IMDOSTRIAL } \\
\text { TRANSPORTATICN } \\
\text { UISCELLANPCES OSES }\end{array}$ & $\begin{array}{l}5,833 \\
2,388 \\
9,668 \\
3,572\end{array}$ & $\begin{array}{l}1,497 \\
5,880 \\
5,381 \\
3,006\end{array}$ & $83.88 \overline{-}$ & $\begin{array}{r}11,727 \\
12,958 \\
7,520 \\
56\end{array}$ & $\overline{-}$ & $\begin{array}{r}31,947 \\
65,984 \\
1,937 \\
1,212\end{array}$ & $\begin{array}{r}- \\
4,025 \\
-\end{array}$ & $\begin{array}{r}31,538 \\
13,342 \\
- \\
613\end{array}$ & $\begin{array}{r}82,542 \\
10,4,577 \\
108,388 \\
8,459\end{array}$ & $\begin{array}{r}21 \% \\
26 \% \\
27 \% \\
2 \%\end{array}$ \\
\hline $\begin{array}{l}\text { TCTAL FINAI } \\
\text { DEHAND SECTORS }\end{array}$ & $-21,461$ & 15,764 & 83,882 & 32,261 & - & 101,080 & 4,025 & 45,493 & 303,966 & $77 \%$ \\
\hline $\begin{array}{l}\text { TRENSPCRHATICN } \\
\text { EL ECTRICITY GEN. } \\
\text { PETROLEOM ERCDOCTS } \\
\text { EATORAL GAS } \\
\text { STRTBETICS }\end{array}$ & $\begin{array}{r}3,818 \\
-14,237 \\
-\end{array}$ & $\begin{array}{r}-879 \\
-\end{array}$ & $\begin{array}{r}-23,482 \\
-\end{array}$ & $\begin{array}{r}-24,711 \\
-\end{array}$ & $\begin{array}{r}58,59 \overline{2} \\
-\end{array}$ & $\begin{array}{r}57,132 \\
5,263 \\
- \\
-\end{array}$ & $\begin{array}{r}70,399 \\
= \\
-\end{array}$ & $\begin{array}{r}-43,305 \\
- \\
- \\
-\end{array}$ & $\begin{array}{r}88,044 \\
545 \\
- \\
-\end{array}$ & $\begin{array}{r}22 \% \\
0 \%\end{array}$ \\
\hline $\begin{array}{l}\text { HET FOEL OSEL } \\
\text { IN TRASSPOHATIOR }\end{array}$ & $-10,419$ & -879 & $-23,482$ & $-24,711$ & 58,592 & 62,395 & 70,399 & $-43,305$ & 88,589 & $22 \%$ \\
\hline $\begin{array}{l}\text { TCTAL GROSS FLCRS } \\
\text { LOSSES \& OUISSIO\&S }\end{array}$ & $\begin{array}{r}25,279 \\
1,573\end{array}$ & $\begin{array}{r}15,764 \\
0\end{array}$ & $\begin{array}{r}83,882 \\
0\end{array}$ & $\begin{array}{l}32,261 \\
-1,272\end{array}$ & $\begin{array}{r}58,592 \\
2,430\end{array}$ & $\begin{array}{r}163,475 \\
-4,417\end{array}$ & $\begin{array}{r}74,424 \\
1,007\end{array}$ & $\begin{array}{r}45,493 \\
3,774\end{array}$ & $\begin{array}{r}392,555 \\
3,097\end{array}$ & $\begin{array}{r}99 \% \\
1 \%\end{array}$ \\
\hline $\begin{array}{l}\text { SOFPLY OP EHFRGY } \\
\text { FOSS IL FOEI } \\
\text { GYDRCELECTEIC } \\
\text { YOCL EAR } \\
\text { GEC. ESOLAR }\end{array}$ & $\begin{array}{l}- \\
-\end{array}$ & $\begin{array}{l}5 \\
-\end{array}$ & $\begin{array}{l}- \\
\overline{-} \\
-\end{array}$ & $\overline{-}$ & $\begin{array}{r}13,872 \\
- \\
-\end{array}$ & $\begin{array}{r}8 ; 062 \\
- \\
-\end{array}$ & $\begin{array}{r}398,766 \\
- \\
-\end{array}$ & $\begin{array}{l}3,18 \overline{-} \\
2,112 \\
1,106\end{array}$ & $\begin{array}{r}420,700 \\
3,180 \\
2,112 \\
1,106\end{array}$ & $\begin{array}{r}99 \% \\
1 \% \\
0 \% \\
0 \%\end{array}$ \\
\hline TCTAI SUPPIY & $=-$ & - & - & - & 13,872 & 8,062 & 398,766 & 6,398 & 427,098 & \\
\hline
\end{tabular}

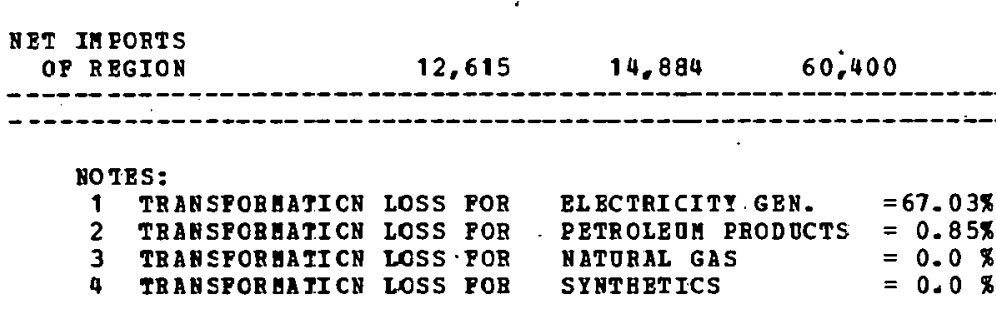


REGIONAL ENE: IGY EALANCE STATEUEYT

PIES MIT MID SCENARIO

\begin{tabular}{|c|c|c|c|c|c|c|c|c|c|c|}
\hline SECTOĀ & $\begin{array}{l}\text { DISTJLLETE } \\
=I L\end{array}$ & $\begin{array}{l}\text { RESTIOAL } \\
\text { OIL }\end{array}$ & $\begin{array}{l}\text { SASOLI NE } \\
\text { (ALL DNI }\end{array}$ & $\begin{array}{c}\text { CTHER } \\
\text { HYDRD- } \\
\text { CAEBO\&S } \\
\text { TS IN } 10 * * 9\end{array}$ & $\begin{array}{c}\text { CROLE } \\
\text { OIL } \\
\text { BTOS }\end{array}$ & $\begin{array}{l}\text { NATORAL } \\
\text { GAS }\end{array}$ & $\operatorname{COAL}$ & BLECTRICITY & $\begin{array}{l}\text { SECTOR } \\
\text { TOTAL }\end{array}$ & \\
\hline 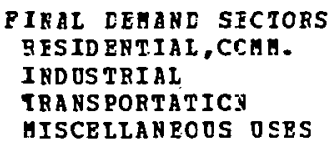 & $\begin{array}{r}3.953 \\
4.556 \\
13.236 \\
1.021\end{array}$ & $\begin{array}{r}850 \\
15.442 \\
2.675 \\
859\end{array}$ & $61.68 \overline{1}$ & $\begin{array}{r}8,553 \\
52,381 \\
3,848 \\
15\end{array}$ & $\begin{array}{l}\overline{-} \\
\overline{-}\end{array}$ & $\begin{array}{r}22,244 \\
214,416 \\
961 \\
332\end{array}$ & $\begin{array}{r}\overline{-} \\
\overline{-}\end{array}$ & $\begin{array}{r}19,494 \\
24,792 \\
164\end{array}$ & $\begin{array}{r}55,134 \\
360,590 \\
82,401 \\
2,391\end{array}$ & $\begin{array}{r}7 \% \\
48 \% \\
1118 \\
0 \%\end{array}$ \\
\hline $\begin{array}{l}\text { TCIAL FINAI } \\
\text { DEMAND SECTORS }\end{array}$ & 23.736 & 19.826 & 61,681 & 104,797 & - & 237,953 & 9,053 & 44,450 & 500,516 & $E 7 \%$ \\
\hline $\begin{array}{l}\text { T3ANSPCRHATICN } \\
\text { BLECTRICITY GEN. } \\
\text { PETR OLEOA FRODOCTS } \\
\text { NATURAL GAS } \\
\text { SY NTAETICS }\end{array}$ & $\begin{array}{r}3,730 \\
-2.5,7 \cdot 7 \\
-\end{array}$ & $\begin{array}{r}-1.527 \\
-\end{array}$ & $\begin{array}{r}-40,76 \overline{7} \\
- \\
-\end{array}$ & $\begin{array}{r}-42,902 \\
-\end{array}$ & $\begin{array}{r}101,725 \\
-\end{array}$ & $\begin{array}{r}59,376 \\
9,137 \\
- \\
-\end{array}$ & $\begin{array}{r}307,546 \\
- \\
-\end{array}$ & $\begin{array}{r}-122,680 \\
= \\
=\end{array}$ & $\begin{array}{r}247,972 \\
949 \\
- \\
-\end{array}$ & $\begin{array}{r}33 \% \\
0 \%\end{array}$ \\
\hline $\begin{array}{l}\text { NET FOFL OSEL } \\
\text { IN TRANSPOFATION }\end{array}$ & $-20,987$ & -1.527 & $-40,767$ & $-62,902$ & 101,725 & 68,513 & 307,546 & $-122,680$ & 248,921 & $\equiv 3 \%$ \\
\hline $\begin{array}{l}\text { TCTAL GROSS FLCRS } \\
\text { LCSSES } \& \text { ONISSIONS }\end{array}$ & $\begin{array}{r}26,48: 6 \\
., 648\end{array}$ & $\begin{array}{r}19,826 \\
0\end{array}$ & $\begin{array}{r}61,681 \\
0\end{array}$ & $\begin{array}{r}104,797 \\
-4,133\end{array}$ & $\begin{array}{r}101,725 \\
4,220\end{array}$ & $\begin{array}{r}306,465 \\
-8,281\end{array}$ & $\begin{array}{r}316,599 \\
4,285\end{array}$ & $\begin{array}{r}44,450 \\
3,688\end{array}$ & $\begin{array}{r}749,437 \\
1,427\end{array}$ & $\begin{array}{r}10 C X \\
0 \%\end{array}$ \\
\hline TCTAL NET OSAGE & $3,4 \div 7$ & $1 \varepsilon .299$ & 20,914 & 57,761 & 105,545 & 298,185 & $320, \varepsilon 84$ & $-74,541$ & 750,865 & \\
\hline
\end{tabular}

\begin{tabular}{|c|c|c|c|c|c|c|c|c|c|c|}
\hline SOEELY OF ENFFGY & & & & & & & & & & \\
\hline FOSS IL FOEI & - & - & - & - & $546, \subseteq 89$ & 145,219 & 18,801 & - & 711,009 & $1 c-0 \%$ \\
\hline HY DR OELPCTRI: & - & - & - & - & - & - & - & 61 & & $0 \%$ \\
\hline BOCL EAR & - & - & - & - & - & - & - & 2,064 & 2,064 & $0 \%$ \\
\hline GEO. ESOLAR & - & - & - & - & - & - & - & 1,080 & 1,080 & $0 \%$ \\
\hline TCTAL SUPPIY & - & - & - & - & $546, \subseteq 89$ & 145,217 & 18,801 & 3,205 & 714,214 & \\
\hline
\end{tabular}

NET IM FORTS
OP REGION


REGIONAL ENE GGY EALANCE STITEMENT PIES MID MID SCENARIO

\begin{tabular}{|c|c|c|c|c|c|c|c|c|c|c|}
\hline SECTCF & $\begin{array}{l}\text { DISTILLLTE } \\
\text { OIL }\end{array}$ & $\begin{array}{l}\text { RESIDDAI } \\
\text { OIL }\end{array}$ & $\begin{array}{l}\text { GASOLINE } \\
\text { (ALL ON] }\end{array}$ & $\begin{array}{c}\text { OTHER } \\
\text { HYDRO- } \\
\text { CARBONS } \\
\text { PS.IN } 10 * 9\end{array}$ & $\begin{array}{c}\text { CROLEF } \\
\text { OII } \\
\text { BTU'S) }\end{array}$ & $\begin{array}{l}\text { NATURAL } \\
\text { GAS }\end{array}$ & $\operatorname{COAL}$ & BLECTRICITY & $\begin{array}{l}\text { SRCTOR } \\
\text { TOTAL }\end{array}$ & \\
\hline $\begin{array}{l}\text { PISAL CEMANC SFCTOES } \\
\text { RESIDENTIAL, CCMM. } \\
\text { INDOSTRIAL } \\
\text { TFANSPORTATICN } \\
\text { WISCELLANECS OSES }\end{array}$ & $\begin{array}{l}2,960 \\
4,965 \\
8,691 \\
1,088\end{array}$ & $\begin{array}{r}732 \\
18,303 \\
1,942 \\
913\end{array}$ & $\begin{array}{r}- \\
- \\
-\end{array}$ & $\begin{array}{r}5,275 \\
12,922 \\
4,018 \\
16\end{array}$ & $\begin{array}{l}- \\
-\end{array}$ & $\begin{array}{r}15,457 \\
51,427 \\
1,271 \\
352\end{array}$ & $\begin{array}{r}- \\
3,450 \\
-\end{array}$ & $\begin{array}{r}10,998 \\
10,763 \\
- \\
174\end{array}$ & $\begin{array}{r}35,422 \\
101,830 \\
52,938 \\
2,533\end{array}$ & $\begin{array}{r}10 \% \\
30, \\
16 \% \\
1 \%\end{array}$ \\
\hline $\begin{array}{l}\text { TCJAI FINAI } \\
\text { DEMAND SECTCRS }\end{array}$ & 17,697 & 21,887 & 37,016 & 22.231 & - & 68,507 & 3.450 & 21,935 & 192,723 & $57 \%$ \\
\hline $\begin{array}{l}\text { TRENSPCRMATICN } \\
\text { ELECTRICITY. GEN. } \\
\text { EETR OLEOM FRCDOCTS } \\
\text { NATORAL GAS } \\
\text { SY NTRETICS }\end{array}$ & $\begin{array}{r}1,840 \\
-11,354 \\
- \\
-\end{array}$ & $\begin{array}{r}- \\
-701 \\
- \\
-\end{array}$ & $\begin{array}{r}-19,728 \\
- \\
-\end{array}$ & $\begin{array}{r}-19,708 \\
- \\
-\end{array}$ & $\begin{array}{r}46.730 \\
- \\
-\end{array}$ & $\begin{array}{r}5,505 \\
4,197 \\
- \\
-\end{array}$ & $\begin{array}{r}206,048 \\
- \\
-\end{array}$ & $\begin{array}{r}-70,774 \\
- \\
-\end{array}$ & $\begin{array}{r}142,619 \\
436 \\
- \\
-\end{array}$ & $\begin{array}{r}42 \% \\
0 \%\end{array}$ \\
\hline $\begin{array}{l}\text { NET FOEI OSFE } \\
\text { IN TRANSPOEMATION }\end{array}$ & $-9,514$ & -701 & $-19,728$ & $-19,708$ & 46,730 & 9,702 & 206,048 & $-70,774$ & 143.055 & $42 \%$ \\
\hline $\begin{array}{l}\text { TCTAL GROSS FLCRS } \\
\text { LCSSES \& CMISSIONS }\end{array}$ & $\begin{array}{r}19.537 \\
1,216\end{array}$ & $\begin{array}{r}21,887 \\
0\end{array}$ & $\begin{array}{r}37,016 \\
0\end{array}$ & $\begin{array}{r}22,231 \\
-876\end{array}$ & $\begin{array}{r}46,730 \\
1,938\end{array}$ & $\begin{array}{l}78,209 \\
-2,113\end{array}$ & $\begin{array}{r}209,498 \\
2,835\end{array}$ & $\begin{array}{r}21,935 \\
1,820\end{array}$ & $\begin{array}{r}335,778 \\
4,820\end{array}$ & $\begin{array}{r}998 \\
1 \%\end{array}$ \\
\hline TCTAL NET OSAGE & 9,399 & 21,185 & 18,288 & 1,646 & $48, \in 68$ & 76,096 & 212,333 & -47.018 & 340,599 & \\
\hline
\end{tabular}

\begin{tabular}{|c|c|c|c|c|c|c|c|c|c|c|}
\hline $\begin{array}{l}\text { SOEFLY OF PNERGY } \\
\text { FCSS IL FOEI }\end{array}$ & & & & & & & & & & \\
\hline & - & - & - & - & 38,885 & 21,215 & 21,061 & - & 81,161 & $9 \in \%$ \\
\hline FY DRCELECIFIC & - & - & - & - & - & - & - & 1,412 & 1,412 & $2 \%$ \\
\hline NOCL EAR & - & - & - & - & - & - & - & 1,018 & 1.018 & $1 \%$ \\
\hline GEO. $\varepsilon$ SOLAR & - & - & - & - & - & - & - & 533 & 533 & 19 \\
\hline TCTAI SUPPIY & - & - & - & - & 38,885 & 21,215 & 21.061 & 2,963 & 84,124 & \\
\hline
\end{tabular}

NEI IM EORTS
CF REGION


REGIONAL ENEFGY EALANCE STATEMZNT
PIES GID YID SCEYARIO

\begin{tabular}{|c|c|c|c|c|c|c|c|c|c|c|}
\hline SECTOF & $\begin{array}{l}\text { DISTILEATE } \\
\text { OIE }\end{array}$ & $\begin{array}{l}\text { RESIDJAL } \\
\text { OIL }\end{array}$ & $\begin{array}{l}\text { GASOLINE } \\
\text { (ALL ONI }\end{array}$ & $\begin{array}{c}\text { OEHER } \\
\text { JYDRO- } \\
\text { CAREONS } \\
\text { TS IE } 10 * 9\end{array}$ & $\begin{array}{c}\text { CRODE } \\
0=\mathrm{L} \\
\text { BTO'SI }\end{array}$ & $\begin{array}{l}\text { NATURA: } \\
\text { GAS }\end{array}$ & COAL & ELECTRICITY & $\begin{array}{l}\text { SECTOR } \\
\text { TOTAL }\end{array}$ & \\
\hline $\begin{array}{l}\text { PINAL CEMANL SFCTORS } \\
\text { RESIDENTIAL,CCHM. } \\
\text { INDOSTRIAL } \\
\text { TRANS PORTATECN } \\
\text { GISCELLANEOOS OSES }\end{array}$ & $\begin{array}{r}590 \\
10,280 \\
8,732 \\
516\end{array}$ & $\begin{array}{r}152 \\
45,264 \\
1,725 \\
518\end{array}$ & $\begin{array}{r}- \\
\overline{-} \\
30,776 \\
-\end{array}$ & $\begin{array}{r}5,524 \\
10,962 \\
943 \\
12\end{array}$ & z- & $\begin{array}{r}13,101 \\
196,993 \\
655 \\
253\end{array}$ & $\begin{array}{r}1 \\
3,231 \\
- \\
-\end{array}$ & $\begin{array}{r}11,683 \\
13,396 \\
- \\
150\end{array}$ & $\begin{array}{r}31,051 \\
285,063 \\
42,832 \\
1,554\end{array}$ & $\begin{array}{r}8 \% \\
76 \% \\
11 \% \\
0 \%\end{array}$ \\
\hline $\begin{array}{l}\text { TCTAL FINAI } \\
\text { DEMAND SZCTCRS }\end{array}$ & 20,218 & $A B, 5 \subseteq 9$ & 30,776 & 28,441 & - & 211,005 & 3,232 & 25,229 & 360,500 & $\leqq 6 \pi$ \\
\hline $\begin{array}{l}\text { TRANSFORMATICN } \\
\text { ELECTRICITR EEN. } \\
\text { PETROLEOM ERCDOCTS } \\
\text { NATORAL GAS } \\
\text { SYNTERTCS }\end{array}$ & $\begin{array}{r}2,117 \\
-29,314 \\
- \\
-\end{array}$ & $\begin{array}{r}-1,842 \\
-\end{array}$ & $\begin{array}{r}-49,174 \\
- \\
-\end{array}$ & $\begin{array}{r}-51.749 \\
- \\
-\end{array}$ & $\begin{array}{r}122 \cdot 703 \\
- \\
-\end{array}$ & $\begin{array}{r}10,821 \\
11,021 \\
-\end{array}$ & $\begin{array}{r}6,1+8 \\
= \\
=\end{array}$ & $\begin{array}{r}-6,307 \\
- \\
-\end{array}$ & $\begin{array}{r}12,779 \\
1,145 \\
- \\
-\end{array}$ & $\begin{array}{l}3 x \\
0 \% \\
\end{array}$ \\
\hline $\begin{array}{l}\text { NET FORL USE } \\
\text { IN TRANSFOEATION }\end{array}$ & $-27,597$ & $-1,842$ & $-49,174$ & $-51,749$ & 122.703 & 21,842 & 6,148 & $-6,307$ & 13,924 & 48 \\
\hline $\begin{array}{l}\text { TCTAL GROSS ELCNS } \\
\text { LCSSES \& OMIESTONS }\end{array}$ & $\begin{array}{r}22,335 \\
1,390\end{array}$ & $\begin{array}{r}48,5 \subseteq 9 \\
0\end{array}$ & $\begin{array}{r}30,776 \\
0\end{array}$ & $\begin{array}{r}27,441 \\
-845\end{array}$ & $\begin{array}{r}122,703 \\
5,090\end{array}$ & $\begin{array}{r}232,847 \\
-6,292\end{array}$ & $\begin{array}{r}9,330 \\
126\end{array}$ & $\begin{array}{r}25,229 \\
2,093\end{array}$ & $\begin{array}{r}374,424 \\
1,564\end{array}$ & $\begin{array}{r}100 \pi \\
09\end{array}$ \\
\hline TOTAL NET OSEGE & $-6,088$ & 46,757 & $-18,397$ & $-37,153$ & 127.793 & 226,555 & 9,506 & 21,015 & 375,988 & \\
\hline
\end{tabular}

\begin{tabular}{|c|c|c|c|c|c|c|c|c|c|c|}
\hline SOFPLY CF ENERGY & & & & & 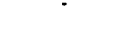 & & & & & \\
\hline FOSS IL FUET & - & - & - & - & 112,876 & 165,145 & - & - & 278,021 & 99\%: \\
\hline HY LROELPCTEIC & - & - & - & - & - & - & - & 35 & 35 & $0 \%$ \\
\hline NOCL EAR & - & - & - & - & - & - & - & 1,171 & 1,171 & $0 \%$ \\
\hline GEC. \& SOLAR & - & - & - & - & - & - & - & 613 & 613 & $0 \%$ \\
\hline TCTAI SOPPIY & - & - & - & - & 112.876 & $165,: 45$ & - & 1,819 & 279,840 & \\
\hline
\end{tabular}

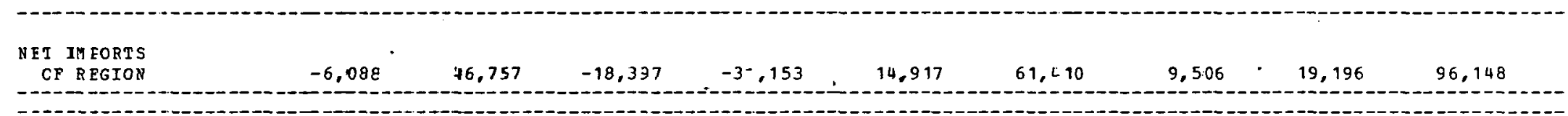

MOTES:

\begin{tabular}{|c|c|c|c|c|}
\hline $\begin{array}{l}\text { TRANSPCR YATICN } \\
\text { TRANSFCR YAFICN }\end{array}$ & $\begin{array}{l}\text { loss } \\
\text { Lass }\end{array}$ & $\begin{array}{l}\text { POF } \\
\text { FOF }\end{array}$ & $\begin{array}{l}\text { ELEETRICITY SEN. } \\
\text { PETEOLEIM PRODOCTS }\end{array}$ & $\begin{array}{l}95 \% \\
8 \in 9\end{array}$ \\
\hline & $L=S S$ & FOP & NATCRAL GAS & \\
\hline & & & SYNIHETICS & \\
\hline
\end{tabular}


REGIONAL ENEFGY EALANCE STATEMENT

\begin{tabular}{|c|c|c|c|c|c|c|c|c|c|c|}
\hline SECTCF & $\begin{array}{l}\text { DISTILLATE } \\
\text { OII }\end{array}$ & $\begin{array}{l}\text { RESIDOAL } \\
\text { OIL }\end{array}$ & $\begin{array}{l}\text { GASOLINE } \\
\text { (ALL OL }\end{array}$ & $\begin{array}{c}\text { OTHER } \\
\text { HYDRO- } \\
\text { CARBONS } \\
\text { IS IN } 10 * * 9\end{array}$ & $\begin{array}{c}\text { CRODE } \\
\text { OII } \\
\text { BTO'S) }\end{array}$ & $\begin{array}{l}\text { NATURAL } \\
\text { GAS }\end{array}$ & $\mathrm{COAL}$ & ELECTRICITY & $\begin{array}{l}\text { SECTOR } \\
\text { TOTAL }\end{array}$ & \\
\hline $\begin{array}{l}\text { PINAL LEMANL SECTOFS } \\
\text { BFSIDENTIAL, CCMM. } \\
\text { INDOSTRIAL } \\
\text { TRANSPORTATICN } \\
\text { MISCELLANEOUS OSES }\end{array}$ & $\begin{array}{r}785 \\
10,255 \\
9,801 \\
855\end{array}$ & $\begin{array}{r}249 \\
52.254 \\
4.636 \\
719\end{array}$ & $\begin{array}{r}- \\
- \\
36,724\end{array}$ & $\begin{array}{r}6,616 \\
31,155 \\
2,332 \\
15\end{array}$ & $\begin{array}{l}\overline{-} \\
-\end{array}$ & $\begin{array}{r}16,005 \\
166,661 \\
1,782 \\
312\end{array}$ & $\begin{array}{r}2 \\
3,289 \\
- \\
-\end{array}$ & $\begin{array}{r}14,947 \\
18,166 \\
- \\
167\end{array}$ & $\begin{array}{r}38,604 \\
281,82.0 \\
55,325 \\
2,068\end{array}$ & $\begin{array}{r}9 \% \\
67 \% \\
13 \% \\
0 \%\end{array}$ \\
\hline $\begin{array}{l}\text { TCTAI FINAI } \\
\text { DEMAND SECTORS }\end{array}$ & 21,736 & $57,9 \mathrm{c8}$ & 36,724 & 40,118 & - & 184,760 & 3,291 & 33,280 & 377,817 & $90 \%$ \\
\hline $\begin{array}{l}\text { TRANSFCRMATICN } \\
\text { ELECTRICITY GEN. } \\
\text { EETRCLEO EFCDOCTS } \\
\text { NATORAL GAS } \\
\text { SYNTHETICS }\end{array}$ & $\begin{array}{r}2,793 \\
= \\
-\end{array}$ & $\begin{array}{l}\overline{-} \\
\overline{-}\end{array}$ & $\begin{array}{l}\bar{z} \\
\bar{z}\end{array}$ & $\begin{array}{l}- \\
\overline{-} \\
-\end{array}$ & $\begin{array}{l}\overline{-} \\
\overline{-}\end{array}$ & $\begin{array}{r}29,013 \\
- \\
-\end{array}$ & $\begin{array}{r}34,306 \\
= \\
=\end{array}$ & $\begin{array}{r}-21,726 \\
- \\
-\end{array}$ & $\begin{array}{r}44,386 \\
- \\
-\end{array}$ & $11 \%$ \\
\hline $\begin{array}{l}\text { UET FOEL OSEL } \\
\text { IN TRANSPOFHATICN }\end{array}$ & 2,793 & - & - & - & - & 29,013 & 34,306 & $-21,726$ & 44,386 & $11 \%$ \\
\hline $\begin{array}{l}\text { FTTAL GROSS FLCHS } \\
\text { ICSSES } \& \text { OMISSIONS }\end{array}$ & $\begin{array}{r}24,529 \\
1,526\end{array}$ & 57,908 & 36,724 & $\begin{array}{r}40,118 \\
-1,582\end{array}$ & $\overline{-}$ & $\begin{array}{r}213,773 \\
-5,776\end{array}$ & $\begin{array}{r}37,597 \\
508\end{array}$ & $\begin{array}{r}33,280 \\
2,761\end{array}$ & $\begin{array}{r}42 \hat{2}, 203 \\
-2,560\end{array}$ & $\begin{array}{rl}10 & 1 \% \\
0 \%\end{array}$ \\
\hline $\begin{array}{l}\text { SOFELY OF ENERGY } \\
\text { FOSS IL FOEL } \\
\text { HYDROELECTFIC } \\
\text { NOCL RAR } \\
\text { GEC.ESOLAR }\end{array}$ & $\begin{array}{l}- \\
\overline{-} \\
-\end{array}$ & $\begin{array}{l}- \\
\overline{-} \\
-\end{array}$ & $\begin{array}{l}- \\
-\end{array}$ & $\begin{array}{l}- \\
-\end{array}$ & $\begin{array}{r}88,946 \\
= \\
-\end{array}$ & $\begin{array}{r}88,497 \\
- \\
-\end{array}$ & $\begin{array}{l}- \\
\overline{-}\end{array}$ & $\begin{array}{r}- \\
46 \\
1,545 \\
808\end{array}$ & $\begin{array}{r}177,443 \\
46 \\
1,545 \\
808\end{array}$ & $\begin{array}{r}99 \% \\
0 \% \\
1 \% \\
0 \%\end{array}$ \\
\hline TCTAL SOPPIY & - & - & - & - & 88,946 & 88,497 & - & 2,399 & 179,842 & \\
\hline
\end{tabular}

-

\section{NET IM FORTS}

OP R RGION

26,055

57.909

36,724

38,535

$-88,946$

119,499

38,105

11,916

239,800

\section{NOTES}

1 TRANSFCRMATICN LOSS FOR

2 TRANSFCRMATICN LCSS PCR
TRANSPCRATICN LCSS FCR

TRANSPCRMATICN LCSS FCR
TRAN SFORMATI CN LCSS FOR

ELECTRICITY GEN

PETROLEOM PRODOCTS $=67.14 \%$

NTURAL GAS

$=0.0 \%$

SYNTHEIICS

$=0.0 \%$
$=0.0 \%$ 
REGI YNAL ENEFGY EALANCE STATEMENT

\begin{tabular}{|c|c|c|c|c|c|c|c|c|c|c|}
\hline SECTEE & $\begin{array}{l}\text { DISEILLATE } \\
\text { OII }\end{array}$ & $\begin{array}{l}\text { RES IDUAL } \\
\text { DIL }\end{array}$ & $\begin{array}{l}\text { GASOLIN } \\
\text { (ALL JN }\end{array}$ & $\begin{array}{c}\text { CTUER } \\
\text { HYDRO- } \\
\text { CAREONS } \\
\text { IS IN } 10 * * 9\end{array}$ & $\begin{array}{c}\text { CROYE } \\
\text { OII } \\
\text { BTOSS) }\end{array}$ & $\begin{array}{l}\text { NATUR AL } \\
\text { GAS }\end{array}$ & $\operatorname{COA} L$ & ZLECTRICITY & $\begin{array}{r}\text { SECTOR } \\
\text { TOTAL }\end{array}$ & \\
\hline $\begin{array}{l}\text { FINAL LEMANC } \equiv \text { ICTORS } \\
\text { RESIDENTIAL, ECMM. } \\
\text { INDOSTRIAL } \\
\text { TRANSPORTATIEN } \\
\text { MISCELIANECE OSES }\end{array}$ & $\begin{array}{r}2,627 \\
7,3.54 \\
8,4.28 \\
251\end{array}$ & $\begin{array}{r}494 \\
31.450 \\
317 \\
192\end{array}$ & $36,36 \overline{-}$ & $\begin{array}{r}4.538 \\
36.540 \\
1.460 \\
7\end{array}$ & $\begin{array}{l}\overline{-} \\
-\end{array}$ & $\begin{array}{r}9,974 \\
56,1 C 2 \\
496 \\
1 \equiv 9\end{array}$ & $\begin{array}{r}33 \\
3,533 \\
- \\
-\end{array}$ & $\begin{array}{r}13,058 \\
23,596 \\
- \\
73\end{array}$ & $\begin{array}{r}30,724 \\
158,590 \\
47,065 \\
672\end{array}$ & $\begin{array}{r}17 \% \\
57 \% \\
17 \% \\
0 \%\end{array}$ \\
\hline $\begin{array}{l}\text { TCTAL FINAI } \\
\text { DEMAND SECICRS }\end{array}$ & 13,630 & 32.453 & 36,364 & 42.545 & - & $66,7 \pi 1$ & $3,5,1$ & 36,727 & 237,051 & $25 \%$ \\
\hline $\begin{array}{l}\text { TEANSFCRMATICA } \\
\text { FLECTRICITY GEN- } \\
\text { FETROLEOM ERCDOCTS } \\
\text { NATORAL GAS } \\
\text { SYNTEETICS }\end{array}$ & $\begin{array}{r}4,123 \\
-25,5+6 \\
- \\
-\end{array}$ & $\begin{array}{r}13.403 \\
-1.640 \\
- \\
-\end{array}$ & $\begin{array}{r}-43,784 \\
-\end{array}$ & $\begin{array}{r}-46.076 \\
-\end{array}$ & $\begin{array}{r}-252 \\
-\end{array}$ & $\begin{array}{r}3,152 \\
9,813 \\
- \\
-\end{array}$ & $\begin{array}{r}31,290 \\
- \\
- \\
-\end{array}$ & $\begin{array}{r}-17,561 \\
- \\
-\end{array}$ & $\begin{array}{r}34,407 \\
1,019 \\
- \\
-\end{array}$ & $\begin{aligned} 12 \% \\
0 \%\end{aligned}$ \\
\hline $\begin{array}{l}\text { NET FOFI OSEL } \\
\text { IN TRANSFOEUATION }\end{array}$ & $-22,4 \geq 3$ & 11.762 & $-43,784$ & -46.076 & 109,252 & 12,065 & $31,2 \leq 0$ & $-17,561$ & 35,426 & $\cdot \Xi x$ \\
\hline $\begin{array}{l}\text { TCIAL CROSS FICNS } \\
\text { LCSSES } \varepsilon \text { OMISSIONS }\end{array}$ & $\begin{array}{r}22,8) 3 \\
1,4 \pi 9\end{array}$ & $\begin{array}{r}45,856 \\
0\end{array}$ & $\begin{array}{r}36,364 \\
0\end{array}$ & $\begin{array}{l}42.545 \\
-1.678\end{array}$ & $\begin{array}{r}109,252 \\
4, \leq 32\end{array}$ & $\begin{array}{l}79,676 \\
-2,153\end{array}$ & $\begin{array}{r}34,86 ? \\
47\end{array}$ & $\begin{array}{r}36,727 \\
3,047\end{array}$ & $\begin{array}{r}272,477 \\
5,640\end{array}$ & $\begin{array}{l}-8 \pi \\
2 \pi\end{array}$ \\
\hline TCIAL NET OSAGE & $-2,3 \geq 3$ & 44,216 & $-7,419$ & -5.209 & 113,784 & 77,523 & $35,3 \Xi 2$ & 22,213 & 278,118 & \\
\hline $\begin{array}{l}\text { SOFELY OF EVEBCY } \\
\text { FCSSIL FOEI } \\
\text { HYLPCELECTEIC } \\
\text { NOCLEAR } \\
\text { GEO. ESOLAR }\end{array}$ & $\begin{array}{l}- \\
\overline{-} \\
-\end{array}$ & $\begin{array}{l}- \\
- \\
-\end{array}$ & $\overline{-}$ & $\begin{array}{l}- \\
- \\
-\end{array}$ & $\begin{array}{r}52,228 \\
- \\
-\end{array}$ & $\begin{array}{r}11,926 \\
- \\
-\end{array}$ & $\begin{array}{l}- \\
- \\
-\end{array}$ & $\begin{array}{r}139 \\
614 \\
321\end{array}$ & $\begin{array}{r}64,154 \\
139 \\
614 \\
321\end{array}$ & $\begin{array}{r}\mathrm{c} 8 \% \\
0 \% \\
1 \% \\
0 \%\end{array}$ \\
\hline TLTAL SOPPLY. & - & - & - & - & 52,228 & 11,926 & - & 1.074 & 55,228 & \\
\hline
\end{tabular}

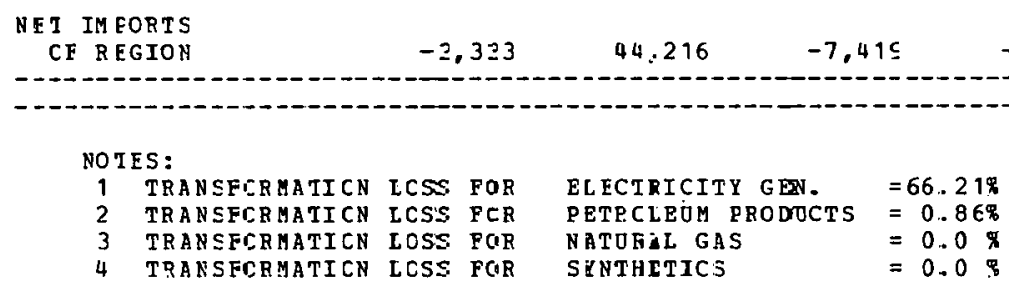


REGIONAL ENEFGY PALANCE STATEMENT

PIES HID MID SCENARIO

\begin{tabular}{|c|c|c|c|c|c|c|c|c|c|c|}
\hline SECTOF & $\begin{array}{c}\text { DISTILLATE } \\
\text { OIL } \\
.\end{array}$ & $\begin{array}{l}\text { RES IDVAI } \\
\text { OIL }\end{array}$ & $\begin{array}{l}\text { GASOLINE } \\
\text { (ALL DNIT }\end{array}$ & $\begin{array}{c}\text { OTHER } \\
\text { HYDRO- } \\
\text { CABBONS } \\
\text { TS IN } 10 * * 9\end{array}$ & $\begin{array}{c}\text { CRODE } \\
\text { OIL } \\
\text { BTO'S) }\end{array}$ & $\begin{array}{l}\text { NATORAL } \\
\text { GAS }\end{array}$ & COAL & ELECTRICITY & $\begin{array}{l}\text { SECTOR } \\
\text { TOTAL }\end{array}$ & \\
\hline $\begin{array}{l}\text { PIEAL CEAARC SECTOES } \\
\text { RESIDENTIAL, CCMH. } \\
\text { IEDOSTRIAL } \\
\text { TEANSPORTATICN } \\
\text { HISCELLANECOS OSES }\end{array}$ & $\begin{array}{r}2,781 \\
1,163 \\
16.328 \\
466\end{array}$ & $\begin{array}{r}222 \\
2,713 \\
796 \\
245\end{array}$ & $52,18 \frac{-}{-}$ & $\begin{array}{r}5,591 \\
6,760 \\
1.705 \\
18\end{array}$ & $\begin{array}{l}\overline{-} \\
\bar{z}\end{array}$ & $\begin{array}{r}8,287 \\
30,404 \\
400 \\
429\end{array}$ & $\begin{array}{r}79 \\
6,962 \\
- \\
1\end{array}$ & $\begin{array}{r}25,000 \\
24,929 \\
- \\
239\end{array}$ & $\begin{array}{r}41,960 \\
72,931 \\
71,411 \\
1,398\end{array}$ & $\begin{array}{r}18 \% \\
31 \% \\
30 \% \\
1 \%\end{array}$ \\
\hline $\begin{array}{l}\text { TCTAI FINAL } \\
\text { DEMAND SECTCRS }\end{array}$ & 20,738 & 3,976 & 52,182 & 14,074 & - & 39,520 & 7,042 & 50,168 & 187,700 & $79 \%$ \\
\hline $\begin{array}{l}\text { TRINSPCRMATICN } \\
\text { FLECTRICITY GEN. } \\
\text { FETR CLEOH ERCDOCTS } \\
\text { EATURAL GAS } \\
\text { SY NTHETICS }\end{array}$ & $\begin{array}{r}6,434 \\
-1,834 \\
-\end{array}$ & $\begin{array}{r}-113 \\
- \\
-\end{array}$ & $\begin{array}{r}-3,025 \\
-\end{array}$ & $\begin{array}{r}-3,183 \\
- \\
-\end{array}$ & $\begin{array}{r}7.548 \\
-\end{array}$ & $\begin{array}{r}678 \\
-\end{array}$ & $\begin{array}{r}59,904 \\
- \\
-\end{array}$ & $\begin{array}{r}-22,877 \\
- \\
-\end{array}$ & $\begin{array}{r}43,461 \\
70 \\
- \\
-\end{array}$ & $\begin{array}{r}18 \% \\
0 \%\end{array}$ \\
\hline $\begin{array}{l}\text { NET FOFI OSET } \\
\text { IN TRANSFOKATIOS }\end{array}$ & 4,599 & -113 & $-3,025$ & $-3,183$ & 7,548 & 678 & 59,904 & $-22,877$ & 43,531 & $18 \%$ \\
\hline $\begin{array}{l}\text { TCIAL GROSS FLCRS } \\
\text { LCSSES } \varepsilon \text { OHISSIONS }\end{array}$ & $\begin{array}{r}27,172 \\
1,691\end{array}$ & $\begin{array}{r}3,976 \\
0\end{array}$ & 52,182 & $\begin{array}{r}14.074 \\
-555\end{array}$ & $\begin{array}{r}7,548 \\
313\end{array}$ & $\begin{array}{l}40,198 \\
-1,086\end{array}$ & $\begin{array}{r}66,946 \\
906\end{array}$ & $\begin{array}{r}50,168 \\
4,162\end{array}$ & $\begin{array}{r}231,231 \\
5,432\end{array}$ & $\begin{array}{r}98 \% \\
2 \%\end{array}$ \\
\hline TCTAL NET OSAGE & 27,029 & 3,862 & 49,157 & 10,335 & 7,861 & 39,111 & 67,852 & 31,453 & 236,663 & \\
\hline
\end{tabular}

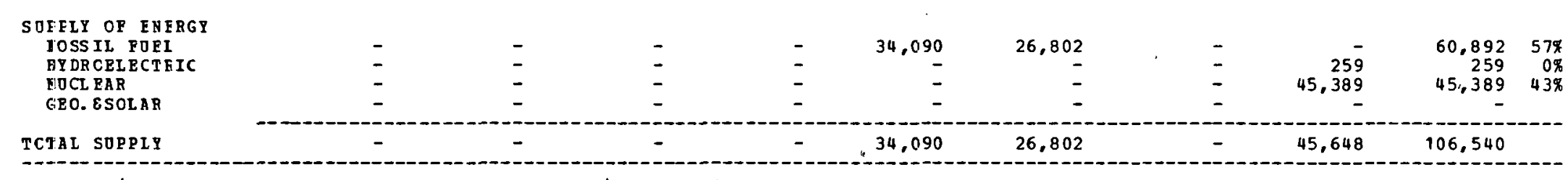

RET IM PORTS
GP REGION


REGIONAL ENEFGI BALANCE STATEMENT

PIES MII MID SCENABIO

\begin{tabular}{|c|c|c|c|c|c|c|c|c|c|}
\hline SECTOE & $\begin{array}{c}\text { DISTILLETE } \\
\qquad=I L\end{array}$ & $\underset{\text { OII }}{\text { RES IIJAL }}$ & $\begin{array}{l}\text { 3ASOLINE } \\
\text { (ALL ONIT }\end{array}$ & $\begin{array}{c}\text { CIRER } \\
\text { HYDRD- } \\
\text { CAEBONS } \\
\text { TS IN } 10 * * 9\end{array}$ & $\begin{array}{l}\text { CRODF } \\
\text { OIL. } \\
\text { BTO'S) }\end{array}$ & $\begin{array}{l}\text { NATJRAL } \\
\text { GAS }\end{array}$ & $\operatorname{COA} L$ & ELECTRICITY & $\begin{array}{l}\text { SECTOR } \\
\text { TOTAL }\end{array}$ \\
\hline $\begin{array}{l}\text { PINIL CENANC SECTORS } \\
\text { RESIDENTIAI, CCHH. } \\
\text { INDOSTRIAL } \\
\text { IRANSPORTATICR } \\
\text { HISCELLANEOES OSES }\end{array}$ & $\begin{array}{r}1,8 \subseteq 1 \\
1,0 \leq 8 \\
12,2 \varepsilon 7 \\
3 \equiv 0\end{array}$ & $\begin{array}{r}156 \\
2,471 \\
1,036 \\
173\end{array}$ & $\begin{array}{r}\overline{-} \\
36,78 \overline{5}\end{array}$ & $\begin{array}{r}3,944 \\
5,844 \\
1,474 \\
14\end{array}$ & $\begin{array}{l}\overline{-} \\
\overline{-}\end{array}$ & $\begin{array}{r}5,660 \\
30,685 \\
342 \\
337\end{array}$ & $\begin{array}{r}51 \\
4,519 \\
- \\
-\end{array}$ & $\begin{array}{r}17,228 \\
21,661 \\
- \\
179\end{array}$ & $\begin{array}{r}28,930 \\
66,208 \\
51,924 \\
1,033\end{array}$ \\
\hline $\begin{array}{l}\text { TCTAL FINAI } \\
\text { DEMAND SPCTCRS }\end{array}$ & $1 E, 5 \vdots 6$ & 3,836 & 36,785 & $\cdot 1,276$ & - & 37,024 & $4,57 \mathrm{C}$ & 39,068 & 148,095 \\
\hline $\begin{array}{l}\text { TRANSPCRHATICA } \\
\text { ELECTRICITY EEN. } \\
\text { PETR OLEUH ERCDOCTS } \\
\text { NATURAL GAS } \\
\text { SY NT BETICS }\end{array}$ & $\begin{array}{r}5.0: 1 \\
-15.78 ; 3 \\
- \\
-\end{array}$ & $\begin{array}{r}3.002 \\
-1.222 \\
=\end{array}$ & $\begin{array}{r}-32.62 \bar{s} \\
\overline{-}\end{array}$ & $\begin{array}{r}-34,33 \overline{8} \\
- \\
-\end{array}$ & 81,418 & $\begin{array}{r}7.31 .3 \\
- \\
-\end{array}$ & $\begin{array}{r}61.833 \\
- \\
=\end{array}$ & $\begin{array}{r}-23,945 \\
- \\
-\end{array}$ & $\begin{array}{r}45,911 \\
759 \\
- \\
-\end{array}$ \\
\hline $\begin{array}{l}\text { NET FOFL OSEL } \\
\text { IN TRANSPOHEATION }\end{array}$ & $-1 c, 7 \varepsilon .2$ & 1.779 & $-32,629$ & $-34,338$ & 81,418 & 7,313 & $61,83 \equiv$ & $-23,945$ & 46,670 \\
\hline $\begin{array}{l}\text { TCTAL GROSS FIORS } \\
\text { LCSSES E OHISEIONS }\end{array}$ & $\begin{array}{r}25,557 \\
7,2=9\end{array}$ & $\begin{array}{r}\epsilon, 838 \\
0\end{array}$ & 36,785 & $\begin{array}{r}11,276 \\
-444\end{array}$ & $\begin{array}{r}81,418 \\
3, \equiv 77\end{array}$ & $\begin{array}{l}44,337 \\
-1,193\end{array}$ & $\begin{array}{r}66.40 \Xi \\
89 \varepsilon\end{array}$ & $\begin{array}{r}39,068 \\
3,241\end{array}$ & $\begin{array}{r}194,765 \\
7,155\end{array}$ \\
\hline TOTAL HET OSAGE & 2,053 & 5.615 & $4,15 \epsilon$ & $-23, .506$ & 84,796 & 43,139 & $67,30 i$ & 18,364 & 201,920 \\
\hline
\end{tabular}

\begin{tabular}{|c|c|c|c|c|c|c|c|c|c|c|}
\hline SOEELY OP ENEESY & & & & & & & & & & \\
\hline FOSS IL FOEI & - & - & - & - & $167, \div 96$ & 14.067 & - & - & 181,363 & \\
\hline HY DRCELECTEIC & - & - & - & - & - & - & - & 202 & 202 & $0 \%$ \\
\hline NOCL BAR & - & - & - & - & - & - & - & - & - & \\
\hline GEC. ESOLAR & - & - & - & & - & - & & - & - & \\
\hline TOTAL SOPPLY & - & - & - & - & 167,296 & 14,067 & - & 202 & 131,565 & \\
\hline
\end{tabular}

NET IM EORTS
OP REGION


RZGICNAL ENEFGY EALANCE STATEMENT

PIES MID MI D SCENARID

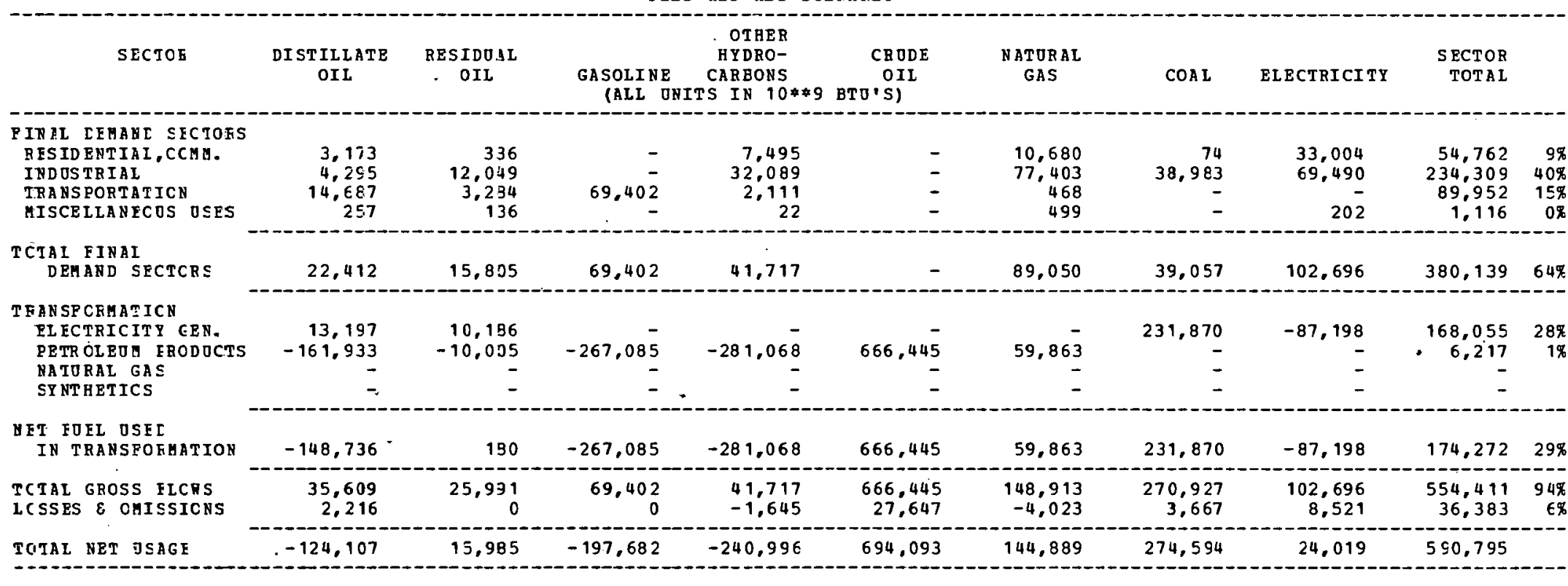

\begin{tabular}{|c|c|c|c|c|c|c|c|c|c|c|}
\hline SOEFLY OP ENERGY & & & & & & & & & & \\
\hline FOSSIL FOEI & - & - & - & - & 20,458 & 6,635 & - & - & 27,093 & $95 \%$ \\
\hline HY DRCELECTEIC & - & - & - & - & - & - & - & 1,384 & 1,384 & $5 \%$ \\
\hline NOCL EAR & - & - & - & - & - & - & - & - & - & \\
\hline GEC. ESOLAR & - & - & - & - & - & $\rightarrow$ & - & - & - & \\
\hline ICTAL SOPPIY & - & - & - & - & 20,458 & 6,635 & - & 1,384 & 28,477 & \\
\hline
\end{tabular}

$-$

673.635

138,254

274,594

22,635

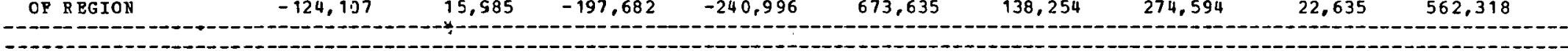

\section{NOT TBS:}

$\begin{array}{lllll}1 & \text { TRANSPORMATICN } & \text { LOSS POR } & \text { ELECTRICITY GEN. } & =65.84 \% \\ 2 & \text { TRANSFCRMATICN } & \text { LOSS POR } & \text { PETROLEOM PROD OCTS } & =0.86 \% \\ 3 & \text { TRANSPORAIICN } & \text { LCSS POR } & \text { NATURAI GAS } & =.0 .0 \% \\ 4 & \text { TRANSPORATICN LCSS FOR } & \text { SYNTHETICS } & =0.0 \%\end{array}$


REGICNAL ENEFGY BALANCE STATEMENT

PIES RIC MID SCENARIO

\begin{tabular}{|c|c|c|c|c|c|c|c|c|c|c|}
\hline SECTOR & $\begin{array}{l}\text { DISTILLATB } \\
\text { OIL }\end{array}$ & $\begin{array}{l}\text { RESIDCAL } \\
\text { OII. }\end{array}$ & $\begin{array}{l}\text { GASOLINE } \\
\text { (AEI D }\end{array}$ & $\begin{array}{c}\text { CTHER } \\
\text { HYDRO- } \\
\text { CAIBONS } \\
\text { NITS IN 10**9 }\end{array}$ & $\begin{array}{c}\text { CRODE } \\
\text { OIL } \\
\text { BTD.'S) }\end{array}$ & $\begin{array}{l}\text { NATURAL } \\
\text { GAS }\end{array}$ & $\cos L$ & ELECTRICITY & $\begin{array}{r}\text { SECTOR } \\
\text { TOTAL }\end{array}$ & \\
\hline $\begin{array}{l}\text { PIHAL CEHANE SECTORS } \\
\text { RESIDENTIAE, CCHH. } \\
\text { INDOSTRIAL } \\
\text { TRANSPORTAIICA } \\
\text { HISCELLANECOS OSBS }\end{array}$ & $\begin{array}{r}3,925 \\
39,268 \\
48,567 \\
2,948\end{array}$ & $\begin{array}{r}\varepsilon 86 \\
156, \leq 51 \\
37, \in 87 \\
2,456\end{array}$ & $161,2: \frac{-}{2}$ & $\begin{array}{r}27,509 \\
1,743,479 \\
18,528 \\
47\end{array}$ & $\begin{array}{l}\overline{-} \\
\overline{-}\end{array}$ & $\begin{array}{r}64,632 \\
1,228,810 \\
14,359 \\
1,038\end{array}$ & $\begin{array}{r}37 \\
16,352 \\
1 \\
-\end{array}$ & $\begin{array}{r}67,730 \\
106,740 \\
- \\
530\end{array}$ & $\begin{array}{r}164,719 \\
2,691,700 \\
280,354 \\
7,019\end{array}$ & $\begin{array}{r}5 \% \\
77 \% \\
8 \% \\
0 \%\end{array}$ \\
\hline $\begin{array}{l}\text { TCTAL FINAL } \\
\text { DEHAND SECTOBS }\end{array}$ & 94.708 & 197,580 & 161,2 i 2 & $1,189,563$ & - & $1,308,839$ & 16.390 & 175,000 & $3,143,792$ & $90 x$ \\
\hline $\begin{array}{l}\text { TBARSP ORHATICY } \\
\text { EL ECTRICISY GER. } \\
\text { PETR OLEOH FRODOCTS } \\
\text { NATORAL GAS } \\
\text { SYNTHETICS }\end{array}$ & $\begin{array}{r}15,561 \\
-387,044 \\
-\end{array}$ & $\begin{array}{r}-60,588 \\
-\end{array}$ & $\begin{array}{r}-1,627,90 \overline{1} \\
-\end{array}$ & $\begin{array}{r}-1.713 .22 \overline{-} \\
- \\
-\end{array}$ & $\begin{array}{r}- \\
4,062.252 \\
-\end{array}$ & $\begin{array}{r}145,961 \\
364, E 93 \\
- \\
-\end{array}$ & $\begin{array}{r}141,500 \\
- \\
-\end{array}$ & $\begin{array}{r}-100,267 \\
- \\
-\end{array}$ & $\begin{array}{r}202,755 \\
37,899 \\
- \\
-\end{array}$ & $\begin{array}{l}6 \% \\
1 x\end{array}$ \\
\hline $\begin{array}{l}\text { NET FOEL DSEL } \\
\text { IN TRANSPOEBATION }\end{array}$ & $-971,483$ & $-50,588$ & $-1,627,95.1$ & $-1,713,223$ & $4,062,252$ & 510,854 & 141,500 & $-100,267$ & $240,65 \underline{4}$ & $7 \%$ \\
\hline $\begin{array}{l}\text { TCTAL GROSS FIORS } \\
\text { LCSSES \& CHISSIONS }\end{array}$ & $\begin{array}{r}110,269 \\
6,863\end{array}$ & $\begin{array}{r}197,580 \\
3\end{array}$ & $\begin{array}{r}161,2: 2 \\
0\end{array}$ & $\begin{array}{r}1.189 .563 \\
-46,921\end{array}$ & $\begin{array}{r}4,062,252 \\
168,523\end{array}$ & $\begin{array}{r}1,819,673 \\
-49,172\end{array}$ & $\begin{array}{r}158,390 \\
2,143\end{array}$ & $\begin{array}{r}175,000 \\
14,520\end{array}$ & $\begin{array}{r}3,384,446 \\
95,962\end{array}$ & $\begin{array}{r}978 \\
3 \pi\end{array}$ \\
\hline TOTAL NET OSAGE & $-369,911$ & 136,595 & $-1,466,778$ & $-570,581$ & $4,230,775$ & $1,770,520$ & 160.533 & 89,253 & 3.480 .408 & \\
\hline $\begin{array}{l}\text { S OEPLY OP EUFRGY } \\
\text { FOSS IL FOEI } \\
\text { UY LROELECTRIC } \\
\text { HOCL EAR } \\
\text { GEO. ESOLAB }\end{array}$ & I & $\begin{array}{l}\overline{-} \\
\overline{-}\end{array}$ & $\bar{z}$ & $\begin{array}{l}- \\
\overline{-}\end{array}$ & $\begin{array}{r}1,455,092 \\
= \\
=\end{array}$ & $\begin{array}{r}1,490,238 \\
- \\
-\end{array}$ & $\begin{array}{l}\text { - } \\
-\end{array}$ & $\begin{array}{r}316 \\
59.157 \\
3,774\end{array}$ & $\begin{array}{r}2,945,330 \\
316 \\
59,157 \\
3,774\end{array}$ & $\begin{array}{r}98 \% \\
0 \% \\
28 \\
0 \%\end{array}$ \\
\hline TOTAL SOPPIE & - & - & - & - & $1,455,092$ & $1,490,238$ & - & 63,247 & $3,008,577$ & \\
\hline
\end{tabular}

MOTES:

\begin{tabular}{|c|c|c|}
\hline $\begin{array}{l}\text { TRAOSFCHAATICN } \\
\text { TRADSPCHATICN } \\
\text { TRADSPOBATICN } \\
\text { TRAESPORATICH }\end{array}$ & $\begin{array}{l}\operatorname{los} \\
\operatorname{los} \\
\operatorname{los} \\
\operatorname{los}\end{array}$ & $\begin{array}{l}\text { PO } \\
\text { PO } \\
\text { FO } \\
\text { PO }\end{array}$ \\
\hline
\end{tabular}


REGICNAL ENEEGY EALANCE SIATEMENT

\begin{tabular}{|c|c|c|c|c|c|c|c|c|c|c|}
\hline SECTOF & $\begin{array}{l}\text { IISTILLATE } \\
\text { OIL }\end{array}$ & $\begin{array}{l}\text { RESIDCAL } \\
\text { OIL }\end{array}$ & $\begin{array}{l}\text { GASOLINE } \\
\text { (ALL }\end{array}$ & $\begin{array}{c}\text { OTHER } \\
\text { HYDRO- } \\
\text { CARBONS } \\
\text { TS IN } 10 * \$ 9\end{array}$ & $\begin{array}{c}\text { CRODE } \\
\text { OIL } \\
\text { BTO'SI }\end{array}$ & $\begin{array}{l}\text { NATORAL } \\
\text { GAS }\end{array}$ & COAL & ELECTRICITY & $\begin{array}{r}\text { SECTOR } \\
\text { TOTAL }\end{array}$ & \\
\hline $\begin{array}{l}\text { PINAL CEMANL SECTOES } \\
\text { GFSIDENTIAL, CCMM- } \\
\text { INDOSTRIAI. } \\
\text { TRANSPORTATICN } \\
\text { UISCELLANEOOS OSIS }\end{array}$ & $\begin{array}{r}1,028 \\
26,665 \\
15,081 \\
1,210\end{array}$ & $\begin{array}{r}280 \\
98, \quad 09 \\
12,579 \\
1,619\end{array}$ & $51.92 \overline{-}$ & $\begin{array}{r}9,341 \\
220,620 \\
6,059 \\
3 \epsilon\end{array}$ & $\begin{array}{l}- \\
\overline{-} \\
-\end{array}$ & $\begin{array}{r}22,424 \\
487,108 \\
4,783 \\
701\end{array}$ & $\begin{array}{r}2 \\
3,824 \\
- \\
-\end{array}$ & $\begin{array}{r}20,517 \\
39,883 \\
- \\
464\end{array}$ & $\begin{array}{r}53,592 \\
876,209 \\
90,431 \\
3,430\end{array}$ & $\begin{array}{r}5 \% \\
79 \% \\
8 \% \\
C \%\end{array}$ \\
\hline $\begin{array}{l}\text { TCTAI FINAI } \\
\text { DEMAND SECTCRS }\end{array}$ & 43,984 & 111,987 & 51.929 & 236,056 & - & 515,016 & 3.826 & 60.864 & $1,023,662$ & $93 \%$ \\
\hline $\begin{array}{l}\text { P A BNSFCRMATICN } \\
\text { FLECTRICITY GEN. } \\
\text { PETROLEOM ERODOCTS } \\
\text { NATURAL GAS } \\
\text { SY NTHEIICS }\end{array}$ & $\begin{array}{r}5,108 \\
-157,107 \\
- \\
-\end{array}$ & $\begin{array}{r}-9, .07 \\
-\end{array}$ & $\begin{array}{r}-259,126 \\
-\end{array}$ & $\begin{array}{r}-272,692 \\
- \\
-\end{array}$ & $\begin{array}{r}- \\
- \\
-\end{array}$ & $\begin{array}{r}53,072 \\
58,079 \\
- \\
-\end{array}$ & $\begin{array}{r}41,522 \\
- \\
-\end{array}$ & $\begin{array}{r}-32,869 \\
- \\
-\end{array}$ & $\begin{array}{r}66,833 \\
6,032 \\
- \\
-\end{array}$ & $\begin{array}{l}\epsilon \% \\
1 \%\end{array}$ \\
\hline $\begin{array}{l}\text { NET FOEL OSEL } \\
\text { IN TRANSOFMATION }\end{array}$ & $-151,999$ & $-9,: 07$ & $-259,126$ & -272.692 & 646,585 & 111,151 & 41,522 & $-\equiv 2,869$ & 72,865 & $7 \%$ \\
\hline $\begin{array}{l}\text { TCTAL GROSS ELONS } \\
\text { LESSES \& OMISSIONS }\end{array}$ & $\begin{array}{r}49,092 \\
3,055\end{array}$ & $\begin{array}{r}111,987 \\
2\end{array}$ & $\begin{array}{r}51,929 \\
0\end{array}$ & $\begin{array}{r}236,056 \\
-9,311\end{array}$ & $\begin{array}{r}646,585 \\
26,823\end{array}$ & $\begin{array}{l}626,167 \\
-16,920\end{array}$ & $\begin{array}{r}45,348 \\
613\end{array}$ & $\begin{array}{r}60,864 \\
5,050\end{array}$ & $\begin{array}{r}1,096,527 \\
9,314\end{array}$ & $\begin{array}{r}99 \% \\
19\end{array}$ \\
\hline
\end{tabular}

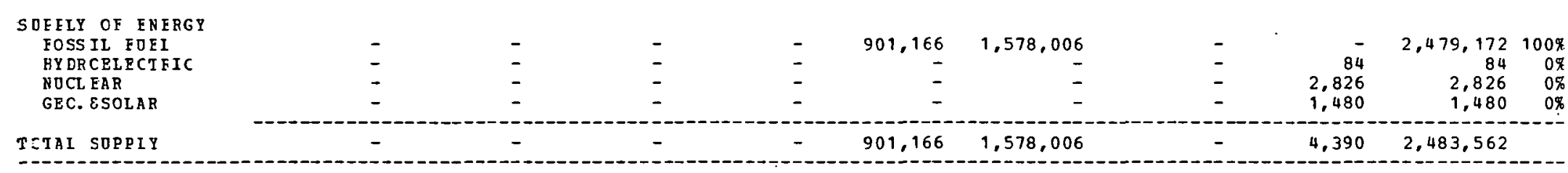

-

\begin{tabular}{l}
$\begin{array}{l}\text { NET IM FORTS } \\
\text { CF REGION }\end{array}$ \\
\hline
\end{tabular}


REGIONAL EHZEGY EALANCE STATEMENT

\begin{tabular}{|c|c|c|c|c|c|c|c|c|c|c|}
\hline SECTCE & $\begin{array}{l}\text { DISTILLATE } \\
\text { OIL }\end{array}$ & $\begin{array}{l}\text { RESIJOAL } \\
\text { CIL }\end{array}$ & $\begin{array}{l}\text { GASOLILE } \\
\text { (ALL }\end{array}$ & $\begin{array}{c}\text { OTFER } \\
\text { H?DFO- } \\
\text { CARBCNS } \\
\text { NITS IN } 10 * \$ 9\end{array}$ & $\begin{array}{c}\text { CROLE } \\
\text { OII } \\
\text { BTO'S) }\end{array}$ & $\begin{array}{l}\text { NATURAL } \\
\text { GAS }\end{array}$ & $\operatorname{COAL}$ & ELECTRICITY & $\begin{array}{r}\text { SECTOR } \\
\text { TOTAL }\end{array}$ & \\
\hline $\begin{array}{l}\text { PIKAL IEMANL STCTCRS } \\
\text { RESIDENTIAL, CCAM. } \\
\text { I NDOSTRIAL } \\
\text { TRANSPORTATICN } \\
\text { MISCELIANECS OSES }\end{array}$ & $\begin{array}{l}2,211 \\
6,655 \\
5,576 \\
432\end{array}$ & $\begin{array}{r}401 \\
2 \varepsilon, 111 \\
4,319 \\
364\end{array}$ & $36,46 \overline{9}$ & $\begin{array}{r}5,042 \\
458,515 \\
5,996 \\
7\end{array}$ & $\begin{array}{l}\bar{z} \\
\bar{z}\end{array}$ & $\begin{array}{r}12,862 \\
414,171 \\
1,554 \\
147\end{array}$ & $\begin{array}{r}- \\
6,77 \bar{C} \\
- \\
-\end{array}$ & $\begin{array}{r}10,733 \\
21,324 \\
- \\
76\end{array}$ & $\begin{array}{r}31,279 \\
945,546 \\
53,914 \\
1,028\end{array}$ & $\begin{array}{r}3 \% \\
E 1 \% \\
5 \% \\
0 \%\end{array}$ \\
\hline $\begin{array}{l}\text { TCTAI FINAI } \\
\text { DEMAND SECICRS }\end{array}$ & 114,904 & $3 \Xi .195$ & $36,46 \mathrm{G}$ & 459.560 & - & 428,735 & $6,77 \mathrm{C}$ & 42,133 & $1,031,767$ & $\varepsilon 9 \%$ \\
\hline $\begin{array}{l}\text { TRANSPCRMATICE } \\
\text { FLECTRICITY GEN. } \\
\text { FETR OLEOM FEODOCTS } \\
\text { NATORAL GAS } \\
\text { SY NTETICS }\end{array}$ & $\begin{array}{r}3,536 \\
-5 \subseteq 3,350 \\
-\end{array}$ & $\begin{array}{r}- \\
-3 E .663 \\
- \\
-\end{array}$ & $\begin{array}{r}- \\
-978,66 i \\
- \\
-\end{array}$ & $\begin{array}{r}- \\
-1,029,901 \\
-\end{array}$ & $\begin{array}{r}2,442, \mathrm{C} 15 \\
- \\
-\end{array}$ & $\begin{array}{r}44,34 t \\
219,354 \\
- \\
-\end{array}$ & $\begin{array}{r}10,267 \\
- \\
-\end{array}$ & $\begin{array}{r}-19,108 \\
- \\
-\end{array}$ & $\begin{array}{r}39,039 \\
22,781 \\
- \\
-\end{array}$ & $\begin{array}{l}3 \% \\
2 \%\end{array}$ \\
\hline $\begin{array}{l}\text { NET FUEL OSEL } \\
\text { IN TRANSFEFATION }\end{array}$ & $-5 \varepsilon 9,8 \geq 4$ & -36.663 & $-978,664$ & $-1,029,901$ & $2,442, C 15$ & 263,693 & $10,26 \pi$ & $-19,108$ & 61,820 & $5 \%$ \\
\hline $\begin{array}{l}\text { TCTAL GROSS FLZWS } \\
\text { LCSSES } \varepsilon \text { OMISSIONS }\end{array}$ & $\begin{array}{r}18,4<0 \\
1,147\end{array}$ & 33.195 & $36,46 \frac{c}{c}$ & $\begin{array}{l}459,560 \\
-18,521\end{array}$ & $\begin{array}{r}2,442, C 15 \\
101, \equiv 07\end{array}$ & $\begin{array}{l}692,434 \\
-18,711\end{array}$ & $\begin{array}{r}17,037 \\
236\end{array}$ & $\begin{array}{r}42,133 \\
3,495\end{array}$ & $\begin{array}{r}1,093,587 \\
68,950\end{array}$ & $\begin{aligned} \subseteq 4 \% \\
6 \%\end{aligned}$ \\
\hline
\end{tabular}

\begin{tabular}{|c|c|c|c|c|c|c|c|c|c|c|}
\hline $\begin{array}{l}\text { SOFFLY OF FNFESY } \\
\text { FCSSIL FOEL }\end{array}$ & - & - & - & - & 67,450 & 66,085 & - & - & 133,536 & $\subseteq 8 \%$ \\
\hline HY DRCELECTFJC & - & - & - & - & - & - & - & 58 & & $0 \%$ \\
\hline NUCL EAR & - & - & - & - & - & - & - & 1,956 & 1,956 & $1 \%$ \\
\hline GEC. ESOLAR & - & - & - & - & - & - & - & 1.024 & 1,024 & $1 \%$ \\
\hline TCTAL SOPEIY & - & - & - & - & 67,450 & 66,085 & - & 3,038 & 136,574 & \\
\hline
\end{tabular}

UET IM PCRTS
CF REGION


REGIONAL ENEFGY FALANCE STATEMENT

\begin{tabular}{|c|c|c|c|c|c|c|c|c|c|c|}
\hline SECTOE & $\begin{array}{l}\text { DISTILLATE } \\
\text { OIL }\end{array}$ & $\begin{array}{l}\text { RESIDUAL } \\
\text { OIL }\end{array}$ & $\begin{array}{l}\text { GASOLINE } \\
\text { (ALL OI }\end{array}$ & $\begin{array}{c}\text { OTHER } \\
\text { AYDRG- } \\
\text { CARBONS } \\
\text { NITS IN } 10 * \$ 9\end{array}$ & $\begin{array}{c}\text { CROLE } \\
\text { OIL } \\
\text { BTJ'S) }\end{array}$ & $\begin{array}{l}\text { NATDRAL } \\
\text { GAS }\end{array}$ & $\operatorname{COAL}$ & ELECTRICITY & $\begin{array}{r}\text { SECTOR } \\
\text { TOTAL }\end{array}$ & \\
\hline $\begin{array}{l}\text { FINRI LEMANC SECTORS } \\
\text { KESIDENTIAI, CCMB. } \\
\text { INDOSTRIAL } \\
\text { IEANSPORTATICN } \\
\text { MISCELLANECTS OSES }\end{array}$ & $\begin{array}{r}20,891 \\
26,548 \\
67,653 \\
5,264\end{array}$ & $\begin{array}{r}4,865 \\
103,104 \\
42,521 \\
4,430\end{array}$ & $\begin{array}{r}\overline{-} \\
312,469 \\
-\end{array}$ & $\begin{array}{r}43,529 \\
1,534,107 \\
59,311 \\
80\end{array}$ & $\begin{array}{l}\overline{-} \\
\overline{-}\end{array}$ & $\begin{array}{r}116,192 \\
1,658,327 \\
15,309 \\
1,735\end{array}$ & $\begin{array}{r}34.764 \\
1 \\
-\end{array}$ & $\begin{array}{r}108,696 \\
130,081 \\
- \\
865\end{array}$ & $\begin{array}{r}294,173 \\
3,486,931 \\
497,264 \\
12,374\end{array}$ & $\begin{array}{r}6 \% \\
74 \% \\
119 \% \\
0 \%\end{array}$ \\
\hline $\begin{array}{l}\text { TCTA I FINAI } \\
\text { DEMAND SBCTCRS }\end{array}$ & 120,356 & 154,920 & 312,469 & $1,637,027$ & - & $1,791,563$ & 34,765 & 239,642 & $4,290,742$ & 917 \\
\hline $\begin{array}{l}\text { TRANSFCRMATICN } \\
\text { ELECTRICITY GEN. } \\
\text { FETRCLEOM ERCDOCTS } \\
\text { FATURAL GAS } \\
\text { SYNTHETICS }\end{array}$ & $\begin{array}{r}20,111 \\
-1,036,632 \\
- \\
-\end{array}$ & $\begin{array}{r}-64.052 \\
-\end{array}$ & $\begin{array}{r}- \\
-1,709,780 \\
-\end{array}$ & $\begin{array}{r}-1,799,294 \\
- \\
-\end{array}$ & $\begin{array}{r}4,266,337 \\
-\end{array}$ & $\begin{array}{r}202,862 \\
383,225 \\
- \\
-\end{array}$ & $\begin{array}{r}252,153 \\
- \\
-\end{array}$ & $\begin{array}{r}-155,652 \\
- \\
-\end{array}$ & $\begin{array}{r}319,474 \\
39.804 \\
- \\
-\end{array}$ & $\begin{array}{l}7 \% \\
1 \%\end{array}$ \\
\hline $\begin{array}{l}\text { NEI FDEL OSEL } \\
\text { IN TRANSFOFMATION }\end{array}$ & $-1,016,521$ & -64.052 & $-1,709,780$ & $-1,799,294$ & 4.266 .337 & $586, C 87$ & 252,153 & $-155,652$ & 359.278 & $8 \%$ \\
\hline $\begin{array}{l}\text { TCTAL GROSS FLCWS } \\
\text { LCSSES \& CMISSIONS }\end{array}$ & $\begin{array}{r}140,467 \\
8,743\end{array}$ & $\begin{array}{r}154,920 \\
3\end{array}$ & $\begin{array}{r}312,469 \\
1\end{array}$ & $\begin{array}{r}1,637,027 \\
-64,571\end{array}$ & $\begin{array}{r}4,266,337 \\
176,990\end{array}$ & $\begin{array}{r}2,377,650 \\
-64,249\end{array}$ & $\begin{array}{r}286,918 \\
3,883\end{array}$ & $\begin{array}{r}239,642 \\
19,884\end{array}$ & $\begin{array}{r}4.650,020 \\
80.684\end{array}$ & $\begin{array}{r}98 \% \\
2 \pi\end{array}$ \\
\hline
\end{tabular}

\begin{tabular}{|c|c|c|c|c|c|c|c|c|c|c|}
\hline $\begin{array}{l}\text { SOFELY OF ENERGY } \\
\text { FOSSIL FOEI } \\
\text { BYDRCELECTEIC } \\
\text { BOCL EAR } \\
\text { GEO. ESOLAF }\end{array}$ & $\begin{array}{l}\bar{z} \\
\bar{z}\end{array}$ & $\begin{array}{l}\overline{-} \\
\overline{-}\end{array}$ & $\begin{array}{l}- \\
-\end{array}$ & $\begin{array}{l}- \\
-\end{array}$ & $\begin{array}{r}705,103 \\
- \\
-\end{array}$ & $\begin{array}{r}556,150 \\
- \\
-\end{array}$ & $\begin{array}{l}- \\
- \\
-\end{array}$ & $\begin{array}{r}330 \\
48,569 \\
5,825\end{array}$ & $\begin{array}{r}1,261,253 \\
330 \\
48,569 \\
5,825\end{array}$ & $\begin{array}{r}9 \in \% \\
0 \% \\
4 \% \\
0 \%\end{array}$ \\
\hline TCEAI SUPPIY & - & - & - & - & 705,103 & 556,150 & - & 54,724 & $1,315,977$ & \\
\hline
\end{tabular}

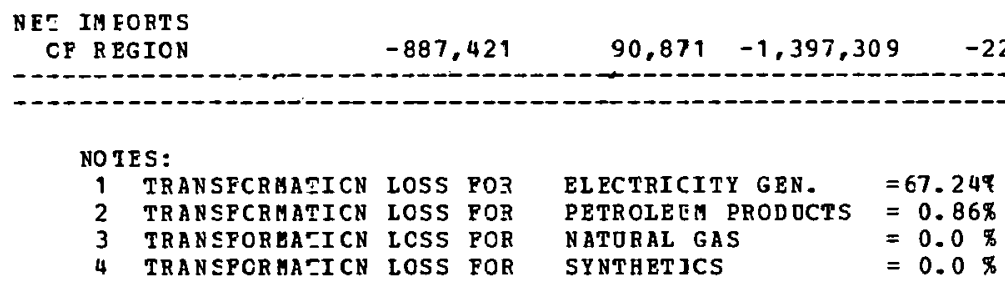


REGIONAL ENEFGY EALANCE STATEMENT

PIES MIE MID SCENARIO

\begin{tabular}{|c|c|c|c|c|c|c|c|c|c|c|}
\hline SECTOK & $\begin{array}{l}\text { DISTILLATE } \\
\text { OII }\end{array}$ & $\begin{array}{l}\text { RESIJUAL } \\
\text { OII }\end{array}$ & $\begin{array}{l}\text { GASOLINE } \\
\text { (ALL OHI }\end{array}$ & $\begin{array}{l}\text { CTHER } \\
\text { HYDRO- } \\
\text { SAEPONS } \\
\text { TS IN } 10 * * 9\end{array}$ & $\begin{array}{c}\text { CBODE } \\
\text { OII } \\
\text { BTUSI) }\end{array}$ & $\begin{array}{l}\text { NATURAL } \\
\text { GAS }\end{array}$ & $\operatorname{CCsL}$ & ELECTRICITY & $\begin{array}{l}\text { SECTOF: } \\
\text { TOTAI }\end{array}$ & \\
\hline $\begin{array}{l}\text { PINAL CEMANC SECTCBS } \\
\text { RESIDENTIAL, CCMH. } \\
\text { INDOSTRIAL } \\
\text { TRANSPORTAZION } \\
\text { MISCELIANECCS OSES }\end{array}$ & $\begin{array}{r}8.700 \\
4,385 \\
20,056 \\
5.367\end{array}$ & $\begin{array}{r}1,650 \\
13,323 \\
7,974 \\
4,517\end{array}$ & $\begin{array}{r}\overline{-} \\
134.431 \\
-\end{array}$ & $\begin{array}{r}: 8,670 \\
1: 3,636 \\
-1,226 \\
112\end{array}$ & $\begin{array}{l}- \\
\overline{-}\end{array}$ & $\begin{array}{r}48,958 \\
205,259 \\
2,859 \\
2,311\end{array}$ & $\begin{array}{r}6.327 \\
-\end{array}$ & $\begin{array}{r}43,969 \\
24,849 \\
- \\
1,292\end{array}$ & $\begin{array}{r}122,157 \\
367,789 \\
176,556 \\
13,599\end{array}$ & $\begin{array}{r}15 \% \\
45 \% \\
22.8 \\
2 . \%\end{array}$ \\
\hline $\begin{array}{l}\text { TCTAI FINAI } \\
\text { DEMAND SRCTCPS }\end{array}$ & 38,508 & 27,664 & 134,031 & 143,644 & - & 259,417 & 6,327 & 70.110 & 680,101 & 83.6 \\
\hline $\begin{array}{l}\text { TRANSFCRMAT }-C N \\
\text { BLECTRICITY GEN. } \\
\text { PETRCLED ERCEOCTS } \\
\text { NATORAL GES } \\
\text { SYNTHETICS }\end{array}$ & $\begin{array}{r}5.884 \\
-2.017 \\
- \\
-\end{array}$ & $\begin{array}{r}-124 \\
-\end{array}$ & $\begin{array}{r}- \\
-3,327 \\
-\end{array}$ & $\begin{array}{r}-3,502 \\
\overline{-}\end{array}$ & $8,30 \overline{3}$ & $\begin{array}{r}76,517 \\
745 \\
- \\
-\end{array}$ & $\begin{array}{r}128,056 \\
- \\
-\end{array}$ & $\begin{array}{r}-69,474 \\
- \\
-\end{array}$ & $\begin{array}{r}140,983 \\
77 \\
- \\
-\end{array}$ & $\begin{array}{r}17.8 \\
0.8\end{array}$ \\
\hline $\begin{array}{l}\text { NET FUEL USIL } \\
\text { IN TRANSFOFMATION }\end{array}$ & 3.866 & -124 & $-3,327$ & $-3,502$ & $\varepsilon, 303$ & $77,2.52$ & 128,056 & $-69,474$ & 141.060 & 17.8 \\
\hline $\begin{array}{l}\text { TCIAL GROSS FLCAS } \\
\text { LCSSES } \varepsilon \text { OMJSSICNS }\end{array}$ & $\begin{array}{r}44.392 \\
2.763\end{array}$ & $\begin{array}{r}27,664 \\
0\end{array}$ & $\begin{array}{r}134,[31 \\
0\end{array}$ & $\begin{array}{r}113,644 \\
-5,665\end{array}$ & $\begin{array}{r}8,303 \\
344\end{array}$ & $\begin{array}{r}336,679 \\
-9,0.37\end{array}$ & $\begin{array}{r}134,383 \\
1,818\end{array}$ & $\begin{array}{r}70,110 \\
5,817\end{array}$ & $\begin{array}{r}821,161 \\
-4,018\end{array}$ & $\begin{array}{r}100.8 \\
0.8\end{array}$ \\
\hline TCTAL NET OSAGE & 45.137 & 27.539 & 131,03 & $1 \equiv 4,476$ & 8,648 & 327,532 & 136,201 & 6,453 & $817,14 \bar{z}$ & \\
\hline $\begin{array}{l}\text { SOEELY OP EFERGY } \\
\text { FOSS IL FOEI } \\
\text { HY DR OELECTRIC } \\
\text { NOCL EAR } \\
\text { GEO. ESOLAF }\end{array}$ & $\begin{array}{l}- \\
-\end{array}$ & $\begin{array}{l}- \\
- \\
-\end{array}$ & $\begin{array}{l}- \\
- \\
-\end{array}$ & $\begin{array}{l}\overline{-} \\
-\end{array}$ & $\begin{array}{r}182,072 \\
- \\
-\end{array}$ & $\begin{array}{r}142,699 \\
- \\
-\end{array}$ & $\begin{array}{l}- \\
\overline{-} \\
-\end{array}$ & $\begin{array}{r}- \\
1,235 \\
3,255 \\
1,704\end{array}$ & $\begin{array}{r}324,771 \\
1,235 \\
3,255 \\
1,704\end{array}$ & $\begin{array}{r}98.6 \\
0.8 \\
1.8 \\
1.5\end{array}$ \\
\hline TCIAI SUPPIY & - & - & - & - & $18 z, 072$ & 142,699 & - & 6,194 & 330,965 & \\
\hline
\end{tabular}

\section{NET IM FORTS}

CF REGION

45.137

27,539

131,103

$1 \equiv 4.476$

$-17 \cong, 423$

184,833

136,201

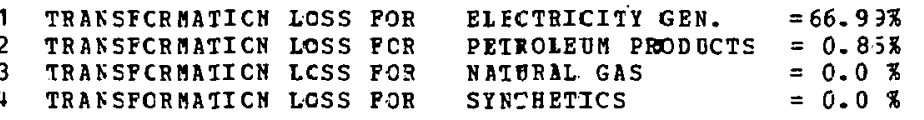


REGIONAL ENERGY EALANCE STATEHENT

\begin{tabular}{|c|c|c|c|c|c|c|c|c|c|c|}
\hline SECTOE & $\begin{array}{c}\text { DESTILLATE } \\
\text { OIL }\end{array}$ & $\begin{array}{l}\text { RESIDDAL } \\
\text { OIL }\end{array}$ & $\begin{array}{l}\text { GASOLI NE } \\
\text { (ALL ONIT }\end{array}$ & $\begin{array}{c}\text { OTBER } \\
\text { HYDRO- } \\
\text { CARBONS } \\
\text { TS IN } 10 * * 9 \\
\end{array}$ & $\begin{array}{c}\text { CRODE } \\
\text { OIL } \\
\text { BTO'SI }\end{array}$ & $\begin{array}{l}\text { NATURAL } \\
\text { GAS }\end{array}$ & $\operatorname{cod} I$ & ELECTRICITY & $\begin{array}{r}\text { SECTOR } \\
\text { TOTAL }\end{array}$ & \\
\hline $\begin{array}{l}\text { TCIAI FINAL } \\
\text { DEHAND SBCTORS }\end{array}$ & 18,212 & 25,928 & 48,573 & 108,430 & - & 241,582 & 3,417 & 32,787 & 478.929 & $85 \%$ \\
\hline 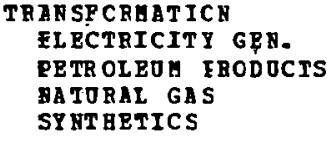 & $\begin{array}{r}2,751 \\
-258,6 \equiv 1 \\
-\end{array}$ & $\begin{array}{r}- \\
-15,9.31 \\
-\end{array}$ & $\begin{array}{r}-426.57 \overline{-} \\
-\end{array}$ & $\begin{array}{r}-448,909 \\
-\end{array}$ & $\begin{array}{r}1,064,416 \\
-\end{array}$ & $\begin{array}{r}45,685 \\
95,611 \\
- \\
-\end{array}$ & $\begin{array}{r}7.990 \\
- \\
-\end{array}$ & $\begin{array}{r}-18,519 \\
- \\
-\end{array}$ & $\begin{array}{r}37,907 \\
9,930 \\
- \\
-\end{array}$ & $\begin{array}{l}7 \% \\
2 \%\end{array}$ \\
\hline $\begin{array}{l}\text { NET FOEL OSEL } \\
\text { IN TRABSPOKAATIOR }\end{array}$ & $-255,880$ & $-15,9.31$ & $-426,576$ & $-448,909$ & $1,064,416$ & 141,296 & 7,990 & $-18,519$ & 47,837 & $9 \%$ \\
\hline $\begin{array}{l}\text { ICIAL GROSS FLORS } \\
\text { LOSSES E OMISSIONS }\end{array}$ & $\begin{array}{r}20,963 \\
1,304 \\
\end{array}$ & $\begin{array}{r}25,9 ? 8 \\
-\quad 0 \\
\end{array}$ & $\begin{array}{r}48,573 \\
0 \\
-\end{array}$ & $\begin{array}{r}108,430 \\
-4,276\end{array}$ & $\begin{array}{r}1,064,416 \\
44,157\end{array}$ & $\begin{array}{r}382,878 \\
-10,346\end{array}$ & $\begin{array}{r}11,407 \\
154\end{array}$ & $\begin{array}{r}32,787 \\
2,720\end{array}$ & $\begin{array}{r}526,766 \\
33,714\end{array}$ & $\begin{array}{r}94 \% \\
6 \%\end{array}$ \\
\hline
\end{tabular}

\begin{tabular}{|c|c|c|c|c|c|c|c|c|c|c|}
\hline SOEPLY OP ENERGY & & & & & & & & & & \\
\hline FOSS IL PORI & - & - & - & - & 531,574 & 671,005 & - & - & $1,202,579$ & $100 \%$ \\
\hline BY DR OELBCT EIC & - & - & - & - & - & - & - & 45 & 45 & $0 \%$ \\
\hline IOCL $\mathrm{BAR}$ & - & - & - & - & - & - & - & 1,522 & 1,522 & $0 \%$ \\
\hline TCTAL SOPPIY & - & - & - & - & 531,574 & 671,005 & _ & 2,364 & $1,204,943$ & \\
\hline
\end{tabular}

-

\section{BET IM PORTS}

OP R BGIOS

$-236,36 \cdot 3$

9,947

$-378,002$

$-344,755$

576,999

$-298,472$

11,561

14.624

No TRS:

TRABSFORAATICY LOSS PCR

TRABSFORATI CY LOSS FOR

TRAYSPORAAICS LOSS FOB

EL BCTRIEITY GER.
PETROLETA PBODOCTS

$\begin{aligned} & =67.18 \% \\ & =0.86 \% \\ & =0.0 \%\end{aligned}$

$\begin{array}{ll}\text { MATORAL GAS } & =0.0 \times \\ \text { SYATEBTICS } & =0.0 \times\end{array}$ 
REGIONZL EEEFGY PALANCE STATEHENT PIES UID IID SCENARIO

\begin{tabular}{|c|c|c|c|c|c|c|c|c|c|c|}
\hline SECTOE & DISTILIATE & $\begin{array}{l}\text { RESIDOAL } \\
=I L\end{array}$ & $\begin{array}{l}\text { GASOLIN } \\
\text { CALL }\end{array}$ & $\begin{array}{c}\text { OT JER } \\
\text { EYD } \\
\text { CER } \\
\text { ITS IN } 10 * * 9\end{array}$ & $\begin{array}{c}\text { CROCE } \\
\text { OIL } \\
\text { ETU'S) }\end{array}$ & $\begin{array}{l}\text { NATUR LL } \\
\text { GAS }\end{array}$ & COAL & ELECTRICITY & $\begin{array}{r}\text { SECTOR } \\
\text { TOTAL }\end{array}$ & \\
\hline $\begin{array}{l}\text { FIRLL CEAANC SFCTORS } \\
\text { RESID RNTIAL,CCHA. } \\
\text { IND OSTRIAL } \\
\text { TRANSPORTATICN } \\
\text { MISCELLANEOOS OSES }\end{array}$ & $\begin{aligned} & 3, 08 \\
& 1, 112 \\
& 5,588 \\
& 553\end{aligned}$ & $\begin{array}{r}655 \\
\therefore, 145 \\
5,902 \\
802\end{array}$ & $\begin{array}{r}- \\
- \\
52,343 \\
-\end{array}$ & $\begin{array}{r}7.254 \\
4.870 \\
8.177 \\
14\end{array}$ & $\begin{array}{l}\overline{-} \\
-\end{array}$ & $\begin{array}{r}18,781 \\
28,18 \mathrm{C} \\
2,125 \\
311\end{array}$ & $\begin{array}{l}4 \overline{0} \\
- \\
-\end{array}$ & $\begin{array}{r}16,336 \\
6,897 \\
- \\
155\end{array}$ & $\begin{array}{r}46,334 \\
43.611 \\
74,135 \\
2,235\end{array}$ & $\begin{array}{r}26 \% \\
24 \pi \\
42 \% \\
1 \%\end{array}$ \\
\hline $\begin{array}{l}\text { TCTAL FINAL } \\
\text { DEHAND SECTORS }\end{array}$ & $\pi 0,561$ & $\subseteq, 504$ & 52,343 & 20,315 & - & 49,397 & 407 & 23,388 & 166,315 & $93 x$ \\
\hline $\begin{array}{l}\text { GRARSFCRHATICT } \\
\text { ELPCTRICITY GEN. } \\
\text { PETROLEO FRODOCTS } \\
\text { NATORAL GAS } \\
\text { SYNTHETICS }\end{array}$ & $\begin{array}{r}1,563 \\
-2, \equiv 85 \\
- \\
-\end{array}$ & $\begin{array}{r}-147 \\
-\end{array}$ & $\begin{array}{r}-3,934 \\
\overline{-}\end{array}$ & $\begin{array}{r}-4.140 \\
-\end{array}$ & $\begin{array}{r}9,816 \\
\overline{-}\end{array}$ & $\begin{array}{r}9,363 \\
881 \\
- \\
-\end{array}$ & $\begin{array}{r}5,699 \\
- \\
-\end{array}$ & $\begin{array}{r}-5,628 \\
- \\
-\end{array}$ & $\begin{array}{r}11,397 \\
91 \\
- \\
-\end{array}$ & $\begin{array}{r}6 \% \\
0 \% \\
-\end{array}$ \\
\hline $\begin{array}{l}\text { WET FOEL OSEC } \\
\text { IN TRANSPOEATION }\end{array}$ & -422 & . -147 & $-3,934$ & $-4,140$ & 9,816 & 10,214 & 5,699 & $-5,628$ & 11,488 & $6 \%$ \\
\hline $\begin{array}{l}\text { TCIAL GROSS FLORS } \\
\text { lCSSES } \& \text { ONISSIONS }\end{array}$ & $\begin{aligned} 12, \subseteq 24 \\
E O 4\end{aligned}$ & $\begin{array}{r}9,504 \\
0\end{array}$ & $\begin{array}{r}52,343 \\
0\end{array}$ & $\begin{array}{r}20,315 \\
-801\end{array}$ & $\begin{array}{r}9,816 \\
407\end{array}$ & $\begin{array}{l}59,641 \\
-1,611\end{array}$ & $\begin{array}{r}6,106 \\
32\end{array}$ & $\begin{array}{r}23,388 \\
1,940\end{array}$ & $\begin{array}{r}177,803 \\
822\end{array}$ & $\begin{array}{r}1008 \\
09\end{array}$ \\
\hline
\end{tabular}

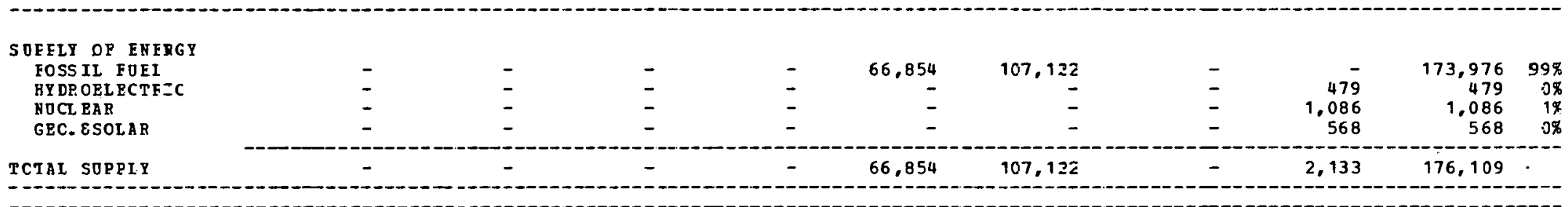

GET IM PORTS
OP PEGION


REgIONAL ENEGGY EALANCE STATEMENT

ONAL ENE KG E EALANCE S
PIES MID MID SCENARIO

\begin{tabular}{|c|c|c|c|c|c|c|c|c|c|c|}
\hline SECTOE & $\begin{array}{l}\text { DI STILLATE } \\
\text { OIL }\end{array}$ & $\begin{array}{l}\text { RESIDDAL } \\
\text { OIL }\end{array}$ & $\begin{array}{l}\text { GASOLIN } \\
\text { (ALL }\end{array}$ & $\begin{array}{c}\text { OTHER } \\
\text { HYDRO- } \\
\text { CARBONS } \\
\text { TS IN } 10 * *\end{array}$ & $\begin{array}{c}\text { CRODE } \\
\text { OIL } \\
\text { BTO'S) }\end{array}$ & $\begin{array}{l}\text { NaTURAL } \\
\text { GAS }\end{array}$ & $\operatorname{COAL}$ & ELECTRICITY & $\begin{array}{r}\text { SECTOR } \\
\text { TOTAL }\end{array}$ & \\
\hline 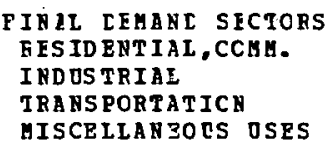 & $\begin{array}{r}5,114 \\
2,235 \\
16,837 \\
2,659\end{array}$ & $\begin{array}{r}831 \\
6,253 \\
2,898 \\
2,237\end{array}$ & 78,927 & $\begin{array}{r}10,981 \\
10,760 \\
8,227 \\
54\end{array}$ & $\begin{array}{l}- \\
- \\
-\end{array}$ & $\begin{array}{r}32,251 \\
136,629 \\
2,041 \\
1,173\end{array}$ & $\begin{array}{r}1 \\
2,8.41 \\
- \\
-\end{array}$ & $\begin{array}{r}22,734 \\
7,688 \\
- \\
635\end{array}$ & $\begin{array}{r}71,912 \\
166,406 \\
108,930 \\
6,758\end{array}$ & $\begin{array}{r}19 \% \\
43 \% \\
28 \% \\
2 \%\end{array}$ \\
\hline $\begin{array}{l}\text { TCTAL PINAI } \\
\text { DEMAND SECTCRS }\end{array}$ & 26,845 & 12,219 & 78,927 & 30,022 & - & 172,094 & 2,842 & 31,057 & 354,006 & $91 \%$ \\
\hline $\begin{array}{l}\text { TE ANSPORMATICN } \\
\text { RLECTRICITY GEN. } \\
\text { PETR OLEOM ERCDOCTS } \\
\text { NATORAL GAS } \\
\text { STNTHETICS }\end{array}$ & $\begin{array}{r}2,607 \\
-68,927 \\
-\end{array}$ & $\begin{array}{r}-4,258 \\
- \\
-\end{array}$ & $\begin{array}{r}-113.684 \\
- \\
-\end{array}$ & $\begin{array}{r}-119,635 \\
- \\
-\end{array}$ & $\begin{array}{r}- \\
283,671 \\
-\end{array}$ & $\begin{array}{r}21,326 \\
25,480 \\
- \\
-\end{array}$ & $\begin{array}{r}7,568 \\
- \\
-\end{array}$ & $\begin{array}{r}-10,097 \\
- \\
-\end{array}$ & $\begin{array}{r}21,404 \\
2,646 \\
- \\
-\end{array}$ & $\begin{array}{l}6 \% \\
1 \%\end{array}$ \\
\hline $\begin{array}{l}\text { BFT FORL OSEL } \\
\text { IN TRARSPOEDATION }\end{array}$ & $-66,320$ & $-4,258$ & $-113,684$ & $-119,635$ & 283,671 & 46,806 & 7,568 & $-10,097$ & 24,050 & $6 \%$ \\
\hline $\begin{array}{l}\text { TCTAL GROSS FLCRS } \\
\text { LCSSES } \& \text { OHISSIONS }\end{array}$ & $\begin{array}{r}29,452 \\
1,833\end{array}$ & $\begin{array}{r}12,219 \\
0\end{array}$ & $\begin{array}{r}78,927 \\
0\end{array}$ & $\begin{array}{r}30,022 \\
-1,184\end{array}$ & $\begin{array}{r}283,671 \\
11,768\end{array}$ & $\begin{array}{r}218,900 \\
-5,915\end{array}$ & $\begin{array}{r}10,410 \\
140\end{array}$ & $\begin{array}{r}31,057 \\
2,576\end{array}$ & $\begin{array}{r}378,056 \\
9,220\end{array}$ & $\begin{array}{r}98 \% \\
28\end{array}$ \\
\hline $\begin{array}{l}\text { SUEELY OP PBERGY } \\
\text { FOSS IL FOEI. } \\
\text { OY DROBLBCTEIC } \\
\text { HOCLEAR } \\
\text { GBO. ESOLAR }\end{array}$ & $\begin{array}{l}- \\
- \\
-\end{array}$ & $\begin{array}{l}- \\
- \\
-\end{array}$ & $\begin{array}{l}- \\
\text { - } \\
-\end{array}$ & $\begin{array}{l}- \\
\overline{-}\end{array}$ & $\begin{array}{r}263,785 \\
- \\
-\end{array}$ & $\begin{array}{r}393,939 \\
- \\
-\end{array}$ & $\overline{-}$ & $\begin{array}{r}36 \overline{8} \\
1.442 \\
755\end{array}$ & $\begin{array}{r}657,724 \\
368 \\
1,442 \\
755\end{array}$ & $\begin{array}{r}100 \% \\
0 \% \\
0 \% \\
0 \%\end{array}$ \\
\hline TCTAI SOPPLY & - & - & - & - & 263,785 & 393,939 & - & 2,565 & 660,289 & \\
\hline
\end{tabular}

\section{SET IM FORTS}

$-34,756$

$-90,797$

31,654

$-180,953$

10,550

20,971

$-273,011$

-

NOTBS:

1 TRAASPCRMATICB LOSS FOR

TRANSPCRAATICN LOSS FOR
TRANSPORAATICN LCSS FOR

TRABSPORAATICN LCSS POR

ELECTRI ZITY GRN.

PETROLEOH PRODOCTS $=67.95 \%$

NATURAL GAS

$=0.86 \%$

SYITEETICS

$=0.0 \%$
$=0.0 \%$ 
REGIOALL ENE GSY EALANCE STATEHENT

PIES IID IID SCRNARIO

\begin{tabular}{|c|c|c|c|c|c|c|c|c|c|c|}
\hline SECTOK & $\begin{array}{l}\text { DISTILLATE } \\
\text { OIL }\end{array}$ & $\begin{array}{l}\text { RESJDUAL } \\
=I L\end{array}$ & $\begin{array}{l}\text { GASOLINE } \\
\text { (ALI OEII }\end{array}$ & $\begin{array}{l}\text { OT JER } \\
\text { WYDTO- } \\
\text { CARBDNS } \\
\text { S IN } 10 * * 9\end{array}$ & $\begin{array}{c}\text { CRODE } \\
\text { OIL } \\
\text { ETO'SI }\end{array}$ & $\begin{array}{l}\text { NATURLL } \\
\text { GAS }\end{array}$ & $\operatorname{COAL}$ & ELECTRICITY & $\begin{array}{r}\text { SECTOR } \\
\text { TOTAL }\end{array}$ & \\
\hline 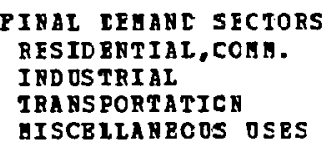 & $\begin{array}{r}4, .551 \\
1, .665 \\
16,-278 \\
2,158\end{array}$ & $\begin{array}{r}646 \\
1,301 \\
1,815\end{array}$ & $73.24 \overline{-}$ & $\begin{array}{r}10,255 \\
2,281 \\
12,304 \\
36\end{array}$ & $\begin{array}{l}\overline{-} \\
\overline{-}\end{array}$ & $\begin{array}{r}34,931 \\
16,008 \\
2,982 \\
789\end{array}$ & $\begin{array}{r}2 \\
1,439 \\
- \\
-\end{array}$ & $\begin{array}{r}19,921 \\
2.609 \\
- \\
392\end{array}$ & $\begin{array}{r}70,706 \\
24,703 \\
104,808 \\
5,191\end{array}$ & $\begin{array}{r}31 \% \\
11 \% \\
47 \% \\
2 \%\end{array}$ \\
\hline $\begin{array}{l}\text { TCTAL FINAL } \\
\text { DEHAND SECTORS }\end{array}$ & 24.452 & $\equiv, 763$ & 73,244 & 24,876 & - & 54,710 & 1,441 & 22,922 & 205,408 & $91 \%$ \\
\hline $\begin{array}{l}\text { TRANSPORHATICD } \\
\text { ELECTRICITY GEN. } \\
\text { PETE OLEUM FRODOCTS } \\
\text { NATORAL GAS: } \\
\text { SY NTETICS }\end{array}$ & $\begin{array}{r}1,524 \\
-7,860 \\
-\end{array}$ & $\begin{array}{r}- \\
-485 \\
- \\
-\end{array}$ & $\begin{array}{r}- \\
-12,965 \\
-\end{array}$ & $\begin{array}{r}- \\
-13,644 \\
-\end{array}$ & $\begin{array}{r}32,351 \\
- \\
-\end{array}$ & $\begin{array}{r}8,304 \\
2,906 \\
-\end{array}$ & $\begin{array}{r}14,483 \\
- \\
-\end{array}$ & $\begin{array}{r}-8,182 \\
- \\
- \\
-\end{array}$ & $\begin{array}{r}16,529 \\
302 \\
- \\
-\end{array}$ & $\begin{array}{l}7 \% \\
0 \%\end{array}$ \\
\hline $\begin{array}{l}\text { DET FOFL OSEL } \\
\text { IN TRANSPOREATION }\end{array}$ & $-5, \leq 36$ & -485 & $-12,965$ & $-13,644$ & 32,351 & $11,21 \mathrm{C}$ & 14,483 & $-8,182$ & 16,831 & $7 \%$ \\
\hline $\begin{array}{l}\text { TCTAL GROSS FLOHS } \\
\text { LCSSES \& OHISSIONS }\end{array}$ & $\begin{aligned} 26, & \equiv 76 \\
1, & \neq 41\end{aligned}$ & $\Xi, 763$ & $\begin{array}{r}73,244 \\
0\end{array}$ & $\begin{array}{r}24.876 \\
-981\end{array}$ & $\begin{array}{r}32,351 \\
1,342\end{array}$ & $\begin{array}{l}65,92 \mathrm{C} \\
-1,781\end{array}$ & $\begin{array}{r}15,924 \\
2 \pi 5\end{array}$ & $\begin{array}{r}22,922 \\
1,901\end{array}$ & $\begin{array}{r}222,239 \\
2,339\end{array}$ & $\begin{array}{r}99 \% \\
1 \%\end{array}$ \\
\hline $\begin{array}{l}\text { SOEFLY OF ENERGY } \\
\text { FOSS IL FOEL } \\
\text { HY DR OELECTEIC } \\
\text { NOCL ZAR } \\
\text { GEO. \&SOLAR }\end{array}$ & $\begin{array}{l}\overline{-} \\
\overline{-}\end{array}$ & $\bar{z}$ & $\begin{array}{l}\bar{z} \\
\bar{z}\end{array}$ & $\begin{array}{l}\overline{-} \\
\overline{-} \\
-\end{array}$ & $\begin{array}{r}21.699 \\
- \\
-\end{array}$ & $\begin{array}{r}107,805 \\
- \\
-\end{array}$ & $\begin{array}{r}84,232 \\
- \\
-\end{array}$ & $\begin{array}{r}3 \overline{2} \\
1.064 \\
557\end{array}$ & $\begin{array}{r}213,736 \\
32 \\
1.064 \\
557\end{array}$ & $\begin{array}{r}99 \% \\
0 \% \\
0 \% \\
0 \%\end{array}$ \\
\hline TCTAL SOPEIY & - & - & - & - & 21.699 & $107,8 \cdot 55$ & $84,2 \Xi 2$ & 1.653 & 215,389 & \\
\hline
\end{tabular}

YET ID.FORTS

OP REGION

$20,-56$

3,277

60,279

10,250

11,994

$-43,656$

$-68,0 \leq 2$

14.988

9.189 
REGIONAL ENE EGY PALANCE STATEMENT

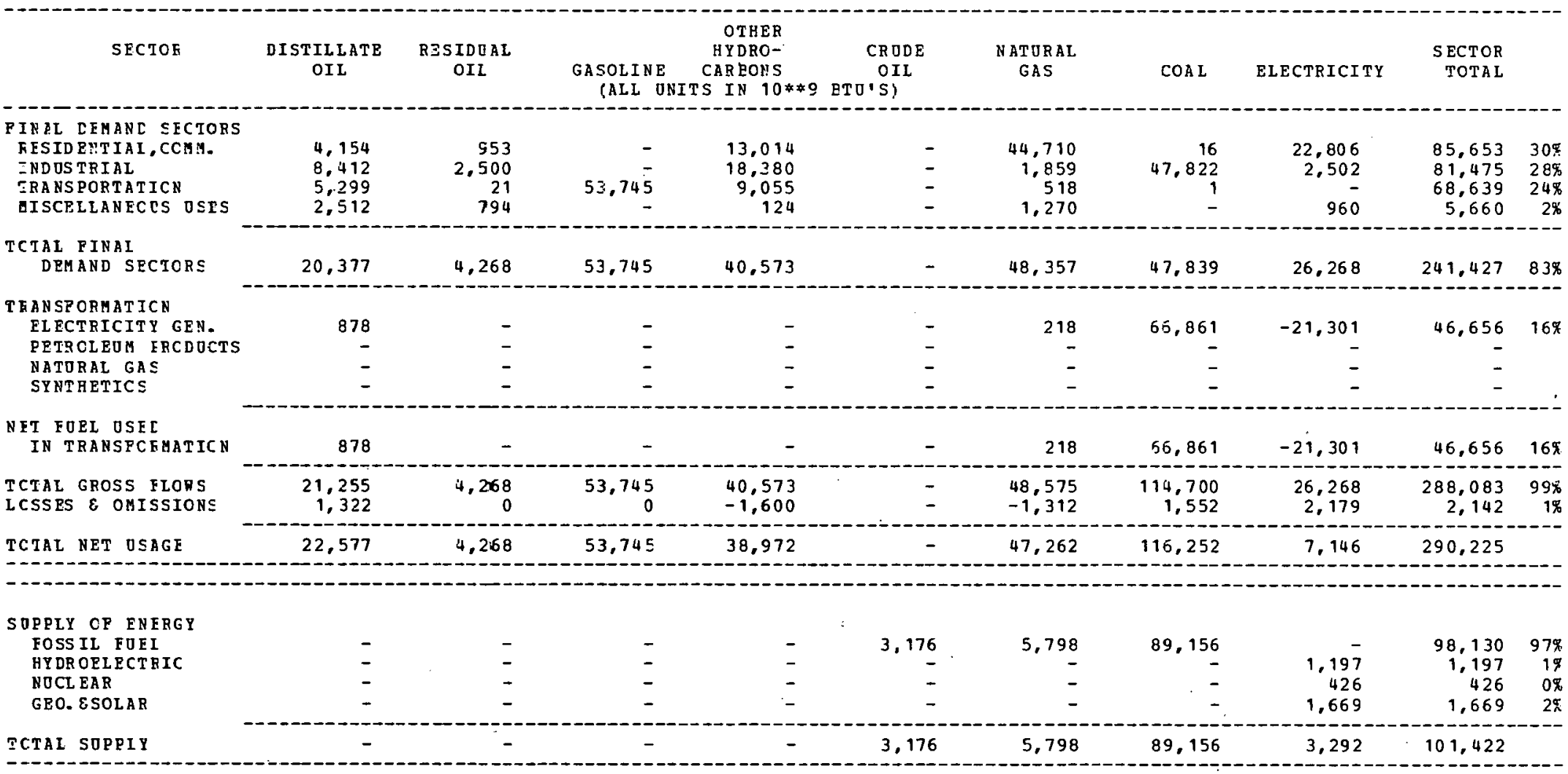

-

\begin{tabular}{l} 
BET IH PORTS \\
OF REGION \\
\hline
\end{tabular}

NOTES:

\begin{tabular}{|c|c|c|c|c|}
\hline & & $\begin{array}{l}\text { POR } \\
\text { POR }\end{array}$ & $\begin{array}{l}\text { ELECTRI =ITY GEN. } \\
\text { PETROLEOM PRODUCTS }\end{array}$ & $\begin{array}{l}=68.66 \% \\
=0.0 \%\end{array}$ \\
\hline NSPORMATI CN & Loss & & NATORAL GAS & $=0.0$ \\
\hline TRANSPORMATICN & & & SYNTBETICS & $=0.0$ \\
\hline
\end{tabular}

3 TRANSPORMATICN LOSS POR NATORAL GAS $=0.0 \%$ 
RE'SICNAL ENERGY EALANCE STATELIENT

FIES MID MID SCENARID

\begin{tabular}{|c|c|c|c|c|c|c|c|c|c|}
\hline SE:TOK & $\begin{array}{c}\text { DISTDLATE } \\
\text { OIL }\end{array}$ & $\begin{array}{l}\text { RESIDJAL } \\
\text { CIL }\end{array}$ & $\begin{array}{l}\text { GASOLIFE } \\
\text { (ALI O }\end{array}$ & $\begin{array}{c}\text { OTRER } \\
\text { HYDRO- } \\
\text { CAMBONS } \\
\text { IS IN } 10 * * 9\end{array}$ & $\begin{array}{c}\text { C3ODE } \\
\text { JIL } \\
\text { BTO'3) }\end{array}$ & $\begin{array}{l}\text { NATCRAL } \\
\text { GRS }\end{array}$ & $\operatorname{COA} L$ & ELECTRICITY & $\begin{array}{r}\text { SECTOR } \\
\text { TOTAL }\end{array}$ \\
\hline $\begin{array}{l}\text { PINAL CEHANL: SECTORS } \\
\text { RESIDENTIAL, CCHM. } \\
\text { INDOSTRIAL } \\
\text { TRENSPORTAJION } \\
\text { MISCELLANEOOS JSES }\end{array}$ & $\begin{array}{r}14,059 \\
29.996 \\
19,838 \\
3.467\end{array}$ & $\begin{array}{r}\equiv, 242 \\
1 E, 056 \\
46 \\
.092\end{array}$ & $173,83 \frac{-}{-}$ & $\begin{array}{r}42,156 \\
50,930 \\
51,223 \\
137\end{array}$ & $\begin{array}{l}- \\
\overline{-} \\
-\end{array}$ & $\begin{array}{r}146,032 \\
22,521 \\
2,540 \\
1,148\end{array}$ & $\begin{array}{r}57 \\
105,652 \\
2 \\
-\end{array}$ & $\begin{array}{r}77,186 \\
10,760 \\
- \\
1,034\end{array}$ & $\begin{array}{r}282,732 \\
234.915 \\
247,885 \\
6.873\end{array}$ \\
\hline $\begin{array}{l}\text { TCTAI FINAL } \\
\text { DEMAND SECTORS }\end{array}$ & 67,360 & 15,436 & 173,836 & 144,446 & - & $172, \in 41$ & 105,711 & 88,980 & 772,410 \\
\hline $\begin{array}{l}\text { TRABSPORMATICN } \\
\text { RL ECTRICITY GEN. } \\
\text { PETR OLEUM ERCDOCTS } \\
\text { NATURAL GAS } \\
\text { SYNTHETICS }\end{array}$ & $\begin{array}{r}\equiv, 122 \\
-3 \epsilon_{0}, 846 \\
- \\
-\end{array}$ & $\begin{array}{r}-1 \cdot, 776 \\
- \\
-\end{array}$ & $\begin{array}{r}- \\
-61,788 \\
- \\
-\end{array}$ & $\begin{array}{r}- \\
-17,526 \\
-\end{array}$ & $124.63 \overline{-}$ & $\begin{array}{r}731 \\
5,248 \\
- \\
-\end{array}$ & $\begin{array}{r}152,678 \\
- \\
-\end{array}$ & $\begin{array}{r}-49,091 \\
- \\
-\end{array}$ & $\begin{array}{r}107,440 \\
1,946 \\
-\end{array}$ \\
\hline $\begin{array}{l}\text { NET FOEL USEL } \\
\text { IY TRANSFOFMATION }\end{array}$ & $-33,724$ & $-1 * .776$ & $-61,738$ & $-17,526$ & 124,634 & 5.979 & 152,678 & $-49,091$ & 109,386 \\
\hline $\begin{array}{l}\text { TCIAL GROSS FLORS } \\
\text { LCSSES E CMISSIONS }\end{array}$ & $\begin{array}{r}7 C, 482 \\
4,387\end{array}$ & $\begin{array}{r}19,+36 \\
0\end{array}$ & $\begin{array}{r}173,830^{\circ} \\
0\end{array}$ & $\begin{array}{r}1.44,446 \\
-5,697\end{array}$ & $\begin{array}{r}124,634 \\
5,170\end{array}$ & $\begin{array}{r}178,620 \\
-4.826\end{array}$ & $\begin{array}{r}258,389 \\
3,497\end{array}$ & $\begin{array}{r}88,980 \\
7,383\end{array}$ & $\begin{array}{r}881,79 \epsilon \\
9,914\end{array}$ \\
\hline TCTAL NET OSAGE & 38,023 & 7,560 & $112,04.3$ & 121,222 & 129,804 & $173, ? 94$ & 261,886 & 47,272 & 891,711 \\
\hline
\end{tabular}

\begin{tabular}{|c|c|c|c|c|c|c|c|c|c|c|}
\hline $\begin{array}{l}\text { SOPELY OP ENERGY } \\
\text { FOSS IL RUEL }\end{array}$ & - & - & - & - & 45,935 & 37.739 & 46,322 & - & $129.99 \epsilon$ & \\
\hline HZDROELECT BIC & - & - & - & - & 40,0 & - & $40.5<-$ & 8,173 & $8,17 \equiv$ & $6 \%$ \\
\hline NDCI EAR & - & - & - & - & - & - & - & 1,430 & $1,43 \bar{c}$ & $1 \%$ \\
\hline G30.ESOLAZ & - & - & - & - & - & - & - & 5,609 & $5,60 \mathrm{~s}$ & $4 \pi$ \\
\hline TCTAL SUPFIY & - & - & - & - & $45,93.5$ & 37.735 & 46,322 & 15,212 & $145,20 E$ & \\
\hline
\end{tabular}

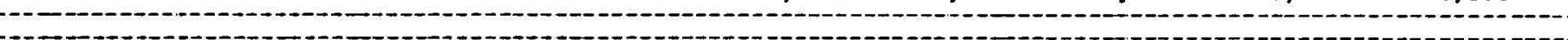

\begin{tabular}{|c|c|c|c|c|c|c|}
\hline \multicolumn{2}{|c|}{$\begin{array}{l}\text { NET IM FORTS } \\
\text { OF REGIOS }\end{array}$} & \multicolumn{2}{|c|}{38,023} & 3,660 & \multicolumn{2}{|c|}{112.043} \\
\hline \multicolumn{7}{|c|}{ NOTES: } \\
\hline 1 & TRZNSPCRMATICN & zosis & POR & ELECRAICIT & GEN. & $=68.54$ \\
\hline 2 & TRAN SPCRMATI CN & zos 3 & FCR & PETR JLEUM & ERDDOCTS & $=1.50 \%$ \\
\hline 3 & TR R N SPCR MA TI CN & $\cos 3$ & FOR & NATOZAL GA & & $=0.3$ \\
\hline 4 & TRRNSPOR AATICN & zosj & FOR & SYAT BETICS & & $=0.3$ \\
\hline
\end{tabular}


REGIONAL ENEFGY BALANCE STATEMENT

PNAL ENEFGY BALANCE STA
PIES MID MID SCENARIO

\begin{tabular}{|c|c|c|c|c|c|c|c|c|c|c|}
\hline SECTOE & $\begin{array}{l}\text { LISTILLATE } \\
\text { OIL }\end{array}$ & $\begin{array}{l}\text { RESIDCAL } \\
\text { OII }\end{array}$ & $\begin{array}{l}\text { GASOLINE } \\
\text { (ALL O }\end{array}$ & $\begin{array}{l}\text { OTHER } \\
\text { HYDRO- } \\
\text { CARBONS } \\
\text { TS IN 10*99 }\end{array}$ & $\begin{array}{c}\text { CRIDE } \\
\text { OIL } \\
\text { ETO'S) }\end{array}$ & $\begin{array}{l}\text { NATURAL } \\
\text { GAS }\end{array}$ & $\operatorname{COAL}$ & ELECTRICITY & $\begin{array}{r}\text { SECTOR } \\
\text { TOTAL }\end{array}$ & \\
\hline $\begin{array}{l}\text { FINAL EFMANL SECTORS } \\
\text { BESIDENTIAL, CCMM. } \\
\text { INDOSTRIAL } \\
\text { TRANSPORTATION } \\
\text { MISCELLANECUS OSZS }\end{array}$ & $\begin{array}{r}2,607 \\
13,665 \\
3,273 \\
753\end{array}$ & $\begin{array}{r}534 \\
2,512 \\
8 \\
531\end{array}$ & $\begin{array}{r}- \\
32.664 \\
-\end{array}$ & $\begin{array}{r}7,025 \\
3,373 \\
7,344 \\
24\end{array}$ & $\begin{array}{l}\text { - } \\
-\end{array}$ & $\begin{array}{r}23,945 \\
29,301 \\
707 \\
208\end{array}$ & $\begin{array}{r}8 \\
11,848 \\
-\end{array}$ & $\begin{array}{r}12,261 \\
2,738 \\
- \\
180\end{array}$ & $\begin{array}{r}46,380 \\
63,837 \\
43,996 \\
1,496\end{array}$ & $\begin{array}{r}12 \% \\
17 \% \\
12 \% \\
0 \%\end{array}$ \\
\hline $\begin{array}{l}\text { TCIAL PINAL } \\
\text { DEMAND SECTORS }\end{array}$ & 20,298 & $.3,785$ & 32,664 & 17,766 & - & 54,161 & 11,856 & 15,179 & 155,709 & $41 \%$ \\
\hline $\begin{array}{l}\text { T ZANSFCRMATICN } \\
\text { ELECTRICITY GEN. } \\
\text { PBTROLEUM FRCDUCTS } \\
\text { NATORAL GAS } \\
\text { SYNTHETICS }\end{array}$ & $\begin{array}{r}637 \\
-13,333 \\
- \\
-\end{array}$ & $\begin{array}{r}-2,414 \\
- \\
-\end{array}$ & $\begin{array}{r}-22,16 \overline{3} \\
- \\
-\end{array}$ & $\begin{array}{r}-15,36 \overline{-} \\
- \\
-\end{array}$ & $\begin{array}{r}50,35 \overline{-} \\
-106,383\end{array}$ & $\begin{array}{r}105 \\
3,526 \\
-93,920\end{array}$ & $\begin{array}{r}321,608 \\
- \\
-\end{array}$ & $\begin{array}{r}-105,025 \\
- \\
-\end{array}$ & $\begin{array}{r}217,325 \\
600 \\
- \\
-3,967\end{array}$ & $\begin{array}{r}57 \% \\
0 \%\end{array}$ \\
\hline $\begin{array}{l}\text { NET FOFL OSEL } \\
\text { IN TRANSFOEMATION }\end{array}$ & $-12,696$ & $-2,414$ & $-22,163$ & $-15,366$ & $-56,030$ & $-90,288$ & 517,944 & $-105,025$ & 213,958 & $56 \%$ \\
\hline $\begin{array}{l}\text { TCTAL GROSS FLORS } \\
\text { ICSSES E CMISSIONS }\end{array}$ & $\begin{array}{r}20,935 \\
1,303\end{array}$ & $\begin{array}{r}3,785 \\
0\end{array}$ & $\begin{array}{r}32,664 \\
0\end{array}$ & $\begin{array}{r}17,766 \\
-700\end{array}$ & $\begin{array}{r}50,352 \\
2.088\end{array}$ & $\begin{array}{l}57,792 \\
-1,561\end{array}$ & $\begin{array}{r}529,800 \\
7,171\end{array}$ & $\begin{array}{r}15,179 \\
1,259\end{array}$ & $\begin{array}{r}373,634 \\
9,560\end{array}$ & $\begin{array}{r}99 \% \\
3 \%\end{array}$ \\
\hline
\end{tabular}

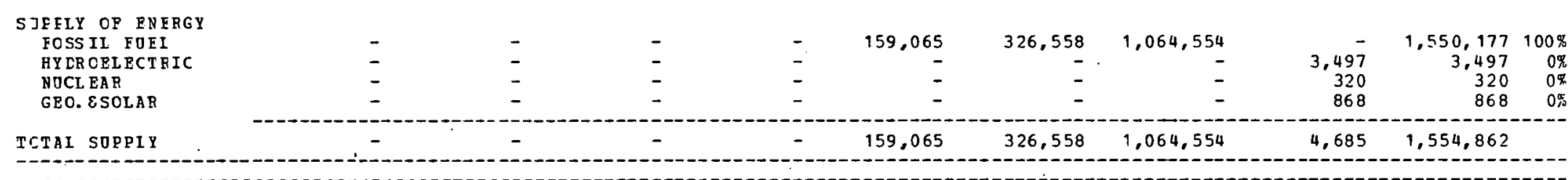

\begin{tabular}{l} 
NET IM PORTS \\
CE REGION \\
\hline
\end{tabular}


REGIONAL EUEEGY EAIANCE STATEMEUT

IONAL EQEEGY PAIANCE STAT
PIES MID MID SCENARIO

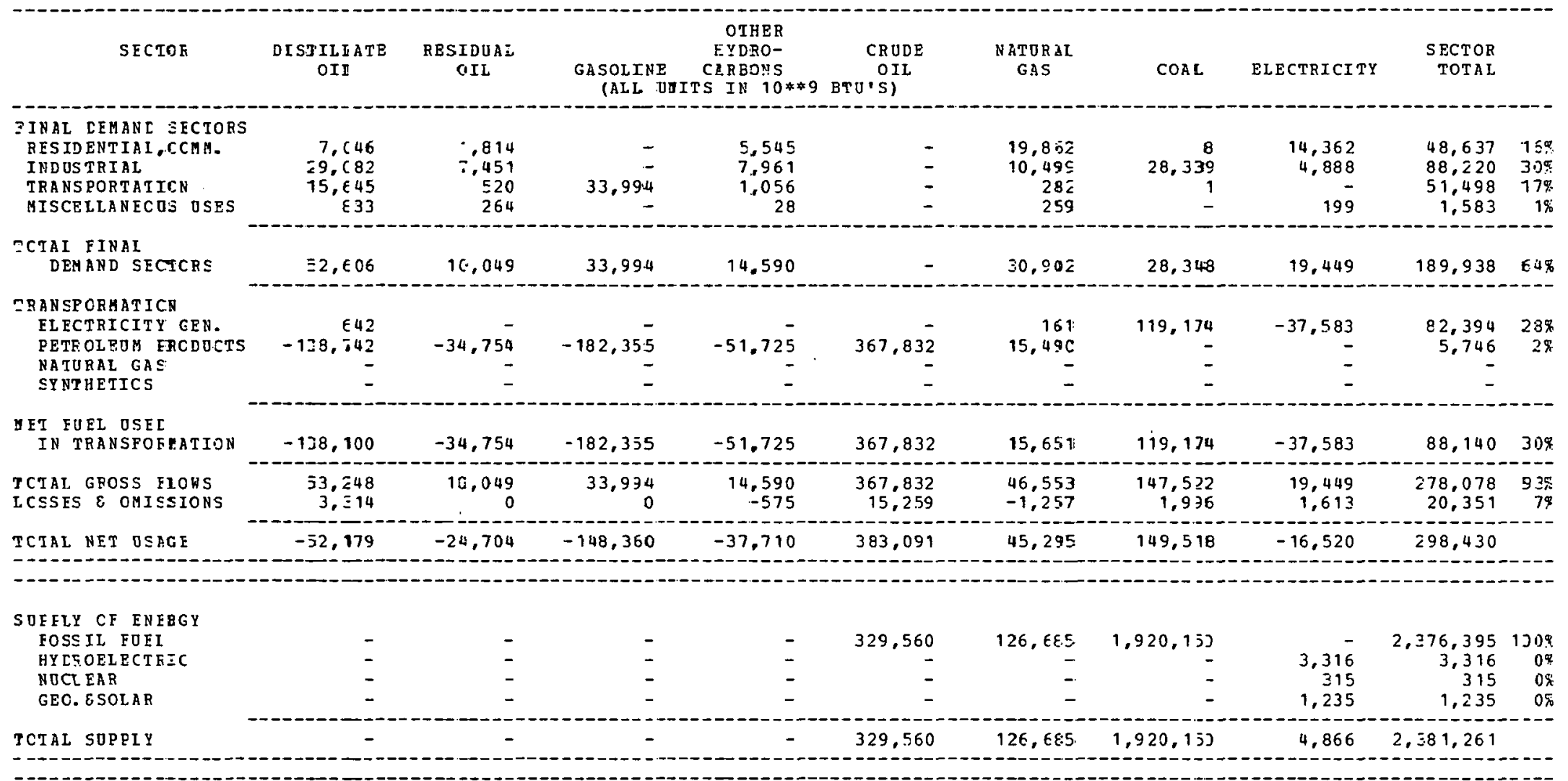

VET IM FORTS

OP REGION $\quad-52,179 \quad-24,704 \quad-148,36] \quad-37,710 \quad 53,531 \quad-81,389 \quad-1,770,631 \quad-21,385 \quad-2,082,830$

-

NOTES:

T TRANSECRMATICN LOSS DOE

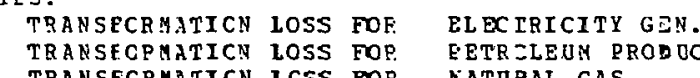

TRANSPORMATICN LOSS FOE

$=5 \varepsilon .67 \%$

EETR ZLEUM PRODOCTS $=1.50 \%$

$\begin{array}{lll}\text { SYNTHETICS } & =0.0 \pi \\ & =0.0 \%\end{array}$ 
REGICNAL ENEFGY EALANCE STETEMENT

\begin{tabular}{|c|c|c|c|c|c|c|c|c|c|c|}
\hline SECICE & $\begin{array}{l}\text { DISTIL LATE } \\
\text { OIL }\end{array}$ & $\begin{array}{l}\text { RESIDUAL } \\
\text { OIL }\end{array}$ & $\begin{array}{l}\text { GASOL INE } \\
\text { (ALL UN }\end{array}$ & $\begin{array}{l}\text { OTHER } \\
\text { HYDRC- } \\
\text { CARBONS } \\
\text { S IN! } 10 * \$ S\end{array}$ & $\begin{array}{c}\text { CROLF } \\
\text { OIL } \\
\text { ETO'S) }\end{array}$ & $\begin{array}{l}\text { NATUFAL } \\
\text { GAS }\end{array}$ & $\operatorname{COAI}$ & ELECTRICITY & $\begin{array}{r}\text { SECTOR } \\
\text { TOTAL }\end{array}$ & \\
\hline $\begin{array}{l}\text { FIN PL CEMANL SECTOFS } \\
\text { RESIDENTIAL, CCMM. } \\
\text { INDOSTPIAL } \\
\text { TEANSPORTAIICN } \\
\text { GISCELLANECS USES }\end{array}$ & $\begin{array}{r}18,411 \\
38,123 \\
26,894 \\
6,073\end{array}$ & $\begin{array}{r}4,104 \\
35,620 \\
232 \\
1,919\end{array}$ & $132,74 \frac{-}{-}$ & $\begin{array}{r}28,623 \\
72,641 \\
9,779 \\
216\end{array}$ & $\begin{array}{l}- \\
\overline{-}\end{array}$ & $\begin{array}{r}91,977 \\
17,003 \\
778 \\
1,587\end{array}$ & $\begin{array}{r}56 \\
152,086 \\
2 \\
1\end{array}$ & $\begin{array}{r}45,576 \\
15,555 \\
- \\
1,633\end{array}$ & $\begin{array}{r}188,747 \\
331,028 \\
170,427 \\
11,429\end{array}$ & $\begin{array}{r}23 \% \\
40 \% \\
21 \% \\
1 \%\end{array}$ \\
\hline $\begin{array}{l}\text { TCJAI FINAI } \\
\text { DEMAND SECTORS }\end{array}$ & 89,501 & 41,875 & 132,742 & 111,259 & - & 111,345 & 152,145 & 62,764 & 701,631 & $86 \%$ \\
\hline $\begin{array}{l}\text { TRANSFORMATICN } \\
\text { ELECTRICITY GEN. } \\
\text { FETROLEOM ERCDOCTS } \\
\text { NATDRAL GAS } \\
\text { SYNTHETICS }\end{array}$ & $\begin{array}{r}2,007 \\
-104,516 \\
- \\
-\end{array}$ & $\begin{array}{r}-33,402 \\
- \\
-\end{array}$ & $\begin{array}{r}- \\
-175,267 \\
-\end{array}$ & $\begin{array}{r}- \\
-49,715 \\
- \\
-\end{array}$ & $\begin{array}{r}353,536 \\
- \\
-102,128\end{array}$ & $\begin{array}{r}500 \\
14,888 \\
- \\
-\end{array}$ & $\begin{array}{r}274,546 \\
- \\
- \\
-\end{array}$ & $\begin{array}{r}-86,801 \\
- \\
- \\
-\end{array}$ & $\begin{array}{r}190,252 \\
5,523 \\
-102,128\end{array}$ & $\begin{array}{r}23 \% \\
1 \% \\
-11 \%\end{array}$ \\
\hline $\begin{array}{l}\text { NET FOEL OSEL } \\
\text { IN TRANSFOFMATION }\end{array}$ & $-102,50 \mathrm{~g}$ & $-33,402$ & $-175,267$ & $-49,715$ & 251,408 & 15,388 & 274,546 & $-86,801$ & 93,647 & $11 \%$ \\
\hline $\begin{array}{l}\text { TCTAL GFOSS FLCWS } \\
\text { LCSSES \& CMISSIONS }\end{array}$ & $\begin{array}{r}91,508 \\
5,695\end{array}$ & $\begin{array}{r}41,875 \\
3\end{array}$ & $\begin{array}{r}132,742 \\
0\end{array}$ & $\begin{array}{r}111,259 \\
-4,388\end{array}$ & $\begin{array}{r}353,536 \\
14,666\end{array}$ & $\begin{array}{r}126,733 \\
-3,424\end{array}$ & $\begin{array}{r}426,691 \\
5,775\end{array}$ & $\begin{array}{r}62,764 \\
5,207\end{array}$ & $\begin{array}{r}897,406 \\
23,534\end{array}$ & $\begin{array}{r}110 \% \\
3 \%\end{array}$ \\
\hline TOTAL NET USAGE & $-7,312$ & 8,473 & $-42,525$ & 57,154 & 266,075 & 123,309 & 432,466 & $-18,829$ & 818,812 & \\
\hline $\begin{array}{l}\text { SOEELY OF ENFRGY } \\
\text { FOSSIL FUEI } \\
\text { HYDROELECTFIC } \\
\text { NOCL EAR } \\
\text { GEO. ESOLAR }\end{array}$ & $\begin{array}{l}- \\
\overline{-} \\
-\end{array}$ & $\begin{array}{l}\overline{-} \\
\overline{-}\end{array}$ & $\begin{array}{l}- \\
\overline{-} \\
-\end{array}$ & $\begin{array}{l}- \\
\overline{-} \\
-\end{array}$ & $\begin{array}{r}159,455 \\
- \\
-\end{array}$ & $\begin{array}{r}158,708 \\
- \\
-\end{array}$ & $\begin{array}{r}1,151,569 \\
- \\
-\end{array}$ & $\begin{array}{r}7.47 \overline{-} \\
978 \\
3,896\end{array}$ & $\begin{array}{r}1,479,732 \\
7,471 \\
978 \\
3,896\end{array}$ & $\begin{array}{r}99 \% \\
1 \% \\
0 \% \\
0 \%\end{array}$ \\
\hline TCIAL SODPIY & - & - & - & - & 169,455 & 158,708 & $1,151,569$ & 12,345 & $1,492,077$ & \\
\hline
\end{tabular}

\begin{tabular}{l} 
NET IM PORTS \\
GP REGION \\
\hline
\end{tabular}




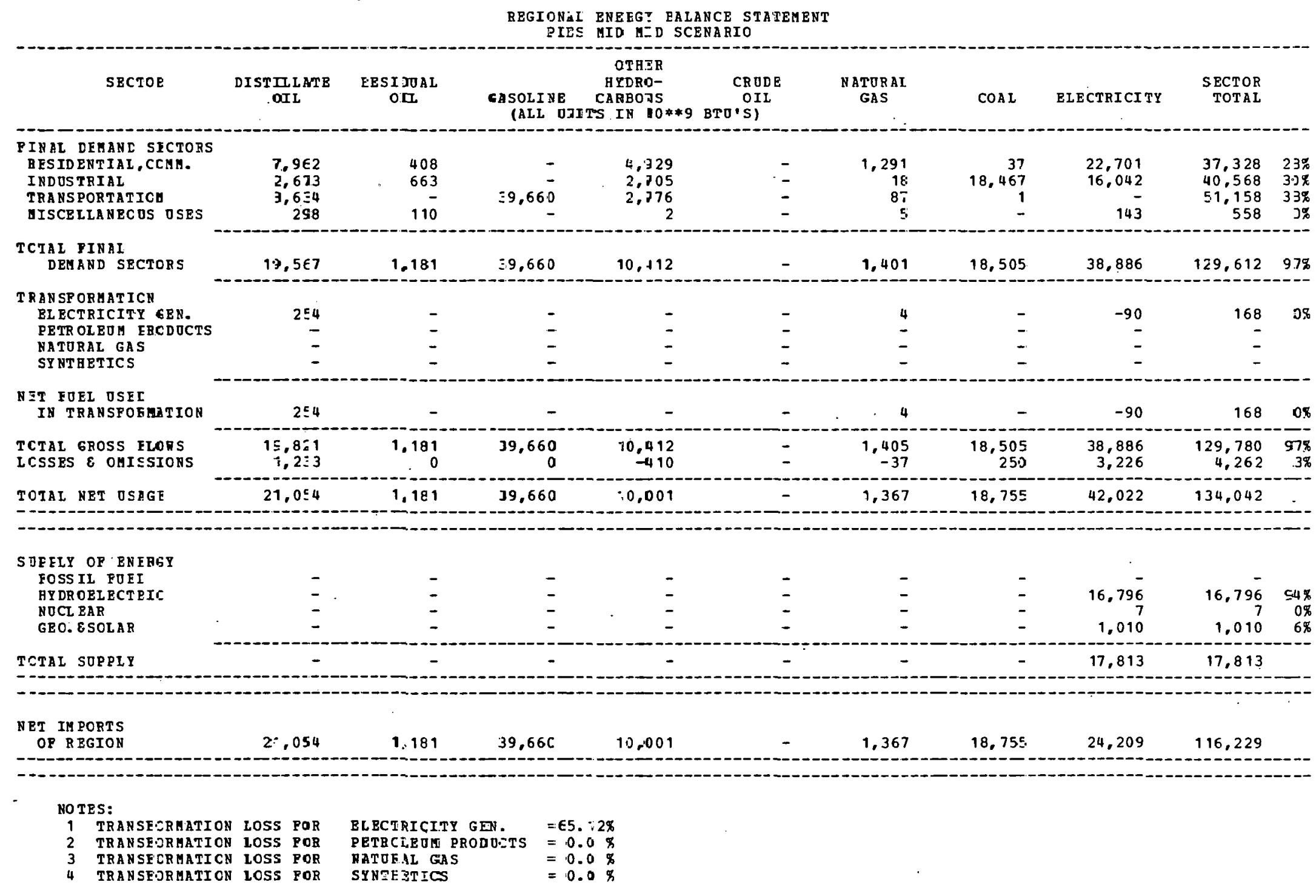


BEGIONAL ENE BGT BALANCE STATEMENT

IES MID MID SCENARIO

\begin{tabular}{|c|c|c|c|c|c|c|c|c|c|c|}
\hline SECTOR & $\begin{array}{l}\text { DISTILLATE } \\
\text { OIL }\end{array}$ & $\begin{array}{l}\text { RESILOAL } \\
\text { OIL }\end{array}$ & $\begin{array}{l}\text { GASOLINE } \\
\text { CALL ON }\end{array}$ & $\begin{array}{c}\text { OTHER } \\
\text { HYDRO- } \\
\text { CARBONS } \\
\text { TS IN } 10 * \$ 9\end{array}$ & $\begin{array}{c}\text { CRODE } \\
\text { OIL } \\
\text { BTO'S) }\end{array}$ & $\begin{array}{l}\text { NATURAL } \\
\text { GAS }\end{array}$ & COAL & ELECTRICITY & $\begin{array}{r}\text { SECTOR } \\
\text { TOTAL }\end{array}$ & \\
\hline $\begin{array}{l}\text { FINAL DEMANI SFCEORS } \\
\text { RESIDENTIAL, CCME. } \\
\text { IND OSTRIAL } \\
\text { TRANSPORTATICN } \\
\text { MISCELLANECOS OSES }\end{array}$ & $\begin{array}{r}3,537 \\
8,279 \\
14.436 \\
580\end{array}$ & $\begin{array}{r}689 \\
3,071 \\
92 \\
184\end{array}$ & 28,505 & $\begin{array}{r}6,048 \\
5,527 \\
4,371 \\
20\end{array}$ & $\overline{-}$ & $\begin{array}{r}20,725 \\
3,828 \\
469 \\
154\end{array}$ & $\begin{array}{r}22 \\
17,708 \\
1 \\
-\end{array}$ & $\begin{array}{r}12,765 \\
26,323 \\
- \\
153\end{array}$ & $\begin{array}{r}43,786 \\
64,736 \\
47,874 \\
1,091\end{array}$ & $\begin{array}{r}27 \% \\
40 \% \\
29 \% \\
1 \%\end{array}$ \\
\hline $\begin{array}{l}\text { TCTAI PINAI } \\
\text { DEMAND SECICRS }\end{array}$ & 26,832 & 4,036 & 28,505 & 15,966 & - & 25,176 & 17,731 & 39,241 & 157,487 & $97 \%$ \\
\hline $\begin{array}{l}\text { TRANSFORMATICN } \\
\text { BLECTRICITY GEN. } \\
\text { FETROLEOM ERCDOCTS } \\
\text { NATORAL GAS } \\
\text { SYNTHETICS }\end{array}$ & $\begin{array}{r}1,295 \\
- \\
-\end{array}$ & $\begin{array}{l}- \\
- \\
-\end{array}$ & $\begin{array}{l}- \\
- \\
-\end{array}$ & - & $\overline{-}$ & $\begin{array}{r}325 \\
-\end{array}$ & $\begin{array}{l}- \\
-\end{array}$ & $\begin{array}{r}-539 \\
- \\
-\end{array}$ & $\begin{array}{r}1,081 \\
- \\
-\end{array}$ & $1 \%$ \\
\hline $\begin{array}{l}\text { YET FOEL DSEL } \\
\text { IN TRANSPOBHATION }\end{array}$ & 1,295 & - & - & - & - & 325 & - & -539 & 1,081 & $1 \%$ \\
\hline $\begin{array}{l}\text { TCTAL GROSS FLCHE } \\
\text { LCSSES \& CMISSIOES }\end{array}$ & $\begin{array}{r}28,127 \\
1,750\end{array}$ & $\begin{array}{r}4,036 \\
0\end{array}$ & $\begin{array}{r}28,505 \\
0\end{array}$ & $\begin{array}{r}15,966 \\
-629\end{array}$ & - & $\begin{array}{r}25,501 \\
-689\end{array}$ & $\begin{array}{r}17.731 \\
240\end{array}$ & $\begin{array}{r}39,241 \\
3,255\end{array}$ & $\begin{array}{r}158,568 \\
3,928\end{array}$ & $\begin{array}{r}98 \% \\
2 \%\end{array}$ \\
\hline
\end{tabular}

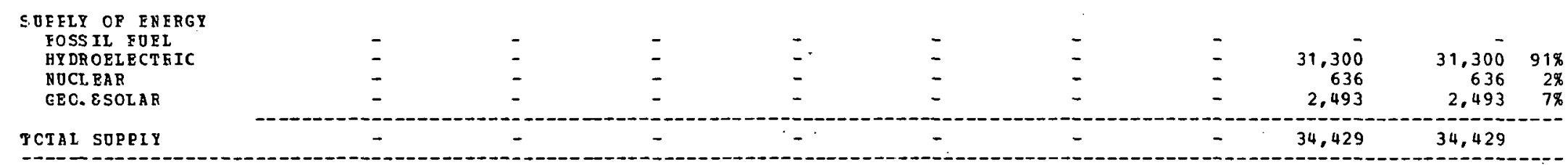

VET IM PORTS

OF R PGION

29,877

4,036

28,505

15,336

24,811

17,971

7,528

128,067

NoTES:

1 TRANSPCRIATICN LOSS POR

TRANSFCREATICN LOSS POR

TTANSPCREATICN LOSS POR

TZANSPOREATICN LCSS FOR

BLECTRICITY GEN.

$\begin{array}{ll} & =66.73 \% \\ \text { DOCTS } & =0.0 \%\end{array}$

PETROLE OY PRODOCTS $=0.0$
$=0.0$

SYNTBETICS

$=0.0 \%$
$=0.0 \%$ 
RE $3=C N A L$ BNIEGY EALANCE STATEMENT

PIES MID MID SCENARIJ

\begin{tabular}{|c|c|c|c|c|c|c|c|c|c|}
\hline SECTOK & $\begin{array}{l}\text { DISTILLATE } \\
\text { CIL }\end{array}$ & $\begin{array}{l}\text { RESIDOAL } \\
\text { OIL }\end{array}$ & $\begin{array}{l}\text { GASOLINE } \\
\text { (ALI ONI }\end{array}$ & $\begin{array}{c}\text { CTRER } \\
\text { HZDRO- } \\
\text { CABEONS } \\
\text { TS IN 10**9 }\end{array}$ & $\begin{array}{c}\text { C?ODE } \\
\text { JIL } \\
\text { BTU' }\end{array}$ & $\begin{array}{l}\text { NATCRAL } \\
\text { GRS }\end{array}$ & $\cos \mathrm{L}$ & ELECTRICIMY & $\begin{array}{l}\text { SECTOR } \\
\text { TOTAI }\end{array}$ \\
\hline $\begin{array}{l}\text { FINLL CEHANT SECTORS } \\
\text { RESIDENTIAI, CCMM. } \\
\text { INDUSTRIAL } \\
\text { TRANSPORTAEICN } \\
\text { MISCELLANECOS OSZS }\end{array}$ & $\begin{array}{r}17.454 \\
1 \div .644 \\
\subseteq .524 \\
522\end{array}$ & $\begin{array}{r}2,247 \\
4,575 \\
994 \\
193\end{array}$ & $\frac{-}{-}$ & $\begin{array}{r}8,888 \\
16,168 \\
5,403 \\
2\end{array}$ & $\begin{array}{l}- \\
\overline{-}\end{array}$ & $\begin{array}{r}2.662 \\
- \\
80 \\
-\end{array}$ & $\begin{array}{r}33 \\
14,031 \\
1 \\
-\end{array}$ & $\begin{array}{r}45,582 \\
42,814 \\
- \\
242\end{array}$ & $\begin{array}{r}76,865 \\
90,232 \\
77,507 \\
959\end{array}$ \\
\hline $\begin{array}{l}\text { TCTAL FINAL } \\
\text { DEMAND SECTCRS }\end{array}$ & $4 C, 144$ & 8,009 & $61,5 \cdot 55$ & 30,461 & - & 2,742 & 14.065 & 88,638 & 245,564 \\
\hline $\begin{array}{l}\text { TRAVSFCRMATICN } \\
\text { ELECTRICIFY EEN: } \\
\text { PETROLEU FBCDOCTS } \\
\text { NATORAL GIS } \\
\text { SYNTHETICS }\end{array}$ & $\begin{array}{r}616 \\
- \\
-\end{array}$ & $\begin{array}{l}- \\
\overline{-} \\
-\end{array}$ & $\begin{array}{l}- \\
\overline{-} \\
-\end{array}$ & $\begin{array}{l}- \\
\bar{z}\end{array}$ & $\begin{array}{l}\overline{-} \\
\overline{-}\end{array}$ & $\begin{array}{l}- \\
\overline{-} \\
-\end{array}$ & $\begin{array}{l}\overline{-} \\
\bar{z}\end{array}$ & $\begin{array}{r}-217 \\
- \\
-\end{array}$ & $\begin{array}{r}399 \\
- \\
-\end{array}$ \\
\hline $\begin{array}{l}\text { NET FOEL OSIZL } \\
\text { ID TRANSFOEMATION }\end{array}$ & 616 & - & - & - & - & - & - & -217 & 399 \\
\hline $\begin{array}{l}\text { TCIAL GROSS FLOAS } \\
\text { LCSSES } \varepsilon \text { ONISSIONS }\end{array}$ & $\begin{array}{r}4 C, 760 \\
\therefore, 537\end{array}$ & $\begin{array}{r}8,009 \\
0\end{array}$ & $\begin{array}{r}61,505 \\
0\end{array}$ & $\begin{array}{l}30,461 \\
-1,201\end{array}$ & - & $\begin{array}{r}2,742 \\
-74\end{array}$ & $\begin{array}{r}14,065 \\
190\end{array}$ & $\begin{array}{r}88,638 \\
7,354\end{array}$ & $\begin{array}{r}245,963 \\
8,806\end{array}$ \\
\hline TCTAL NET OSAGE & 43,297 & 8,009 & 61,505 & 29,259 & - & 2,667 & 14,255 & 95,775 & 254,765 \\
\hline $\begin{array}{l}\text { SOFFLY CF ENERGY } \\
\text { FOSS IL FOEI } \\
\text { HYDR CELECTRIC } \\
\text { NDCL EAR } \\
\text { GEC. ESOLA3 }\end{array}$ & $\begin{array}{l}\overline{-} \\
\overline{-}\end{array}$ & $\begin{array}{l}- \\
-\end{array}$ & $\begin{array}{l}- \\
- \\
-\end{array}$ & $\begin{array}{l}- \\
-\end{array}$ & $\begin{array}{l}- \\
-\end{array}$ & $\begin{array}{l}- \\
- \\
-\end{array}$ & $\begin{array}{l}- \\
- \\
-\end{array}$ & $\begin{array}{r}303,449 \\
\frac{-}{2,264}\end{array}$ & $\begin{array}{r}303,44 \overline{9} \\
\overline{-} \\
2,264\end{array}$ \\
\hline TСTAL SOPPLP & - & - & - & - & - & - & - & 305,713 & $305,71 \equiv$ \\
\hline
\end{tabular}

\section{NET IM FORTS}

OP REGION

43, $297 \quad 8,509$

61.505

29.259

2,567

14.255

$-209.937$

$-50,943$

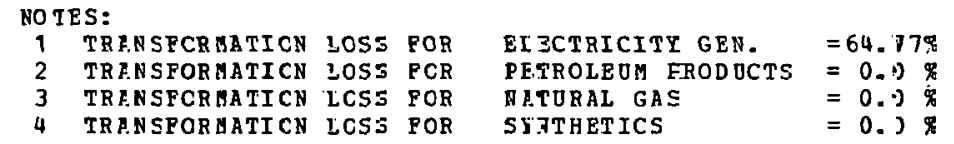


REGIONAL ENERGY EALANCE STATEMENT

PIES MID MID SCENARIO

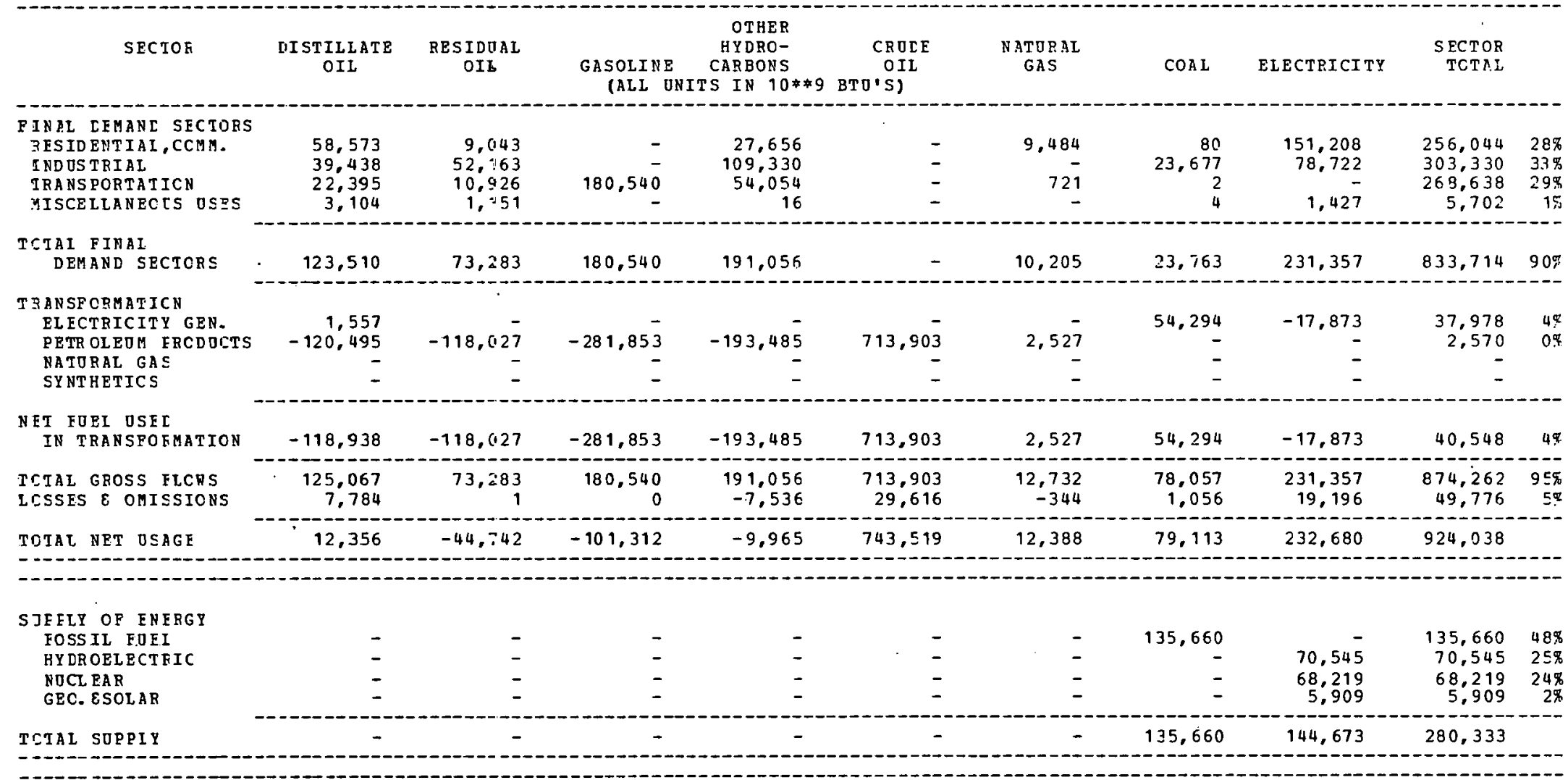

\begin{tabular}{|c|c|c|c|c|c|c|c|c|c|}
\hline NET IM FORTS & & & $\bullet$ & & & & & & \\
\hline OF REGION & 12,356 & $-44,742$ & $-101,312$ & $-9,965$ & 743,519 & 12,388 & $-56,546$ & 88,007 & 643,705 \\
\hline
\end{tabular}

-

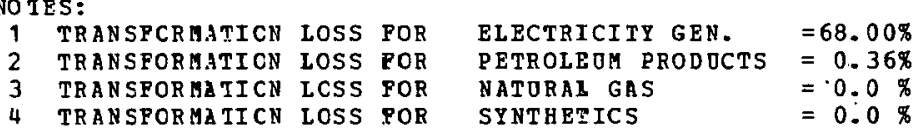

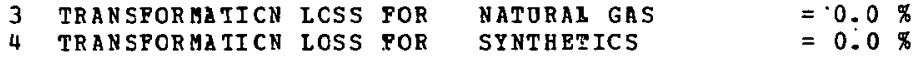


REGIONAL EHZRGY BALANCE STATEMEN-

PIET MID MID SCENARIO

\begin{tabular}{|c|c|c|c|c|c|c|c|c|c|c|}
\hline SECTOF & $\begin{array}{c}\text { DISTZLLITE } \\
\text { OIL }\end{array}$ & $\begin{array}{l}\text { RESIJUAL } \\
\text { CIL }\end{array}$ & $\begin{array}{l}\text { GASOLIGE } \\
\text { (ALL E }\end{array}$ & $\begin{array}{c}\text { OTFER } \\
\text { HZDFD- } \\
\text { CARBCYS } \\
=S \text { IN } 10 * 9\end{array}$ & $\begin{array}{c}\text { CROEE } \\
\text { OII } \\
\text { BTOSI) }\end{array}$ & $\begin{array}{l}\text { NATURAL } \\
\text { GAS }\end{array}$ & COAL & ELECTRICITY & $\begin{array}{r}\text { SECTOR } \\
\text { TOTAL }\end{array}$ & \\
\hline $\begin{array}{l}\text { FINAL DEHANC SECTCRS } \\
\text { RESIDENTIAI, CCAN. } \\
\text { INDOSTRIAL } \\
\text { TRANSPORTATION } \\
\text { MISCELLANEOS OSES }\end{array}$ & $\begin{array}{r}11.285 \\
7.207 \\
6.0 .32 \\
383\end{array}$ & $\begin{array}{r}1.863 \\
1.876 \\
757 \\
142\end{array}$ & $34,87 \stackrel{-}{-}$ & $\begin{array}{r}5,159 \\
4,723 \\
3,581 \\
2\end{array}$ & $\begin{array}{l}\overline{-} \\
\overline{-}\end{array}$ & $\begin{array}{r}1,774 \\
5 \\
5\end{array}$ & $\begin{array}{r}2 C \\
2,24 \epsilon \\
1 \\
-\end{array}$ & $\begin{array}{r}28,192 \\
11,997 \\
- \\
176\end{array}$ & $\begin{array}{r}48,303 \\
28,049 \\
45,405 \\
703\end{array}$ & $\begin{array}{l}\equiv 4 \% \\
\Sigma 0 \% \\
\equiv 2 \% \\
0 \%\end{array}$ \\
\hline $\begin{array}{l}\text { TCTAI FINAI } \\
\text { DEMAND SBCTORS }\end{array}$ & 24,917 & 4.638 & $34,87 \subseteq$ & 13,565 & - & 1,829 & $2,26 i$ & 40,365 & 122,460 & $\varepsilon 6 \%$ \\
\hline $\begin{array}{l}\text { TFANSPCRHATICE } \\
\text { FLECTRICITY EEN. } \\
\text { PETR OLEOM FPCDOCTS } \\
\text { NATURAL GAS } \\
\text { SYNTHETICS }\end{array}$ & $\begin{array}{r}251 \\
- \\
-\end{array}$ & $\begin{array}{l}- \\
- \\
-\end{array}$ & $\begin{array}{l}- \\
- \\
-\end{array}$ & $\begin{array}{l}- \\
\overline{-} \\
-\end{array}$ & $\begin{array}{l}- \\
\overline{-} \\
-\end{array}$ & $\begin{array}{l}- \\
- \\
-\end{array}$ & $\begin{array}{r}22,62 \bar{z} \\
\overline{-} \\
-\end{array}$ & $\begin{array}{r}-7,307 \\
- \\
- \\
-\end{array}$ & $\begin{array}{r}15,566 \\
- \\
-\end{array}$ & 11\%. \\
\hline $\begin{array}{l}\text { NET FURL OSEL } \\
\text { IN TRANSFOEDATICN }\end{array}$ & $25 i$ & - & - & - & - & - & $22,62=$ & $-7,507$ & 15,566 & $i 1 \%$ \\
\hline $\begin{array}{l}\text { TCTAL GROSS FECHS } \\
\text { LCSSES } \& \text { OMISSIONS }\end{array}$ & $\begin{array}{r}25,168 \\
1,556\end{array}$ & $\begin{array}{r}4.638 \\
0\end{array}$ & 34,879 & $\begin{array}{r}13.565 \\
-535\end{array}$ & - & $\begin{array}{r}1,823 \\
-43\end{array}$ & $\begin{array}{r}24,885 \\
336\end{array}$ & $\begin{array}{r}40, \equiv 65 \\
3, \Xi 49\end{array}$ & $\begin{array}{r}138,026 \\
4,668\end{array}$ & $\begin{array}{r}\subseteq 7 \% \\
3 \%\end{array}$ \\
\hline TOJAL NET OSAGE & 25.734 & $L, 638$ & 34,879 & 13.029 & - & 1,773 & 25,225 & 36,407 & 142,694 & \\
\hline $\begin{array}{l}\text { S OEPLY DF ENEBGY } \\
\text { FOSS IL FUEI } \\
\text { HYDROELECTFIC } \\
\text { NOCLEAR } \\
\text { GEO.ESOLAR }\end{array}$ & $\begin{array}{l}- \\
-\end{array}$ & $\begin{array}{l}\bar{z} \\
\overline{-}\end{array}$ & $\begin{array}{l}- \\
- \\
-\end{array}$ & $\begin{array}{l}- \\
- \\
-\end{array}$ & $\begin{array}{l}- \\
- \\
-\end{array}$ & $\begin{array}{l}- \\
- \\
-\end{array}$ & - & $\begin{array}{r}55,669 \\
65,575 \\
1,031\end{array}$ & $\begin{array}{r}55,669 \\
55,575 \\
1,031\end{array}$ & $\begin{array}{r}+6 \% \\
54 \% \\
1 \%\end{array}$ \\
\hline TOTAL SOPPIY & - & - & - & - & - & - & - & 122,275 & 122,275 & \\
\hline
\end{tabular}

\section{NET IM FORTS}

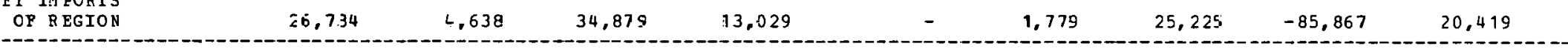

NOTES:

\begin{tabular}{|c|c|c|c|c|}
\hline & U. & FOR & & \\
\hline TRA & LOS & POR & UM PROEOCTS & \\
\hline AIICN & LOS & FoR & RAL GAS & 0. \\
\hline
\end{tabular}


ZEGIONAL ENEFGY EALANCE STATEMENT

PIES MID MID SCENARI

\begin{tabular}{|c|c|c|c|c|c|c|c|c|c|c|}
\hline SECTOE & $\begin{array}{l}\text { DISTILLATE } \\
\text { OIL }\end{array}$ & $\underset{O I L}{\operatorname{RESIDUL}}$ & $\begin{array}{l}\text { GHSOLINE } \\
\quad \text { ALL } 0\end{array}$ & $\begin{array}{c}\text { OTHER } \\
\text { HYDRO- } \\
\text { CARBONS } \\
\text { TS IN 10*\$9 }\end{array}$ & $\begin{array}{c}\text { CRODE } \\
\text { OIL } \\
\text { BTO'S) }\end{array}$ & $\begin{array}{l}\text { NATURAL } \\
\text { GAS }\end{array}$ & $\mathrm{COAL}$ & ELECTRICITY & $\begin{array}{r}\text { SECTOR } \\
\text { TOTAL }\end{array}$ & \\
\hline $\begin{array}{l}\text { FIN PL CFMANL SECTORS } \\
\text { RESIDENTIAL, CCMM. } \\
\text { INDOSTRIAL } \\
\text { TRANSPORTATICN } \\
\text { MISCELLANECOS OSES }\end{array}$ & $\begin{array}{r}52,654 \\
49,270 \\
33,331 \\
1,192\end{array}$ & $\begin{array}{r}9.919 \\
32.401 \\
2.556 \\
442\end{array}$ & $\begin{array}{r}- \\
164,21 \frac{-}{-}\end{array}$ & $\begin{array}{r}22,255 \\
68,447 \\
14,087 \\
7\end{array}$ & $\begin{array}{l}\overline{-} \\
\overline{-}\end{array}$ & $\begin{array}{r}7,709 \\
- \\
280 \\
-\end{array}$ & $\begin{array}{r}163 \\
37,198 \\
2 \\
1\end{array}$ & $\begin{array}{r}116,356 \\
118,179 \\
- \\
535\end{array}$ & $\begin{array}{r}209,056 \\
305,495 \\
214,467 \\
2,177\end{array}$ & $\begin{array}{r}27 \% \\
40 \% \\
28 \% \\
0 \%\end{array}$ \\
\hline $\begin{array}{l}\text { TCIAI FINAI } \\
\text { DEMAND SECTORS }\end{array}$ & 136,447 & 45,318 & 164,211 & 104,796 & - & 7,989 & 37,364 & 235,070 & 731,195 & $95 \%$ \\
\hline $\begin{array}{l}\text { TRANSPORMATICN } \\
\text { FLECTRICITY GEN. } \\
\text { PETROLEOM ERCDOCTS } \\
\text { NATURAL GAS } \\
\text { SYNTHETICS }\end{array}$ & $\begin{array}{r}2,112 \\
-46,782 \\
- \\
-\end{array}$ & $\begin{array}{r}-45,823 \\
- \\
-\end{array}$ & $\begin{array}{r}- \\
-109,428 \\
-\end{array}$ & $\begin{array}{r}-75,120 \\
- \\
-\end{array}$ & $\begin{array}{r}- \\
277,169 \\
-\end{array}$ & $\begin{array}{r}- \\
981 \\
-\end{array}$ & $\begin{array}{r}1,584 \\
- \\
-\end{array}$ & $\begin{array}{r}-1,247 \\
- \\
- \\
-\end{array}$ & $\begin{array}{r}2.449 \\
997 \\
- \\
-\end{array}$ & $\begin{array}{l}0 \% \\
0 \%\end{array}$ \\
\hline $\begin{array}{l}\text { NET FOEL USEL } \\
\text { IN TRANSPOFHATION }\end{array}$ & $-44,670$ & $-45,823$ & $-109,428$ & $-75,120$ & 277,169 & 981 & 1,584 & $-1,247$ & 3,446 & $0 \%$ \\
\hline $\begin{array}{l}\text { TCIAL GROSS FICRS } \\
\text { LCSSES } E \text { OMISSIONS }\end{array}$ & $\begin{array}{r}138,559 \\
8,624\end{array}$ & $\begin{array}{r}45,318 \\
0\end{array}$ & $\begin{array}{r}164,211 \\
0\end{array}$ & $\begin{array}{r}104,796 \\
-4,133\end{array}$ & $\begin{array}{r}277, .169 \\
11.498\end{array}$ & $\begin{array}{r}8,970 \\
-242\end{array}$ & $\begin{array}{r}38,948 \\
527\end{array}$ & $\begin{array}{r}235,070 \\
19,504\end{array}$ & $\begin{array}{r}734,641 \\
35,780\end{array}$ & $\begin{aligned} 95 \% \\
5 \%\end{aligned}$ \\
\hline
\end{tabular}

\begin{tabular}{|c|c|c|c|c|c|c|c|c|c|c|}
\hline $\begin{array}{l}\text { SOFELY CF ENERGY } \\
\text { POSS }\end{array}$ & - & - & - & & 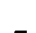 & & 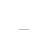 & - & - & \\
\hline HY DR OELECTEIC & - & - & - & - & - & - & - & 144,572 & 144,972 & $87 \pi$ \\
\hline NOCL EAR & - & - & - & - & - & - & - & 15,247 & 15,247 & $9 \%$ \\
\hline GEC. ESOLAR & - & - & - & - & - & - & - & 6,003 & $6,00.3$ & $4 \pi$ \\
\hline TOTAL SOPPIY & - & - & - & - & - & - & - & 166,222 & 166,222 & \\
\hline
\end{tabular}

\begin{tabular}{|c|c|c|c|c|c|c|c|c|c|}
\hline OP R BGION & 100,401 & -504 & 54.783 & 25,542 & 288,667 & 8,727 & 39,475 & 87,105 & 604.199 \\
\hline
\end{tabular}

\section{NOTES:}

1 TRANSFCRATICN LOSS FOR TRANSFORMATICN LOSS POR TRANSPOR ATICN LCSS ROR TRA NSPOAAIICN LCSS PO
ELECTRICITY GEN. $\quad=66.26 \%$

NATOEAL GAS

NATUEAL GAS

$=0.0 \%$ 
REEIONAL 3NEFGY EALANCE STAIE.AENT

PIES IIL MID SCENARIC

\begin{tabular}{|c|c|c|c|c|c|c|c|c|c|c|}
\hline SECTOE & $\begin{array}{c}\text { DISTIELATE } \\
\text { OLL }\end{array}$ & $\begin{array}{l}\text { RESIDUAL } \\
\text { OIL }\end{array}$ & $\begin{array}{l}\text { GASOLINE } \\
\text { (ALI ONIT }\end{array}$ & $\begin{array}{c}\text { CTAER } \\
\text { HYDRO- } \\
\text { OAFBONS } \\
5 \text { II } 10 * \$ 9\end{array}$ & $\begin{array}{c}\text { CE ODE } \\
\text { CIL } \\
\text { BTU S }\end{array}$ & $\begin{array}{l}\text { NATURAL } \\
\text { GAS }\end{array}$ & CCF.I & ELECTRICITY & $\begin{array}{l}\text { SECTOR } \\
\text { TOTAL }\end{array}$ & \\
\hline 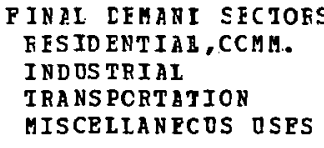 & $\begin{array}{r}19.711 \\
13.630 \\
11.821 \\
574\end{array}$ & $\begin{array}{r}3,763 \\
4,241 \\
728 \\
213\end{array}$ & $62,37 \frac{-}{-}$ & $\begin{array}{r}8,301 \\
12,023 \\
3,916 \\
3\end{array}$ & $\begin{array}{l}- \\
- \\
-\end{array}$ & $\begin{array}{r}2,880 \\
- \\
37 \\
-\end{array}$ & $\begin{array}{r}65 \\
4 r .01 \\
1 \\
-\end{array}$ & $\begin{array}{r}42,847 \\
19,894 \\
- \\
243\end{array}$ & $\begin{array}{r}77,567 \\
54,489 \\
78,931 \\
1,033\end{array}$ & $\begin{array}{r}359 \\
258 \\
36 \% \\
08\end{array}$ \\
\hline $\begin{array}{l}\text { TCTAL PINAL } \\
\text { DEMAND SECTOAS }\end{array}$ & 45.736 & 8,945 & 62,578 & 24,243 & - & 2,957 & $4, .267$ & 62,984 & 212,020 & $97 \%$ \\
\hline $\begin{array}{l}\text { TEANSFCRHATICN } \\
\text { FLECTRICIJY EEN. } \\
\text { PETROLEOM FRCLOCTS } \\
\text { NATURAL GES } \\
\text { SY NTHETICS }\end{array}$ & $\begin{array}{r}391 \\
- \\
-\end{array}$ & $\begin{array}{l}\overline{-} \\
\overline{-}\end{array}$ & $\begin{array}{l}\overline{-} \\
\overline{-}\end{array}$ & $\begin{array}{l}\overline{-} \\
\overline{-}\end{array}$ & $\begin{array}{l}- \\
\overline{-}\end{array}$ & $\begin{array}{l}\overline{-} \\
\overline{-}\end{array}$ & $\begin{array}{l}\bar{z} \\
\bar{z}\end{array}$ & $\begin{array}{r}-138 \\
- \\
-\end{array}$ & $\begin{array}{r}253 \\
- \\
-\end{array}$ & 09 \\
\hline $\begin{array}{l}\text { NFT FOEI OSEI } \\
\text { IN TRANSEGMATION }\end{array}$ & 391 & - & - & - & - & - & - & -138 & 253 & $0 \%$ \\
\hline $\begin{array}{l}\text { TCTAL GROSS FLCRS } \\
\text { LCSSES } \varepsilon \text { OMISSIONS }\end{array}$ & $\begin{array}{r}46.127 \\
2.871\end{array}$ & $\begin{array}{r}8,945 \\
0\end{array}$ & $\begin{array}{r}62,378 \\
0\end{array}$ & $\begin{array}{r}24.243 \\
-956\end{array}$ & - & $\begin{array}{r}2,957 \\
-80\end{array}$ & $\begin{array}{r}4, i 67 \\
64\end{array}$ & $\begin{array}{r}62,984 \\
5,226\end{array}$ & $\begin{array}{r}212,27 \equiv \\
7,12 E\end{array}$ & $\begin{array}{r}97 \% \\
3 \%\end{array}$ \\
\hline
\end{tabular}

\begin{tabular}{|c|c|c|c|c|c|c|c|c|c|c|}
\hline $\begin{array}{l}\text { SOFPLY CF ERERGY } \\
\text { FOSS IL FOEL }\end{array}$ & - & - & - & - & - & - & - & - & - & \\
\hline HY DR OELECTIIC & - & - & - & - & - & - & - & 20,150 & 20,150 & $93 \%$ \\
\hline NUCL BAR & - & - & - & - & - & - & - & - & & \\
\hline GEO. ESOLAE & - & - & - & - & - & - & - & 1,609 & 1,609 & $7 \%$ \\
\hline TCTAL SOPPIY & - & - & - & - & - & - & - & 27,759 & 21,759 & \\
\hline
\end{tabular}

NET IM FORTS
OF REGION


FEgIONAL ENEEGY EALANCE STATEMENT

\begin{tabular}{|c|c|c|c|c|c|c|c|c|c|}
\hline SECIOF & $\begin{array}{l}\text { DISTILEATE } \\
\text { OIE }\end{array}$ & $\begin{array}{l}\text { RESIDUAL } \\
\text { OIL }\end{array}$ & $\begin{array}{l}\text { GASOLINE } \\
\text { (ALL UNIT }\end{array}$ & $\begin{array}{l}\text { OTHER } \\
\text { HYDRO- } \\
\text { CARBONS } \\
\text { S IN } 10 * \$ 9\end{array}$ & $\begin{array}{c}\text { CROLE } \\
\text { OIL } \\
\text { BTO'S\} }\end{array}$ & $\begin{array}{l}\text { NATURAL } \\
\text { GAS }\end{array}$ & $\operatorname{COA} L$ & BLECTRICITY & $\begin{array}{l}\text { SECTOR } \\
\text { TOTAL }\end{array}$ \\
\hline $\begin{array}{l}\text { FINAL CEMANC SFCIOHS } \\
\text { PESIDENTIAL, CCMM. } \\
\text { INDOSTRIAL } \\
\text { TRANSPORTATICN } \\
\text { MISCELLANECES OSES }\end{array}$ & $\begin{array}{r}8,037 \\
2,234 \\
4.945 \\
475\end{array}$ & $\begin{array}{r}539 \\
424 \\
42 \\
178\end{array}$ & $\begin{array}{r}- \\
- \\
-\end{array}$ & $\begin{array}{r}4,739 \\
1,775 \\
2,476 \\
2\end{array}$ & $\begin{array}{l}- \\
-\end{array}$ & $\begin{array}{r}884 \\
62 \\
-\end{array}$ & $\begin{array}{r}36 \\
9,149 \\
- \\
-\end{array}$ & $\begin{array}{r}22,502 \\
10,677 \\
- \\
245\end{array}$ & $\begin{array}{r}36,737 \\
24,259 \\
45,593 \\
900\end{array}$ \\
\hline $\begin{array}{l}\text { TCTAI FINAI } \\
\text { DEMAND SECTCRS }\end{array}$ & 15,691 & 1,183 & 38,068 & 8,992 & ? & 946 & 3,185 & 33,424 & 107,489 \\
\hline $\begin{array}{l}\text { TE AN SPORMATICN } \\
\text { EL ECTRICITY EEN. } \\
\text { PETROLEOH ERCDOCTS } \\
\text { NATORAL GAS } \\
\text { SY NTHETICS }\end{array}$ & $\begin{array}{r}208 \\
- \\
-\end{array}$ & $\begin{array}{l}- \\
\overline{-}\end{array}$ & $\begin{array}{l}\overline{-} \\
\overline{-}\end{array}$ & $\begin{array}{l}- \\
-\end{array}$ & $\begin{array}{l}- \\
-\end{array}$ & $\begin{array}{l}- \\
- \\
-\end{array}$ & $\begin{array}{l}- \\
-\end{array}$ & $\begin{array}{r}-73 \\
- \\
- \\
-\end{array}$ & $\begin{array}{r}135 \\
- \\
-\end{array}$ \\
\hline $\begin{array}{l}\text { MET FOFL OSEL } \\
\text { IN TRANSFOKHATION }\end{array}$ & 208 & - & - & - & - & - & - & -73 & 135 \\
\hline $\begin{array}{l}\text { TCIAI GROSS FLCRS } \\
\text { LCSSES E OMISSIONS }\end{array}$ & $\begin{array}{r}15,899 \\
989\end{array}$ & $\begin{array}{r}1,193 \\
0\end{array}$ & $\begin{array}{r}38,068 \\
0\end{array}$ & $\begin{array}{r}8,992 \\
-354\end{array}$ & - & $\begin{array}{l}946 \\
-25\end{array}$ & $\begin{array}{r}9,185 \\
124\end{array}$ & $\begin{array}{r}33,424 \\
2,773\end{array}$ & $\begin{array}{r}107,624 \\
3,507\end{array}$ \\
\hline
\end{tabular}

\begin{tabular}{|c|c|c|c|c|c|c|c|c|c|c|}
\hline $\begin{array}{l}\text { SOFPLY OP ENERGY } \\
\text { FCSSIL FOEL }\end{array}$ & - & - & - & - & - & - & - & - & . - & \\
\hline HY DR OEL ECT BIC & - & - & - & - & - & - & - & 16,515 & 16,515 & $95 \%$ \\
\hline NOCL EAR & - & - & - & - & - & - & - & - & - & \\
\hline GBC. \&SOLAB & - & - & - & - & - & - & - & 853 & 853 & 5\%. \\
\hline TCTAI SOPPIY & - & - & - & - & - & - & - & 17,368 & 17,368 & \\
\hline
\end{tabular}

\section{NET IMFORTS}

16,888

1.133

38,068

8,637

920

9,309

18.756

93,763

-

\section{NOTES :}

$\begin{array}{llll}\text { TRANSPCRHAIICN } & \text { lOSS POR } & \text { ELBCTRICITY GEN. } & =64.90 \% \\ \text { TRANSPCRMATICN } & \text { LOSS POR } & \text { PETROLEOA PRODOCTS } & =0.0 \% \\ \text { TRANSPCRAIICN } & \text { lOSS POR } & \text { NATURAL GAS } & =0.0 \% \\ \text { TRA SPCRAIICN } & \text { LOSS POR } & \text { SYNTHETICS } & =0.0 \%\end{array}$


REGICNAL ENB FGY PALANCE STATEMETT

\begin{tabular}{|c|c|c|c|c|c|c|c|c|c|c|}
\hline SECTOA & $\begin{array}{l}\text { DISTILEATE } \\
\text { OIL }\end{array}$ & $\begin{array}{l}\text { RSSIDJAL } \\
\text { DIL }\end{array}$ & $\begin{array}{l}\text { SASOLILE } \\
\text { (ALL O }\end{array}$ & $\begin{array}{c}\text { OZHER } \\
\text { AY DRO- } \\
\text { CAREONS } \\
\text { TS ID } 10 * \approx 9\end{array}$ & $\begin{array}{c}\text { CR DDE } \\
O I L \\
\text { BTU'S] }\end{array}$ & $\begin{array}{l}\text { NaTURAZ } \\
\text { GAS }\end{array}$ & COAL & ELECTBICITY & $\begin{array}{r}\text { SECTOR } \\
\text { TOTAL }\end{array}$ & \\
\hline $\begin{array}{l}\text { PINAL DEMARE SFCTOKS } \\
\text { RESIDERTIAL,CCMM. } \\
\text { INDUSTRIAL } \\
\text { TRANSPORTATIOH } \\
\text { UISCELLANECS OSES }\end{array}$ & $\begin{array}{r}3,457 \\
3,599 \\
7,530 \\
149\end{array}$ & $\begin{array}{r}40 \\
2,543 \\
5 \\
\equiv 7\end{array}$ & $\begin{array}{r}- \\
34,982 \\
-\end{array}$ & $\begin{array}{r}\equiv, 022 \\
\equiv, 171 \\
11,394 \\
1\end{array}$ & $\begin{array}{l}- \\
-\end{array}$ & $\begin{array}{r}6,007 \\
21,273 \\
1,023 \\
263\end{array}$ & $\begin{array}{r}1 \\
3,757 \\
- \\
-\end{array}$ & $\begin{array}{r}9,999 \\
11,898 \\
- \\
115\end{array}$ & $\begin{array}{r}21,526 \\
45,246 \\
55,029 \\
565\end{array}$ & $\begin{array}{l}15 \% \\
\vdots 1 \% \\
\vdots 8 \% \\
0 \%\end{array}$ \\
\hline $\begin{array}{l}\text { TCTAI PINAL } \\
\text { DEHAND SECTORS }\end{array}$ & 14,335 & 2,620 & 34,982 & $1 \leqq, 588$ & - & 28,571 & 3.758 & 22,012 & 122,366 & $84 \%$ \\
\hline $\begin{array}{l}\text { TRANSPOFMATICN } \\
\text { EL ECTRICITZ GEY. } \\
\text { PETROLEUA EBCDOCTS } \\
\text { NATORAL GAE } \\
\text { SY NTHETICS }\end{array}$ & $\begin{array}{l}18 \\
- \\
-\end{array}$ & $\begin{array}{l}\overline{-} \\
\overline{-}\end{array}$ & $\bar{z}$ & $\begin{array}{l}\overline{-} \\
\overline{-}\end{array}$ & $\begin{array}{l}- \\
\overline{-}\end{array}$ & $\begin{array}{r}17,367 \\
- \\
-\end{array}$ & $\begin{array}{r}15,999 \\
= \\
=\end{array}$ & $\begin{array}{r}-11,960 \\
- \\
-\end{array}$ & $\begin{array}{r}21,424 \\
- \\
-\end{array}$ & $15 \%$ \\
\hline $\begin{array}{l}\text { NET EOEL OSE } \\
\text { IN TRANSPOEMATION }\end{array}$ & 18 & - & - & - & - & $17,36.7$ & 15,979 & $-11,960$ & 21,424 & $15 \%$ \\
\hline $\begin{array}{l}\text { TCTAI GROSS EICRS } \\
\text { LCSSES \& OMISSIORS }\end{array}$ & $\begin{array}{r}14,853 \\
924\end{array}$ & $\begin{array}{r}2,620 \\
0\end{array}$ & 34,932 & $\begin{array}{r}1 \equiv .588 \\
-614\end{array}$ & $\overline{-}$ & $\begin{array}{l}45,938 \\
-1,241\end{array}$ & $\begin{array}{r}19.757 \\
257\end{array}$ & $\begin{array}{r}22,012 \\
1,826\end{array}$ & $\begin{array}{r}143,790 \\
1,162\end{array}$ & $\begin{array}{r}99 \% \\
1 \%\end{array}$ \\
\hline TCIAI NET OSEGE & 15,777 & 2.620 & 34,932 & $18 ., 973$ & - & 44,696 & 20,024 & 11,878 & 144,952 & \\
\hline $\begin{array}{l}\text { S OEPLY OF EYIRGY } \\
\text { FOSS IL FOEY } \\
\text { HYDROELBCIEIC } \\
\text { NOCLEAR } \\
\text { GEC. \&SOLAR }\end{array}$ & $\begin{array}{l}\overline{-} \\
\overline{-}\end{array}$ & - & I & - & - & $\begin{array}{l}\overline{-} \\
-\end{array}$ & $\begin{array}{l}\overline{-} \\
\overline{-}\end{array}$ & $\begin{array}{r}41 \overline{3} \\
5 \overline{3} \\
1,383\end{array}$ & $\begin{array}{r}41 \overline{3} \\
53 \\
1,383\end{array}$ & $\begin{array}{r}22 \% \\
3 \% \\
75 \%\end{array}$ \\
\hline TCTAL SOPPLY & - & - & - & - & - & - & - & 1,849 & 1,849 & \\
\hline
\end{tabular}

NET IM FORTS

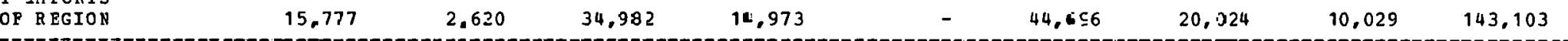

-

ROTES:

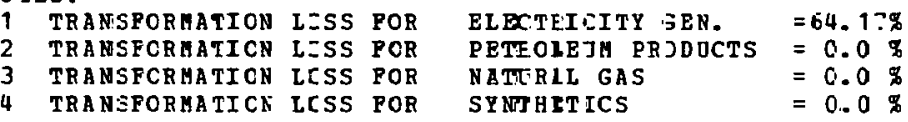


RZGIONAL ENE BGY RALANCE STATEHENT

PIES MID MID SCENARIO

\begin{tabular}{|c|c|c|c|c|c|c|c|c|c|c|}
\hline SECTOF & $\begin{array}{l}\text { DISTILLATE } \\
\text { OIL }\end{array}$ & $\begin{array}{l}\text { RESIDOAL } \\
\text { CIL }\end{array}$ & $\begin{array}{l}\text { GASOLINE } \\
\text { (ALL ONI }\end{array}$ & $\begin{array}{l}\text { OTHER } \\
\text { HYDRD- } \\
\text { CAREONS } \\
\text { TS IN } 10 * 9\end{array}$ & $\begin{array}{c}\text { CRODE } \\
\text { OII } \\
\text { BTU'S) }\end{array}$ & $\begin{array}{l}\text { NATORAL } \\
\text { GAS }\end{array}$ & COAL & ELECTRICITY & $\begin{array}{r}\text { SECTOR } \\
\text { TOTAL }\end{array}$ & \\
\hline $\begin{array}{l}\text { PIRZL CEMAXC SECTCRS } \\
\text { RESIDENTIAL,CCHA. } \\
\text { IYDOSTRIAL } \\
\text { TZANSPORTATICH } \\
\text { UISCELLANEOOS OSES }\end{array}$ & $\begin{array}{r}5,309 \\
6,173 \\
4,958 \\
253\end{array}$ & $\begin{array}{r}171 \\
3,836 \\
3 \\
69\end{array}$ & 53,243 & $\begin{array}{r}3,938 \\
8,581 \\
23,347 \\
4\end{array}$ & - & $\begin{array}{r}11,982 \\
23,938 \\
2,093 \\
351\end{array}$ & $\begin{array}{r}4 \\
579 \\
- \\
-\end{array}$ & $\begin{array}{r}15,462 \\
15,186 \\
-176\end{array}$ & $\begin{array}{r}36,866 \\
64,293 \\
83,644 \\
853\end{array}$ & $\begin{array}{r}12 \% \\
22 \% \\
28 \% \\
0 \%\end{array}$ \\
\hline $\begin{array}{l}\text { TCTAI FINAL } \\
\text { DEHAND SECTORS }\end{array}$ & 16,693 & 4,079 & 53,243 & 35,370 & - & 38,364 & 6,583 & 30,824 & 185,656 & $62 \%$ \\
\hline 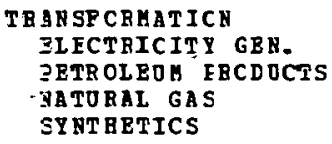 & $\begin{array}{r}1,789 \\
- \\
-\end{array}$ & $\begin{array}{l}\overline{-} \\
\overline{-}\end{array}$ & $\begin{array}{l}- \\
\overline{-}\end{array}$ & $\begin{array}{l}\overline{-} \\
\overline{-}\end{array}$ & $\begin{array}{l}\overline{-} \\
\overline{-}\end{array}$ & $\begin{array}{r}10,972 \\
= \\
-\end{array}$ & $\begin{array}{r}149,828 \\
- \\
-\end{array}$ & $\begin{array}{r}-54,124 \\
- \\
-\end{array}$ & $\begin{array}{r}108,465 \\
- \\
-\end{array}$ & $36 \%$ \\
\hline $\begin{array}{l}\text { NET FOEL OSEL } \\
\text { IE TRASPOEATTIOD }\end{array}$ & 1,789 & - & - & - & - & 10,972 & 149,828 & $-54,124$ & 108,465 & $36 \%$ \\
\hline $\begin{array}{l}\text { TCTAL GROSS FIORS } \\
\text { LCSSES \& OUISSIONS }\end{array}$ & $\begin{array}{r}18,482 \\
1,150\end{array}$ & $\begin{array}{r}4,079 \\
0\end{array}$ & $\begin{array}{r}53,243 \\
0\end{array}$ & $\begin{array}{l}35,8.70 \\
-1,414\end{array}$ & - & $\begin{array}{l}49,336 \\
-1,333\end{array}$ & $\begin{array}{r}156,411 \\
2,117\end{array}$ & $\begin{array}{r}30,824 \\
2,557\end{array}$ & $\begin{array}{r}294,121 \\
3,077\end{array}$ & $\begin{array}{r}99 \% \\
1 \%\end{array}$ \\
\hline TCTAL NET OSAGE & 19,632 & 4.079 & 53,243 & 34.455 & - & 48,002 & 158,528 & $-20,742$ & 297,198 & \\
\hline
\end{tabular}

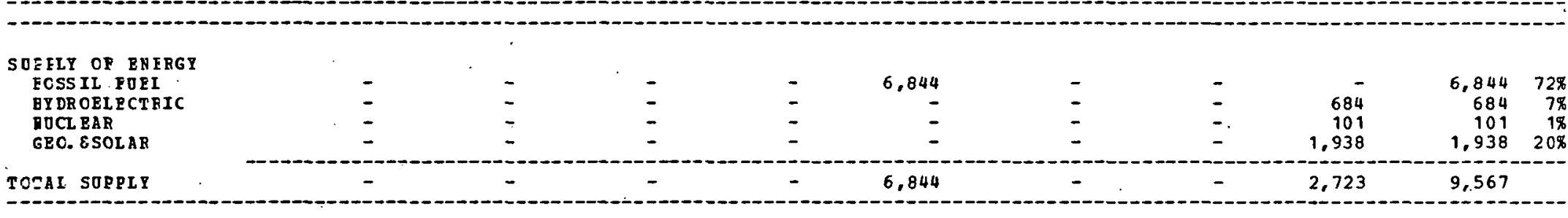

NET IM PORTS
OF RBGION


REGIONLL EEREGY PALANCE STATEMENT

PIEL ELEEGY PALANCE STA
PIES MID YID SCERARIO

\begin{tabular}{|c|c|c|c|c|c|c|c|c|c|c|}
\hline SECIOK & $\begin{array}{l}\text { DISIILIATE } \\
\text { OII }\end{array}$ & $\underset{\text { GIL }}{\text { RESIDDAL }}$ & $\begin{array}{l}\text { GASOLINE } \\
\text { (ALL ONI }\end{array}$ & $\begin{array}{l}\text { OTHER } \\
\text { FYDRO- } \\
\text { CARBDNS } \\
\text { TS IN } 10 * \$ 9\end{array}$ & $\begin{array}{c}\text { CRODE } \\
\text { OII } \\
\text { BTO'S) }\end{array}$ & $\begin{array}{l}\text { NRTORAL } \\
\text { GAS }\end{array}$ & $\operatorname{COAL}$ & ELECTRICITY & $\begin{array}{l}\text { SECTOR } \\
\text { TOTAL }\end{array}$ & \\
\hline $\begin{array}{l}\text { EIN II CEMANC SECTOFS } \\
\text { RESIDENTIAL, SCMM. } \\
\text { INDUSTRIAL } \\
\text { TRANSPORTATIEN } \\
\text { MISCELLANECES OSES }\end{array}$ & $\begin{array}{r}9,: 06 \\
6,: 89 \\
\times 2,-83 \\
=90\end{array}$ & $\begin{array}{r}0,783 \\
8,453 \\
- \\
193\end{array}$ & $199,11 \overline{-}$ & $\begin{array}{r}11,885 \\
26,062 \\
43,594 \\
6\end{array}$ & $\begin{array}{l}- \\
-\end{array}$ & $\begin{array}{r}50,575 \\
93,610 \\
5,345 \\
1,358\end{array}$ & $\begin{array}{r}8 \\
17,380 \\
1 \\
-\end{array}$ & $\begin{array}{r}51,947 \\
23,327 \\
- \\
597\end{array}$ & $\begin{array}{r}125,913 \\
175,630 \\
290,249 \\
2,949\end{array}$ & $\begin{array}{r}17 \% \\
23 \% \\
38 \% \\
0 \%\end{array}$ \\
\hline $\begin{array}{l}\text { TCTAI FINAL } \\
\text { DEHAND SECTCRS }\end{array}$ & 59,473 & 10,433 & 199,117 & 81,547 & - & 150.935 & $17,3 \leq 9$ & 75,871 & 594,741 & $78 \%$ \\
\hline $\begin{array}{l}\text { TR ANSECFMATICN } \\
\text { PLECTRICITS GEN. } \\
\text { PETROLEOM ERCDOCTS } \\
\text { NATURAL GAS } \\
\text { SY HT HETICS }\end{array}$ & $\begin{array}{r}.27,276 \\
-67,346 \\
- \\
-\end{array}$ & $\begin{array}{r}19,627 \\
-65,967 \\
- \\
-\end{array}$ & $\begin{aligned}-157,5 \equiv & \overline{1} \\
& -\end{aligned}$ & $\begin{array}{r}-108,14 \overline{-} \\
-\end{array}$ & $\begin{array}{r}399.008 \\
-\end{array}$ & $\begin{array}{r}24,93 i \\
1,412 \\
- \\
-\end{array}$ & $\begin{array}{r}147,064 \\
- \\
-\end{array}$ & $\begin{array}{r}-76,655 \\
- \\
- \\
-\end{array}$ & $\begin{array}{r}142,293 \\
1,435 \\
-\end{array}$ & $\begin{array}{r}19 \% \\
0 \%\end{array}$ \\
\hline $\begin{array}{l}\text { NET FUEL DSEL } \\
\text { IN IRANSFOEMATION }\end{array}$ & $-40,070$ & $-45,340$ & $-157,5 \equiv 1$ & $-109,141$ & 399.008 & 26,393 & $147,06.4$ & $-76,655$ & 143,728 & $19 \%$ \\
\hline $\begin{array}{l}\text { TCTAI ERCSS ILCHS } \\
\text { LCSSES } 8 \text { CMISSIONS }\end{array}$ & $\begin{array}{r}86,749 \\
5,399\end{array}$ & $\begin{array}{r}30,066 \\
0\end{array}$ & $\begin{array}{r}199,117 \\
a\end{array}$ & $\begin{array}{l}81,547 \\
-\equiv, 216\end{array}$ & $\begin{array}{r}399,008 \\
16,552\end{array}$ & $\begin{array}{r}177,298 \\
-4,770\end{array}$ & $\begin{array}{r}164,453 \\
2,226\end{array}$ & $\begin{array}{r}75,871 \\
6,295\end{array}$ & $\begin{array}{r}738,469 \\
22,467\end{array}$ & $\begin{array}{r}97 \% \\
3 \%\end{array}$ \\
\hline $\begin{array}{l}\text { SOEELY CF ENIRGY } \\
\text { FOSS IL FOEI. } \\
\text { HY CR CELECTEIC } \\
\text { NOCLEAR } \\
\text { GEC. ESOLAR }\end{array}$ & $\begin{array}{l}- \\
- \\
-\end{array}$ & $\begin{array}{l}\overline{-} \\
\overline{-}\end{array}$ & - & $\begin{array}{l}- \\
- \\
-\end{array}$ & $\begin{array}{r}4.948 \\
- \\
-\end{array}$ & $\begin{array}{r}1,727 \\
- \\
-\end{array}$ & $\begin{array}{r}558,252 \\
- \\
-\end{array}$ & $\begin{array}{r}50 \\
49,141 \\
49.383 \\
4,765\end{array}$ & $\begin{array}{r}564,927 \\
50,141 \\
49.383 \\
4.765\end{array}$ & $\begin{array}{r}84 \% \\
7 \% \\
7 \% \\
1 \%\end{array}$ \\
\hline TCTAI SUPPIY & - & - & - & - & $4: 948$ & $1,7.27$ & 558,252 & 104,289 & 669,216 & \\
\hline
\end{tabular}

\section{NET IM FCRTS}

CF REGION

\section{NOTES:}

1 TRANSFCRMATICN LOSS POR

2 TRAN SPCRHATICN LOSS FCR

TRANEFCREATICN LCSS POA

TRANEPORAAICN LOSS PCR

LECTRICITY EEN .

ETROLEUM PRCDUCTS =64.99\%

NATURAL GAS

$=0.36 \%$

SYNTHETICS

$=0.0 \mathrm{~B}$
$=0.0 \mathrm{~m}$ 


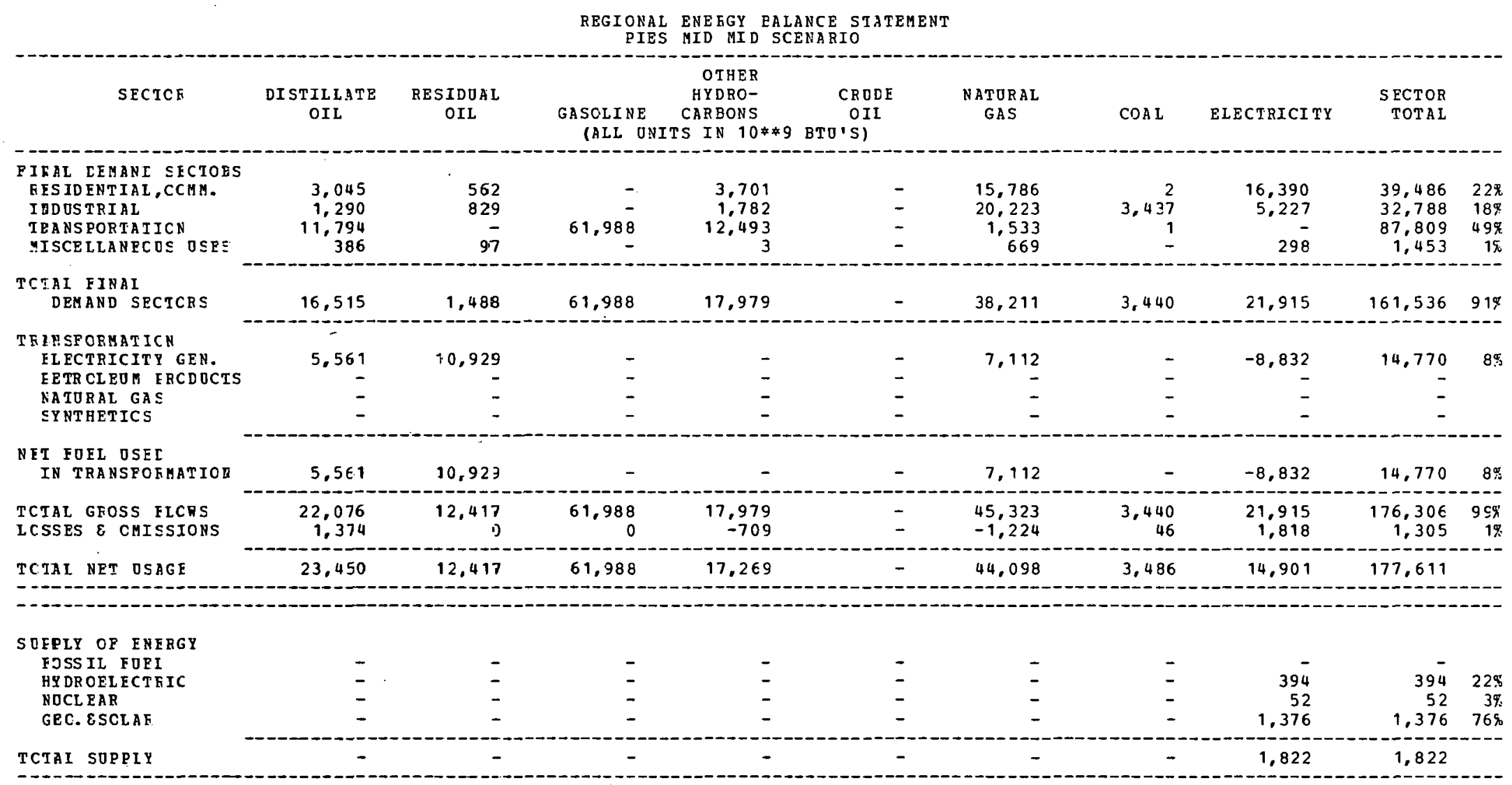

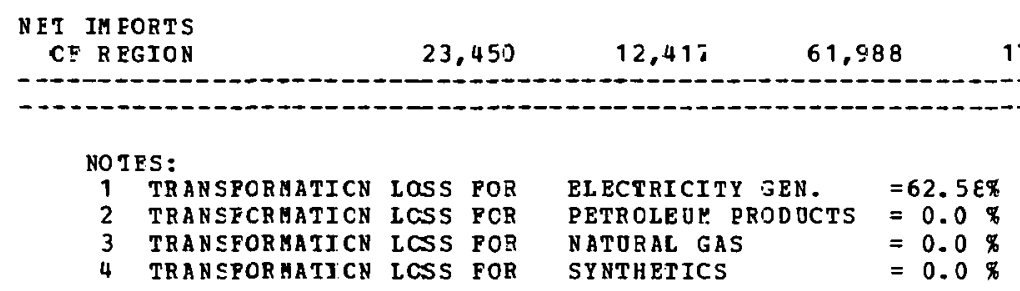


REGIONAL EIZFGY EALAHCE STATEMZNT
PIZS MLD MID SCENARIO

\begin{tabular}{|c|c|c|c|c|c|c|c|c|c|}
\hline SECTSR & $\begin{array}{l}\text { DISTILLATE } \\
\text { OIL }\end{array}$ & $\begin{array}{l}\text { RESIDJAI } \\
\text { DIL }\end{array}$ & $\begin{array}{l}\text { GASOL] NE } \\
\text { (ALL ONIT }\end{array}$ & $\begin{array}{l}\text { OTHER } \\
\text { AYIRO- } \\
\text { CAREONS } \\
\text { IS IY } 10 * \$ 9\end{array}$ & $\begin{array}{l}\text { CRODE } \\
\text { OII } \\
\left.3 T 0^{\circ} S\right]\end{array}$ & $\begin{array}{l}\text { NATURAL } \\
\text { GAS }\end{array}$ & COAl & ELECTFICITY & $\begin{aligned} \text { SECTOR } \\
\text { TOTAL }\end{aligned}$ \\
\hline $\begin{array}{l}\text { FINAL CEMANL SECTOES } \\
\text { BESIDENTIAL,CCHM. } \\
\text { IND OSTRIAL } \\
\text { TRANSPORTATICN } \\
\text { MISCELLANECES OSES }\end{array}$ & $\begin{array}{l}2,131 \\
1,692 \\
6,686 \\
663\end{array}$ & $\begin{array}{r}135 \\
1,1 \leq 6 \\
7,076 \\
1 \in 6\end{array}$ & $\begin{array}{r}- \\
135,330 \\
-\end{array}$ & $\begin{array}{r}\mathrm{c}, 121 \\
-238 \\
23.860 \\
10\end{array}$ & $\overline{-}$ & $\begin{array}{r}48,757 \\
16,832 \\
5,183 \\
2,394\end{array}$ & $\begin{array}{r}\text { Ero } \\
- \\
-\end{array}$ & $\begin{array}{r}31,275 \\
.8,263 \\
6 \\
1.261\end{array}$ & $\begin{array}{r}91,419 \\
32,091 \\
178,146 \\
4,494\end{array}$ \\
\hline $\begin{array}{l}\text { TCTAL FINAI } \\
\text { DEMAND SECTCRS }\end{array}$ & 11,172 & B,573 & 135,330 & 36,229 & - & 73,171 & 870 & 40,805 & 306,150 \\
\hline $\begin{array}{l}\text { TR ANSFCRMATICN } \\
\text { EL ECTRICITY GER. } \\
\text { PETROLEOM ERCDOCTS } \\
\text { NATORAL GA } \\
\text { SYNTHETICS }\end{array}$ & $\begin{array}{r}5,895 \\
-32,4 E 7 \\
- \\
-\end{array}$ & $\begin{array}{r}35,824 \\
-31,822 \\
-\end{array}$ & $\begin{array}{r}-75,972 \\
- \\
-\end{array}$ & $\begin{array}{r}-52,16 \frac{-}{-} \\
-\end{array}$ & $\begin{array}{r}192,479 \\
- \\
-\end{array}$ & $\begin{array}{r}13,244 \\
\mathrm{E} 81 \\
- \\
-\end{array}$ & $\begin{array}{l}- \\
- \\
-\end{array}$ & $\begin{array}{r}-19,912 \\
- \\
-\end{array}$ & $\begin{array}{r}35.051 \\
693 \\
- \\
-\end{array}$ \\
\hline $\begin{array}{l}\text { NFT FOEL OSEL } \\
\text { IN TRANSPOEATIOE }\end{array}$ & $-26,592$ & 4,002 & $-75,932$ & $-52,166$ & 192.479 & $13, \leq 25$ & - & $-19,912$ & 35,744 \\
\hline $\begin{array}{l}\text { TCTAL GROSS ILORS } \\
\text { LCSSES \& OMISSIONS }\end{array}$ & $\begin{array}{r}17,067 \\
1,062\end{array}$ & $\begin{array}{r}\$ 4,397 \\
0\end{array}$ & $\begin{array}{r}135,330 \\
0\end{array}$ & $\begin{array}{r}35,229 \\
-1.429\end{array}$ & $\begin{array}{r}192,479 \\
7,985\end{array}$ & $\begin{array}{l}87,0,96 \\
-2,553\end{array}$ & $\begin{array}{r}870 \\
11\end{array}$ & $\begin{array}{l}40,805 \\
3,385\end{array}$ & $\begin{array}{r}341,894 \\
8,663\end{array}$ \\
\hline
\end{tabular}

\begin{tabular}{|c|c|c|c|c|c|c|c|c|c|c|}
\hline $\begin{array}{l}\text { SOFELY OF ENFRGP } \\
\text { FOSS IL FOEI }\end{array}$ & - & - & - & - & - & - & - & - & - & \\
\hline HYDRCELACTKIC & - & - & - & - & - & - & - & 734 & 734 & 19: \\
\hline NOCL EAR & - & - & - & - & - & - & - & 51,288 & 51,288 & $94 \%$ \\
\hline GEO. \& SOLAR: & - & - & - & - & - & - & - & 2,563 & 2,563 & $5 \%$ \\
\hline TCTAL SUPPIY & - & - & - & - & - & - & - & 54,585 & 54,585 & \\
\hline
\end{tabular}

\section{NET IM FORTS}

$-14,357$

12,575

$59, \equiv 38$

$-17,366$

\begin{tabular}{|c|c|c|c|c|c|}
\hline \multicolumn{6}{|c|}{ NOTES: } \\
\hline & TRAE SPCRHATICR & IOSS & FOR & ELECTRICITY GEN. & $=63.7 .7$ \\
\hline 2 & TRA YSPORMATICU & IOSS & POR $>>>>>1$ & PEPZOLEOM PFODOCTS & 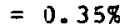 \\
\hline 3 & TRA SSFORMATICR & $\operatorname{IcsS}$ & FOR & NATJRAL GAS & $=0$ \\
\hline 4 & TRAYSPOBMATICN & & POR & ST DTHBT ICS & \\
\hline
\end{tabular}


REGIONAL ENE EGY PALANCE STATEMENT

\begin{tabular}{|c|c|c|c|c|c|c|c|c|c|c|}
\hline SECTCE & $\begin{array}{l}\text { JISTIILATE } \\
\text { OIL }\end{array}$ & $\begin{array}{l}\text { E.ESIDJAL } \\
\text { OIL }\end{array}$ & $\begin{array}{l}\text { GASOLINE } \\
\text { (ALL O }\end{array}$ & $\begin{array}{c}\text { OTHER } \\
\text { HYYRO- } \\
\text { CAREONS } \\
\text { TS IN } 10 * *\end{array}$ & $\begin{array}{c}\text { CEOLE } \\
\text { CIL } \\
\text { BTO'S) }\end{array}$ & $\begin{array}{l}\text { NATURAL } \\
\text { GAS }\end{array}$ & $\operatorname{COAL}$ & ELECTRICITY & $\begin{array}{r}\text { SECTOR } \\
\text { TOTAL }\end{array}$ & \\
\hline $\begin{array}{l}\text { FINAL CEMANL SFCTOFS } \\
\text { FESIDENTIAL, CCMA. } \\
\text { INDDSTRIAL } \\
\text { TRANSPORTATICN } \\
\text { MISCELLANEOCS OSES }\end{array}$ & $\begin{array}{r}13,281 \\
39,230 \\
100,803 \\
3,198\end{array}$ & $\begin{array}{r}926 \\
78,902 \\
51,919 \\
302\end{array}$ & $815,07 \bar{z}$ & $\begin{array}{r}54,969 \\
317,163 \\
174,985 \\
25\end{array}$ & $\begin{array}{l}- \\
-\end{array}$ & $\begin{array}{r}301,603 \\
555,667 \\
38,024 \\
6,324\end{array}$ & $\begin{array}{r}3 \\
61,476 \\
3 \\
-\end{array}$ & $\begin{array}{r}203,356 \\
127,117 \\
353 \\
2,889\end{array}$ & $\begin{array}{r}574,138 \\
1,179,555 \\
1,181,165 \\
13,238\end{array}$ & $\begin{array}{r}17 \% \\
36 \% \\
36 \% \\
0 \%\end{array}$ \\
\hline $\begin{array}{l}\text { TCIAI FINAL } \\
\text { DEMAND SECICRS }\end{array}$ & 156,512 & 132,549 & 315,078 & 547,142 & - & 901,618 & 61,482 & 333,715 & $2,948,096$ & $89 \%$ \\
\hline $\begin{array}{l}\text { TRANSP ORMATICN } \\
\text { ELECTRICITY GER. } \\
\text { PETR OLEOM FRODOCTS } \\
\text { NATURAL GAS } \\
\text { SY NT AETICS }\end{array}$ & $\begin{array}{r}54,253 \\
-419,876 \\
- \\
-\end{array}$ & $\begin{array}{r}23 \varsigma, 349 \\
-411,27 \epsilon \\
-\end{array}$ & $\begin{array}{r}-982,142 \\
-\end{array}$ & $\begin{array}{r}-674,21 \overline{-} \\
60,020\end{array}$ & $\begin{array}{r}2,487,662 \\
- \\
-\end{array}$ & $\begin{array}{r}108,895 \\
8,806 \\
- \\
-54,300\end{array}$ & $\begin{array}{l}- \\
\overline{-} \\
-\end{array}$ & $\begin{array}{r}-146,901 \\
- \\
-\end{array}$ & $\begin{array}{r}255,296 \\
8,956 \\
- \\
5,720\end{array}$ & $\begin{array}{l}8 \% \\
0 \%\end{array}$ \\
\hline $\begin{array}{l}\text { NET FOEL OSFE } \\
\text { IN TRANSPEATION }\end{array}$ & $-365,623$ & $-172,227$ & -982.142 & $-614,198$ & $2,487,662$ & 63,401 & - & $-146,901$ & 269,972 & $8 \%$ \\
\hline $\begin{array}{l}\text { TCTAL GFOSS FLONS } \\
\text { LCSSES } \varepsilon \text { CMISSIONS }\end{array}$ & $\begin{array}{r}210,765 \\
13,118\end{array}$ & $\begin{array}{r}371,598 \\
7\end{array}$ & $\begin{array}{r}315,078 \\
3\end{array}$ & $\begin{array}{l}607,162 \\
-23,949\end{array}$ & $\begin{array}{r}2,487,662 \\
103,201\end{array}$ & $\begin{array}{r}1,019,319 \\
-27,544\end{array}$ & $\begin{array}{r}61,482 \\
832\end{array}$ & $\begin{array}{r}333,715 \\
27,689\end{array}$ & $\begin{array}{r}3,218,068 \\
93,359\end{array}$ & $\begin{array}{r}97 \% \\
3 \%\end{array}$ \\
\hline OTAL NET OSAGE & $-195,992$ & $-39,670$ & $-167,060$ & $-91,005$ & $2,590,863$ & 937.474 & 62,314 & 214,503 & $3,311,427$ & \\
\hline
\end{tabular}

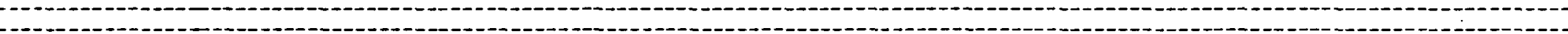

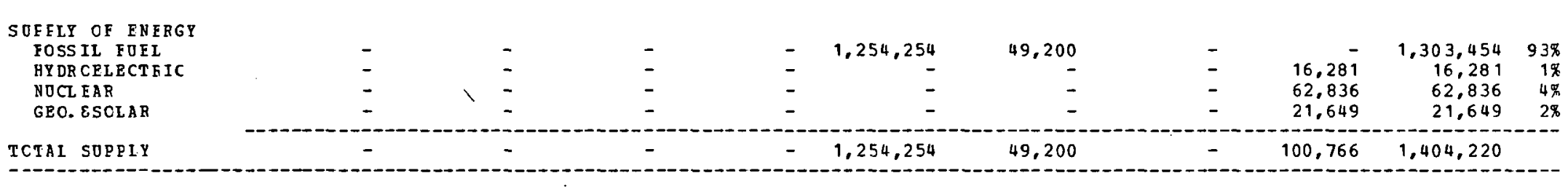

\begin{tabular}{|c|c|c|c|c|c|c|c|c|c|}
\hline $\begin{array}{l}\text { NET IM FORTS } \\
\text { OF REGION }\end{array}$ & $-195,992$ & $-39,570$ & $-167,060$ & $-91,005$ & $1,336,609$ & 888,274 & 62,314 & 113,737 & $1,907,207$ \\
\hline
\end{tabular}

\begin{tabular}{|c|c|c|c|c|c|}
\hline \multicolumn{6}{|c|}{ NOTES: } \\
\hline & TRAN SFCRHATICN & LOSS & & ELECTRICITY GEN - & $=63.48 \%$ \\
\hline 2 & TRAN SFCRAATICN & LOSS & POR & PETROLEOK PRODOCTS & $0.36 \%$ \\
\hline 3 & TRAN SFORHATI CN & LCSS & POR & NATORAL GAS & $=0.0 \%$ \\
\hline 4 & TRAN SPCR HATI CN & LOSS & POR & SYNTHET ICS & $=9: 53 \%$ \\
\hline
\end{tabular}


REGI JTAL ENEFGY EALANCE STATEMENT PIES MID. UID SCENARI

\begin{tabular}{|c|c|c|c|c|c|c|c|c|c|c|}
\hline SECT JF & $\begin{array}{l}\text { DI STIL LATE } \\
\text { OIL }\end{array}$ & $\begin{array}{c}\text { RESIDDAL } \\
\text { EIL }\end{array}$ & $\begin{array}{l}\text { GASOLI N: } \\
\text { [ALI }]\end{array}$ & $\begin{array}{c}\text { OTIER } \\
\text { HYDIO- } \\
\text { CARBONS } \\
\text { TS IN } 10 * \$ 9\end{array}$ & $\begin{array}{c}\text { CRODE } \\
\text { OII } \\
\text { BTO'SI }\end{array}$ & $\begin{array}{l}\text { NATOREL. } \\
\text { GAS }\end{array}$ & $\operatorname{COAL}$ & ELECTRICITY & $\begin{array}{r}\text { SECTOR } \\
\text { TOTAL }\end{array}$ & \\
\hline $\begin{array}{l}\text { FINPL CFMANL SECTOAS } \\
\text { RESIDENTIAI, CCAM. } \\
\text { IND OSTRIAL } \\
\text { TRANSPORTATICN } \\
\text { MISCELLANECOS OSES }\end{array}$ & $\begin{array}{r}1, \pi 79 \\
3,596 \\
113,118 \\
\Xi 77\end{array}$ & $\begin{array}{r}76 \\
\vdots, 190 \\
2.082 \\
94\end{array}$ & 83,131 & $\begin{array}{r}5.603 \\
6.556 \\
6.990 \\
2\end{array}$ & $\begin{array}{l}- \\
-\end{array}$ & $\begin{array}{r}29,675 \\
100,122 \\
1,516 \\
750\end{array}$ & $\begin{array}{r}- \\
3,99 \\
1 \\
-\end{array}$ & $\begin{array}{r}18,523 \\
12,823 \\
90 \\
344\end{array}$ & $\begin{array}{r}55,156 \\
129,856 \\
106,928 \\
1,567\end{array}$ & $\begin{array}{r}17 \% \\
+1 \% \\
34 \% \\
0 \%\end{array}$ \\
\hline $\begin{array}{l}\text { TCIAI FINAI } \\
\text { DEMAND SECECRS }\end{array}$ & $18, \pi 70$ & 5,442 & 83,131 & 19,151 & - & 132,063 & 3,170 & $\Xi 1,780$ & 293,507 & 32.5 \\
\hline $\begin{array}{l}\text { TEANSFCEMATICR } \\
\text { FL FCTRICITY GEN. } \\
\text { PETROLOUM FRCDOCTS } \\
\text { NATURAI GAS } \\
\text { SYNTHETICS }\end{array}$ & $\begin{array}{r}- \\
-\equiv 1, E 61 \\
-\end{array}$ & $\begin{array}{r}\Xi, 374 \\
-6 C, 398 \\
-\end{array}$ & $\begin{array}{r}-144,232 \\
-\end{array}$ & $\begin{array}{r}-99.012 \\
- \\
-\end{array}$ & $\begin{array}{r}365,325 \\
-\end{array}$ & $\begin{array}{r}10,314 \\
1,29 \Xi \\
- \\
-\end{array}$ & $\begin{array}{l}- \\
- \\
-\end{array}$ & $\begin{array}{r}-4,984 \\
- \\
- \\
-\end{array}$ & $\begin{array}{r}8,704 \\
1,315 \\
- \\
-\end{array}$ & $\begin{array}{l}3 \% \\
0 \%\end{array}$ \\
\hline $\begin{array}{l}\text { BET FOFL OSEL } \\
\text { IN GRANSFOFGATION }\end{array}$ & $-\leqq 1, \in 61$ & $-57,024$ & $-144,232$ & -99.012 & 365,325 & 11,607 & - & $-4,984$ & 10,019 & $3 \%$ \\
\hline $\begin{array}{l}\text { TCTAL GFOSS FLCRS } \\
\text { ICSSES } \& \text { CMISSIONS }\end{array}$ & $\begin{array}{r}18,570 \\
1,-68\end{array}$ & $\varepsilon, 8,16$ & $\begin{array}{r}83,131 \\
0\end{array}$ & $\begin{array}{r}19.151 \\
-755\end{array}$ & $\begin{array}{r}365,325 \\
15,155\end{array}$ & $\begin{array}{r}143,67 G \\
-3,882\end{array}$ & $\begin{array}{r}3,170 \\
42\end{array}$ & $\begin{array}{r}31,780 \\
2,636\end{array}$ & $\begin{array}{r}303,526 \\
14,366\end{array}$ & $\begin{aligned} 95 \% \\
5 \%\end{aligned}$ \\
\hline
\end{tabular}

\begin{tabular}{|c|c|c|c|c|c|c|c|c|c|c|}
\hline $\begin{array}{l}\text { SOEFLY CF ENESGY } \\
\text { FOSS IL FOFI }\end{array}$ & & & & & & & & & & \\
\hline HY DRCELECT FIC & - & - & - & $\overline{-}$ & 801,230 & $34,25 \varepsilon$ & - & 33.787 & 835,498 & $\begin{array}{r}94 \% \\
3 \%\end{array}$ \\
\hline NOCL EAR & - & - & - & 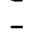 & - & $\overline{-}$ & $\overline{-}$ & $\begin{array}{l}23,181 \\
25,275\end{array}$ & $\begin{array}{l}23,787 \\
25,275\end{array}$ & \\
\hline GEC. $\varepsilon 5 O L A F$ & - & - & - & - & - & - & - & $1, \$ 96$ & 1,996 & $0 \%$ \\
\hline TCTAI SOPPIY & $\rightarrow$ & - & - & - & 801,230 & $34,2.5 \varepsilon$ & - & 51,058 & 886,556 & \\
\hline
\end{tabular}

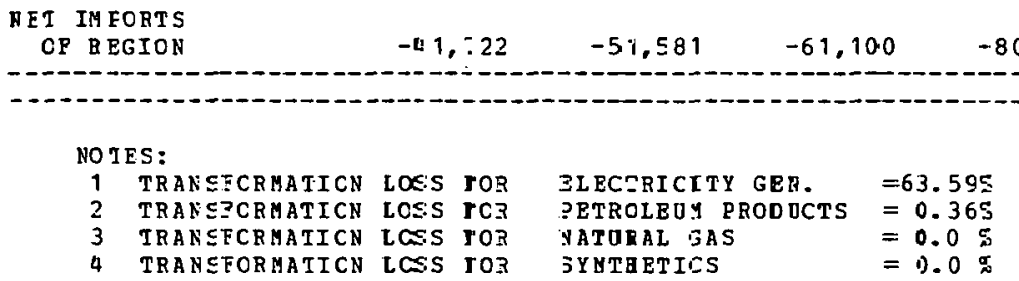




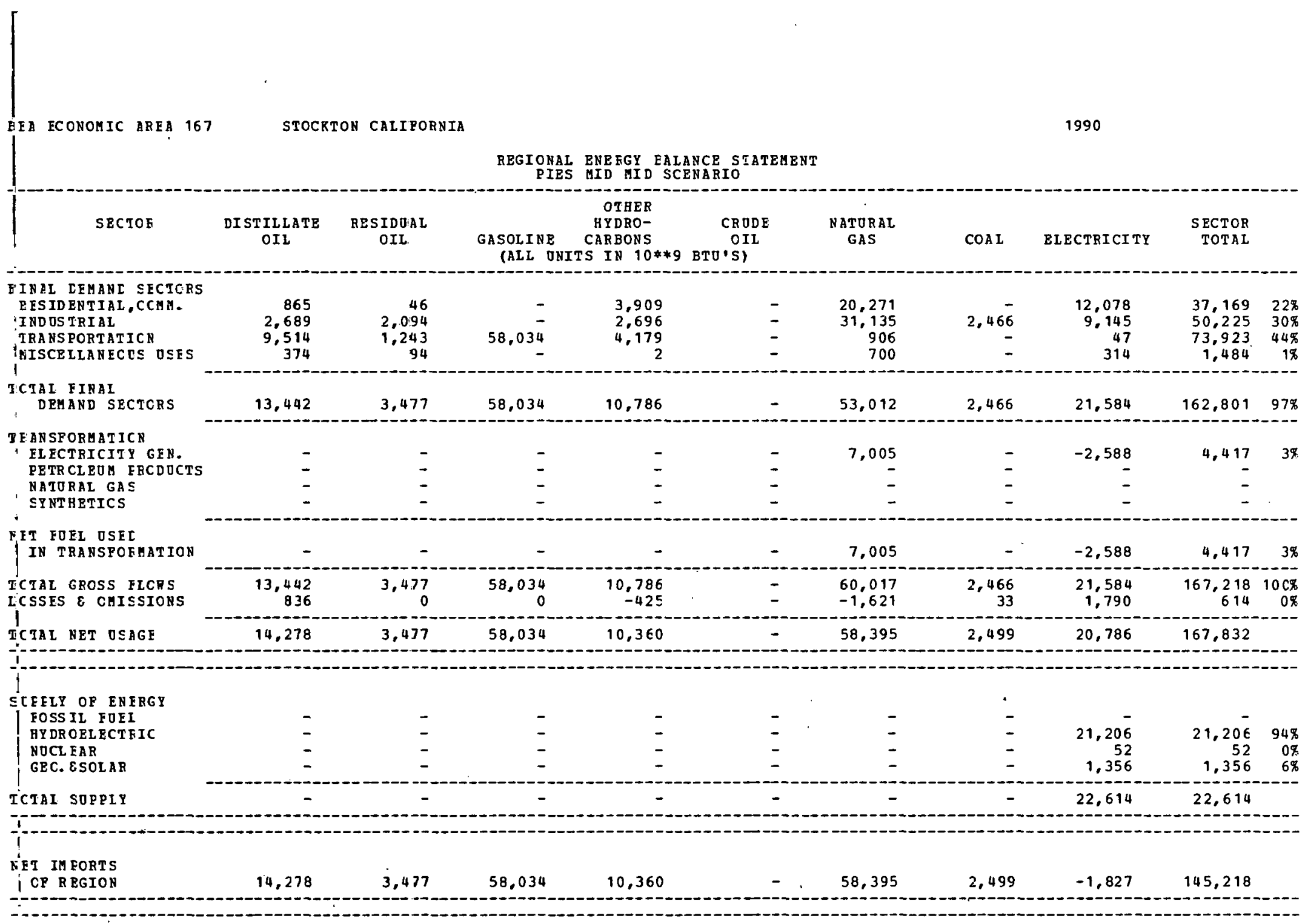

\section{NO TES:}

1 TRANSPCRAATICN LOSS FOR TRANSFCRMATICN LOSS ECR TRANSPCRMATICN ICSS FCR

ELECTRICITY GEN. $\quad=63.05 \%$ PETROLEJM PRODOCTS $=0.0 \%$ $\begin{array}{ll}\text { NATURAL GAS } & =0.0 \%\end{array}$

4 TRANSPORARTICN ICSS FCR SYNTHETICS 
REGICNA: ENEEGY EALANCE STATEMETT

\begin{tabular}{|c|c|c|c|c|c|c|c|c|c|c|}
\hline SECICE & $\begin{array}{c}\text { DISTELLATE } \\
\text { OIL }\end{array}$ & $\begin{array}{l}\text { RESIDUAL } \\
\text { GIL }\end{array}$ & $\begin{array}{l}\text { GASOLIEE } \\
\text { (ALI ENIT }\end{array}$ & $\begin{array}{c}\text { OTHER } \\
\text { HTDEO- } \\
\text { CRRBCNS } \\
\text { TS IN 10**9 }\end{array}$ & $\begin{array}{c}\text { CRODE } \\
\text { OII } \\
\text { BTO'SI }\end{array}$ & $\begin{array}{l}\text { NATURAL } \\
\text { GAS }\end{array}$ & $\operatorname{COAL}$ & ELECTRICITY & $\begin{array}{r}\text { SECTOR } \\
\text { TOTAL }\end{array}$ & \\
\hline $\begin{array}{l}\text { PINAL LEHANL SECTORS } \\
\text { RESIDENTIAL,CCHM. } \\
\text { INDOSTRIAL } \\
\text { TRANSPORTATICN } \\
\text { HISCELLANEOOS OSES }\end{array}$ & $\begin{array}{r}1,627 \\
2.032 \\
12,4.79 \\
1.073\end{array}$ & $\begin{array}{r}105 \\
1,493 \\
2,523 \\
269\end{array}$ & $\begin{array}{r}\overline{-} \\
\overline{-} \\
102,409\end{array}$ & $\begin{array}{r}6.902 \\
2.334 \\
8.448 \\
8\end{array}$ & $\begin{array}{l}- \\
\overline{-}\end{array}$ & $\begin{array}{r}36,855 \\
21,677 \\
1,833 \\
2,026\end{array}$ & 998 & $\begin{array}{r}23,529 \\
7.639 \\
141 \\
911\end{array}$ & $\begin{array}{r}69,018 \\
36,173 \\
127,834 \\
4,287\end{array}$ & $\begin{array}{r}28 \% \\
15 \% \\
52 \% \\
2 \%\end{array}$ \\
\hline $\begin{array}{l}\text { TCIAL FINAL } \\
\text { DEHAND SECACRS }\end{array}$ & 17.211 & 4.390 & 102,409 & 17.692 & - & 62,391 & 959 & 32,220 & 237,312 & $56 \%$ \\
\hline $\begin{array}{l}\text { TA ANSPCRHATICR } \\
\text { EL ECTRICITY GEN. } \\
\text { PETR CLEDH ERCDOCTS } \\
\text { NATORAL GAS } \\
\text { SYNTHETICS }\end{array}$ & $\begin{array}{r}2,640 \\
- \\
-\end{array}$ & $\begin{array}{l}- \\
-\end{array}$ & $\begin{array}{l}\bar{z} \\
\bar{z}\end{array}$ & $\begin{array}{l}- \\
-\end{array}$ & $\begin{array}{l}- \\
-\end{array}$ & $\begin{array}{r}10,457 \\
- \\
-\end{array}$ & $\bar{z}$ & $\begin{array}{r}-5,002 \\
- \\
-\end{array}$ & $\begin{array}{r}8,095 \\
- \\
-\end{array}$ & $3 x$ \\
\hline $\begin{array}{l}\text { NET FOFL OSEC } \\
\text { IN TRANSPOBAATION }\end{array}$ & 2,640 & - & - & - & - & 10,457 & - & $-5,002$ & 8,095 & $3 \%$ \\
\hline $\begin{array}{l}\text { TCIAL GROSS FIONS } \\
\text { LCSSES } \& \text { OMISIIONS }\end{array}$ & $\begin{array}{r}-7,851 \\
1,2,35\end{array}$ & 4,390 & $\begin{array}{r}102,409 \\
1\end{array}$ & $\begin{array}{r}17.692 \\
-697\end{array}$ & $\overline{-}$ & $\begin{array}{l}72,848 \\
-1,9 \in 8\end{array}$ & $\begin{array}{r}999 \\
13\end{array}$ & $\begin{array}{r}32,220 \\
2,673\end{array}$ & $\begin{array}{r}245,407 \\
1,256\end{array}$ & $\begin{array}{r}99 \% \\
1 \%\end{array}$ \\
\hline
\end{tabular}

\begin{tabular}{|c|c|c|c|c|c|c|c|c|c|c|}
\hline SOEPLT OF ENFEGI & & & & & & & & & & \\
\hline FOSSIL FOEI. & - & - & - & - & 32,065 & 35,673 & - & - & 67,738 & $+8 \%$ \\
\hline HY DR OELECT FIC & $\cdot$ & - & - & - & - & - & - & 53,745 & 53,745 & $32 \%$ \\
\hline NOCL EAR & - & - & - & - & - & - & - & 17,751 & 17,751 & $13 \%$ \\
\hline GEC. \& SOL AR & - & - & - & - & - & - & - & 2,023 & 2,023 & 18 \\
\hline
\end{tabular}

\begin{tabular}{l} 
RET IM FORTS \\
OF BEGION \\
\hline
\end{tabular}

NOTES:

\begin{tabular}{|c|c|c|c|c|}
\hline $\begin{array}{l}\text { TRANSPCBHATICN } \\
\text { TRANSFCRATICN }\end{array}$ & & $\begin{array}{l}\text { POR } \\
\text { POR }\end{array}$ & $\begin{array}{l}\text { ELBCTRICI TY GEN, } \\
\text { PETROLE O PRODUCTS }\end{array}$ & $\begin{array}{l}=61.819 \\
=0.0 \mathrm{~g}\end{array}$ \\
\hline & & & YATUEAL GAS & \\
\hline & & & ETIES & \\
\hline
\end{tabular}


REGIONAL ENEEGY EALANCE STATEMENT

PIES MID YID SCENARIO

\begin{tabular}{|c|c|c|c|c|c|c|c|c|c|c|}
\hline SECTOE & $\begin{array}{l}\text { DISTILLATE } \\
\text { OIL }\end{array}$ & $\begin{array}{l}\text { EESIDOAL } \\
\text { OIL }\end{array}$ & $\begin{array}{l}\text { GASOLINE } \\
\text { (ALL O }\end{array}$ & $\begin{array}{c}\text { OTHER } \\
\text { HYDRO- } \\
\text { CARBONS } \\
\text { TS IN } 10 * *\end{array}$ & $\begin{array}{c}\text { CRODE } \\
\text { OIL } \\
\text { BTO'SI }\end{array}$ & $\begin{array}{l}\text { NATURAL } \\
\text { GAS }\end{array}$ & $\operatorname{COAL}$ & ELECTRICITY & $\begin{array}{r}\text { SECTOR } \\
\text { TOTAL }\end{array}$ & \\
\hline $\begin{array}{l}\text { FINAL CEMANL SFCTDRS } \\
\text { GESIDEYTIAL, CCMM. } \\
\text { INDOSTRIAL } \\
\text { IRANSPORTATICN } \\
\text { MISCELLANECCS OSES }\end{array}$ & $\begin{array}{r}296 \\
955 \\
2.813 \\
109\end{array}$ & $\begin{array}{r}19 \\
518 \\
1,244 \\
27\end{array}$ & $\begin{array}{r}- \\
- \\
-\end{array}$ & $\begin{array}{r}1,217 \\
520 \\
4.183 \\
1\end{array}$ & $\begin{array}{l}- \\
- \\
-\end{array}$ & $\begin{array}{r}6,611 \\
3,709 \\
909 \\
193\end{array}$ & $\begin{array}{r}-\overline{77} \\
\overline{-}\end{array}$ & $\begin{array}{r}4,356 \\
1,836 \\
22 \\
84\end{array}$ & $\begin{array}{r}12,499 \\
7,615 \\
27,246 \\
414\end{array}$ & $\begin{array}{r}25 \% \\
15 \% \\
548 \\
1 \%\end{array}$ \\
\hline $\begin{array}{l}\text { TCTAI FINAL } \\
\text { DEMAND SECTCRS }\end{array}$ & 4,173 & 1,808 & 18,075 & 5.921 & - & 11,422 & 77 & 6,298 & 47,774 & $95 \pi$ \\
\hline $\begin{array}{l}\text { TEANSFCEMATICN } \\
\text { ELECTRICITY GEN. } \\
\text { EETROLEUM ERCDOZTS } \\
\text { NATURAL GAS } \\
\text { STNTETICS }\end{array}$ & $\begin{array}{r}1.760 \\
- \\
-\end{array}$ & $\begin{array}{l}- \\
-\end{array}$ & $\begin{array}{l}- \\
- \\
-\end{array}$ & $\begin{array}{l}\overline{-} \\
-\end{array}$ & $\begin{array}{l}- \\
- \\
-\end{array}$ & $\begin{array}{r}2,044 \\
- \\
-\end{array}$ & $\begin{array}{l}\overrightarrow{-} \\
\overrightarrow{-}\end{array}$ & $\begin{array}{r}-1,514 \\
- \\
-\end{array}$ & $\begin{array}{r}2,290 \\
- \\
-\end{array}$ & $5 \pi$ \\
\hline $\begin{array}{l}\text { NFT FOFI DSEL } \\
\text { IN TRANSFCEATIEN }\end{array}$ & 1,760 & - & - & - & - & 2,044 & - & $-1,514$ & 2,290 & $5 \%$ \\
\hline $\begin{array}{l}\text { TCTAL GROSS FICRS } \\
\text { LCSSES E OMISSIONS }\end{array}$ & $\begin{array}{r}5,933 \\
369\end{array}$ & $\begin{array}{r}1,808 \\
0\end{array}$ & $\begin{array}{r}13,075 \\
0\end{array}$ & $\begin{array}{r}5.921 \\
-233\end{array}$ & $\overline{-}$ & $\begin{array}{r}13,466 \\
-363\end{array}$ & $\begin{array}{r}77 \\
1\end{array}$ & $\begin{array}{r}6.298 \\
522\end{array}$ & $\begin{array}{r}50.064 \\
295\end{array}$ & $\begin{array}{r}99 \% \\
1 \%\end{array}$ \\
\hline
\end{tabular}

-

\begin{tabular}{|c|c|c|c|c|c|c|c|c|c|c|}
\hline $\begin{array}{l}\text { SOFELI CF ENFRGY } \\
\text { FCSS IL FOEI }\end{array}$ & - & - & - & - & 1,124 & 1,253 & - & - & 2,377 & $6 \%$ \\
\hline HY CROELECTAIC & - & - & - & - & - & - & - & 39,893 & 39,893 & $93 \%$ \\
\hline NOCL EAR & - & - & - &.- & - & - & - & 15 & 15 & $0 \%$ \\
\hline GEC. ESOLAR & - & - & - & - & - & - & - & 395 & 395 & $1 \%$ \\
\hline
\end{tabular}

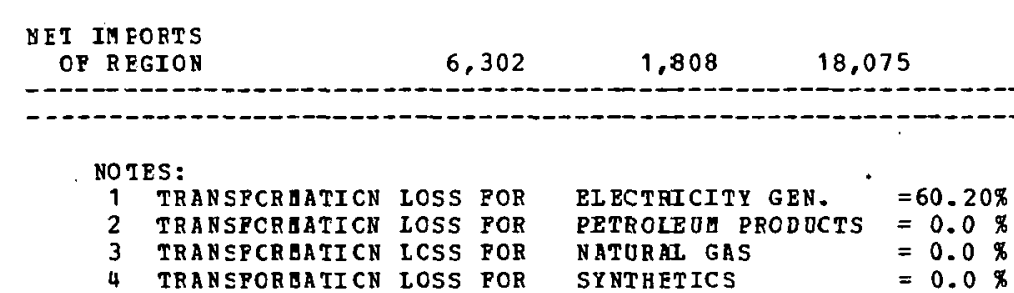


REGIONAL ENEFGY EALANCE STATEUENT
PIES MID MID SCEHARIO

\begin{tabular}{|c|c|c|c|c|c|c|c|c|c|c|}
\hline SBCIOE & $\begin{array}{l}\text { DISTIELATE } \\
\text { OIL }\end{array}$ & $\begin{array}{l}\text { BESIDUAL } \\
\text { OIL }\end{array}$ & $\begin{array}{l}\text { GASOLI NE } \\
\text { (ALIL }\end{array}$ & $\begin{array}{c}\text { OTHER } \\
\text { HYDRO- } \\
\text { CARBONS } \\
\text { TS IN } 10 * * 9\end{array}$ & $\begin{array}{c}\text { CRODE } \\
\text { OIL } \\
\text { BTO'S) }\end{array}$ & $\begin{array}{l}\text { NATURAL } \\
\text { GAS }\end{array}$ & $\operatorname{COAL}$ & ELECTRICITY & $\begin{array}{r}\text { SECTOR } \\
\text { TOT AL }\end{array}$ & \\
\hline $\begin{array}{l}\text { PINLI CEHANL SFCTOBS } \\
\text { RESIDENTIAL, CCHA. } \\
\text { IND OSTRIAL } \\
\text { TRANSPORTATICN } \\
\text { GISCELLAHECS OSBS }\end{array}$ & $\begin{array}{r}121 \\
1.275 \\
777 \\
20\end{array}$ & $\begin{array}{r}5 \\
580 \\
155 \\
5\end{array}$ & $8,31 \overline{-}$ & $\begin{array}{l}559 \\
811 \\
554 \\
-\end{array}$ & $\bar{z}$ & $\begin{array}{r}2,875 \\
3,157 \\
120 \\
38\end{array}$ & $38 \overline{8}$ & $\begin{array}{r}1,666 \\
1,453 \\
4 \\
17\end{array}$ & $\begin{array}{r}5,226 \\
7,664 \\
9,932 \\
80\end{array}$ & $\begin{array}{r}21 \% \\
31 \% \\
40 \% \\
0 \%\end{array}$ \\
\hline $\begin{array}{l}\text { TCTAL PINAL } \\
\text { DEMAND SBCTCRS }\end{array}$ & 2,193 & 755 & 8,312 & 1,924 & - & 6,190 & 388 & 3,140 & 22,902 & $92 \%$ \\
\hline $\begin{array}{l}\text { TRANSPCRHATICN } \\
\text { EL ECTRICITY GEN. } \\
\text { PETROLEOH FECDOCTS } \\
\text { NATORAL GAS } \\
\text { SY NTHETICS }\end{array}$ & $\begin{array}{l}\bar{z} \\
\bar{z}\end{array}$ & $\begin{array}{r}1,958 \\
- \\
-\end{array}$ & $\begin{array}{l}\bar{z} \\
\overline{-}\end{array}$ & $\bar{z}$ & I & $\begin{array}{r}1,019 \\
= \\
-\end{array}$ & $\begin{array}{l}\bar{z} \\
\bar{z}\end{array}$ & $\begin{array}{r}-1,062 \\
- \\
- \\
-\end{array}$ & $\begin{array}{r}1,925 \\
- \\
-\end{array}$ & $8 \%$ \\
\hline $\begin{array}{l}\text { NET FOFI OSEE } \\
\text { IN TRANSOSGATION }\end{array}$ & - & 1.958 & - & - & - & 1,019 & - & $-1,062$ & 1,925 & $8 \%$ \\
\hline $\begin{array}{l}\text { TCTAL GROSS FLORS } \\
\text { LCSSES } \& \text { CMISSIONS }\end{array}$ & $\begin{aligned} & 2 . 193 \\
& 136\end{aligned}$ & $\begin{array}{r}2.723 \\
0\end{array}$ & $8, \geq 12$ & $\begin{array}{r}1,924 \\
-75\end{array}$ & - & $\begin{array}{r}7,209 \\
-194\end{array}$ & $\begin{array}{r}388 \\
5\end{array}$ & $\begin{array}{r}3,140 \\
260\end{array}$ & $\begin{array}{r}24,827 \\
131\end{array}$ & $\begin{array}{r}99 \% \\
1 \%\end{array}$ \\
\hline TOTAL NET OSAGE & 2,329 & 2.723 & 8,312 & 1,848 & - & 7,1014 & $\Xi 93$ & 2,338 & 24,958 & \\
\hline $\begin{array}{l}\text { SOEELY OF ENEBGY } \\
\text { FOSS IL FOEI } \\
\text { HYDROFLBCTIIC } \\
\text { NOCLEAR } \\
\text { GEC. ESOLAR }\end{array}$ & $\bar{z}$ & $\begin{array}{l}- \\
-\end{array}$ & $\begin{array}{l}- \\
- \\
-\end{array}$ & $\overline{-}$ & $\begin{array}{r}795 \\
- \\
-\end{array}$ & $\begin{array}{r}387 \\
- \\
-\end{array}$ & $\begin{array}{l}\bar{z} \\
\bar{z}\end{array}$ & $\begin{array}{r}2,269 \\
1,225 \\
198\end{array}$ & $\begin{array}{r}1,682 \\
2,269 \\
1,225 \\
198\end{array}$ & $\begin{array}{r}31 \% \\
42 \% \\
23 \% \\
4 \%\end{array}$ \\
\hline TCTAL SOPPIY & - & - & - & - & 795 & 387 & - & 3,692 & 5,374 & \\
\hline
\end{tabular}

\begin{tabular}{|c|c|c|c|c|c|c|c|c|c|}
\hline $\begin{array}{l}\text { NET IM EORTS } \\
\text { OP REGION }\end{array}$ & 2,329 & 2,723 & 8,312 & 1,848 & -795 & 6,127 & 393 & $-1,353$ & 19,584 \\
\hline
\end{tabular}
FO TES:
TRANSPCRHATICN LCSS POR PETEOIROA PRTDDCTS = NATRIRAL GAS $=0.0$ 
REGIONAL ENE FGY EALANCE STATEMENT

PIES MID MID SCENARIO

\begin{tabular}{|c|c|c|c|c|c|c|c|c|c|c|}
\hline SECTOF & $\begin{array}{l}\text { DISTILLATE } \\
\text { OIL }\end{array}$ & $\begin{array}{l}\text { RESIDJAL } \\
\text { OIE }\end{array}$ & $\begin{array}{l}\text { GASOLINE } \\
\text { (ALL ON }\end{array}$ & $\begin{array}{l}\text { OTAER } \\
\text { HYDRO- } \\
\text { CARBONS } \\
\text { TS IN 10**9 }\end{array}$ & $\begin{array}{c}\text { CRODE } \\
\text { OIL } \\
\text { BTO'S) }\end{array}$ & $\begin{array}{l}\text { NATURAL } \\
\text { GAS }\end{array}$ & $\operatorname{COAL}$ & ELECTRICITY & $\begin{array}{r}\text { SECTOR } \\
\text { TOTAL }\end{array}$ & \\
\hline $\begin{array}{l}\text { FINAL CEMANC SECTORS } \\
\text { RESIDENTIAL, CCMH. } \\
\text { INDOSTRIAL } \\
\text { TRANSPORTATICN } \\
\text { MISCELLABCLS OSES }\end{array}$ & $\begin{array}{r}6,673 \\
15,181 \\
53,071 \\
1,860\end{array}$ & $\begin{array}{r}480 \\
56,373 \\
46,591 \\
467\end{array}$ & $\begin{array}{r}- \\
- \\
404,757 \\
-\end{array}$ & $\begin{array}{r}27,297 \\
185,392 \\
157,343 \\
16\end{array}$ & $\begin{array}{l}- \\
-\end{array}$ & $\begin{array}{r}149,660 \\
143,393 \\
34,204 \\
4,045\end{array}$ & $\begin{array}{r}1 \\
18,750 \\
2 \\
-\end{array}$ & $\begin{array}{r}101,053 \\
51,461 \\
238 \\
1,905\end{array}$ & $\begin{array}{r}285,164 \\
471,150 \\
696,306 \\
8,293\end{array}$ & $\begin{array}{l}17 \% \\
29 \% \\
42 \% \\
1 \%\end{array}$ \\
\hline $\begin{array}{l}\text { TCTAL FINAL } \\
\text { DEMAND SECTORS }\end{array}$ & 76.785 & 104,511 & 404,757 & 370,048 & - & 331,302 & 18,753 & 154.657 & $1,460,913$ & $89 \%$ \\
\hline $\begin{array}{l}\text { TRANSFCRHATICN } \\
\text { ELECTRICITY GEN. } \\
\text { FETROLEOM ERCDOCTS } \\
\text { NATORAL GAS } \\
\text { SYNTHETICS }\end{array}$ & $\begin{array}{r}11,773 \\
-269,969 \\
- \\
-\end{array}$ & $\begin{array}{r}114,070 \\
-264,439 \\
- \\
-\end{array}$ & $\begin{array}{r}-631,49 \overline{0} \\
-\end{array}$ & $\begin{array}{r}-433,503 \\
- \\
-\end{array}$ & $1,599,498$ & $\begin{array}{r}50,195 \\
5,662 \\
- \\
-\end{array}$ & $\begin{array}{l}\overline{-} \\
-\end{array}$ & $\begin{array}{r}-63,350 \\
- \\
-\end{array}$ & $\begin{array}{r}112,688 \\
5,759 \\
- \\
-\end{array}$ & $\begin{array}{l}7 \% \\
0 \%\end{array}$ \\
\hline $\begin{array}{l}\text { NET FOFI USEL } \\
\text { IS TRANSFOEMATION }\end{array}$ & $-258,196$ & $-150,369$ & $-631,490$ & $-433,503$ & $1,599,498$ & 55,857 & - & $-63,350$ & 118,447 & $7 \%$ \\
\hline $\begin{array}{l}\text { TCIAL GROSS FLCRS } \\
\text { ICSSES E OHISSIONS }\end{array}$ & $\begin{array}{r}88,558 \\
5,512\end{array}$ & $\begin{array}{r}218,581 \\
4\end{array}$ & $\begin{array}{r}404,757 \\
1\end{array}$ & $\begin{array}{l}370,048 \\
-14,596\end{array}$ & $\begin{array}{r}1,599.498 \\
66,355\end{array}$ & $\begin{array}{l}387,159 \\
-10,461\end{array}$ & $\begin{array}{r}18.753 \\
253\end{array}$ & $\begin{array}{r}154,657 \\
12,832\end{array}$ & $\begin{array}{r}1,579,360 \\
59,902\end{array}$ & $\begin{array}{r}969 \\
4 \%\end{array}$ \\
\hline ICTAL RET OSAGE & $-175,898$ & -45.753 & $-226,731$ & $-78,051$ & 1.665 .853 & 376,697 & 19,006 & 104,139 & $1.639,262$ & \\
\hline $\begin{array}{l}\text { SOEELY OP ENERGY } \\
\text { FCSSIL FOEI } \\
\text { HYDROELECTEIC } \\
\text { NDCLEAR } \\
\text { GEC. ESOLAR }\end{array}$ & $\begin{array}{l}\overline{-} \\
-\end{array}$ & - & $\begin{array}{l}- \\
-\end{array}$ & $\begin{array}{l}- \\
-\end{array}$ & $\begin{array}{r}121,235 \\
- \\
-\end{array}$ & $\begin{array}{r}41,466 \\
= \\
=\end{array}$ & - & $\begin{array}{r}- \\
2.780 \\
370 \\
27,663\end{array}$ & $\begin{array}{r}162,701 \\
2,780 \\
370 \\
27,663\end{array}$ & $\begin{array}{r}84 \% \\
1 \% \\
0 \% \\
14 \%\end{array}$ \\
\hline TCTAL SUPEIY & - & - & - & - & 121,235 & 41,466 & - & 30,813 & 193,514 & \\
\hline
\end{tabular}

RET IM PORTS
CP REGION




\begin{tabular}{|c|c|c|c|c|c|c|c|c|c|c|}
\hline \multicolumn{11}{|c|}{$\begin{array}{l}\text { REGICNAL EVERGY EALANCE STATEMEUT } \\
\text { PIZS MED MID SCENARIO }\end{array}$} \\
\hline SECJJE & $\begin{array}{l}\text { DISTILLATE } \\
\text { OIL }\end{array}$ & $\begin{array}{l}\text { RESEDEAL } \\
\text { OIL }\end{array}$ & $\begin{array}{l}\text { GASOLINE } \\
\text { (ALL OAI }\end{array}$ & $\begin{array}{l}\text { OTHER } \\
\text { BYDRO- } \\
\text { CARBONS } \\
\text { TS IN } 10 * * 9\end{array}$ & $\begin{array}{c}\text { CRODE } \\
\text { OIL } \\
\text { BTO'S) }\end{array}$ & $\begin{array}{l}\text { NATUR3L } \\
\text { GAS }\end{array}$ & $\operatorname{COAL}$ & ELECTRICITY & $\begin{array}{r}\text { SECTOR } \\
\text { TOTAL }\end{array}$ & \\
\hline 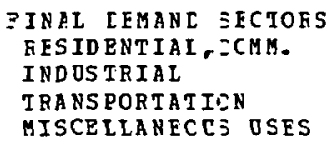 & $\begin{array}{r}17.571 \\
61,295 \\
=1,371 \\
1,110\end{array}$ & $\begin{array}{r}147 \\
6.5,563 \\
5,445 \\
412\end{array}$ & $\begin{array}{r}\overline{-} \\
28,407 \\
-\end{array}$ & $\begin{array}{r}6,764 \\
20,396 \\
71,134 \\
9\end{array}$ & $\begin{array}{l}\bar{z} \\
\bar{z}\end{array}$ & $\begin{array}{r}1,907 \\
- \\
23 \epsilon\end{array}$ & $\begin{array}{r}48 \\
4,697 \\
\frac{2}{2}\end{array}$ & $\begin{array}{r}13,115 \\
3,361 \\
- \\
665\end{array}$ & $\begin{array}{r}39,554 \\
155,305 \\
126,594 \\
2,198\end{array}$ & $\begin{array}{r}12 \% \\
46 \% \\
38 \% \\
1 \%\end{array}$ \\
\hline $\begin{array}{l}\text { TCTAI FINAL } \\
\text { DEMAND SECTCRS }\end{array}$ & 121,347 & $71,57.3$ & $28,40.7$ & 98.303 & - & $2,14 \equiv$ & 4,737 & 17,141 & 323,651 & $96 \%$ \\
\hline $\begin{array}{l}\text {-RANSPCFHATICA } \\
\text { ELECTRICITY GEN. } \\
\text { PETROLEOM FACDOCTS } \\
\text { NATORAL GAS: } \\
\text { SYNTHETICS }\end{array}$ & $\begin{array}{r}1,012 \\
-28,995 \\
- \\
-\end{array}$ & $\begin{array}{r}- \\
-2 \varepsilon, 401 \\
-\end{array}$ & $\begin{array}{r}- \\
-67,822 \\
-\end{array}$ & $\begin{array}{r}-46.559 \\
-\end{array}$ & $\begin{array}{r}- \\
171,787 \\
-\end{array}$ & $\begin{array}{r}60 \bar{E} \\
- \\
-\end{array}$ & $\begin{array}{l}- \\
\overline{-} \\
-\end{array}$ & $\begin{array}{r}-356 \\
- \\
-\end{array}$ & $\begin{array}{r}656 \\
618 \\
- \\
-\end{array}$ & $\begin{array}{l}0 \% \\
0 \%\end{array}$ \\
\hline $\begin{array}{l}\text { DET FOFI USEL } \\
\text { IN TRANSFCEATION }\end{array}$ & $-27,983$ & $-2 E, 401$ & $-67,822$ & -46.559 & 171.787 & 608 & - & -356 & 1,274 & $0 \%$ \\
\hline $\begin{array}{l}\text { TCTAL GROSS FLCWS } \\
\text { LCSSES } \varepsilon \text { CISSIONS }\end{array}$ & $\begin{array}{r}11) 2,359 \\
6,371\end{array}$ & 71,573 & $\begin{array}{r}28,41) 7 \\
0\end{array}$ & $\begin{array}{l}98.303 \\
-3.877\end{array}$ & $\begin{array}{r}171,787 \\
7,126\end{array}$ & $\begin{array}{r}2,75 \pi \\
-.74\end{array}$ & $\begin{array}{r}4,737 \\
54\end{array}$ & $\begin{array}{r}17,149 \\
1,422\end{array}$ & $\begin{aligned} & 24,525 \\
& 11,033\end{aligned}$ & $\begin{aligned} 57 \% \\
3 \pi\end{aligned}$ \\
\hline TCIAL NEI OSAGE & 79.735 & $4 \equiv .173$ & $-39,414$ & 47.866 & 178,913 & 2,676 & 4,801 & 18,207 & 335,958 & \\
\hline
\end{tabular}

\begin{tabular}{|c|c|c|c|c|c|c|c|c|c|c|}
\hline SOFELY CF ENESGY & & & & & & & & & & \\
\hline FOSSIL FOEI & 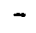 & - & - & - & $4,978,761$ & $6,797,80.4$ & 14,652 & - & $11,791,225$ & 1308 \\
\hline HY DECELECTF $=\mathrm{C}$ & - & - & - & - & - & - & - & 2,914 & 2,914 & $0 x$ \\
\hline NOCLEAR & - & - & - & - & - & - & - & - & - & \\
\hline GEO. ESOLAR & - & - & - & - & - & - & - & 438 & 438 & $0 \%$ \\
\hline TCTAL SOPPIY & - & - & - & - & $4,978,761$ & $6,797,8014$ & 14,663 & 3,352 & $11,794,577$ & \\
\hline
\end{tabular}

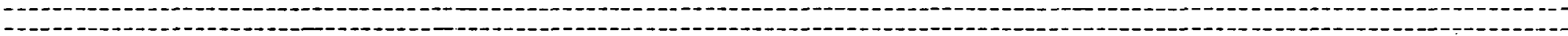

\begin{tabular}{|c|c|c|c|c|c|c|}
\hline $\begin{array}{l}B \mathrm{ET} \\
\mathrm{CP}\end{array}$ & $\begin{array}{l}\text { RTS } \\
\text { ION }\end{array}$ & & .735 & 43,173 & $-39,4$ & \\
\hline & S: & & & & & \\
\hline 1 & TRAN CECPMATICM & 1055 & $F O R$ & $E \mathrm{ECTRIC^{-1 } \mathrm { T }}$ & $G=N$ & $=61,82 \pi$ \\
\hline 2 & TRANSECGHATCN & loss & POP. & EETR $=L E \cup A$ & ROBUCTS & $=c .36 \%$ \\
\hline 3 & TRANSECRUATI CN & Loss & FOP & ЕАTOAAL GA & & $=0.0 \mathrm{~g}$ \\
\hline 4 & TRANSEORHATICN & lcss & FOP & CYNT BETICS & & $=c .0$ \\
\hline
\end{tabular}


REGIONAL ENE FGY EALANCE STATEMENT
PIES MID MID SCENARIO

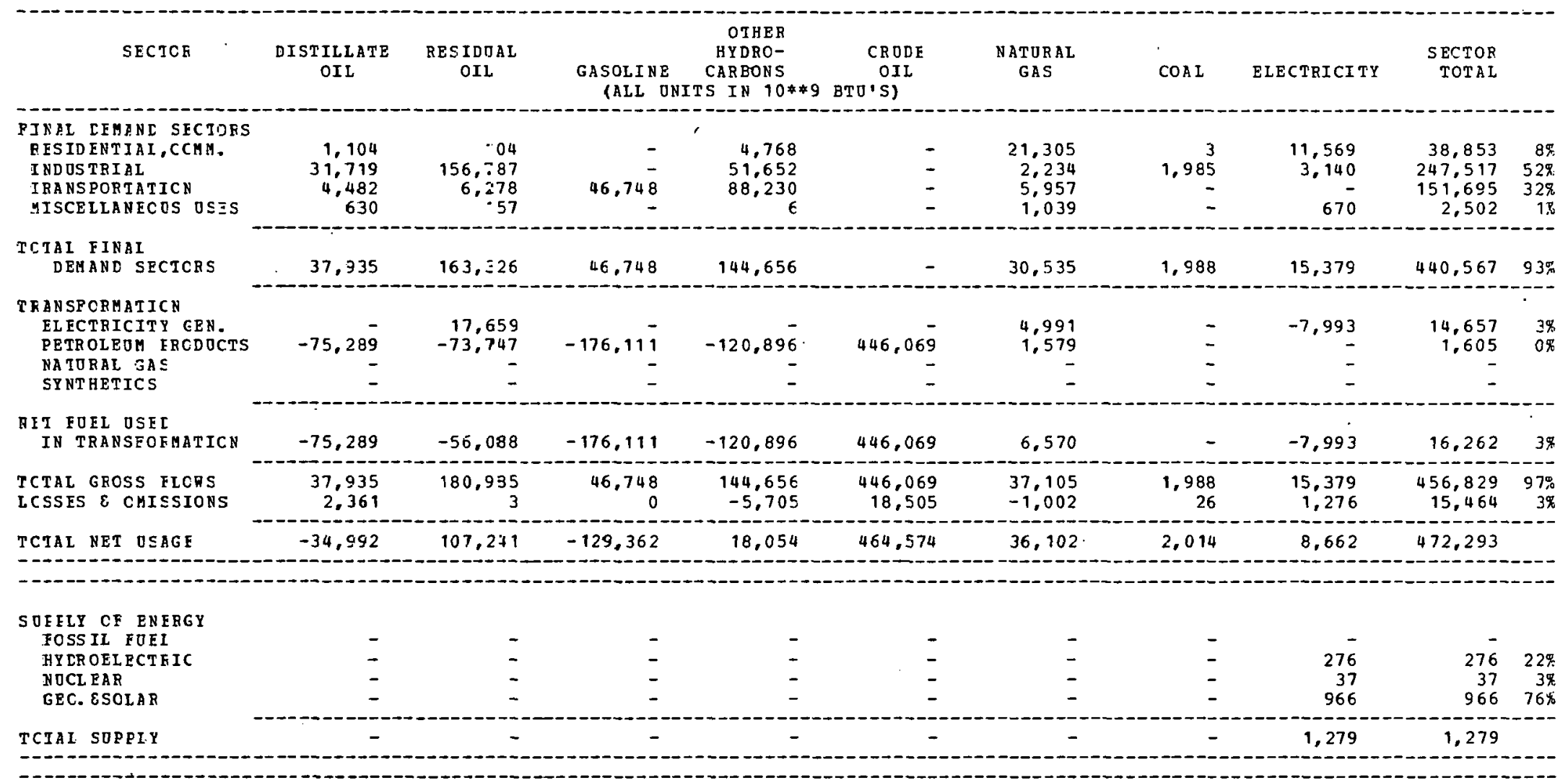

NEI IMECRTS
DF REGION


THIS PAGE

\section{WAS INTENTIONALLY LEFT BLANK}


INTERNAL DISTRIBUTION

1. S. I. Auerbach

2. D. J. Bjornstad

3. R. S. Carlsmith

4. H. S. Chang

5. W. S. Chern

6. T. A. Corey

7. R. M. Davis

8. J. E. Dobson

9. W. Fulkerson

10. R. B. Honea

11-12. Judy Johnson

13. C. R. Kerley

14. R. S. Konke1

15. A. S. Loeb1

16. J. B. Mills

17. W. R. Mixon

18. D. L. O'Neal
19. S. C. Parikh

20. D. C. Parzyck

21. P. L. Rice

22. T. H. Row

23. D. N. Stuckwish

24. D. P. Vogt

25. G. Westley

26. T. J. Wilbanks

27. D. J. Wilkes

28-53. Regional Economics Analysis Group

54-55. Central Research Library

56. Document Reference Section

57-58. Laboratory Records

59. Laboratory Records - RC

60. ORNL Patent Office

\section{EXI'ERNAL DISTRIBUTION}

61. Dr. Richard Ball, Division of Environmental Impacts, E-201, U.S. Department of Energy, Washington, D.C. 20545.

62. Professor Peter D. Blair, University of Pennsylvania, School of Public and Urban Policy, 39 th and Walnut Streets B1, Philadelphia, Pennsylvania 19104.

63. Dr. Roger Bolton, Joint Center for Urban Studies of the MIT and Harvard Universities, 53 Church Street, Cambridge, Massachusetts 02138.

64. Mr. Pau1 Braden, EDA, Room 6018, Department of Commerce Building, Washington, D.C. 20006.

65. Dr. Steven Coelen, University of Tennessee, Department of Economirs, 1974 Alcoa Highway, Knoxville, Tennessee 37916.

66. Mr. Mike Cosgrove, Gulf Oil Corporation, 2 Houston Center, 909 Fannin Street, Houston, Texas 77001.

67. Dr. Robert E. Coughlin, Regional Science Research Institute, 3831 Walnut Street, Philadelphia, Pennsylvania 19104.

68. Professor Joseph Davidson, University of Dayton, Dayton, Ohio 45469.

69. Mr. John Flory, EDA, Room 6018, Department of Commerce Building, Washington, D.C. 20006.

70. Professor John W. Green, Economic Research Service, U.S. Department of Agriculture, Economics Department, Colorado State University, Ft. Collins, Colorado 80523.

71. Professor David Greytak, Syracuse University, Metropolitan Studies Center, 607 University Avenue, Syracuse, New York 13201.

72. Dr. Paul Gronki, Brookhaven National Laboratory, Associated Universities, Inc., Upton, L.I., New York 1197.3. 


\section{EXTERNAL DISTRIBUTION (Continued)}

73. Dr. Richard D. Gustely, Chief of the Analysis Branch, Regional Economic Analysis Division, Bureau of Economic Analysis, U.S. Department of Commerce, Washingtun, D.C. 20230.

74. Dr. Ivars Gutmanis, Suite 310, 1747 Pennsylvania Avenue, N.W., Washington, D.C. 20006.

75. Professor Niles Hansen, Department of Economics, University of Texas, Austin, Texas 78712.

76. Professor Jim Hartnett, Energy Resources Center, University of Illinois, P.0. Box 4340, Chicago, Illinois 60680 .

77. Ur. Irving Huch, Resourccc for the Future, 1755 Massachusetts Avenue, Washington, D.C. 20036.

78. Dr. Joan Hock, Director, Regional Assessments Division, EV-24, MS-F.2n1, nepartment of Energy, Germantown D-247, Washington, D.C. 20545 .

79. Professor Walter Isard, Curmell University, Ithaca, New York. 14580.

80. Professor Dale Jorgenson, Department of Economics, Harvard University, Cambridge, Massachusetts 02138.

81. Dr. Hillard Kaufman, Jack Faucett Association, 5454 Wisconsin Avenue, Chevy Chase, Maryland 20015.

82. Professor J.R. Lakshmanan, Boston University, Department of Geography, 48 Cummington Street, Boston, Massachusetts 02215.

83. Dr. Kathryn Lyall, Housing and Urban Development, Washington, D.C. 20410.

84. Dr. Bert Mason, SERI, 1536 Cole Blvd., Golden, Colorado 80401.

85. Dr. Jedil MeTarland, ED , Room 6018, Department of Commerce Building, Washington, D.C. 20230.

86. Dr. Glenn Morris, LASL, University of California, P.0. Box 1663, Los Alamos, New Mexico 87b4b.

87. Mr. C. W. Myers, Room 7F089, DUE, forrescal Bulldling, Washington, D.C. 20585 .

88. Dr. Rogor Nail1, nffire nf Yolicy and Evaluation, U.S. DOE, Forrestal Building, Room 7F089, Washington, D.C. 20585.

89. Dr. Robert A. Nakosteen, Tennessee Valley Authority, 400 Commerce Avenue, Knoxville, l'ennessee 37902.

90. Professor Walter Page, Departmenl of Liconomice, Wubl Virginia University, Morgantown, West Virginia 26506.

91. Dr. Phill1p Patterson, Chief, Data Analysis Branch, Division of Transportation and Conservation, Office of Conservation, 20 Massachusetts Avenue, Washington, D.C. 20345.

92. Dr. Joel Reaser, Excell Corpuraliun, 11800 Eunrloe Valley Drive, Reston, Virginia 22901.

93. Dr. John Ross, Department of Housing and Urban Development, Washington, D.C. 20410.

94. Professor Seymour. Sacks, Syracuse University, Metropolitan Studies Center, 607 University $\Lambda$ venue, Syracuse, New York 13201.

95. Dr. James Savitt, New York State Energy Office, Agency Building No. 2, Empire Plaza, Albany, New York 12223.

96. Dr. Roger Schul1, Director, Environmental Impacts Division EV-23, MS-E-201., U.S. DOE, Washington, D.C. 20545. 


\section{EXTERNAL DISTRIBUTION (Continued)}

97. Mr. Bud Skinner, Southern Growth Policies Board, P.0. Box 12293, Research Triangle Park, North Carolina 27709.

98. Mr. Edward J. Smith, EDD ESC5, U.S. Department of Agriculture, Washington, D.C. 20250.

99. Dr. Benjamin H. Stevens, Regional Science Research Institute, 256 N. Pleasant Street, Amherst, MA 01002.

100. Dr. T. Takayama, Director, Office of Energy Use Analysis, Office of Applied Analysis, Energy Information Administration, Federal Building, Room 4416, 12th and Pennsylvania Ave., N.W., Washington, D.C. 20461.

101. Mr. William Thomas, Institute for Defense Analysis, 400 Army Navy Drive, Arlington, Virginia 22202.

102. Dr. Ronald White, DOE, MS-7A139, Forrestal Building, Washington, D.C. 20585 .

103-128. EDA, Room 6018, Department of Commerce Building, Washington, D.C. 20006.

129. Asst. Mgr. Energy Research and Development, DOE-ORO.

130-156. Technical Information Center, P.0. Box 62, Oak Ridge, TN 37830 . 